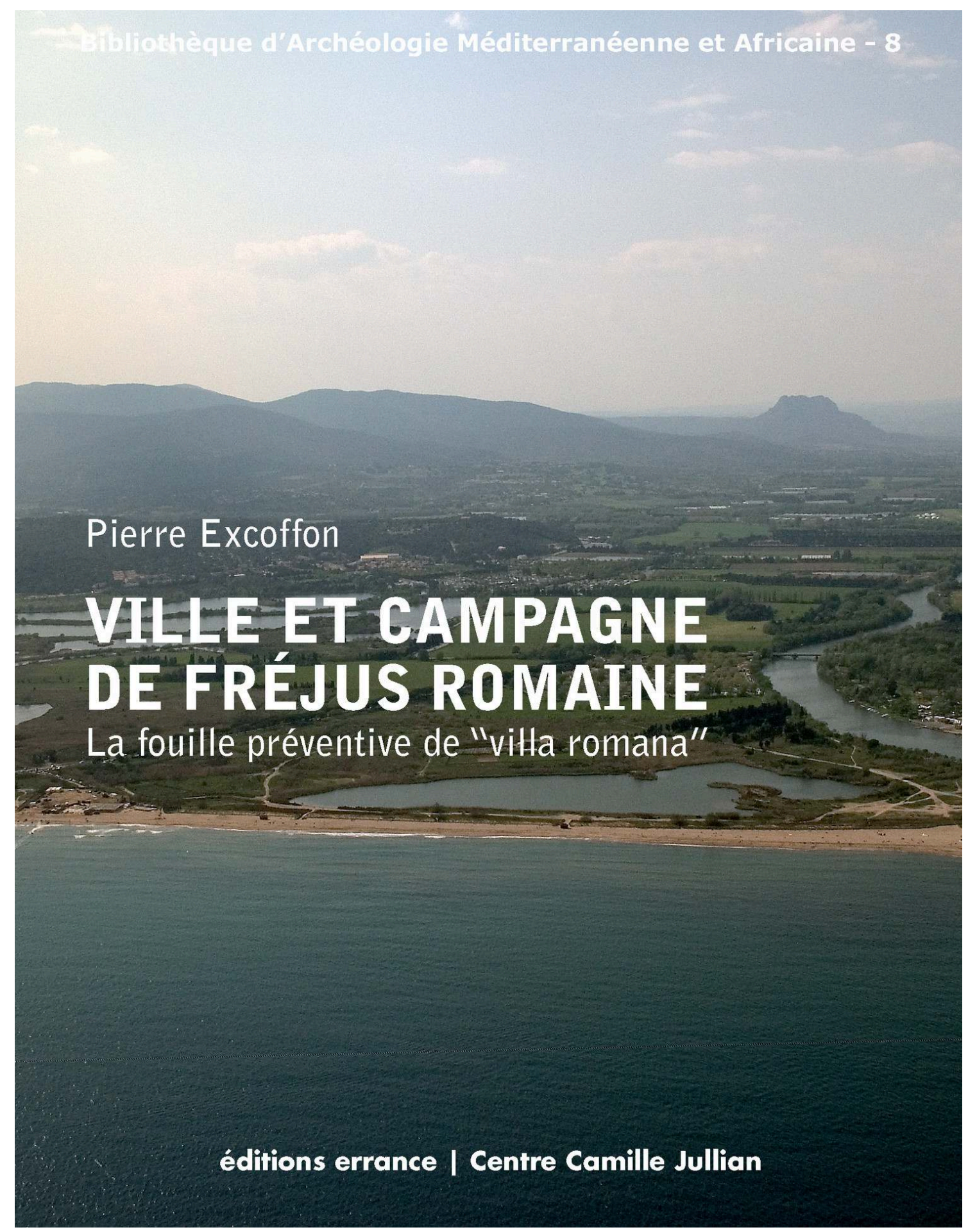




\section{Ville et campagne de Fréjus romaine}

La fouille préventive de "Villa Romana »

\section{Pierre Excoffon (dir.)}

DOI : 10.4000/books.pccj.936

Éditeur : Publications du Centre Camille Jullian, Éditions Errance

Lieu d'édition : Aix-en-Provence

Année d'édition : 2011

Date de mise en ligne : 13 février 2020

Collection : Bibliothèque d'archéologie méditerranéenne et africaine

ISBN électronique : 9782957155774

\section{Qbooks}

http://books.openedition.org

\section{Édition imprimée}

Date de publication : 1 juillet 2011

ISBN : 9782877724623

Nombre de pages : 320

\section{Référence électronique}

EXCOFFON, Pierre (dir.). Ville et campagne de Fréjus romaine : La fouille préventive de "Villa Romana ». Nouvelle édition [en ligne]. Aix-en-Provence : Publications du Centre Camille Jullian, 2011 (généré le 02 avril 2020). Disponible sur Internet : <http://books.openedition.org/pccj/936>. ISBN : 9782957155774. DOI : https://doi.org/10.4000/books.pccj.936.

(c) Publications du Centre Camille Jullian, 2011

Conditions d'utilisation:

http://www.openedition.org/6540 


\section{$\mathrm{B}$ ibliothèque d'Archéologie \\ Méditerranéenne et Africaine 8}


Dans la lignée des anciens Travaux du Centre Camille Jullian, la Bibliothèque d'Archéologie Méditerranéenne et Africaine (BiAMA) regroupe des travaux (monographies, actes de colloques, ouvrages collectifs) en relation avec les programmes scientifiques du Centre Camille Jullian, sur l'histoire et l'archéologie de la Gaule méridionale, de l'Afrique du Nord et du bassin méditerranéen. La BiAMA peut comprendre des sous-séries, comme la collection Études massaliètes (EtMassa).

\section{Responsable légal :}

Dominique Garcia, Directeur du CCJ

Directeur de la publication :

Henri Tréziny

Comité de pilotage :

Xavier Delestre, Dominique Garcia, Henri Tréziny

Conception graphique :

Véronique Gémonet

Mise en page :

Joris Pâques

\section{Comité de lecture :}

Ph. Borgard (CCJ, CNRS), M.-Br. Carre (CCJ, CNRS), X. Delestre (DRAC PACA), D. Garcia (CCJ, Université de Provence), M. Griesheimer (CCJ, Université de Provence), A. Hermary (CCJ, Université de Provence), Ph. Jockey (CCJ, Université de Provence), M. Lombardo (Professeur à l'Université de Lecce), T. S. Loseby (Professeur à l'Université de Sheffield), J.-M. Mignon (Service archéologique départemental du Vaucluse), P. Pomey (CCJ, CNRS), L. Rivet (CCJ, CNRS), J. Sanmarti (Professeur à l'Université de Barcelone), H. Tréziny (CCJ, CNRS), C. Virlouvet (CCJ, Université de Provence), E. Voutiras (Professeur à l'Université de Thessalonique).

Conseiller scientifique pour ce volume $: \mathrm{X}$. Lafon

C 2011 pour tous pays,

Éditions Errance, éditeur du groupe Actes Sud,

7 , rue Jean Du Bellay 75004 Paris

Tél. : 0443268582

Fax : 0143293488

Courriel : contact@editions-errance.fr

http://www.libairie-epona.fr

Centre Camille Jullian

Maison Méditerranéenne des Sciences de l'Homme

5 rue du Château de l'Horloge. BP 647, 13094 Aix-en-Provence Cedex 2

ISBN : 978-2-87772-462-3

ISSN : 2101-2849

Illustration de couverture :

Vue de la basse vallée de l'Argens (cl. Ville de Fréjus - M. Heller ${ }^{\circledR}$ )

Illustration $4^{e}$ de couverture :

Puits rectangulaire en bois du I ${ }^{\text {er }}$ siècle apr. J.-C. (cl. P. Excoffon)
Publications du Centre Camille Jullian

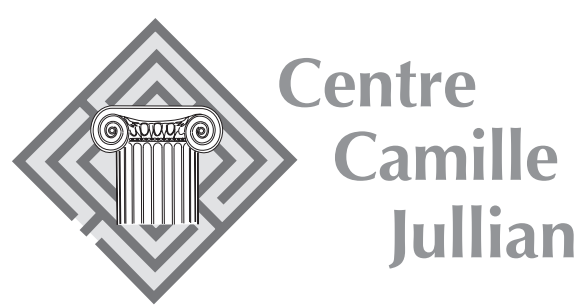

Ouvrage financé par

la Ville de Fréjus et le

le Ministère de la Culture (DRAC - PACA)
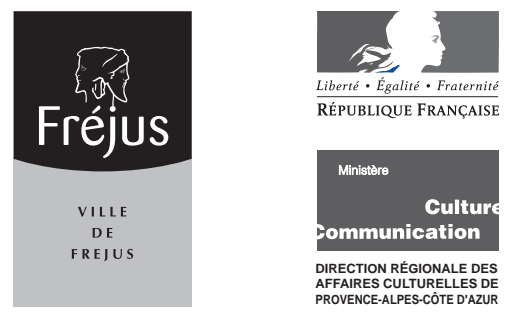

Envoyer les manuscrits à :

Henri Tréziny

Bibliothèque d'Archéologie Méditerranéenne et Africaine

Centre Camille Jullian

Maison Méditerranéenne des Sciences de l'Homme

5 rue du Château de l'Horloge. BP 647,

13094 Aix-en-Provence Cedex 2 


\section{Ville et Campagne DE FRÉJus Romaine}

\section{La fouille préventive de «Villa Romana»}

\section{Pierre EXCOFFON}

Avec les contributions de S. Ardisson, J.-Fr. Berger, G. Boetto, S. Bonnet, L. Bouby, M. Cullin-Mingaud, B. Devillers, M. Dubar, M. El Amouri, I. Figueiral, S.-D. Fontaine, J. Françoise, S. Greck, Fr. Guibal, S. Guillon, M. Leguilloux, Y. Lemoine, S. Martin, E. Pellegrino, Ph. Ponel, C. Schaal et P. Verdin 
Direction scientifique

Pierre Excoffon (P. E.)

(Ville de Fréjus - Service du Patrimoine)

\section{Géomorphologie}

Stéphane Bonnet (S. B.)

(Mission Archéologique - Ville d'Aix-enProvence)

Benoit Devillers (B. D.)

(Lattes UMR 5140/CNRS)

\section{Malacologie}

Sophie Martin (S. M.)

(IMEP/CNRS)

Palynologie

Sébastien Guillon (S. G.)

(CEPAM/CNRS)

Phytolithologie

Pascal Verdin (P. V.)

(INRAP/CEPAM/CNRS)

Analyse des minéraux lourds

Michel Dubar (M. D.)

(CEPAM/CNRS)

\section{Micromorphologie}

Jean-François Berger (J.-Fr. B.)

(CEPAM/CNRS)

\section{Carpologie}

Laurent Bouby (L. B.)

(CBAE/CNRS)

Isabel Figueral (I. F.)

(INRAP/CBAE)

Caroline Shaal (C. S.)

[Pôle d'Archéologie Interdépartemental

Rhénan (PAIR)]

Anthracologie

Isabel Figueral (I. F.)

(INRAP/CBAE)

\section{Xylologie}

Sandra Greck (S. Gr.)

(Ipso Facto/IMEP/CNRS)

Frédéric Guibal (Fr. G.)

(IMEP/CNRS)

Céramologie

Emmanuel Pellegrino (E. P.)

(CEPAM/CNRS)

Étude du Verre

Souen-Deva Fontaine (S.-D. F.)

(CCJ / CNRS / Université de Provence)

\section{Mobilier métallique}

Yvon Lemoine (Y. L.)

(Service Départemental d'Archéologie du Var)
Archéozoologie

Martine Leguilloux (M. L.)

(Centre Archéologique du Var)

Paléoentomologie

Philippe Ponel (P. P.)

(IMEP/CNRS)

Architecture navale

Giula Boetto (G. B.)

(CCJ/CNRS)

Numismatique

Joël Françoise (J. F.)

(Arc Numismatique)

Étude sur la Vannerie

Magalie Cullin-Mingaud (M. C.-M.)

(ANHIMA/CNRS)

Étude des Thermes de Villeneuve

Sandrine Ardisson (S. A.)

(CEPAM/CNRS)

Datation Radiocarbone

Tomasz Goslar

Poznan Radiocarbon Laboratory

Relevés de terrain

Élise Devidal

(Ville de Fréjus - Service du Patrimoine)

Restitutions et dessins

Mourad El-Amouri (M. E.-A)

(Ipso Facto/Ville de Fréjus - Service du

Patrimoine)

Topographie

Chantier : Françoise Laurier

(Service Départemental d'Archéologie

du Var)

SIG : Christophe La Rocca

(Ville de Fréjus - Service du Patrimoine)

Photographies d'objets

Christine Durand

(CCJ/CNRS)

Prise de vue en ballon aéorostationaire Ville de Fréjus - Altivue $@$
Institut Méditerranéen d'Écologie et de Paléoécologie

(UMR 6116, CNRS), Europôle méditerranéen de l'Arbois, 13545 Aix-en-Provence, Pavillon Villemin, BP 80, (IMEP)

Centre Camille Jullian

(UMR 6573, CNRS), MMSH, Université de Provence, 5 rue du Château-de-l'Horloge, BP 647, 13094 Aix-en-Provence (CCJ)

Centre d'Études Préhistoire, Antiquité, Moyen Âge

(UMR 6130, CNRS), 24 avenue des Diables Bleus, 06357, Nice cedex 4 (CEPAM)

Laboratoire d'Archéologie Médiévale Méditerranéenne

(UMR 6572, CNRS), MMSH, Université de Provence, 5 rue du Château-de-l'Horloge, BP 647, 13094 Aix-en-Provence (LAMM)

Centre de Bio-Archéologie et d'Écologie (UMR 5059, CNRS), Institut de Botanique, 163 rue Auguste-Broussonet, 34090 Montpellier (CBAE)

Laboratoire de Chrono-Écologie (UMR6565, CNRS), Université de Franche-Comté, 16 route de Gray, 25030 Besançon

Institut National de Recherches Archéologiques Préventives Direction interrégionale Méditerranée (régions Corse, Languedoc-Roussillon, Provence-Alpes), 561 rue Étienne-Lenoir, km delta, 39000 Nîmes (INRAP)

Poznań Radiocarbon Laboratory ul. Rubien 46, 61-612 Poznan, Poland

Centre Archéologique du Var 14 boulevard Bazeilles, 83000 Toulon (CAV)

Service Départemental d'Archéologie du Var Le Clos de la Tour, rue Gustave-Bret, 83600 Fréjus 


\section{Sommaire}

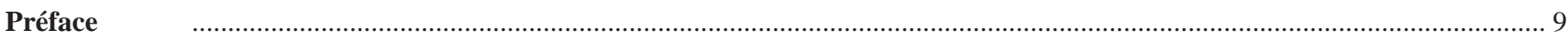

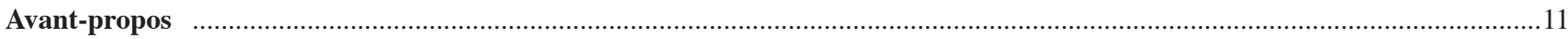

Introduction

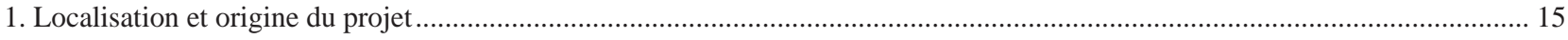

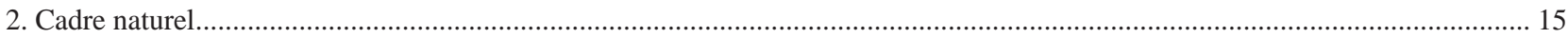

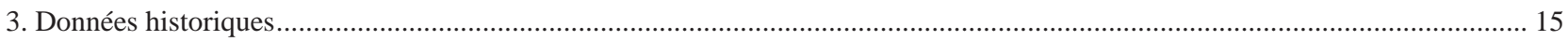

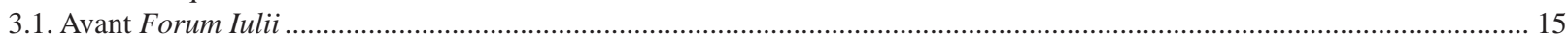

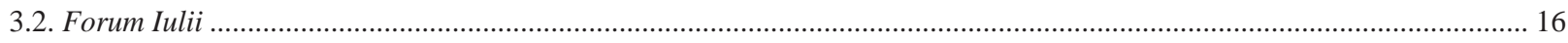

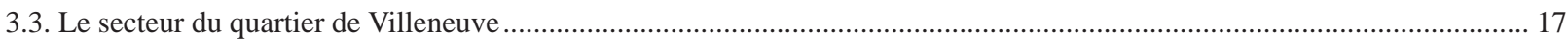

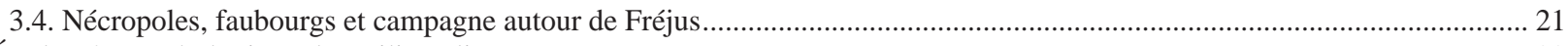

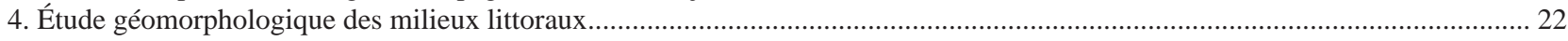

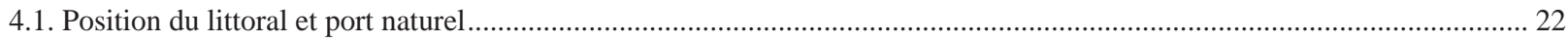

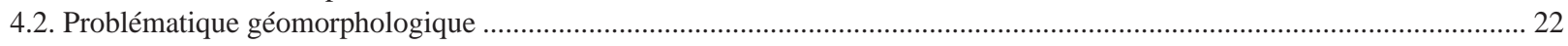

PREMIÈRE PARTIE : LA FOUILLE

Chapitre 1 : la plage du milieu du $I^{\text {er }}$ siècle av. J.-C.

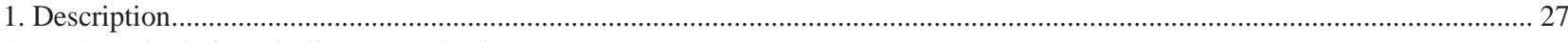

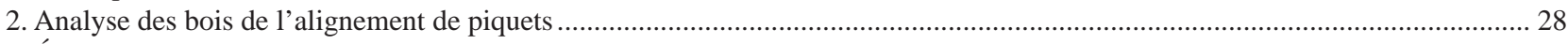

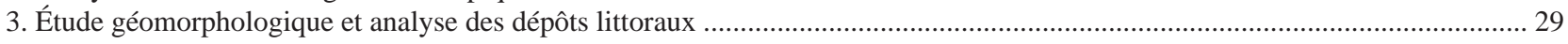

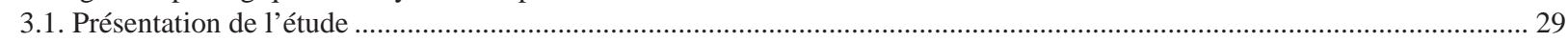

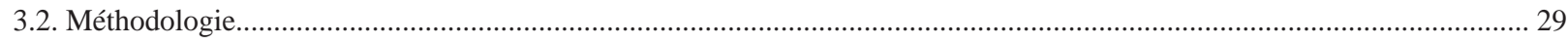

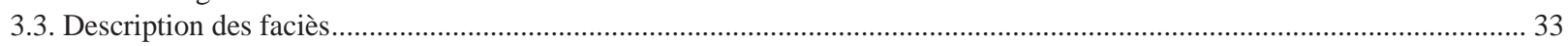

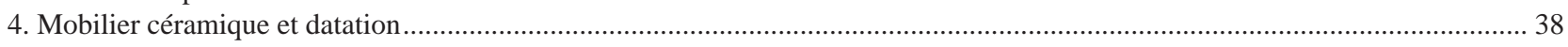

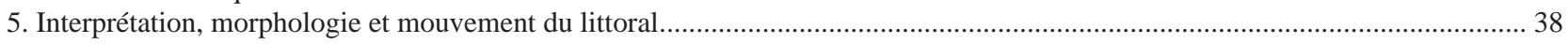

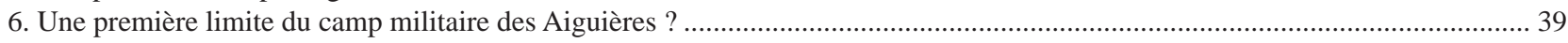

Chapitre 2 : les jardins de la fin du ${ }^{\text {er }}$ siècle av. J.-C. et de la première moitié du siècle suivant

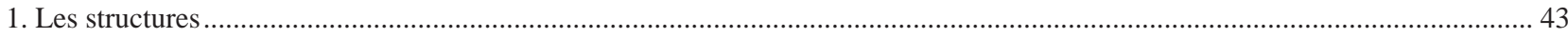

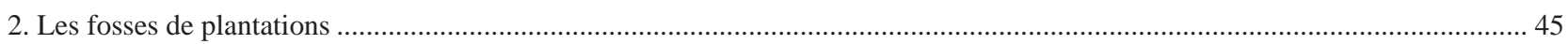

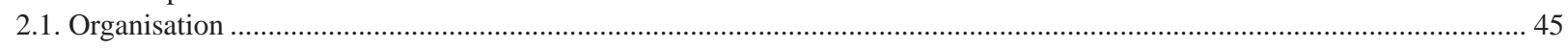

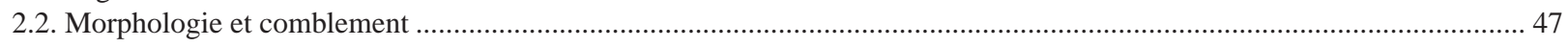

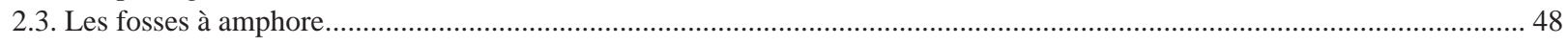

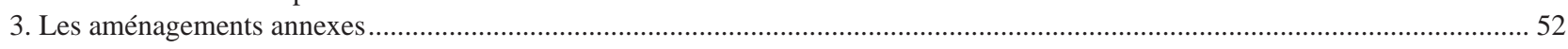

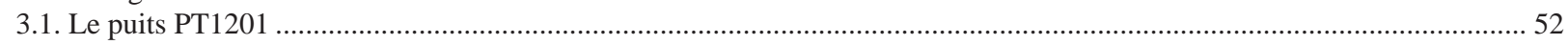

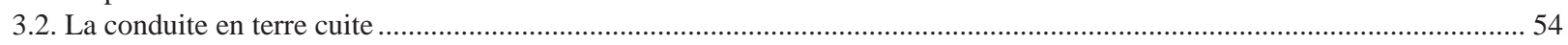

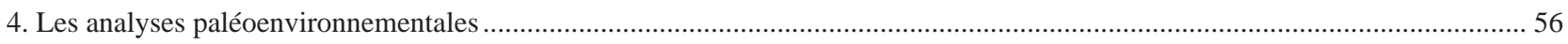

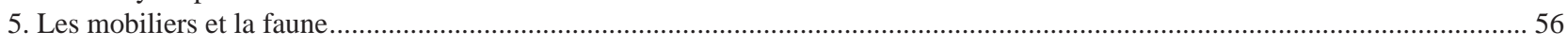

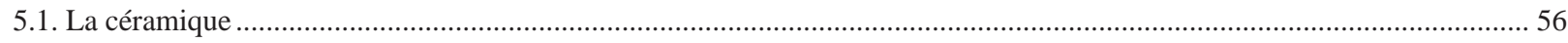

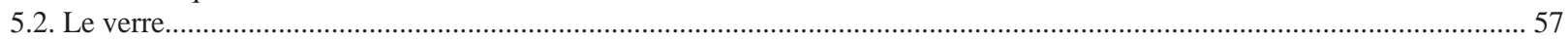

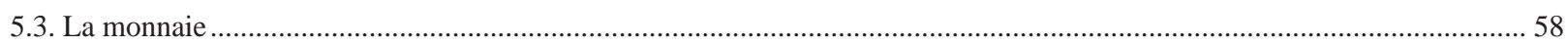

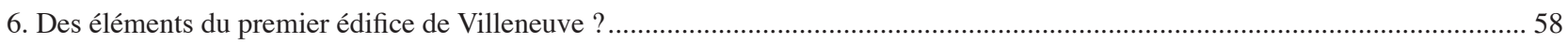

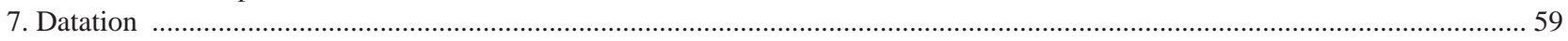

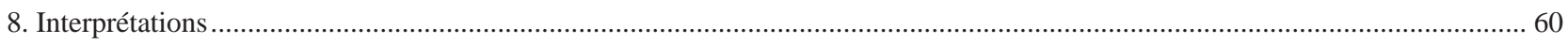

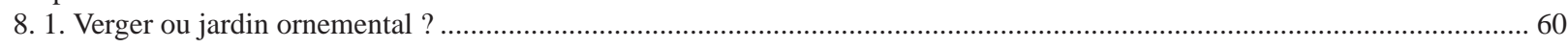

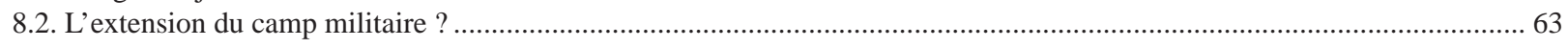

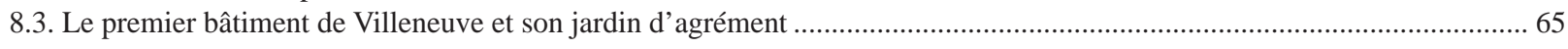


Chapitre 3 : les abords des thermes de villeneuve durant la deuxième moitié du I ${ }^{\text {er }}$ siècle apr. J.-C.

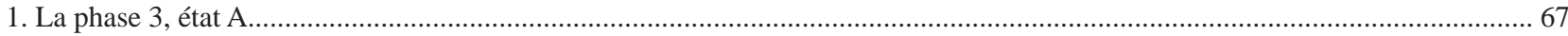

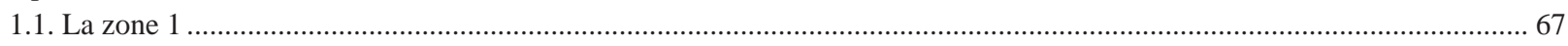

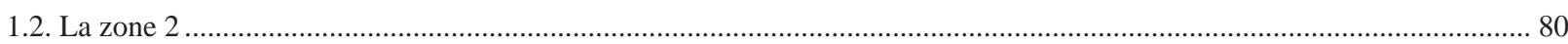

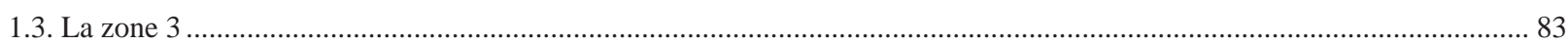

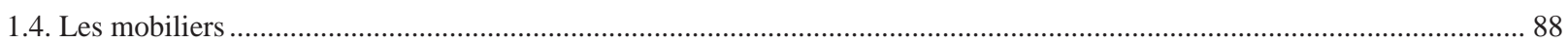

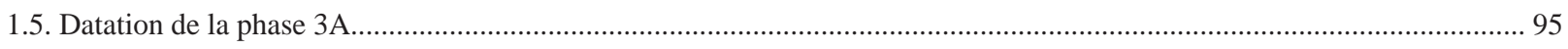

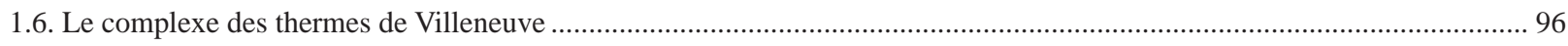

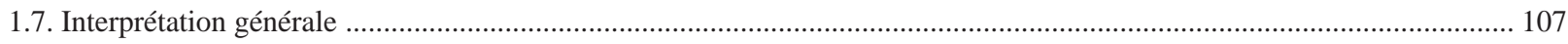

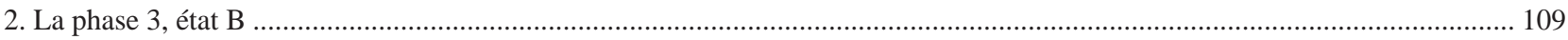

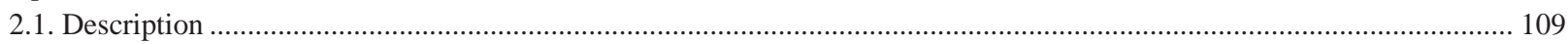

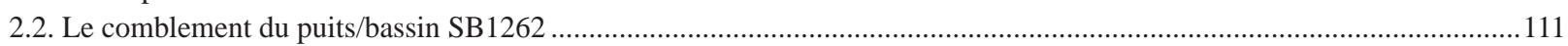

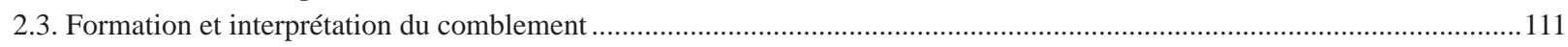

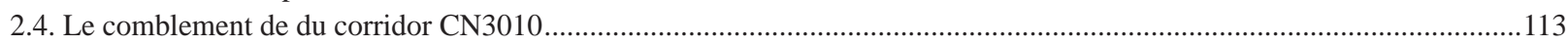

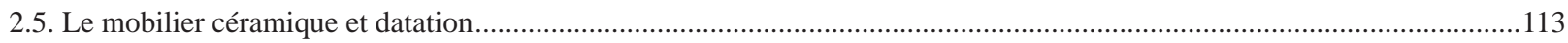

Chapitre 4 : une lanière cultivée aux II ${ }^{\mathrm{e}}$, III ${ }^{\mathrm{e}}$ et $\mathrm{IV}^{\mathrm{e}}$ siècles apr. J.-C.

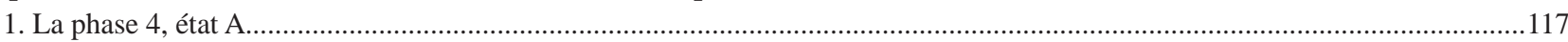

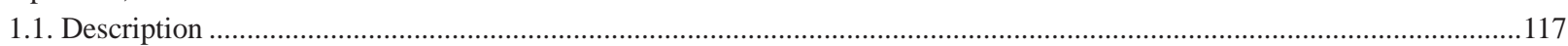

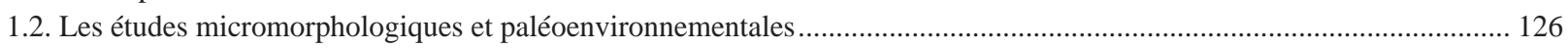

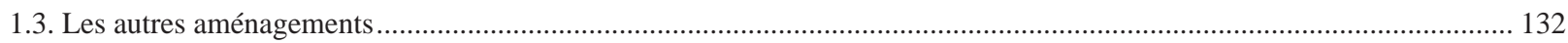

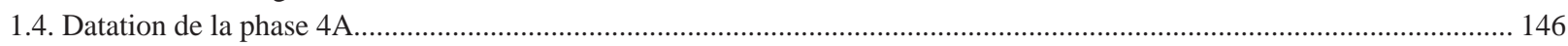

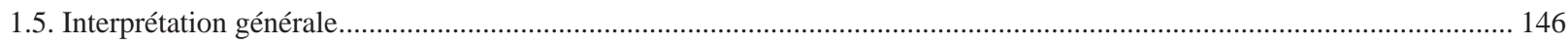

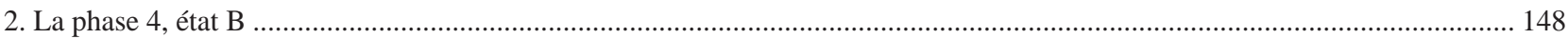

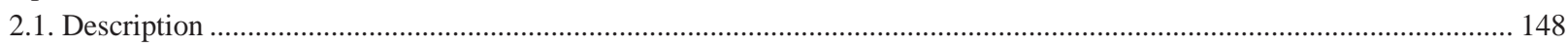

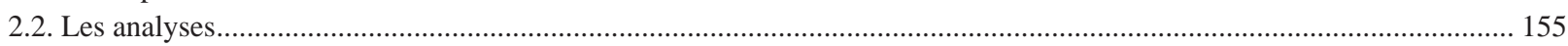

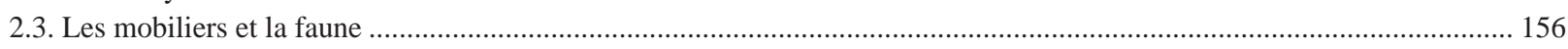

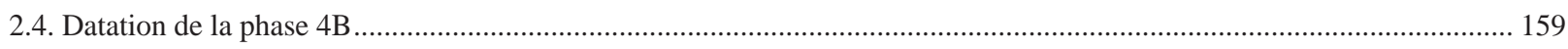

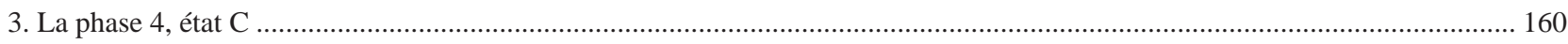

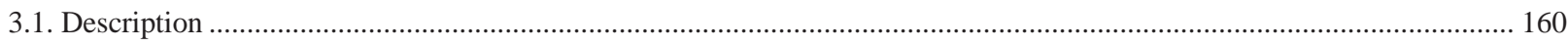

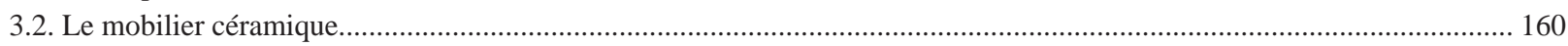

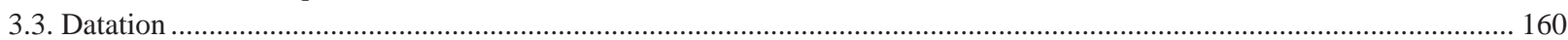

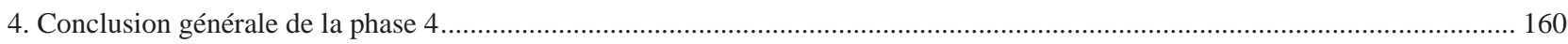

\section{Chapitre 5 : l'époque moderne}

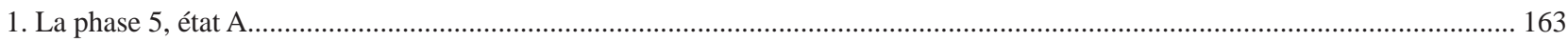

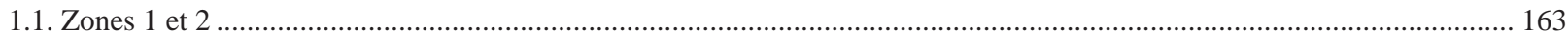

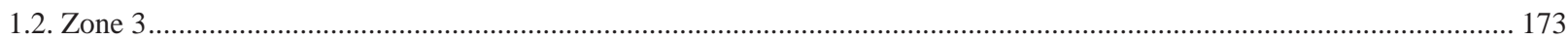

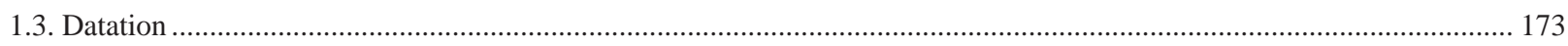

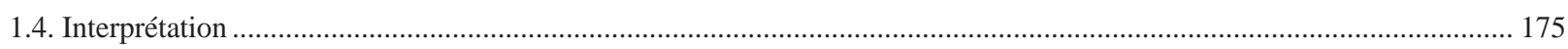

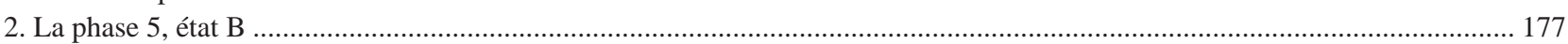

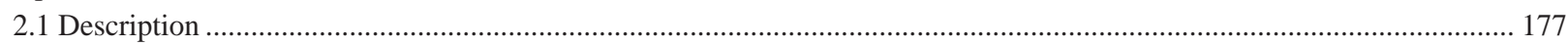

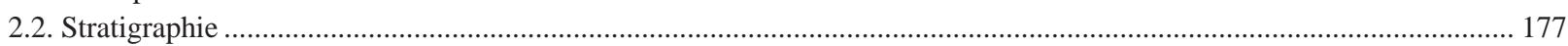

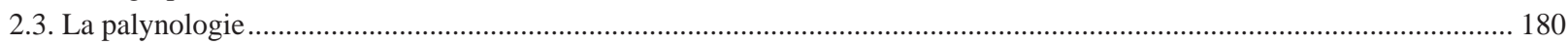

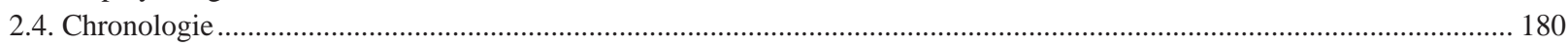

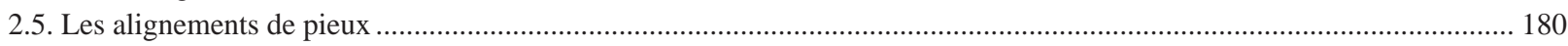

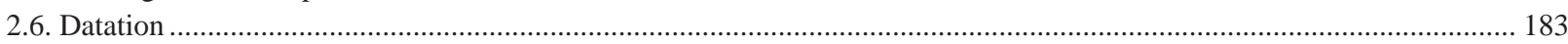

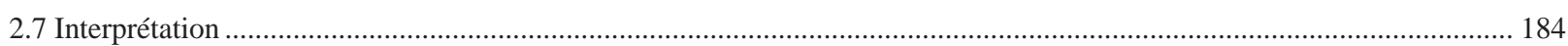

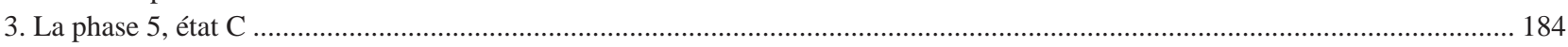

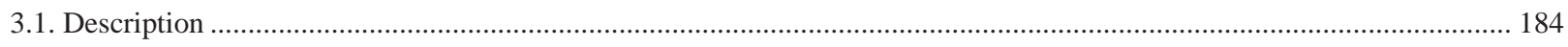

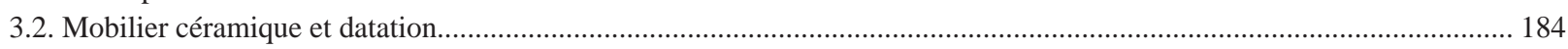

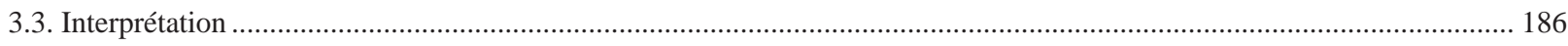

\section{Chapitre 6 : l'époque contemporaine}

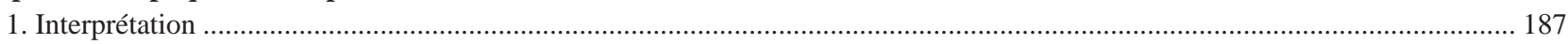

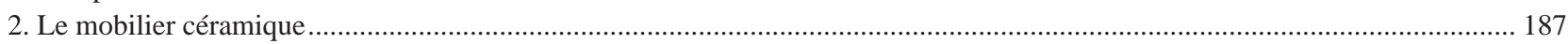


Conclusion : synthèse archéologique et restitutions paléoenvironnementales

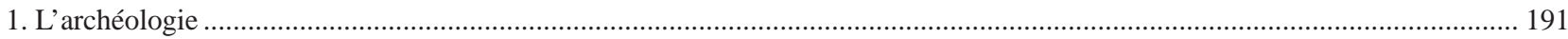

2. Restitution pluridisciplinaire du milieu et des activités humaines sur le site de Villa Romana ............................................... 193

2.1. Des approches multiples pour la restitution du milieu à l'échelle locale .................................................................... 193

2.2. Un sol sableux et une présence constante de l'eau : la prégnance du milieu littoral ........................................................ 193

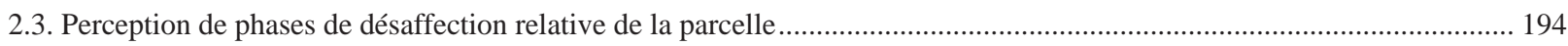

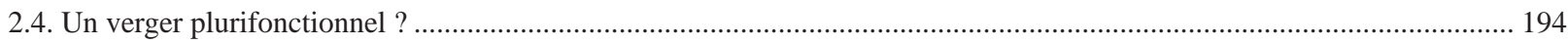

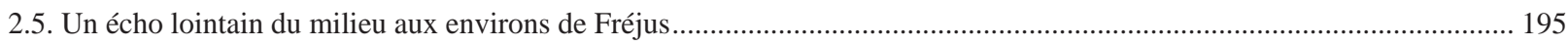

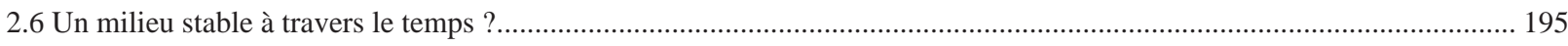

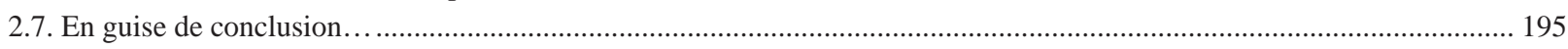

3. Restitution géomorphologique du littoral d'après les données de fouilles sur Fréjus............................................................ 196

DEUXIÈME PARTIE : ANALYSES ET ÉTUDES

Chapitre 1 : les vestiges de navires antiques : études architecturale et dendrologique

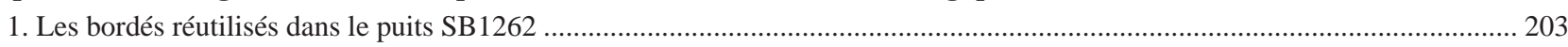

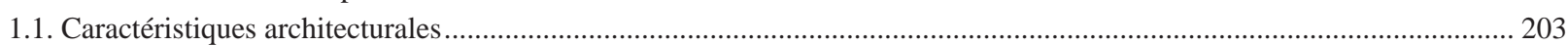

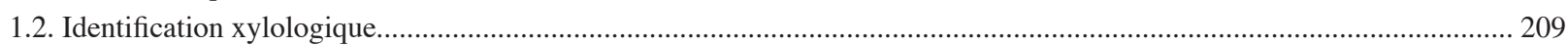

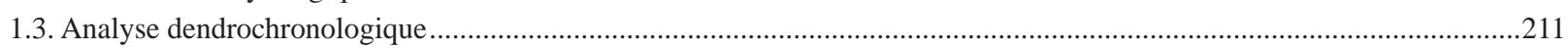

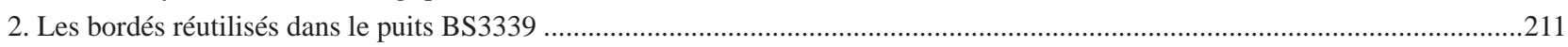

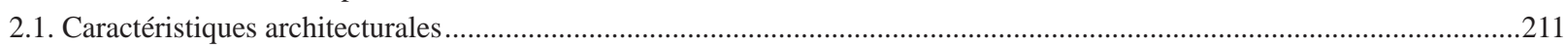

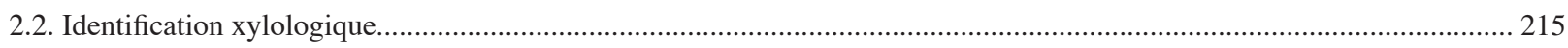

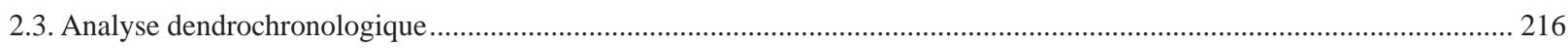

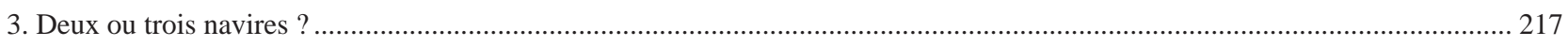

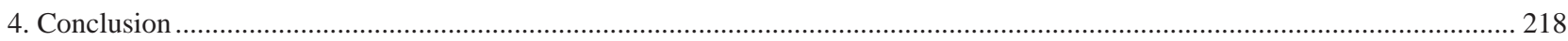

\section{Chapitre 2 : minéraux lourds}

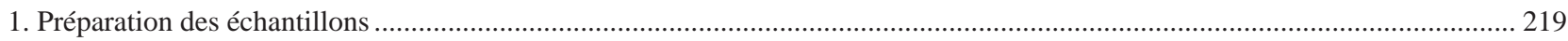

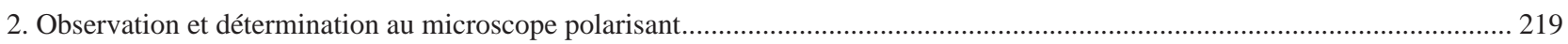

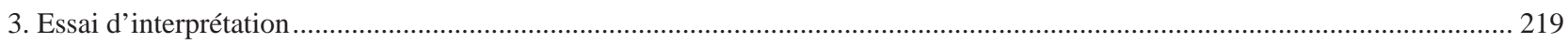

\section{Chapitre 3 : graines, fruits bois et charbons d'un espace horticole}

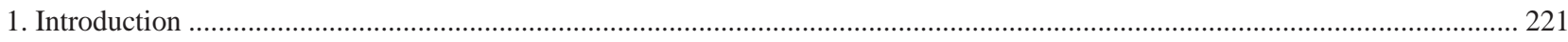

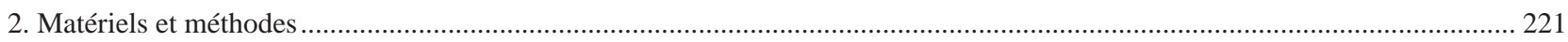

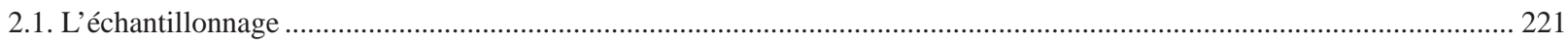

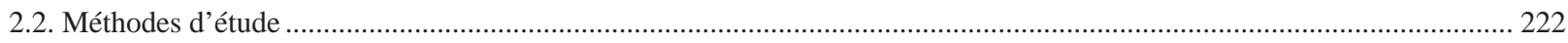

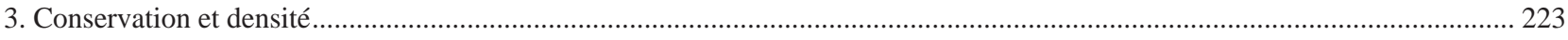

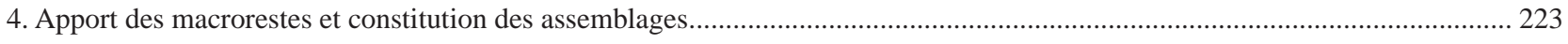

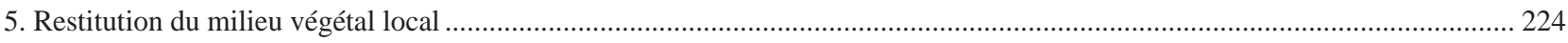

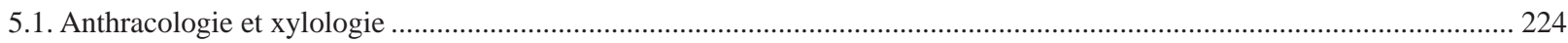

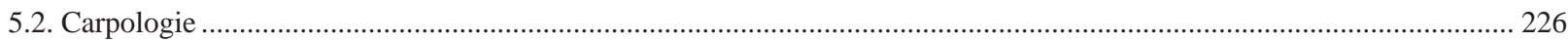

6. Rôles économiques et symboliques des plantes attestées dans la Gaule romaine ……...................................................... 228

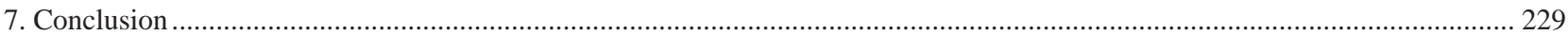

\section{Chapitre 4 : analyses polliniques des structures agraires}

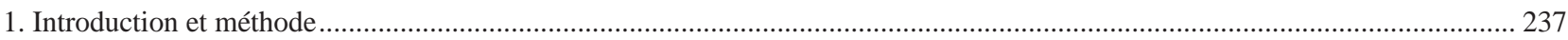

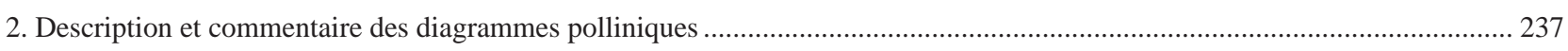

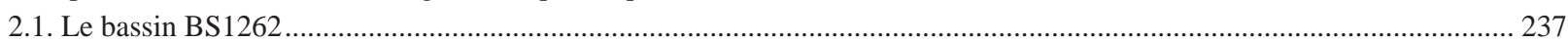

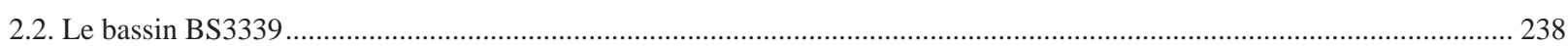

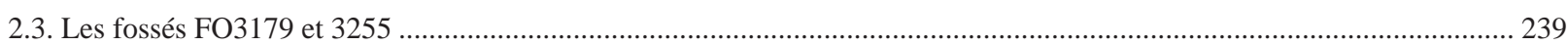

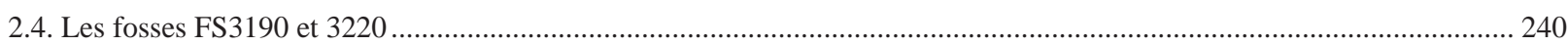

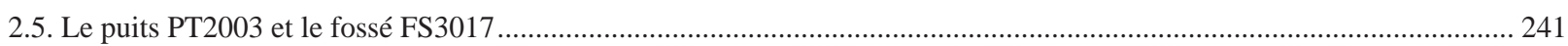

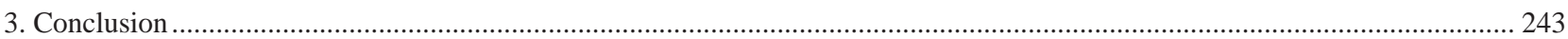


Chapitre 5 : analyses entomologiques (coléoptères)

1. Introduction

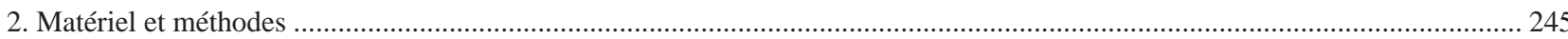

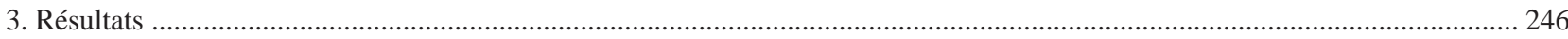

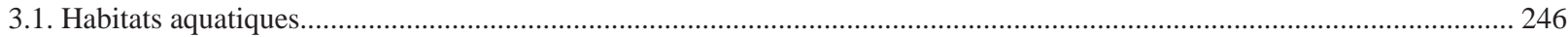

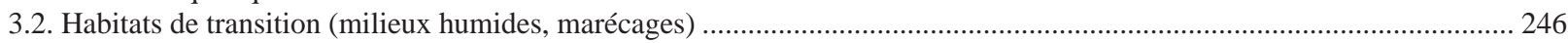

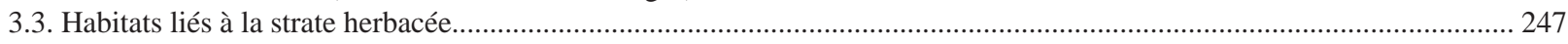

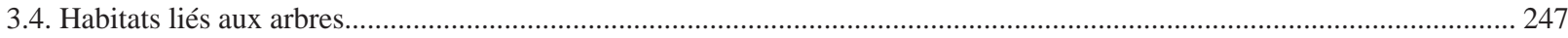

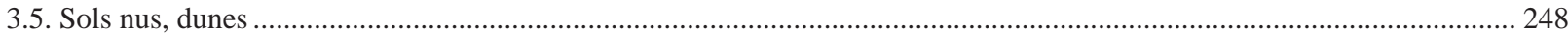

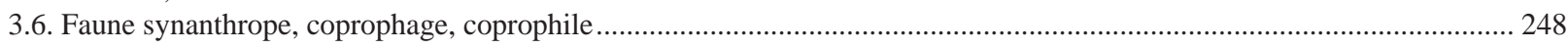

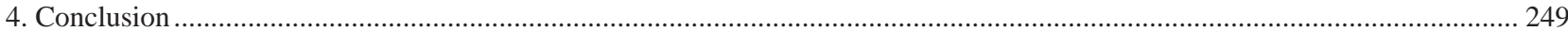

TROISIÈME PARTIE : BIBLIOGRAPHIE ET INVENTAIRES

Bibliographie

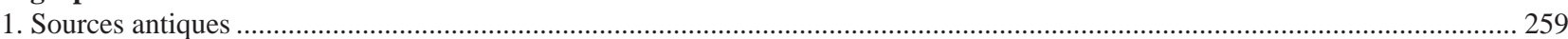

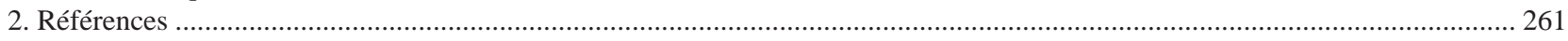

\section{Inventaires}

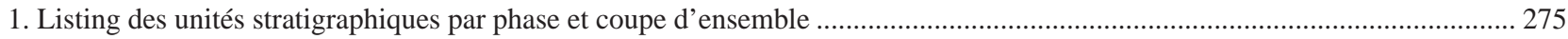

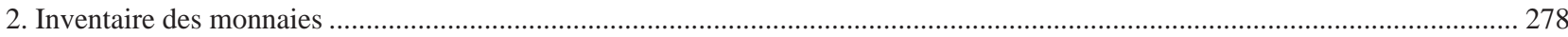

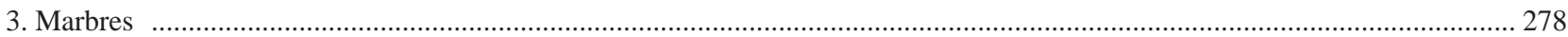

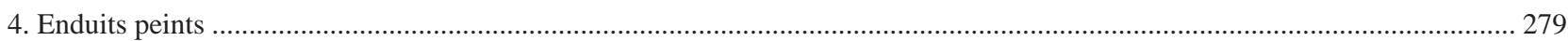

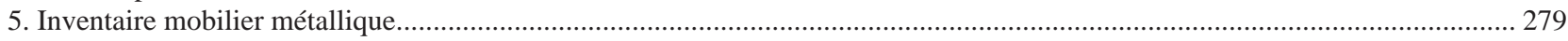

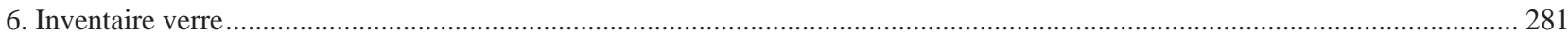

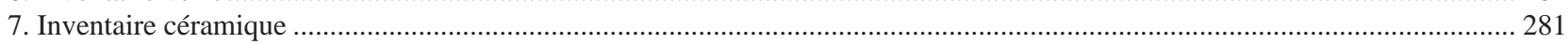

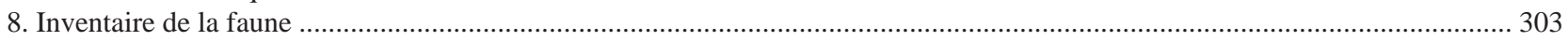




\section{Préface}

J'ai plaisir à préfacer en ma qualité de conservateur régional de l'archéologie cet ouvrage publié sous la direction scientifique de Pierre Excoffon.

D'abord, parce que cette contribution collective met en exergue les compétences d'un jeune collègue qui a su s'attacher des collaborations indispensables pour l'étude de cette fouille qui présente un contexte archéologique et environnemental d'une très grande richesse. En menant à son terme la réalisation de cet ouvrage, Pierre Excoffon montre combien il a su s'impliquer dans l'archéologie fréjusienne en s'entourant des meilleurs spécialistes.

Ensuite, parce que cette publication trouve place dans la collection des BiAMA, quelques mois seulement après la parution d'une autre synthèse présentée par Lucien Rivet sur les fouilles réalisées entre 1979 et 1989 dans le groupe épiscopal et à ses abords. Ces deux ouvrages, publiés de manière rapprochée, attestent de manière positive d'une longue tradition de recherche archéologique dans cette ville où se côtoient et se complètent avec succès les fouilles préventives et programmées.

Enfin, parce que les résultats de cette fouille, terminée en 2007, sont mis à la disposition de tous dans des délais brefs après l'achèvement des études de la post-fouille.

Depuis maintenant plus d'une quarantaine d'années, la communauté archéologique est pleinement investie dans cette reconquête de l'histoire de la cité antique de Fréjus. À cet égard, ce qui a été accompli dans cette ville, tout au long de la seconde moitié du $\mathrm{XX}^{\mathrm{e}}$ siècle et jusqu'à aujourd'hui, est exemplaire. On peut même à ce titre considérer Fréjus comme un modèle sur le plan national. Rares sont en effet les villes qui offrent un bilan scientifique d'une telle importance avec des acquis fondamentaux aussi nombreux comme l'a excellemment montré la synthèse publiée en 2000 dans la série des « Atlas topographiques des villes de Gaule Méridionale ».

Ce viatique archéologique est le fruit de l'investissement important de nombreux chercheurs parmi lesquels s'inscrit au tout premier plan la personnalité de Paul-Albert Février. Cette recherche est aussi marquée par l'implication de toutes les institutions (Culture, CNRS, Université, collectivités, INRAP) qui ont su avec intelligence œuvrer dans le souci de l'intérêt général, en parfaite complémentarité les unes avec les autres.

Nous devons également cette réussite au soutien constant des municipalités successives. Très tôt en effet, la Ville de Fréjus a disposé d'un service archéologique. Elle a su au fil des années renforcer cette structure et la moderniser pour qu'elle conserve toute son efficacité. C'est donc tout logiquement que ce service participant comme opérateur agréé à l'archéologie préventive, tient une place centrale dans la gestion du patrimoine communal et dans la dynamique de recherche.

Cette conjonction de facteurs favorables, étendue sur une longue période, offre maintenant aux archéologues la possibilité de disposer d'une documentation scientifique inédite d'une très riche densité.

Par petites touches, au gré des opérations de diagnostics et de fouilles préventives notamment et par les publications qui suivent, le vaste puzzle de la topographie de Forum Iulii s'étoffe et se précise. Tous ces apports sont majeurs et donnent un éclairage nouveau sur l'urbanisme en Gaule Narbonnaise comme on a pu l'apprécier lors de la tenue 
du VIII ${ }^{e}$ Colloque Historique de Fréjus en novembre 2010. Ils permettent de rouvrir des dossiers de grande ampleur comme celui de l'amphithéâtre mais aussi d'initier de nouvelles recherches sur le paléoenvironnement par exemple.

C'est d'ailleurs sur cette dernière thématique que le présent volume apporte des données significatives en dressant le bilan de la documentation acquise sur le site de la «Villa Romana » occupé depuis le premier siècle avant J.-C. Il complète également les renseignements sur des aspects géomorphologiques et environnementaux de la basse vallée de l'Argens et du cordon littoral que l'on situe un temps à l'emplacement même de la fouille. De manière plus générale, cette opération contribue à préciser l'histoire de l'occupation humaine dans ce quartier de Villeneuve localisé au sud-ouest de la ville à plus de cinq cents mètres du rempart antique. Un secteur qui possédait déjà deux sites archéologiques majeurs : la Ferme de Villeneuve, voisine de la fouille, renfermant les vestiges encore en élévation d'un ensemble thermal reconnu depuis 1613 par Nicolas-Claude Fabry de Peiresc et celui du camp de la flotte d'Agrippa fouillé par Christian Goudineau dans les années 80 dont les résultats ont été publiés tout récemment.

Je souhaite donc que cette contribution collective prenne place au rang qu'elle mérite par sa qualité scientifique et je forme le vœu que d'autres publications, alliant données de fouilles préventives et programmées, suivent pour compléter ce panorama archéologique des périodes antique mais aussi médiévale et moderne.

Il appartient aux archéologues d'approfondir ce sillon de la connaissance pour que Fréjus contemporain s'enrichisse encore de l'histoire de son passé. Il est aussi indispensable que ces acquis soient mis à la disposition des responsables administratifs et politiques en charge du territoire de Fréjus. Cette publication participe à cet enjeu majeur. Ainsi, le Fréjus du XXI ${ }^{\mathrm{e}}$ siècle prendra encore mieux appui sur ce socle unique de son histoire antique marquée par des personnages illustres tel Agricola et des faits historiques majeurs comme le mouillage de la flotte militaire de Cléopâtre après la bataille d'Actium en 31 avant J.-C. qui lui font tutoyer la « Grande Histoire ».

Xavier Delestre

Conservateur général du Patrimoine Conservateur régional de l'Archéologie Région Provence-Alpes-Côte d'Azur 


\section{Avant-propos}

Parce qu'une fouille archéologique est une aventure humaine formidable, et avant tout un travail d'équipe, je tiens ici à revenir, en quelques lignes seulement, sur l'histoire des ces fouilles. Cette «aventure » a commencé le 23 octobre 2006 sur le terrain pour se finir en mars 2008 à la remise du rapport final d'intervention, avant de se remettre à la tâche pour enfin aboutir à la publication.

Au total, 40 personnes sont directement concernées : 15 sur la fouille ${ }^{1}$ et 25 pour la post-fouille, la partie immergée de l'iceberg...

À cette publication, j'ai ajouté les principales données issues d'un diagnostic archéologique réalisé sur le bâtiment des Thermes de Villeneuve que j'ai mené avec Sandrine Ardisson en 2008². L'enchaînement soutenu des opérations préventives sur la commune de Fréjus ces dernières années n'a pas facilité la tâche et c'est grâce à une étroite collaboration entre tous et à l'engagement de respecter les délais impartis à chacun, tâche ô combien difficile, que cette publication peut être livrée aujourd'hui, trois ans après la remise du rapport final.

La fouille préventive de Villa Romana ne fait pas exception à la règle, elle a été rendue possible grâce à la constitution d'une équipe d'archéologues et de spécialistes et à une étroite collaboration entre tous les acteurs du projet, du promoteur aux maçons, en passant par les entreprises de rabattement de nappe phréatique et d'installation des palplanches, les terrassiers et les services de la Ville de Fréjus. C'est donc une quantité considérable de personnes qui ont permis de mener cette opération de fouille à son terme, ils sont donc nombreux à mériter notre gratitude 3 .

Près de $13500 \mathrm{~m}^{3}$ de terre et de sable ont été retournés à la main ou à la pelle mécanique, en quatre mois de fouille. Difficile de remercier chaque fouilleur mais cet ouvrage est aussi le leur. Pour lutter contre les inondations de décembre 2006, Stéphane Bonnet, Christian Arhab, Nicolas Portalier et Mourad El Amouri ont redoublé de volonté et fait tourner les pompes à plein régime. La mise en place des palplanches et du système d'épuisement de nappe n'a pas été non plus une mince affaire, d'autant que la fouille était déjà bien entamée et les niveaux archéologiques nettoyés ! La vigilance et les « énervements contrôlés » de Juliette Michel y ont pour beaucoup contribué...

L'organisation de la fouille s'est faite autour de trois responsables de zone : Raphaële Guilbert-Berger, Juliette Michel et Nicolas Portalier. Les questions géomorphologiques étaient suivies par Stéphane Bonnet et la coordination des études paléobotaniques par Laurent Bouby. Quel plaisir pour moi de travailler avec eux!

Enfin, sur ce chantier parfois ingrat et aux découvertes spectaculaires rares, la collecte d'informations a été longue et fastidieuse mais la présence d'une nappe phréatique haute a permis la conservation de précieuses données paléoenvironnementales : sans la minutie et l'organisation sans faille de Sandra Greck, la gestion de plus de 600 prélèvements aurait été tout simplement impossible. Sandra a surtout été la pierre angulaire de cette fouille, sur laquelle je me suis largement appuyé. Je lui fais part ici de toute ma reconnaissance.

\footnotetext{
1 Équipe de fouille : Sabine Dupuy, Élisabeth Lefeuvre, Juliette Michel, Mélissa Savanier, Élise Devidal, Raphaëlle Guilbert-Berger, Sandra Greck, Mourad El Amouri, Guillaume Hairy, Antoine Pasqualini, Bertrand Ruelle, Nicolas Portalier, Stéphane Bonnet, Christian Arhab et Pierre Excoffon.

2 Équipe de fouille : Sandrine Ardisson, Audrey Peltier-Buda, Hélène Garcia, Ambre Thuvignon, Lenaïc Riaudel, Dorian Boyer et Pierre Excoffon.

3 Noël Fabiano, Marc et Jonathan Vaniambourg (JMV), Luc Maratray (Pompe Énergie), José Lopez (Ville de Fréjus - Services Techniques), Stéphane Gress et Jacques Born (Kauffman et Broad), José Rivas (coordinateur), Stéphane Bontoux (coordinateur SPS), Marina Dutartre et Pascale Denis (Ville de Fréjus Service du Patrimoine)...
} 
Sans la clairvoyance et l'expérience de Michel Pasqualini, qui a su nous guider dans l'organisation du projet, tout cela aurait été bien plus compliqué encore...

Les relevés pierre à pierre sont, pour l'essentiel et sauf mention contraire, l'œuvre du coup de crayon d'Élise Devidal. Pour les découvertes du diagnostic sur la Ferme de Villeneuve, je tiens vivement à remercier Sylvestre Roucole, «l'incontournable », pour la qualité de ses relevés...

La topographie est le fait de Françoise Laurier, à l'époque salariée du Centre Archéologique du Var, dont les visites régulières ont ponctué la campagne de fouille.

Mon entière gratitude à Joris Pâques pour sa qualité d'infographiste certes, mais surtout pour sa formidable patience pour supporter les interminables « dernières modifications »... La même reconnaissance à Sandrine Baiocchi pour sa remarquable efficacité à traquer « la dernière c@quille »...

Je remercie Xavier Lafon pour sa relecture et ses remarques avisées.

Enfin, je tiens à remercier l'ensemble des archéologues, spécialistes et amis qui sont passés sur le site ou durant la post-fouille et la rédaction du présent volume pour nous conseiller ou nous encourager, parmi eux : Sylvie Saulnier, Lucien Rivet, Henri Broise, Jean-Marie Gassend, Roger Boiron, Corinne Landuré, Chérine Gébara, Jean-Marie Michel, Suzane Roscian, Emmanuel Botte, Alain Badie, Grégoire Poccardi, Danielle Soustelle Guillaume Vanhess et bien d'autres...

Pierre Excoffon 


\section{Introduction}

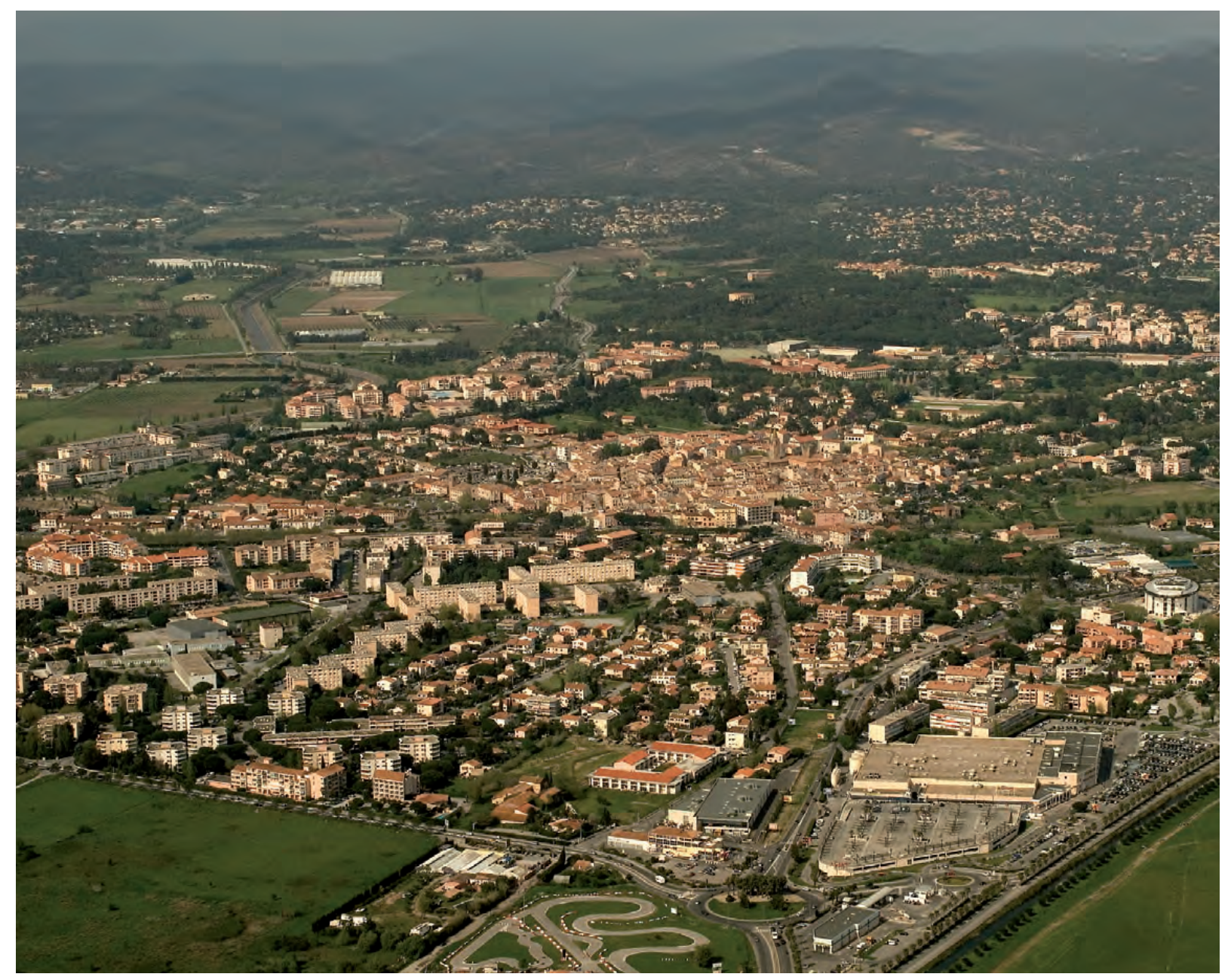

Vue aérienne avec, au premier plan, le quartier de Villeneuve, au second, la ville de Fréjus et, en arrière plan, le massif de l'Estérel (Cl. Ville de Fréjus / M. Heller ${ }^{\odot}$. 



\title{
Introduction
}

\author{
(P. E., S. B., coll. S. A. et B. D.)
}

\section{Localisation et origine du projet}

Le quartier de Villeneuve se trouve à l'est de la ville de Fréjus et s'étend au-delà de la butte Saint-Antoine jusqu'au quartier de Villepey. Il est aujourd'hui distant d'environ $1,5 \mathrm{~km}$ du bord de mer et se compose essentiellement d'espaces résidentiels bordés au sud par une zone commerciale. Le secteur de la fouille se situe dans la partie sud-ouest, à l'angle de l'avenue du 8 mai 1945 et de la rue Jean-Carrara, en limite de la zone commerciale. Jouxtant la Ferme de Villeneuve classée Monument Historique, ce terrain est resté vierge de construction malgré la pression immobilière forte dans ce quartier depuis les années 60. En 1998, faisant suite au dépôt d'un permis de construire, un diagnostic archéologique est demandé par l'État et réalisé par l'AFAN (Michel 1998). Initialement prévu sur l'ensemble de la parcelle, les résultats de ce dernier inciteront l'État à réduire l'étendue du projet immobilier à un tiers de la surface disponible.

\section{Cadre naturel}

Le territoire de Fréjus se situe à la jonction de plusieurs ensembles géologiques remarquables : à l'ouest, le massif cristallin des Maures ; au nord, les massifs calcaires et, à l'est, le massif d' origine volcanique de l'Estérel. Au centre se dessine l'extrémité orientale de la dépression permienne au sol de grès, constituant l'axe de passage naturel entre Fréjus et Toulon et ceinturant au nord le massif des Maures. Le cadre occupé par le site de Villa Romana se développe au sein d'une plaine alluviale, étirée entre Maures et Estérel, au débouché de la dépression permienne où coulent les basses vallées de l'Argens et du Reyran, avant de se jeter dans la Méditerranée (fig. 1). Le fleuve Argens, navigable depuis la mer jusqu' au Muy, prend sa source à 116 km, à Seillons dans les massifs calcaires. Le Reyran, long de $25 \mathrm{~km}$, prend sa source à Bagnols-en-Forêt dans les massifs de rhyolite. De récents travaux ont montré que les alluvions de l'Argens colmatent progressivement la ria holocène depuis le pont d'Argens (situé à $9 \mathrm{~km}$ en amont du site nous concernant), où on localise le rivage 7000 ans avant notre ère (Dubar 2004a et 2008). $\mathrm{Au} \mathrm{VII}^{\mathrm{e}}$ siècle av. J.-C., le rivage aurait progressé jusqu'aux environs des Escaravatiers à Puget-surArgens (à $3 \mathrm{~km}$ du rivage actuel), puis encore de $1000 \mathrm{~m}$ plus au sud aux alentours du $\mathrm{I}^{\text {er }}$ siècle av. J.-C. Le littoral devait ainsi dessiner un golfe profond entre les premiers massifs des Petites Maures et la pointe du Lion de Terre à Saint-Raphaël. Le promontoire rocheux, sur lequel la ville de Fréjus est installée, devait s'avancer en pointe. Aujourd'hui, au fond de la baie, s'étire une bande sableuse de $6 \mathrm{~km}$ de long, délimitée par les massifs des Maures et de l'Estérel, où se déversent, dans une même embouchure, l'Argens et le Reyran. En arrière de cette plage, le remblaiement par des alluvions étendues et maîtrisées a permis l'enrichissement des sols et favorisé le développement de l'agriculture jusqu'à l'expansion urbaine récente liée au tourisme de masse.

\section{Données historiques}

\subsection{Avant Forum Iulii}

Si l'on connait le nom des peuples celto-ligures occupant la région de Fréjus avant la conquête romaine : les Oxybi sur l'Estérel et les Suelteri dans les Maures, on ne sait presque rien sur l'organisation de leur territoire. Polybe (XXXIII, 8-10) nous apprend qu'à la suite de nombreuses attaques ligures et du siège d'Antipolis et Nikaia (Antibes et Nice), les Massaliotes firent appel à Rome en 154 avant notre ère. Envoyé par le Sénat, Quintus Opimius défit les Oxybiens auxquels s'étaient joints les Déciates et rendit aux Massaliotes les territoires perdus. Enfin, reste une énigme, celle de la capitale des Oxybiens, nommée Aigitna, dont la localisation nous échappe entièrement ${ }^{1}$.

1 Plusieurs sites ont été envisagés pour localiser Aigitna : Théoule, La Napoule, Fréjus... 


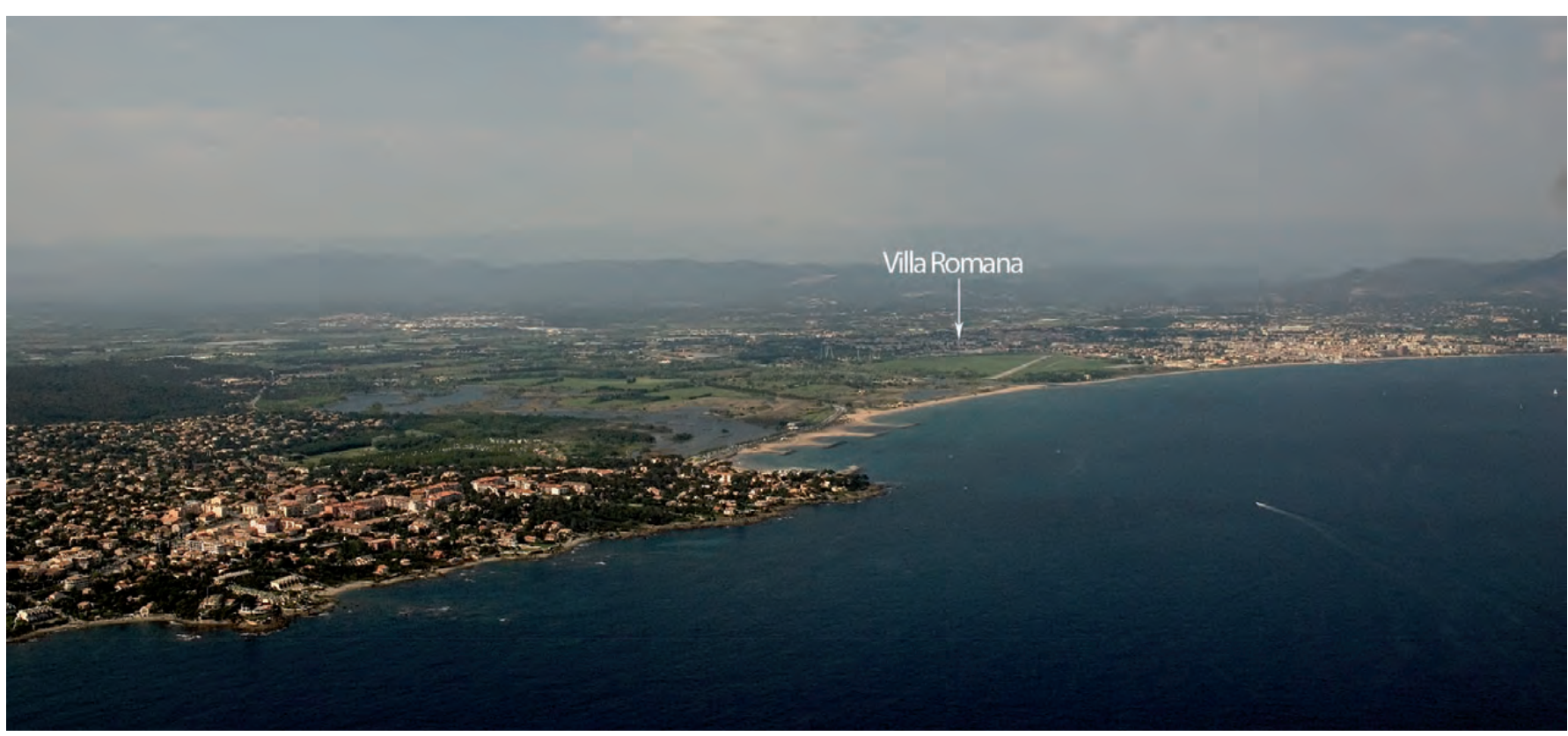

Fig. 1. Vue aérienne de la basse vallée de l'Argens avec localisation du site (Cl. Ville de Fréjus / M. Heller@).

Sur le territoire proche de Fréjus, 19 établissements sont recensés aux $\mathrm{II}^{\mathrm{e}}$ et $\mathrm{I}^{\mathrm{er}}$ siècles av. J.-C. (Bertoncello 2005 , 46) et aux alentours immédiats de la ville, moins d'une dizaine d'habitats fortifiés de hauteurs occupés durant le deuxième âge du Fer est connue, tous en retrait de la mer (fig. 2). À l'emplacement de la ville antique, des traces d'occupation plus anciennes sont connues (butte Saint-Antoine, Théâtre Romain) (Excoffon 2008 et Rivet et al. 2000, 470), mais restent trop ténues pour définir un mode d'occupation permanent ou temporaire. Sur cette quasi-absence d'occupations proches de la mer pour le deuxième âge du Fer, Strabon (IV, 1, 5) fournit un élément d'explication en signalant qu'à partir de 122 av. J.-C., selon la volonté de Rome, une bande littorale large de 8 à 12 stades $^{2}$ dépendait du domaine massaliète. Mais notons également que la présence massaliète n'est pas pour autant plus remarquable...

C'est donc dans ce contexte évidemment équivoque que s'implante la fondation césarienne.

\subsection{Forum Iulii}

Bien que discutée, la date de fondation de Forum Iulii est antérieure à 43 av. J.-C., puisque le nom est mentionné par Plancus dans une lettre adressée cette année là à Cicéron $(X, 15,3$ et $X, 17,1)$. En revanche, elle ne saurait être antérieure à 49, date du Siège de Marseille et ainsi donc, de la fin de la possession par cette ville de la frange côtière permise par Rome depuis 122 (Gascou,

\footnotetext{
2 Soit 1,3 à 2,2 km.
}

Janon 1985,14$)^{3}$. On ne connaît pour ainsi dire rien de la forme de ce premier « marché », simple bourgade si l'on suit C. Jullian (1886), étape sur la route de l'Italie vers l'Espagne (fig. 3). Pour Chr. Goudineau, la signification même du terme forum n'a qu'une valeur administrative et n'implique nullement une fonction particulière attribuée à la localité (Goudineau, Brentchaloff 2009, 578-579). Tacite (IV, 5, 1) nous éclaire en signalant qu'après la bataille d'Actium, en septembre 31 av. J.-C., les navires d'Antoine et leurs équipages capturés par Octave y sont envoyés. C'est à ce moment que serait édifié le camp militaire découvert dans le quartier des Aiguières à Villeneuve (Goudineau 1982 et Goudineau, Brentchaloff 2009). Fréjus devient quelques années plus tard, entre 29 et 27 av. J.-C., une colonie de droit romain avec la déduction de vétérans de la VIII Légion et devient Forum Iulii Octavanorum quae Pacensis appellatur et Classica (Pline, III, 4, 35). C'est après cette date que la localité commence réellement à se développer suivant un premier schéma urbain partant de la butte SaintAntoine, réseau désigné A et orienté NL $15^{\circ}$ ouest (Rivet et al. 2000) dont les traces ne subsistent que dans le quart sud-est de la ville, généralement sous la forme de soubassement fait de gros moellons simplement équarris et liés à la terre (fig. 4). Des traces sont présentes dans les quartiers de la cathédrale (Rivet 2010, 33-37) et

3 Cette fondation pourrait, selon P. Gros, être attribuée à Tibérius Claudius Nero, père du futur empereur Tibère (Gros 2008, 24) lorsque celui-ci est envoyé en Gaule pour déduire les colonies de Narbonne et d'Arles, donc entre l'automne 46 et les ides de mars 44 (Suétone, IV, 2). 


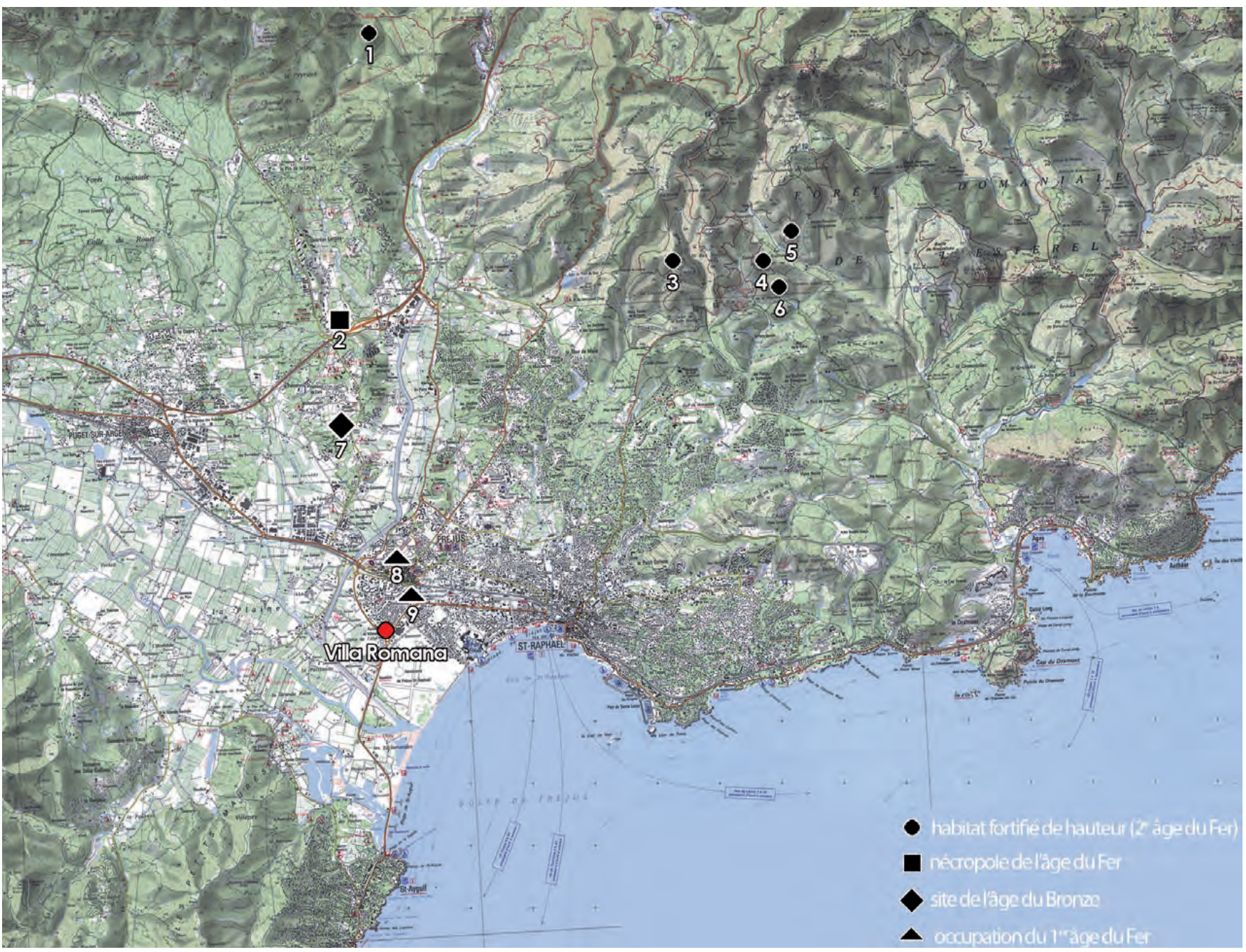

Fig. 2. Localisation des sites protohistoriques

1. Habitat de hauteur fortifié La Gardiette 1 / 2. Incinération et habitat du Capitou $\left(\mathrm{Vle}^{\mathrm{e}}\right.$ - Ve s. av. J.-C.) / 3. Habitat de hauteur fortifié du Barban (IIle et ler s. av. J.-C., réoccupation au IIIe S. apr. J.-C.) / 4. Habitat de hauteur fortifié du Bonnet du Capélan 1 (Ile et ler s. av. J.-C.) /

5. Habitat de hauteur fortifié Gué de la Cabre / 6. Habitat de hauteur fortifié du Bonnet de Capelan 2 La Péguière / 7. Occupation de l'âge du Bronze La Cigale d'Or / 8. Théâtre romain Les Claus 2 / 9. Butte Saint-Antoine.

de Mangin (Pasqualini et al. 2006) (fig. 4 - $\mathrm{n}^{\text {os }} 1$ et 2). La datation de ces contextes est difficile, au plus tôt ils pourraient remonter au dernier tiers du Irr siècle av. J.-C.

Les années 29-27 av. J.-C. apparaissent séduisantes puisqu'elles correspondent à la date de la déduction de la colonie...

À partir des années 15 apr. J.-C., un nouveau réseau, B, orienté NL $38,5^{\circ}$ ouest est implanté selon un axe exprimé par le decumanus reliant la Porte de Rome (fig. 4 - $\mathrm{n}^{\circ}$ 3) à la Porte des Gaules (fig. 4 - $\mathrm{n}^{\circ}$ 4) et recoupant perpendiculairement le cardo reliant les portes piétonnes de l'Agachon (fig. 4 - $n^{\circ}$ 5) et de Notre-Dame (fig. 4 - $n^{\circ} 6$ ). L'enceinte, dont l'édification commence dès le début du $\mathrm{I}^{\text {er }}$ siècle apr. J.-C., est longue de $3750 \mathrm{~m}$ et englobe une superficie d'environ 46 ha à la fin de ce même siècle.

Le quartier de Villeneuve, excentré, paraît être quelque peu délaissé au profit du reste de la ville mais, si son développement cesse dans le courant de la deuxième moitié du Ir siècle apr. J.-C., il continue d'être occupé (fig. 5).

\subsection{Le secteur du quartier de Villeneuve}

Les recherches archéologiques dans le quartier de Villeneuve sont déjà anciennes, en particulier en raison des vestiges imposants que constituent les Thermes de Villeneuve $^{4}\left(\right.$ fig. 6 - n ${ }^{\circ} 1$ ).

4 À l'époque moderne, une ferme avec étable, grange et habitation y est installée. Sa dernière fonction en 1998 est celle d'une exploitation vinicole. C'est le terme «Ferme de Villeneuve » qui apparaît sur les plus anciens documents et plans cadastraux et qui signale ce bâtiment. Il donnera à la fin du XVII ${ }^{e}$ siècle son nom au quartier, anciennement désigné quartier Saint-Pierre en raison d'une chapelle mentionnée dès le XII ${ }^{\mathrm{e}}$ siècle. 


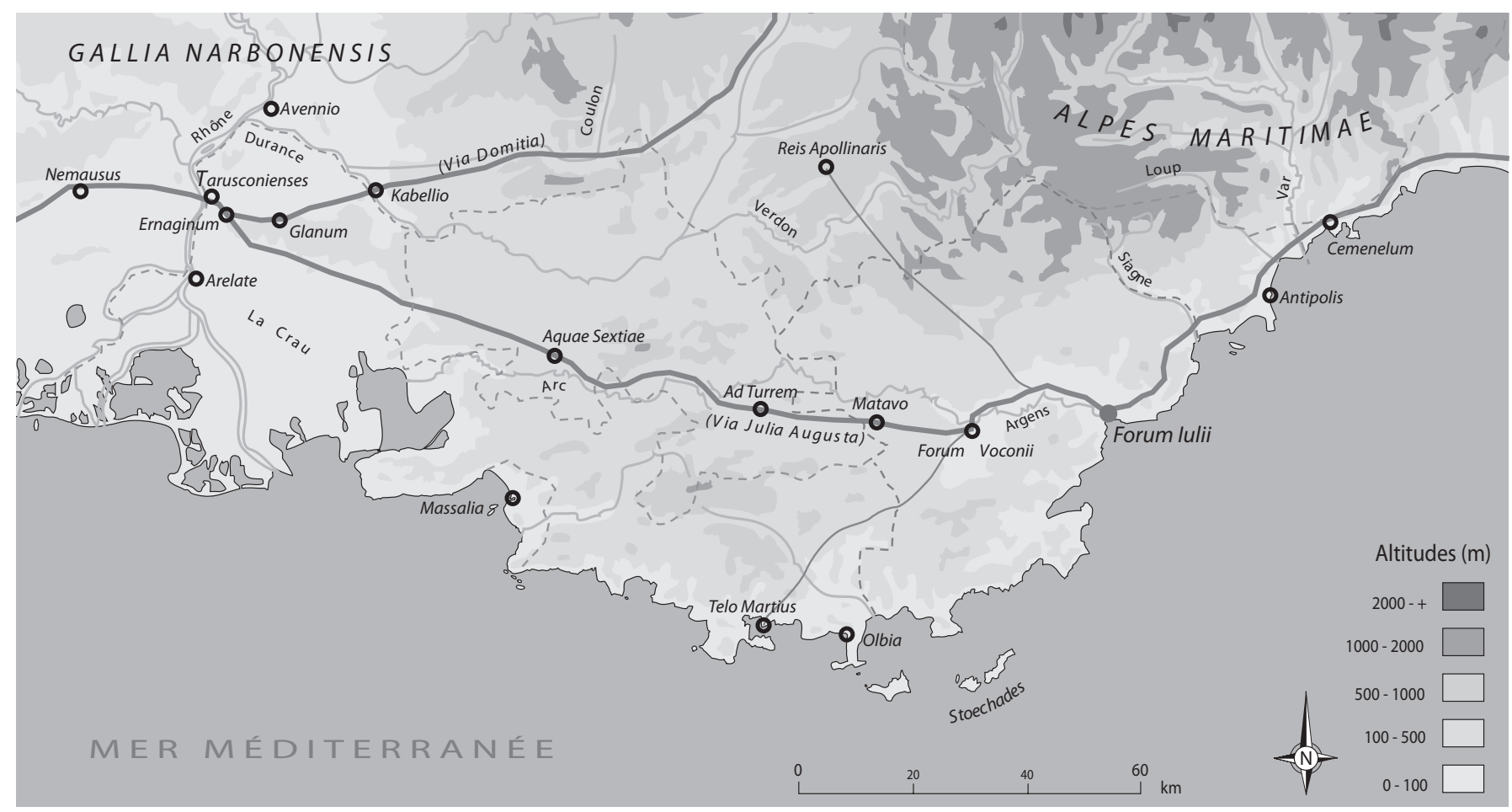

Fig. 3. Situation de Forum Iulii sur la via Iulia Augusta.

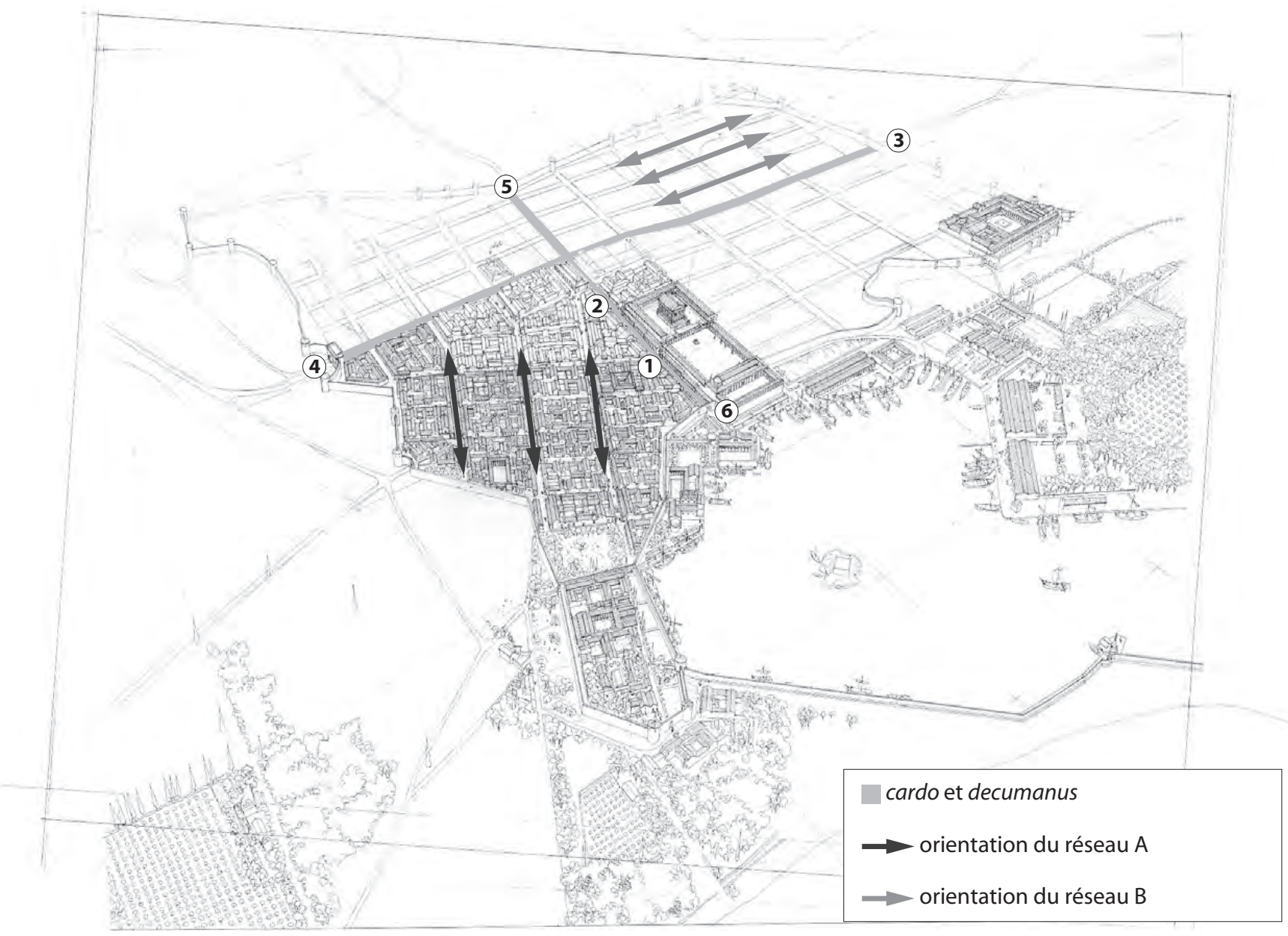

Fig. 4. Les deux réseaux de Forum Iulii et les axes principaux (d'après l'esquisse de J.-Cl. Golvin). 


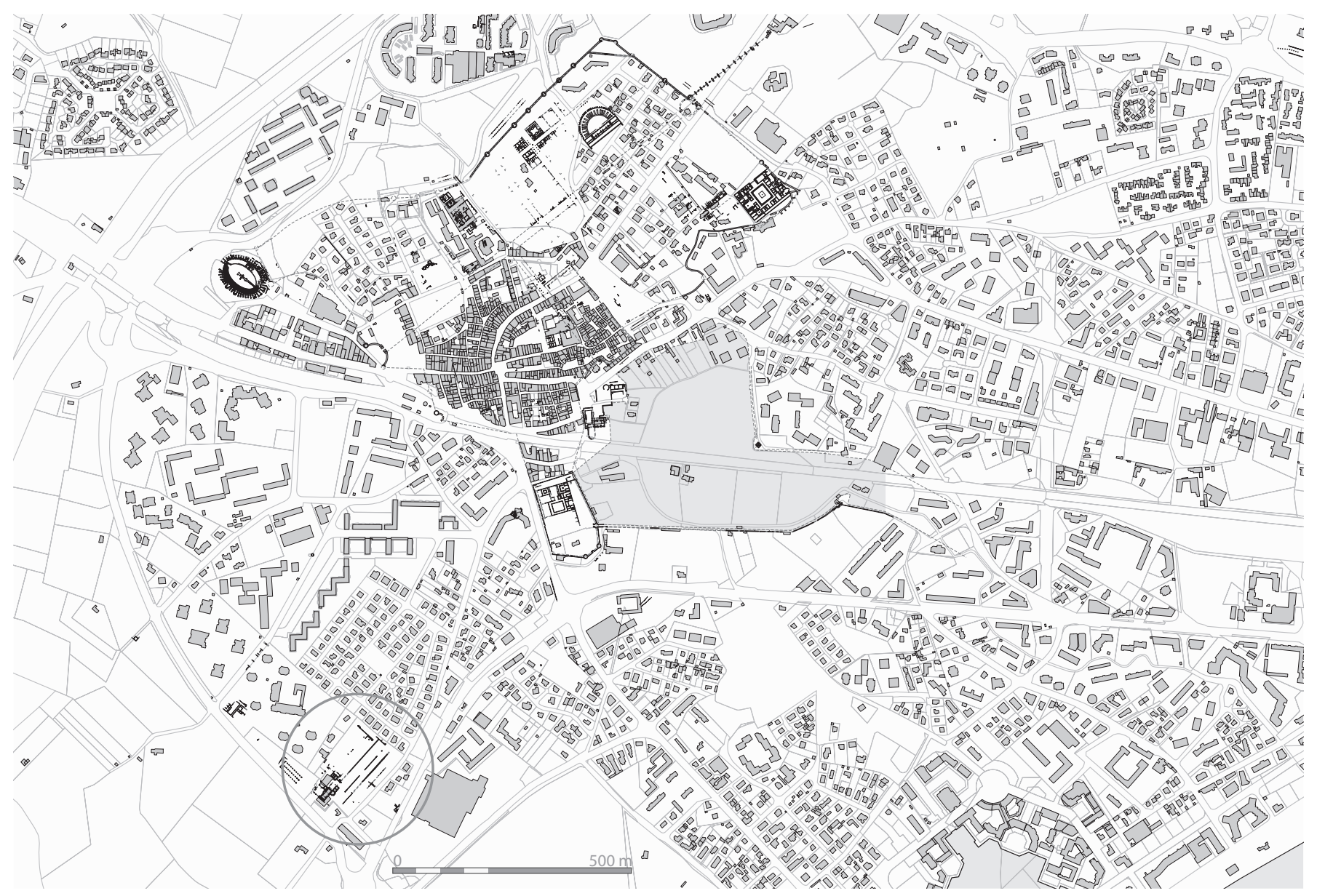

Fig. 5. La colonie de Forum Iulii au Ile s. apr. J.-C. et localisation du site de Villa Romana (fonds topographique Ville de Fréjus / Rivet et al. 2000).

Ce monument est reconnu et identifié comme des thermes pour la première fois en 1630 par N.-Cl. Fabry de Peiresc qui en fait un premier croquis. Ce bâtiment attirera l'attention de l'ensemble des historiens et érudits qui ont travaillé sur Fréjus.

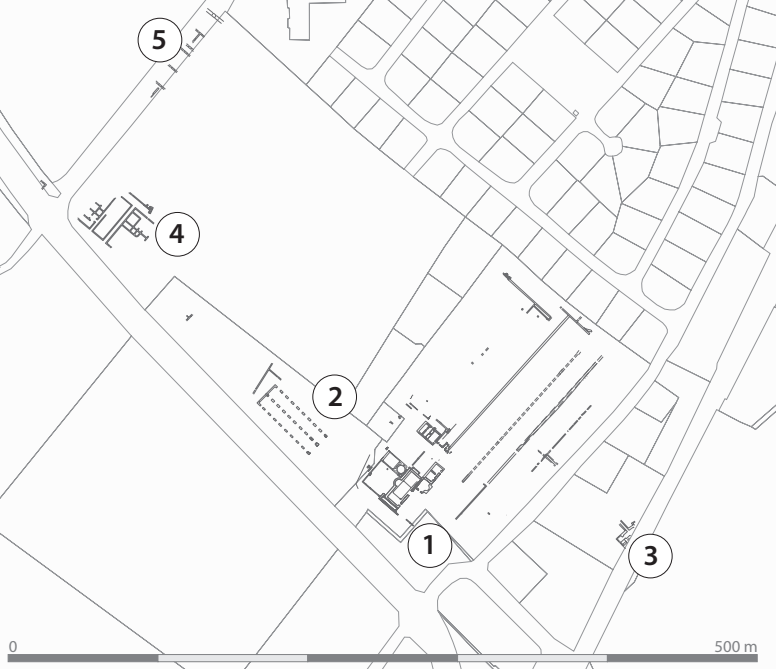

Fig. 6. Quartier de Villeneuve : les opérations effectuées aux alentours de Villa Romana.
Tous y sont allés de leurs fouilles, plus ou moins importantes, et de leurs identifications et interprétations ${ }^{5}$. En 1849, les premiers relevés précis (plans et élévations) sont l'œuvre de Ch. Texier. À la fin du XIX $\mathrm{X}^{\mathrm{e}}$ siècle, J.-A. Aubenas donne une description détaillée de cet ensemble qui sera classé en 1886 au titre des Monuments Historiques. Les premières fouilles d'importance sont réalisées en 1920 par A. Donnadieu. Depuis, plusieurs publications et études ont permis d'apporter quelques éclairages nouveaux et de nouvelles hypothèses (Février 1956 ; Bouet 2003 ; Rivet et al. 2000 et Gébara, Michel 2004). Mais la dernière intervention sur le terrain remonte aux mois de mars et avril 2008, lorsque le Service du Patrimoine de la Ville de Fréjus est à nouveau intervenu sur le monument suite à un dépôt de permis de construire... Ainsi S. Ardisson et P. Excoffon ont réalisé un diagnostic archéologique dans et aux abords immédiats du bâtiment. Les résultats topographiques de l'opération, réalisée postérieurement à la fouille de Villa Romana, présentent un complexe bien plus important que celui envisagé par

5 Celles-ci sont répertoriées scrupuleusement dans l'Atlas topographique de Fréjus (Rivet et al. 2000, 334-339). 
BIBLIOTHÈQUE D’ ARCHÉOLOGIE MÉDITERRANÉENNE ET AFRICAINE - 8

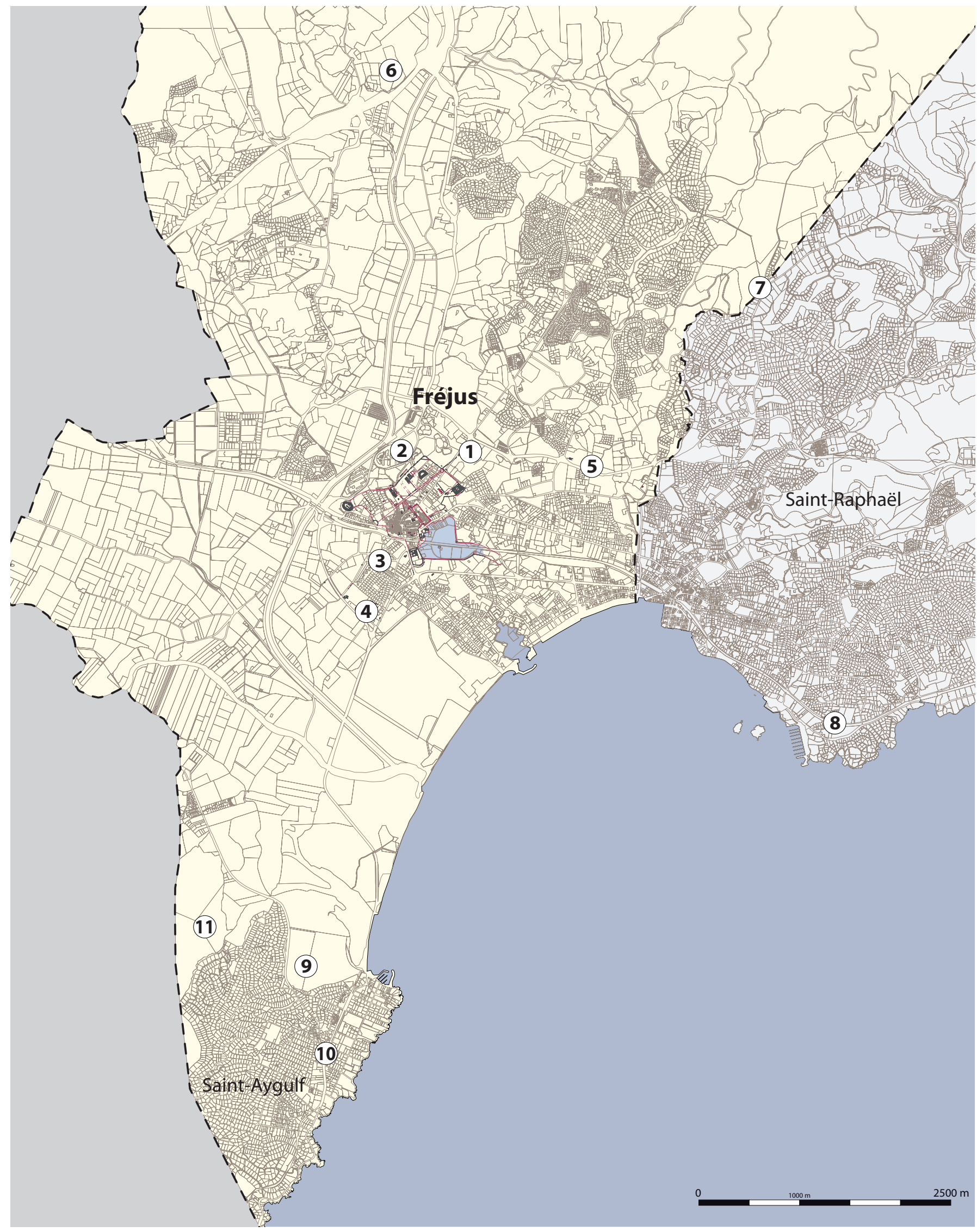

Fig. 7. Les environs immédiats de Forum Iulii. 
les seuls vestiges restés en élévation et ont été intégrés aux plans fournis dans ce volume.

À ce jour le projet immobilier n'a pas encore abouti...

D'autres sondages et fouilles archéologiques ont été réalisés aux abords immédiats du monument. En 1988, une série de sondages provoquée par la construction d'une résidence hôtelière a permis la découverte d'un égout (fig. $6-\mathrm{n}^{\circ} 2$ ), peut-être en lien avec le bâtiment thermal, et surtout d'un édifice à deux nefs délimitées par trois rangés de dix bases de piliers (48,40 m x 17,30 m) (Borréani, Jaget 1988). Ce dernier est interprété comme un horreum daté de la première moitié du Ier siècle apr. J.-C. En 2005, au sud de Villa Romana, le long de l'avenue de l'Argens, fut réalisé un diagnostic en prévision de l'édification d'un magasin de bricolage (Michel 2005) (fig. 6 - $n^{\circ} 3$ ). Les vestiges découverts, en partie immergés par la nappe phréatique, n'ont pu être interprétés. Ils correspondent à un espace long de 8,60 m et large de $3 \mathrm{~m}$, délimité par de puissants murs d'environ $1,50 \mathrm{~m}$ d'épaisseur. Cette structure est construite symétriquement à l'arrivée d'un corridor maçonné venant du nord. Mais l'intérêt archéologique du quartier avait déjà été révélé dès 1976, lors de la construction du lotissement de « l'Argentière » (fig. 6 $n^{\circ} 4$ ) où les terrassements avaient livré une forte quantité de mobilier et de monnaies antiques. Enfin, et surtout, la fouille menée par Chr. Goudineau entre 1979 et 1981 au quartier des Aiguières (fig. $6-n^{\circ} 5$ ) a permis de mettre au jour d'importants vestiges démontrant d'une part la richesse archéologique de ce quartier excentré et, d'autre part, l'ancienneté de son occupation comme camp de la Flotte (Goudineau, Brentchaloff 2009). La publication de cet ouvrage arrivant in extremis au moment de remettre notre manuscrit, les principales données concernant en particulier le camp ont pu malgré tout être, du moins dans leurs grandes lignes, prises en compte dans notre développement. L'actuel quartier de Villeneuve apparaît comme l'un des plus anciennement occupés 6 , au moins depuis 28 av. J.-C., voire avant, comme tente de le démontrer de façon très convaincante Chr. Goudineau en s'appuyant certes davantage sur les textes et sur la configuration ancienne du littoral que sur des résultats archéologiques évidents $(2009,580)$. Il s'agirait alors d'un camp militaire, situé en bord de mer au sein de « l'anse qui incurvait le rivage » et formant un port naturel. Toutefois, l'état le plus ancien mis au jour par les fouilles remonte aux années 10-5 av. J.-C. Il s'agit alors d'îlots allongés séparés par des ruelles assainies

6 Nous entendons par là, la plus ancienne occupation romaine. Sur le site de la ville antique, des traces d'occupation protohistoriques ont été observées [butte Saint-Antoine, quartier du Théâtre (Excoffon 2008)] mais elles sont bien antérieures et sans lien avec l'installation des premiers colons. par des alignements d'amphores. Ces aménagements, correspondant à des casernements, connaîtront plusieurs modifications et reprises jusqu'en 40-50 apr. J.-C. À partir de cette date, le secteur commence à montrer des signes de désaffection, avant un abandon définitif vers 65-75 apr. J.-C. Une réoccupation modeste durant l'Antiquité tardive est ensuite attestée (Goudineau, Brentchaloff 2009).

\subsection{Nécropoles, faubourgs et campagne autour de Fréjus}

Trois nécropoles d'importance sont bien reconnues par l'archéologie. L'une se situe au nord de la ville antique dans le quartier actuel du Pauvadou (fig. $7-\mathrm{n}^{\circ} 1$ ), une autre à l'est le long de la voie venant d'Italie, dans le quartier actuel de Saint-Lambert (fig. 7 - $n^{\circ} 2$ ) et, enfin, une à l'ouest entre le quartier de Villeneuve et la butte Saint-Antoine (fig. $7-\mathrm{n}^{\circ} 3$ ). D'autres zones plus modestes, voire des tombes ou des mausolées isolés, sont attestées et impliquent une vision moins stricte de l'organisation des nécropoles, d'autant que les axes de communication autour de Fréjus, le long desquels s'érigeaient généralement ces monuments, restent mal connus.

Les quartiers suburbains connus sont peu nombreux. Outre celui de Villeneuve (fig. $7-\mathrm{n}^{\circ} 4$ ), une partie importante d'un autre quartier situé sur la voie littorale menant vers Antibes, a été mise au jour à l'occasion d'une fouille préventive au Chemin de Valescure (fig. 7 - $n^{\circ} 5$ ). Jouxtant un atelier de production de céramiques, un vaste bâtiment construit dans le courant du I ${ }^{\text {er }}$ siècle apr. J.-C. le long de le voie a été découvert et interprété comme un entrepôt (Cotto 2009).

Plusieurs fermes et villae sont attestées autour de Fréjus, avec plus ou moins de précision, mais permettent d'esquisser une organisation du territoire proche (Février 1977). La fouille récente menée par M. Pasqualini dans le quartier du Capitou témoigne de l'existence de ce type d'implantation dès le I ${ }^{\text {er }}$ siècle av. J.-C. (fig. 7 - n' 6). D'autres sont connues, soit par des fouilles comme le Suveret au nord-est de Valescure, soit par des sondages ou prospections, comme à Saint-Raphaël sous l'actuel casino (fig. 7 - ${ }^{\text {os }} 7$ et 8). À l'ouest du quartier de Villeneuve, plusieurs autres établissements sont présents, notamment la villa de Villepey (ou villa Podii), ou celles de la Gaillarde et du Reydissard (fig. 7 - nos 9, 10 et 11). Bien que difficiles à dater, donc à intégrer dans un processus d'évolution, ces fermes et villae témoignent d'une structuration du territoire dès l'implantation des premiers colons et donc de déduction de terres selon une cadastration qui reste toujours à définir. 


\section{4. Étude géomorphologique des milieux littoraux}

\subsection{Position du littoral et port naturel}

Depuis la remontée relative du niveau marin postglaciaire, la plaine deltaïque actuelle de l'Argens, à l'instar des autres plaines provençales de niveau de base, a connu des mutations paysagères très importantes (Dubar 2003, 263-270 et Dubar, Anthony 1995, 329343). Du fait de la forte implantation humaine au sein de cette basse vallée, notamment durant l'Antiquité, de nombreuses recherches archéologiques ont été effectuées à proximité de Forum Iulii. L'étude de la répartition des sites a permis de traiter, indirectement, des milieux anciens affectant cet espace mais cette approche était limitée par le faible nombre de sites ; on ne sait pas s'il s'agit d'une réelle absence d'occupation ou d'un enfouissement trop profond des vestiges (Bertoncello 1999 ; Brentchaloff, Stutz 1997, 63-70 ; Fiches et al. 1995, 205-261 et Violino 1990, 149-151). La réalisation, depuis 1995, de plusieurs études paléoenvironnementales, rattachées ou non à des opérations archéologiques, a apporté des éléments permettant de mieux appréhender l'évolution des milieux depuis 6000 ans, période à laquelle la basse plaine s'est constituée grâce au ralentissement de la remontée du niveau marin, à la diminution de l'espace d'accommodation et à l'augmentation du taux de sédimentation (Bertoncello, Devillers 2006, 223226 ; Bertoncello et al. 2008 ; Cohen 1991 et 1997, 6-12 ; Dubar 2009, 39-43 ; Devillers et al. 2007, 329336 ; Devillers, Bonnet 2006, 197-203 ; Excoffon, Devillers 2006, 205-221 et Fiches et al. 1995, 205261). Cependant, la complexité de l'imbrication des corps sédimentaires et le nombre encore insuffisant d'études spécifiques n'ont pas permis d'identifier, à l'échelle de la basse vallée, la totalité des mutations paysagères durant l'Holocène. La divergence des résultats entre les différentes études concernant la restitution du trait de côte à l'époque antique traduit cette difficulté. Le diagnostic archéologique du Théâtre d'Agglomération réalisé en 2006, en contrebas de la butte Saint-Antoine, a apporté le premier point d'accroche incontestable pour la restitution des lignes de rivage au cours du premier siècle av. J.-C. Outre une estimation du niveau marin pour la fin du Irr siècle av. J.-C. compris dans une fourchette allant de $-0,210$ à $-0,392 \mathrm{~m}$ NGF, cette opération a mis en évidence un changement de nature du rivage au tout début du $I^{\text {er }}$ siècle apr. J.-C. En effet, la côte rocheuse battue par la mer qui se développait jusqu'alors autour de la butte Saint-Antoine s'est transformée en une plage sableuse en raison de l'avancée du cordon littoral vers le sud-ouest (Excoffon, Devillers 2006, 205-221 ; Devillers et al. 2007, 329-336 et Excoffon et al. 2010).

La restitution du trait de côte que nous avions alors proposée (Excoffon, Devillers 2006, 215, fig. 15), permettait d'envisager un littoral baignant l'extrémité sud du quartier de Villeneuve, hypothèse confirmée par la fouille de Villa Romana (fig. 8). Dès lors, l'existence d'un port naturel, ou du moins d'un mouillage établi dans un estuaire formé par l'Argens, le Reyran et la Garonne, devient une hypothèse plus envisageable. Le premier à supposer l'existence d'un port dans ce secteur de Fréjus est Ch. Texier (1849, 189-190). La réalité d'une anse profonde au niveau du débouché de l'Argens et d'un possible mouillage se confirme en 1957, lors de la découverte dans les étangs de Villepey d'une épave au lieu-dit la Clavelède (Boyer, Février 1971, 159-166). Puis, dans le cadre d'un programme de recherche sur la basse-vallée de l'Argens ${ }^{7}$, le croisement des données géomorphologiques et l'interprétation des photos aériennes ont permis de confirmer cette vision d'une embouchure large et profonde. L'existence possible d'un port antérieur à celui associé à l'agglomération a été mise en lumière en prenant comme base la datation actuellement retenue pour la construction du bassin du grand port aux alentours du changement d'ère (Rivet et al. 2000 et Gébara, Morhange 2010). En effet, la réception des bateaux capturés par Octave lors de la bataille d'Actium en 31 av. J.-C. implique nécessairement l'existence d'un port, ou du moins d'un mouillage conséquent, dès cette époque. Si le quartier de Villeneuve est le plus anciennement occupé, il convient naturellement de le restituer dans ce secteur. Si sa localisation exacte reste à définir, il apparaît aujourd'hui crédible de le rapprocher du « camp de la flotte » (Goudineau, Brentchaloff 2009, 41-50). Néanmoins, il convient par prudence d'envisager sa localisation dans une aire vaste, comprise entre les étangs de Villepey et le camp proprement dit. À cette question, Chr. Goudineau et D. Brentchaloff proposent une restitution du rivage à l'Antiquité séduisante mais téméraire en dessinant une anse profonde à l'ouest de Villeneuve alors que rien ne permet de le justifier (ibid., 41-50 et fig. 85).

\subsection{Problématique géomorphologique}

Le site est distant d'environ $1,5 \mathrm{~km}$ du rivage actuel. Ce secteur est sujet à la progradation littorale

7 Résultats partiellement publiés dans Fiches et al. 1995. 


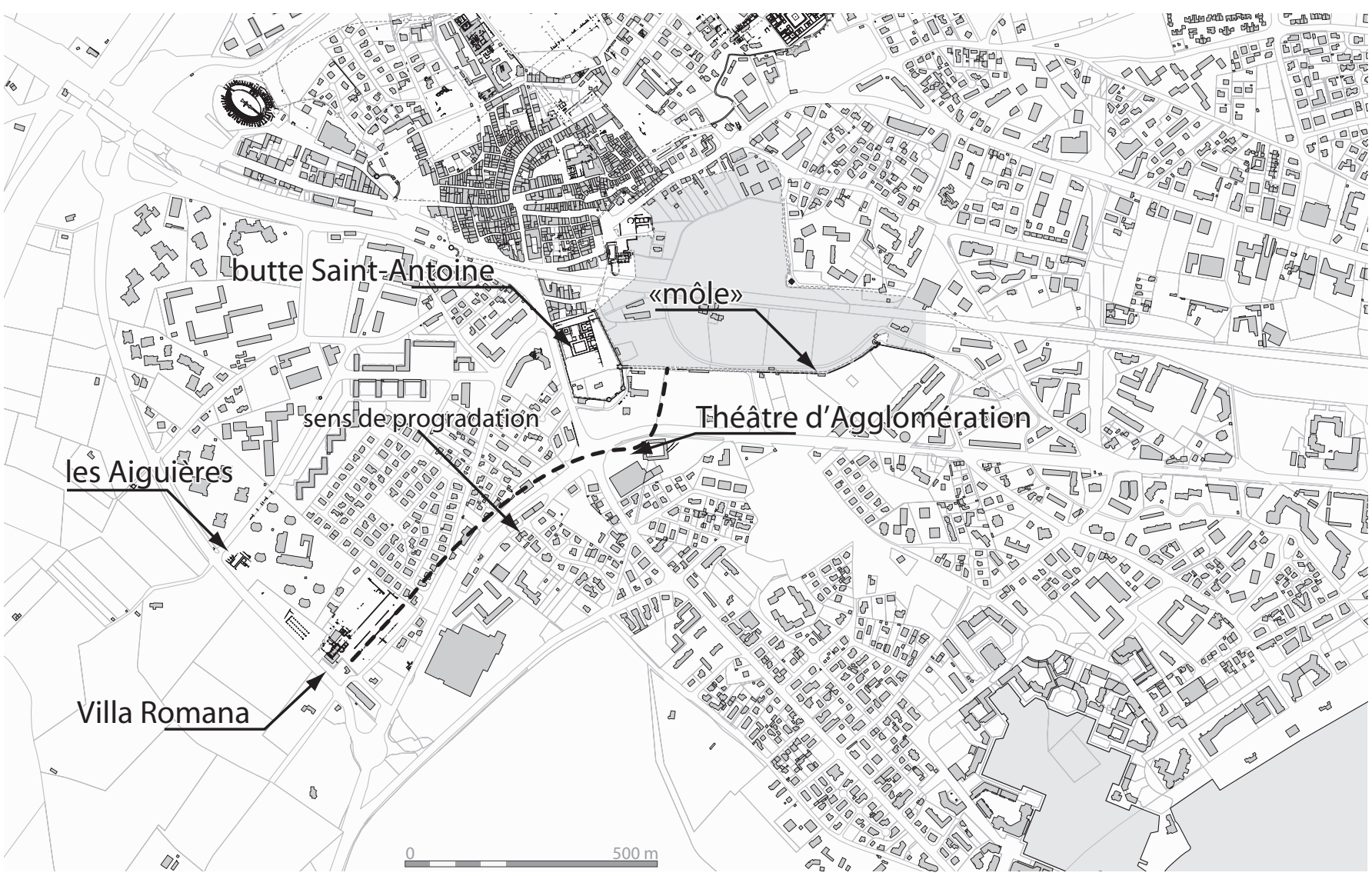

Fig. 8. Localisation du trait de côte restitué d'après les opérations de fouilles récentes.

durant l'Holocène récent (Cohen 1991 et 1997, 6-12 ; Dubar 2004b, 47-54 ; Dubar et al. 2005, 147-157 ; Gébara, Chouquer 1996, 91-103 et Bertoncello et al. 2003 et 2004), les paléomilieux sont ici très mobiles et variés (cordon littoral, milieux lagunaires, plaine deltaïque, etc.). Comparées aux découvertes du Théâtre d'Agglomération, ces observations annoncent une évolution du trait de côte et des milieux littoraux très rapide et contrastée dans le quartier de Villeneuve autour du changement d'ère. Dans ce contexte morphodynamique, l'étude des relations entre l'occupation des sols et la mobilité des milieux est particulièrement riche du point de vue scientifique. En effet, l'implantation de diverses activités socioéconomiques (militaire, hydraulique et agricole) dans des terrains gagnés sur la mer à l'échelle d'une génération et dans des paysages diversifiés pose la question des stratégies de développement de la colonie, de la gestion et de l'aménagement des milieux littoraux. Cette opération a été l'occasion de mieux comprendre la paléogéographie des environs de Fréjus depuis l'Antiquité. Les investigations paléoenvironnementales ont permis d'établir un état spatialisé et diachronique de l'évolution des milieux qu'ils soient littoraux ou fluviaux. Pour ce faire, une approche pluridisciplinaire a été adoptée. L'un des axes de recherche essentiel à la compréhension des paléoenvironnements observés lors de ce chantier a été la reconnaissance fine et fiable de différentes formations sédimentaires littorales. Cette dernière a été rendue possible grâce à la combinaison de nombreuses analyses stratigraphique (S. Bonnet et B. Devillers), granulométrique (S. Bonnet), minéralogique (M. Dubar), malacologique (S. Martin) et microfaunistique (ostracodes) (S. Bonnet et P. Carbonel). L'évolution du couvert végétal et l'utilisation des sols dans un contexte de plaine alluviale ont été traitées grâce à la réalisation d'analyses palynologique ( $\mathrm{S}$. Guillon), anthracologique (I. Figueral), carpologique (L. Bouby, I. Figueral et C. Schaal), xylologique (S. Greck et Fr. Guibal) et pédologique (J.-Fr. Berger). Afin de mieux rendre compte de la diversité spatiale des différents types de milieux et de leur évolution, il a été nécessaire de multiplier les échantillonnages et les bermes témoins, dont certaines pouvaient atteindre $50 \mathrm{~m}$ de longueur. Pour appréhender au mieux la géométrie des différents corps sédimentaires composant ce site, ces enregistrements ont été complétés par la réalisation de quelques carottages de profondeur n'excédant pas les cinq mètres. 
Le phasage des paléoenvironnements a été assuré par la détermination des artefacts mis au jour et par la réalisation de datation $\mathrm{AMS}^{8}$ pour les couches vierges de tout indice archéologique. Le calibrage de ces dernières a été obtenu à partir de la courbe atmosphérique de Reimer (Reimer et al. 2004) et calculé par le logiciel OxCal v3.10 (l'intervalle de confiance utilisé ici est de 95,4\%, soit deux sigma).

8 Datations effectuées sur des charbons à l'aide d'un spectromètre de masse couplé à un accélérateur de particules au Poznan Radiocarbon Laboratory. 


\section{Première partie}

\section{LA FOUILLE}

\section{Avertissement}

En raison du peu de structures bâties conservées et pour délimiter les zones durant la fouille, nous avons suivi des axes majeurs et permanents durant toute l'occupation du site. Deux murs longitudinaux (MR2002 et 2004), divisant la fouille en trois zones à peu près égales, ont ainsi fourni un zonage défini pour l'ensemble de la fouille et pour chaque phase. La zone 1 au nord de MR2004, d'une surface totale de $1700 \mathrm{~m}^{2}$, la zone 2 entre MR2004 et MR2002, de $1062 \mathrm{~m}^{2}$ et la zone 3 au sud de MR2002, de $2125 \mathrm{~m}^{2}$. Au sein de chacune de ces grandes zones, trois secteurs théoriques d'égale superficie, ont été créés.

Cinq phases d'occupation ont été caractérisées par la fouille couvrant une période allant du I rer siècle av. J.-C. jusqu'au XVII ${ }^{e}$ siècle. Les périodes postérieures ne sont qu'esquissées dans la présente étude. Plusieurs périodes d'abandon relatif ont été observées et constituent notamment le hiatus entre les phases de l'Antiquité et l'occupation moderne.

L'ensemble des études archéologiques et paléoenvironementales a été intégré dans le corps du développement en suivant les phases chronologiques. Une partie de ces études est présentée de façon plus détaillée dans la deuxième partie : analyses et études. Afin de ne pas surcharger le développement, les inventaires ont été condensés, ainsi que le listing de l'ensemble des unités stratigraphiques et la grande coupe nord-sud, à laquelle fait référence le phasage d'ensemble, sont présentés intégralement dans la troisième partie : bibliographie et inventaires.

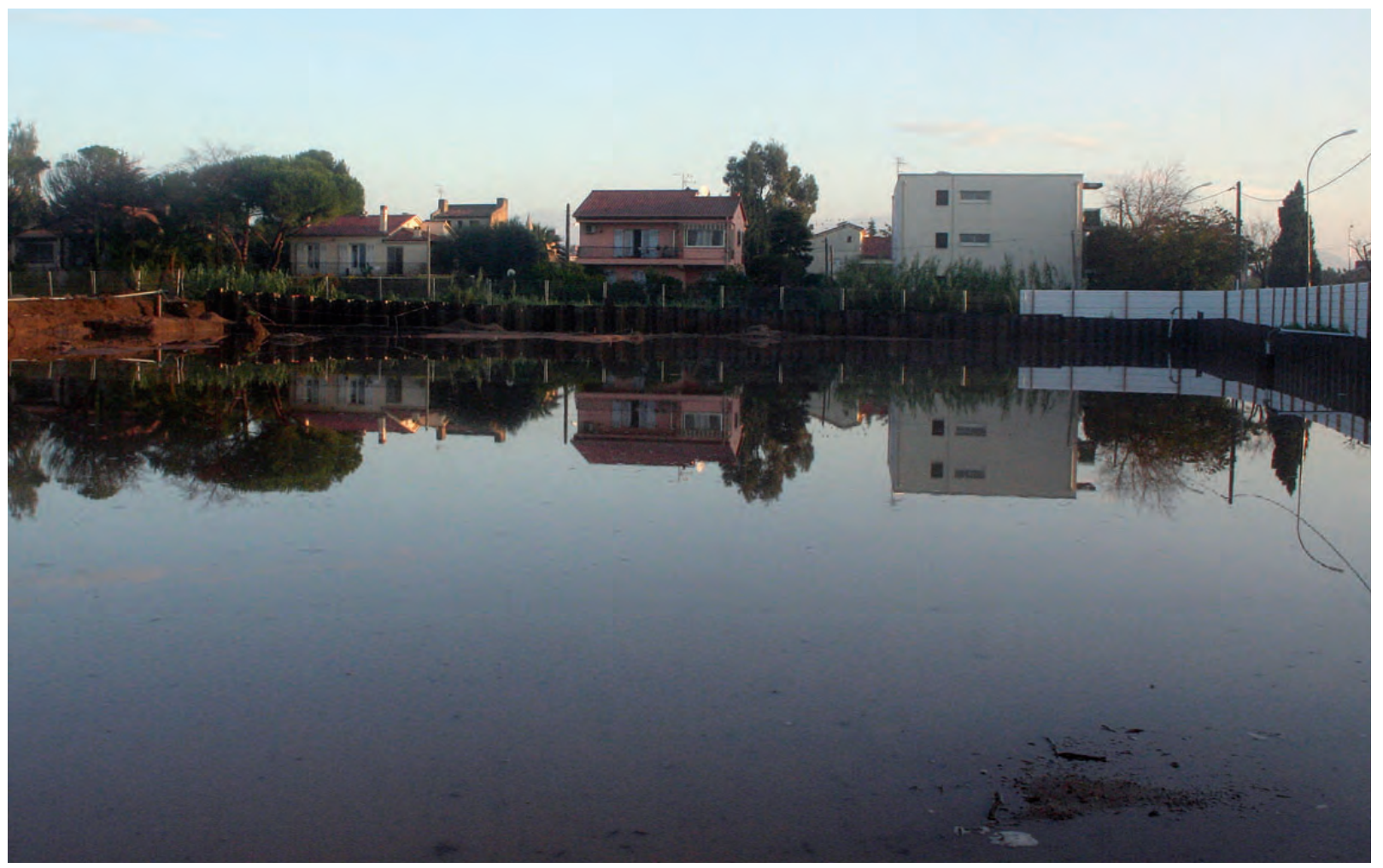

Vue du chantier après les inondations de décembre 2006.

(Cl. P. Excoffon). 
PREMIÈRE PARTIE : LA FOUILLE

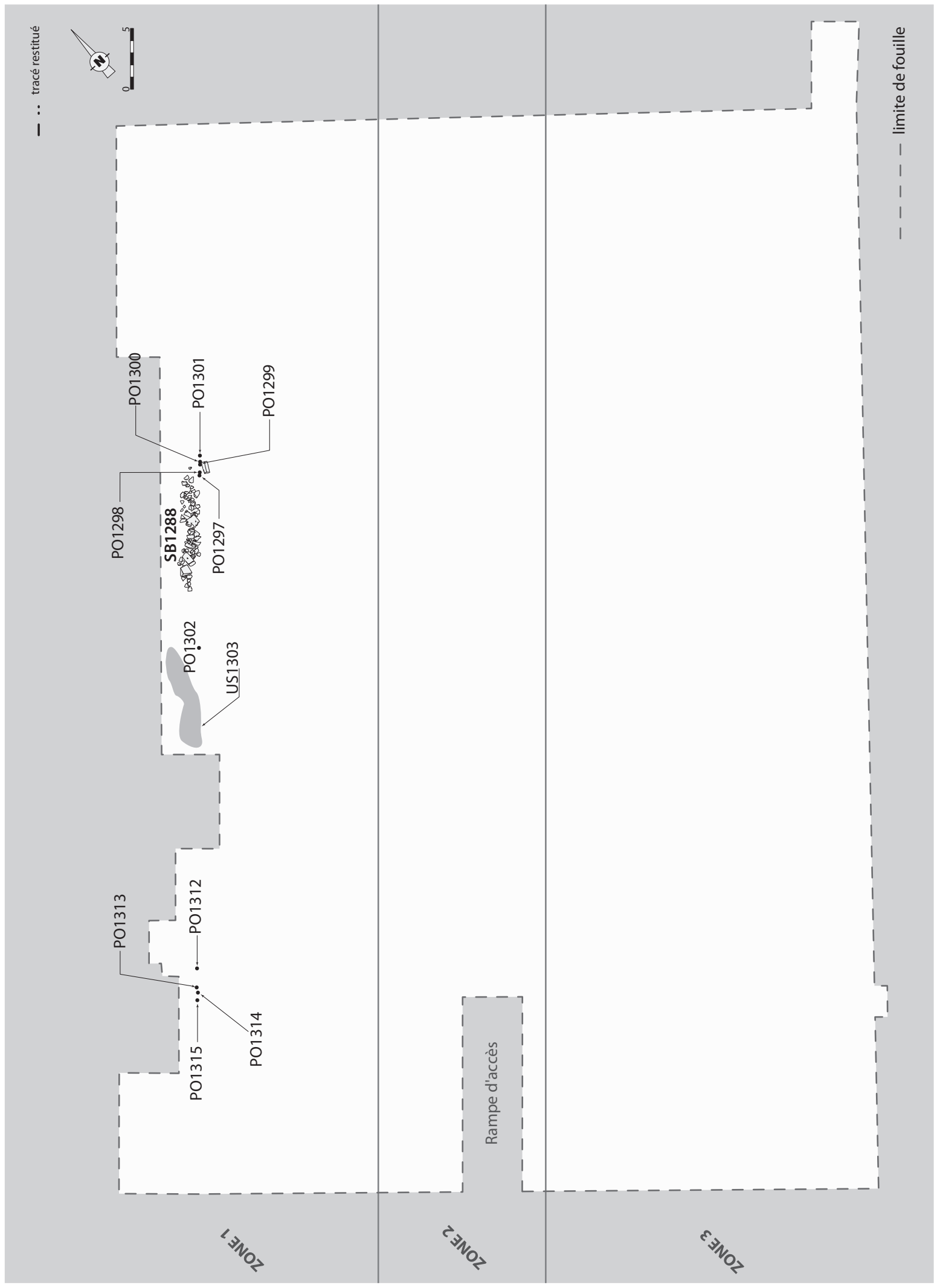

Fig. 9. Plan d'ensemble des vestiges de la phase 1. 


\section{Chapitre 1}

\section{La plage du milieu du I'r siècle av. J.-C.}

\section{Description \\ (P. E.)}

La phase la plus ancienne reconnue correspond essentiellement sur le terrain à une importante unité sableuse recouvrant l'ensemble du site (US1068). Ce niveau sableux marque un litage des sables qui ne présente que quelques rares témoins anthropiques et correspond à un haut de plage. Il s'agit des plus anciens niveaux émergés dont les premiers aménagements perceptibles sont constitués par quelques structures diffuses : un amas allongé de blocs (SB1288) et un alignement de piquets en bois constituent un même ensemble fonctionnel (fig. 9). La cinquantaine de tessons découverte dans ces niveaux présente une usure marquée due à l'érosion marine.

Un amas de blocs de grès brun (fig. 10), partiellement ensablé, est apparu au nord. Il mesure une dizaine de mètres de long pour deux mètres de large (fig. 11). L'ensemble ne présente aucune organisation particulière et la majorité des blocs n'est pas disposée à plat. La côte altimétrique maximale se situe à $0,82 \mathrm{~m}$ NGF et la base du dépôt est à une côte de 0,20 m NGF, soit une épaisseur totale de $0,62 \mathrm{~m}$, pour un volume total de pierres estimé à $12,4 \mathrm{~m}^{3}$ Les blocs les plus gros mesurent $0,85 \mathrm{~m} \mathrm{x}$ $0,40 \mathrm{~m} \mathrm{x} 0,40 \mathrm{~m}$, soit près de $400 \mathrm{~kg}^{1}$. Certains d'entre eux présentent des marques d'érosion, essentiellement au niveau des arêtes. Seul un gros bloc de forme allongée comporte des marques d'outils. Celles-ci se présentent sous la forme d'une amorce de saignée dans le sens de la largeur et d'un trou de $6 \mathrm{~cm}$ x $4 \mathrm{~cm}$ x $3 \mathrm{~cm}$ sur ce qui devait correspondre à un lit d'attente. La majorité des autres éléments s'apparente à de gros rebus informes. À quelques mètres à l'est, d'autres blocs ont été repérés sur une superficie moindre mais à une même altimétrie. Située à l'emplacement de la rampe de circulation des engins mécaniques, cette zone, que nous avons pu seulement localiser, n'a pas été précisément relevée, ni

1 Nous avons retenu comme masse volumique du grès $2600 \mathrm{~kg} / \mathrm{m}^{3}$.

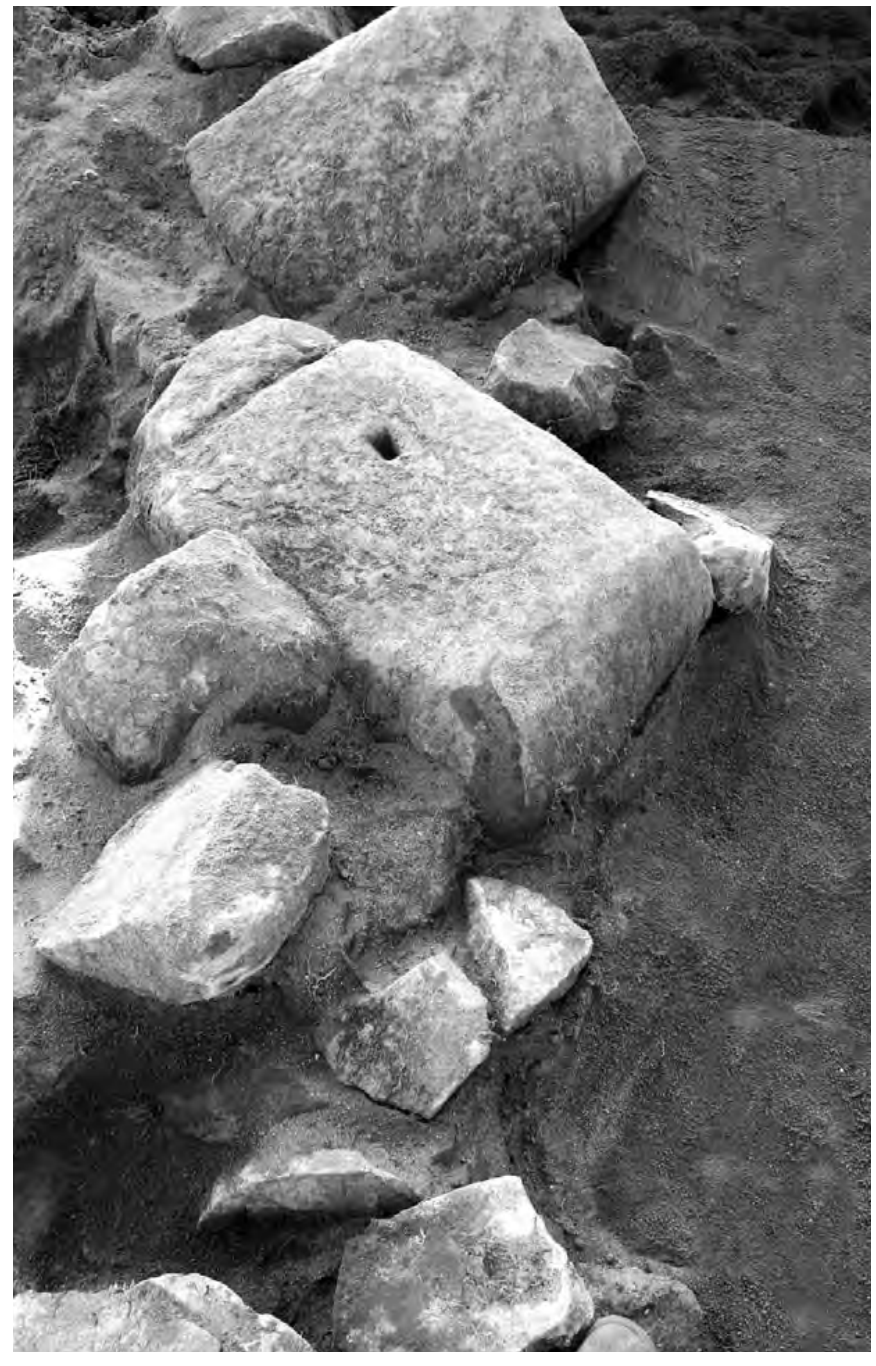

Fig. 10. Détail de l'amas de blocs.

photographiée ; toutefois, elle doit être mise en rapport avec l'amas de blocs mentionné ci-avant avec lequel elle constitue le même ensemble.

Lors de la même phase a été mise en place une série de piquets en bois, exactement alignés sud-ouest/ nord-est (fig. 12). Cet ensemble limite au sud les deux amas de blocs. D'une série sans doute plus importante, 


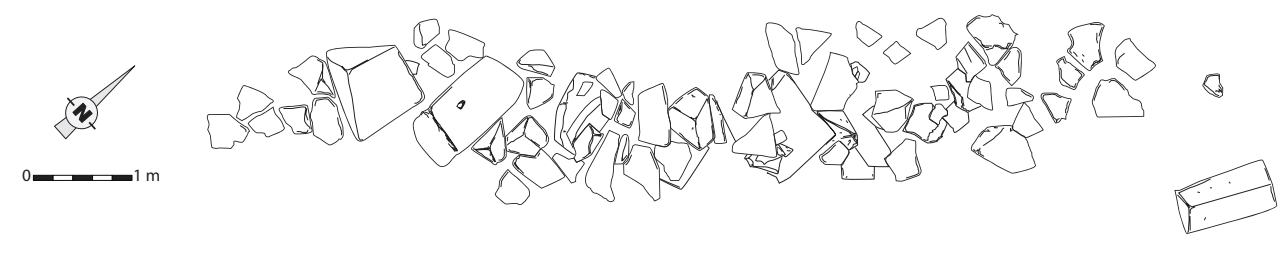

Fig. 11. Relevé de l'amas SB1288

ne subsistaient que dix piquets ${ }^{2}$ en chêne taillés en pointe. Seules les parties basses et les pointes étaient conservées, plantées directement dans le sable (fig. 13). Il est donc impossible de déterminer précisément le niveau à partir duquel ils ont été mis en place. La côte altimétrique à laquelle ils ont été découverts varie de $-0,444 \mathrm{~m}$ NGF en moyenne pour la série la plus à l'ouest et de $-0,926 \mathrm{~m}$ NGF en moyenne pour la série la plus à l'est. Les deux extrémités (PO1315/PO1031) sont distantes de 45,25 m. Dans la moitié est, un piquet situé à $1,75 \mathrm{~m}$ plus au sud a également été découvert mais ne paraît pas constituer le même ensemble.

\section{Analyse des bois de l'alignement de piquets PO1296/PO13123}

(S. Gr., F. G.)

L'alignement de piquets se divise en deux groupes : le premier, dans le secteur 1, est composé de six individus (PO1296) et le second, dans le secteur 3, de quatre individus (PO1312) (tab. 1 et fig. 14).

Ces dix piquets découverts en position initiale et dont il ne reste que la pointe se trouvaient sous le niveau de la nappe phréatique dans un très mauvais état de conservation, en particulier l'ensemble PO1312 dont le bois était très érodé et en partie décomposé. Les traces de façonnage des pointes étaient peu visibles, l'écorce et les derniers cernes avaient disparu pour la plupart ; seul le piquet PO1297 présentait encore un fragment d'écorce qui était probablement en place sur tous les piquets lors de leur installation.

Les piquets étaient espacés de 30 à $60 \mathrm{~cm}$ environ les uns des autres. Il s'agit, pour la plupart de tiges torses plus ou moins épaisses, d'un diamètre moyen de $5,5 \mathrm{~cm}(4,5$ à $7,2 \mathrm{~cm})^{4}$ et longues de 23 à $63 \mathrm{~cm}$ conservés, démunies de leurs ramifications et appointées. Seules deux d'entre elles provenaient de tiges d'arbre fendues (1302:1/2) ou refendues (1313: 1/4). Leur pointe rudimentaire, confectionnée pour faciliter leur enfoncement dans le

PO1297, 1298, 1299, 1300, 1301, 1302, 1312, 1313, 1314 et 1315.

3 Pour les méthodes d'analyses dendrologiques, voir infra p. 203.

4 Il s'agit du diamètre conservé ; le diamètre d'origine doit être en moyenne augmenté d'au moins $1 \mathrm{~cm}$.

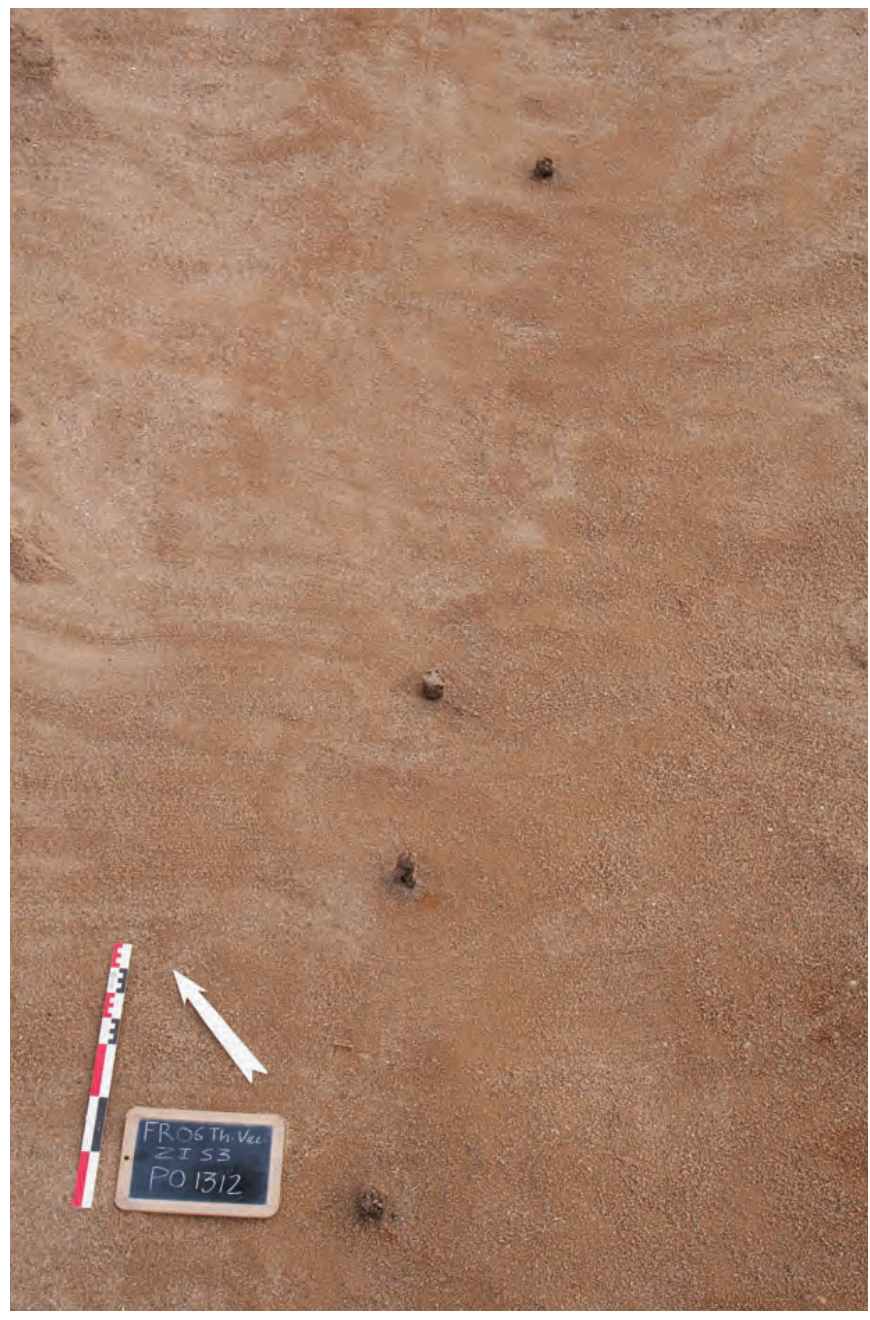

Fig. 12. Une partie de l'alignement de piquets.

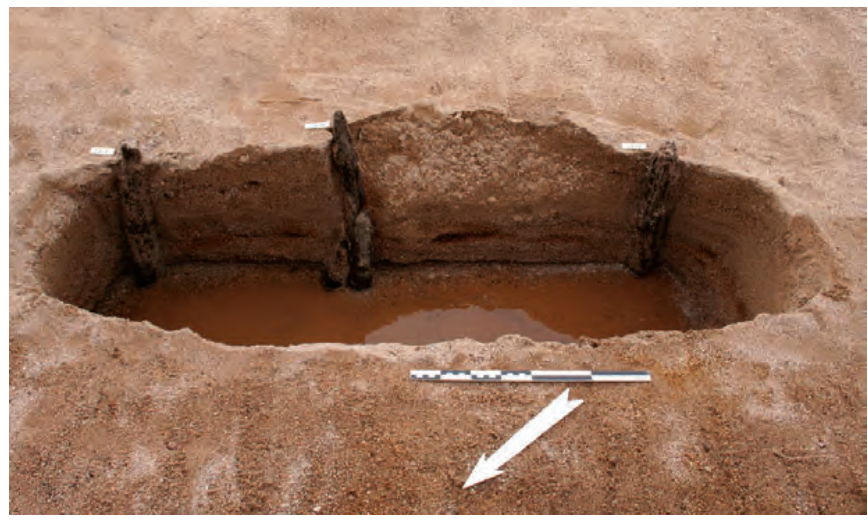

Fig. 13. Vue en coupe des piquets au sein de l'US1068. 
sol, était définie par 3 ou 4 pans ou par un biseau retaillé (PO1302).

Les piquets ont été confectionnés dans les jeunes tiges de deux taxons communs de la région méditerranéenne : le chêne à feuillage caduc (Quercus sp.) pour deux individus et le chêne liège (Quercus suber L.) pour les huit autres. Parmi les chênes caducifoliés ${ }^{5}$, il s'agit sans doute du chêne pubescent, espèce méditerranéenne présente sur tout le littoral méditerranéen français jusqu'à 1400 m d'altitude. Le chêne liège, quant à lui, espèce méditerranéo-atlantique, est localisé particulièrement aujourd'hui sur les sols siliceux des massifs de l'Estérel et des Maures jusqu'à 600 m d'altitude (Lieutaghi 2004 et Rameau et al. 1989).

L'emploi de ces deux essences rend compte d'un approvisionnement en bois probablement effectué depuis les massifs proches du site. Compte tenu de la faible dimension de ce corpus majoritairement représenté par du bois de chêne liège, n'offrant qu'un faible nombre de cernes (35 au maximum) et ne reflétant que la croissance juvénile de l'arbre, l'analyse dendrochronologique n'a pas pu être appliquée à ce matériel. Cet ensemble de piquets plutôt hétérogène - par le diamètre des bois, le traitement des pointes ainsi que la diversité des essences - et rudimentaire (tiges torses, encore pourvues de leur écorce, traitement des pointes élémentaire et peu soigné) correspondait probablement à une construction légère, d'exécution simple et rapide, réalisée à l'aide de bois rapidement disponibles dans les environs immédiats du site.

\section{3. Étude géomorphologique et analyse des dépôts littoraux}

(S. B.)

\subsection{Présentation de l'étude}

L'étude stratigraphique des paléoplages mises au jour lors des opérations archéologiques effectuées auparavant sur le territoire communal de Fréjus a démontré qu'elles se sont toutes formées en au moins deux temps. Constituées à leur base d'un dépôt issu de l'action des vagues et des courants, leur sommet provient d'un nappage de sable éolien associé à des remaniements typiques d'un haut de plage.

De la même manière, sur le site de Villa Romana, l'édification de l'épaisse formation sableuse d'origine littorale qui constitue le socle de la sédimentation historique (phase 1), provient de la combinaison de

5 La distinction spécifique est impossible sur la base de l'étude anatomique du bois de chêne caducifolié (Schweingruber 1990). différents processus et dynamiques sédimentaires de nature variée, qui se traduisent par la présence en son sein de trois types distincts de dépôts qui correspondent à des plages immergées, à des hauts de plage et à plusieurs épisodes de tempêtes.

Bien que ces corps sédimentaires aient été analysés déjà plusieurs fois dans la basse vallée de l'Argens ainsi qu'à proximité de notre zone d'étude, des questions restent en suspens :

- Définir les modalités de changement au sein d'un littoral meuble. Le diagnostic du Théâtre d'Agglomération avait démontré le passage d'une côte rocheuse à une plage de sable (Excoffon, Devillers 2006). Cependant, en raison des faibles étendue et profondeur des tranchées, la mutation longitudinale du littoral meuble n'avait pu être suffisamment appréhendée ;

- Localiser les zones d'apport sédimentaire (Grau, embouchure, estuaire...), ainsi que les sources sédimentaires (bassins versants du Reyran, de l'Argens...). Ces dernières constituent un facteur de premier ordre dans les mutations paysagères des milieux littoraux. Pour ce faire, une étude des minéraux lourds a été réalisée par M. Dubar (voir supra p.219-220) ;

- Localiser la/les ligne(s) de rivage(s) et en évaluer sa/ses mobilité(s) latérale(s).

Ces problématiques géomorphologiques ont une résonance toute particulière dans un contexte anthropique où les dynamiques en action vont conditionner l'implantation humaine ainsi que la nature des aménagements. Concernant ces problématiques, l'intérêt de la fouille de Villa Romana réside principalement dans les conditions d'observation de la stratigraphie, bien meilleures que lors des opérations précédentes, et dans la présence de vestiges au sein même de ces formations littorales.

Après avoir analysé en détail les différents types de dépôts, nous nous intéresserons à leur emboîtement complexe qui confère un caractère inédit à la stratigraphie de ce site. L'enchevêtrement des corps littoraux, la faible quantité de matière organique disponible ainsi que la découverte d'artéfacts très rarement identifiables, n'ont permis qu'une datation large de cette phase. Par souci de cohérence et afin d'éviter des répétitions lors de la description des phases suivantes, nous traiterons ici de la formation littorale dans son ensemble. De ce fait, nous présenterons simultanément les formations sédimentaires de la phase 1 et les dépôts progradants des zones 2 et 3 qui constituent la phase 2 .

\subsection{Méthodologie}

L'interprétation des différents corps sédimentaires constituant les paléoplages s'appuie sur l'utilisation 
PREMIÈRE PARTIE : LA FOUILLE

\begin{tabular}{|c|c|c|c|c|c|c|c|}
\hline Zone & Secteur & Fait & US & $\begin{array}{c}\text { Longueur } \\
\text { (cm) }\end{array}$ & $\begin{array}{l}\text { Diamètre } \\
(\mathbf{c m})\end{array}$ & $\begin{array}{l}\text { Essence } \\
\text { ligneuse }\end{array}$ & Débit \\
\hline \multirow{10}{*}{ I } & \multirow{6}{*}{1} & \multirow{6}{*}{ PO 1296} & 1297 & 65 & 7,2 & Chêne liège & brin \\
\hline & & & 1298 & 34 & 5,6 & Chêne liège & brin \\
\hline & & & 1299 & 56 & 6 & Chêne liège & brin \\
\hline & & & 1300 & 45 & 7 & Chêne liège & brin \\
\hline & & & 1301 & 23 & 4,5 & Chêne liège & brin \\
\hline & & & 1302 & 33 & 5 & Chêne liège & fendu $(1 / 2)$ \\
\hline & \multirow{4}{*}{3} & \multirow{4}{*}{ PO 1312} & 1312 & 46 & 4,5 & Chêne liège & refendu $(1 / 4)$ \\
\hline & & & 1313 & 52 & 4 & Chêne caducifolié & brin \\
\hline & & & 1314 & 61 & 5,5 & Chêne caducifolié & brin \\
\hline & & & 1315 & 46 & 5 & Chêne liège & brin \\
\hline
\end{tabular}

Tab. 1. Tableau des paramètres descriptifs des piquets alignés P01296 et P01312.

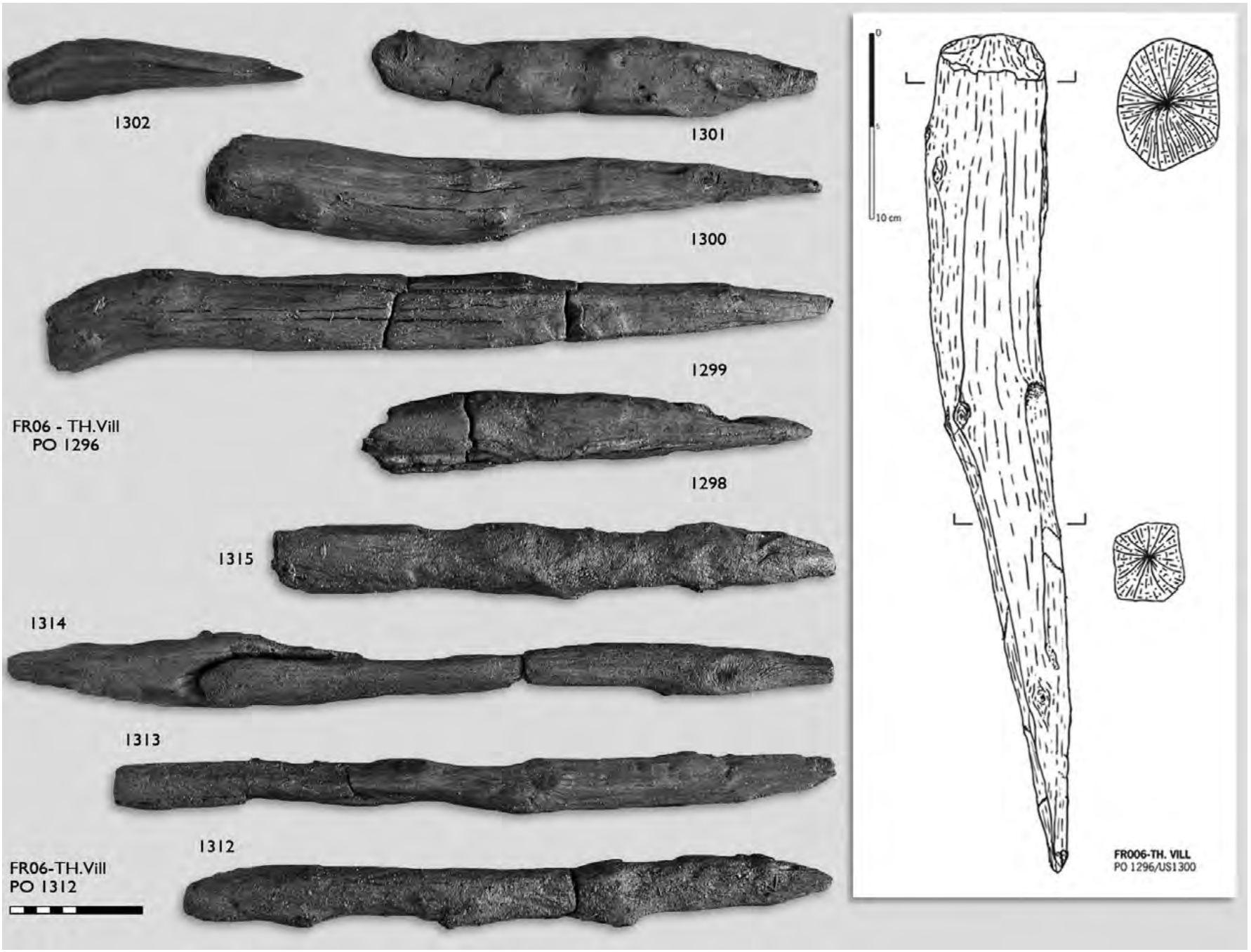

Fig. 14. Relevé et photographies des pieux (S. Greck). 
d'études réalisées sur des littoraux actuels (Degiovanni 1971 ; Georges 1998 ; Morhange 1994 et 2001 et Vella 1999). Les critères de comparaison utilisés sont les paramètres granulométriques (grain moyen, asymétrie, classement, texture) et la lecture des structures sédimentaires (stratigraphie). Pour faciliter la compréhension de nos propos à venir, nous rappelerons ici brièvement les différents milieux constitutifs des littoraux actuels (Degiovanni 1971 ; Georges 1998 et Vella 1999) (fig. 15).

\subsubsection{L'arrière-plage ou plage émergée}

Correspondant du point de vue biologique à l'étage supralittoral, ce milieu s'étend de la limite de l'estran au pied des dunes, si elles existent.

Il est caractérisé par trois processus morphologiques principaux :

- La plage émergée est occupée par la mer lors des tempêtes ou des marées barométriques exceptionnelles qui sont à l'origine de laisses de mer. Ces dépôts généralement mal triés sont enrichis de débris coquillés et d'éléments flottés comme du bois et des charbons. Ces laisses forment des gradins ou bermes au sein de la plage émergée qui présente habituellement une pente irrégulière ;

- Les sables fins d'origines marine et côtière sont souvent remobilisés par le vent. Ceci engendre un granoclassement de l'aval vers l'amont, les particules étant généralement de plus en plus fines vers l'amont ;

- Enfin, l'arrière-plage peut être assujettie à des ruissellements plus ou moins intenses remaniant ainsi les dépôts qui la constituent.

Les caractéristiques sédimentologiques permettent donc de distinguer la plage aérienne caractérisée par une texture principalement sableuse, un grain moyen nettement plus grossier que celui de la plage sousmarine et des litages subhorizontaux, à faible pendage (entre 5 et $10 \%$ ) sur le bourrelet de plage. Les litages subparallèles et subhorizontaux de l'arrière-plage ne

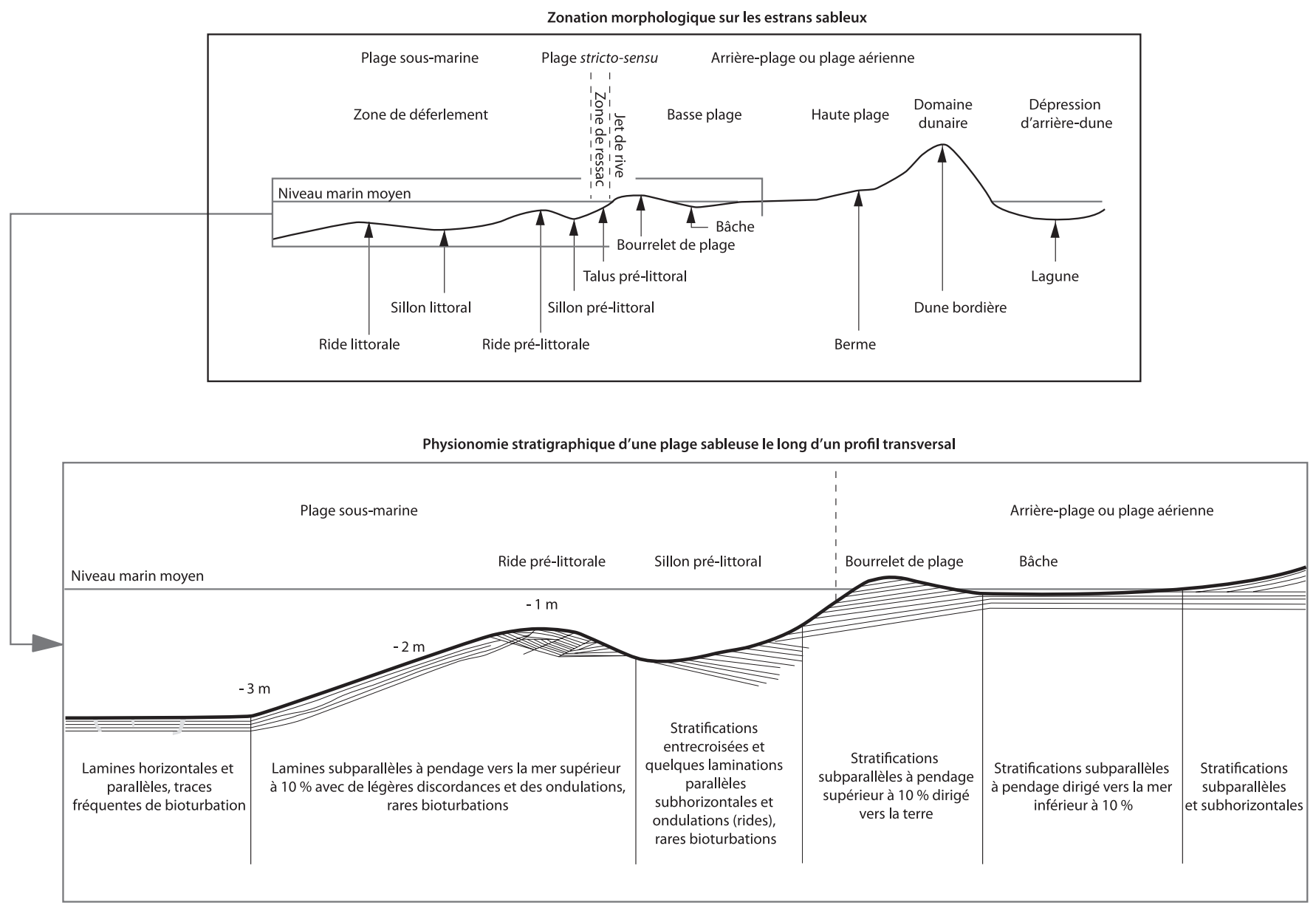

Fig. 15. Localisation et détermination des différentes unités géomorphologiques constituant une plage sableuse (S. Bonnet, à partir d'un document de $\mathrm{Cl}$. Vella). 


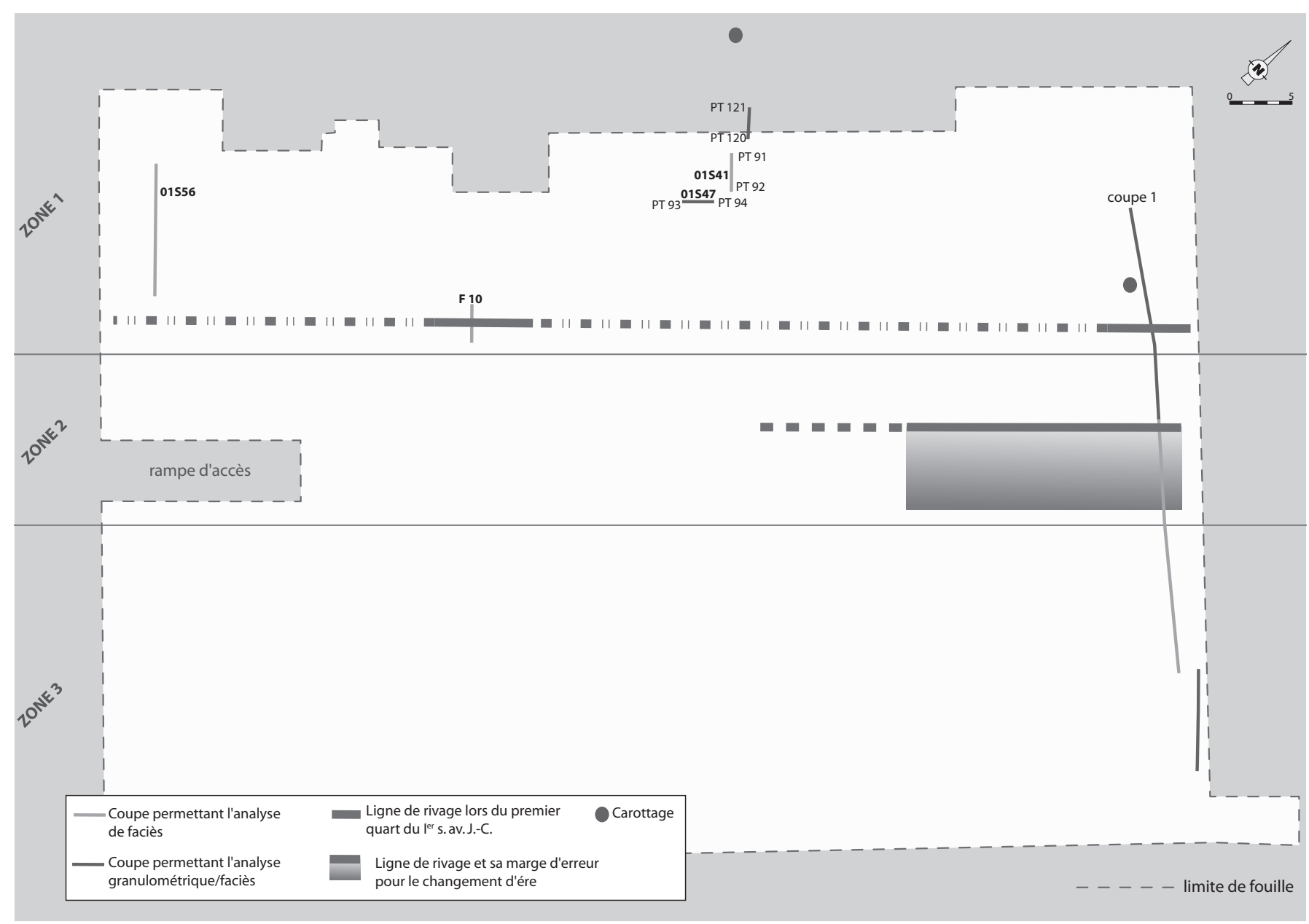

Fig. 16. Localisation des différentes coupes sédimentaires permettant l'analyse paléoenvironnementale (S. Bonnet).

se distinguent de ceux de l'infralittoral que par leur granulométrie plus fine.

\subsubsection{La plage proprement dite ou estran}

L'estran, qui est un bon marqueur du niveau moyen de la mer, est réduit en Méditerranée du fait de la faiblesse du marnage variant de 15 à $30 \mathrm{~cm}$ (rapport du Port Autonome de Marseille 1993 et Morhange, 1994 et 2001, 96-101). Cet espace intertidal ${ }^{6}$, qui correspond à la zone dite médiolittorale, est à assimiler au secteur balayé par le jet de rive et le courant de retour.

\subsubsection{La plage immergée ou sous-marine}

Appelée également étage infralittoral, cette zone, toujours immergée, subit l'action des vagues contre le fond. De l'amont vers l'aval, on trouve :

- Un talus prélittoral dans la zone où déferlent les vagues. Il est l'indicateur morphologique et granu-

6 Zone du rivage où alterne la marée. lométrique le plus précis du niveau moyen de la mer. Cependant, sa fossilisation est extrêmement rare (Degiovanni 1971). En effet, il se situe légèrement à l'aval de la zone de ressac et son sommet se localise sous quelques centimètres d'eau. Se situant au contact du déferlement des vagues et du courant de retour, où la turbulence est maximale, le talus prélittoral est composé de matériel grossier qui correspond à un dépôt forcé (King, Cuchlaine 1972) ;

- Vers le large, on identifie de nombreuses microformes comme le sillon prélittoral, à la base du talus, puis une ou plusieurs rides séparées par des sillons littoraux.

La plage sous-marine dans son ensemble est, d'un point de vue sédimentaire, plus variée que la plage émergée et l'estran. Mais, globalement, les sables qui la constituent sont fins ou très fins et on constate une décroissance rapide de la taille du grain moyen depuis la ride littorale vers les zones profondes. Les structures sont très variées, subparallèles à un pendage fort (10 à $15 \%$ ), orientées tantôt vers la côte (sillon prélittoral), tantôt vers le large. Ces structures sont entrecroisées 
avec une forte oblicité au niveau de la ride prélittorale et horizontale au delà de -3 m (Vella 1999).

\subsubsection{Méthode opérée sur le site}

Dans le souci de percevoir au mieux les différentes zones constituant les paléoplages, six tranchées ont été effectuées. Le but était de former un transect de référence d'orientation nord-ouest/sud-est (fig. 16 et coupe 1). Ceci a permis de réaliser plusieurs coupes longitudinales des milieux littoraux passés. Chaque axe possède son pendant est-ouest dans le but de déterminer le sens de progradation du cordon littoral et d'identifier la forme latérale des paléoplages. La proximité de la nappe d'eau, malgré la mise en place de l'efficace dispositif de rabattement de nappe, nous a empêché de descendre au delà de - $0,30 \mathrm{~m}$ NGF et tous les carottages effectués en deçà de cette limite ont été infructueux en raison du fluage des sables.

Le prélèvement de 34 échantillons sur l'ensemble des divers enregistrements sédimentaires permet de réaliser une étude granulométrique précise.

\subsection{Description des faciès}

Sur le site de Villa Romana, trois faciès caractéristiques ont été mis en évidence par l'étude géomophologique.

\subsubsection{De la zone de déferlement à la zone de jet de rive (faciès 1)}

\section{Caractéristiques granulométriques}

Provenant de l'avancée d'un cordon littoral par un ensablement rapide, ce premier type de sédimentation se matérialise par une formation interstratifiée de sable massif qui atteint la côte altimétrique maximum de 0,80 m NGF (coupe 1). La remontée de la nappe phréatique, à environ -0,50 m NGF, nous a empêchés d'appréhender sa base. Afin de s'affranchir de cette contrainte, plusieurs carottages à percussion ont été réalisés sur l'ensemble du site, qui ont permis d'estimer, dans la partie occidentale, une épaisseur minimale de ce corps progradant de $3,10 \mathrm{~m}$. Cette formation, essentiellement sableuse, comporte néanmoins de rares passées caillouteuses ainsi qu'une proportion anecdotique de limon n'excédant pas $10 \%$. Ce dépôt hétérogène de sable moyen à grossier, moyennement trié, comme l'indiquent les valeurs de l'indice de tri allant de 0,45 à 0,94 , présente une alternance d'asymétries positives et négatives qui traduit une succession des processus de décantation et de lessivage (fig. 17). La combinaison de ces caractéristiques granulométriques démontre que cette unité est assujettie à des dynamiques marines telles que l'action des vagues (Reineck, Singh 1980). Le milieu de sédimentation associé à ce type de lithofaciès est donc probablement entre la zone de déferlement et la basse plage.

\section{L'interstratification du dépôt reflète les contours d'anciennes lignes de rivage}

L'édification de cette formation découle d'une succession de phases d'accumulation et d'érosion comme en témoignent les nombreuses surfaces de discordance progressive visibles en son sein. Elles dessinent les limites d'une multitude de lentilles oblongues, emboîtées les unes aux autres et qui se distinguent par leurs formes et par l'organisation interne des particules.

Pouvant dépasser 0,70 m d'épaisseur, ces couches, plus ou moins effilées, s'étendent sur des longueurs très variables. Alors qu'elles atteignent $12 \mathrm{~m}$ de long dans les zones 1 et 3 , elles ne dépassent pas $7 \mathrm{~m}$ dans la zone 2 . La forte inclinaison de l'extrémité sud-est de certaines de ces lentilles, comprise entre 30 et $40 \%$, rappelle le contour de talus prélittoraux qui sont définis, entre autres, par leur pente importante orientée vers le large. En outre, la granulométrie et la structuration des dépôts situés de part et d'autre de cette paléotopographie valident cette hypothèse. D'un côté, ces surfaces d'érosion s'inscrivent au sommet d'un cortège de sable grossier organisé en lits obliques et parallèles à faible pendage (inférieur à $5 \%$ ), typique des bourrelets de plage ; de l'autre, elles sont fossilisées par des couches issues d'un milieu à l'énergie fluctuante mais relativement importante correspondant à la zone de swach (jet de rive) (Reineck, Singh 1973 et Vella 1999). Ces couches sont marquées par une forte variabilité de la granulométrie qui se manifeste par de nombreux lits de sables et de granules parallèles et obliques, au pendage supérieur à $10 \%$, qui peuvent s'entrecroiser localement. Enfin, la position altimétrique de ces surfaces ne vient pas contredire cette identification et nous permet même de préciser que nous nous situons sur le haut de ces talus.

$\mathrm{La}$ reconnaissance certaine de ces formes est essentielle à la reconstitution de l'évolution de la morphologie du littoral car le talus prélittoral correspond peu ou prou à la ligne de rivage et à sa base (la zone de ressac) et constitue un bon marqueur du niveau marin (Morhange 1994). La remontée de la nappe phréatique sur le site n'a cependant pas permis d'appréhender la base de ces surfaces ni de déterminer l'altitude du niveau de base durant l'Antiquité. De plus, l'observation ponctuelle de ces formes et la difficulté pour les dater, ont fortement limité la possibilité de les relier les unes aux autres. 
De ce fait, il a été délicat de percevoir la géométrie des lignes de rivage qui se sont succédées sur le site. Néanmoins, la datation de certaines d'entre elles, coïncidant avec celle réalisée sur d'autres traits de côte découverts lors d'interventions archéologiques plus anciennes, a permis de préciser la position et l'évolution des rivages aux abords de Forum Iulii, depuis sa fondation jusqu'après le changement d'ère.

\section{Un bas de plage aménagé}

Repérés dans deux tranchées situées dans la partie sud-est de la zone 1, deux talus prélittoraux, distants l'un de l'autre de $61 \mathrm{~m}$, possèdent la particularité d'être recouverts localement, à leur sommet (situé environ à $0,40 \mathrm{~m} \mathrm{NGF}$ ), par un amas de tegulae posées à plat et légèrement inclinées vers le sud-est (fig. 18). L'absence d'érosion et de concrétions marines, démontre
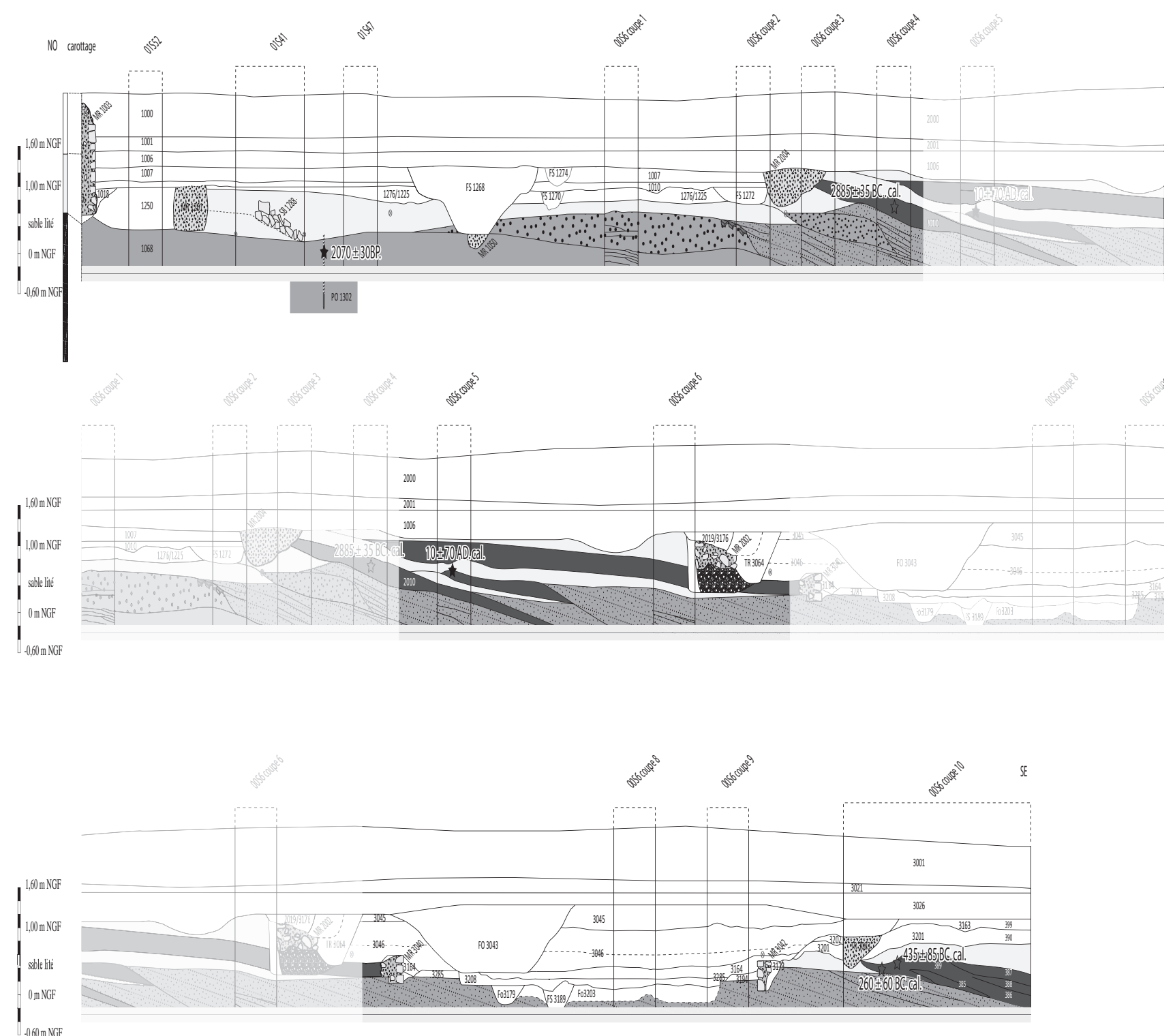

Identification de la géometrie des différents corps sableux littoraux composant l'enregistrement stratigraphique 0056 (exagération verticale $200 \%$ )

$\square$ Sédimentation et structure établies dans un contexte de plaine d'inondation Niveau de la mer et marge d'erreur (fin ler s. av. J.-C.)

De la zone de déferlement à la zone de jet de rive
Dépôts modaux de plage émergée
Dépôts de haute énergie (tempêtes)

_ Dépôts de haute énergie (tempêtes)

Coupe 1. Identification de la géométrie des différents corps sableux littoraux (S. Bonnet). 


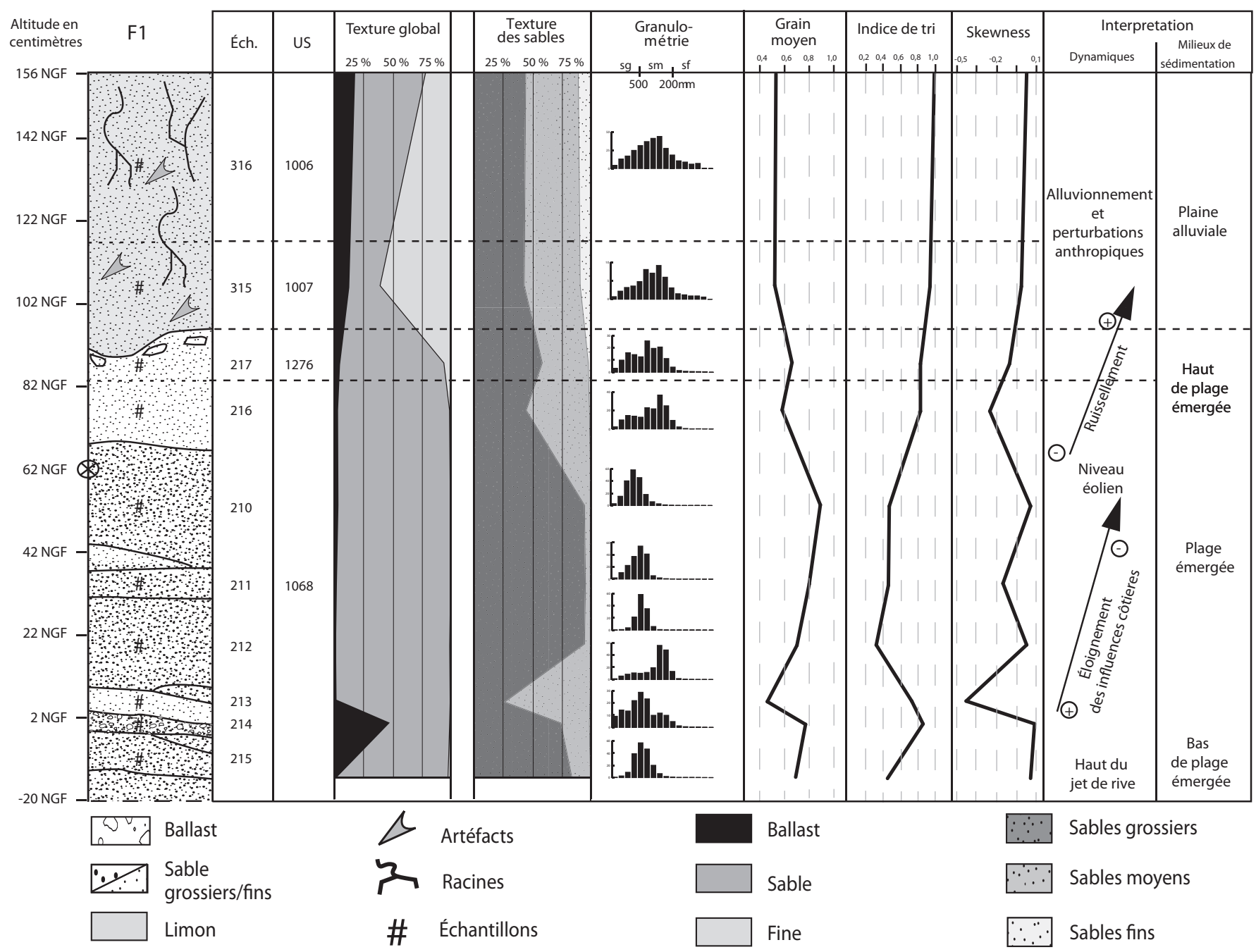

Fig. 17. Analyses sédimentaires de la coupe 1 (S. Bonnet).

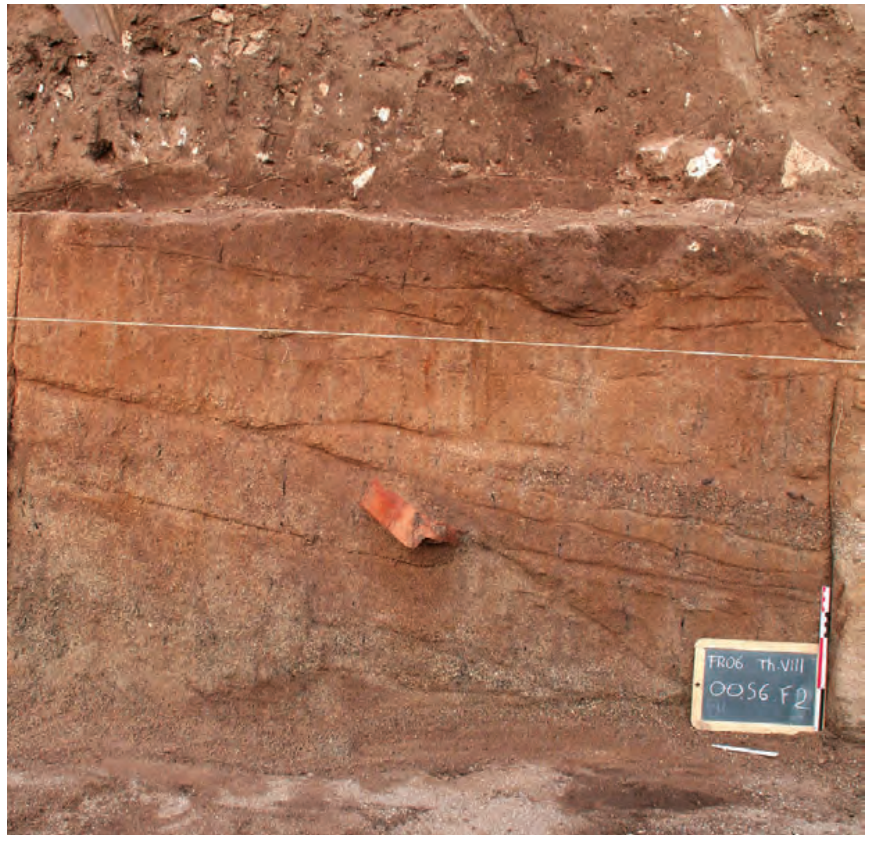

Fig. 18. Amas de tegulae fossilisant une paléotopographie littorale. que ces artéfacts, entiers ou peu fragmentés, n'ont pu être transportés par les vagues. L'aspect organisé de ces dépôts confirme qu'ils proviennent d'une action anthropique, dont le but nous échappe.

Bien qu' aucune datation précise n'ait pu être obtenue, ces aménagements légers, sans lien stratigraphique, semblent contemporains, comme le suggèrent leur aspect commun ainsi que la forme et l'altitude identique des talus qu'ils recouvrent. Selon cette hypothèse il est donc possible de raccorder ces deux zones de jet de rive et d'appréhender du même coup l'extension latérale d'une ligne de rivage antique au niveau de l'emprise de la fouille.

\section{Sens de progradation et origine des apports sédimentaires}

L'étude, sur deux tranchées perpendiculaires, du pendage de lits sableux visibles au sein de certaines lentilles observées dans la zone 3, a démontré que 
l'avancée du cordon littoral s'est effectuée du nord/ nord-ouest au sud/sud-est, ce qui confirme les observations réalisées lors du diagnostic du Théâtre d'Agglomération. Ce sens de progradation démontre que l'édification de la plage provient de la reprise, par la dérive littorale et selon une direction nord, de l'importante charge sédimentaire rejetée à l'embouchure de l'Argens et des cours d'eau provenant de l'Estérel, comme le Reyran. L'analyse minéralogique menée par M. Dubar sur cinq échantillons extraits à partir de couches appartenant à ce premier faciès devait permettre de préciser l'origine des apports détritiques. Cette étude s'est fondée sur la variation de la concentration de certains minéraux lourds tels que les staurotides et autres minéraux du métamorphisme. Ils permettent, dans notre cas, de distinguer les sédiments issus du bassin versant du Reyran de ceux transportés par l'Argens.

Malgré une légère fluctuation de l'abondance de certains minéraux qui se traduit, pour un des échantillons, par la prédominance de l'Argens et/ou l'étiage du Reyran, cette analyse ne fait que confirmer la double origine des apports détritiques.

\section{Datation}

La faible quantité de matière organique et la découverte d'artéfacts rarement datables ont fortement limité l'établissement d'un cadre chronologique précis concernant les dépôts de ce faciès et donc, par extension, des aménagements de tegulae et du trait de côte leur étant associés.

Cependant, la chronostratigraphie établie sur le site, ainsi que la datation d'une laisse de tempête intercalée au sein de ces dépôts «progradants » ont permis de démontrer qu'ils se sont déposés, dans la zone 1 et 2 , au plus tard au changement d'ère.

Bien qu'imprécis, ce cadre chronologique indique que la mise en place de cette sédimentation dans ces deux zones s'est produite lorsque le niveau marin se situait à une position égale ou inférieure à la fourchette altimétrique du niveau marin mesuré au Théâtre d'Agglomération. Rappelons que ce diagnostic avait permis d'estimer la position du niveau marin pour la fin du Ir siècle av. J.-C. entre $-0,392 \mathrm{~m}$ et $-0,21 \mathrm{~m}$ NGF (Excoffon, Devillers 2006, 205-221).

Dans la partie sud-est du chantier, l'absence de datation archéologique pour ce faciès devait être compensée par la réalisation de deux dates AMS provenant d'une laisse de tempête. Cependant, leur non conformité avec le cadre chronostratigraphique a démontré qu'elle n'était pas valide. La raison du vieillissement de ces dépôt sera expliquée ultérieurement.

\subsubsection{La plage émergée (faciès 2)}

\section{Description}

Visible sur l'ensemble du site entre 0,20 et 1,50 m NGF, le second type de dépôt qui constitue le sommet de la phase 1 prend l'aspect de couches homogènes de sable pur n'excédant pas 0,80 m d'épaisseur (coupe 1). Alors qu'elles nappent généralement les corps sédimentaires de bas de plage décrits supra, elles peuvent ponctuellement, dans la zone 2, s'intercaler entre ces derniers ou entre des laisses de tempête.

Composées principalement de sable grossier et moyen, ces couches de $11 \mathrm{~m}$ de longueur maximum, sont les mieux triées de la phase 1, comme le démontrent les valeurs de l'indice de tri qui peut atteindre 0,32 . Suivant une répartition gaussienne, la fraction sableuse peut cependant être marquée ponctuellement par une légère asymétrie négative. Selon ces éléments, ce type de sédimentation est caractéristique de celle observée sur une arrière-plage assujettie à des dynamiques de faible énergie. Dans ce contexte supralittoral, l'accroissement de la taille du grain moyen et la dégradation du tri peuvent traduire le passage d'un haut à un bas de plage (Georges 1998 et Vella 1999).

La taille importante du grain moyen (allant de 350 à $890 \mu \mathrm{m}$ ) démontre que la part des sables éoliens dans l'engraissement de cette plage émergée est faible. Bien que surprenante, cette observation est conforme à celle réalisée sur une des plages actuelles de Fréjus qui se localise à droite de la «Villa des sables » (Georges 1998). Cette particularité s'explique, selon cette étude, par le vannage éolien vers l'amont des particules les plus fines. Seuls alors les apports plus grossiers, provenant des surcotes, ne sont pas remobilisés.

À l'instar des dépôts de plage émergée, ces couches présentent de rares litages parallèles horizontaux qui peuvent cependant être légèrement inclinés vers le sud-est. Cette variation semble caractériser les dépôts de bourrelet (bas de plage).

Il est intéressant de noter qu'à l'extrémité nord-ouest de la zone 1 apparaissent des corps sableux arborant de nombreux litages au fort pendage dirigé vers le sud (sup. à $10 \%$ ). Dans l'étage supralittoral, une telle organisation se retrouve dans les couches constituant les pieds de dune. Si la forte érosion à cet endroit n'a pas permis de vérifier cette hypothèse, la réalisation d'un carottage au nord-ouest du site a démontré l'exhaussement de la limite supérieure du niveau de sable soufflé. Même s'il est actuellement impossible de déterminer les processus à l'origine de cette paléotopographie, il est toutefois possible de la relier à la présence d'un paléocordon dunaire. 
Traversant la zone 1 du sud-ouest au nord-est, un talus au contour irrégulier, pouvant atteindre $0,85 \mathrm{~m}$ de hauteur, vient entailler les sédiments de haut de plage, y compris le pied de dune. Ce gradin nommé « berme » peut être le stigmate de l'érosion par des épisodes de tempêtes. Ce dénivelé est particulièrement intéressant puisqu'il présente de nombreux aménagements.

\subsubsection{Les dépôts de haute énergie (faciès 3)}

\section{Description}

Les deux types de formations décrits précédemment sont entrecoupés, dans la zone 2 et dans la partie sud-est de la zone 3 , par des couches hétérogènes qui présentent un pendage marqué vers le sud-est. Observées entre $-0,20 \mathrm{~m}$ et $1,10 \mathrm{~m}$ NGF, ces formations se caractérisent par une longueur variable, allant de 3,90 à $13 \mathrm{~m}$, et par une épaisseur n'excédant pas 0,30 m (coupe 1). L'absence d'organisation de ces dépôts moyennement triés et la valeur négative de l'indice d'asymétrie qui évoque la prédominance des processus de décantation, démontrent que le troisième faciès s'apparente à une sédimentation forcée (due à un excès de charge) qui s'est étalée le long d'un profil de plage émergée.

Alors que ces couches prennent généralement l'apparence de lentilles de sable grossier contenant une proportion de ballast pouvant atteindre $20 \%$, elles se matérialisent dans la partie sud-est de la zone 3 par des passées obliques de galets organisés qui recèlent quelques tessons roulés de datation indéterminable.

Malgré leur forte différence de texture, ces dépôts sont les stigmates de l'accroissement momentané de la compétence des dynamiques littorales. Le caractère ponctuel de ces couches indique que cette augmentation de l'énergie du milieu provient vraisemblablement de la dégradation des conditions météorologiques marines et non du rapprochement d'une embouchure, comme pourrait le suggérer leur faciès.

\section{Caractérisation de la nature des dynamiques en action}

Les données granulométriques seules ne permettent pas de déterminer si ces lentilles découlent d'évènements exceptionnels, comme une tempête, ou du fonctionnement modal d'une plage qui se caractérise par des processus plus ordinaires, plus fréquents et d'amplitude moyenne.

L'étude qualitative de la malacofaune et l'incohérence des dates AMS réalisées sur des charbons piégés dans ces couches semblent cependant créditer l'hypothèse d'une laisse de tempête.
La détermination de la malacofaune prélevée dans ces dépôts indique un mélange important d'assemblages terrestres, fluviaux et lagunaires/côtiers. Même si l'état de conservation des coquilles est variable, il est généralement de mauvaise qualité : cassures, fragmentations multiples. Seul un événement de tempête est capable de mobiliser une thanatocénose autant diversifiée et aussi mal conservée.

Les charbons constituant ces dépôts semblent issus, pour la majorité, du remaniement de stocks anciens comme le montre la non-conformité de la datation AMS de certains d'entre eux avec le cadre chronostratigraphique établi pour le site. Situées en effet au sud-est des corps sableux mis en place après le milieu du Ir siècle apr. J.-C. ( $c f$. phase 3 ), ces couches devraient être plus récentes, la progradation des rivages s'effectuant du nord-ouest vers le sud-est. Or, leurs datations s'échelonnent de $2885 \pm 5$ BC. cal à $10 \pm 70$ AD. cal, en passant par $435 \pm 85$ BC. cal et $260 \pm 60$ BC. cal. Seule la forte intensité d'épisodes de tempêtes pourrait être à l'origine d'un tel brassage expliquant le vieillissement de ces dépôts et les fluctuations des datations.

Comme le démontrent les études de dépôts actuels de tempêtes, l'interprétation des données granulométrique et structurale de tels niveaux nécessite la connaissance de différents facteurs tels que la hauteur de la houle, la position de la ligne de rivage, la nature des stocks infralittoraux remobilisés (Bruzzi, Provansal 1996, 129-137). Dans l'impossibilité d'obtenir ce genre d'informations, il serait hasardeux de distinguer le rôle joué par les surcotes ou par les houles au sein de cette sédimentation.

\section{Ligne de rivage au changement d'ère}

La date radiocarbone la plus récente est la seule a être considérée comme valide, puisque la seule à être en adéquation avec le contexte chronostratigraphique. Elle démontre que le dépôt de tempête situé au centre de la zone 2 s'est constitué au changement d'ère, plus précisément aux alentours de la première décennie. Étant donné le possible remaniement du matériel daté, ce résultat nous donne seulement un terminus post quem et non une datation absolue. Il est recoupé, à sa base, par un dépôt modal de bas de plage, ce qui démontre qu'à cette période le rivage se situait à proximité. Cependant, la nature de cet indicateur nous donne plus une fourchette qu'une limite précise. Les vestiges de la phase 2 sont donc contemporains des dépôts observés en partie sud-est de la zone 2 et dans la zone 3, ce qui permet d'envisager l'occupation en lien avec la proximité du littoral. 


\section{Mobilier céramique et datation}

$$
\text { (P. E., E. P.) }
$$

Les niveaux constituant cette phase ont livré très peu de mobilier. Parmi les fragments découverts, seuls deux sont identifiables. Il s'agit d'une amphore à saumure de Bétique représentée par une anse (US2010) et d'un fond d'amphore massaliète (US1294). Dans l'amas de blocs ont été retrouvés et reconnus des fragments de panses d'amphores de Bétique appartenant probablement à des Haltern 70. Tous ces fragments présentent une érosion marquée et proviennent des niveaux de sable lités recouvrant cet ensemble. À ce dernier, il faut encore ajouter un bord de vase de stockage en céramique modelée au décor peigné qui semble appartenir à l'âge du Fer (fig. 19).

La datation fournie ne permet guère de situer précisément la période, seuls les éléments concomitants à la mise en place de la phase suivante nous autorisent à situer la fin de cette phase avant le dernier tiers du $\mathrm{I}^{\text {er }}$ siècle av. J.-C. Le mobilier découvert concorde tout à fait avec cette datation puisque les amphores de Bétique, comme celles de Marseille, sont produites dès le milieu du Ier siècle av. J.-C.

La datation radiocarbone effectuée ${ }^{7}$ sur l'un des piquets (PO1302, \#628) ${ }^{8}$, issu d'un bois jeune, confirme que celui-ci a bien été abattu durant le Ir siècle av. J.-C. et probablement vers le milieu de ce siècle?

\section{Interprétation, morphologie et mouvement du littoral (phases 1 et 2)}

$$
\text { (S. B., B. D., P. E.) }
$$

L'amas de blocs situé au sein d'une zone sableuse signifie qu'ils y ont été apportés. La zone de prélèvement de ces blocs se situe au minimum à plus de $500 \mathrm{~m}$; en effet le rocher le plus proche directement accessible se situe au pied de la butte Saint-Antoine. La configuration de certains blocs, comportant des traces évidentes de transformation, incite à supposer qu'ils ont été transportés dans un but précis, soit directement depuis la zone d'extraction, soit depuis une

\footnotetext{
7 Given are intervals of calendar age, where the true ages of the samples encompass with the probability of ca. $68 \%$ and ca. $95 \%$. The calibration was made with the OxCal software. INFORM : References - Atmospheric data from Reimer et al. 2004 ; OxCal v3.10 Bronk Ramsey 2005 ; cub r :5 sd :12 prob usp [chron].

8 Code labo. Poz-20219.

9 FR06 \#628 PO1296/1302 : 2070 $\pm 30 \mathrm{BP}$

$68.2 \%$ probability / 160BC (12.6\%) 130BC / 120BC (55.6\%) 40BC / 95.4\% probability / 180BC $(95.4 \%) 0 \mathrm{AD}$.
}

zone de construction, où ces blocs ont été écartés par les constructeurs pour des raisons inconnues.

L'alignement de pieux pourrait évoquer une sorte de ganivelle protégeant de l'érosion les terrains situés immédiatement au nord. Elle est peut-être complétée dans un second temps par l'apport des gros blocs de grés disposés en tas assurant le blocage des sables en protégeant l'arrière-plage déjà occupée. Les traces d'une occupation proche du site sont perceptibles. Outre les quelques tessons retrouvés, l'amas de tegulae fossilisant une paléotopographie littorale est remarquable (fig. 18). Les données sédimentologiques et géomorphologiques permettent au mieux de situer la ligne de rivage à cette époque au milieu de la parcelle. L'aménagement de blocs et de pieux serait donc directement installé sur un haut de plage dans le but probable de protéger et de stabiliser la zone située immédiatement en arrière.

Bien que le cadre chronologique de cette phase de progradation soit délicat à établir, plusieurs indices directs et indirects de la position des lignes de rivage attestent que la mer atteignait ce secteur au moins à partir du premier quart du Ir siècle av. J.-C. et ce, jusqu'à la première moitié du Irr siècle apr. J.-C., au plus tard.

Alors qu'un trait de côte daté d'avant le dernier tiers du Irer siècle av. J.-C. a été localisé au niveau de la limite méridionale de la zone 1 , un bas de plage à proximité plus ou moins immédiate du rivage semble se situer une dizaine de mètres plus au sud, aux alentours du changement d'ère (fig. 16). D'autres marqueurs de la zone de déferlement, et donc de la position du trait de côte, ont été observés mais sans jamais pouvoir être datés, au vu, rappelons-le, de la rareté voire de l'absence de matière organique et d'artéfact identifiable. Ces dynamiques littorales sont impulsées par un apport sédimentaire important. Comme le démontre l'analyse des minéraux lourds conduite par M. Dubar, les alluvions illustrent une double provenance du sédiment. En effet, elle permet en outre de différencier le remaniement, par les processus côtiers, des dépôts résultant de crues de l'Argens par rapport à ceux provenant du débordement du Reyran. Cette progradation des rivages, due à l'importante charge sédimentaire transportée par l'Argens ainsi que par les cours d'eau provenant de l'Estérel, suit un sens nord-nord-ouest/sud-sud-est. L'évolution de l'interstratification de cette formation littorale, grossièrement d'une zone à l'autre, permet de démontrer que la progradation s'est effectuée de façon discontinue, par impulsions. L'ensemble des dépôts de plage (haut de plage, zone de déferlement, ainsi que les dépôts issus d'épisodes de tempêtes) présentent des formes variables et des discordances d'érosion plus ou moins marquées attestant de la discontinuité du phénomène. Il est intéressant de noter que, dans les 


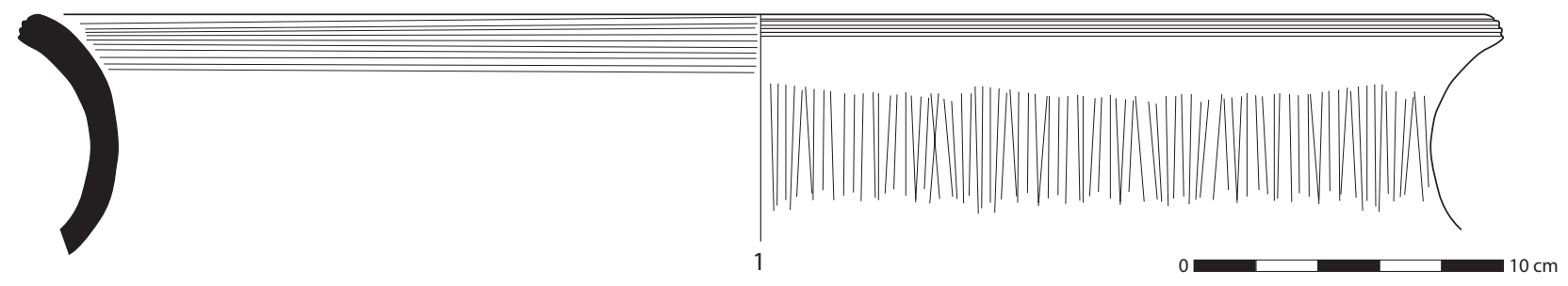

Fig. 19. Bord de vase de l'âge du Fer découvert en phase 1 (E. Pellegrino).

parties nord et sud (zones 1 et 3), les dépôts se superposent strictement. Les corps sédimentaires sont assez étirés et présentent un pendage faible, les discordances d'érosion sont peu marquées. Ces caractéristiques correspondent à une progradation rapide, pouvant correspondre à des plages émergées de grande taille, où l'accrétion sédimentaire d'origine littorale est faible, à l'instar de l'édification des systèmes dunaires (Posamentier et al. 1992). À l'inverse, dans la partie centrale du chantier (zone 2), les dépôts s'entrecoupent, la variété des corps sédimentaires augmente, les discordances d'érosion sont très marquées et le pendage de ces dépôts s'accentue. L'érosion marine semble donc plus importante. Ce changement de dynamique implique une vitesse de progradation ralentie, voire une légère stabilisation de la ligne de rivage. Il peut être combiné à une fluctuation du taux de sédimentation ainsi qu'à une modification des conditions météorologiques marines se traduisant par l'augmentation du nombre de tempêtes et de surcotes. Cette stabilisation de la ligne de rivage, en contexte de progradation, favorise l'exhaussement de la plage émergée. Ce processus peut également être renforcé par la mise en place du mur 2002 ( $c f$. phase 2), ce qui n'est pas remis en cause par la stratigraphie. Cette ride littorale peut donc provenir de la combinaison de facteurs naturels et anthropiques directs (création d'une barrière face aux embruns).

Nous travaillons ici vraisemblablement à l'échelle de la séquence et non à celle de la série ou de la formation. Ces fluctuations ne sont donc pas nécessairement à interpréter comme le reflet de crises ou de mutations paysagères mais traduisent, en fait, le fonctionnement normal d'une plage. L'intérêt d'une étude aussi fine réside dans la compréhension des modes d'occupation dans ce type de milieu.

La phase progradante observée lors de la phase 1 indique une avancée rapide du littoral. Cette progradation rapide des rivages, qui suit un sens nord-nord-ouest/sud-sud-est, est due à l'importante charge sédimentaire transportée par l'Argens ainsi que par les cours d'eau provenant de l'Estérel. Les rapports entre l'avancée du trait de côte, les fluctuations des apports sédimentaires et l'accroissement des activités humaines induites par la colonisation romaine ne peuvent être explicités avec les seules données obtenues à partir de ces opérations. Enfin, s'il est tentant d'assimiler l'accélération du phénomène de progradation par le développement massif de la population, accompagné d'une mise en culture intensive accentuant dès lors le phénomène d'érosion, cette thématique ne pourra être abordée qu'à la lumière d'un corpus de donnés suffisamment représentatif de la ria colmatée. Selon les conclusions de notre étude, il serait intéressant de pondérer et de discuter les résultats de certaines études régionales démontrant un faible détritisme durant l'Antiquité.

Déjà, plusieurs opérations, conduites au gré des aménagements immobiliers, offrent une vision en pointillés du littoral, de sa position et de son évolution (fig. 20). La corrélation des informations fournies par la fouille de «Villa Romana » au sud-ouest de la ville et par le diagnostic du « Théâtre d'Agglomération », localisé plus à l'est, permet de situer sur une carte la position théorique du rivage entre l'Argens et le port de Fréjus avant le changement d'ère (Excoffon et al. 2010). Enfin, les découvertes récentes faites dans le cadre de la fouille $\mathrm{du}$ « Kipling », rue Aristide-Briand, d'un vivier antique et de niveaux marins (Excoffon 2010d) permettent également d'envisager un phénomène de progradation similaire à l'est du bassin portuaire antique. Encore trop lacunaires dans ce secteur de la ville, les opérations archéologiques n'ont pour l'heure pas permis de définir un trait de côte pour la période antique.

\section{Une première limite du camp militaire des Aiguières ?}

(P. E.)

Entre 1979 et 1981, à moins de 300 m au nord-ouest du site de Villa Romana, dans la résidence des Aiguières, une fouille dirigée par Chr. Goudineau a permis de mettre au jour d'importants vestiges orientés NL $49^{\circ}$ dont « le plan des bâtiments, très compartimentés, 


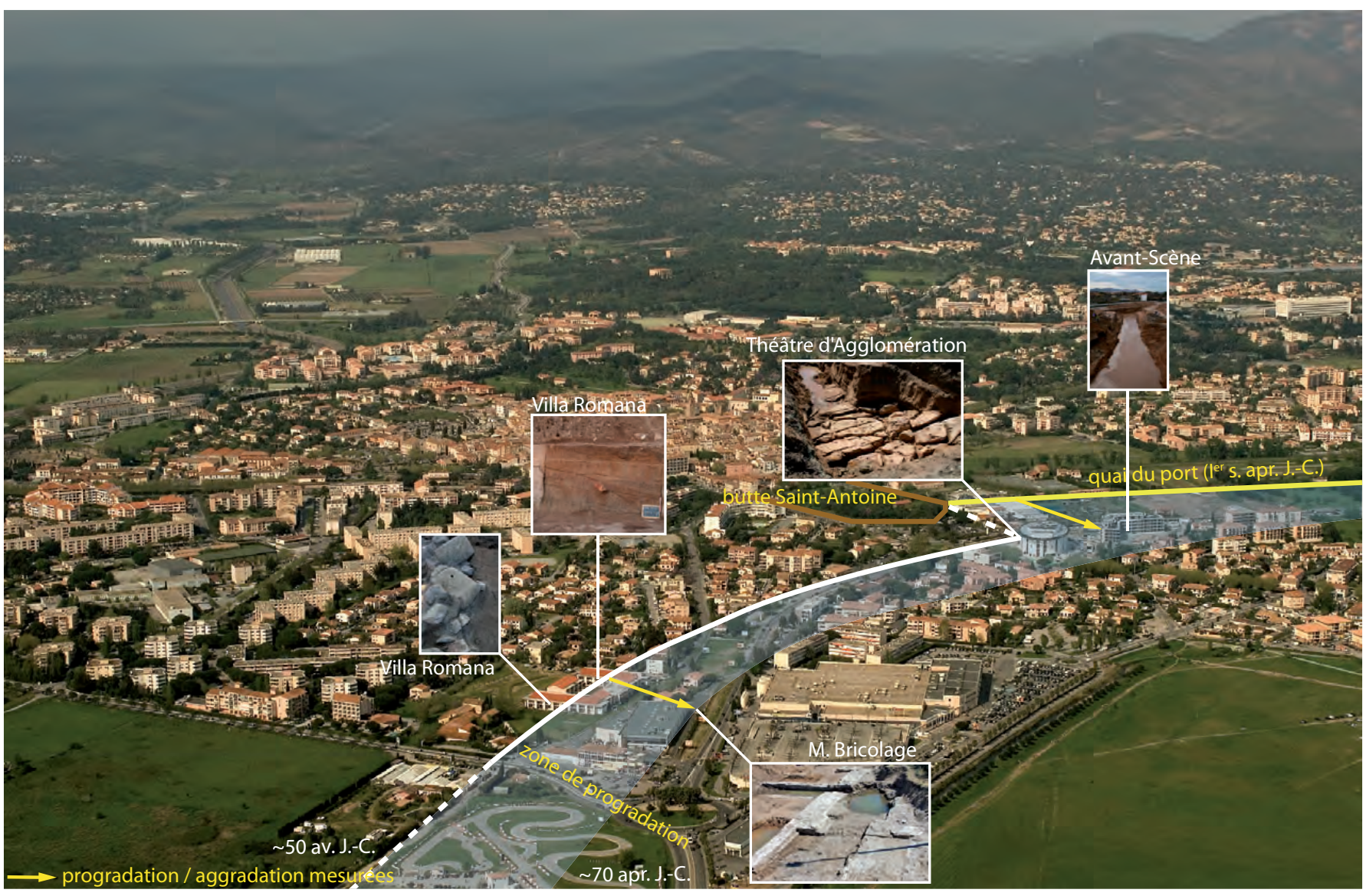

Fig. 20. Différentes opérations ont permis de préciser la position du littoral entre le milieu du ler s. av. J.C. et le Ile s. apr. J.-C. (cl. Ville de Fréjus / M. Heller@).

et une série de découvertes mobilières conduisent à interpréter (...) comme ceux d'un camp militaire » (Rivet et al. 2000, 444). La position de ce camp à proximité de l'embouchure de l'Argens incite à l'attribuer à celui de la flotte établie ici par Auguste (Goudineau 1981 et Goudineau, Brentchaloff 2009). Si, pour l'essentiel, les constructions découvertes remontent à la première moitié du Irr siècle apr. J.-C., l'abondance du matériel numismatique antérieur au changement d'ère, la présence de tessons d'arétine précoce et la découverte d'un fragment d'enduit peint du deuxième style schématique avaient convaincu les archéologues d'une occupation plus ancienne du site, aux alentours des années 30 av. J.-C. Même si ces divers éléments ne sont apparus à eux seuls comme décisifs, l'idée d'une occupation ancienne du quartier demeure (Goudineau, Brentchaloff 2009, 56-57). L'absence de construction contemporaine serait due d'une part à l'origine des matériaux employés pour cette première installation, essentiellement des matériaux périssables et, d'autre part, à la présence de la nappe phréatique plus haute aujourd'hui qu'à l'époque antique. Sur ce point, les fouilles de Villeneuve ont confirmé cette «montée » du niveau de la nappe, mais également et surtout, une présence humaine dans ce secteur peu après le milieu du $\mathrm{I}^{\text {er }}$ siècle av. J.-C. Quoiqu'il en soit, c'est essentiellement l'installation des navires pris lors de la bataille d'Actium en 31 av. J.-C. qui incite $\mathrm{Chr}$. Goudineau à envisager dès cette époque un camp dans le quartier de Villeneuve. Si la fouille de Villa Romana ne permet pas d'apporter une réponse, elle démontre en revanche les traces d'un aménagement du littoral du début de la deuxième moitié du $\mathrm{I}^{\text {er }}$ siècle av. J.-C. et donc d'une occupation du quartier au moment de l'installation des navires. L'alignement de piquets reprend une orientation proche de celle des Aiguières (NL $47^{\circ}$ ouest) et qui d'ailleurs restera la même pour les phases suivantes sur le site de Villa Romana.

Les limites du camp que proposent les auteurs de cette récente publication sont déduites des vestiges bâtis repérés par les fouilles des Aiguières et de la Ferme de Villeneuve d'après les observations de Ch. Texier (fig. 21), et donc postérieures aux premiers aménagements périssables et datables de la fin du $\mathrm{I}^{\text {er }}$ siècle av. J.-C. Ce que nous constatons alors en bord de plage sur le site de Villa Romana dans les années 50-30 av. J.-C. correspondrait à une limite antérieure à 


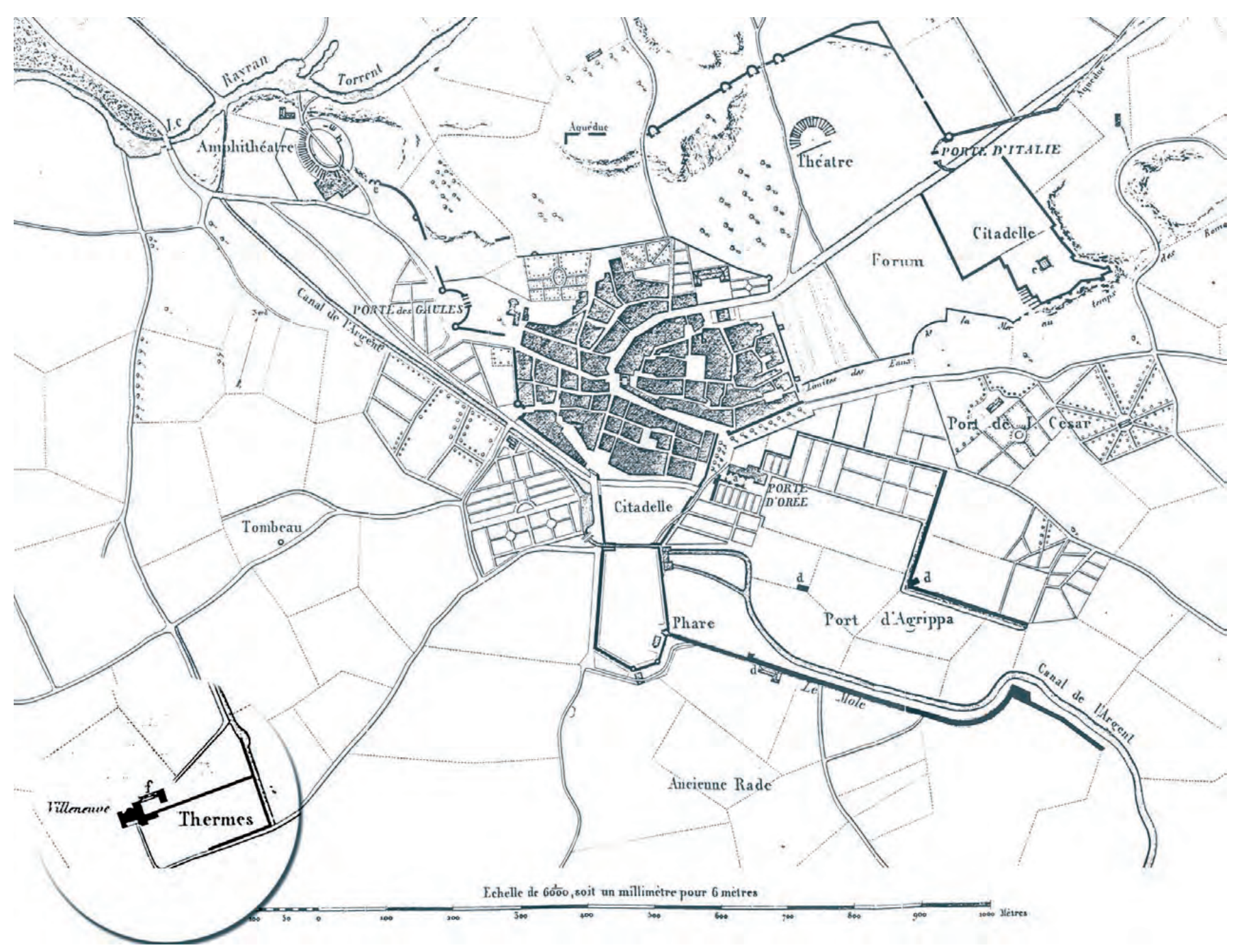

Fig. 21. Plan de Ch. Texier (1849, pl. II) représentant, au niveau de Villeneuve, un mur longeant l'actuelle rue Jean-Carrara.

l'édification « en dur » du camp. La progradation rapide constatée en ce point est un phénomène qui a déjà été observé au pied de la butte Saint-Antoine et ailleurs (Excoffon, Berger 2008 et Excoffon et al. 2010). Ainsi, la limite méridionale de ce premier camp se trouverait directement sur la plage. Cette découverte peut constituer un point supplémentaire pour appuyer l'hypothèse d'une « installation dans l'oppidum Foroiuliense des navires pris à la bataille d'Actium » (Goudineau, Brentchaloff $2009,56)$ et ainsi conforter l'idée de ces mêmes auteurs : «... les traces d'un ancien état (...) pourraient provenir d'un autre endroit du camp, un camp plus restreint, qui n'aurait été développé qu'à la fin du Irr siècle av. J.-C., une fois la paix définitivement instaurée près du « littoral gaulois le plus proche » (ibid., 57). Quoiqu'il en soit, l'aménagement du bord de plage, s'il ne participe pas directement de l'organisation d'un camp dès cette époque, apparaît tout de même en phase chronologique avec les premières mentions écrites de l'existence de Forum Iulii, qui apparaissent dans la correspondance de Cicéron (voir supra p. 16), près de vingt ans avant la déduction de la colonie. 



\section{Chapitre 2}

\section{Les jardins de la fin du I ${ }^{\text {er }}$ siècle av. J.-C. et de la première moitié du siècle suivant}

Il s'agit des premiers aménagements établis sur le haut de plage constitué par l'épais niveau sableux (fig. 22 et coupe 2a). Comme nous l'avons décrit précédemment, la mer a « reculé » et le rivage se trouve alors plusieurs dizaines de mètres plus au sud. Ce niveau, dont la surface marque un faible pendage vers le sud, paraît se stabiliser aux alentours de 0,90/1 m NGF et ne s'exhaussera que très peu durant les époques suivantes en raison de son éloignement continu du rivage et donc des apports sédimentaires. Les niveaux contemporains de cette phase n'ont été mis en évidence que dans la partie nord du terrain, le long d'une bande de $20 \mathrm{~m}$ de large. Cette zone correspond à un espace non couvert, constitué d'une bande cultivée et matérialisé par la présence d'un double alignement de fosses, d'un puits et de murs de clôtures. Bien que très remaniés par les époques suivantes, il est possible que les terrains constitués au sud (zones 2 et 3 ) étaient vierges de tout aménagement et correspondaient à un haut de plage ouvert ${ }^{1}$.

\section{Les structures}

(P. E.)

En limite sud de la zone 1 est édifié un mur d'un mètre de large, d'orientation est-ouest et faiblement fondé dans une tranchée étroite (MR2004) (fig. 23). On le retrouve sur toute la longueur du terrain, soit $85 \mathrm{~m}$, mais il était nécessairement plus long. Largement épierré, il n'en subsiste que quelques portions isolées ${ }^{2}$. Il est constitué d'un parement en gros moellons mal équarris de part et d'autre d'un blocage de mortier et pierrailles (fig. 24 et 25). Bien que d'aspect très rustique, un certain effort semble avoir été fait pour présenter un parement nord vertical (fig. 26), alors que le parement sud n'est fait que

1 Les terrains situés au sud ont été excavés aux époques postérieures, oblitérant toute trace d'occupation antérieure.

2 Ce mur sera presque entièrement épierré au début de l'époque moderne, en ne laissant dans la tranchée correspondante que les fragments de mortier inutilisables. de gros moellons mal agencés, disposés à plat avec un mortier très débordant (fig. 27). L'altimétrie des niveaux sableux situés au sud de ce mur ${ }^{3}$, de plus de $1,30 \mathrm{~m}$ NGF, ainsi que l'aspect du parement sud, indiquent qu'il pouvait jouer un rôle contre l'avancée du sable depuis la limite littorale. Dans tous les cas, il servait de mur de clôture.

Au nord, un mur (MR1261) d'orientation est-ouest est conservé partiellement sur une très courte distance, mais sa tranchée d'épierrement (US1214) se suit d'un bout à l'autre du site (fig. 28). Sa trace a été repérée sur 72,50 m mais il outrepassait largement les limites de la fouille. La tranchée d'épierrement présente un retour court vers le nord pouvant correspondre à une division de l'espace. La seule portion conservée correspond à une semelle de fondation, faite de gros moellons et de mortier, mise en place sur un radier en hérisson plus étroit (fig. 29 et 30). On constate ici le même phénomène que pour le mur MR2004. Sur l'aspect de l'élévation du mur nous ne connaissons presque rien, excepté ce que nous a livré le comblement de sa tranchée d'épierrement (US1261 et 1249). Outre un clou de section carrée et tête aplatie, le comblement et le niveau d'épandage de destruction employés dans la fondation du mur plus tardif, MR1003, ont livré plusieurs fragments d'enduits peints blancs et rouges, ainsi qu'un élément de maçonnerie courbe. N'est conservé de ce dernier qu'un fragment composé d'une partie interne faite de gros cailloux mêlés dans un mortier sableux, d'une couche d'enduit de mortier, lui-même recouvert d'une couche d'enduit plus fin. Sur celui-ci, des traces de peinture blanche sont encore visibles par endroits. Il pourrait s'agir d'éléments de colonne maçonnée, peut-être une demi-colonne engagée. On peut penser également qu'au moins un parement était enduit, contrairement au mur MR2004. Complétant cet ensemble, un dernier mur, toujours orienté est-ouest sur toute la longueur du chantier, est bâti au centre de la zone (MR1050). Malheureusement il n'en subsiste qu'une tranchée d'épierrement de

3 Il ne s'agit que de la surface « conservée ». 


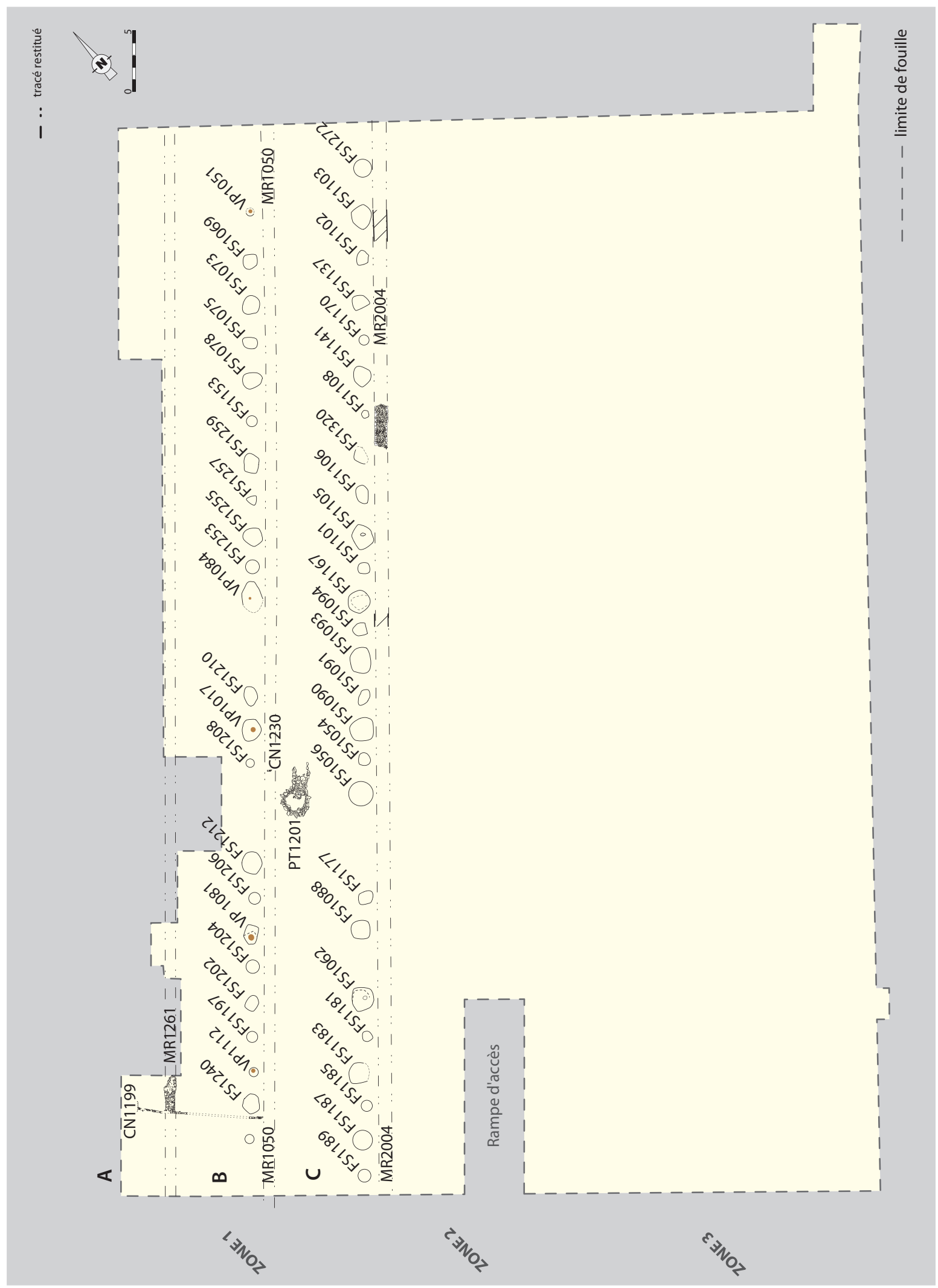

Fig. 22. Plan d'ensemble des vestiges de la phase 2 . 

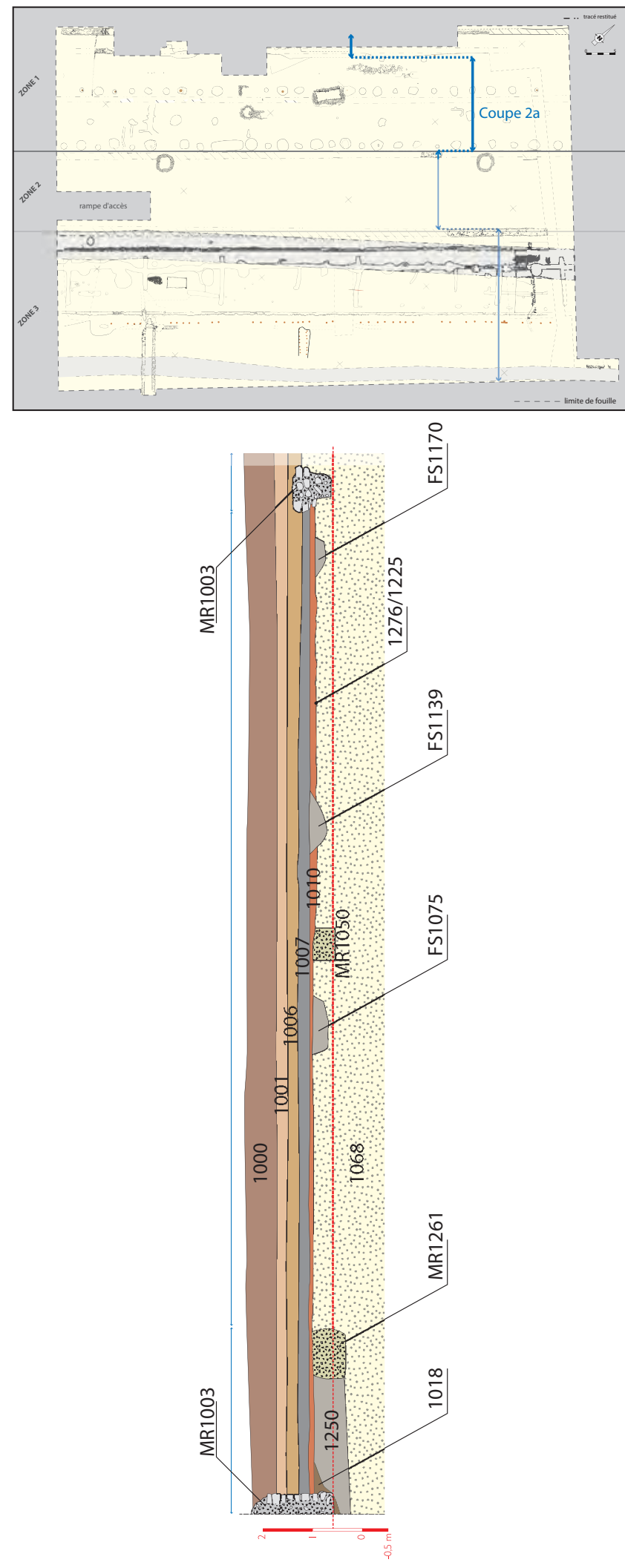

Coupe $2 \mathrm{a}$.
0,90 $\mathrm{m}$ de large (MR1050) comprenant des nodules de mortier et quelques très rares moellons (fig. 31). La largeur de la tranchée suggère un mur sensiblement plus étroit que les deux autres. Ce mur délimite la zone de fouille en deux secteurs de dimensions proches, désignés $B$ au nord $(656 \mathrm{~m})$ et $C$ au sud $(722 \mathrm{~m})$. Il pourrait s'agir d'un mur bahut marquant un léger dénivelé entre les deux secteurs. Le mur MR1050 était probablement un muret (mur d'appui ou mur bahut) et le mur MR2004 un mur de clôture sensiblement plus haut. Le sol (1225) est constitué de sable damé et légèrement enrichi en limon. C'est à partir de cette surface que sont aménagés deux alignements de fosses de plantation le long des murets MR2004 et MR1050 (fig. 40). Altimétriquement, la surface du sol au nord du mur MR1050 se situe à une dizaine de centimètres (alt. moyenne $1 \mathrm{~m}$ NGF) au dessus du sol contemporrain au sud (alt. moyenne 0,90 m NGF), le muret MR1050 servant alors de mur de terrasse.

\section{Les fosses de plantations} (P. E.)

\subsection{Organisation}

Dans le secteur B, 23 fosses ont été découvertes contre le mur MR1050 suivant un alignement est/ouest (fig. 32). Cet ensemble est désigné SFO1084. Six d'entres elles contenaient une amphore coupée et enterrée. Les fosses sont toutes de formes plus ou moins ovales, mais on peut déterminer deux formats, un grand dont le diamètre varie de 1,20 à 1,60 $\mathrm{m}$ pour une profondeur supérieure à $0,70 \mathrm{~m}$ et un petit, d'un diamètre moyen de $1 \mathrm{~m}$ pour une profondeur à peine supérieure à $0,30 \mathrm{~m}$. Bien que les traces de certaines fosses aient disparu, l'organisation de l'ensemble paraît respecter une certaine logique, à savoir une alternance entre les grandes et les petites fosses. L'espacement des fosses est assez constant mais diffère entre la moitié est et la moitié ouest. Ainsi, à l'ouest, la distance bord à bord est de $1,50 \mathrm{~m}$ et de $2,75 \mathrm{~m}$ si l'on prend le centre des fosses ; à l'est, on retrouve respectivement $2 \mathrm{~m}$ et $3 \mathrm{~m}$. Si l'on projette ces données sur l'ensemble de l'alignement, on peut restituer au total 29 fosses. Six fosses contenaient des amphores VP1304, 1112, 1081, 1017, 1084 et 1051 et deux fragments de fond découverts hors des fosses dans des niveaux remaniés, laissent présager qu'il pouvait y en avoir d'avantage.

Dans le secteur C, 26 fosses ont été découvertes suivant un alignement est-ouest (SFO1093) contre le mur MR2004. Se retrouvent, par alternance, des grandes et des petites fosses. La forme générale de celles-ci, 


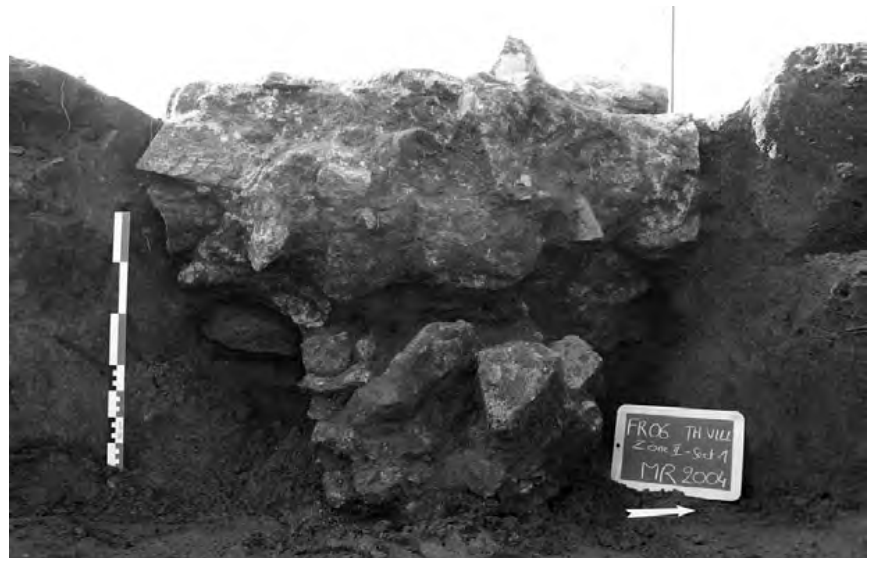

Fig. 23. Vue en section du mur MR2004.

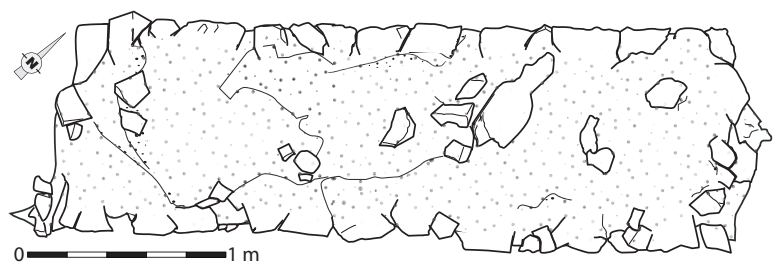

Fig. 24. Relevé en plan de la partie conservée du mur MR2004

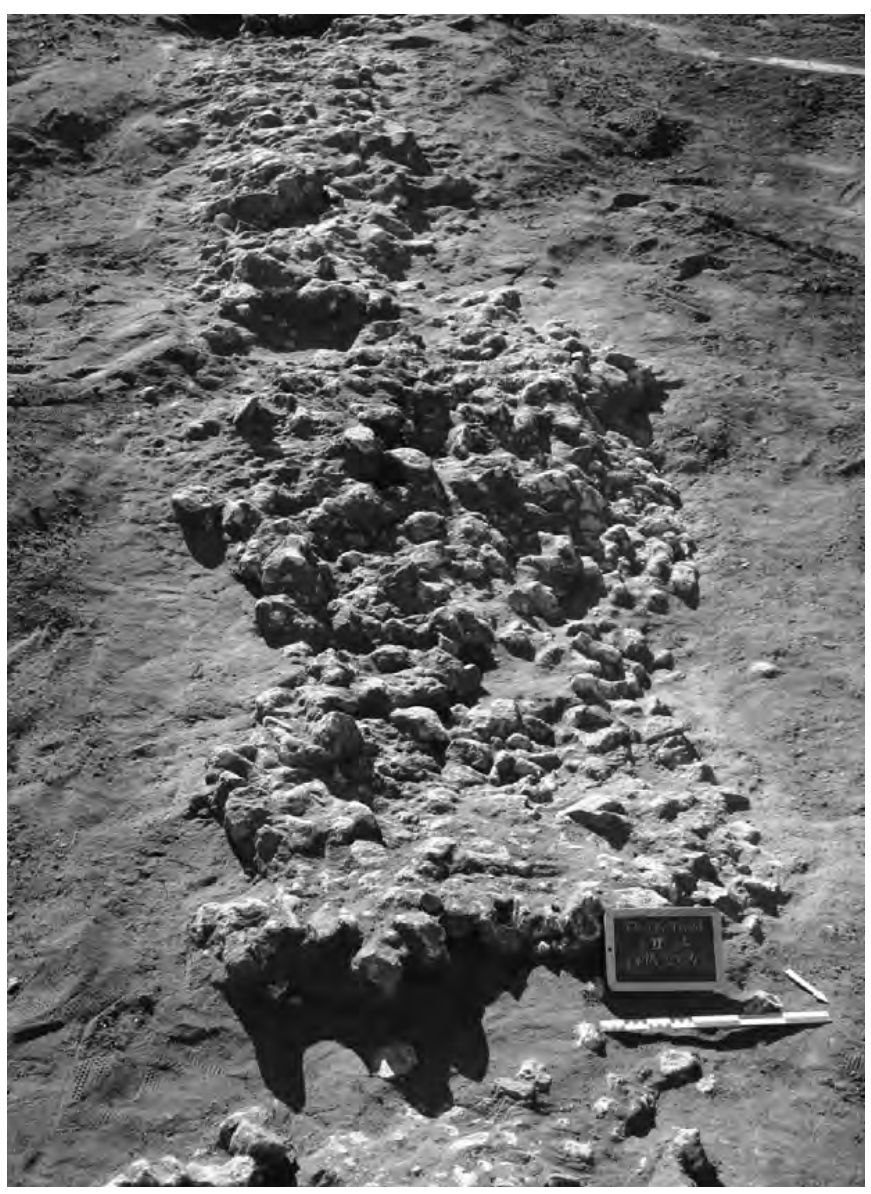

Fig. 25. Tranchée d'épierrement du mur MR2004.

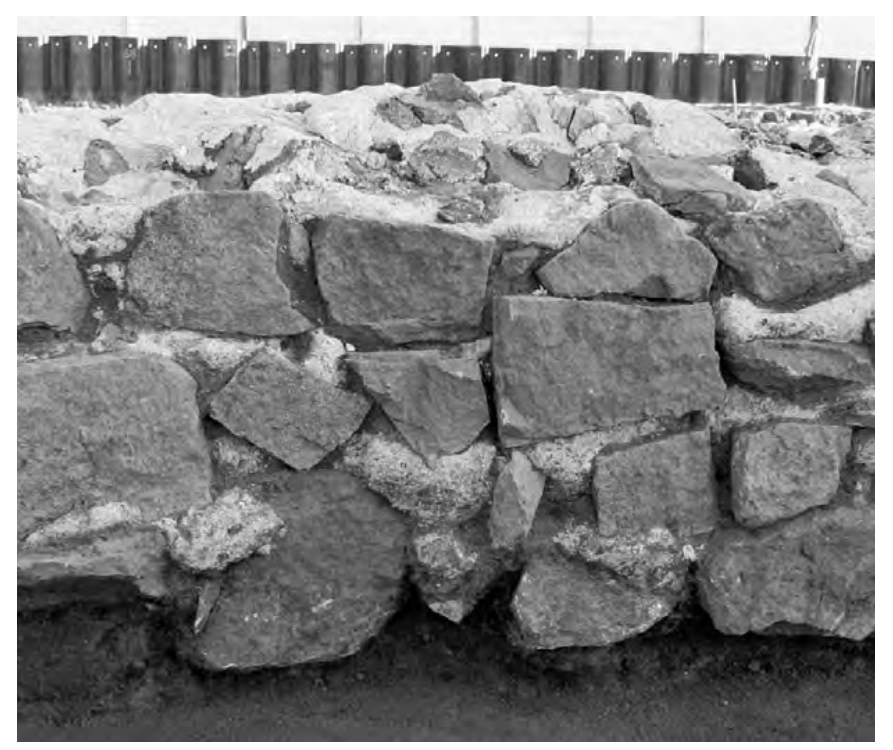

Fig. 26. Détail du parement nord du mur MR2004.

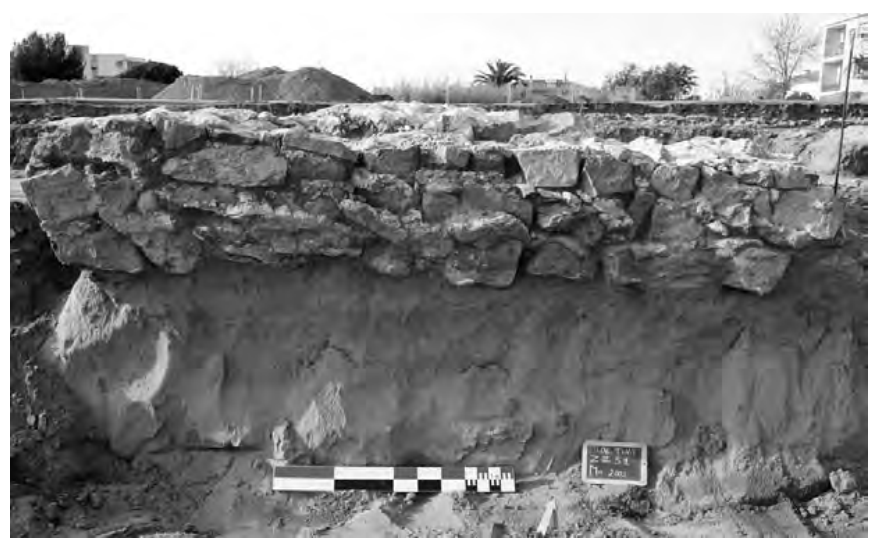

Fig. 27. Parement sud du mur MR2004, aménagé sur le sable.

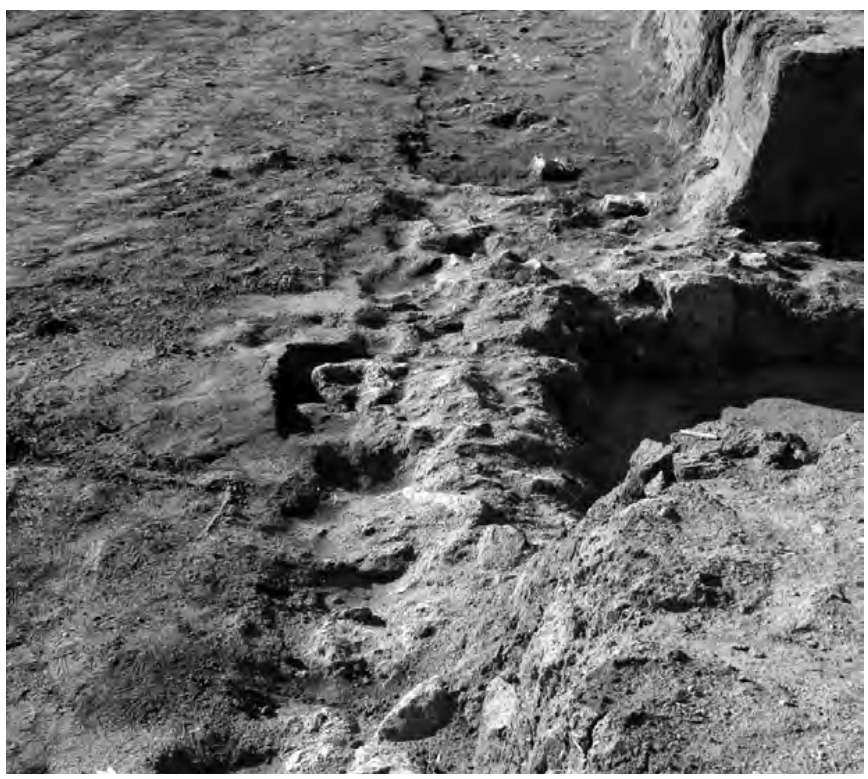

Fig. 28. Tranchée d'épierrement (TR1214) du mur MR1261, vue de l'est. 


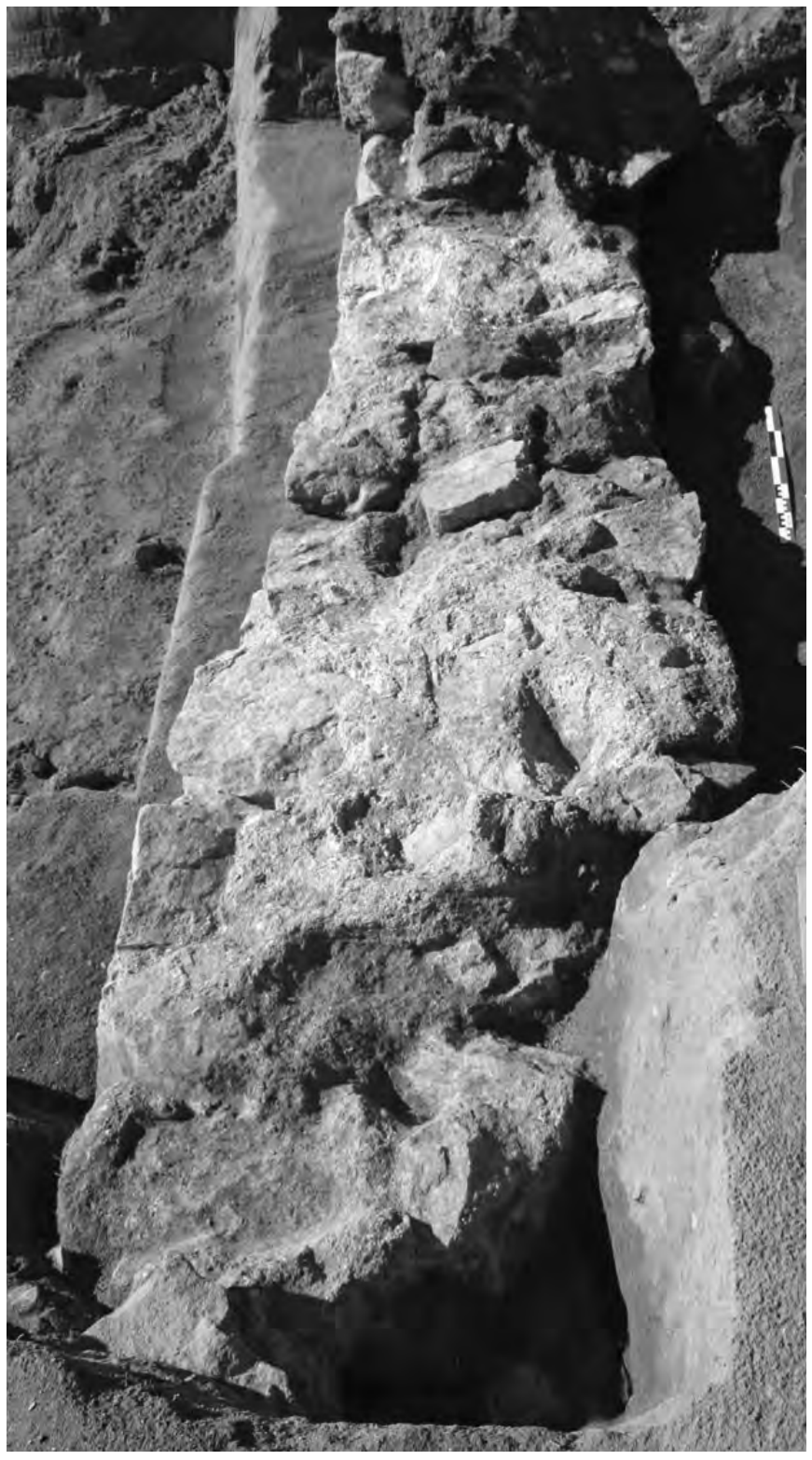

Fig. 29. Courte section conservée du mur MR1261.

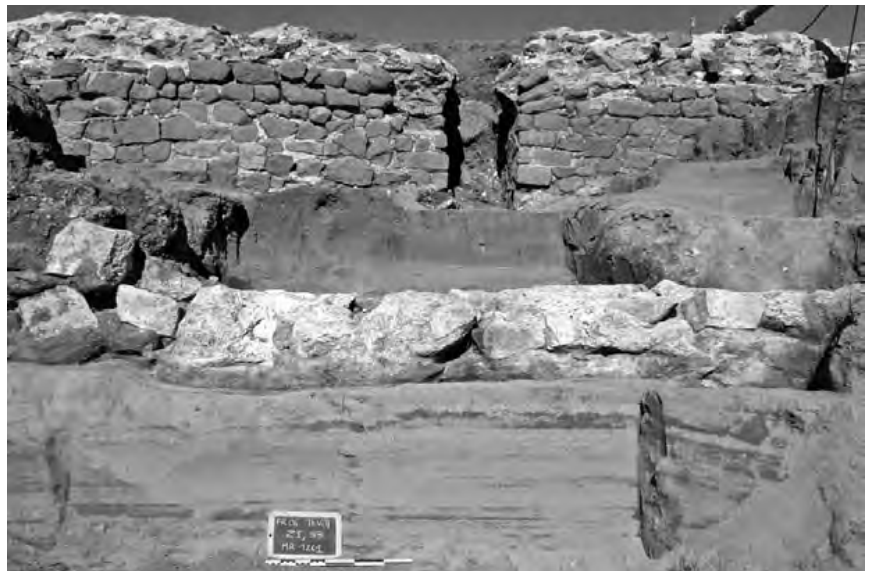

Fig. 30. Les fondations du mur MR1261 sont placées dans les sables lités de la plage de la phase précédente. comme l'espacement entre elles, est similaire à celle du secteur B. En revanche, aucune d'entre elles ne renfermait de demi-amphore. Au total on peut restituer, comme pour SFO1084, 29 fosses sur l'ensemble de l'alignement.

\subsection{Morphologie et comblement}

Les fosses ont été creusées dans le sable et sont de forme ovale ou vaguement circulaire. Les petites fosses ont souvent les parois les plus régulières et offrent, en coupe, un profil semi-circulaire, alors que les grandes fosses ont des parois bien moins régulières (fig. 33 et 34). L'aspect des parois résulte sans doute de la technique de creusement ; en effet, l'ouvrier se trouvait tantôt à l'extérieur pour les petites, tantôt à l'intérieur pour les plus grandes. Le volume moyen pour les petites fosses est de l'ordre de $0,40 \mathrm{~m}^{3}$ et de $1,50 \mathrm{~m}^{3}$ pour les grandes.

Les 49 fosses fouillées comprenaient toutes un comblement de terre gris brun à dominante sablolimoneuse présentant quelques charbons et de rares céramiques, radicalement différent du substrat sableux. Dans les plus grandes fosses (FS1062, 1093, 1212 et 1202), une stratigraphie du comblement a pu être mise en évidence, essentiellement par des variations de teinte, la présence de cailloux ou autres. Dans quelques fonds de fosses, on note des apports de cailloux, graviers ou parfois, morceaux de mortier (FS1202/US1219, FS1257/US1258, FS1090/US1126, FS1102/US1146 et FS1187/US1188). Plus fréquentes encore sont les marques d'oxydation localisées dans les parties les plus hautes du comblement, souvent horizontalement, parfois au centre de la fosse, en particulier pour la fosse FS1062/US1058 (fig. 35). Enfin, dans plusieurs comblements ont été retrouvées des mottes argileuses jaunes, le plus souvent en fond de fosse (FS1073, 1090) (fig. 36).

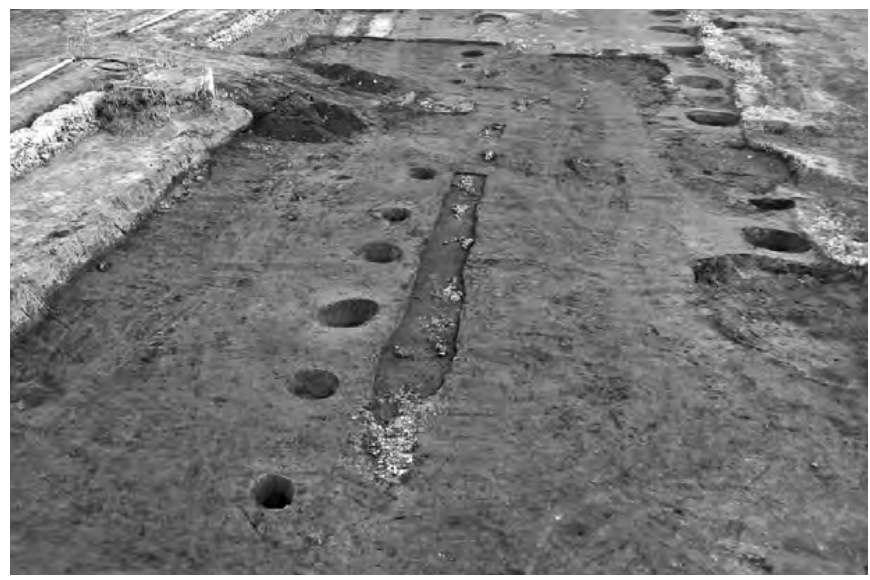

Fig. 31. Tranchée d'épierrement du muret MR1050 où apparaissent des nodules de mortier, vue de l'ouest. 


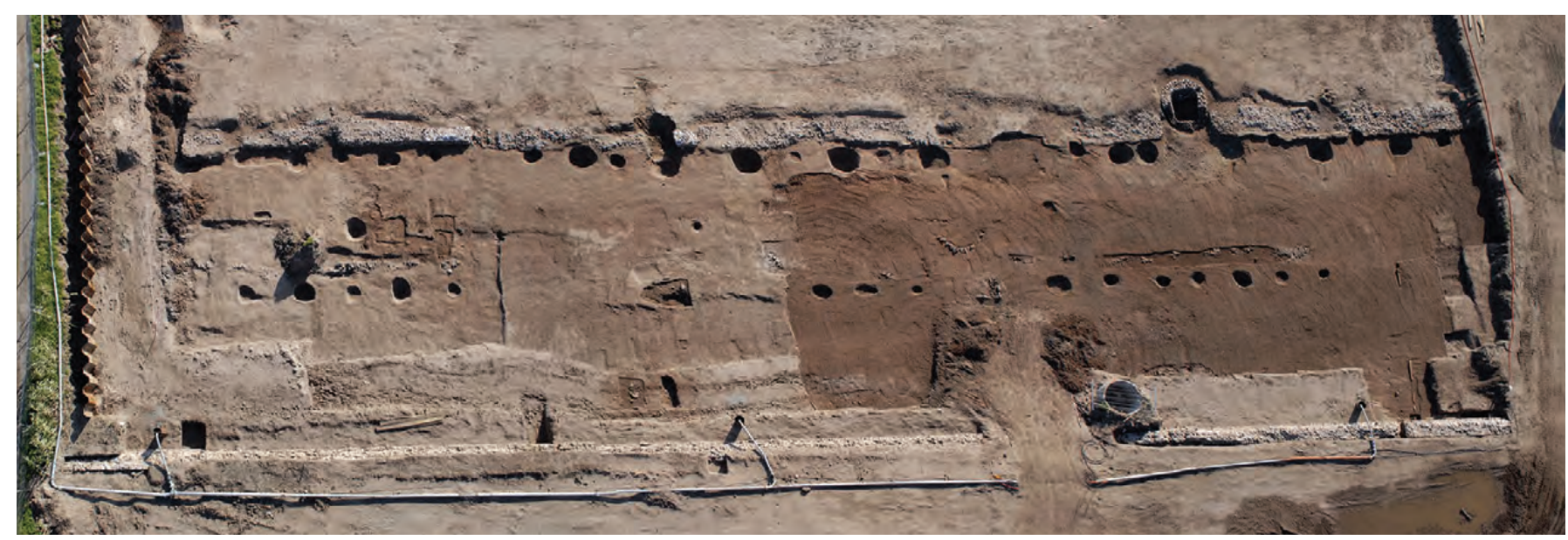

Fig. 32. Vue verticale de la zone 1, où apparaissent une partie des fosses des deux alignements.

\subsection{Les fosses à amphore}

\subsubsection{Morphologie et comblement}

Les six fonds d'amphores, situés dans l'alignement SFO1084, se trouvaient dans des fosses similaires aux autres et ont été mis en place dans un comblement également de même nature, gris brun sablo-limoneux. Les amphores les mieux conservées (VP1012, 1017, 1081 et 1084) sont plus ou moins inclinées au sein des fosses et la découpe est horizontale. Toutes les découpes se sont faites sous le col, certaines au milieu de la panse, d'autres ont conservé au moins l'épaulement (fig. 37). Enfin, certaines sont coupées selon une ligne oblique permettant de présenter une ouverture plus large que le diamètre des amphores. Pour assurer le draînage, la majorité des amphores a été fendue après leur installation dans la fosse ; seule une amphore (VP1084) a été percée d'un trou dans la panse (fig. 38) et pour d'autres, comme VP1304, une cassure a permis d'ôter un tesson. Le comblement des amphores se présente de façon identique. Au fond, comme dans les fosses, on trouve un sédiment gris brun sablo-limoneux, sur une quinzaine de centimètres, contenant de nombreux fragments de l'amphore découpée ${ }^{4}$, employés à l'évidence comme éléments de drainage (B) (fig. 39). Le comblement supérieur (A) est fait d'une terre argilolimoneuse de teinte rouge. L'ensemble des comblements a été prélevé, ponctuellement pour la palynologie et la phytolithologie, en masse pour un tamisage en vue des analyses carpologiques et anthracologiques. Lors du tamisage, au sein du comblement (1067) de l'amphore en place VP1017, un petit bronze de Fréjus à la proue armée et au capricorne a été découvert, tendant à confirmer que la mise en pot a dû être effectuée sur place.

446 fragments dans VP1051; il s'agit d'éléments du col et de la lèvre.

\subsubsection{La typologie des amphores}

Les amphores employées sont de types différents : une Dressel 6A, deux Pascual 1, une Dressel 7/11, une Haltern 70 et une Dressel 1B. À l'évidence, le choix n'apparaît donc nullement technique mais simplement représentatif de ce dont on pouvait disposer à Fréjus à l'époque augustéenne.

Le vase VP1081 (fig. $40-n^{\circ} 1$ ) est une amphore vinaire de la côte adriatique, type Dressel 6A, dont subsiste la base du col jusqu'au fond. Il s'agit d'une amphore massive, aux parois épaisses dont la pâte est assez fine, beige clair en surface et rose orangé à la cassure avec de gros grains de chamotte. Les anses sont rondes, droites et massives, la panse s'évase vers le bas et le pied est en pointe tronconique pleine. La morphologie de cette amphore rappelle les Dressel 6A découvertes dans l'épave de la Tradelière, échouée au large de Cannes, et datée de la fin du Ir $^{\text {r }}$ siècle av. J.-C. ${ }^{5}$ (Fiori, Joncheray 1975 ; Pollino 1986). Les importations de la côte adriatique dans ce conteneur restent rares à cette époque en Gaule comme le souligne A. Tchernia (1986, 148), mais leur diffusion commence dès le milieu du $\mathrm{I}^{\mathrm{er}}$ siècle av. J.-C., où elles supplantent progressivement les Lamboglia 2 (Cipriano, Carre 1989, 84-85). Si l'on ajoute cet individu aux cinq complets découverts récemment dans les fouilles de l'amphithéâtre, l'idée d'une importation relativement importante depuis la côte adriatique vers Fréjus tendrait à être confirmée (Excoffon 2010a).

Le vase VP1017 (fig. 40 - no 2) est une amphore à saumure de Bétique du type Dressel 7/11. Seul le fond est conservé sur une hauteur de $39 \mathrm{~cm}$. La pâte est légèrement feuilletée, de teinte beige orangé avec de fines

5 La datation du naufrage est toutefois discutable et pourrait être encore remontée antérieurement à la dernière décennie du Ir siècle av. J.-C. 

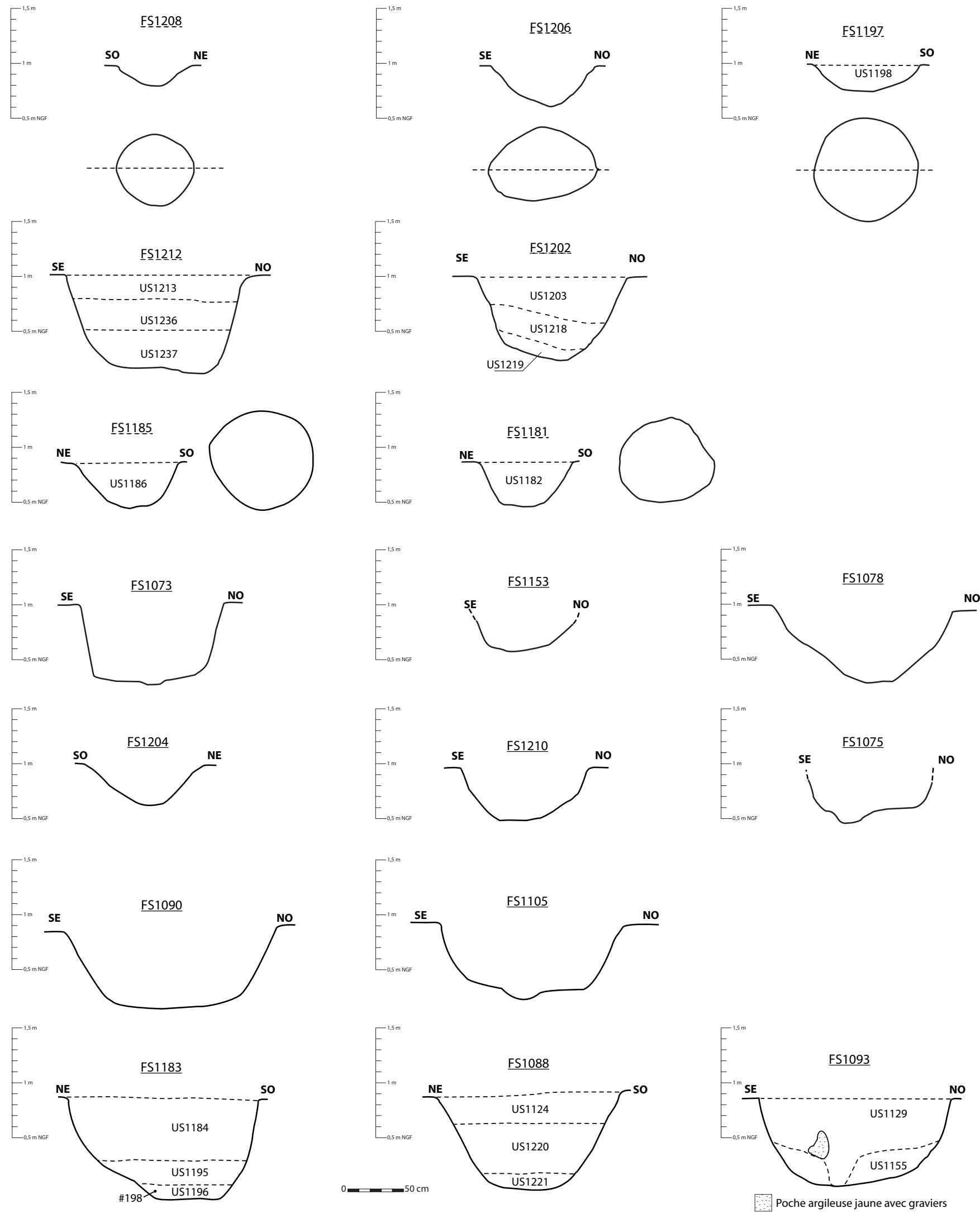

Fig. 33. Profils des fosses des alignements SFO1084 et SFO1093. 

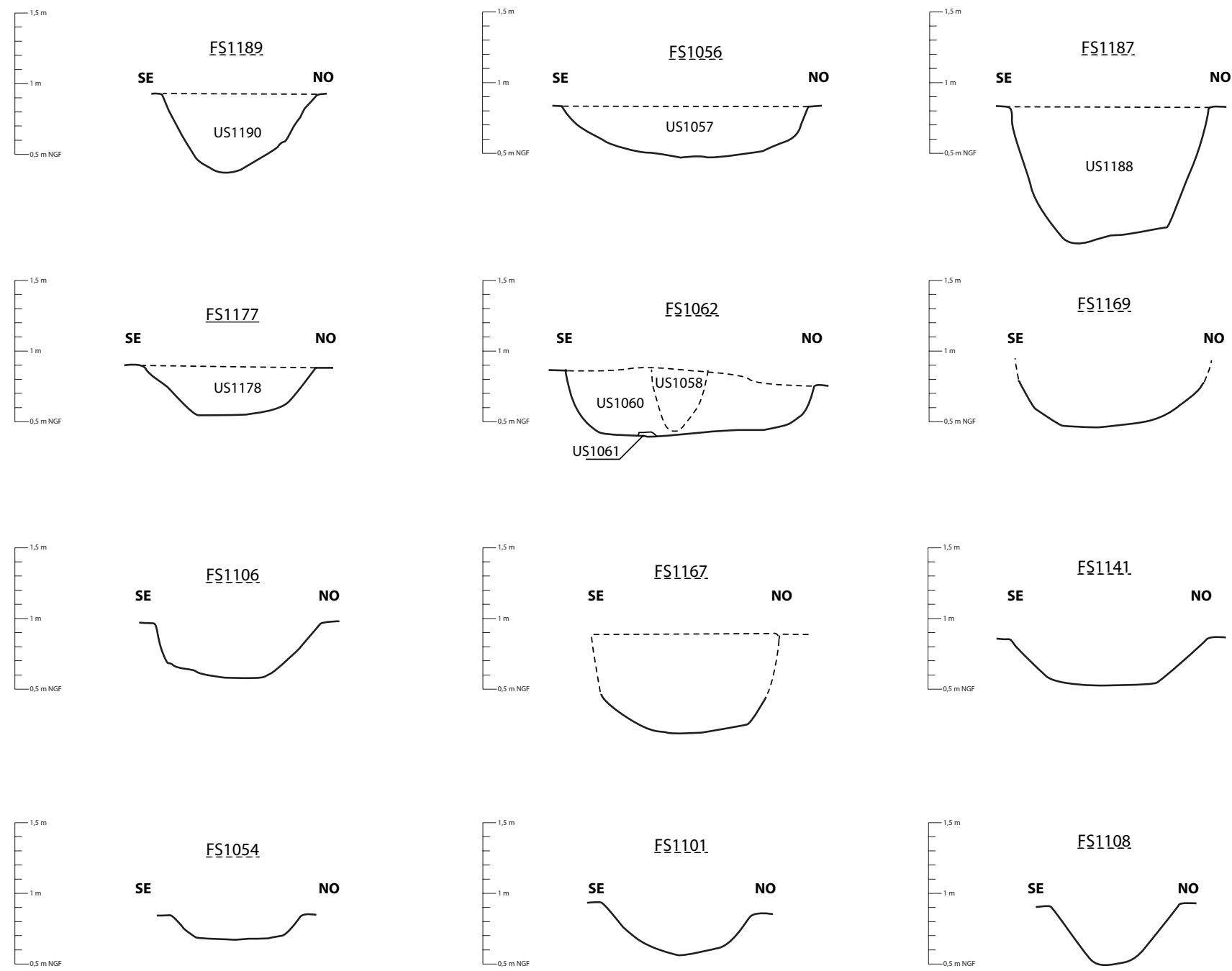

FS1ㅗㅇㅛ
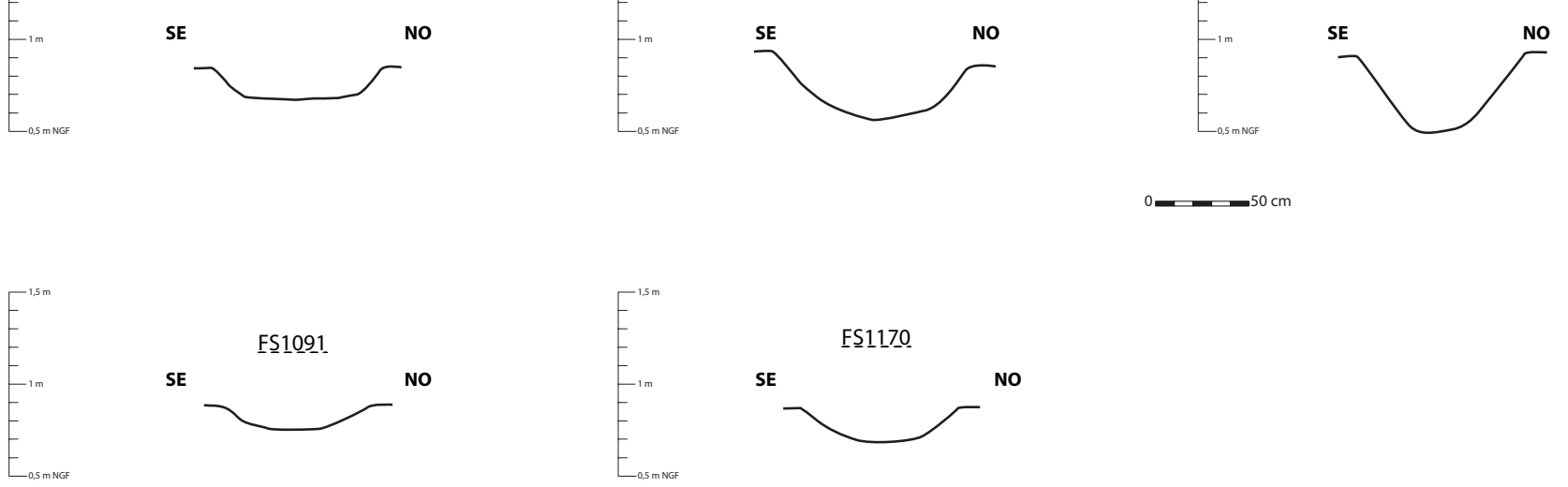

Fig. 34. Profils des fosses des alignements SFO1084 et SFO1093.

inclusions. Le pied est haut et creux. Ces modèles sont fréquents dès la deuxième moitié du Irr siècle av. J.-C.

Les vases VP1051 et 1112 (fig. $40-\mathrm{n}^{\text {os }} 3$ et 4) appartiennent à des fonds d'amphores à vin de Tarraconaise du type Pascual 1. Les pâtes des deux exemplaires sont similaires, une couleur jaune, une texture sableuse et de nombreuses inclusions blanches de quartz. Tous les deux présentent un pied massif en pointe aplatie, l'exemplaire 1051 est cassé et comporte une estampille sur le pilon, dans un cartouche carré portant deux lettres en relief illisibles. Ce type d'amphore se généralise en Gaule durant la seconde moitié du $\mathrm{I}^{\text {er }}$ siècle av. J.-C.

Le vase VP1304 (fig. 40 - n 5) est une amphore à vin de Bétique du type Haltern 70 qui circule durant la deuxième moitié du Ir siècle av. J.-C. Seul le bas de panse est conservé sur $45 \mathrm{~cm}$. La pâte est beige orange, sableuse et friable. Le pied est court et en pointe.

Le vase VP1084 (fig. 41) est une amphore à vin de la côte tyrrhénienne du type Dressel 1B. 


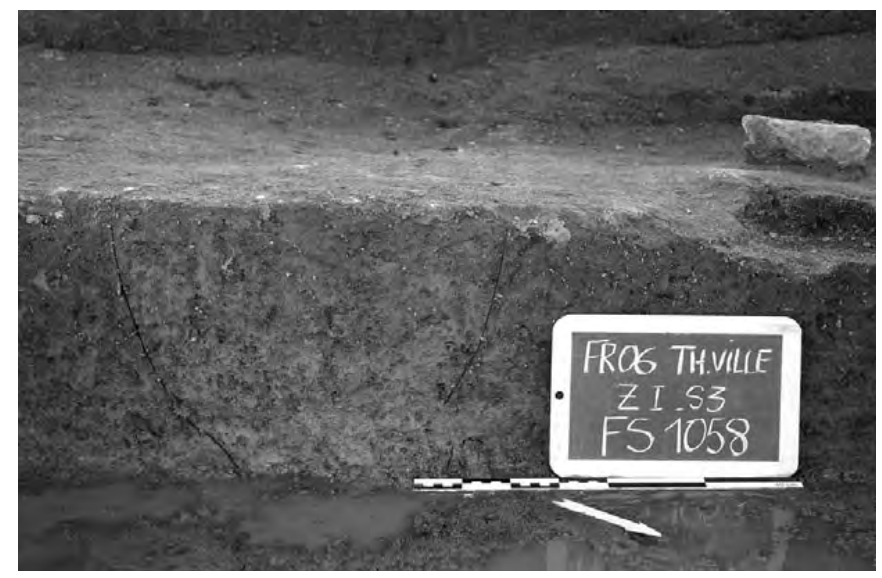

Fig. 35. Vue en coupe du comblement (1058) de la fosse SF1062.

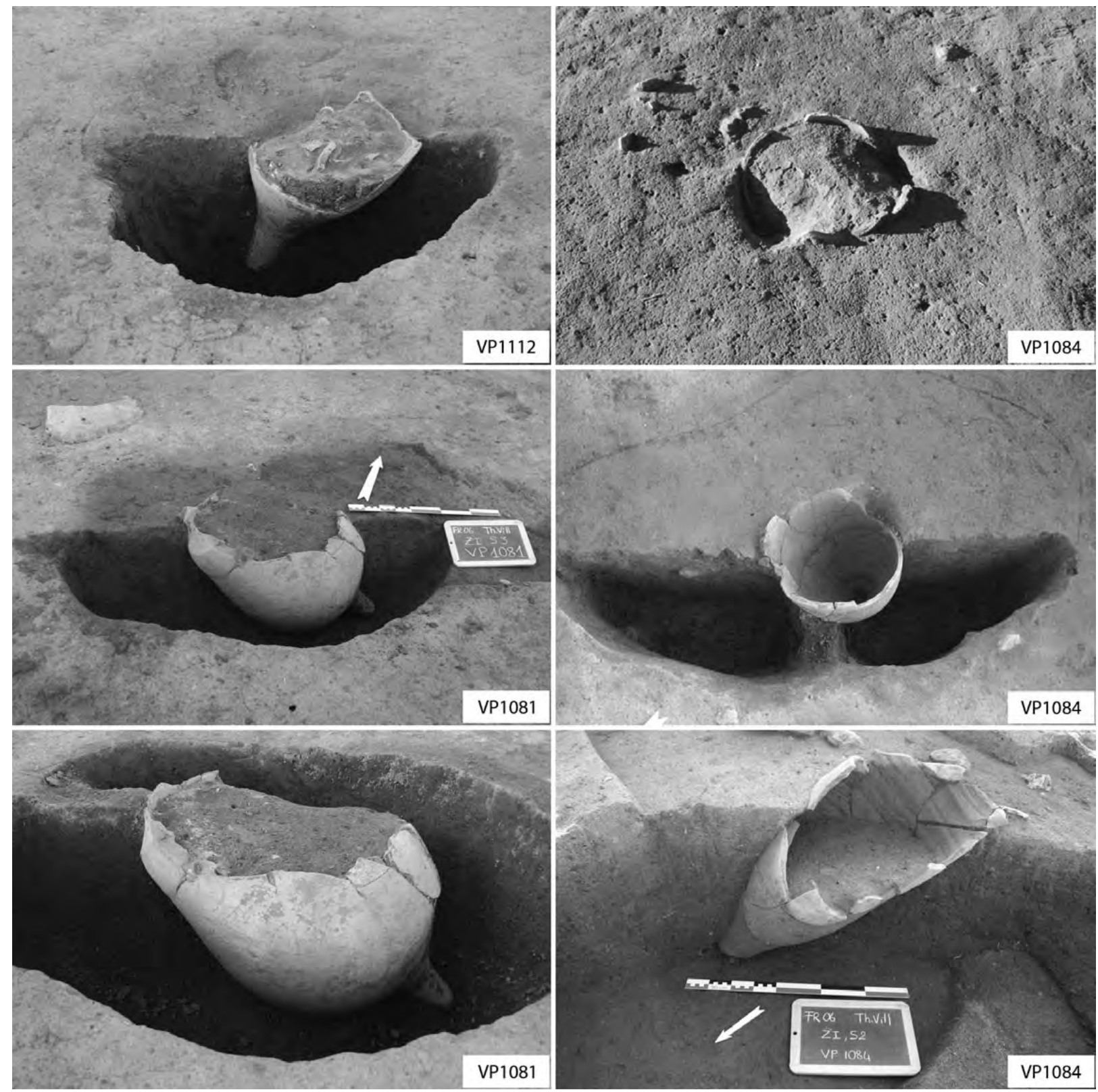

Fig. 37. Quelques amphores remployées dans les fosses.

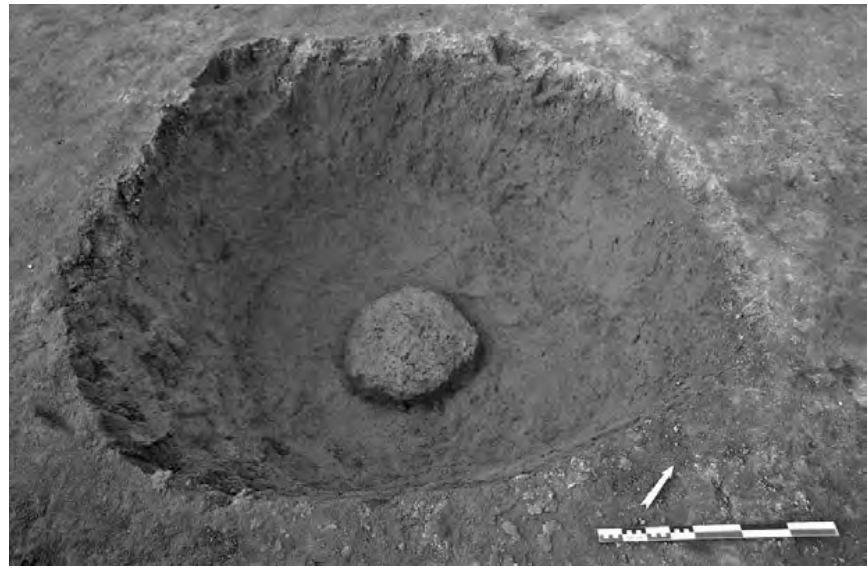

Fig. 36. Motte argileuse jaune retrouvée au fond de la fosse FS1090. 


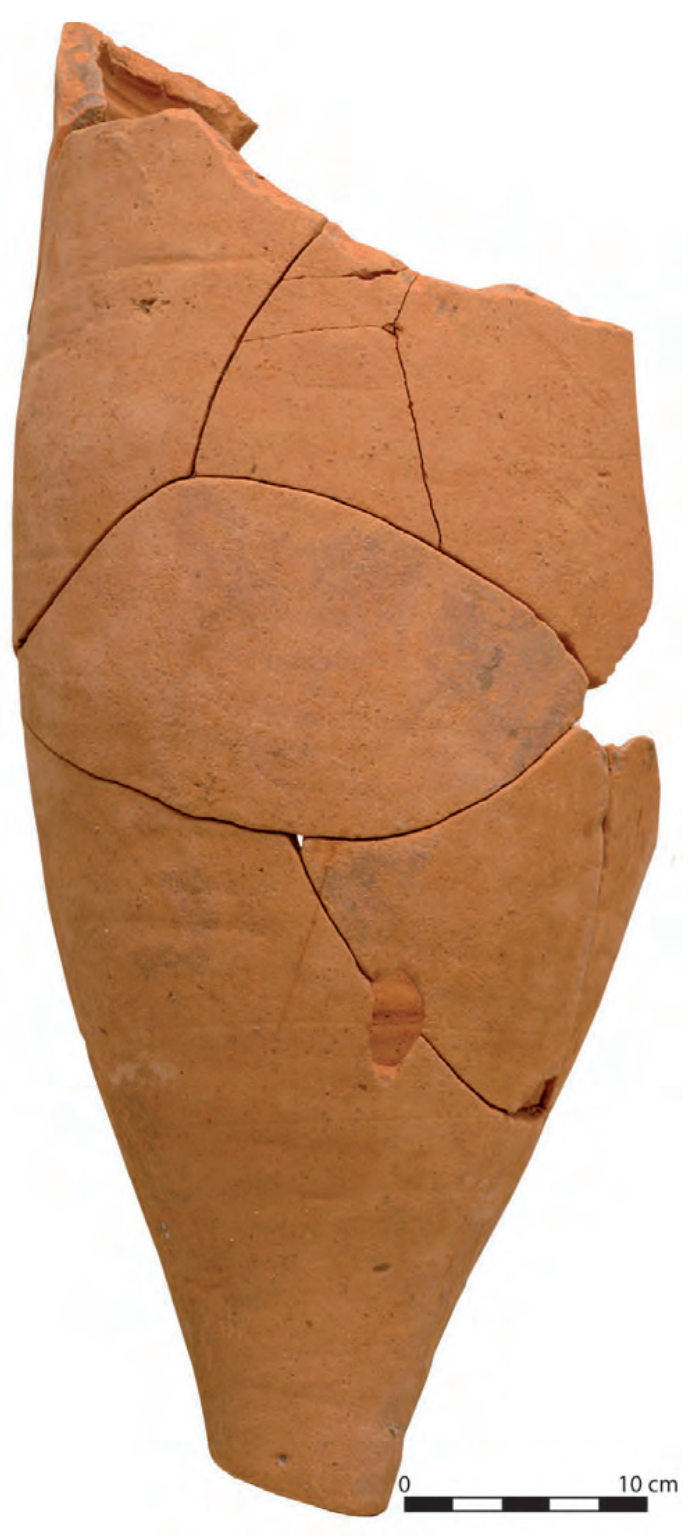

Fig. 38. Amphore coupée et présentant un trou d'écoulement (VP1084) (cl. Chr. Durand - CCJ).

Le plus grand profil est conservé du pied (cassé) jusqu'à l'amorce de l'épaulement, soit $65 \mathrm{~cm}$. Le comblement de l'amphore comprenait, parmi les tessons de panse, un bord de la lèvre. La pâte est orangée avec de fines inclusions. Le pied est plein, la panse fuselée, l'épaulement est en angle vif et la lèvre en bandeau. Aucun fragment d'anse n'a été découvert. Malgré l'absence du col et du pied, l'ensemble permet de restituer une amphore assez haute, d'environ $1,20 \mathrm{~m}^{6}$.

Parmi les amphores à vin républicaines, le type Dressel 1B est celui qui arrive le plus tardivement en Gaule. La date consulaire la plus récente découverte

6 En moyenne, pour ce type, le rapport panse/fond/col est de l'ordre de 7/4.

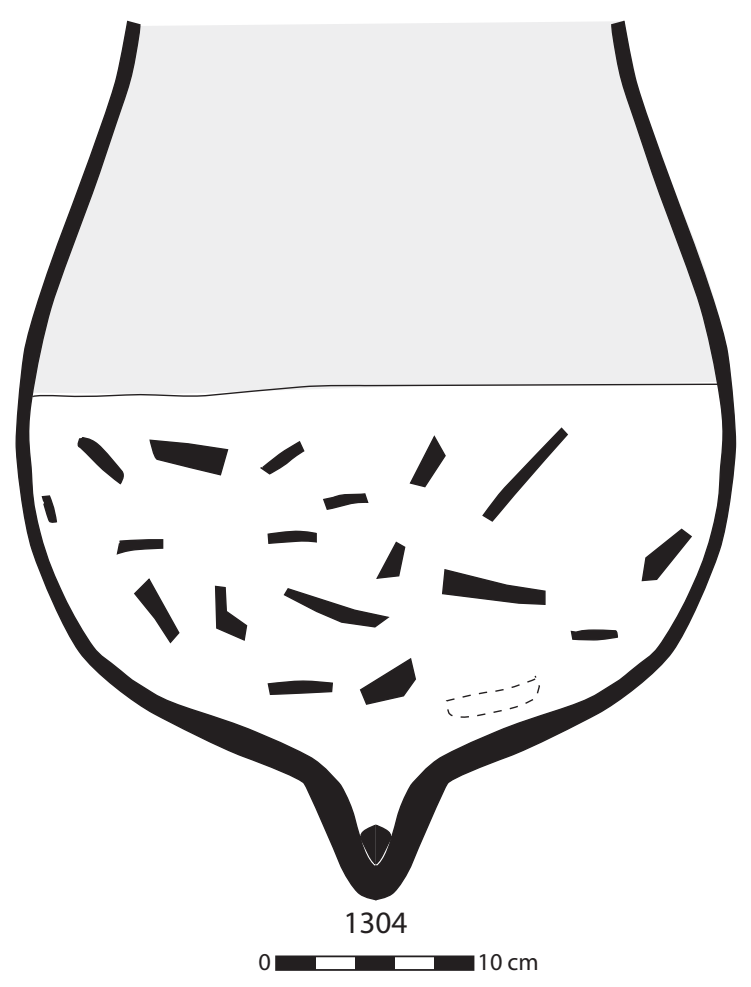

Fig. 39. Coupe du comblement de l'amphore VP1304.

sur Dressel 1B remonte à 13 av. J.-C. (Zevi 1996) et constitue dès lors un terminus post quem. Les épaves les plus tardives connues sont pourtant antérieures à cette date (Desbat 1998, 31).

\section{Les aménagements annexes}

$$
\text { (P. E.) }
$$

\subsection{Le puits PT1201}

Au sein du secteur $\mathrm{C}$ a été mis au jour un puits creusé dans le sable et présentant un cuvelage de gros blocs bruts agencés irrégulièrement. Il est pourvu d'un corridor d'accès depuis le nord-est, donnant sur une volée de cinq marches de faible hauteur menant au fond (fig. 42 et 43). La dernière s'apparente à une sorte de marchepied horizontal calé avec des fragments de tuiles. La hauteur des marches varie sur l'ensemble autour d'une moyenne de $15 \mathrm{~cm}$. Il semble que nous puissions sans trop de doutes en ajouter une au-dessus de la deuxième, portant leur nombre total à 6 . Le fond sableux situé à une cote altimétrique de $-0,68 \mathrm{~m}$ NGF, ne dispose pas d'aménagement particulier. Les niveaux supérieurs étaient dérasés à quelques centimètres au-dessus de la surface du sol (alt. 0,90/0,96 m NGF). Le puits est profond de seulement $1,58 \mathrm{~m}$. Au fond se trouvait un faible niveau organique (US1246) lié à son utilisation. 

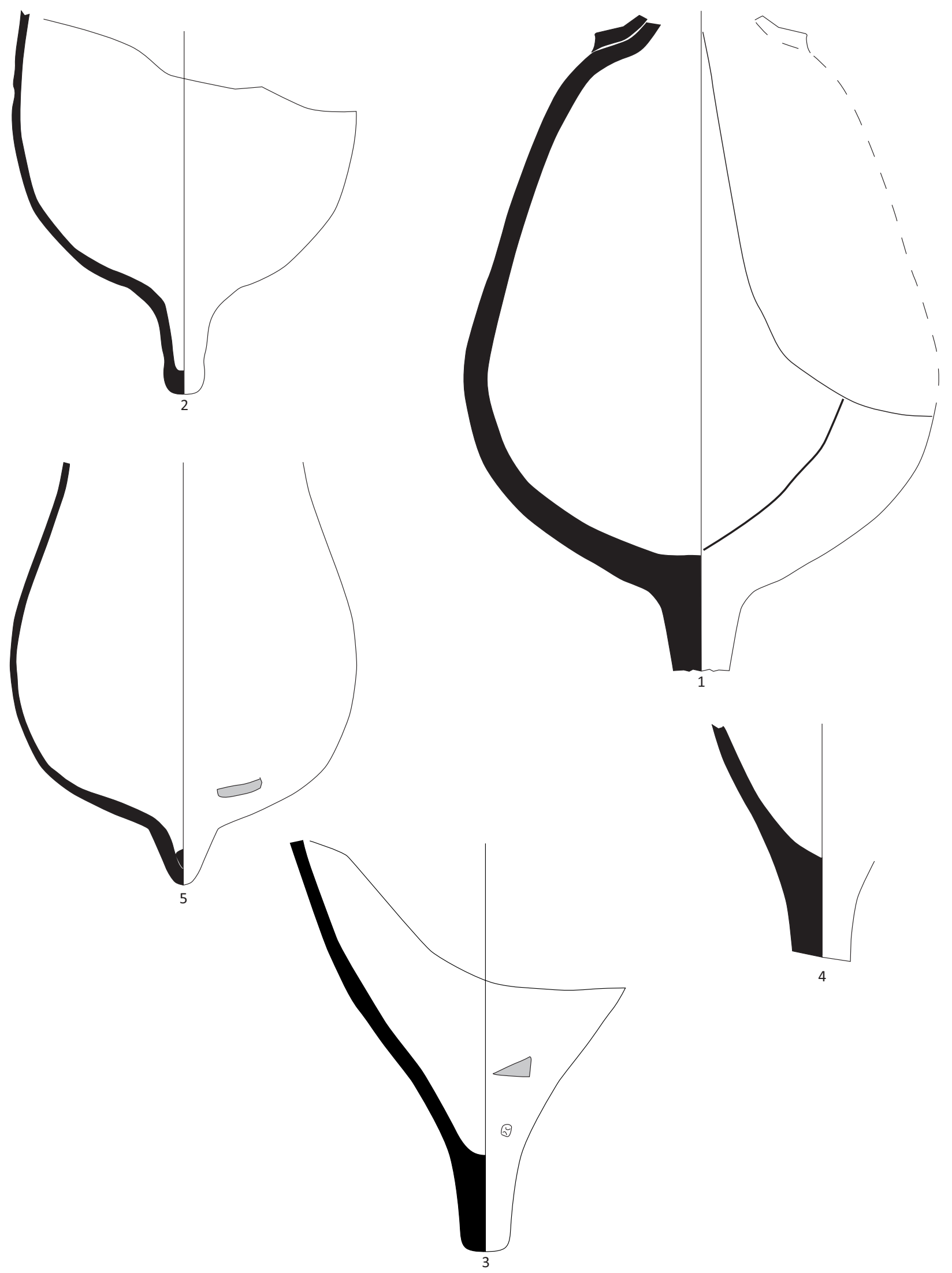

Fig. 40. Amphores remployées dans les fosses. 
Celui-ci a été entièrement prélevé. Le fond était régulièrement curé et entretenu, comme le montrent son profil en cuvette et la faible épaisseur du dépôt. Ce type de puits à escalier évoque celui découvert récemment au Bas-Lauvert à Antibes par I. Daveau (INRAP), également tout proche du rivage antique. La fonction de ce puits est là aussi assez énigmatique. Plus proche de nous, mais de facture plus monumentale, un puits du $\mathrm{I}^{\text {er }}$ siècle apr. J.-C. muni de trois marches est connu aux Aiguières (Goudineau 1982, 286). Ce type de puits à marches se rencontre aussi en milieu proprement urbain, comme c'est le cas à Nîmes dans la domus fouillée sous l'immeuble des AGF (Darde et al. 1990, 59).

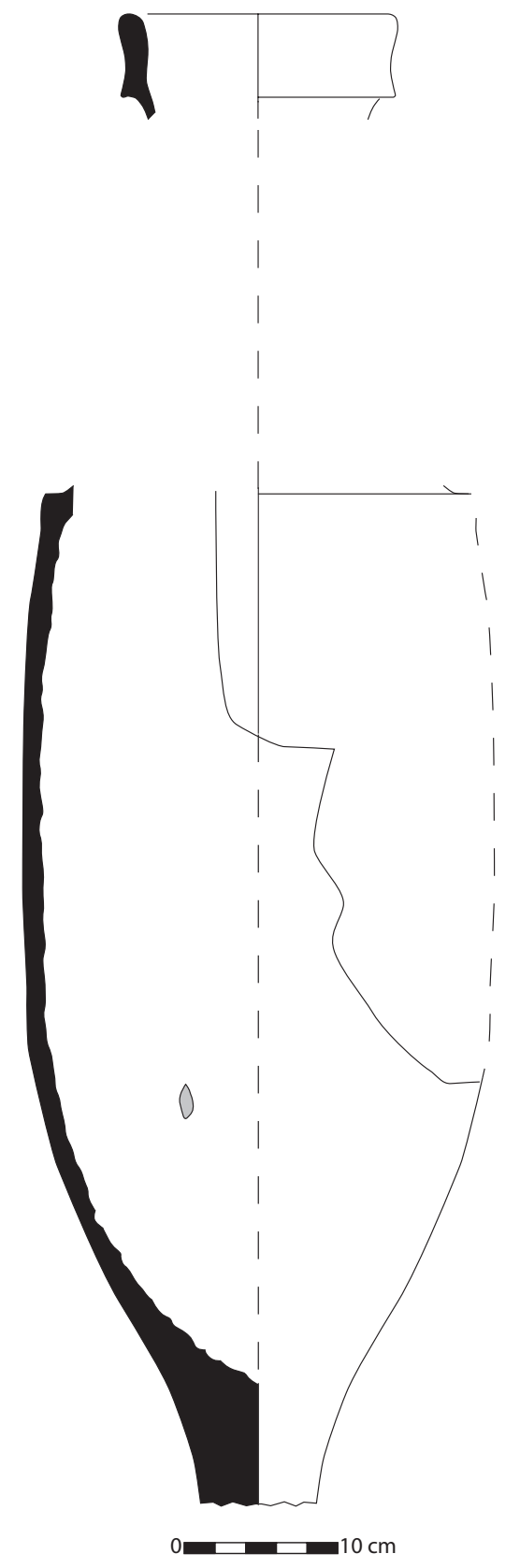

Fig. 41. Amphore Dressel 1B remployée dans la fosse 1084 .

\subsection{La conduite en terre cuite}

Une conduite en terre cuite d'orientation nord-ouest/ sud-est a été découverte dans les secteurs A et B (fig. 44). Sept sections étaient conservées, ainsi que d'autres, plus fragmentaires, disposées dans le même alignement (US1200). Une longueur de 10,75 m est restituable pour la section repérée, si l'on raccorde entre elles les portions conservées (fig. 45). Les sections de tuyaux s'emboîtant les unes dans les autres, ont une longueur de $0,44 \mathrm{~m}$ pour un diamètre de $0,12 \mathrm{~m}$, soit des sections d'un pied et demi. Deux formes ont été employées (fig. 46). La nature de leur pâte varie, tantôt orange avec un fin dégraissant, tantôt plus beige avec un gros dégraissant de quartz. Altimétriquement, le point haut se trouve au nord à $1,12 \mathrm{~m}$ NGF pour un point bas au sud de 0,95 m NGF, soit un léger pendage en direction du sud/sud-est de $0,12 \mathrm{~m}$ sur $10,75 \mathrm{~m}$ de long. Le sens d'écoulement se faisant donc du nord-ouest vers le sud-est. À son extrémité nord-ouest, le conduit est

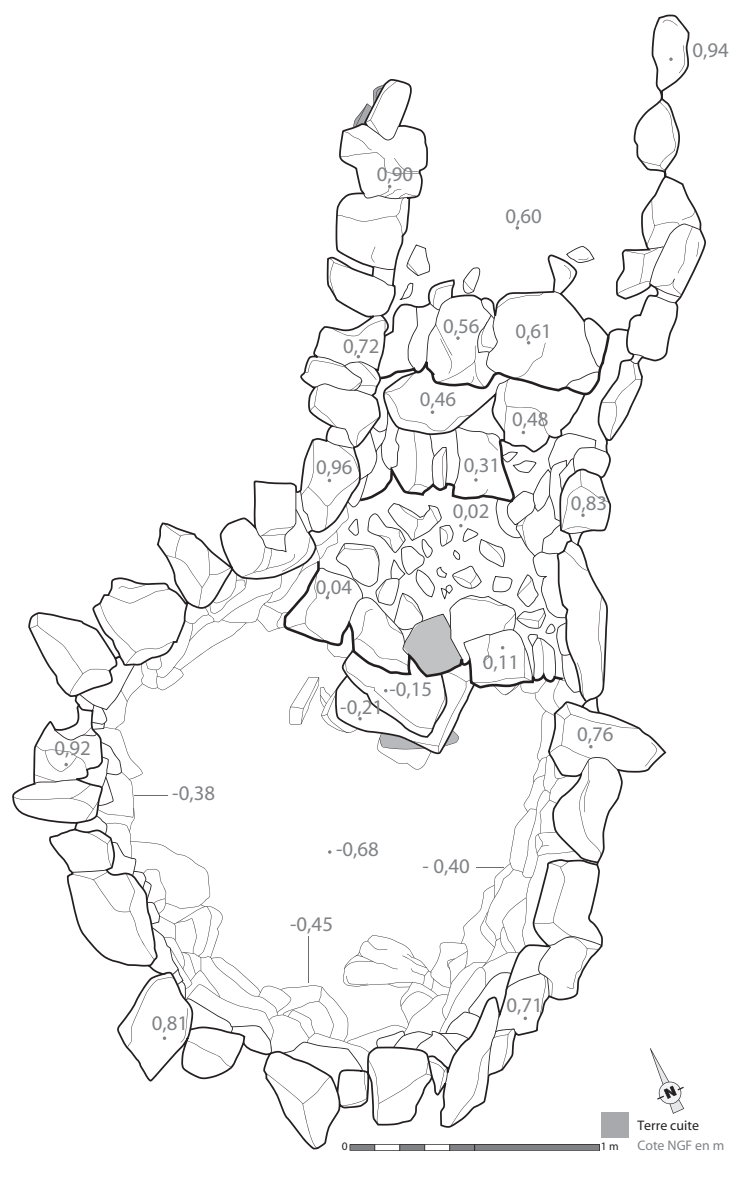

Fig. 42. Plan du puits PT1201. 


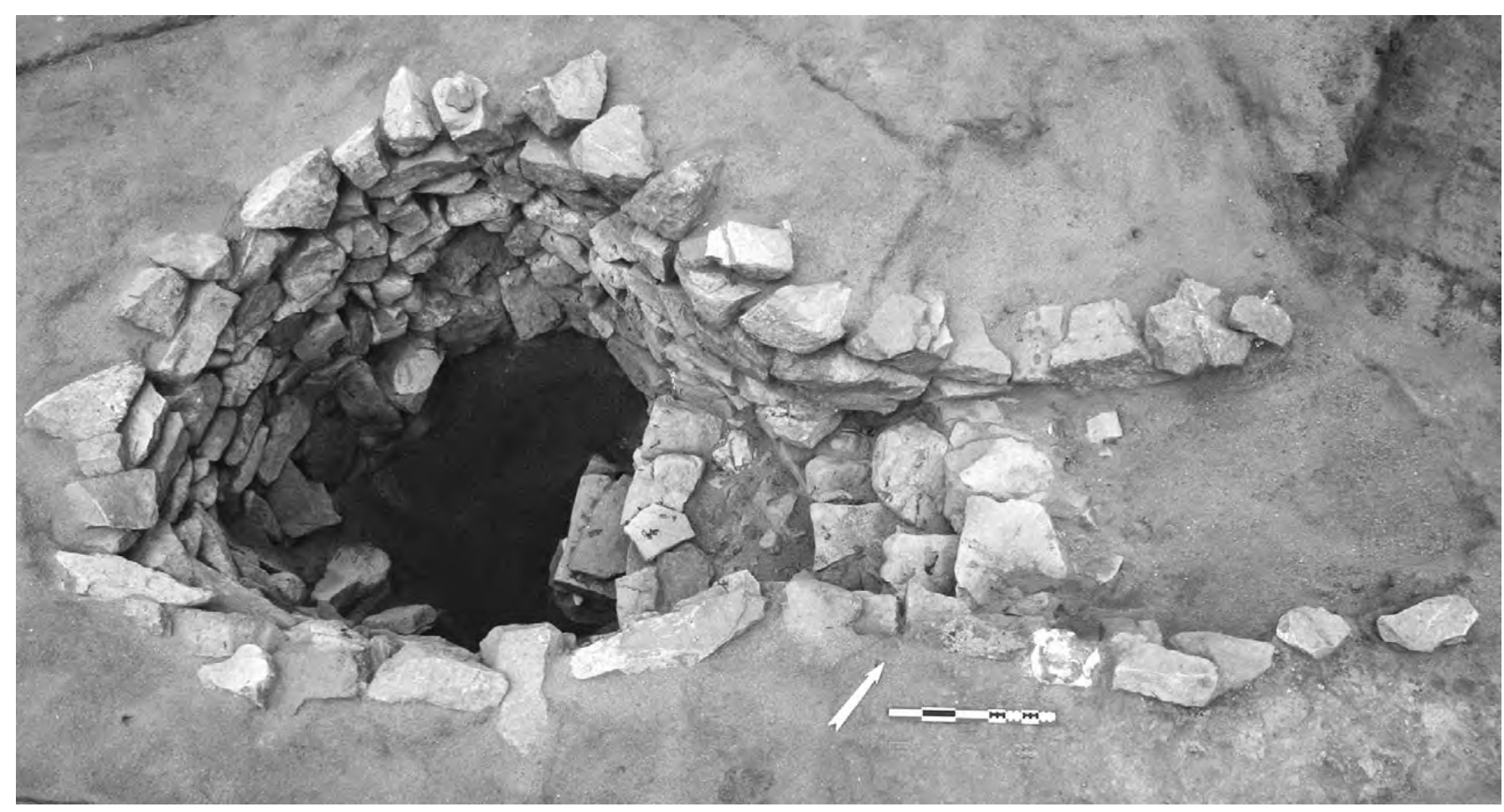

Fig. 43. Vue verticale du puits PT1201.

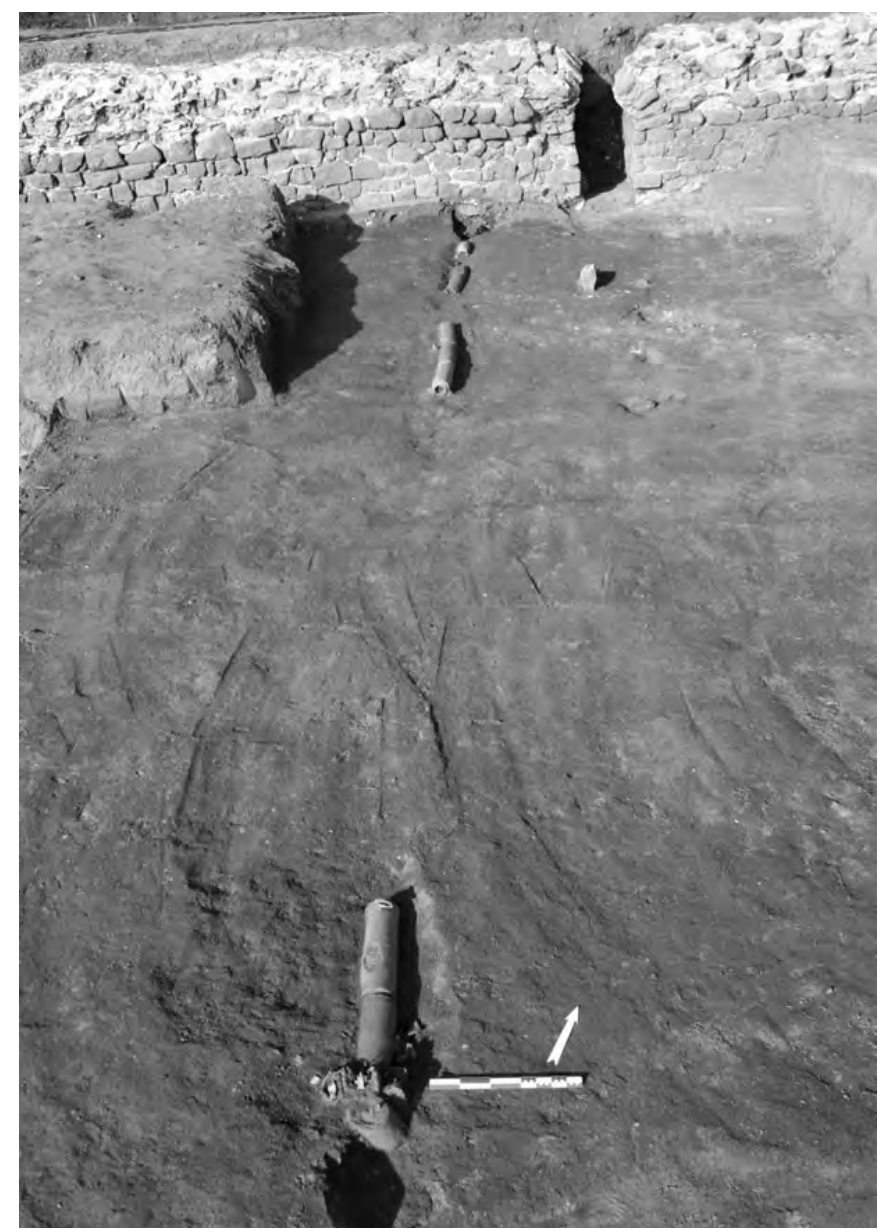

Fig. 44. Conduite CN1199, vue du sud. coupé par la fondation d'un mur plus tardif, MR1003, il devait donc probablement continuer. À l'emplacement de la tranchée d'épierrement de MR1261 le conduit est interrompu. Il est probable qu'à l'origine il traversait le mur. À son extrémité sud, il apparaît très perturbé au moment où il entrait en contact avec le muret MR1050. Sur la tranchée d'épierrement de ce même mur a été découverte une section désignée sur le plan CN1230. Enfin, dans le comblement du puits PT1201, deux fragments de canalisation identiques ont également été découverts. À l'évidence, la récupération des murs et la transformation des lieux à la phase suivante ont profondément transformé le tracé initial de la conduite.Il est très possible que ces tuyaux permettaient de canaliser et d'acheminer l'eau de drainage des terrains situés plus au nord en les amenant dans le puits PT1201. En outre, les rares éléments du tuyau conservés en dehors de l'alignement nord-sud, se trouvent à l'emplacement du mur 1050 et dans le comblement du puits. Ce type de canalisation, dans des contextes proches, évoque le réseau de canalisation en terre cuite mis au jour dans la majestueuse villa découverte à Fishbourne dans le Sussex en Angleterre (Cunliffe 1998, 97, fig. 50 et 100$)^{7}$ ou encore la conduite forcée de même type employée pour le jardin de la villa augustéenne de Caumont-sur-Durance (Mouraret 2003, 130).

7 La villa était alimentée par un aqueduc. 


\section{Les analyses paléoenvironnementales}

\author{
(S. G., L. B., I. F., C. S., P. V.)
}

Le large échantillonnage réalisé lors de la fouille, en particulier des fosses et du puits PT1201, n'a fourni aucun résultat dans le cadre de l'étude pollinique. Le puits PT1201, situé entre les deux rangées de fosses, paraissait un excellent piège, malheureusement la nature du comblement (sables grossiers) a rendu l'analyse pollinique impossible. Quant aux comblements des fosses et des amphores horticoles, deux tests palynologiques réalisés dans la fosse VP1017 et le comblement de l'amphore retrouvée dans la fosse VP1304 sont venus confirmer leur caractère remanié et oxydé. Un même constat a dû être fait pour l'étude carpologique, les conditions de conservation n'étant pas réunies.

Sept noyaux de prunes (Prunus domestica subsp. insititia) non carbonisés ont été recueillis dans le fond du puits. Néanmoins, l'analyse fine du prélèvement réalisé dans cette structure (US1245, comblement inférieur), a dû être abandonnée du fait du caractère très sableux des refus de tamis et de leur extrême pauvreté en macrorestes végétaux. Malgré tout, de rares fragments de charbon ont permis d'identifier la bruyère, le chêne à feuillage persistant et une cistacée. Devant la faiblesse des données paléoenvironnementales, nous avons opté pour une étude phytolithlogique. La question principale posée lors de cette étude était de déceler, dans les niveaux de comblement des fosses de plantation, les restes des végétaux qui y ont été plantés et/ou le type d'amendement qui y a été pratiqué. L'analyse effectuée dans la fosse FS1105 (US1148) a livré un assemblage qui ne se caractérise par aucun taxon spécifique pouvant être relié à une éventuelle plante mise en terre dans cette fosse. Elle contient environ un tiers de phytolithes de taxons dicotylédones ${ }^{8}$, ce qui ne nous permet pas de tirer de conclusions.

\section{Les mobiliers et la faune}

\subsection{La céramique}

(E. P.)

Le mobilier de la phase 2 représente un ensemble assez limité. On compte une majorité d'amphores, surtout de Tarraconaise, ainsi que de très nombreux fragments de céramique à pâte calcaire, appartenant à de petits ou moyens vases de stockage ou de transport. Parmi les

8 Plantes angiospermes qui germent avec deux feuilles, les monocotylédones germent avec une seule feuille.
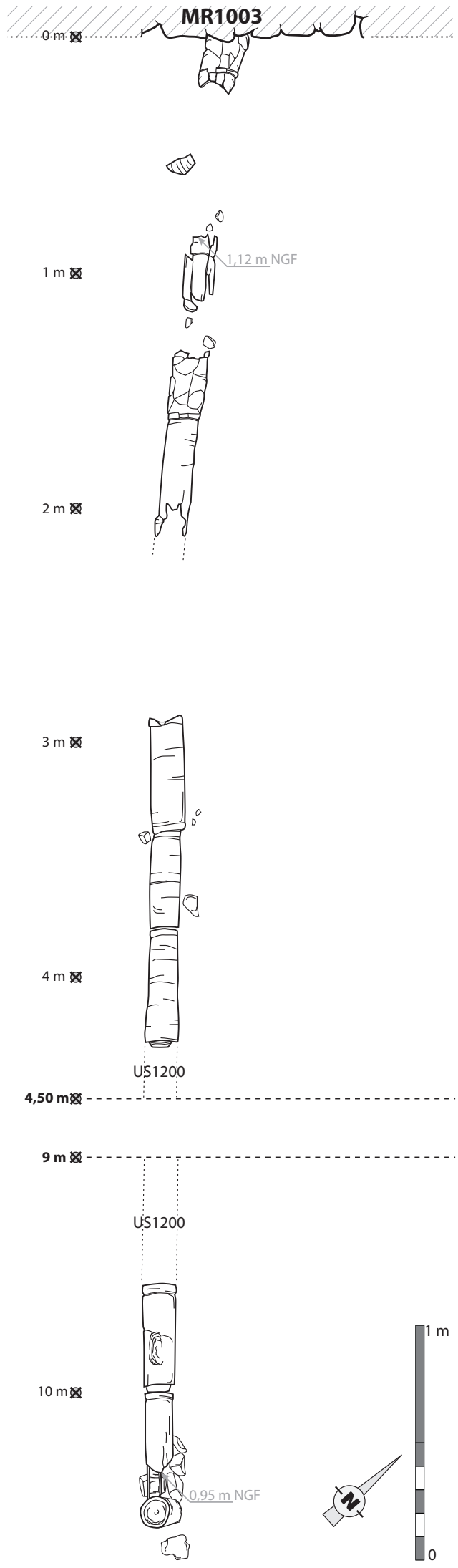

Fig. 45. Relevé de la tuyauterie CN1199. 
amphores, on reconnaît cinq objets étêtés ayant servi de pots horticoles : une Haltern 70 (fig. 40 - $\mathrm{n}^{\circ}$ 5), une Dressel 7/11 (fig. 40 - $\mathrm{n}^{\circ}$ 2) de Bétique, deux Pascual 1 (fig. $40-\mathrm{n}^{\text {os }} 3$ et 4 ) de Tarraconaise, une Dressel 1B (fig. 41) et une Dressel 6A (fig. $40-\mathrm{n}^{\circ} 1$ ) italiques. On signalera encore un fond de gobelet à paroi fine de type Mayet V (fig. 47 - $\mathrm{n}^{\circ}$ 1). Son dépôt est contemporain des plantations. Le mobilier provenant du comblement des fosses se limite à peu de chose. On reconnaît un bord de gobelet à paroi fine de type Mayet XXVI (fig. 47 - nº 2) qui

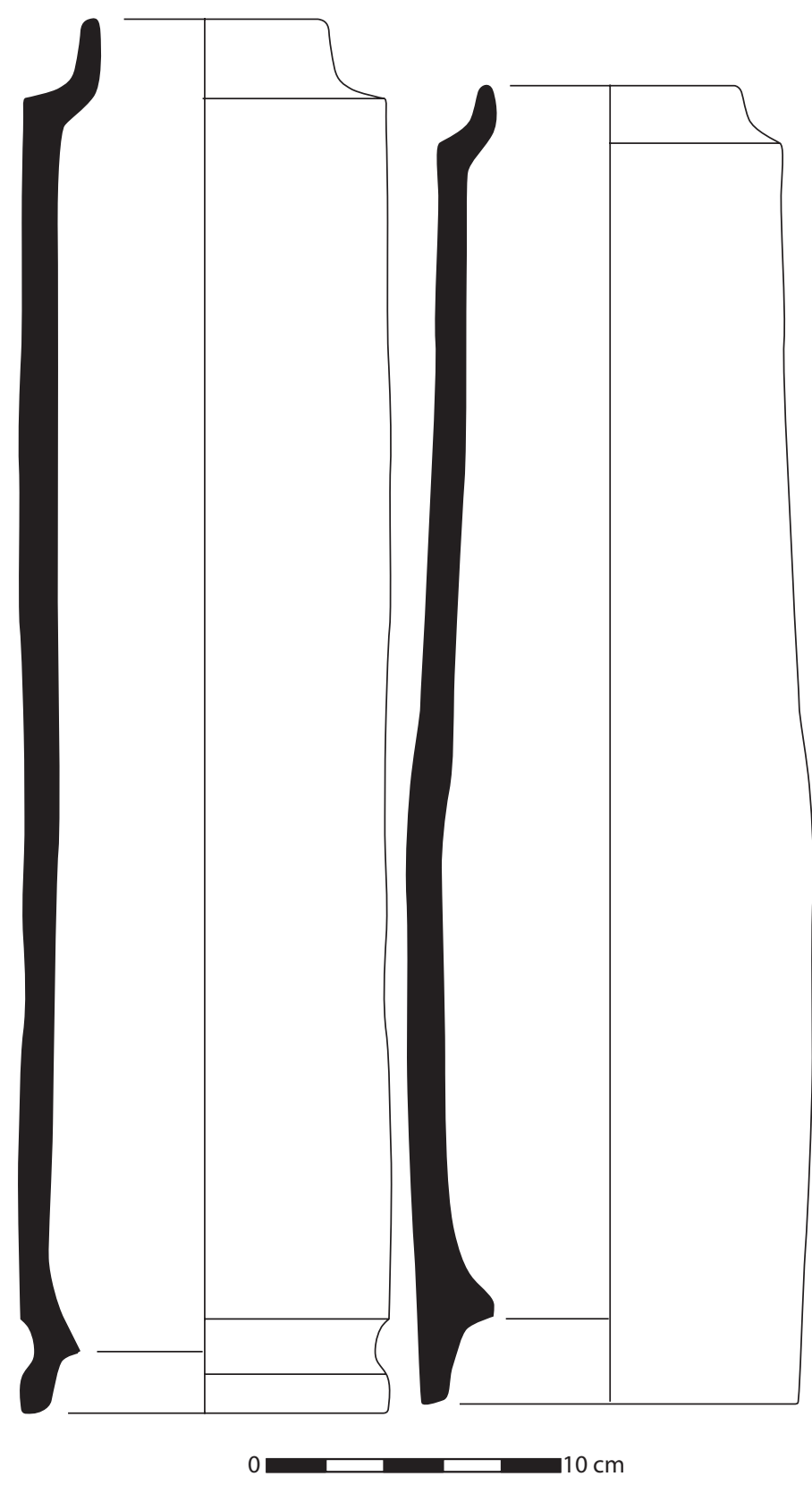

Fig. 46. Éléments en terre cuite de la canalisation CN1199. nous emmène dans le dernier quart du $\mathrm{I}^{\mathrm{er}}$ siècle av. J.-C. au plus tôt, un couvercle à pâte claire (fig. 47 - no 3), une coupe Pasqualini 1D (fig. $47-\mathrm{n}^{\circ} 4$ ), une anse d'amphore gauloise ainsi que le bord d'un autre gobelet à paroi fine assez mal conservé qui pourrait appartenir au type Mayet XVII ou XXIX d'époque augustéenne (fig. $47-n^{\circ} 5$ ). On note la quasi-absence des céramiques culinaires, qui ne sont représentées que par quelques tessons de céramique à pâte brune (fig. 47 - $\mathrm{n}^{\circ}$ 6) et de kaolinitique, ainsi que par un couvercle en céramique modelée aux parois minces (fig. $47-\mathrm{n}^{\circ} 7$ ) qui semble appartenir à l'époque augustéenne. Cet ensemble paraît indiquer que les fosses ont été creusées au plus tôt dans le dernier tiers du $\mathrm{I}^{\text {er }}$ siècle av. J.-C.

\subsection{Le verre

$$
\text { (S.-D. F.) }
$$

Les fragments de vases en verre témoignant de l'occupation du site au cours de la phase 2, peu nombreux, sont tous issus de niveaux tardifs (phase 4 et 5) où ils sont considérés comme résiduels. Trois individus peuvent être antérieurs ou légèrement postérieurs au changement d'ère : le fragment de linear-cut violet (fig. 48 - $\mathrm{n}^{\circ} 1$ ), le probable élément de préhension mosaïqué et le fragment de vase cobalt, moulé rainuré (fig. 48 - $\mathrm{n}^{\circ} 2$ ).

Le fragment de bol linear-cut, orné d'une large rainure interne, se rattache aux productions de vases moulés qui marquent les premières importations de masse sur le littoral de la Narbonnaise. Fabriqués dès les dernières décennies du I ${ }^{\mathrm{er}}$ siècle av. J.-C., ils circulent durant le premier tiers du Irr siècle apr. J.-C. Ils marquent habituellement les niveaux d'occupation de la période augusto-tibérienne (Fontaine 2003 ; Foy 2005 et Foy et al. 2008) et ont été retrouvés en nombre considérable sur le site des Aiguières (Cottam, Price 2009).

Le fragment polychrome, bien que non formellement identifié, pourrait correspondre à un élément de préhension, de petite dimension, apposé à chaud sur un vase dont nous ne pouvons définir la forme. Il pourrait aussi s'agir d'une terminaison de « mélangeur ». Quoiqu'il en soit, la technique de fabrication employée le rattache aux productions tardohellénistiques ou augusto-claudiennes également diffusées en Méditerranée nord-occidentale. Le fragment de vase moulé bleu cobalt à décor de rainures, ne peut être rattaché à une forme précise, mais la qualité de la facture, la teinte et la technique employées, font référence à une production précoce. 


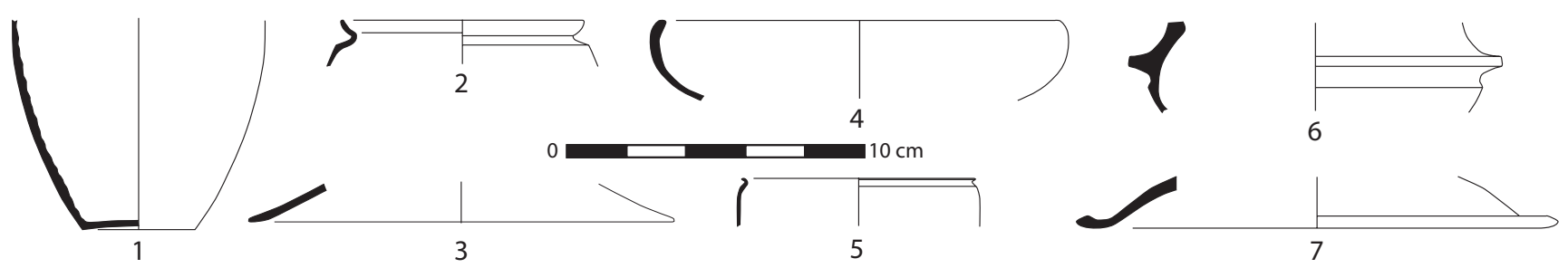

Fig. 47. Mobilier céramique de la phase 2.

Quoiqu'extrêmement fragmentaires et peu abondants, ces éléments que l'on sait diffusés en Méditerranée nord-occidentale au cours du premier siècle de l'Empire, font écho aux riches ensembles de cette période exhumés des sites voisins et notamment des sites des Aiguières et de l'Argentière (Price 1988 et Cottam, Price 2009).

\subsection{La monnaie}

Dans le comblement de l'une des amphores (VP1017, US1067) a été découverte une monnaie en bronze dans un très mauvais état de conservation (fig. 49). Il s'agit d'une monnaie de $1,16 \mathrm{~g}$ et de $12 \mathrm{~mm}$ de diamètre. Le champ droit comporte une proue de navire avec rostre et le revers un capricorne avec un globe. Malgré le mauvais état de conservation, il est possible d'identifier un petit bronze de Fréjus, frappé entre 31-27 av. J.-C., en commémoration de la victoire d'Actium ( $R P C$ vol. I part. 1 et $2,156, \mathrm{n}^{\circ} 534$ ).

\section{Des éléments du premier édifice de Villeneuve?}

(P. E.)

C'est dans le développement de la phase suivante, 3A, que sera traitée la mise en place d'un puits rectangulaire SB1262. Celui-ci étant construit essentiellement avec des matériaux de remplois provenant très probablement de la phase antérieure, il convenait de replacer la description de ces éléments ici, dans la phase 2. En effet, on peut supposer, a priori, que pour ce type d'aménagement ne nécessitant pas de matériaux spécifiques, les éléments employés proviennent des environs immédiats.
Une grande partie des matériaux utilisés dans les parois était constituée d'éléments de sols en béton, employés comme parpaings. Au total c'est plus de $6 \mathrm{~m}$ de sol qui ont été ainsi remployés (fig. 50). Quelques blocs seulement sont des bétons de tuileau, dont certaines surfaces sont particulièrement bien soignées et peuvent être rapprochées de la technique de l'opus signinum, avec décors de crustae. La grande majorité provient de sols de béton composés de mortier de chaux et d'un gros agrégat très dense, fait de cailloux en calcaire anguleux de teinte blanche à grise.

Ont aussi été réutilisés plusieurs éléments de colonnes, montées en brique en quart de rond et mortier. Les sections complètes présentent six éléments en quart de rond au mieux, chacun épais de $5 \mathrm{~cm}$, soit des portions de $1 / 6$, pour un diamètre de fût de $0,36 \mathrm{~m}$. Pour chaque assise, les joints sont croisés alternativement et aucune trace de stuc ou d'enduit n'a été retrouvée en surface. Ces découvertes de colonnes mises en parallèle avec celles faites au niveau de la tranchée de récupération de MR1261, en particulier les enduits courbes, confirment la présence d'un ensemble de colonnes sans doute en rapport avec le mur MR1261, qui aurait alors constitué le stylobate d'une colonnade. Cette supposition, si elle pouvait être confirmée, permettrait de restituer un portique à cet endroit. Des restes d'enduits peints de couleurs rouge et blanche ont également été découverts.

En outre, des éléments d'architecture en grès ont été remployés. Les deux fragments L.04 et L.05, remployés séparément, composent un seul et même élément brisé en deux (fig. 51). Il s'agit d'un bloc de $0,30 \mathrm{~m} \times 0,21 \mathrm{~m} \times 0,21 \mathrm{~m}$ comportant une moulure sur trois faces. Le profil de celle-ci présente, au-dessus d'un corps finement aplani de 9,5 cm de hauteur, un bandeau
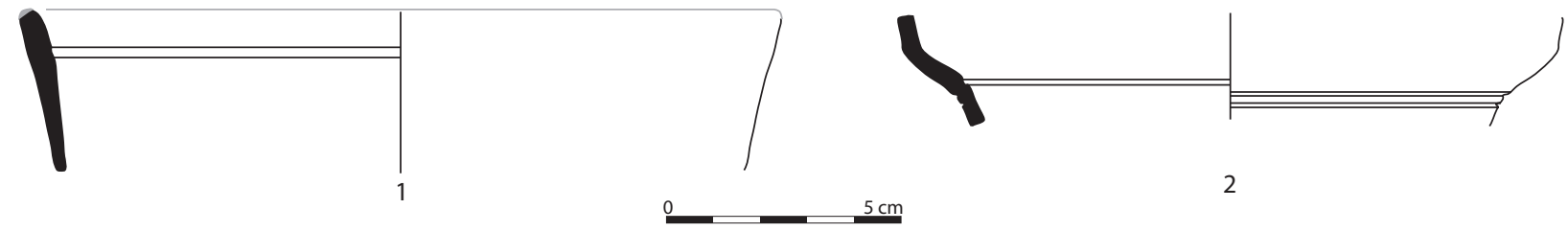

Fig. 48. Mobilier en verre. 


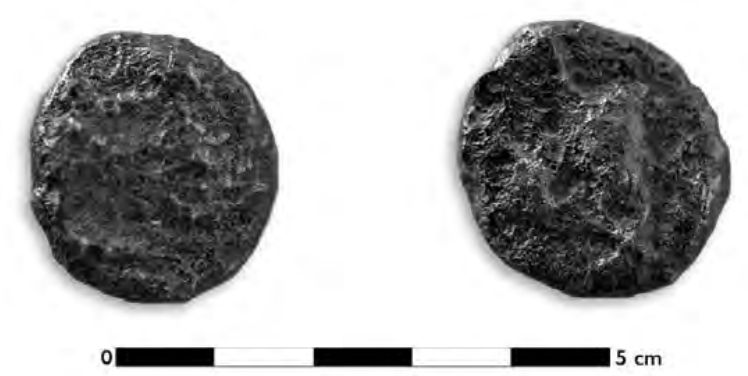

Fig. 49. Petit bronze de Fréjus.

taluté de $3 \mathrm{~cm}$ de large. Il est surmonté d'un filet droit de $1 \mathrm{~cm}$ sur lequel se trouve une doucine droite de $3,5 \mathrm{~cm}$, que surmonte un listel plat de $1 \mathrm{~cm}$. L'ensemble est couronné d'un bandeau de $3 \mathrm{~cm}$. La face arrière est grossièrement démaigrie, les arêtes ont été dégagées par une ciselure périmétrale. Le lit de pose et la face arrière sont grossièrement aplanis, sans doute à l'aide d'une broche, alors que la surface du lit d'attente a été finement taillée à l'aide d'un ciseau grain d'orge large de $2 \mathrm{~cm}$ et muni de 5 dents pointues. Cet outil est fréquemment utilisé à Fréjus pour certaines finitions sur des éléments de grand appareil, comme à la butte Saint-Antoine ou à l'amphithéâtre (Thernot, Excoffon 2010, 86-87). Il s'agirait ici d'un des premiers emplois de l'outil à Fréjus (fig. 52). Il est difficile de replacer cette moulure de couronnement, qui pourrait correspondre soit à un retour d'angle de podium soit à un chapiteau de pilastre ou bien encore à un couronnement de tête de mur.

Pour le bloc L.03, les moulures sont similaires, mais présentes seulement sur une face. La partie basse, le col, est plus haute $(12 \mathrm{~cm})$. Les mêmes types d'outils ont été employés. Sur le seul côté conservé, la surface a été traitée de deux façons : une large moitié a été démaigrie à l'aide d'une pointe, alors que la partie en rapport avec l'arête de la face moulurée a été plus finement lissée à l'aide d'un ciseau grain d'orge. À l'évidence, il s'agissait de

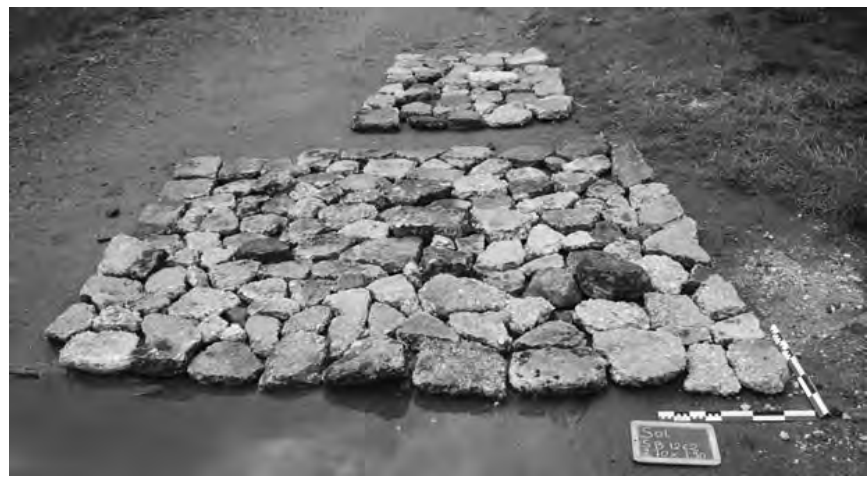

Fig. 50. $6 \mathrm{~m}^{2}$ de sol de béton.

préparer un cadre, une surface de joint pour un autre bloc qui lui était directement accolé. L'absence de retour de la moulure sur les côtés du bloc laisse supposer qu'il s'agit là d'une partie de corniche aux proportions strictement identiques à celles du bloc précédent. Dès lors, il pourrait très probablement s'agir du même monument, dont la corniche courant sur la façade se retrouverait, soit en décrochement au niveau des piédroits, soit en doublement avec d'éventuels chapiteaux de pilastres. La mise en relation avec la colonnade supposée border au nord la bande fouillée, permettrait de restituer un portique couronné d'une corniche en grès et protégeant peut-être une allée bétonnée couverte, aux plinthes peintes en rouge et blanc, permettant de circuler à pied sec au sein du jardin.

\section{Datation}

(P. E.)

La monnaie, les amphores remployées et le mobilier s'accordent pour dater la mise en place de la phase 2 durant le dernier tiers du Irr siècle av. J.-C. En effet, le phénomène marquant étant l'aménagement du jardin, ce sont les amphores qui apportent les informations les plus probantes. Le terminus ante quem est fourni
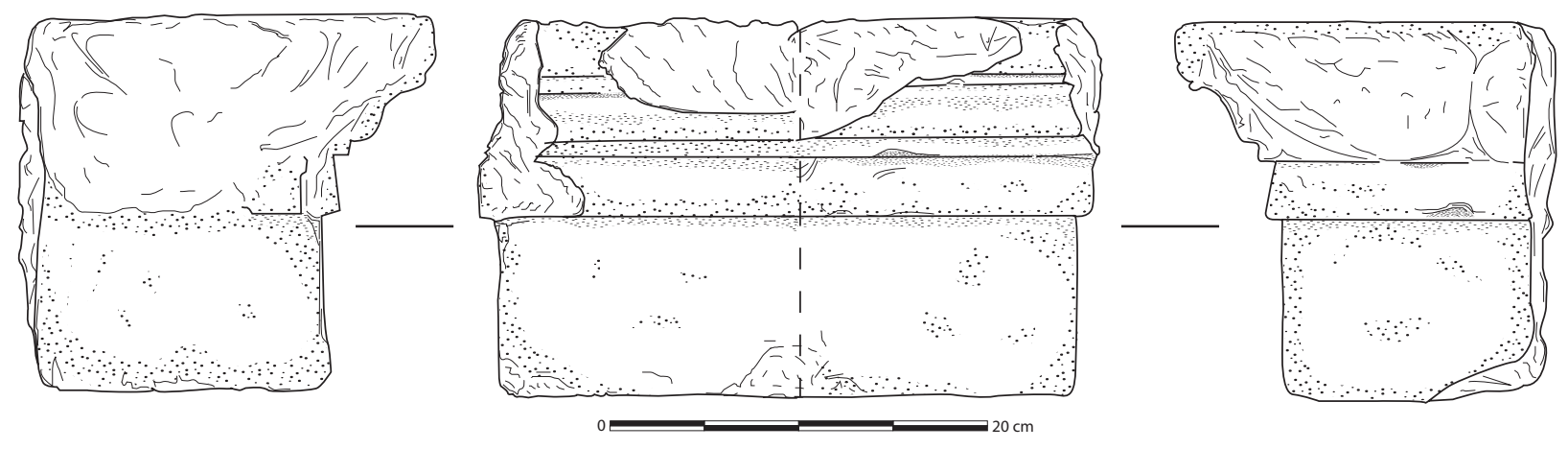

Fig. 51. Couronnement mouluré (M. El Amouri). 


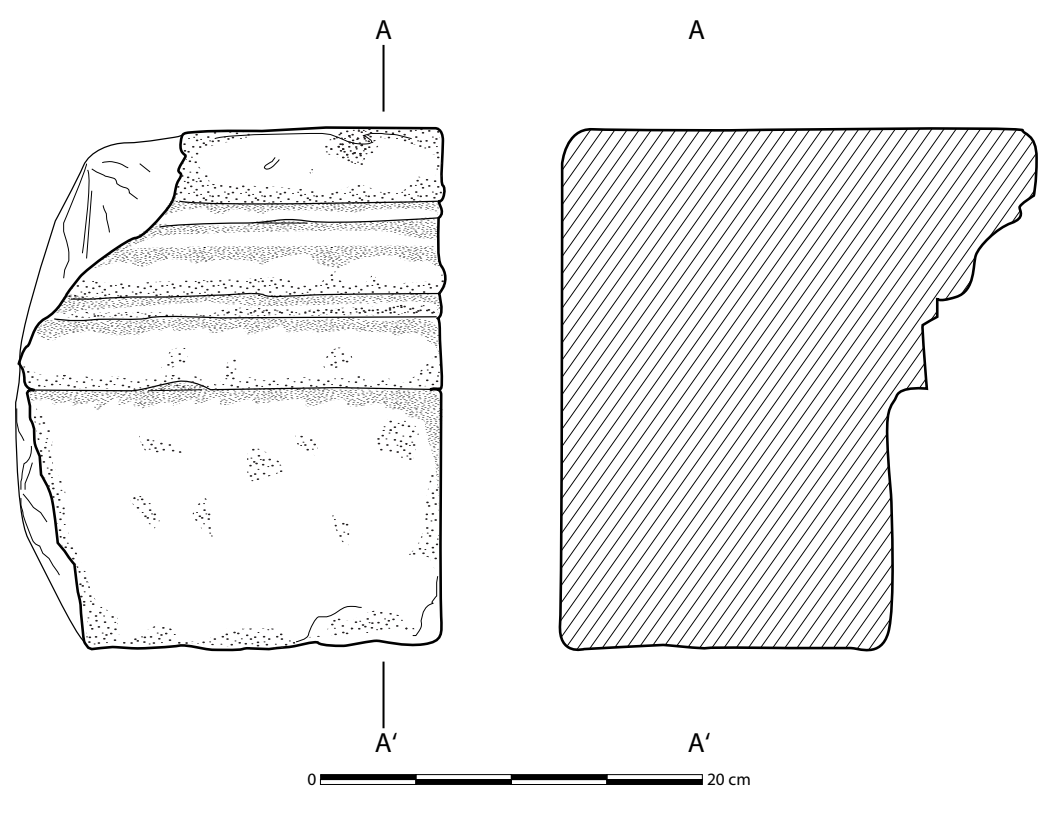

Fig. 52. Corniche moulurée (M. El Amouri).

par une Dressel 1B complète et le terminus post quem par la monnaie de Fréjus. L'amphore italique pourrait constituer un élément résiduel, mais l'assemblage (Haltern 70, Pascual 1 et Dressel 6A) qui l'accompagne n'incite pas à l'envisager comme tel. En outre, l'absence d'amphore gauloise et de Dressel 2/4 d' Italie, marqueurs les plus fréquents pour illustrer la fin du Ir siècle av. J.-C. et le début du suivant à Fréjus, oriente également en ce sens. Ainsi, la configuration de la fouille nous oblige à raisonner à partir d'assemblage amphorique et l'image du commerce que reflète cet ensemble, constituant le jardin, apparaît comme celle du dernier tiers du ${ }^{{ }^{\text {er }}}$ siècle av. J.-C. ${ }^{9}$ Certes fragile, cette démonstration à partir d'éléments présents et absents constitue le seul raisonnement valable en l'état de la documentation.

Les niveaux de fonctionnement en rapport avec cette phase sont très ténus. En effet, le sol s'exhausse peu et les apports de matériel sont faibles. Ce sont essentiellement les niveaux liés aux réaménagements de la phase suivante qui permettent de fournir un terminus à cette phase. Le comblement du puits PT1201 constitue l'élément le plus significatif de cette transformation. Malheureusement, son comblement effectué en une seule fois est pauvre en mobilier. Parmi quelques tessons de céramiques claires et d'amphores diverses, se trouvaient deux cols complets d'amphores massaliotes, l'un de type Bertucchi 6A, l'autre de type 7. Découvertes dans la partie sommitale du comblement (1233 et 1227), ces

9 Le contexte « vide sanitaire » découvert sous l'amphithéâtre de Fréjus, illustre lui le commerce au tout début du I $^{\text {er }}$ siècle apr. J.-C. et présente de fait des modéles absents de notre assemblage (Excoffon 2010a). deux amphores pourraient être contemporaines des travaux de remblaiement. Le type 6A est typique des premières productions des Carmes de la deuxième moitié du $\mathrm{I}^{\text {er }}$ siècle av. J.-C. (Bertucchi 1992, 99-110). Ces amphores sont produites jusque dans le courant de la première moitié du Ir siècle apr. J.-C. (Bertucchi 1990, 16). Le type 7 est plus caractéristique des $\mathrm{I}^{\mathrm{er}}$ et $\mathrm{II}^{\mathrm{e}}$ siècles apr. J.-C., mais leur apparition est à situer dans la première moitié du I $^{\text {er }}$ siècle apr. J.-C. (Bertucchi 1992, 115). La présence simultanée dans un même comblement de ces deux amphores marseillaises évoque donc une chronologie dans la première moitié du I ${ }^{\text {er }}$ siècle. Également, la présence d'un fragment de bol en verre linear-cut appuie cette tendance. Enfin, les niveaux de mise en place de la phase suivante confirment cette chronologie (voir supra p. 95) et permettent de situer au plus tard la fin de la phase 2, sensiblement vers le milieu du Ir siècle apr. J.-C.

\section{Interprétations}

(P. E.)

\section{1. Verger ou jardin ornemental ?}

Les deux alignements de fosses sont parallèles, d'orientation NL $47^{\circ}$ ouest, et chaque fosse de chaque secteur se trouve face à une autre, leur centre respectif étant séparé de $9 \mathrm{~m}$. Ainsi, le maillage est orthogonal et aligné selon l'orientation des grands murs rythmant la zone. En reliant l'ensemble, on obtient un réseau régulier, dont la base approximative est de $2,90 \mathrm{~m} \times 9 \mathrm{~m}$ (fig. 53). Le fait que les fosses ne soient pas parfaitement circulaires, avec des limites qui ne sont pas toujours bien conservées, fausse quelque peu le rendu et empêche une approche plus précise de l'organisation du réseau. Toutefois, si l'on rétablit une moyenne pour l'ensemble, on peut s'autoriser une conversion en pieds romains, soit une organisation selon un quadrillage de 10 pieds par 30 .

Une attention particulière a également été portée dans chaque alignement, où alternent de façon régulière les grandes et les petites fosses. $\mathrm{S}$ ans présager de la nature des plantes cultivées dans ces fosses, il apparaît évident que les grands spécimens étaient alternés de façon régulière avec des plus petits. Les grandes fosses ont pu accueillir des arbres : l'espacement entre elles l'autorise. Les sept noyaux de prunes découverts dans le puits permettent peut-être d'envisager la présence d'au moins un prunier parmi ces arbres... 


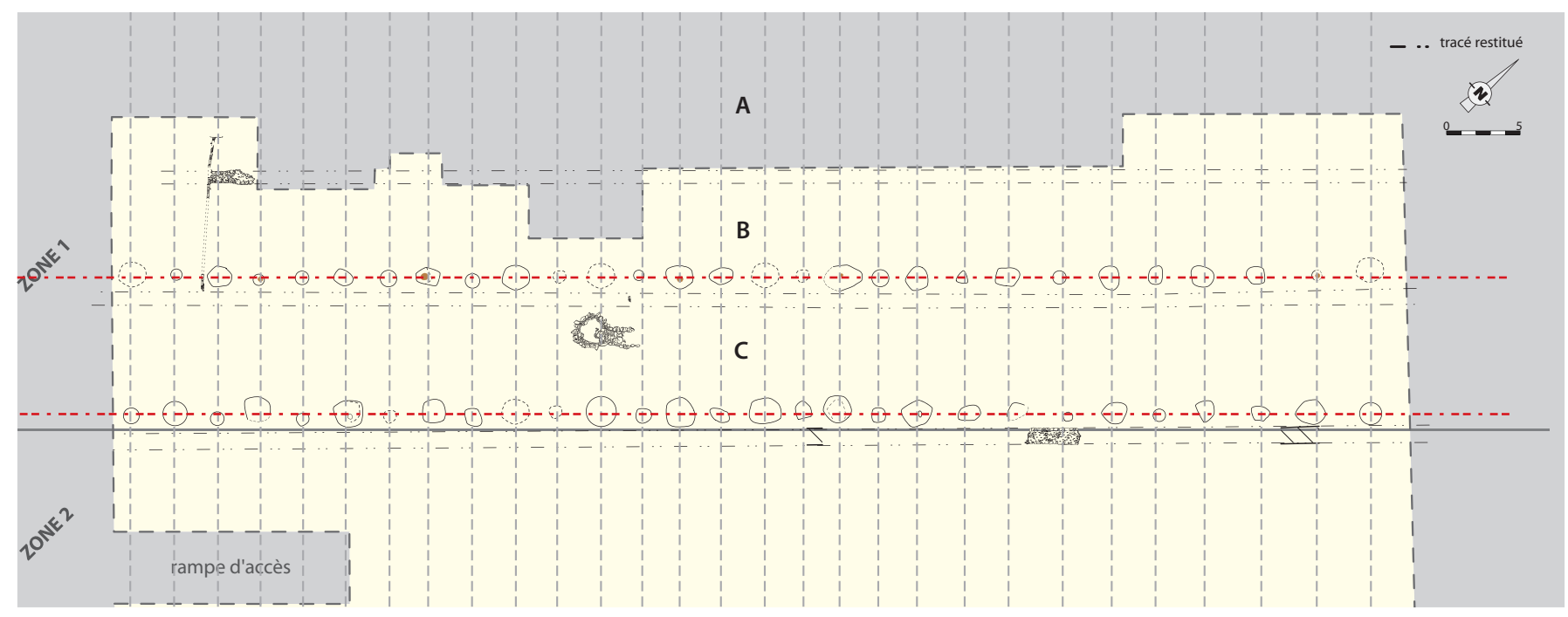

Fig. 53. Report du quadrillage théorique d'organisation du jardin.

La faiblesse de l'apport sableux et de l'exhaussement des sols au regard de la phase précédente montre un ralentissement dans l'ensablement du haut de plage, ainsi que l'efficacité du mur de clôture MR2004. Mais s'agissait-il d'une plantation à vocation agricole de type verger ou ornementale de type jardin d'agrément ? Ou alors, sommes-nous en présence d'un ensemble groupant les deux fonctions?

Tout d'abord, on peut se demander si le lieu choisi : un bord de plage mal adapté à l' agriculture (en particulier si l'on cherche un certain rendement pour alimenter un camp) n'est pas un indice suffisant pour restituer ici plutôt un jardin d'agrément. De plus, l'organisation générale, comme la volonté d'un rythme alternant grandes et petites fosses, associée à un probable portique d'apparat, ainsi que la présence de pots de plantations incitent à restituer un jardin à vocation ornementale. Par comparaison, un verger optimise la place disponible, dans un but évident de rentabilité. Pour illustrer cet aspect, on peut citer celui découvert au nord de la villa gallo-romaine de Jonzac en Charente-Maritime qui présente une soixantaine de fosses circulaires, mesurant entre 50 et $80 \mathrm{~cm}$ de diamètre pour $20 \mathrm{~cm}$ de profondeur, dont le plan d'ensemble s'apparente à un quadrillage régulier de $1,50 \mathrm{~m}$ d'espacement entre chaque fosse (Melmoth 2007, 41). Dans un tel cas, peu d'espaces sont laissés vides et l'on ne retrouve pas non plus d'alternance entre la taille des fosses. À l'inverse, l'image que nous avons des jardins romains est celle d'espaces plus aérés, pour les jardins publics en général, au maillage un peu plus lâche et laissant même, dans certains cas, de larges allées pour la promenade et la méditation. Si certains jardins des maisons de Pompéi, ou bien encore la fresque de la maison de Livie à Rome, montrent une densité de plantations plus soutenue, très éloignée de ce que l'on observe à Villa Romana, celle-ci n'empêche pas l'aménagement d'espaces de circulation dégagés et d'une organisation générale maîtrisée.

L'organisation et l'aménagement interne des jardins d'agrément connus dans le monde romain sont encore rarement attestés mais plusieurs exemples font déjà office de référence. À Rome, sur le mont Palatin, les fouilles des jardins sacrés du sanctuaire d'Héliogabale ont livré une organisation régulière en bandes délimitant de larges allées qui, sur de nombreux points et toutes proportions gardées, s'apparente à la nôtre. On retrouve l'emploi d'amphores coupées (ici retournées bords vers le bas) ainsi qu'une variation dans les proportions des fosses. Cette découverte a permis de restituer une alternance d'alignements de buissons bas et d'arbres plus hauts (Villedieu 2001, 94-98). Un autre exemple d'amphores alignées remployées comme vases horticoles nous est fourni par le jardin entourant le canopus de la villa Adriana à Tivoli (Jashemski, Ricotti 1992, 582-583).

Également, dans le nord de la Gaule, la centaine de pots horticoles et les quelques fonds d'amphores du jardin de la villa de Richebourg (Yvelines) forment des maillages orthogonaux selon un module de $4 \mathrm{~m}$ (Barat, Morize 2003). Enfin, récemment à Fréjus, la fouille du site des Poiriers dans le quart sud-est de la ville antique, a révélé la présence d'amphores alignées, coupées et retournées col en bas employées dans le vestibule à ciel ouvert de thermes publics (Excoffon 2010b).

Lors du diagnostic archéologique réalisé sur les thermes de Villeneuve en 2008 (Excoffon, Ardisson 2008), deux murs faits de gros moellons équarris formant un angle droit - les rapprochant fortement dans leur conception des murs organisant le jardin (MR2001 et 2004) - ont été découverts (fig. 54). Sans datation précise, nous pouvons supposer qu'ils participent à 


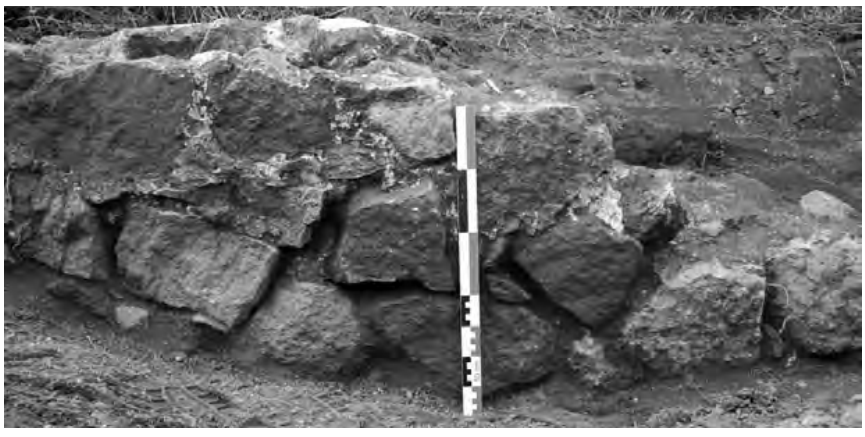

Fig. 54. Mur de limite est du jardin. dès lors une vue ouverte sur la mer, l'élément paysager indispensable (fig. 56) (Grimal 1984)...

En résumé, les trois allées parallèles que dessinent les plantations rappellent une portion d'une promenade, probablement en terrasses, évocation lointaine des « promenades » à la mode dès le $\mathrm{I}^{\text {er }}$ siècle av. J.-C. (ibid., 173-180). Cette disposition en terrasses évoque davantage encore les jardins situés dans les zones suburbaines, proches de la ville, souvent en lien avec des sanctuaires ou des villae. Ainsi, le grand jardin de la villa de Livie comportait des terrasses

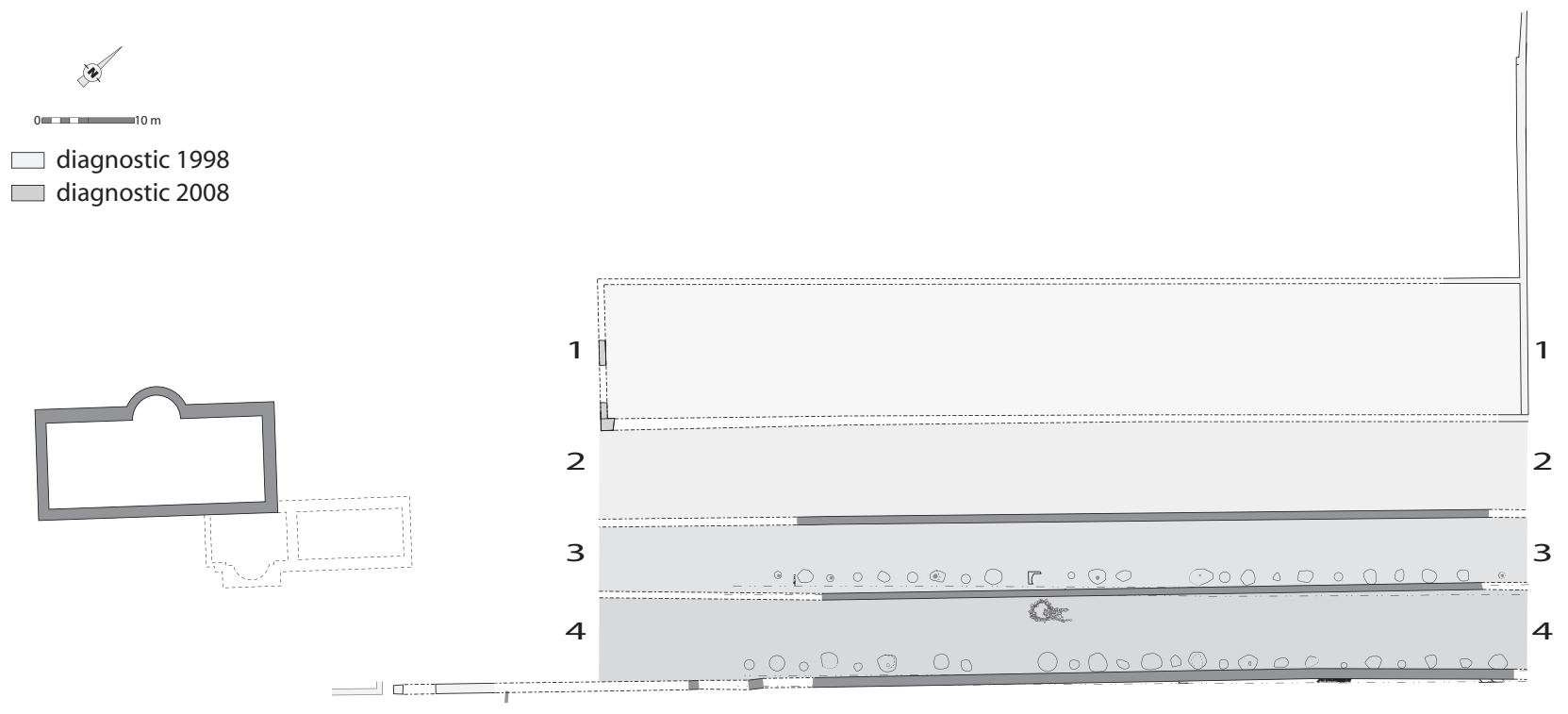

Fig. 55. Plan des vestiges de la zone d'après les diagnostics archéologiques

(Michel 1999 et Excoffon, Ardisson 2008) et la fouille de Villa Romana.

une même série d'aménagements qui trouve également un probable prolongement dans la partie orientale du même terrain (situé immédiatement au nord de Villa Romana) sondé en 1998 lors du diagnostic réalisé par J.-M. Michel (Michel 1999). Là, trois murs (15, 17 et 19), construits à double parement de blocs bruts (16 à $32 \mathrm{~cm}$ ) et remplissage de cailloux et mortier, semblent délimiter la partie nord-est d'un quadrilatère allongé, parallèle aux lanières dessinées par les jardins de Villa Romana (fig. 55). Sans datation précise non plus, ces murs sont toutefois estimés remonter à une première phase. Ainsi, en replaçant ces différentes structures dans la topographie de la phase 2 de Villa Romana, ils permettent de restituer une troisième et une quatrième bandes parallèles, altimétriquement plus hautes, que l'on pourrait supposer être un espace également pourvu de plantations et donc constituer deux terrasses supplémentaires. Ces considérations permettent de restituer l'image de jardins étagés en terrasses offrant entourées de portiques (Klynne, Liljenstolpe 2001). Cette restitution permet d'envisager un ensemble de $45 \mathrm{~m}$ de large pour $100 \mathrm{~m}$ de long soit une superficie de $4500 \mathrm{~m}^{2}$. Ces dimensions n'ont rien d'exceptionnelles aux regards d'autres jardins connus du monde romain, ainsi celui de la villa de Fishbourne dans le Sussex couvrait $6750 \mathrm{~m}^{2}$ et celui de la villa de Richebourg dans les Yvelines, $1500 \mathrm{~m}^{2}$. En milieu urbain, les dimensions sont nettement moindres, à Saint-Romain-en-Gal les jardins des domus excèdent exceptionnellement les $1000 \mathrm{~m}^{2}$ (Le Glay 1981) et à Conimbriga au Portugal les dimensions sont encore inférieures (Alarcão, Étienne 1981).

L'ensemble des prélèvements effectués au sein des fosses de plantations n'a pas fourni de résultat exploitable pour les études archéobotaniques. Dès lors, toute reconstitution du contexte botanique nous est impossible et l'on peut seulement s'inspirer des jardins pompéiens dont la richesse et la diversité des plantes 
cultivées ont été mises en lumière par les travaux de W. F. Jashemski : des fouilles, anciennes et récentes, ont permis, notamment grâce à l'étude des empreintes des réseaux racinaires, de confirmer en partie ce que nous livraient jusqu'à présent les textes latins et l'iconographie (Jashemski 1979 et 1981, 46-47). Le mélange d'arbres fruitiers, feuillus et conifères, fleurs saisonnières, vignes, voire des légumes à l'image de la Maison du Navire Europe ou celle de Poppée à Oplontis, semblait être la norme.

\subsection{L'extension du camp militaire ?}

Chr. Goudineau propose de situer la limite sud-est du camp militaire au niveau de l'angle que formeraient les deux murs mentionnés par $\mathrm{Ch}$. Texier dans son plan de 1829 (190) (fig. 21). Ce dernier a, semble-t-il, pu observer des vestiges bien plus importants que ceux visibles de nos jours. En voici sa description : « les jardins des Thermes (...) étaient défendus par un môle semblable à celui du port; il subsiste encore dans son intégrité. Sa longueur est de 132 mètres, et sa largeur de 4 mètres ; il est coupé à angle droit par un second môle de 100 mètres de long. " Ce second môle est représenté sur son plan le long de la rue Jean-Carrara ; il se situerait à environ $60 \mathrm{~m}$ au sud du mur 1003 (phase 3).
Ch. Texier est le seul auteur à présenter ce retour qui n'apparaît pas sur le plan anonyme de 1825 , ni sur celui de Chr. de Villeneuve-Bargemont, pourtant tous deux contemporains de Ch. Texier. Nous avons cherché en vain jusqu'à la limite nord de la rue Jean-Carrara la trace de ce large mur. Pourtant, si l'on restitue les distances proposées par Ch. Texier sur le site, le mur devait se situer sur l'emprise de la fouille et la précision de son relevé est généralement suffisamment fiable pour que le mur ne puisse se trouver beaucoup plus au sud. De plus, la répartition des sédiments sableux repérés dans les niveaux situés sur le site sont en opposition avec l'idée d'un môle bloquant la diffusion de ces sables. Sur le site, un mur moderne (MR3003) bordant un fossé (FO3081) est localisé précisément à $57 \mathrm{~m}$ du grand mur MR1003. Il est le seul approximativement sur le tracé de ce mur. Il est donc envisageable que $\mathrm{Ch}$. Texier ait considéré ce mur comme étant un retour antique, commettant ainsi une possible erreur d'interprétation. Ce constat nous permet de considérer, toujours avec prudence, que la première limite probable du camp est à situer plus au nord, au moins d'une dizaine de mètres. L'amas de blocs et l'alignement de pieux peuvent alors apparaître comme une limite originelle potentielle, en tout cas antérieure aux deux dernières décennies du $\mathrm{I}^{\text {er }}$ siècle av. J.-C. et contemporaine des premiers aménagements en matériaux

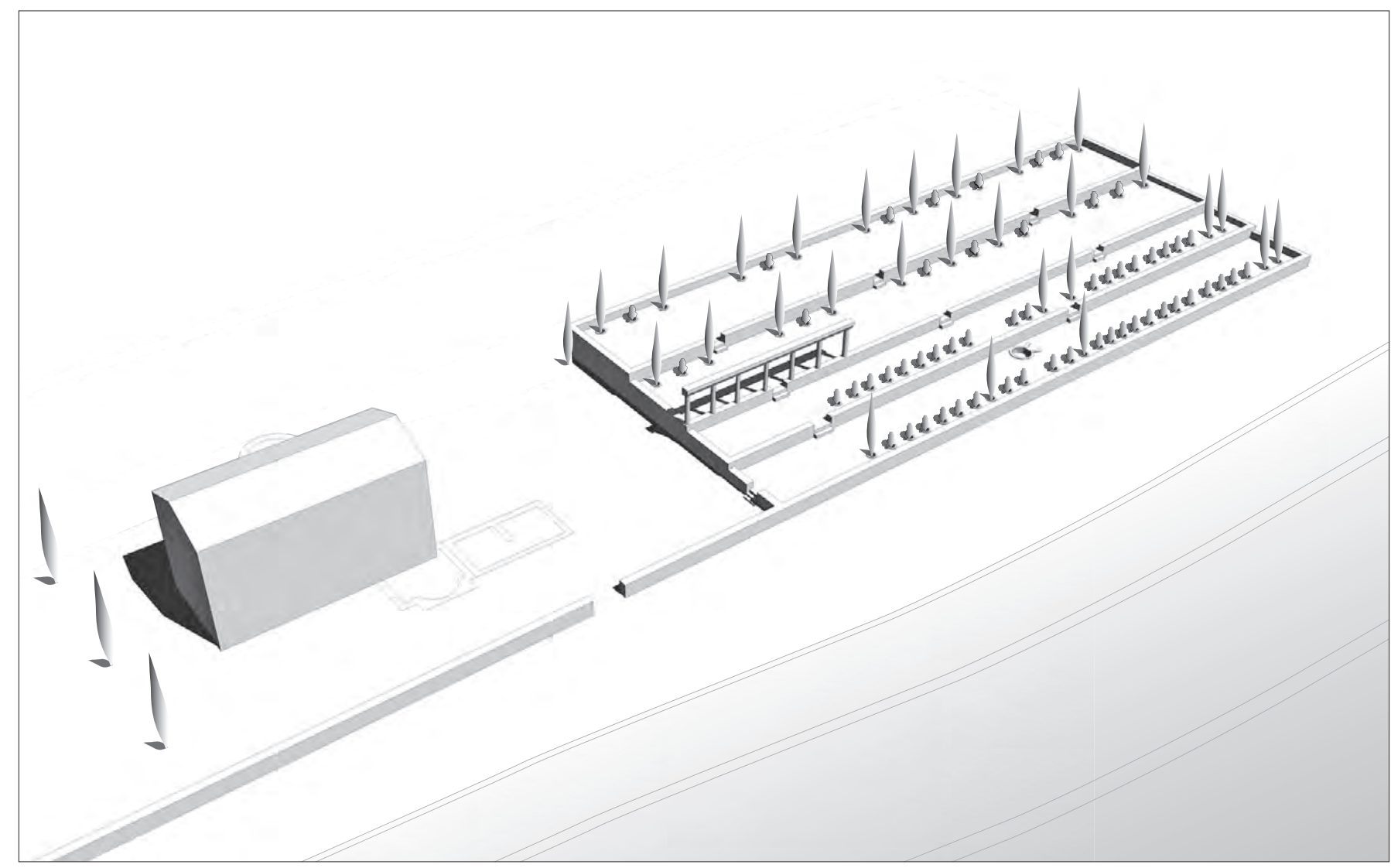

Fig. 56. Hypothèse de restitution de l'aménagement du jardin dans son contexte (J. Pâques). 


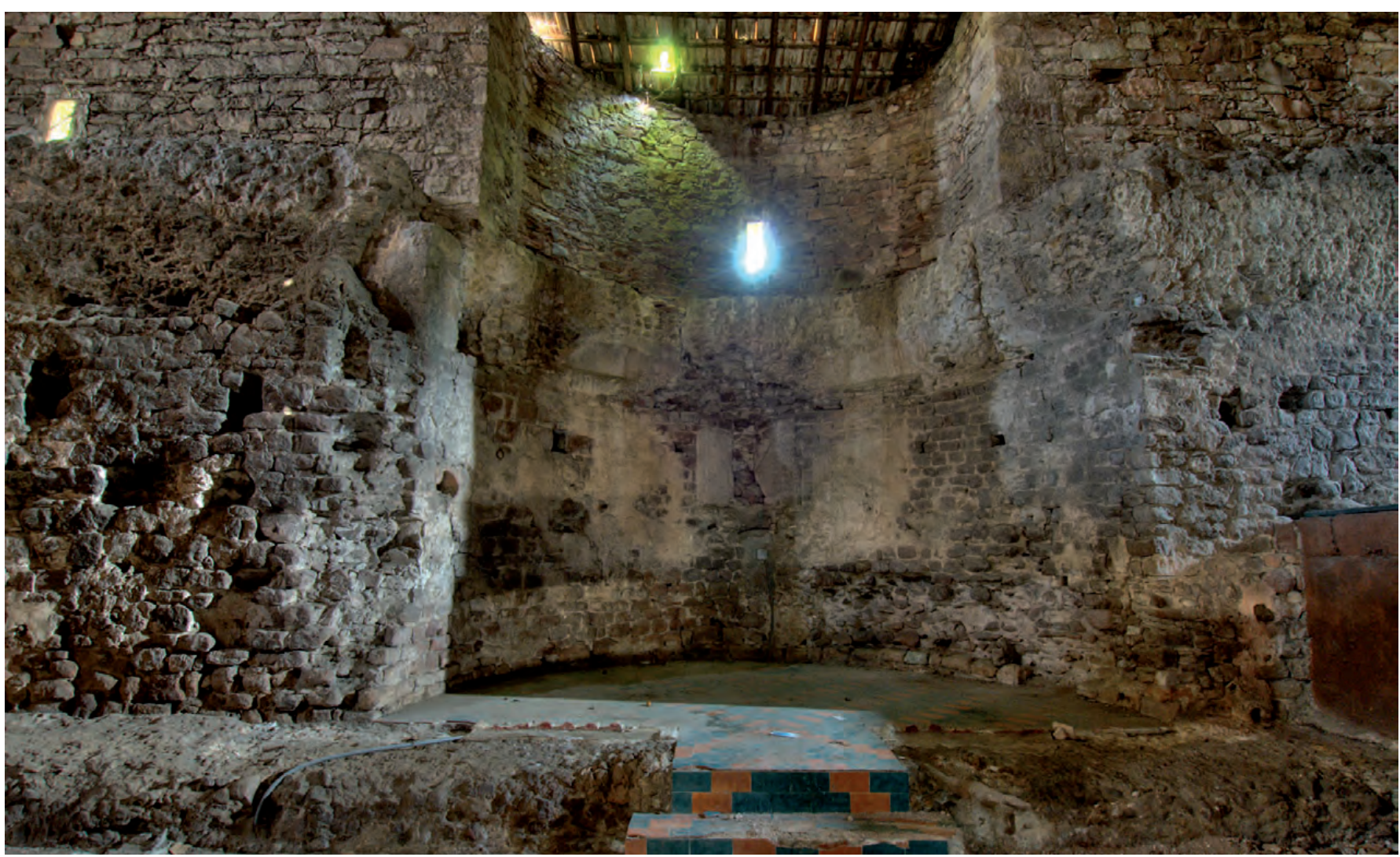

Fig. 57. Vue de l'intérieur de la grande salle des thermes ( $\mathrm{Cl}$. Ville de Fréjus - R. Hacquardº).

périssables constituant le camp initial. Ces installations correspondraient aux premiers aménagements littoraux destinés à stabiliser la plage située immédiatement au sud de ce premier camp.

En revanche, les phases suivantes marquent une extension des terrains vers le sud par progradation littorale. Les limites occidentale et septentrionale du camp n'ayant pu être archéologiquement démontrées, ce léger décalage ne remet nullement en cause les restitutions hypothétiques du développement total du camp d'environ $600 \mathrm{~m}$ x $300 \mathrm{~m}$ proposées par Chr. Goudineau et D. Brentchaloff pour la fin du I ${ }^{\text {er }}$ siècle av. J.-C. (Goudineau, Brentchaloff 2009, 39). Mais reconnaissons que tout est ici question de chronologie...

L'élément de réponse le plus significatif pourrait être fourni par le bâtiment que cet ensemble jouxtait. En effet, la compréhension globale ne peut être envisagée sans raccorder ces vestiges aux constructions connues plus au nord. C'est durant cette phase que, pensons-nous, le premier bâtiment de la «Ferme de Villeneuve » est édifié. Il apparaît, essentiellement à partir d'observations d'ordre architectural, que ce bâtiment a connu deux phases de construction, les thermes de Villeneuve tels qu'on les connaît aujourd'hui ayant été bâtis sur un bâtiment antérieur. Chr. de Villeneuve-Bargemont en 1803 est, semble-t-il, le premier à proposer cette interprétation (Villeneuve-Bargemont 1812, 82-84), qui sera reprise par l'ensemble de ses successeurs, en particulier J.-A. Aubenas et A. Donnadieu qui réaliseront les fouilles les plus conséquentes sur l'édifice. À la vue des murs de façade de la grande pièce à abside, il apparaît assez nettement que l'appareil employé pour les parties basses (le premier état) est bien différent de celui que l'on retrouve pour les parties supérieures (le second état). Pour le premier, les moellons sont plus gros (10 à $15 \mathrm{~cm})$, simplement équarris, et disposés en assises de hauteurs variables. Pour le second, les moellons sont plus petits (9 à $12 \mathrm{~cm}$ ), mieux calibrés, disposés en assises plus régulières et l'on retrouve pour certaines salles des arases de briques (fig. 57). Dans les deux cas, c'est un grès brun qui a été employé. P.-A. Février fournit une analyse très pertinente de cet ensemble et détermine aussi deux phases de construction qu'il date, par analogie avec les autres édifices de Fréjus et de Provence orientale pour le premier bâtiment, de la fin du I ${ }^{\text {er }}$ siècle av. J.-C., et le second, de la fin du Ir et le $\mathrm{II}^{\mathrm{e}}$ siècle apr. J.-C. (Février 1956, 175). Cette proposition se trouve confortée par le réexamen par D. Brentchaloff $\mathrm{du}$ mobilier archéologique issu des fouilles de Donnadieu, qui détermine un premier horizon durant le dernier quart du $\mathrm{I}^{\mathrm{er}}$ siècle av. J.-C. (Rivet et al. 2000, 339). L'arrachement des murs MR1050 et MR1261 ne 
permet pas de comparer leur mise en œuvre avec les parements visibles du premier état. En revanche, même si la fonction est différente, on constate que le parement conservé du mur MR2004 est fait de moellons de grès brun grossièrement équarris, que l'on peut rapprocher du premier état du bâtiment de Villeneuve. Mais c'est essentiellement l'argument de la chronologie qui permet de rapprocher la phase 2 de la fouille de Villa Romana du premier édifice. L'ensemble, jardin et bâtiment, nous paraît donc contemporain et mis en place durant les deux dernières décennies du ${ }^{\mathrm{er}}$ siècle av. J.-C.

\subsection{Le premier bâtiment de Villeneuve et son jardin d'agrément}

S'il ne fait pas de doute que l'ensemble aujourd'hui visible sous la ferme moderne de Villeneuve appartient à des thermes, la question reste débattue pour l'état antérieur, contemporain de la phase 2 de Villa Romana. En effet, A. Donnadieu reconnait deux ensembles différents mais tous deux à vocation thermale : le premier étant les thermes des équipages, le second ceux des officiers. A. Bouet réexamine cet ensemble (Bouet 2003b, 103-107) et s'interroge sur la possible vocation curative du second bâtiment, mais n'émet pas de nouvelle hypothèse sur la nature du bâtiment le plus ancien ; il relève toutefois que la datation et le plan de l'ensemble sont problématiques. Ch. Gébara et J.-M. Michel (Gébara, Michel 2002, 280-283) proposent eux de voir dans les différents appareils « des campagnes de réfection et de transformations profondes », mais qu'il s'agit « d'un seul ensemble thermal doté de plusieurs phases de construction et peut-être de différentes sections » (ibid., 281). L. Rivet est le seul à proposer une fonction non thermale au premier édifice à abside, qu'il propose de rapprocher témérairement du praetorium du camp de la Flotte (Rivet et al. 2000, 444). Chr. Goudineau et D. Brentchaloff en font eux un édifice majeur dans le camp duquel découlerait toute son organisation planimétrique (Goudineau, Brentchaloff 2009, 37-40).

Si l'on considère que l'édifice de Villeneuve se situe dans l'emprise du camp, l'hypothèse d'un ensemble thermal édifié dans le dernier quart du ${ }^{\text {er }}$ siècle av. J.-C. n'est pas incompatible non plus.

La fouille des espaces extérieurs ne permet pas directement de trancher entre les différentes hypothèses et l'existence d'un jardin trouve sa justification dans les deux cas, celui des thermes ou d'un praetorium ${ }^{10}$.

À Villeneuve, les portions de murs les plus anciennes, signalées par leur technique de construction, définissent un bâtiment rectangulaire pourvu d'une abside au nord. Sa superficie est de $210 \mathrm{~m}^{2}$ et l'abside mesure environ $5 \mathrm{~m}$ de diamètre. L. Rivet propose une restitution de ce premier édifice en complétant la façade sud-ouest (Rivet et al. 2000, 343, fig. 622). Dans l'idée de restituer là le logement du commandant, l'existence d'un environnement monumentalisé, que permettent surtout d'évoquer les éléments remployés en masse dans le puits SB1262 de la phase suivante, n'est pas surprenante. La présence d'un bâtiment à vocation non thermale antérieur aux thermes permettrait sans doute d'expliquer la nature «peu claire » du plan de l'ensemble. Mais, quoiqu'il en soit, si cette fonction originelle nous échappe encore, la fonction thermale du bâtiment apparaît ancienne (voir infra p. 106). L'étude du bâtiment proposée ci-après par S. Ardisson montre l'existence d'un plan thermal de type ancien qui pourrait laisser supposer une première transformation de l'édifice dès le début du $\mathrm{I}^{\text {er }}$ siècle apr. J.-C. Si tel était le cas, cette première évolution du bâtiment n'a pas impliqué de modifications notables au niveau de l'aménagement du jardin.

Enfin, il faut reconnaître que même si la datation repose sur un nombre réduit de fragments, et pour ces périodes il s'agit d'une tendance générale à Fréjus, elle coïncide avec les horizons chronologiques les plus anciens repérés au sein de la ville (Rivet et al. 2000, Rivet 2010 et Pasqualini et al. 2006) et identifiés comme contemporains des premières constructions du réseau $\mathrm{A}$, marqueur du déclanchement du développement de la cité de Forum Iulii.

Ainsi, cette extension du camp de la flotte serait contemporaine des premières installations sur la butte de grès où s'édifiera la ville, probablement au moment de la déduction. Dès lors, si l'orientation diffère, c'est parce que les jardins suivent nécessairement une orientation plus ancienne, celle du premier camp, NL $47^{\circ}-49$ ouest, la même que l'alignement de piquets aménageant la plage lors de la phase précédente. Le choix d'orienter les constructions selon le réseau $\mathrm{A}, \mathrm{NL} 15^{\circ}$ ouest, résulte d'une décision particulière, sans doute due à la localisation de ces constructions nouvelles, situées à plus de $800 \mathrm{~m}$ de là et sur une éminence rocheuse.

10 À l'image, entre autres, des imposantes structures du camp algérien de Lambèse. 



\section{Chapitre 3}

\section{Les abords des thermes de Villeneuve durant la deuxième moitié du I ${ }^{\text {er }}$ siècle apr. J.-C.}

\section{La phase 3, état $A$}

Les vestiges en rapport avec cette phase concernent essentiellement les zones 1 et 3. Comme durant la phase précédente, la bande centrale (zone 2) est un terrain sableux exhaussé, dont les niveaux d'occupation ont totalement disparu. Il en est de même pour une partie de la zone 3, excavée lors des phases suivantes, mais la présence de structures situées sous les sols permet de retrouver la trace de quelques aménagements (fig. 58).

\subsection{La zone 1}

(P. E.)

\subsubsection{Description et stratigraphie}

$\mathrm{Au}$ sud-ouest, le mur MR2004 sert toujours de limite avec les niveaux sableux de plage, alors que les murs MR1050 et MR1261 sont totalement épierrés et leurs tranchées recouvertes. La présence uniforme d'un niveau sableux ocre rouge légèrement limoneux (US1010) recouvrant l'ensemble des aménagements de la phase précédente, indique clairement que le jardin est alors totalement transformé et toutes les plantations supprimées (fig. 59 et 60). Au nord, le mur MR1003 est construit et limite le nouveau niveau sableux ocre rouge. La surface de cet apport, d'une épaisseur variant entre 10 et $15 \mathrm{~cm}$, s'établit à une altitude moyenne de 1,10 m NGF, malgré un léger pendage sud-ouest. Il permet ainsi de niveler l'ensemble de la zone, atténuant le décalage antérieur entre les secteurs B et C ( $c f$. coupe 2a). En outre, il apparaît qu'un fort décalage altimétrique existe avec les terrains situés au nord. Bien que ce terrain soit extérieur à la zone fouillée, plusieurs observations faites lors du diagnostic archéologique réalisé en 1999, nous permettent de définir les niveaux de fonctionnement (Michel 1999). De nombreuses structures bâties ont été découvertes dans cette partie, sous une faible épaisseur de terre et les niveaux sableux apparaissent peu en dessous de la surface d'arase des murs. Toutefois, les données altimétriques (NGF) font défaut et ne permettent pas d'aller plus en avant dans cette interprétation. Il n'empêche qu'à la lecture du rapport, l'idée d'une surface de sol plus élevée dans la partie nord apparaît assez évidente. D'autres éléments viennent étayer cette hypothèse, comme le creusement d'une fosse après la fouille qui a permis de visualiser le sommet du corps sableux à une altitude minimale de 1,50 m NGF. Ce point a été confirmé par un carottage manuel. Au vu de ces indices, il semble que l'on puisse affirmer que le mur MR1003 servait de clôture sud et de mur de soutènement. Ce dernier employait des éléments de destruction du mur MR1261, comme des fragments d'enduits peints, dans sa tranchée de fondation. Il a été repéré sur toute la longueur de la parcelle et se prolongeait au-delà. Situé en limite de fouille, seul son parement sud a été dégagé. Il s'agit d'un mur massif, bâti en opus caementicium à double parement, d'une largeur de 1,15 m (fig. 61). La fondation, en tranchée (US1018), marque un léger empâtement. Le cœur du mur est fait d'un mortier compact englobant de nombreux cailloux et moellons anguleux. Le parement est réalisé avec des moellons de grès brun équarris, simplement dressés sur la face visible et de dimensions variables. Les assises sont peu régulières (fig. 62). Là où ils sont conservés, les joints sont regarnis et affleurants. Aucune trace d'enduit n'a été observée. Au-delà d'un mètre de haut, le parement a été entièrement récupéré laissant seulement apparaître le remplissage intérieur. Au plus haut, le mur est conservé sur 1,60 m et ne marque pas de fruit. Dans le mur a été ménagé un passage voûté (CN1132) dont l'arc en plein cintre est ouvert au niveau de l'extrados suite à la récupération des matériaux ${ }^{1}$ (fig. 63 et 64). L'ouverture est large de $0,50 \mathrm{~m}$ pour une hauteur sous l'intrados de $1,10 \mathrm{~m}$ et pour une flèche restituable de 0,32 $\mathrm{m}$ (corde au sommet de l'intrados). Les voussoirs taillés sont en grès brun de $0,32 \mathrm{~m}$ de longueur. Les piédroits ont bénéficié, là où ils n'ont pas été repris,

\footnotetext{
1 Le matériel découvert dans le comblement supérieur remonte au début de l'époque moderne (US1134). À cette époque, le mur et le voûtement sont repris et les vides comblés.
} 


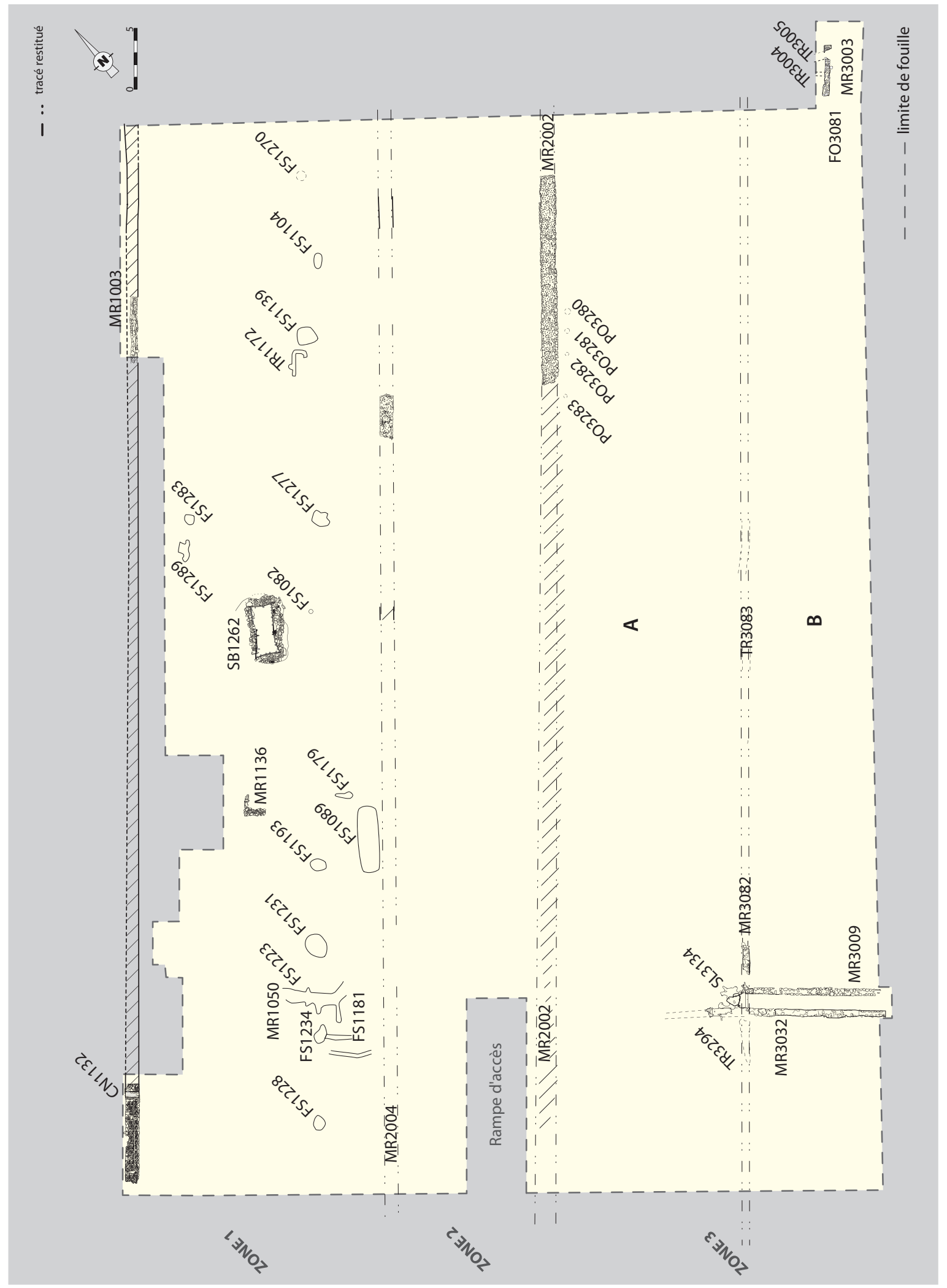

Fig. 58. Plan d'ensemble des vestiges de la phase 3. 


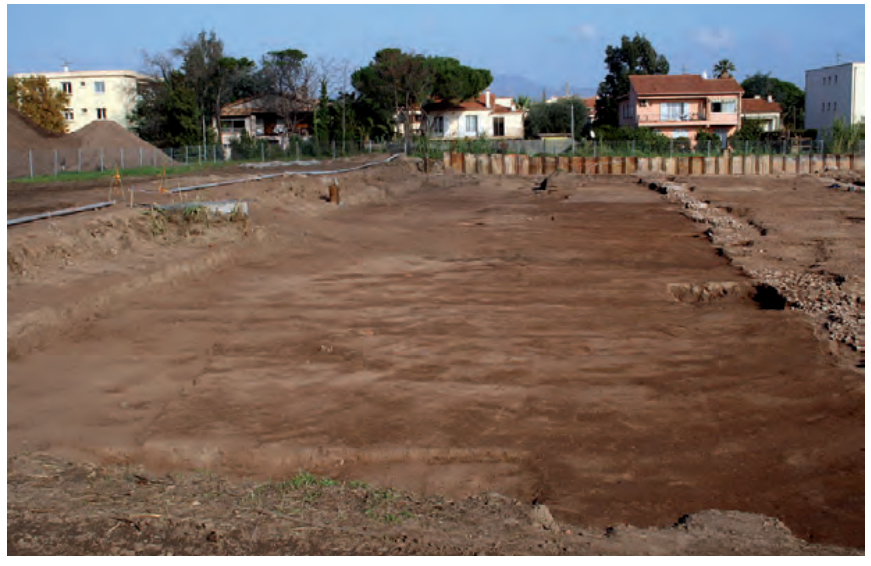

Fig. 59. Vue de l'ouest de la surface du jardin de la phase 3.

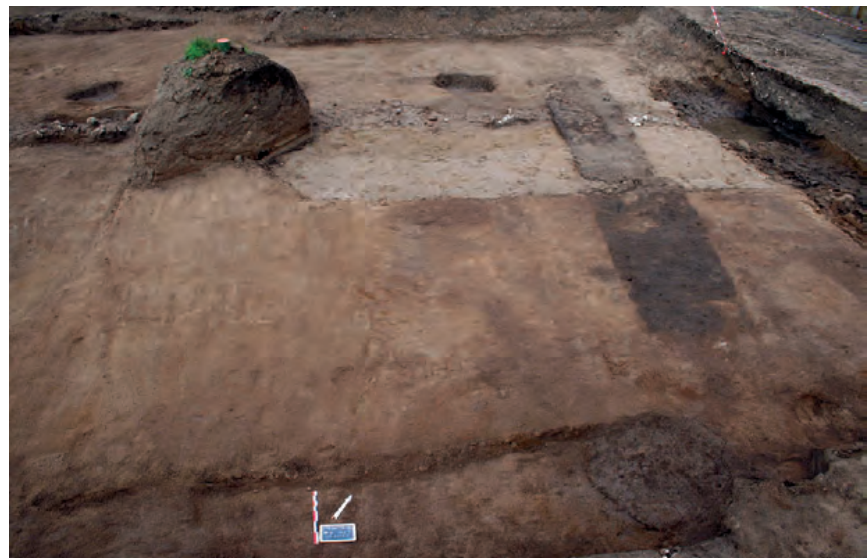

Fig. 60. Au premier plan, la surface rouge 1010 recouvrant la couche sableuse 1068, visible à l'arrière-plan de la photographie (la bande sombre correspond à une des tranchées de diagnostic).
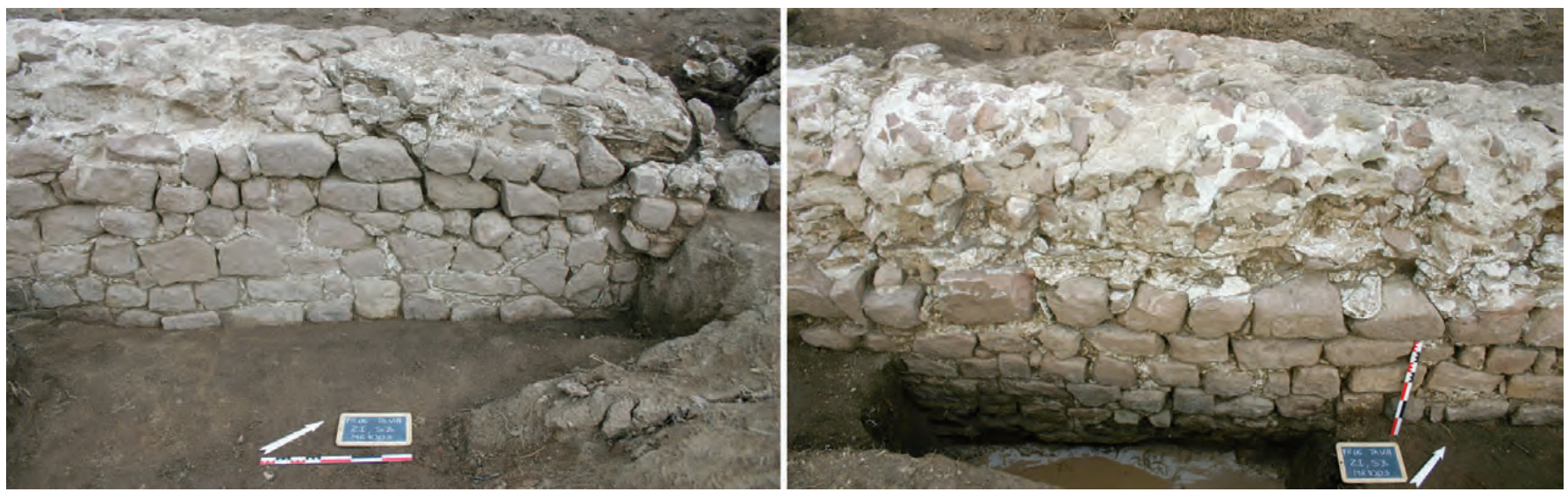

Fig. 61. Le mur MR1003.
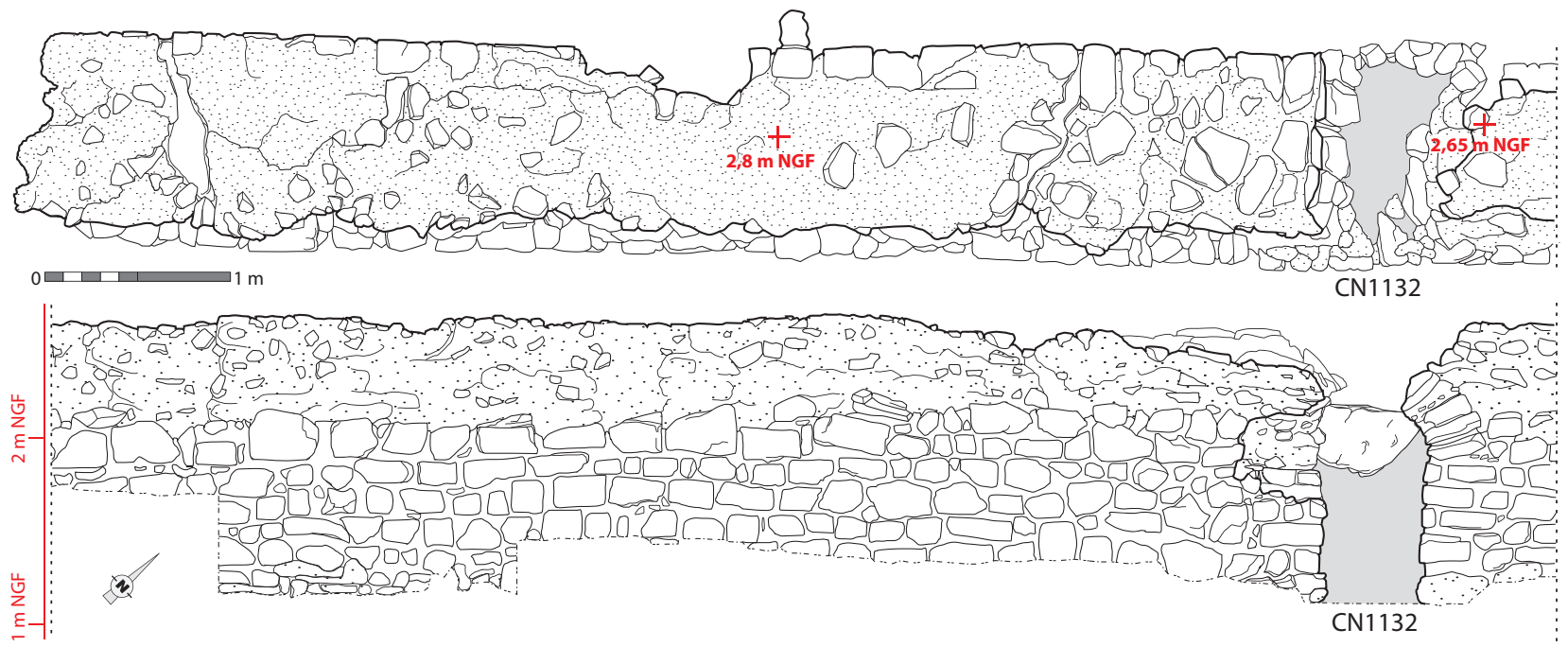

Fig. 62. Relevé du mur MR1003 (M. El Amouri). 
d'un soin particulier, les moellons sont soigneusement taillés, les arêtes vives et les joints réguliers. L'ensemble est très similaire à l'ouverture voûtée découverte lors du diagnostic archéologique de 1999 dans la parcelle voisine située au sud-ouest (Michel 1999, 7) qui semble appartenir à la même phase de construction. La fonction de cette ouverture est difficile à définir sans connaître la nature du terrain situé en arrière.

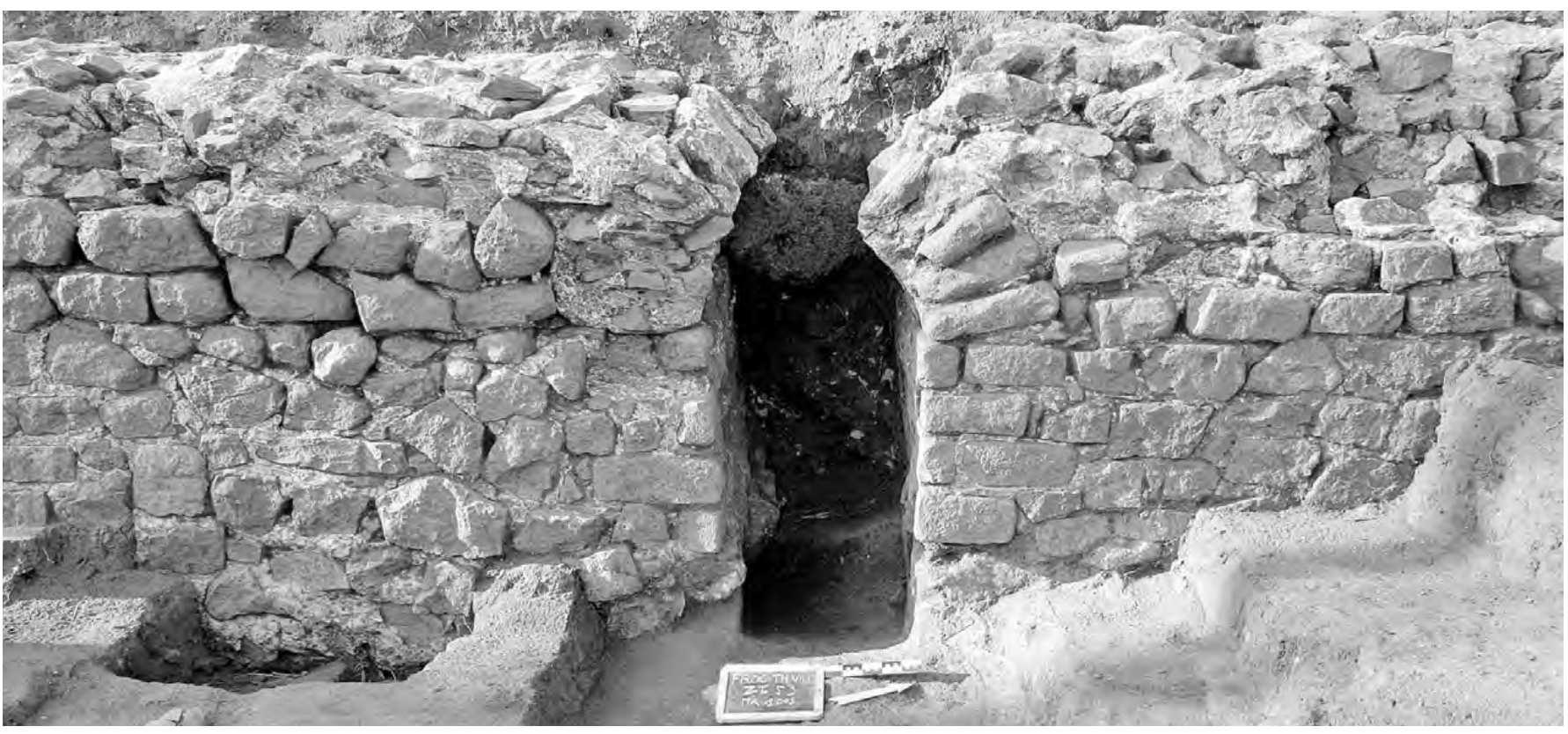

Fig. 63. L'ouverture CN1132.

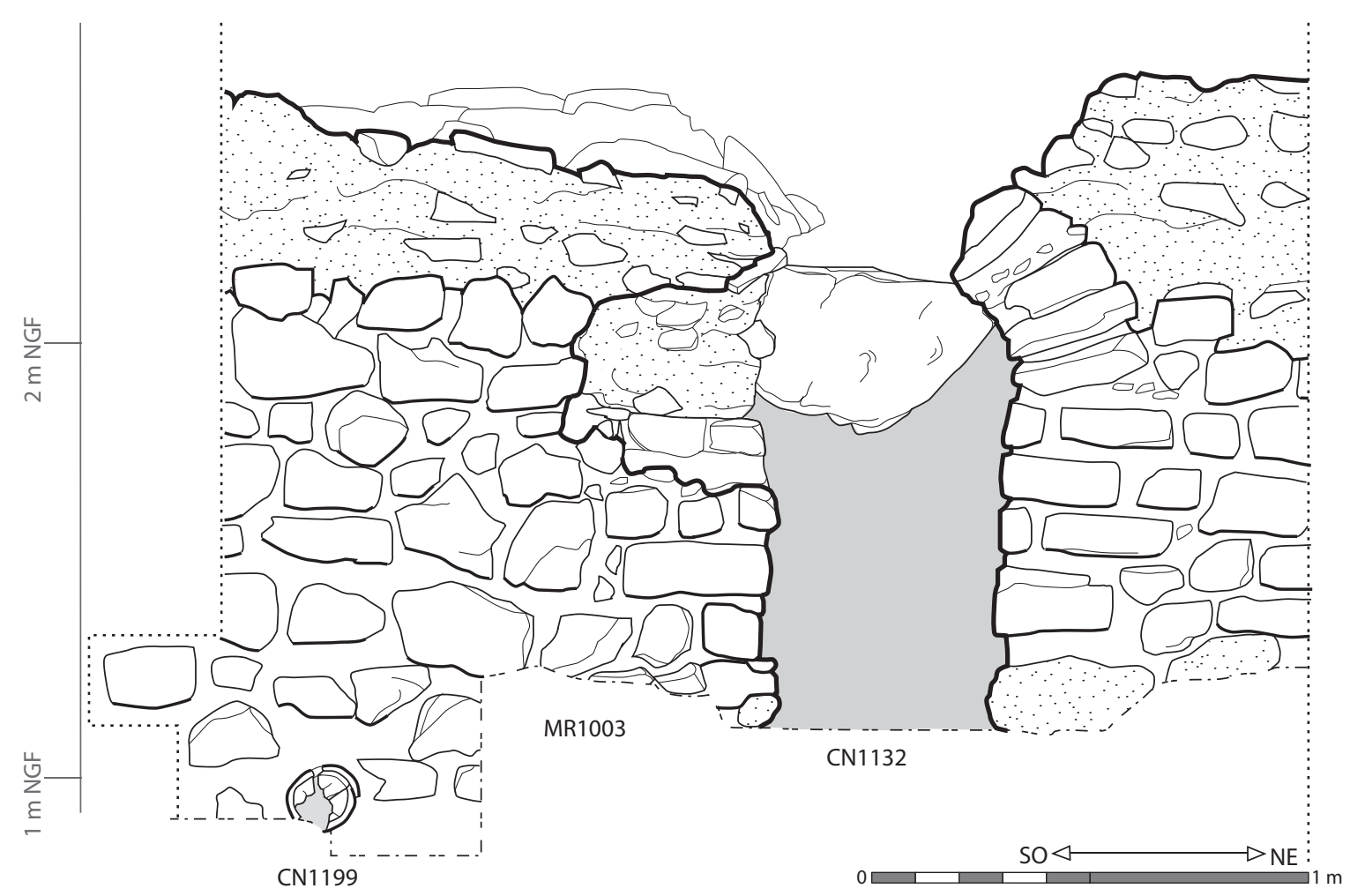

Fig. 64. Relevé de l'ouverture CN1132. 


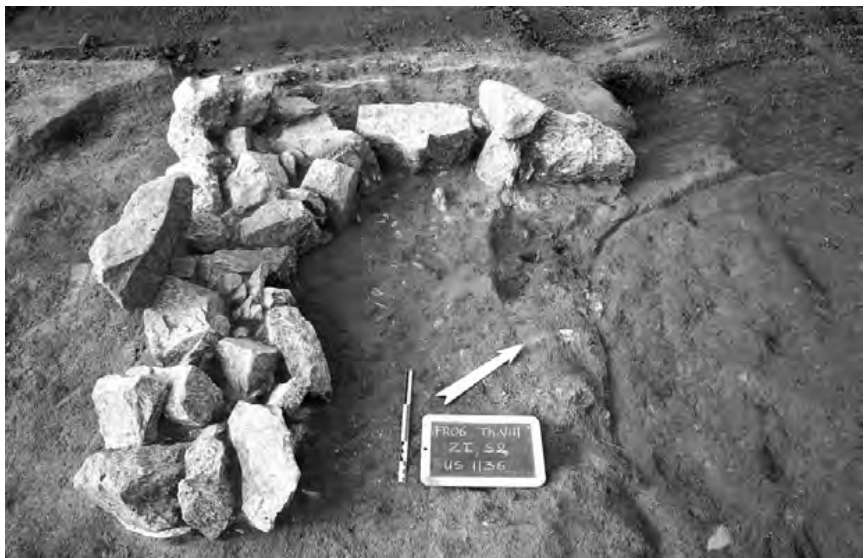

Fig. 65. Structure bâtie MR1136.

Il pourrait s'agir d'une conduite fermée destinée à évacuer l'eau d'infiltration du terrain situé en arrière, sorte de chantepleure ou barbacane. Cette évacuation est mise en place au niveau de l'ancienne conduite CN1199 condamnée lors de l'édification du mur MR1003.

Enfin, dans la partie nord apparaît l'angle nord-ouest d'une structure bâtie (MR1136) en moellons et mortier (fig. 65). Compte tenu de la faiblesse des fondations et de la nature de l'appareillage, nous supposons qu'il s'agissait d'une structure relativement légère qui n'a malheureusement laissé que peu de traces et pour laquelle aucune fonction ne peut être identifiée.

\subsubsection{Les fosses de plantation}

Après la mise en place du remblai sableux, de nouvelles fosses sont creusées (fig. 66). Quinze ont été dénombrées. Neuf d'entre elles sont alignées est-ouest. Les comblements sont à dominante limoneuse brun gris et la composition est très proche de celle des fosses de la phase précédente.

Comme pour la phase antérieure, il s'agit de fosses de plantation réalisées et comblées selon un procédé tout à fait similaire.

- Fosse FS1104 : forme ovale de $126 \mathrm{~cm}$ x $64 \mathrm{~cm}$ et profonde de $20 \mathrm{~cm}$, située entre les murs MR2004 et MR1050. Le comblement (US1144) est argilo-sableux, brun gris et homogène.

- Fosse FS1139 : forme ovale de $172 \mathrm{~cm}$ x $165 \mathrm{~cm}$ et profonde de $78 \mathrm{~cm}$. Le comblement inférieur (US1152) est une couche indurée argilo-sableuse, brun gris, avec de nombreux charbons reposant sur le sable (fond de fosse). Quelques moellons sont présents.

Le comblement supérieur (US1140) est argilo sableux brun gris avec taches d'oxydation. On note la présence d'un murex partiellement brûlé.

- La fosse FS1193 : de forme ovale $97 \mathrm{~cm}$ x $130 \mathrm{~cm}$. $\mathrm{Au}$ sommet se trouvait une concentration de tuiles.
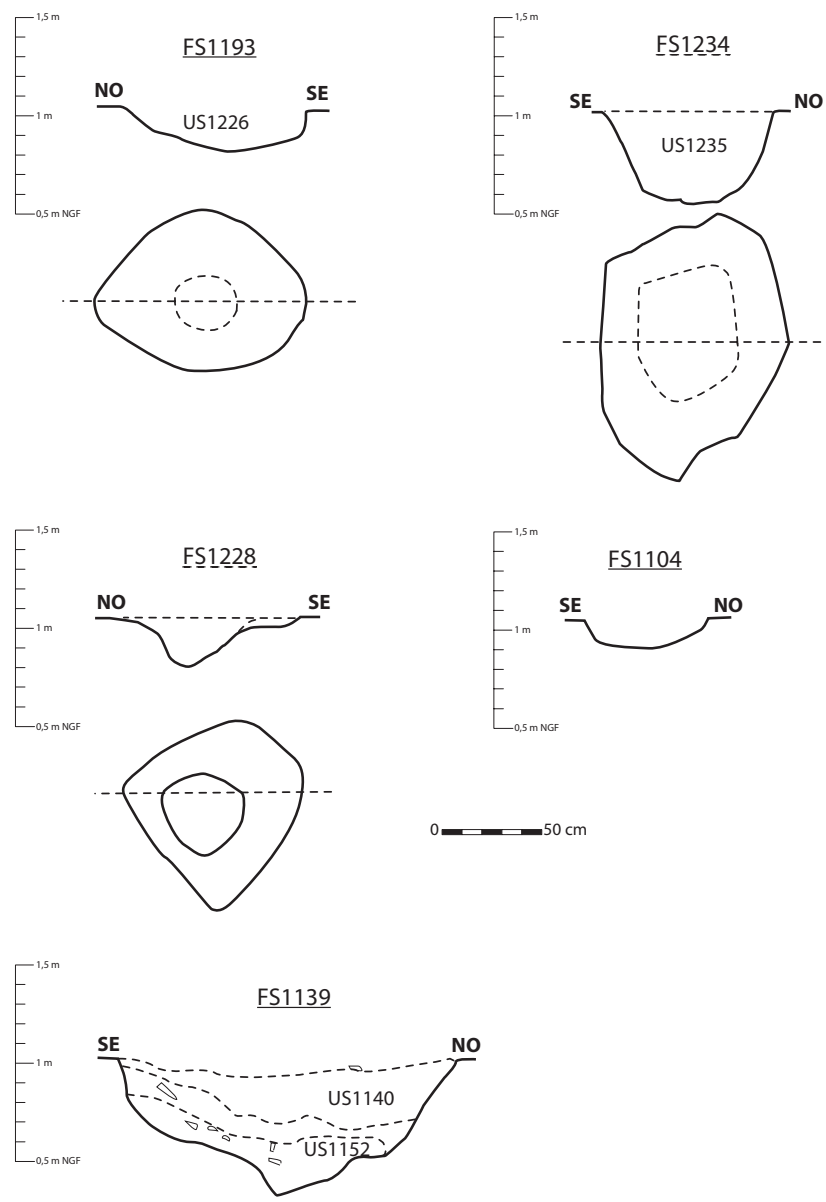

Fig. 66. Coupes des fosses de plantation de la phase 3 .

Le comblement de la fosse (US1226) est essentiellement composé de tessons et de fragments de tuiles au sein d'une matrice argilo-sableuse brun gris avec taches d'oxydation.

- La fosse FS1228 : de forme ovale $108 \mathrm{~cm} \mathrm{x} 87 \mathrm{~cm}$ et profonde de $28 \mathrm{~cm}$.

Le comblement (US1229) est argilo-sableux brun gris avec traces d'oxydation.

- La fosse FS1231 : de forme circulaire (diamètre $130 \mathrm{~cm}$ ) et profonde de $53 \mathrm{~cm}$.

Le comblement (US1232) est argilo-sableux brun gris avec de nombreuses céramiques

- La fosse FS1234 : de forme ovale $111 \mathrm{~cm}$ x $84 \mathrm{~cm}$ et profonde de $40 \mathrm{~cm}$.

Le comblement (US1235) est argilo-sableux brun gris et comprend de nombreuses céramiques et fragments de tuiles.

- La fosse FS1270 : de petite dimension, de forme circulaire (diamètre $85 \mathrm{~cm}$ ) et profonde de $30 \mathrm{~cm}$. 
Le comblement (US1271) est argilo-sableux brun gris, avec des graviers vers le fond et des tâches d'oxydation.

- La fosse FS1277 : fosse de moyenne dimension.

Contre le muret MR2004, une grande fosse (FS1089) de 4,30 m x 2,20 m sur 0,80 m de profondeur a été creusée. Sa fonction reste énigmatique. Les tranchées 1223 et 1172 sont également difficiles à interpréter. Ces deux tranchées n'étaient pas comblées par le même matériau limoneux que les fosses mais par un comblement plus sableux. Il s'agit probablement de tranchées ouvertes, peut-être de canaux de drainage creusés à même le sable.

\subsubsection{Les analyses}

\subsubsection{Carpologie}

(L. B., I. F., C. S.)

Une même série d'analyses que pour la phase 2 a été tentée sur l'ensemble de ces fosses. Comme on pouvait le craindre, les fosses de plantations FS1139 et VP1017, situées au dessus de la nappe phréatique, n'ont pas livré de résultats carpologiques significatifs. Le prélèvement de la fosse 1139 contenait seulement quelques fragments attribuables à des pignons (Pinus pinea).

Devant la faiblesse des résultats obtenus nous avons décidé de ne pas pousser plus avant l'étude de ce type de structures afin de privilégier les différents aménagements présentant des niveaux humides.

\subsubsection{Les phytolithes}

\section{(P. V.)}

FS1139, US1140

L'assemblage de phytolithes issus du comblement de la fosse est caractérisé par la présence de phytolithes d'Arecaceae (palmiers) (2,6 \%) (Piperno 2006). Cette présence de phytolithes de palmiers peut s'expliquer aussi bien par le contexte archéologique qu'environnemental. En effet, ce taxon est présent dans la végétation méditerranéenne à l'état sauvage (Chamaerops humilis L., le palmier nain) (Flora Europaea, vol. 5, 267). Mais les palmiers fournissent des phytolithes en grande quantité et il est possible que cette présence de phytolithes de ce taxon soit parfaitement intrusive : ils peuvent provenir de régions lointaines, apportés par le vent. Cependant, par la découverte de phytolithes de ce taxon dans le contexte d'une fosse de plantation, nous ne pouvons écarter l'hypothèse de la présence de cet arbre employé pour la vannerie ${ }^{2}$, son caractère alimentaire, décoratif et symbolique : à Rome, les palmes honoraient

2 Varron I, 22, 1 et Columelle, XI, 2, 90. les vainqueurs. C'était une plante également à usage religieux, surtout depuis l'introduction des cultes orientaux au I ${ }^{\text {er }}$ siècle apr. J.-C. (culte d'Isis).

Cette découverte est donc compatible avec la nature du site de Fréjus-Villeneuve, aussi bien comme témoin de l'environnement que comme partie intégrante d'un jardin botanique (d'agrément, médicinal et potager), du $\mathrm{I}^{\text {er }}$ siècle apr. J.-C. Mais en l'état actuel des connaissances, il n'est pas possible de trancher cette question.

\subsubsection{Le puits $S B 1262$}

(P. E., S. Gr., S. G., F. G., M. E. -A.)

Un puits est aménagé au centre nord de la zone dans le courant de la phase, à l'emplacement de certaines fosses de la phase précédente et sur le tracé de l'ancien mur MR1050. Il s'agit d'un puits de forme rectangulaire creusé jusqu'à la nappe phréatique située à l'époque entre $-0,5$ et $0 \mathrm{~m}$ NGF (fig. 67).

\subsubsection{Reconstitution et technique de montage}

Une large fosse ovale $(4,60 \mathrm{~m} \times 6,20 \mathrm{~m})$, profonde de $1,90 \mathrm{~m}$, a d'abord été creusée dans le sable. Afin d'éviter l'effondrement des parois de sable pendant le creusement, les puisatiers ont ensuite monté un coffrage en bois ${ }^{3}$ maintenu par une trentaine de pieux de bois ${ }^{4}$ profondément plantés dans le sable à l'intérieur de la structure. Le coffrage a donc été mis en place du haut vers le bas au fur et à mesure qu'ils creusaient à l'intérieur. Pour éviter l'infiltration de sable, l'arrière du coffrage a été comblé avec du matériau tout venant, essentiellement des éléments de récupération (fragments de sols, éléments de colonnes en briques, tuiles, fragments de corniche en pierre...) (chap. 2, 6) (fig. 68). Au final, le puits mesurait $4 \mathrm{~m} \mathrm{x} \mathrm{1,60} \mathrm{m} \mathrm{pour}$ environ 1,90 $\mathrm{m}$ de profondeur. Le coffrage ayant servi à sa construction sert donc également de cuvelage. Cette technique de construction, surtout possible lorsque la nappe est peu profonde, trouve des parallèles encore à l'époque actuelle, notamment dans le désert du Sahel (Barouin 2003, 207).

La position de la nappe phréatique n'a permis la conservation du cuvelage que sur moins de $0,50 \mathrm{~m}$ de hauteur.

\subsubsection{Le cuvelage en bois}

Le cuvelage est composé de fragments de bordés de navire encore maintenus par 33 pieux découverts

3 Il s'agit de morceaux de bordés de bateaux remployés (171).

4 Long. moyenne $140 \mathrm{~cm}$, max. $166 \mathrm{~cm}$. 


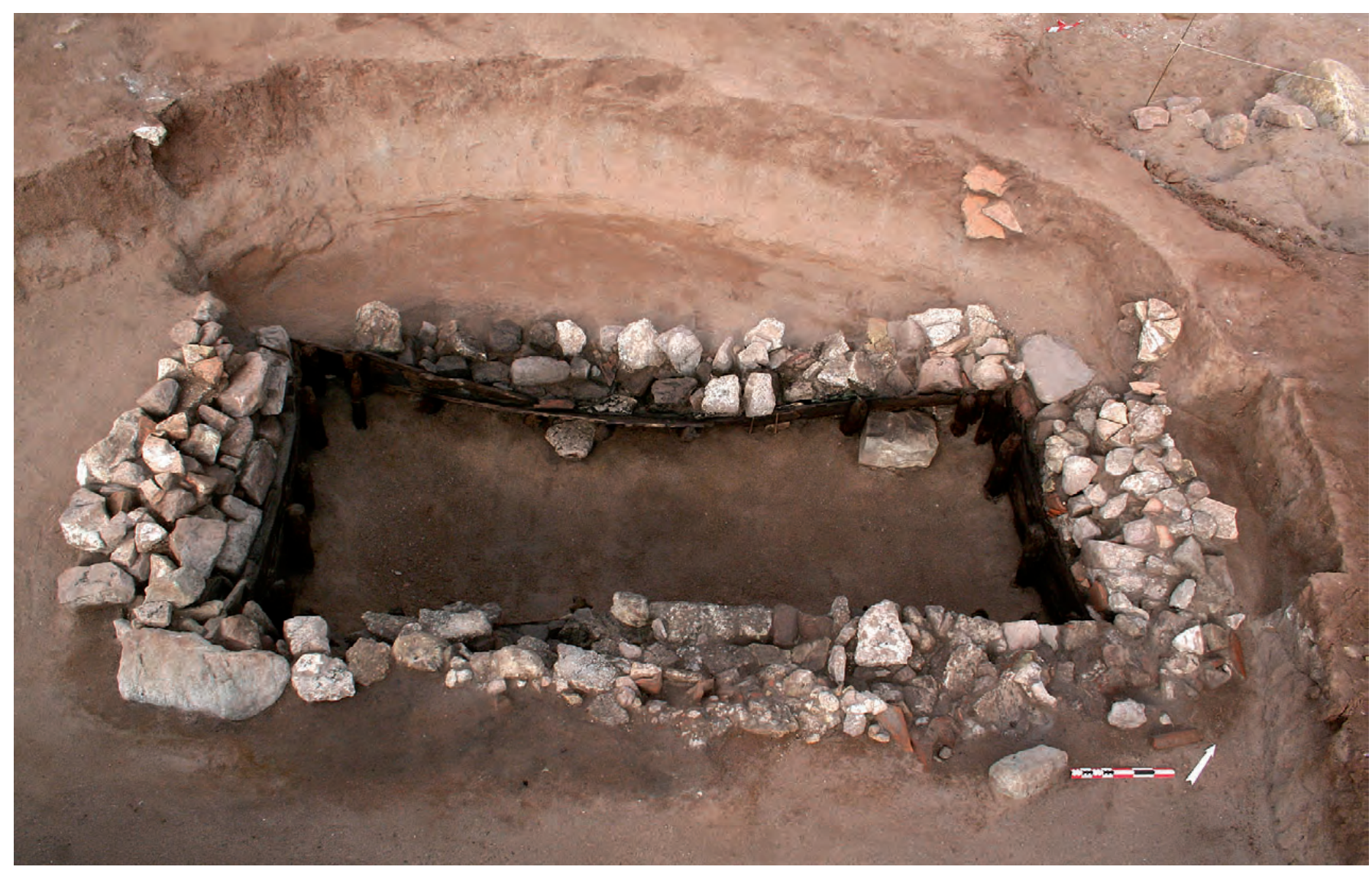

Fig. 67. Puits SB1262.

en place. La paroi nord-ouest était la seule effondrée vers l'intérieur, les trois autres étaient encore en place malgré la pression exercée par le comblement de pierres extérieur au caisson.

Les pieux au fût droit sont élagués et présentent des traces d'outils à chaque nœud (fig. 69 et 70). Ils portaient encore leur écorce, très bien conservée pour la plupart mais décomposée pour d'autres. Leur sommet est cassé, sans doute à la suite de l'effondrement de la structure, ou présente un cône d'érosion probablement survenu depuis la phase d'abandon du puits. Certains pieux sont cassés au niveau de la base du comblement ; ils peuvent être associés aux deux parties sommitales des pieux effondrés retrouvées au sein du comblement.

Plusieurs pieux ont pu être extraits et observés dans leur totalité. Leur longueur conservée a été mesurée ou estimée mais leur longueur originale demeure inconnue car tous étaient érodés ou cassés. Les pieux conservés jusqu'au sommet des parois du puits ont une longueur moyenne de $140 \mathrm{~cm}$ (long. max. $166 \mathrm{~cm}$ ) et un diamètre
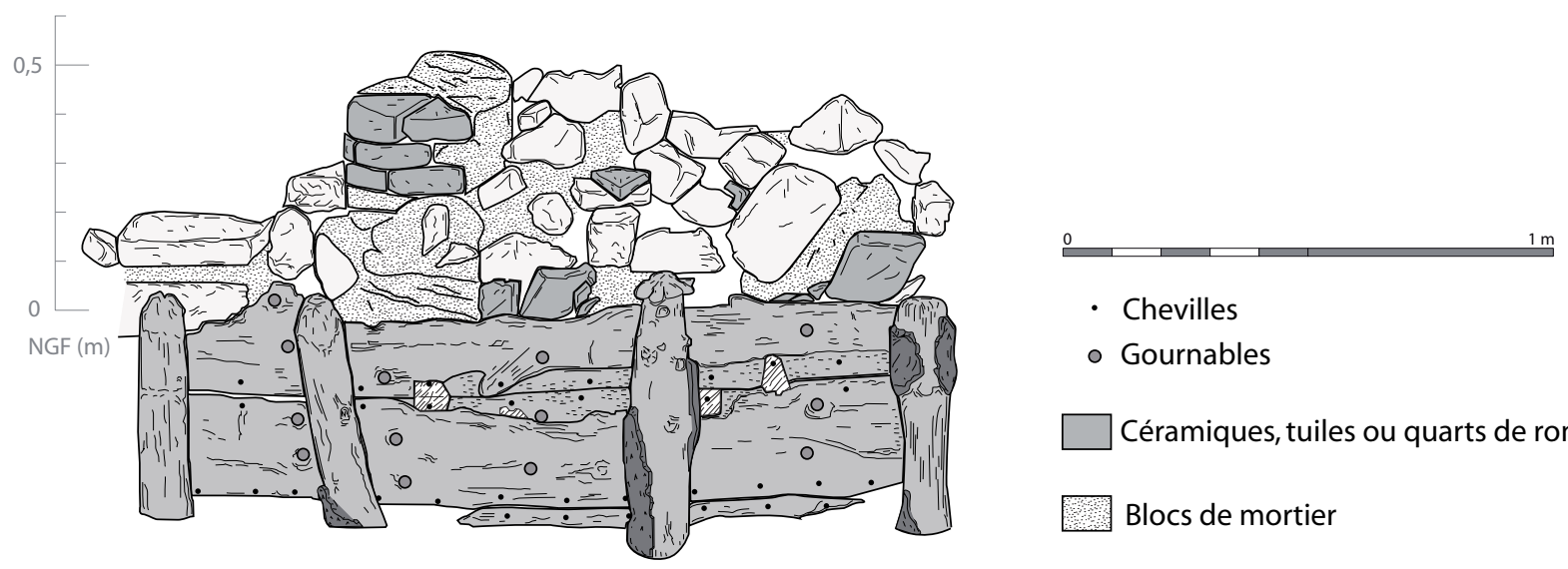

Fig. 68. Paroi nord-est du puits SB1262 (M. El Amouri). 
PREMIÈRE PARTIE : LA FOUILLE

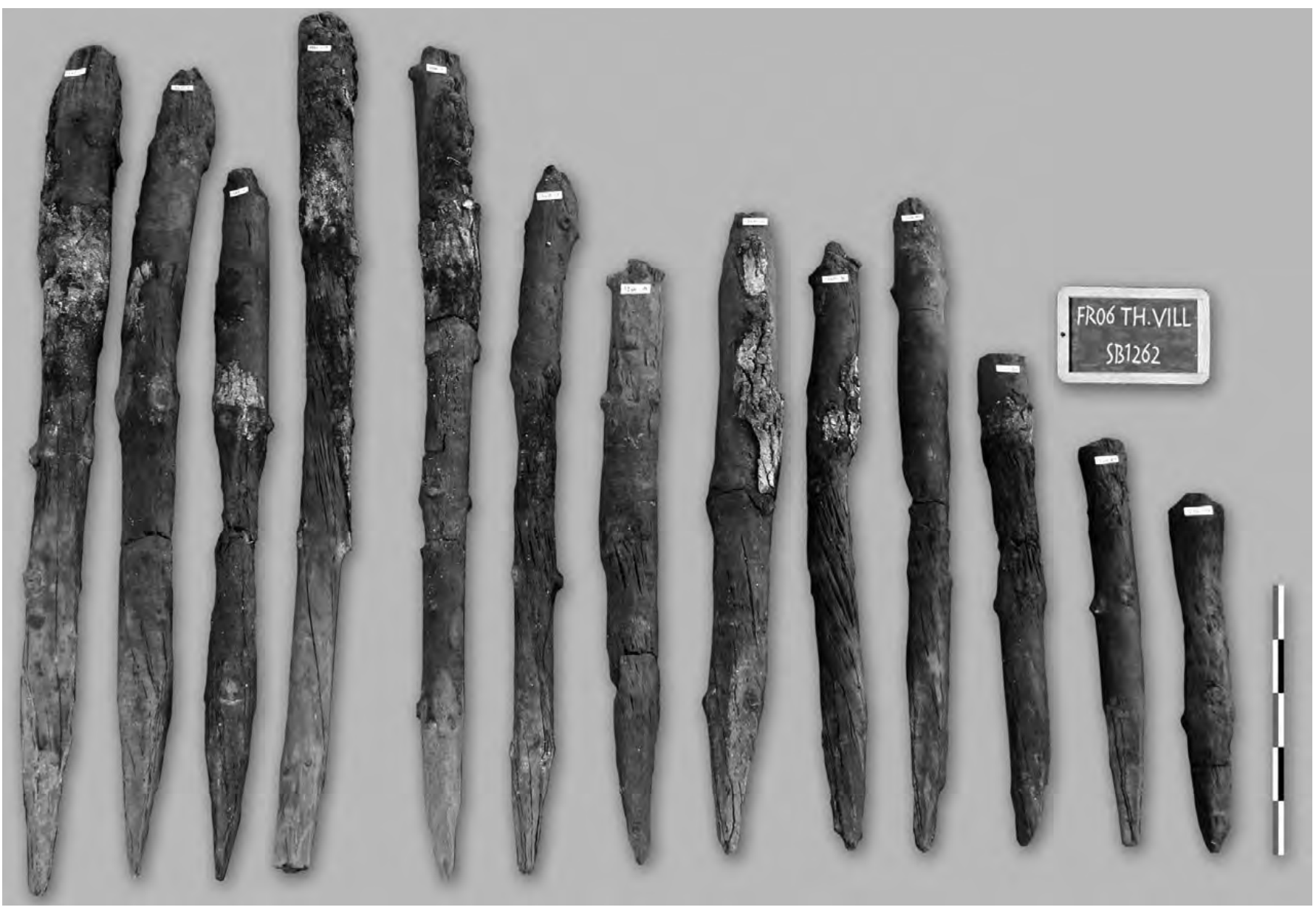

Fig. 69. Pieux maintenant le coffrage du cuvelage du puits.

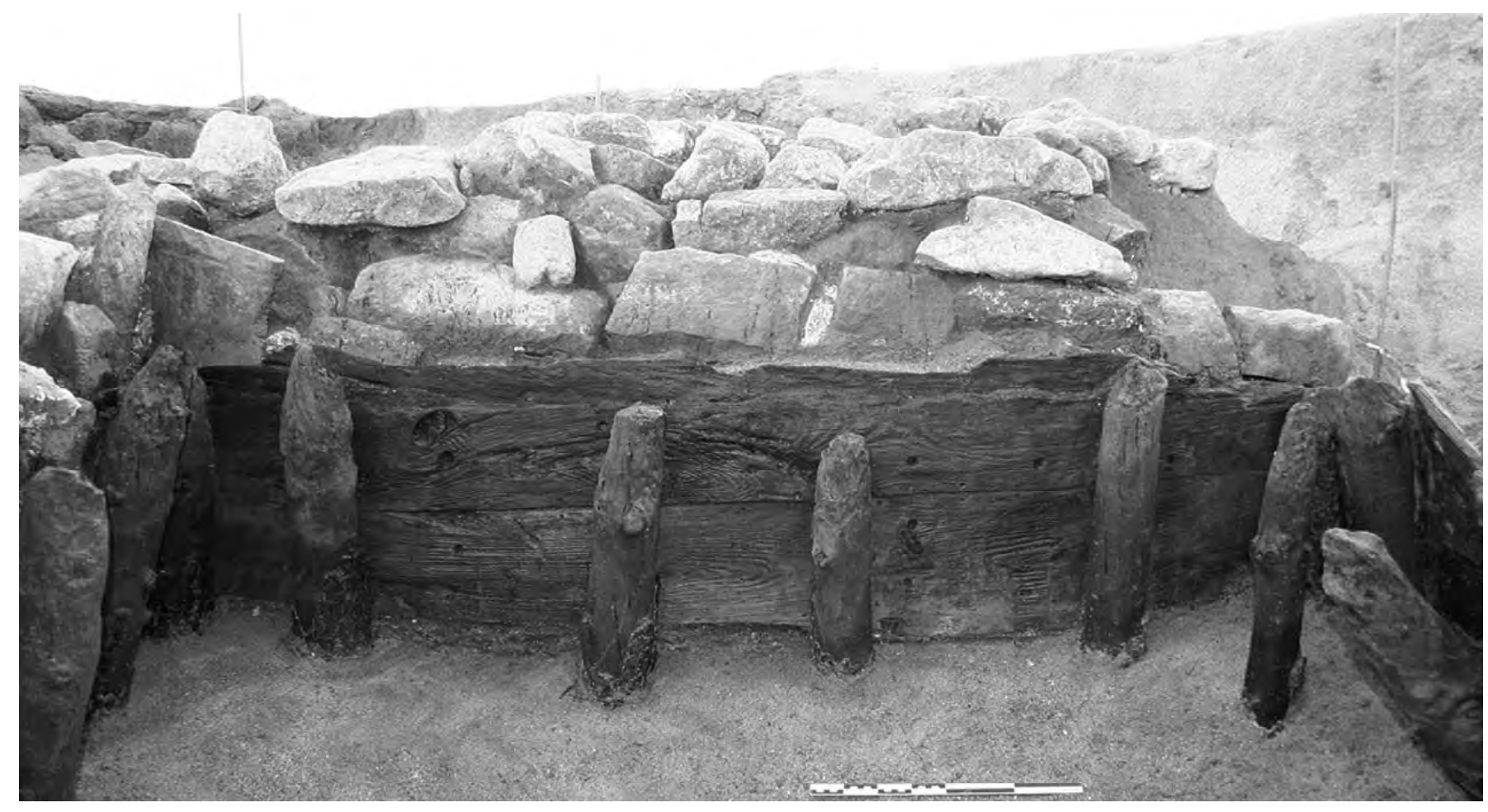

Fig. 70. Coffrage en bois de SB1262. 


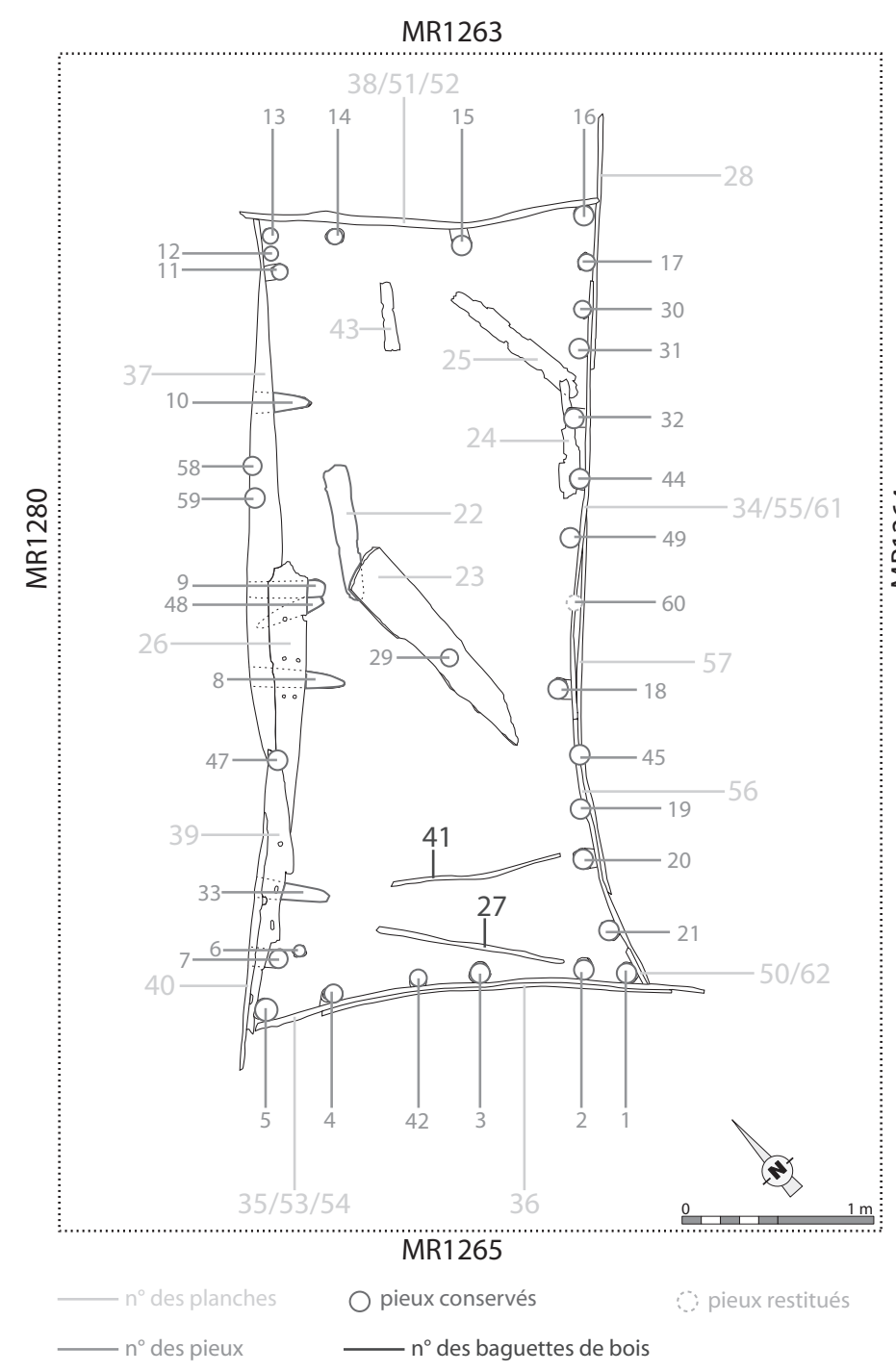

Fig. 71. Localisation des pieux et planches.

moyen de $11 \mathrm{~cm}$, écorce comprise (tab. 02). Deux pieux (6 et 12), plus courts (long. 90 et $64 \mathrm{~cm}$; diamètres 9 et $7 \mathrm{~cm}$ ) disposés contre la paroi MR1280 (fig. 71) semblent installés postérieurement aux autres, sans doute pour soutenir la paroi probablement déjà fragilisée avant l'écroulement de l'ensemble de la structure. La pointe des pieux ${ }^{5}$ est formée de quatre pans plus ou moins égaux débités sur une longueur de 20 à $37 \mathrm{~cm}$ à l'aide d'une herminette à tranchant droit.

Les pieux, encore pourvus de leur écorce, ont tous été confectionnés dans des pins d'Alep/brutia (Pinus halepensis Mill./Pinus brutia Ten. $)^{6}$ à peine âgés de 10

5 Il a été difficile d'extraire toutes les pointes qui n'ont pu être examinées que sur neuf pieux.

6 Après observation à l'oeil nu de l'ensemble des pieux, l'analyse anatomique a été réalisée sur un échantillon de quatre individus. Compte tenu du caractère juvénile des arbres et du faible nombre de cernes observés, l'analyse dendrochronologique n'a pas été mise en oeuvre sur ce matériel. à 15 ans. Un approvisionnement sur un perchis de pin local semble probable ${ }^{7}$. Une sélection délibérée des billes est attestée par l'homogénéité de diamètre, de longueur, de rectitude des fûts et d'essence. Le soin particulier apporté à la réalisation des longues pointes des pieux a permis d'atteindre la profondeur suffisante au bon soutien des murs du caisson dans le substrat de sable grossier.

\subsubsection{Stratigraphie des dépôts contemporains du fonctionnement de la structure}

Seul un fin niveau argileux gris foncé lié à l'utilisation du puits a été mis en évidence (1287) sur le fond sableux du bassin (1292). Ce niveau au fond de la structure est composé de matières organiques décomposées accumulées au centre de la structure et d'une concentration de gastéropodes. Ce niveau était toutefois très perturbé par la présence de gros éléments liés à l'affaissement et à l'effondrement des parois (1291). L'analyse pollinique de ce niveau de fonctionnement (\#341) met en évidence $90 \%$ de grains de pollen d'herbacées. On observe d'importantes valeurs de Poacées, de Cypéracées, d'Ombéliferes (Apiaceae) et de Rumex sp. Un cortège de plantes que l'on retrouve facilement sur les sols acides, sableux, secs à humides.

\subsubsection{Hypothèse de fonctionnement}

À l'évidence, la forme du puits trouve sa justification dans son mode de puisage particulier. Vitruve $(X, 4)$ présente différentes machines destinées à puiser de l'eau en l'élevant, notamment pour l'irrigation des jardins.

À partir de ces données textuelles et de la présence dans le fond du puits de deux blocs taillés (fig. 72 et 73), une hypothèse peut être avancée en rapprochant notre système de celui d'une roue élévatrice. Le bloc le mieux conservé est creusé d'une mortaise, présentant une usure circulaire marquée et d'une encoche (fig. 74). Si l'on restitue le bloc à plat, l'encoche a pu servir à recevoir une des extrémités d'un essieu, la mortaise servant elle à recevoir un axe vertical permettant de faire tourner une roue à engrenage horizontal, actionnant l'engrenage vertical associé à la roue elle-même. En symétrie se trouvait un bloc simplement pourvu d'une encoche destinée à recevoir l'autre extrémité de l'essieu. Celui-ci était ensuite bloqué par une fermeture fichée par deux attaches (fig. 75). Il est ainsi possible de restituer un axe

7 Pour la distribution géographique du pin d'Alep et du pin brutia voir Quézal, Médail 2003. 


\begin{tabular}{|c|c|c|c|c|c|c|c|}
\hline Fait & US & Index & Longueur (cm) & Diamètre (cm) & Essence ligneuse & Débit & L pointe $(\mathrm{cm})$ \\
\hline \multirow{35}{*}{ SB1262 } & \multirow{4}{*}{1263} & 13 & +80 & 10,5 & Résineux & brin & - \\
\hline & & 14 & +104 & 10 & Résineux & brin & - \\
\hline & & 15 & 129 & 11,5 & Type Pin d'Alep & brin & 37 \\
\hline & & 16 & 124 & 13 & Résineux & brin & 28 \\
\hline & \multirow{12}{*}{1264} & 17 & 138 & 10,5 & Résineux & brin & - \\
\hline & & 18 & 115 & 12 & Résineux & brin & 34 \\
\hline & & 19 & +75 & 12 & Résineux & brin & - \\
\hline & & 20 & 128 & 12 & Résineux & brin & - \\
\hline & & 21 & +142 & 12 & Résineux & brin & - \\
\hline & & 30 & 117 & 11 & Résineux & brin & - \\
\hline & & 31 & +130 & 12 & Résineux & brin & - \\
\hline & & 32 & +120 & 11 & Résineux & brin & - \\
\hline & & 44 & 95 & 10 & Résineux & brin & 27 \\
\hline & & 45 & +50 & 11,5 & Type Pin d'Alep & brin & - \\
\hline & & 49 & 83 & 11,5 & Résineux & brin & 34 \\
\hline & & 60 & 50 & 12 & Résineux & brin & - \\
\hline & \multirow{6}{*}{1265} & 1 & 166 & 12,5 & Résineux & bri & - \\
\hline & & 2 & 161 & 12,5 & Résineux & brin & - \\
\hline & & 3 & +120 & 12 & Résineux & brin & - \\
\hline & & 4 & 139 & 11 & Résineux & brin & 26 \\
\hline & & 5 & +130 & 11 & Résineux & brin & - \\
\hline & & 42 & 127 & 11 & Type Pin d'Alep & brin & 31 \\
\hline & \multirow{2}{*}{1266} & 22 & +82 & 11 & Résineux & brin & - \\
\hline & & 48 & +39 & 9 & Résineux & brin & - \\
\hline & \multirow{11}{*}{1280} & 6 & 90 & 9 & Résineux & brin & - \\
\hline & & 7 & 166 & 12 & Résineux & brin & 26 \\
\hline & & 8 & - & 10,5 & Résineux & brin & - \\
\hline & & 9 & +65 & 12 & Résineux & brin & - \\
\hline & & 10 & +90 & 11,5 & Type Pin d'Alep & brin & - \\
\hline & & 11 & +65 & 10,5 & Résineux & brin & - \\
\hline & & 12 & 64 & 7 & Résineux & brin & - \\
\hline & & 33 & 90 & 10,5 & Résineux & brin & - \\
\hline & & 47 & +40 & 10,5 & Résineux & brin & - \\
\hline & & 58 & 64 & 11 & Résineux & brin & 20 \\
\hline & & 59 & - & 12 & Résineux & brin & - \\
\hline
\end{tabular}




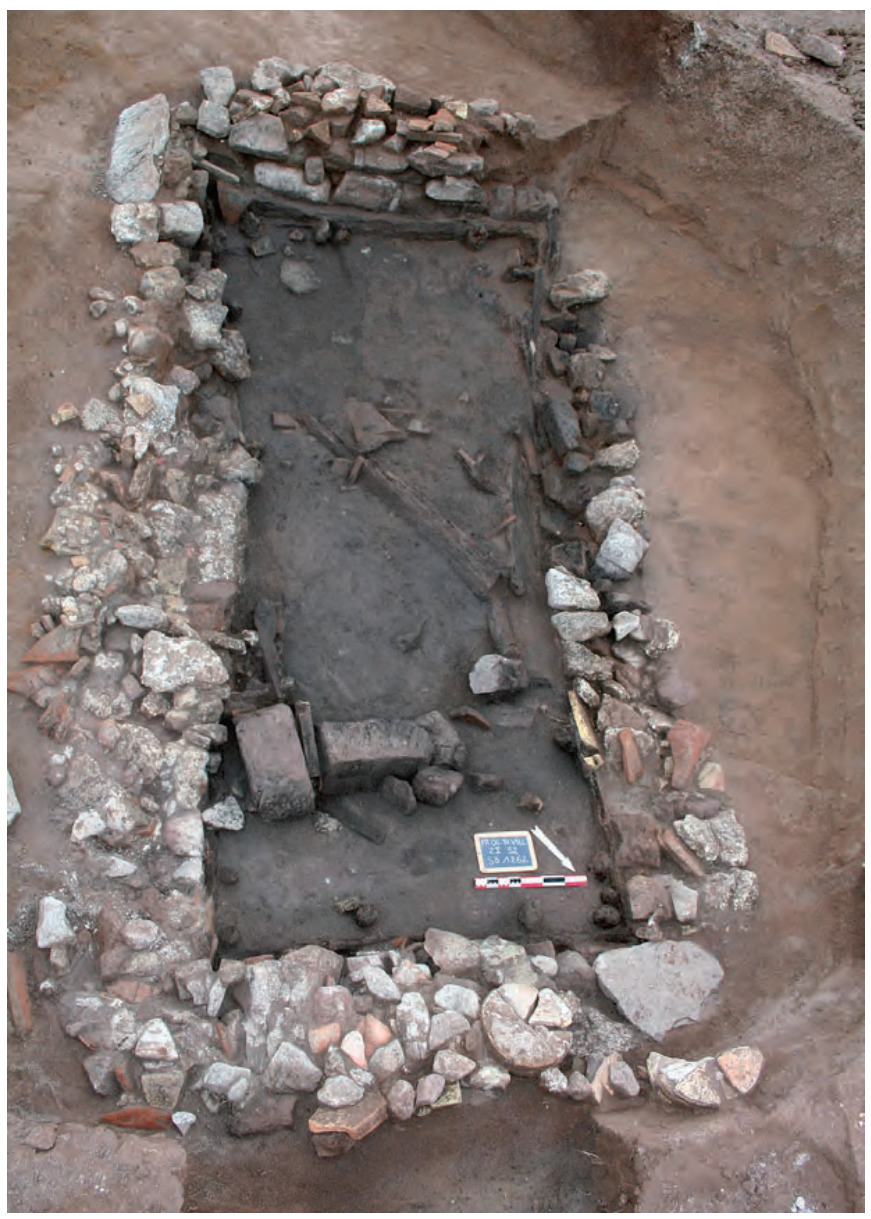

Fig. 72. Premiers comblerments du puits, avec une partie du système de puisage effondré.

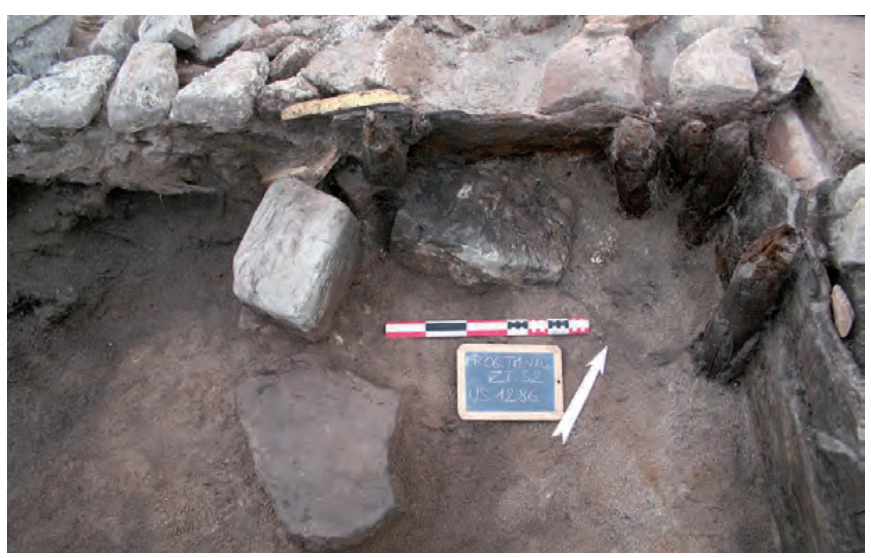

Fig. 73. Blocs latéraux nord du système de puisage effondrés.

de $1,60 \mathrm{~m}$ et une roue d'un diamètre inférieur à $3,80 \mathrm{~m}$ que l'on peut déduire de la profondeur et des dimensions du puits. Ce système permettait d'élever l'eau de près d'un mètre au dessus du sol du jardin.

Actuellement l'hypothèse retenue est donc une roue de type noria ou saqiya de faible diamètre et à traction humaine ou animale (Al-Hassan, Hill 1986). La faible profondeur de l'ensemble et la configuration générale ne permettent pas de restituer une roue à chaîne à godets, mais plutôt une roue en bois à augets intégrés (fig. 76 et 77), à l'image de la restitution faite de la noria de « l'Oratoire A » de Salone en Croatie (Morvillez et al. $2005)^{8}$. La forme rectangulaire du puits de Villeneuve, plaide également en faveur d'une roue à auges, les puits à chaînes à godets étant généralement carrés ou circulaires (Bouet 2005, 25). De ce fait, on se rapproche de la seconde description de Vitruve $(\mathrm{X}, 4,3)$ où l'on trouve une roue montée autour d'un essieu, à laquelle on fixe des caisses étanchéifiées avec de la poix et de la cire, «...ainsi, quand des hommes feront tourner la roue avec leurs pieds, les gets pleins, portés jusqu'au haut puis revenant vers le bas, déverseront d'euxmêmes, directement, dans le réservoir toute l'eau qu'ils auront élevée. » Les dimensions du puits et de la roue s'approchent de celles constatées sur le site de la villa du Pré Guillemin à Chassey-Lès-Montbozon en HauteSaône (Bouet 2005, 25). Là, A. Bouet restitue une roue à auges de $4 \mathrm{~m}$ de diamètre dans un puits rectangulaire de $4,10 \mathrm{~m}$ x 0,65 m. Le système de roue à augets permet de surélever l'eau au mieux à trois quarts du diamètre de la roue (Callebat 2003, 141), soit de $2,85 \mathrm{~m}$ pour une roue de 3,80 m à Villeneuve. De fait l'eau était élevée de près d'un mètre au dessus du sol du jardin. Dans d'autres proportions, un parallèle nous est fourni par une mosaïque d'Apamée du $\mathrm{V}^{\mathrm{e}}$ siècle montrant l'irrigation d'un jardin à l'aide d'une noria à aubes actionnée par courant d'eau (Dulière 1974). En terme de proportions, l'exemple de Villeneuve évoque l'hypothèse retenue lors des la fouille de la ZAC des Halles à Nîmes, en l'occurrence une roue de $2 \mathrm{~m}$ permettant de monter l'eau de $1 \mathrm{~m}$ (Monteil 1993, 53-62).

Enfin, la proximité de l'axe vertical implique nécessairement que l'axe de rotation pour faire tourner la roue devait englober le puits, donc avoir un diamètre d'environ $5 \mathrm{~m}$.

\subsubsection{Caractéristiques de la roue: quelques indices...}

Seuls une planche (1266-23) et un piquet (1266-29) mis au jour dans le comblement du puits, différents des pièces de bateau qui forment le cuvelage, peuvent être hypothétiquement attribués à la roue ${ }^{9}$.

D'une longueur minimale de $1,42 \mathrm{~m}$ pour une largeur de $28,5 \mathrm{~cm}$ et une épaisseur de $3,5 \mathrm{~cm}$, la planche

8 L'emploi de roue à chaîne à godets se retrouve surtout lorsque la nappe est profonde : $25 \mathrm{~m}$ à Pompéi, $16 \mathrm{~m}$ à Barzan.

9 Comme les éléments de la machinerie en bois mis au jour dans un puits aux thermes de Barzan (Bouet 2003a, 117) ou les morceaux de la roue à aubes du bassin d'eau douce de la bourse à Marseille (Varoqueaux, Gassend 2001). 
PREMIÈRE PARTIE : LA FOUILLE

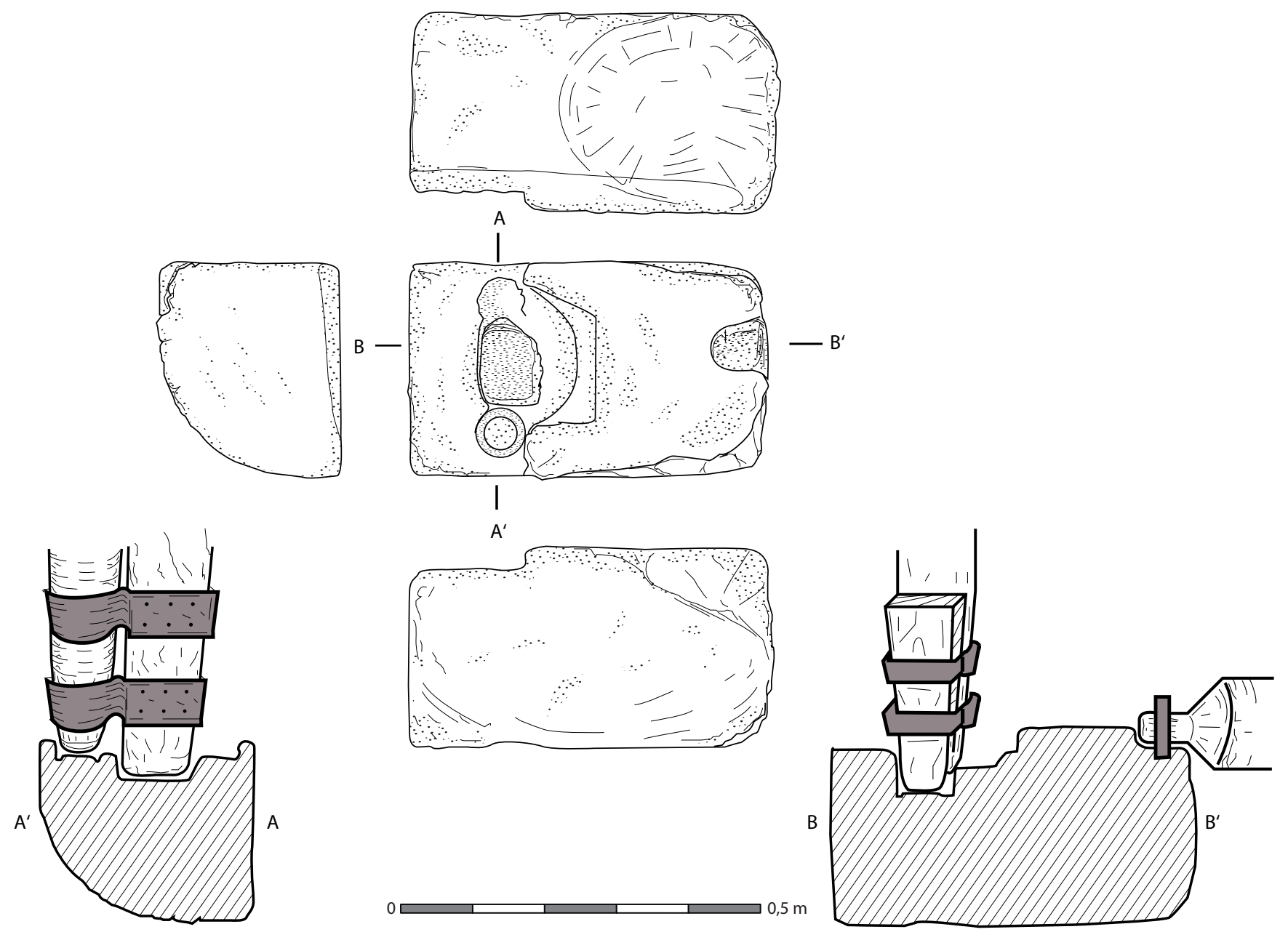

Fig. 74. Bloc sud avec système d'ancrage (M. El Amouri).

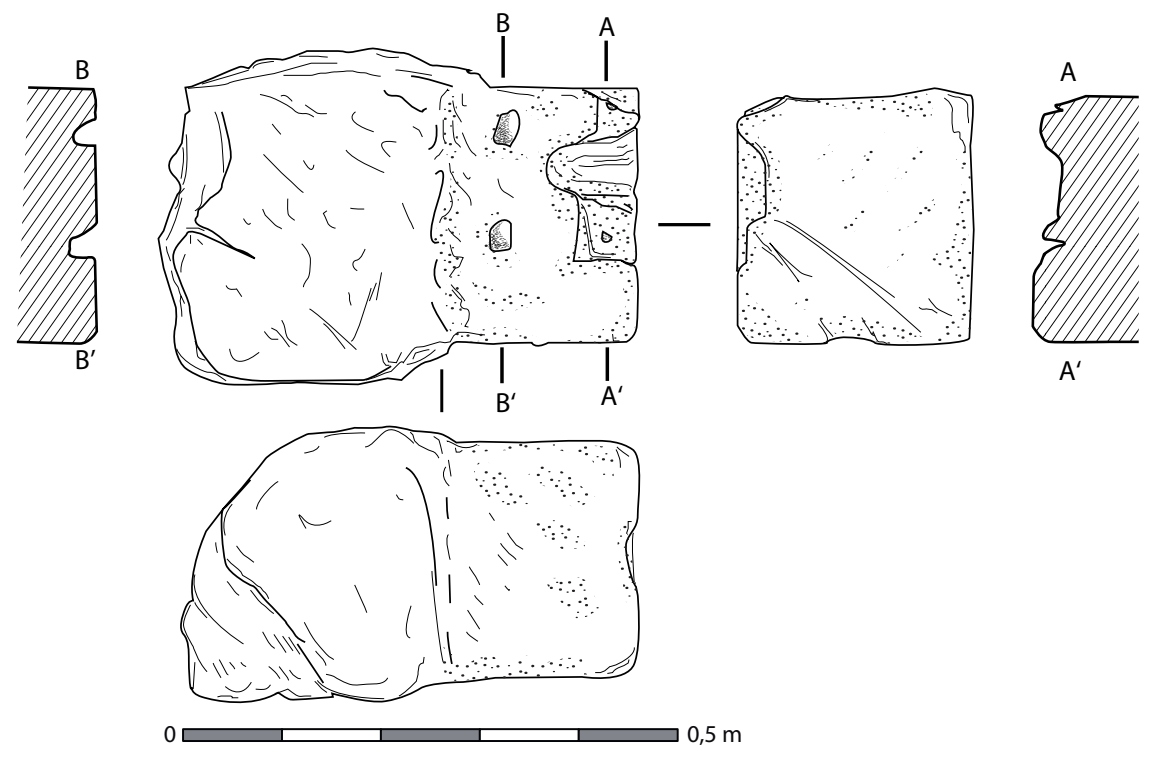

Fig. 75. Bloc nord (M. El Amouri). 


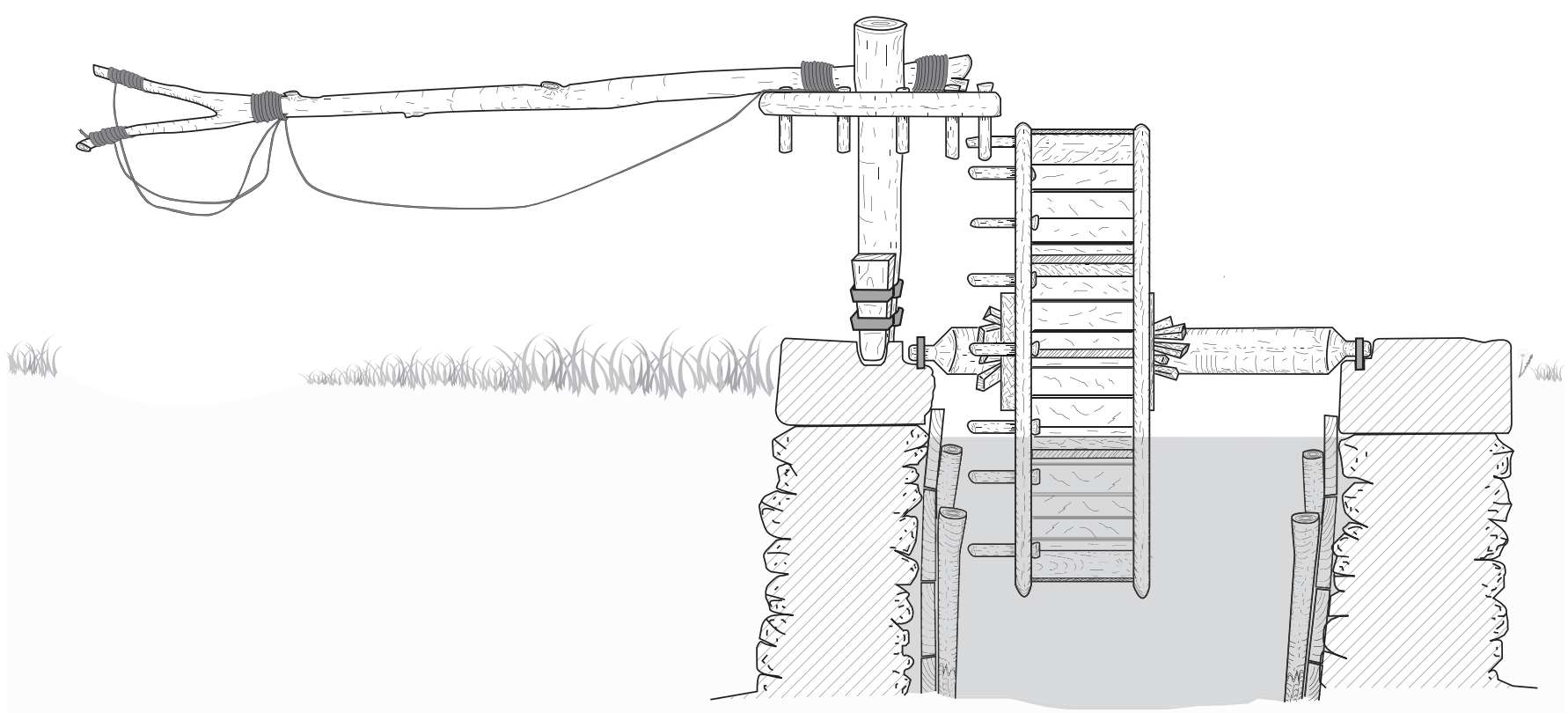

Fig. 76. Reconstitution hypothétique du puits vue en coupe (M. El-Amouri).

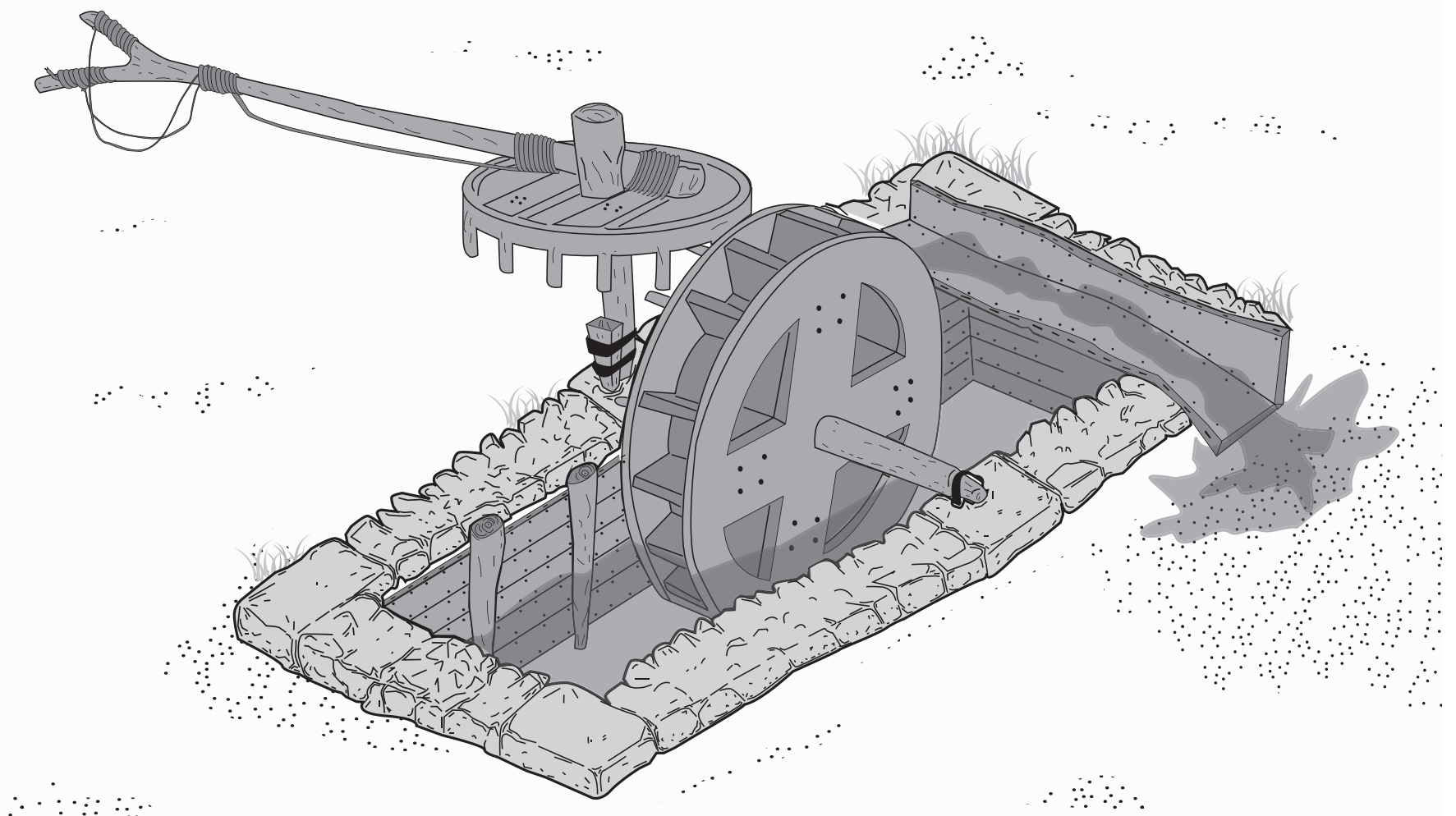

Fig. 77. Reconstitution hypothétique de la noria (M. El-Amouri). 
1266-23, à bords droits, ne présente aucune trace d'assemblage. Une de ses extrémités était légèrement biseautée dans sa largeur, l'autre était cassée. Percée de deux clous situés dans l'axe longitudinal central, espacés de $86 \mathrm{~cm}$ l'un de l'autre, elle a été débitée sur fausse dosse dans le tronc d'un sapin (Abies sp.).

L'analyse des épaisseurs de cernes a livré une chronologie individuelle longue de 112 ans qui ne peut être en relation ni avec les autres chronologies issues du site ni avec d'autres chronologies antiques de sapin (Guibal, Pomey 2003 et 2004), sans doute en raison de l'exemplaire unique de l'échantillon et de sa singularité taxonomique.

Il pourrait s'agir de l'un des rayons renforçant la structure de la roue, la partie biseautée correspondant alors à la partie fichée dans l'axe. Pour un diamètre de roue maximal de 3,80 m, l'hypothèse est crédible. La position des deux pointes de clous, disposées dans l'axe pourrait indiquer la position de renforts latéraux entre rayons.

Le piquet 1266-29 a été débité dans une tige d'orme non refendu (Ulmus sp.). D'un diamètre de $5 \mathrm{~cm}$, il était conservé sur une hauteur de $50 \mathrm{~cm}$. Encore en place, il était enfoncé dans le sol au centre du comblement, grâce à son extrémité taillée en pointe à quatre pans. Sa proximité avec la planche 1266-23 qu'il soutenait encore lors de leur découverte peut présager d'une participation possible à l'aménagement de la roue.

\subsubsection{Interprétation}

\section{(P. E.)}

La fonction de ce puits parait donc être directement liée à l' approvisionnement en eau du secteur cultivé, sans doute un jardin, que constitue la zone 1 à cette époque. L'absence de trace d'un dispositif de distribution de l'eau n'est pas contradictoire avec l'image de nombreux exemples contemporains, celui-ci pouvait être en bois et n'aurait donc pas été conservé. Il est plus difficile en revanche de mettre cet aménagement en rapport direct avec l'alimentation en eau des thermes de Villeneuve, bien que cette question reste à élucider (Gébara, Michel 2002, 282-283). L'utilisation d'une noria n'est en aucun cas contradictoire avec l'approvisionnement de thermes, ce type d'alimentation n'a rien d'exceptionnel, rappelons simplement qu'à Pompéi, avant la construction de l'aqueduc, les thermes étaient tous alimentés par des puits équipés de machinerie (Bouet 2005, 12). À Villa Romana, le format et l'aménagement du puits laissent perplexe, d'autant que le puits se situe à une cote altimétrique inférieure à celle des thermes. Quoiqu'il en soit, ce puits permet de confirmer, comme le suggèrent Ch. Gébara et J.-M. Michel, que l'alimentation des thermes directement à partir de la nappe peut être envisagée (Gébara, Michel 2002, 283). En résumé, le puits nous paraît en réalité directement lié à l'irrigation des plantations mises en évidence, donc à l'entretien du jardin.

\subsection{La zone 2}

(P. E.)

Lors de cette phase un nouveau grand mur d'orientation sud-ouest/ nord-est (MR2002) est édifié à $12 \mathrm{~m}$ en avant du premier mur MR2004. Ce mur n'est conservé que dans sa partie nord-est sur une longueur de $17,50 \mathrm{~m}$ mais la trace de sa récupération est bien visible sur toute la longueur du chantier (fig. 78 et 079), soit une distance de $66 \mathrm{~m}$. Ainsi on restitue un mur de plus de 73,50 $\mathrm{m}$ de longueur minimum. Dans sa partie conservée, le mur est large de 1,35 m. Il est constitué d'un nu appareillé de moellons de grès équarris, uniquement sur sa face sud ; au nord, au contact de la bande sableuse zone 2 (US2010), il n'apparaît qu'en fondation. Il s'agit donc, comme pour le mur MR2004, d'une structure jouant un rôle de mur terrasse. Pour l'essentiel, le cœur du mur, ou remplissage, est constitué de pierrailles, dont certaines atteignent $20 \mathrm{~cm}$, mêlées dans une matrice de mortier très compacte et bien dosée (fig. 80). Il s'agit d'un soubassement ou socle de 0,45 m de haut, dont la surface a été lissée, pour présenter un « lit d'attente » horizontal afin de recevoir le corps du mur. De celui-ci il ne reste rien. Faut-il imaginer une élévation à double parement et blocage interne plus étroite ? Ou encore une colonnade ? Le soin particulier apporté à la surface d'attente du soubassement laisse entrevoir encore d'autres hypothèses, comme celle d'une élévation en terre massive compactée par exemple.

Le dégagement au nord a permis la mise au jour de creusements

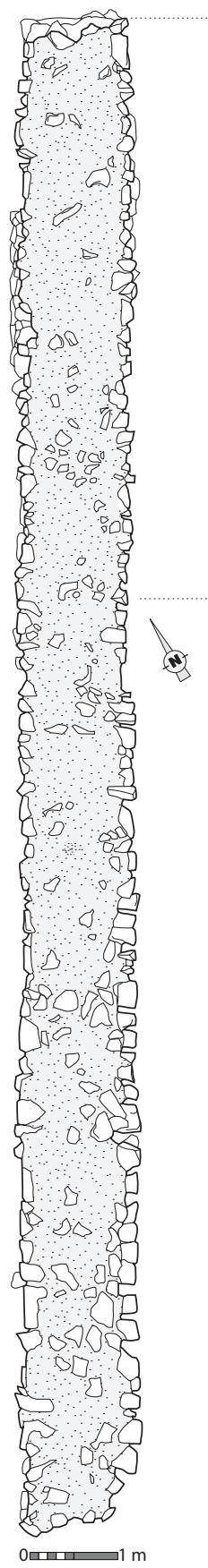

Fig. 78. Relevé du mur MR2002. 

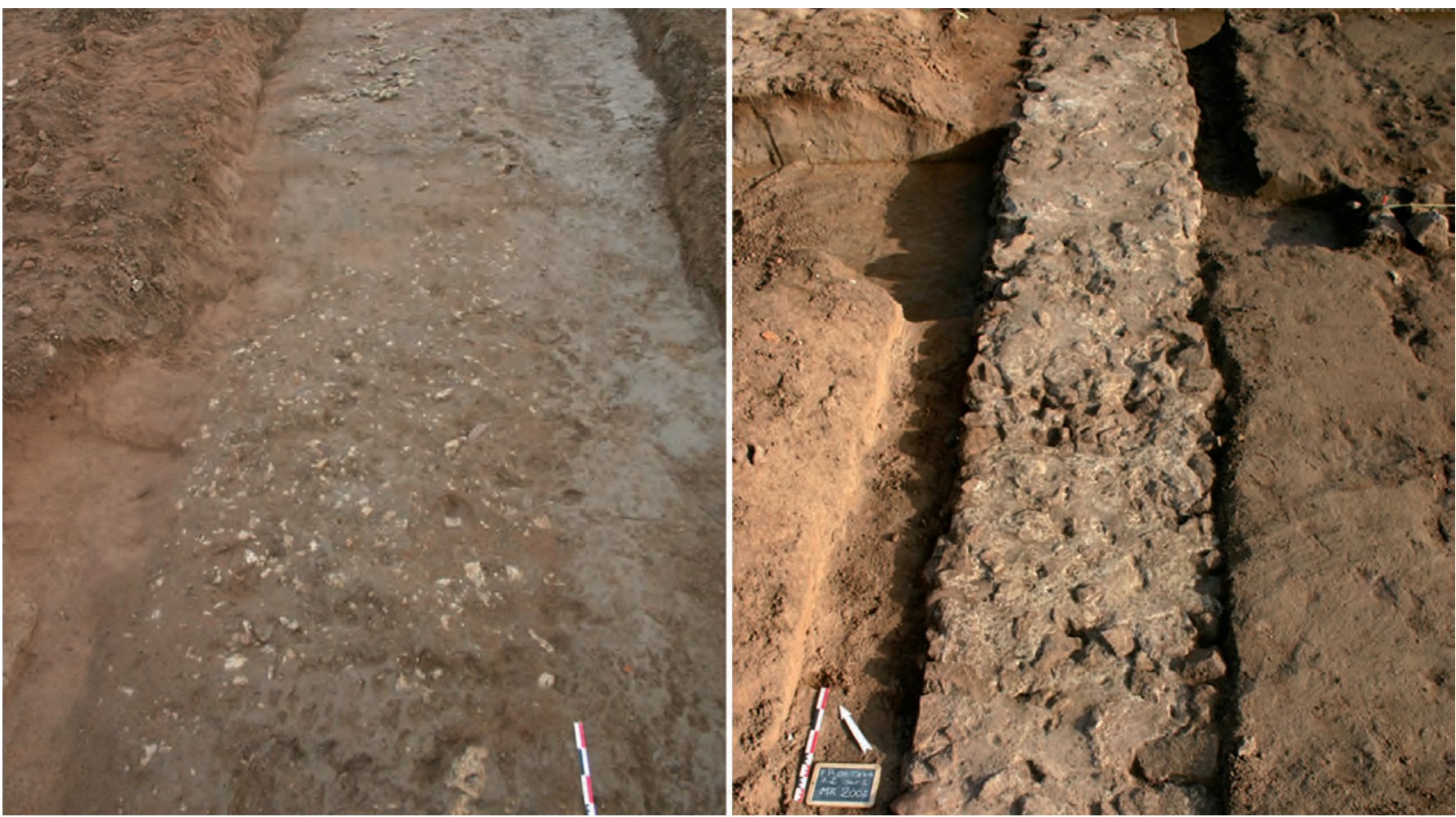

Fig. 79. Partie épierrée et partie conservée du mur MR2002.

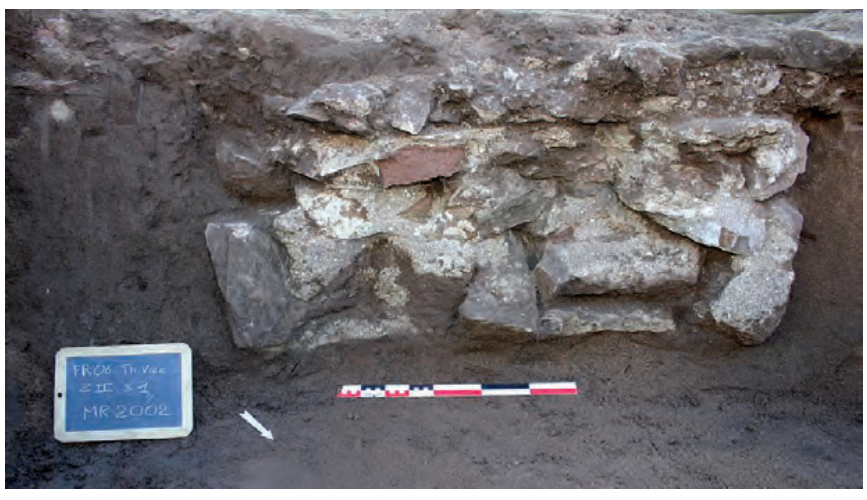

Fig. 80. Vue en coupe du mur MR2002.

horizontaux localisés sous la fondation (US2041) (fig. 81 et 82). Ceux-ci sont espacés irrégulièrement entre $0,40 \mathrm{~m}$ et $1,40 \mathrm{~m}$ et creusés sur la largeur du mur. Contrairement au mur MR2004, ce mur ne possède pas de fondations rétrécies, le soubassement est directement installé à plat sur le sable. Les empreintes circulaires pourraient correspondre au négatif laissé par des poutres disposées perpendiculairement au mur, permettant d'éviter son enfouissement en assurant une répartition des charges plus homogène au fur et à mesure de sa construction. Leur rôle s'apparente à celui des sablières, bien qu'ici elles ne soient pas disposées dans l'axe du mur il s'agirait donc d'une fondation sur rondins horizontaux d'une vingtaine de centimètres de diamètre.

Le socle MR2002 est une structure compacte complète, que l'on doit concevoir comme une sorte d'énorme monolithe en mortier dont la charge, une fois sèche, se répartit sur l'ensemble de sa base. La mise en place des rondins perpendiculaires devait permettre essentiellement d'éviter l'enfouissement de certaines sections avant la prise complète du mortier de chaux. De même, le mur ayant été bâti sur une grande longueur - plus de 73,50 m- la volonté de conserver une surface horizontale a sans doute nécessité une préparation du terrain en amont, notamment en disposant des éléments de bois horizontaux, perpendiculairement au tracé du mur. Toutefois, force est de constater nous n'avons

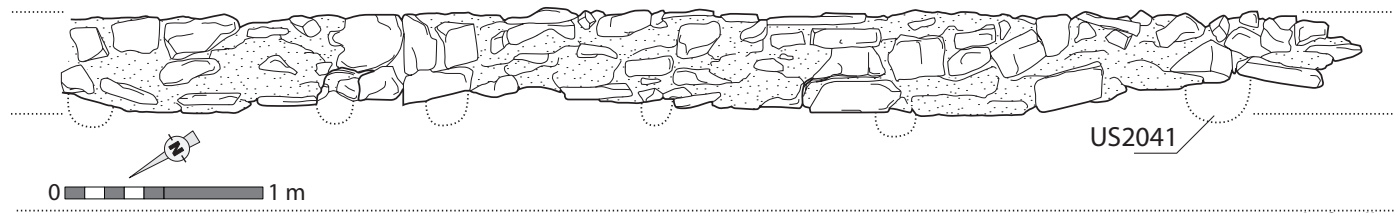

Fig. 81. Relevé du parement nord en élévation du mur MR2002. 


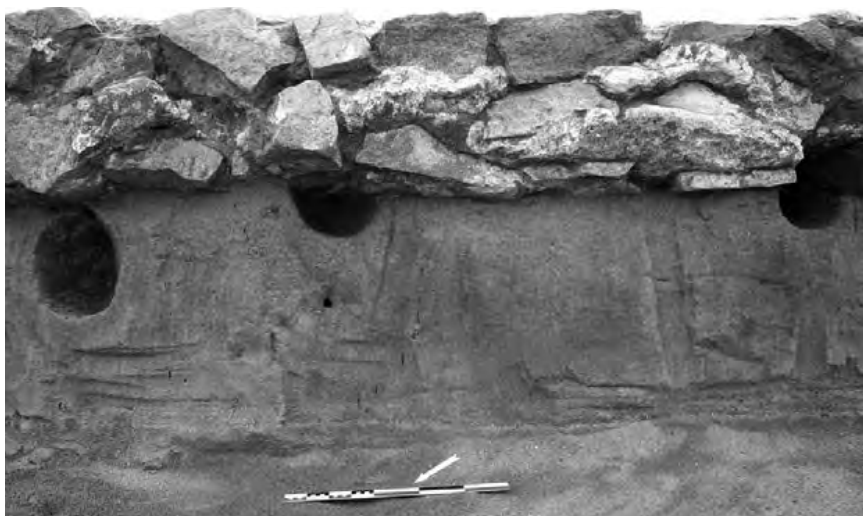

Fig. 82. Vue des persements sous la fondation.

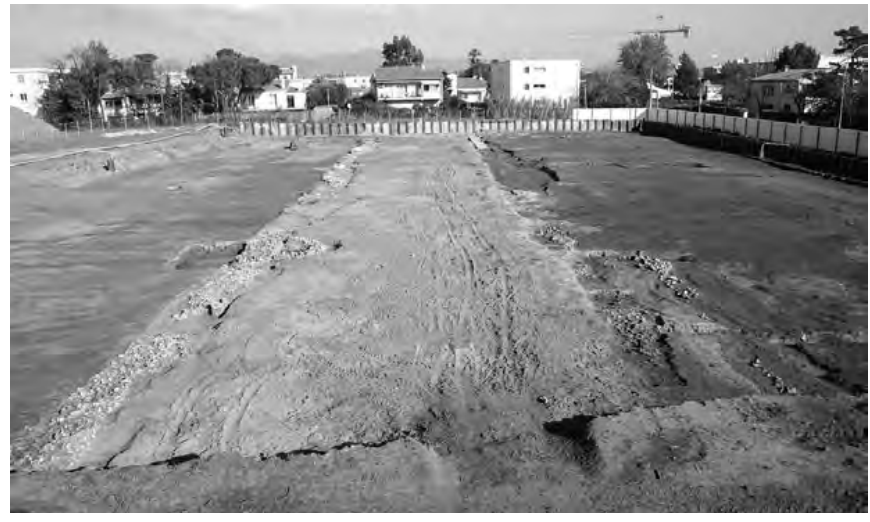

Fig. 83. Bande de sable constituant la zone 2.

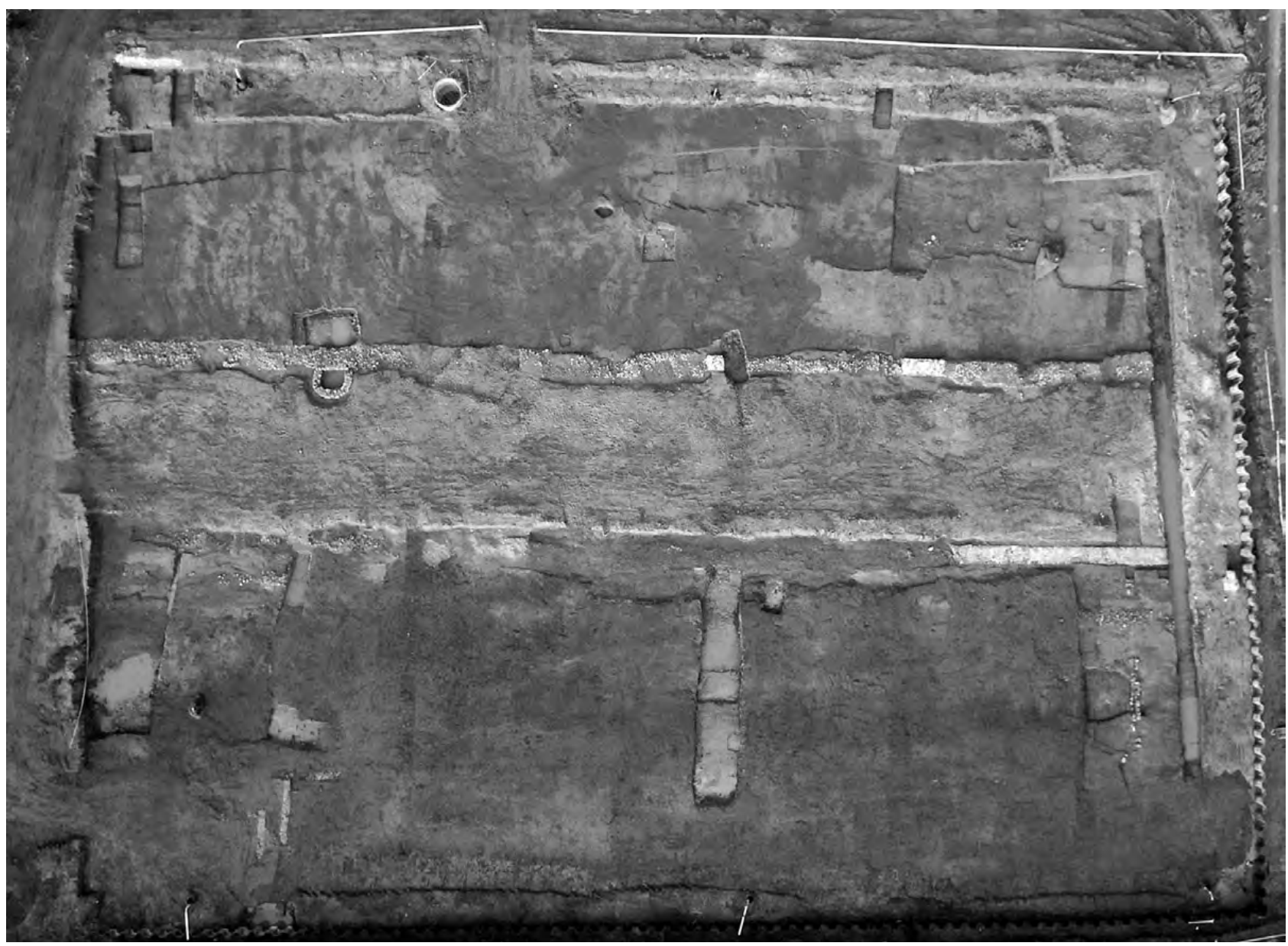

Fig. 84. Vue verticale de basse altitude où apparaît nettement, au centre, la bande de sable constituant la zone 2.

encore trouvé aucune comparaison se rapprochant de ce mode de construction pour l'époque antique dans le monde romain.

L'édification de ce mur MR2002 marque donc la délimitation d'une nouvelle zone (zone 2), qui se matérialise sur le terrain sous la forme d'une bande de sable de $12 \mathrm{~m}$ de large (fig. 83 et 84). À l'intérieur des deux murs MR2004 et 2002, le sable apparaît à une cote altimétrique haute d'environ 1,30/1,40 m NGF, et les deux murs marquent la limite avec des terrains plus limoneux. L'analyse de la grande coupe stratigraphique permet de démontrer l'antériorité de ces niveaux sableux (coupe 2b). Il s'agit de sables lités et triés (US2010) tout à fait similaires au niveau 1068 de la zone 1 et au niveau sableux US3138 de la zone 3. C'est donc l'excavation des corps sableux situés au nord et au sud de la zone 2 


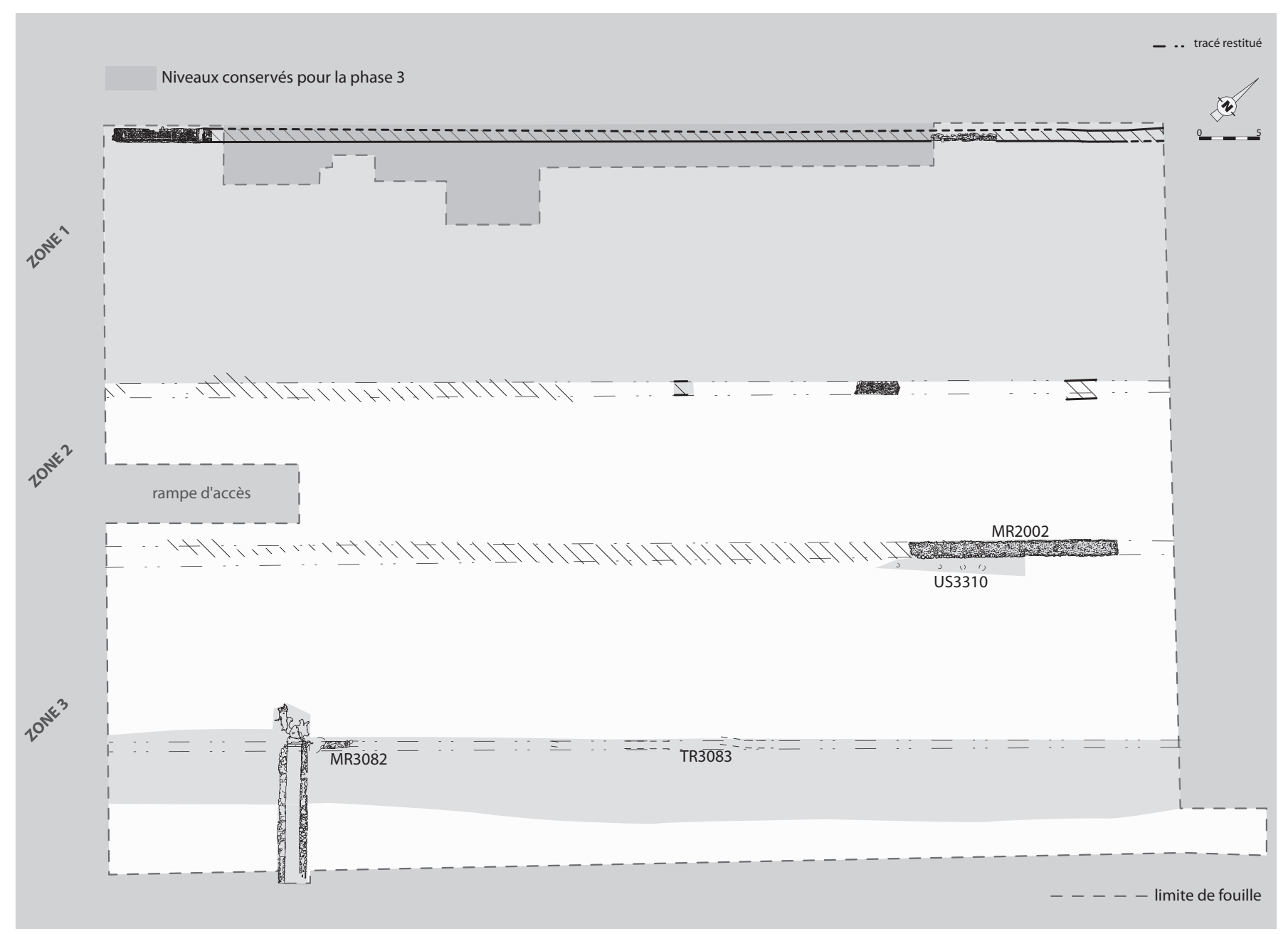

Fig. 85. Restitution des niveaux de la phase 3 conservés sur l'ensemble du chantier.

qui a provoqué l'exhaussement de la bande de sable, seul témoin du haut de plage consécutif à la phase 1 . Ainsi les deux murs MR2004 et 2002 ont contenu durant plusieurs siècles une bande de sable naturel.

\subsection{La zone 3}

(P. E.)

C'est au sud-est du mur MR2002 que se place la zone 3, couvrant une surface de $2125 \mathrm{~m}^{2}$. Les niveaux contemporains de la phase 3 ne sont présents que sur une portion étroite contre le mur MR2002 et dans le tiers sud de la zone. En effet, le terrain sera profondément remanié et excavé durant les phases suivantes (en particulier phases 4A et 5B), détruisant largement les niveaux antérieurs. Toutefois nous avons pu restituer la stratigraphie de l'ensemble de la zone dans ses grandes lignes (fig. 85).

Le seul élément structurant de l'ensemble est un long mur (MR3082, TR3294/3083) toujours d'orientation sud-ouest/nord-est, très largement épierré.
Le secteur A concerne l'espace situé au nord de ce mur et le secteur B celui du sud.

\subsubsection{Le secteur A}

Il s'agit du secteur le plus bouleversé par les réaménagements postérieurs. À son extrémité nordest, directement au contact du mur MR2002, un niveau de circulation est conservé (US3310) à une altimétrie de 0,65 m NGF. De texture sablo-limoneuse, de teinte brun rouge et d'une dizaine de centimètres d'épaisseur (US3311), il s'appuie contre le parement sud du mur MR2002. Il recouvre le niveau de sable naturel lité (US3138) correspondant au sable de plage (phases 1 et 2). La texture est assez proche de la surface contemporaine de la zone 1 (US1010), située 0,40/0,45 m plus haut. Dans ce niveau est creusé un alignement de quatre trous de poteaux orienté sud-ouest/nord-est (PO3280, 3281, 3282 et 3283) dont on peut supposer, sans trop de doutes, qu'il composait un ensemble bien plus long (fig. 86). Les creusements sont de forme elliptique, d'un diamètre 


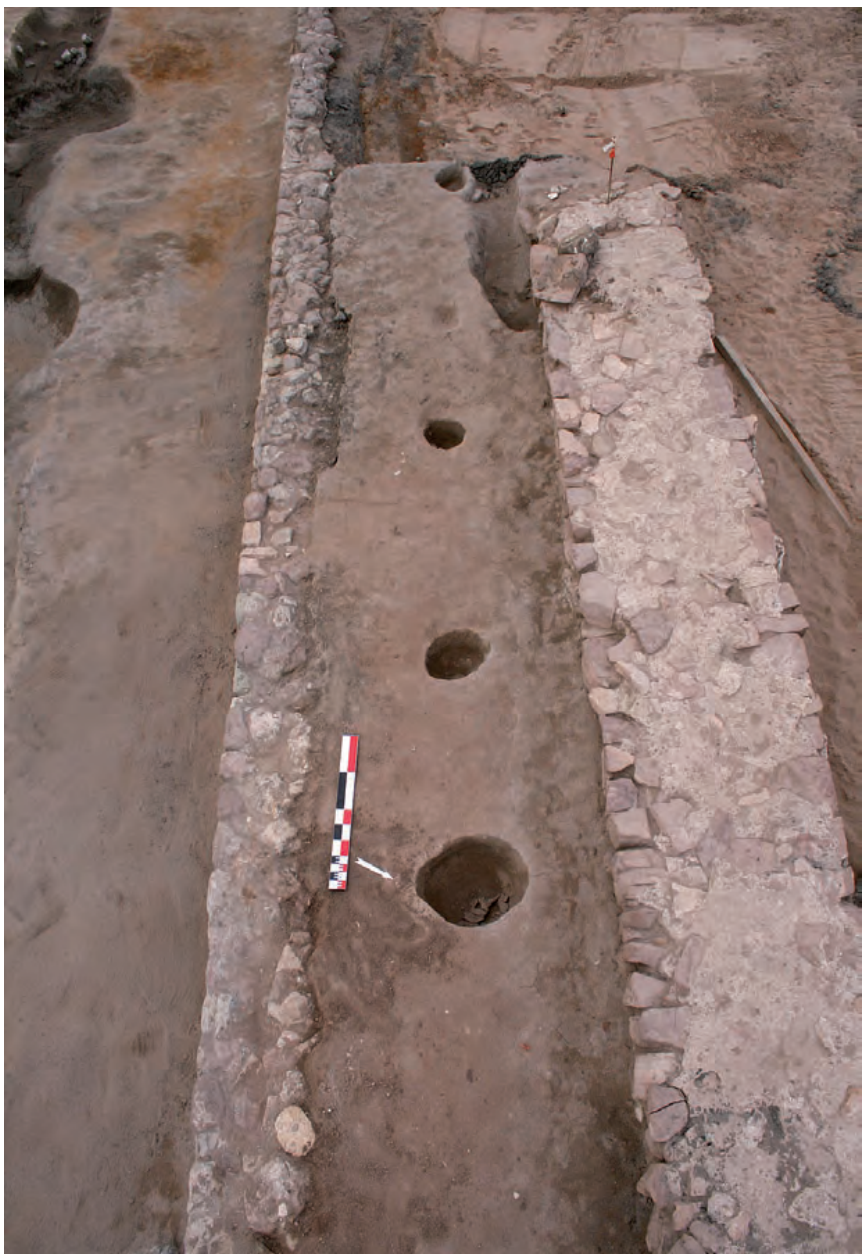

Fig. 86. Alignement de trous de poteaux.

moyen variant de 0,30 à $0,50 \mathrm{~m}$. Les profondeurs sont plus constantes, environ $0,25 \mathrm{~m}$. Les comblements sont de nature sablo-argileuse indurée gris clair mélangés à de la chaux. Quelques petits cailloux complètent le remplissage. Cet ensemble correspond probablement aux traces d'un alignement de poteaux parallèles au mur MR2002 dont la destination finale nous échappe.

$\mathrm{Au}$ sud du secteur, le dérasement du mur MR3082 sur la grande majorité de son parcours, a accentué l'érosion des sols situés au nord qui n'étaient pas atteints par les terrassements postérieurs. C'est uniquement au contact de la partie conservée du mur MR3082 et à l'amorce du corridor CN3010 que des lambeaux de sols attribuables à cette phase ont été observés. Il s'agit d'un mur d'orientation sud-ouest/nord-est repéré sur toute la longueur du chantier soit sur $87,5 \mathrm{~m}$. Presque entièrement épierré (TR3294/3083), il ne subsiste que quelques traces fugaces de sa tranchée d'épierrement (fig. 87). La partie conservée sur $2,50 \mathrm{~m}$ de long seulement ${ }^{10}$ correspond à un niveau de pierrailles mélangées à un

10 La partie conservée équivaut à moins de $3 \%$ du mur originel.

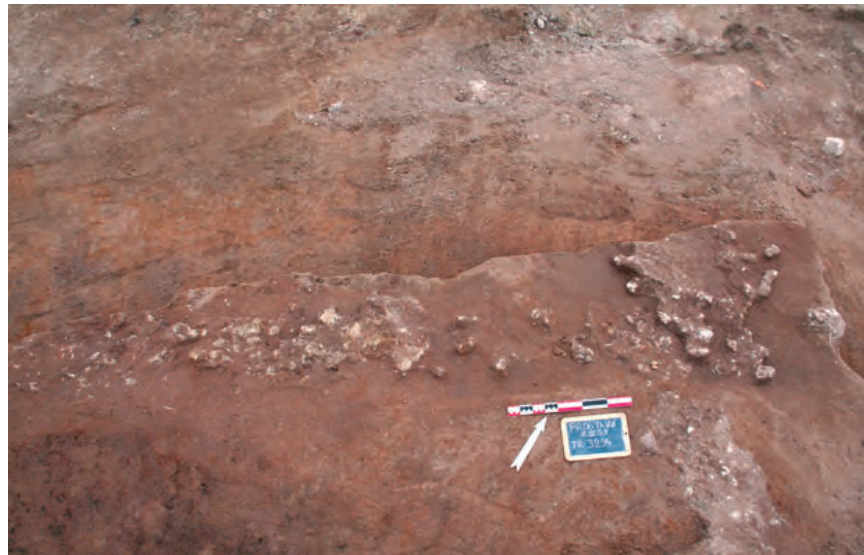

Fig. 87. Tranchée d'épierrement du mur MR3082 (TR3294).

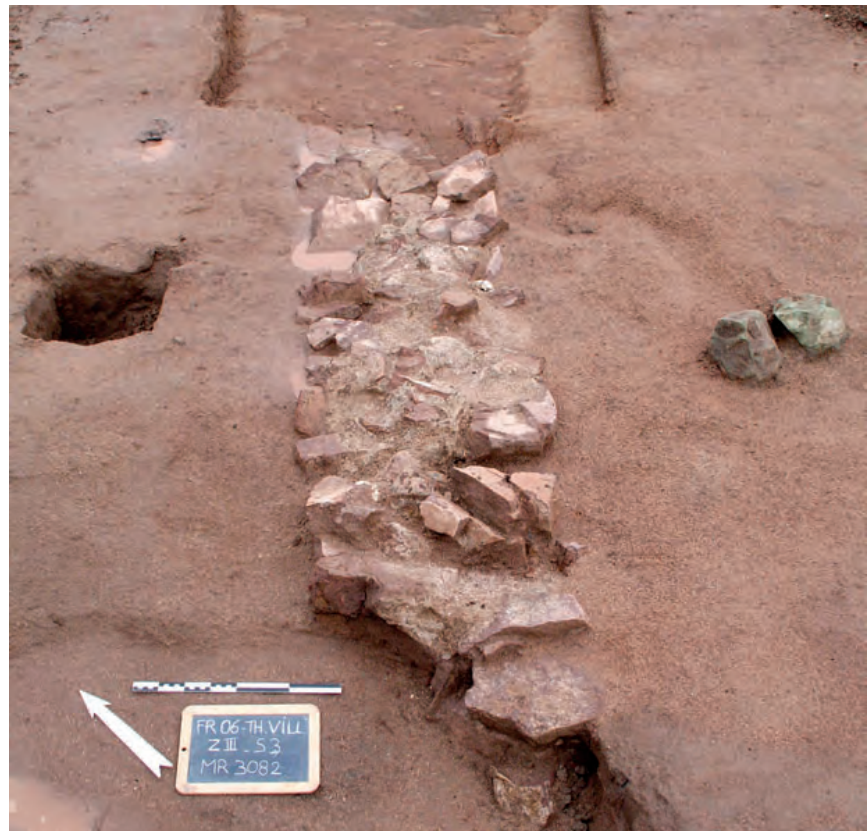

Fig. 88. Partie conservée du mur MR3082.

mortier sableux sur 0,50 m d'épaisseur (fig. 88). Les parements, constitués d'une seule assise conservée, sont un alignement grossier de moellons de grès brun rouge équarris ou bruts, de dimensions variables. La texture sablo-limoneuse brun rouge comporte de nombreux points communs avec le niveau 3311 décrit précédemment. On le retrouve également au dessus des niveaux sableux US3138. La surface de ce niveau paraît très altérée par les aménagements postérieurs et il est difficile de définir une cote altimétrique précise. La variation altimétrique avec les niveaux conservés au nord-est (US3310) paraît finalement assez faible. Le reste de sol de béton SL3136 conservé à l'amorce du corridor CN3010 est à la cote $0,48 \mathrm{~m}$ NGF, mais on ne peut malheureusement pas définir la nature exacte de l'occupation. On peut toutefois supposer l'existence d'une stratigraphie relativement horizontale composée 
d'un apport sablo-limoneux brun rouge assez similaire au niveau 1010 de la zone 1.

La faiblesse du matériel récolté dans ces niveaux permet seulement de supposer une occupation moins intense.

\subsubsection{Le secteur $B$}

\subsubsection{La stratigraphie}

Le niveau situé directement au sud du mur MR3082 est constitué d'un sable rouge enrichi en limon (US3163), que l'on retrouve contre la tranchée TR3083 (récupération du mur MR3082), et repose sur le niveau de sable lité US3138. Celui-ci s'étendait au sud probablement jusqu'au mur MR3082, mais la connexion entre les deux est très perturbée. La surface de fonctionnement n'a pas été mise en évidence sur l'ensemble du secteur, son altitude actuelle se situe entre 0,95 et $1,05 \mathrm{~m}$ NGF. Une prise de vue à basse altitude permet de distinguer nettement la bande conservée de teinte oxydée à dominante rouge (fig. 84).

\subsubsection{La galerie $\mathrm{CN} 3010$}

Il s'agit d'un espace de circulation étroit bâti dans le sable et partiellement enterré, au sein des niveaux US3163 et 3138, que nous avons suivi sur $12,50 \mathrm{~m}$ de long jusqu'à l'extrémité sud du chantier (fig. 89 et 90). Au sud, il se prolongeait au-delà de la rue Jean-Carrara. Il s'agit de l'amorce d'un couloir de 1,30 m de large hors œuvre, orienté nord-est/sud-ouest, conservé sur une hauteur de $0,76 \mathrm{~m}$. Les bordures latérales sont constituées par deux murs de 0,60 m de large (MR3009 et 3032). Les deux murs sont construits de façon similaire avec un unique parement, constituant la paroi interne du corridor. Les moellons sont assez grossièrement assisés et de taille variable $(25 \mathrm{~cm}$ x $20 \mathrm{~cm}$ à $15 \mathrm{~cm}$ x $10 \mathrm{~cm})$. Ils présentent surtout leur face la plus plane pour constituer l'intérieur du corridor. Les nombreuses irrégularités sont ensuite entièrement lissées par un rejointoiement

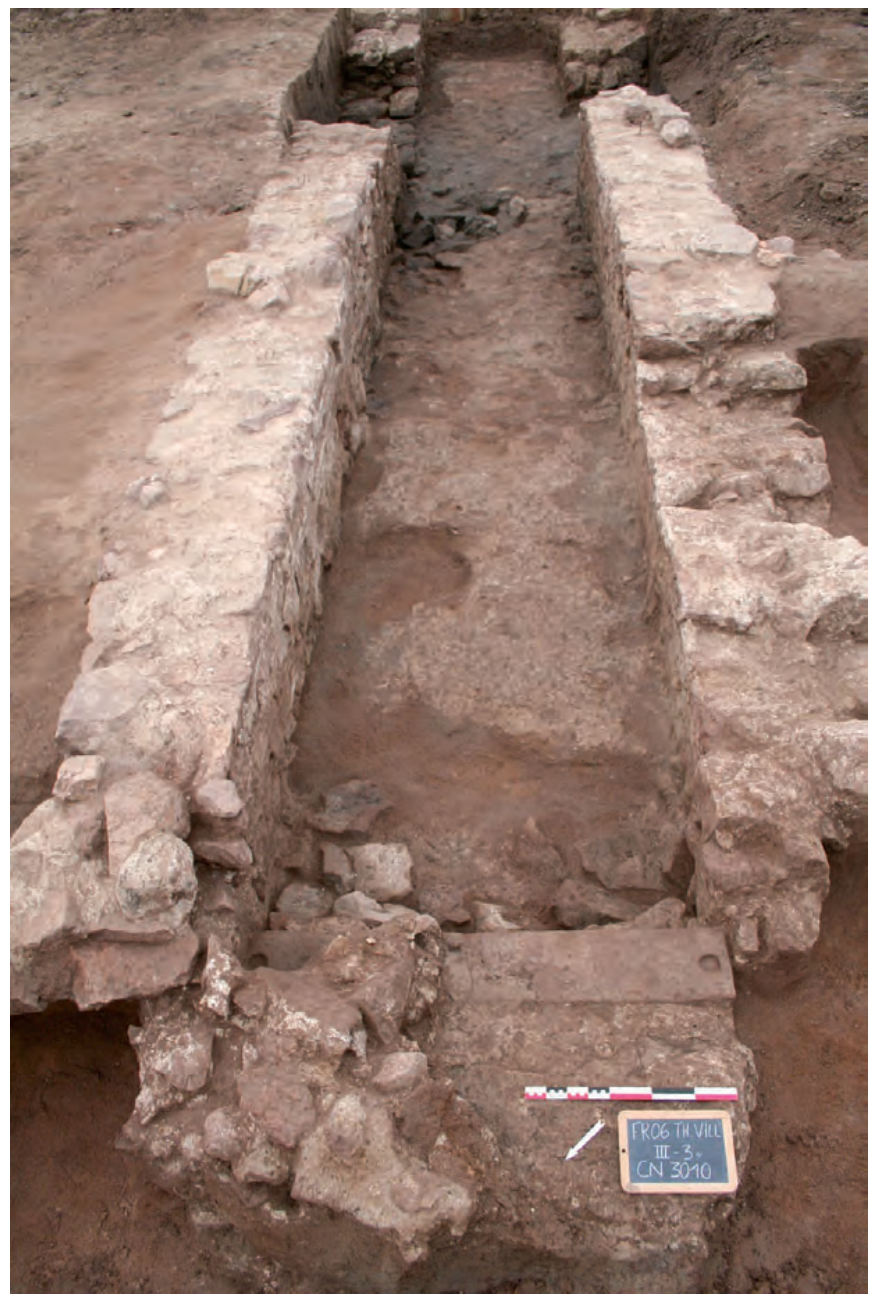

Fig. 90. La galerie CN3010, vue du nord.

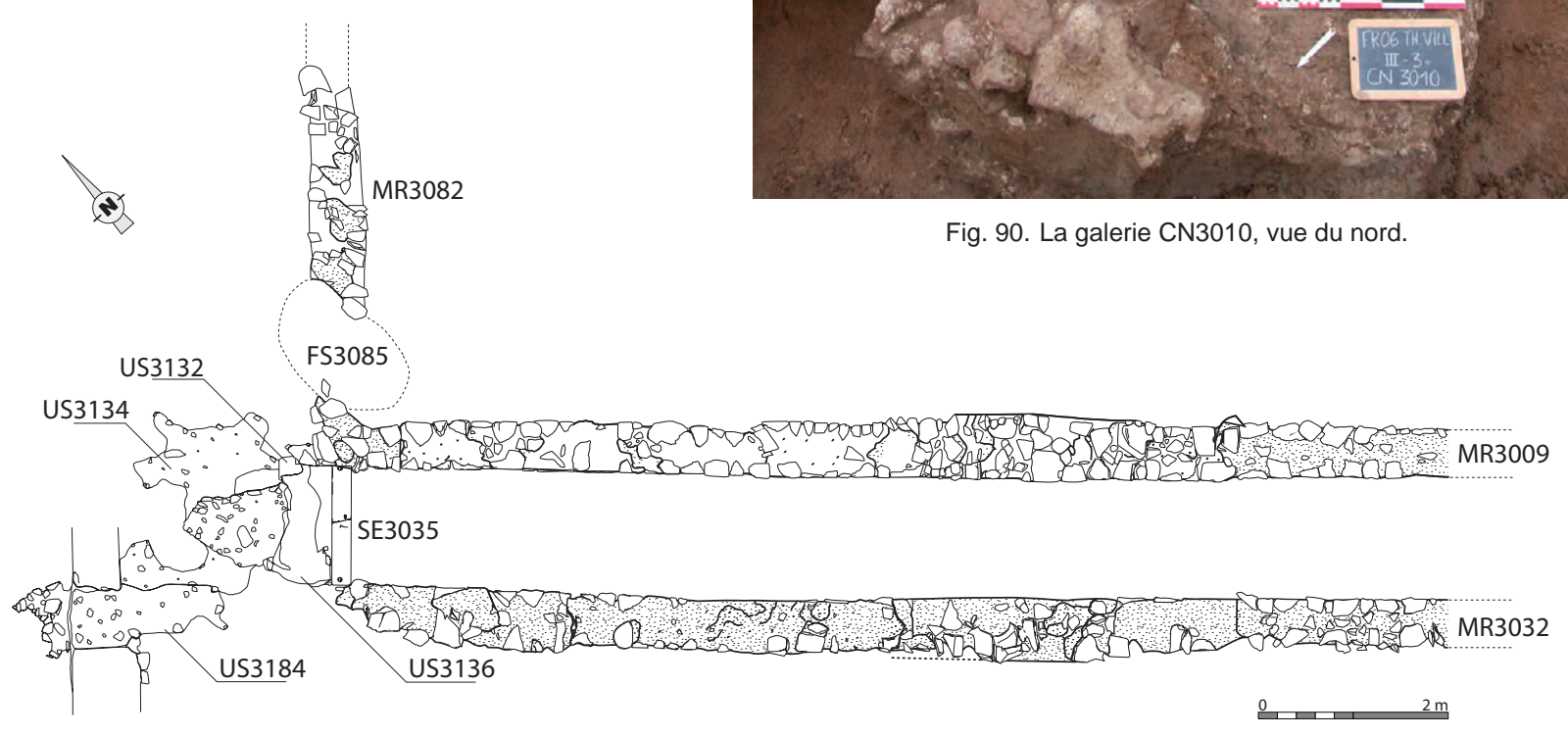

Fig. 89. Relevé de la galerie CN3010. 


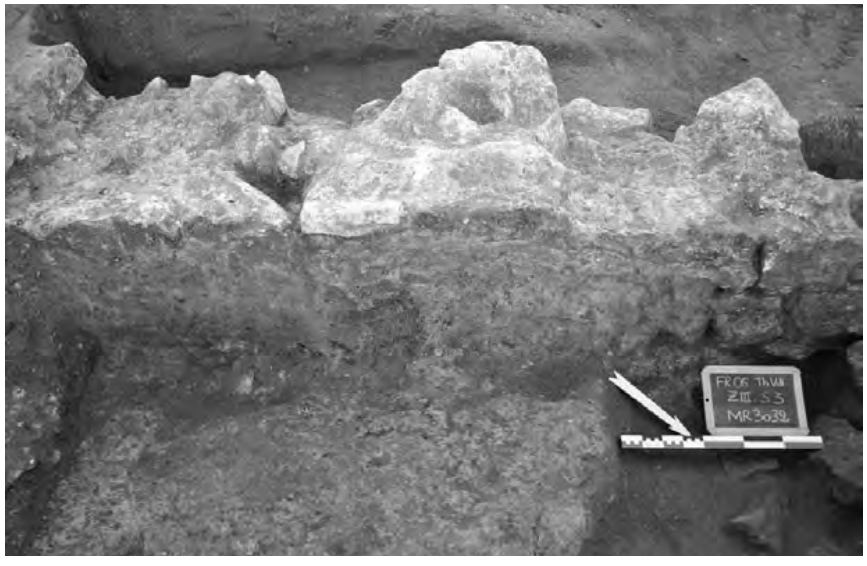

Fig. 91. Les parements intérieurs de CN3010 sont repris par un rejointement au mortier.

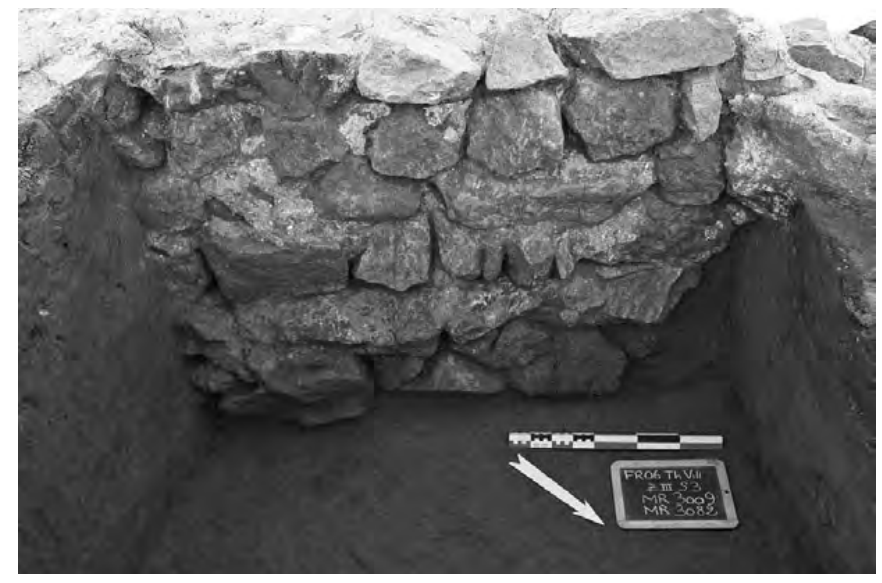

Fig. 92. Les parements sont lissés avec un enduit de mortier de chaux.

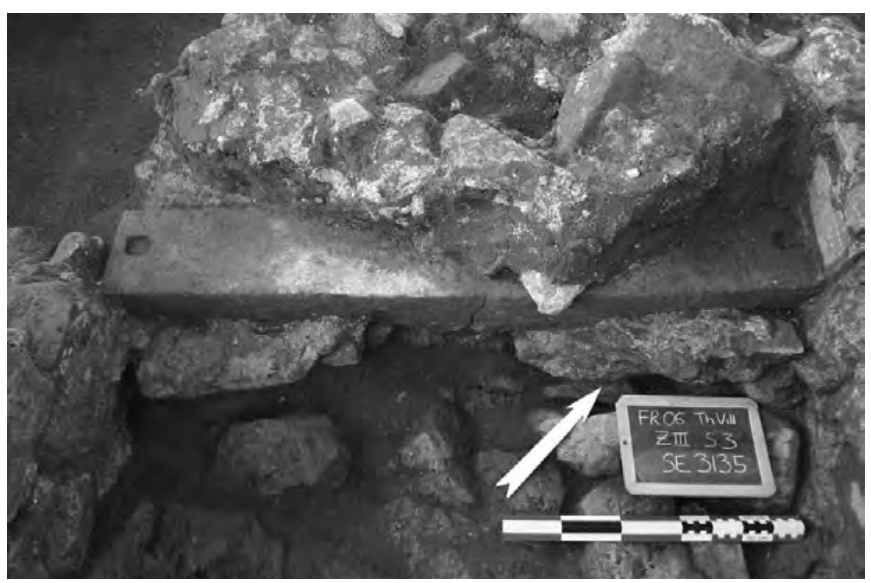

Fig. 93. Le seuil SE3135 en cours de dégagement.

au mortier, puis l'application d'un enduit de mortier de chaux et de sable (fig. 91).

À l'extérieur du couloir, la paroi est en fondation (fig. 92). Le lien entre le long mur MR3082 et la galerie n'a été observé qu'à la jonction avec le mur MR3009 bien que celle-ci ait été perturbée par une fosse moderne. Les deux ne sont pas liés mais ne résultent pas nécessairement de deux phases de construction distinctes. Le fond (US3011) est composé d'un niveau de mortier sableux appliqué directement sur le sable préalablement damé. La surface a été lissée et présente de nombreux gros grains de sable roulés de couleur sombre. L'ensemble est épais de 4 à $5 \mathrm{~cm}$ et ne remonte que faiblement sur la base des parements des murs latéraux. Le fond est situé à une cote altimétrique de $0,34 \mathrm{~m} \mathrm{NGF}$ et ne présente pas de pendage sud-est significatif. Pour simplifier le développement qui suit, nous appellerons cet espace « galerie maçonnée » à défaut d'une définition plus précise.

L'accès à cette galerie se faisait à partir d'un seuil (SE3135) situé à l'extrémité nord-ouest (fig. 93). Celui-ci est placé juste en avant de l'amorce du conduit, sur un blocage de cailloux, de moellons et de mortier. Il s'agit d'un bloc monolithique d'arkose violet de $1,25 \mathrm{~m}$ de long pour $0,20 \mathrm{~m}$ de large et haut de $0,12 / 0,15 \mathrm{~m}$. Toutes les faces sont taillées. Le pas se situait à une cote de 0,48 m NGF. La surface a été finement piquetée et ne présente pas une usure marquée par le piétinement, hors le frottement de la gâche. Les arêtes sont également assez vives. Il s'agit d'un seuil à pas de $0,20 \mathrm{~m}$, sans feuillure. Celui-ci possède deux crapaudines circulaires de $4,6 \mathrm{~cm}$ de diamètre (profondeur $0,5 \mathrm{~cm}$ ), désaxées vers la face avant $(0,08 \mathrm{~m})$ et chacune à moins de $0,05 \mathrm{~m}$ des faces latérales. Enfin, à $0,50 \mathrm{~m}$ de la face latérale gauche et à $0,05 \mathrm{~m}$ de la face arrière se trouvait une gâche rectangulaire $(0,04 \mathrm{~m} \times 0,02 \mathrm{~m} \times 0,025 \mathrm{~m})$. Il s'agit donc d'une porte à double vantaux mobiles dont un était bloqué par un verrou vertical. La position de la gâche désaxée vers l'est, laisse supposer la présence de deux vantaux non symétriques, le battant gauche étant plus court $(0,50 \mathrm{~m})$ que le battant droit $(0,65 \mathrm{~m})$. La trace d'impact à l'avant de la gâche (barre de verrou ?) côté extérieur et la présence de pierres en saillis en avant du seuil à l'intérieur du corridor, permettent d'affirmer que les vantaux s'ouvraient vers l'extérieur (fig. 94). Pour accéder à l'intérieur de la galerie, le seuil constituait une marche d'une dizaine de centimètres. En avant, il reste du perron originel un sol de mortier sur radier de pierre (US3134) dont la surface lissée est au même niveau que la surface du seuil, soit 0,48 m NGF.

\subsubsection{Interprétation}

En 2005, un diagnostic archéologique réalisé par l'INRAP ${ }^{11}$ dans la parcelle BK345 située de l'autre côté de la rue Jean-Carrara, avait permis la mise au jour de vestiges situés dans le prolongement de la galerie $\mathrm{CN} 3010$, à $72 \mathrm{~m}$ en direction du sud-est.

11 Fouille J.-M. Michel arrêtée 2005/3838, dossier INRAP 2005, 200. 


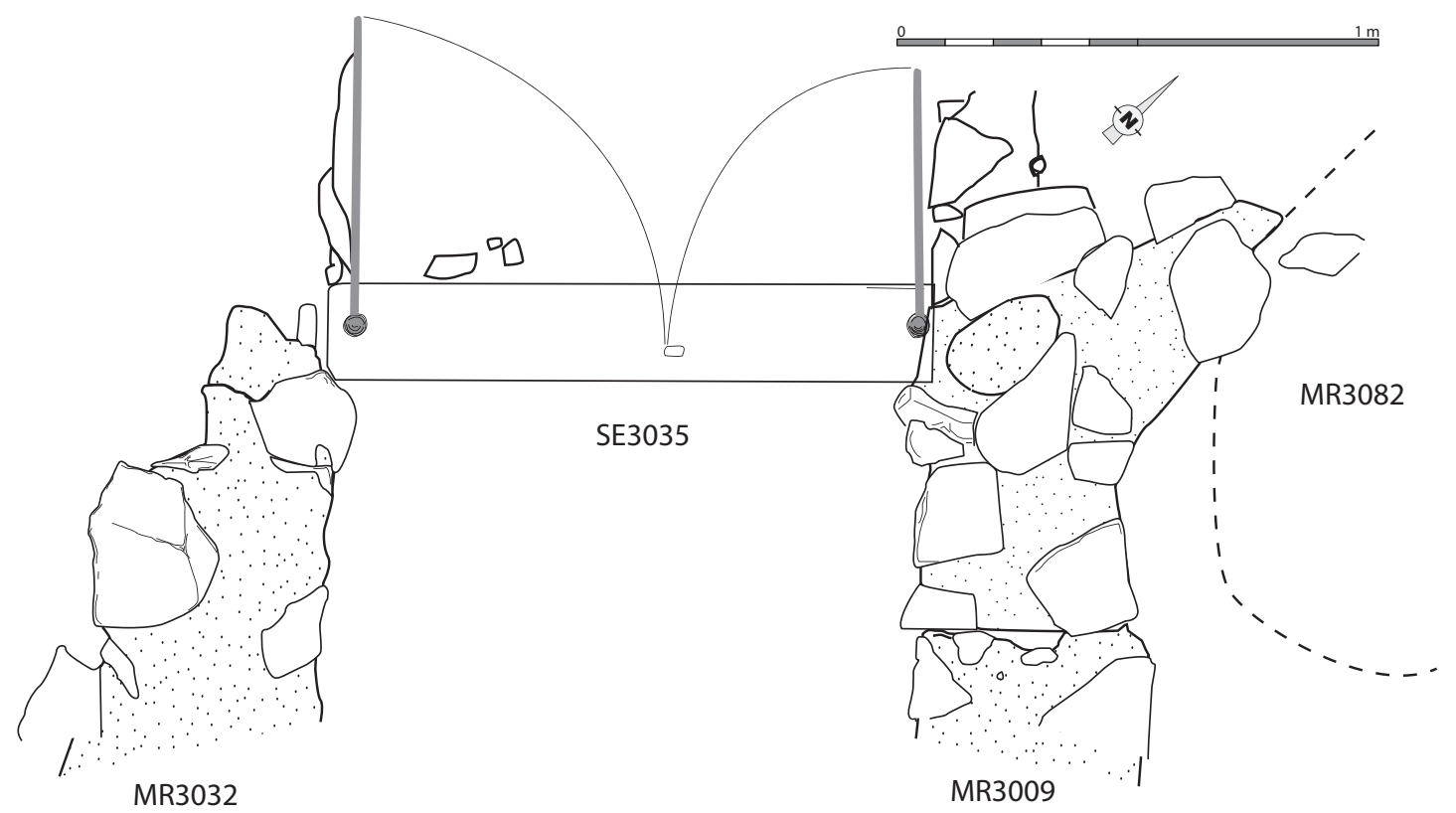

Fig. 94. Relevé du seuil SE3135 et position probable des vantaux.

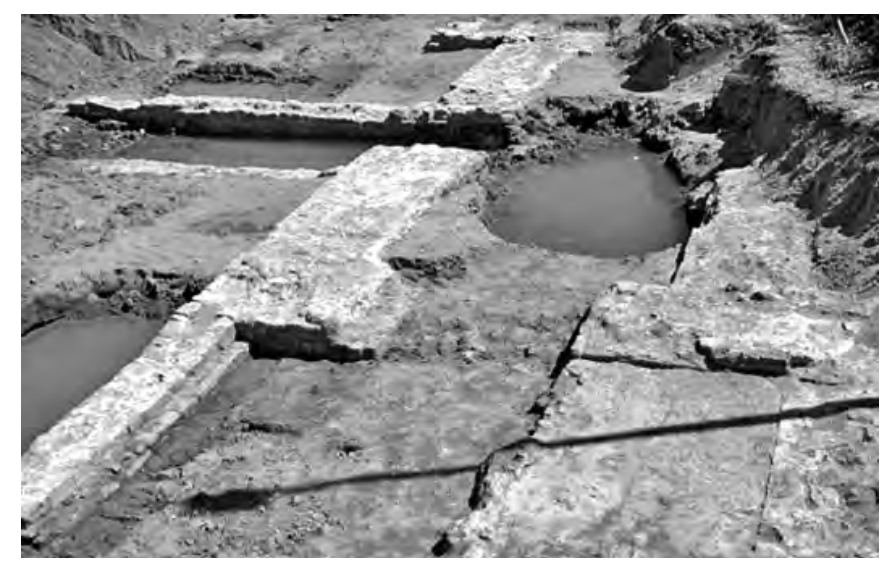

Fig. 95. Vue des vestiges dégagés (J.-M. Michel - INRAP).

Une portion avait déjà été repérée sur 7,20 m de long aboutissant dans un espace limité par de gros murs maçonnés d'organisation complexe (Michel 2005) (fig. 95 et 96). L'orientation du corridor est légèrement différente $^{12}$, mais le prolongement de la section découverte à Villeneuve s'accorde assez précisément avec la portion anciennement dégagée plus au sud (fig. 97). Les proportions (1,50 $\mathrm{m}$ de large) et la nature de la construction permettent d'envisager assez sûrement qu'il s'agit du même ensemble. Il convient ainsi de restituer une galerie de $92 \mathrm{~m}$ de long. Le fond de l'extrémité sud se situait à une cote de 0,01 m NGF (Michel 2005, 14, fig. 4), alors que le point haut se situe à $0,36 \mathrm{~m}$ NGF du côté de l'ouverture nord sur le terrain de Villa Romana. Ainsi, sur $92 \mathrm{~m}$ de long, la pente

12 Elle s'oriente de quelques degrés plus vers le nord.

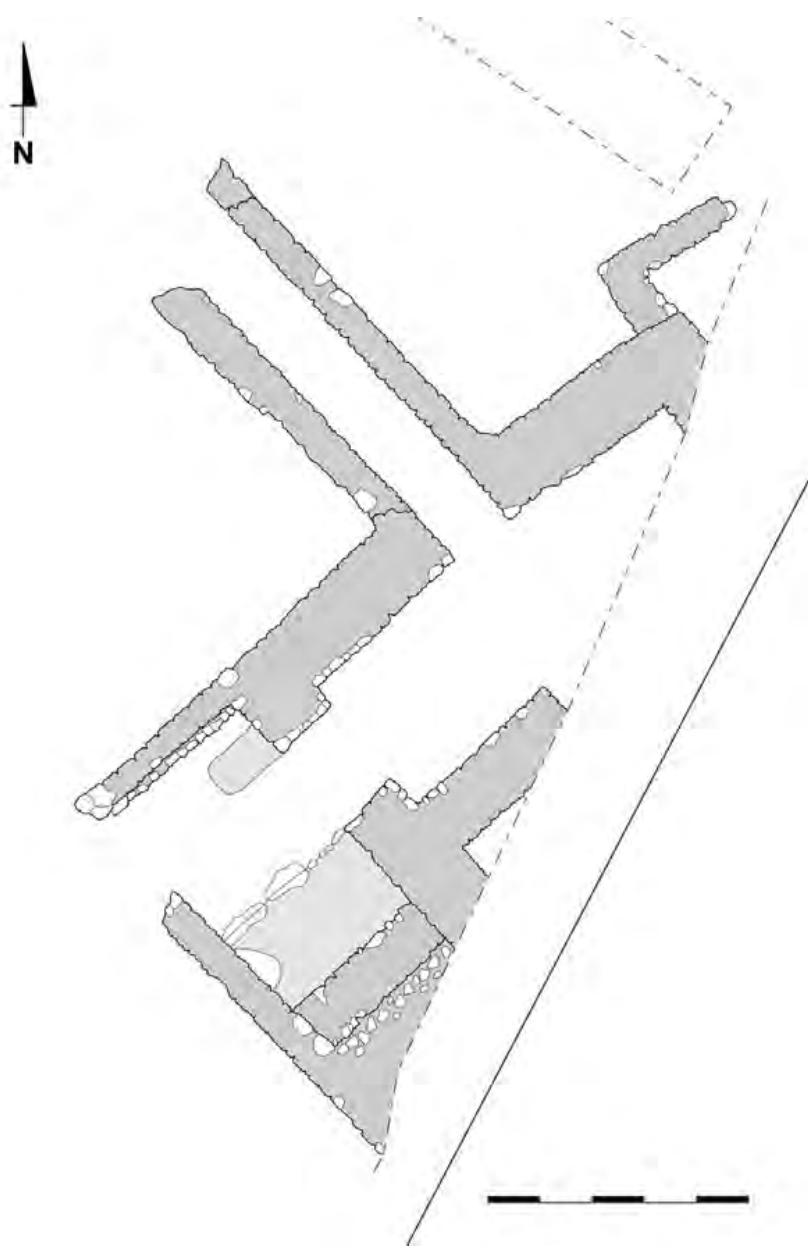

Fig. 96. Relevé des structures découvertes lors du diagnostic sur le terrain de M. Bricolage par J.-M. Michel (DAO F. Guériel - INRAP). 
n'est que de $0,36 \mathrm{~m}$, soit une pente très faible de l'ordre de $0,39 \%$.

Lors du diagnostic, l'hypothèse d'un collecteur destiné à conduire de l'eau depuis les thermes de Villeneuve avait été retenue par les auteurs. Plusieurs indices permettent aujourd'hui de réfuter cette hypothèse au profit d'un corridor piétonnier maçonné. Premièrement, la pente est extrêmement faible, moins de $0,40 \%$, alors que les nombreux collecteurs repérés au sein de la ville antique atteignent en moyenne une pente de $2 \%$ (Clos de la Tour, Mangin...) (Rivet et al. 2000, 385 ; Pasqualini et al. 2006, 50-52). Il en va de même pour les arrivées d'eau, ainsi le canal de l'aqueduc « penche » en moyenne de $1,2 \%$. Sous la limite des $1 \%$, l'écoulement des eaux n'est plus assuré et l'eau stagne si elle n'est pas propulsée par une force. La largeur de la galerie est également très différente des collecteurs, qui ne dépassent que très exceptionnellement $1 \mathrm{~m}$ de large. L'absence totale de béton hydraulique et la finesse du sol recouvrant le sable ne plaident pas non plus en faveur d'une circulation hydraulique. Enfin, la présence d'un seuil avec crapaudines entérine définitivement l'hypothèse d'un corridor à usage piétonnier. Le comblement US3131 et 3130 ne comportait pas, dans la partie dégagée, d'éléments de maçonnerie pouvant laisser envisager la nature du couvrement. D'ailleurs, il ne s'agissait peut être pas d'une galerie

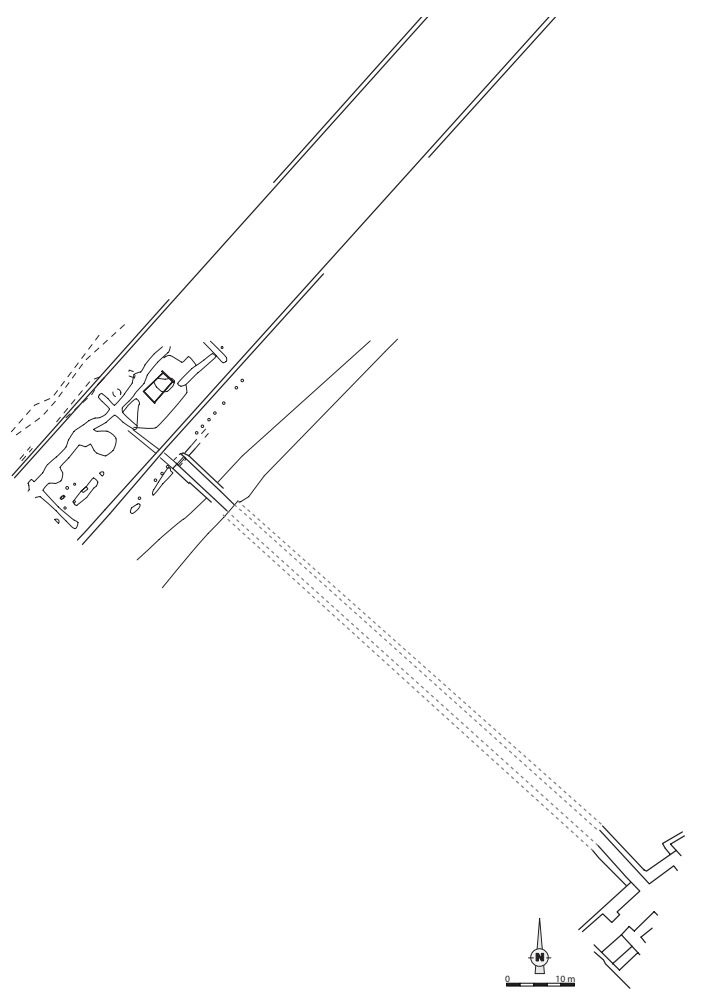

Fig. 97. Raccordement hypothétique entre les deux zones de fouilles. couverte, mais simplement d'un « passage bâti », encaissé dans le sable de plage. Mais alors, un corridor piétonnier dans quel but? Nous tenterons de répondre à cette question dans le cadre de l'interprétation générale de la phase 3A.

\subsection{Les mobiliers}

\subsubsection{La céramique}

(E. P.)

La phase 3A a fourni un mobilier conséquent, mais très fragmenté. L'ensemble est dominé par les amphores gauloises et les céramiques à pâte claire selon le nombre de restes (NR). Le mobilier s'inscrit dans une fourchette comprise entre le second quart du ${ }^{\text {er }}$ siècle apr. J.-C. et le second quart du $\mathrm{II}^{\mathrm{e}}$ siècle apr. J.-C. Le terminus ante quem est donné par un bord de plat en céramique africaine de cuisine de type Hayes 23B (fig. 98 - $\mathrm{n}^{\circ} 1$ ) et un bord de coupe en sigillée claire A de type Hayes 14A (fig. $98-\mathrm{n}^{\circ}$ 2) qui apparaissent, au plus tôt, dans le second quart du $\mathrm{II}^{\mathrm{e}}$ siècle apr. J.-C. Le mobilier le plus ancien est une assiette en sigillée italique de type Consp. 3.1 (fig. $98-n^{\circ} 3$ ) et une coupe Consp. 33.5 (fig. $98-n^{\circ} 4$ ) qui renvoient à la première moitié du Ir ${ }^{\text {er }}$ siècle apr. J.-C. Le reste du mobilier fin semble majoritairement se situer entre le milieu du $\mathrm{I}^{\mathrm{er}}$ et le début du $\mathrm{II}^{\mathrm{e}}$ siècle apr. J.-C. et ne pas être postérieur [Mayet 37/38 (fig. $98-\mathrm{n}^{\circ}$ 5), Drag. 18A (fig. 98 - n ${ }^{\text {os }} 6$ et 7), Drag. 35 (fig. $98-n^{\circ} 8$ ), Drag. 37A (fig. 98 - $\mathrm{n}^{\circ}$ 9), Hermet 9 (fig. $98-\mathrm{n}^{\circ} 10$ ), Ritterling 8B (fig. 98 - n 11), Drag. 18/3 (fig. 98 - $n^{\circ} 12$ ) et Ritterling 12].

Les amphores donnent des résultats similaires. On compte une majorité de gauloises [deux gauloises 2 dont une provenant probablement de l'atelier de Saint-Lambert à Fréjus (fig. 99 - n 1), trois gauloises 4, une gauloise 5 et une gauloise 6] qui nous entraîne dans la seconde moitié du I ${ }^{\text {er }}$ siècle apr. J.-C. au plus tôt. Elles peuvent être associées à des amphores africaines anciennes dont un bord d'Ostia 59 (fig. 99 - $n^{\circ} 2$ ) et un fond de Tripolitaine 1 ainsi qu'à une amphore de Bétique de type Dressel 20 représentée par une anse et un fond. Le reste semble devoir être rangé dans le mobilier du début du fonctionnement de la phase. On y reconnaît au moins trois amphores de Bétique de type Dressel 7/11, un bord de Dressel 2/4 de Tarraconaise, ainsi que deux encolures d'amphores massaliètes impériales de type Bertucchi 6A et 7A (fig. $99-\mathrm{n}^{\circ}$ 3).

Les céramiques communes sont presque aussi nombreuses que les amphores en terme de quantité (NR). Le NMI des premières est même deux fois plus élevé que celui des secondes. Parmi elles, on compte une grande majorité de céramiques à pâte calcaire. 


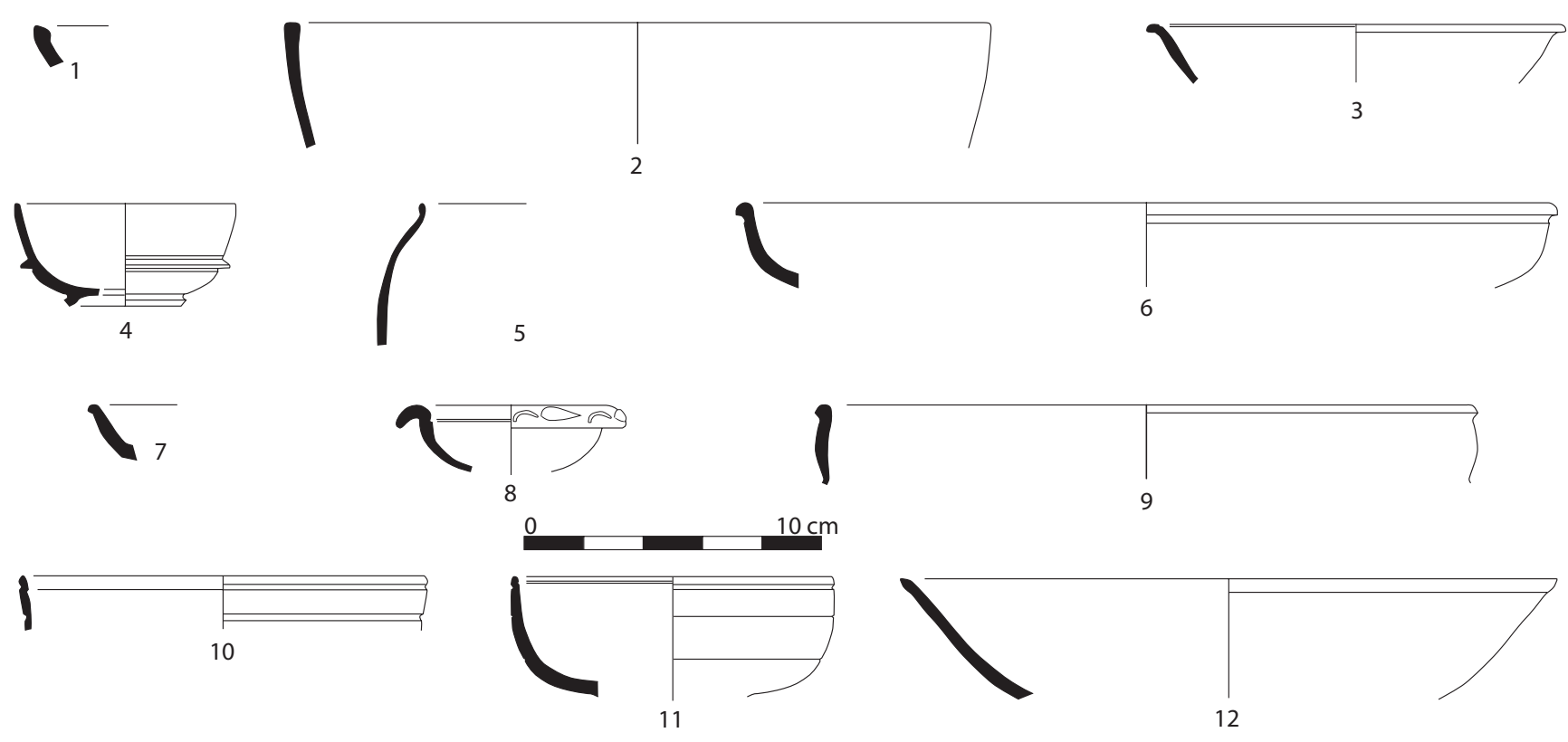

Fig. 98. Les céramiques de la phase 3A.

On reconnaît des produits caractéristiques de la région Fréjus/Argens aux $\mathrm{I}^{\mathrm{er}} / \mathrm{II}^{\mathrm{e}}$ siècles apr. J.-C. (Pasqualini 1998) :

- 7 coupes de type Pasqualini 1B (fig. 99 - nos 4 à 6),

- 4 coupes de type Pasqualini 4 (fig. 99 - nos 7 à 10),

-3 coupes de type Pasqualini 6 (fig. 99 - $\mathrm{n}^{\text {os }} 11$ à 13),

- un pichet de type Pasqualini B (fig. 99 - $\mathrm{n}^{\circ} 14$ ).

On trouve encore quelques objets un peu moins courants que l'on rencontre à Fréjus dans des contextes du début du Irr siècle apr. J.-C. en particulier sur le site des Aiguières (Rivet 1983) :

-2 grandes coupes lèvres pendantes (fig. $99-n^{\circ} 15$ ) et à bord mouluré (fig. $99-\mathrm{n}^{\circ} 16$ ) que l'on peut rapprocher des types 24 et 32 (ibid., fig. 39 et 41 ),

- 1 bord de pot à lèvre aplatie (fig. $99-n^{\circ} 17$ ) qui rappelle le type 1 (ibid., fig. 29),

- 2 bords de vases moulurés (fig. 99 - nos 18 et 19) que l'on peut rapprocher des types 2 et 3 (ibid., fig. 29).

On dénombre enfin une série de pièces à pâte calcaire auxquelles on ne trouve pas d'équivalent satisfaisant, notamment des cruches ou des pichets (fig. $100-\mathrm{n}^{\text {os }} 1$ à 6), une bassine à marli massif (fig. $100-\mathrm{n}^{\circ} 7$ ), trois bords de gobelets à lèvre pendante (fig. 100 - $\mathrm{n}^{\text {os }} 8$ à 10), une coupe-couvercle (fig. $100-\mathrm{n}^{\circ} 11$ ) et une série de vases de stockage (fig. 100 - nos 12 à 14 ).

Les céramiques culinaires sont particulièrement mal représentées. On ne reconnaît qu'une douzaine d'objets appartenant à sept catégories différentes. À côté du plat Hayes 23B rattaché à la fin de la phase, on compte un bord de pot à feu en céramique kaolinitique $\mathrm{du}$ Verdon (fig. $100-\mathrm{n}^{\circ} 15$ ) et trois modelées des Maures de type Bérato 160 (fig. 100 - nos 16 à 18).
Le reste semble antérieur au $\mathrm{II}^{\mathrm{e}}$ siècle apr. J.-C., voire renvoyer à la première moitié du $\mathrm{I}^{\text {er }}$ siècle apr. J.-C. C'est le cas d'un bord de cruche kaolinitique de type Goudineau 1, de deux bords de pots à feu en céramique modelée proche du type Bérato 150 (fig. 100 - $\mathrm{n}^{\circ}$ 19), de trois petits pots à feu à pâte grise ou brune de Fréjus (fig. $100-\mathrm{n}^{\circ}$ 20) que l'on retrouve au Aiguières dans un contexte du Ir siècle apr. J.-C. (Rivet 1994, fig. 14), ainsi que deux bords de plats en céramique à vernis rouge pompéien (fig. 100 - $\mathrm{n}^{\text {os }} 21$ et 22). Pour terminer, il faut encore noter la découverte de deux bords de dolia (fig. $100-\mathrm{n}^{\text {os }} 23$ et 24 ).

\subsubsection{Instrumentum \\ (Y. L.)}

Forces (lat. forfex) - Inv. $\mathrm{n}^{\circ} 3$ - Alliages cuivreux long. : $82 \mathrm{~mm}$; larg. : $20 \mathrm{~mm}$; H. : $7 \mathrm{~mm}$

Les forces (fig. 101), ciseaux à double lames parallèles réunies par un ressort, n'ont pas connu de transformation typologique depuis leur origine. Elles sont présentes dans des tombes masculines et plus rarement féminines du début du second âge du Fer (Déchelette 1914, 1280 ; Jacobi 1974, 88-89 et Perrin 1990) et de l'époque mérovingienne. Au cours de la période romaine, les forces sont «assez peu fréquentes dans les sépultures gallo-romaines » (Feugère 1989, 190) et sont plus généralement attestées en contexte domestique, artisanal et agricole. La très grande majorité des forces connue est de grande taille (de 150 à plus de $400 \mathrm{~mm}$ ), réalisée strictement en fer, matériau robuste adapté à l'usure de la tonte ou de la découpe des tissus. 

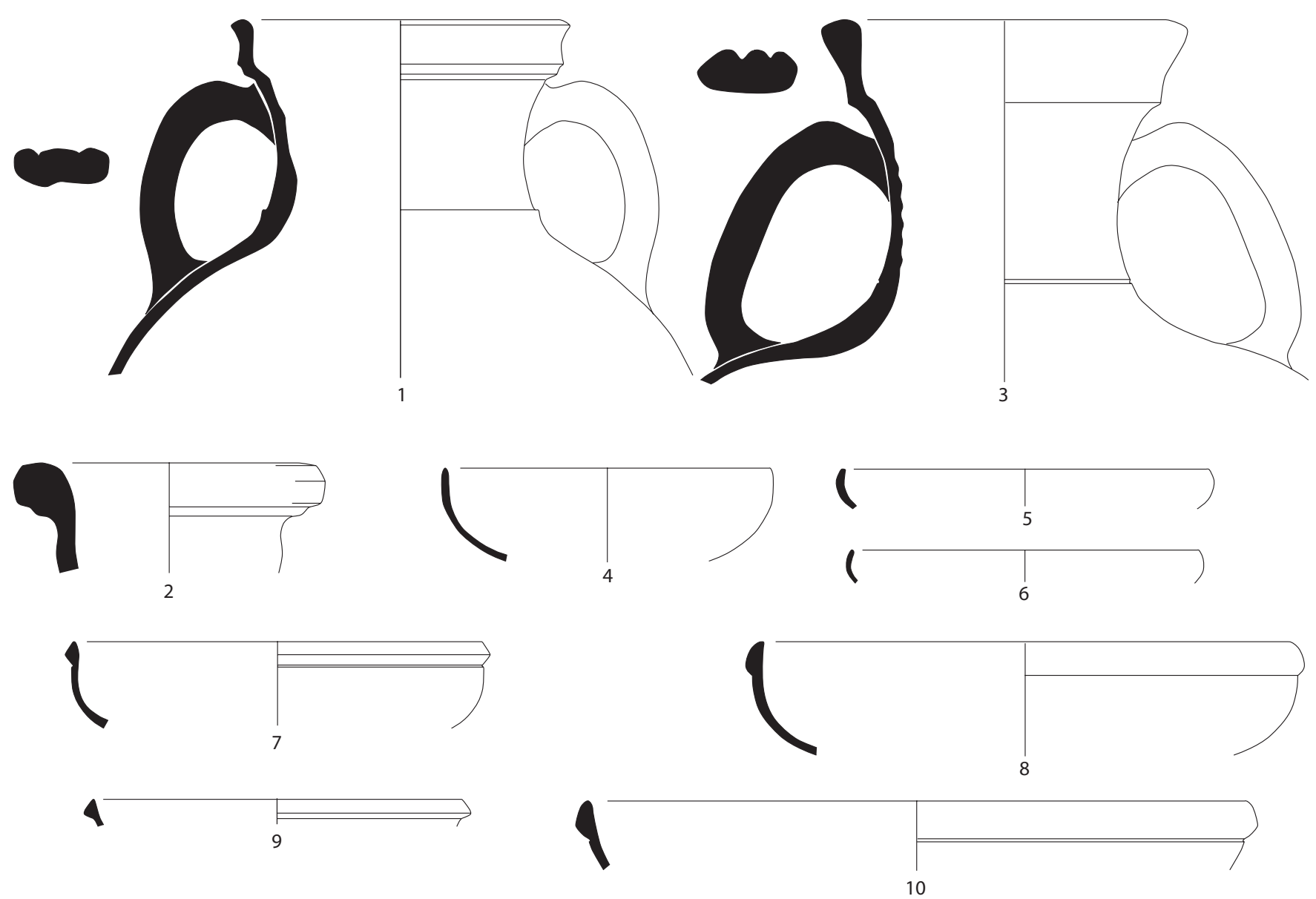

1
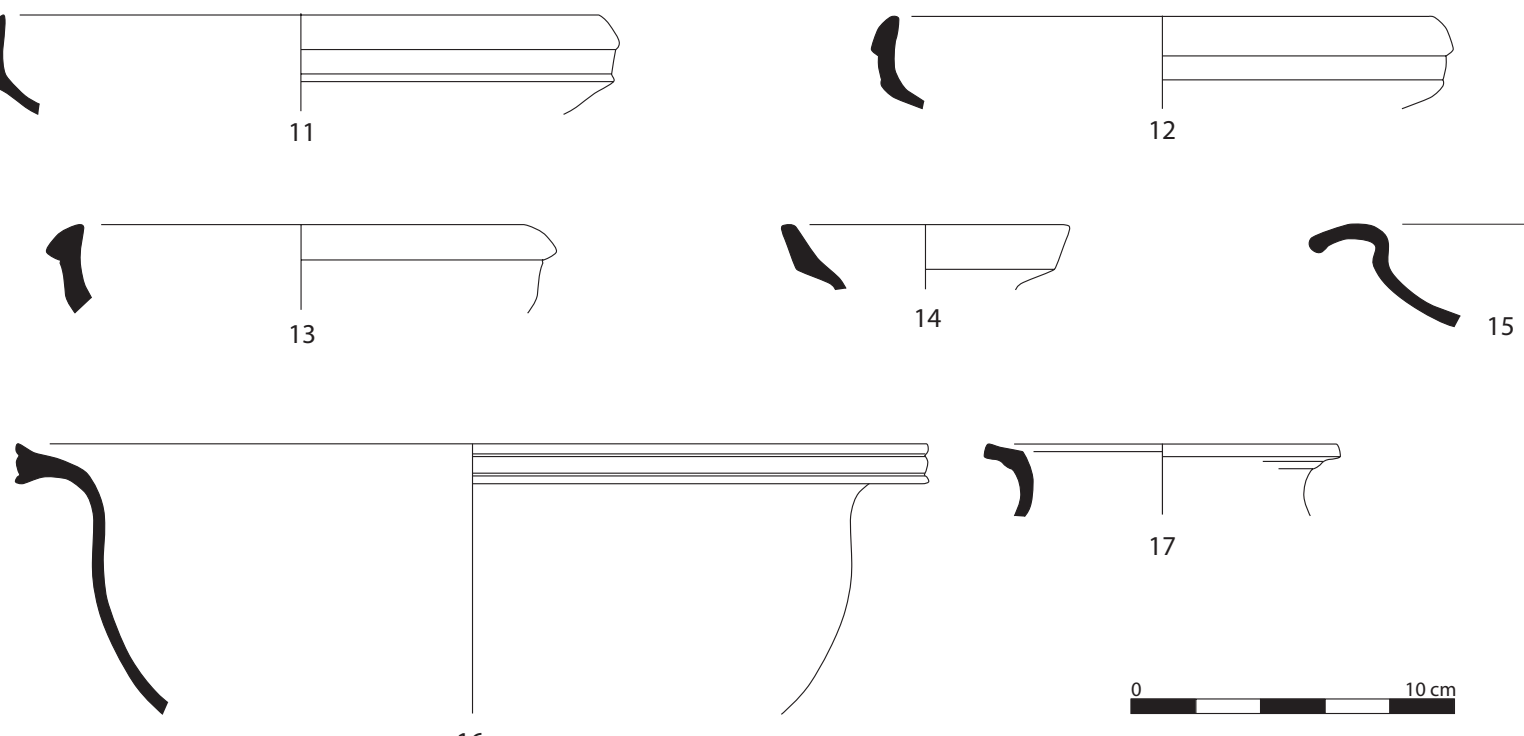

16

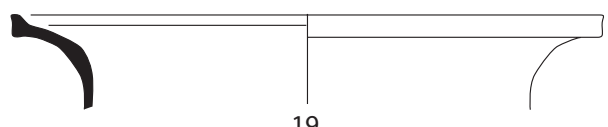

Fig. 99. Les céramiques de la phase 3A. 
$\sum_{1}$
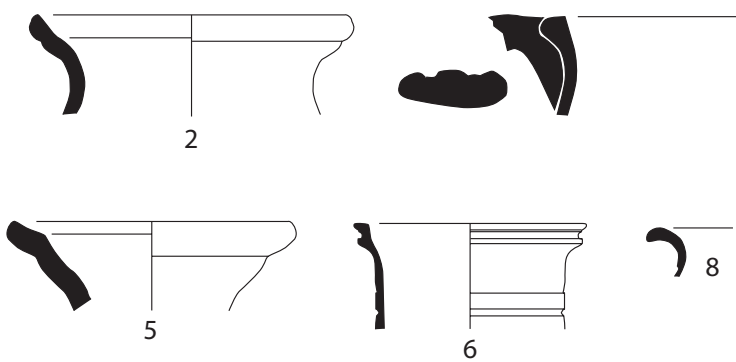

7
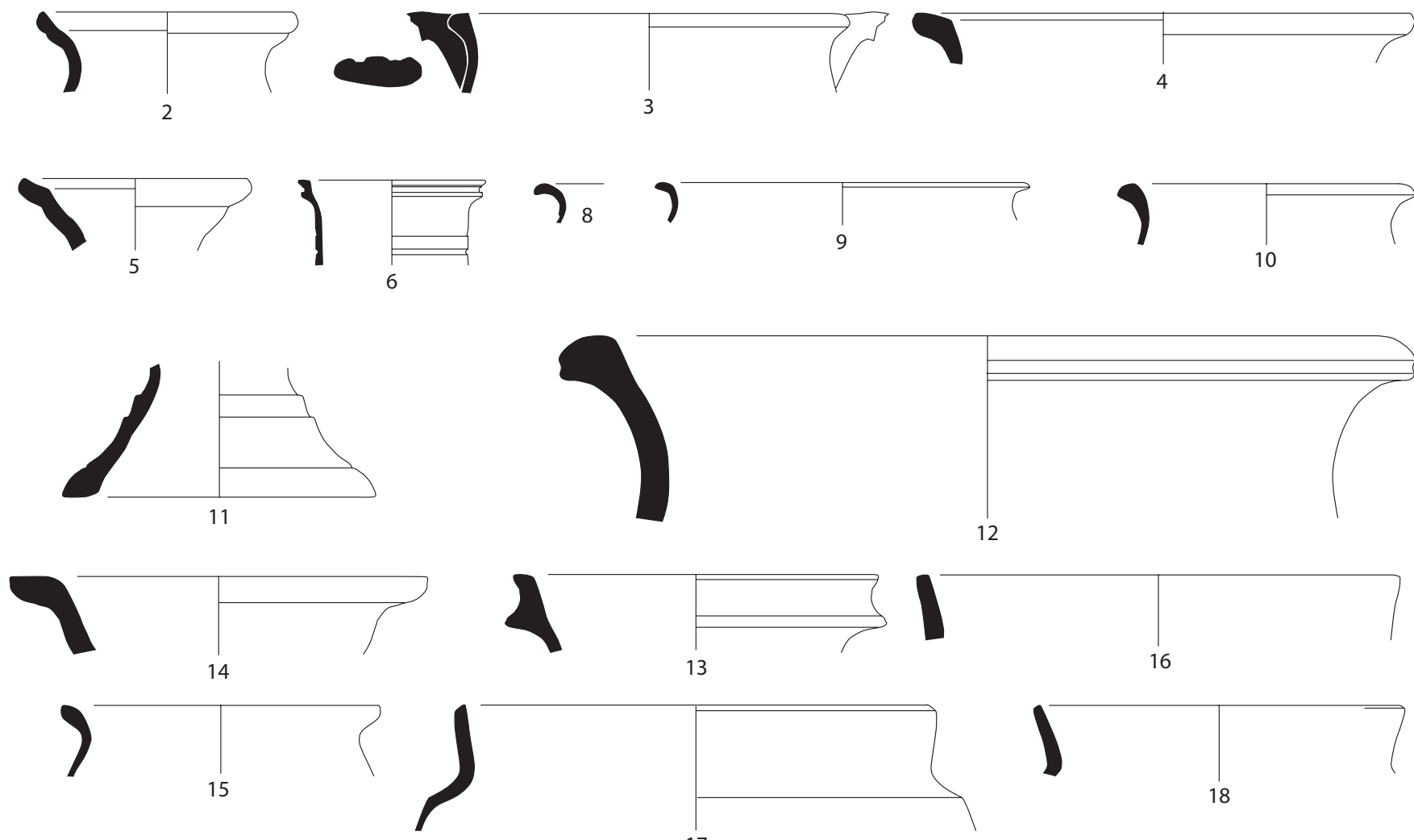

1

)
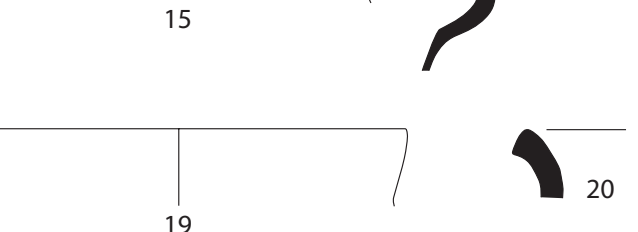

19

20

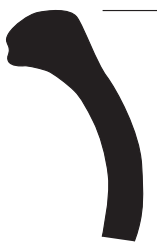

13
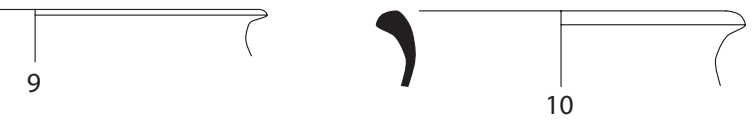

12

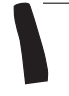

17

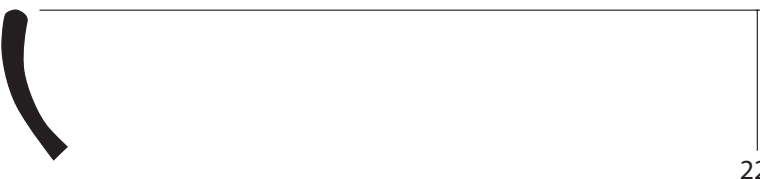

22
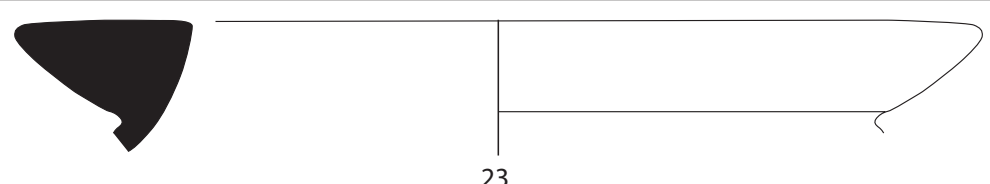

23
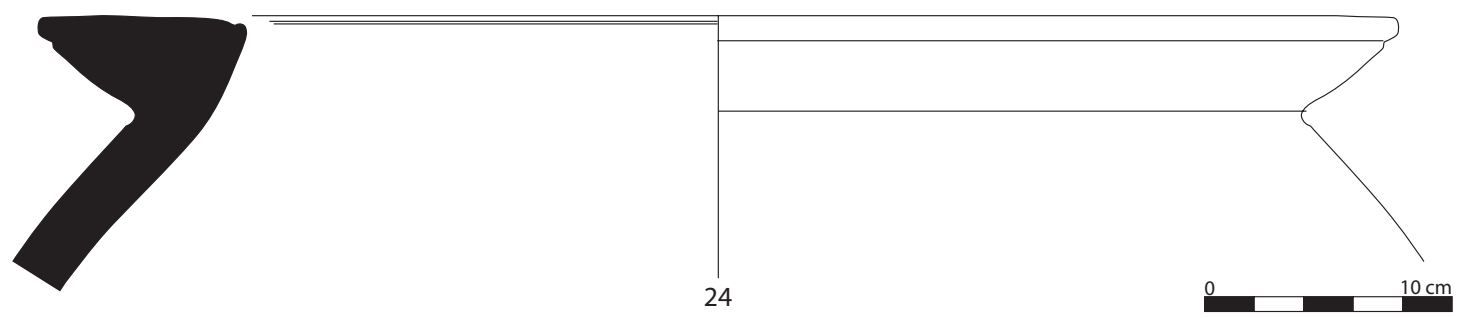

Fig. 100. Les céramiques de la phase 3A. 
Le travail de la laine et du tissu employait les forces afin de tondre les moutons mais également pour la découpe des tissus et la teinte des draps après tissage. Ce dernier usage est illustré sur une stèle conservée au musée de Sens (Yonne) (Espérandieu 1911, n 2768). L'importance du forfex dans ces activités est capitale et se manifeste sur quelques stèles funéraires où le défunt porte son instrument de travail : stèle au musée du Berry à Bourges (Cher) (Espérandieu 1908, $\mathrm{n}^{\circ}$ 1461) et stèle de Saint-Ambroix (Cher) (Espérandieu 1910, n 2739).

Dans l'agriculture, les forces permettaient de tailler les petites branches d'arbres, de récolter les fruits et de couper les grains de raisin avariés (Columelle, XII, 43, 10).

En médecine, le forfex pouvait être utilisé lors d'interventions chirurgicales. Celse, médecin romain du Ir siècle apr. J.-C., présente les instruments utilisés en médecine et cite le forfex (De la médecine, VII, 16, 27-28 ; Manchia 1998, 45). D'après G. Penso, ce type d'outil a été retrouvé parmi d'autres instruments médicaux à Pompéi (Penso 1984, 396, fig. 206) et à Avenches (ibid., 418, fig. 214).

Dans le domaine personnel, les forces pouvaient être utilisées comme des instruments de toilette «destinés à la coupe des cheveux, des moustaches et de la barbe » (Perrin 1990). Cet outil, essentiellement masculin, était employé pour la toilette personnelle (Boon 1991 et Eckardt, Crummy 2008, 35-36), mais faisait également partie du trousseau du tonsor, le coiffeur barbier (Martial, VI, LII et VIII, LII) parmi lesquels figuraient la pince à épiler, le peigne, le miroir ou encore le rasoir. Les forces étudiées ici font partie de cette catégorie peu représentée.

L'exemplaire retrouvé dans les jardins des thermes de Villeneuve (Lemoine 2008) a été découvert dans un niveau daté entre l'époque flavienne et la fin du $\mathrm{II}^{\mathrm{e}}$ siècle apr. J.-C. Ces forces en bronze de petites dimensions (long. : $82 \mathrm{~mm}$; larg. : $20 \mathrm{~mm}$; H. : $7 \mathrm{~mm}$ ) sont munies d'un ressort en $\mathrm{U}$ et peuvent être apparentées au type Manning 3 (Manning 1985 et Duvauchelle 2005, 76-77). Cette typologie rassemble les forces d'une longueur inférieure à $150 \mathrm{~mm}$.

Le forfex de Fréjus présente plusieurs spécificités : il a été découvert dans un contexte archéologique singulier pour ce type d'objet et le matériau employé rend cet instrument original puisque seuls trois exemplaires en bronze nous sont connus en Gaule : l'un découvert sur le site de « Nord-Est Cathédrale » à Fréjus dans un niveau de circulation d'une voie datée du $\mathrm{III}^{\mathrm{e}}$ siècle apr. J.-C. (Rivet 2010, 116, n 495), le second, retrouvé en Eureet-Loire à Terminiers aux Échelles, est conservé au musée de la Société Dunoise (Ollagnier, Joly 1994, 306), et le troisième fait partie du fonds du musée d'Orléans (Besson 2003, 153). Les propriétés mécaniques des alliages cuivreux rendent l'utilisation des forces

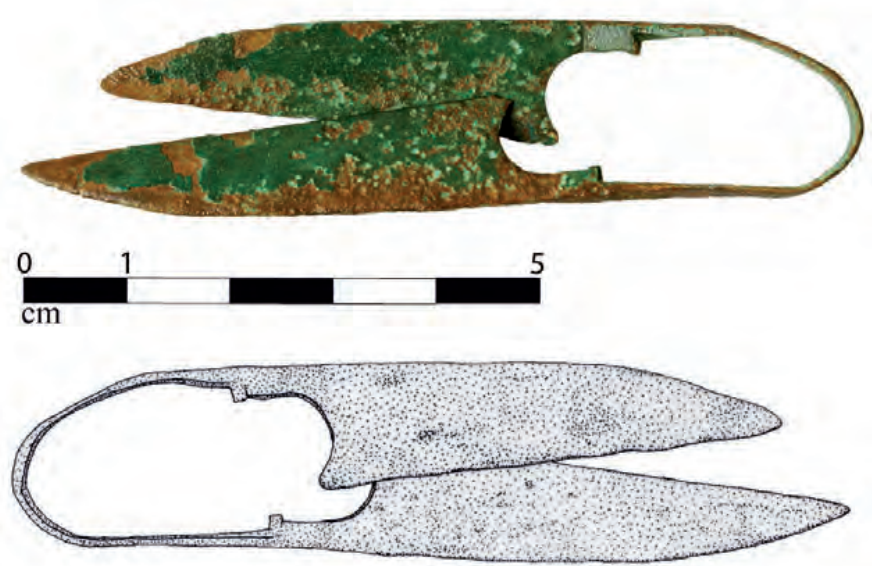

Fig. 101. Ciseaux à barbe (Y. Lemoine).

délicate : la torsion du ressort en $\mathrm{U}$ n'assure plus le strict parallélisme des lames et accentue l'usure des lames.

L'ensemble des autres forces de type Manning 3 attesté à notre connaissance en Gaule est constitué en alliages ferreux. Parmi ces exemplaires on peut citer : Fontaine-Étoupefour (Calvados) (Halbout, Pilet, Vaudour, $\mathrm{n}^{\circ} 128$ - long. : $107 \mathrm{~mm}$, $\mathrm{II}^{\mathrm{e}}$ siècle apr. J.-C.), Orléans (Loire) (Ferdière 1984 - long. : env. 120 mm), Escolives-Sainte-Camille (Yonne) (long. : $119 \mathrm{~mm}$ ), nécropole des Sagnes à Pontarion (Creuse) (Lintz 2001, 62, $\mathrm{n}^{\circ} 238.10$ - long. : env. $100 \mathrm{~mm}$ ).

À Lyon (Rhône), deux exemplaires composites (dont un complet d'une longueur de $83 \mathrm{~mm}$ ) comportent des lames en fer et le ressort en bronze (Boucher, Perdu, Feugère 1980, nos 426 et 427).

En Germanie, on pourra noter huit forces en fer de ce type (long. min. : $114 \mathrm{~mm}$ ) conservées au musée romain d'Avenches en Suisse (Duvauchelle 2005). De même, à Cologne, des forces ont été retrouvées dans la tombe d'un barbier datée des III /IV siècles apr. J.-C. (Haberey 1932). Enfin, en Bretagne, des forces de petite taille de type Manning 3 (long. : 76 et $86 \mathrm{~mm}$ ) sont connues (Manning 1985, pl. 14).

La découverte des forces dans une aire des thermes, pourrait renvoyer à un usage lié aux pratiques des usagers des thermes où le trousseau type, constitué du strigile, de l'aryballe, de la pince à épiler et du rasoir (Pasquinucci 1987, 22) pourrait avoir été complété par des ciseaux destinés, par exemple, à égaliser l'épaisseur de la barbe ou à entretenir la taille des cheveux ou de la moustache (Virgili 1989).

L'appartenance à un usager des thermes n'est pas l'unique option envisageable. En effet, on peut également imaginer qu'il s'agit de l'outil de travail d'un coiffeur barbier (usage professionnel). Cette possibilité nous permettrait d'enrichir nos connaissances sur 
l'implantation des tonstrina (échoppes de coiffeur barbier) dans l'enceinte de thermes publics.

À Fréjus, l'association des forces au contexte chronologique (entre l'époque flavienne et la fin du $\mathrm{II}^{\mathrm{e}}$ siècle apr. J.-C.), pourrait témoigner du phénomène de mode du port de la barbe que l'on retrouve à partir de 120 apr. J.-C. sous le règne et l'influence de l'empereur Hadrien. Ainsi, au début du $\mathrm{II}^{\mathrm{e}}$ siècle apr. J.-C. « la majorité des Romains se contente donc d'une simple taille [de la barbe] et d'un coup de peigne [...] effectuée avec des ciseaux de fer (forfex) » (Carcopino 1939, 188).

\subsubsection{La monnaie}

(J. F.)

C'est dans la construction du cuvelage du puits SB1262 (MR1264) qu'a été découverte cette monnaie. Elle permet de fournir un terminus à cette structure. Il s'agit d'un sesterce de Domitien, fait d'un alliage de cuivre et étain (fig. 102). La légende au droit porte l'inscription : IMP(CAESDOMI)TAVGGERM.CAS (XI à XIII CENS PERPP) avec sur le champ le buste de l'empereur nu à droite avec couronne de lauriers. Le champ du revers représente Domitien à cheval tenant un bouclier et faisant chuter un ennemi ainsi que les lettres SC. Il s'agit d'une monnaie de $24,80 \mathrm{~g}$ pour $33 \mathrm{~mm}$ de diamètre, frappée dans les ateliers de Rome entre 85 et 89 apr. J.-C. (RIC vol. II, 190 à 199, nº ex. 361).
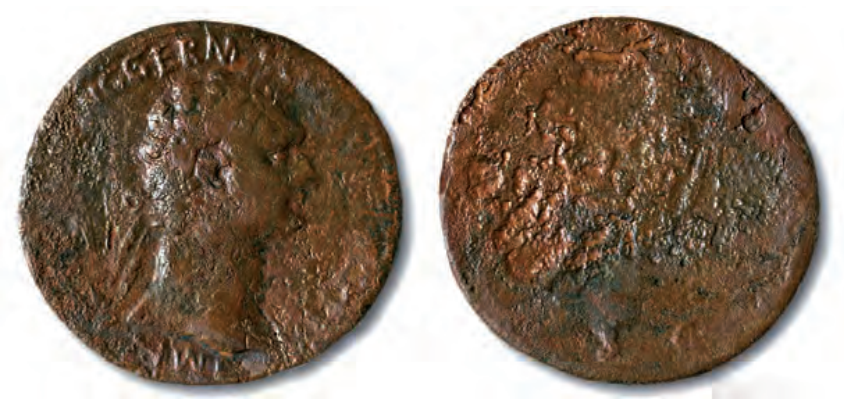

Fig. 102. Sesterce de Domitien découvert dans le massif de la fondation du puits SB1262.

\subsubsection{La faune}

(M. L.)

Le matériel osseux de cette phase constitue un lot peu important de 51 fragments identifiés en fonction de l'espèce et du segment anatomique ${ }^{13}$. Les ossements de ces niveaux peuvent être classés dans la catégorie

13 Tous les ossements ont été pris en compte, les os du crâne, les vertèbres et les côtes dans la mesure où leur fragmentation permettait l'identification de l'espèce. Les éléments de discrimination entre mouton et chèvre sont ceux qui ont été publiés par J. Boessneck dans son article paru en 1969. des déchets de consommation. Ces dépôts ont été identifiés en fonction d'un ensemble de critères relatifs au dénombrement des restes par espèces, par segments anatomiques présents et par détermination des âges d'abattage.

En raison de la petite quantité de restes déterminés, le nombre d'espèces relevées dans les lots est limité (sept espèces différentes, terrestres et marines pour chaque état). Celles-ci sont presque uniquement terrestres et domestiques. De même, les restes d'animaux non consommés, comme les équidés et les chiens, sont toujours en nombre restreint (3\% à $15 \%$ du matériel total déterminé). L'origine des dépôts explique la composition particulière de ces ensembles formés par les déchets provenant de l'alimentation carnée.

La composition du mobilier de cette phase offre une répartition spécifique : les restes d'ovins et de caprins sont les plus abondants, $60 \%$ du nombre total des ossements déterminés (tab. 03). Parmi ces derniers, les os de deux animaux âgés de 2 à 4 ans ont été identifiés ${ }^{14}$. Les ossements des porcs et des bovins sont moins nombreux : les restes de suidés ne représentent que $14 \%$ du matériel (dont deux animaux âgés de 18 à 24 mois) et les restes de bovins, $12 \%$ des fragments.

Les premiers résultats de l'analyse indiquent une consommation prépondérante de la viande d'ovins et de caprins sur le site. Mais il convient néanmoins de rester prudent sur ces résultats en raison du faible nombre de restes répertoriés.

Ce tableau diffère de celui observé sur les autres sites urbains de la région pour la même période (fig. 103). En effet, au Ir siècle apr. J.-C., la viande de mouton et de chèvre n'est pas la plus fréquemment consommée, on lui préfère la viande de porc, ce phénomène est observable jusqu'au Bas-Empire.

Sur le site des Aiguières (Columeau 1991, 61) au tout début du I Ir siècle apr. J.-C., les restes de porcs représentent presque la moitié des ossements identifiés (47\%); ils sont deux fois plus nombreux que les ossements d'ovins et de caprins $(28 \%)$. Dans le mobilier du $\mathrm{II}^{\mathrm{e}}$ siècle (Columeau 1991, 72), les proportions évoluent peu, les restes de porcs représentent toujours la moitié du mobilier récolté $(51 \%)$ et les os de petits ruminants environ le quart (29\%). À Aix-en-Provence, les déchets alimentaires du II ${ }^{\mathrm{e}}$ siècle des sites urbains du Palais Monclar et des Thermes ${ }^{15}$, sont composés pour moitié d'ossements de porcs, respectivement $37 \%$ et $57 \%$ dunombrederestesdéterminés pour chacun des sites et d'un quart d'ossements de bovins.

14 Les âges ont été déterminés en fonction du degré d'épiphysation des articulations (Barone 1986, 76) et de l'état d'éruption des dents (Hillson 1986). 15 Étude à paraître dans Claude, Nin (dir.) - Les fouilles archéologiques du Palais Monclar (1992-1996). 


\begin{tabular}{|c|c|c|c|c|c|c|}
\hline $3 \mathrm{~A}$ & Ovins & Porcs & Bovins & Chevaux & Poules & Chiens \\
\hline \multicolumn{7}{|l|}{ Chevilles Os. } \\
\hline Têtes & 1 & 1 & & & & \\
\hline Dents isolées & 2 & & 1 & & & \\
\hline Cervicales & 2 & & & & & \\
\hline Thoraciques & & 1 & & 2 & & \\
\hline \multicolumn{7}{|l|}{ Lombaires } \\
\hline \multicolumn{7}{|l|}{ Sacrums } \\
\hline \multicolumn{7}{|l|}{ Caudales } \\
\hline Côtes/Stern. & 3 & 1 & & & & \\
\hline Scapulas & 2 & & 1 & & 1 & \\
\hline Humérus & & 2 & & & 1 & \\
\hline Radius & 1 & & & & & \\
\hline Ulnas & & & & & 1 & \\
\hline Pelvis & 12 & & 1 & & & 1 \\
\hline \multicolumn{7}{|l|}{ Fémurs/pat. } \\
\hline Tibias/Fib. & 4 & & 2 & & & \\
\hline \multicolumn{7}{|l|}{ Carpes } \\
\hline Métacarpes & & 1 & & & & \\
\hline Tarses & 1 & & & & & \\
\hline Métatarses & 2 & & & 1 & & \\
\hline Phalanges & 1 & 1 & 1 & & & \\
\hline \multicolumn{7}{|l|}{ Autres } \\
\hline Total NRD & 31 & 7 & 6 & 3 & 3 & 1 \\
\hline
\end{tabular}

tab. 03 : Restitution des restes de l'état 3A, par segments anatomiques (NRD).

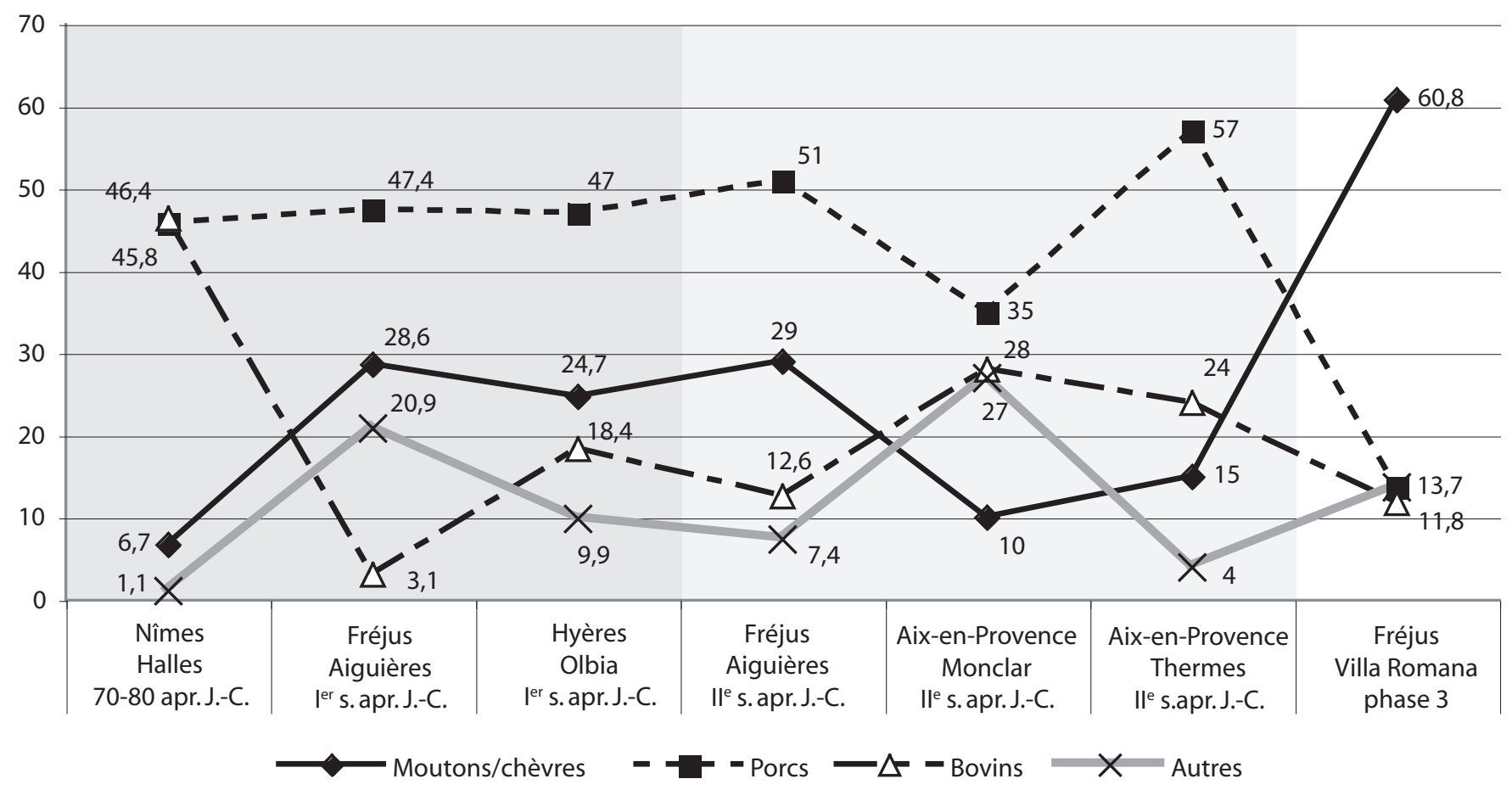

Fig. 103. Comparaison de différents sites urbains de la même période. 
Les os de moutons et de chèvres ne dépassent pas $15 \%$ du mobilier dans ces gisements.

Des proportions équivalentes se rencontrent dans d'autres lots issus des villes de la Narbonnaise : à Nîmes, dans le dépotoir d'une domus constitué dans la seconde moitié du Irer siècle apr. J.-C., les ossements de porcs $(45,8 \%)$ et de bovins $(46,4 \%)$ se retrouvent à part égale parmi les déchets alimentaires de ce dépôt. Les restes de moutons/chèvres sont en très faible quantité $(6,7 \%)^{16}$.

Sur les agglomérations de taille plus modeste, le phénomène reste identique. Sur le site de Forum Voconii (Cannet-des-Maures, Var), la proportion de restes de porcs est élevée dans les niveaux du II ${ }^{\mathrm{e}}$ siècle après J.-C. Les fragments de suidés dominent très largement dans le matériel (63,7 \% des restes identifiés) ; ils témoignent d'une préférence marquée pour la viande de cet animal ${ }^{17}$. À Olbia (Hyères, Var), les ossements de porcs sont les plus nombreux : entre le Ir et le III $^{\mathrm{e}}$ siècle : ils représentent $47 \%$ à $33 \%$ des restes identifiés contre seulement $25 \%$ à $29 \%$ pour les ossements de petits ruminants ${ }^{18}$.

Pour le Haut-Empire, la composition du spectre faunique sur le site de Villa Romana montre, bien que le nombre de restes soit minime, une différence marquée avec des ensembles contemporains. Elle semble indiquer une préférence pour la viande de petits ruminants par les populations urbaines locales alors qu'elle est en nette diminution au $\mathrm{I}^{\mathrm{er}}$ siècle apr. J.-C. sur de nombreux sites urbains de Narbonnaise. Il reste difficile de déterminer l'origine d'une telle disproportion. Est-elle à chercher dans la localisation du site, à la périphérie de la ville, propice au développement d'un certain type d'élevage ? Des parallèles peuvent en effet être établis entre le mobilier de ce site et celui de gisements ruraux de la même époque sur lesquels les restes d'ovins/caprins représentent plus de la moitié du mobilier osseux (Leguilloux 1989). Mais il est également possible que le constat soit faussé par le petit nombre de restes conservés.

\subsection{Datation de la phase $3 \mathrm{~A}$}

$$
\text { (P. E., E. P.) }
$$

La mise en place de cette phase suit directement la fin de la phase précédente, sans qu'aucune période d'abandon n'ait été décelée. C'est donc le comblement des structures anciennes (comblement du puits...), la constitution des niveaux de construction des murs réorganisant l'ensemble et la mise en place du

16 Fouille de la ZAC des Halles (Gardeisen 1993, 250 et 255).

17 Responsables du chantier : F. Martos et G. Congès. M. Leguilloux - Les Blaïs (Cannet-des-Maures, Var) 2001-2005. Rapport d'étude des restes osseux animaux, janvier 2005.

18 Faune de la phase 5, îlot VI (Leguilloux 2006, fig. 1, 425). niveau 1010 qui constituent les faits déclencheurs de la phase 3A et permettent ainsi de la dater. Les aménagements annexes comme le puits SB1262 apparaissent dans le courant de cette phase. La phase 2 s'achève vers le milieu du $\mathrm{I}^{\text {er }}$ siècle apr. J.-C. comme tend à le montrer le comblement du puits PT2001. Le remplissage (1020) de la tranchée de fondation (1018) du mur MR1003 n'a pas livré beaucoup de mobilier (amphore massaliète, pâte claire et sigillée gauloise). Les comblements des fosses sont plus riches en mobilier que pour la phase précédente. L'étude de ce matériel permet d'estimer leur mise en place au moment de la restructuration générale. La fosse 1139, avec son remplissage 1140, est celle qui a fourni le plus de mobilier, soit 34 fragments. On y trouve un plat en vernis rouge pompéien de type Goudineau 15, un pot à feu 160 de la typologie de J. Bérato. À cela s'ajoutent des amphores africaines et italiques, des pâtes claires, d'autres modelées...

L'urne à encolure en baïonnette constitue le témoin le plus récent, puisque ce modèle n'apparaîtrait pas avant le deuxième quart du $\mathrm{I}^{\text {er }}$ siècle apr. J.-C. (Bérato 1993, 323). La fosse FS1231 (comblement 1232) a fourni aussi plusieurs fragments de modelées, associés à des sigillées sud-gauloises dont une coupe Vertault A et un gobelet de type Hermet 9, ainsi qu'un bord d'amphore africaine type Ostia 59. La coupe à paroi convexe Vertault est produite entre 20 et 40 apr. J.-C., le fragment de bord identifié comme une forme Hermet 9 ne serait pas produit avant 60 apr. J.-C. Ces indices confirment les données stratigraphiques, à savoir que ce réseau de fosses (SFO1152) est bien postérieur à ceux de la phase 2 . Nous serions, à en croire le comblement de la fosse FS1232, après le milieu du $\mathrm{I}^{\mathrm{er}}$ siècle apr. J.-C.

La découverte d'une monnaie frappée à l'effigie de l'empereur Domitien entre 85 et 89 apr. J.-C. dans l'un des murs du puits (MR1264), permet de situer sa mise en place dans le dernier quart du ${ }^{\text {er }}$ siècle apr. J.-C. Les fragments de céramique découverts dans ces murs s'accordent avec cette datation.

La datation radiocarbonne d'un bordé de la paroi $1264^{19}$, permet de situer l'abattage des arbres employés dans la construction du bateau remployé, au plus tôt durant le deuxième tiers du $\mathrm{I}^{\mathrm{er}}$ siècle apr. J.-C. Également, une datation $\mathrm{C} 14$ réalisée sur un charbon ${ }^{20}$ provenant de l'épaisseur du sol de la zone 1 (US1010)

19 (\#634 SB 1262-1264/5) (Code labo : Poz-20222). Les datations proposées après calibrage sont : 68,2\% de probabilité ; 65AD (68,2\%) 130AD ; 95,4\% de probabilité ; 20AD $(95,4 \%)$ 220AD.

20 Code Labo Poz-21261 
(\#260) confirme cet horizon chronologique en fournissant un terminus en 80 apr. J.-C. ${ }^{21}$

Ainsi, si on superpose ces datations avec les données stratigraphiques et la monnaie de Domitien, on peut conclure que le bateau a été mis en chantier dans le courant du I ${ }^{\text {er }}$ siècle apr. J.-C. et abandonné durant le même siècle, sans avoir dépassé la soixantaine d'années.

Nous proposons de situer la mise en place de la phase $3 \mathrm{~A}$ au début de la seconde moitié du $\mathrm{I}^{\text {er }}$ siècle apr. J.-C.

\subsection{Le complexe des thermes de Villeneuve (S. A.)}

Le complexe thermal de Villeneuve présente un ensemble de bâtiments relativement bien conservés, pour certaines pièces jusqu'à la voûte et ce, vraisemblablement en raison d'une réoccupation précoce d'une partie des édifices (fig. 104 et 105). Connu depuis le XVII ${ }^{\mathrm{e}}$ siècle, ce monument a été étudié de nombreuses fois et les sources iconographiques sont importantes (fig. 106).

L'état le mieux conservé correspond à la dernière grande phase d'occupation. Celle-ci est en rapport avec la phase 3A de la fouille de Villa Romana. Plusieurs restructurations sont observables et nous ne reviendrons pas ici sur la fonction originelle du bâtiment. Nous nous contenterons de décrire principalement les dernières phases de fonctionnement à partir des données récentes issues du diagnostic réalisé sur le monument en 2008 et permettant de compléter le plan (Excoffon, Ardisson 2008) (fig. 107).

\subsubsection{Organisation et fonctionnement des bâtiments}

Le bâtiment thermal reste assez peu connu dans son ensemble et de nombreuses zones d'ombre subsistent malgré un état de conservation exceptionnel. L'emprise totale du complexe, tout comme le choix de son emplacement et de son organisation, restent flous. Néanmoins, les sondages pratiqués lors du diagnostic réalisé en 2008 au nord, à l'est et au sud révèlent une étendue bien plus importante que celle supposée jusque là. Ces derniers ont permis de définir une superficie minimale des bâtiments couverts et des espaces de service (hors zone 11, palestre et jardins) de près de $1250 \mathrm{~m}^{2}$. À l'évidence, ce nombre est inférieur à la superficie totale de l'ensemble. En ajoutant le bâtiment oriental (zone 11), la superficie couverte dépasse les $1800 \mathrm{~m}^{2}$ ce qui en fait alors un ensemble thermal déjà

$2168 \%$ de probabilité : 40BC $(59.5 \%) 30 \mathrm{AD}$ et $35 \mathrm{AD}(8,7 \%) 50 \mathrm{AD} /$ $95,4 \%$ de probabilité : 60BC $(95,4 \%)$ 80AD

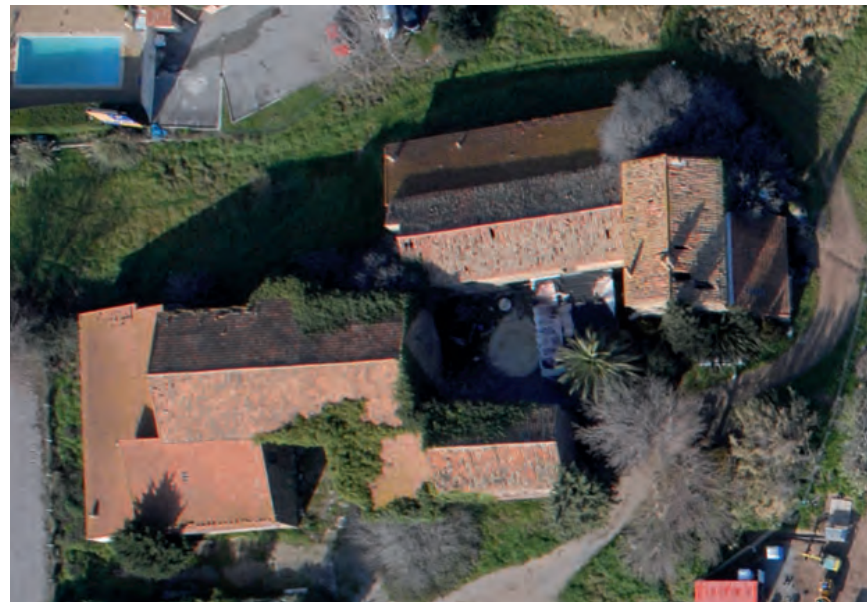

Fig. 104. Photographie verticale de l'ensemble de la Ferme de Villeneuve (cl. Ville de Fréjus - Altivue ${ }^{\odot}$ ).

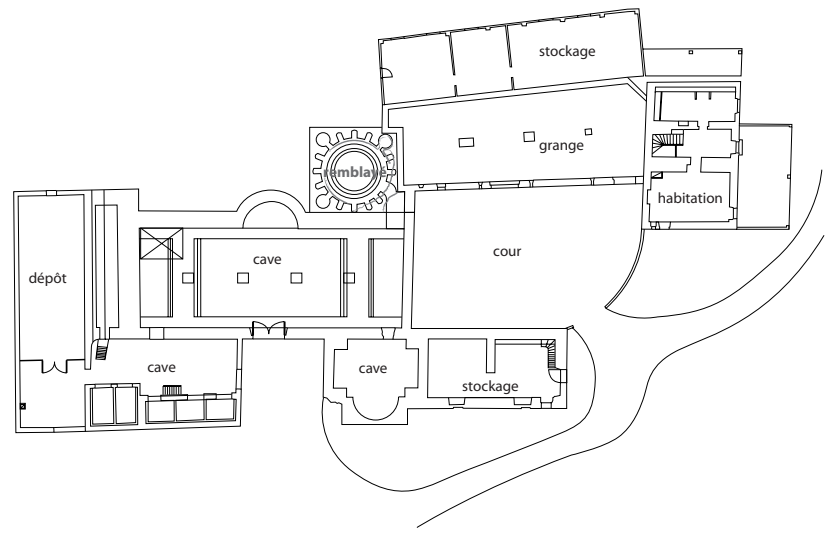

Fig. 105. Plan de la Ferme de Villeneuve (ensemble des bâtiments et aménagements actuels).

important si on le compare aux autres complexes de la Gaule.

Par ailleurs, les salles retrouvées dans les sondages au nord des bâtiments remettent totalement en question l'organisation de l'édifice. La présence d'une salle chauffée jouxtant un frigidarium (au nord) renouvelle les problématiques. C'est en tout cas la preuve que d'autres salles thermales existent et viennent éclairer différemment le plan (zones $3 \mathrm{~A}$ et $\mathrm{C}$ et 7 ).

Enfin, si l'évidence de deux états distincts entre le premier bâtiment à abside et le développement de l'ensemble thermal était un fait déjà reconnu, l'existence de plusieurs états postérieurs au sein des thermes a également été clairement mise en évidence. Toutefois la concordance de ces derniers avec la fouille de Villa Romana reste encore non définissable.

Le plan n'étant pas connu dans sa totalité, loin s'en faut, la description des salles se fera arbitrairement du nord au sud. La zone 4, close au nord et à l'est, pourrait 
(91)

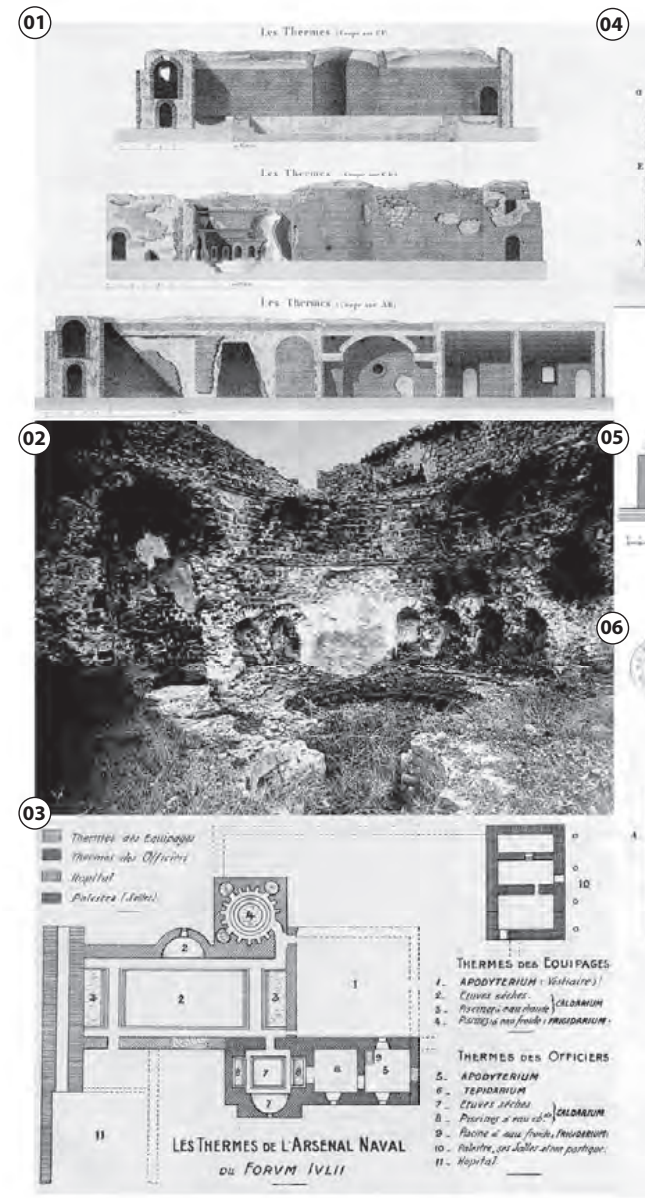

(4)

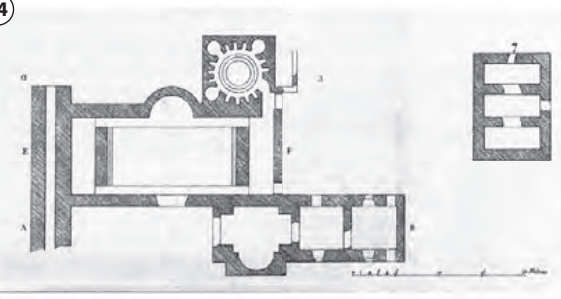

(07)

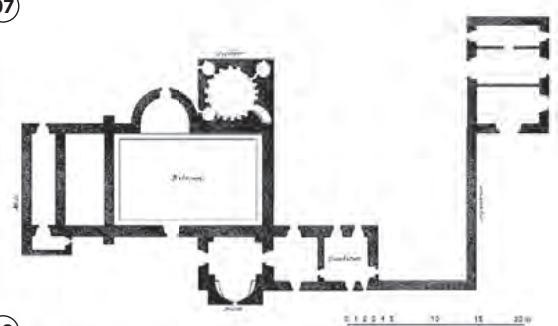

8

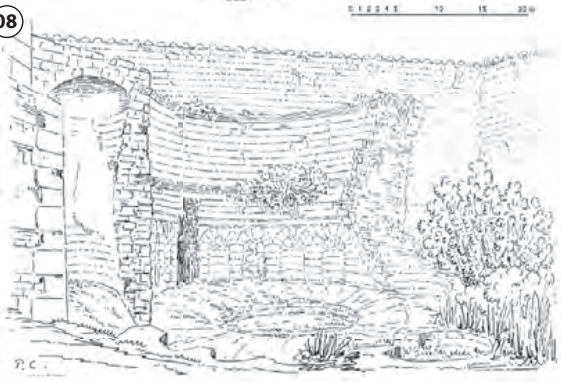

(99)

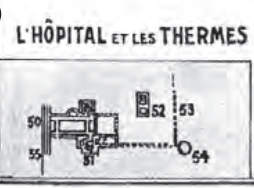

(10)

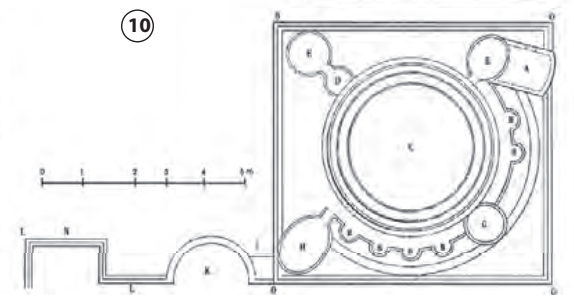

Fig. 106. Plans anciens

01. Texier (1849, PI. 5 fig. 4, 5 et 6) / 02. Fouille Aubenas 1881 (Rivet et al. 2000, fig. 611) / 03. Donnadieu (1928, fig. 31) / 04. Texier (1849, PI. 5, fig. 3) / 05. Aubenas (1881, PI. 1, fig. 3) / 06. Aubenas (1881, PI. 1, fig. 1) / 07. Fabry de Peyresc (Rivet 2000, fig. 602) / 08. Salle à niches, P. Coste (Rivet et al. 2000, fig. 607) / 09. Forma Orbis Romani (1931) / 10. Salle à niches d'après Chr. Villeneuve-Bargemont, 1829 (Rivet et al. 2000 , fig. 603).

correspondre à une espace de service ${ }^{22}$. Le bâtiment proprement dit comprend au nord une pièce rectangulaire de $63 \mathrm{~m}^{2}$ au sol sur hypocauste (zone 3A) jouxtant une autre salle au sol de béton de tuileau (zone 3C) (fig. 108) $)^{23}$.

$\mathrm{Au}$ sud de ces dernières, une pièce de plan circulaire considérée comme un frigidarium (zone 3B) de type campanien avec piscine centrale et alvéoles latérales, est assez proche du frigidarium des thermes de Stabies à Pompéi. Cette pièce d'environ $25 \mathrm{~m}^{2}$, dont la couverture est assurée par une coupole, a connu en réalité deux phases distinctes d'utilisation. Dans un premier temps, une série de niches basses (long. 0,54 m, haut. : 1,20 m et prof. $0,60 \mathrm{~m}$ ) est aménagée. Onze sont conservées

22 D'importants niveaux de cendre et de charbons ont d'ailleurs été constatés dans les sondages de la partie est de cette zone.

23 Ces pièces inédites ont été découvertes lors du diagnostic de 2008 et ne sont donc que partiellement connues. sur un total probable de seize, si on les restitue sur l'ensemble de la pièce (fig. 109 à 111). Leur fonction n'a pas encore été définie avec exactitude : s'agissait-il, dans un premier temps de baignoires individuelles d'eau chaude situées dans une pièce chauffée ${ }^{24}$ ou simplement de niches décoratives ? Dans un second temps, ces niches sont partiellement condamnées par la mise ne place d'un bassin central circulaire de 3,90 m de diamètre et $0,72 \mathrm{~m}$ de profondeur ${ }^{25}$, et au moins quatre niches sont obstruées par l'aménagement de trois bassins circulaires de taille réduite et de plan assez proche (entre $1,5 \mathrm{~m}$ et $2 \mathrm{~m}$ ). A. Bouet interprète ces bassins comme des douches, hypothèse qu'il appuie sur la présence d'une bouche circulaire située en contre-haut (fig. 112). Toutefois la dimension de $0,44 \mathrm{~m}$ de diamètre nous fait plutôt pencher pour une fenêtre de type oculus

24 Par un brasero par exemple.

25 La vidange de ce dernier a été vue par J.-A. Aubenas. 


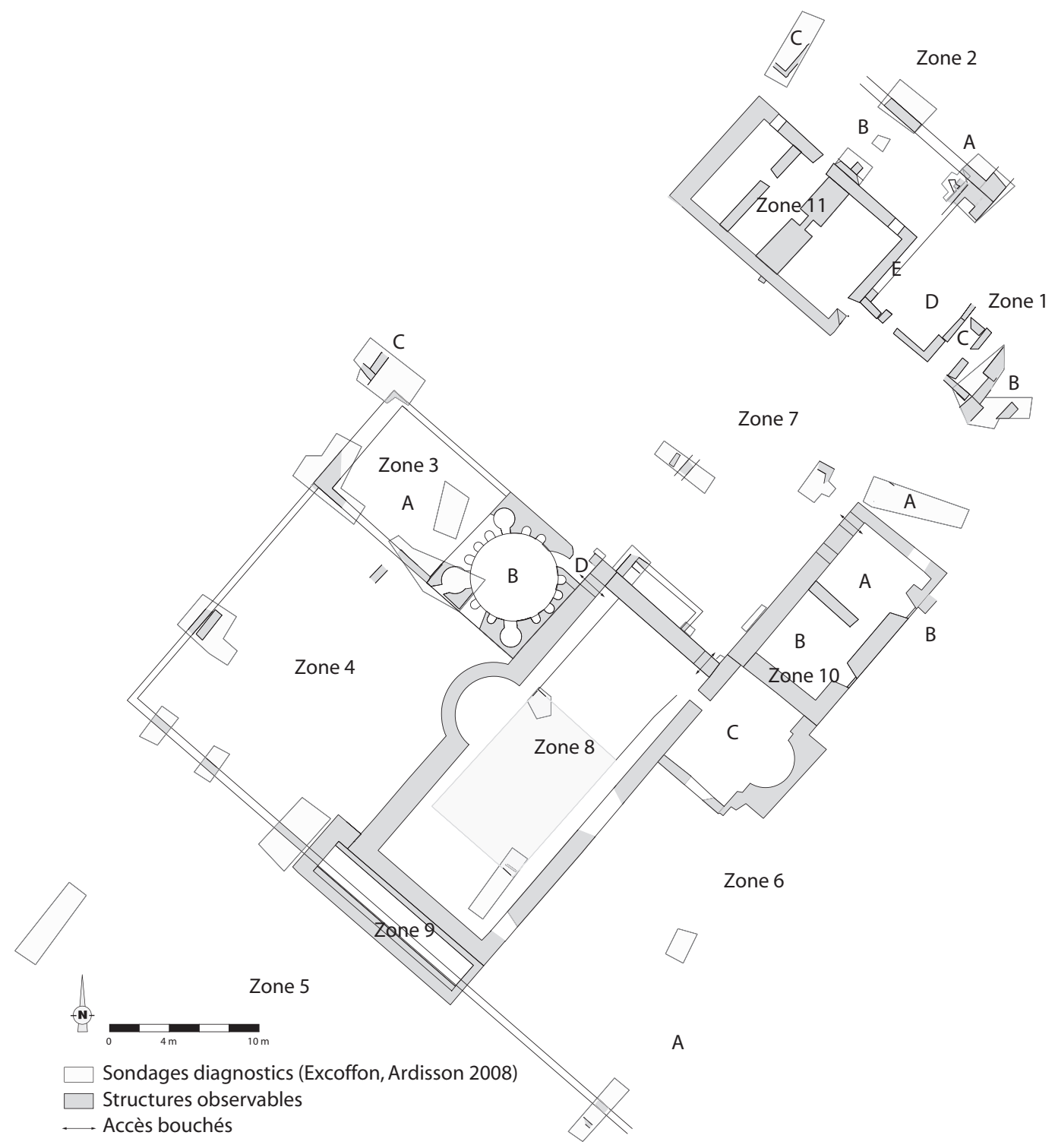

Fig. 107. Plan des thermes de Villeneuve (d'après Excoffon, Ardisson 2008).

qu'une arrivée d'eau. Enfin, l'accès depuis la grande pièce (zone 8) est condamné peut être à ce moment. $\mathrm{Si}$ la transformation de la pièce est évidente, la question de la destination reste en suspens, d'autant que les auteurs divergent sur ce point. Pour Ch. Villeneuve-Bargemont, Ch. Texier et J.-A. Aubenas, il s'agissait d'une pièce chauffée, pour A. Donnadieu d'une pièce froide, hypothèse également soutenue par A. Bouet. Toutefois, les restructurations mises en évidence par le diagnostic archéologique impliquent de reconsidérer la question, et d'y voir une pièce chauffée ${ }^{26}$ dans un premier temps (état 1),

26 On peut mettre également à la faveur de cette hypothèse la présence d'un couloir d'accès réduit, ainsi que sa situation entre deux salles chauffées (3A et 8$)$. puis froide dans un second (état 2). L'hypothèse d'un laconicum transformé en frigidarium apparaît donc la plus crédible. En outre, les bases des niches du premier état n'ayant pu être mises en évidence, l'hypothèse de baignoires individuelles ne peut être confirmée, mais, si celle-ci devait se vérifier, nous serions en présence d'un type de pièce chauffée d'inspiration plutôt orientale ${ }^{27}$.

27 Dans ce cas de figure, on peut alors supposer qu'il s'agissait de baignoires individuelles d'eau chaude communes dans les bains de type grec. La continuité de ce modèle, après son abandon en Grèce aux $\mathrm{II}^{\mathrm{e}} / \mathrm{I}^{\mathrm{er}}$ siècles av. J.-C., appliquée aux thermes de type romain trouve une résonnance en Égypte où une forme hybride développée au début de l'Empire, combine des éléments grecs et romains (Broise 2009 et Fournet, Redon 2010). Pour l'heure, rien ne permet d'aller plus en avant dans cette restitution mais l'arrivée de légionnaires originaires d'Égypte dans le cadre du rapatriement des bateaux d'Antoine et Cléopâtre, donne à cette hypothèse toute sa dimension. 


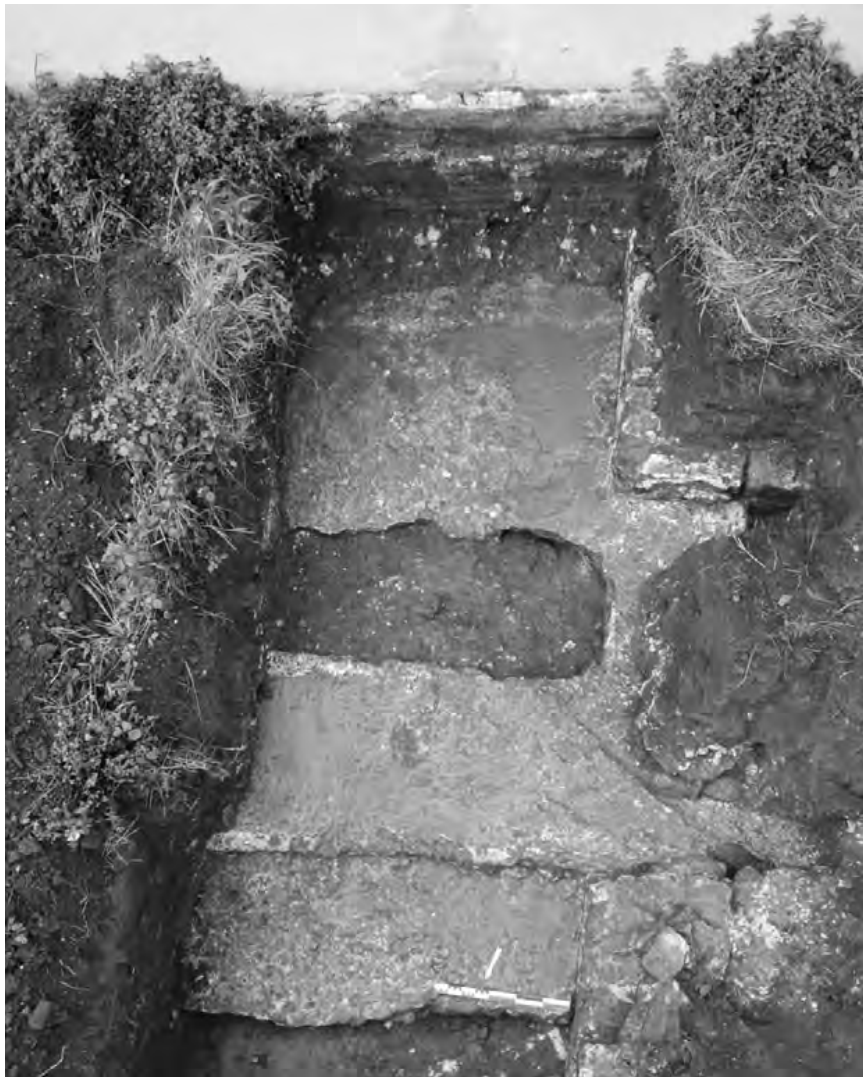

Fig. 108. Sol de béton, zone 3C.

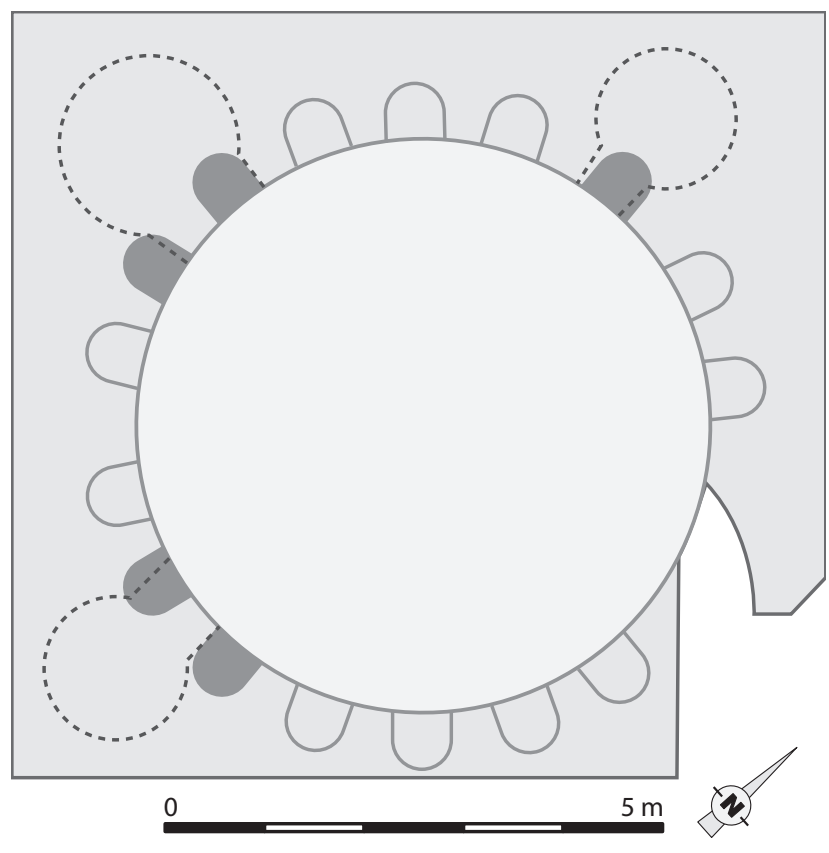

Fig. 110. Reconstitution théorique du premier état de la salle 3B.

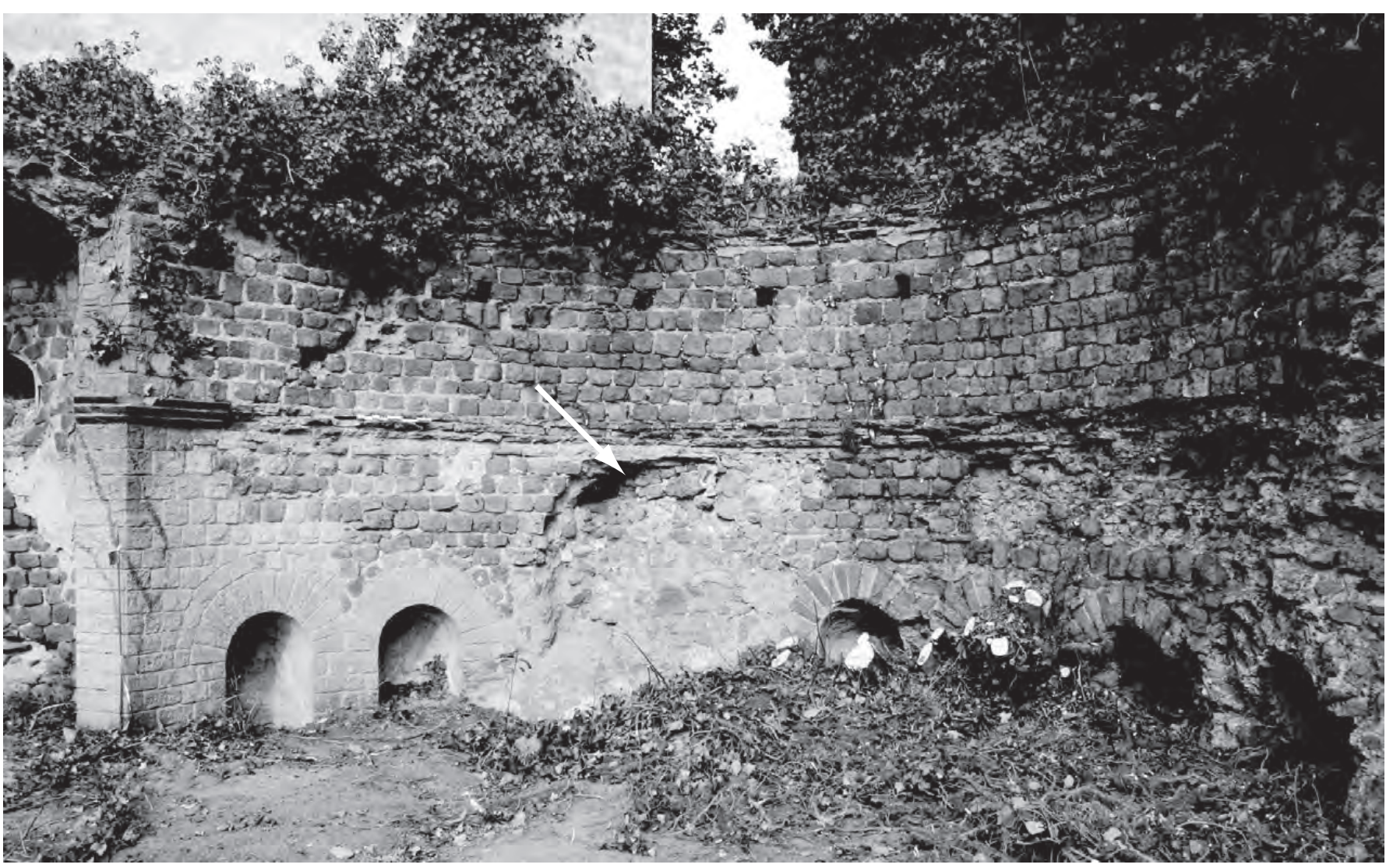

Fig. 109. Vue de la pièce circulaire 3B, avec localisation de l'accès bouché. 


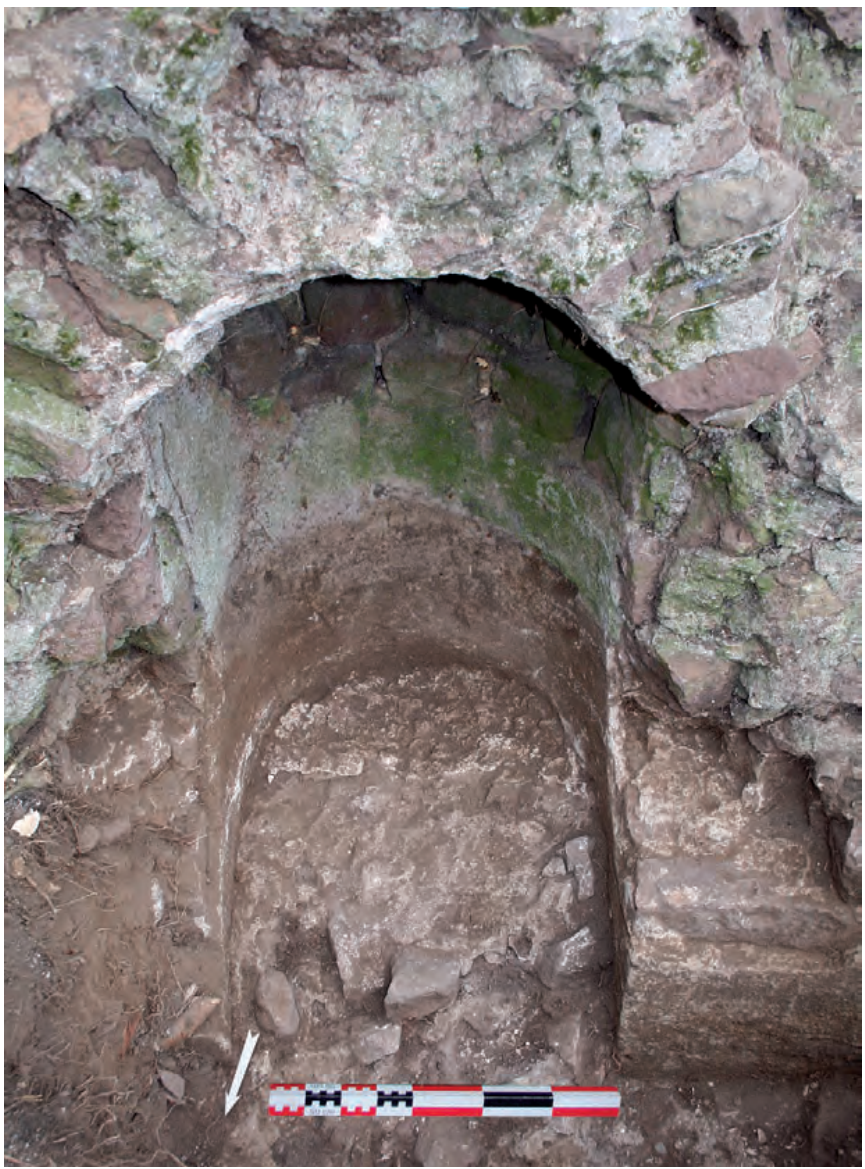

Fig. 111. Niche conservée et partiellement comblée (état 2, salle 3B).

Quoiqu'il en soit, la condamnation du passage vers la grande pièce (zone 8), au profit d'une ouverture vers une zone très probablement ouverte (zone 7), entérine l'idée d'une transformation en frigidarium dans la seconde phase.

L'accès à cette salle, depuis la zone 8 , se faisait donc initialement par un couloir assez étroit et sinueux (D), véritable « sas thermique ». Cette salle (zone 8) couverte d'une voûte en plein cintre, dont la maçonnerie emploie comme agrégat un matériau de faible densité, inconnu à Fréjus ${ }^{28}$, pourrait correspondre à un caldarium à grand bassin de nage ou «piscine chauffée » (selon la typologie de A. Bouet) (fig. 113 et 114). Au centre se trouvait une grande piscina de $10 \mathrm{~m}$ de long et $7 \mathrm{~m}$ de large avec une profondeur relativement importante de $1,65 \mathrm{~m}$. Cette structure, aux parois recouvertes de béton de tuileau peint en rouge, serait chauffée, selon les archéologues antérieurs, par un système d'hypocauste sur pilettes dont quelques briques auraient été retrouvées.

En 2008, lors du diagnostic, les deux sondages effectués dans cette piscine n'ont pas permis de confirmer

28 L'analyse de M. Dubar a conduit à définir cette roche comme une cinérite à ponce (silice bulleuse)

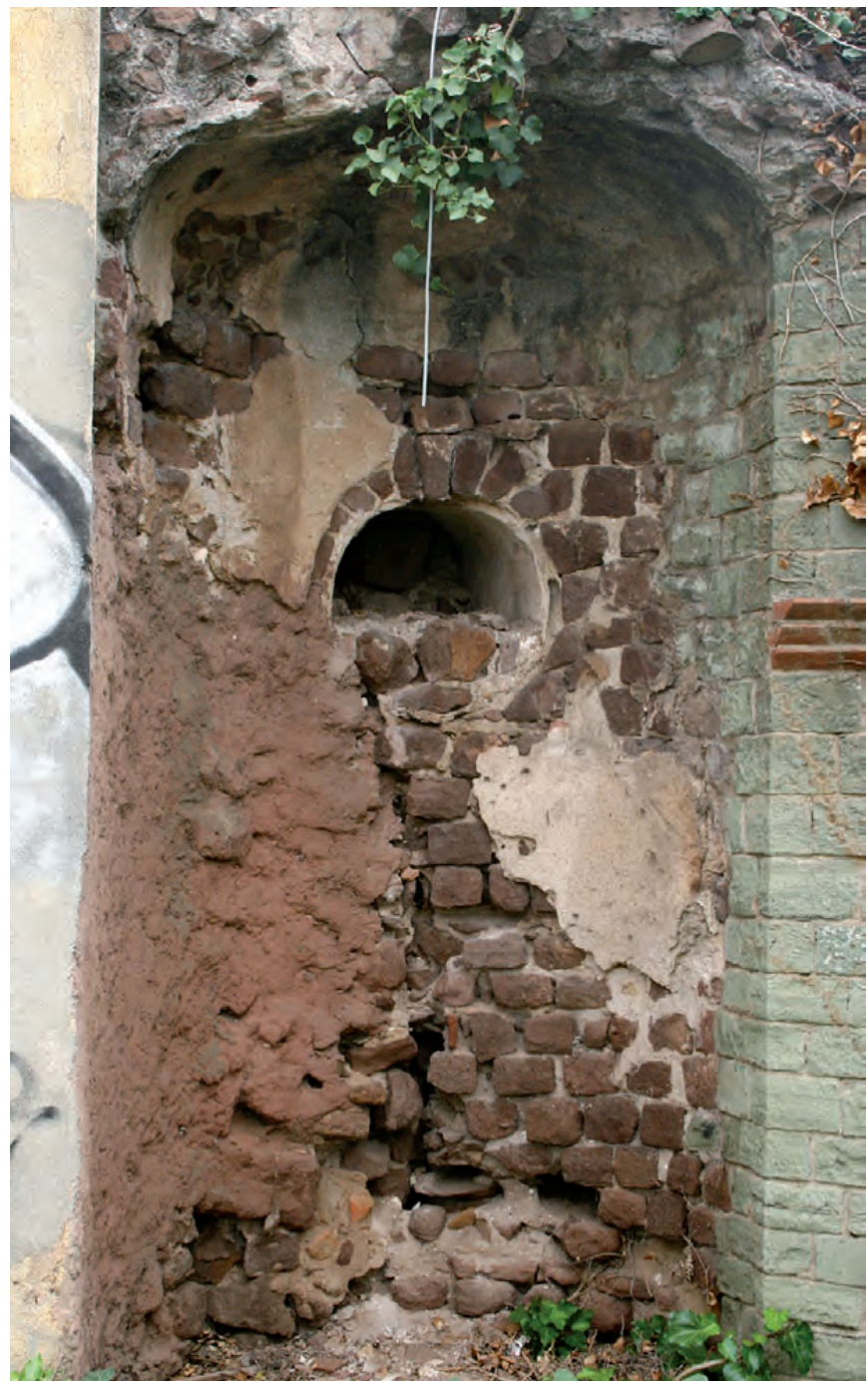

Fig. 112. Alvéole située dans l'angle nord-est (état 2), conservée jusqu'au sommet de la coupole, un oculus (?) est visible au fond.

ce point, ni même si la construction de ce bassin central remontait à l'origine du bâtiment ${ }^{29}$. L'accès au bassin se faisait par deux escaliers de trois marches disposés aux extrémités est et ouest. Du fait de sa profondeur et de ses dimensions, la natation pouvait y être pratiquée aisément. Il est donc possible d'y voir un bassin d'entraînement destiné à l'exercice physique. Ce bassin était peut-être chauffé (modérément) comme nos actuelles piscines, ce qui en permettait d'autre part l'usage tout au long de l'année. Toutefois, le dispositif technique nécessaire au fonctionnement de ce système n'a pu être retrouvé. En effet, l'existence d'un hypocauste sous le bassin implique une profondeur certaine (espaces de service, praefurnium... $)^{30}$.

29 En outre, ces sondages ont permis la découverte de fragments de mosaïque qui pouvaient constituer le fond de ce bassin.

30 Le fond du bassin se situe à $1,22 \mathrm{~m} \mathrm{NGF}$. 


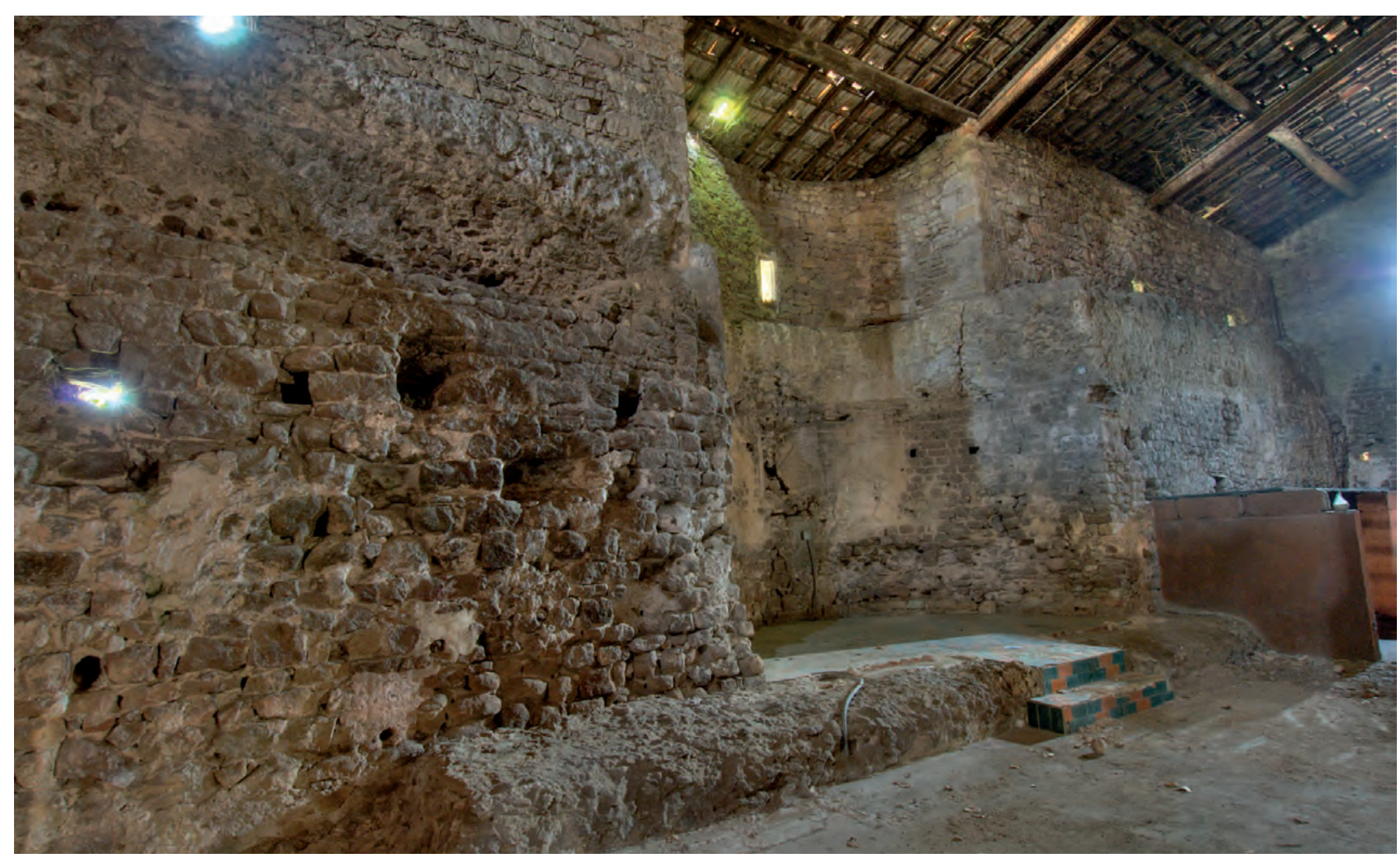

Fig. 113. Zone 8, vue du mur nord et de l'abside (cl. Ville de Fréjus - R. Hacquard॰).

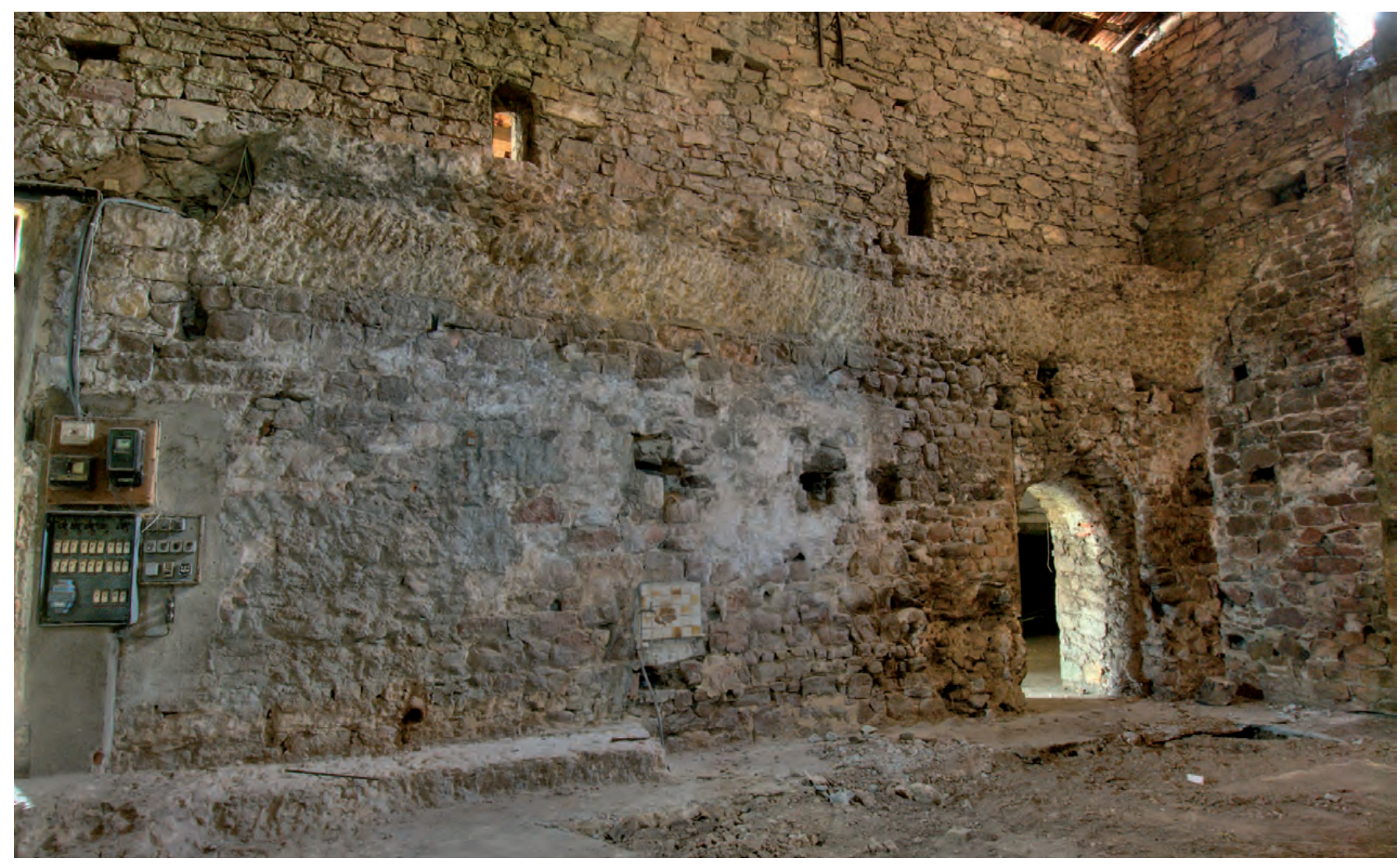

Fig. 114. Vue de la grande salle (zone 8), mur sud (cl. Ville de Fréjus - R. Hacquardº). 


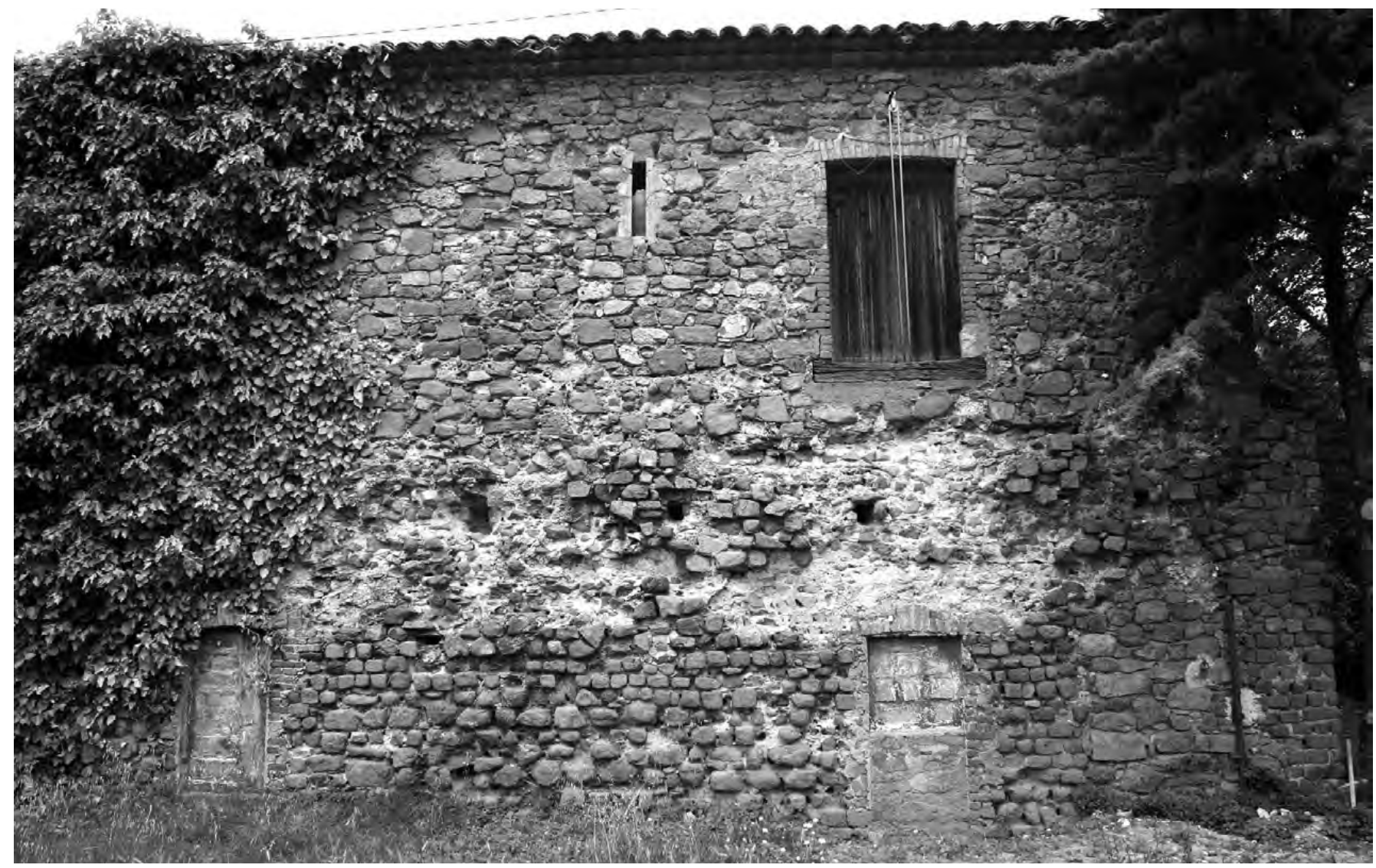

Fig. 115. Mur de façade sud (zone 10).

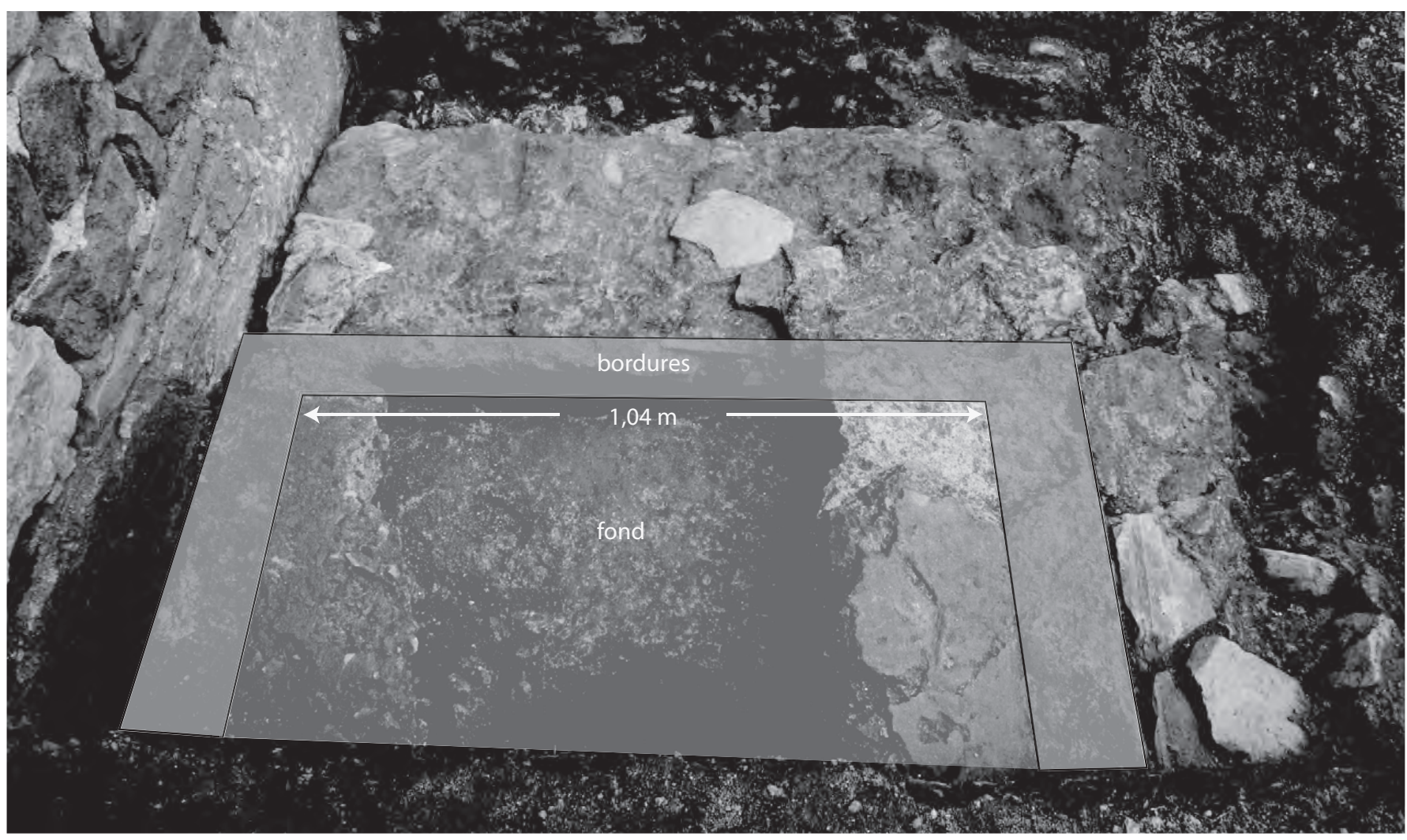

Fig. 116. Extrêmité nord du bassin rectangulaire de la zone 7 . 


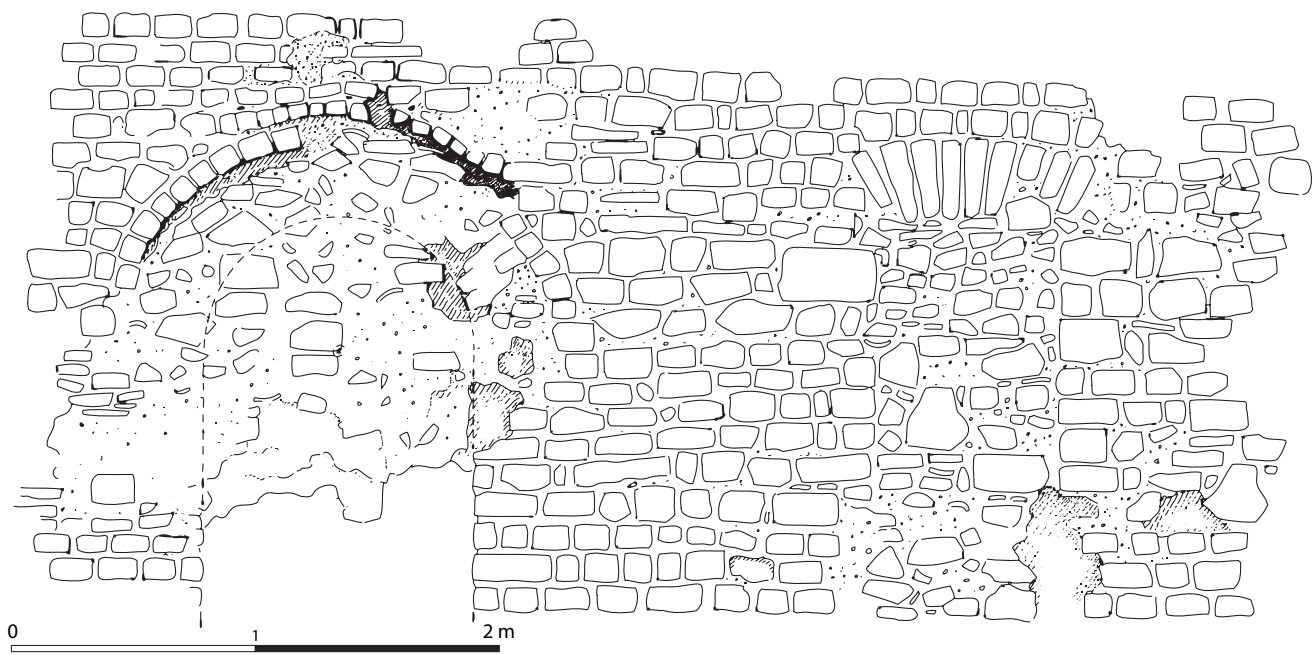

Fig. 117. Relevé de la façade nord de la zone 10 donnant sur la zone 7. Une ouverture bouchée et une fenêtre sont clairement identifiables (S. Roucole)

La galerie technique souterraine (zone 9B) ${ }^{31}$ est située à l'ouest du bassin et, même si le niveau de circulation n'est pas précisément connu, il pourrait correspondre à l'entretien et au fonctionnement de l'hypocauste du bassin.

Cette pièce aurait également disposé de deux bassins latéraux décrits par A. Donnadieu, mais qui n'ont pas été retrouvés lors du diagnostic (fig. 106 - nº6). De faible profondeur $(0,80 \mathrm{~m})$, ils semblent accompagnés d'un troisième situé dans l'abside centrale. Celle-ci, de pratiquement $5 \mathrm{~m}$ de diamètre, présente une fenêtre étroite sur l'extérieur.

Les accès à cette salle se faisaient par le nord depuis la pièce circulaire (3A), par l'est depuis la zone 7 ainsi que par le sud depuis la pièce 10C. Contrairement à ce que pensait $\mathrm{A}$. Donnadieu, aucun accès ne paraît desservir l'ouest, la porte identifiée de ce côté est en fait une fenêtre transformée tardivement.

De par ses installations, la salle aurait pu avoir plusieurs fonctions distinctes : l'échauffement dans la grande piscine centrale par la pratique de la natation et/ou le délassement dans l'un des deux, peut-être trois, bassins latéraux. Cet usage s'effectuant, après s'être échauffé, dans une étuve ${ }^{32}$ qui reste à localiser au moins pour l'état de fonctionnement le plus tardif. Le baigneur pouvait ensuite procéder au choc thermique en accédant peut-être à une natatio extérieure, par exemple dans la zone 7.

Concernant les autres salles thermales situées au sud-est du bâtiment (zone 10), les hypothèses sont diverses. La salle la plus à l'est $\left(28 \mathrm{~m}^{2}\right)(10 \mathrm{~A})$ présente

31 Actuellement presque entièrement comblée jusqu'à la voûte.

32 Le laconicum circulaire (3B) pouvant parfaitement jouer ce rôle. un sol de béton et sa fonction diffère selon les chercheurs précédents (J. Aubenas et A. Donnadieu). Les accès, peut-être deux portes au nord et au sud, et les ouvertures, tantôt deux fenêtres, tantôt niches ou armoires, restent à confirmer. L'observation des élévations révèle en façade sud (fig. 115) la présence d'une porte et en façade nord, celle d'une fenêtre. Par ailleurs, la salle est dotée d'une arrivée d'eau, sans doute pour l'alimentation d'une fontaine ou d'un labrum. Un passage à l'ouest permettait d'entrer dans la pièce suivante (10B) aux dimensions quasi similaires. Selon J.-A. Aubenas, cette salle disposait d'une ouverture au sud et peut-être d'une porte au nord.

La salle suivante (10C) $\left(40 \mathrm{~m}^{2}\right)$ semble, compte tenu de son plan, être un caldarium. Cette pièce présente à l'est et à l'ouest une exèdre quadrangulaire pouvant accueillir des bassins ou baignoires. Une abside dotée d'une petite fenêtre est aménagée dans la paroi sud de la pièce, qui devait disposer d'un labrum. Compte tenu du plan de la salle, on peut imaginer que l'accès à cette dernière se faisait uniquement depuis la salle 8 et non par la salle B à l'est ${ }^{33}$.

Toute la partie centrale du complexe (zone 7) ne nous livre pour l'instant que peu d'informations. Les récentes recherches ont mis au jour un sol et des enduits en béton de tuileau ainsi qu'un bassin rectangulaire (1,04 m de large) appuyé sur le mur est de la zone 8 et ayant connu au moins deux états différents (fig. 116 et 117). La zone 7 est accessible directement depuis les zones 8 et 3B via le couloir (3D). L'interprétation de cette zone reste difficile.

33 L'accès par une des exèdres latérales généralement destinées aux baignoires ou bassins paraît peu probable et n'a par ailleurs pas été retrouvé. 
S'agissait-il d'un espace extérieur type palestre ou d'un intérieur froid (vestibule d'entrée, frigidarium) ? Quoiqu'il en soit, la place centrale de la zone et ses accès en font un espace à part entière dans le parcours du baigneur. Si les zones 7 et 10 paraissent être parties intégrantes du complexe thermal, la zone 11 ne semble pas avoir un lien direct avec le parcours du baigneur. Les investigations menées récemment sur ce bâtiment ne nous renseignent pas non plus sur sa fonction. Les trois salles voûtées ${ }^{34}$ qui la composent (zone 11A, B et $\mathrm{C}$ ) devaient donner sur un péristyle à l'est qui a été observé lors des fouilles réalisées par A. Donnadieu en 1927. Ce constat n'a pu jusqu'alors être confirmé. Les sols d'origine ne sont pas observables et leur position altimétrique est inconnue. Il est intéressant de souligner que cet édifice se trouve aujourd'hui légèrement en surplomb par rapport aux autres bâtiments. Le large mur entre les salles A et B paraît doublé et les voûtes ont été retouchées. L'exigüité de ces deux salles, le niveau altimétrique apparent des $\operatorname{sols}^{35}$ de l'ensemble ainsi que la largeur des murs (plus de 1,20 m) pourraient être des éléments plaidant en faveur de l'hypothèse d'au moins deux citernes jumelées dans cette partie. Toutefois, l'enchevêtrement de structures découvertes au sud de la zone 11, ni datées, ni interprétées, incite à la prudence sur l'interprétation de cet ensemble.

Proposer une nouvelle interprétation ${ }^{36}$ sur l'organisation et le fonctionnement de ces édifices nous paraît, compte tenu du peu d'éléments disponibles, prématuré. De plus, la multiplication apparente des salles chauffées et l'ampleur du complexe posent la question de l'existence éventuelle de deux parcours parallèles. Par ailleurs, l'emplacement et l'orientation fonctionnelle des installations, lient volontiers l'activité de ces thermes au camp militaire dans lequel $\mathrm{Chr}$. Goudineau l'inscrit (Goudineau, Brentchaloff 2009).

Nous reprenons qu'en partie l'hypothèse d'A. Bouet qui interprète plutôt l'édifice comme des thermes curatifs du fait, principalement, de la présence du caldarium à grand bassin de nage plusieurs fois attesté dans des complexes ayant cette vocation (zone 8), car cet élément typologique, en l'absence de source thermale connue sur le territoire de Fréjus, ne peut à lui seul justifier une telle fonction. Cela n'exclut toutefois pas la possibilité que des soins aux huiles essentielles et à l'eau de mer aient pu y être prodigués. Il paraît de ce fait plus opportun d'y voir un complexe hygiénique ayant pu réaliser, dans

34 Dont les voûtes d'origine sont encore en place.

35 Les niveaux actuels de circulation ne correspondent pas aux surfaces antiques.

36 Déjà largement effectuée par les auteurs antérieurs (Ch. Texier, J.-A. Aubenas, A. Donnadieu, P.-A Février et A. Bouet). un tel contexte (camp militaire), ces trois fonctions : l'hygiène, l'entraînement et les soins des militaires. Seules des opérations de terrain (étude complète du bâti et fouilles), pourraient nous permettre de mieux connaître cet ensemble de bâtiments d'un grand intérêt, tant d'un point de vue technique que d'un point de vue historique. Par là même, l'ensemble de structures découvertes lors du diagnostic (zone 1), pourrait être ainsi rattaché à l'édifice thermal.

\subsubsection{Les systèmes de chauffage et d'alimentation en eau}

\subsubsection{Le chauffage}

Le chauffage des salles devait être assuré par un certain nombre de foyers probablement disposés de part et d'autre du bâtiment afin d'assurer le chauffage de l'ensemble des pièces chaudes. Pourtant, aucun d'entre eux n'a pu être mis en évidence lors des diverses campagnes de fouilles. Les hypothèses actuelles tendraient à placer les foyers au sud, devant la zone 8 (zone 6), pour alimenter à la fois cette pièce et le secteur $\mathrm{C}$ de la zone 10.

Toutefois, il faut noter que cette situation au sud n'est pas en accord avec la tendance habituelle de réserver les parties sud « aux activités nobles »... On peut également en situer un autre au nord, dans la zone 4, pour alimenter à la fois la zone 8 (qui, en raison de sa taille, devait disposer de plusieurs foyers) et les salles de la zone 3 . Le couloir de service 9A desservant les probables hypocaustes de la grande piscine confirmerait cette hypothèse (fig. 118). À l'intérieur des pièces, les seuls éléments de chauffage en place ont été retrouvés dans la salle 3A. Il s'agit de pilettes d'hypocauste de briques carrées liées à l'argile. Dans cette même pièce, disposant d'un béton de sous sol en tuileau, des fragments de grosses briques de type suspensura ont été découverts dans le remblai.

Par ailleurs, des éléments du système de chauffage des murs ont été retrouvés dans les remblais, zones 5/6. Ils appartiennent à des tubuli de forme quadrangulaire peignés sur une face afin de faciliter l'accroche des mortiers.

\subsubsection{La gestion de l'eau}

La nature de l'approvisionnement en eau est pour l'heure difficile à mettre en évidence. L'hypothèse de Ch. Texier selon laquelle une citerne était présente à l'ouest du bâtiment a pu être confirmée en zone 9A (fig. 119). Des éléments concernant l'arrivée de l'eau dans les salles thermales ont par ailleurs été repérés. Ainsi, la zone 8 est directement alimentée en eau par un 


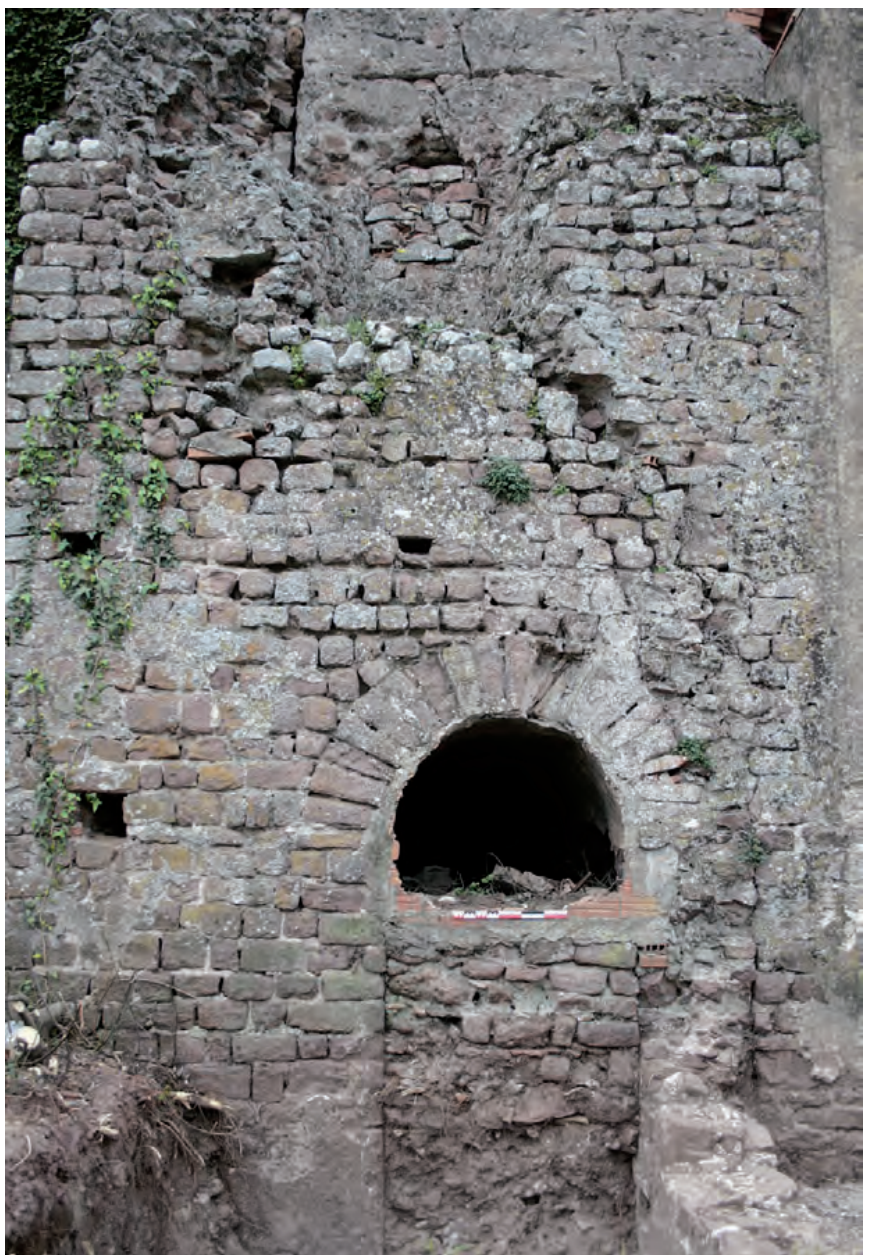

Fig. 118. Accès au couloir de service depuis la zone 4.

tuyau en terre cuite provenant de la citerne située juste au dessus. Il n'est probablement pas le seul de l'espace si l'on tient compte des autres orifices identifiés dans la maçonnerie.

Dans la zone 10, l'alimentation en eau se faisait par un tuyau, probablement en plomb, longeant la façade sud jusque dans le secteur 10C, comme l'a montré un sondage réalisé dans le cadre du diagnostic.

En revanche, le mode d'évacuation des eaux usées n'a pas été précisé et l'égout signalé par A. Donnadieu au nord-ouest des bâtiments n'a pas été retrouvé. D'où venait l'eau destinée à l'alimentation de ce complexe ? La question reste en suspens... L'hypothèse, déjà rejetée par Ch. Gébara $(2002,281)$, selon laquelle un aqueduc apportait l'eau aux thermes semble de moins en moins probable en l'absence totale de vestiges pouvant y être associés. En outre, la présence toute proche de la nappe phréatique (entre 0 et $0,50 \mathrm{~m} \mathrm{NGF}$ ) et les éléments observés lors de la fouille de Villa Romana, nous laissent envisager l'existence de puits et de systèmes de levage qui auraient pu, du moins en partie, alimenter les bâtiments. L'existence d'une noria à l'ouest de la citerne

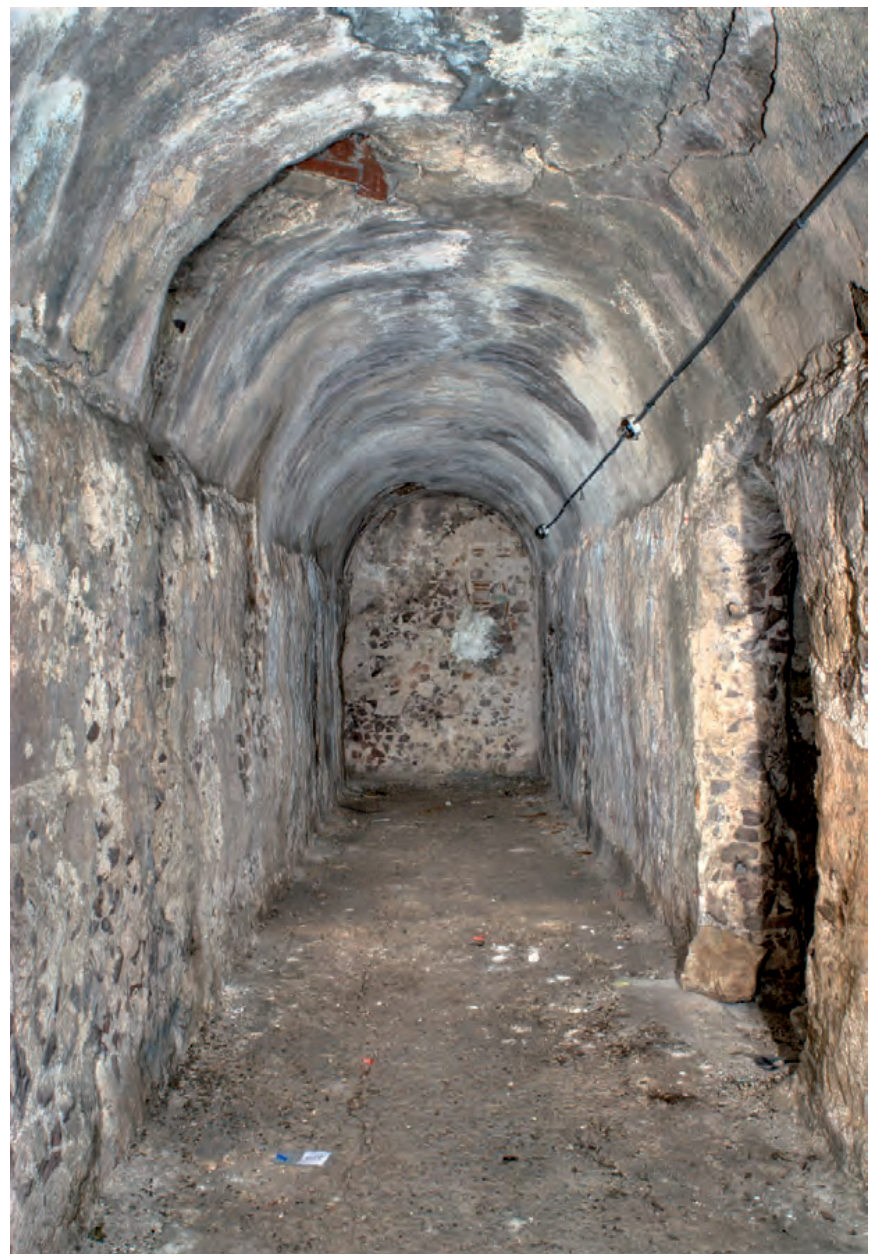

Fig. 119. Vue du sud de la citerne 9B.

9A parait une solution possible, mais pour le moment invérifiable ${ }^{37} \ldots$

\subsubsection{Typologie et datation}

La datation du complexe thermal de Villeneuve reste ardue à partir des seules données de fouilles. Si l'on se réfère aux anciennes hypothèses, A. Donnadieu liait déjà sa construction à l'installation du camp naval et le datait de la fin de la République. L'étude, par D. Brentchaloff, de la céramique issue de ces fouilles met en évidence une occupation du site à partir de la fin du Ir siècle av. J.-C. mais elle ne date pas pour autant le bâtiment thermal.

L'extrême complexité chronologique des bâtiments dévoilée lors du diagnostic se traduit par plusieurs états distincts, qui restent difficiles à étendre sur l'ensemble de l'édifice. Il est aujourd'hui clair qu'il existe au moins deux phases structurellement différentes, auxquelles

37 Cet type d'alimentation en eau est largement attestée pour la même période à Ostie, par exemple pour les bains des Six Colonnes ou ceux de l'Envieux (Poccardi 2006, 130). 
s'ajoutent des restructurations, par exemple la transformation du bassin de la zone 7. Enfin, les indices d'une occupation postérieure à l'activité balnéaire sont bien confirmés.

Un premier état, d'abord identifié sur certaines élévations de murs, semble correspondre à des bâtiments antérieurs à l'installation des thermes tels qu'on les perçoit aujourd'hui. Le bâti de cette période se caractérise par un appareil assez grossier de blocs et moellons sommairement assisés de grès brun rouge juste équarris, auquel pourrait se rattacher toute une série de structures découvertes lors des sondages (dans les zones 2, 1 et 5) et qui sont construites selon la même technique. L'existence de ce premier état se perçoit également dans le plan des bâtiments encore en élévation. En effet, les pièces identifiables paraissent davantage s'adapter à des salles existantes plutôt que résulter d'un chantier de construction unique, un constat qui est nettement probant pour la zone 8. Ceci se traduit par un plan des édifices thermaux original qui ne respecte souvent pas les principes de construction des installations balnéaires. Les aménagements correspondant à ce premier état sont trop restreints pour y voir une quelconque structure balnéaire. Aucun matériau technique des thermes (pilettes, tubuli...) ou même équipement hydraulique, n'a pu être associé au bâtiment primitif.

C'est seulement dans la seconde phase que les réaménagements indiquent clairement l'installation des bâtiments thermaux. Ils se traduisent au niveau des techniques de construction par la présence d'un petit appareil de moellons de grès brun rouge assisés et taillés, intégré dans des élévations déjà existantes (fig. 120). Il s'agit donc de restructurations antiques des maçonneries lors de la construction du nouvel édifice. Indépendamment de la fouille de Villa Romana, les seuls indices chronologiques actuels sont issus de l'analyse typologique des bâtiments ${ }^{38}$, sur lesquels A. Bouet avait émis les premières hypothèses (Bouet 2004).

Le caldarium à schola labri (zone 10C) - à deux solia opposés - nous fournit un indice chronologique majeur pour le bâtiment thermal. Il apparaît à la fin du Irr siècle av. J.-C. et est surtout reproduit à partir de la deuxième moitié du I ${ }^{\text {er }}$ siècle apr. J.-C. ainsi que dans le courant du siècle suivant, tant à Ostie qu'en Narbonnaise. Le plan du probable frigidarium circulaire (zone 8) à quatre piscinae (type 4B) se développe rapidement dans les édifices campaniens à l'époque augustéenne. Cependant, ce type ne présente aucun plan strictement identique et les dimensions sont très variées. Il faut donc nuancer les rapprochements qui peuvent être faits entre ces

38 Ces indices, sans constituer des preuves formelles, permettent néanmoins de dresser un premier faciès chronologique de l'édifice.

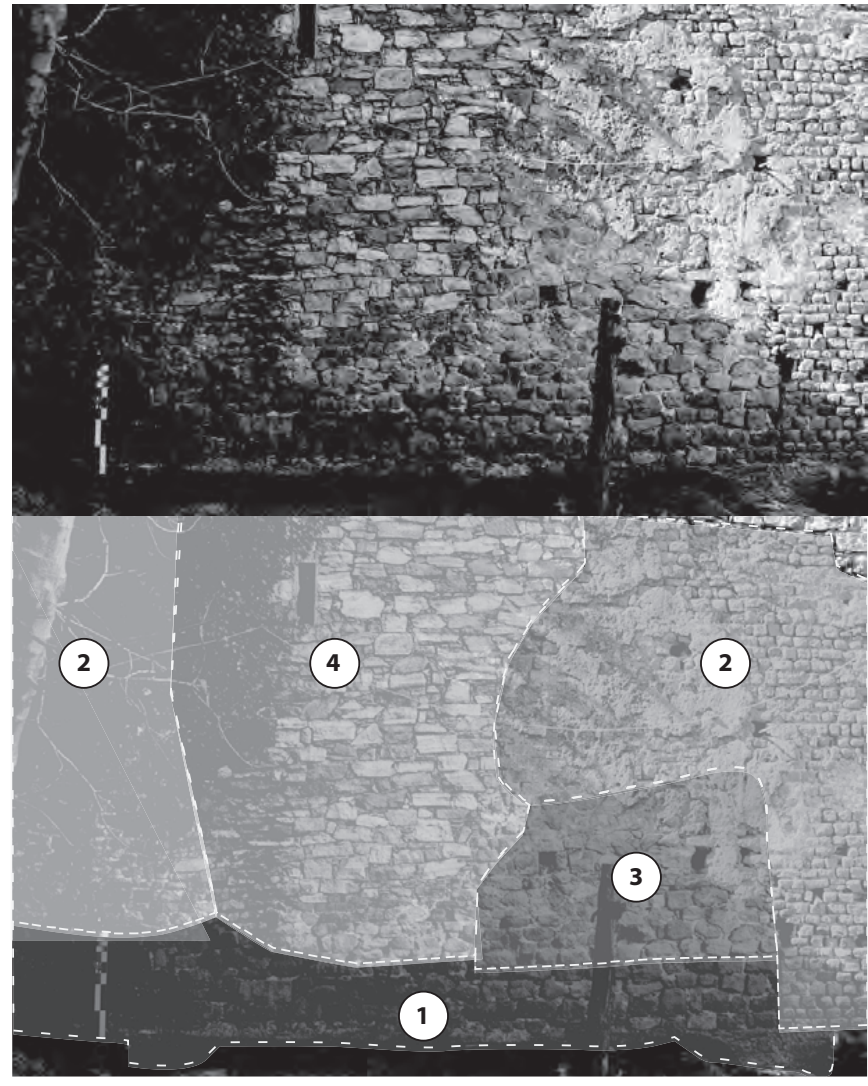

Fig. 120. Façade ouest, zone 7, où apparaissent les différents appareils employés dans les parements.

1. mur ancien (phase 2) / 2. mur en petit appareil (phases $2 / 3$ )

/ 3. rechapage (phase 5 ?) / 4. remontage du XIX siècle.

types de salles. En Campanie, elles sont en rapport avec la transformation du laconicum en frigidarium, mais aucune ne présentent de niches décoratives comme celles que nous avons à Villeneuve. De plus, l'identification de cette dernière n'est pas assurée et sa disposition entre deux pièces chauffées (zones $3 \mathrm{~A}$ et 8 ) pourrait tout autant la rapprocher d'un laconicum circulaire (type 1A) comme celui de la Plateforme. Ce plan ancien (dès le $\mathrm{III}^{\mathrm{e}}$ siècle av. J.-C.), très courant en Italie, a longtemps perduré. On le retrouve à Saint-Bertrand-de-Comminges, dans les thermes du Nord à la fin du Irr siècle apr. J.-C. ou au début du siècle suivant (Aupert 2001).

Enfin, la salle à piscine chauffée (zone 8), si elle était avérée, est un autre élément datant à prendre en compte : elle est présente en Campanie dans les complexes thermaux après le milieu du ${ }^{\text {er }}$ siècle apr. J.-C., mais aucune de ces pièces n'a, en revanche, pu être datée en Gaule Narbonnaise. On retrouve, par ailleurs, ce type de salle dans les thermes curatifs de Chassenon en Aquitaine, datés de la fin du $\mathrm{I}^{\mathrm{er}}$ siècle apr. J.-C. (Hourcade et al. 2004). L'absence de pilettes rondes appuierait plutôt une activité thermale dans le courant du Ir siècle apr. J.-C. Ce matériau apparaitrait dans la 
deuxième moitié du Ier siècle apr. J.-C. (Bouet 1999, 159) pour être largement diffusé au $\mathrm{II}^{\mathrm{e}}$ siècle apr. J.-C. L'utilisation d'autres matériaux tels que les tubuli destinés au chauffage des murs n'apporte pas d'élément nouveau. Ils étaient déjà couramment employés dans les constructions thermales du milieu du I ${ }^{\text {er }}$ siècle apr. J.-C. (Bouet 1999, 66 - 67) et utilisés depuis la fin du I ${ }^{\text {er }}$ siècle av. J.-C., il n'est donc pas étonnant de les retrouver dans les remblais du complexe.

D'un point de vue historique, l'abandon probable du camp, donc du quartier, vers le milieu du I ${ }^{\text {er }}$ siècle apr. J.-C. (Goudineau, Brentchaloff 2009, 58) est à prendre en considération. Dès lors, la transformation d'un tel ensemble ne peut s'envisager que dans le cadre d'une volonté affirmée de poursuivre une activité thermale suburbaine, ou résulter d'une récupération des bâtiments dans un cadre privé, par exemple pour les dépendances d'une villa.

La question de la chronologie peut donc être encore débattue, même en rapprochant ces éléments de la fouille de Villa Romana. En prenant en compte l'ensemble de ces données, la date de mise en service proposée pour les thermes de Villeneuve pourrait se situer vers le changement d'ère pour la première transformation des bâtiments. Celle-ci interviendrait donc dans le courant de la phase 2, et n'aurait pas d'incidence directe sur les jardins attenants. Son ultime transformation remonterait, quant à elle, au milieu du Irr siècle apr. J.-C.

\subsection{Interprétation générale}

$$
\text { (P. E.) }
$$

\subsubsection{Les jardins des thermes de Villeneuve?}

Aux vues des découvertes, il apparaît que cette phase est consécutive du démontage d'une partie des bâtiments environnants de la phase précédente. Le remploi de matériaux de construction, dont le puits SB1262 est l'illustration la plus flagrante, paraît confirmer cette idée. Déjàles sondages réalisés par J.-M. Michel (Michel 1999) avaient permis de mettre en évidence la réutilisation de gravats et autres enduits dans la construction de nouveaux murs sur les terrains situés immédiatement au nord. Les nombreuses restructurations et modifications observées sur les bâtiments des thermes de Villeneuve pourraient en être à l'origine. Toutefois, la mise en relation du phénomène de récupération avec le bâtiment thermal de Villeneuve est interprétée différemment par Ch. Gébara et J.-M. Michel. Pour eux, les éléments de récupération sont issus du démontage du bâtiment thermal après son abandon définitif, qu'ils situent vers le milieu du Irr siècle apr. J.-C. (Gébara, Michel 2002, 281). Notre sentiment est qu'il s'agit, en réalité, de la transformation et du réaménagement des thermes dans la seconde moitié du I ${ }^{\text {er }}$ siècle apr. J-C., avec, dans une certaine mesure, l'emploi de matériaux de récupération issus des structures et bâtiments antérieurs. Dans tous les cas, les réaménagements que l'on observe dans les espaces extérieurs/jardins de Villa Romana ne sont que la conséquence d'une transformation du bâtiment qu'ils jouxtent. Ainsi, l'ensemble de fosses et le puits SB1262 constituent des aménagements extérieurs, en relation directe avec l'ensemble thermal de Villeneuve. Il s'agit ici du réaménagement des jardins. Que ces aménagements résultent de la construction de nouveaux thermes à l'emplacement d'un ensemble originel à vocation non thermale, ou de la transformation de thermes déjà existants mis en place dans le courant de la phase précédente (supra), la présence de jardins associés à de tels monuments n'est pas un fait isolé, puisque cette tendance trouve naturellement ses antécédents à Rome (Grimal 1984, 260). La mode des jardins clos apparaît ainsi dans les thermes de Néron, de Titus puis de Trajan.

Selon A. Bouet (2003b, 139), les aires découvertes associées aux thermes peuvent être diverses : une palestre, un campus (ou un complexe sportif) et un jardin. Outre la présence de fosses de plantation, la superficie de l'ensemble paraît trop importante pour imaginer une palestre. En effet, comme le souligne A. Bouet, les palestres couvrent en général une superficie égale ou inférieure à celle de l'ensemble des pièces de bains (ibid., 144). Dans le cas des thermes de Villeneuve, il émet d'ailleurs l'hypothèse que cette dernière se trouve immédiatement à l'est de la grande salle voûtée à abside (ibid., 104, fig. 71). Le campus est généralement d'une superficie plus importante que la palestre et A. Bouet propose de restituer ce type d'espace dans le vaste terrain situé à l'est des thermes et au nord de la fouille, immédiatement au dessus du mur MR1003 (ibid., 146). Les découvertes réalisées à l'occasion du diagnostic archéologique par J.-M. Michel (1999) ne permettent pas d'assurer cette hypothèse, mais ne l'interdisent pas non plus.

Pour la zone 1, la présence de fosses de plantation et d'un puits nous fait pencher pour l'hypothèse d'un jardin de $20 \mathrm{~m}$ de large pour plus de $82 \mathrm{~m}$ de longueur. Il s'agirait donc plutôt d'un lieu d'agrément que d'un endroit à vocation sportive. Un lieu qui, selon P. Grimal, entretient des rapports subtils avec les bains et qui intéresse davantage la sensibilité romaine (1984, 194). Peu de jardins thermaux sont connus en Gaule narbonnaise. A. Bouet n'en recense que deux cas (2003b, 146-147) : l'un à Saint-Vincent-de-Gaujac, de petites dimensions, l'autre pour les thermes du palais du Miroir, à Saint-Romain-en-Gal. Ce dernier cas se rapprocherait davantage de l'exemple de Villeneuve 


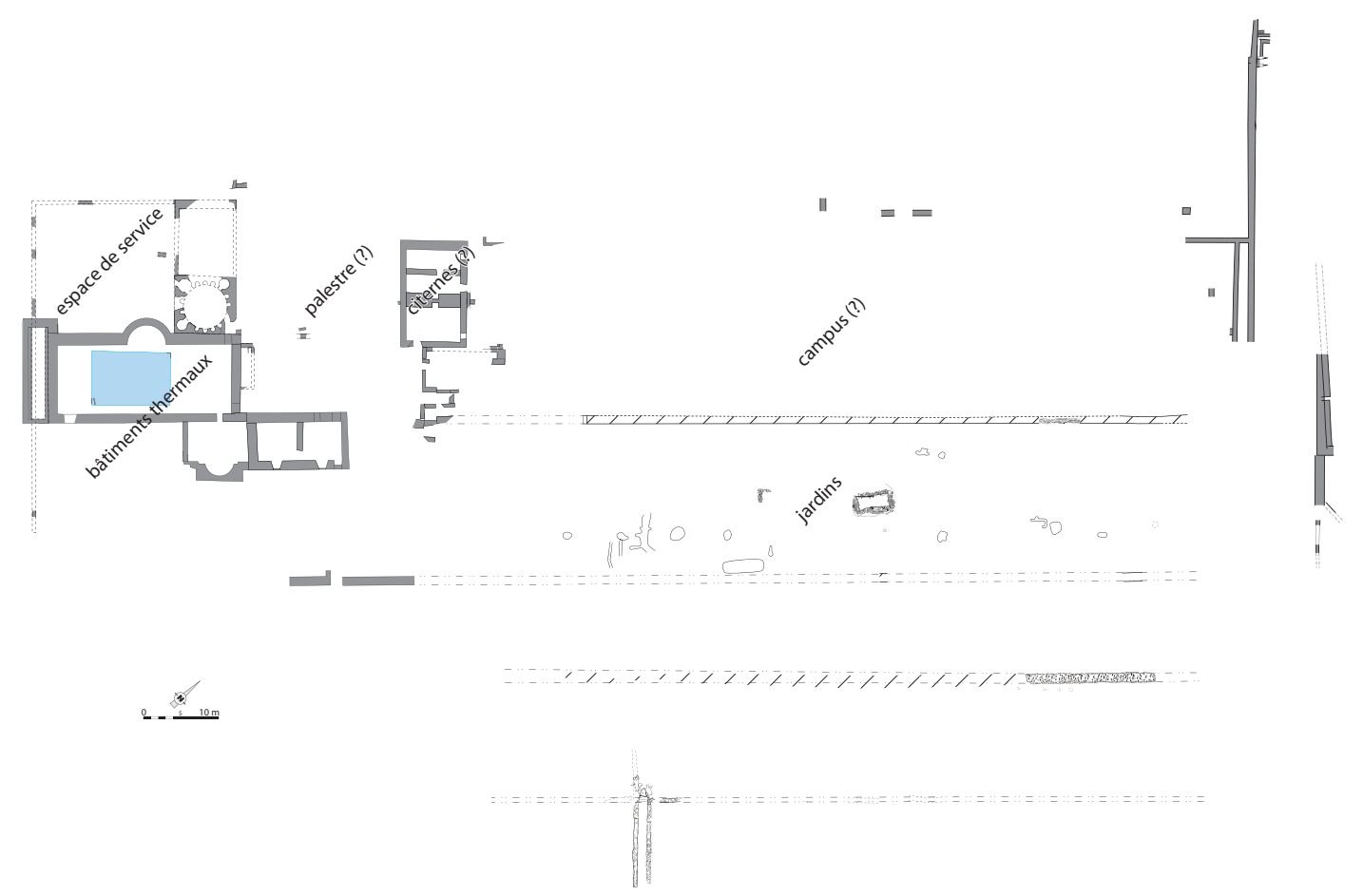

Fig. 121. Plan d'ensemble avec thermes, jardins et aménagements hypothètiques.

car il s'agit d'une bande allongée de $40 \mathrm{~m}$ de large pour une longueur inconnue mais qu'il suppose aux environs de $100 \mathrm{~m}$ et fermée au sud par une grande abside semicirculaire. Au Portugal, les thermes de Conimbrigia comporteraient aussi un jardin en plus de vastes espaces destinés au sport. Il se présente sous la forme d'une aire allongée de 18,60 m sur $45 \mathrm{~m}$ comportant une terrasse et située en contrebas de l'édifice thermal (Alarcão, Étienne 1981). Dans le cas des thermes de Villeneuve, il apparaît, comme nous l'avons mentionné, qu'il existait aussi un dénivelé entre la zone située immédiatement au nord du mur MR1003 et du jardin. En outre, aucune communication entre les deux zones, campus et jardin, n’a été mise en évidence (fig. 121).

Pour A. Bouet, ce phénomène de développement des zones non balnéaires se constate en Gaule à la fin du $\mathrm{I}^{\mathrm{er}}$ siècle et au $\mathrm{II}^{\mathrm{e}}$ siècle apr. J-C. (ibid., 147), il en va de même à Rome à partir du règne de Néron (Grimal 1984, 190 et 195), ou au Portugal à la même période qu'en Gaule à l'image des thermes de Trajan à Conimbriga (Alarcão, Étienne 1981, 77-80).

Comme pour la phase précédente, les études paléoenvironnementales n'ont pas fourni de résultat probant en raison des mauvais contextes de conservation. Seule l'étude phytolithologique fournit un résultat intéressant en présumant la présence du palmier. Cet arbre, fréquemment représenté dans l'iconographie romaine, était cultivé dans les jardins romains pour ses valeurs ornementales (Jashemski 1981, 47).
La question qui apparaît en toile de fond est naturellement celle de la destination du bâtiment thermal. Son ultime transformation au milieu du Ir siècle apr. J.-C. n'a, de toute évidence, aucun lien avec le camp, qui d'ailleurs amorce une phase de désaffection démontrée par les fouilles des Aiguières. Ainsi cette transformation est à mettre en lien soit avec un réaménagement public, soit avec la récupération du bâtiment dans une sphère privée. La fouille ne permet pas de trancher sur ce point, mais la désaffection du quartier plaide en faveur de la reprise du bâtiment dans un domaine privé, peut-être une villa.

\subsubsection{Les zones limitrophes au sud}

La limite sud-est de ce jardin semble toujours marquée par le mur de clôture MR2004, mais un nouveau mur, MR2002 est construit à $12,50 \mathrm{~m}$ plus au sud. La fonction de ce dernier pourrait être de constituer une nouvelle terrasse en retenant une large bande de sable constituant l'ensemble de la zone 2, stabilisant de cette façon les sols au nord. Au-delà de cette limite que constitue le mur MR2004, se met en place un nouvel espace dont la destination nous échappe presque entièrement en raison des surcreusements postérieurs. S'agit-il de l'extention du jardin vers le sud ? Peut-on y voir une palestre pour les thermes ? Seules les traces fugaces d'un long mur MR3082 et le corridor CN3010 permettent d'appréhender qu'un rôle spécifique était 

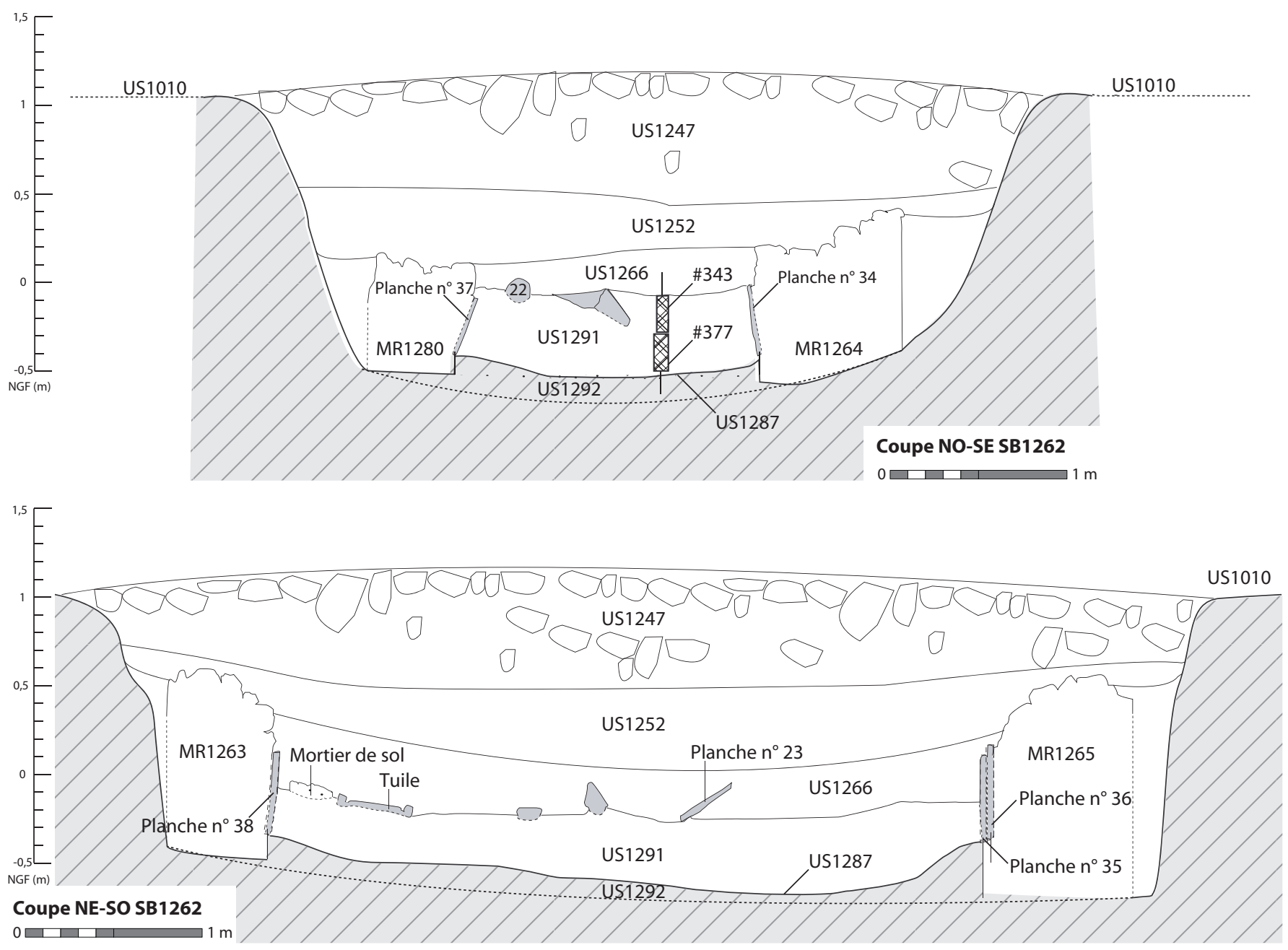

Fig. 122. Coupes du remplissage du puits SB1262.

alors dévolu à cet espace, sans pour autant nous en donner clairement la fonction. Rien ne permet de suggérer qu'elle est à mettre en relation avec l'ensemble thermal, d'autant que la zone 2, vierge, sépare les deux entités. Dans ce contexte, il est bien difficile de définir la fonction du corridor. À quoi pouvait-il servir ? Pour tenter de répondre à cette question, il convient de reprendre les données issues du diagnostic archéologique réalisé dans la parcelle située de l'autre côté de la rue Jean-Carrara par J.-M. Michel (Michel 2005). Reconsidérons ici ces découvertes...

La galerie (désignée CN3010 sur les fouilles de Villeneuve et espace 2 sur le diagnostic) aboutit après $92 \mathrm{~m}$ dans un espace délimité par de puissants murs d'environ 1,50 m de large. Cet espace long de 8,60 m et large de $3 \mathrm{~m}$, est construit symétriquement à l'arrivé du corridor situé au centre de la limite nord-ouest. Il communique vers l'est par une ouverture large et peutêtre aussi au sud. La nappe phréatique n'a pas permis d'atteindre le fond de cet espace. Quoiqu'il en soit, les structures s'étendent vers le sud sous l'avenue de
l'Argens. Les données archéologiques ne permettent pas d'interpréter cet aménagement.

La situation topographique fournit toutefois quelques pistes. En effet, il s'agit à ce jour des constructions antiques les plus méridionales et donc les plus proches du littoral antique. Dès lors, compte tenu de l'éloignement relatif de la côte à cette époque, une mise en relation de cette structure avec la mer est envisageable. Une fonction de débarcadère paraît séduisante, le corridor aménagé dans le sable de plage faisant le lien entre celui-ci et le quartier.

\section{La phase 3, état $B$}

\subsection{Description}

(P. E.)

La phase 3B correspond à l'abandon des structures mises en place dans le courant de l'état précédent. L'ensemble de ces niveaux est apparu assez important puisque certaines zones semblent connaître 
une période relativement longue d'abandon. Les niveaux les plus représentatifs sont naturellement les comblements des structures en creux, le bassin SB1262 ou encore le corridor CN3010. Le niveau de recouvrement (1007) qui se constitue au dessus de la surface du jardin (1010) appartient en partie à cette phase, mais l'absence de surface de circulation n'a pas permis de différencier cette phase des apports postérieurs, jusqu'à la reprise d'activité marquée par d'autres fossés de plantations lors de la phase 4 .

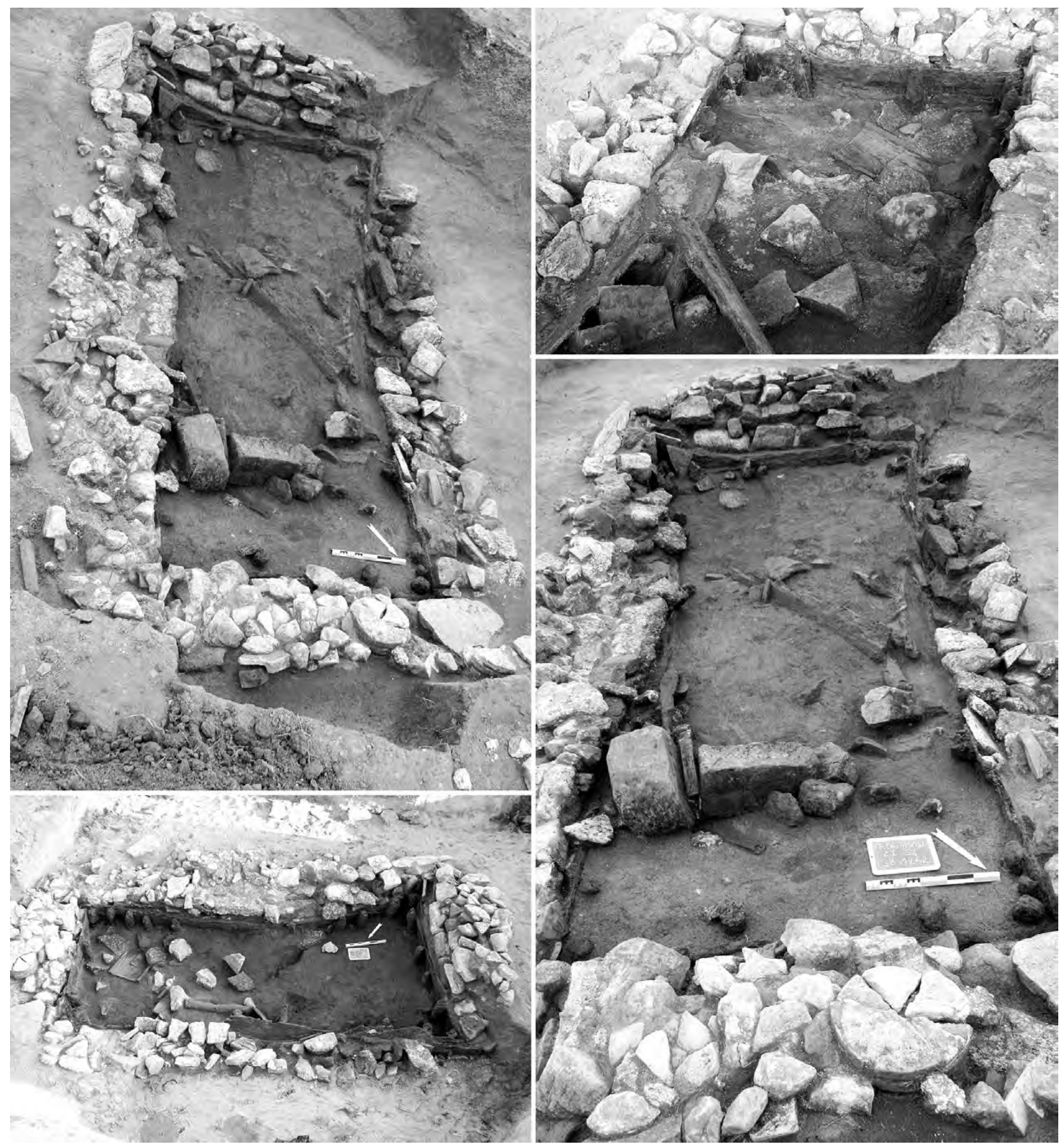

Fig. 123. Comblement du puits SB1262. 


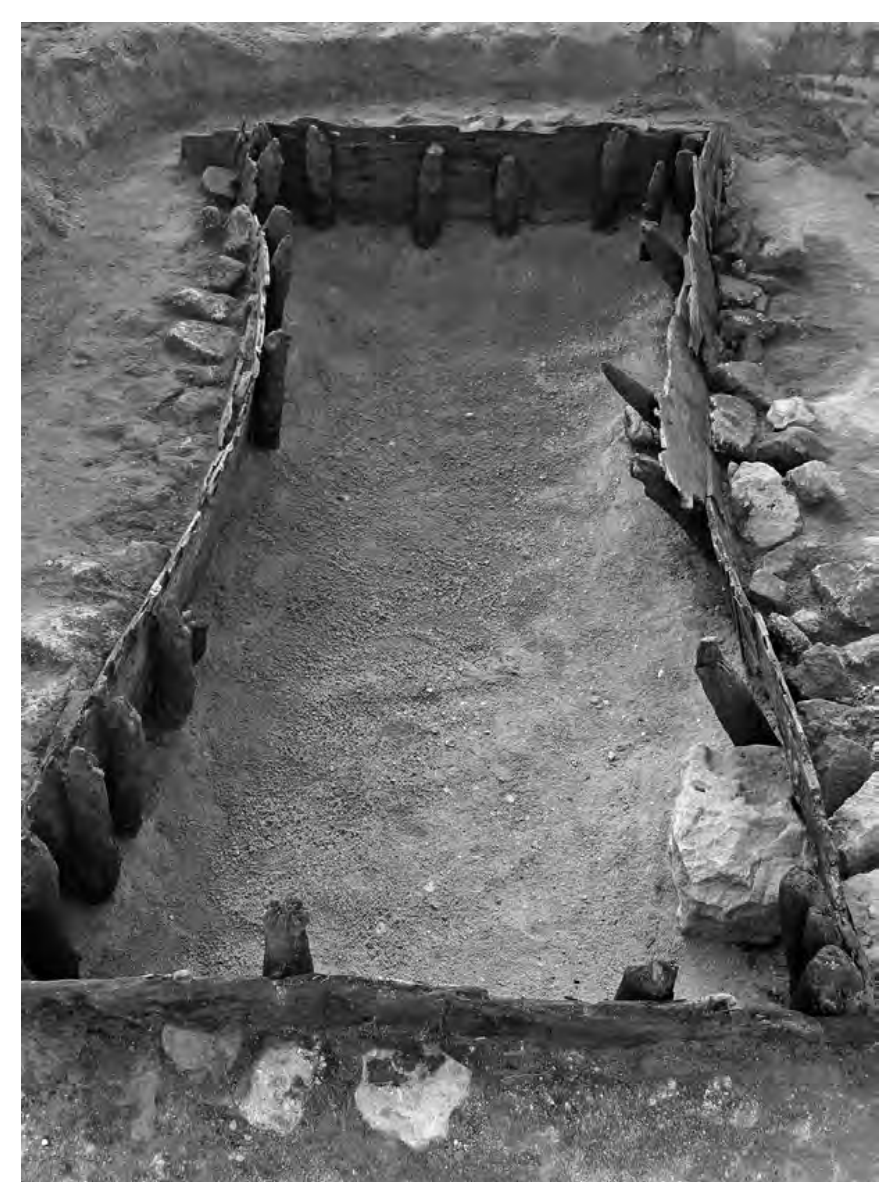

Fig. 124. Sous la pression, le coffrage en bois a commencé à céder et présente une courbure significative.

Ailleurs, dans les zones 2 et 3, l'érosion des sols et les surcreusements postérieurs ont totalement oblitéré ces niveaux.

\subsection{Le comblement du puits/bassin SB1262 (P. E.)}

Commençons par une description de la stratigraphie du comblement (fig. 122). Le dernier comblement (US1247) de plus de 0,50 m d'épaisseur était composé de quelques matériaux de construction (tuiles, mortiers, briques en quart de ronde, moellons...) résultant de l'effondrement des parois, le tout englobé dans un sédiment brun rouge à dominante sableuse. Sous ce comblement se trouve une couche (US1252) plus organique, un peu plus sombre, compacte et plus limoneuse. Les matériaux de destruction y sont beaucoup plus nombreux. Il s'agit essentiellement de morceaux de sol en béton, fûts de colonne en briques en quart de rond, enduits peints et tuiles. C'est sous ce niveau que les parois en pierres ont été retrouvées en place. On relève également un niveau de comblement (US1266) consécutif à l'abandon du bassin, dans lequel se retrouvent des éléments de bois provenant des parois et des blocs liés à son utilisation (1286) (fig. 123). Le niveau est brun foncé, sablo-limoneux et peu compact. En dessous prend place la couche 1292. Le sédiment est limoneux et très sombre. Les gros éléments sont concentrés dans la partie nord-est. Beaucoup de coquilles sont également associées à cet ensemble, avec du bois naturel ou travaillé, de morceaux d'écorce, de petits charbons, un fragment de cuir, des tessons de céramique et un clou dans un morceau de bois.

L'effondrement semble s'être fait depuis la paroi nord-ouest. En effet, la poussée des bords du puits est particulièrement bien visible pour la paroi 1280 , où le coffrage en bois a commencé à céder et présente une courbure significative (fig. 124). Il est possible que cette poussée ait déjà été un problème inquiétant lors du fonctionnement du puits. Le bloc mis en place près de l'angle nord pourrait justement avoir joué un rôle de calage de la paroi. En effet, il apparaît nettement que l'effondrement se situe uniquement dans la partie non soutenue par le bloc disposé à plat au fond du puits. Une forte courbure est également bien présente pour la paroi opposée mais là, les pieux verticaux paraissent avoir mieux résisté.

\subsection{Formation et interprétation du comblement}

\section{(L. B., I. F., S. Gr., S. G., S. M., C. S.)}

Les études archéobotaniques apportent des informations convergentes sur cette phase d'abandon.

Tout d'abord, en ce qui concerne le niveau et la qualité des eaux présentes dans le bassin, via les valeurs importantes de Lemna minor (lentilles d'eau) et de Botryococcus (algues vertes se développant en colonie à la surface des eaux stagnantes), détectées par la palynologie, semblent indiquer la présence d'eaux dormantes peu profondes. Manifestement ces algues et lentilles se sont développées au sein des niveaux de comblement. Absentes des niveaux inférieurs, en particulier de ceux contemporains du fonctionnement $\mathrm{du}$ puits (phase $3 \mathrm{~A}$ ), leur prolifération est mise en rapport avec l'arrêt du système de puisage. Cet élément démontre que le comblement du puits ne résulte pas d'une action immédiate, mais d'un processus plus lent de destruction/abandon. Tout porte à croire que lors de cette phase d'abandon, et peut-être encore lors de la suivante (4A), le puits n'est pas entièrement comblé et que de l'eau stagnante s'y trouve encore. Ainsi, la végétation locale associée au bassin présente des variations par rapport aux niveaux de la phase précédente. Un des points nodaux est l'augmentation des valeurs de céréales, leur présence à hauteur de $3 \%$ laisse supposer un apport assez local. Ce signal est donc à mettre en 


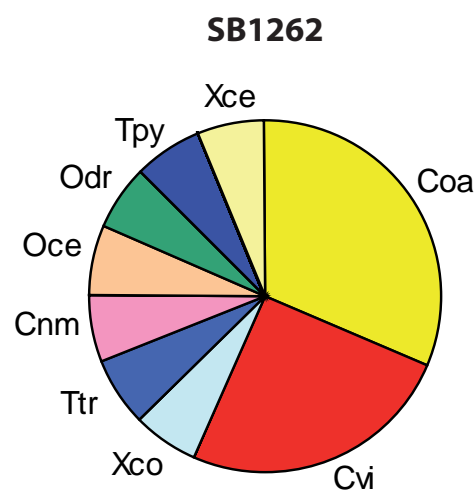

$\begin{array}{ll}\square \text { Cochlicella acuta (Coa) } & \square \text { Cernuella virgata (Cvi) } \\ \square \text { Vallonia pulchella (Vpl) } & \square \text { Toltecia pusilla (Tpu) } \\ \square \text { X. conspurcata/ M. armillata (Xco) } & \square \text { Oxyloma elegans (Oel) } \\ \square \text { Trochoidea trochoides (Ttr) } & \square \text { Cepaea nemoralis (Cne) } \\ \square \text { Monacha cf. cantiana (Mcn) } & \square \text { Theba pisana (Tpi) } \\ \square \text { Oxychilus cf. cellarius (Oce) } & \square \text { Vertigo pygmaea (Vpy) } \\ \square \text { Oxychilus draparnaudi (Odr) } & \square \text { Candidula gigaxii (Cgi) } \\ \square \text { Trochoidea pyramidata (Tpy) } & \square \text { Vallonia costata (Vco) } \\ \square \text { Cochlicopa lubrica agg.(Clu) } & \square \text { Lauria cylindracea (Lcy) } \\ \square \text { Succinea oblonga (Sob) } & \square \text { Rumina decollata (Rde) } \\ \square \text { Testacella haliotidea (Tha) } & \square \text { Limacelles (Lim) }\end{array}$

$\square$ Xerosecta cespitum (xce)

Fig. 125. Proportion des estimations d'abonce des taxons malacologiques terrestres pour le puits 162 .

relation directe avec la phase suivante. Il faut toutefois considérer que la carpologie, via la présence de restes carbonisés, détecte le probable rejet dans le bassin de déchets de traitement et/ou de préparation des céréales, certes peu important mais qui a pu contribuer à l'apport de pollens. Les données carpologiques confirment par ailleurs totalement les enseignements de la palynologie sur le milieu aquatique. Les plantes aquatiques - elles mêmes largement dominées par Chara sp. - sont typiques des eaux permanentes, stagnantes à faiblement courantes. La lentille d'eau est également identifiée par de nombreux restes, de même que la renoncule aquatique et la zannichellie. Il s'agit manifestement de plantes qui se développaient dans le bassin. Les plantes des lieux humides croissent sur des sols périodiquement inondés ; la plus fréquente (Cyperus sp.) affectionne, pour bon nombre de ses espèces, les sols sablonneux humides.

Un cortège assez important de taxons au caractère nitrophile bien marqué se range dans les grands groupements génériques actuels des mauvaises herbes des cultures (13 taxons) et des lieux rudéraux (6 taxons). Ces groupements représentent au total légèrement plus de $5 \%$ des restes imbibés. Pour beaucoup, ces plantes sont des ubiquistes des milieux cultivés et rudéraux aux sols fortement perturbés et enrichis par l'action de l'homme. Le cortège mis en évidence se rapproche

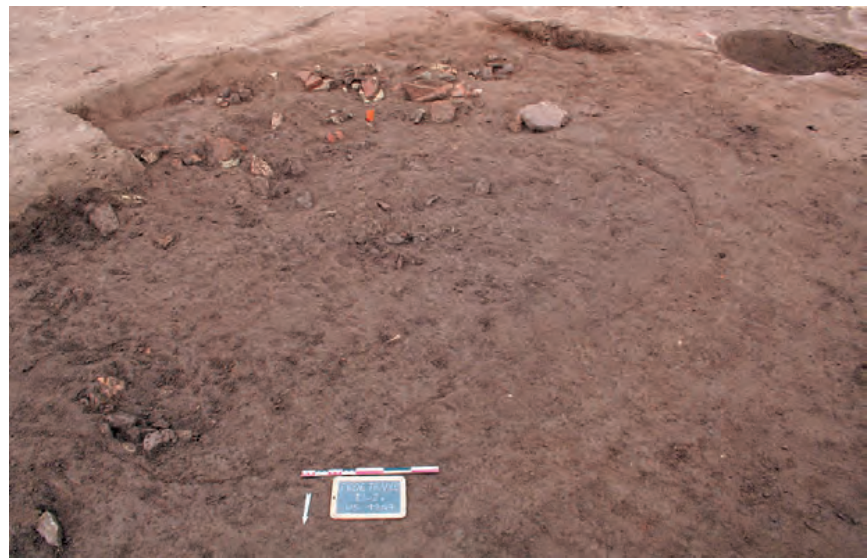

Fig. 126. Comblement et nivellement définitif du puits SB1262.

largement du groupement des cultures sarclées décrit par Braun-Blanquet (1952) pour la France méditerranéenne ; environ les 3/4 des adventices et rudérales attestées dans le bassin sont répertoriées dans le groupement type des vignobles du Languedoc et de Provence occidentale : Calendula arvensis, Chenopodium album, Euphorbia helioscopia, Euphorbia peplus, Fumaria officinalis, Heliotropium europaeum, Lamium amplexicaule, Malva parviflora, Mercurialis annua, Polygonum persicaria, Portulaca oleracea, Rumex pulcher, Solanum nigrum. Toutefois, un nombre presque aussi important de ces taxons est également très fréquent dans les groupements nitrophiles des abords des habitations et des décombres. L'abandon de la zone se traduit en outre par la présence marquée de semences et d'épines de ronce dans le bassin.

L'étude malacologique montre le même phénomène : le cortège aquatique est dominé par des petits bivalves (Sphaerium sp. / Pisidium sp.) et le planorbe Anisus leucostoma. Anisus leucostoma est caractéristique des milieux temporaires d'eau stagnante; elle vit dans les eaux troubles, sur les plantes aquatiques. C'est une espèce particulièrement tolérante quant à la qualité du milieu aquatique ; elle peut même être qualifiée d'espèce de milieux intermittents : c'est-à-dire qu'elle supporte plusieurs périodes d'exondation dans la même année (Yacine-Kassab, 1979). Cet assemblage indique donc que le puits ne fonctionne plus en tant que tel : il est en partie comblé et il contient des eaux de moindre qualité, probablement asséchées une partie de l'année. Le cortège terrestre, quant à lui, donne une bonne perception du milieu environnant le puits au moment de son comblement (fig. 125). Il est dominé par Cochlicella acuta et Cernuella virgata traduisant des milieux herbacés hauts. La présence d'espèces xérophiles, méditerranéennes (Trochoidea pyramidata, Trochoidea trochoides et Xerosecta cespitum) indique la grande xéricité de ces formations 
végétales : cet assemblage est typique des friches rudérales méditerranéennes.

À l'évidence, le puits n'a pas servi de dépotoir après l'arrêt de son fonctionnement, constituant aussi un autre élément pouvant induire un abandon de la zone. La présence continue et majoritaire d'espèces végétales aquatiques, comme la très bonne conservation des bois du cuvelage en partie basse, démontrent que son abandon n'est pas dû à un assèchement de la nappe, mais peut-être à l'instabilité de la paroi MR1280.

Quoiqu'il en soit, la stratigraphie du comblement montre la présence d'une phase d'abandon (US1291), l'éboulement des structures apparaît essentiellement dans les niveaux 1266/1252.

L'ultime comblement (US1247), plus riche en matériaux sableux, pourrait correspondre à un remblaiement, plus tardif, destiné sans doute à assainir complètement l'endroit (fig. 126). Ainsi, ce niveau pourrait être mis en relation directe avec la phase suivante 4A, d'autant que c'est au sein de celui-ci que les éléments de mobilier les plus tardifs ont été découverts : une amphore de type africaine 1A (Bonifay 2004, fig. 56) et une coupe Desbat 8 en sigillée claire B. Ces objets apparaissent dans le dernier quart du II ${ }^{e}$ siècle apr. J.-C. au plus tôt, mais perdurent jusque dans un III" siècle avancé.

\subsection{Le comblement de du corridor $\mathrm{CN3010}$ (P. E.)}

Le comblement définitif du corridor est disposé sur un niveau à dominante limoneuse gris clair d'une vingtaine de centimètres d'épaisseur, comprenant des éléments de décomposition du sol de mortier (US3013, 3131 et 3133). Ce niveau recouvrant le sol de béton n'est pas uniforme et ne se trouve pas sur la totalité du sol. Il est difficile de définir s'il s'agit d'un niveau contemporain de l'utilisation du couloir, plutôt que d'une sédimentation en rapport avec son abandon. Le mobilier archéologique y est quasiment absent à l'exception d'un fragment de cruche à bec trilobé en argile kaolinitique. Le reste du comblement est très compact (US3130, 3132 et 3184). Probablement volontaire, il est constitué de matériaux divers (moellons, fragments de mortiers, céramiques...) compris dans une matrice sablo-limoneuse brun clair (fig. 127).

\subsection{Le mobilier céramique et datation (E. P.)}

Malgré la présence de quelques témoins certainement résiduels du $\mathrm{I}^{\mathrm{er}}$ siècle, le mobilier de la phase 3B appartient au $\mathrm{II}^{\mathrm{e}}$ siècle apr. J.-C.

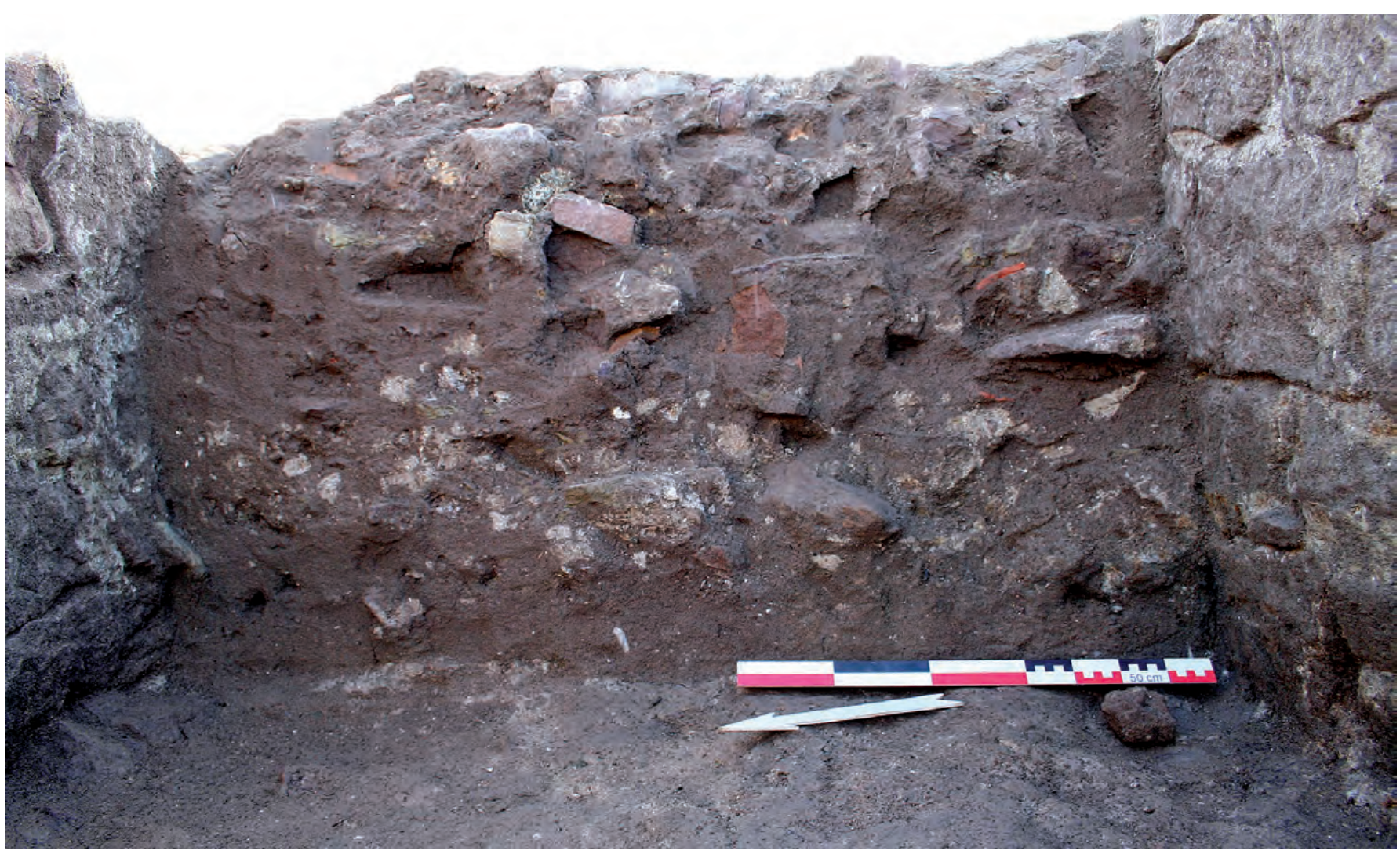

Fig. 127. Comblement du corridor CN3010, à la base le premier comblement limoneux est visible. 
Le terminus ante quem est donné par une marmite de type Hayes 197 (fig. $128-\mathrm{n}^{\circ} 1$ ) et un couvercle de type Hayes 196 (fig. $128-\mathrm{n}^{\circ}$ 2), une amphore de type africaine 1A (Bonifay 2004, fig. 56) (fig. $128-\mathrm{n}^{\circ}$ 3) et une coupe Desbat 8 (fig. 128 - ${ }^{\circ} 4$ ) en sigillée claire B. Ces objets apparaissent dans le dernier quart du $\mathrm{II}^{\mathrm{e}}$ siècle au plus tôt, mais perdurent jusque dans un $\mathrm{III}^{\mathrm{e}}$ siècle apr. J.-C. avancé. Ils sont associés à des céramiques contemporaines qui ne dépassent pas le début du III $^{\text {e }}$ siècle apr. J.-C. au plus tard, comme une coupe en sigillée claire A de type Hayes 6 (fig. 128 - $n^{\circ}$ 5) et une amphore de type Dressel 20F (fig. 128 - $n^{\circ}$ 6) ou même le dernier tiers du $\mathrm{II}^{\mathrm{e}}$ siècle apr. J.-C., notamment une coupe en sigillée gauloise de type Drag. 27.

Dans ce contexte, les amphores gauloises sont relativement les plus fréquentes en nombre de restes
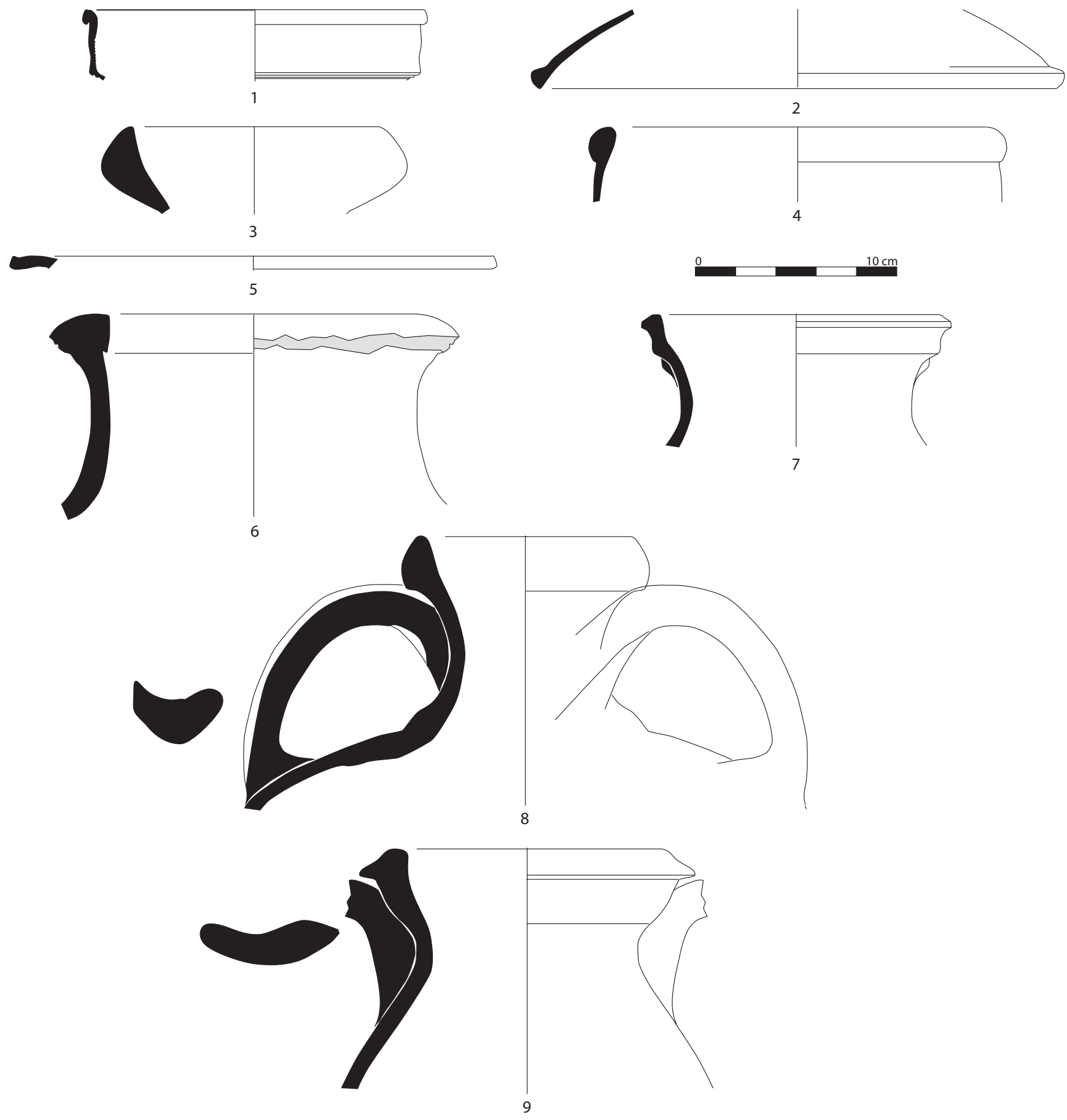

Fig. 128. Les céramiques de la phase 3B. 


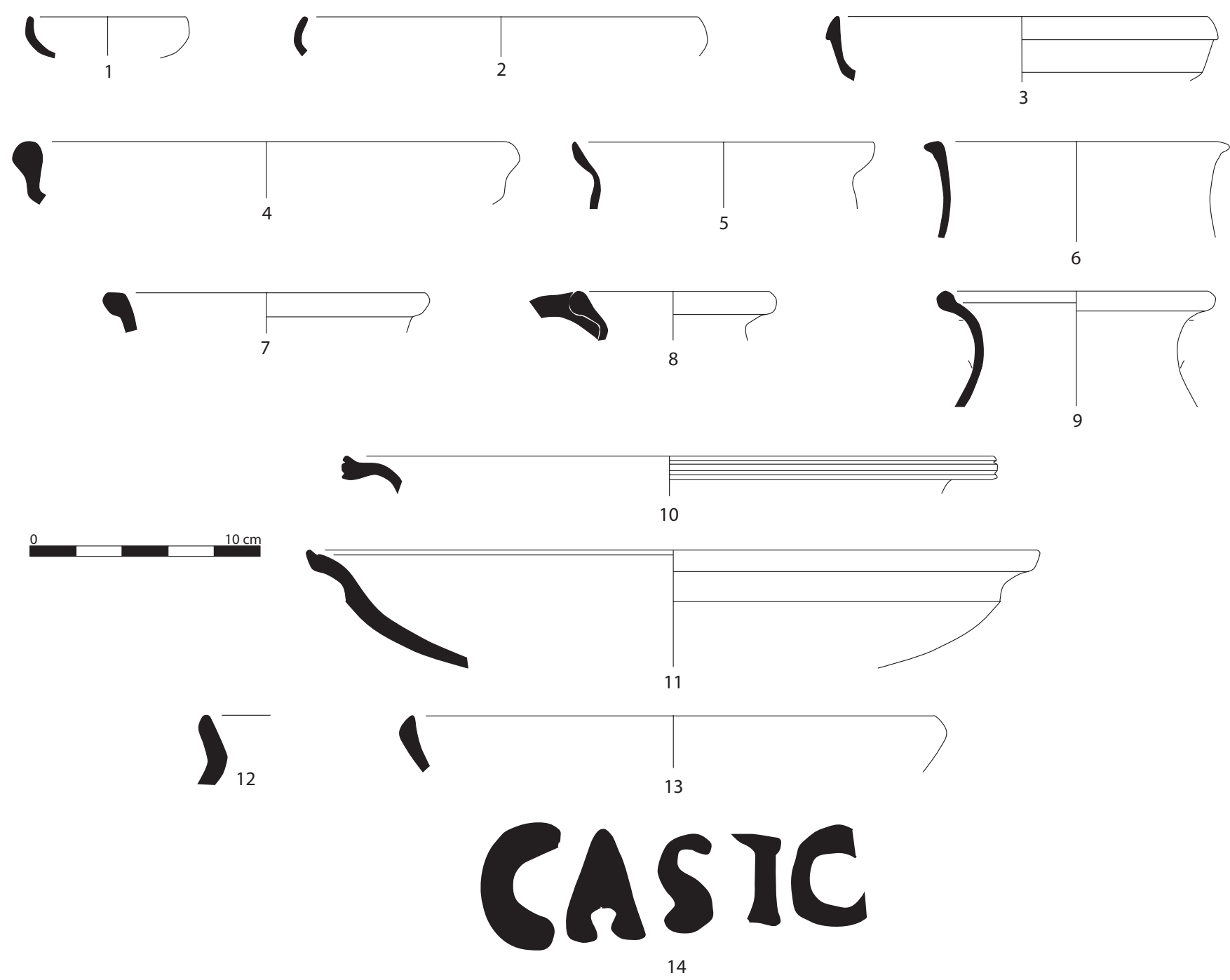

Fig. 129. Les céramiques de la phase $3 B$ (n¹4 : éch. 1/1).

(NR). On compte une amphore du type 3 (fig. $128-\mathrm{n}^{\circ} 7$ ) et trois du type 4 (fig. $128-n^{\circ} 8$ ). Il faut encore signaler la présence du col d'une amphore de Bétique appartenant à une variante du type Beltran 2B (fig. 128 - $\mathrm{n}^{\circ}$ 9). Ce type appartient au I ${ }^{\text {er }}$ et à la première moitié du $\mathrm{II}^{\mathrm{e}}$ siècle apr.J.-C. Comme dans la phase précédente, les céramiques à pâte claire restent les mieux représentées. On reconnaît deux coupes de type Pasqualini 1D (fig. 129 - $\mathrm{n}^{\text {os }} 1$ et 2) et deux coupes de type Pasqualini 6 (fig. $129-\mathrm{n}^{\text {os }} 3$ et 4), mais aussi le bord de huit vases à verser ou de petits conteneurs (fig. $129-\mathrm{n}^{\text {os }} 5$ à 9) et de deux grandes coupes à bord mouluré (fig. 129 - $\mathrm{n}^{\text {os }} 10$ et 11 ).
Une partie de ces objets est probablement résiduelle, notamment les grandes coupes. Les seuls parallèles typologiques connus se trouvent sur le site des Aiguières, mais dans un contexte du début du $\mathrm{I}^{\text {er }}$ siècle apr. J.-C. (Rivet 1983, fig. 41). On remarque encore la rareté des céramiques culinaires. Six objets ont été identifiés, mais seuls quatre d'entre eux peuvent être rattachés à cette phase. Il s'agit de la marmite et du couvercle africains évoqués plus haut et de deux modelées varoises de type Bérato 60 et 421 (fig. 129 - $\mathrm{n}^{\text {os }} 12$ et 13). Il faut encore évoquer ici la présence d'une marque sur tuile du potier Castoris (fig. 129 - $\mathrm{n}^{\circ} 14$ ). 



\section{Chapitre 4}

\section{Une lanière cultivée aux II ${ }^{\mathrm{e}}$, III ${ }^{\mathrm{e}}$ et $\mathrm{IV}^{\mathrm{e}}$ siècles apr. J.-C.}

\section{La phase 4 , état $A$}

\subsection{Description}

(P. E.)

\subsubsection{Les zones 1 et 2}

Les zones 1 et 2 ne présentent pas de traces d'occupation postérieure et semblent avoir été abandonnées sans nouvel aménagement. Les niveaux de recouvrement n'ont pas livré de mobilier significatif de la phase 4A, ni même comme élément résiduel dans les niveaux supérieurs. D'une façon plus générale, on peut rapprocher cette observation de celle faite pour le quartier des Aiguières qui connaît une phase d'abandon vers le milieu du $\mathrm{II}^{\mathrm{e}}$ siècle apr. J.-C., puis une timide réoccupation à la fin de l'Antiquité (Rivet et al. 2000, 330 et Goudineau, Brentchaloff 2009, 59-60). Sur le site de Villa Romana, cette phase d'abandon correspond à notre phase 3B et les réoccupations postérieures du secteur durant les $\mathrm{III}^{\mathrm{e}}$ et $\mathrm{IV}^{\mathrm{e}}$ siècles concernent exclusivement la zone 3 (fig. 130 et 131).

\subsubsection{La zone 3}

\subsubsection{La lanière cultivée (PAA3063)}

Sur toute la longueur de la parcelle est creusée, dans un sable lité (3138), une tranchée de 10,70 m de large (PAA3063), bordée par deux murets de soutènement : MR3042 au sud-est et MR3040 au nord-ouest. L'ensemble a été repéré sur $85 \mathrm{~m}$ de long mais s'étendait d'avantage de part et d'autre du chantier et délimite un espace de $1062,50 \mathrm{~m}^{2}$ (fig. 132). Le fond de cette lanière est à une cote altimétrique oscillant entre 0,30 et $0,40 \mathrm{~m}$ NGF. Bien que les niveaux ${ }^{1}$ de la phase précédente soient très érodés de part et d'autre de la tranchée, le creusement de cette dernière est au minimum d'une

1 En effet, nous avons situé ces niveaux pour la phase 3 au minimum à une cote située aux alentours de $1 \mathrm{~m}$ NGF. profondeur de 0,60 m. Les travaux de terrassement ont donc nécessité, uniquement dans la partie visible de la fouille, le déplacement d'au moins $300 \mathrm{~m}^{3}$ de sable, soit prés de 500 tonnes$^{2}$. Pour faciliter l'étude, trois secteurs ont été déterminés.

\subsubsection{Les murets de soutènement MR3040 et MR3042}

Contrairement aux murs des époques antérieures, situés altimétriquement à une cote supérieure, la quasi-totalité de la base assisée en moellons de chacun des deux murs est conservée. Ceux-ci sont de construction identique. Larges d'environ $0,50 \mathrm{~m}$, ils ne sont parementés que du côté de la bande excavée (fig. 133). La hauteur conservée atteint au mieux $0,50 \mathrm{~m}$ et comprend au maximum quatre assises. Le noyau du mur est fait d'un mortier sableux de teinte jaune, relativement friable. Ce remplissage a été mis en place directement contre les bordures du creusement de la tranchée, sans doute légèrement talutées, puis comblées par un sédiment sablolimoneux et des gravats après l'édification des murets. Cette dernière opération, tranchée (US3173) et comblement (US3174), a été mise en évidence sur une partie du muret MR3042, les traces étaient moins visibles (US3177) pour le muret MR3040. Les moellons employés sont majoritairement en grès, on retrouve quelques conglomérats et arkoses et, encore plus exceptionnellement, de la rhyolite. Les formes et dimensions sont variables (de $0,50 \mathrm{~m} \times 0,20 \mathrm{~m}$ à $0,10 \mathrm{~m} \times 0,15 \mathrm{~m}$ ). Deux moellons confectionnés à partir d'une roche de teinte jaune à verdâtre et comprenant des inclusions de gros grains sombres ont également été dénombrés. L'aspect rappelle fortement les éléments employés dans les thermes de Villeneuve pour la confection des voûtes (voir supra p. 100) (Excoffon, Ardisson 2008, 53).

2 Données prises sur une masse volumique apparente moyenne pour le sable de $1500 \mathrm{~kg} / \mathrm{m}^{3}$. 


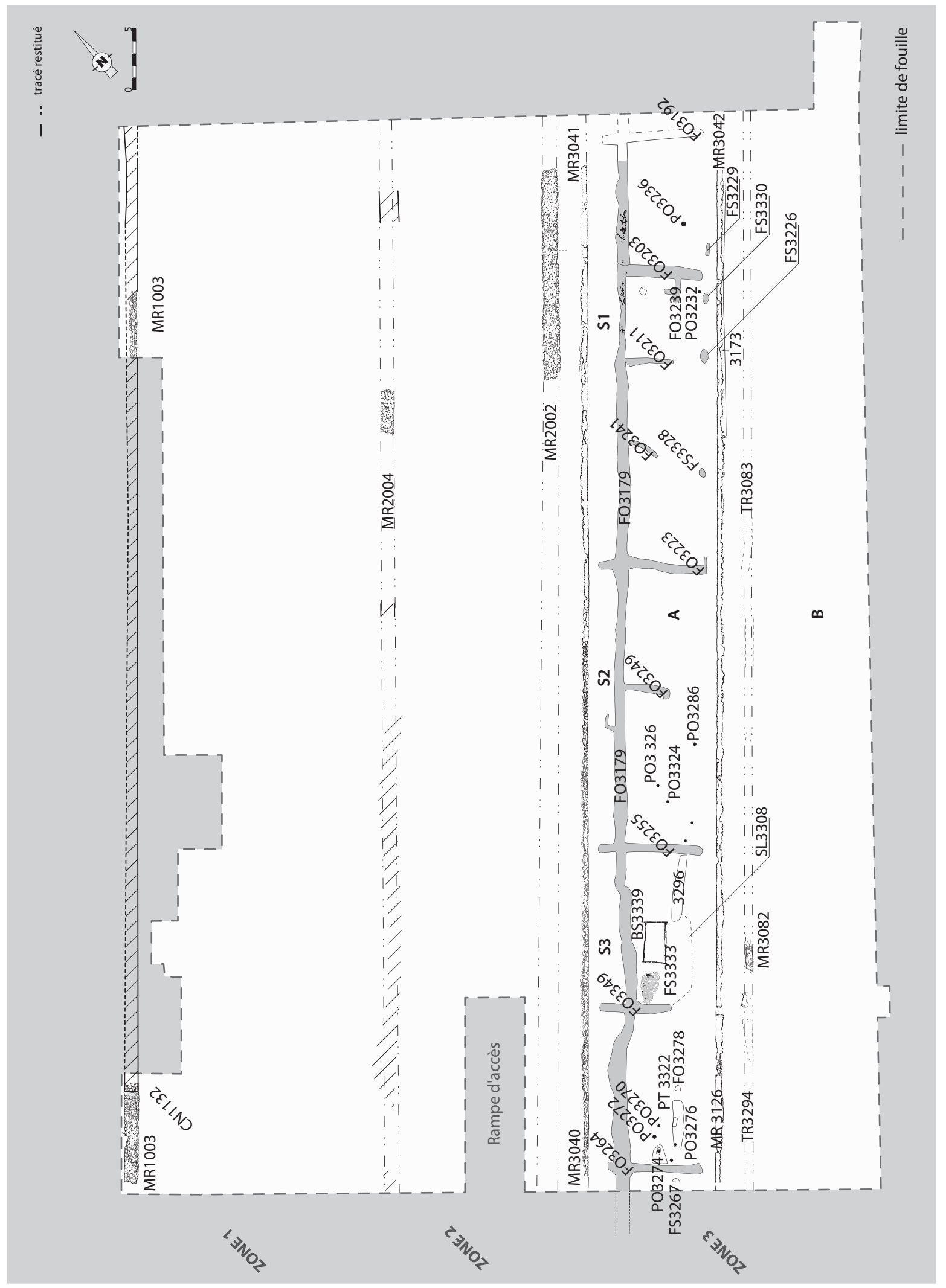

Fig. 130. Plan d'ensemble des vestiges de la phase 4A. 


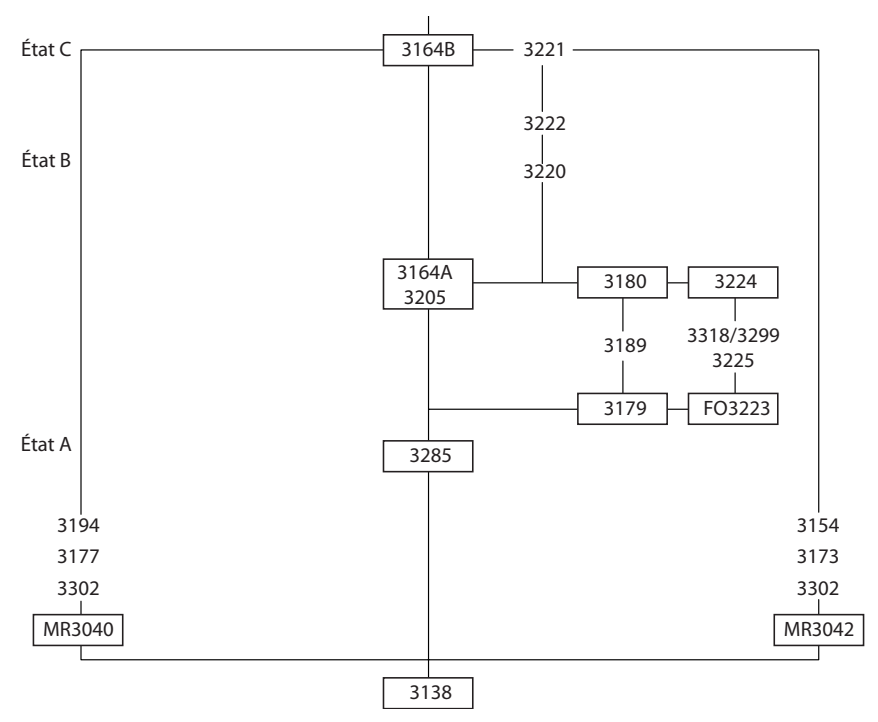

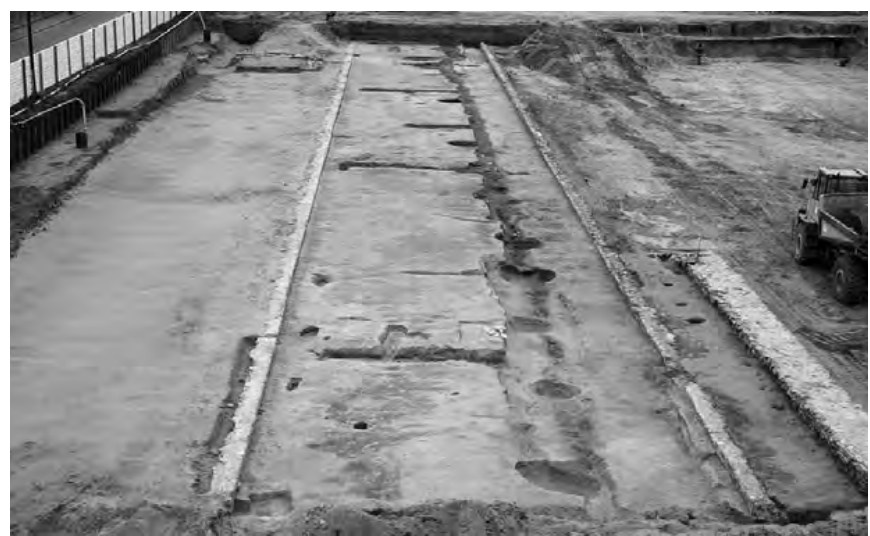

Fig. 132. Vue d'ensemble de la lanière PAA3063, vue de l'est.

Fig. 131. Diagramme stratigraphique de l'ensemble de la phase 4.

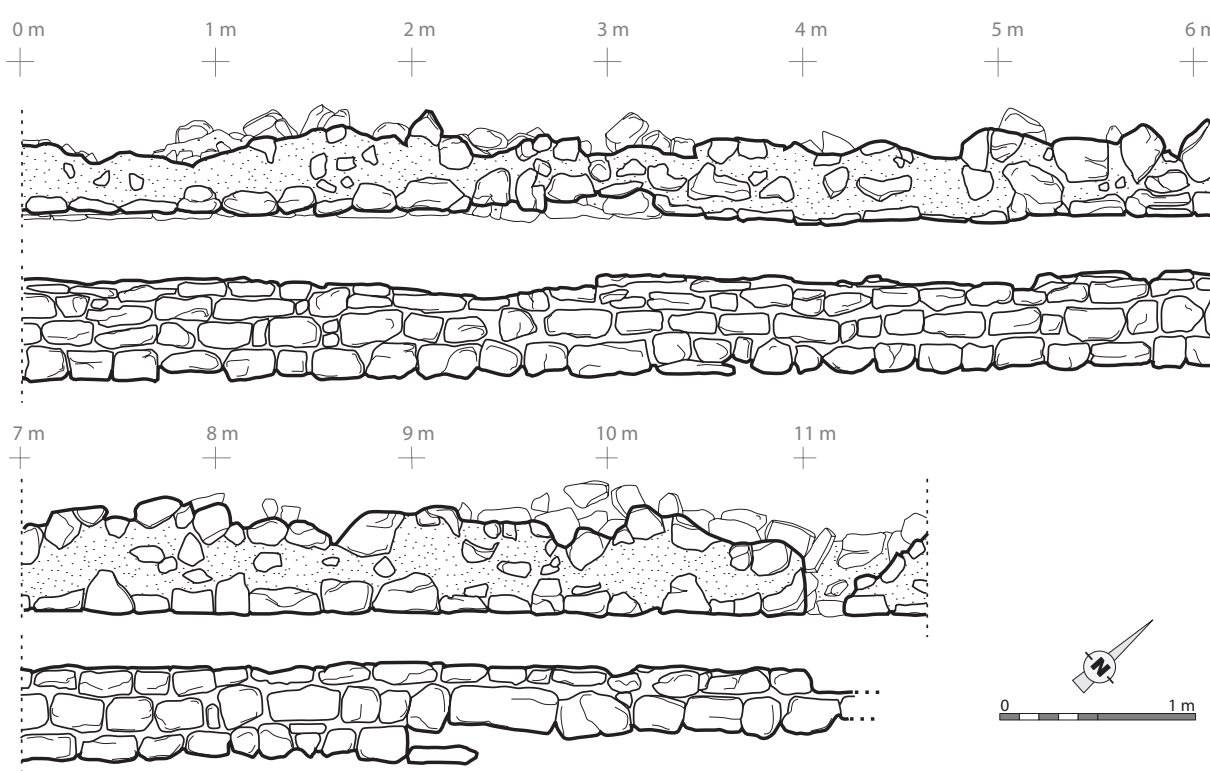

Fig. 133. Relevé en plan et en élévation d'une section du mur MR3040.

Les deux murets possèdent des assises peu régulières et la disposition des moellons est le plus souvent en panneresse. Le nu du mur est soigné, le parement est vertical et n'a pas été rejointoyé. Le soin apporté à l'agencement de ces éléments, à l'aspect assez disparate, relève tout de même d'une mise en œuvre de qualité. Des résidus du niveau de construction comprenant des éclats de grès sont mêlés à un sédiment sablo-limoneux gris vert (US3194) mis en évidence le long des parements des deux murets (fig. 134). Leur base a été installée dans une légère dépression (US3302), comblée par ce même niveau. Ces derniers pouvaient être, à l'origine, un peu plus hauts mais leur largeur et leur mode de construction ne permettent pas d'imaginer qu'ils s'élevaient beaucoup plus, d'autant que leur rôle était de retenir la poussée des sables. L'absence de barbacane, ou chantepleure, se justifie par la nature du sol sableux, très perméable, permettant l'infiltration rapide des eaux de pluie. Sans doute faut-il supposer que les deux murets étaient surmontés d'une palissade en bois, ou plus sûrement en terre crue comme pourraient l'indiquer les nombreux agrégats argileux mis en évidence par l'étude micromorphologique des aménagements qu'ils enserrent. La nature des deux murs induit une avancée quasi nulle du corps sableux contrairement aux époques précédentes. Il ne s'agit plus de lutter contre l'ensablement mais de maintenir les abords de la tranchée. En effet, l'éloignement progressif du rivage, allié à 
d'autres facteurs qui nous échappent encore sur les aménagements situés plus au sud, suppose une stabilisation des sols dans le secteur de Villeneuve à cette époque où le rivage, plus éloigné, n'influe plus de la même manière.

\subsubsection{La lanière secteur $A$ : PAA3063}

À l'intérieur de la lanière délimitée par les deux murets plusieurs fosses et fossés d'orientation nord-est/ sud-ouest ont été découverts, tous raccordés à un long fossé (FO3179) perpendiculaire, suivant la même orientation que les deux murets. Le fossé FO3179 a été reconnu sur $85 \mathrm{~m}$ de long, sans interruption. Il se prolongeait au-delà des limites de la fouille. Il s'agit d'un fossé large à l'ouverture d'environ $1 \mathrm{~m}$ et de section en cuvette. Il est creusé à même le sable sans aménagement spécifique pour les bordures. Son tracé est relativement rectiligne (fig. 135). Sa profondeur varie faiblement d'un bout à l'autre, entre 0,30 et $0,45 \mathrm{~m}$, mais son sommet a

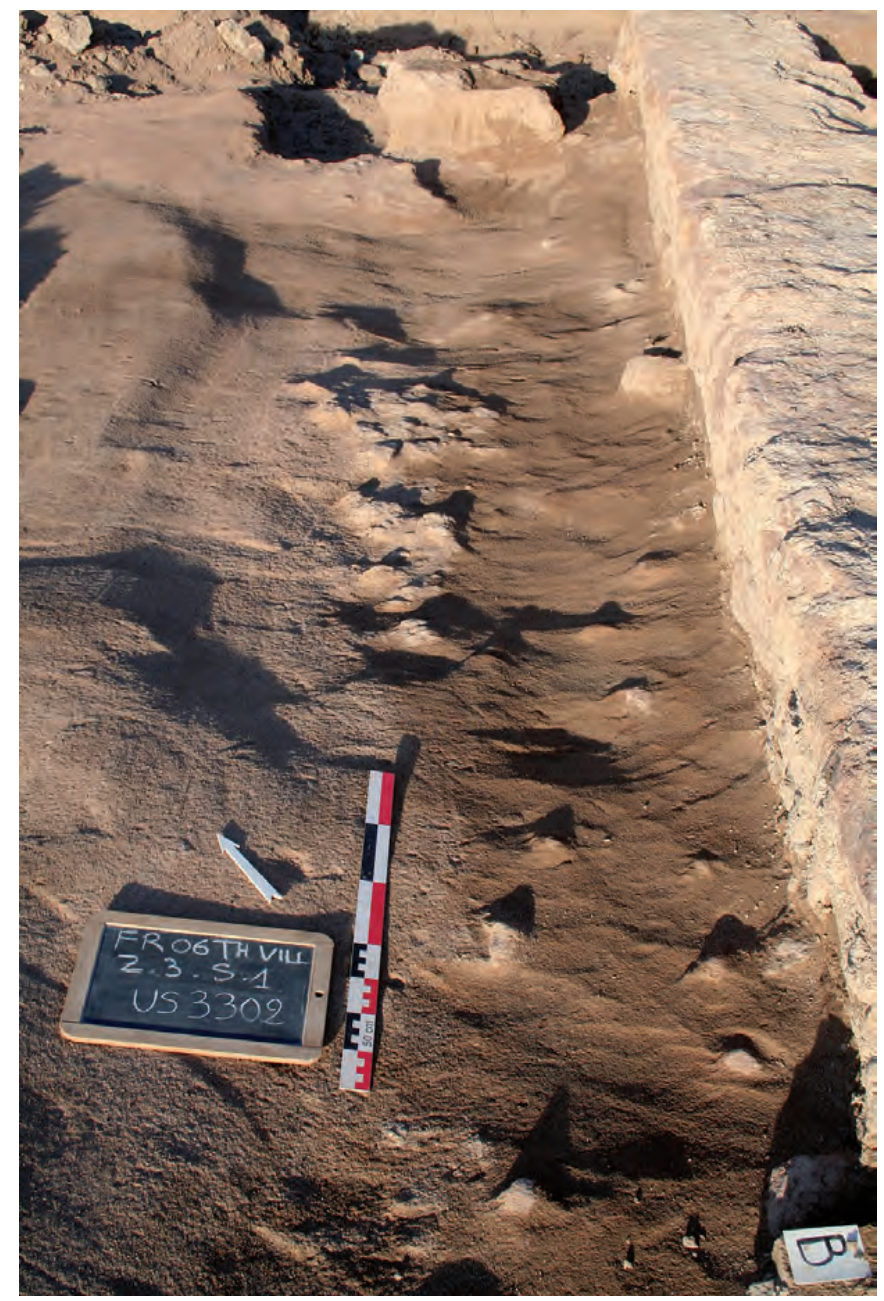

Fig. 134. Des éclats de grès sont mêlés au sédiment, il s'agit des résidus du niveau de construction. été partiellement recreusé par un autre fossé à l'époque moderne, oblitérant ainsi pour une large part les liens stratigraphiques immédiats. Le long du tracé du fossé se raccorde perpendiculairement une série de huit tranchées d'orientation sud-ouest/nord-est ; trois s'arrêtent sur le fossé, cinq le traversent et se prolongent vers le mur MR3040, cinq sont à peu près similaires et mesurent 6,25 m jusqu'à leur connexion avec le fossé FO3179 : il s'agit des fossés FO3264, 3255, 3223, 3203 et 3192 (fig. 136). Des creusements secondaires ont également été réalisés, à l'image de FO3241 (comblement 3242) (fig. 137) et FO3211 (comblements 3212 et 3213), peu profonds et courbes. Concentrées dans le secteur 1, cinq fosses FS3328, 3226, 3330, 3229 et 3239 ont un premier comblement sombre qui rappelle celui des fossés. Une douzaine de trous de poteaux disséminés sur l'ensemble de la parcelle complètent l'ensemble des structures en creux (fig. 138). Enfin, les seuls sols de fonctionnement nettement conservés concernent une petite surface où se distinguent des traces d'activités artisanales (secteur A3).

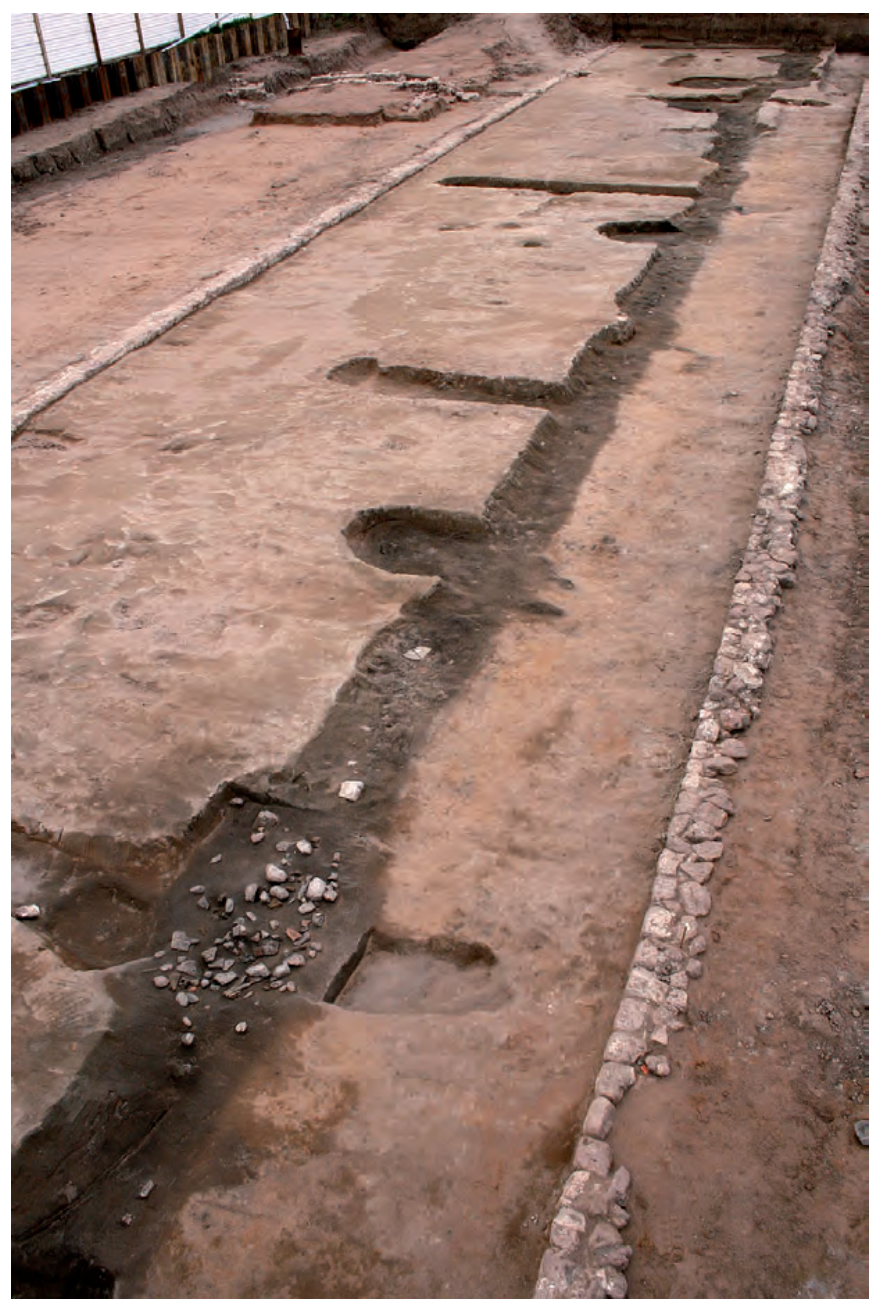

Fig. 135. La tranchée FO3179 dont le tracé est relativement rectiligne. 


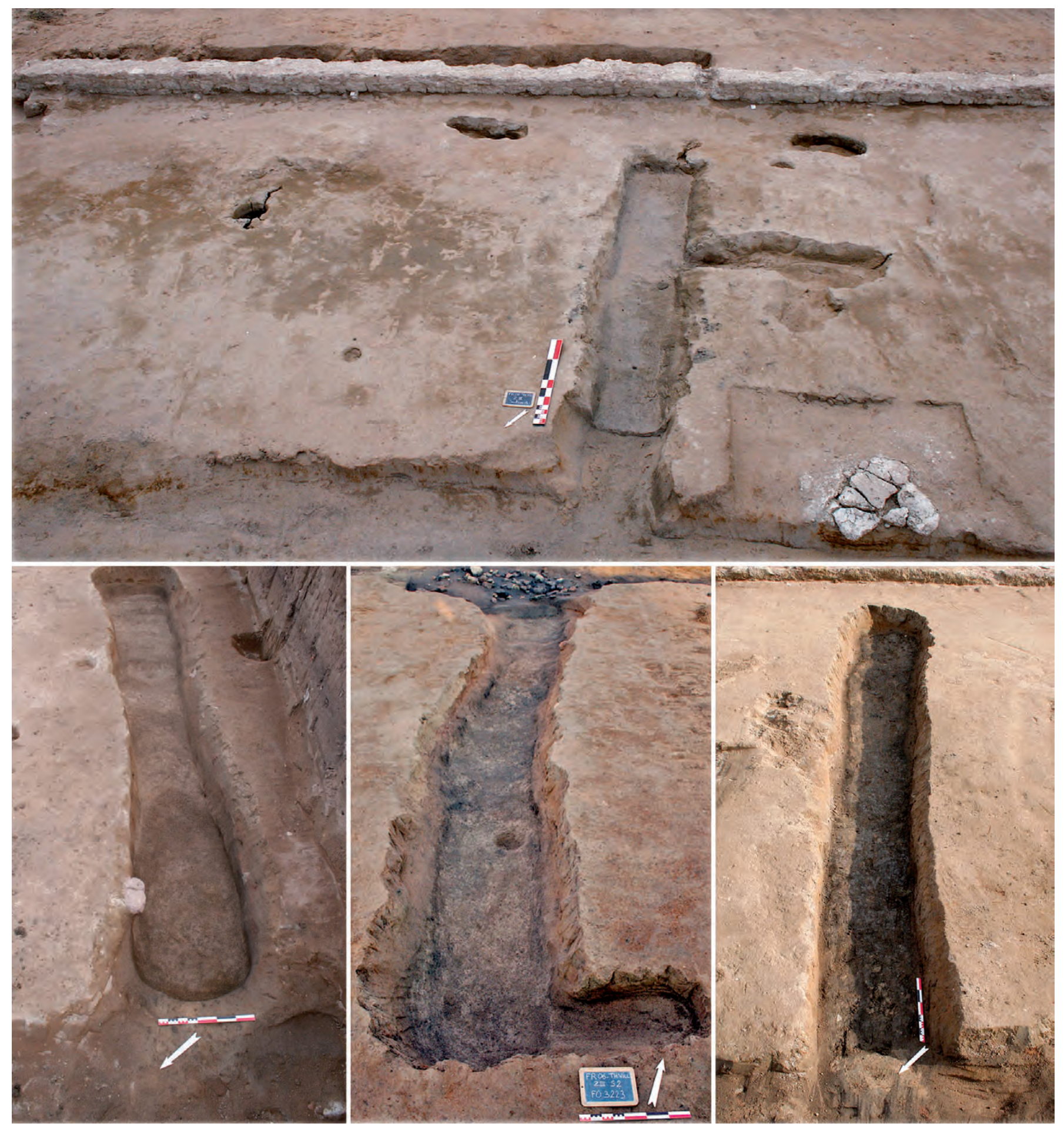

Fig. 136. Les tranchées et fossés perpendiculaires à FO3179.

\subsubsection{La stratigraphie des sols et des fossés}

Le décaissement relatif au creusement de la lanière a été effectué au sein des corps sableux antérieurs (US3138/3074) et c'est donc sur une surface sableuse que la sédimentation s'est mise en place (coupe 2c, fig. 131). Certains niveaux contemporains de la construction des murets y ont été repérés comme une aire de gâchage très localisée de $0,45 \mathrm{~m}$ x $0,47 \mathrm{~m}$ (US3165), au centre de la lanière dans le secteur 1 . Le premier niveau de sédimentation (US3285) contemporain du creusement du réseau de fossés se constitue sur l'ensemble de la tranchée. Il s'agit d'une couche compacte sablo-limoneuse de couleur brun gris 


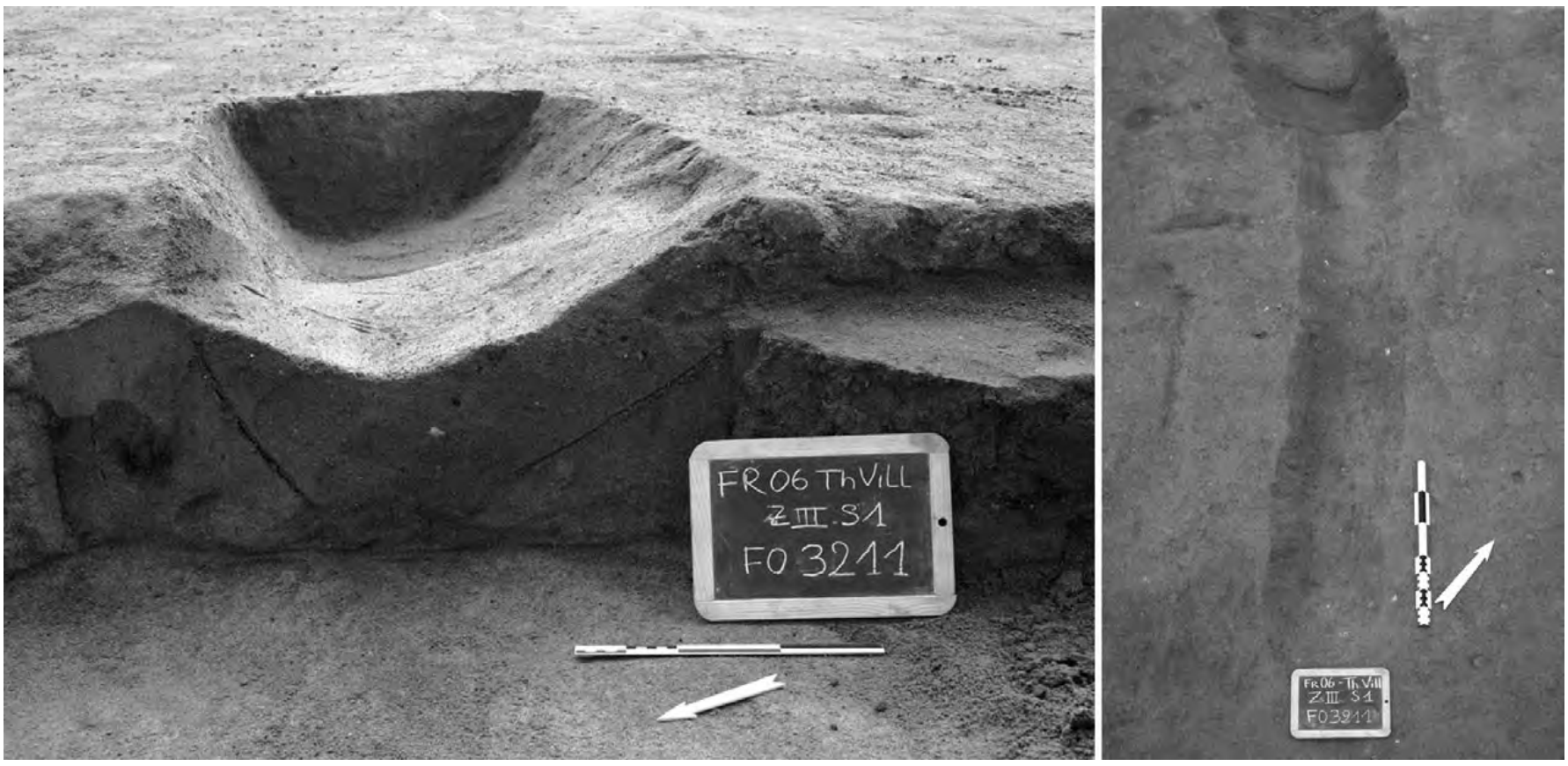

Fig. 137. Des tranchées « secondaires » ont également été creusées, à l'image de FO3211.

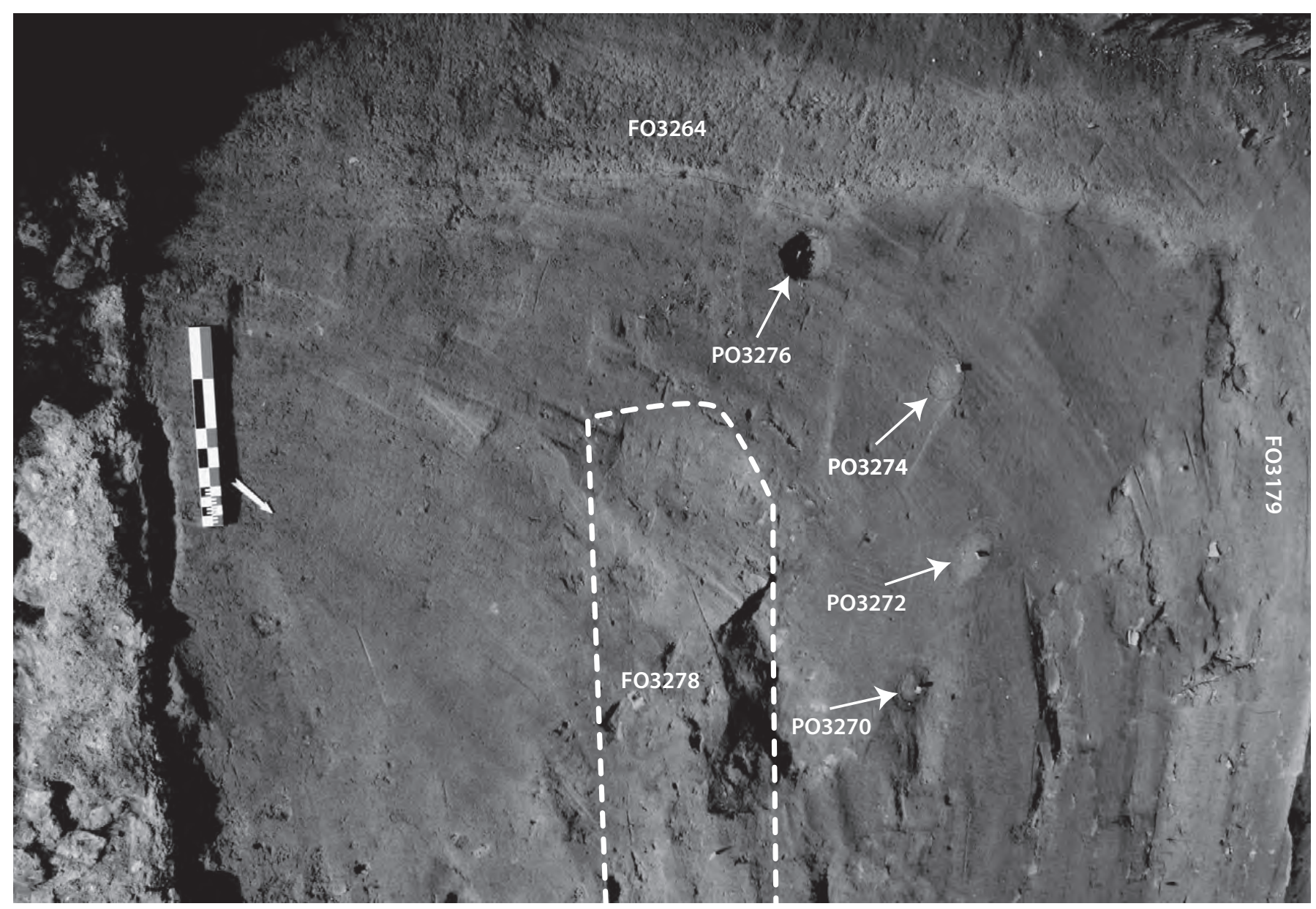

Fig. 138. Ensemble de fosses, fossés et trous de poteaux à l'extrémité ouest du secteur 3 . 

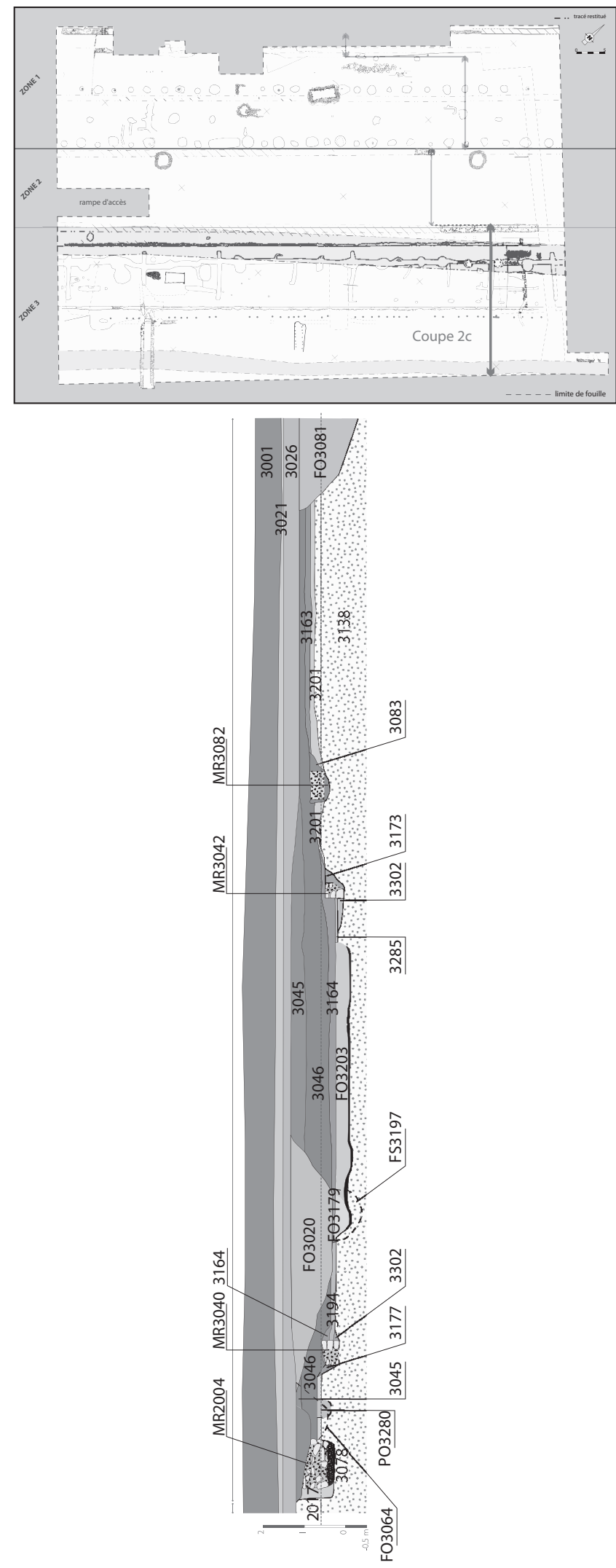

Coupe 2c. de 5 à $15 \mathrm{~cm}$ d'épaisseur. C'est à partir de ce niveau, très imperméable, que l'ensemble du système fossoyé a été mis en place. La surface $(3304,3308,3309)$ varie assez fortement d'un endroit à l'autre, notamment en fonction de la présence plus ou moins marquée de charbons ou de tessons. Ainsi, certains amas de tessons (US3206) signalent clairement cette surface. Sur l'ensemble de la tranchée, la surface contemporaine du fonctionnement du réseau de fossés (3285 et SL3308) ne montre pas de pendage net, altimétriquement, l'ensemble se situe entre 0,335 et $0,285 \mathrm{~m} \mathrm{NGF}$, soit une variation de l'ordre de $5 \mathrm{~cm}$.

Dans le secteur 3, entre les fossés 3255 et 3264 et autour du bassin (BS3339), une surface d'occupation apparait plus marquée. En effet, un piétinement important, associé à une activité artisanale sans doute plus importante qu'ailleurs, a produit un sol compact, très charbonneux (SL3308, 3210, 3336 et 3312). Sur ce sol a été découvert, à plat, un sesterce de Faustine divinisée (fig. 139, 140 et 174).

Des éléments de briques rubéfiées et des résidus de fonte de bronze ont été retrouvés répandus sur ce sol sans pour autant qu'une structure clairement identifiée n'ait été découverte à proximité. La cote altimétrique de ce niveau se situe entre 0,38 et $0,39 \mathrm{~m}$ NGF et paraît s'être exhaussée plus rapidement que le reste de la surface 3285 . La fouille de ce niveau a montré que la composition de la couche est tout à fait similaire à l'ensemble et que seule la surface présente un aspect assez différent.

L'ensemble des fossés constituant le réseau PAA3063 est creusé directement dans le sable 3138 (fig. 141). Le comblement résultant du fonctionnement du fossé FO3179 est composé d'un premier niveau sablolimoneux noir d'une épaisseur variant entre 5 et $10 \mathrm{~cm}$, riche en éléments organiques : 3182, 3189 et 3303.

Les fossés d'orientation nord-ouest/sud-est présentent une section arrondie et une profondeur moyenne de $30 \mathrm{~cm}$ (fig. 142). Chacun d'entre eux comporte un premier comblement riche en matières organiques, notamment des feuilles et brindilles, tapissant le fond sur une dizaine de centimètres (fig. 143). Au sein de cet ensemble étaient disposés de nombreux sarments de vignes comme pour la fosse FO3223 (3225) (fig. 144), parfois même directement sur le sable comme dans FO3264 (fig. 145). Les comblements supérieurs ont pu être observés de façon plus ou moins fine en fonction des conditions de fouille et de leur état de conservation. Là où l'observation a été la plus poussée, au moins trois comblements distincts ont été relevés : le comblement sombre organique, un comblement intermédiaire sablo-limoneux et argileux gris, induré et caillouteux et, enfin, le comblement sommital sablo-limoneux 


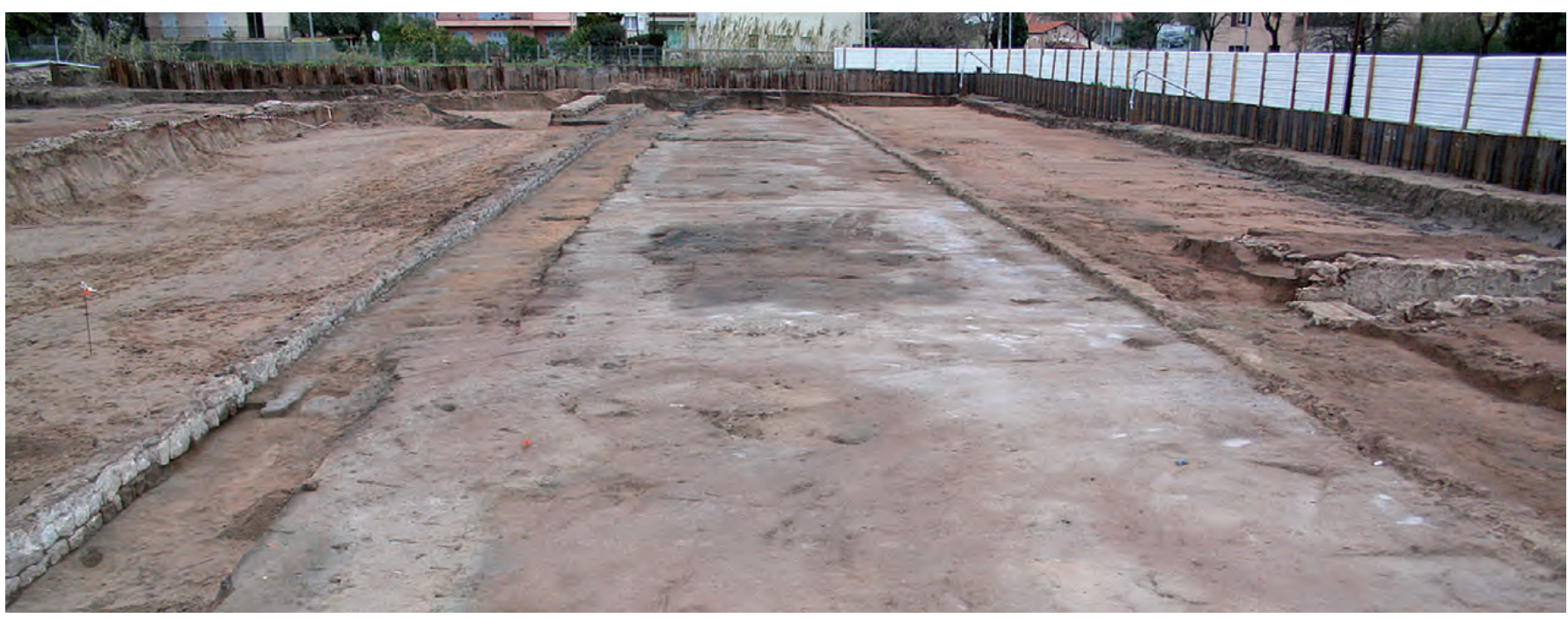

Fig. 139. Une activité artisanale, sans doute plus marquée qu'ailleurs, a produit un sol compact, très charbonneux. Le rectangle sombre au second plan correspond à cet espace.

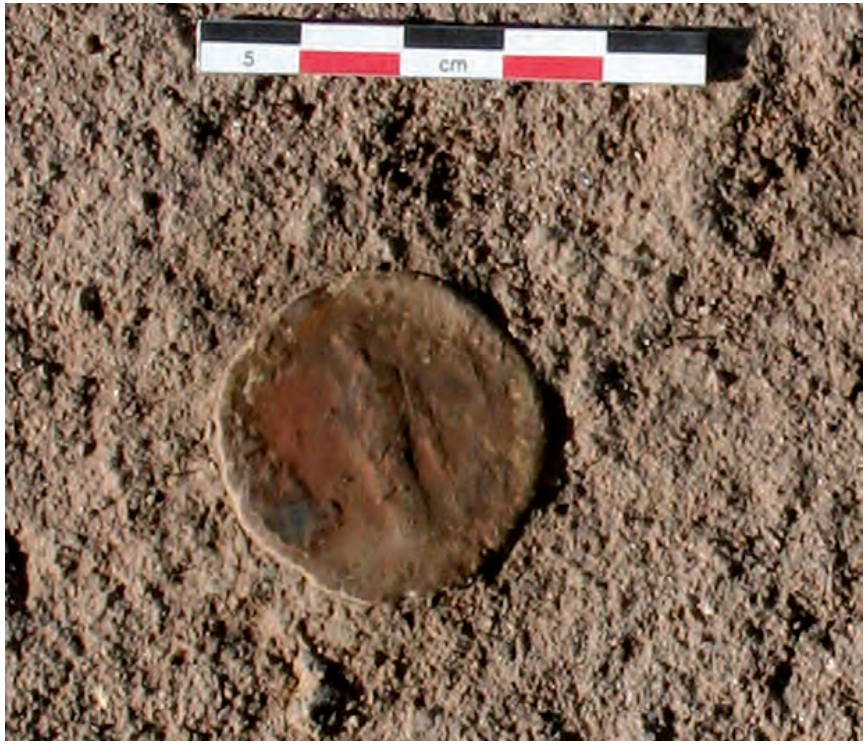

Fig. 140. Monnaie abandonnée sur le sol SL3308.

gris (FO3223 et FO3192). Là où la distinction au sein du comblement supérieur n'a pas été possible, il a été systématiquement noté la présence d'une interface sablo-argileuse grise, souvent enrichie en petit cailloux, graviers ou quelques tessons, souvent assez indurée et distincte du comblement final (FO3264, FO3255, FO3249, FO3211 et FO3203). Les compositions des deux comblements supérieurs sont très proches et la distinction a été difficile lors de la fouille. Le comblement supérieur est à dominante sablo-limoneuse, compacte et de couleur grise. Il ne comble pas entièrement le fossé qui constituait donc toujours, une fois rempli, une légère dépression. Enfin, à partir de certains fossés ont été creusées de plus petites fosses allongées, c'est le cas de FO3223 et FO3203 (FO3239).

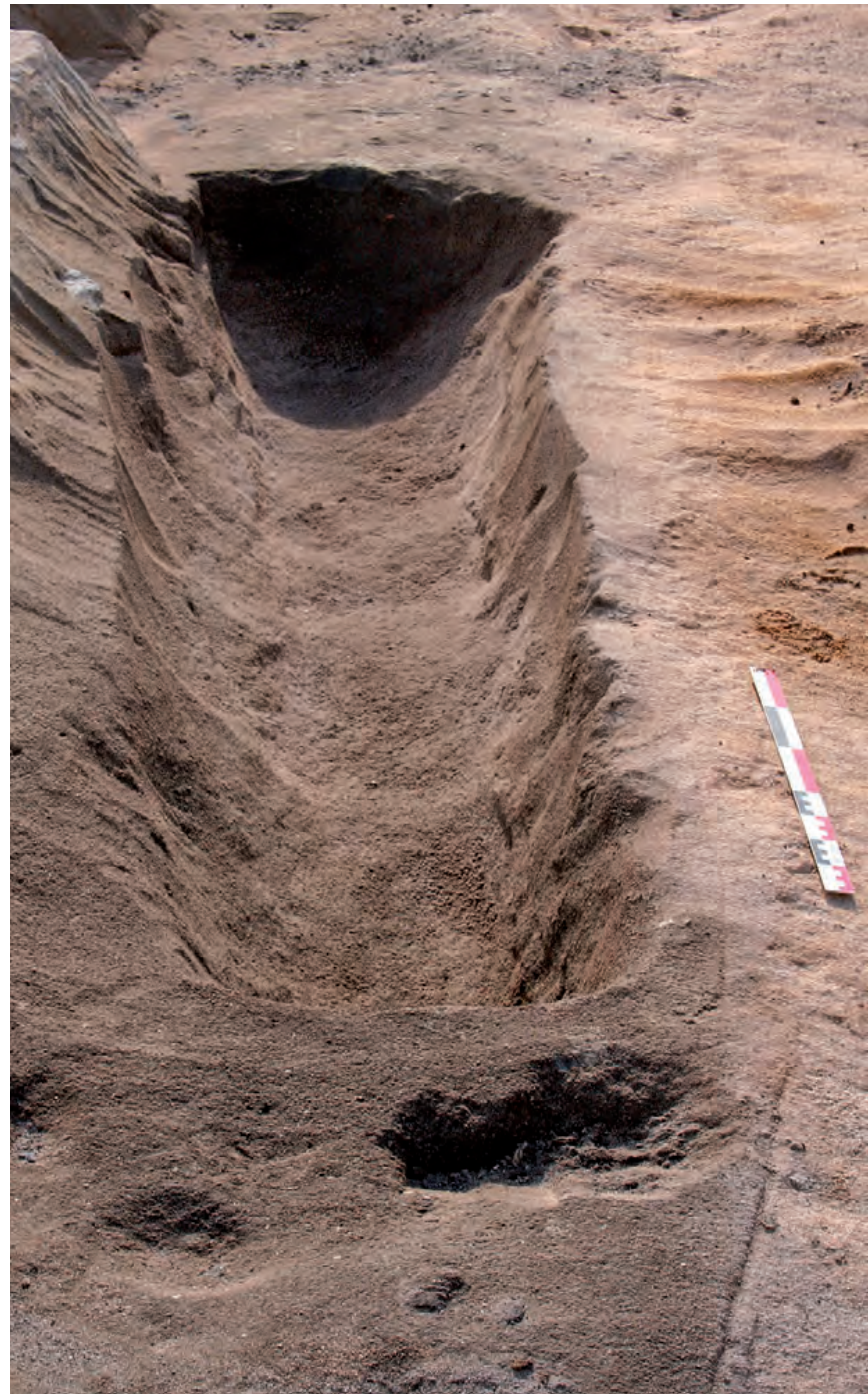

Fig. 141. L'ensemble des fossés constituant le réseau PPA3063 (ici FO3179) est creusé directement dans le sable. 
CHAPITRE 4 : UNE LANIÈRE CULTIVÉE AUX II ${ }^{\mathrm{e}}$ III ${ }^{e}$ ET IVe SIÈCLES APR. J.-C.

\begin{tabular}{|l|c|c|c|c|}
\hline & Longueur & Largeur (moyenne) & Profondeur & Comblements \\
\hline FO3264 & $7,70 \mathrm{~m}$ & $0,80 \mathrm{~m}$ & $0,30 \mathrm{~m}$ & 3266,3265 \\
\hline FO3349 & $5,90 \mathrm{~m}$ & $0,80 \mathrm{~m}$ & $0,29 \mathrm{~m}$ & 3348,3347 \\
\hline FO3255 & $8,60 \mathrm{~m}$ & $0,70 \mathrm{~m}$ & $0,32 \mathrm{~m}$ & 3257,3256 \\
\hline FO3249 & $3,60 \mathrm{~m}$ & $0,70 \mathrm{~m}$ & $0,30 \mathrm{~m}$ & 3251,3250 \\
\hline FO3223 & $9,00 \mathrm{~m}$ & $0,80 \mathrm{~m}$ & $0,28 \mathrm{~m}$ & $3225,3318,3299,3224$ \\
\hline FO3211 & $4,00 \mathrm{~m}$ & $0,40 \mathrm{~m}$ & $0,20 \mathrm{~m}$ & 3213,3212 \\
\hline FO3203 & $6,00 \mathrm{~m}$ & $0,90 \mathrm{~m}$ & $0,30 \mathrm{~m}$ & 3207,3204 \\
\hline FO3192 & $8,40 \mathrm{~m}$ & $?$ & $0,34 \mathrm{~m}$ & $3193,3208,3164$ \\
\hline
\end{tabular}

Fig. 142. Caractéristiques des fossés perpendiculaires de PPA3063.
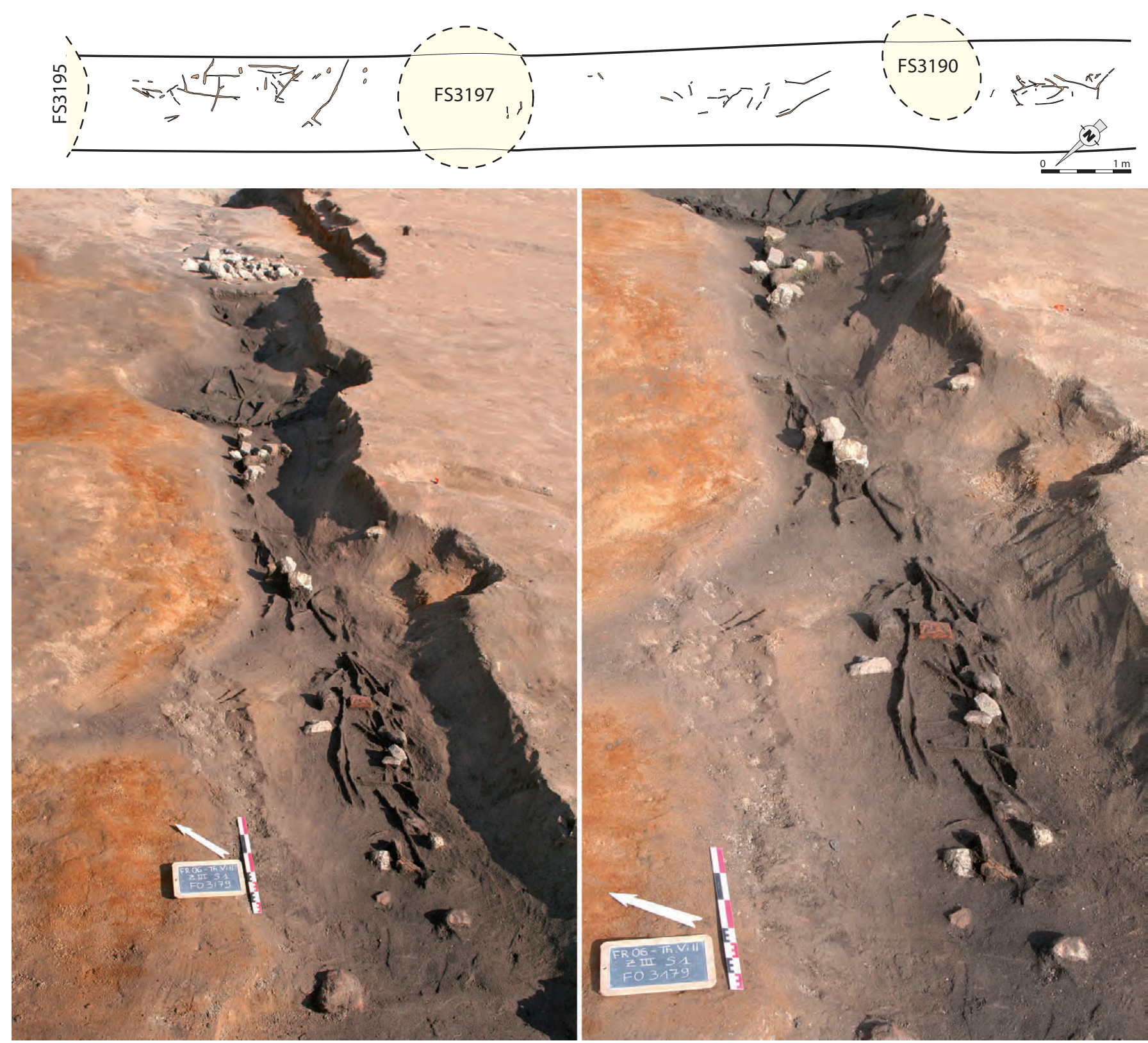

Fig. 143. Comblement inférieur du fossé FO3179.

Sur le relevé, correspondant à l'extrémité orientale du fossé, les fosses constituent des aménagements plus tardifs. 


\subsection{Les études micromorphologiques et paléoenvironnementales}

La fonctionnalité de l'assemblage des fossés, fosses et trous de poteau découverts est assez complexe à déterminer. Lors de la fouille, de nombreuses interrogations se sont posées. S'agissait-il de fossés ouverts ? Ont-ils été comblés rapidement ? Étaient-ils en eau ? S'agissait-il de tranchées de défoncement ? De provignage ? Les trous de poteau correspondaient-ils à des échalas ? Des treilles ? Les données micromorphologiques et paléoenvironnementales apportent une première série d'informations importantes concernant notamment la mise en eau des fossés.

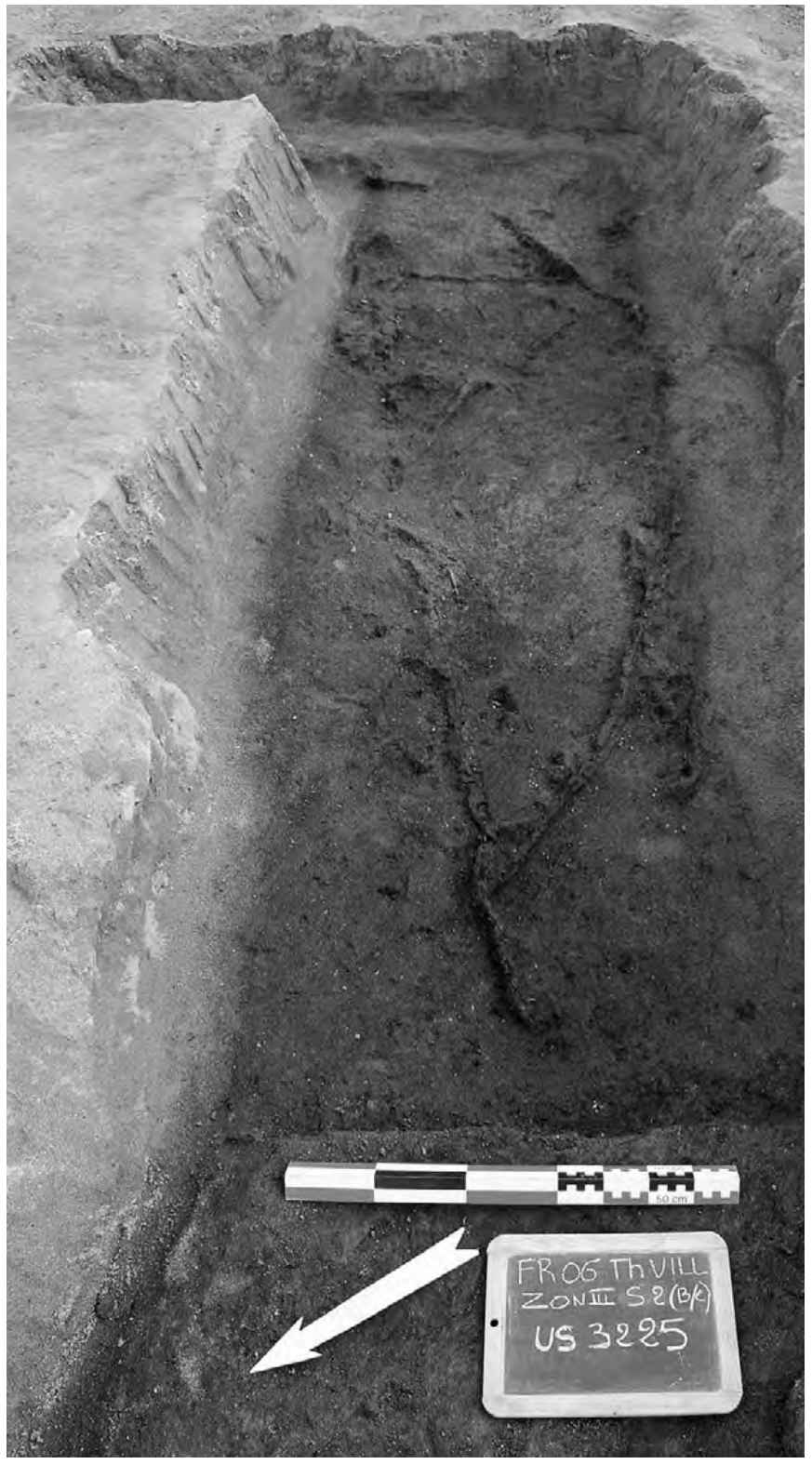

Fig. 144. Au sein de cet ensemble étaient disposés de nombreux sarments de vignes (3225), comme dans FO3223.

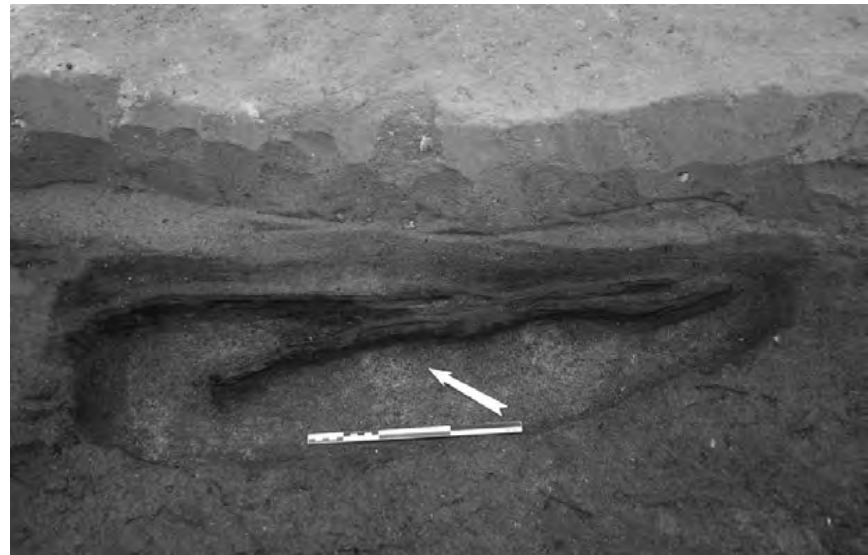

Fig. 145. On retrouve ces sarments également directement sur le sable et recouverts de compost, comme dans FO3264.

\subsubsection{Analyse micromorphologique des fossés 3179 et 3255}

$$
\text { (J.-Fr. B.) }
$$

\section{Matériaux et méthodes}

Les échantillons ont été obtenus par un carottage manuel effectué dans l'axe de chaque fossé. Un tube de $\mathrm{PVC}$ de $10 \mathrm{~cm}$ de diamètre a été enfoncé par percussion depuis le sommet du niveau de décapage archéologique correspondant à la phase $4 \mathrm{~A}$, datée de la fin du $\mathrm{III}^{\mathrm{e}}$ siècle au début du $\mathrm{IV}^{\mathrm{e}}$ siècle. Les carottes obtenues présentaient une longueur de $50 \mathrm{~cm}$, intégrant l'épaisseur totale de chaque fossé et une dizaine de centimètres du substrat, représenté localement par un niveau de plage émergée fossile attribuable au début de la période antique. Les carottes en PVC ont été ensuite ouvertes dans le laboratoire de sédimentologie du CÉPAM à Valbonne et divisées en deux parties égales, partagées entre le palynologue et le géoarchéologue. Les deux demi-carottes ont été envoyées au laboratoire de Géographie de Caen pour être indurées par des résines synthétiques et découpées en plaquettes de $12,5 \mathrm{~cm}$ de longueur. Ces plaquettes ont ensuite été collées sur une lame de verre et abrasées jusqu'à une épaisseur moyenne de 50 microns permettant une bonne lecture sous un microscope pétrographique, selon une chaîne opératoire mise au point par P. Guilloré (1985). L'analyse du comblement de chaque fossé repose donc sur 4 lames minces qui ont été observées dans un premier temps sous une binoculaire à lumière naturelle transmise (de x1 à x40) permettant de travailler sur les principaux traits macroscopiques et d'isoler les principales unités sédimentaires, puis dans un second temps sous un microscope pétrographique (de x25 à x400) pour travailler sur les microconstituants du sol, la microstructure et les différents traits pédologiques (en lumière naturelle ou polarisée analysée). 


\section{Résultats}

L'étude s'est focalisée sur les deux séquences de comblement de ces fossés, synchrones d'après les contextes archéologique et stratigraphique, et apparemment liées d'un point de vue fonctionnel. $\mathrm{La}$ fouille avait permis de formuler l'hypothèse d'un même réseau fossoyé, associant un collecteur principal (FO3179) et plusieurs fossés secondaires perpendiculaires, moins larges et moins profonds (fig. 130). L'objectif de l'étude de lames minces par la méthode de la microscopie optique en lumière transmise, était d'apporter des éléments permettant de discuter de l'origine du comblement (processus sédimentaire, vitesse, origine des matériaux sédimentaires) et de son évolution post-dépositionnelle (processus pédologiques principalement) pour comparer les deux remplissages et éventuellement les associer au sein du même réseau fonctionnel, puis de discuter de la fonction de ces fossés et du niveau de l'aquifère local (fig. 146 et 147).

L'analyse révèle que les faciès supérieurs apparaissent presque identiques dans les deux fossés, par leur granularité et la composition de leur matrice fine. Ils se caractérisent par l'accumulation de particules fines (limons et argiles de décantation) et de matière organique à l'état amorphe et intégrée à la matrice sédimentaire fine, témoignant ainsi d'une phase de ralentissement des dynamiques sédimentaires dans l'axe du réseau fossoyé. Les fossés n'apparaissent alors plus vraiment fonctionnels d'un point de vue hydraulique, ce qui correspond à l'abandon de leur entretien, associé à leur atterrissement lent et à leur eutrophisation. D'après les traits d'évolution pédologique (forte agrégation granulaire, bioturbation totale), d'oxydation du sédiment et la concentration de carbonates de calcium secondaires (revêtements et hyporevêtements micritiques dans la porosité racinaire fossile et dans les fissures interagrégats, petits nodules) observés dans les $20 \mathrm{~cm}$ supérieurs du remplissage des fossés (phase 4A), ces faciès supérieurs témoignent de la disparition des traits d'hydromorphie qui prévalaient dans les sédiments sous-jacents et d'une forte augmentation de l'évapotranspiration. Cette pédogenèse, associée à un changement des conditions stationnelles du milieu, pourrait avoir été favorisée par plusieurs facteurs cumulatifs (arrêt de l'alimentation en eau du réseau hydraulique, légère baisse du niveau marin conditionnant l'aquifère locale, climat plus chaud et $\mathrm{sec})$. Ces conditions réduisent fortement la préservation des matériaux organiques. Les matériaux de colmatage terminaux des fossés de la phase 4B sont constitués de limons argileux brunâtres, aux caractéristiques très proches sur le terrain. L'étude stratigraphique $\mathrm{du}$ secteur montre par ailleurs que ces processus de brunification s'appliquent aussi à l'horizon supérieur de la plage dans lequel les fossés hydrauliques ont été creusés (horizonation pédologique). Les plantations associées à cette phase d'occupation (vigne, olivier, prunier...) ont pu profiter de cette période d'évolution pédologique (développement d'un sol de type brun calcaire), favorable à l'enrichissement naturel des sols littoraux (bonnes qualités agrologiques). Le contexte chronostratigraphique du secteur révèle donc que les processus pédologiques prédominent sur le site de Villeneuve, au cours d'un épisode correspondant au IV ${ }^{\mathrm{e}}$ et au début du Ve siècle apr. J.-C. Cette phase pourrait correspondre à une moindre anthropisation (abandon momentané de l'exploitation du secteur, avant le développement arboricole plus tardif ?) d'après les marqueurs polliniques associés (associations végétales témoignant d'un enfrichement). Cette phase de pédogenèse et d'assèchement climatique au cours du Bas-Empire romain a d'ailleurs été largement identifiée dans le Sud de la France dans le cadre d'études géoarchéologiques menées dans les milieux fluviaux des bassins du Rhône (Berger, Brochier 2006) et du Vidourle (Berger et al. 2003).

Les faciès sédimentaires inférieurs diffèrent par leur granulométrie (nettement plus grossière en FO3179). Ils témoignent d'une compétence des écoulements assez énergique, d'un haut niveau de l'aquifère et d'une concentration de débris végétaux. Les pollens, les microfossiles non polliniques (algues) et les mollusques identifiés dans les mêmes horizons enregistrent également un haut niveau de l'aquifère dans ces premiers niveaux de comblement, associés à la fin du III' ${ }^{\mathrm{e}}$ siècle ou au début du IVe siècle apr. J.-C. (études de S. Guillon et S. Martin).

L'étude de la morphologie, de la structure et de la composition sédimentaire des matériaux de comblement de ce réseau hydraulique permet de proposer deux principales hypothèses sur sa fonction. Est-il purement associé à une pratique de drainage permettant de rabattre le niveau de l'aquifère local, comme les indices biologiques discutés ci-dessus semblent le démontrer ou se rattache-t-il à une fonction irriguante ? Des exemples récents ont mis en évidence une fonction double (drainage/irrigation) de certains réseaux hydrauliques dans le haut bassin du Rhône, à proximité de la ville du Vernai à Saint-Romain-de-Jalionas (Berger et al. 2003 et Royet et al. 2004). Les apports d'eau d'irrigation transiteraient alors par l'intermédiaire d'un canal principal (FO3179).

Plusieurs indices sédimentaires et polliniques permettent de retenir cette seconde hypothèse. La structure microlitée de la première partie du remplissage du canal ou collecteur FO3179, associée à des sables moyens à grossiers souvent bien classés et lavés, indique des flux 


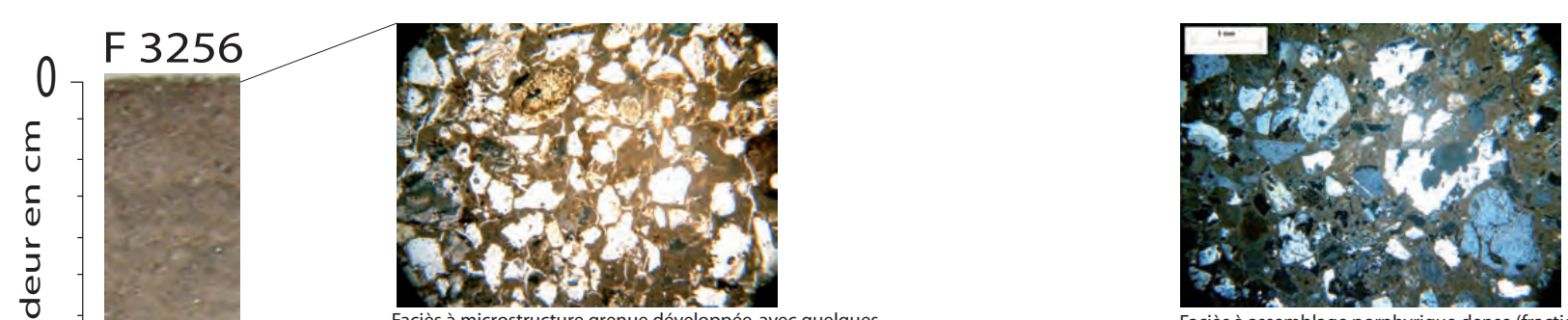

Faciès à assemblage porphyrique dense (fraction sableuse développée et grossière) ( $L P$, unité $1 \mathrm{~b} / 1 \mathrm{c})$

\section{$\frac{1}{4}$}

10

U1 revêtements carbonatés gris (LN, unité 1$)$

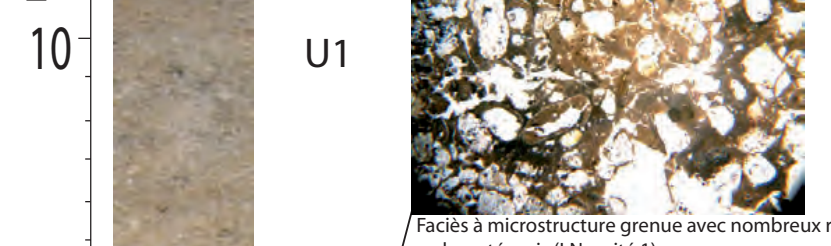

reux revêtements carbonatés gris ( $\mathrm{LN}$, unité 1$)$

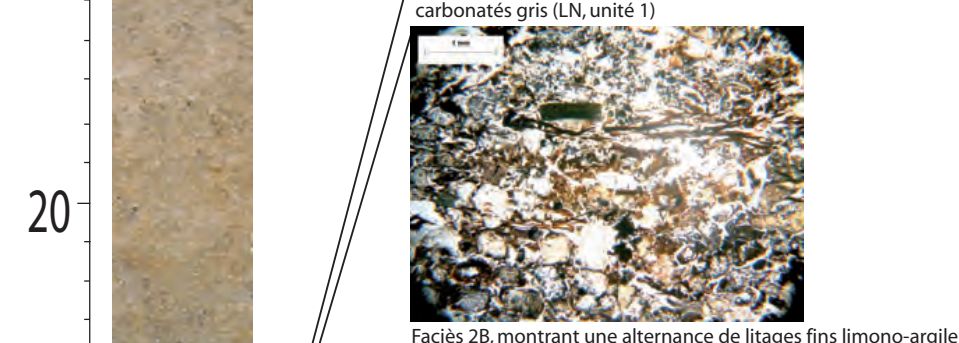

Faciès $2 \mathrm{~B}$, montrant une alternance de litages fins limono-argileux riche en $\mathrm{M}-\mathrm{O}$ 列 et des lits sableux grossiers majoritairement quartzeux $(\mathrm{LN}, 36 \mathrm{~cm})$

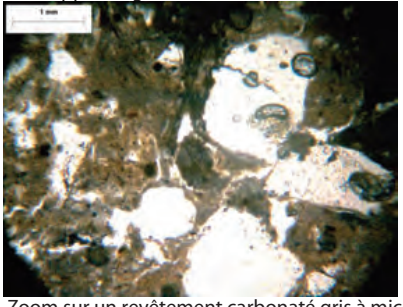

sur un revêtement carbon

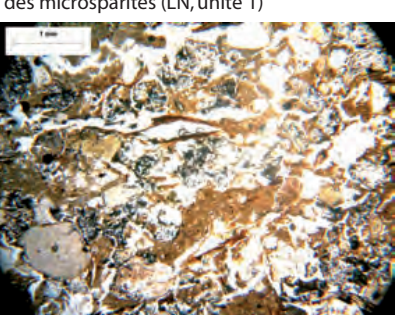

Faciès $2 \mathrm{~A}$, avec la même organisation, mais plus bioturbée $(\mathrm{LN}, 36 \mathrm{~cm})$

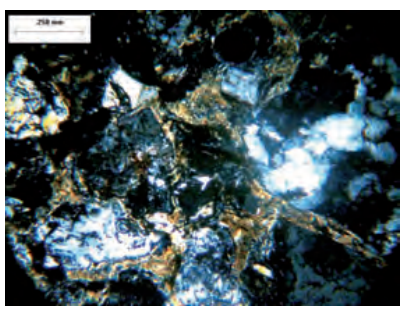

U2

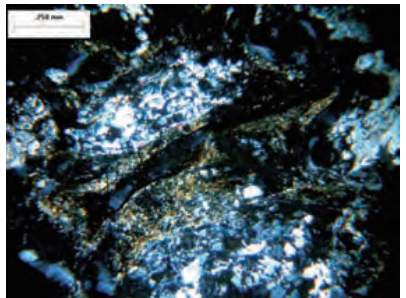

Faciès $2 \mathrm{~A}$, agrégats d'argile pédologique de sol fersiallitique

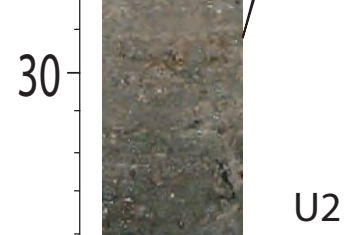

metamorphiques.

aciès $2 B$, Zoom sur un agrégat de sol fersiallitique roule montrant un squelette bien développé et une matrice argileuse décarbonatée granostriée (LP, $36 \mathrm{~cm})$
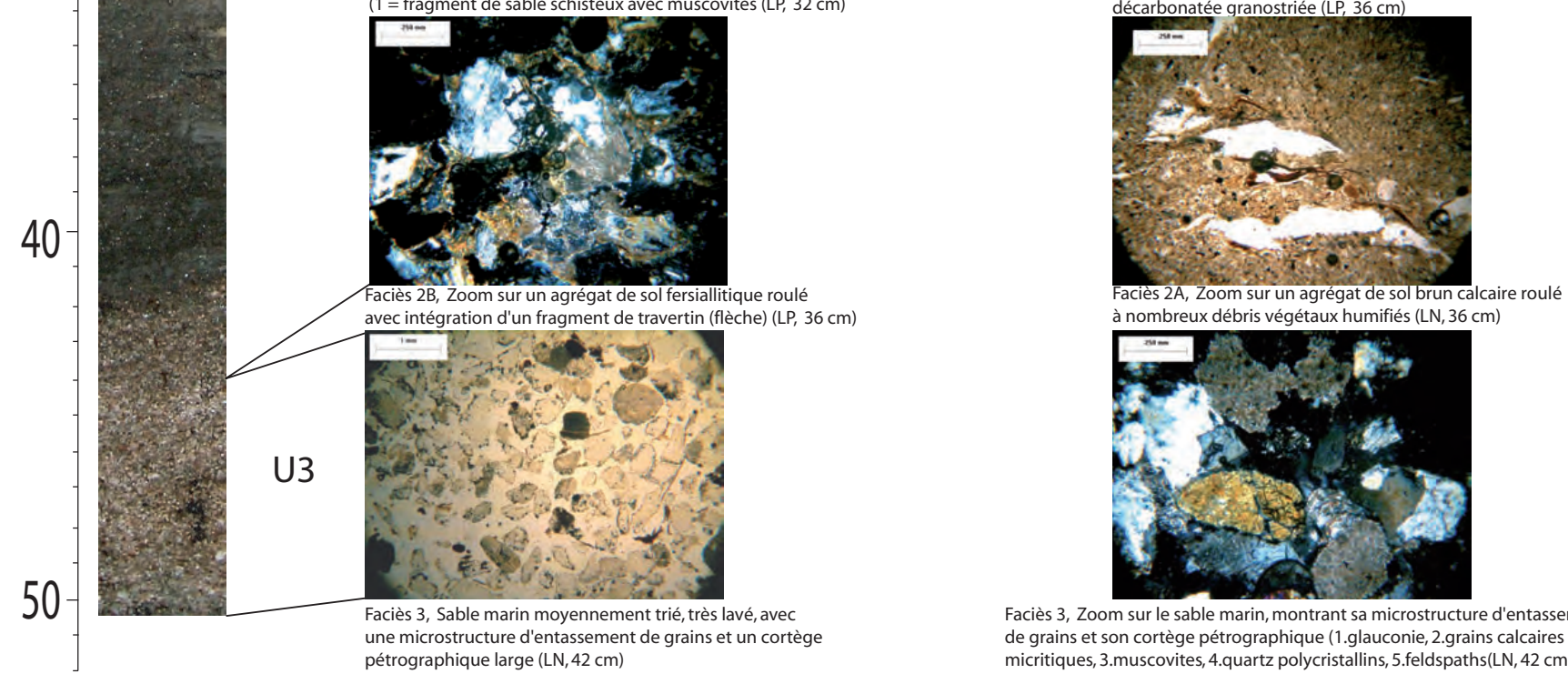

à nombreux débris végétaux humifiés $(\mathrm{LN}, 36 \mathrm{~cm})$

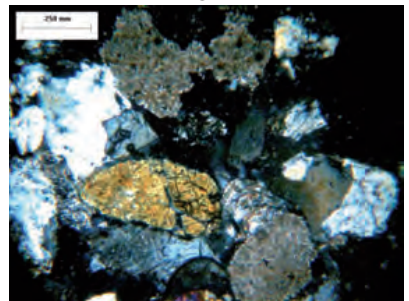

Faciès 3 , Zoom sur le sable marin, montrant sa microstructure d'entassement de grains et son cortège pétrographique (1.glauconie, 2.grains calcaires micritiques, 3.muscovites, 4.quartz polycristallins, 5. feldspaths $(\mathrm{LN}, 42 \mathrm{~cm})$

Fig. 146. Photographies des principaux faciès identifiés en microscopie dans le remplissage du fossé FO3255. 


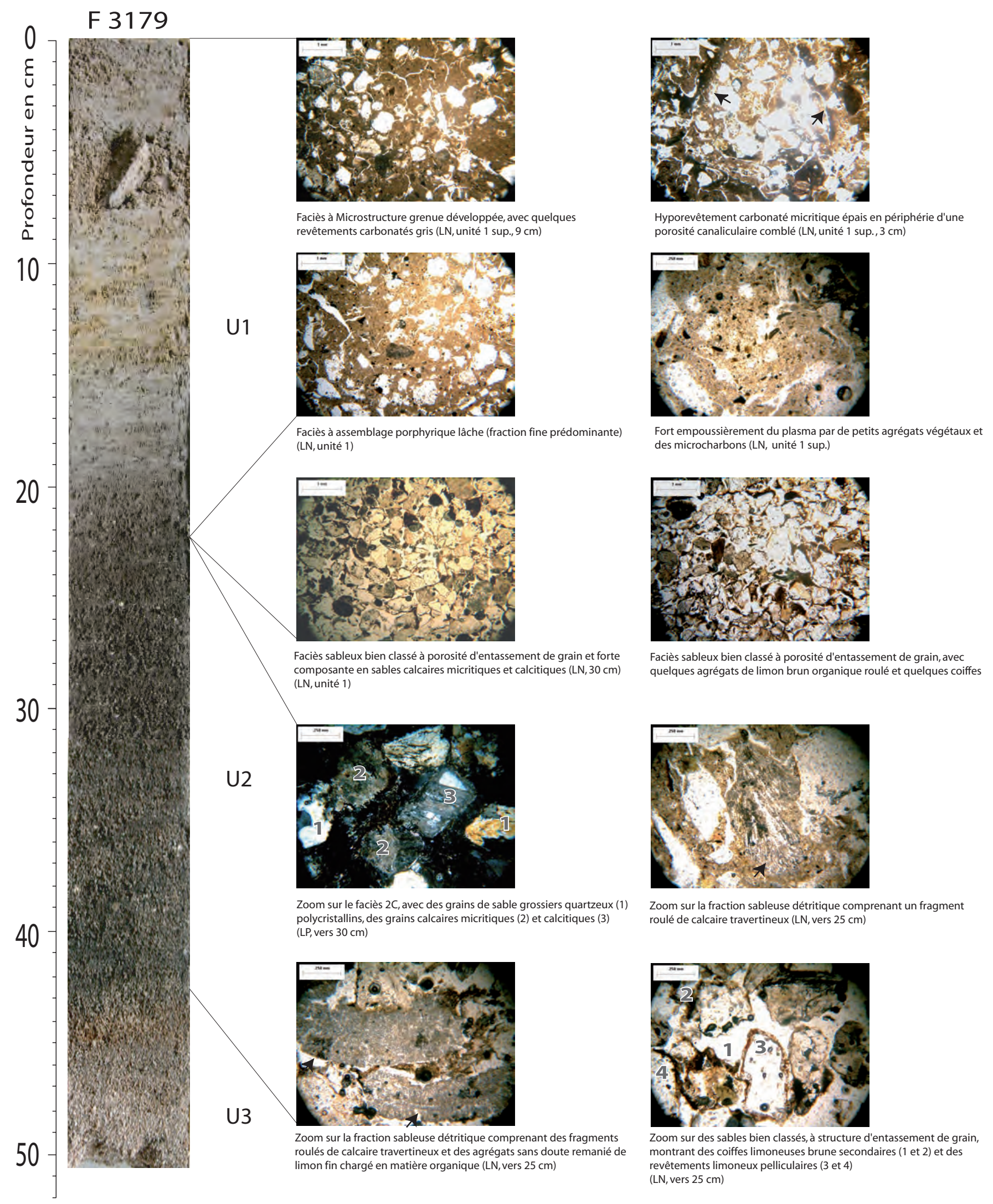

Fig. 147. Photographies des principaux faciès identifiés en microscopie dans le remplissage du fossé FO3179. 
hydriques assez continus et une énergie assez soutenue du courant tractif. La présence de nombreuses coiffes et revêtements limoneux peu orientés entre les grains sableux marque des phases d'illuviations brutales, lors de mises en eau sans doute moins terrigènes, intercalées entre deux phases de dépôts sableux. La présence régulière, mais jamais importante, de fragments de travertin au sein du cortège pétrographique des sables lités pourrait signer l'origine des eaux irriguées : des aqueducs ou des canaux dérivant l'eau des rivières de l'arrière-pays calcaire, à charge minérale rhyolitodoléritique, gréseux permien et métamorphique. L'alternance d'horizons fins chargés en matières organiques et de lits sableux grossiers dans les fossés (ou canaux) secondaires, apparaît topographiquement surélevés par rapport à FO3179. Cette structure et cette composition des sédiments alluvionnés en fond de fossé témoigneraient alors d'apports en eau rythmés (annuels, saisonniers ?), qui associeraient des dépôts sableux caractéristiques de la phase d'irrigation et des dépôts de limons fins riches en éléments végétaux, caractéristiques de phénomènes de décantation lors de l'arrêt de cette alimentation. Cette dernière phase serait suivie d'une eutrophisation et d'un assèchement temporaire entre deux apports hydriques. L'originalité du spectre pollinique des fossés 3179 et 3255 montre un écho nettement plus régional que celui des puits et des bassins analysés par ailleurs sur le site [avec 20 à $40 \%$ de pollens exogènes issus des milieux siliceux (bruyère arborescente) ou plus calcicoles (chêne pubescent)]. L'arrivée d'eaux lointaines pourrait être alors une explication à cette variété du spectre pollinique.

Cette hypothèse n'explique pourtant pas toutes les différences observées entre le fossé principal (3179) et son émissaire (3255) lors du premier remplissage de ce réseau hydraulique. Pourquoi la même rythmicité (dépôt fin organo-minéral, dépôt sableux) ne s'observe-t-elle pas dans le grand collecteur si les mêmes dynamiques les caractérisent ? Ces différences peuvent en partie s'expliquer par leurs différences hiérarchique et topographique : les flux sont plus concentrés dans le canal d'amenée principal et la charge de fond, très sableuse, ne peut sans doute pas atteindre les fossés secondaires dont le fond est situé topographiquement à une dizaine de centimètres plus haut. La fréquence et la forte énergie des flux liquides et solides transitant dans le collecteur 3179 élimineraient alors saisonnièrement les fins lits organiques qui ont pu se former entre deux phases d'irrigation. Cette explication «taphonomique » pourrait justifier la présence de fragments végétaux et organo-minéraux roulés entre les grains de sable lités du fossé 3179 .

Un dernier point reste à discuter : la présence de nombreux agrégats argileux exogènes d'origine

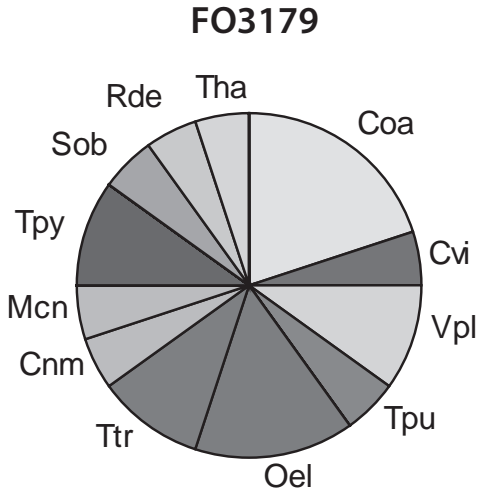

Fig. 148. Proportion des estimations d'abondance des taxons malacologiques terrestres pour le fossé 3179 (cf. fig. 125).

fersiallitique dans le fond du fossé secondaire 3255. Ils sont strictement associés à ce fossé et ne semblent pas arriver avec les eaux d'irrigation. Leur origine apparaît donc locale. Il pourrait s'agir de vestiges roulés depuis un mur ou une construction en terre crue, dont les éléments issus de la désagrégation auraient été transportés jusqu'au fond du fossé lors d'épisodes pluvieux particulièrement concentrés, responsables de ruissellements en périphérie du réseau fossoyé. On pourrait aussi imaginer le remaniement d'apports de terre exogènes accumulés sur le site dans le but de le niveler ou d'enrichir le niveau de plage sableux, peu propice à des cultures ou des jardins décoratifs (création d'un sol de jardin artificiel). Cependant, les sols rouges méditerranéens ne présentent pas une très bonne fertilité ce qui pose le problème de leur utilisation à des fins agricoles.

\subsubsection{La malacologie}

\section{(S. M.)}

\section{Le fossé FO3179 US3189 \#505}

L'assemblage \#505 du fossé FO3179 montre des formations herbacées hautes et relativement sèches (Cochlicella acuta, Trochoidea pyramidata et Trochoidea trochoides) (fig. 148).

Par ailleurs, le développement d'espèces plus hygrophiles (Vallonia pulchella, Succinea oblonga), voire franchement palustres (Oxyloma elegans), semble lié au fonctionnement du fossé. On peut y associer les deux espèces dulcicoles Anisus leucostoma et Gyraulus albus : ce sont deux espèces de milieux aquatiques temporaires d'eau stagnante, peu exigeantes quant à la qualité du milieu.

Cet assemblage permet de reconstituer un fossé supportant une mise en eau régulière permettant le développement de plantes aquatiques et de végétation de type roselière, au sein d'un milieu largement ouvert et sec de type friche rudérale méditerranéenne. 


\section{FO3223}

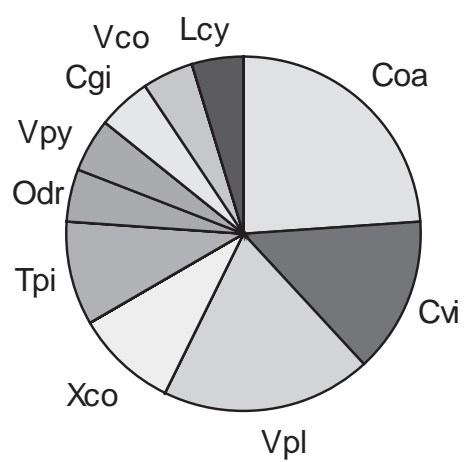

Fig. 149. Proportion des estimations d'abondance des taxons malacologiques terrestres pour le fossé 3223 (cf. fig. 125).

\section{Le fossé FO3223 US3318 \#486}

(Fossé 3323, secteur 2, sommet du comblement inférieur du fossé - 10 litres).

L'assemblage \#486 du fossé FO3223 traduit des formations herbacées hautes de type prairiales (Cochlicella acuta, Theba pisana, Cernuella virgata), relativement humides (Vallonia pulchella) (fig. 149).

La présence de faune plus sciaphile (Xerotricha conspurcata/Microxeromagna armillata, Lauria cylindracea, Vallonia costata et Oxychilus draparnaudi) indique le développement local de litière foliacée.

Par rapport aux assemblages du fossé précédent, on note la quasi-absence des espèces aquatiques, ce qui suggère l'absence de mise en eau du fossé FO3223.

\section{Le fossé FO3223 US3225 \#491}

(Fossé 3323, secteur 2, base du comblement inférieur du fossé - 10 litres).

Cet assemblage est difficile à interpréter car il comprend très peu de malacofaune : cette rareté peut s'expliquer par un comblement rapide de la structure.

Les deux espèces terrestres présentes (Cochlicella acuta et Cernuella virgata) indiquent des herbacées hautes de type friche rudérale méditerranéenne.

\subsubsection{La palynologie}

$$
\text { (S. G.) }
$$

\section{Les fossés FO3179 et 3256}

Il s'agit de deux fossés orthonormés associés au bassin BS3339. Étant donné leur contemporanéité et leur fonctionnalité sur le même réseau drainant, ils seront traités ici conjointement.

L'analyse pollinique a été menée grâce à deux carottages réalisés dans les comblements des fossés. Six échantillons ont été prélevés sur le carottage P.503 pour le fossé FO3179, quatre sur le carottage P.501 pour le fossé FO3256. Contrairement aux autres structures analysées dans cette étude (fosses, puits et bassin) l'image de la végétation enregistrée dans les fossés est moins locale, à l'image de la courbe des taxons arboréens, notamment celle de la pinède et du maquis à bruyères arborescentes (Erica arborea) et chênes (Quercus sp.) de l'arrière-pays siliceux, avec des valeurs oscillant entre 20 et $40 \%$ de l'apport pollinique total à Roquebrune-sur-Argens en basse vallée en amont de Fréjus (Dubar et al. 2004). L'enregistrement du fossé FO3179, globalement mieux conservé que celui du fossé FO3256, met en évidence en dehors de l'écho plus lointain de la pinède, une anticorrélation entre les valeurs du chêne (vert et pubescent) et celles de la bruyère arborescente (Erica arborea). Cette observation montre que les chênes subissent des dégradations (entre 8 et $20 \mathrm{~cm}$ et au delà de $33 \mathrm{~cm}$ sur P.503) (fig. 263) d'origine anthropique (écobuage, tallis, défrichement, déboisement) et/ou accidentelles (feux...), favorisant le développement de la bruyère, pionnière dans le maquis (Lieutaghi 2006).

Concernant le fonctionnement des fossés, plus particulièrement le long fossé longitudinal FO3179 qui traverse toute la parcelle fouillée, les courbes de Spirogyra et Zygnema (spores d'algues d'eau douce stagnante, peu profonde et riche en matières organiques) indiquent qu'au-delà de $20 \mathrm{~cm}$ de profondeur, le fond du fossé était, temporairement sans doute, sous les eaux de la nappe haute. Une humidité édaphique largement associée à la courbe des Brassicaceae qui venaient coloniser les bords du fossé et qui décroît avec les marqueurs hygrophiles. Le haut de la séquence du fossé FO3179 marque, dans un premier temps, son atterrissement puis son abandon, marqué par un niveau largement sujet aux phénomènes d'oxydation qui a sans doute entraîné une conservation différentielle des grains de pollen mais qui présente une dominance des Cichorieae (herbacées de friche et de prairie). Une des questions à laquelle on voulait tenter de répondre par l'analyse palynologique de ces fossés, était de savoir si l'on pouvait retrouver l'écho pollinique des rameaux de vigne retrouvés au fond de ces traces agraires. Avant tout, afin de vouloir retrouver l'écho pollinique d'un quelconque signal, il convient d'en définir la nature. Ici, le pourquoi de la présence des rameaux de vignes au fond de ces structures reste encore énigmatique. S'agissait-il de pieds cultivés au fond du fossé ? L'absence de grains de pollen de Vitis dans les séquences étudiées et la présence d'eau dormante ne vont pas dans ce sens. S'agissait-il de rameaux disposés de manière à aménager le fond ou les berges des fossés, auquel cas pouvait-il s'agir de restes de taille d'une réelle culture ? L'analyse pollinique ne nous est pas ici d'un grand secours. Les questions sont nombreuses mais les réponses le sont moins. 


\subsubsection{La phytolithologie}

(P. V)

\section{FO3255-US3257}

Cette unité stratigraphique est caractérisée par la présence abondante de phytolithes de dicotylédones $(86,5 \%)$. Les phytolithes provenant spécifiquement de l'épiderme des dicotylédones sont nombreux (20,7\%). Les phytolithes d'urticacées sont présents (1,8\%), ainsi que des concentricystes (algues) (0,9\%).

La présence conjointe de ces restes peut être le reflet d'un rejet massif de feuilles ou plus largement de restes végétaux qui ont pu pourrir sur place : la présence d'algues concentricystes est indicatrice d'une eutrophisation du milieu.

$\mathrm{Si}$ on interprète la présence d'orties comme ayant poussé sur place sur les déchets, le caractère décomposé de ce niveau est fort probable (l'ortie est une plante nitrophile).

\subsubsection{La carpologie}

$$
\text { (L. B., I. F., C. S.) }
$$

\section{Le fossé FO3223-US3325}

Selon l'analyse carpologique, la présence occasionnelle d'eau à l'intérieur ou aux abords du fossé est documentée par l'enregistrement de quelques taxons affectionnant les sols humides à périodiquement inondés (Juncus sp., Phragmites communis et Ranunculus sardous). Ce groupe représenterait plus de $29 \%$ du total des effectifs. Toujours d'après les données carpologiques, les ligneux pouvant faire l'objet d'une exploitation fruitière sont composés de cinq taxons, chacun représenté par quelques restes isolés. Il s'agit du noisetier (Corylus avellana), du figuier (Ficus carica), du pin pignon (Pinus pinea), du pommier (Malus sylvestris) et de la vigne (Vitis vinifera). La majeure partie de l'assemblage est constituée de mauvaises herbes des cultures ou des lieux rudéraux (Chenopodietea) : Euphorbia helioscopia, Fumaria offcicinalis, Heliotropium europaeum et Portulaca oleracea.

Aucun reste de bois gorgé d'eau n'est conservé mais plusieurs charbons de bois semblent renvoyer à la chênaie méditerranéenne et à la garrigue/maquis : Quercus (feuillage persistant) prédomine, accompagné sporadiquement de Cistaceae/Ericaceae, Erica, Juniperus (genévrier) et Pistacia lentiscus (lentisque).

\subsubsection{Interprétation}

(P. E.)

Il transparaît donc une mise en eau régulière du long fossé, alors que les fossés perpendiculaires apparaissent eux plus souvent secs et comblés plus rapidement. La fouille a montré pour chaque fosse et fossé que les remplissages n'étaient pas uniformes et la micromorphologie a permis de caractériser les comblements et paraît confirmer l'utilisation du grand collecteur comme un fossé d'irrigation saisonnier ; les creusements perpendiculaires jouant alors un rôle de répartiteur au sein de la parcelle.

À l'inverse, la disposition du réseau permet également de jouer un rôle drainant lors de fortes précipitations, facilité par le décalage altimétrique entre les petits fossés et le grand, servant de fait d'évacuation principale et évitant ainsi la stagnation des eaux néfastes aux cultures.

\subsection{Les autres aménagements}

\subsubsection{Les traces d'activités dans le secteur A3}

Sur l'ensemble de la parcelle plantée, les traces d'activités artisanales ont été mises en évidence. Comme nous l'avons vu, c'est essentiellement la présence d'un sol (SL3308) compact, « sale » et très localisé, qui a permis dans un premier temps de déterminer la position de ce secteur (fig. 139).

La surface se situe précisément entre les fossés FO3349 et 3255, sur une superficie d'environ $80 \mathrm{~m}^{2}$ se limitant au sud à quelques mètres de MR3042. Sur et dans ce sol ont été découverts plusieurs fragments de briques vitrifiées, ainsi que des scories de bronze, répandus sur l'ensemble du sol. Celui-ci recouvrait une fosse (FS3333) contenant quatorze amphores africaines à huile brisées. Contemporain du sol, un bassin aménagé avec des planches en bois a été creusé dans le sable (BS3339).

\subsubsection{Le bassin BS3339}

\subsubsection{Description \\ (P. E)}

Il s'agit là d'un bassin installé directement dans le sable. De forme rectangulaire (1,72 m x 3,14 m), il est composé de quatre planches de récupération plaquées contre le sable et maintenues par quatre pieux (issus aussi d'une récupération) et plantés à l'intérieur de la structure (fig. 150 à 153).

Le bassin paraît peu profond, moins d'une quarantaine de centimètres. En replaçant sa partie haute au niveau du sol contemporain SL3308, au niveau duquel la perturbation du bassin est apparue, on peut reconstituer un bassin d'une profondeur minimum de près de $0,80 \mathrm{~m}$. 
CHAPITRE 4 : UNE LANIÈRE CULTIVÉE AUX II ${ }^{e}$, III ${ }^{e}$ ET IVe SIÈCLES APR. J.-C.

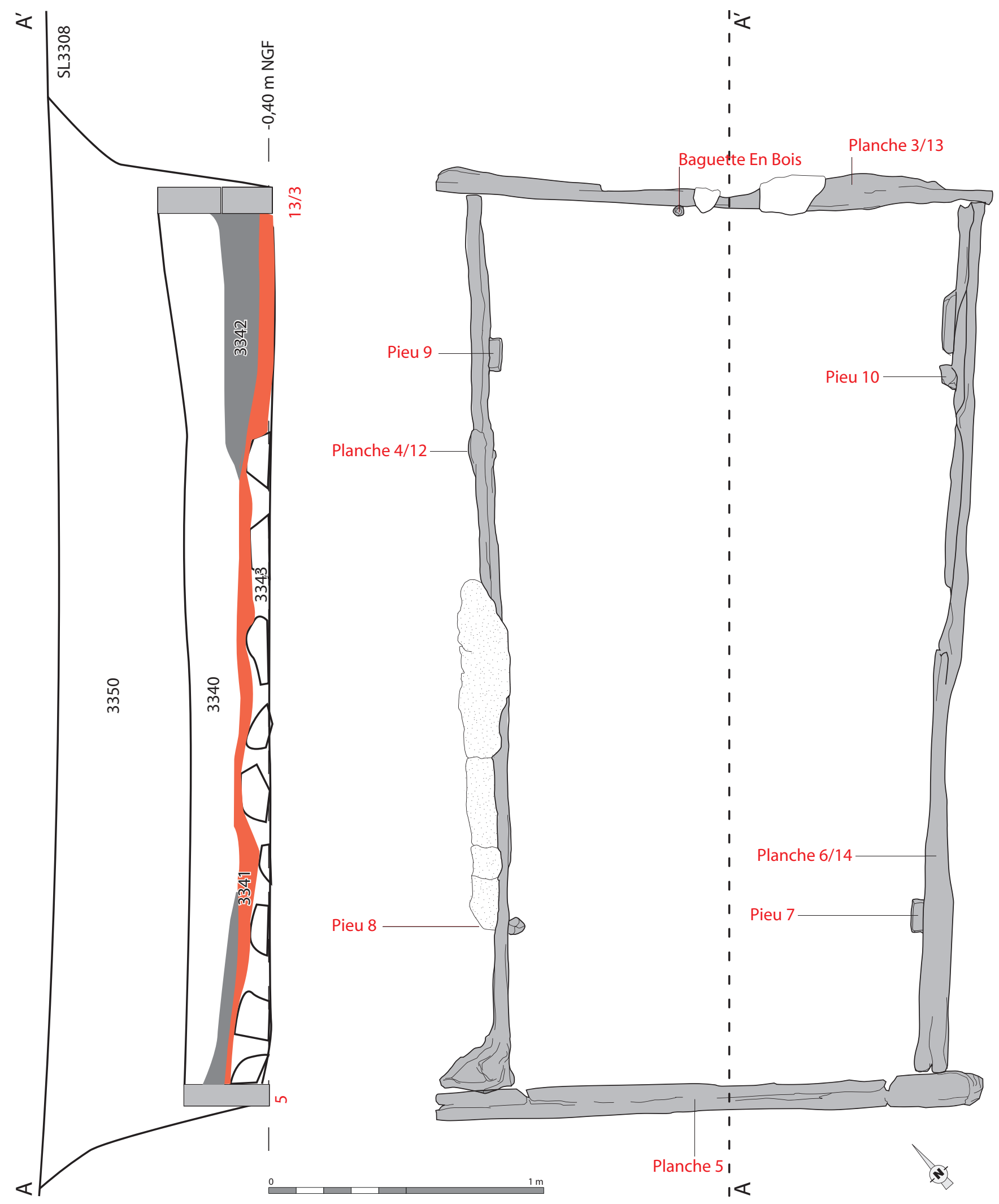

Fig. 150. Stratigraphie du comblement et relevé du bassin BS3339. 


\subsubsection{Cuvelage en bois de récupération} (S. Gr., F. G.)

BS3339 était, comme le puits SB1262, composé de quatre planches en bois remployées, posées de champ et soutenues à l'intérieur par des pieux. La planche MR5 se distinguait des trois autres issues de bordés de navires antiques et présentées en annexe.

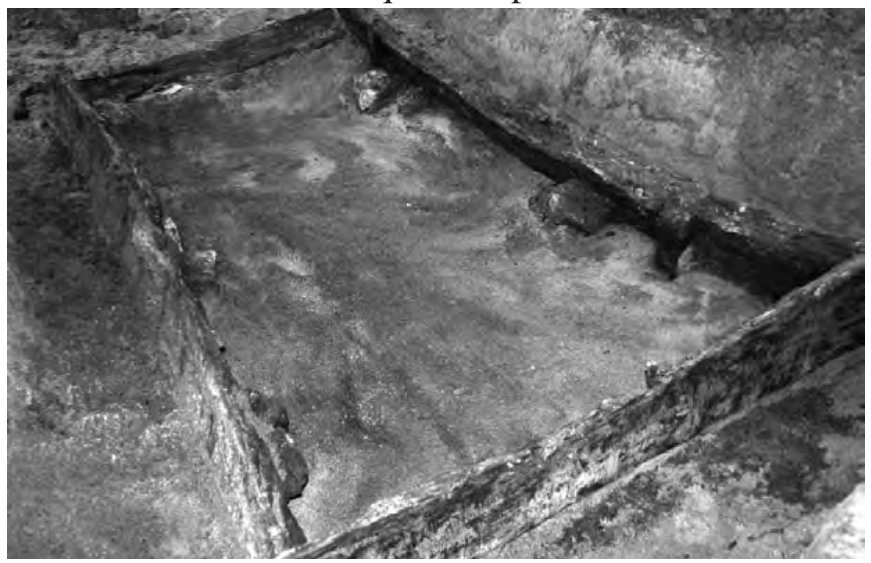

Fig. 151. Bassin rectangulaire

composé de quatre planches de récupération.

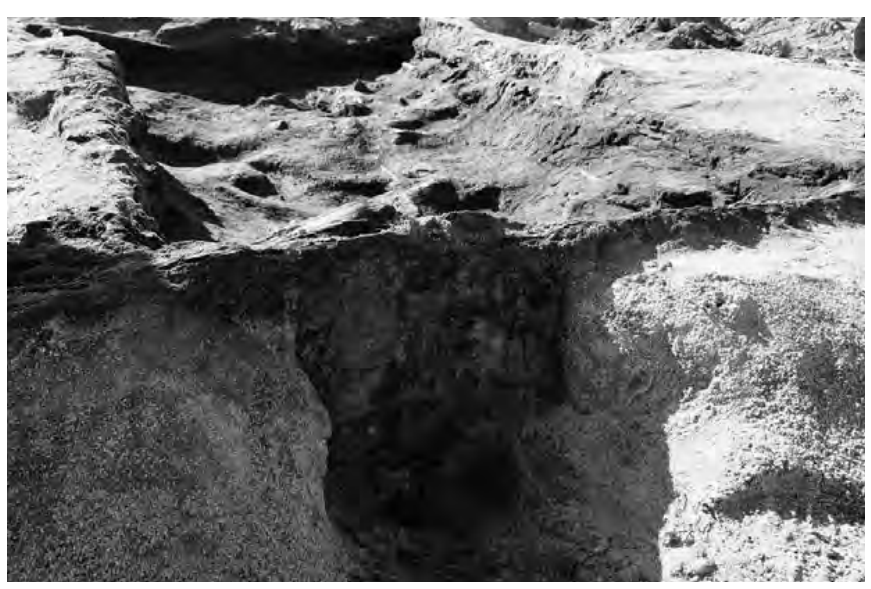

Fig. 152. Les planches sont plaquées contre le sable.

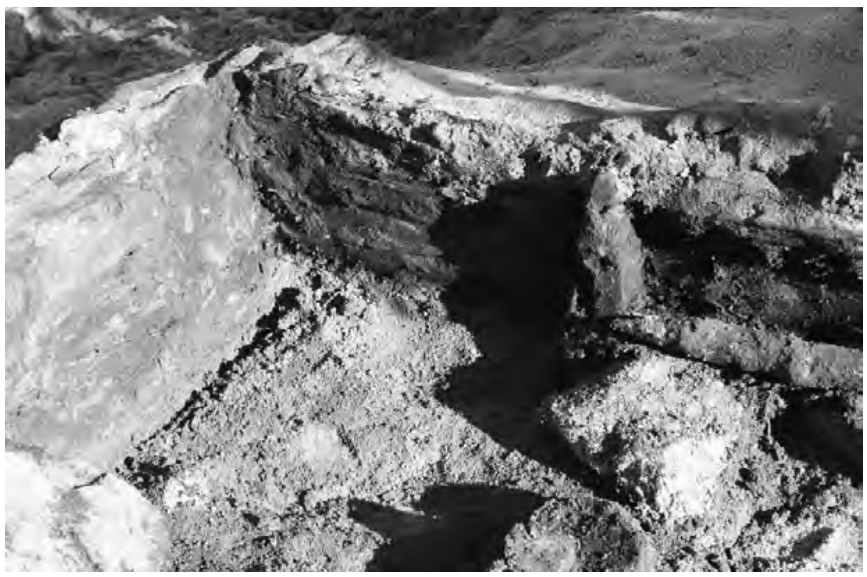

Fig. 153. Le coffrage est maintenu par quatre pieux.
Confectionnée dans un tronc de sapin (Abies sp.), elle mesurait $2 \mathrm{~m}$ de longueur pour $41 \mathrm{~cm}$ de largeur et $8 \mathrm{~cm}$ d'épaisseur. Son remploi est attesté par la présence d'aménagements qui demeurent énigmatiques car ils n'ont aucune fonction évidente au sein du cuvelage du bassin. Le premier est formé de deux perforations cylindriques situées au milieu du bord inférieur de la face interne de la planche et la traversant obliquement vers le can inférieur (fig. 154). Le deuxième est formé de deux mortaises profondes de forme ovoïde, disposées à la base de la face interne dans les deux angles inférieurs de la planche; elles semblent se rejoindre au niveau d'encoches longitudinales profondes partant de ces mortaises, formant deux tranchées de la largeur de celles-ci, dont la profondeur va diminuant vers le centre. Les caractéristiques de cet élément l'apparentent à un seuil de porte en bois avec crapaudine.

La chronologie individuelle résultant de l'analyse dendrochronologique de cette planche est longue de 70 ans mais ne synchronise à aucune autre chronologie connue ${ }^{3}$.

Quatre pieux (3339-7, 8, 9 et 10) découverts dans leur position initiale (fig. 150) maintenaient encore en place les parois lors de leur découverte.

Parmi ces pieux de dimensions voisines, trois - débités dans un tronc en bois de chêne caducifolié (Quercus sp.) - présentaient des traces de remploi (3339-7, 8 et 10) (fig. 156 à 158). Des traces de scie relevées sur les faces, sans doute témoins de la confection des pièces d'origine, plus grandes, contrastaient avec des traces d'herminette relevées sur les pointes, prouvant que ces pièces avaient été réduites et appointées pour confectionner des pieux. D'autres éléments confirment le remploi : une mortaise circulaire creusée dans la pointe du pieu 3339-8 ressemblant à un trou de cheville, une autre mortaise rectangulaire aménagée sur une des faces du pieu 3339-10 dans laquelle venaient se loger transversalement une cheville et un clou enfoncé sur la face opposée.

La fonction initiale de ces pièces est malheureusement difficile à déterminer compte tenu de leur état de conservation et de la transformation qu'elles ont subie. Le quatrième pieu (3339-9), plus classique, se distingue des autres par l'essence de son bois, le chêne vert ou chêne kermès (Quercus ilex / coccifera L.) ${ }^{4}$ et par son traitement qui n'évoque pas un remploi (fig. 159).

\footnotetext{
3 Guibal, non publié.

4 Le type anatomique Quercus ilex/coccifera regroupe deux taxons impossibles à distinguer sur la base d'une analyse anatomique de leur bois : le chêne vert (Quercus ilex L.) et le chêne kermès (Quercus coccifera L.) (Schweingruber 1990).
} 


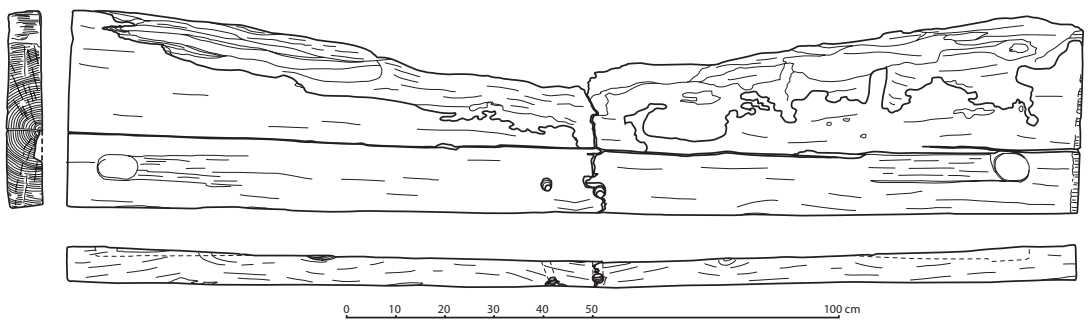

Fig. 154. La paroi MR5 (G. Boetto).

\begin{tabular}{|c|c|c|c|c|c|c|c|}
\hline \multirow{2}{*}{ Fait } & Index & $\begin{array}{c}\text { Dimensions }(\mathbf{c m}) \\
\mathbf{L} \text { x I }\end{array}$ & Essence ligneuse & Débit & Âge & Moelle & Dernier cerne \\
\hline \multirow{3}{*}{ BS3339 } & 7 & $75 \times 11-$ ép. 8 & chêne caducifolié & équarri à cœur & 32 & présente & - \\
\cline { 2 - 8 } & 8 & $69 \times 10-$ ép. 10 & chêne caducifolié & équarri à cœur & 112 & présente & - \\
\cline { 2 - 8 } & 9 & $77 \times 18-$ ép. 7 & type chêne vert & fendu (1/2) & - & - & - \\
\cline { 2 - 8 } & 10 & $76 \times 14-$ ép. 8 & chêne caducifolié & faux quartier & 67 & proche & - \\
\hline
\end{tabular}

Fig. 155. Paramètres descriptifs des pieux du bassin BS3339.

Il s'agit d'un pieu fendu d'une longueur de $77 \mathrm{~cm}$ pour une largeur de $18 \mathrm{~cm}$ et une épaisseur de $7 \mathrm{~cm}$.

L'analyse dendrochronologique des pièces de chêne à feuillage caduc a permis de bâtir une chronologie moyenne (Fréjus 4) longue de 67 ans basée sur la synchronisation de deux chronologies individuelles issues des pieux 3339-7 et 3339-10 dont les années terminales ne différent que de huit années (fig. 155). Ces résultats nous permettent d'avancer que ces bois étaient probablement associés dans la même structure d'origine qui reste indéterminée. Aucun synchronisme n'a pu être établi avec d'autres chronologies locales de chênes méditerranéens antiques (Guibal 1992 et Guibal, Pomey 2003, 2004) ni avec des chronologies de référence représentatives du chêne dans des régions plus septentrionales (fig. 160).

\subsubsection{Stratigraphie du comblement} (P. E)

Dans le fond, essentiellement concentré dans la moitié ouest et directement au contact du sable (environ $-0,40 \mathrm{~m}$ NGF), se trouvait un amas de pierres et de fragments de mortier (US3343) (fig. 161). Une couche très organique à dominante argilo-limoneuse de teinte rouge et comprenant de nombreux végétaux (US3341), recouvrait ce niveau sur une dizaine de centimètres (fig. 162 et 163). Il apparaît que ce premier comblement était directement lié à l'utilisation du bassin. Quelques pierres recouvraient ce niveau. Celui-ci était recouvert essentiellement sur les bords du bassin d'un autre niveau organique plus sombre, composé essentiellement de brindilles de bois (US3342). Enfin un dernier comblement (US3340) recouvrait l'ensemble.

\subsubsection{Les analyses}

\section{La malacologie \\ (S. M.)}

\section{BS3339 US3341 \#610}

Les espèces récoltées dans l'échantillon \#610 du bassin BS3339 indiquent la présence d'herbacées hautes (Cochlicella acuta, Cernuella virgata) relativement humides (Vallonia pulchella) (fig. 164). On note également l'occurrence d'un peu de litière foliacée (X. conspurcata / M. armillata et Toltecia pusilla). Cet assemblage atteste donc de milieux largement ouverts, de type prairies, à proximité du bassin.

$\mathrm{La}$ malacofaune aquatique concernant le fonctionnement $\mathrm{du}$ bassin est tout à fait particulière puisqu'elle est monospécifique. Seule l'espèce Aplexa hypnorum est représentée et elle est très abondante. Cette espèce est habituellement plutôt rare dans les sédiments archéologiques (Martin 2004). L'arrivée d'Aplexa hypnorum dans le bassin semble donc accidentelle ; le bassin n'est probablement pas raccordé à un canal ou un fossé, ce qui aurait apporté une malacofaune dulcicole bien plus diversifiée. Aplexa hyponorum a pu ensuite bénéficier de l'absence de compétiteurs pour se développer en populations très abondantes (plusieurs milliers d'individus pour cet échantillon). Dans le milieu naturel, ses habitats de prédilection sont les eaux pures, claires (Germain 1931), stagnantes, alcalines et chargées en matière organique (Yassine-Kassab 1979). La présence d'Aplexa hypnorum dans le bassin BS3339 peut donc être interprétée comme la marque d'un milieu aquatique renouvelé régulièrement et relativement limpide. Yassine-Kassab (1979) indique également qu'il 
a retrouvé cette espèce, dans les milieux aquatiques actuels de la région lyonnaise, en contexte de cariçaies en sous-bois, le fond du milieu aquatique étant recouvert de feuilles mortes ; ce qui pourrait correspondre ici à l'identification d'une litière foliacée par le cortège malacologique terrestre.

\section{BS3339 US3341 \#618}

Cet échantillon \#618 du bassin BS3339 est identique à l'échantillon précédent \#610 : les légères variations de composition peuvent s'expliquer par un biais méthodologique entre les deux assemblages : \#618 concerne un échantillon de faible volume (1 litre), identifié sur le terrain comme une concentration de coquilles, tandis que \#610 est un échantillon de volume standard (10 litres), réalisé sans qu'une concentration quelconque de coquilles n'ait été privilégiée lors du prélèvement. Comme pour l'assemblage \#610, les formations prairiales sont prédominantes, tandis que Aplexa hypnorum est le seul escargot du cortège aquatique.

\section{BS3339 US3342 \#609}

Le bassin 3339 comprenait un comblement concentré vers les angles et les parois. Cet échantillon \#609 du bassin BS3339 est très semblable aux deux échantillons précédents \#610 et \#618, provenant également du comblement du bassin BS3339. Il traduit globalement des formations herbacées assez hautes. Cependant, la présence plus importante de taxons sciaphiles (Oxychilus cellarius, Oxychilus draparnaudi et Toltecia pusilla) suggère le développement local d'une litière, dans une zone plus ombragée que pour les deux autres échantillons provenant du bassin.
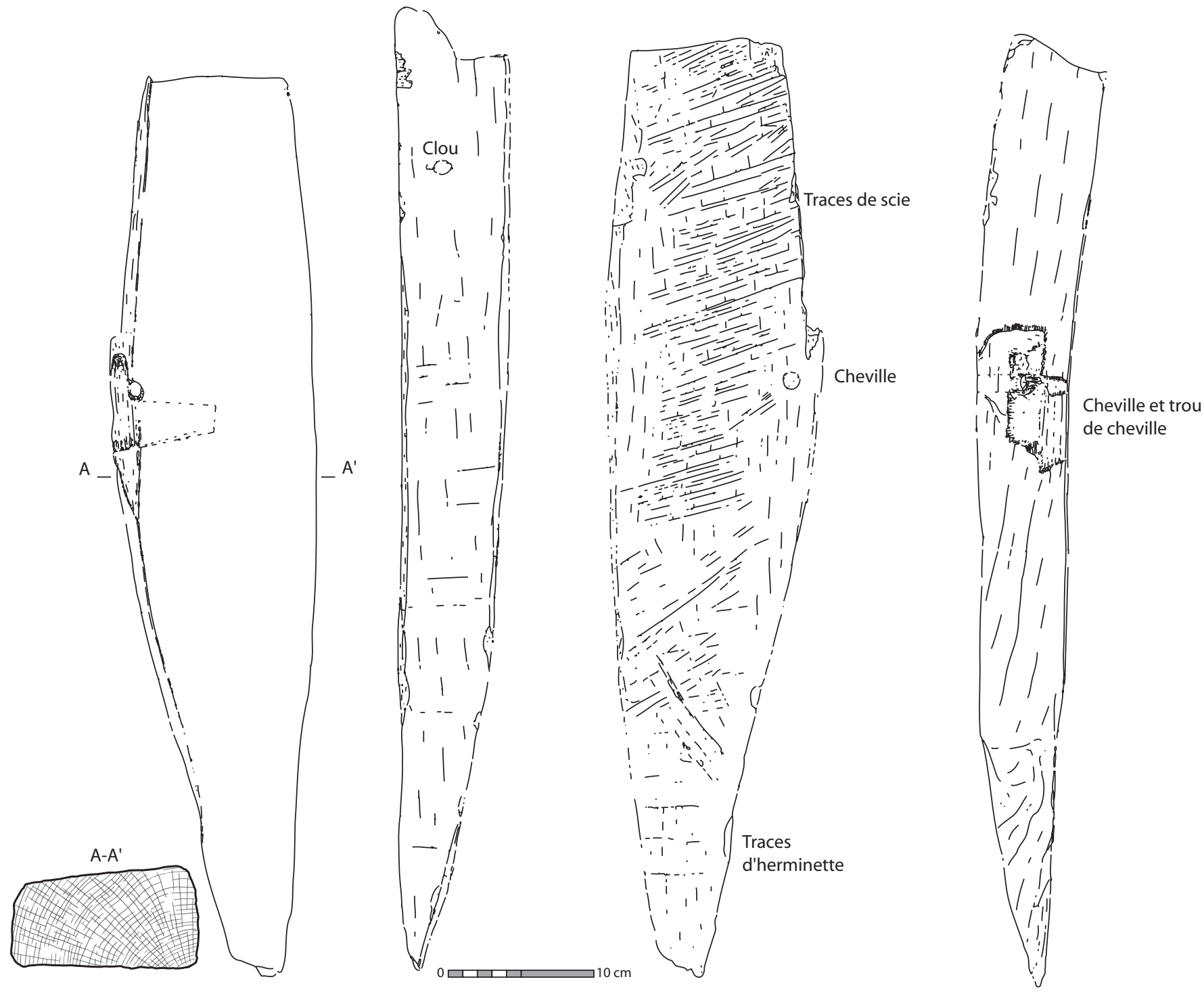

Fig. 156. 3339 - 10 (S. Greck). 


\section{La palynologie}

\section{(S. G.)}

Dans le cadre de l'analyse pollinique, un petit carottage de $30 \mathrm{~cm}$ réalisé au moyen d'un petit tube PVC nous a permis d'obtenir une séquence des différents faciès sédimentaires de comblement du bassin. La base de la séquence (de 29 à $21 \mathrm{~cm}$ ), dans laquelle ont été retrouvées des tiges de saules, est très organique et les limons argileux bruns foncés y sont légèrement sableux. Entre 21 et $20 \mathrm{~cm}$, un lit organique noir, très riche en malacofaune, se dépose. Les limons-sableux ou sables-limoneux gris à bruns constituent le sommet de la séquence.

Cinq échantillons prélevés au sein du carottage ont fait l'objet d'une analyse. À partir de la détermination et du comptage des spores et grains de pollen, trois zones polliniques ont été définies. En zone A, à la base de la séquence, tandis que la courbe de Lemna minor (lentilles d'eau) met en évidence la présence d'eau dormante dans le bassin (sans doute des eaux de la nappe haute), les valeurs du plantain lancéolé (Plantago lanceolata) des

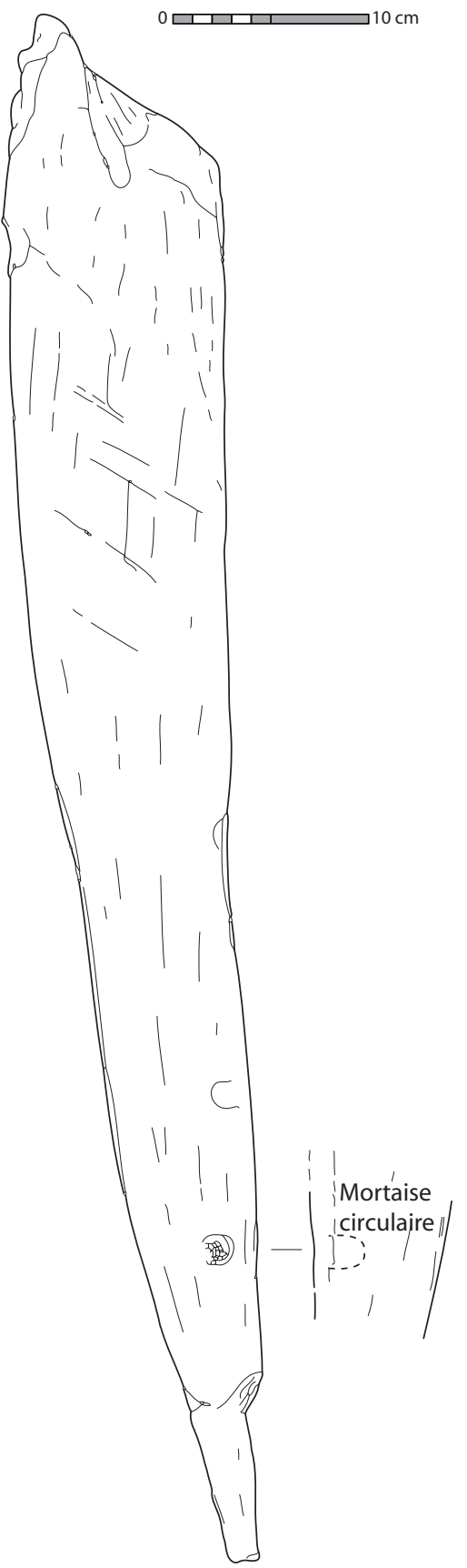

Fig. 157. 3339 - 8 (S. Greck).

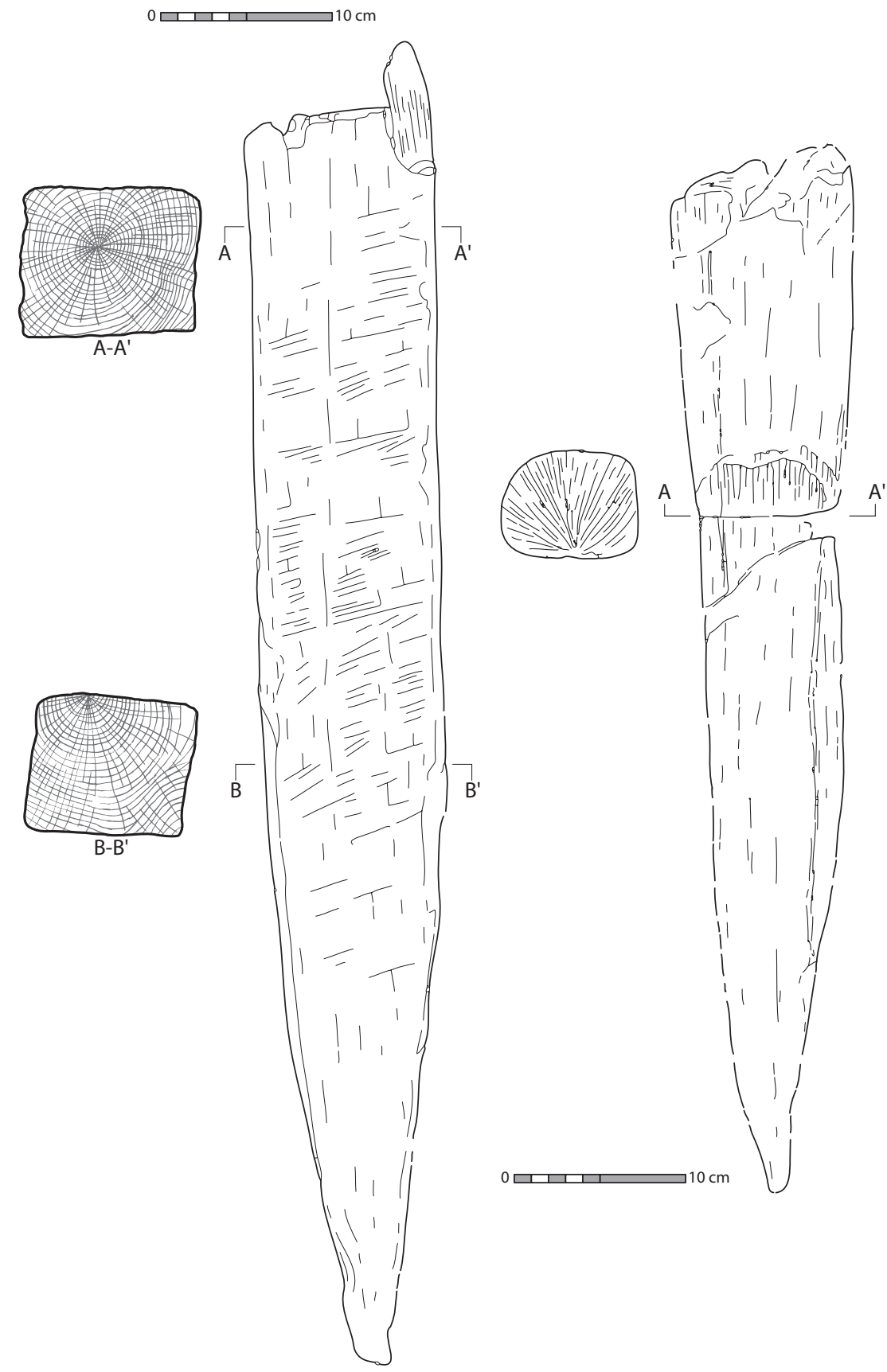

Fig. 158. 3339 - 7 (S. Greck).
Fig. 159. 3339 - 9 (S. Greck). 


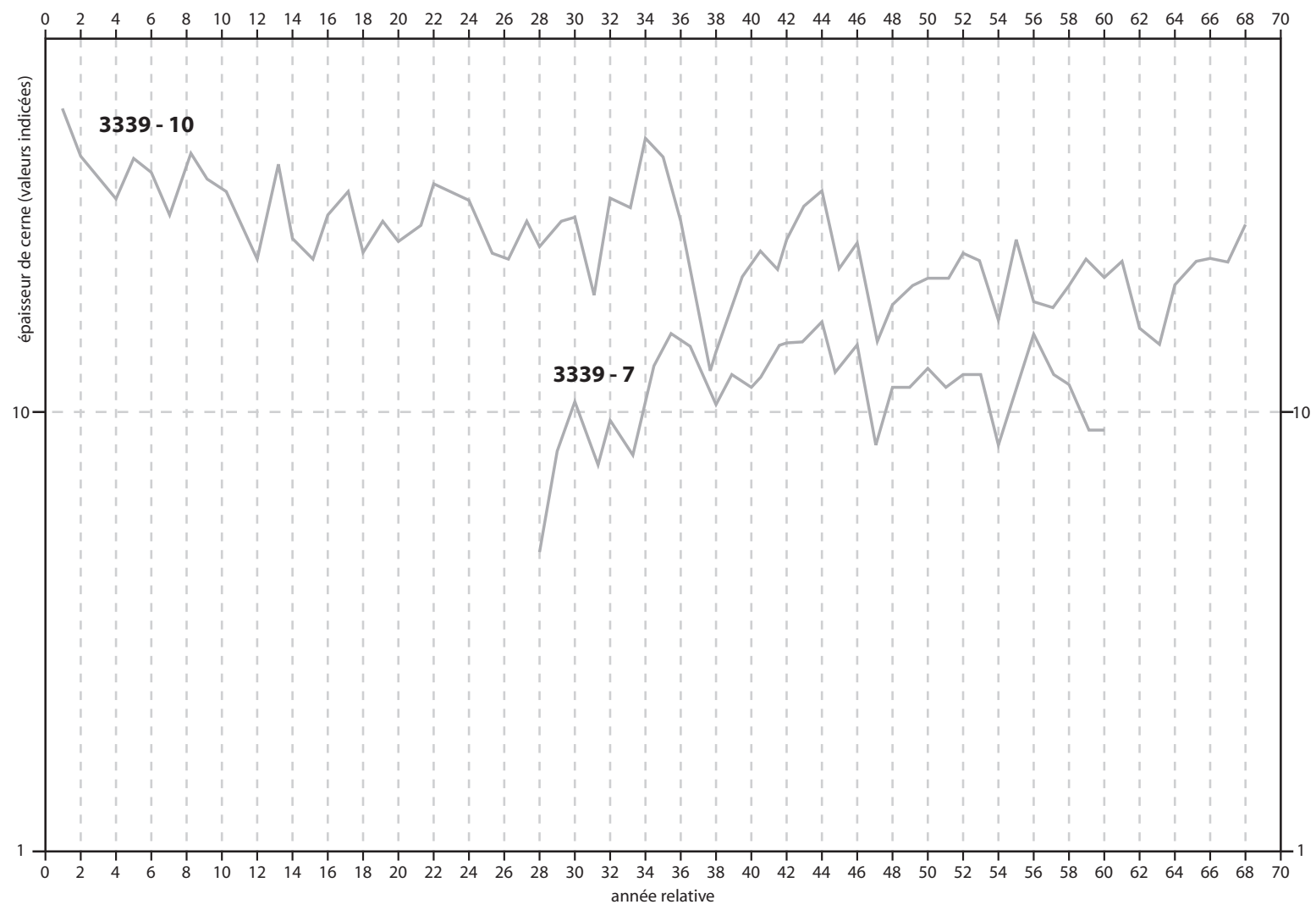

Fig. 160. Courbes représentatives des chronologies individuelles constitutives de la chronologie moyenne Fréjus 4.

Poaceae, Apiaceae et des céréales, en interzone A1 témoignent de l'anthropisation du milieu environnant. Concernant les pratiques anthropiques, les valeurs du saule (Salix) méritent également d'être commentées. Associées dans les mêmes niveaux à des tiges du même arbre et, étant donné la relative absence dans les autres structures du site du signal pollinique de cet arbre (généralement présent dans les formations ripicoles aux bords des cours d'eau), on peut émettre l'hypothèse d'un apport issu de la préparation des branchages de saule aux abords du bassin, lesquels pouvaient être ensuite plongés dans les eaux de ce dernier afin de faciliter leur travail en vannerie.

Par la suite, la courbe de Lemna minor nous incite à voir dans les zones $\mathrm{B}$ et $\mathrm{C}$ un atterrissement du bassin associé sans doute à une diminution du niveau de la nappe. Les indices d'anthropisation (céréales, plantes rudérales) se font alors plus discrets, au profit d'une nette augmentation des valeurs des Cyperaceae et des Cichorieae. Le dessèchement du bassin semble entraîner une colonisation de ses fonds, ombragés encore humides, par les Cyperaceae, lesquelles supportent moins bien les sols sableux environnants. Une série d'indices qui fait supposer un abandon du bassin pour la partie supérieure de la séquence.

\section{La phytolithologie \\ (P. V.)}

L'échantillon provenant de l'unité stratigraphique US3340 est dominé par les phytolithes d'herbacées (graminées/cypéracées). Ces phytolithes se présentent sous forme de squelettes siliceux produits par la décomposition des tiges des plantes $(52,2 \%)$. Mais ce phénomène est aussi observé pour les phytolithes de dicotylédones (12,6\% de squelettes siliceux). La décomposition sur place d'un amas de végétaux est très probable, la présence d'algues concentricystes s'ajoutant à l'argumentation précédente. La présence d'un tas de compost composé de végétaux divers, mais dominé par les herbacées est plausible.

\section{La carpologie}

$$
\text { (L. B., I. F., C. S.) }
$$

Un seul prélèvement carpologique, assez pauvre (38 restes), a pu être étudié concernant le comblement supérieur du bassin 3339 .

Le milieu aquatique est marqué par la présence de Ceratophyllum demersum. Cette plante pourrait être un indice de la présence d'eau stagnante dans le bassin. 


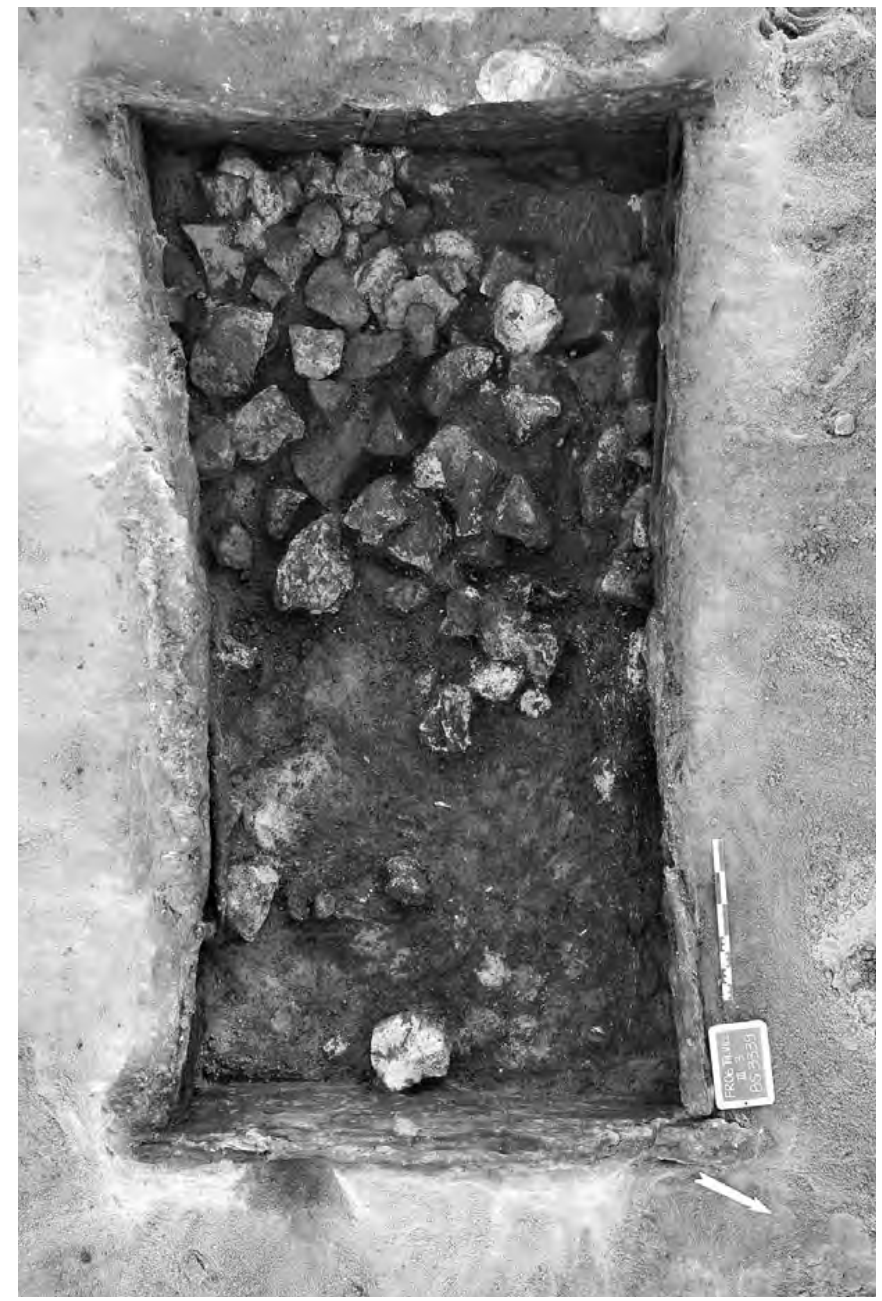

Fig. 161. Dans le fond du bassin BS3339 se trouvait un amas de pierres et de fragments de mortier (US3343).

Par ailleurs les akènes de Carex sp. seraient un indice de l'humidité édaphique à proximité du bassin.

Pépins de Vitis vinifera et pignons carbonisés de Pinus pinea évoquent une production fruitière. Les semences de mauvaises herbes sont sporadiques. Le comblement inférieur est mieux connu par l'analyse de deux US et de plusieurs centaines de restes. La discussion se fonde principalement sur un unique prélèvement tamisé à $0,4 \mathrm{~mm}$. Le milieu aquatique est attesté par la présence marquée $(15,8 \%$ des effectifs) de lentille d'eau ( Lemna minor). Les plantes des lieux humides représentent de 30 à $40 \%$ du total des effectifs corrigés. Il s'agit de Carex sp., de Cyperus sp. et de Ranunculus sardous.

Les arbres cultivés (35 à $49 \%$ du total des effectifs) sont en majorité documentés par des restes de Ficus carica, Prunus domestica subsp. insititia et Vitis vinifera. Notons également la présence remarquable d'un arbre planté, le cyprès (Cupressus sempervirens). Les adventices des milieux cultivés et les rudérales sont

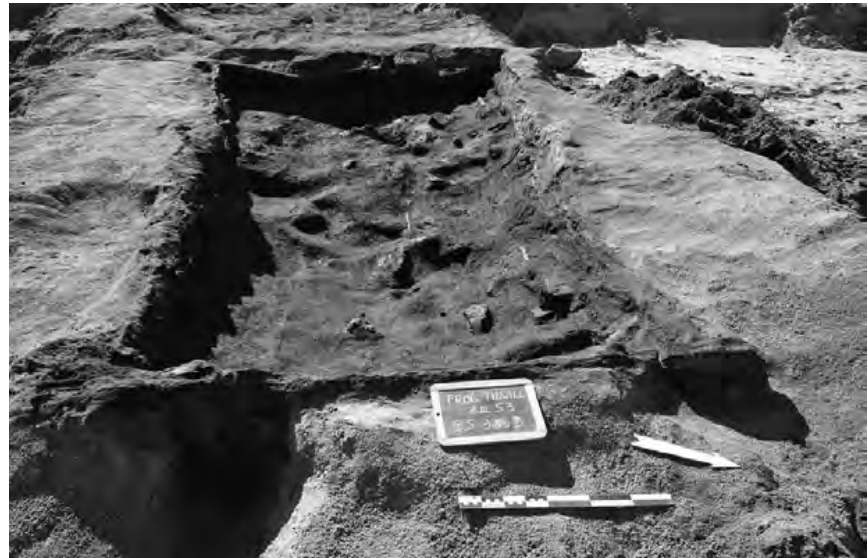

Fig. 162. Sur une dizaine de centimètres, une couche très organique et à dominante argilo-limoneuse de teinte rouge (US3341).

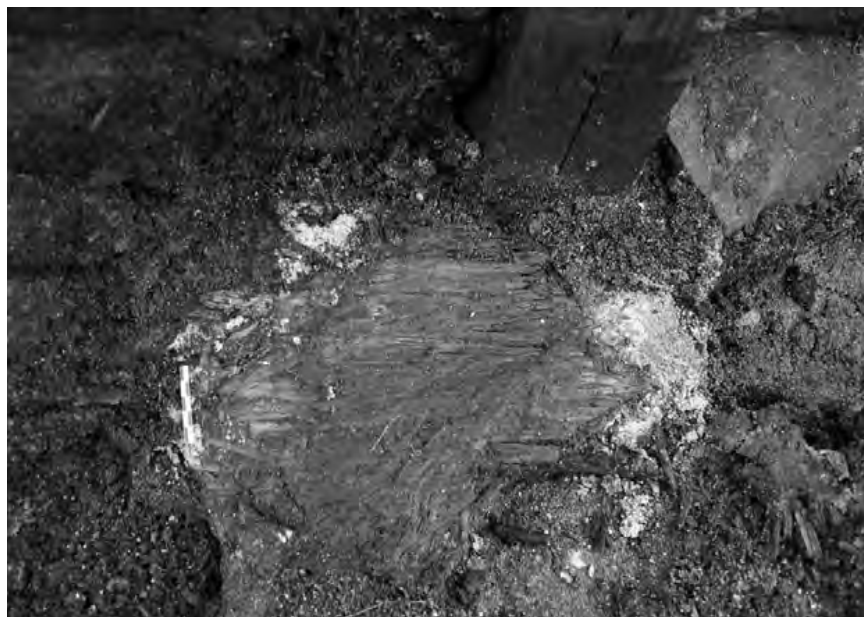

Fig. 163. Au sein de la couche 3341 subsistaient de nombreux restes végétaux (ici, une concentration de tiges plates).

relativement peu nombreuses : Chenopodium album, Daucus carota, Euphorbia helioscopia, Fumaria officinalis (la plus abondante) et Silene gallica. À ce groupe pourrait être rattachée la ronce (Rubus fruticosus agg.) qui semble témoigner d'un enfrichement un peu plus prononcé mais sa présence est ponctuelle.

\section{La xylologie et l'anthracologie}

(I. F., L. B., C. S., S. Gr, F. G.)

Les bois gorgés d'eau sont issus de deux unités stratigraphiques des comblements supérieur et inférieur $\mathrm{du}$ bassin BS3339. Deux taxons seulement sont distingués dans le comblement supérieur : le saule et/ ou peuplier (Salix/ Populus) et la vigne (Vitis vinifera).

Dans le premier prélèvement issu du comblement inférieur (\#610), plusieurs petites tiges ont été identifiées comme saule ou peuplier; les éléments anatomiques observés ne permettant pas de trancher entre les deux genres. Cependant, l'identification sûre du saule dans 
un des spécimens, dont l'anatomie était moins abîmée, permet d'envisager l'hypothèse que toutes les tiges puissent appartenir à cette essence. Ceci d'autant que le deuxième prélèvement (\#621-622) concerne uniquement un amas de tiges très aplaties de saule (Salix). Il s'agit vraisemblablement de restes destinés à la vannerie.

Les autres essences identifiées dans le comblement inférieur incluent la vigne, le chêne liège et le pin sylvestre ou pin noir (Pinus type sylvestris).

Également au sein du comblement se trouvait une perche de $199 \mathrm{~cm}$, encore pourvue de son écorce, confectionnée dans une jeune tige de bois de genévrier (Juniperus sp.) par un élagage grossier et peu soigné. L'extrémité (diamètre de $1 \mathrm{~cm}$ ) est composée d'une pointe à six pans de $13 \mathrm{~cm}$ de longueur. L'autre extrémité (diamètre de $1 \mathrm{~cm}$ ) a conservé un embranchement taillé, formant une petite fourche de $1,5 \mathrm{~cm}$ de longueur composée de deux brins de $0,8 \mathrm{~cm}$ de diamètre.

\subsubsection{Fonctions et hypothèses}

(M. C.-M., P. E.)

Durant la quatrième phase, la nappe phréatique se situe à un niveau relativement proche de la surface de circulation contemporaine du fonctionnement du bassin. L'étude micromorphologique confirme d'ailleurs ce point. En effet, l'ensemble de la structure, au niveau des angles et naturellement du fond, n'est pas étanche. Ainsi, il paraît peu probable qu'il ait été rempli artificiellement ; il pourrait plutôt s'agir là d'un bassin lié directement à l'utilisation de la nappe.

Les différentes analyses opérées sur les divers comblements permettent de proposer une série d'hypothèses. Avant tout, il convient de reconnaître que la mise en place d'un tel bassin - dans un milieu ouvert et non au sein d'un atelier d'artisan - peut correspondre à une grande variété d'activités, plus ou moins en rapport les unes avec les autres. La notion de multifonctionnalité doit sans doute prévaloir dans ce cas précis.

\section{Un bassin lié au trempage des brins de saule?}

Le contenu de cette structure a livré, entre autres choses, des rameaux de saule bruts disposés en fagots (fig. 165). L'une des fonctions de ce bassin peut vraisemblablement être liée à une activité de vannerie, comme le mentionnent les agronomes latins. Ceux-ci préconisent en effet l'installation, dans les domaines ruraux, de bassins destinés à des usages divers dont le trempage de l'osier, indispensable pour assouplir les brins préalablement au tressage. Ainsi Varron : «Dans la cour extérieure il faut qu'il y ait un bassin pour faire macérer le lupin et tout ce qui, plongé dans l'eau, devient plus propre à l'usage » $(\mathrm{I}, 13,3)$, repris par Columelle, plus

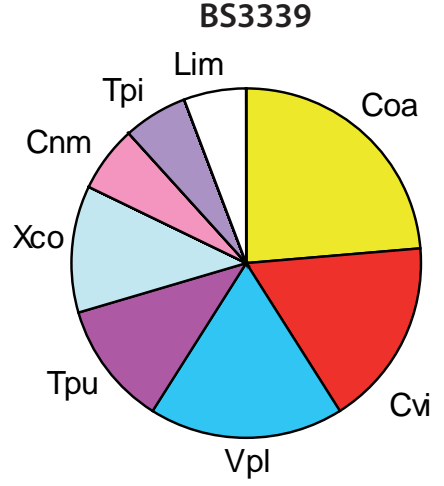

Fig. 164. Proportion des estimations d'abondance des taxons malacologiques terrestres pour le bassin 3339 (cf. fig. 125).

disert : "Les dépendances d'une ferme se composent [...] de deux bassins au moins : l'un servira aux oies et au bétail, l'autre à faire macérer les lupins, l'osier, les baguettes et autres choses utiles de ce genre » $(\mathrm{I}, 6)$, puis par Palladius : " Car il faudra qu'il y ait à proximité de la ferme deux bassins, soit creusés dans le sol soit taillés dans la pierre. Il est facile de les remplir d'eau de source ou de pluie : l'un sera destiné au bétail et aux oiseaux aquatiques, l'autre servira à faire tremper les baguettes, les cuirs, le lupin, et, d'une façon générale, tout ce qui à la campagne se met communément dans l'eau » (I, 31). Certaines des structures mises au jour lors des fouilles de fermes, en Italie, correspondent aux descriptions des agronomes (Rossiter 1978, 11, 32-33).

Directement liée aux travaux des champs, la vannerie constitue souvent une activité de complément pratiquée généralement l'hiver, comme le montre notamment la mosaïque du calendrier rustique de Saint-Romain-enGal, où deux hommes, l'un fabricant un panier, l'autre portant un fagot d'osier, illustrent la saison hivernale (Coulon 2006, 151 et Leclerc 2004, 27, fig. 12).

\section{Culture et usages du saule}

La culture du saule était avantageuse et offrait à l'agriculteur de multiples possibilités d'exploitation, aussi bien pour l'écorce que pour les rameaux. Les agronomes se montrent plus ou moins prolixes concernant la plantation et l'entretien des saussaies. Parmi eux, Columelle (IV, 30-31) est celui qui livre le plus de détails sur l'osiériculture, dans un long chapitre dédié aux jougs et aux liens destinés à la vigne. Le naturaliste Pline l'Ancien (XVII, 141-143) fournit quant à lui une description plus brève de la culture du saule. En effet, pour les auteurs anciens, planter et entretenir des saussaies (salicta) allait de pair avec la culture de la vigne, car les saules fournissaient de l'écorce pour ligaturer les sarments : «Coupez l'osier en temps voulu, 
écorcez-le et liez les brins serré ; conservez l'écorce. Quand il en sera besoin dans la vigne, plongez-en dans l'eau, et palissez » (Caton, 33, 5).

La présence d'une saussaie permettait en outre au personnel du domaine de tresser paniers et corbeilles
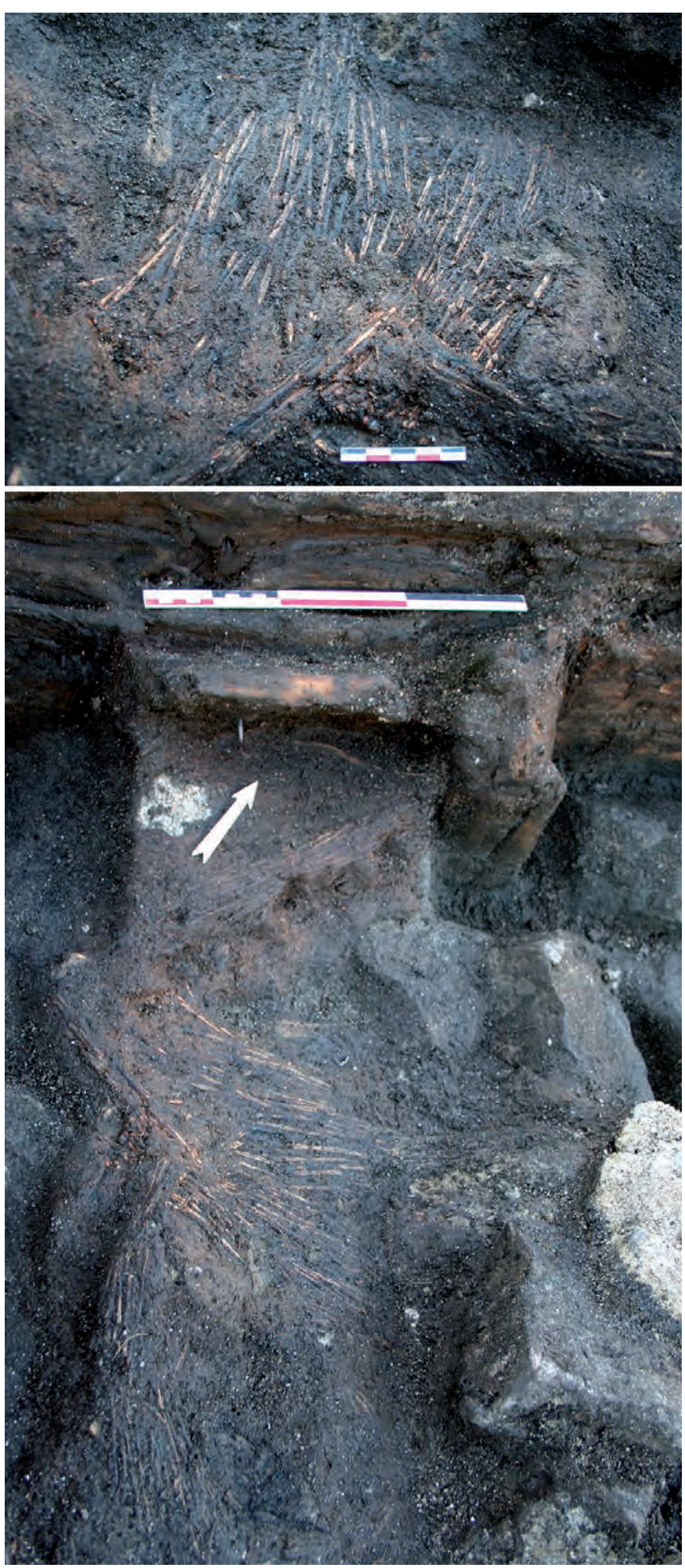

Fig. 165. Le contenu de cette structure a livré des rameaux de saules bruts, disposés en fagots. nécessaires aux récoltes. Caton $(33,5)$ explique que si l'écorce servait pour la vigne, on n'en conservait pas moins les rameaux décortiqués, utiles en vannerie : « Conservez les brins pour en faire des paniers. » Toujours selon Caton $(1,7)$, le domaine idéal devait comporter, dans l'ordre : un vignoble, un jardin irrigué, une saussaie, une oliveraie. On notera que l'agronome cite la saussaie en troisième position parmi les cultures qui se doivent de figurer dans tout domaine bien géré.

Enfin, l'importance accordée à l'entretien de l'oseraie est confortée par un argument que Caton est le seul des agronomes à fournir. Au nombre du personnel indispensable à la bonne marche d'un vignoble, il compte un esclave spécialisé dans l'entretien de la saussaie, le salictarius : "Comment doit être équipé un vignoble de cent jugères : un fermier, une fermière, dix manœuvres, un bouvier, un ânier, un osiériste, un porcher, en tout seize personnes »(Caton, 11). Il existe de nombreuses espèces de saule (famille des Salicacées) mais seulement une dizaine d'entre elles se prêtent à la vannerie en donnant de l'osier. Les plus courantes en France, de nos jours, sont $S$. viminalis L., Salix alba ssp. vitellina L., S. purpurea L., Salix triandra ssp. amygdalina L., dont le vannier utilise les rejets coupés chaque année.

Pour l'Antiquité, c'est chez le naturaliste Pline l'Ancien (XVI, 174) que l'on peut lire une énumération de diverses espèces du genre Salix associées aux usages qui leur étaient réservés : «Le saule présente dès l'abord plusieurs espèces : les uns élèvent à une grande hauteur des perches propres à faire les jougs des vignes, et leur écorce en lanières donne des liens ; d'autres fournissent des baguettes souples et flexibles pour attacher; d'autres très minces, donnent des ouvrages de vannerie d'une finesse remarquable ; d'autres encore, plus solides, des corbeilles et autres ustensiles de paysans ; d'autres, plus blancs, qu'on écorce et qui se laissent facilement manier, donnent des ustensiles dont la souplesse dispense de faire les mêmes en cuir, et sont encore excellents pour les si agréables chaises-longues. » Le naturaliste évoque ensuite les caractéristiques et les emplois des différentes variétés citées : "On refend le saule grec rouge ; le saule d'Amérie est plus blanc, mais un peu plus cassant ; aussi l'emploie-t-on sans le refendre pour les liens. En Asie, on distingue trois espèces d'osiers : le noir, plus propre à la vannerie, le blanc aux besoins des paysans, un troisième très court, nommé hélix. Chez nous aussi, beaucoup de gens ont des noms pour autant d'espèces : l'osier viminal ou purpurin, l'osier vitellin, nommé d'après sa couleur, plus mince, et un troisième, l'osier gaulois, le plus fin » (Pline, XVI, 177).

Columelle (IV, 30) est plus bref mais ajoute à la confusion concernant l'identification des espèces : «N'importe 
quelle espèce d'osier on plantera, pourvu qu'il soit très flexible. On estime cependant qu'il y a trois espèces principales de saule : le saule grec, le saule gaulois, et celui du pays des Sabins, que plusieurs appellent saule d'Amérie. Le saule grec est jaune, le gaulois est d'une couleur de pourpre passé et ses baguettes sont très minces ; celui d'Amérie les a grêles et rouges » (Cullin-Mingaud 2010a).

\section{La préparation du saule aujourd'hui}

C'est après les premières gelées d'hiver, que l'osier est coupé. Il est alors trié, calibré puis mis en bottes. On le place ensuite dans des bassins pour repartir en végétation au printemps. C'est en mai/juin, en pleine montée de la sève, qu'il est alors pelé. Il existe deux types d'osier : l'osier brut et l'osier blanc (Barbier, Pichonnet 2001, 19-20). Pour l'osier blanc, les bottes sont disposées debout dans un bassin nommé routoir, rempli de $15 \mathrm{~cm}$ d'eau. Il est coupé au moment de la montée en sève, donc au printemps, et immédiatement débarrassé de son écorce à l'aide d'une machine à décortiquer. Le séchage s'effectue en plein air afin que le soleil blanchisse l'osier. L'osier blanc ainsi obtenu peut être stocké plusieurs années jusqu'à son utilisation. Un trempage de quelques heures suffit à celui-ci pour pouvoir être souple. En revanche, l'osier brut, également appelé osier gris, n'a subi aucun traitement si ce n'est une dessiccation de plusieurs mois. Étant donné que les rameaux ont conservé leur écorce, il nécessite un trempage de plusieurs jours afin de l'assouplir avant utilisation.

\section{Un bassin de trempage}

La nature des végétaux gisant dans le fond du bassin ainsi que leur calibrage et leur disposition ne laissent aucun doute sur un des usages auxquels était destinée la structure : celui du trempage de l'osier. Il n'a pas été possible d'aller plus en avant dans la détermination des éléments de saule découverts au fond du bassin. Les rameaux sont rouges et fins : pourrait-il s'agir de Salix alba ssp. uitellina (saule à pousses jaunes ou osier jaune), une variété à longs rameaux fins, jaune orangé ou rougeâtre, sous-espèce du saule blanc (Lieutaghi 2004, 1127) ? Cette espèce se rapprocherait du saule grec décrit tantôt comme jaune par Columelle, tantôt comme rouge par Pline. Pourrait-il s'agir du saule pourpre (Salix purpurea $\mathrm{L}$.), dont l'osier rouge est employé en vannerie fine ? Ce saule, qui correspondrait à l'osier viminal ou purpurin de Pline, produit au début de sa croissance de jeunes rameaux droits et pourpres, qui deviennent ensuite verdâtres ou gris (ibid., 1122). Il serait pour le moins hasardeux de trancher, à la fois en raison de la difficulté à déterminer avec précision les restes de saule et en raison de celle qui consiste à chercher à rattacher des espèces aux descriptions des auteurs anciens. Pas plus chez Pline que chez Columelle on ne peut savoir si les saules ont été décrits par la couleur de leurs osiers (jeunes pousses dont la couleur de l'écorce diffère de celle de l'arbre adulte) ou par celle de leur bois ou de leurs feuilles... De surcroît, la recension des variétés de saules citées dans les sources n'exclut pas la présence d'autres espèces existant localement. En Gaule, par exemple, l'analyse du matériau composant une nasse découverte à Châlon-sur-Saône a attesté l'utilisation du saule à oreillettes (Salix aurita L.) ou du saule cassant (Salix fragilis L.) (Monthel 2000, 173). Qu'elle qu'ait été l'espèce retrouvée à Fréjus, la présence encore bien conservée d'écorce sur les brins de saule du bassin indique que la macération concernait de l'osier brut. Comme nous l'avons dit, l'osier brut doit être immergé plusieurs jours avant de s'assouplir et d'être utilisé. Il semble que nous soyons précisément en cours de cette dernière opération. Les brins ont été triés, calibrés et disposés en fagots sur les bords du bassin. Ainsi, la perche de 1,99 m à l'extrémité fourchue en bois de genévrier découverte contre la paroi sud, était-elle peut-être employée pour immerger totalement les brins, avant de les caler sous des pierres (fig. 166). Quoiqu'il en soit, il s'agit là, non pas d'un bassin appartenant à un artisan vannier professionnel, un vitor, selon le terme classique latin ${ }^{5}$, mais à des agriculteurs pratiquant sans doute la vannerie de manière occasionnelle, en fonction des nécessités du moment ou du rythme des saisons (Mingaud 1992 ; Cullin-Mingaud 2010a et 2010b).

La découverte de Villeneuve est d'autant plus digne d'intérêt que, pour la première fois, un témoignage archéologique sur la pratique de la vannerie en contexte rural est mis en évidence, corroborant ainsi les informations livrées par la littérature technique antique. On connaît peu d'exemples de fagots ou bottes en attente de mise en ouvre. On peut citer l'exemple de Pompéi Regio III, insula 3, $\mathrm{n}^{\circ} 2$ (via dell'Abbondanza), où ont été découvertes sur les restes d'un balcon, en 1914, des bottes de végétaux carbonisés, identifiés à l'époque à des tiges de diss (Ampelodesma tenax), une espèce méditerranéenne de la famille des graminées.

Comme à proximité de la découverte une inscription électorale peinte faisait mention de fabricants de nattes, les tegettarii, il est probable que le stock déposé sur le balcon constituait le matériau d'un desdits artisans, déposé à l'air libre pour sécher ; le séchage des végétaux préliminairement à leur stockage à l'abri de

5 Le nom de métier viminarius, issu de vimen, l'osier, est, pour sa part, attesté une seule fois en épigraphie. 


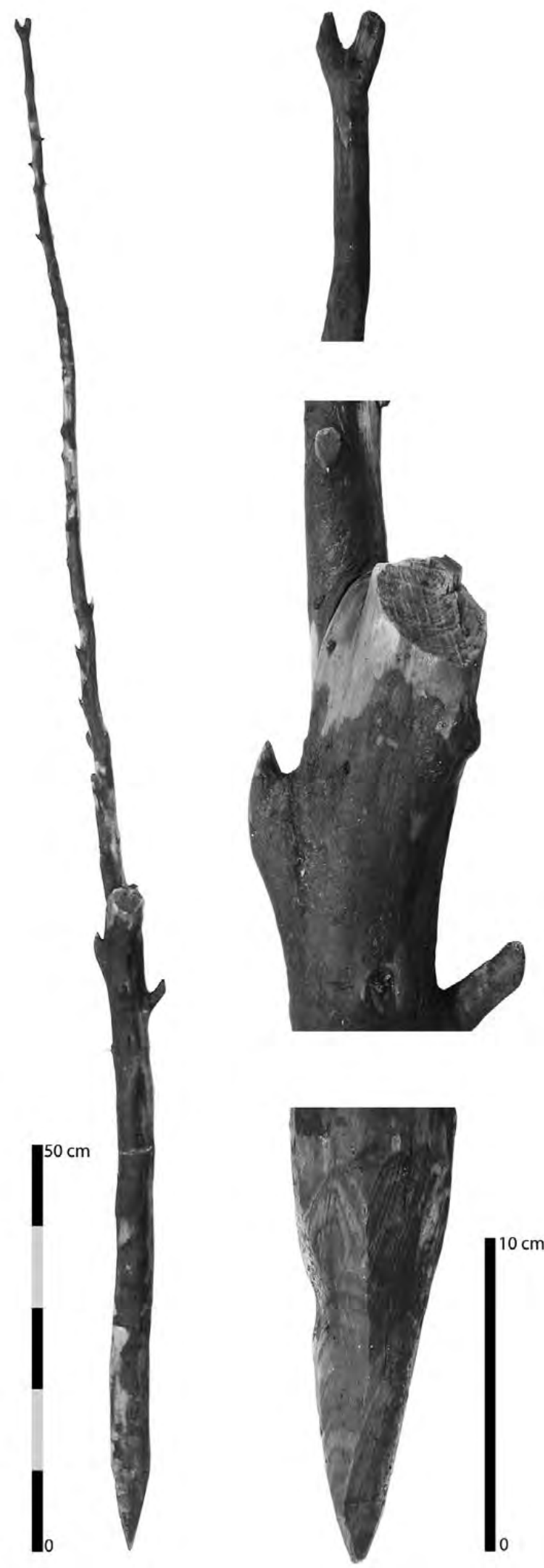

Fig. 166. Perche à l'extrémité fourchue. la lumière et de l'humidité est toujours indispensable. Le diss est en effet une espèce tout à fait propre à la fabrication de nattes et de sparteries. L'arrêt du dégagement de cette partie de la ville n'a pas permis de compléter cette découverte. Un autre exemple pompéien provient de fouilles plus récentes menées sur la via di Nocera (1992 ; maison réétudiée de 2003 à 2005). Celles-ci sont venues attester de nouveau la présence de fabricants de nattes dans la cité. Un atelier comportant un bassin de trempage peu profond et de forme allongée, astucieusement alimenté par un système de récupération des eaux pluviales lié à une citerne, est remarquablement conservé (Regio I, insula 14, $\mathrm{n}^{\circ}$ 2).

On y a mis au jour plusieurs fagots de tiges de graminées calcinées, calibrées puis rangées verticalement dans des pièces obscures, en attente d'être mises en œuvre. Cet atelier réoccupe une habitation délaissée par ses habitants, sans doute à la suite d'un des tremblements de terre ayant précédé l'éruption du Vésuve de 79 apr. J.-C., celui de 62 ou un séisme postérieur.

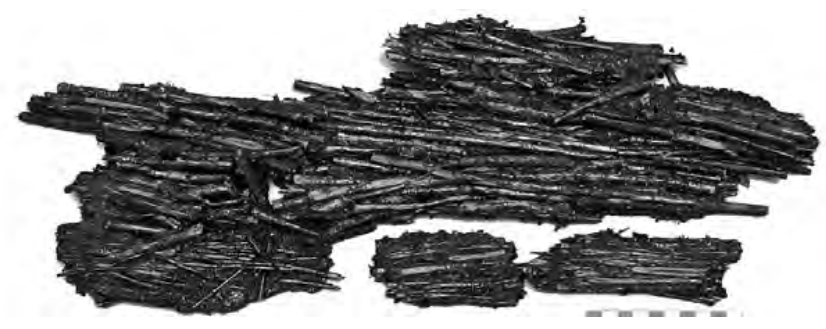

Fig. 167. Une partie du fagot après nettoyage (cl. Chr. Durand / CCJ).

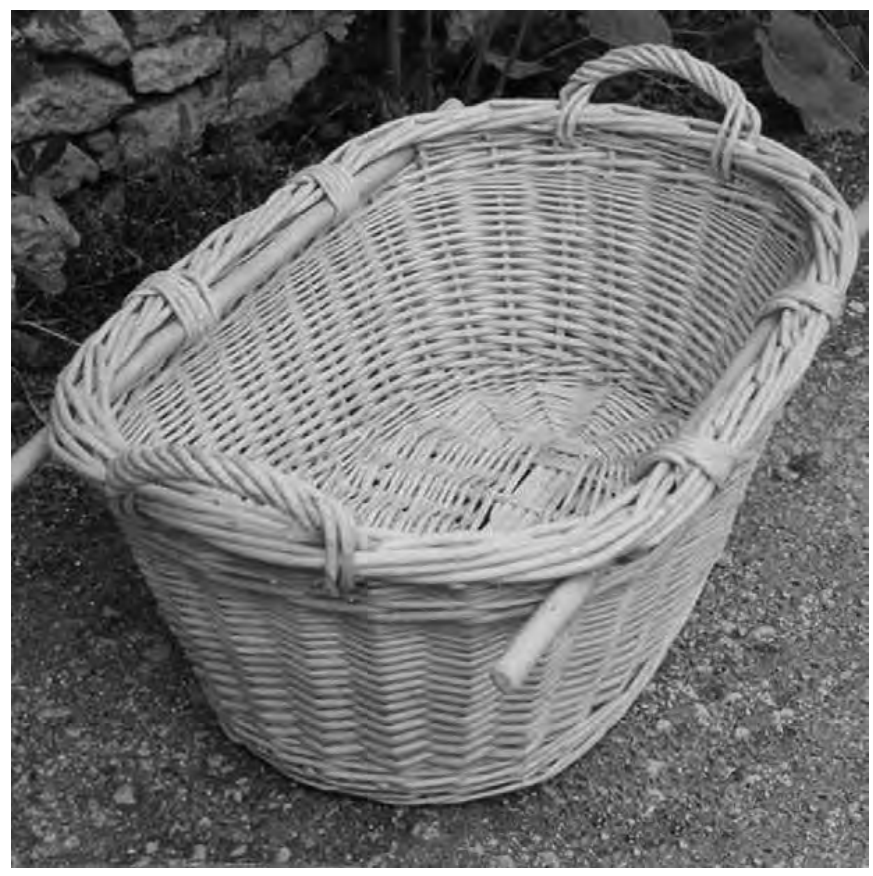

Fig. 168. Banaste pour la récolte des fruits (cl. G. Barbier). 
Unique exemple connu d'atelier de vannerie urbain dans les provinces occidentales de l'empire romain, il constitue un modèle précieux en présentant des éléments caractéristiques de cette activité artisanale : bassin et espace de stockage de la matière première à l'abri de la lumière, pourvu d'un plancher destiné à préserver les chaumes de l'humidité du sol (Cullin-Mingaud 2007 et 2010a).

\section{Fonction des brins et hypothèse ${ }^{6}$}

Les brins ont été triés, calibrés et préparés en vue d'une fonction précise (fig. 167). Plusieurs sont coupés en biseau et certains sont très effilés. Ces brins étaient peut-être déjà préparés pour la fabrication d'un panier de récolte. Une hypothèse sur l'ensemble peut être avancée, les gros brins servant pour les montants et les poignées ; pour le tressage, les brins étaient peut-être fendus à cause de leur grosseur. Les plus fins étaient utilisés pour le tressage du fond, la torche du bas et du haut ${ }^{7}$, les plus petits servant peut-être dans une partie haute de la vannerie, voire, par exemple, la banaste pour la récolte des fruits (fig. 168).

\section{Un bassin à compost?}

Bien que l'on ne puisse supposer que l'activité citée précédemment soit compatible avec la préparation de compost, l'analyse des niveaux supérieurs (3340 et 3342) du comblement permet toutefois d'émettre cette hypothèse. Il s'agit de deux niveaux très organiques, très sombres et comportant de nombreux fragments et brindilles de bois.

Il semble que ce soit dans un second temps que le bassin trouve cette nouvelle fonction, à moins qu'il ne faille, là aussi, l'attribuer au traitement de brins de saule peu flexibles enfouis dans le fumier comme le mentionne Columelle (XI, 2, 90) : «On peut aussi émonder le saule que l'on a coupé la veille pour le travail de la veillée, et en préparer des liens pour la vigne ; s'il est d'une nature peu flexible, il faut le couper quinze jours d'avance, et quand il est émondé l'enfouir dans le fumier, afin qu'il s'y assouplisse. Si au contraire, coupé depuis longtemps, il s'est desséché, on le fera macérer dans une mare. » Ce type de structures, sûrement fréquentes à l'époque romaine, n'est qu'exceptionnellement conservé. Lorsque le cas se présente tout de même, l'identification de leur fonction est souvent complexe. Ainsi, récemment dans l'Oise, à Longueil-Sainte-Marie, une fosse constituée de planches et de parois de fagots de brindilles sur une ossature de piquets de bois a été interprétée, avec

6 Nous devons l'hypothèse de restitution à G. Barbier, artisan vannier.

7 Travail à trois brins en général qui permet de maintenir les montants verticaux en donnant de la solidité à la base du panier (Barbier, Pichonet 2001). beaucoup de prudence, comme un bac à décanter/ tremper ou à rincer la laine (Marinval et al. 2002, 260).

\subsubsection{Le dépôt d'amphores FS3333 (3335)}

\section{(P. E., E. P.)}

Un dépôt de 14 amphores africaines du type A brisées en plusieurs morceaux était enterré dans une fosse (FS3333), creusée à même le sable (fig. 169, 170 et 171). Celles-ci étaient recouvertes par un niveau de circulation (3210, SL3308) contemporain du réseau de fossés. 2703 fragments de panses ont été dénombrés. Aucun d'entre eux ne portait de trace de poix. Il est désormais bien établi qu'elles contenaient de l'huile. En l'absence des sols contemporains de la phase 3A, il est difficile de situer chronologiquement cet ensemble : soit à la fin de la phase $3 \mathrm{~A}$, soit au tout début de la phase 4A. Chronologiquement, les 14 individus se rapprochent de la forme africaine 1A de Cl. Panella (Panella 1973, 575579 et Bonifay 2004, 107) (fig. 173). Elles présentent toutes un bord dont la face externe est convexe, voire hémicirculaire, et une face interne presque droite. Pour

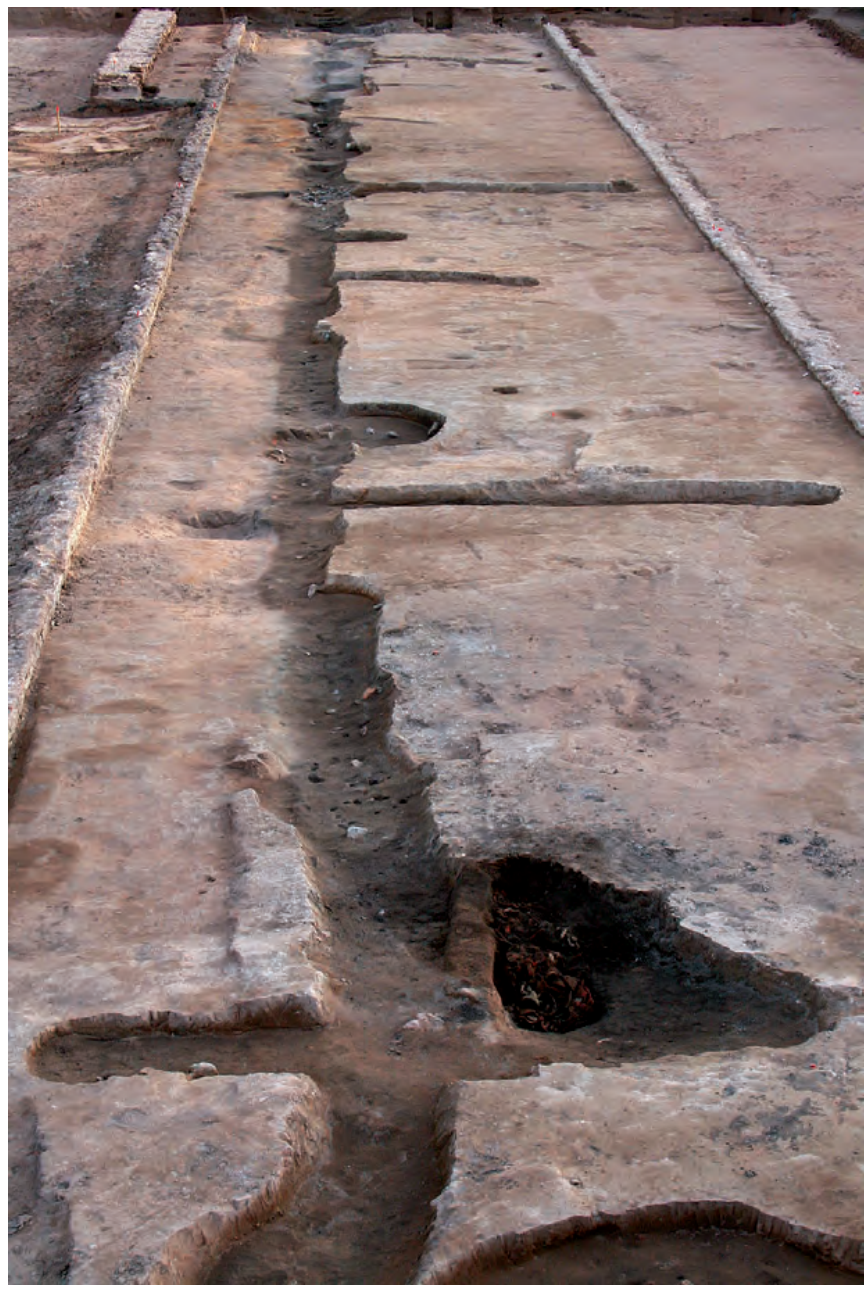

Fig. 169. Le dépôt d'amphores FS3333 aménagé dans le sable. 
M. Bonifay, ces amphores apparaissent durant la seconde moitié du $\mathrm{II}^{\mathrm{e}}$ siècle apr. J.-C. et perdurent jusqu'au début du siècle suivant (ibid., 107). La datation ne permet donc pas de trancher, puisqu'elle s'accorde aussi bien avec la fin de la phase $3 \mathrm{~A}$ qu'avec le début de la phase 4A. Le fait que seuls les fragments de ces 14 amphores aient été découverts dans la fosse nous incite à situer ce dépôt après l'excavation de la tranchée PAA3063. En effet, dans le cas où il s'agirait du résidu d'une fosse antérieure constituée de bien plus d'amphores, il serait étonnant de ne retrouver que ces 14 amphores. La présence de ce dépotoir ne trouve pas d'interprétation précise.

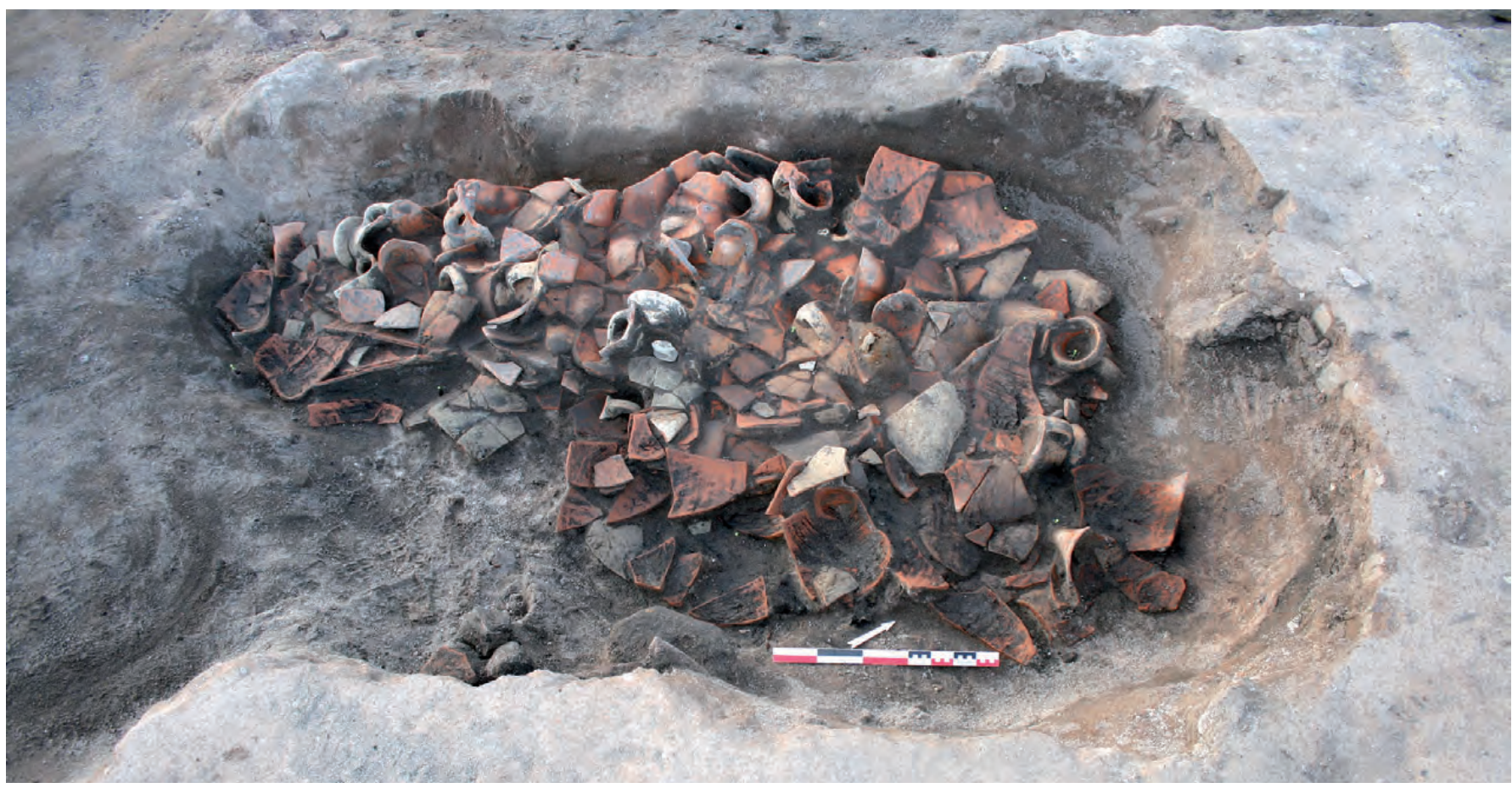

Fig. 170. Le dépôt d'amphores FS3333.

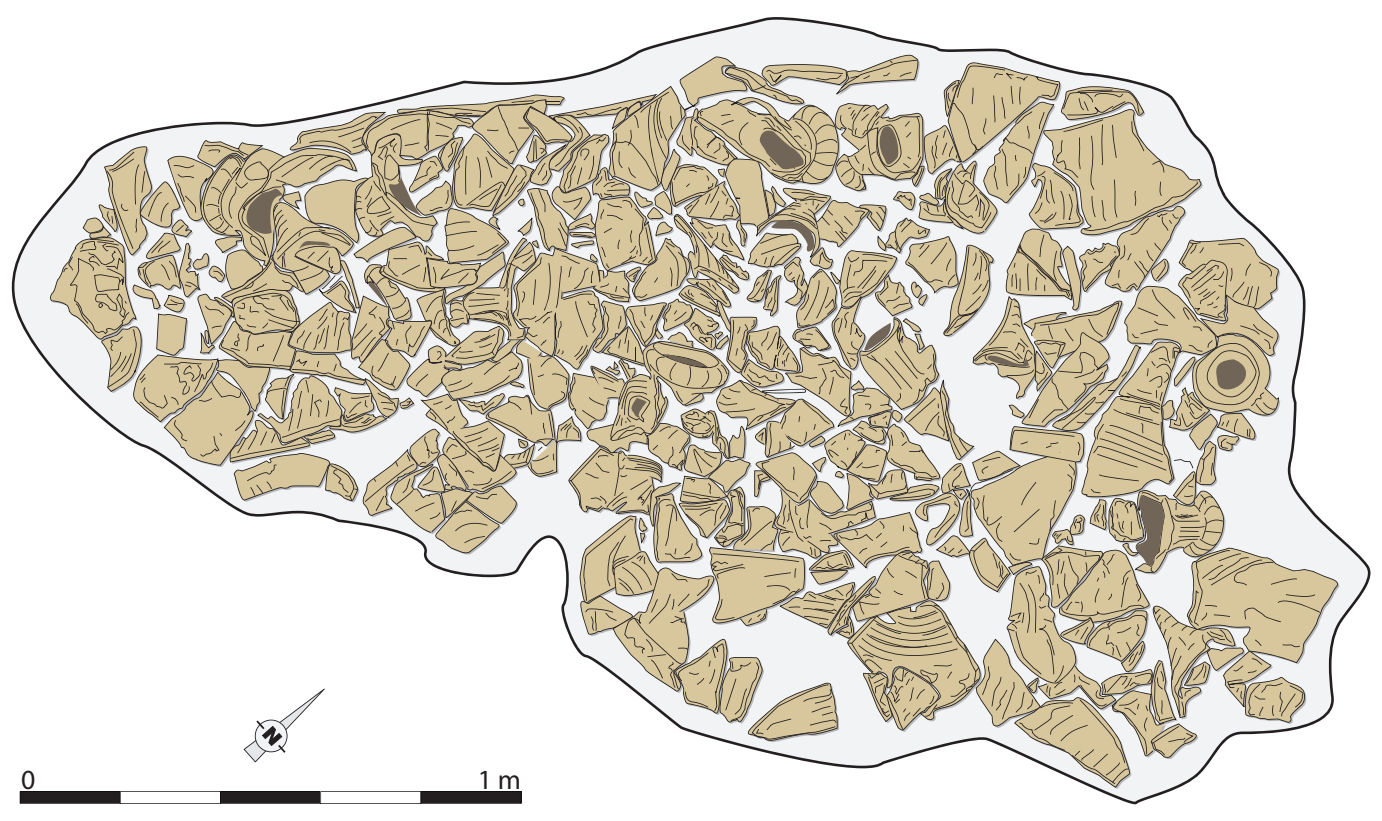

Fig. 171. Le dépôt d'amphores FS3333. 
1.4. Datation de la phase $4 \mathrm{~A}$

(P. E., J. F., E. P.)

\subsubsection{La céramique}

La phase 4A a fourni un ensemble particulièrement conséquent de céramiques. La prépondérance des amphores s'explique par le dépotoir (US3335) contenant quatorze amphores de type africaine 1A (fig. $173-\mathrm{n}^{\text {os }} 1$ à 27). Le terminus ante quem semble se situer entre la fin du $\mathrm{II}^{\mathrm{e}}$ siècle et le début du $\mathrm{III}^{\mathrm{e}}$ siècle apr. J.-C., comme le montre la présence de ces amphores. La présence d'un col d'amphore probablement de type Empoli, produite dès le III ${ }^{e}$ siècle apr. J.-C., va dans le même sens (fig. 172). Le reste du mobilier apporte peu d'indications chronologiques. En effet, on retrouve exclusivement du mobilier résiduel dans ce contexte.

\subsubsection{La monnaie}

Directement pris dans le sol 3308, une monnaie a été découverte. Il s'agit d'un sesterce dans un état de conservation moyen (fig. 174). La légende au droit est DIVA FAVSTINA et, sur le champ, se trouve un buste féminin à droite avec chignon perlé. Au revers se trouve la légende AUGUSTA et le champ représente, entre les deux lettres SC, Cérès debout à gauche tenant des épis de blé et une torche dans la main gauche. Cette monnaie de 29,04 grammes, a été frappée dans les ateliers de Rome, après la mort de Faustine en 141 apr. J.-C. (RIC vol. III, $163, \mathrm{n}^{\circ} 1119$ ).

\subsubsection{Datation par le radiocarbone}

La datation a été effectuée sur un fragment de bois de vigne ${ }^{8}$ découvert dans le fond du grand fossé FO3179 (US3189). La date fournie est large, entre le milieu du $\mathrm{II}^{\mathrm{e}}$ siècle et le début du IV ${ }^{\mathrm{e}}$ siècle apr. J.-C. ${ }^{9}$

\subsubsection{Conclusion sur la datation}

L'ensemble des données exploitables convergent vers une mise en place durant la seconde moitié du $\mathrm{II}^{\mathrm{e}}$ siècle apr. J.-C. Les données du radiocarbone, comme celles des amphores de la fosse 3333 et l'aspect usé de la monnaie vont dans le sens d'une datation à la fin

\footnotetext{
8 Code Villeneuve : \# 631, code labo : Poz-20220.

$91780 \pm 30 \mathrm{BP} / 68.2 \%$ probability / 210AD (68.2\%) 330AD / 95.4\% probability / 130AD (95.4\%) 340AD.
}

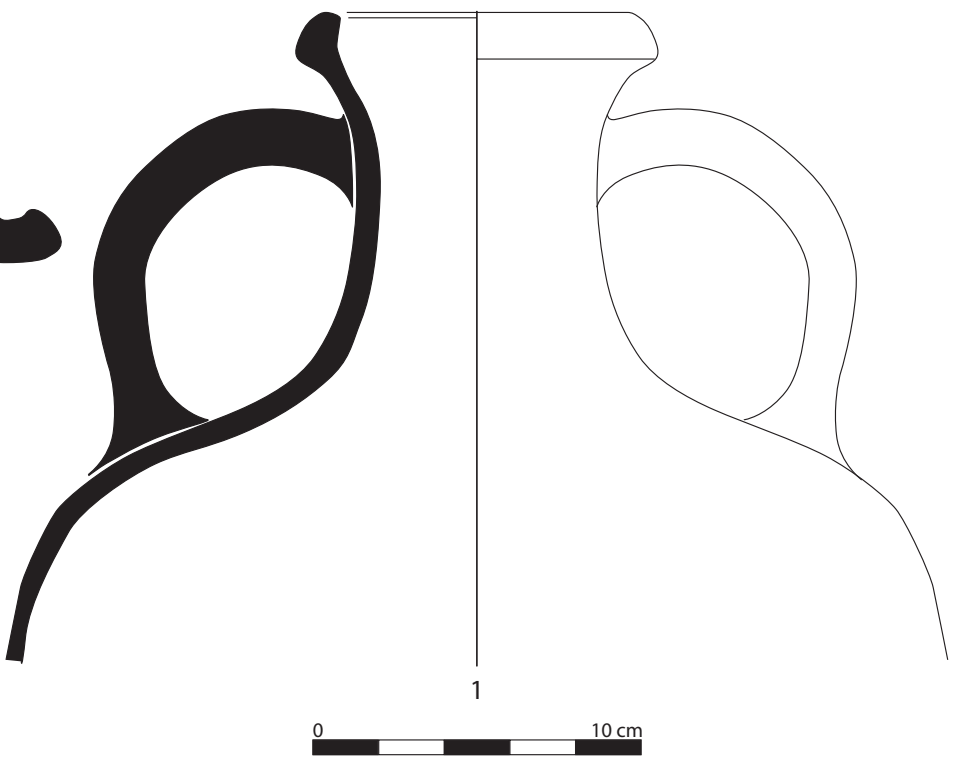

Fig. 172. Amphore d'Empoli .

du II' siècle apr. J.-C., au plus tôt, voire au début du siècle suivant.

\subsection{Interprétation générale \\ (P. E., L. B.)}

La création de cette lanière encaissée offre le double intérêt de protéger les plantations des embruns de la mer proche et de se rapprocher considérablement de la surface de la nappe phréatique et de faciliter ainsi l'irrigation. Les analyses archéobotaniques réalisées dans les différentes structures en creux permettent de restituer au sein de cette lanière une culture majoritairement arboricole, où se côtoient figuiers, pins pignon, pruniers, cyprès (à proximité du bassin BS3339) et, bien sûr, la vigne. Celle-ci pouvait être conduite en taille basse mais vraisemblablement mariée aux arbres. La configuration générale de l'espace cultivé dans du sable de plage au sein d'une bande rectiligne, protégé par des murets et à proximité du rivage n'est pas sans rappeler la culture du vin de sable. En effet, le parallèle avec les vignobles landais de Cap Breton établis à l'embouchure de l'Adour aux $\mathrm{XIV} / \mathrm{XV}^{\mathrm{e}}$ siècles et proliférant dès le XVIII ${ }^{\mathrm{e}}$ siècle (Taillentou 2005) est tentant (fig. 175), à la nuance prêt que l'on a dans la parcelle de la Villa Romana des cultures plus diversifiées. En restituant au-dessus des deux murets MR3040 et 3042 une palissade végétale solidement arrimée, la similitude avec les récits des observateurs des XVIII $/ \mathrm{XIX}^{\mathrm{e}}$ siècles sur les côtes landaises (ibid. 26-31) est encore renforcée. À l'évidence, la topographie et la planimétrie de la bande ne sous-entend pas que celle-ci soit aménagée au revers et sur le flanc d'une dune littorale, comme sur la 

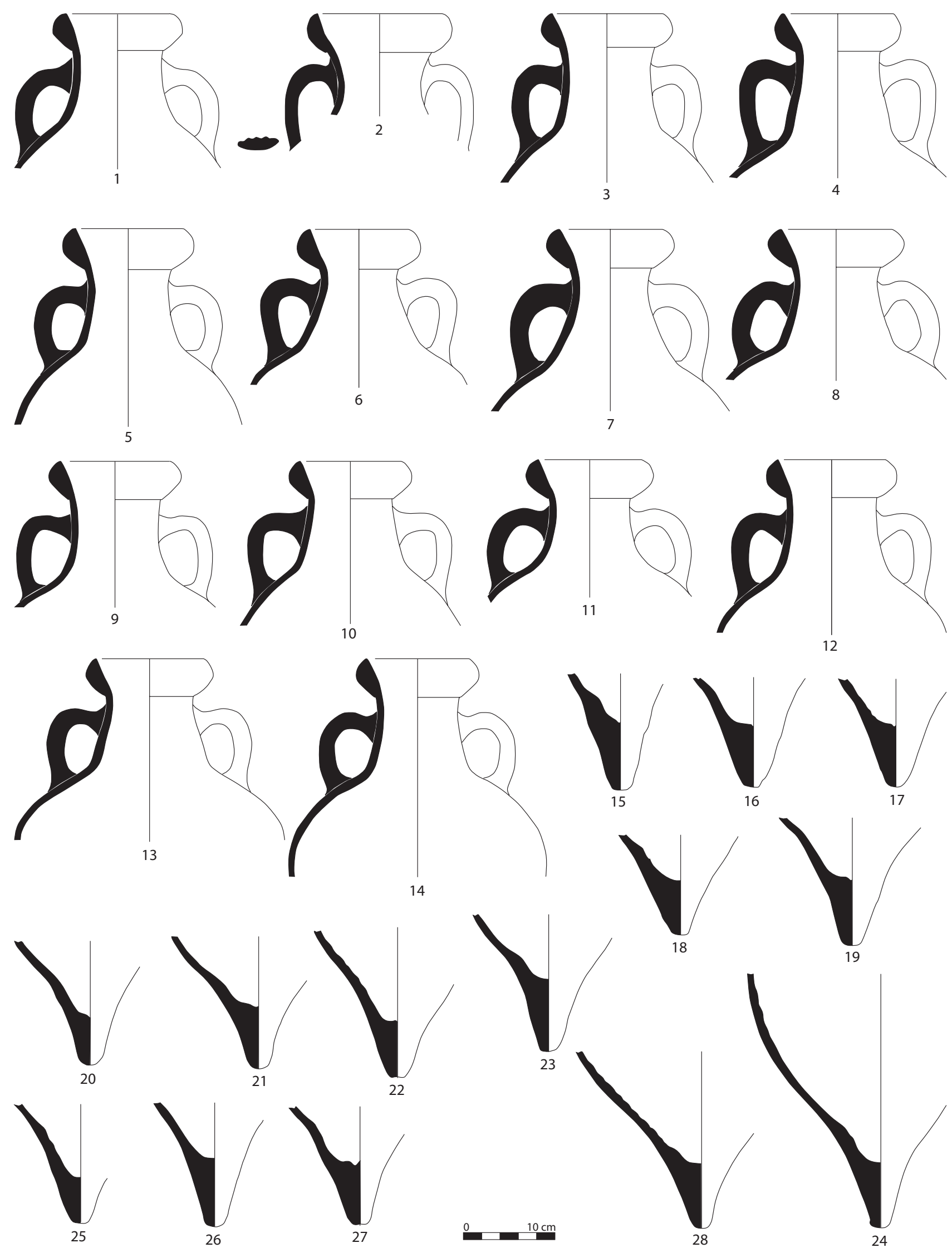

Fig. 173. Amphores de la fosse FS3333. 
côte atlantique. À Villeneuve, la protection des cultures contre le sable et les embruns est notamment assurée par le caractère encaissé de la bande cultivée. Mais les agronomes latins sont malheureusement peu prolixes au sujet de ce type de culture viticole. On remarque cependant qu'ils citent comme tuteurs fréquents de la vigne mariée des arbres qui affectionnent les sols frais, comme l'orme notamment, voire humides, comme le peuplier et le saule (Virgile, II, 221 ; Columelle, V, 6-7 ; Pline, XIV, 10-11 et XVII, 200-202), ce qui laisse penser que la culture de la vigne dans des terres basses était chose relativement commune durant l'Antiquité. Pline (XVII, 35) stipule que l'orme est au premier rang des arbres à choisir pour porter la vigne, puis vient le peuplier noir, tous deux étant favorisés de par leur feuillage peu épais. Or, au moins orme et saule sont attestés à la Villa Romana par des bois gorgés d'eau, le saule précisément pour la phase $4 \mathrm{~A}$, et la présence du peuplier n'est pas à exclure (Salix / Populus); nous avons émis l'hypothèse que ces arbres puissent être utilisés comme tuteurs de la vigne. Columelle (V et VI) signale que l'orme possède l'avantage de produire un feuillage excellent pour nourrir le bétail en même temps que d'être un parfait support pour la vigne, il précise comment en faire des pépinières et comment le planter sur le terrain. L'orme fait notamment partie des arbres complantés avec la vigne en Gaule, de même que le saule, qu'il conseille de réserver aux terrains marécageux où les autres arbres viendraient difficilement car le saule altèrerait le goût du vin produit par les vignes auxquelles il est marié (Columelle, V et VII). Pline (XIV, 7) précise que le Cécube, vin italien réputé, venait autrefois de terrains marécageux plantés de peupliers. Le long fossé FO3179 était ouvert et pouvait servir de fossé de drainage car la surface sablo-limoneuse recouvrant le sable est assez imperméable.

Les travaux de terrassement pour aménager la lanière ont occasionné le déplacement d'un volume important de sable ${ }^{10}$. Où ce sable a-t-il été transporté et dans quel but ? Aucune trace d'un apport aussi volumineux de sable n'a été perçue sur l'ensemble des fouilles. Lors du diagnostic archéologique réalisé sur le terrain situé de l'autre côté de la rue Jean-Carrara (Michel 2005), un important recouvrement sableux non lité et probablement remanié a été découvert au-dessus des structures romaines mises au jour, contemporaines de la phase $3 \mathrm{~A}$ de notre fouille. De façon très hypothétique, on peut supposer que cet apport de sable volumineux résulte de ce décaissement. Ainsi, cet apport aurait pu constituer une dune artificielle située au sud de la zone 3 et protégeant la bande cultivée des embruns.

10 Nous avons estimé pour la seule partie fouillée $318 \mathrm{~m}^{2}$, soit 477 tonnes.

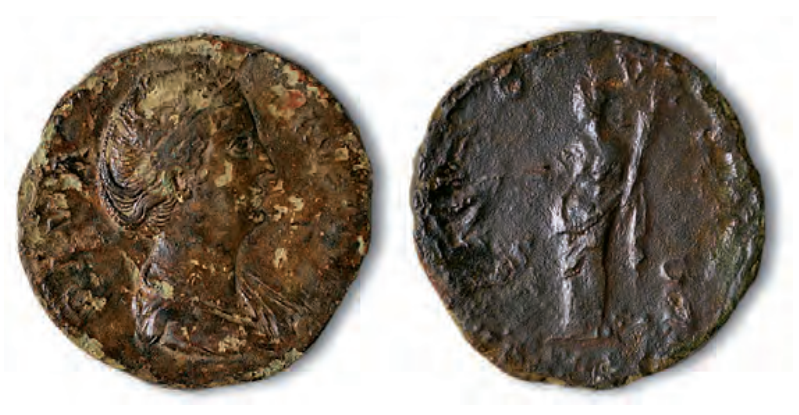

Fig. 174. Sesterce de Faustine divinisée.

Pour cette période, les exemples d'exploitations viticoles sont plus rares que pour les époques antérieures. La fin du $\mathrm{II}^{\mathrm{e}}$ siècle et le $\mathrm{III}^{\mathrm{e}}$ siècle apr. J.-C. correspondent à une période de recul de la viticulture en Narbonnaise et notamment en Provence (Brun, Congés 1996). Aucun vignoble de cette période n'a encore été attesté par l'archéologie (Boissinot, Puig 2006, 21). Doit-on voir dans l'exploitation de Villeneuve une nouvelle forme de viticulture, modifiant ainsi pour partie la conception que l'on pouvait avoir des modèles d'exploitation durant le Haut-Empire ? À moins que la viticulture ne se replie alors sur une forme d'exploitation moins extensive, une viticulture urbaine et péri-urbaine, qui a pu exister au Haut-Empire et qui existait encore au Moyen Âge, comme par exemple autour et dans Paris ce qui constituait la partie centrale du fameux vignoble de France des XII/ XVe siècles (Dion 1959).

\section{La phase 4 , état $B$}

\subsection{Description}

(P. E., L. B., S. Gr)

\subsubsection{La zone 3}

Cette nouvelle phase se caractérise par le creusement d'une série de fosses, pouvant atteindre plus d'un mètre de diamètre et venant recouper le long fossé FO3179 (fig. 176). Aucune nouvelle structure bâtie n'est mise en place au cours de cette phase, mais les murets limitant la bande cultivée de l'état antérieur marquent toujours la parcelle. Les relations stratigraphiques entre ces nouvelles fosses et le réseau de fossés de l'état précédent sont difficiles à établir, essentiellement en raison de l'uniformité des sédiments de recouvrement. Il s'agit d'un niveau sablo-limoneux gris qui recouvre l'ensemble de la parcelle, constitué durant toute la phase 4. Durant l'état B, la surface ne s'exhausse que d'un peu plus d'une dizaine de centimètres et les nouvelles fosses sont creusées, alors que le long fossé FO3179 n'est pas 

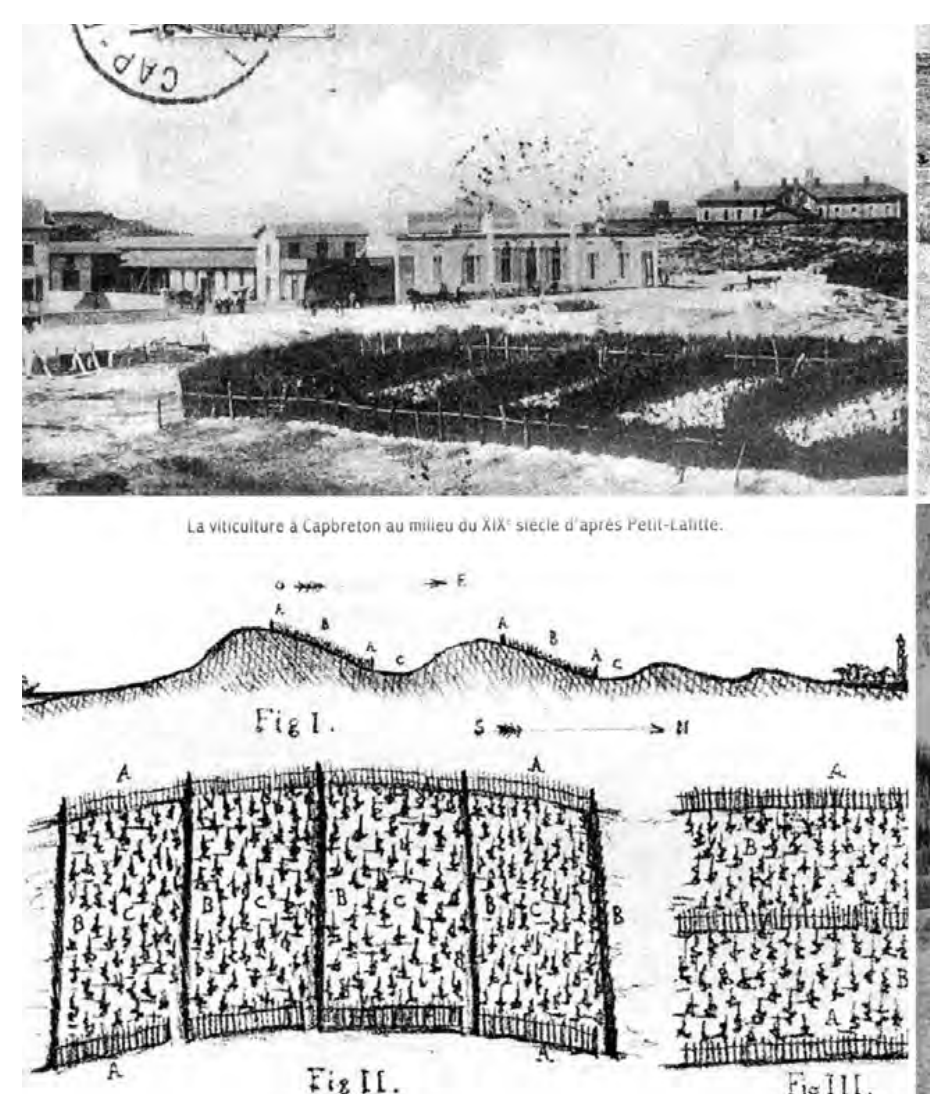

Fis II.

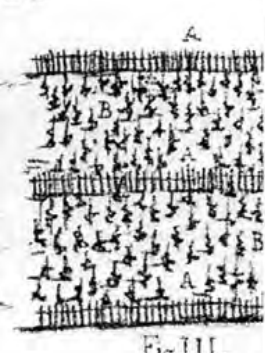

Fis III.

Fig. 175. Les vignobles de Cap Breton établis à l'embouchure de l'Adour (Taillentou 2005).

totalement comblé par le sédiment sablo-limoneux gris bleuté (US3180). Ce fait laisse entrevoir une période d'abandon entre les deux états. La stratigraphie ne permet pas clairement de mettre en évidence ce point que nous ne pouvons dès lors que supposer. Toutes les fosses sont creusées plus profondément que les fossés antérieurs. Enfin, les trois fosses FS3190, 3195 et 3197 ont été tronquées par le fond d'un canal moderne (FO3020).

\subsubsection{Les fosses}

La fosse FS3195 est de forme ovale (2,10 m x 2,30 m). Elle est creusée en partie dans le fossé FO3179 qu'elle traverse jusqu' au sable dans lequel son fond est aménagé. Elle est profonde d'une cinquantaine de centimètres et comblée par un sédiment sablo-limoneux gris noir (3196). Au centre se trouve une forte concentration de cailloux et de gros fragments de tuiles et de céramiques dont les plus gros éléments se retrouvent jusqu'au fond de la fosse (fig. 177, 178 et 179).

La fosse FS3197 est à peu près circulaire de $1,50 \mathrm{~m}$ de diamètre, de profil plus tronconique que la précédente, mais de même profondeur. Le sédiment comblant l'ensemble de la fosse jusqu'à l'ouverture (3198) est lui aussi sablo-limoneux gris noir et certains
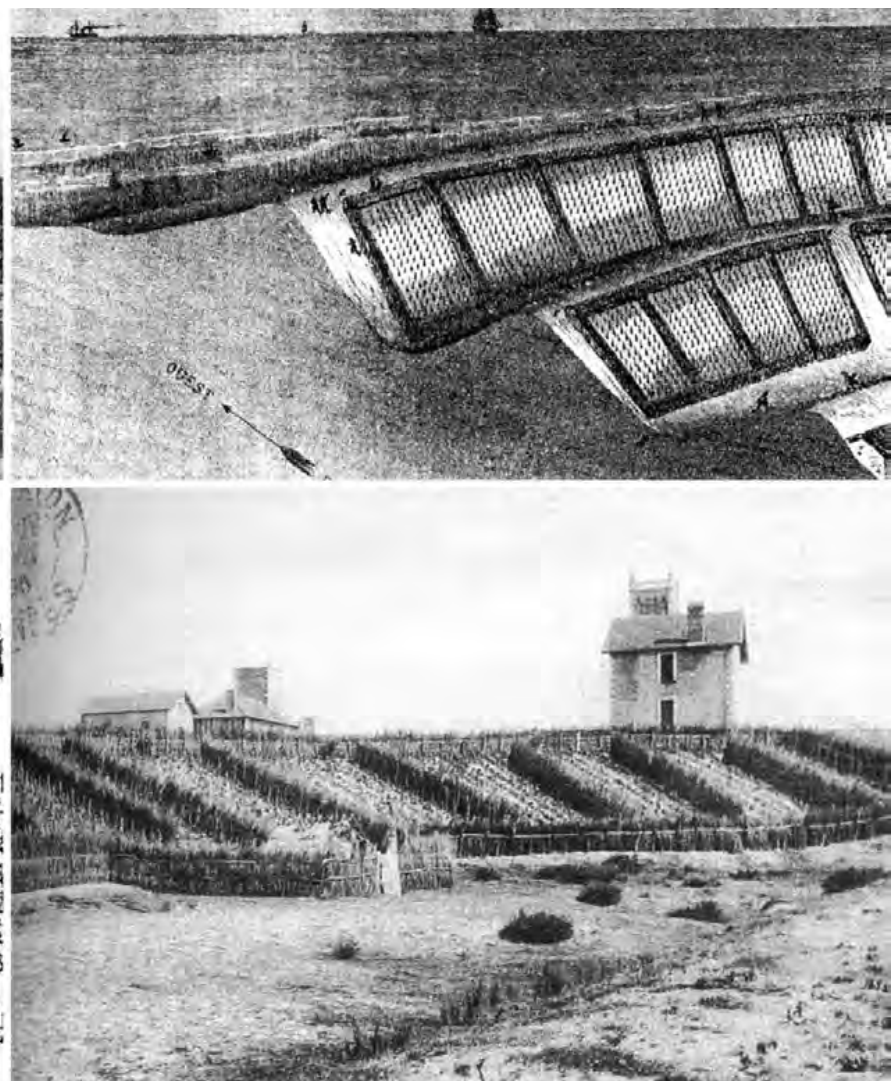

restes de végétaux et d'insectes ont été prélevés. Au fond est aménagé un calage de moellons et de blocs, dont l'un est appuyé contre la paroi de la fosse. Au centre du calage a été mise en évidence une motte lenticulaire (diamètre de $0,75 \mathrm{~m}$ et épaisseur de $0,23 \mathrm{~m}$ soit $0,13 \mathrm{~m}^{3}$ ) à dominante argilo-limoneuse très pure, gris noir (3315), comprenant de nombreux restes organiques et quelques pierres (fig. 180).

La fosse FS3190, de forme vaguement circulaire $(1,50 \mathrm{~m} \times 1,60 \mathrm{~m})$, profonde de $0,45 \mathrm{~m}$, est creusée au sein du fossé FO3179. Le comblement (3191) est sablo-limoneux gris noir avec une importante variation granulométrique du haut vers le bas et au centre de la fosse. On retrouve également en son centre une partie plus argilo-limoneuse. On relève la présence de nombreuses brindilles de bois, quelques gros morceaux de bois sans écorce et quelques fragments d'écorces fines. Ce bois est surtout concentré contre la paroi sud de la fosse (fig. 181 et 182). Quelques pierres sont présentes en bordure de fosse dont un fragment de marbre.

La fosse FS3199 est de forme circulaire d'un diamètre de $1,80 \mathrm{~m}$ et de $0,55 \mathrm{~m}$ de profondeur. Le comblement supérieur (3301) correspond à l'épandage consécutif à l'abandon de la zone (phase 4C, similaire à 3164B). Le comblement inférieur (3200) est de nature sablo-limoneuse gris noir. 


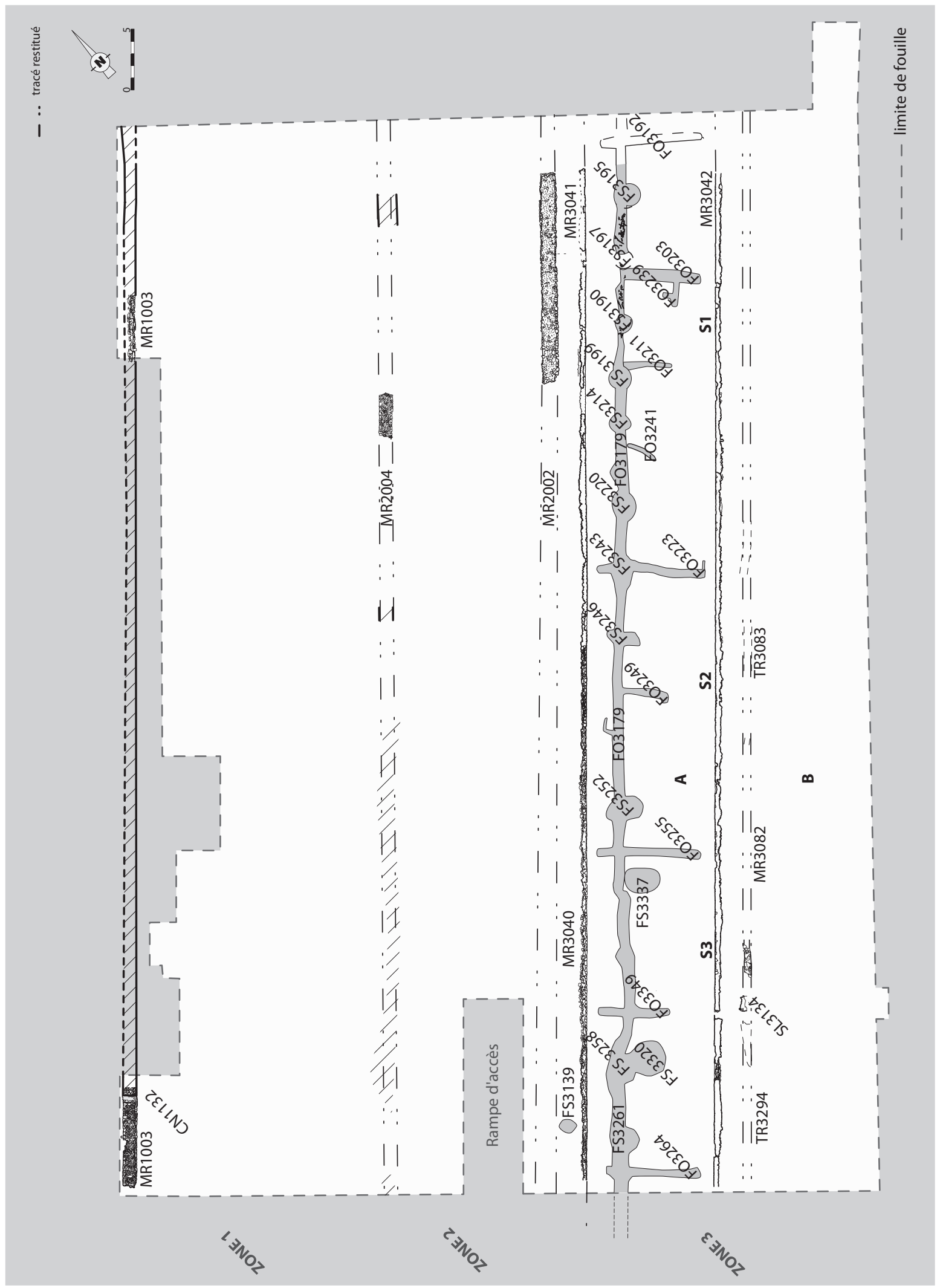

Fig. 176. Plan d'ensemble des vestiges de la phase 4B. 
$\mathrm{Au}$ sommet de la couche, on trouve un limon sableux avec un amas de blocs disposés en cercle de manière organisée et la présence d'os brûlés et de fragments de tuiles. En profondeur, le comblement devient très argileux avec énormément de matière organique. Quelques moellons sont présents. Le fond présente plusieurs niveaux de comblements, dont la présence d'une passe sableuse, puis de nouveau de l'argile avant le sable naturel (US3138).

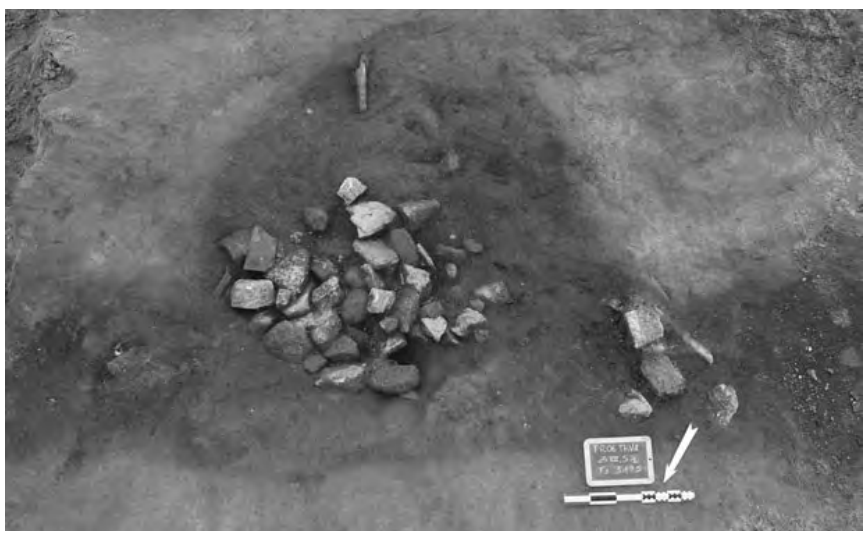

Fig. 177. La fosse FS3195 pleine.

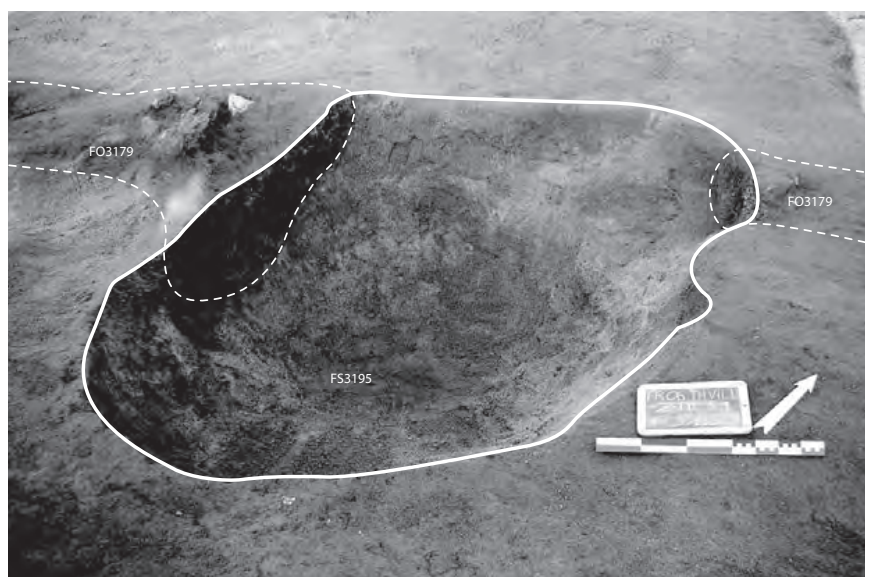

Fig. 178. La fosse FS3195 vide.

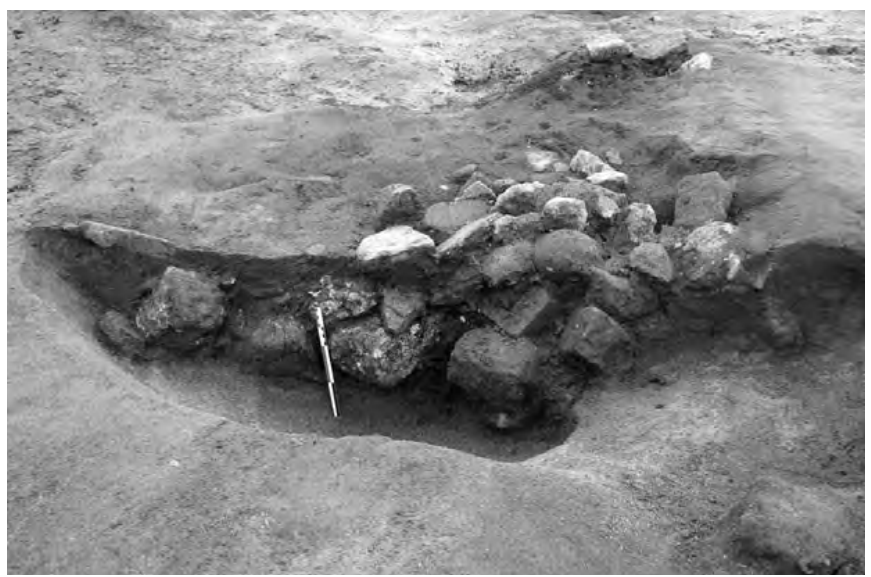

Fig. 179. Comblement de FS3195 en coupe.

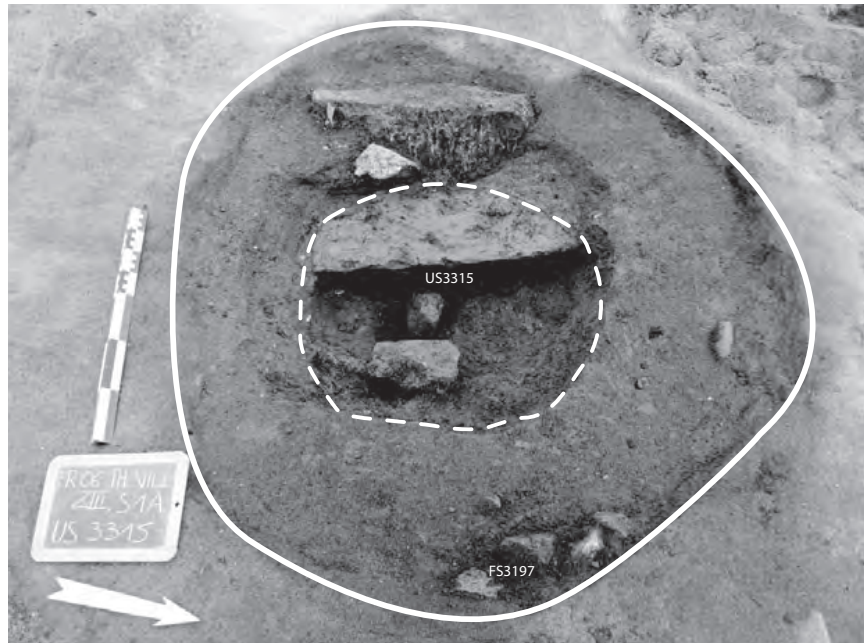

Fig. 180. La fosse FS3197.

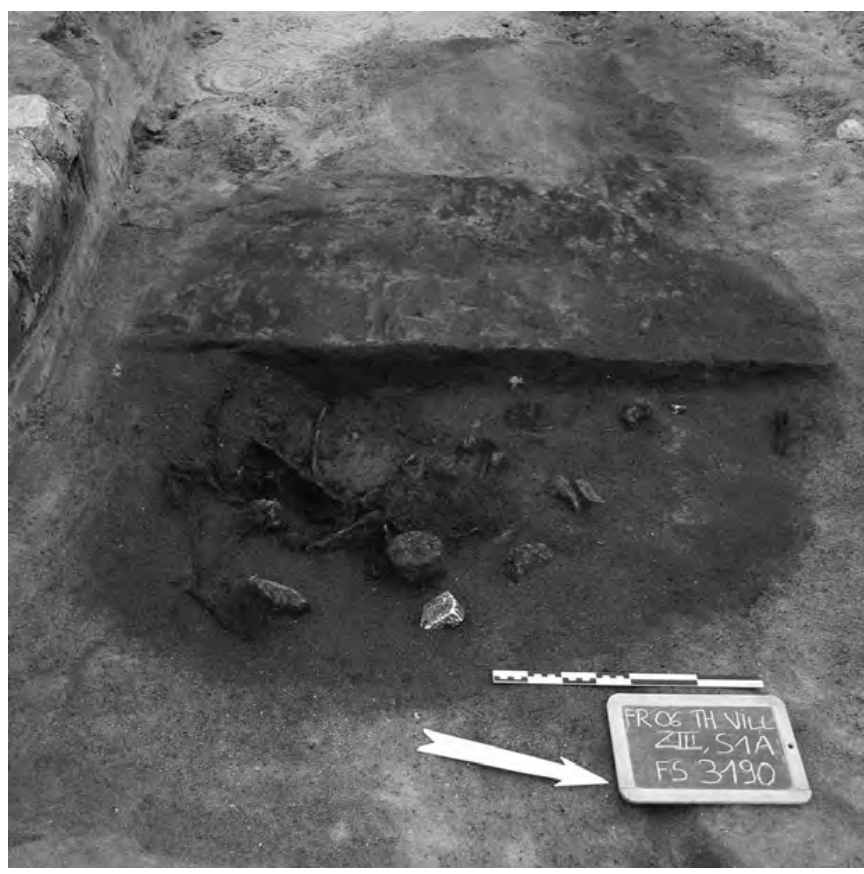

Fig. 181. La fosse FS3190.

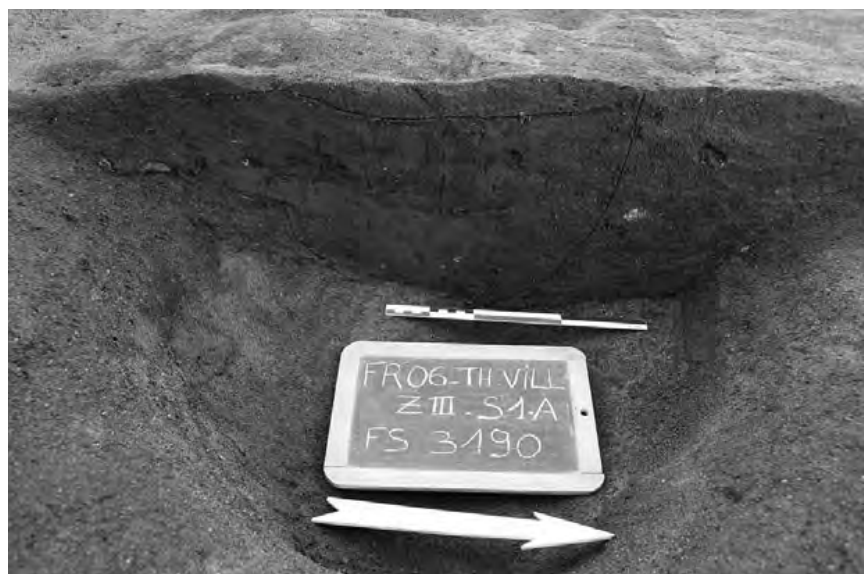

Fig. 182. La fosse FS3190 avec une concentration plus fine au centre. 

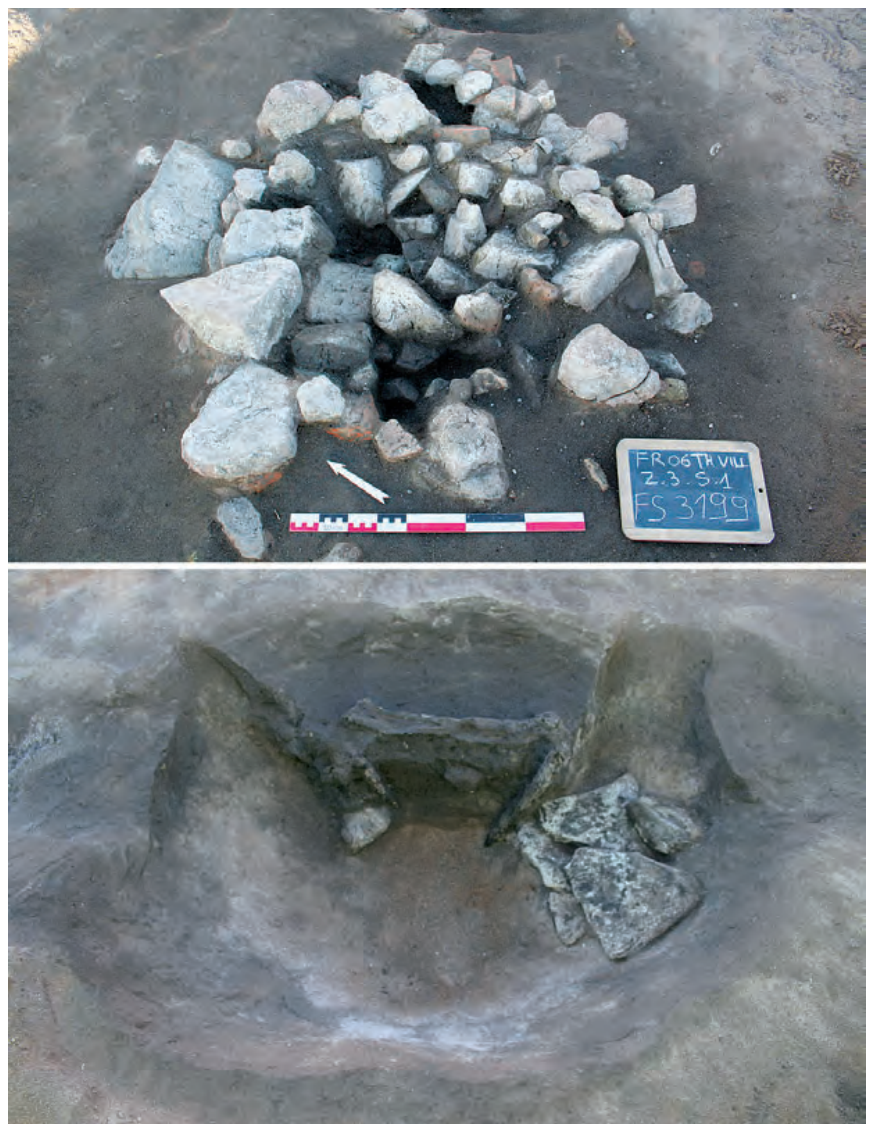

Fig. 183. La fosse FS3199.

Dans ce comblement, deux piquets appointés sont en position verticale, au nord de la fosse, avec, entre les deux, un troisième morceau de bois non taillé et disposé horizontalement (fig. 183). L'ensemble est « calé » par des moellons et des fragments de plaque de mortier, peutêtre des restes d'enduit remployés. La disposition des piquets évoque un système de tuteur en « V » permettant d'envisager un pallissage des arbres.

La fosse FS3214 est de forme ovale (1,40 m x 1,70 m) et profonde de $0,60 \mathrm{~m}$. Son comblement sommital
(3215) correspond à la phase d'abandon. En dessous, le comblement est noir et un peu plus sableux que dans les autres fosses (3216). Il s'agit d'un sédiment très organique composé de couches hétérogènes et de poches sableuses ou argileuses. À $5 / 10 \mathrm{~cm}$ de la surface, à l'ouest de la fosse, un ensemble de racines est situé à proximité d'un calage, dont les ramifications suivent les parois de la fosse (fig. 184). Il s'agit de trois essences différentes : la vigne (Vitis vinifera), le saule (Saule) et une autre angiosperme, peut-être du figuier ou du frêne. Également, on relève une concentration de graines au centre-est de la fosse. Il s'agit de 23 graines de gourde calebasse (Lagenaria siceraria).

Durant l'Antiquité, les fruits de la calebasse étaient utilisés autant pour la confection de récipients ou ustensiles divers que pour être consommés. La plante est originaire d'Afrique tropicale ou subtropicale mais sa culture en zone méditerranéenne est possible. Il a même été proposé, à partir d'exemples récents, que la plante ait pu être cultivée dans des lieux particulièrement favorables du nord de la France à l'époque romaine (Marinval et al. 2002).

La fosse FS3220 est un ovale de 1,90 m x 2,10 m pour $0,40 \mathrm{~m}$ de profondeur. Sous le colmatage final sablo-limoneux (3221) correspondant au recouvrement sédimentaire consécutif à l'abandon de la parcelle, on rencontre un comblement sablo-limoneux gris noir (3222). Cette couche est globalement sableuse avec au centre une zone plus argileuse au contact d'éléments de bois. On y relève moins de brindilles que dans les autres fosses, mais elle contient une grosse branche de $7 \mathrm{~cm}$ de diamètre, posée sur le fond (fig. 185).

La fosse FS3243 est creusée à l'intersection des fossés antérieurs FO3179 et 3223. Elle est de forme plus quadrangulaire et d'une profondeur de 0,60 m. L'ensemble est recouvert par le même niveau sablo-limoneux gris que les autres fosses (fig. 186). Au-dessous, le comblement intermédiaire (3298) est

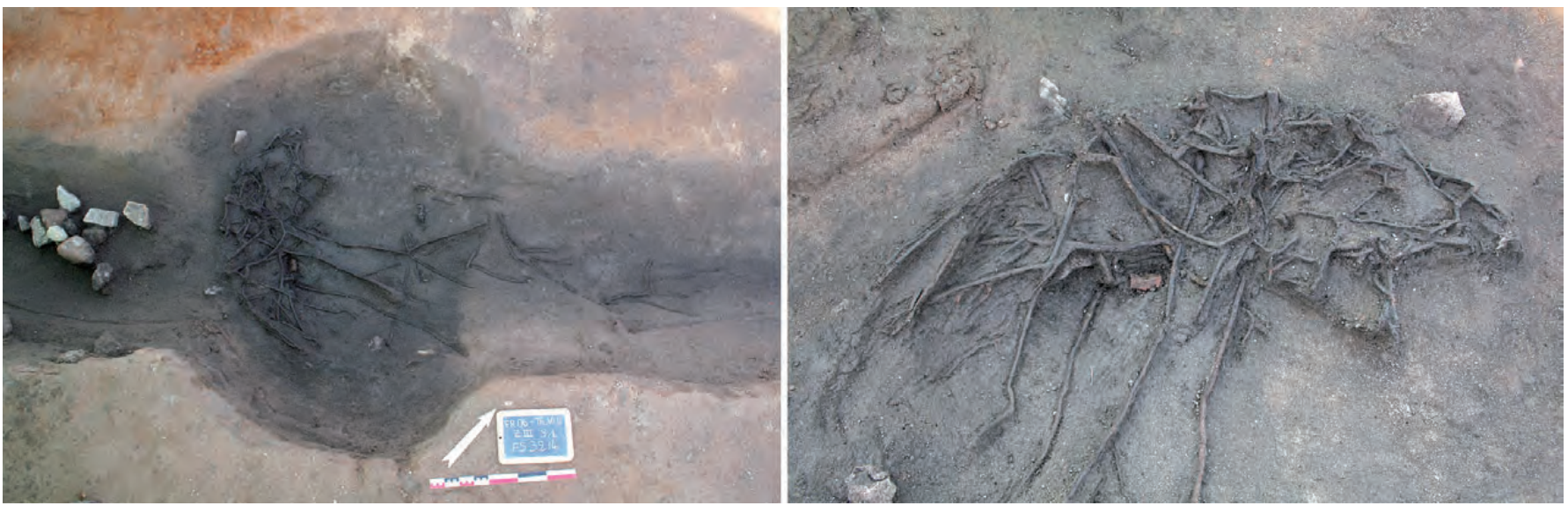

Fig. 184. La fosse FS3214. 


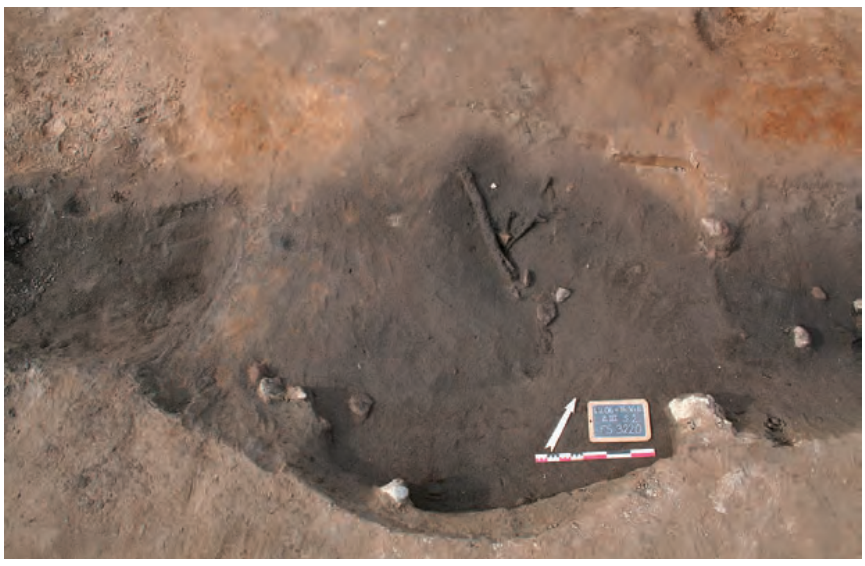

Fig. 185. La fosse FS3220.
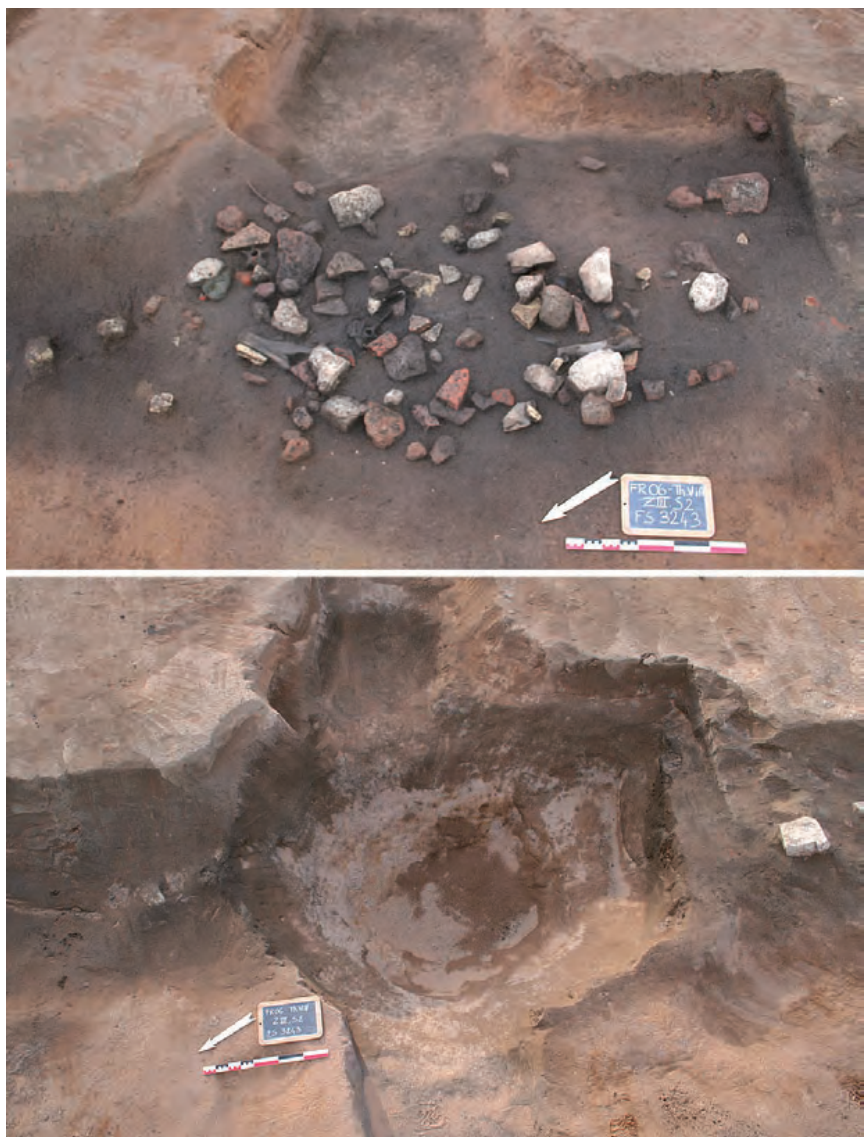

Fig. 186. La fosse FS3243.

composé essentiellement de sable. Ce niveau apparaît plus argileux en surface, avec la présence d'os d'animaux et de cailloux, et devient ensuite plus sableux. Le comblement inférieur (3245) est sablo-limoneux noir et contient de nombreuses pierres, éléments de faune et céramiques. Quelques gros charbons et une grosse scorie ont été retrouvés dans sa partie nord-ouest. On note également la présence de gros moellons de grès et des fragments de dalles en mortier appuyées contre la paroi ouest.
La fosse FS3246 est un ovale de 1,50 m x $2 \mathrm{~m}$ pour $0,59 \mathrm{~m}$ de profondeur. Son comblement uniforme est constitué d'un sédiment sablo-limoneux gris noir (3248).

La fosse FS3252 est un ovale de $2 \mathrm{~m}$ x 2,85 m pour $0,60 \mathrm{~m}$ de profondeur (fig. 187A). Le pan nord était calé par de gros fragments de panses d'amphores (fig. 187D). Le comblement inférieur (3254) est sablolimoneux gris noir. Il comprend de nombreux tessons d'amphores gauloises. Des éléments de mortier de chaux, peut-être des récupérations d'enduit, formaient un coffrage carré de $0,65 \mathrm{~m}$ de côté (fig. 187B et C). La partie inférieure de ce comblement devient plus meuble et sableuse.

La grande fosse FS3337 est de forme ovale de $2 \mathrm{~m} \times 2,95 \mathrm{~m}$ et profonde de plus de $0,80 \mathrm{~m}$. Contrairement aux autres fosses, elle est déconnectée du fossé ancien FO3179. Le comblement (3338) est sablo-limoneux gris noir et comprend des restes de faune, de la céramique et les morceaux d'une planche de chêne caducifolié (Quercus sp.). Débitée sur quartier, cette planche était d'une longueur minimale de $1,40 \mathrm{~m}$, pour une largeur de 0,16 à $0,18 \mathrm{~m}$ et une épaisseur de $0,03 \mathrm{~m}$. Son analyse dendrochronologique a permis d'acquérir une chronologie individuelle longue de 118 ans comprenant 21 cernes d'aubier qui contribuent à proposer une date d'abattage assez proche (le chêne caducifolié présente, en moyenne, environ $25 \pm 15$ cernes d'aubier ${ }^{11}$. Aucune corrélation satisfaisante avec les chronologies moyennes locales du Sud de la France n'a pu être retenue.

La fosse FS3320 est de forme grossièrement circulaire de 3,50 $\mathrm{m}$ de diamètre pour $0,90 \mathrm{~m}$ de profondeur. Elle ne se trouve pas directement sur le fossé antérieur FO3179 (fig. 188) et son remplissage sablo-limoneux gris noir (3321) présente des restes de bois, de la céramique, de la faune et des fragments de tuiles.

La fosse FS3258 est aménagée au sein du fossé FO3179, tout à côté de FS3320. Elle est de forme grossièrement circulaire de $2,40 \mathrm{~m}$ de diamètre pour $0,60 \mathrm{~m}$ de profondeur. Son comblement (3260) sablo-limoneux n'a pas pu être fouillé.

La fosse FS3261 a été creusée pour moitié au sein de FO3179. Elle est circulaire, de 2,30 $\mathrm{m}$ de diamètre, et profonde de $0,65 \mathrm{~m}$. Le comblement inférieur est sombre et compact, de nature sablo-limoneuse (US3263). En son centre le niveau devient plus argileux. On note la présence de fragments de céramique enduits de poix et de trois blocs déposés en vrac au fond, dont l'un était fiché verticalement (fig. 189).

Une fosse FS3139, complétant cet ensemble, a été découverte au nord du mur MR3040, donc en dehors de

11 Estimation faite à partir des travaux réalisés sur le chêne sessile et le chêne pédonculé dans l'Est de la France (Lambert 1998). 
la bande cultivée. Située sous le fossé moderne FO3020, sa surface de creusement a été largement tronquée et il est de ce fait impossible de la rattacher stratigraphiquement à un état précis.
Le mobilier est peu représentatif et ne permet pas non plus de la situer chronologiquement. En revanche, son comblement sablo-limoneux gris noir (US3140) l'apparente aux fosses de l'état B.
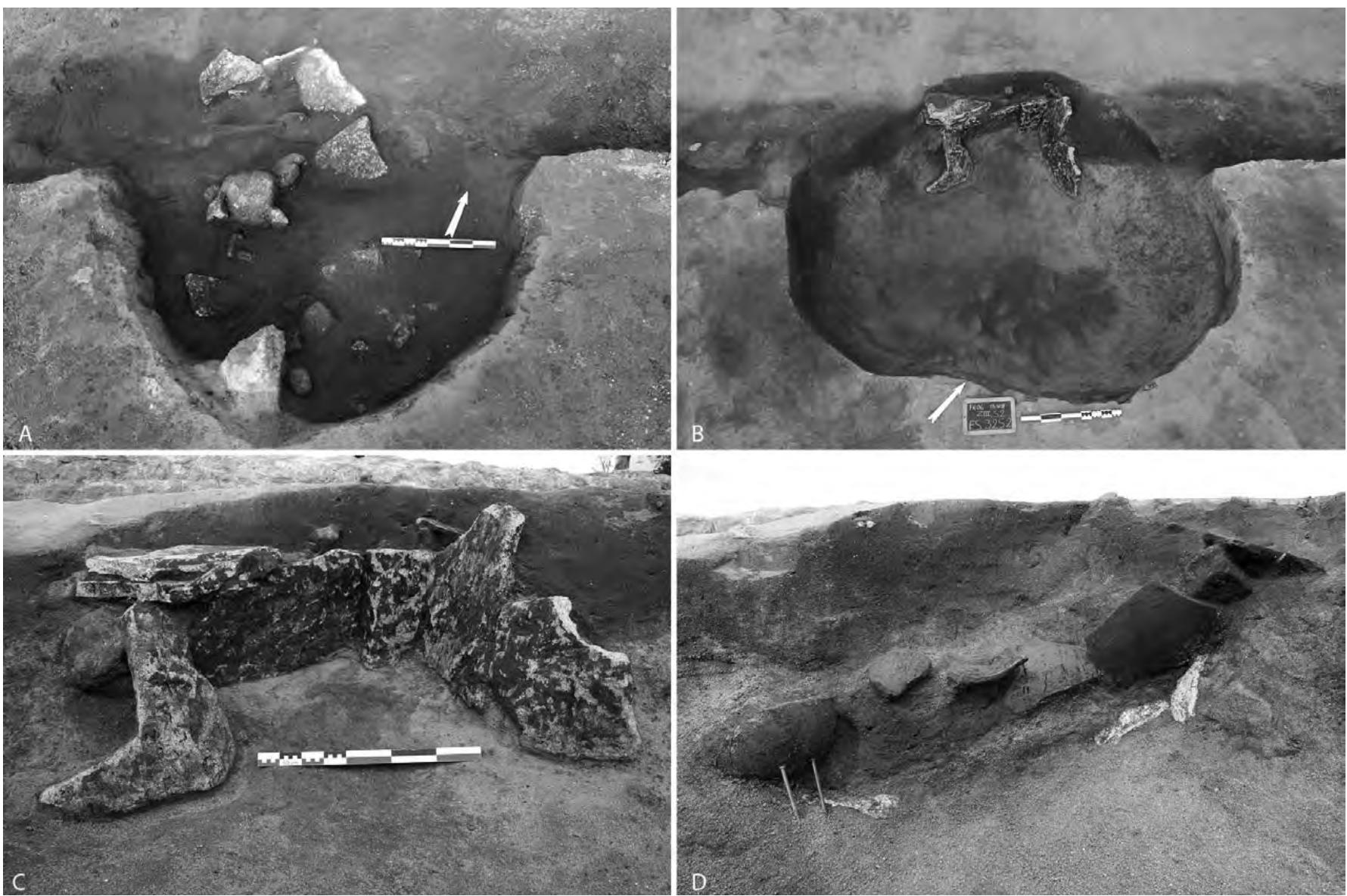

Fig. 187. La fosse FS3252.

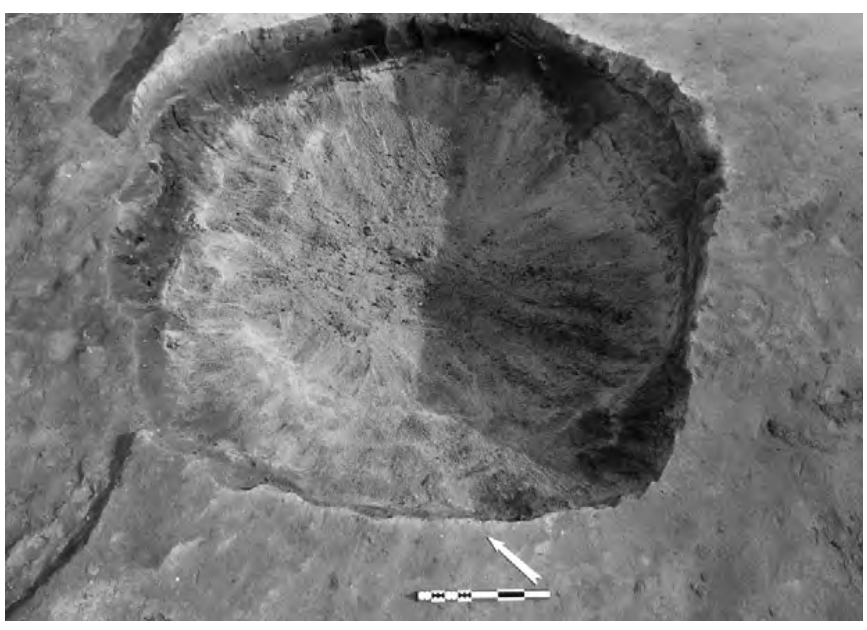

Fig. 188. La fosse FS3320.

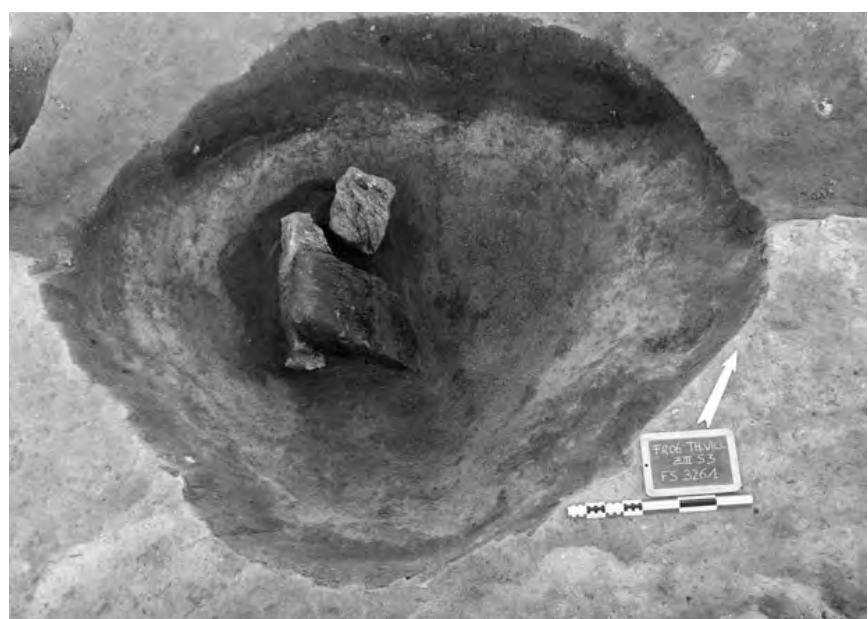

Fig. 189. La fosse FS3261. 


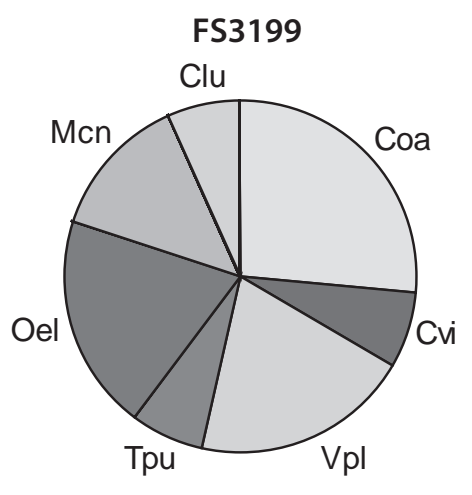

Fig. 190. Proportion des estimations d'abondance des taxons malacologiques terrestres pour la fosse 3199 (cf. fig. 125).

\subsection{Les analyses}

\subsubsection{La palynologie}

(S. G.)

\section{Les fosses FS3190 et 3220}

(fig. 265)

Les données exploitables sont assez faibles et correspondent à deux échantillons prélevés dans la fosse FS3190 et à un prélèvement isolé réalisé dans la fosse FS3220.

La palynologie montre, par les taux très faibles du pin et du maquis, qu'il y avait très peu d'apports régionaux et donc que les fosses fonctionnaient indépendamment du fossé FO3179 alors comblé.

Les valeurs respectives des lentilles d'eau (Lemna minor) et des Brassicaceae marquent la présence temporaire d'eau dormante, ou du moins un haut niveau de la nappe.

Les valeurs des céréales et des rudérales (rumex acetosa/oseille des prés, Artemisia/armoise, Plantago lanceolata/plantain lancéolé) sont le témoin d'une possible activité agropastorale.

\subsubsection{La malacologie}

(S. M.)

\section{FS3199 US3200 \#535}

Cet assemblage comprend peu de malacofaune mais elle est relativement bien diversifiée (fig. 190). Elle indique des formations prairiales (Cochlicella acuta) relativement humides (Vallonia pulchella). L'abondance de l'espèce palustre Oxyloma elegans traduit le développement d'une végétation de type roselière à proximité ou à l'intérieur de la fosse ; cette espèce peut être associée à l'espèce aquatique Anisus leucostoma de milieu temporaire et stagnant. Enfin, la présence de Monacha cantiana suggère un certain embroussaillement du milieu local. On peut donc suggérer l'existence d'une prairie saisonnièrement engorgée et comprenant des micro-habitats plus fermés de type broussailles.

\subsubsection{L'entomologie \\ (P. P.)}

Deux échantillons non «stériles » provenant des fosses FS3199 et FS3197 sont extrêmement riches en fragments et en taxons de coléoptères, avec 164 taxons. Les autres ordres d'insectes recueillis sont peu nombreux (hétéroptères en très petit nombre).

\subsubsection{Habitats aquatiques}

Peu nombreuses, on note seulement sept espèces de Dytiscides - tous des ubiquistes - dont Guignotus pusillus, Agabus bipustulatus et Colymbetes fuscus qui vivent dans tous types de collections d'eau : flaques, étangs, rivières à cours lent... Les groupes d'aquatiques les mieux représentés sont les Hydraenidae et les Dryopidae ; cette dernière famille est particulièrement riche en individus mais ne compte qu'un seul taxon, Dryops sp., vivant dans la boue au bord des cours d'eau et des mares, parfois en très grand nombre. Pas moins de 167 spécimens ont été dénombrés. Quelques espèces d'Hydrophilides vivent exclusivement dans les eaux stagnantes ou les parties les plus calmes des cours d'eau : Helophorus sp., Helochares lividus, Limnoxenus niger, Hydrophilus caraboides.

\subsubsection{Faune synanthrope, coprophage, coprophile}

Cette catégorie est l'une des plus importantes dans les assemblages. Il faut signaler au premier rang des espèces bien connues le charançon Sitophilus granarius, grand destructeur de céréales entreposées et presque exclusivement synanthrope. Toutefois, un seul spécimen a été identifié. Les autres espèces constantes des habitations humaines où des denrées alimentaires sont stockées dans des conditions de conservation précaires sont totalement absentes, ce qui indique qu'aucun lieu de stockage de denrées alimentaires n'était présent à proximité des points de prélèvement. Aglenus brunneus est une espèce dont le biotope favori est l'accumulation de paille moisie à l'intérieur de bergeries. Enfin, un grand groupe d'espèces est composé d'insectes coprophages (se nourrissant directement d'excréments) ou coprophiles (liés indirectement aux excréments), le passage aux détritiphages liés aux matières animales ou végétales en décomposition se faisant de manière progressive. Dans nos assemblages fossiles, il s'agit des Hydrophilides 
Cercyon, de Megasternum boletophagum, de tous les Histérides, de beaucoup de Staphylins comme les Oxytelus, les Xantholinus, le Scarabéide Pleurophorus caesus. Les autres Scarabéides Onthophagus et Aphodius sont des coprophages biens caractérisés, alors qu'Aphodius granarius fréquente plus volontiers les matières en décomposition. Cette communauté de coprophages est particulièrement riche, avec de grandes espèces comme le Scarabaeus semipunctatus (proche du scarabée sacré), le Gymnopleurus, le Sisyphus schaeferi, etc. L'abondance du petit coprophage Onthophagus furcatus dans les échantillons analysés est remarquable.

\subsubsection{Carpologie, anthracologie et xylologie}

$$
\text { (L. B., I. F., C. S.) }
$$

\subsubsection{La carpologie}

Un prélèvement carpologique provenant de la fosse FS3220 a livré seulement quatre carporestes imbibés. Il s'agit de semences de nitrophiles, adventices ou rudérales, Fumaria officinalis et Solanum nigrum, ainsi que d'une plante affectionnant souvent les sols humides (Carex sp.). L'indigence des résultats n'autorise aucune interprétation carpologique de la fosse. La fosse de plantation n'a pas fait l'objet de prélèvement sédimentaire mais de multiples semences non carbonisées ont été recueillies lors de la fouille : il s'agit pour totalité de graines de gourde calebasse (Lagenaria siceraria) (pl. 1, D).

\subsubsection{La xylologie et l'anthracologie}

L'analyse anatomique de trois fragments de bois provenant de la fosse 3214 a mis en évidence la présence de trois essences différentes : la vigne (Vitis vinifera), le saule (Salix sp.) et une autre angiosperme non identifiée spécifiquement en raison des dommages subis par la structure anatomique. Les éléments observables nous font penser soit au figuier soit au frêne. Enfin, cinq taxons sont distingués parmi les charbons inclus dans le comblement de la fosse 3220 : Fraxinus (frêne), Prunus type avium (rosacée type merisier), Pinus sp. (pin d'Alep ou pin pignon), Quercus (caduc) et Ulmus.

\subsection{Les mobiliers et la faune}

\subsubsection{La céramique}

$$
\text { (E. P.) }
$$

L'ensemble du mobilier mis au jour reste modeste. Le terminus ante quem est donné par une petite série de pièces de céramique renvoyant au Bas-Empire, localisée dans le comblement de quatre fosses de culture (US3198, 3200, 3245, 3321, 3338). Il s'agit de deux bords de pots à feu en céramique à pâte brune liguro-provencale tardive (fig. $191-\mathrm{n}^{\text {os }} 1$ et 2 ), d'un couvercle africain de type Hayes 196 (fig. $191-\mathrm{n}^{\circ}$ 3) appartenant à une variante tardive du IVe siècle apr. J.-C. (Bonifay 2004, fig. 121 $\mathrm{n}^{\circ} 8$ ), d'un bord d'amphore de type africaine 3A / Keay 25.1 (fig. $191-\mathrm{n}^{\circ}$ 4) et d'un bord d'amphore Keay LII (fig. $191-\mathrm{n}^{\circ}$ 5). Ces deux derniers objets renvoient au $\mathrm{IV}^{\mathrm{e}}$ siècle apr. J.-C.

\subsubsection{Instrumentum}

(Y. L.)

Épingle à cheveux à tête zoomorphe - Inv. n $32-$ Alliages cuivreux - H. : $51 \mathrm{~mm}$; long. : $32 \mathrm{~mm}$

Cette épingle en bronze représente un coq debout au modelé sommaire découvert dans un contexte chronologique daté de la première moitié du $\mathrm{IV}^{\mathrm{e}}$ siècle apr. J.-C. (phase 4B).

L'oiseau présente deux pattes jointives formant le départ d'une longue tige dont les ergots sont confondus et disposés sur une protubérance. En dessous se développe la tige de section ovale dont l'extrémité n'est pas conservée. Les ailes sont légèrement détachées du corps qui est stylisé en forme de croissant. La queue est généreusement développée. La surface originelle a disparu et les seuls témoignages conservés du plumage sont matérialisés par le collier en relief au niveau du cou de l'oiseau et les nombreuses irrégularités de surface qui attestent la présence d'un traitement du plumage sur l'ensemble du corps du gallinacé. La tête est brisée et seul le vestige du début du relief de la caroncule est conservé sur une face (fig. 192).

De nombreuses représentations de coq sont attestées dans la statuaire en bronze gallo-romaine (FaiderFeytmans 1957, nos 168 à 178 ; Rolland 1965, n ${ }^{\text {os }} 278$ et 278 bis ; Boucher 1971, 107, no 79 ; Boucher, Tassinari 1976, 96-97, n 97 ; Oggiano-Bitar 1984, ${ }^{\text {os }} 298$ et 299 ; Feugère 2001) et témoignent de l'importance du culte à Mercure (Faider-Feytmans 1979, n 31). Dans le département du Var, on connaît un exemplaire de figurine de coq en plomb retrouvé lors des fouilles de Besagne-Dutasta à Toulon en 1985 (inédit). Attribut privilégié du dieu au caducée, le roi de la basse-cour peut également « être associé à Esculape, dont il est la victime sacrificielle par excellence et il figure également parmi les animaux associés aux lares domestiques » (Santrot et al. 1996, 274).

Le type d'épingle en bronze à tête zoomorphe (Lerat 1962, 524, fig. 14 et 15) est connu durant toute l'époque romaine. Cependant, malgré la rareté des représentations de coq, on pourra signaler quelques 

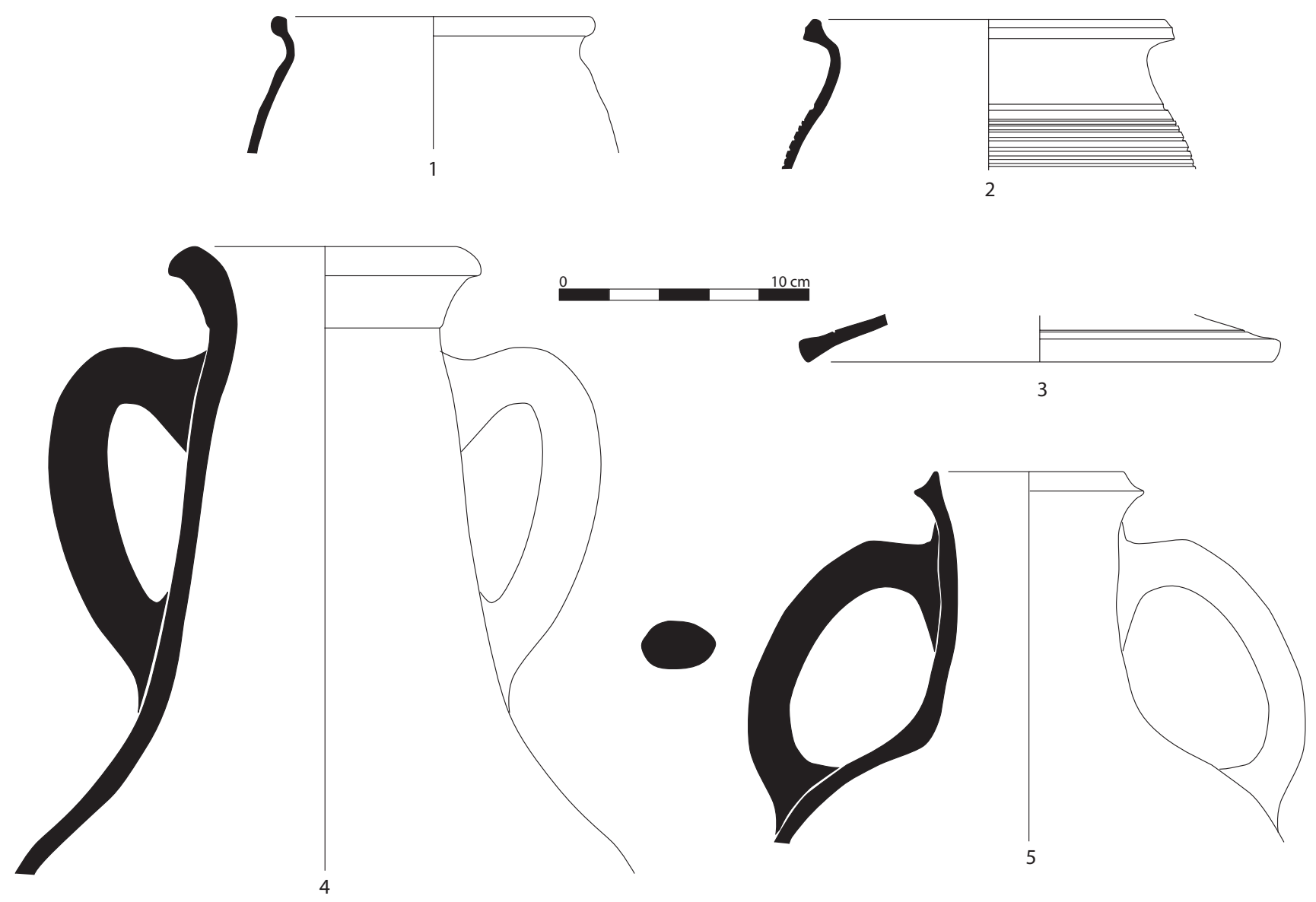

Fig. 191. Matériel céramique de la phase 4B.

comparaisons, malheureusement non datées, avec l'exemplaire de Fréjus à Autun (Autun-Augustodunum 1987, 201, n 381-f), Rennes (Labaune-Jean 2009, 31) ou encore Mercin-et-Vaux (Aisne) (Pichon 2002, 306).

Afin d'apporter des indices mieux documentés, notamment en ce qui concerne la datation, il convient de se rapprocher des études réalisées sur les épingles en os travaillé à têtes zoomorphes. Ainsi, certaines épingles en os de type Béal A.XX, 9 et A.XX, 1 peuvent
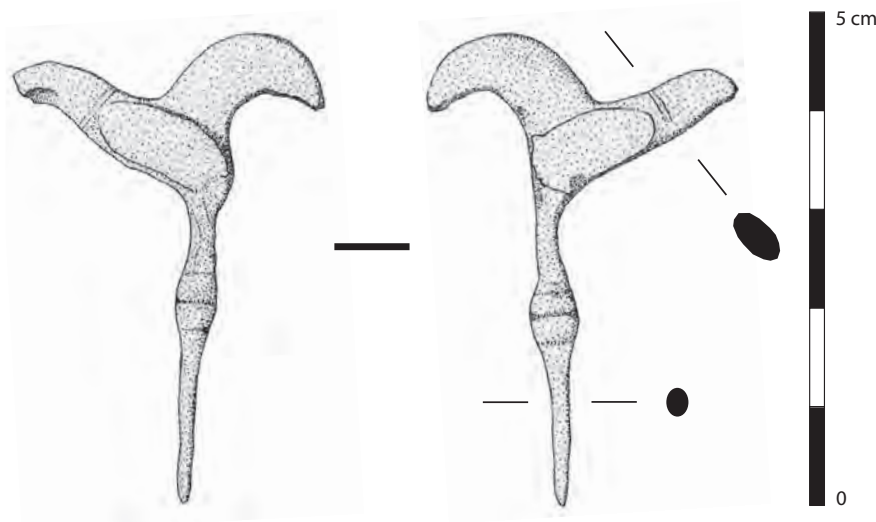

Fig. 192. Épingle à cheveux à tête zoomorphe. présenter des têtes sculptées en forme d'oiseaux. On retrouve ce type d'objet en Gaule : Nîmes (Béal 1984, $\mathrm{n}^{\circ}$ 242), Vienne (Cat. Dijon 1978, $\mathrm{n}^{\circ}$ 326), Lyon (Béal $1983, n^{\circ} 741$ ) ou encore Rouen (Rouen 1982, $n^{\circ} 107$ ) mais également à travers l'Empire romain : en Bretagne (Portchester Castle : Cunliffe 1975, $\mathrm{n}^{\circ}$ 97), en Germanie (Mayence : Lindenschmidt 1889, pl. XVIII, $\mathrm{n}^{\circ} 29$ ) ou encore en Pannonie (Biró 2003, fig. 8-9 ; 2005, 204). La très grande majorité de ces épingles est datée du $\mathrm{IV}^{\mathrm{e}}$ siècle apr. J.-C. et correspond très exactement au contexte de découverte de l'exemplaire de Fréjus.

Cette analogie entre les épingles en bronze et en os travaillé tend à montrer que la représentation de volatiles, quelle que soit l'espèce représentée, est caractéristique du IVe siècle apr. J.-C.

\subsubsection{La faune}

(M. L.)

Les niveaux du Bas-Empire ont livré un plus grand nombre de restes osseux (73 fragments identifiés). Parmi ceux-ci, les restes de bovins forment l'ensemble le plus important : 49,3\% du nombre total de restes 


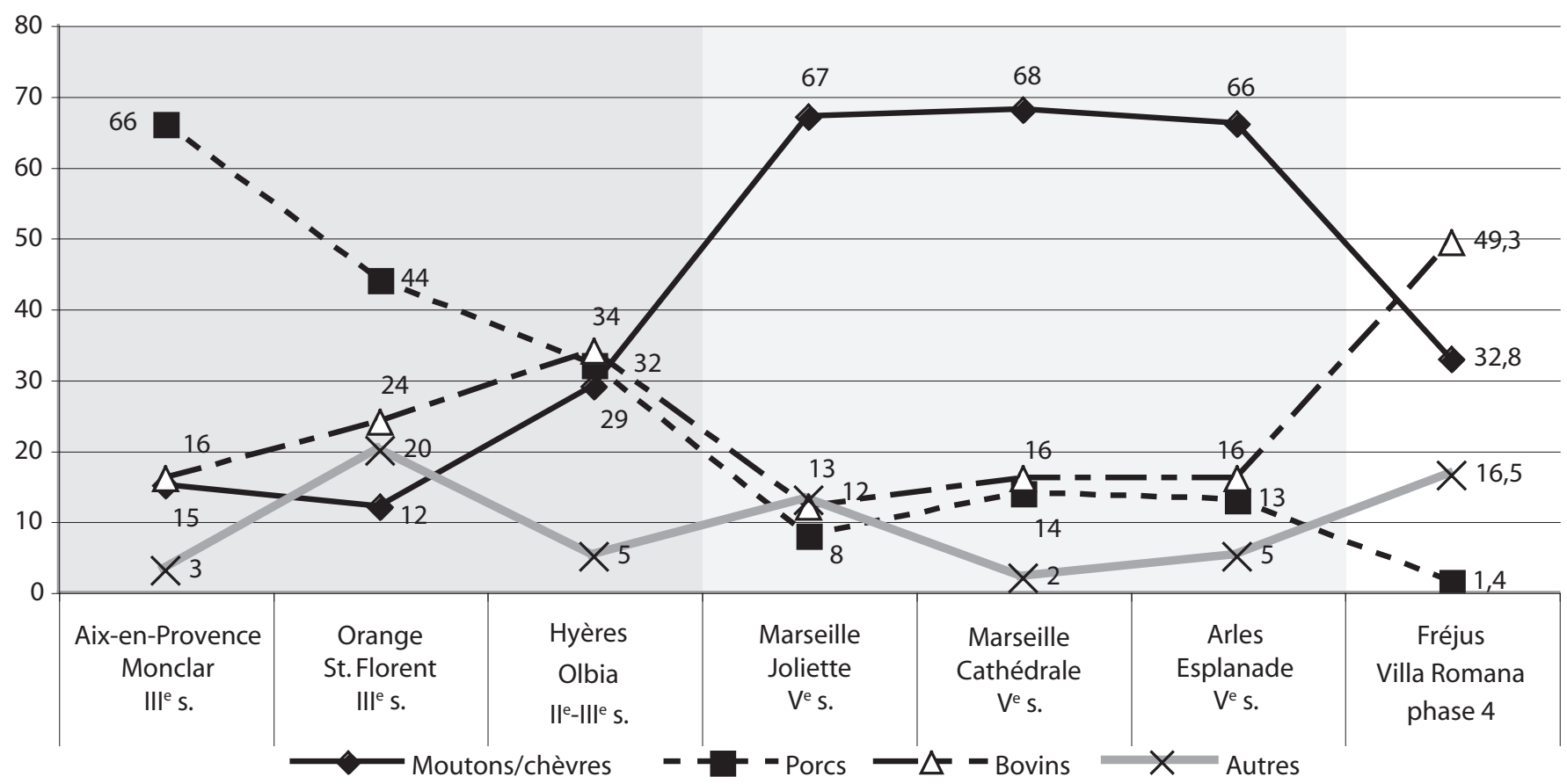

Fig. 193. Comparaison de différents sites urbains de la même période.

déterminés pour les états A et B de la phase 4 (fig. 193). L'âge d'une dizaine individus a pu être établi : la majorité était adulte (sept animaux de plus de 4 ans), seul un petit nombre de jeunes a été identifié (trois individus de moins de 3 ans). Les restes de petits ruminants et de porcs sont en diminution par rapport à la phase 3, les fragments d'ovins/caprins ne représentent qu'un tiers du mobilier (32,8 \% du NRD), mais la plus forte baisse concerne les os de porcs qui ne comptent que $1,4 \%$ des fragments osseux déterminés.

Les mesures ostéométriques sont rares, trois mesures de tailles de bovins ont cependant été relevées en fonction des critères établis par A. von Den Driesch (1976) : deux vaches mesurant respectivement 125 et $130 \mathrm{~cm}^{12}$ et un taureau mesurant $136 \mathrm{~cm}$ au garrot ${ }^{13}$. Ces tailles entrent dans la moyenne des animaux évoluant sur les sites urbains du sud de Narbonnaise aux périodes du Bas-Empire (Forest, Rodet-Belarbi 1998). Les proportions de restes par espèces contrastent avec celles des contextes urbains similaires de la province. Dans les villes comme Aix-en-Provence ou Orange, les mobiliers présents dans les dépotoirs urbains contiennent une forte proportion de restes de porcs. Sur le site aixois de Monclar $^{14}$, ils représentent plus de la moitié du

12 Ostéométrie : $1^{\text {er }}$ radius GL : 301, Bp : 90, BFp : 82, $\mathrm{SD}: 45, \mathrm{Bd}: 79 / 2^{\mathrm{e}}$ radius GL : 290, Bp : 83,5, BFp : 77,6, $\mathrm{SD}: 43,2, \mathrm{Bd}: 74,5, \mathrm{BFd}: 69,5$.

13 Ostéométrie : métatarse GL : 227, Bp : 51, SD : 29,1, Bd : 59.

14 Étude à paraître dans Claude (S.), Nin (N.) (dir.) : Les fouilles archéologiques du Palais Monclar (1992-1996). mobilier osseux (66\% des restes), alors que les bovins $(16 \%$ des restes) et les petits ruminants $(15 \%)$ sont en faible quantité. À Orange, plusieurs habitations dans la ville antique ${ }^{15}$ ont livré du matériel du $\mathrm{III}^{\mathrm{e}}$ siècle : les ossements bovins représentent une part non négligeable de celui-ci. Dans le quartier de Pourtoules, ils sont aussi nombreux que les os de porcs $(25 \%$ pour les restes de porcs, $22 \%$ pour les restes de bovins), seul le mobilier provenant du site de Saint-Florent, présente un déséquilibre dans les proportions de restes porcins et bovins, mais ces derniers représentent malgré tout un quart du matériel osseux (respectivement $44 \%$ et $24 \%$ du NRD). Dans ces lots de faune issus des deux sites d'Orange, les ossements d'ovins et de caprins ne sont qu'une faible partie du mobilier (17\% et $12 \%$ du NRD). Sur le site d'Olbia-de-Provence (Hyères, Var), entre le Ire et le $\mathrm{III}^{\mathrm{e}}$ siècle apr. J.-C., les restes de bovins augmentent progressivement tandis que les ossements de porcs diminuent. En termes de pourcentages de nombre de restes, ces deux espèces se retrouvent à égalité au Bas-Empire, $32 \%$ pour les os de porcs, $34 \%$ pour les os de bovins et $29 \%$ pour les moutons $/$ chèvres $^{16}$. Sur de nombreux sites urbains, la quantité des ossements d'ovins/caprins dans le matériel faunique n'augmente qu'après le Bas-Empire au détriment des restes de suidés en forte diminution. Le faible taux de fragments osseux de cette espèce dans les niveaux de la phase 4 ne trouve

15 Quartiers de Pourtoules et de Saint Florent d'Orange (Columeau 2002, 109).

16 Faune de la phase 4, l'îlot VI (Leguilloux 2006, fig. 1, 425). 
des parallèles sur d'autres sites urbains qu'à partir du $\mathrm{V}^{\mathrm{e}}$ siècle apr. J.-C.C'est le cas en particulier de plusieurs sites marseillais ${ }^{17}$ ainsi que des sites arlésiens ${ }^{18}$. Les niveaux de l'Antiquité Tardive dans ces deux grandes villes présentent des taux élevés de restes d'ovins et de caprins, en moyenne $65 \%$ des ossements identifiés. Les caractéristiques du mobilier osseux de cette phase, à l'instar de ce qui avait été observé au cours de la phase précédente, ne trouvent de parallèles que dans le monde rural. De telle composition faunique, à savoir la forte présence d'ossements de moutons/chèvres dans le mobilier se rencontre dans les faunes des villae de la même période ${ }^{19}$.

Les exploitations agricoles toujours en activité dans la région pendant cette période de l'Antiquité livrent une faune marquée par d'importants restes osseux d'ovins/ caprins (un tiers du mobilier dans la plupart des cas) et de bovins (entre un tiers et la moitié du mobilier selon les cas) traduisant une activité pastorale fortement marquée par les petits ruminants et la multiplication des troupeaux de bovidés.

\subsection{Datation de la phase 4B}

\section{(P. E.)}

De l'étude du mobilier céramique il ressort que la phase 4B se met en place dans le courant du IV siècle apr. J.-C. La datation C14 effectuée sur un fragment de bois ${ }^{20}$ découvert dans le comblement de la fosse FS3220 (3222) permet d'envisager une mise en culture au moins jusqu'à la première moitié du Ve siècle apr. J.-C. ${ }^{21}$

\subsubsection{Interprétation}

\section{(L. B., P. E.)}

L'ensemble des analyses convergent pour définir ces creusements comme des fosses de plantations. Le milieu paraît également moins humide que lors de l'état

17 Ces proportions restent stables quelle que soit la localisation du site, en secteur urbanisé ou en zone portuaire (Jourdan 1977, Leguilloux 1995, Leguilloux 1998).

$1866 \%$ du NRD sur le site de l'Esplanade (Congès, Leguilloux 1991).

19 La villa du Quartier Régine à Puits-Ste-Réparade (Bouches-du-Rhône) (Chapon et al. 2007), Les Laurons aux Arcs-sur-Argens (Var) (Bérato, Borréani, Leguilloux 1990), St-Michel à La Garde (Var) (Columeau 1991) et Les Mesclans à La Crau (Var) (Leguilloux 1996-1997).

20 Vaucluse, Avignon, Musée Calvet - Rolland 1965, nos 278 et 278 bis ; Isère, Vienne - Boucher 1971, n 79, 107 ; Rhône, Décines-Charpieu Boucher, Tassinari 1976, 96-97, n 97 ; Aude, Moussan - Feugère 2001 ; Bouches-du-Rhône, Aix-en-Provence-Marseille - Oggiano-Bitar 1984, $\mathrm{n}^{\text {os }}$ 298-299 ; Belgique, Grobbendonk - Faider-Feytmans 1979, n $31 / 1$ Code Villeneuve : \#632, code labo : Poz-20287.

21 FR06 \#632 1570 $\pm 30 \mathrm{BP} / 68.2 \%$ probability / 430AD (68.2\%) 540AD / $95.4 \%$ probability / 420AD (95.4\%) 560AD. antérieur et le long fossé de ce même état semble déjà partiellement colmaté et donc hors d'usage.

La distinction entre l'influence de l'environnement local et les taxons provenant directement des espèces mises en terre dans les fosses permet de supposer un espace complanté. Des arbres cultivés étaient très probablement présents : des figuiers, de la vigne, mais aussi probablement des pins pignon, des pruniers et des saules. La vigne pouvait être conduite en taille basse mais également mariée aux arbres, notamment aux essences précédemment citées. Ce dernier type de culture pourrait être nettement illustré par la fosse FS3214. L'existence de cultures herbacées est également envisageable d'après la carpologie, en particulier la culture du fenouil et de la gourde calebasse. D'autres arbres et herbacées cultivés sont plus ponctuellement attestés (noyer, mûrier, noisetier, aneth, céréales, coriandre...) ; les éléments à l'appui d'une culture sur place sont de fait plus labiles. Un important cortège de mauvaises herbes ou plantes rudérales documenté par la carpologie va dans le sens d'une exploitation horticole de la parcelle. Toutefois, les informations dont nous disposons ne permettent pas de spécifier si cet usage est au maximum de son activité ou si le terrain connaît déjà un début d'abandon, les arbres fruitiers seraient alors dans un milieu en voie d'enfrichement. Un certain embroussaillement du milieu local est notamment illustré par l'étude malacologique qui met en lumière la présence de Monacha cantiana.

L'existence de cultures de surfaces intercalaires (maraîchage) peut être envisagée entre les cultures de vignes et autres fruitiers. Le comblement sombre, à dominante sablo-limoneuse, emplissant les fosses correspond probablement à un enrichissement du sol à base de fumier et d'apport d'engrais organique, comprenant des excréments et des matières animales et végétales en décomposition comme le laisse supposer la présence de nombreux coprophages et détritiphages.

La présence de nombreux ossements d'animaux, probables reliefs de repas, peut s'accorder aux prescriptions de nombreux auteurs comme le rappelle Pline (XVII, 2) : «Les autres auteurs s'accordent pour regarder comme le premier des engrais le résidu des repas humains. »Une fois comblées et plantées, les fosses présentaient encore une faible dépression.

La lecture d'une organisation spécifique au sein de l'ensemble de fosses n'est pas aisée. À l'exception de la fosse FS3139, toutes les autres se trouvent soit sur le tracé de l'ancien fossé FO3179, soit à son contact direct. De fait, elles suivent un alignement cohérent avec la phase précédente, sud-ouest/nord-est.

Dans le secteur A1, l'espacement entre les 8 fosses (de FS3195 à FS3246) varie de 2,50 $\mathrm{m}$ à $5 \mathrm{~m}$, avec une moyenne que l'on situe vers $3,80 \mathrm{~m}$. S'il ne ressort 
aucune véritable régularité métrologique, l'espacement entre les fosses laisse à l'évidence la place à des arbres pour se développer. Pline (XVII, 17) rappelle l'importance de cet espacement et donne comme seule valeur un minimum de neuf pieds. Il précise également que cet espacement varie en fonction de l'arbre planté, par exemple pour un figuier il doit être plus important que pour un grenadier... La nécessité de conduire au mieux les arbres afin de dégager des espaces non ombragés pour permettre le développement d'autres cultures comme celles des calebasses par exemple, est illustrée par la découverte de piquets obliques signifiant la présence d'un système de tuteur en « V » permettant le pallissage. Enfin, le choix d'espèces affectionnant les milieux humides (saules, frênes, figuiers, calebasses...) est manifeste.

L'apparence de l'exploitation que nous renvoient la fouille et les analyses botaniques, montre un lieu riche de nombreuses variétés, que celles-ci soient cultivées directement sur la parcelle fouillée ou à proximité. Cette image évoque de façon frappante le domaine idéal décrit par Caton (1) : «Si vous me demandez quel est le meilleur domaine, je vous répondrai : sur un domaine de cent arpents, et bien situé, la vigne est la meilleure récolte, si elle est productive ; je place ensuite un potager arrosable ; au troisième rang une oseraie, en quatrième l'olivier ; en cinquième une prairie ; en sixième, les céréales, en septième un taillis ; puis un verger, et enfin un forêt de chênes. » On notera que sur les deux époques d'exploitation, l'essentiel de ces cultures est attesté.

\section{La phase 4, état $C$}

\subsection{Description}

(P. E.)

L'état C correspond à l'abandon de la zone cultivée (zone 3) qui se matérialise par le comblement définitif des hauts de fosses de plantation et le dépôt d'un niveau sablo-limoneux gris recouvrant le fond de la bande anciennement en culture (3164B, 3025, 3035, 3060).

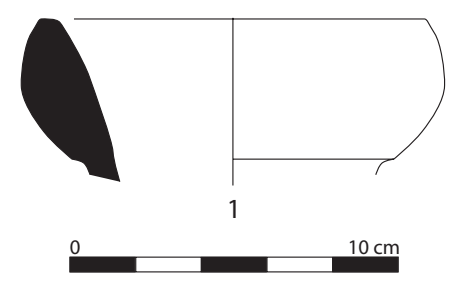

Fig. 194. Matériel céramique de la phase 4C.
Cette couche est comprise entre les deux murs MR3040 et 3042 et recouvre leur arase.

Son épaisseur est variable et sa texture est très hétérogène, elle peut paraître très limoneuse et compacte par endroit, ou bien beaucoup plus sableuse et meuble. L'origine de ce dépôt paraît être une sédimentation naturelle d'origine fluviatile issue des crues du Reyran.

\subsection{Le mobilier céramique}

(E. P.)

L'ensemble du mobilier mis au jour est résiduel. La pièce la plus tardive est le bord d'une amphore africaine 2C (fig. 194) dont les exemplaires les plus récents datent du IVe siècle apr. J.-C. (Bonifay 2004, 114).

\subsection{Datation \\ (P. E.)}

L'abandon de la parcelle cultivée doit être situé dans le courant du Ve siècle apr. J.-C. Les niveaux de recouvrement ne sont composés que de matériel résiduel et l'absence de mobilier de l'Antiquité tardive et du Moyen Âge paraît indiquer un abandon assez rapide et généralisé de la zone.

\section{Conclusion générale de la phase 4}

(P. E.)

Les traces d'occupation remontant à ces périodes ont été jusque là très ténues dans le quartier de Villeneuve. Jusqu'alors elles étaient surtout représentées par des inhumations ${ }^{22}$. À $200 \mathrm{~m}$ au sud du mausolée de la Tourrache, une tombe en bâtière isolée mentionnée par P.-A. Février en 1950 pourrait, selon L. Rivet (Rivet et al. 2000, 344) dater de l'Antiquité tardive. Les deux tombes, de même type, découvertes à l'occasion du diagnostic archéologique dans la partie nord du terrain (Michel 1999, 14), n'ont malheureusement pas été datées, mais pourraient probablement remonter à l'Antiquité tardive. À Villa Romana, une calotte crânienne découverte dans le fond d'un grand fossé de l'époque moderne dans la partie sud du site (FO3081, US3137) atteste également qu'une zone de nécropole existait anciennement à proximité.

22 Une zone funéraire s'étendait entre le quartier Villeneuve et le Clos Saint-Antoine dès le Ir siècle apr. J.-C., comme en témoigne le Mausolée de la Tourache ou encore le fragment d'inscription découvert par J.-F. Girardin à Villeneuve, daté antérieurement au règne de Claude (Gascou, Janon 1985, $\mathrm{n}^{\text {os }}$ 16-51-52. Le fragment de pulvinus d'autel funéraire découvert dans le puits PT2003 édifié à l'époque moderne (voi infra p. 170-171) remonte à la même période et pourrait donc provenir de ce même secteur. 
Également, lors d'un diagnostic archéologique réalisé sur la parcelle située immédiatement au sud de la rue Jean-Carrara, une sépulture bouleversée a été observée, sans datation précise ${ }^{23}$. Enfin, lors du diagnostic réalisé sur les thermes de Villeneuve (Excoffon, Ardisson 2008, 35-36) une tombe bâtie en briques bipédales (SP4010) a été découverte le long du mur de clôture MR4012. Repérée dans la nappe phréatique, elle n'a pas été fouillée et sa datation reste discutable, mais nous avons malgré tout proposé de dater cette tombe de la fin de l'Antiquité.

Bien qu'aucune trace de réoccupation pour ces périodes n'ait jamais été découverte dans les bâtiments thermaux, le fait qu'ils soient restés en élévation jusqu'à nos jours laisse supposer qu'ils aient pu être utilisés et réaménagés durant cette même époque. La découverte de céramiques tardives, dont un pot liguro-provençal dans les sondages réalisés récemment dans le bâtiment (Excoffon, Ardisson 2008) constitue un argument supplémentaire pour envisager l'utilisation de ce bâtiment encore durant la phase 4B de Villa Romana.

Plus au nord, dans le quartier des Aiguières, une « fréquentation » est attestée jusqu'au IVe siècle apr. J.-C. sur les décombres d'un monument antique, où 297 monnaies constantiniennes ont été découvertes (Goudineau, Brentchaloff 2009, 24-25 et 59-60).

Cette réoccupation est qualifiée de campement et d'abri provisoire, bien que la découverte du numéraire pousse les auteurs à relativiser ce caractère temporaire.

Cette zone ne se trouve qu'à un peu plus de $200 \mathrm{~m}$ des thermes de Villeneuve. L'ensemble de ces découvertes et la mise en évidence de terres agricoles sur le site de Villeneuve montrent un aspect bien différent de ce quartier que l'on disait relativement déserté après la fin du II ${ }^{\mathrm{e}}$ siècle apr. J.-C. Bien sûr, quoique contemporaines, ces diverses découvertes éparses ne relèvent peut-être pas d'un même ensemble mais montrent tout de même que le secteur reste occupé et actif au moins jusqu'au début du Ve siècle apr. J.-C.

L'existence d'une zone agricole au-delà des remparts de la ville à partir du $\mathrm{III}^{\mathrm{e}}$ siècle et jusqu'au $\mathrm{V}^{\mathrm{e}}$ siècle apr. J.-C. est un phénomène qui jusque là n'avait jamais été mis en évidence. En effet, au $\mathrm{III}^{\mathrm{e}}$ siècle apr. J.-C., Fréjus, comme le reste de la Provence, a connu une période de mutation. Dans la ville, de nombreux secteurs sont abandonnés et l'occupation paraît se disséminer au sein de la ville antique. Les découvertes récentes tendent à donner une image plus contrastée de l'occupation et révèlent une cartographie en « peau de léopard » pour les $\mathrm{IV}^{\mathrm{e}}$ et $\mathrm{V}^{\mathrm{e}}$ siècles apr. J.-C. (Excoffon 2010c).

Les découvertes de Villeneuve montrent que si l'occupation en ville tend à se relâcher, l'exploitation des champs directement au contact de la cité n'est absolument pas délaissée. Mais il serait trop optimiste d'employer un tel argument pour atténuer les stigmates d'une crise qui paraît pourtant bien réelle. En effet, ce phénomène pourrait y être directement lié, comme l'effet d'une pression comprimant une espace beaucoup plus vaste que le seul périmètre urbain de Fréjus. Ainsi, si l'on considère le quartier suburbain de Villeneuve comme tel jusqu'à la fin du $\mathrm{II}^{\mathrm{e}}$ siècle apr. J.-C., cela suppose nécessairement que les champs exploités par la ville se trouvent au-delà de cette limite. Le fait que cette zone se transforme en espace agricole au III siècle apr. J.-C., montre finalement un phénomène de repli. L'espace urbain diminue et les zones de cultures se resserrent autour d'un noyau réduit.

Quoiqu'il en soit, les données sur l'exploitation agricole autour de Fréjus sont archéologiquement bien trop faibles aujourd'hui pour privilégier un modèle, qu'il soit à tendance expansive ou régressive. 



\section{Chapitre 5}

\section{L'époque moderne}

Entre la fin de l'activité agricole, phase 4B/C datable du milieu du Ve siècle apr. J.-C., et la reprise d'une installation au début de l'époque moderne, aucune trace d'occupation ni même de fréquentation n'a été perçue sur le site, qui paraît totalement abandonné durant près d'un millénaire. La découverte d'un fragment de bol à la croix en céramique pisane caractéristique du XIV siècle (Amouric et al. 1999, 30) ne peut à elle seule indiquer une reprise de l'activité sur le site durant le bas Moyen Âge. Cette reprise à l'époque moderne se caractérise par la récupération des matériaux de construction, issus des murs antiques et la mise en culture de l'espace.

\section{La phase 5, état $A$}

\subsection{Zones 1 et 2}

\subsubsection{Description}

(P. E.)

C'est sur un épais remblai, d'une épaisseur moyenne de $30 \mathrm{~cm}$ et à dominante sablo-limoneuse brun clair (US1007), recouvrant l'ensemble des niveaux antérieurs, que se développe l'occupation à caractère agricole de la phase 5A(fig. 195). Celle-ci a été seulement mise en évidence dans la zone 1 , où les deux murs antiques MR1003 et MR2004 continuent de structurer l'espace. On est d'ailleurs frappé par la continuité et la préservation d'orientations communes depuis l'époque romaine jusqu'à la période moderne, qui structurent profondément et durablement l'ensemble du quartier (fig. 196). L'observation du parcellaire fossile par Ch. Gébara et G. Chouquer dans le quartier de Villeneuve montre l'existence d' « une morphologie particulièrement régulière qui surprend, d'autant plus qu'elle respecte deux des orientations présumées antiques » (Gébara, Chouquer 1996, 97). Sur ce point, il est intéressant de reprendre les constatations des auteurs : «La question se pose, de toutes façons, de savoir dans quelles conditions il a pu y avoir influence des orientations antiques sur ces nouveaux parcellaires, quelle que soit leur date (...) Il faut sans doute admettre que le paysage conservait des éléments morphologénétiques susceptibles d'être repris et prolongés, même à une époque où l'on avait complètement oublié le souvenir des parcellaires romains » (ibid., 98). À l'évidence, un élément de réponse nous est fourni par la présence de longs murs bâtis lors des phases 2 (MR2004), 3 (MR1003, MR2002 et MR3082) et 4 (MR3040 et MR3042) qui sont très probablement, au moins en partie, responsables de cette préservation (fig. 197).

Ce constat montre combien il convient de rester prudent sur l'attribution, à une époque donnée, de vestiges reprenant une orientation rattachable à un réseau pourtant bien antique, mais relevant en réalité d'une action plus récente...

\subsubsection{Les traces agraires}

(P. E.)

Des traces agraires ont été découvertes pour cette période, essentiellement dans le quart nord-est de la fouille. Ces traces recouvraient probablement l'ensemble de la zone 1, mais le temps limité de la fouille nous a incités à ne les étudier en détail que sur une petite surface réservée, d'une trentaine de mètres carrés (fig. 198).

Il s'agit de quatre tranchées ou sillons de culture (TR1008, 1011, 1036, 1015) mesurant entre 0,60 et $0,70 \mathrm{~m}$ de large et visibles sur environ $6 \mathrm{~m}$ de long. L'espacement entre les trois premières est constant, environ $0,30 \mathrm{~m}$, la quatrième est distante de plus de $1 \mathrm{~m}$, peut-être pour ménager un passage. Les comblements sont tous constitués d'une terre sablo-limoneuse brun jaune, compacte à très compacte, et comprennent des cailloutis et quelques tessons de céramique (fig. 199). Plusieurs fosses sont contemporaines de ces tranchées, à l'image de FS1079, de forme ovale de $40 \mathrm{~cm} \times 80 \mathrm{~cm}$ et comblée d'un apport sablo-limoneux (1072). À la même époque sont construits, à l'aplomb du mur antique MR2004, dans la zone 2, deux puits : PT2003 et PT2031. 
PREMIÈRE PARTIE : LA FOUILLE

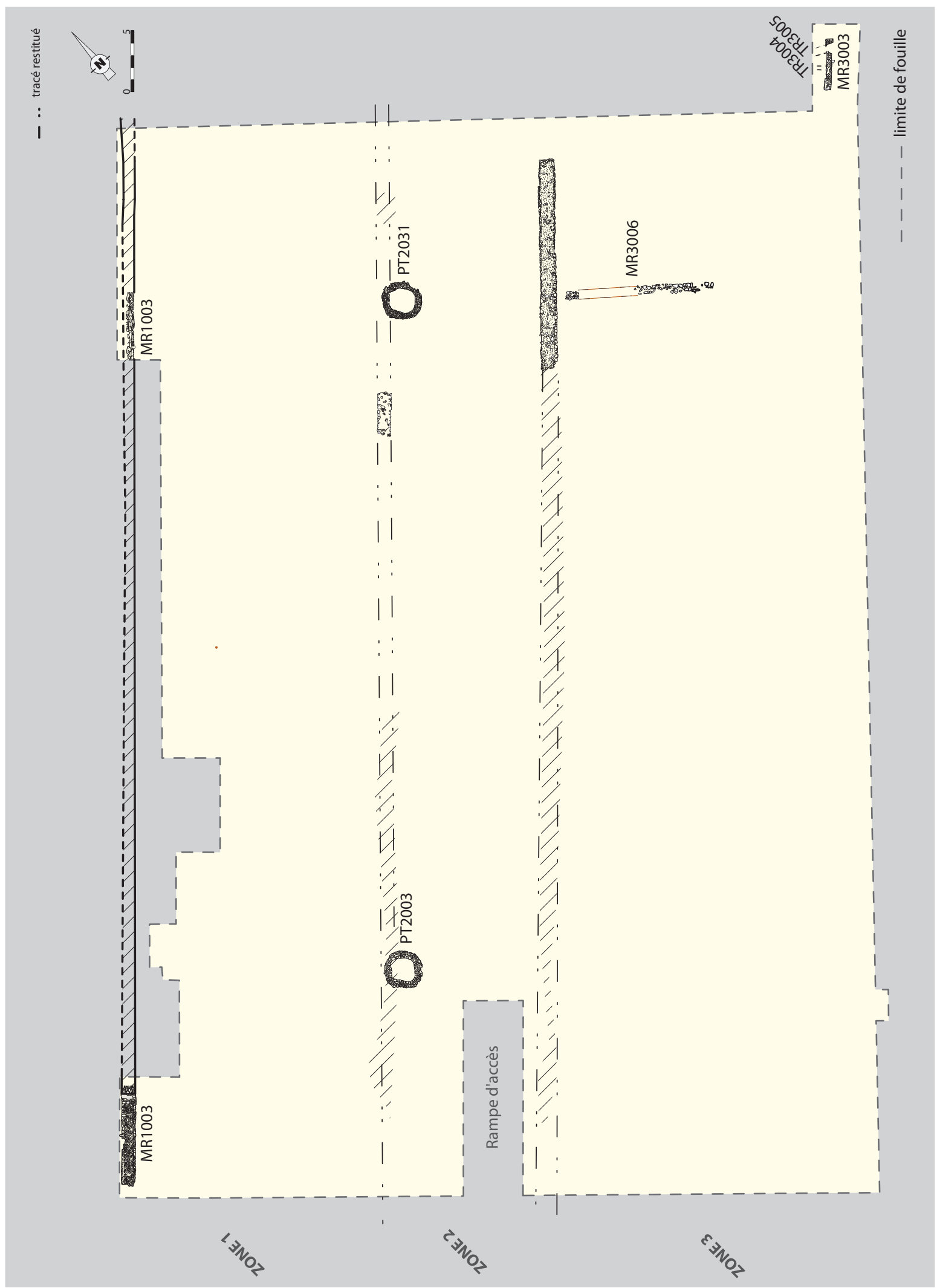

Fig. 195. Plan d'ensemble des vestiges de la phase 5A. 


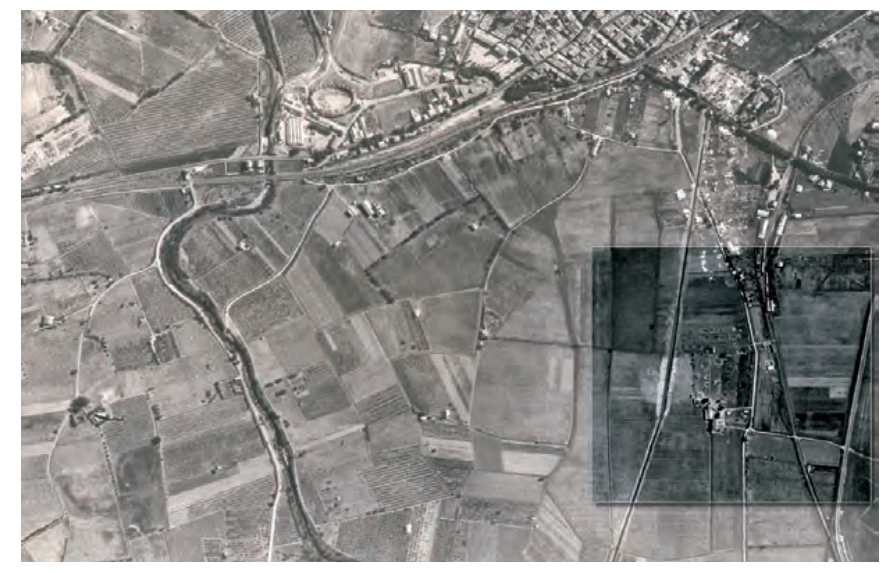

Fig. 196. Vue aérienne de Villeneuve, où l'on observe la morphologie régulière du parcellaire (photothèque $\mathrm{CCJ}$ ).

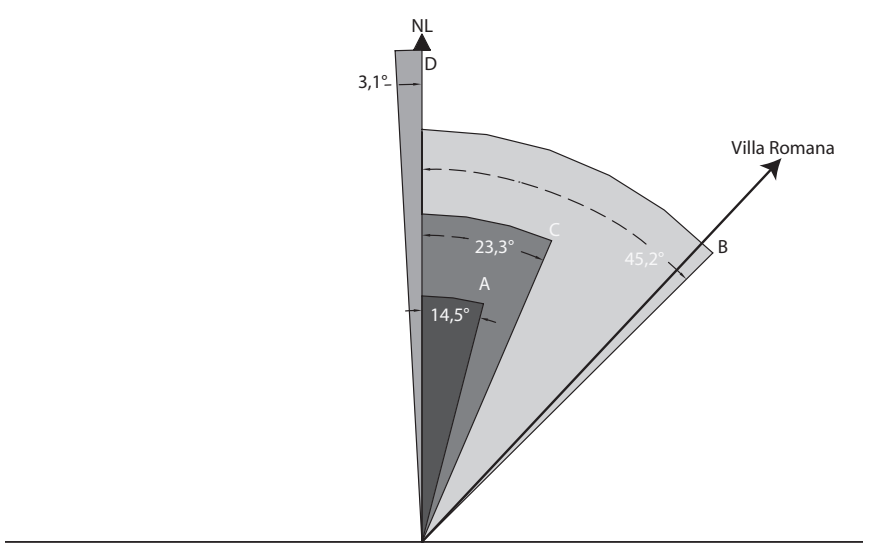

Fig. 197. Les quatre orientations supposées antiques d'après photo-interprétation (Gébara, Chouquer 1996) et orientation de Villa Romana.

\subsubsection{Les puits de la zone 2}

\subsubsection{Description du mode de construction (P. E., S. Gr, F. G.)}

Il s'agit de deux puits construits de façon similaire, mais tous deux ne sont conservés qu'en dessous de leur margelle ; ainsi, seul leur cuvelage a pu être observé (fig. 200 et 201). Les deux puits forment des cercles comprimés en raison de leur mode de construction. Ils ont un diamètre approximatif de $2 \mathrm{~m}$ et sont conservés sur environ 1,50 $\mathrm{m}$. Le cuvelage, en pierre de récupération pour l'essentiel, est large de $0,60 \mathrm{~m}$ (fig. 202).

Dans le cuvelage du puits PT2031 (US2031/2038) est remployé un fragment de meule rotative en rhyolite. Il s'agit d'un fragment de la partie tournante, le catillus,

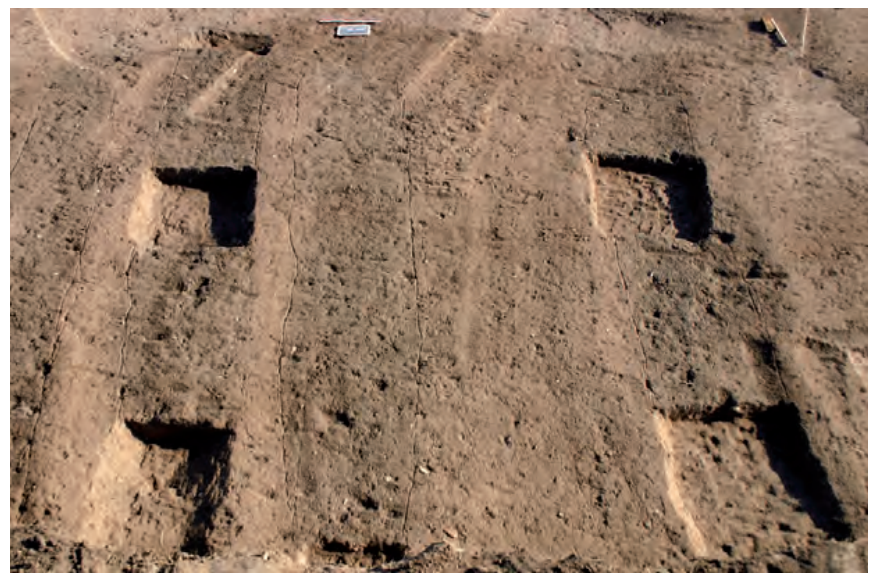

Fig. 198. Quatre sillons, ou tranchées, de culture ont été mis en évidence.
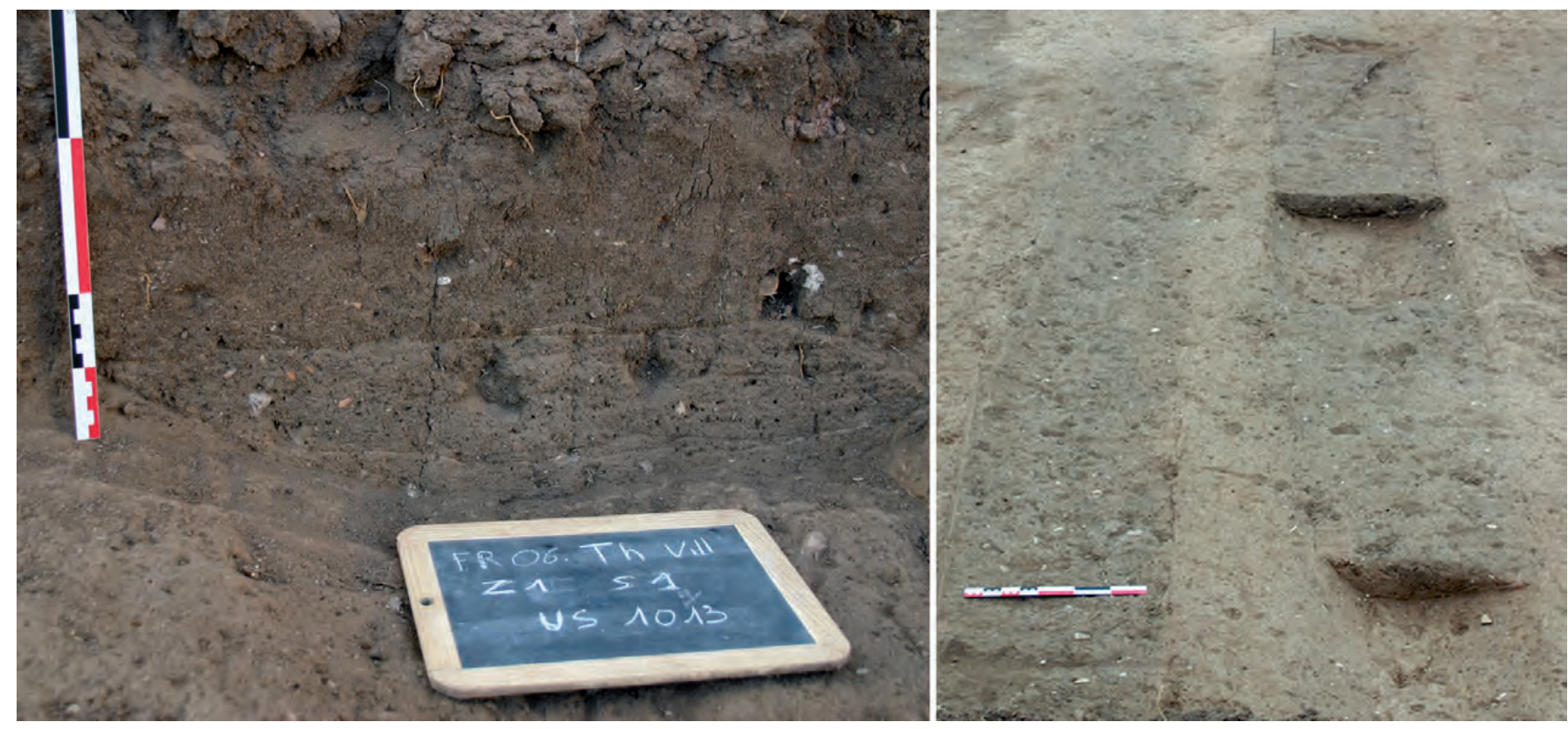

Fig. 199. Les tranchées en cours de dégagement et l'aspect de leur comblement (vue en coupe). 
sur lequel est creusé le logement circulaire du manche permettant d'activer la meule (fig. 203). S'y trouvait aussi un fragment d'une inscription lapidaire sur marbre, dont seule la lettre « $\mathrm{M}$ » et un point triangulaire sont conservés. Cette plaque fut déjà remployée une première fois durant l'Antiquité, comme placage en marbre mouluré (fig. 204).

Le cuvelage de PT2003 (US2003) a livré deux éléments de placage en marbre blanc à grain fin, ainsi qu'un fragment en grès à profil courbe d'un pulvinus d'autel funéraire ( $c f$. fig. 210 et 211).

Les parois du cuvelage ont été montées sur des fondations faites d'une sablière basse (fig. 205, 206 et 207), constituée par un ensemble de quatre fûts en

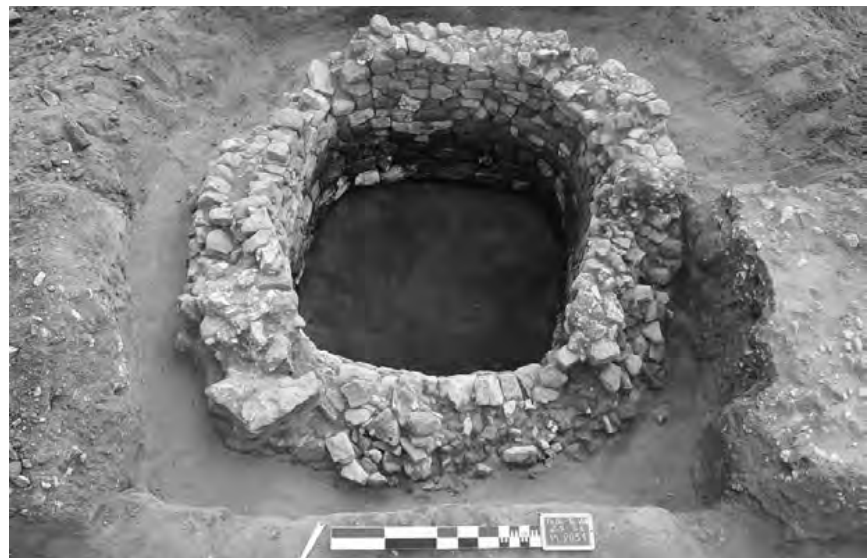

Fig. 200. Le puits PT2031.
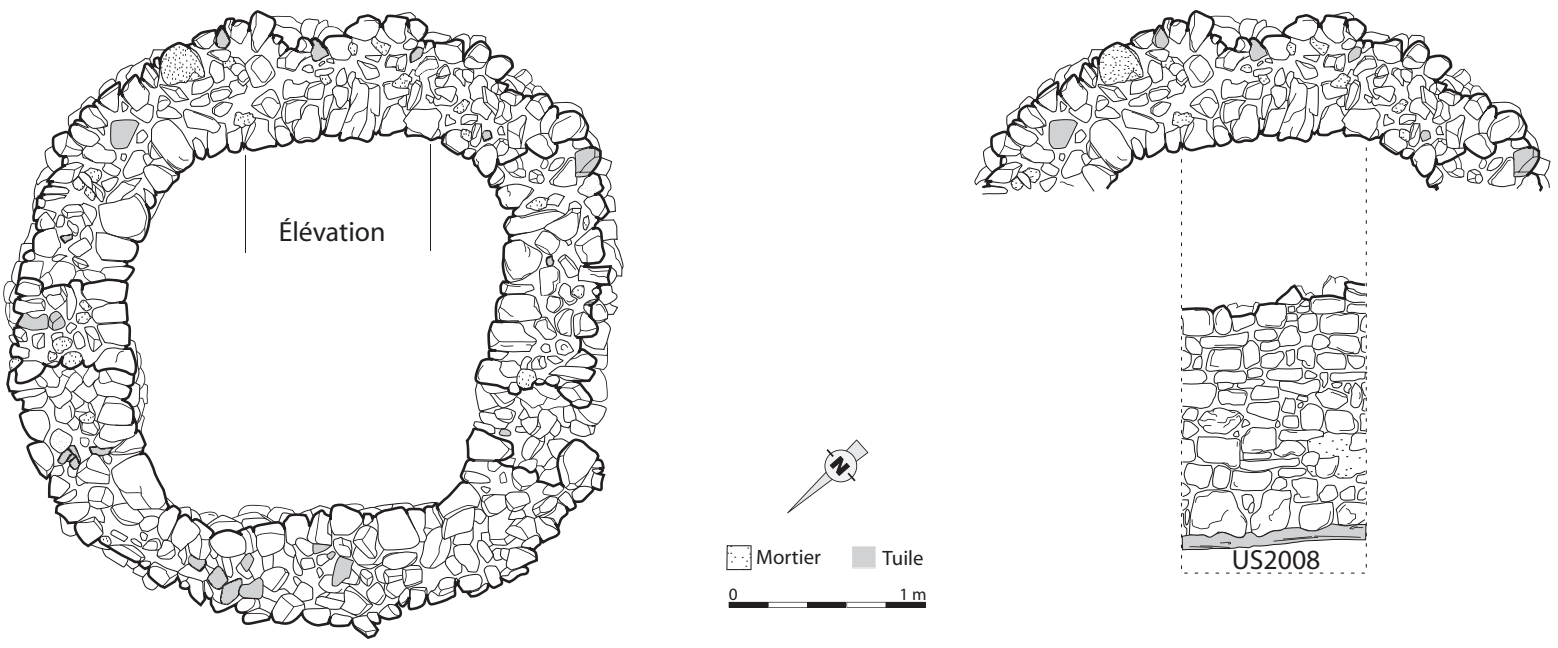

Fig. 201. Relevé et section de l'élévation du cuvelage du puits PT2003.

bois. Ces fûts, d'une longueur moyenne de 2,60 m (de 2,35 à 2,96 $\mathrm{m}$ ) pour un diamètre maximal moyen de $13,25 \mathrm{~cm}$ (de 12 à $15 \mathrm{~cm}$ ) (fig. 208), sont disposés de manière à former un quadrilatère plus ou moins arrondi, leurs extrémités se croisant perpendiculairement et se chevauchant deux par deux. Encochés, ils sont assemblés à mi-bois et chevillés, à raison d'une cheville par assemblage insérée verticalement.

Plusieurs traces d'outils ont été relevées à la surface du bois. Ainsi, l'extrémité la plus épaisse des fûts, correspondant à la base des troncs, présentait des traces d'abattage à la hache, formées par deux biseaux opposés et sculptés par de larges arrêtes crantées. Les traces d'un équarrissage plus ou moins régulier se distinguaient sur les faces longitudinales inférieures et supérieures, formées de cupules débitées à l'aide d'une herminette à tranchant droit. Les encoches, réalisées aux extrémités de chaque fût et destinées à l'assemblage à mi-bois, profondes d'environ $3 \mathrm{~cm}$, ont été confectionnées à la scie et à l'herminette. Les chevilles, longues d'environ $15 \mathrm{~cm}$ et d'un diamètre de 2 à $3 \mathrm{~cm}$, ont été taillées,

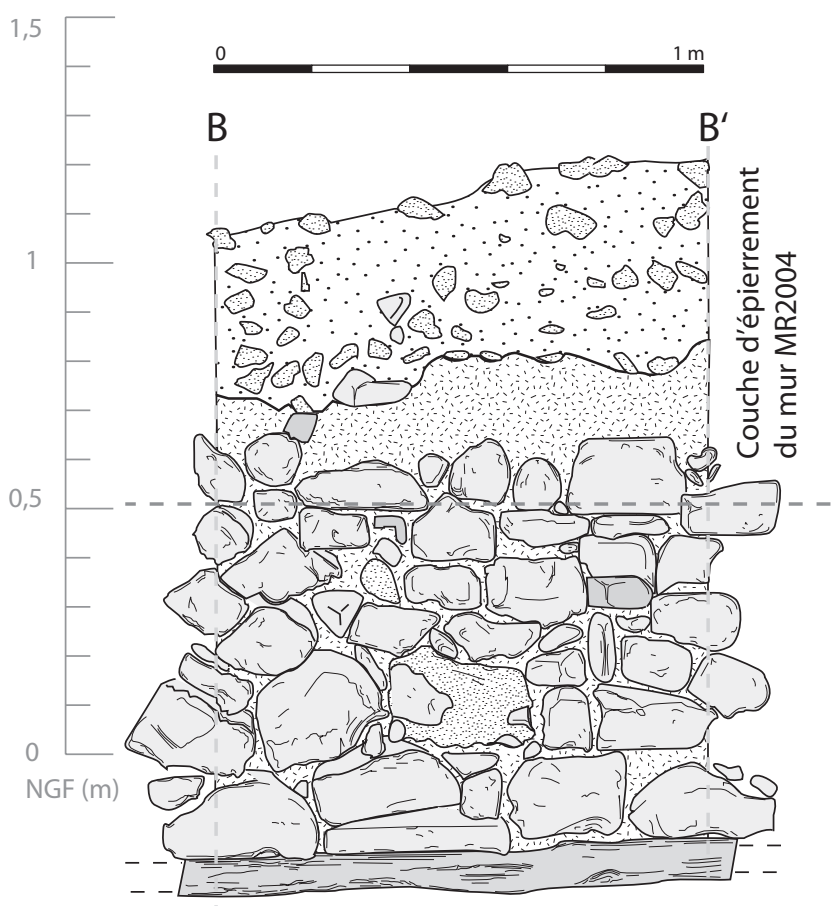

Fig. 202. Relevé et section de l'élévation du cuvelage du puits PT2031. 


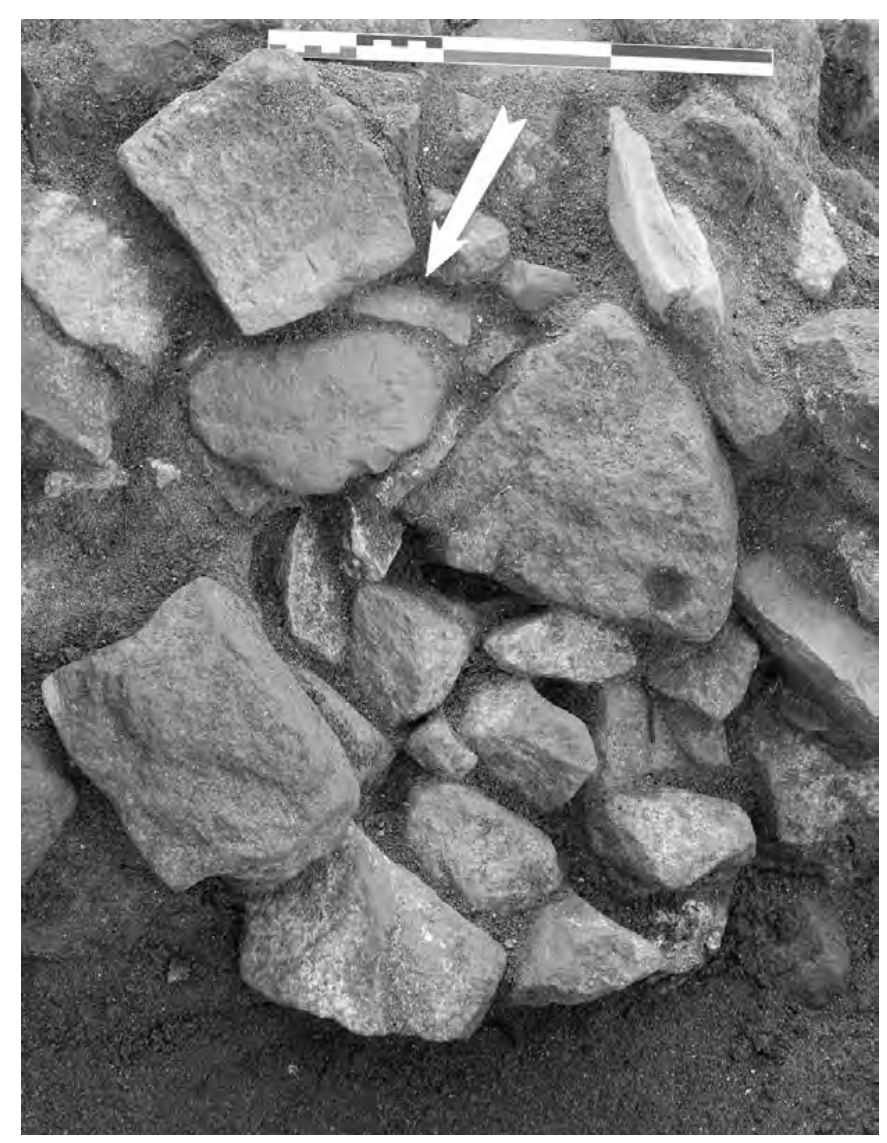

Fig. 203. Dans le cuvelage de MR2031 est remployé un fragment de meule rotative en rhyolite.

une fois insérées, pour s'ajuster à la hauteur des deux pièces assemblées ${ }^{1}$.

L'analyse dendrologique menée sur les bois du PT2003 révèle que les constructeurs ont eu recours à de jeunes pins d'Alep (Pinus halepensis/brutia) ${ }^{2}$ encore pourvus de leur écorce fine. Cette essence ligneuse, d'origine régionale et locale (Quézel, Médail 2003), sans doute extraite à proximité immédiate du site, présente un tronc tortueux caractéristique (Lieutaghi 2004 et Rameau et al. 1989) que l'on distingue nettement dans la forme arrondie des fûts. À ce caractère naturel, s'ajoute la présence de traces de compression observées sur ces fûts, qui affecte l'anatomie des troncs et des branches soumis à des conditions de gravité différentes d'une face à l'autre.

L'analyse dendrochronologique menée sur ces quatre pièces a conduit à une chronologie moyenne longue de

1 L'essence résineuse identifiée à l'œil nu semble être semblable à celle des fûts, le bois étant de même couleur et présentant les mêmes caractères anatomiques macroscopiquement distincts.

2 Le type anatomique Pinus halepensis/brutia regroupe 2 taxons indissociables anatomiquement (Schweingruber 1990) mais l'origine lointaine du pin brutia (Méditerrannée orientale) nous autorise à dire qu'il s'agit, ici, de pin d'Alep.
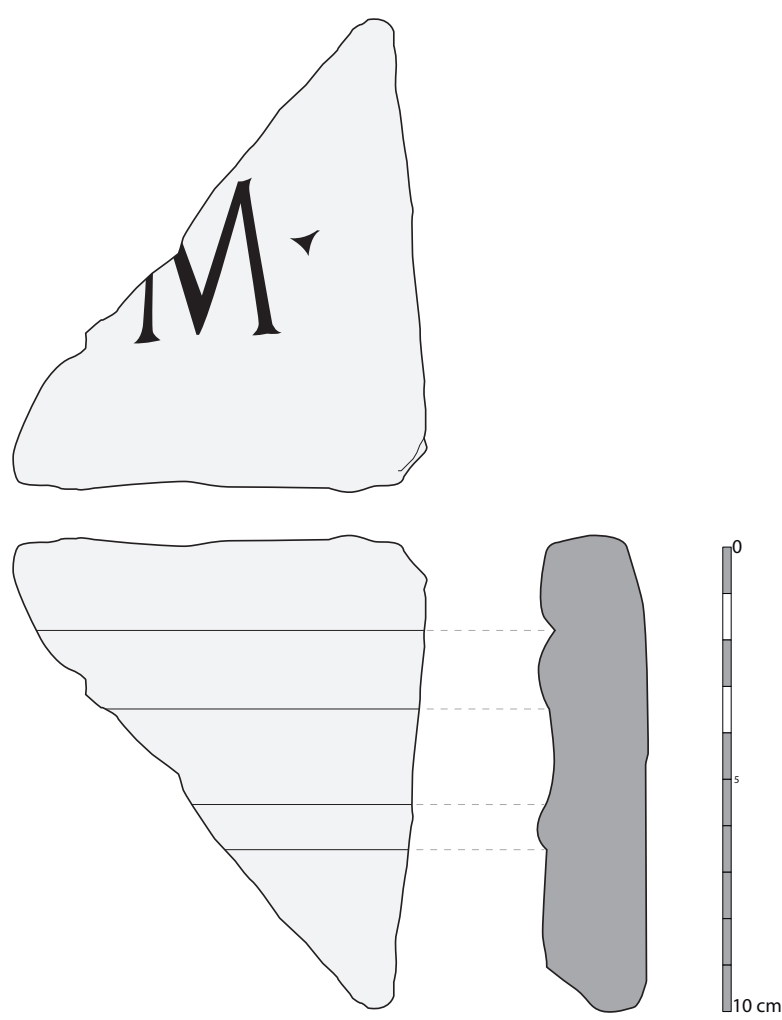

Fig. 204. Fragment d'angle de placage

en marbre mouluré, remployé dans une inscription lapidaire.

35 ans, obtenue essentiellement par corrélation visuelle (fig. 209) ${ }^{3}$. La présence de la totalité du bois final sur le dernier cerne correspondant à l'année d'abattage nous révèle que les arbres ont été abattus pendant la période de repos cambial (automne/hiver). Aucune corrélation n'a été dégagée vis-à-vis d'autres chronologies moyennes antiques de pin d'Alep.

Cette technique de montage des fondations par un cadre en bois supportant un parement en pierres, est à mettre en rapport avec la nature du substrat, en l'occurrence du sable, ceci afin d'éviter l'enfoncement $\mathrm{du}$ cuvelage par une répartition sur une surface horizontale de la charge (principe des sablières basses). Cette technique d'entablures croisées à assemblage à mi-bois était souvent employée dans l'Antiquité pour réaliser la base de puits peu profonds. C'est par exemple le cas des puits du sanctuaire gallo-romain

3 Les indices statistiques sont très faibles (TVPV inférieur à 2 et TVH souvent inférieur à 3); une seule synchronisation statistique et visuelle est évidente entre 2025 et 2026 (TVH de 4,1). Les difficultés de l'interdatation sont dues au caractère juvénile des bois étudiés (la croissance juvénile est davantage soumise aux contraintes édaphiques qu'aux paramètres climatologiques) ainsi qu'aux caractéristiques autécologiques particulières du pin d'Alep. 


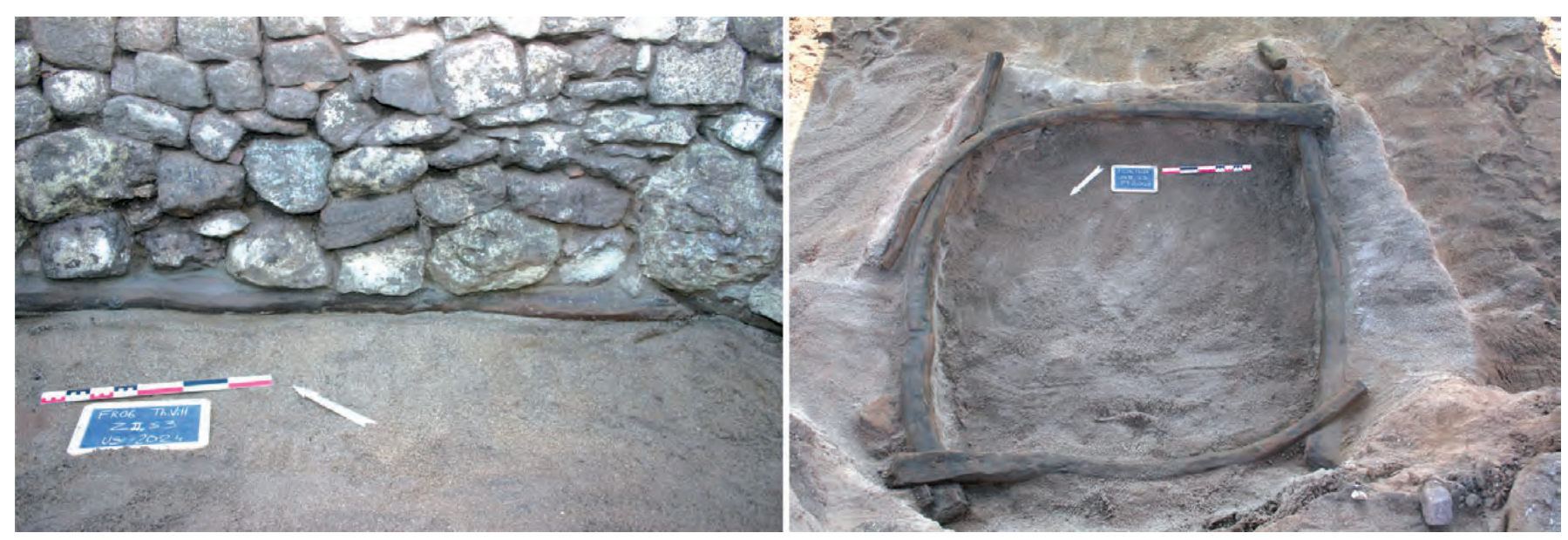

Fig. 205. Démontage du puits PT2031.

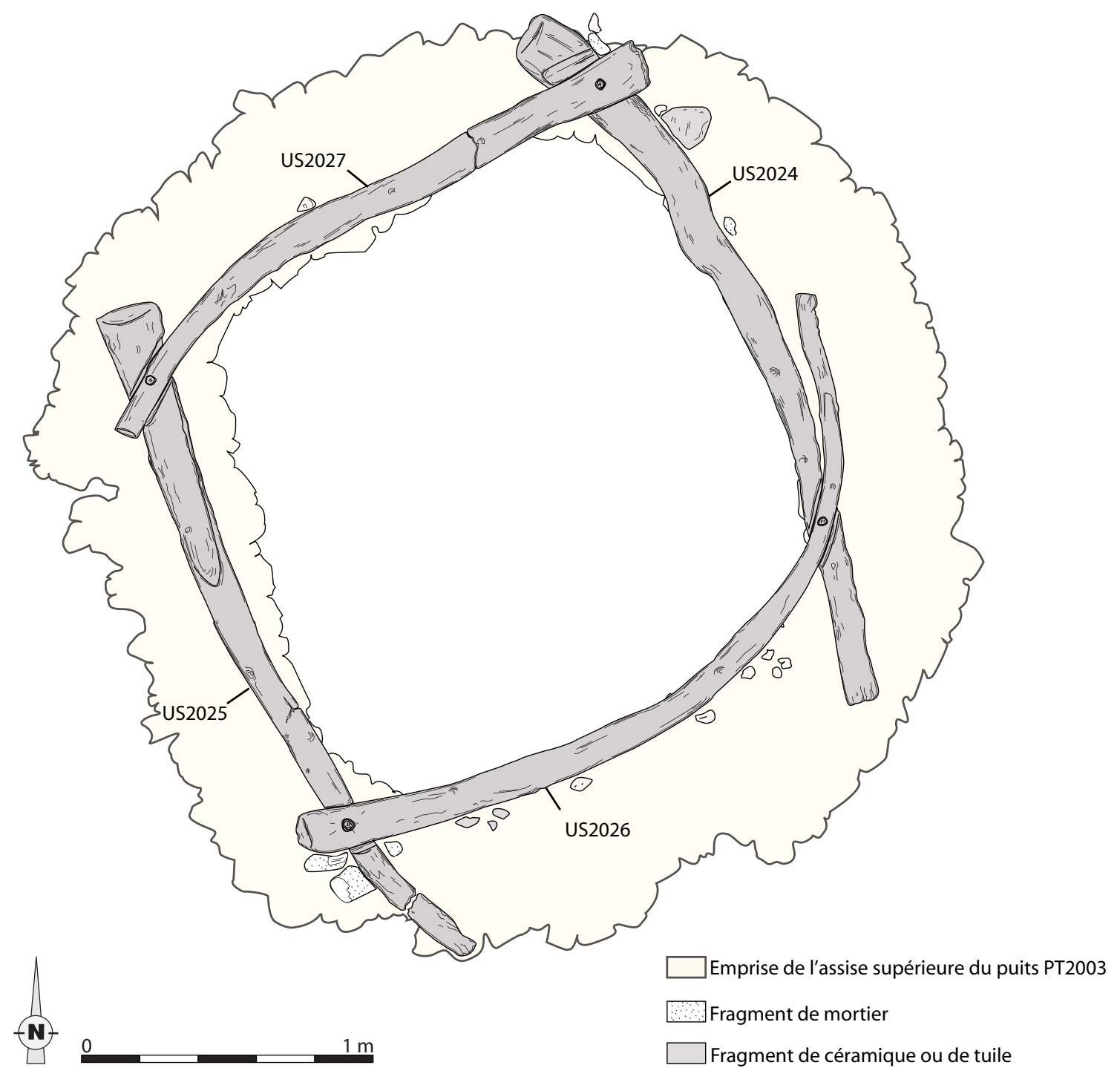

Fig. 206. Relevé des fondations sous le cuvelage en pierre du puits PT2003. 

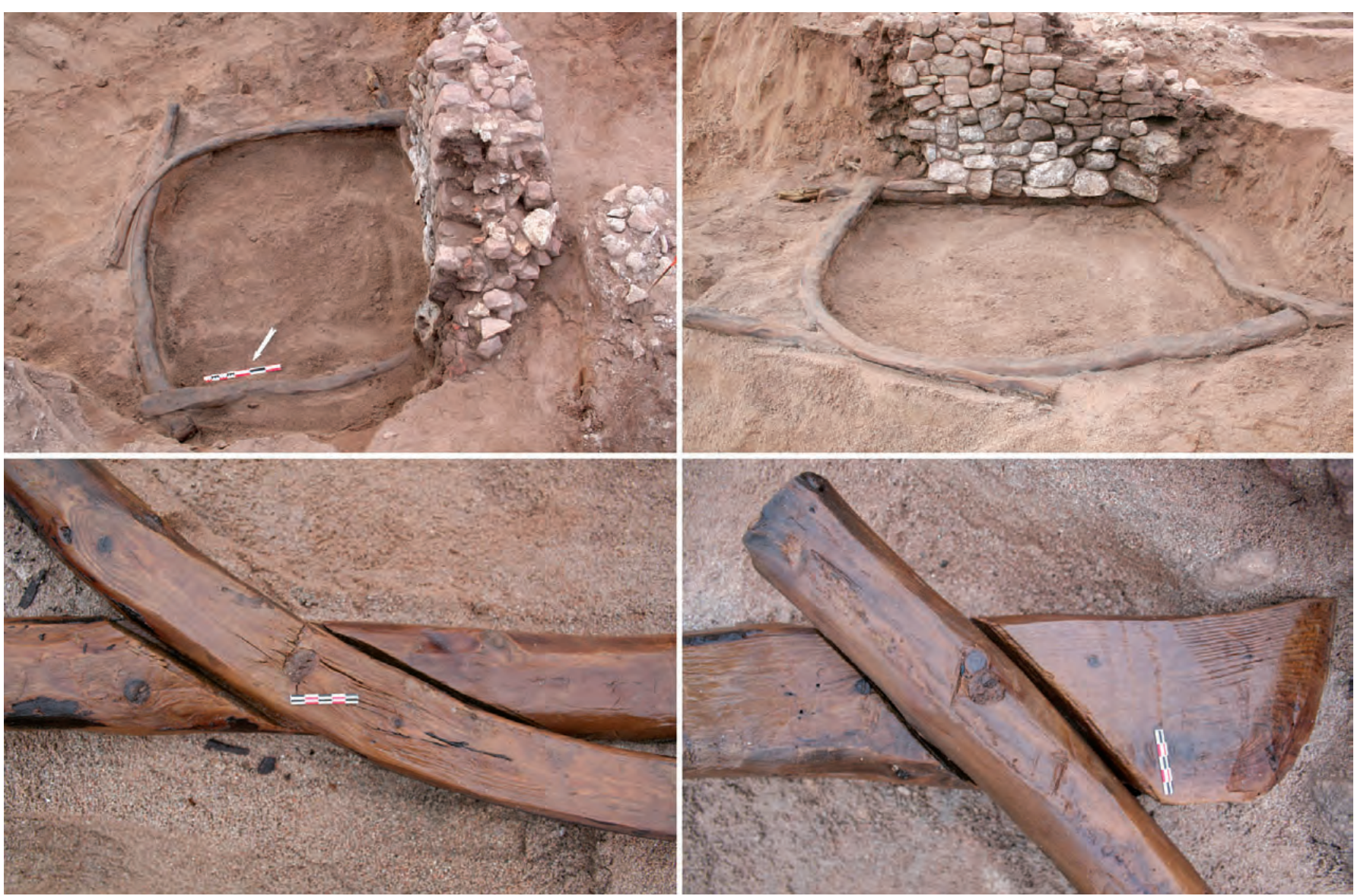

Fig. 207. Démontage du puits PT2003.

du Clos du Détour dans le Loiret (Mille 2000). À Fréjus, un puits de ce type daté de l'Antiquité tardive a été récemment mis au jour sur le site du Kipling, rue Aristide-Briand ; lui aussi peu profond, il était aménagé dans le sable ${ }^{4}$. Ceux de Servon en Seine-et-Marne sont de la même époque et construits selon le même procédé (Dietrich 1992, 36). Des fondations par assemblage à mi-bois sont également connues sur des sites du Moyen Âge et de l'époque moderne. Il en est ainsi dans le village de Vallange en Moselle, où des fouilles récentes ont montré que chaque unité d'exploitation jouissait d'un puits à bascule, dont certains étaient construits sur des fondations du même type, employant du hêtre. Sur ce site, les puits existent entre le $\mathrm{VIII}^{\mathrm{e}}$ et le $\mathrm{XV}^{\mathrm{e}}$ siècles (Gérard 2007, 54).

\begin{tabular}{|c|c|c|c|c|c|c|c|c|}
\hline Secteur & Fait & US & $\begin{array}{c}\text { Dimensions (cm) } \\
\text { L x l }\end{array}$ & Essence ligneuse & Débit & Âge & Moelle & Dernier \\
\hline \multirow{4}{*}{3} & \multirow{4}{*}{ PT2003 } & 2024 & $270 \times 10-14$ & pin d'Alep & brin & 31 & présente & écorce \\
\hline & & 2025 & $242 \times 11-12$ & pin d'Alep & brin & 32 & présente & cambium \\
\hline & & 2026 & $284 \times 10-12$ & pin d'Alep & brin & 35 & présente & écorce \\
\hline & & 2027 & $235 \times 10-14$ & pin d'Alep & brin & 31 & présente & écorce \\
\hline \multirow{4}{*}{1} & \multirow{4}{*}{ PT2031 } & 2042 & $245 \times 10-13$ & résineux & brin & - & présente & écorce \\
\hline & & 2043 & $253 \times 10-12$ & résineux & brin & - & présente & écorce \\
\hline & & 2044 & $260 \times 10-14$ & résineux & brin & - & présente & écorce \\
\hline & & 2045 & $296 \times 12-15$ & résineux & brin & - & présente & écorce \\
\hline
\end{tabular}

Fig. 208. Paramètres descriptifs des fûts des puits PT2003 et PT2031.

4 Fouilles Service du Patrimoine - Ville de Fréjus, P. Excoffon (dir.) 


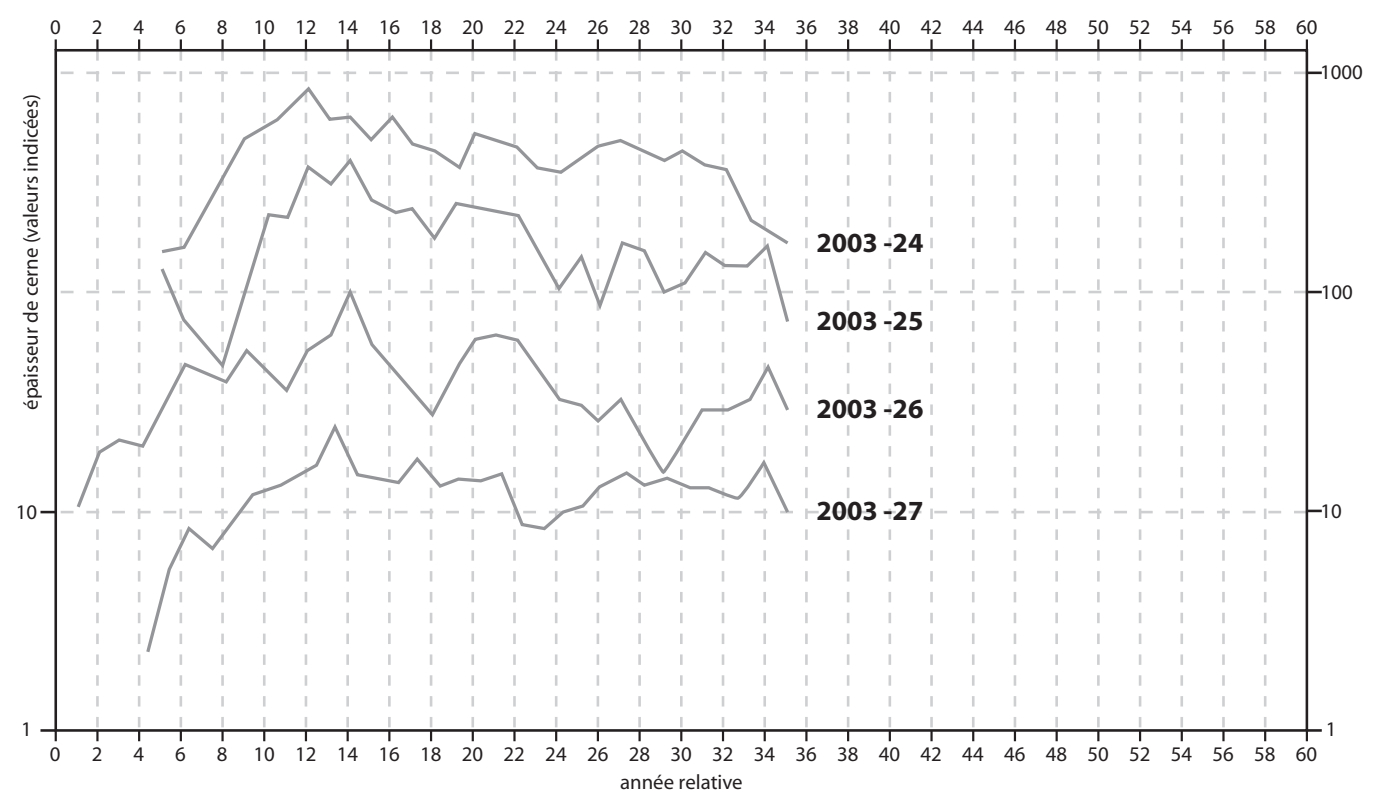

Fig. 209. Courbes représentatives des chronologies individuelles constitutives de la chronologie moyenne Fréjus 5.

\subsubsection{Le pulvinus d'autel funéraire du puits PT2003} (Y. L.)

Dimensions conservées : long. : 19,8 cm H. : $19,3 \mathrm{~cm}$ - épaisseur : $21,3 \mathrm{~cm}$.

Ce bloc de grès rouge feldspathique a été découvert remployé en parement pour le cuvelage du puits PT2003. Il peut être identifié comme une extrémité de pulvinus appartenant à un autel funéraire (fig. 210).

Le pulvinus est un élément décoratif, en forme de coussin allongé (traduction du terme latin), disposé sur les bordures latérales d'une table d'autel appartenant à un type de monument funéraire de plan quadrangulaire, daté majoritairement entre la seconde moitié du ${ }^{\text {Ir }}$ siècle av. J.-C. et le Ir siècle apr. J.-C. (fig. 211).

À Fréjus, la morphologie et la décoration du rouleau correspondent à un schéma commun à l'ensemble des pulvini : il prend la forme d'un balustre couché décoré de feuilles lancéolées à nervures centrales imbriquées en écailles ${ }^{5}$ et sculptées en bas-relief. La partie conservée du rouleau présente trois rangées de feuilles en arc d'ogive, dont le diamètre restitué peut être d'environ

5 La définition exacte de ce motif n'est jamais clairement déterminée : il peut être considéré indistinctement, au même titre que les couronnements de mausolées décorés d'un motif analogue dont le type apparaît en Gaule Narbonnaise à partir du second quart ou du milieu du I ${ }^{\text {er }}$ siècle av. J.-C. (mausolées des Iulii à Glanum - Saint-Rémy-de-Provence, Bouches-duRhône - et d'Argenton - Le Fugeret, Alpes-de-Haute-Provence), comme des feuilles de laurier ou des écailles imbriquées. À Nîmes, P. Varène (1970) emploie la terminologie : " feuilles de laurier imbriquées », à Cucuron, G. Hallier, R. Guéry, H. Lavagne et J. Gascou (1990) utilisent le terme : " écailles imbriquées », R. Robert (2003) décrit des «feuilles lancéolées en écailles ».
$30 \mathrm{~cm}$, mesure équivalente au pied romain. Le rouleau est posé sur une base lisse haute de $5 \mathrm{~cm}$ et débordante de $4 \mathrm{~cm}$ à son pied. Le lit de pose est plat et gradiné. La terminaison du rouleau est ornée d'un médaillon circulaire, à l'origine bordé d'un listel, dont seule la partie inférieure gauche est conservée et montre un œil droit allongé à l'orbite lisse et aux paupières finement ourlées, entouré d'une surface recouverte de fines écailles imbriquées. Ce type de représentation ne semble pas connaître de parallèle : les médaillons de pulvinus sont très fréquemment ornés d'une tête de gorgone ou d'une rosace (Beltrán Fortes 2004).

Même si ce type de décoration de monument funéraire devait être couramment rencontré en Gaule Narbonnaise, seuls sept ${ }^{6}$ pulvini sont désormais identifiés à travers ce territoire à Vienne (Robert 2003, Nesp Vienne $n^{\circ}$ 278), Cucuron (Hallier et al. 1970, 169-170, fig. 25), Arles ((Rothé, Heijmans 2008, 451, fig. 526 - Inv. n ${ }^{\circ}$ 92.00.108) ${ }^{7}$, Nîmes (Varène 1970, 109-110, fig. 20-21), Narbonne (Rodà de Llanza 2000, fig. 15 - Base NEsp NAR 83, 84 et 85) et Toulouse (Badie à paraître) ${ }^{8}$.

6 Neuf blocs sont connus appartenant à sept autels funéraires (trois extrémités de pulvini appartiennent au même autel à Narbonne et sont conservées au lapidarium Lamourguier).

7 Nous remercions A. Charron (Musée de l'Arles antique) qui nous a permis d'accéder à plusieurs clichés du pulvinus dont l'identification était jusqu'alors indéterminée : " élément architectonique en marbre en forme de cylindre (long. : $1,5 \mathrm{~m}$; diamètre : $23 \mathrm{~cm}$ ) décoré d'écailles et orné aux extrémités de fleurs $»$.

8 Tous nos remerciements à A. Badie (IRAA-CNRS) qui nous a informé de la présence de ce bloc remployé dans l'amphithéâtre de Toulouse. 


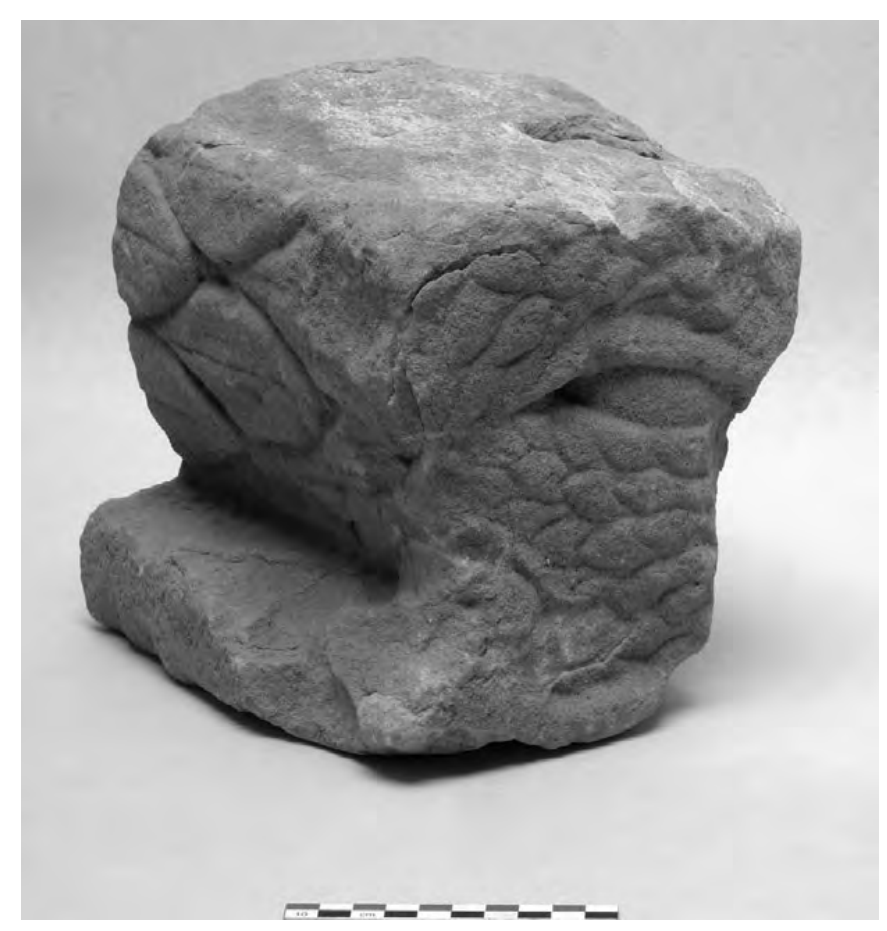

Fig. 210. Pulvinus (cl. Chr. Durand / CCJ).

Dans le contexte de Fréjus, cet élément décoratif s'inscrit parmi un groupe homogène de sculptures funéraires en grès réalisées localement : neuf stèles funéraires figurées ; neuf blocs de couronnement décorés de feuilles en écailles imbriquées dont six à Fréjus, deux à Saint-Raphaël et un exemplaire au Cannet-des-Maures ; deux acrotères colossaux funéraires découverts hors contexte à Fréjus ; une sculpture funéraire animale (lion, chien, sphinge) provenant de l'enclos A de la nécropole du Pauvadou; un bas-relief décoré d'une tête de taureau découvert sur la route de Puget-sur-Argens à Fréjus au début du XIX ${ }^{\mathrm{e}}$ siècle ; un bas-relief figurant une tête de bovidé remployé dans la construction de la tour médiévale de la vieille église de Saint-Raphaël ou encore un fragment de frise dorique découvert au domaine de Palayson à Roquebrune-sur-Argens dont les métopes sont alternativement décorées de phiales et de bucranes. L'ensemble de cette production d'œuvres destinées à l'ornementation des nécropoles de Fréjus et de son territoire antique est principalement daté entre la première moitié du $\mathrm{I}^{\mathrm{er}}$ siècle apr. J.-C. et le $\mathrm{II}^{\mathrm{e}}$ siècle apr. J.-C. Le pulvinus est vraisemblablement daté du $\mathrm{I}^{\text {er }}$ siècle apr. J.-C., période durant laquelle on connaît la présence d'ateliers de sculpture installés localement à Fréjus. Le pulvinus d'autel funéraire de Fréjus complète le corpus existant publié en Gaule Narbonnaise, et la connaissance de ce type d'œuvre funéraire dont le motif peu commun du médaillon pourrait rendre compte d'une liberté du sculpteur initié partiellement au vocabulaire iconographique traditionnel de ce type de monument.

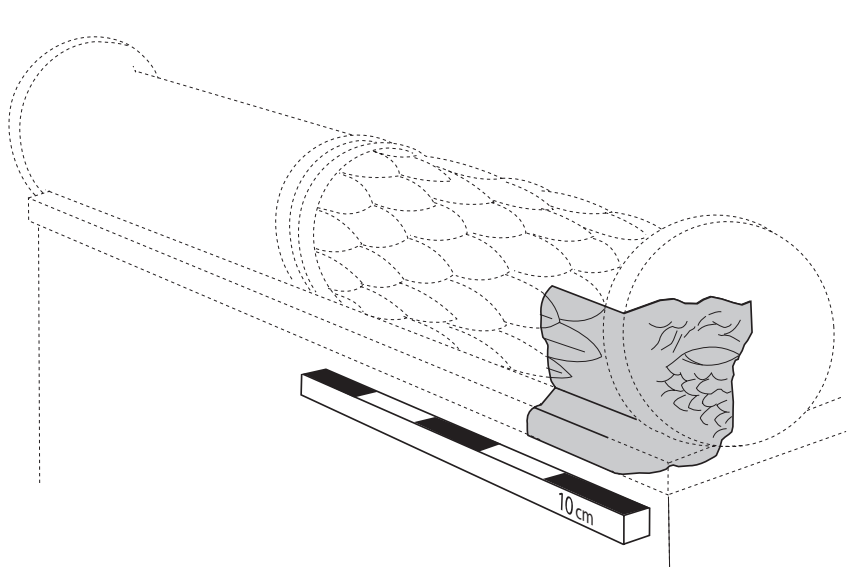

Fig. 211. Restitution du pulvinus (Y. Lemoine).

\subsubsection{Comblements}

(P. E.)

Les comblements sont faits de diverses couches sablo-limoneuses plus ou moins riches en matières organiques. Toutefois, et on peut d'une certaine façon le regretter, ils n'ont pas servi de dépotoir.

\section{PT 2003}

- 2008 : Couche sableuse brun moyen, gris. Présence de limons, pas de coquilles marines. On retrouve des blocs issus de la destruction.

-2021: Couche de destruction de PT2003. Blocs dans du sable limoneux noir. Présence de coquilles d'escargots et de murex. La couche de destruction traverse la couche 2022. Ensemble de blocs de destruction dans la totalité du puits. Peu de mobilier.

- 2022 : Couche sous l’US2021, pénétrée en partie par les blocs de cette dernière sur sa partie supérieure. Présence de bois conservés et de fragments de tuiles dans cette couche (fig. 212).

- 2023 : Sable gris sous l'US2022.

\section{PT2031}

- 2032 : Couche sablo-limoneuse.

- 2035 : Couche humide, sablo-limoneuse noire à pendage horizontal. Présence des premiers éléments de destruction (fig. 213). Forte présence de débris végétaux concentrés au milieu du puits dans la partie basse (fig. 214).

- 2037 : Couche de sable gris.

\subsubsection{Les analyses}

\subsubsection{La palynologie}

(S. G.)

L'analyse du puits PT2003 révèle, notamment avec l'échantillon \#190 (fig. 266) une claire mise en céréaliculture locale marquée avant tout par les $5 \%$ de 


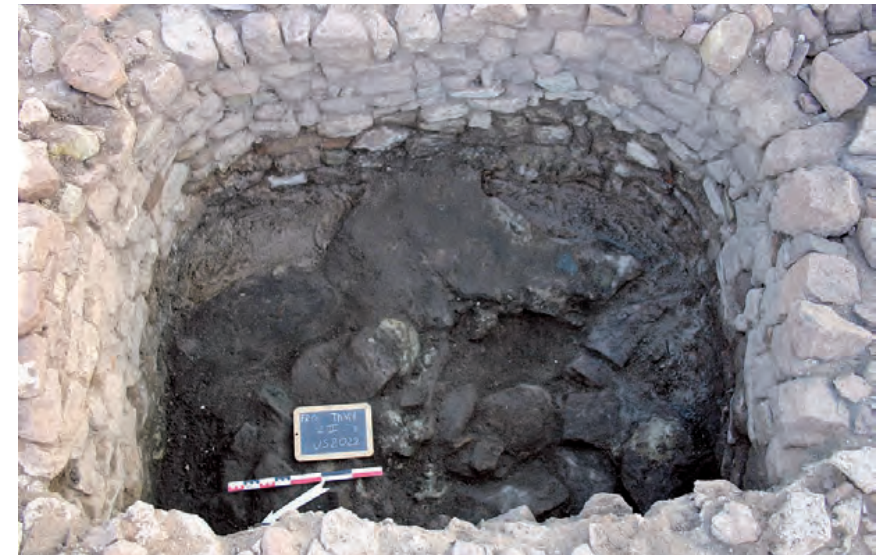

Fig. 212. Comblement au fond du puits PT2001.

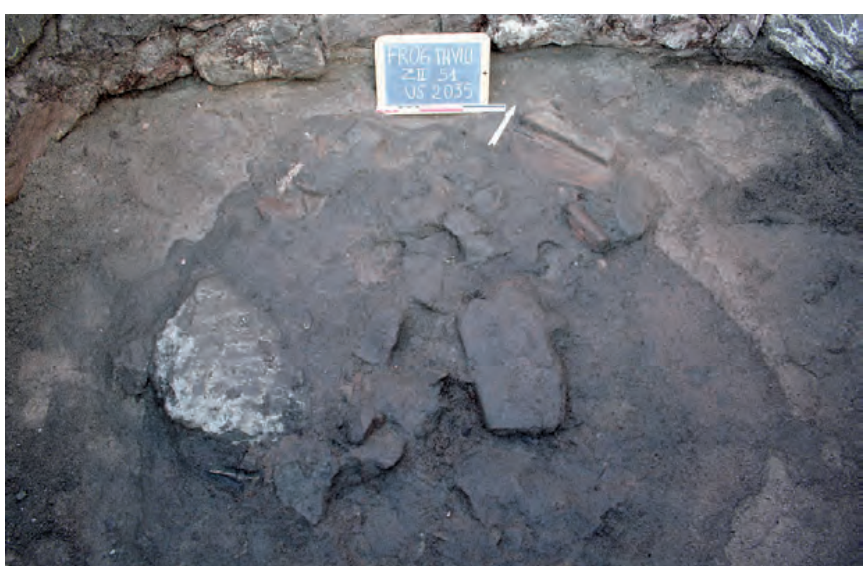

Fig. 213. Présence des prmiers éléments de destruction, fond de l'US2035.

grains de pollen de céréales mais, également, par les valeurs significatives du genre Papaver dont fait partie la messicole Papaver rhoeas (coquelicot). La dominance des Brassicaceae est encore une fois à mettre en relation avec l'importante humidité édaphique.

\subsubsection{La carpologie}

(L. B., I. F., C. S.)

Deux prélèvements carpologiques provenant du fond du puits ont été étudiés (\#369 et \#352).

Les résultats des deux prélèvements provenant de la même unité stratigraphique (US2035) (tab. 14) ont été traités ensemble. L'ensemble des diaspores est conservé par imbibition. L'analyse carpologique a révélé une densité de carporestes importante, soit 1603 diaspores comptés, ce qui représente 312 diaspores par litre de sédiment. Le spectre des taxons est relativement important, soit 52 taxons pour l'ensemble des deux prélèvements étudiés.

Les plantes aquatiques sont représentées par une seule espèce, Lemna minor, qui affectionne les eaux stagnantes.

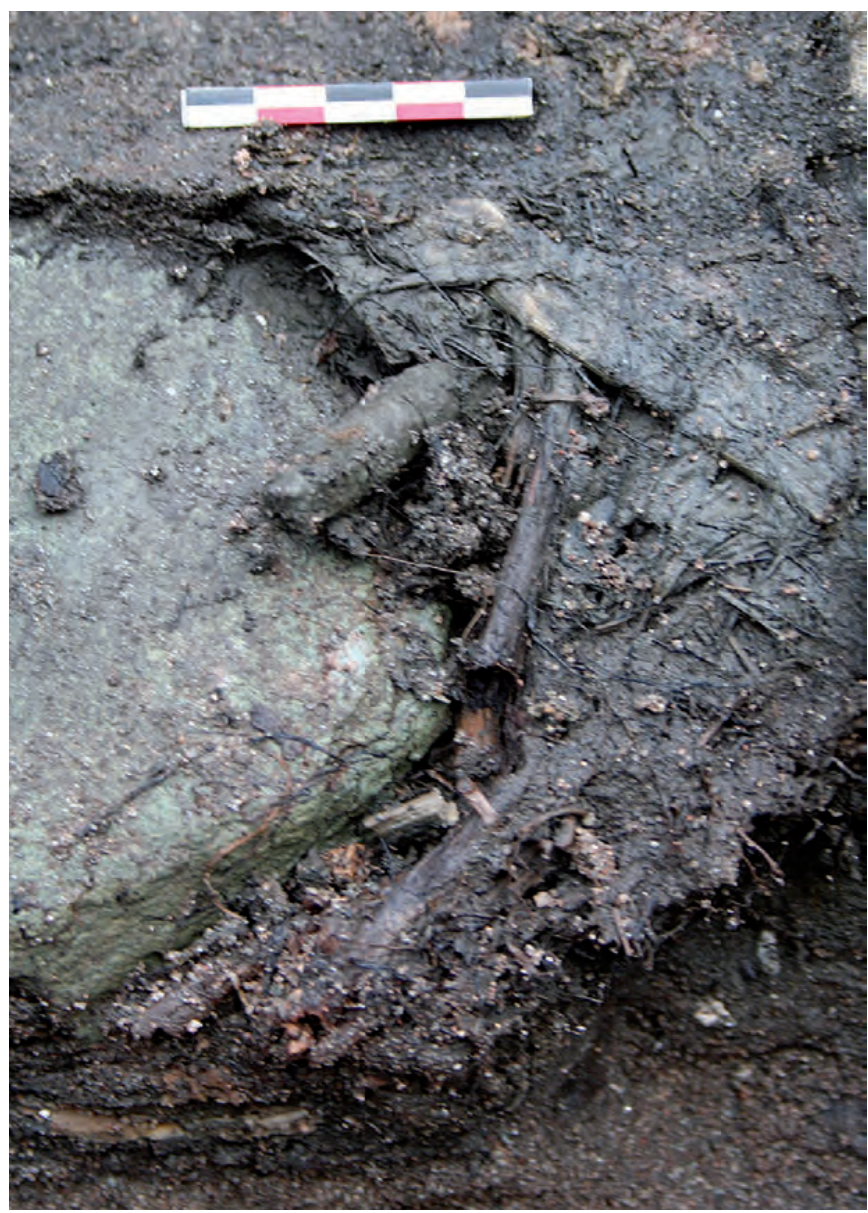

Fig. 214. Présence des débris végétaux, concentrés au centre.

Les graines de cette plante d'eau représentent moins de $2 \%$ du total des effectifs corrigés de l'assemblage carpologique de la structure PT2031/US2035.

Les carporestes de plantes de milieux humides, croissant dans les zones régulièrement inondées ou sur sols humides, représentent près de $1 \%$ du total des effectifs. Ce groupement est constitué de Carex sp. de forme bivalve et trigone, de $c f$. Carduus personata, de Cyperus sp., Eleocharis sp., Ranunculus sardous et de Scirpus sylvatica.

Les restes de fruits cultivés représentent $9 \%$ du total des effectifs. Deux espèces cultivées ont été identifiées, ce sont Ficus carica (le figuier) et Vitis vinifera (la vigne). Le caractère fortement marqué et proéminent du bec des pépins archéologiques, nous conduit à les considérer comme provenant plus probablement de la vigne cultivée que de sa parente sauvage indigène, Vitis vinifera subsp. sylvestris.

Cependant, gardons à l'esprit que l'identification stricte des deux sous-espèces de vignes demeure difficile car la variabilité morphologique des pépins est très forte, en fonction du génotype mais également des conditions 
environnementales (Jacquat, Martinoli 1999 ; Bouby, Marinval 2001 et Bouby et al. 2006). L'intégration des quelques pépins entiers du puits 2031 dans une analyse morphométrique diachronique à l'échelle suprarégionale apportera vraisemblablement des précisions sur le statut et la caractérisation variétale des vignes de Villeneuve.

Les akènes de figues sont présents en grand nombre, soit 106 éléments entiers et fragmentés. Si cet effectif paraît important, il ne faut pas oublier qu'un seul « fruit » de figuier peut contenir plusieurs dizaines d'akènes.

Trois taxons identifiés, Foeniculum vulgare (le fenouil), Brassica nigra (la moutarde noire) et Lactuca type sativa/scariola (la laitue) pourraient être des plantes cultivées : les deux premières pour leurs graines condimentaires, la troisième pour ses feuilles comestibles en salade. Ces plantes potentiellement cultivées, représentent $5,7 \%$ du total des effectifs (essentiellement fenouil et moutarde), ce qui ne peut constituer un argument à l'appui ou à l'encontre de l'hypothèse d'une mise en culture. Ces plantes peuvent se développer naturellement comme mauvaises herbes des lieux anciennement cultivés et rudéraux.

L'assemblage du puits est dominé par trois ensembles écologiques : les mauvaises herbes des cultures, les rudérales et les plantes des lieux secs ou sablonneux. Le groupe des mauvaises herbes des cultures représente $33,7 \%$ du total des effectifs et 10 taxons, soit (par ordre décroissant des effectifs) Anthemis arvensis, Fumaria offcinalis, Portulaca oleracea, Heliotropium europaeum, Euphorbia helioscopia, Papaver dubium, Stellaria media, Solanum nigrum, Calendula arvensis et Anagallis arvensis. Toutes ces plantes sont annuelles, une partie sont des annuelles de printemps dont la croissance et la floraison s'opèrent à la sortie de l'hiver et au printemps ; d'autres sont des annuelles d'hiver, dont la croissance et la floraison ont lieu à la fin de l'été et en automne. Remarquons qu'aucune de ces plantes n'est strictement inféodée aux cultures ; elles se développent également sur les terrains incultes, en friches et dans les lieux rudéraux.

Les diaspores des plantes rudérales, c'est-à-dire des chemins, des décombres, des friches et autres lieux incultes, représentent près de $12 \%$ du total des effectifs de l'assemblage et 8 taxons. Ce sont Capsella bursa-pastoris, Marrubium vulgare, Sonchus oleraceus, Euphorbia exigalpeplus, Lamium amplexicaule, Malva parviflora, Mava sylvestris et Urtica urens.

Le groupe des lieux sableux/secs est composé de seulement 5 taxons (Lobularia maritima, Medicago littoralis, Silene gallica, Stachys arvensis/ocymastrum et Tribulus terrestris) mais il regroupe plus de $26 \%$ des carporestes. Il doit être directement rattaché à l'ambiance sablonneuse et rocailleuse du milieu littoral.
Dans l'ensemble, le cortège de plantes herbacées du puits 2031 affiche un net caractère psammophile et xérophile.

\subsubsection{L'anthracologie et la xylologie \\ (L. B., I. F., C. S.)}

Deux US ont fourni du matériel végétal. L'US2035 (comblement inférieur) a fourni un nombre très réduit de restes carbonisés, parmi lesquels on remarque Erica et Pinus. Dans l'US2037 (fond) les éléments identifiés, lors de l'analyse des charbons, incluent Arbutus unedo (Arbousier), Cistaceae, Erica arborea, Erica, Fraxinus, Pinus, Quercus (feuillage caduc), Quercus (feuillage persistant).

Une fois de plus, le mauvais état des échantillons nous empêche de distinguer Pinus halepensis de Pinus pinea. Cependant certains caractères nous font pencher plutôt pour Pinus pinea.

\subsection{Zone 3}

(P. E.)

Sur l'ensemble de la zone 3 se met en place une unité stratigraphique distincte d'une épaisseur d'environ0,30/0,35m:3046/3012/3053/3034/3022/3057. Il s'agit d'un dépôt sablo-limoneux avec des taches d'oxydation verticales, probablement d'origine fluviatile. L'organisation des particules indique une sédimentation en cours de pédogenèse. La variation granulométrique présente un aspect plus limoneux à la base qu' au sommet. Cette couche recouvre totalement les structures antiques (MR3042, 3040 et 3083) et comble définitivement la lanière cultivée PAA3063. Au sein de l'US3046 est bâti un mur d'orientation globalement nord-sud MR3006 (fig. 215 et 216). Il n'est conservé que sur 7,50 m et a été traversé par un fossé plus tardif (FS3020). Toutefois, on peut restituer une longueur de $12,20 \mathrm{~m}$ avec l'autre portion. Il est large de $0,80 \mathrm{~m}$ et n'est conservé que sur une seule assise de 0,20 m de hauteur. Les moellons employés, dans un mortier maigre, sont très hétérogènes (grès, schiste, basalte, bloc de mortier) et indiquent clairement l'usage d'éléments de remploi. La fonction de ce mur n'a pu être mise en évidence, il peut s'agir d'un mur de limite de parcelle.

\subsection{Datation}

\subsubsection{La céramique}

(E. P.)

Le mobilier de la phase 5A est constitué aux trois quarts de mobilier résiduel antique en nombre de restes 


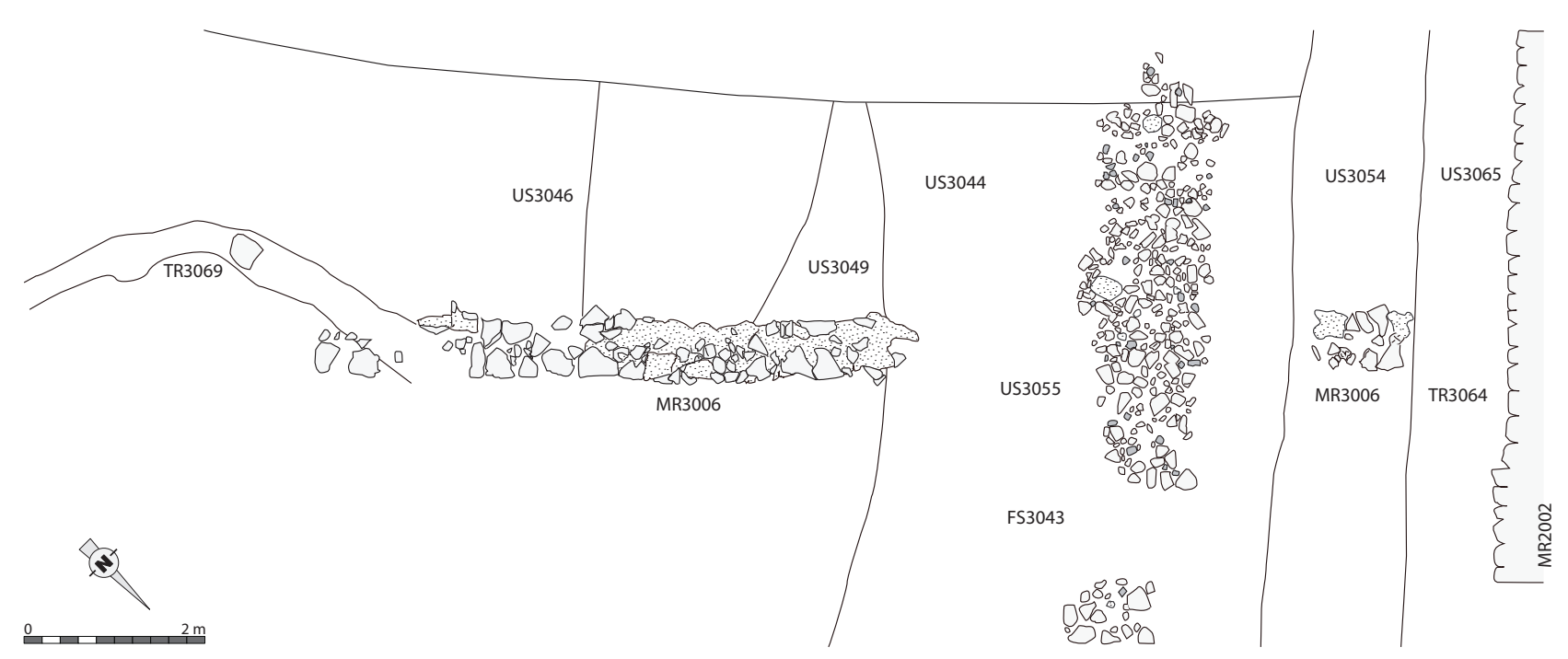

Fig. 215. Vue du mur MR3006 recoupé par un fossé postérieur.

et un peu plus de la moitié en nombre d'individus. On y retrouve le mobilier vu dans les phases précédentes. Plus anecdotique est la découverte d'un fragment de bol à la croix en céramique pisane caractéristique du XIVe siècle (Amouric et al. 1999, 30). Le reste du mobilier se compose de céramiques d'époque moderne dont une majorité de productions fréjusiennes à glaçure jaune et occasionnellement verte. On compte une assiette profonde à grand marli (fig. $217-\mathrm{n}^{\circ} 1$ ), une coupe individuelle (fig. 217 - $\mathrm{n}^{\circ}$ 2) et une jatte de préparation (fig. $217-\mathrm{n}^{\circ} 3$ ). Le profil de l'ensemble paraît se situer plutôt dans le XVI ${ }^{\mathrm{e}}$ siècle (Amouric et al. 1999, 67-71).

La partie du remblaiement préalable à la mise en place des structures agraires qui a pu être fouillée (US1007), a livré le lot de céramiques qui apparaît comme le plus significatif. Parmi le mobilier, on note la prédominance des productions de Fréjus, essentiellement des fragments de jarres et de coupes. L'absence d'éléments plus tardifs permet de supposer une mise en place du remblai entre la fin du XVe siècle et le début du XVI ${ }^{\mathrm{e}}$ siècle. L'examen du mobilier archéologique contenu dans les puits permet, avec difficulté, de situer leur abandon dans le temps mais montre en tout cas la complexité de dater un aménagement seulement à partir de son comblement. En effet, on constate que le comblement du puits PT2003 compte, sur un total de 29 fragments, uniquement du matériel antique. Heureusement, le puits PT2031 a livré 31 fragments dont un de graffite polychrome et deux de céramique glaçurée, qui ont permis de confirmer les impressions de la fouille elle-même. Le cas du puits PT2003 comblé uniquement par du mobilier antique à l'époque moderne est un cas riche d'enseignements sur la complexité des datations des structures en creux. La présence d'un tesson en céramique à « graffite

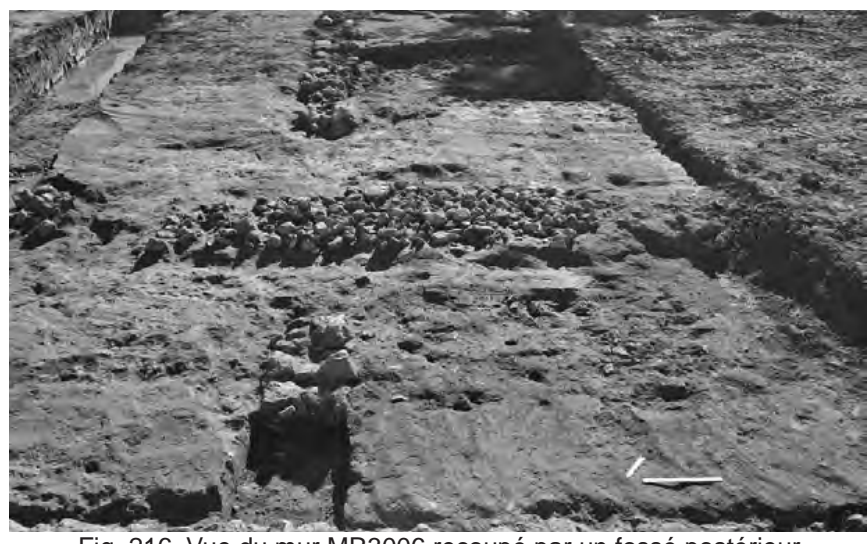

Fig. 216. Vue du mur MR3006 recoupé par un fossé postérieur.

polychrome » pisane nous emmène, pour le comblement, au plus tôt dans la seconde moitié du $\mathrm{XVI}^{\mathrm{e}}$ siècle (Amouric et al. 1999, 80-86).

\subsubsection{Datation radiocarbone \\ (P. E.)}

Concernant la date de mise en place des deux puits, aucun élément de datation direct n'a été découvert dans les niveaux de construction. Une datation $14 \mathrm{C}$ a été tentée sur les sablières basses du puits PT2003 ${ }^{9}$ pour définir la période de construction. Celle-ci a certes confirmé que le comblement ne pouvait remonter à l'Antiquité, mais fourni une datation très haute pour l'abattage du bois : dans le courant du XIII' ${ }^{\mathrm{e}}$ siècle $^{10}$.

9 Codes : labo Poz-20221, fouille ThVil. \#633.

10 FR06 \#633 PT 2003-2025 : 745 30BP / 68.2\% probability / 1250AD (68.2\%) 1285AD / 95.4\% probability / 1220AD (95.4\%) 1290AD. 


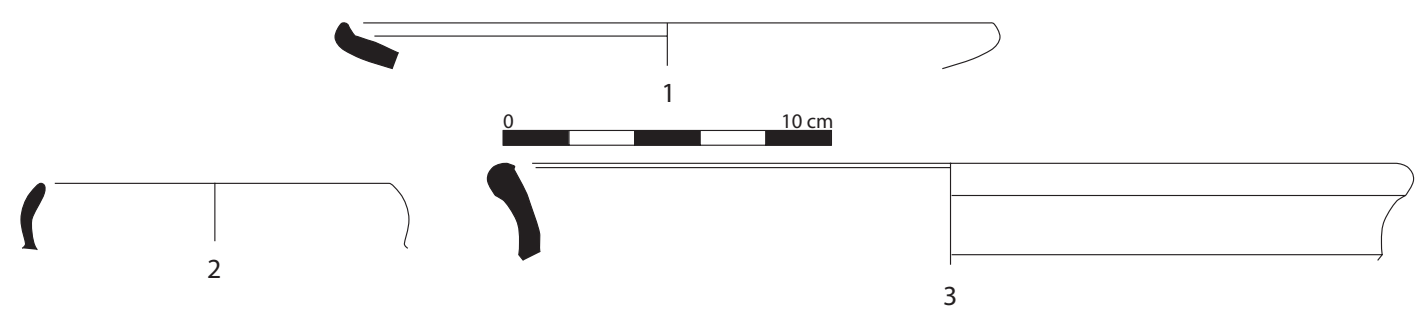

Fig. 217. Matériel céramique de la phase 5A.

Que peut-on en conclure ? Cette datation n'est pas confirmée par le mobilier découvert sur le site, le tesson le plus proche étant un fragment de bol à la croix en céramique pisane, attribuable au plus tôt à la fin du $\mathrm{XIII}^{\mathrm{e}}$ siècle. Les bois après leur coupe ont nécessité un temps de préparation et probablement de trempage. Mais s'agissant seulement de fûts pour fonder un puits, on ne peut raisonnablement pas imaginer une période excédant quelques années, nous portant ainsi au plus tard au début du XIVe siècle. Reste alors à supposer qu'il s'agit d'éléments de remploi. Là encore, l'étude des éléments ne permet pas de corroborer cette hypothèse. En effet, les fûts ne portent pas d'autres traces que celles strictement nécessaires à la réalisation d'un assemblage à mi-bois. Il est donc difficile de trancher. L'analyse du mobilier sur l'ensemble de la fouille, y compris du matériel hors stratigraphie et résiduel, témoigne d'une fréquentation à la fin du XIV siècle au plus tôt. Rappelons aussi que le haut des deux puits, margelle comprise, a été arraché à une période bien plus tardive. Ainsi, les sols contemporains de leur utilisation ont totalement disparu, nous privant à l'évidence d'éléments de datation plus directs...

\subsection{Interprétation}

(P. E.)

C'est à partir du milieu du XIVe siècle que les blés de la région de Fréjus et de Roquebrune-sur-Argens commencent à être reconnus (Février 1964, 66 et 1959). $\mathrm{Au} \mathrm{XVe} \mathrm{siècle,} \mathrm{Fréjus} \mathrm{ravitaille} \mathrm{en} \mathrm{blé} \mathrm{de} \mathrm{nombreuses}$ villes en France et en Italie. Comme le suggère P.-A. Février « cette grande activité économique a favorisé l'extension du bourg agricole qu'était Fréjus » (ibid. 67). C'est toute la plaine de la basse vallée de l'Argens qui connaît alors une forte exploitation à partir de la fin du $X V^{e}$ siècle, correspondant à un accroissement considérable de la population (Février 1959, 58).

La vigne connaît également un développement à cette période. En effet, le cadastre de 1518 montre que, notamment dans la vallée du Reyran, la vigne côtoyait les champs de blé et tenait une place de tout premier plan (Robion 1987, 65). La présence importante de traces de vignes dans le puits PT2031 trouve ici une justification, tout comme les pollens de céréales.

Les traces d'exploitation repérées sur le site de Villa Romana sont donc à mettre en relation avec la réocupation des thermes de Villeneuve. Le bâtiment, alors toujours partiellement en élévation, est transformé. Ainsi, le grand bâtiment à abside et les trois pièces dans son prolongement seraient remaniés en une sorte de bergerie, et, à l'est, les contructions robustes seraient récupérées pour servir d'habitation. Outre les céramiques modernes découvertes lors du diagnostic effectué en 2008 (Excoffon, Ardisson 2008), l'aménagement d'un encadrement de porte à linteau surmonté d'une triple accolade à moulure croisée (fig. 218) témoigne de cette réocupation probablement durant le $\mathrm{XV}^{\mathrm{e}}$ siècle et avant la transformation en bastide à la fin du XVII ${ }^{\mathrm{e}}$ siècle.

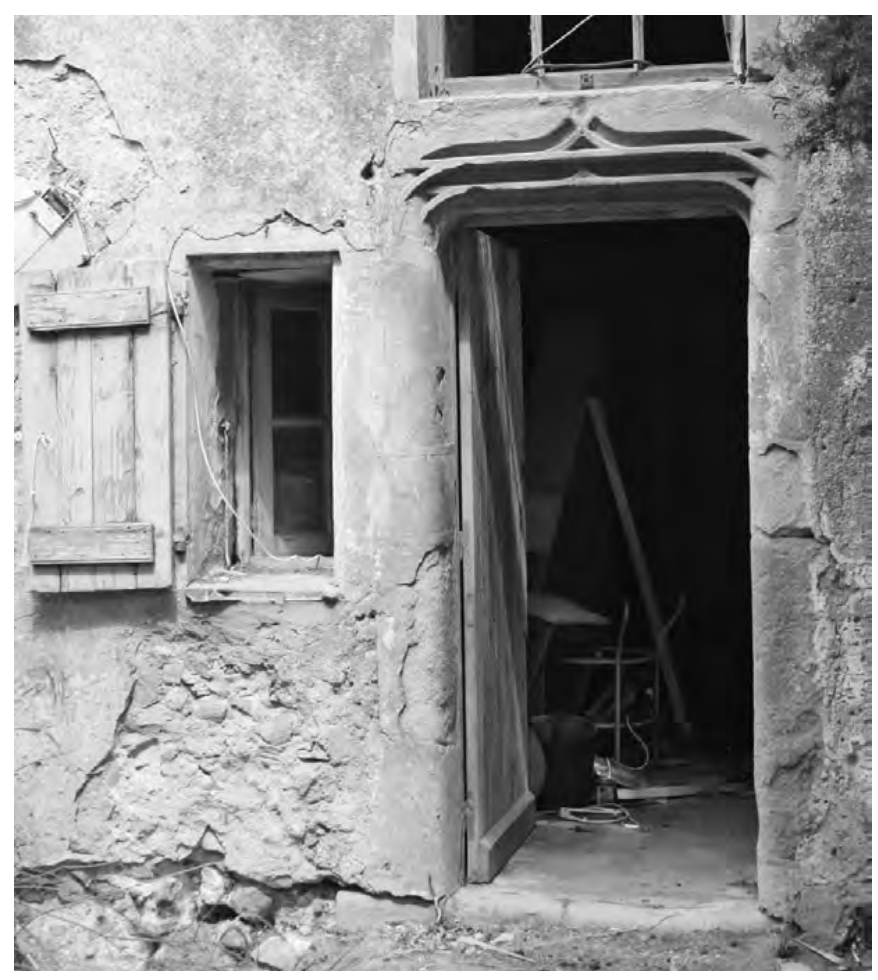

Fig. 218. Porte de la ferme moderne avec linteau à triple accolade à moulure croisée. 


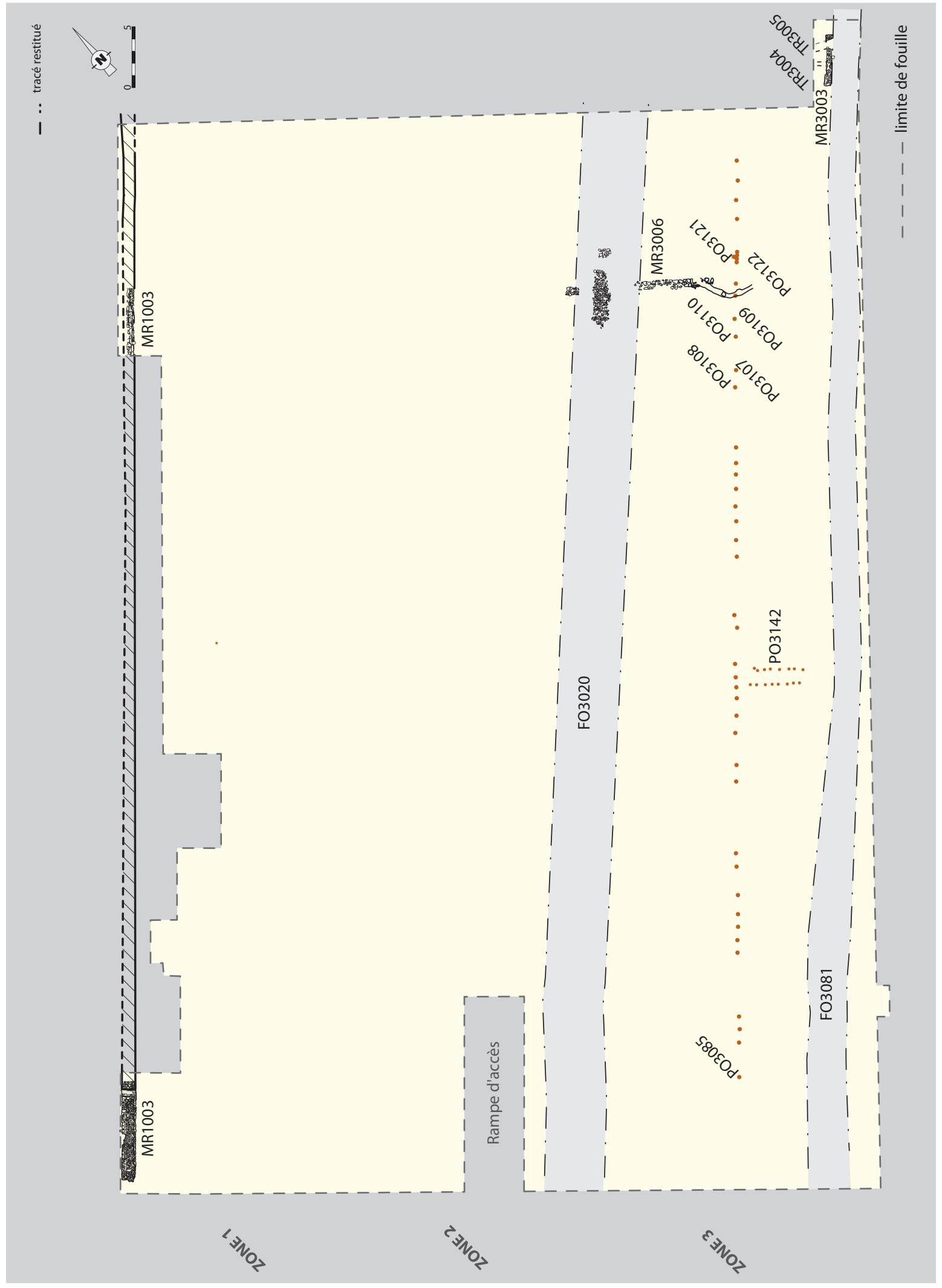

Fig. 219. Plan d'ensemble des vestiges de la phase 5B. 

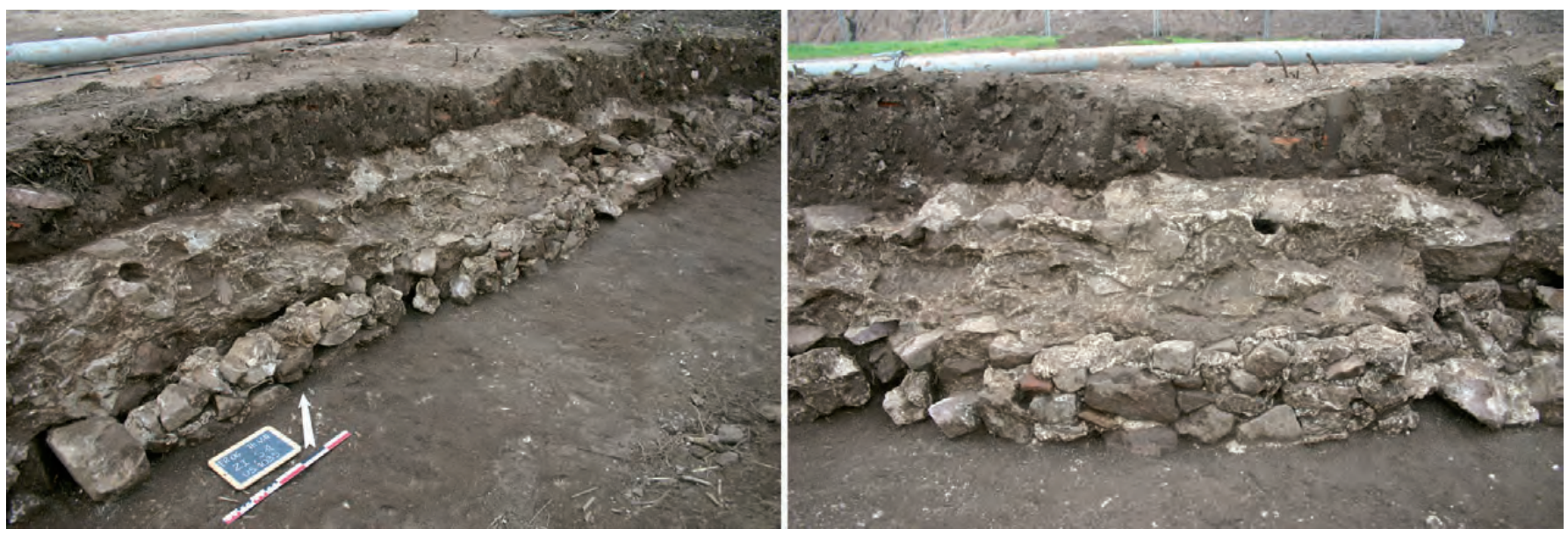

Fig. 220. Les parements sont partiellement remontés, notamment dans la partie est, où de la céramique glaçurée jaune est remployée comme calage.

\section{La phase 5, état B}

\subsection{Description}

(P. E.)

Cette phase est marquée par la récupération et la réutilisation de matériaux de construction (fig. 219). Les murs MR2002 et 2004 sont en grande partie épierrés (respectivement 2014/2019/3176 et 2005). Le long mur MR1003 marque toujours une limite dans la topographie et les parements sont partiellement remontés, notamment dans la partie est où de la céramique glaçurée jaune est remployée comme calage (1135) (fig. 220). L'ouverture antique CN1132 est également comblée (1134 et 1150) ${ }^{11}$ et intégrée au parement (1133) (fig. 221), comme le prouvent les fragments de jarres glaçurées découverts dans le comblement sablo-limoneux brun. Nous situons également dans le courant de cette phase l'abandon et le comblement des deux puits PT2003 et 2031. Lors de cette phase sont également creusés deux larges fossés (FS3020 et 3081) orientés est/ouest.

\subsection{Stratigraphie (P. E.)}

Ce nouvel état est marqué par la mise en place d'un nouveau remblai sablo-limoneux brun (1006) sur environ $0,25 \mathrm{~m}$ d'épaisseur (coupes $2 \mathrm{a}$ et $2 \mathrm{~b}$ ). Le sommet de cette couche se trouve en moyenne à 1,50 m NGF. À partir de sa surface a été creusée une large fosse (FS1268) vaguement circulaire (diamètre : 3,60 m), dont le

11 L'US1150 correspond probablement à un comblement plus ancien mêlant niveau d'abandon et comblement contemporain de la phase 5B, et lié à l'apport du remblai 1007 .

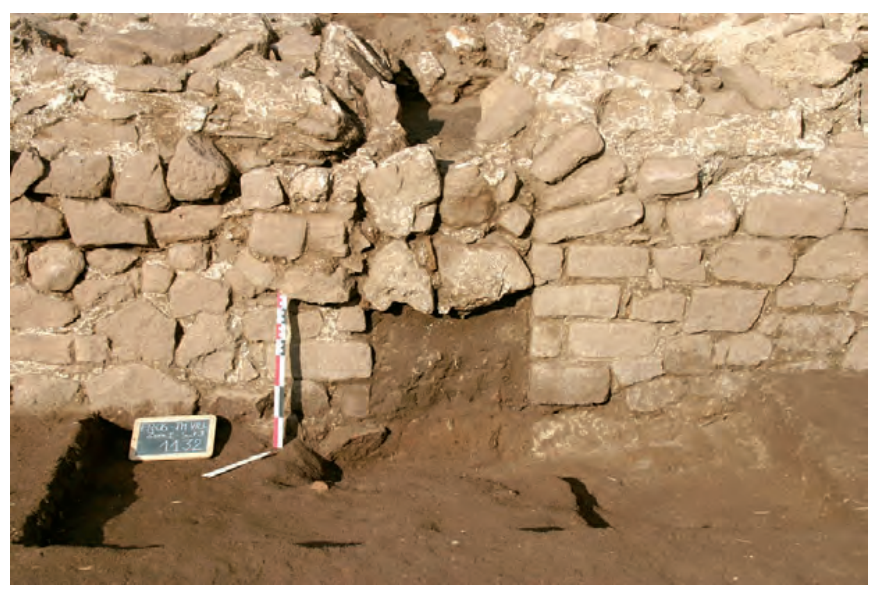

Fig. 221. L'ouverture antique CN1132 est également comblée.

comblement est sablo-limoneux gris brun (1269). Plus au sud se trouvent deux US de remblaiement, mises en place en deux temps : 3045 et 3026. Celles-ci, à dominante limoneuse grise, paraissent d'origine fluviatile.

\subsubsection{Les fossés FO3020 (3043) et FO3081 (3017)}

Ces deux fossés rectilignes traversaient la totalité du chantier d'est en ouest et leur orientation diffère légèrement des structures antérieures (fig. 222). Le sens d'écoulement est en direction de l'est.

\subsubsection{Le fossé FO3020}

Le creusement est de section arrondie, l'ouverture varie de $5 \mathrm{~m}$ à $5,30 \mathrm{~m}$ et sa profondeur, assez constante sur l'ensemble du tracé, est d'environ 1,30 m. L'entretien régulier du fossé transparaît à travers les traces de curage 

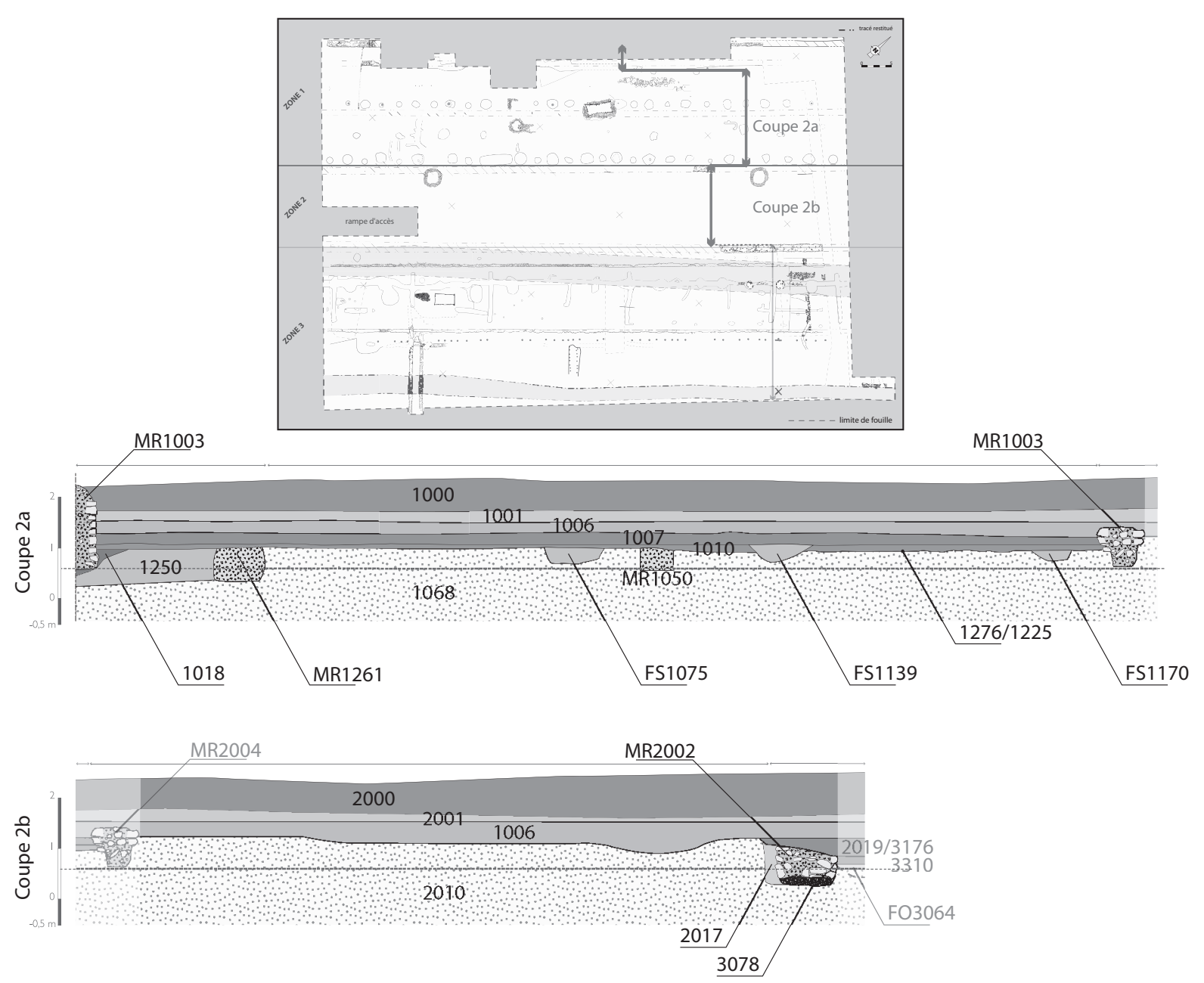

Coupes $2 \mathrm{a}$ et $2 \mathrm{~b}$.

bien visibles (US3019)12, mais marquant néanmoins progressivement une réduction du gabarit initial. Le comblement du fossé, qui appartient dans ses derniers niveaux de colmatage à l'état suivant désigné $5 \mathrm{C}$, comprend plusieurs niveaux biens distincts (fig. 223).

\subsubsection{Le fossé FS3081}

Il s'agit également d'un creusement de section arrondie. L'ouverture du fossé est moins large que celle du précédent, environ $3 \mathrm{~m}$. Cette largeur n'est observable que dans le tiers ouest de la fouille ; au-delà, la bordure sud du fossé outrepassait les limites de la fouille. Ce fossé plus étroit est toutefois plus profond que le fossé FS3020, soit environ 1,60 m. Il est creusé

12 Il s'agit d'une US composite regroupant des niveaux liés à l'abandon du fossé. Cette US a donc été enregistrée dans l'état suivant (5C) mais comporte des subdivisions par lettre pour l'étude micro et macromorphologique. directement dans les niveaux des phases antérieures. À l'est il traverse le corridor antique CN3010. Les bordures n'ont pas bénéficié d'aménagement spécifique jusqu'à l'extrémité orientale de la fouille où a été dégagé un mur bordant le canal : MR3003 (fig. 224). Repéré sur une longueur de $4,10 \mathrm{~m}$, il est large de $0,38 \mathrm{~m}$ à $0,54 \mathrm{~m}$ pour une hauteur de 0,30 à $0,38 \mathrm{~m}$. Il s'agit d'un mur de direction est/ouest constitué de moellons liés par un mortier jaune. La paroi sud présente un parement assisé fait de moellons de petite taille. Le parement nord, quant à lui, est mal assisé avec débordement des moellons. Enfin, le mur est traversé par une petite tranchée, TR3004, de $0,30 \mathrm{~m}$ de large (fig. 225). Quelques niveaux liés à son fonctionnement ont été perçus, il s'agit de dépôts argilo-limoneux gris, très plastiques, très riches en matières organiques et morceaux de bois gorgés d'eau. À cette époque, le fossé est entretenu et régulièrement curé comme le montrent des traces d'entretien mises en évidence (fig. 226). 


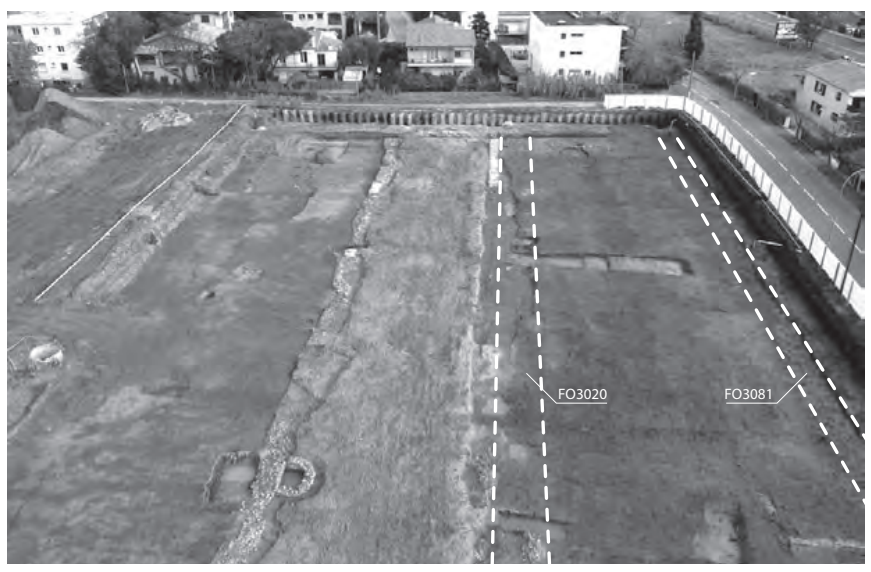

Fig. 222. Ces deux fossés rectilignes

traversaient la totalité du chantier d'est en ouest.

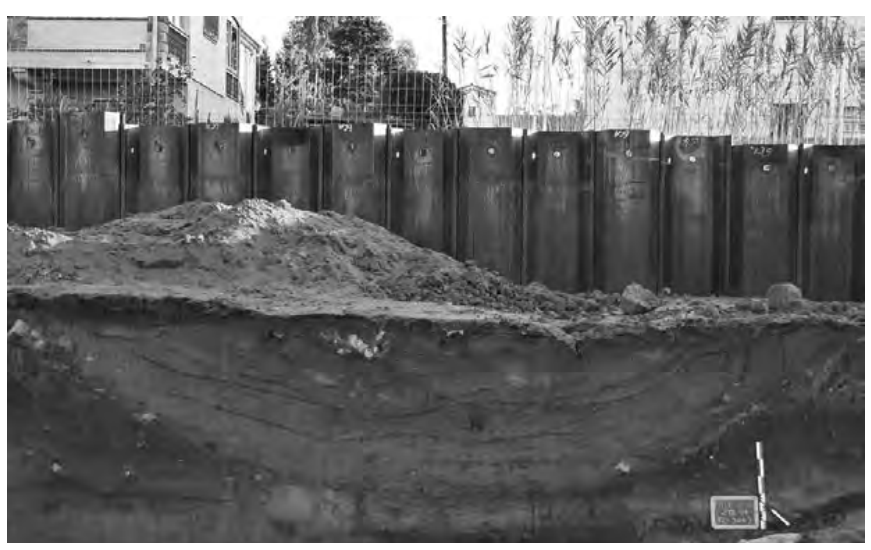

Fig. 223. Le comblement du fossé FO3020 comprend plusieurs niveaux bien distincts.

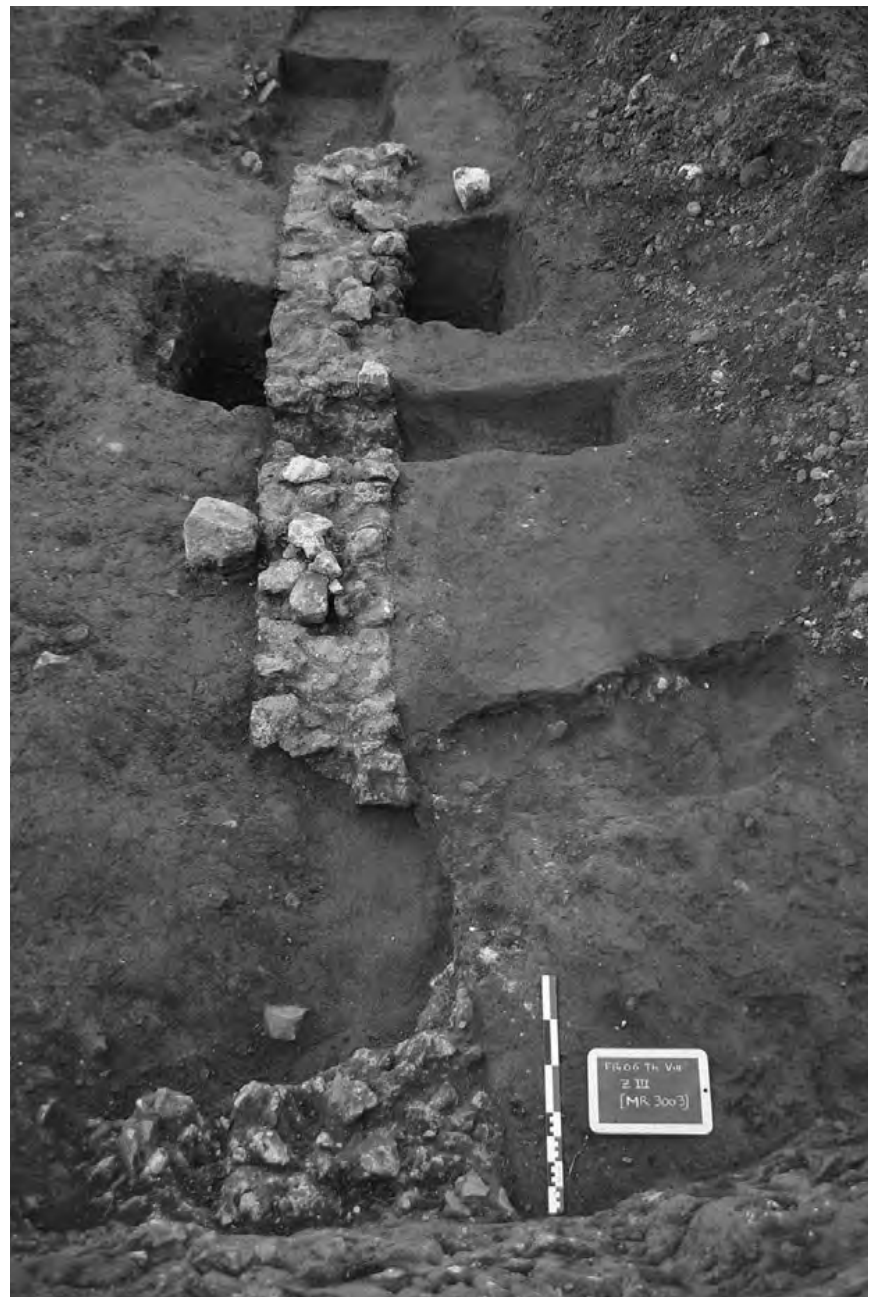

Fig. 224. Le mur MR3003 bordant le fossé FS3081/3017.

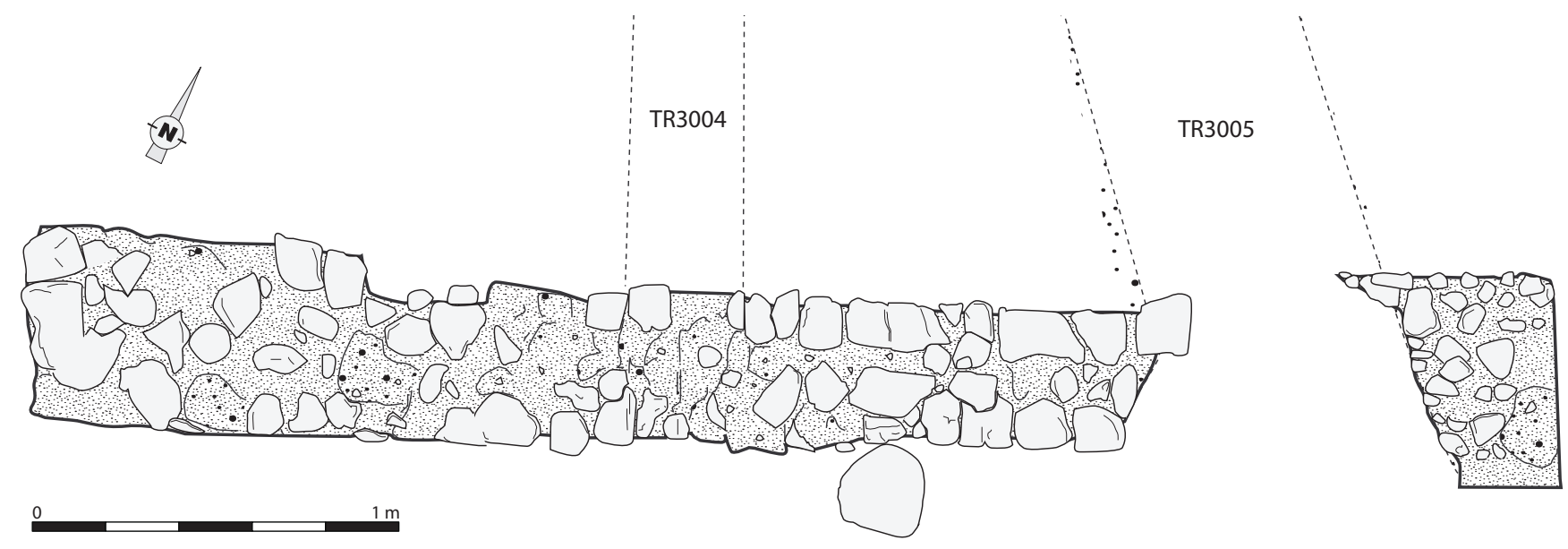

Fig. 225. Relevé du mur MR3003 et de la tranchée TR3004. 


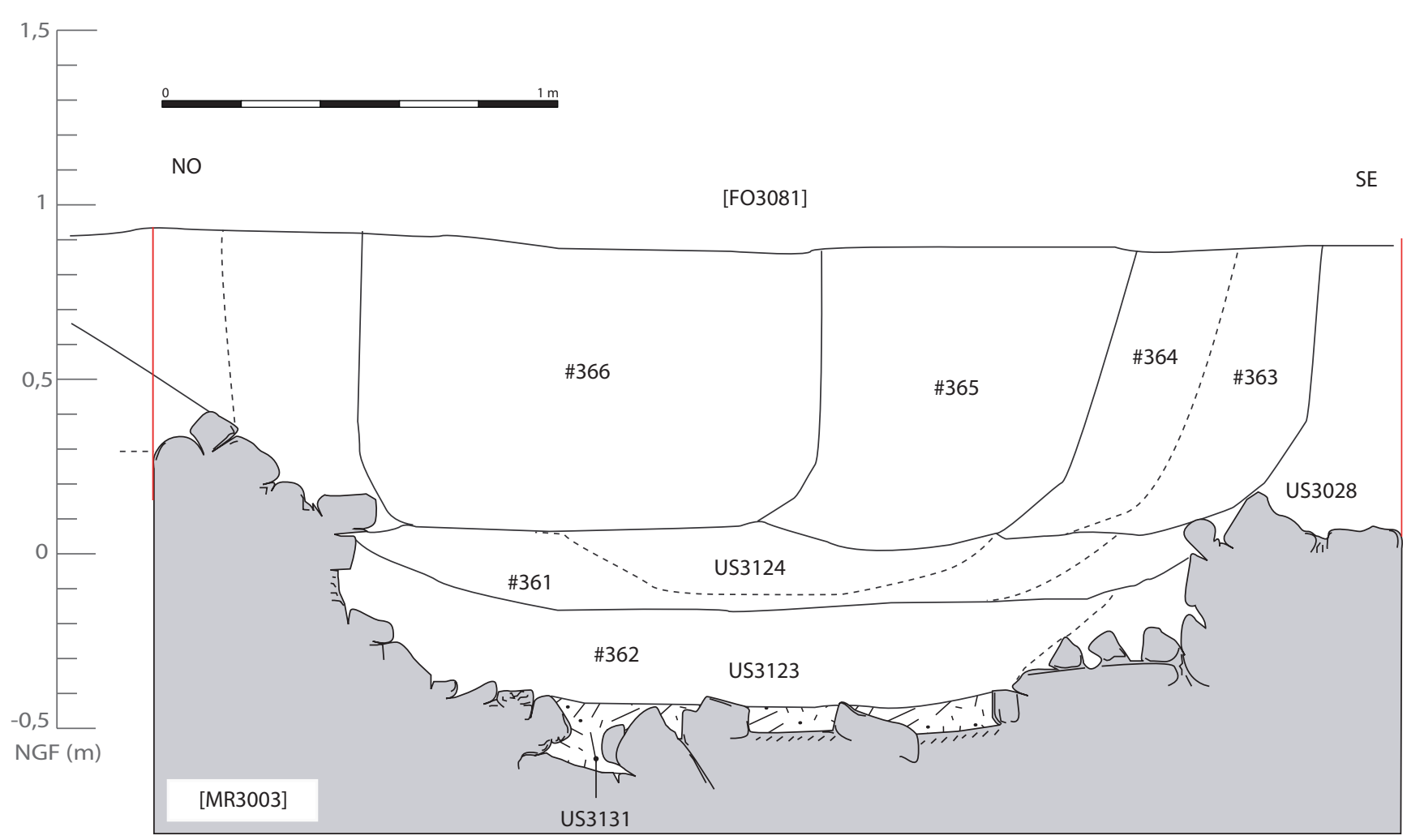

Fig. 226. Relevé en coupe du comblement de FS3081/3017,

au niveau où celui-ci recoupe le corridor antique CN3010.

\subsection{La palynologie}

(S. G.)

L'analyse pollinique nous permet ici, grâce au puits d'une part et au fossé d'autre part, de bénéficier d'une image pollinique de la végétation à la fois locale et régionale. Le signal, largement dominé par la pinède et la bruyère arborescente (Erica arborea) sur toute la séquence du fossé FO3017, montre un maquis très fréquemment soumis aux différents phénomènes d'éclaircissements anthropiques ou naturels, que sont l'écobuage, les incendies accidentels et/ou l'exploitation de la chênaie, etc. Les valeurs du plantain lancéolé (Plantago lanceolata), des Apiacaeae, des Chenopodiaceae et de Polygonum sp. peuvent laisser penser à la mise en pâture d'espaces avoisinants.

\subsection{Chronologie}

(P. E.)

Bien qu'il soit difficile de le prouver, le creusement de ces deux fossés ne paraît pas simultané. En effet, le sommet du fossé FO3081 (1,35 m NGF) est altimétriquement plus bas que le fossé FO3020 (1,55 m NGF). Il n'est pas impossible de supposer que l'un, FO3020, prend la succession de l'autre, FO3081.

\subsection{Les alignements de pieux} (P. E., S. Gr, F. G.)

Dans la partie sud, sur toute la longueur du site, d'ouest en est, une série de poteaux en bois (PO3085) était plantée au sein de l'US3026 ${ }^{13}$, suivant globalement les orientations antérieures. De cet alignement orienté nord-est/sud-ouest, 44 bases de pieux étaient conservées, disposées selon une maille d'environ un mètre ${ }^{14}$. Formant un ensemble très homogène, les pieux se présentaient sous la forme de fûts appointés débités dans des troncs d'une essence résineuse, sans doute du pin (Pinus sp. $)^{15}$, conservés sur une longueur variant de 8 à $57 \mathrm{~cm}$. Encore pourvus de leur écorce épaisse (intacte ou en décomposition), leur diamètre moyen était de 12,5 cm (de 7 à $15 \mathrm{~cm}$ ). Leur extrémité, de 10 à $15 \mathrm{~cm}$ de longueur, très courte, était taillée en biseau et

13 La conservation des pieux étant essentiellement due à la présence de la nappe, c'est elle qui a permis leur conservation jusqu'à une certaine hauteur, sans rapport avec la couche dans laquelle ils étaient plantés.

14 Au sein de cet alignement, dans le secteur 1, on note une particularité formée par une concentration de cinq pieux (3112) présentant, dans l'ensemble, les mêmes paramètres morphologiques que les autres, dont la disposition rapprochée ne respectait plus la même maille, mais qu'il nous est malheureusement impossible d'interpréter.

15 Il s'agit d'une estimation sur la base d'une observation à l'œil nu. 


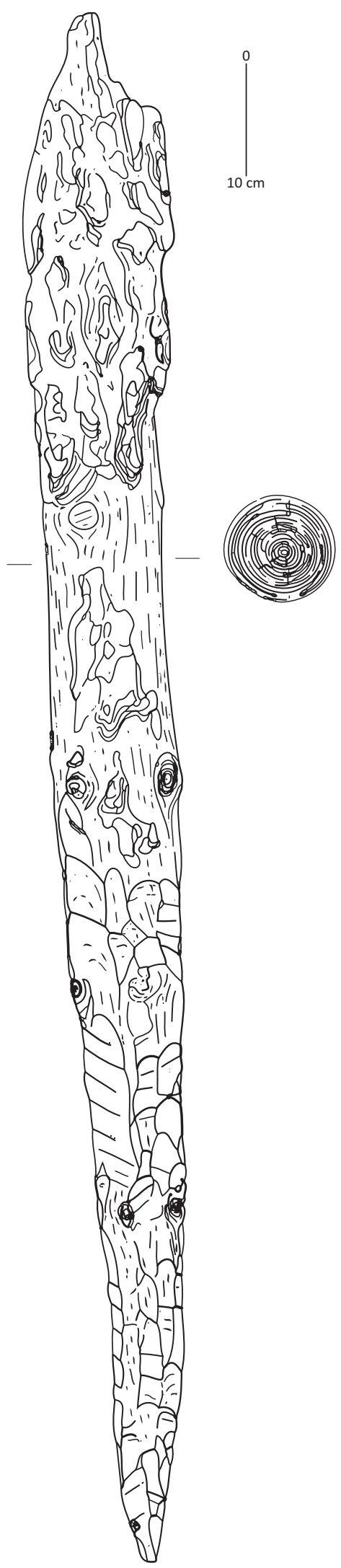

Fig. 227. PO3142/US3152. seul un individu possédait une pointe à 2 pans (3100). Ainsi, compte tenu du faible enfoncement dans le sol, cet alignement de pieux ne peut être associé qu'à une construction légère et d'exécution simple et rapide, bien que soignée. Il constituait une sorte de palissade sans doute à mettre en relation avec le fossé FO3081, strictement parallèle, dont il n'était séparé que de quelques mètres.

Un deuxième série de poteaux (PO3142), contiguë, était composée de 20 pieux disposés selon deux rangées parallèles orientées nord-ouest/sud-est, rejoignant de manière perpendiculaire l'alignement $\mathrm{PO} 3085^{16}$.

Il s'agit aussi de pieux confectionnés dans une essence résineuse, sans doute du pin (seul le pieu 3166 semble avoir été débité dans le bois d'une espèce de pin distincte des autres), dont le diamètre moyen sur écorce (conservée) était de $11 \mathrm{~cm}$ (de 8 à $14 \mathrm{~cm}$ ). Deux d'entre eux, qui ont été prélevés et examinés, étaient conservés sur une longueur respective de 108 et $130 \mathrm{~cm}$. Le pieu 3152 présentait une pointe couvrant près de la moitié de sa longueur, soit $60 \mathrm{~cm}$ environ, taillée à l'aide d'un outil à tranchant droit dont les coups sont marqués par des facettes peu profondes aux lignes d'éclatement perpendiculaires à l'axe du tronc et se chevauchant selon un tracé longitudinal. Un autre outil à tranchant courbe a servi aux finitions de la pointe, à raison de nombreuses percussions ayant creusé des facettes concaves, aux arêtes saillantes, suivant plusieurs axes longitudinaux sur le pourtour du pieu (fig. 227) ${ }^{17}$. La longueur et le diamètre de ces pieux ainsi que leur enfoncement profond, grâce à de longues pointes réalisées de manière soignée, permettent de lier le double alignement PO3142 à une structure plus massive que l'alignement de poteaux précédent. Cet ensemble de poteaux étant associé à l'US3129 correspondant à l'épandage du fossé FO3081, il pourrait s'agir de poteaux porteurs d'une superstructure en élévation, d'un aménagement de berge, ou plutôt d'une limite à cet épandage, comme un ponton utile lors des périodes de crues. L'hypothèse d'un chemin de bois traversant le fossé est séduisante mais ne peut être avancée qu'avec prudence dans la mesure où aucun pieu n'a été retrouvé dans le comblement du fossé.

\footnotetext{
16 Cet alignement correspond aux pieux découverts dans l'angle sud-est de la parcelle lors des diagnostics archéologiques (Michel 1999, 17, tranchée 19). 17 Le nombre élevé de pieux aurait justifié l'entreprise d'une analyse dendrochronologique, mais compte tenu du caractère juvénile des arbres à peine âgés de 20 ans au moment de leur abattage et des raisons déjà évoquées plus haut dans un tel cas, celle-ci n'a pas été mise en oeuvre sur ce matériel.
} 
PREMIÈRE PARTIE : LA FOUILLE
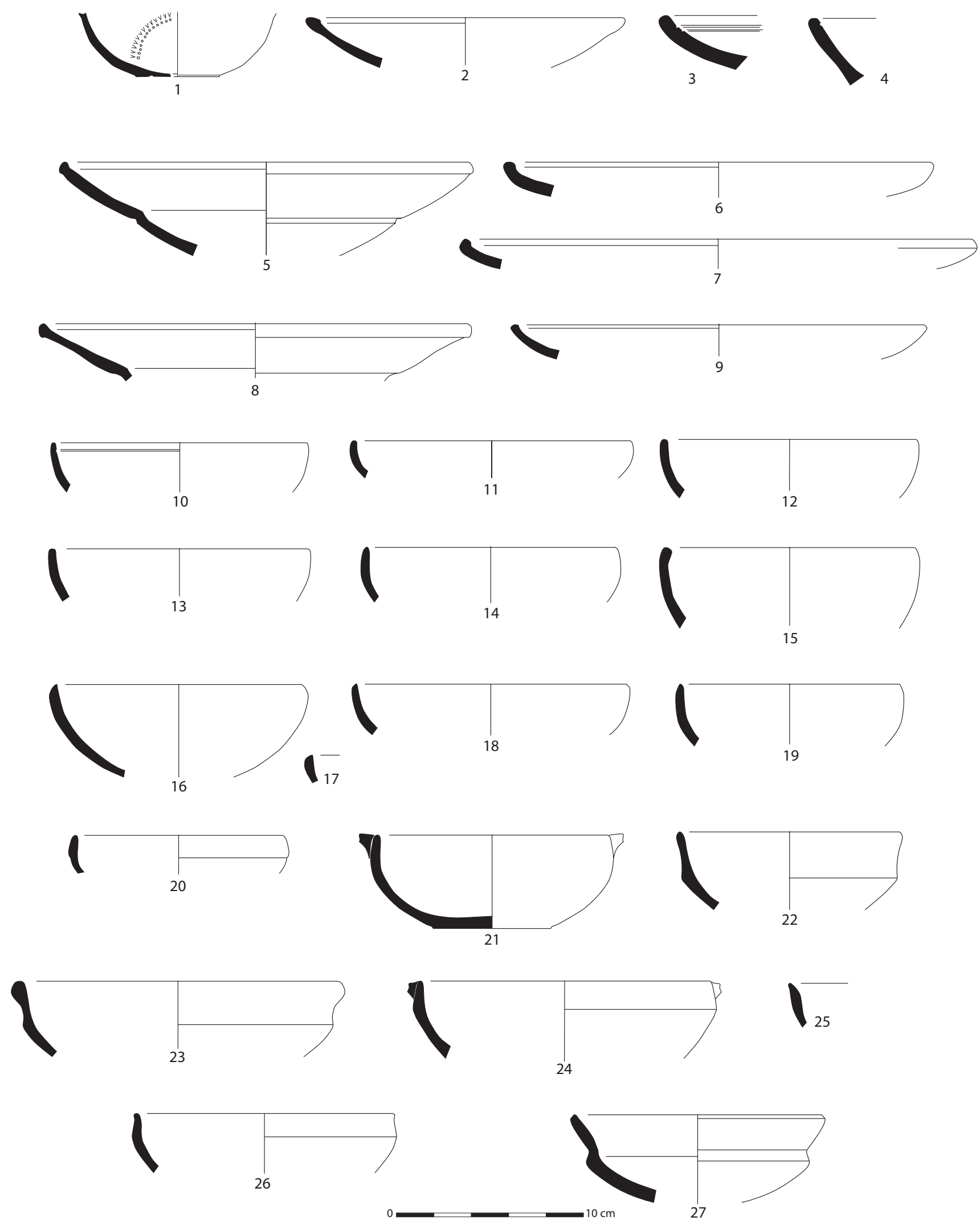

Fig. 228. Le mobilier céramique de la phase 5B. 


\subsection{Datation}

\subsubsection{Le mobilier céramique}

\section{(E. P.)}

La phase $5 \mathrm{~B}$ a fourni un lot de céramiques plus modeste, mais comparable à celui de la phase $5 \mathrm{~A}$, bien que les céramiques résiduelles y occupent une place encore plus importante (plus de $90 \%$ du nombre de restes et plus de $95 \%$ des individus). On signalera seulement le fond d'une petite coupe ou d'une râpe (fig. 228 - $\mathrm{n}^{\circ}$ 1) en sigillée claire D (Treglia 2002) qui appartient probablement à une variante tardive du type Hayes 91D du VII ${ }^{e}$ siècle (Atlante 1981, tav. XLIX.7).

Sur l'ensemble de tessons de céramiques modernes, on retrouve une majorité de fragments de céramique glaçurée fréjusienne dont :
- Des bords d'assiettes à grand marli (fig. 228 - nos 2 à 9),

- Des coupes individuelles hémisphériques simples (fig. $228-\mathrm{n}^{\text {os }} 10$ à 20) dont une avec des languettes de préhension sur la lèvre (fig. $228-\mathrm{n}^{\circ} 21$ ),

- Des coupes individuelles à bord en bandeau plus ou moins développé (fig. 228 - $\mathrm{n}^{\text {os }} 22$ à 27),

- De grandes coupes à bord en bandeau (fig. 229 - $\mathrm{n}^{\text {os }} 1$ et 2) et à bord en gouttière (fig. 229 - no 3),

- Des jattes de préparation (fig. 229 - $n^{\text {os }} 4$ à 6),

- Des bords de pots d'hygiène (fig. 229 - $\mathrm{n}^{\text {os }} 7$ et 8),

- Des cruches (fig. 229 - no 9),

- Un pot à anse de panier (fig. 229 - no 10).

On trouve encore un fragment en céramique pisane à «graffite polychrome» et quelques communes modernes (fig. 229 - nos 11 à 15).

L'ensemble donne un terminus tout aussi imprécis que le mobilier de la phase 5A, mais certainement antérieur à la fin du XVII ${ }^{\mathrm{e}}$ siècle.
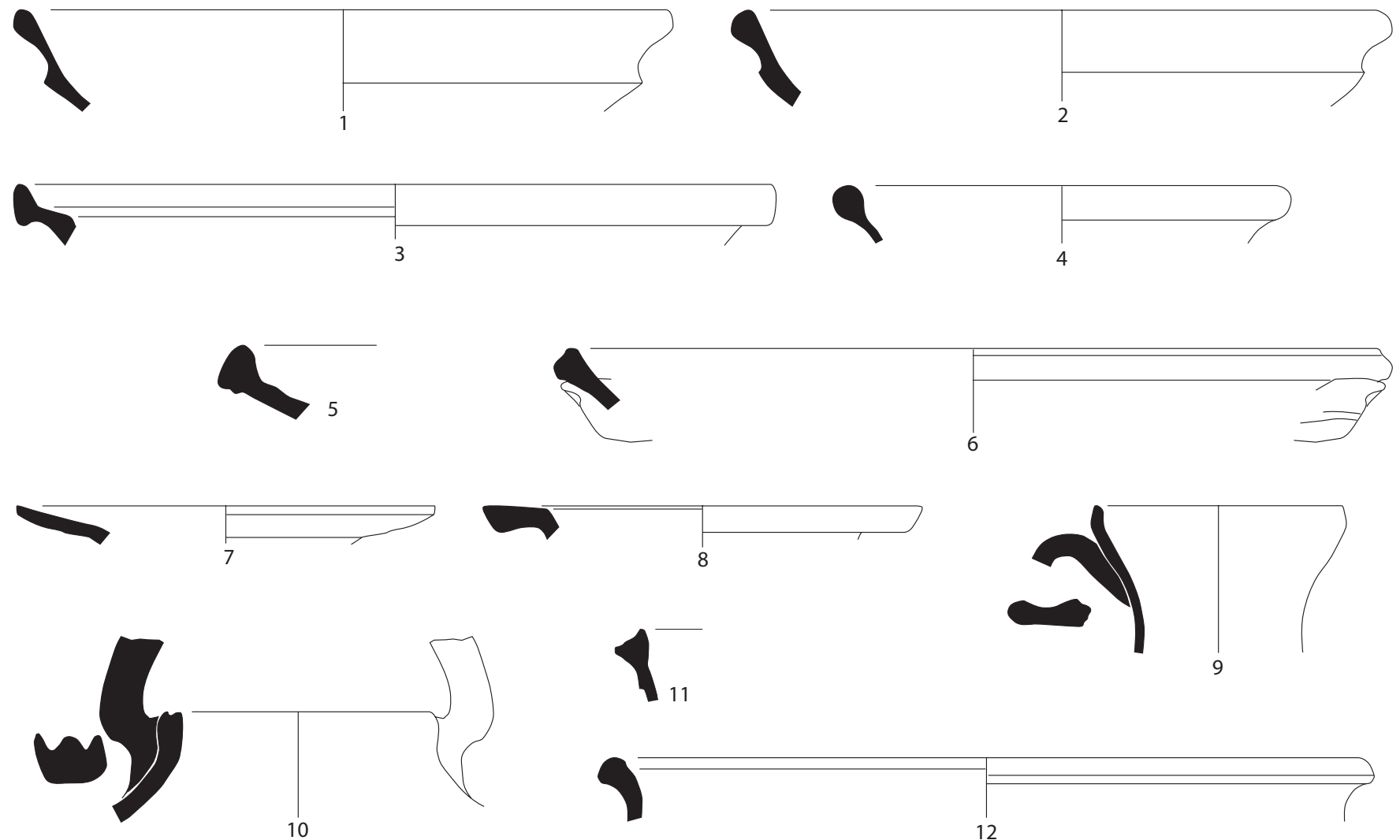

10
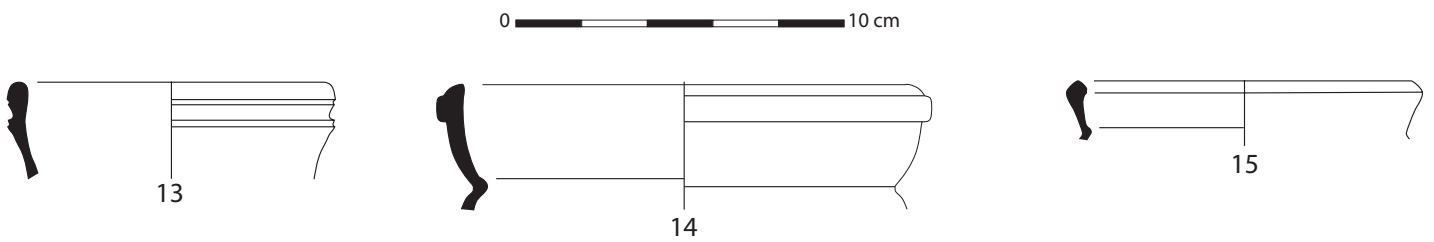

Fig. 229. Le mobilier céramique de la phase 5B. 


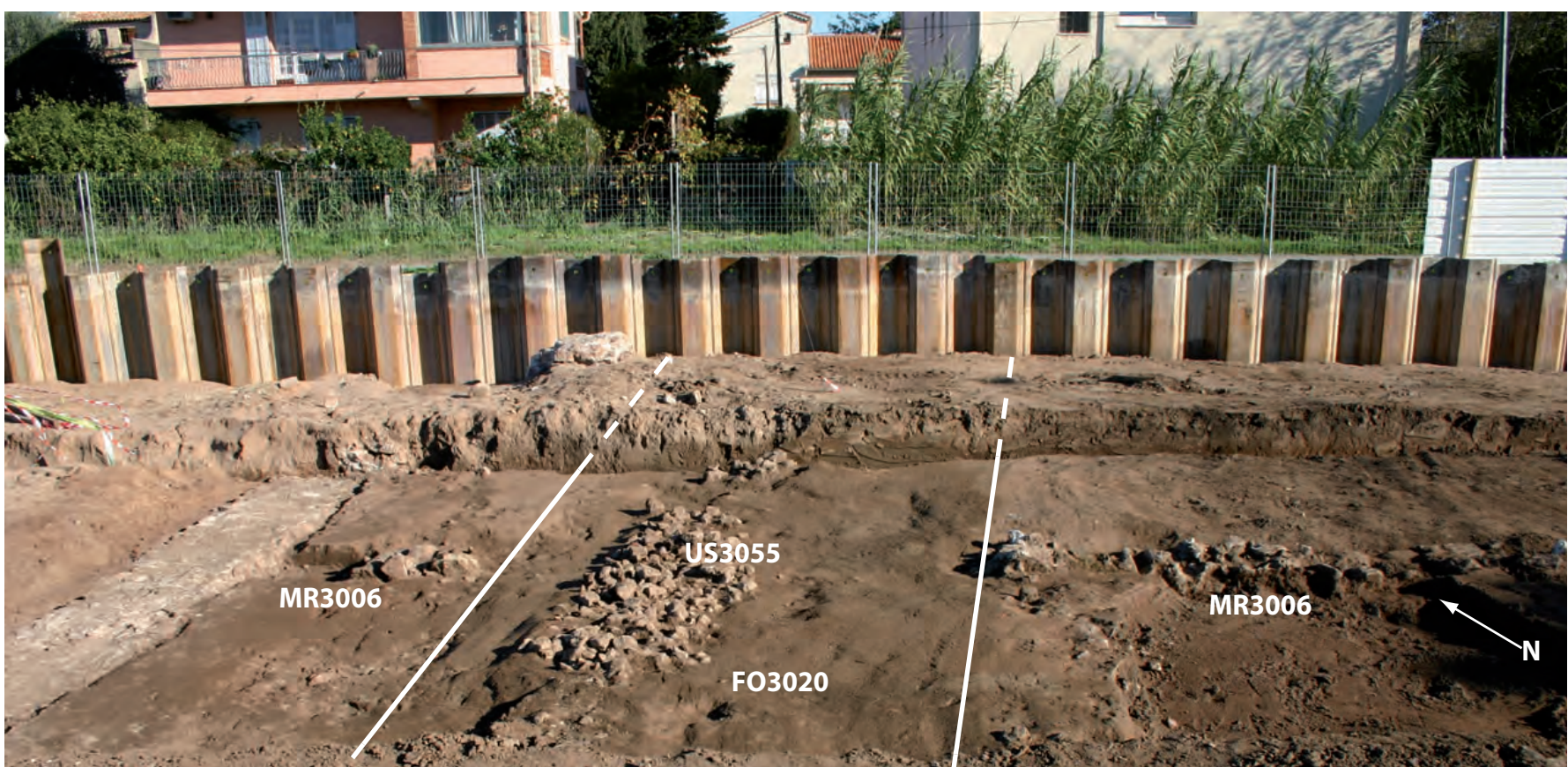

Fig. 230. Amas de pierraille

que l'on retrouve tout au long du comblement de FO3020.

\subsubsection{Datation C14}

(P. E.)

Compte tenu des précédentes interprétations faites au sujet de cet alignement de pieux repéré lors du diagnostic de J.-M. Michel en 1998, dans un premier temps interprété comme berge d'un chenal reliant l'Argens au bassin portuaire, puis plus récemment encore (Gébara, Morhange 2010, 47) comme des aménagements de berges antiques, deux datations radiocarbones ont été effectuées ${ }^{18}$.

$\mathrm{La}$ datation $^{19}$ obtenue indiquant le courant du XVIII ${ }^{e}$ siècle et montrant ainsi une période de fonctionnement encore plus récente que celle suggérée par l'étude du mobilier céramique, évacue définitivement, faut-il l'espérer, cette volonté tenace de voir ces alignements de pieux remonter à l'Antiquité.

\subsection{Interprétation}

(P. E.)

C'est durant cet état que s'observe de façon plus nette l'épierrement d'une partie des structures antiques existantes, en particulier les grands murs MR2002 et 2004. Ce fait indique clairement que ces murs ne marquaient plus aucune limite à cette époque.

18 Codes labo: Poz-21732 et Poz-21733

19 Respectivement $165 \pm 30 \mathrm{BP}$ et $145 \pm 30 \mathrm{BP}$
La récupération des matériaux de construction pourrait être mise en rapport avec la réoccupation des thermes antiques de Villeneuve.

\section{La phase 5, état $\mathrm{C}$}

\subsection{Description}

(P. E.)

Ce dernier état de la phase 5 correspond essentiellement sur le terrain au colmatage définitif des deux fossés, impliquant nécessairement une transformation dans la pratique agricole de la zone.

La partie sommitale du comblement de chaque fossé présente des caractéristiques qui permettent d'exclure un colmatage faisant suite à un abandon. En effet, la partie haute des comblements a été empierrée pour assainir définitivement la zone, à l'image des amas de pierraille que l'on retrouve tout au long du comblement de FO3020 (3007, 3023 et 3055) (fig. 230).

\subsection{Mobilier céramique et datation \\ (E. P.)}

Dans la phase 5C, qui correspond à la fin du fonctionnement des différentes structures dès la phase 5, le mobilier d'époque moderne dépasse le mobilier résiduel antique en nombre d'individus. Malgré la quantité de céramiques recueillie, il est difficile de 
distinguer la datation de la phase $5 \mathrm{C}$ de celle des phases $5 \mathrm{~A}$ et $5 \mathrm{~B}$. En effet, on y retrouve une majorité de céramiques glaçurées de Fréjus, notamment :

- Des assiettes creuses à large marli (fig. 231 - nos 1 à 7),

- Des coupes hémisphériques (fig. 231 - $\mathrm{n}^{\text {os }} 8$ à 10),

- De grandes coupes à bord en bandeau (fig. 229

- $\mathrm{n}^{\circ} 11$ ) et à bord en gouttière (fig. 231 - $\mathrm{n}^{\circ} 12$ ),

- Quelques cruches (fig. 231 - $\mathrm{n}^{\text {os }} 13$ et 14),

- Quelques jattes (fig. 231 - $\mathrm{n}^{\circ} 15$ ),

- Des pots à bord droit (fig. 231 - $\mathrm{n}^{\text {os }} 16$ et 17).

Cependant, on signale encore quatre fragments de céramique à pâte blanche et glaçure verte métallique
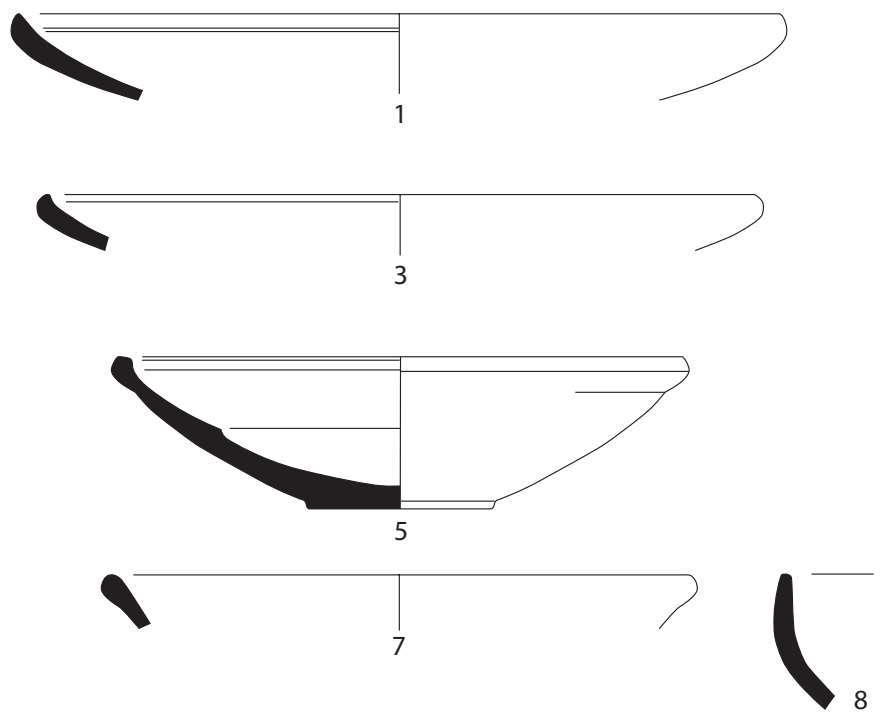

appartenant à deux objets. Le premier semble être une coupe à bord ourlé, le second, une bouteille ventrue à anses de préhension horizontales. On connaît des objets au profil semblable à Martigues et sur l'épave de la Dorothea, datés de la seconde moitié du XVII ${ }^{e}$ siècle (Amouric et al. 1999, 214, 236). Si l'on accepte ce parallèle, ce sont donc ces fragments qui donnent le terminus de la phase 5C. De façon marginale, il faut encore noter la présence d'un fragment de bol en faïence de la région de Valence. Le décor bleu sur fond blanc est semblable à celui des coupes mises au jour dans l'épave Carro 4, à l'ouest de Marseille, datée du milieu du $\mathrm{XV}^{\mathrm{e}}$ siècle (Amouric et al. 1999, fig. 90-91).
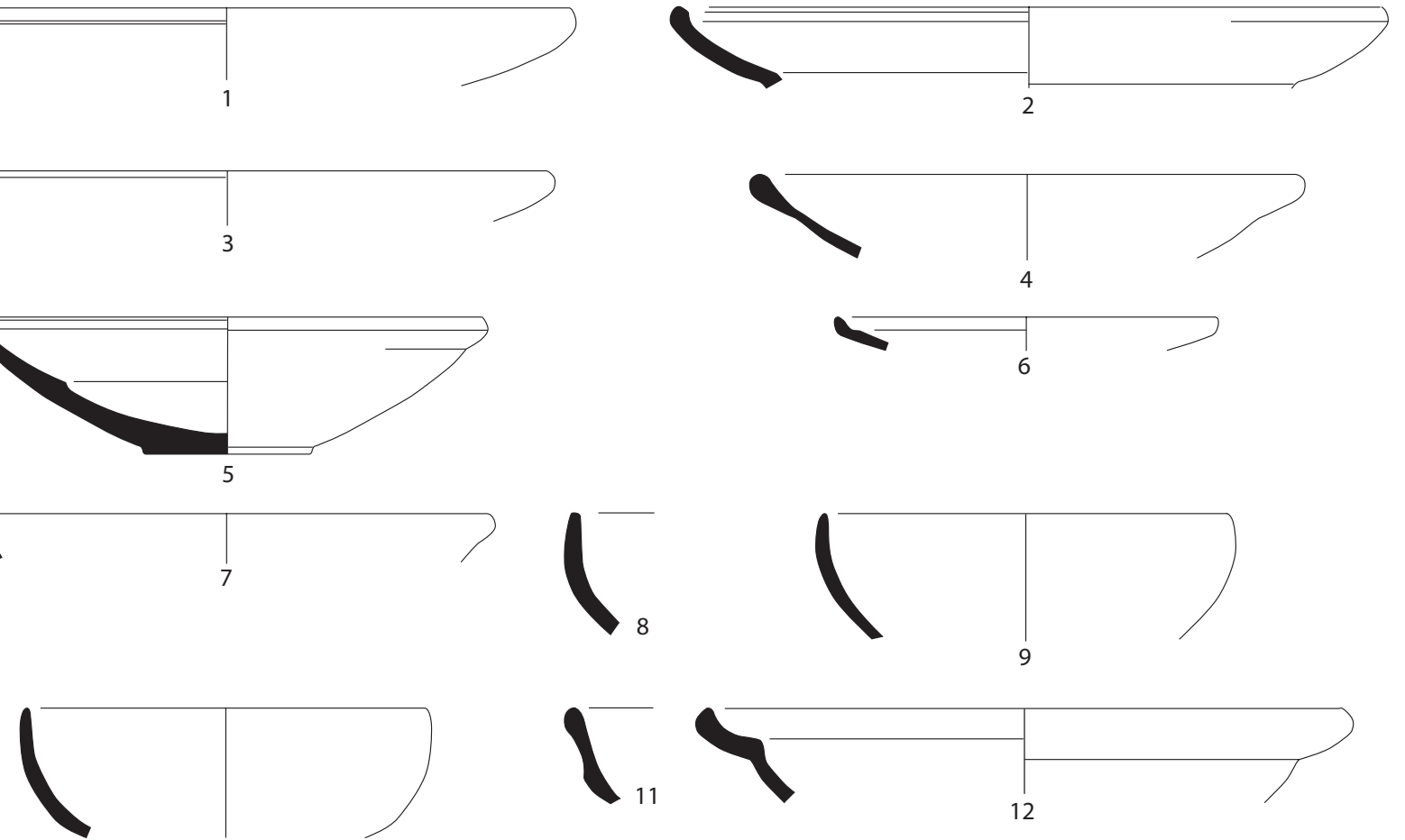

10
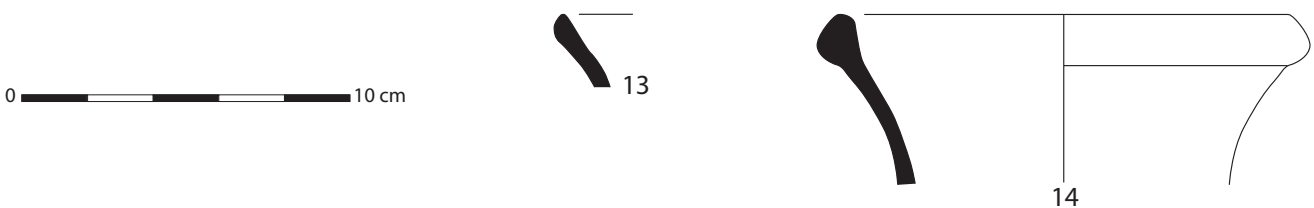
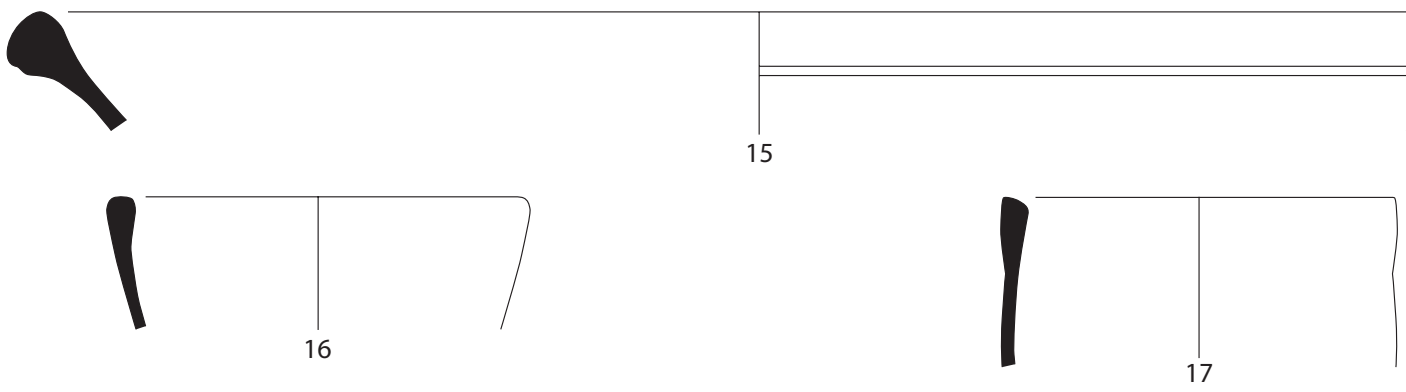

Fig. 231. Le mobilier céramique de la phase 5C. 


\subsection{Interprétation}

(P. E.)

Ces derniers aménagements, principalement l'assainissement des deux grands fossés, doivent être mis en relation avec la transformation du domaine probablement sous la volonté du nouveau propriétaire. En effet, la bastide de Villeneuve telle qu'elle apparaît dans ces grandes lignes aujourd'hui, remonterait à la fin du XVII siècle (Rivet et al. 2000, 333). Selon J.-F. Girardin, qui signale l'existence de structures antiques sous la Ferme de Villeneuve, le bâtiment se trouvait en 1729 sur « un domaine considérable, appartenant à M. de Suffret» (Girardin 1729, 61-63).

La ferme n'est pas représentée sur la carte de Goguet de 1752, mais on peut voir dans le secteur concerné le long du chemin dit de Villeneuve, la représentation de nombreux champs cultivés. 


\section{Chapitre 6}

\section{L'époque contemporaine}

\section{Interprétation}

(P. E.)

Cette dernière phase, qui va de la fin du XVII ${ }^{e}$ siècle à nos jours, n'a été que partiellement abordée. Le secteur est toujours resté une zone agricole jusqu'à la construction actuelle. La fruiticulture est restée prépondérante durant le $\mathrm{XX}^{\mathrm{e}}$ siècle, où ce sont des pruniers qui ont succédé aux vignes, après l'inondation du terrain causé par la rupture du barrage du Malpasset.

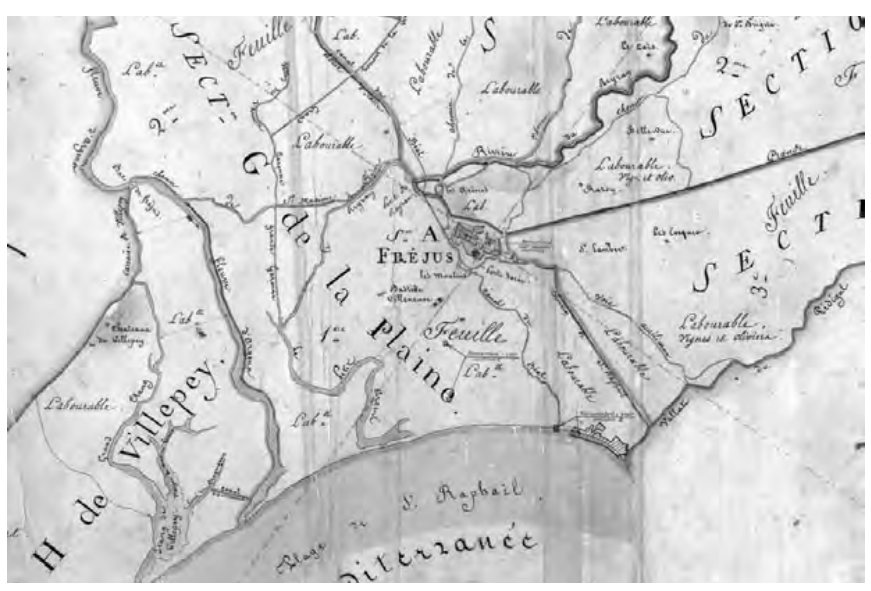

Fig. 232. Extrait du cadastre napoléonien de 1826.

La ferme n'apparaît qu'en 1825, sur une carte anonyme, puis sur le cadastre napoléonien de 1826, à cheval sur deux parcelles : 115 et 108 (fig. 232 et 233). Il faut y voir deux bastides, dont l'une avec terrasse, deux écuries et une bergerie avec cour. C'est en 1886 que le bâtiment sera classé Monument Historique.

\section{Le mobilier céramique}

(E. P.)

Le mobilier de la phase 6 est relativement riche. Hormis quelques témoins antiques, on retrouve :

- Une majorité de céramiques locales du XVI et du début du XVII ${ }^{\mathrm{e}}$ siècle (fig. 234 - nos 1 à 12);
- Un bord de coupe en céramique à « graffite polychrome » pisane (fig. $234-\mathrm{n}^{\circ} 13$ ) contemporain ; on ne trouve aucun témoin du XVIII siècle ;

-- Quelques céramiques communes modernes (fig. $234-\mathrm{n}^{\text {os }} 14$ à 16) ;

- Un bord de jarre (fig. 234 - $\mathrm{n}^{\circ}$ 17).

Le mobilier subactuel est rare. On compte quatre bords d'objets en porcelaine mécanique renvoyant au plus tôt au $\mathrm{XIX}^{\mathrm{e}}$ siècle ou au début du $\mathrm{XX}^{\mathrm{e}}$ siècle De façon anecdotique, on soulignera encore la présence de deux témoins d'une fréquentation du site au Moyen Âge. Il s'agit d'un bord de marmite à pâte grise grésée et d'un bord de marmite à glaçure interne jaune de l'Uzège (fig. $\left.234-\mathrm{n}^{\circ} 18\right)$. Ce dernier est daté des XIV et XVe siècles (Amouric et al. 1995, fig. 102-103, 107).

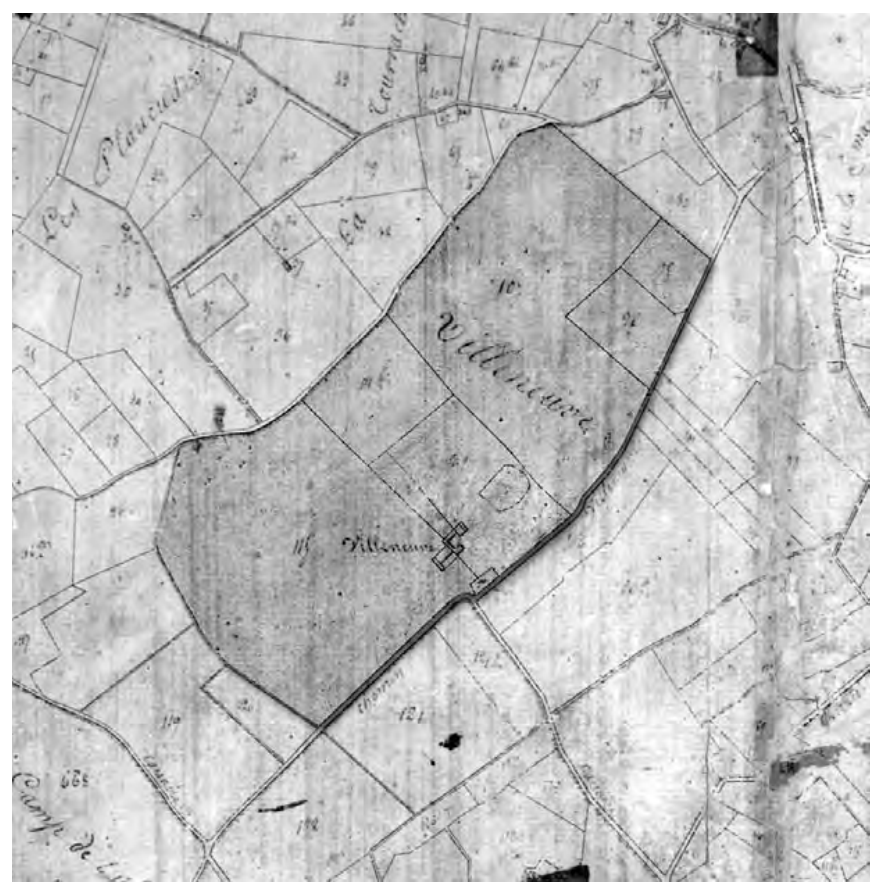

Fig. 233. Détail du cadastre napoléonien de 1826. 
PREMIÈRE PARTIE : LA FOUILLE
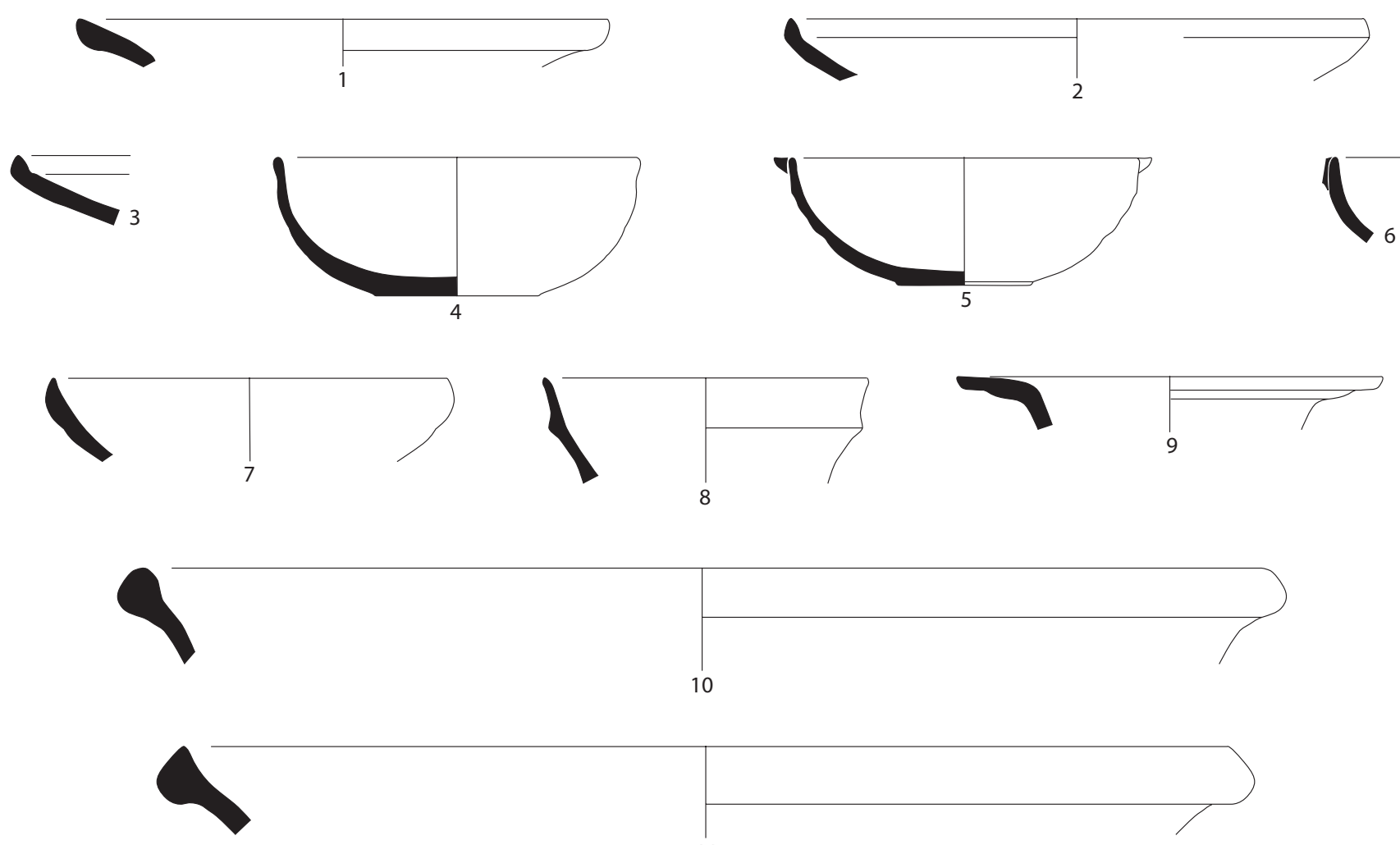

10
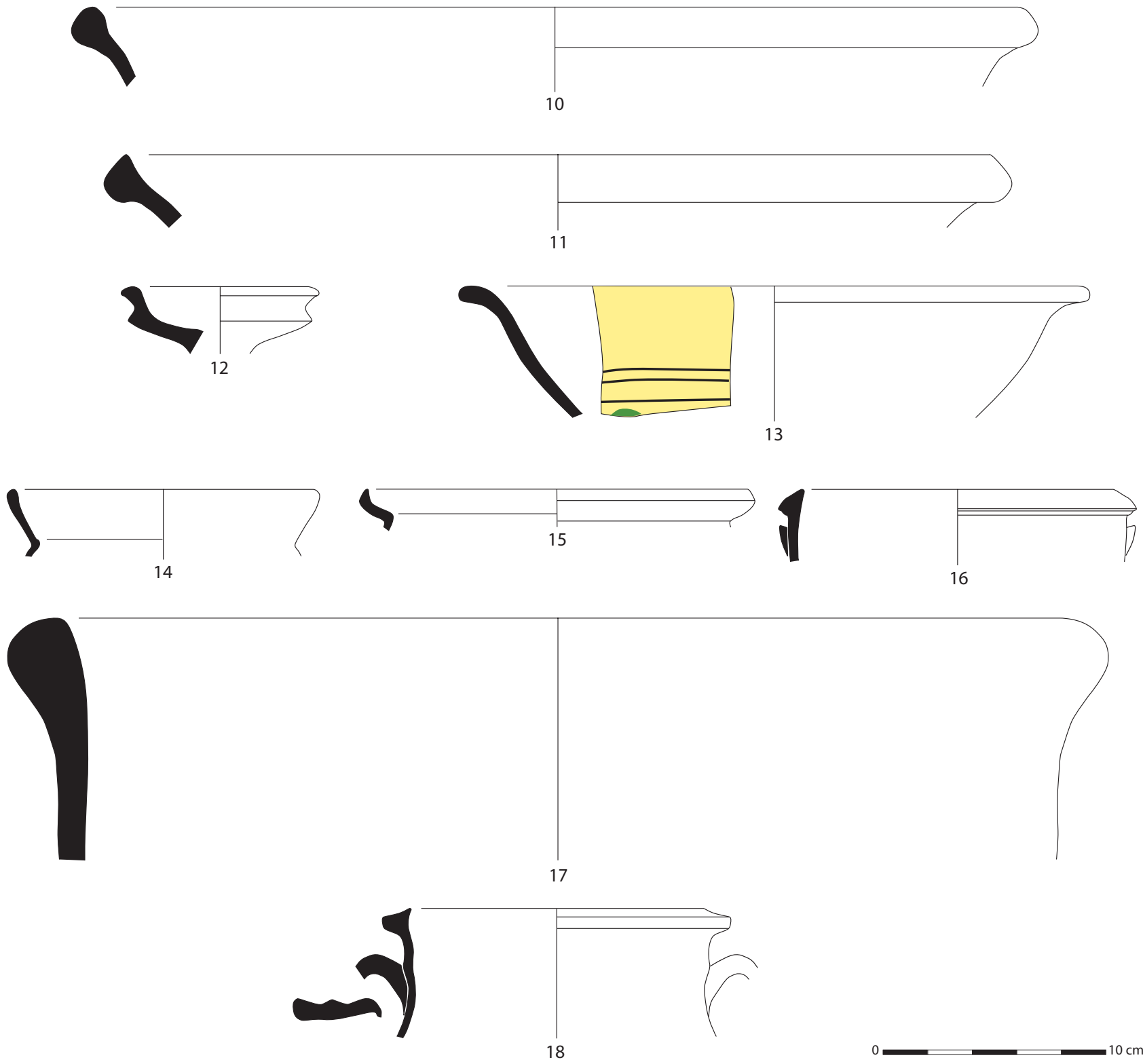

Fig. 234. Le mobilier céramique de la phase 6. 


\section{Conclusion}

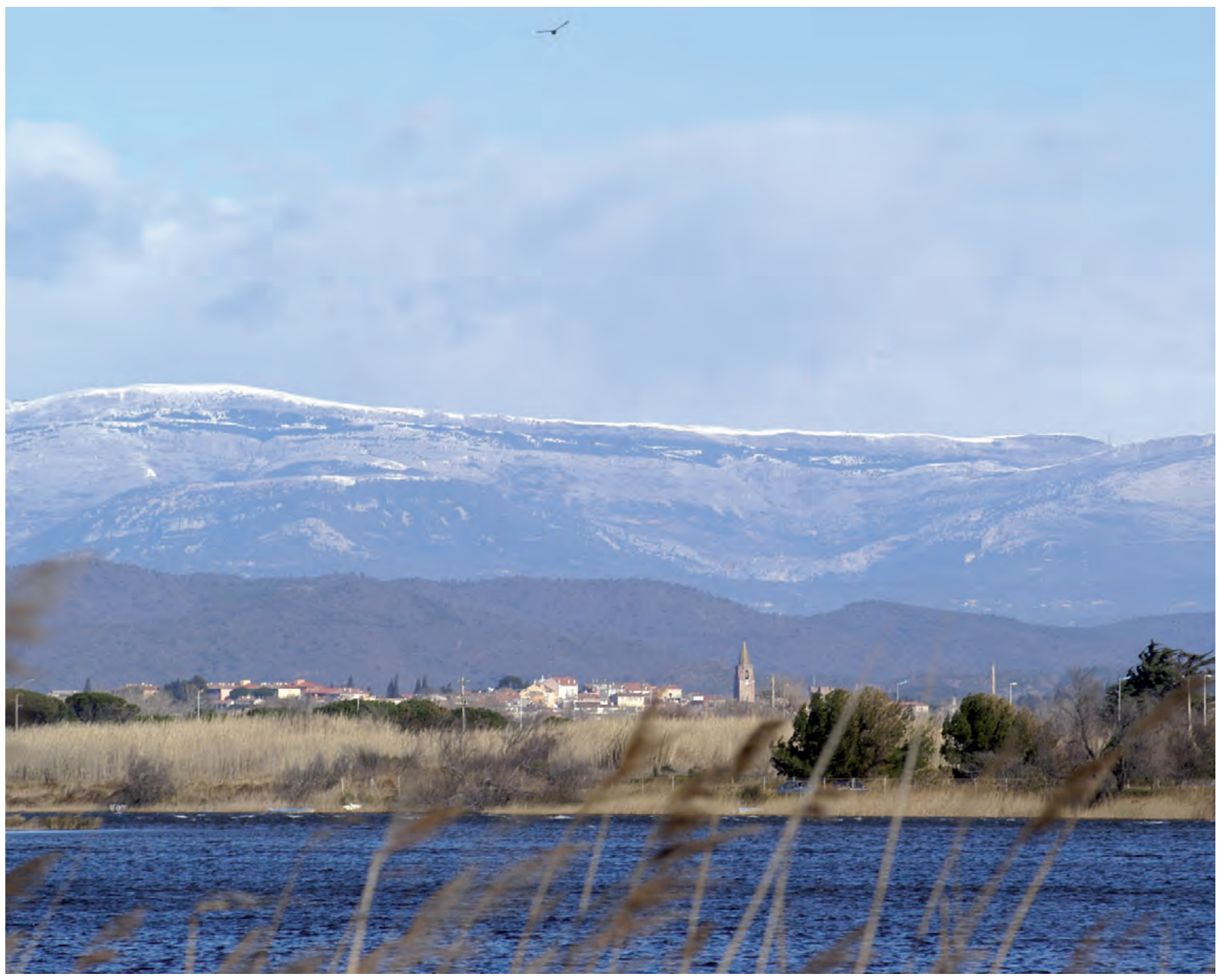

Vue de Fréjus depuis les étangs de Villepey avec, en arrière plan, les sommets enneigés du plateau de Canjuers (Cl. Ville de Fréjus / R. Hacquard ${ }^{\odot}$ ). 



\section{Conclusion}

\section{Synthèse archéologique et analyses paléoenvironnementales}

\section{L'archéologie}

(P. E.)

Par la nature de ses découvertes, la fouille de Villa Romana a permis d'apporter des données entièrement nouvelles sur l'environnement d'un quartier suburbain de Forum Iulii en fournissant un cadre naturel à des vestiges bâtis relativement denses. La position du littoral et son recul rapide ont fortement influé sur le développement de ce secteur et lui ont conféré une place de choix, en particulier durant les premiers temps de la colonisation. Ces travaux ont été également l'occasion de confirmer certaines hypothèses envisagées par les fouilles antérieures. À l'image du quartier dans son ensemble, bien documenté depuis les publications de l'Atlas topographique et des fouilles des Aiguières (Rivet et al. 2000 et Goudineau, Brentchaloff 2009), le site de Villa Romana a connu une évolution en plusieurs phases. Un témoignage ténu lié aux premiers aménagements de bord de mer, aux alentours du milieu du ${ }^{\text {er }}$ siècle av. J.-C. permet de confirmer l'occupation ancienne du secteur, déjà « supposée » par les fouilles des Aiguières. Pour cette époque, nous ne pouvons qu'observer des aménagements ponctuels destinés à stabiliser le littoral. Ces derniers impliquent nécessairement l'existence d'aménagements en arrière de la plage, que l'on est tout naturellement tenté de rattacher aux premières décennies de Forum Iulii, avant même qu'elle ne devienne colonie. En élargissant le champ de vision, on pourrait prolonger cet aménagement du littoral jusqu'au pied de la butte Saint-Antoine, où des structures situées sous le grand bâtiment augustéen pourraient remonter aux années 40/30 av. J.-C. (Rivet et al. 2000, 290) et constituer la limite orientale de ces premiers aménagements.

La phase suivante marque le développement du quartier à partir du dernier tiers du Irr siècle av. J.-C., sur des terrains gagnés en peu de temps sur la mer. La progradation rapide du littoral qui témoigne, pour partie, d'une accélération des défrichements et de la mise en culture, est immédiatement mise à profit pour étendre l'espace occupé. À partir de ce moment, l'usage des terrains fouillés sera défini pour près de deux siècles comme jardin d'agrément. Leur évolution durant cette période permet d'entrevoir de façon indirecte les évolutions du quartier dans son ensemble, en particulier en tentant de raccorder notre fouille avec celle de Chr. Goudineau aux Aiguières. Ainsi, la phase 2 de Villa Romana correspondrait à l'état 1 du site des Aiguières, où le camp en dur serait construit. L'intégration au sein du camp militaire implique de positionner le site dans l'angle sud-est du camp. La fouille n'apporte rien sur ce point, ni même sur le caractère militaire du secteur. Ainsi, c'est essentiellement la chronologie haute qui permet d'associer les aménagements des phases 1 et 2 avec l'installation de la flotte et donc, du camp. Il va de soi que les aménagements de plage, puis du jardin, s'accordent sans difficulté avec l'image d'un camp de la flotte de première importance. Mais force est de reconnaître que rien ne le confirme non plus. Toutefois, d'autres éléments apportent, en arrière-plan, des témoignages évoquant la présence de ces militaires aux origines théoriquement orientales... Il s'agit en réalité d'éléments parfois anodins auxquels nous devons donner une résonnance manifeste, compte tenu de ce contexte particulier. Tout d'abord, il y a l'existence dans l'ensemble thermal d'une pièce circulaire probablement chauffée et comprenant une série de renfoncements bas dont l'allure générale conduit S. Ardisson à conclure qu'il s'agit d'un laconicum transformé en frigidarium, fait courant notamment en Campanie. Toutefois, la présence tout autour de la pièce de niches basses pour le premier état en font un modèle unique et apparente cette dernière à une tholos de type grec qui, associée à des thermes de type romain, constitue une configuration essentiellement connue en Égypte... Il est également à noter la présence de phytolithes de palmier (Arecaceae), espèce probalement cultivée sur place et employée couramment dans les cultes orientaux. Enfin, bien que remployés à une époque bien plus tardive, on a découvert sur le terrain de Villa Romana des éléments d'un navire de grandes dimensions, entre 30 et $40 \mathrm{~m}$ (ci-après étude de G. Boetto, S. Greck et Fr. Guibal, Fréjus-Villeneuve 
3), construit antérieurement à la fin du II ${ }^{\mathrm{e}}$ siècle av. J.-C. Ces restes témoignent de la présence à proximité de Villeneuve de grands navires anciens et désarmés...

L'amorce d'un certain "déclin » dès le début de l'époque flavienne, observé sur le site des Aiguières, trouve ici un parallèle avec une diminution quantitative des plantations entretenues dans le jardin lors de la phase 3. Cette période correspond au développement maximal de la cité de Forum Iulii qui, entre la fin du $\mathrm{I}^{\mathrm{er}}$ et le début du II ${ }^{\mathrm{e}}$ siècle apr. J.-C., est parée de l'ensemble de son programme monumental. Le désintérêt apparent pour le quartier de Villeneuve trouve sans doute en partie son explication dans son caractère excentré, peut-être à l'image de ce qui se produit dans le quartier extra-urbain oriental du Chemin de Valescure, délaissé à la même période.

Nous avons alors évoqué la possibilité qu'à ce moment là, l'ensemble jardins/thermes soit intégré dans une grande villa, dont le centre serait situé en dehors de la zone. Sur le site de Villa Romana, les indices d'un abandon du site apparaissent vers le milieu du $\mathrm{II}^{\mathrm{e}}$ siècle apr. J.-C. (phase $3 \mathrm{~B}$ ), et trouve là encore un écho sur le site des Aiguières. Mais celui-ci semble d'une très courte durée. En effet, l'occupation marquée par la phase suivante illustre en réalité un changement de fonction avec le développement d'un espace agricole, aux cultures variées. Ainsi, si le quartier, ou la partie de villa, perd sa fonction initiale, la zone n'est pas pour autant désertée. Dans le cas où le site serait partie intégrante d'une villa, la transformation d'un espace thermal en zone agricole semble s'accorder avec la phase de prospérité agricole du IIe siècle, comme l'atteste la même transformation (pars urbana en pars rustica) mise en évidence pour la villa de Saint-Martin à Taradeau par exemple. En revanche, à Villeneuve, rien ne permet de penser que les bâtiments thermaux soient alors utilisés en tant que pars rustica, mais l'abandon de leur fonction primitive semble inéluctable. Au final, le paysage que livre cette découverte apparaît plus en accord avec le développement de la ville dans le courant du $\mathrm{II}^{\mathrm{e}}$ siècle apr. J.-C. En effet, la proximité du quartier de Villeneuve avec le cœur de la ville et sa situation au débouché du Reyran et de l'Argens, permettent difficilement d'envisager une vaste zone abandonnée et en friche dès cette époque. L'essor d'espaces cultivés permet donc de restituer une plaine agricole étendue jusqu'à la ville, cette situation se maintenant au moins jusqu'au tout début du Ve siècle apr. J.-C. À partir de cette date, le secteur ne présente plus de témoignages d'occupation notable jusqu'aux alentours du XIV siècle. La reprise d'une activité agricole, ainsi que probablement la réoccupation du bâtiment thermal transformé en ferme, attendront plus de dix siècles. La période moderne est marquée par le développement dans le quartier de Villeneuve d'une agriculture variée, tournée vers le blé, la vigne et la fruiticulture. Cette situation évoluera peu jusqu'aux années 1960 qui voient le début d'une urbanisation dense dans ce quartier. 


\section{Restitution pluridisciplinaire du milieu et des activités humaines sur le site de Villa Romana}

\author{
(L. B., P. E., I. F., S. G., S. M., P. P., C. S., P. V.)
}

\subsection{Des approches multiples pour la restitution du milieu à l'échelle locale}

Les fouilles de Villa Romana ont livré un nombre relativement limité de structures bâties et peu de mobilier archéologique au regard de la superficie fouillée. Même si divers aménagements désignent clairement un espace à vocation horticole au sens large, ce sont, pour une bonne part, les structures en creux (puits, bassins, fosses de plantation et creusements divers) et leur contenu qui ont fourni le matériau nécessaire à l'interprétation fonctionnelle de la parcelle. L'apport conjoint des archéologues et des paléoenvironnementalistes s'est avéré être la seule option susceptible d'apporter les réponses aux questions posées par la fouille. Le choix s'imposait donc de multiplier et de croiser les approches bioarchéologiques et paléoécologiques, dans le but de restituer l'environnement et les activités à l'échelle locale ainsi que leurs évolutions à travers le temps. Des analyses anthracologiques, xylologiques, carpologiques, malacologiques, entomologiques, palynologiques et phytolithologiques ont donc été mises en œuvre, dans des conditions variant avec le matériel étudié selon les impératifs de la fouille d' urgence et dans le souci constant de croiser les résultats en privilégiant l'examen des aménagements et des niveaux sédimentaires communs.

Les résultats obtenus offrent une rare cohérence. D'une part parce que les sédiments échantillonnés sont souvent identiques (conditions humides et anoxiques favorables à une bonne conservation), d'autre part parce que les modes de dépôt apparemment homogènes privilégient l'apport local. Ce dernier point s'explique par les faibles dimensions des structures échantillonnées, fonctionnant comme des petits pièges sédimentaires peu soumis au transport plus lointains (par hydrochorie notamment) et par l'impact limité de la faible diversité des activités humaines pratiquées sur place.

Ces résultats concernent principalement les phases 3 (fin $\mathrm{I}^{\mathrm{e}} / \mathrm{II}^{\mathrm{e}}$ siècle apr. J.-C.) et $4 \mathrm{~A}-\mathrm{B}$ (fin $\mathrm{II}^{\mathrm{e}} / 1^{\text {ère }}$ moitié du $\mathrm{V}^{\mathrm{e}}$ siècle apr. J.-C.). La période antique a fait l'objet d'un échantillonnage privilégié par rapport à l'occupation moderne ultérieure ; elle est effectivement la mieux représentée et comporte les niveaux les mieux conservés. La problématique d'utilisation de l'espace dans le cadre de l'aménagement périurbain périphérique soulève alors des questions plus particulières. La phase 2 (fin $\mathrm{I}^{\mathrm{er}}$ siècle av. J.-C. / milieu I ${ }^{\text {er }}$ siècle apr. J.-C.) reste malheureusement mal connue, le sédiment oxydant de remplissage des fosses de plantation étant défavorable au piégeage et à la conservation de la plupart des écofacts, de même que le comblement sableux du puits 1201, seule structure ouverte et anoxique disponible.

La vocation de la parcelle tournée dès l'Antiquité vers l'exploitation agricole sous diverses formes a été clairement dévoilée par ces études pluridisciplinaires. Elles ont permis de dégager un certain nombre de points à plus ou moins grande échelle que nous nous proposons de résumer ici. Ainsi, l'éloignement progressif du littoral transparaît dans l'évolution du site, les phases de relatif abandon indécelables par l'archéologie classique ont été nettement cernées et l'environnement immédiat de la parcelle apparaît également grâce à ces études bioarchéologiques et paléoécologiques.

\subsection{Un sol sableux et une présence constante de l'eau : la prégnance du milieu littoral}

Le caractère littoral et humide de la parcelle transparaît largement dans les analyses. La présence d'eau stagnante, peu profonde et riche en matières organiques est détectée par la carpologie, l'entomologie, la malacologie et la palynologie dans les bassins 1262 et 3339 ainsi que dans plusieurs fossés (notamment 3179 et 3199 ), où se développent une flore et une faune aquatiques caractéristiques. Dans les fossés, la nappe d'eau semble temporaire. Partout, il s'agit d'eau douce comme le montre l'absence d'animaux ou de végétaux halophiles.

L'humidité édaphique aux abords des structures en eau, dans leur comblement ultime et probablement dans les points bas de la parcelle, est identifiée par le développement d'une végétation de roselières, de bas marais et de prairies humides (cypéracées, joncs, roseaux) colonisée par des communautés diversifiées d'arthropodes (de Carabidae notamment) et de mollusques. Le caractère sablonneux des sols est tout aussi manifeste. Il entraîne dans les parties hautes et à la saison estivale une sécheresse édaphique qui se traduit par la présence de maigres communautés végétales typiques du littoral méditerranéen sableux. Un petit groupe d'arthropodes, typiques des sols dénudés et sablonneux et même des dunes vives du littoral méditerranéen, fréquente ce même milieu. La parcelle étudiée devait se situer à l'interface entre un milieu de marécages littoraux et un milieu dunaire.

C'est donc sur ce type de sol que se développe l'activité agricole ${ }^{1}$ de la parcelle durant l'Antiquité,

1 Sur ce point, l'idée est venue à certains d'entre nous de supposer par ce biais des activités agricoles situées en bordure de marécage littoral comme moyen de compenser la rareté des pluies en région méditerranéenne. 
impliquant un mode de culture adapté, un enrichissement en engrais organiques et une irrigation spécifique.

\subsection{Perception de phases de désaffection relative de la parcelle}

Dans la plupart des cas, les sédiments analysés semblent conservés à l'intérieur des structures en creux à la faveur d'un mauvais entretien de ces dernières, correspondant vraisemblablement à des phases de désaffection relative de la parcelle. Ceci est lisible dans les bassins, soumis à un comblement progressif entraînant d'abord une eutrophisation des eaux puis l'atterrissement complet. Le développement de la végétation hygrophile peut également résulter de la désaffection de la parcelle pouvant, par exemple, matérialiser un mauvais entretien des structures de drainage comme le laissent envisager les analyses macromorphologiques de leur comblement.

Le milieu reste néanmoins largement ouvert mais se trouve colonisé par une végétation dominante de type friche méditerranéenne. La carpologie permet de caractériser précisément cette végétation : il s'agit d'un groupement d'adventices et rudérales annuelles, nitrophiles, particulièrement commun en zone méditerranéenne, dans les vignobles et aux abords des lieux habités. L'entomologie offre des parallèles frappants avec ces résultats, par exemple par l'identification d'espèces caractéristiques des malvacées. La malacologie et la palynologie perçoivent tout aussi nettement cette végétation.

Ici et là, l'enfrichement peut être légèrement plus prononcé avec le développement de ronces, comme c'est probablement le cas à proximité du bassin 1262 si l'on en croit l'abondance des témoins carpologiques dans son remplissage. Un parasite spécifique de la ronce (Coroebus rubi) a par ailleurs été perçu par l'entomologie à proximité du fossé 3197. La malacologie enregistre Monacha cantiana dans le fossé 3199, témoin d'un certain embroussaillement local.

Le processus de désaffection semble similaire au cours et surtout à la fin des phases 3 et 4 .

\subsection{Un verger plurifonctionnel ?}

Malgré le faible investissement mis dans son entretien, la parcelle semble toujours exploitée par l'homme. Les analyses carpologiques et xylologiques croisées et répétées, en accord avec la présence de fosses de plantation, montrent que la culture principale est celle d'arbres fruitiers. Les espèces les mieux attestées sont le figuier et la vigne, le prunier domestique et le pin pignon. La carpologie apporte la trace du mûrier, du noisetier, du noyer et du pommier. Ajoutons que la palynologie perçoit ponctuellement, ici et là, Corylus (noisetier), Ficus (figuier), Juglans (noyer), Vitis (vigne), voire Prunus (prunier), auxquels elle ajoute Olea (olivier).

Un ou plusieurs cyprès, arbres ornementaux plantés à proximité du bassin 3339, témoignent peut-être de fonction de jardin d'agrément qu'aurait connu la parcelle par le passé, à moins qu'ils n'aient été employés en haie coupe-vent pour protéger les cultures (Albertini 2009, 202) ou encore, comme chez Varron (I, 15), pour clôturer la propriété.

L'étude des bois et charbons permet la mise en évidence d'autres essences, non fruitières, mais connues par les textes latins pour avoir été plantées comme support de la vigne : orme, saule, peut-être peuplier (Pline, XVII, 35 ; Columelle, V, 6). Une telle fonction peut être envisagée ici, d'autant qu'elle constituerait une bonne adaptation à l'humidité ambiante. Le saule, retrouvé sous la forme d'un fagot de tiges trempées dans le bassin 3339, faisait sans doute l'objet d'un usage en vannerie, en particulier pour la fabrication de paniers ou pour fournir des liens servant à attacher la vigne.

Parmi les arbres épars semblent pousser quelques cultures annuelles, condiments et légumes tels que fenouil, coriandre et calebasse.

La parcelle pouvait également accueillir des cultures de céréales. C'est l'hypothèse qui se dégage de l'analyse pollinique, compte tenu des taux relativement élevés de Cerealia dans les bassins 1262 et 3339. De tels carrés de céréales n'étaient pas exceptionnels dans les jardins urbains de la France du Moyen Âge (HigounetNadal 1992). La carpologie identifie également, mais plus discrètement, des restes de céréales et de leurs adventices, fréquemment sous forme carbonisée, ce qui laisse envisager un apport artificiel par l'intermédiaire du rejet de déchets domestiques. Les deux hypothèses, non exclusives, sont avancées.

La parcelle de Villa Romana illustre donc sans équivoque la coltura promiscua vantée par les agronomes latins, de Pline à Columelle, largement pratiquée dans la péninsule italienne depuis l'Antiquité et notamment en Campanie (Albertini 2009, 221 et 236).

S'il contribue de façon minoritaire à la constitution des assemblages, l'apport dans la parcelle de déchets organiques provenant d'habitats voisins est évident, ne serait-ce qu'au travers du mobilier céramique et des vestiges fauniques. Il est certainement à l'origine de l'abondante faune entomologique de coprophages et coprophiles retrouvée notamment dans les fossés 3197 et 3199. Il manifeste vraisemblablement un enrichissement de la terre cultivée par fumure à base de matières excrémentielles animales et de déchets organiques domestiques. Ceci n'est pas non plus incompatible avec la fréquentation de la parcelle par des animaux 
domestiques, hypothèse formulée par la palynologie et qui trouve un écho là encore chez les auteurs anciens, mais aussi dans les pratiques contemporaines près d'Aigues-Mortes (vin de sable) où les apports en fumure naturelle sont fournis par les moutons venant paître l'hiver au milieu des vignes.

\subsection{Un écho lointain du milieu aux environs de Fréjus}

L'analyse des bois, des charbons, des pollens et de certains coléoptères traduit la présence de divers arbres et arbustes qui ne poussaient probablement pas dans la parcelle, même si certains, en particulier ceux identifiés par la xylologie, pouvaient encore être présents localement. Plusieurs groupements semblent se distinguer. On verrait bien les quelques taxons mésophiles ou mésohygrophiles identifiés pousser sur les sols profonds, relativement frais, parfois humides, des vallées alluviales locales (Reyran, Argens) ou en certains points du littoral. On pense ici notamment à l'aulne, au charme, au charme-houblon, au frêne, à l'hêtre et, pourquoi pas, au sapin, auxquels pouvaient encore se mêler orme et saule, que nous avons proposé de localiser sur la parcelle.

La pinède est bien présente, tant dans les spectres palynologiques qu'anthracologiques. Elle se trouvait vraisemblablement sur les cordons littoraux comme sur les massifs de l'arrière-pays. Les formations mésophiles (chênaie méditerranéenne) et xérophiles (subéraie des sols cristallins) sont aussi bien perçues. Mais une chênaie qui est fortement dégradée si l'on en croit la fréquence des taxons caractéristiques du maquis ou de la garrigue, plus particulièrement celle de la bruyère, bien perçue tant par l'anthracologie que par la palynologie, et celle du ciste, perçue dans les assemblages entomologiques sous forme d'un charançon associé à ce genre.

Il n'est pas anodin de constater que, parmi les restes ligneux, les taxons que l'on situerait sur la base de leur écologie dans d'autres milieux que celui du périmètre des fouilles sont clairement mieux suggérés par l'anthracologie que par la xylologie. En effet, les charbons de bois sont davantage susceptibles de voyager que les petits fragments de bois non carbonisés, par exemple par la collecte de bois de feu dans les environs de la ville puis l'épandage des charbons dans le terrain cultivé, avec des déchets domestiques utilisés comme fumure organique. La palynologie est l'autre discipline percevant le mieux ces groupements situés à quelques distances de la Villa Romana. Le signal est habituellement marginal mais peut atteindre des taux plus importants dans certaines structures, plus spécialement dans les fossés 3179 et 3256 .
La présence d'une pinède à proximité immédiate du site n'est toutefois pas enregistrée par l'analyse entomologique, ce qui conduit à moduler l'interprétation fournie par les autres disciplines. On sait en effet que, contrairement à l'enregistrement entomologique qui est très local, le pollen de pin est susceptible de voyager sur de longues distances. L'interprétation de pourcentages élevés de pollen de pin ne doit donc pas conduire à envisager la présence d'une pinède toute proche. Les seuls ligneux détectés localement par l'analyse entomologique sont le tamaris, le chêne et probablement des arbres hygrophiles associés aux ripisylves.

\subsection{Un milieu stable à travers le temps ?}

$\mathrm{Si}$, de l'analyse des deux phases d'époque romaine (3 et 4), il se dégage un semblable verger mal entretenu, accueillant sans doute quelques cultures annuelles et quelques arbres d'ornement, il est remarquable de constater que l'impression est la même pour l'époque moderne à la lecture des quelques résultats disponibles. La carpologie atteste encore la présence des deux fruitiers majoritaires, vigne et figuier, retrouve des traces de cultures annuelles (fenouil et peut-être moutarde noire) et identifie la même végétation de mauvaises herbes des vignobles, jardins mal entretenus et abords des habitations (groupements hygrophiles et psamoxérophiles identiques). Tout au plus se dessine peut-être un certain assèchement du milieu. La palynologie perçoit encore la présence des céréales.

Cette même discipline, complétée par l'anthracologie, restitue la même chênaie méditerranéenne dégradée dans l'arrière-pays et une emprise similaire du pin. Mais notre perception du milieu environnant le site et la ville n'est qu'un vague écho. Les contextes analysés ne procurent pas la finesse et la continuité d'enregistrement aptes à véritablement restituer l'évolution du milieu environnant. Très ponctuellement, par exemple, la palynologie détecte un épisode de dégradation par le feu de la chênaie au cours de la phase 4A dans le fossé 3179 . De semblables phénomènes nous sont inaccessibles à une échelle plus générale et sur la longue durée.

\subsection{En guise de conclusion...}

La fouille de Villa Romana constitue à ce jour, à Fréjus, l'unique cas où le croisement de telles études a été entrepris. Plusieurs facteurs expliquent cette situation : tout d'abord le contexte archéologique et la préservation exceptionnelle des écofacts due au caractère humide de la parcelle, ensuite la situation en dehors du tissu urbain surexploité de la ville de Fréjus et, enfin, les moyens apportés par l'aménageur dans le cadre de fouilles 
préventives. Cet ensemble de paramètres est rarement réuni ; l'occasion était donc plus que jamais à saisir. Si, en définitive, l'espace fouillé peut paraître modeste et ne constituer qu'une exploitation relativement réduite dont le centre véritable nous échappe, les données qu'il fournit n'en sont pas moins exceptionnelles. La diversité des espèces cultivées illustre un mode de culture bien décrit par les agronomes latins. De plus, la surface exploitée relativement réduite et la culture par endroits de plantes annuelles semblent signifier une exploitation, bien loin des grandes exploitations agricoles du Haut-Empire organisées autour de villae et entretenues par d'innombrables esclaves et exportant massivement leur production. Enfin, la reconstitution du milieu environnant n'a pu être qu'esquissée mais les données sont encourageantes et appellent de nouvelles investigations, en particulier dans ce secteur de la ville où la proximité de la nappe phréatique favorise, entre autres, la conservation des pollens et des restes d'insectes.

\section{Restitution géomorphologique du littoral d'après les données de fouilles sur Fréjus}

$$
\text { (S. B., B. D.) }
$$

À l'échelle de la basse vallée de l'Argens, les paléoenvironnements restitués sur le site de Villa Romana s'insèrent dans le processus continu du colmatage sédimentaire de la vallée submergée depuis environ 6000 ans (Dubar 2003, 263-270 et 2004, 47-54).

Les marqueurs de la position de la ligne de rivage durant l'Antiquité, mis au jour lors de cette opération, enrichissent la réflexion géoarchéologique menée depuis 2006 dans le sud-est de la ville de Fréjus. Ils viennent compléter le corpus des données obtenues dans le cadre d'opérations d'archéologie préventive réalisées par le Service Archéologique de la Ville de Fréjus $^{2}$ et par l'INRAP $^{3}$ ainsi que lors de différentes campagnes de carottages, effectuées dans l'ensemble de la vallée ${ }^{4}$ et, plus précisément, de part et d'autre du bassin portuaire antique (Bony et al. à paraître ; Bony 2008 et Gébara, Morhange 2010). Les résultats de ces différentes interventions, qui présentent des degrés de précision fortement variables selon les chantiers, ont permis de replacer, dans ce secteur, le trait de côte aux alentours

\footnotetext{
2 Tel que les diagnostics du Théâtre d'Agglomération (Excoffon, Devillers 2006) et de 1'Avant-scène (Excoffon, Berger 2008).

3 Tel que le diagnostic de M. Bricolage / Avenue de l'Argens (Michel 2005).

4 Les carottages ont été effectués dans le cadre du PCR « Occupation du sol et patrimoine archéologique dans la basse vallée de l'Argens » dirigé par Fr. Bertoncello. (Bertoncello 2006, 157-162).
}

du changement d'ère et lors de la deuxième moitié du $\mathrm{I}^{\text {er }}$ siècle apr. J.-C. et d'apporter, de ce fait, de nouvelles données sur la progradation des rivages entre ces deux périodes (vitesse, sens et morphogénèse).

Aux alentours du changement d'ère, alors que le rivage borde le pied de la butte Saint-Antoine au nord-est, plus au sud-ouest, une plage de sable le repousse à une soixantaine de mètre à l'est des thermes de Villeneuve (Excoffon et al. 2010) (fig. 235). Étant donné que cette restitution se base sur des indices incontestables de la position du trait de côte recueillis lors des opérations de Théâtre d'Agglomération et de Villa Romana, cette dernière a été adoptée comme l'hypothèse la plus recevable par deux études récemment proposées (Goudineau, Brentchaloff 2009, 41-50 et Bertoncello et al. 2008). Cette proximité de la mer permet de considérer d'un regard nouveau l'aménagement du bassin portuaire. Malgré une chronologie floue concernant la construction du port, il semble que même la date la plus récente communément admise du changement d'ère (Rivet et al. 2000) le situe à proximité immédiate de la mer. Ainsi, son quai sud constituerait un môle protégeant le fond de baie des houles et des apports sédimentaires de l'Argens (Excoffon, Devillers 2006). Ces données ont permis de clore un débat de plusieurs siècles sur la position du port par rapport à la mer.

Concernant la deuxième moitié du Ir siècle apr. J.-C., seuls des indices indirects nous ont permis de proposer une limite du trait de côte. En effet, des vestiges bien datés de cette époque ont été mis au jour le long de l'Avenue de Provence sur le site de l'Avant-Scène (fosse et large fossé aménagés sur la plage) et celui de M. Bricolage (extrémité est d'un corridor également mis en évidence lors de la fouille de Villa Romana et datant du courant de la seconde moitié du Irr siècle apr. J.-C.). C'est donc par défaut que nous situons la ligne de rivage au-delà de ces vestiges, la distance qui les sépare ne pouvant être appréhendée : la mer se situe au minimum 160 m à l'est du site de Villa Romana et moins d'une centaine de mètre à l'est du pied de la butte Saint-Antoine (Excoffon et al. 2010).

L'étude de la répartition des indices directs et indirects de la position du rivage entre le changement d'ère et la seconde moitié du Ir siècle apr. J.-C., au sud de la ville, nous a permis de proposer des estimations pour la vitesse de progradation du littoral :

$-30 \mathrm{~cm} / \mathrm{an}$ entre le dernier tiers du Ir siècle av. J.-C. et le changement d'ère,

$-170 \mathrm{~cm} / \mathrm{an}$ au minimum entre le changement d'ère et la deuxième moitié du Ir siècle apr. J.-C.

Bien que ces estimations, valables uniquement pour notre zone d'étude, restent à affiner en raison de la précision fortement variable des marqueurs 


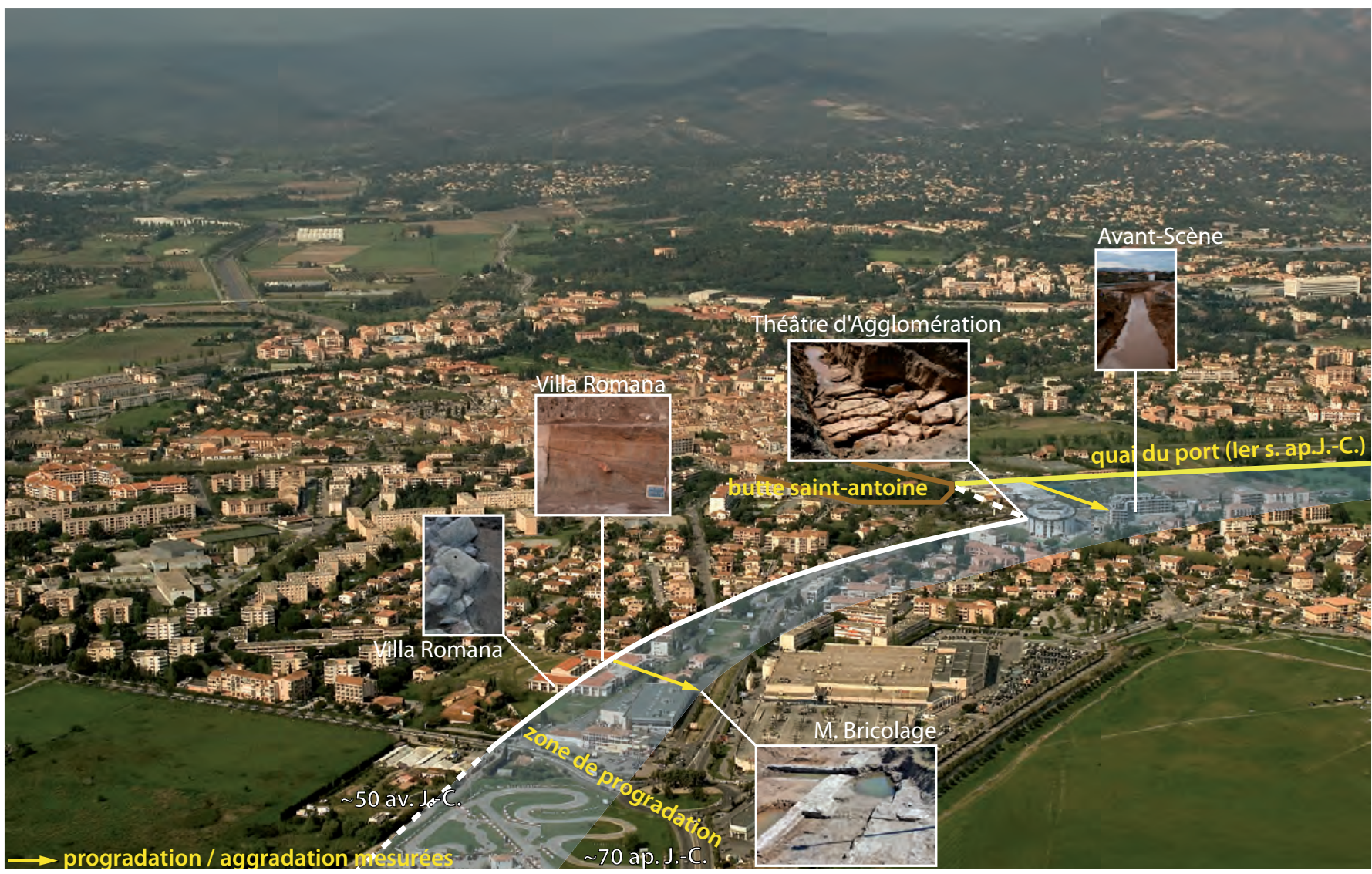

Fig. 235. Différentes opérations ont permis de préciser la position du littoral entre le milieu du ler siècle av. J.-C. et le Ile siècle apr. J.-C.

(cl. Ville de Fréjus - M. Heller ${ }^{\oplus}$ ).

archéologiques ou géomorphologiques utilisés, elles ont le mérite d'être les premières à avoir été proposées pour la basse vallée de l'Argens. Cette progradation rapide des rivages, qui suit un sens nord, nord-est/sud, sud-est, est due à l'importante charge sédimentaire transportée par l'Argens ainsi que par les cours d'eau provenant de l'Estérel. Cette évolution morphologique semble avoir conditionné la modification constante des aménagements portuaires à cette époque, rendant actuellement délicate leur compréhension et leur restitution à une période précise. Inversement, la construction du port a pu aussi modifier fortement les dynamiques de sédimentation et ainsi participer, localement, à l'accélération du phénomène de progradation.

En élargissant notre champ d'étude à l'échelle de la basse vallée de l'Argens, il est intéressant de noter que les propositions de restitution de la ligne de rivage aux alentours du changement d'ère diffèrent d'un modèle à l'autre (fig. 236). Alors que Chr. Goudineau, Ch. Gébara et G. Chouquer envisagent, avec des approches différentes, une baie très échancrée au centre de la vallée, le schéma proposé par Fr. Bertoncello et son équipe (Bertoncello et al. 2008) dessine une côte régularisée, avec des lagunes éparses en amont, de Villa
Romana au centre des étangs de Villepey (Bertoncello 2008 ; Gébara, Chouquer 1996, 91-103 et Goudineau, Brentchaloff 2009, 41-50) ${ }^{5}$. L'utilisation de nombreuses données paléoenvironnementales pour la constitution de ce dernier modèle lui confère, à l'heure actuelle, le plus grand degré de véracité. De plus, le dernier modèle numérique de la progradation holocène du rivage pour la basse vallée proposé par M. Dubar confirme cette restitution (Dubar 2009, 39-43). Le mouillage du camp de la flotte ne serait donc pas installé dans une baie protégée, ainsi que le propose Chr. Goudineau, mais soit au sein d'une lagune, soit à l'embouchure du fleuve. En raison du taux de sédimentation relativement élevé, provoquant vraisemblablement une évolution rapide de la paléobathymétrie (formation de bancs de sable), aucune de ces deux positions ne paraît idéale. Il faut peutêtre alors envisager l'existence d'un autre mouillage plus favorable au séjour d'une flotte conséquente comme celle capturée lors de la bataille d'Actium.

5 Les deux schémas proposés restituent un contour de la basse vallée relativement similaire bien que Chr. Goudineau et $\mathrm{D}$. Brentchaloff se fondent sur une réflexion topographique et paléotopographique et Ch. Gébara et G. Chouquer, sur une étude photo-interprétative. 


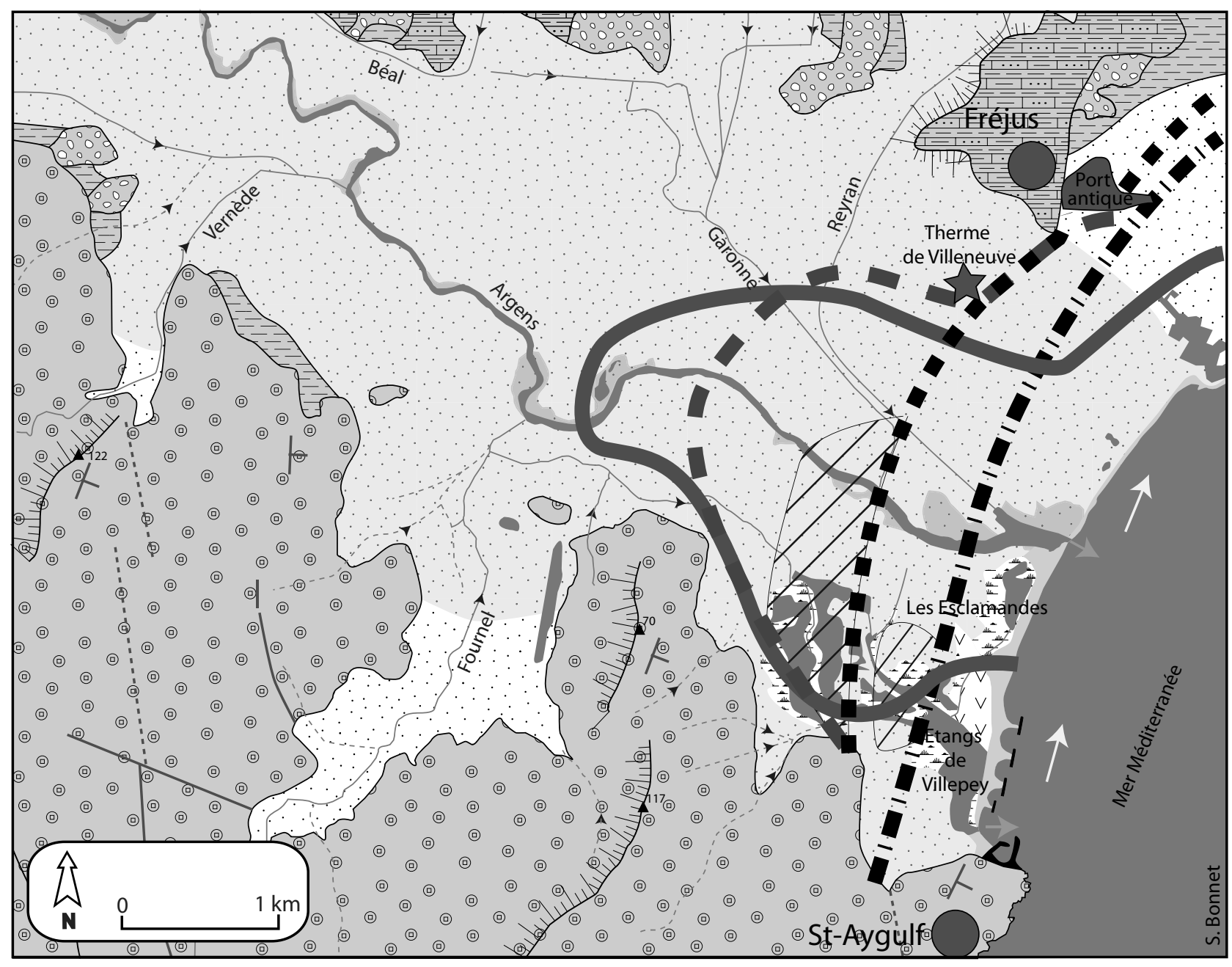

Source : carte géologique au 1/50 000 Fréjus-Cannes, Carte IGN 1/25 000, Cartographie interactive CARMEN (DREAL PACA)

\section{Tectonique}

1 Pendage

- Faille

..... Faille masquée

\section{Géomorphologie structurale}

Unité des gneiss orientaux : les Maures

Unité de grés: formation du Mitan Unité hétérogéne de marne, limons, sables et graviers : formation du Pliocéne

Nappe fluviale caillouteuse : terrasse Pleistocène

Alluvions récentes

\section{Versants}

Tा111 Ligne de crête

$\Delta^{117} \quad$ Sommet
Géomorphologie fluviale et dynamqiues associées

$\rightarrow$ Cours d'eau pérenne

-. Rivière/torrent temporaire

Lit moyen

Lit majeur

$\rightarrow$ Apport sédimentaire

Géomorphologie littorale et dynamqiues associées

Mer, lagune, étang

Milieu lagunaire:

pellicule d'eau et bancs de sable mobiles

$\checkmark$ Milieu humide hors d'eau riche en plante halophile

Cordon littoral

Dérive littorale
Restitutions de la position des lignes de rivages à l'Antiquité

ligne de rivage pour l'antiquité Gébara/Chouquer 1996

ligne de rivage pour l'antiquité Goudineau et al. 2009

ligne de rivage pour le changement d'ère Bertoncello et al. 2009

- - ligne de rivage pour l'Antiquité Dubar 2009

- I ligne de rivage pour le haut empire Bertoncello et al. 2009

I lagunes associées aux reconstitution de F. Bertoncello et al. 2009

Fig. 236. Carte synthétisant les différentes restitutions du trait de côte durant l'Antiquité dans la basse vallée de l'Argens (S. Bonnet). 
Les résultats préliminaires de la fouille de l'immeuble « le Kipling », rue Aristide-Briand (Excoffon 2010d), au nord de la limite septentrionale supposée du port antique, ont montré que cette zone pouvait être assimilée à un fond de baie ouverte comme l'atteste la présence d'un cordon sableux littoral qui s'appuie sur la côte rocheuse. L'étude récente de carottes réalisées au sein du port et de son chenal d'accès confirme cette configuration paysagère, qui persisterait jusqu'en $2025 \pm 30 \mathrm{BP}$ (Bony 2008 et Gébara, Morhange 2010).

À l'origine de Forum Iulii, le plan d'eau « préportuaire », bien que relativement protégé, était donc ouvert plus largement sur la haute mer, enserré entre les deux pointes rocheuses de la butte SaintAntoine et de la Plate-Forme, et pouvait donc accueillir des navires de grande taille. Si la présence au nord du pied de la butte Saint-Antoine d'une baie ouverte, mais protégée par deux avancées rocheuses, est fortement vraisemblable, il nous est impossible de confirmer la forme initiale de ce possible mouillage : mouillage naturel plus ou moins aménagé ou port ouvert sur la mer ? L'étude paléoenvironnementale réalisée par G. Bony va dans le sens de cette deuxième hypothèse (Bony et al. à paraître et Bony 2008).

Cette proposition constitue seulement une réflexion préliminaire mais elle a le mérite de proposer de nouvelles pistes de recherche. $\mathrm{Si}$, jusqu'à présent, les études paléoenvironnementales et géoarchéologiques se sont focalisées sur la basse vallée de l'Argens, le temps est désormais venu d'appréhender l'évolution morphologique du littoral plus au nord durant l'Holocène, entre Fréjus et Saint-Raphaël. Cette nouvelle approche permettrait de répondre à de nombreuses interrogations archéologiques et géoarchéologiques sur la limite septentrionale du bassin portuaire et sur l'importance des fleuves côtiers, tel que le Valescure, dans le phénomène de progradation des rivages au nord-est de la ville. 

Deuxième Partie

\section{Analyses \\ et études}
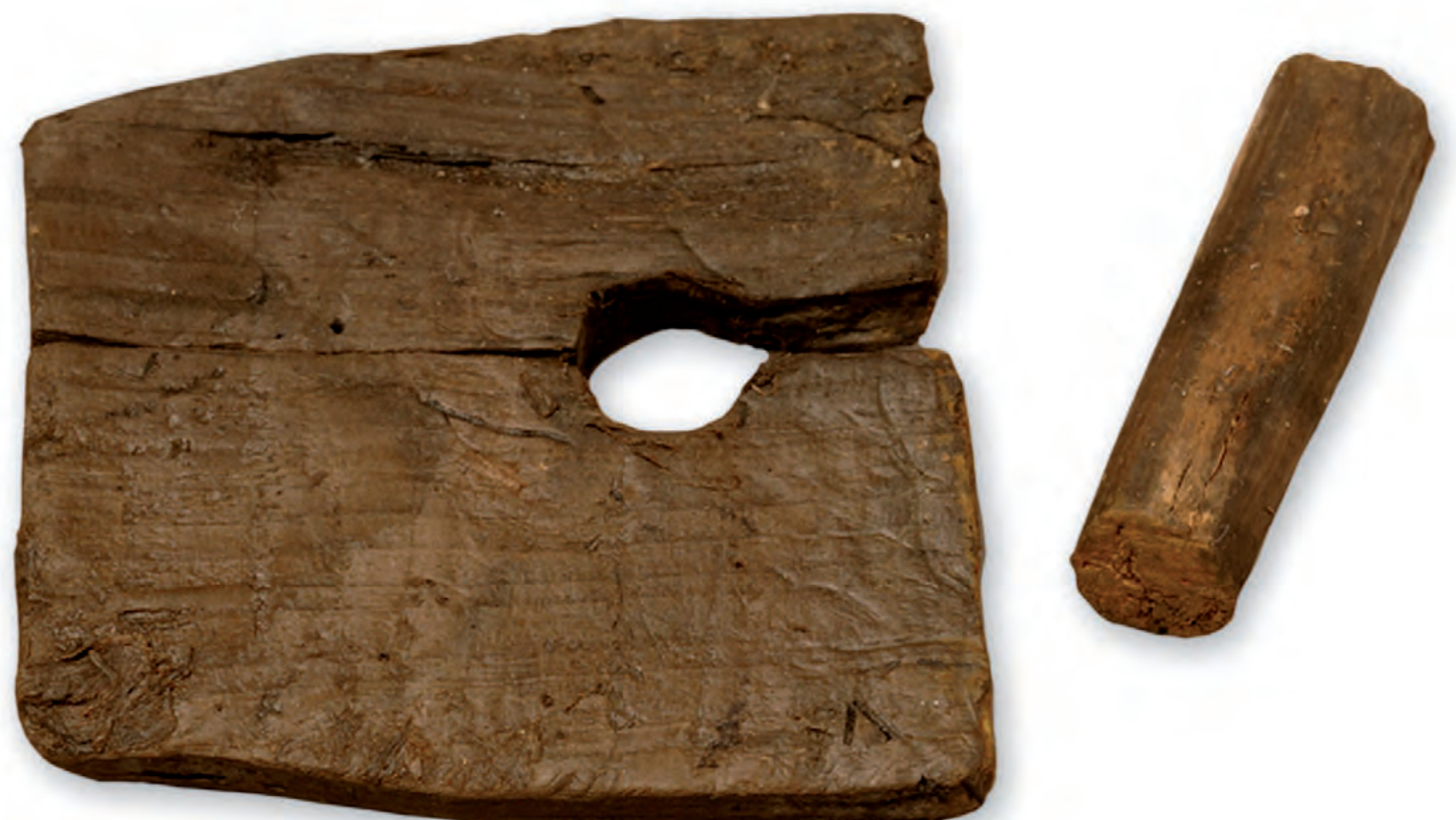

Tenon et cheville

(cl. Chr. Durand - CCJ). 



\title{
Chapitre 1
}

\section{Les vestiges de navires antiques : études architecturale et dendrologique}

\author{
(G. Boetto, S. Greck, Fr. Guibal)
}

Les cuvelages des puits SB1262 et BS3339 de Villeneuve se composent, pour l'essentiel, d'ensembles de fragments de bordés appartenant, probablement, à trois navires antiques. Ces bordages sont assemblés, à intervalles réguliers, par des tenons bloqués au moyen de chevilles enfoncées dans l'épaisseur de chaque planche, selon un système d'assemblage commun dans la construction navale méditerranéenne d'époque gréco-romaine ${ }^{1}$. Des fragments de bordages isolés, mais toujours munis d'assemblages à tenons chevillés, ainsi que des planches sans aucune trace de liaisons internes complètent l'aménagement des parois de ces puits. Ces dernières, n'étant pas issues de la réutilisation de navires, ne seront pas prises en compte dans ce texte.

Tous ces bordages ont été étudiés après démontage. Dans la plupart des cas, les deux faces, correspondant aux côtés interne et externe du navire d'origine, ont pu être analysées.

Pour la détermination des essences ligneuses, les échantillons de bois (prélevés systématiquement) ont fait l'objet d'une observation macroscopique préalable à la loupe binoculaire suivie d'un examen au microscope à transmission de coupes minces selon les trois plans traditionnels d'observation. L'analyse anatomique du bois a été menée à l'aide d'atlas d'anatomie des bois européens (Jacquiot 1955 ; Jacquiot et al. 1973 ; Schweingruber 1982, 1990 et Vernet et al. 2001).

La documentation dendromorphologique (Guibal, Pomey 1998) a été rassemblée sur la base d'un relevé métrologique d'observations relatives à la structure et à la forme du bois (moelle, écorce, aubier, forme de la tige), à son traitement technique (débit, traces d'outils) ainsi que d'autres éléments intéressant l'étude dendrologique (traces d'insectes xylophages, de carbonisation, etc.).

L'étude dendrochronologique n'a été réalisée que sur les bois les plus appropriés à la pratique de cette méthode. Les chronologies individuelles d'épaisseur de cernes ont été calculées sur la base d'une moyenne

1 Le réseau de mortaisage est de type « évolué » (Pomey, Rieth 2005). d'une à trois séries numériques enregistrées par échantillon (précision : 1/1000 mm). L'interdatation des chronologies réalisée sur les séries numériques brutes ou transformées en valeurs indicées a été menée à l'aide de tests paramétriques appliqués au coefficient de corrélation intersériel et de tests non paramétriques appliqués aux courbes des variations interannuelles de l'épaisseur des cernes. Afin de procéder à leur validation, les propositions de synchronisme ont été vérifiées par comparaison visuelle et graphique (Langouët, Giot 1992 ; Lambert 1998 ; Lambert, Lavier 2002 et Lambert et al. 1988).

\section{Les bordés réutilisés dans le puits SB1262}

\subsection{Caractéristiques architecturales}

Quatre portions de bordés et sept bordages isolés ont été utilisés pour la construction du puits SB1262 (tab. 4). En règle générale, ces planches conservent leur largeur maximale d'origine, comprise entre $20 \mathrm{~cm}\left(\mathrm{n}^{\text {os }} 39\right.$ et $50)$ et $30 \mathrm{~cm}\left(\mathrm{n}^{\circ} 28\right)$, tandis que leurs extrémités ont été retaillées pour s'adapter à la nouvelle construction. Parmi tous ces éléments, nous avons pu identifier deux ensembles aux caractéristiques architecturales homogènes.

Le premier groupe est constitué par les bordages employés dans la construction de la paroi MR1263 $\left(\mathrm{n}^{\text {os }} 38,51\right.$ et 52$)$ et la planche $\mathrm{n}^{\circ} 40$ utilisée dans la paroi MR1280 (fig. 237).

Le deuxième ensemble regroupe tous les autres bordages qui composent les parois MR1264 et MR1265, ainsi que les planches isolées ( $\mathrm{n}^{\text {os }} 26,37$ et 39) de la paroi MR1280 (fig. 238).

Le premier ensemble présente des bordages plus épais et des éléments d'assemblage plus larges et plus profonds que le deuxième (tab. 4 et 5). Le rapport de l'écartement moyen à la largeur moyenne des mortaises révèle que le réseau de mortaisage du 


\begin{tabular}{|c|c|c|c|c|c|c|c|c|c|c|c|c|c|c|}
\hline \multirow{2}{*}{$\begin{array}{l}\text { Fait } \\
\text { Puits }\end{array}$} & \multirow{2}{*}{$\begin{array}{l}\text { US } \\
\text { Paroi }\end{array}$} & \multirow{2}{*}{$\begin{array}{l}\text { Index } \\
\text { Planche }\end{array}$} & \multicolumn{4}{|c|}{ Dimensions } & \multirow[b]{2}{*}{ Réparation } & \multicolumn{2}{|c|}{ Poix } & \multirow{2}{*}{$\begin{array}{c}\text { Empreinte } \\
\text { pied } \\
\text { couple }\end{array}$} & \multirow{2}{*}{$\begin{array}{c}\text { Encoches } \\
\text { triang. } \\
\text { pour clous }\end{array}$} & \multicolumn{2}{|c|}{ Outillage } & \\
\hline & & & $\begin{array}{l}\text { longueur } \\
\text { (cons.) }\end{array}$ & $\begin{array}{c}\text { largeur } \\
(\max )\end{array}$ & $\begin{array}{l}\text { largeur } \\
\text { (cons.) }\end{array}$ & $\begin{array}{l}\text { ép. } \\
\text { moyen }\end{array}$ & & int. & ext. & & & int. & ext. & \\
\hline \multirow{19}{*}{ SB1262 } & \multirow{3}{*}{ MR1263 } & 38 & & & 22 & 4,15 & & & & & & & & en frag. \\
\hline & & 51 & & 24 & & 3,5 & & & & & & & & $\begin{array}{l}\text { en frag. } \\
\text { carbonisation }\end{array}$ \\
\hline & & 52 & & & & & & & & & & & & non analysée \\
\hline & \multirow{8}{*}{ MR1264 } & 28 & 133 & & 30 & 3 & $\mathrm{X}$ & & $\mathrm{X}$ & & $\mathrm{X}$ & & & \\
\hline & & 34 & 350 & 25 & & 2,75 & & $\mathrm{X}$ & $X$ & $\mathrm{X}$ & & & & \\
\hline & & 55 & 299 & 23 & & 2,6 & $\mathrm{x}$ & $\mathrm{X}$ & $\mathrm{X}$ & $\mathrm{x}$ & $\mathrm{x}$ & & herm. & \\
\hline & & 56 & 118,5 & 11,5 & & 3 & & & $\mathrm{X}$ & & & scie & & \\
\hline & & 61 & 36,5 & & 4,5 & 2,8 & & $\mathrm{X}$ & $\mathrm{X}$ & $\mathrm{x}$ & & & & \\
\hline & & 57 & & & & 2,2 & & & & & & & & non analysée \\
\hline & & 50 & 36 & 20 & & 2 & & & $\mathrm{X}$ & $\mathrm{x}$ & & & scie & \\
\hline & & 62 & 32,5 & & 6 & 2 & & & $\mathrm{X}$ & $\mathrm{x}$ & & & & \\
\hline & \multirow{4}{*}{ MR1265 } & 35 & 239 & 19 & & 2,5 & & $\mathrm{X}$ & $\mathrm{X}$ & $\mathrm{x}$ & & & & \\
\hline & & 54 & 66 & & 3,5 & 2,6 & & $\mathrm{X}$ & $\mathrm{X}$ & $\mathrm{x}$ & & & & \\
\hline & & 53 & 241 & 23 & & 2,4 & $\mathrm{X}$ & $\mathrm{X}$ & $\mathrm{X}$ & $\mathrm{X}$ & & & & $\begin{array}{c}\text { rép. depuis face } \\
\text { ext. }\end{array}$ \\
\hline & & 36 & & & & & & & & & & & & non analysée \\
\hline & \multirow{4}{*}{ MR1280 } & 26 & 208 & & 22 & 2,5 & $\mathrm{x}$ & & $\mathrm{X}$ & $\mathrm{X}$ & & scie & & en frag. \\
\hline & & 37 & 266 & & 22,5 & 2,9 & $\mathrm{x}$ & & $\mathrm{X}$ & $\mathrm{x}$ & $\mathrm{x}$ & scie & & 1 clou horiz. \\
\hline & & 39 & 80 & & 20 & 3 & & & & & & & & en frag. \\
\hline & & 40 & 111 & & 23,5 & 3,6 & & & $\mathrm{X}$ & & & & & en frag. \\
\hline
\end{tabular}

Tab. 4. Dimensions et caractéristiques des bordages du puits SB1262.

\begin{tabular}{|c|c|c|c|c|c|c|c|c|c|c|c|c|c|c|c|c|c|}
\hline \multirow{2}{*}{$\begin{array}{l}\text { Index } \\
\text { Planche }\end{array}$} & \multicolumn{4}{|c|}{ Mortaises } & \multicolumn{3}{|c|}{ Tenons } & \multicolumn{4}{|c|}{ Chevilles } & \multicolumn{4}{|c|}{ Tenons de réparation } & \multicolumn{2}{|c|}{ Chev. de rép. } \\
\hline & largeur & prof. & ép. & écart & largeur & ép. & $\begin{array}{l}\text { longueur } \\
\text { (cons.) }\end{array}$ & diam. & $\begin{array}{l}\text { diam. } \\
\text { (int.) }\end{array}$ & $\begin{array}{l}\text { diam. } \\
\text { (ext.) }\end{array}$ & écart & largeur & ép. & $\begin{array}{c}\text { longueur } \\
\text { (cons.) }\end{array}$ & écart & diam. & écart \\
\hline 38 & 7,75 & 6 & 0,65 & & 5,6 & 0,6 & & 0,95 & & & & & & & & & \\
\hline 51 & 7,1 & 6 & 0,65 & 4,25 & 5,75 & 0,6 & & 0,95 & & & & & & & & & \\
\hline 52 & & & & & & & & & & & & & & & & & \\
\hline 28 & & & & & & & & & & & & 5,75 & 0,65 & 6,25 & 20 & 0,7 & \\
\hline 34 & 6 & 4,8 & 0,7 & 5,75 & & & & & 0,75 & 0,86 & 13,8 & & & & & & \\
\hline 55 & & & & & & & & & & & & 4,6 & 0,5 & 10,9 & & & \\
\hline 56 & & & & & & & & & & & & & & & & & \\
\hline 61 & & & & & & & & & & & & & & & & & \\
\hline 57 & & & & & & & & & & & & & & & & & \\
\hline 50 & 5,5 & 4 & 0,68 & 5,75 & 4,6 & 0,55 & & 0,8 & & & 11,7 & & & & & & \\
\hline 62 & & & & & & & & & & & & & & & & & \\
\hline 35 & 6 & 4,5 & & & 5 & 0,6 & 4,5 & & 0,7 & 0,83 & 12,1 & & & & & & \\
\hline 54 & & & & & & & & & & & & & & & & & \\
\hline 53 & & & & & & & & & & & & 5,3 & & & 10 & & 15,9 \\
\hline 36 & & & & & & & & & & & & & & & & & \\
\hline 26 & 6,8 & 5,1 & 0,65 & & & 0,4 & & 1 & & & 17,6 & 4,3 & 0,6 & 6,4 & 17,7 & 0,95 & 24,4 \\
\hline 37 & 6,1 & & & 9,25 & & & & 0,86 & & & 14,4 & 4,5 & & 6,2 & 18,3 & 0,75 & 23,5 \\
\hline 39 & 5,5 & 5,25 & 0,7 & 12 & & & & 0,87 & & & & & & & & & \\
\hline 40 & 8 & & & 6,5 & & & & 1,2 & & & 13 & & & & & & \\
\hline
\end{tabular}

Tab. 5. Dimensions et caractéristiques des assemblages des bordages du puits SB1262. 

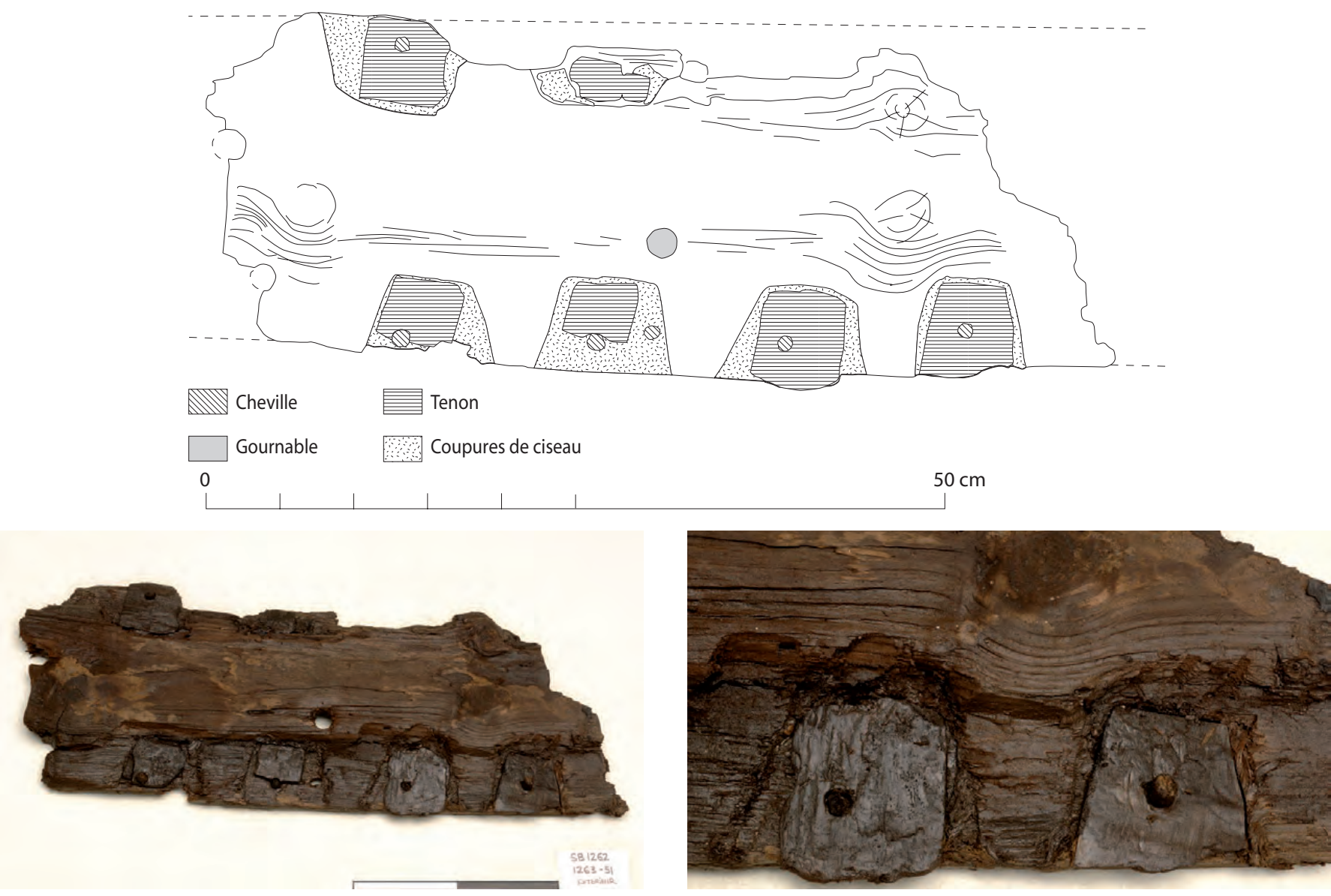

Fig. 237. Le fragment de bordage $n^{\circ} 51$ de l'épave Fréjus-Villeneuve 1 ,

réutilisé dans la paroi MR1263 du puits SB1262 (G. Boetto - cl. Chr. Durand - CCJ).

premier groupe est plus dense que celui du deuxième ${ }^{2}$. Ce dernier est néanmoins relativement serré puisque son rapport varie de 1 à $2^{3}$.

Le bordage MR1280-37, appartenant au deuxième groupe, présente une extrémité en biseau (fig. 238) qui identifie un assemblage oblique du bordé. Ce biseau conserve un clou métallique à tête carrée (côté : 2,4 cm), chassé horizontalement dans l'épaisseur du bordage et qui assurait la fermeture du biseau sur la planche adjacente.

Le deuxième ensemble se distingue par plusieurs bordages de réparation (MR1264, $\mathrm{n}^{\text {os }} 28$ et 55,

2 Nous pouvons calculer, pour le premier groupe, un rapport inférieur à $1(0,7)$ contre un rapport supérieur à $1(1,33)$ pour le second groupe. Les résultats signifient que, dans l'espace laissé entre deux mortaises des planches du premier groupe, moins d'une mortaise peut loger (exactement 0,7 ) tandis que dans l'espace laissé entre deux mortaises sur le reste des bordés, un peu plus d'une mortaise peut venir s'y insérer (exactement 1,15).

3 On peut en effet considérer qu'un rapport écartement/largeur des mortaises inférieur ou égal à 1 est très serré ; un rapport compris entre 1 et 2 est serré et un rapport supérieur ou égal à 2 est moyennement serré (Marlier $\left.2008,156, \mathrm{n}^{\circ} 16\right)$.
MR1265-53 et MR1280, $\mathrm{n}^{\text {os }} 26$ et 37) caractérisés par la présence de tenons (tab. 4 et 5) insérés dans des mortaises pratiquées à partir de la face interne ou externe du bateau. Leur extrémité est ensuite rabotée afin de boucher l'encoche (ou lumière) quadrangulaire ouverte à la surface du bordage (fig. 239 à 241). Deux traits parallèles tracés à la pointe sèche indiquent l'emplacement des lumières (fig. 242). Des chevilles verrouillent l'assemblage et une couche de poix est appliquée pour garantir l'étanchéité des joints ${ }^{4}$.

Enfin, ces assemblages sont plus espacés que les assemblages d'origine comme le montre l'écart moyen des petites chevilles de verrouillage, respectivement $14 \mathrm{~cm}$ et 21,3 cm (tab. 5).

Dans les deux ensembles de bordés, des gournables en bois (diamètre moyen : 1,6 cm et 1,4 cm) assuraient

4 Les tenons de réparation ont été observés, pour la première fois, sur l'épave Kyrenia découverte à Chypre et datée du IVe siècle av. J.-C. (Steffy 1985 et 1999). Ce type de réparation est commun également à l'époque romaine : voir, par exemple, les réparations des épaves découvertes à Naples (Boetto 2005 et 2009). 


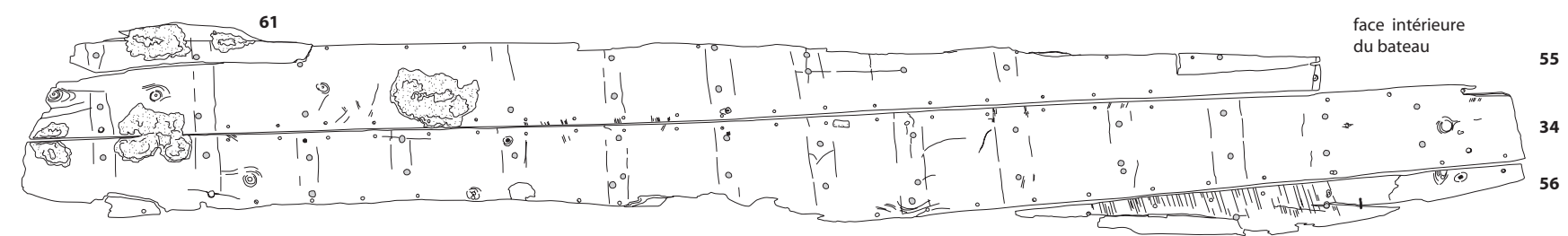

MR1264/34 - 55- 56 - 61
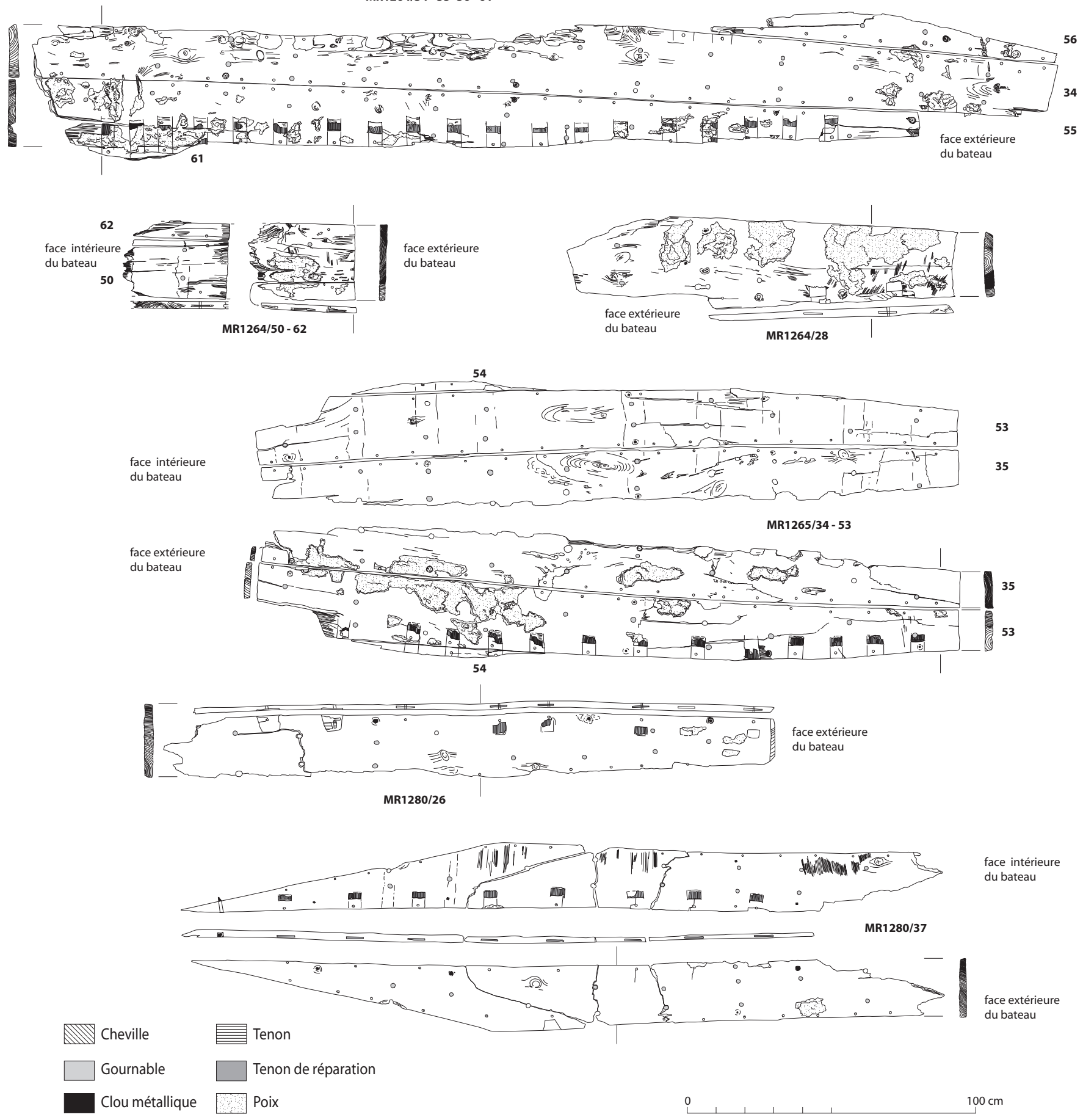

Fig. 238. Les fragments de bordages de l'épave Fréjus-Villeneuve 2, réutilisés dans les parois puits SB1262 (G. Boetto et S. Greck). 
Tenon de

réparation

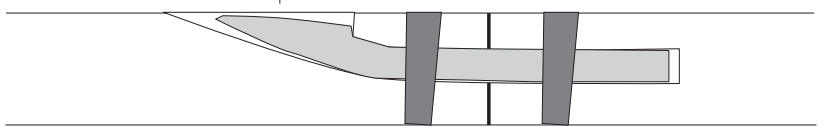

Bordage de

réparation

Chevilles

Fig. 239. Section shématique d'un assemblage par tenon de réparation (G. Boetto). l'assemblage entre les bordages et la charpente transversale du navire dont aucun élément n'est conservé (tab. 6). Dans le deuxième ensemble, des clous métalliques (en cuivre et en fer) ontété observés (fig. 243). L'extrémité du bordage de réparation MR1264-55 était bloquée sur la membrure par un couple de clous, probablement en fer. Parfois, les têtes de ces clous étaient chassées dans des encoches triangulaires (côté : $2 / 2,5 \mathrm{~cm}$ ) aménagées dans la face qui correspond au côté externe de la coque du navire d'origine (fig. 244 et $245)^{5}$. Les deux ensembles de bordés conservent, sur une ou sur les deux faces, une couche de poix, témoignage

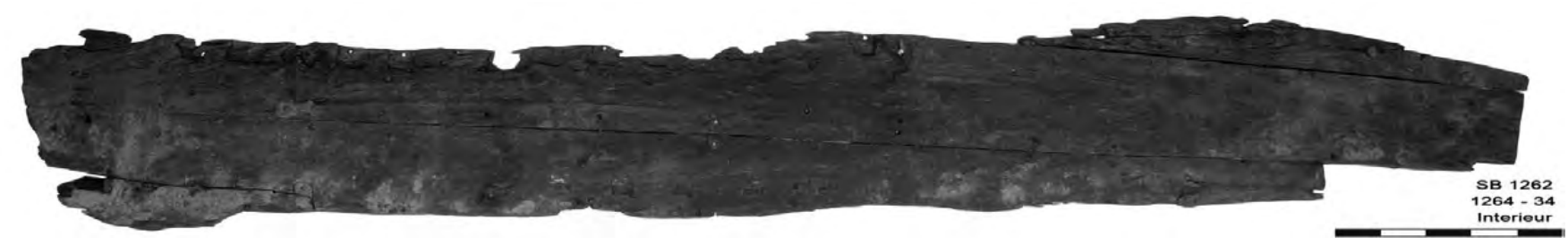

Fig. 240. Le fragment de bordés MR1264-1261, 55, 34 et 56 correspondant à la face extérieure du bateau

(cl. Chr. Durand - CCJ).

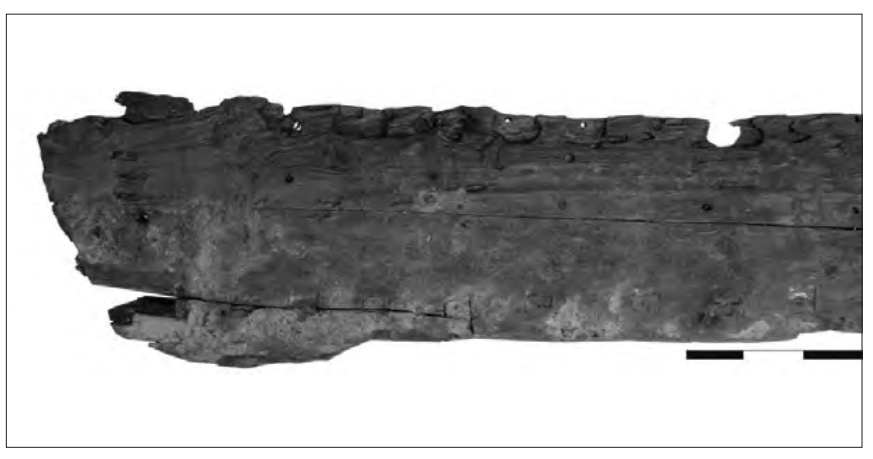

Fig. 241. Détail des tenons de réparation du bordage MR1264-55 (cl. Chr. Durand - CCJ).

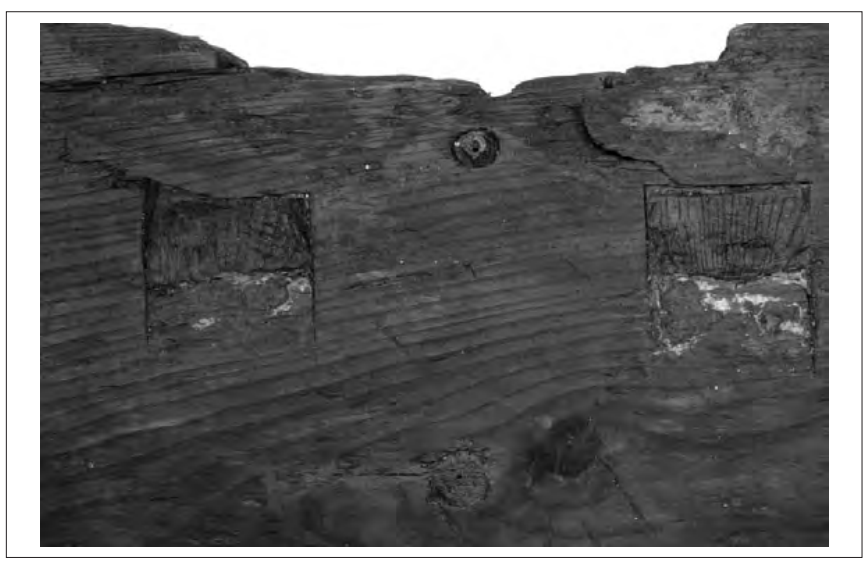

Fig. 242. Détail des tenons de réparation du bordage MR1264-55 : deux traits tracés à la point sèche indiquent l'emplacement des lumières (cl. Chr. Durand - CCJ). d'une ancienne protection interne et externe de la coque (fig. 238 et tab. 4). Cette couche est épaisse de 0,8 à $1 \mathrm{~cm}$ (fig. 246). Elle a aussi été observée sur le can (tranche) de certains bordages (fig. 247).

Dans le deuxième ensemble de bordés, la trace des empreintes laissées par les pieds des membrures est rendue apparente par l'absence, à l'emplacement des couples, de la poix de protection (fig. 248 et 249). La largeur de ces couples (moyenne : 6,2 cm) et leur maille ou espacement (moyenne : $17 \mathrm{~cm}$ ) ont pu être restituées (tab. 6).

Sur la planche MR1264-28, l'emplacement des membrures était marqué par des lignes parallèles tracées à la pointe sèche.

L'espacement entre couples est obtenu par la distance moyenne entre les assemblages membrure/bordé. L'espacement est plus important $(27,5 \mathrm{~cm})$ dans le premier ensemble que dans le deuxième $(20,8 \mathrm{~cm})$ (tab. 6) sur lequel des traces d'outillage (scie et herminette) sont également visibles.

Pour conclure, ces deux ensembles de bordés semblent bien appartenir à deux embarcations différentes.

5 Des encoches tétraédriques ou triangulaires ont aussi été observées sur l'épave Fiumicino 1 (IVe/Ve siècles apr. J.-C.) sur laquelle la plupart des évidements est associée à un assemblage par clous obliques (Boetto 2000 et 2008). Pour les comparaisons et une discussion générale: Boetto 2006 et 2010. 


\begin{tabular}{|c|c|c|c|c|c|c|c|c|c|c|c|}
\hline \multirow{2}{*}{$\begin{array}{l}\text { Fait } \\
\text { Puits }\end{array}$} & \multirow{2}{*}{$\begin{array}{l}\text { US } \\
\text { Paroi }\end{array}$} & \multirow{2}{*}{$\begin{array}{l}\text { Index } \\
\text { Planche }\end{array}$} & \multicolumn{3}{|c|}{ Membrure } & \multicolumn{3}{|c|}{ Gournables } & \multicolumn{3}{|c|}{ Clous } \\
\hline & & & largeur & $\begin{array}{l}\text { maille de } \\
\text { bord à bord }\end{array}$ & $\begin{array}{l}\text { maille entre } \\
\text { assemblages }\end{array}$ & diam. & $\begin{array}{l}\text { diam. } \\
\text { (int.) }\end{array}$ & $\begin{array}{l}\text { diam. } \\
\text { (ext.) }\end{array}$ & \multicolumn{2}{|c|}{ diam. tête } & tige \\
\hline \multirow{19}{*}{ SB1262 } & \multirow{3}{*}{ MR1263 } & 38 & & & & & & & & & \\
\hline & & 51 & & & 27,7 & 1,72 & & & & & \\
\hline & & 52 & & & & & & & & & \\
\hline & \multirow{8}{*}{ MR1264 } & 28 & 9 & & 27 & 1,26 & & & $\mathrm{X}$ & 1,6 & \\
\hline & & 34 & 6,5 & 17,7 & 23,7 & 1,4 & & & $\mathrm{X}$ & & \\
\hline & & 55 & & & & & & & & & \\
\hline & & 56 & & & & & & & & & \\
\hline & & 61 & & & & & & & & & \\
\hline & & 57 & & & & & & & & & \\
\hline & & 50 & 4,5 & & & & 1,3 & 1,45 & $\mathrm{X}$ & 1,5 & \\
\hline & & 62 & & & & & & & & & \\
\hline & \multirow{4}{*}{ MR1265 } & 35 & 7,4 & 16 & 24 & 1,4 & & & $\mathrm{X}$ & 2 & 0,7 \\
\hline & & 54 & & & & & & & & & \\
\hline & & 53 & & & & & & & & & \\
\hline & & 36 & & & & & & & & & \\
\hline & \multirow{4}{*}{ MR1280 } & 26 & 5,5 & & 26,4 & 1,4 & & & $\mathrm{X}$ & 2,5 & 1 \\
\hline & & 37 & 4,5 & 17,7 & 23 & 1,4 & & & $\mathrm{X}$ & 2,5 & \\
\hline & & 39 & & & & & & & & & \\
\hline & & 40 & & & 28 & 1,5 & & & & & 1,2 \\
\hline
\end{tabular}

Tab. 6. Dimensions et caractéristiques de la membrure et de ses assemblages avec les bordages du puits SB1262.

\begin{tabular}{|c|c|c|c|c|c|c|c|c|c|c|c|c|c|}
\hline \multirow{2}{*}{$\begin{array}{l}\text { Fait } \\
\text { Puits }\end{array}$} & \multirow{2}{*}{$\begin{array}{l}\text { US } \\
\text { Paroi }\end{array}$} & \multirow{2}{*}{$\begin{array}{l}\text { Index } \\
\text { Planche }\end{array}$} & \multicolumn{2}{|c|}{ Essence ligneuse } & \multicolumn{4}{|c|}{ Débit } & \multirow{2}{*}{ Âge } & \multicolumn{3}{|c|}{ Moelle } & \multirow{2}{*}{$\begin{array}{l}\text { Dernier } \\
\text { cerne }\end{array}$} \\
\hline & & & $\begin{array}{l}\text { type Pin } \\
\text { d'Alep }\end{array}$ & $\begin{array}{l}\text { type Pin } \\
\text { sylvestre }\end{array}$ & quartier & $\begin{array}{c}\text { faux- } \\
\text { quartier }\end{array}$ & dosse & indét. & & présente & proche & absente & \\
\hline \multirow{19}{*}{ SB1262 } & \multirow{3}{*}{ MR1263 } & 38 & & $\mathrm{x}$ & & $\mathrm{x}$ & & & 77 & & $\mathrm{X}$ & & non \\
\hline & & 51 & & $\mathrm{x}$ & & $\mathrm{x}$ & & & 36 & & $\mathrm{x}$ & & non \\
\hline & & 52 & & $\mathrm{X}$ & $\mathrm{X}$ & & & & 31 & & & $\mathrm{X}$ & non \\
\hline & \multirow{8}{*}{ MR1264 } & 28 & $\mathrm{X}$ & & $\mathrm{X}$ & & & & 75 & & $\mathrm{X}$ & & non \\
\hline & & 34 & $\mathrm{x}$ & & & $\mathrm{x}$ & & & 20 & & $\mathrm{x}$ & & non \\
\hline & & 55 & $\mathrm{X}$ & & & $\mathrm{x}$ & & & 43 & & $\mathrm{x}$ & & non \\
\hline & & 56 & $\mathrm{X}$ & & & & & $\mathrm{X}$ & & & & $\mathrm{x}$ & non \\
\hline & & 61 & $\mathrm{X}$ & & & & & $\mathrm{X}$ & & & & $\mathrm{x}$ & non \\
\hline & & 57 & $\mathrm{x}$ & & & & & $\mathrm{x}$ & & & & $\mathrm{X}$ & non \\
\hline & & 50 & $\mathrm{x}$ & & & & $\mathrm{X}$ & & 25 & & & $\mathrm{X}$ & non \\
\hline & & 62 & $\mathrm{X}$ & & $\mathrm{x}$ & & & & 15 & & & $x$ & non \\
\hline & \multirow{4}{*}{ MR1265 } & 35 & $\mathrm{X}$ & & & & $\mathrm{x}$ & & 23 & & $\mathrm{x}$ & & non \\
\hline & & 54 & $\mathrm{X}$ & & & & & $\mathrm{x}$ & - & & & $\mathrm{x}$ & non \\
\hline & & 53 & $\mathrm{X}$ & & & $\mathrm{x}$ & & & 26 & & $\mathrm{x}$ & & non \\
\hline & & 36 & $\mathrm{X}$ & & & $\mathrm{x}$ & & & 36 & & $\mathrm{X}$ & & non \\
\hline & \multirow{4}{*}{ MR1280 } & 26 & $\mathrm{X}$ & & $\mathrm{x}$ & & & & 78 & & & $x$ & non \\
\hline & & 37 & $\mathrm{X}$ & & & $\mathrm{X}$ & & & 65 & & & $\mathrm{X}$ & non \\
\hline & & 39 & $\mathrm{X}$ & & & $\mathrm{X}$ & & & 41 & & $\mathrm{x}$ & & non \\
\hline & & 40 & & $\mathrm{x}$ & $\mathrm{X}$ & & & & 82 & $\mathrm{X}$ & & & non \\
\hline
\end{tabular}

Tab. 7. Résultats des analyses dendrologiques des bordages du puits SB1262. 


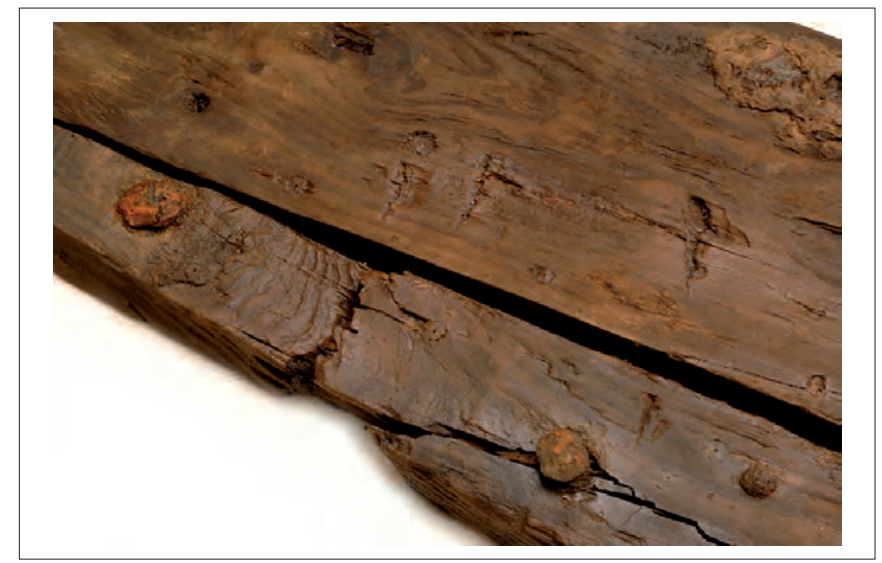

Fig. 243. Détail de la tête de deux clous en fer, utilisés pour fixer le bordage MR1264-56 à la membrure (cl. Chr. Durand - CCJ).

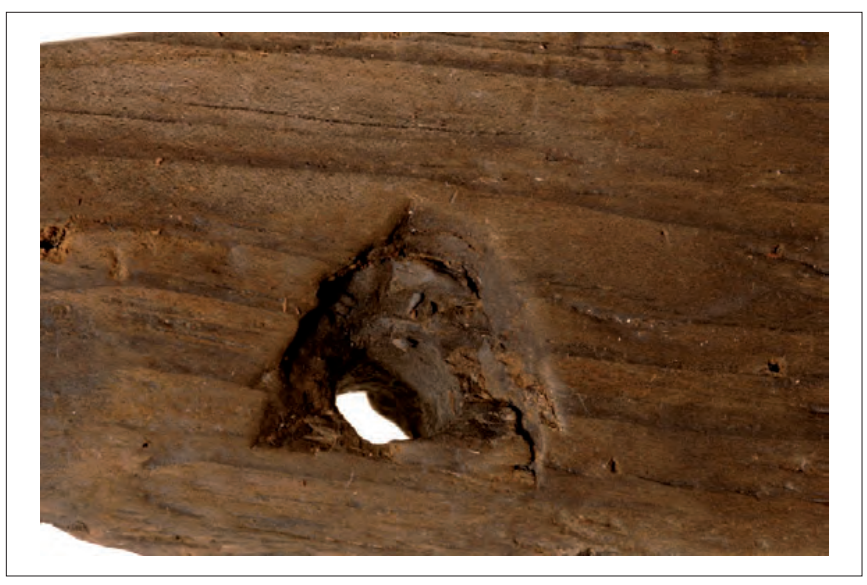

Fig. 245. Détail d'une encoche triangulaire (cl. Chr. Durand - CCJ).

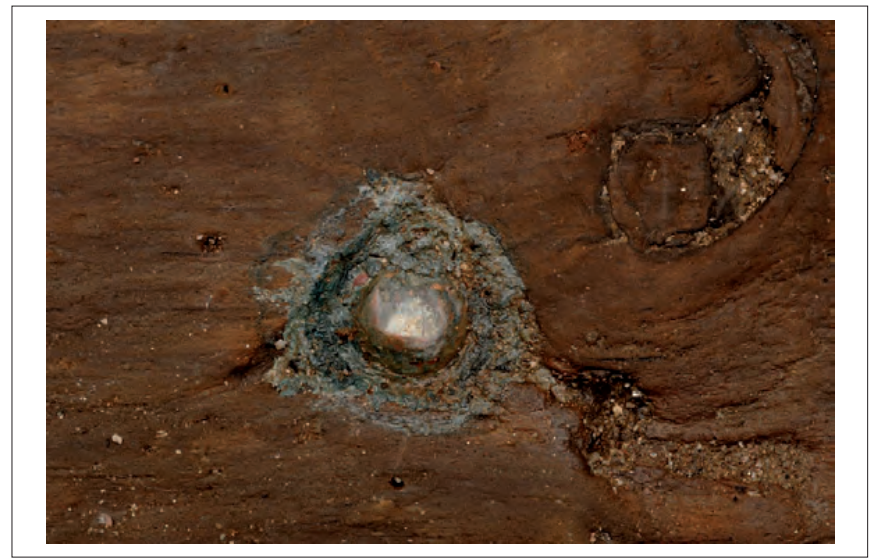

Fig. 244. Détail de la tête d'un clou en cuivre

chassé dans une encoche triangulaire dans le bordage MR1264-55 (cl. Chr. Durand - CCJ).

de celles-ci, ainsi que trois planches de la paroi MR1280 ( $\mathrm{n}^{\text {os }} 26,37$ et 39 ) ont été réalisées en bois de type pin d'Alep ${ }^{6}$. Le fragment de bordage MR1280-40 et les bordés de la paroi MR1263 ont été réalisés en bois du type pin sylvestre (tab. 7) ${ }^{7}$.

L'appellation pin de type «pin d'Alep » désigne deux taxons dont la distinction par l'anatomie de leur bois est particulièrement difficile : le pin d'Alep (Pinus halepensis Mill.) et le pin brutia (Pinus brutia Ten.). Ces deux taxons qui dominent la végétation forestière du littoral méditerranéen de basse altitude se répartissent de part et d'autre du bassin méditerranéen : le pin d'Alep, dans la partie occidentale (en France, il est particulièrement répandu en Provence) et le pin brutia, dans sa partie orientale (Quézel, Médail 2003).

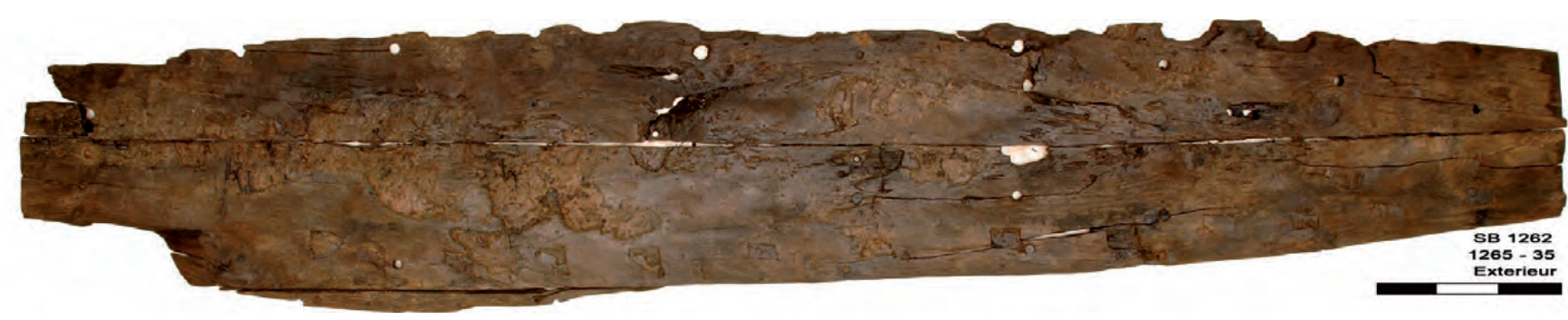

Fig. 246. Le fragment de bordés MR1265-35, 53 et 54,

enduit d'une couche de poix de protection et correspondant à la face extérieure du bateau (cl. Chr. Durand - CCJ).

\subsection{Identification xylologique}

L'analyse anatomique réalisée sur l'ensemble des bordages a révélé que ceux-ci étaient débités dans deux types d'essences résineuses : le pin de type pin d'Alep et le pin de type pin sylvestre. Du point de vue xylologique, les bordages se répartissent en deux groupes. Les portions de bordés matérialisées par les parois MR1264 et MR1265, y compris les fragments se situant au-dessus
Le pin de type «pin sylvestre » désigne trois taxons tout aussi impossibles à discriminer sur la base de l'analyse de leur bois : le pin sylvestre (Pinus sylvestris L.), le pin à crochets (Pinus uncinata Ram.)

6 Ces planches appartiennent au deuxième ensemble identifié grâce à l'analyse des caractéristiques architecturales.

7 Ces planches appartiennent au premier ensemble identifié grâce à 1'analyse des caractéristiques architecturales. 


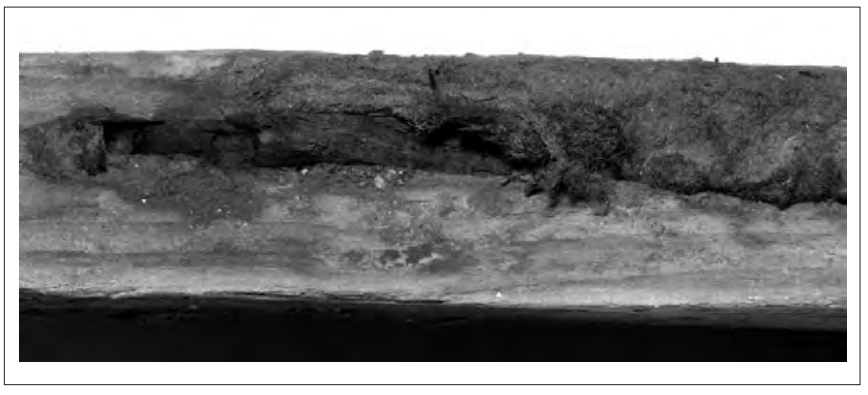

Fig. 247. Détail de la poix de calfatage, observée sur le can des bordés MR1265-35, 53 et 54 (cl. Chr. Durand - CCJ).
Saint-Gervais 3 (148-150 apr. J.-C.), Laurons 1 (IVe siècle apr. J.-C.), Laurons 2 (fin $\mathrm{II}^{\mathrm{e}}$ siècle apr. J.-C.) (Guibal, Pomey 1999, 20, tableau 2) et Dramont E (début Ve siècle apr. J.-C.) (Guibal 1995, 181-187). Bien que les qualités physiques et mécaniques de ce type de pin soient modestes ${ }^{8}$, le pin d'Alep a probablement été largement utilisé dans la construction navale en raison de la proximité des pinèdes littorales et des chantiers navals (Rival 1991, 28, 31).

Le bois de pin de type pin sylvestre a été identifié sur le bordé des navires Napoli A et Napoli C (fin I ${ }^{\text {er }}$ siècle apr. J.-C.) (Allevato et al. 2009 et 2010), Chrétienne A,

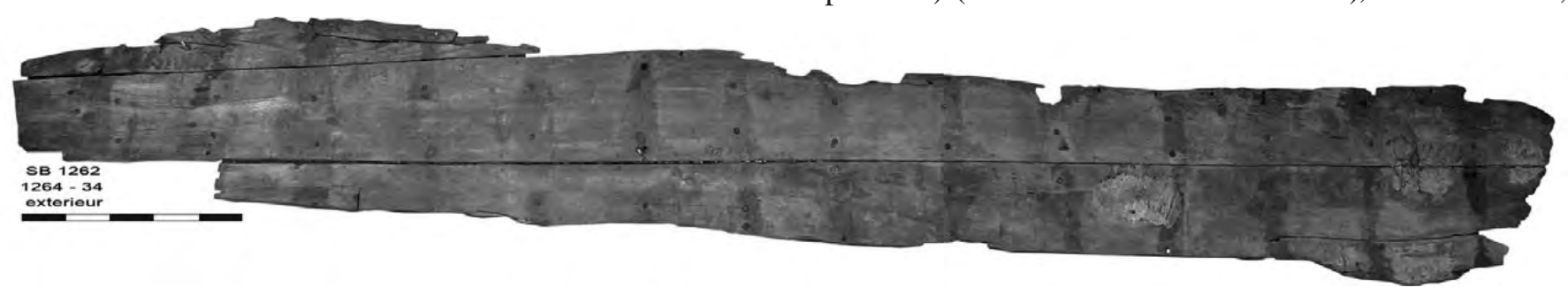

Fig. 248. Le fragment de bordés MR1264-61, 55, 34 et 56, correspondant à la face intérieure du bateau.

Les empreintes laissées par les membrures non conservées sont visibles (cl. Chr. Durand - CCJ).

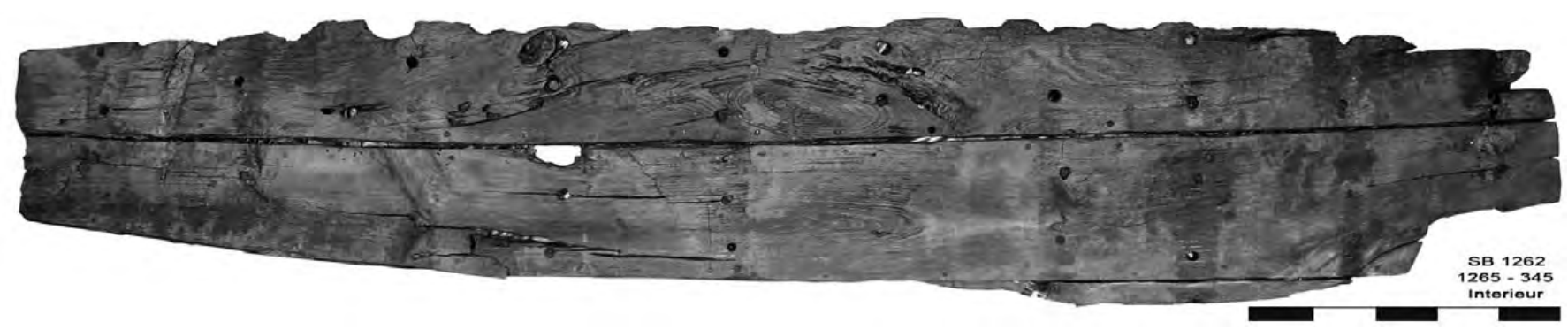

Fig. 249. Le fragment de bordés MR1265-35, 53 et 54, correspondant à la face intérieure du bateau.

Les empreintes laissées par les membrures non conservées sont visibles (cl. Chr. Durand - CCJ).

et le pin noir (Pinus nigra Arn.). Si le pin sylvestre peuple les collines et les montagnes de la majeure partie de l'Europe, de la Sierra Nevada à la Sibérie, le pin à crochets se localise davantage dans les hautes montagnes des Alpes et des Pyrénées, tandis que le pin noir occupe de préférence les plaines et les basses montagnes de l'aire circumméditerranéenne et l'étage montagnard des Alpes Centrales (Lieutaghi 2004 et Rameau et al.1989).

Le pin d'Alep figure parmi les essences le plus souvent identifiées sur les épaves antiques de Méditerranée. Citons, par exemple, le bordé des embarcations JulesVerne 7 (525-510 av. J.-C.) (Pomey 1998, 151, n 6), Kyrenia (fin IV siècle av. J.-C.) (Steffy 1994, 43), Nemi 1 et 2 (Ir siècle apr. J.-C.) (Ucelli 1950, 152), Barthélemy $B$ (second quart du $\mathrm{I}^{\mathrm{er}}$ siècle apr. J.-C.) (Wicha 2003, 72), en association avec d'autres résineux sur les épaves Jules-Verne 9 (525-510 av. J.-C.) (Pomey 1998, 150, n 3), Chrétienne A (second quart du Ir siècle apr. J.-C.), Jeaume-Garde B (début Irr siècle apr. J.-C.),
Jaume-Garde B, Pointe de Pomègues et Cap de l'Esterel ( ${ }^{\text {er }}$ siècle av. J.-C.), Dramont A et Plane I (vers 50 av. J.-C.), Tradelière (15-10 av. J.-C.) et Saint-Gervais 3 (Guibal, Pomey 2003).

Pour ce qui relève des éléments d'assemblage des bordages $^{9}$, les chevilles de blocage des tenons ont été confectionnées dans différents bois de feuillus ${ }^{10}$ et les tenons ont été débités dans du bois de chêne de type chêne vert (Quercus ilex/coccifera L.) ${ }^{11}$, un taxon très largement rencontré pour ce type de pièce sur les épaves antiques de Méditerranée (Guibal 1991, tableau 1 ;

8 La résine abondante, par exemple, peut entrâner des difficultés de sciage (Giordano 1980, 186-187 et Vernet, Keller 1986, 214).

9 Les identifications ont été effectuées à l'œil nu sur les planches des parois MR1264 et 1265

10 Angiosperme dicotylédone, essences feuillues non identifiées à ce jour. 11 Le chêne de type chêne vert comprend deux taxons impossibles à distinguer sur la base d'une analyse anatomique de leur bois : le chêne vert (Quercus ilex L.) et le chêne kermès (Quercus coccifera $\mathrm{L}$.). 


\begin{tabular}{|c|c|c|c|c|c|c|c|c|c|c|c|}
\hline \multirow{2}{*}{$\begin{array}{l}\text { Fait } \\
\text { puits }\end{array}$} & \multirow{2}{*}{$\begin{array}{l}\text { US } \\
\text { Paroi }\end{array}$} & \multirow{2}{*}{$\begin{array}{l}\text { Index } \\
\text { Planche }\end{array}$} & \multicolumn{4}{|c|}{ Dimensions } & \multicolumn{2}{|c|}{ Résine } & \multirow{2}{*}{$\begin{array}{c}\text { Empreinte } \\
\text { pieds } \\
\text { couples }\end{array}$} & \multicolumn{2}{|c|}{ Outillage } \\
\hline & & & $\begin{array}{c}\text { longueur } \\
\text { (cons.) }\end{array}$ & $\begin{array}{c}\text { largeur } \\
(\max )\end{array}$ & $\begin{array}{l}\text { largeur } \\
\text { (cons.) }\end{array}$ & $\begin{array}{c}\text { ép. } \\
\text { moyen }\end{array}$ & int. & ext. & & int. & ext. \\
\hline \multirow{6}{*}{ BS3339 } & \multirow{2}{*}{ MR3/13 } & 3 & 195 & & 16 & 8 & $\mathrm{X}$ & & $\mathrm{x}$ & pointe sèche & \\
\hline & & 13 & 195 & & 24,5 & 8,5 & $\mathrm{x}$ & & $\mathrm{x}$ & pointe sèche & \\
\hline & \multirow{2}{*}{ MR4/12 } & 4 & 317,5 & & 13,5 & $8 / 8,5$ & $\mathrm{x}$ & & $\mathrm{x}$ & pointe sèche & \\
\hline & & 12 & 317,5 & & 21 & 8 & $\mathrm{x}$ & & $\mathrm{x}$ & pointe sèche & \\
\hline & \multirow{2}{*}{ MR6/14 } & 6 & 323,3 & & 11 & $8 / 8,5$ & $\mathrm{X}$ & & $\mathrm{x}$ & pointe sèche & \\
\hline & & 14 & 323,3 & & 30 & $8 / 8,5$ & $\mathrm{X}$ & & $\mathrm{X}$ & pointe sèche & \\
\hline
\end{tabular}

Tab. 8. Dimensions et caractéristiques des bordages du puits BS3339.

Rival 1991, tableaux 7, 10 et 11 et Guibal, Pomey 1999, 21, tableau 5), tandis que quelques gournables ont été réalisés dans des essences résineuses ${ }^{12}$.

\subsection{Analyse dendrochronologique}

Une analyse dendrochronologique a été conduite sur quatre planches en pin de type pin sylvestre et neuf planches en pin de type pin d'Alep.

Des synchronismes visuels et statistiques significatifs ont permis de distinguer deux groupes (Fréjus 1 et Fréjus 2) constitués des séries individuelles suivantes :

- MR1280-40, MR1263-52 (type « pin sylvestre ») ;

- MR1264-34, MR1264-55, MR1265-36, MR126553, MR1280-26, MR1280-37, MR1280-39 (type « pin d'Alep »).

Les deux chronologies moyennes calculées à partir de ces séries individuelles sont respectivement longues de 82 et 78 années. Les années terminales des séries individuelles qui les composent diffèrent de 51 années pour Fréjus 1 et de 34 années, au plus, pour Fréjus 2 du fait du débit des planches, réalisé tantôt sur dosse tantôt sur quartier, de l'usure et de l'état de conservation après son enfouissement (fig. 250 et 251). Aucun synchronisme n'a pu être mis en évidence entre ces deux chronologies moyennes. Cela peut confirmer que les bordages en pin de type sylvestre et ceux de type pin d'Alep n'appartiennent pas à la même embarcation. Mais l'absence de synchronisme peut tout aussi refléter la différence taxonomique entre les deux essences ou bien la faible représentativité des chronologies moyennes liée au faible nombre d'échantillons analysés et à la faible longueur des séries individuelles. Les deux chronologies moyennes ont ensuite été comparées, en l'absence de chronologies de référence de pins disponibles pour la région méditerranéenne, à d'autres chronologies moyennes locales de pin de type sylvestre et de pin d'Alep, issues, notamment, de l'étude d'épaves antiques

12 Gymnosperme. Les essences résineuses n’ont pas été identifiées à ce jour.
(Guibal, Pomey 1998, 2003 et 2004). Malheureusement, aucune corrélation satisfaisante n'a été dégagée et les chronologies moyennes demeurent donc flottantes.

\section{Les bordés réutilisés dans le puits BS3339}

\subsection{Caractéristiques architecturales}

Les fragments de bordés réutilisés pour construire le cuvelage de trois des parois du puits BS3339 (MR4/12, MR3/13 et MR6/14) présentent des caractéristiques architecturales très proches et appartiennent probablement à la coque d'un même navire antique (tab. 8). Ces fragments se limitent à deux bordages assemblés par des tenons chevillés qui ne conservent ni leur longueur ni leur largeur d'origine (fig. 252 et 253) ; leur épaisseur varie de 8 à $8,5 \mathrm{~cm}$. Au niveau des assemblages (tab. 9), les tenons sont d'une largeur moyenne égale à 7,8 cm, d'une épaisseur moyenne de $1,2 \mathrm{~cm}$ et d'une longueur moyenne de $24 \mathrm{~cm}$ (fig. 254 et $255 \mathrm{a}$ et $\mathrm{b})$. Leur extrémité est légèrement chanfreinée. Ils sont espacés d'environ $6 \mathrm{~cm}$ et disposés sur le can de la planche, légèrement en quinconce. Ces assemblages internes sont donc très serrés (tab. 9) ${ }^{13}$. Les chevilles, tronconiques, ont une section prismatique et ont été insérées depuis la face interne de la coque (diamètre interne : $1,9 \mathrm{~cm}$, diamètre externe : $1,44 \mathrm{~cm}$ ). Elles sont en moyenne espacées de $14 \mathrm{~cm}$. Sur le bord de contact des planches de la portion de bordé MR4/12, la présence d'une mince couche de poix a été décelée ; un fragment du matériau d'étanchéité (ou calfatage), peut-être du tissu, a été prélevé. La face interne de ces trois bordés est enduite d'une couche de poix dont l'épaisseur peut atteindre $1 \mathrm{~cm}$. Des zones dépourvues de calfatage indiquent le passage des couples du navire. Ces empreintes, larges en moyenne de 7,6 cm (entre 5,5 et $9 \mathrm{~cm}$ ), sont espacées de bord à bord de 22,8 cm (de 19,5 à $29 \mathrm{~cm}$ ). Cette valeur fournit une indication sur l'espacement des couples du

13 Rapport entre écart moyen et largeur moyenne des tenons égal à 0,77 . 
DEUXIÈME PARTIE : ANALYSES ET ÉTUDES

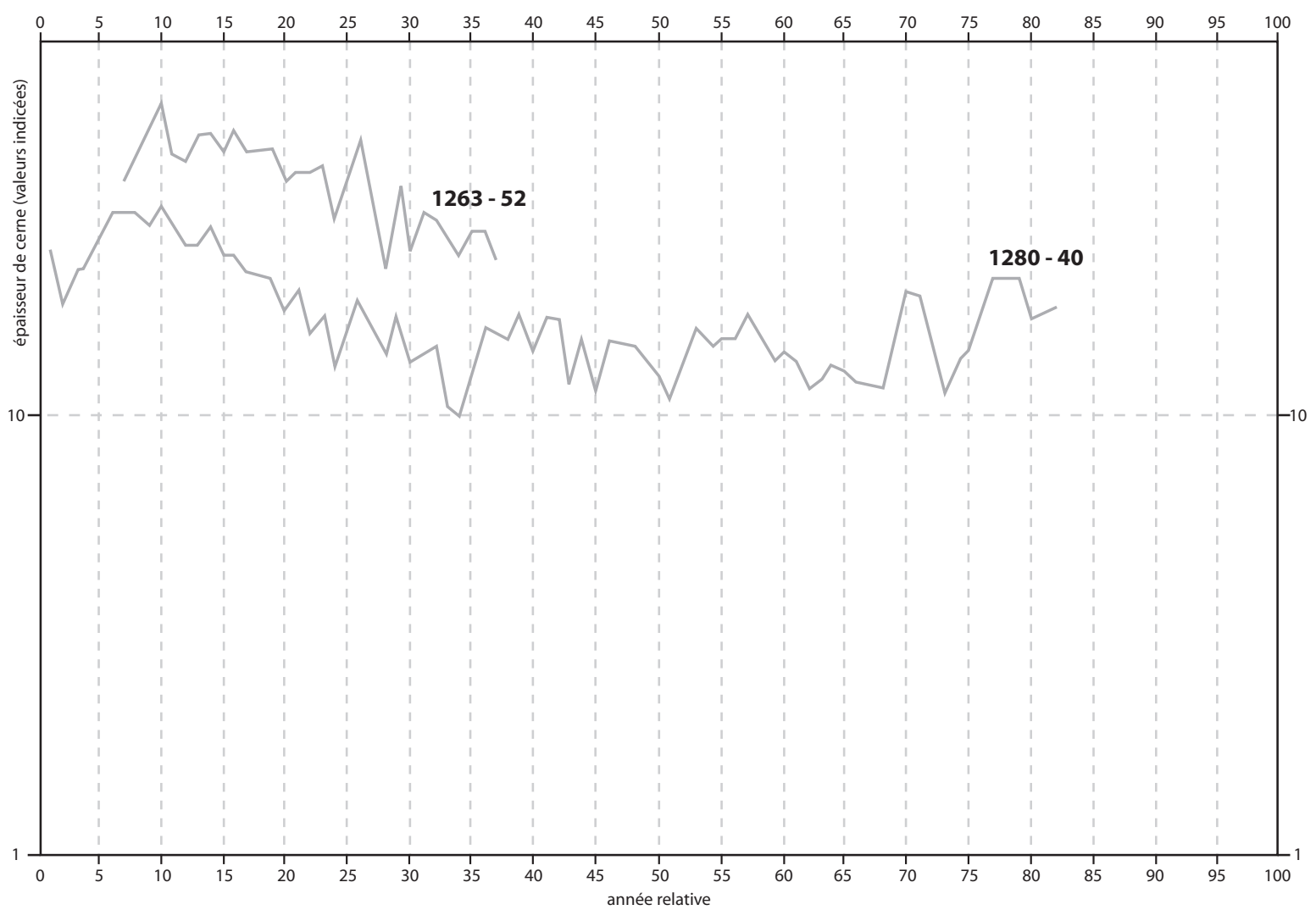

Fig. 250. Courbes représentatives des chronologies individuelles constitutives de la chronologie moyenne Fréjus 1.

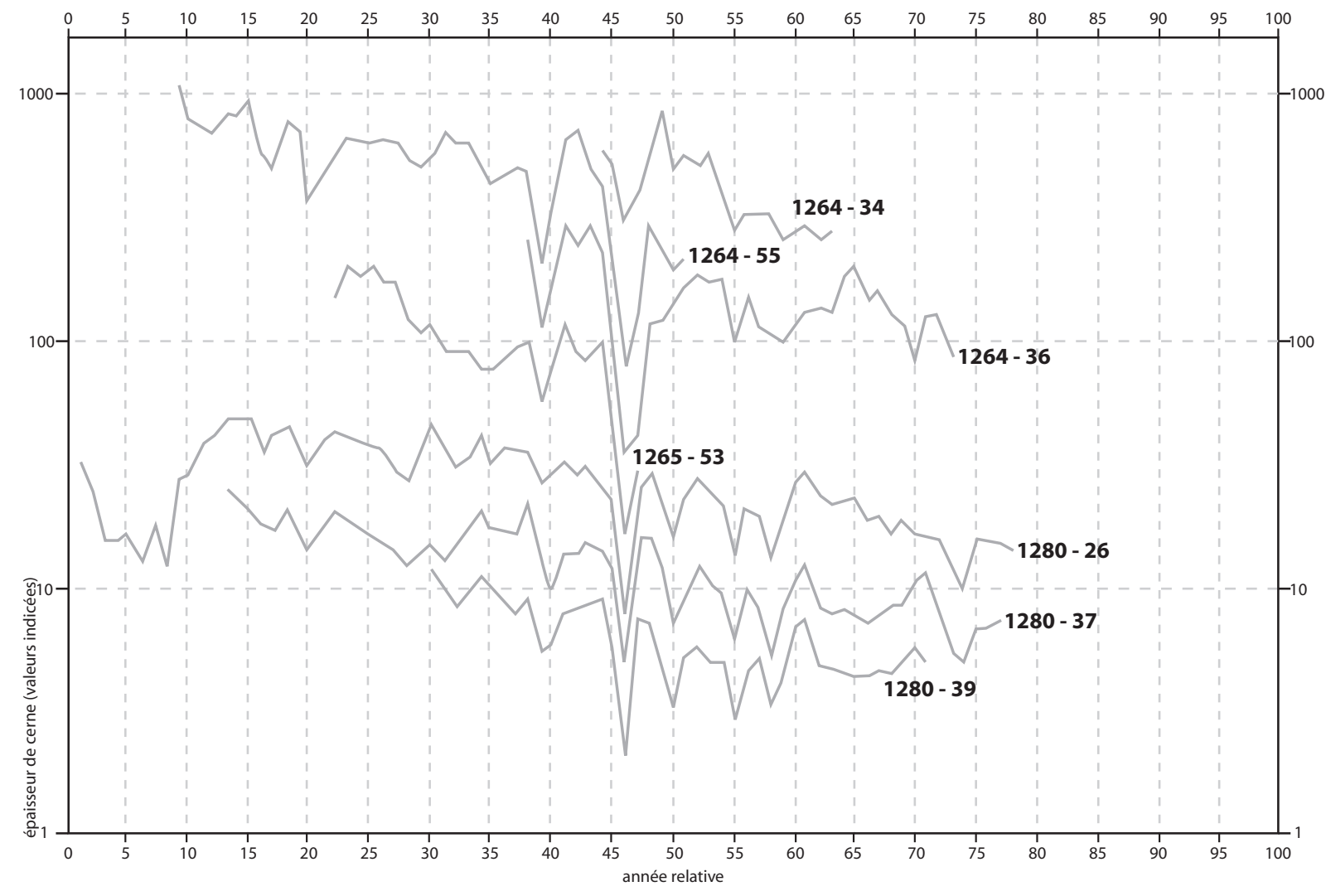

Fig. 251. Courbes représentatives des chronologies individuelles constitutives de la chronologie moyenne Fréjus 2. 

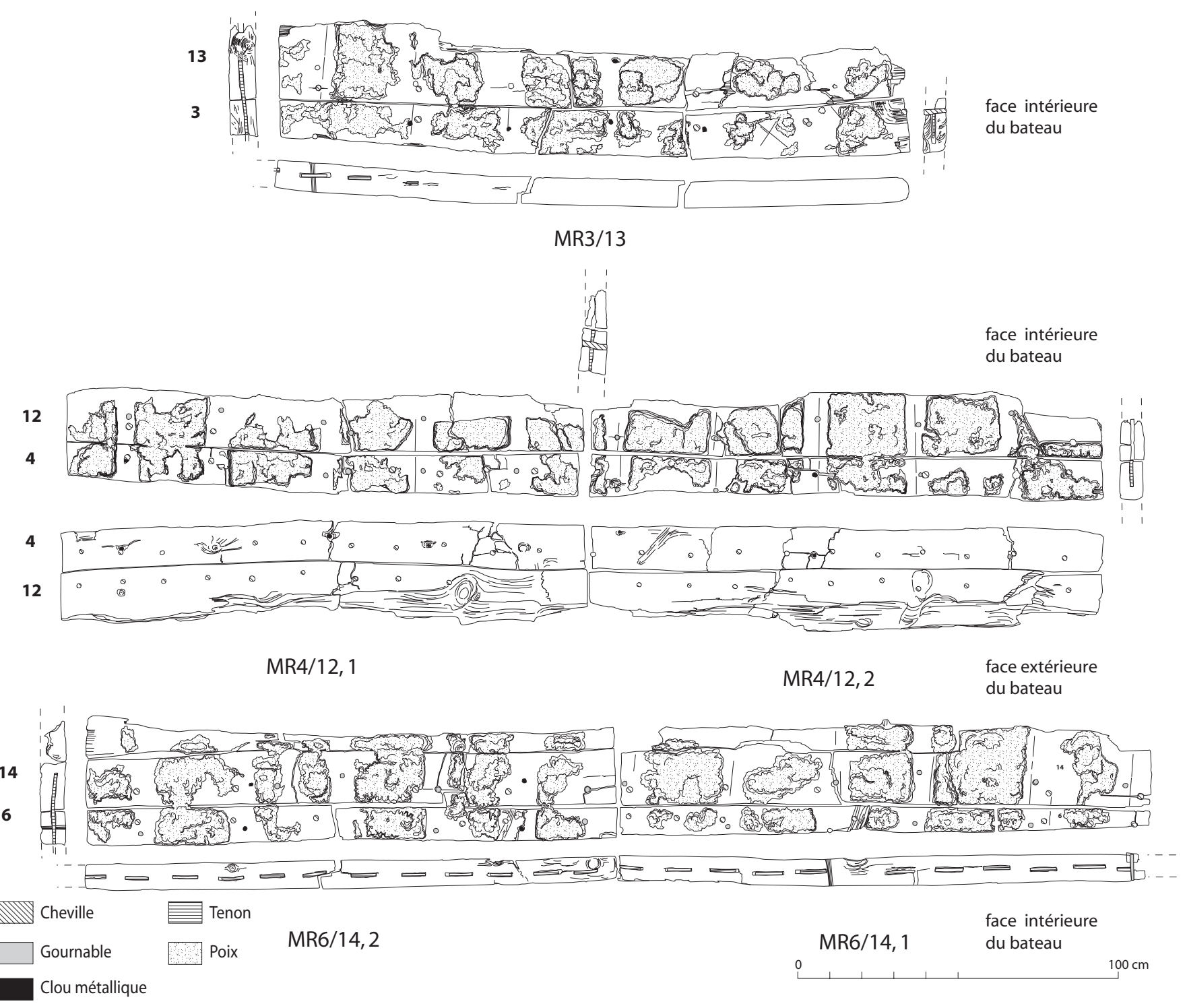

Fig. 252. Les fragments de bordages de l'épave Fréjus-Villeneuve 3

(G. Boetto).

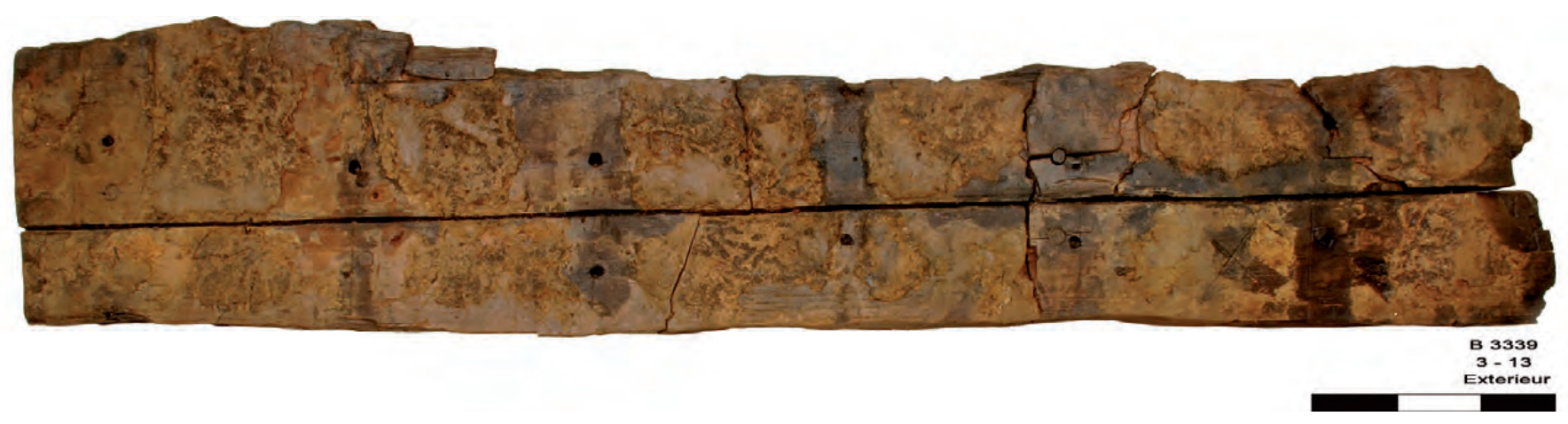

Fig. 253. Le fragment de bordés MR3/13 correspondant à la face intérieure du bateau. L'épaisse couche de poix et les empreintes laissées par les membrures non conservées sont visibles

(cl. Chr. Durand - CCJ). 
DEUXIÈME PARTIE : ANALYSES ET ÉTUDES

\begin{tabular}{|c|c|c|c|c|c|c|c|c|c|c|c|c|c|}
\hline \multirow{2}{*}{$\begin{array}{l}\text { Fait } \\
\text { Puits }\end{array}$} & \multirow{2}{*}{$\begin{array}{l}\text { US } \\
\text { Paroi }\end{array}$} & \multirow{2}{*}{$\begin{array}{l}\text { Index } \\
\text { Planche }\end{array}$} & \multicolumn{4}{|c|}{ Mortaises } & \multicolumn{3}{|c|}{ Tenons } & \multicolumn{4}{|c|}{ Chevilles } \\
\hline & & & largeur & prof. & ép. & écart & largeur & ép. & $\begin{array}{l}\text { longueur } \\
\text { (cons.) }\end{array}$ & diam. & $\begin{array}{l}\text { diam. } \\
\text { (int.) }\end{array}$ & $\begin{array}{l}\text { diam. } \\
\text { (ext.) }\end{array}$ & écart \\
\hline \multirow{6}{*}{ BS3339 } & \multirow{2}{*}{ MR3/13 } & 3 & 9,5 & 14 & 1.2 & 5,75 & 8 & 1,1 & 24 & & 1,86 & 1,44 & 14,1 \\
\hline & & 13 & & & & & & & & & & & \\
\hline & \multirow{2}{*}{ MR $4 / 12$} & 4 & 7,6 & 12 & 1.3 & 6,85 & 7,6 & 1,3 & 21 & & 1,94 & 1,44 & 14,2 \\
\hline & & 12 & & & & & & & & & & & \\
\hline & \multirow{2}{*}{ MR6/14 } & 6 & 8,37 & 13.2 & 1.3 & 5,58 & 7,74 & 1,2 & 22,2 & & 1,82 & & 13,9 \\
\hline & & 14 & & & & & & & & & & & \\
\hline
\end{tabular}

Tab. 9. Dimensions et caractéristiques des assemblages des bordages du puits BS3339.

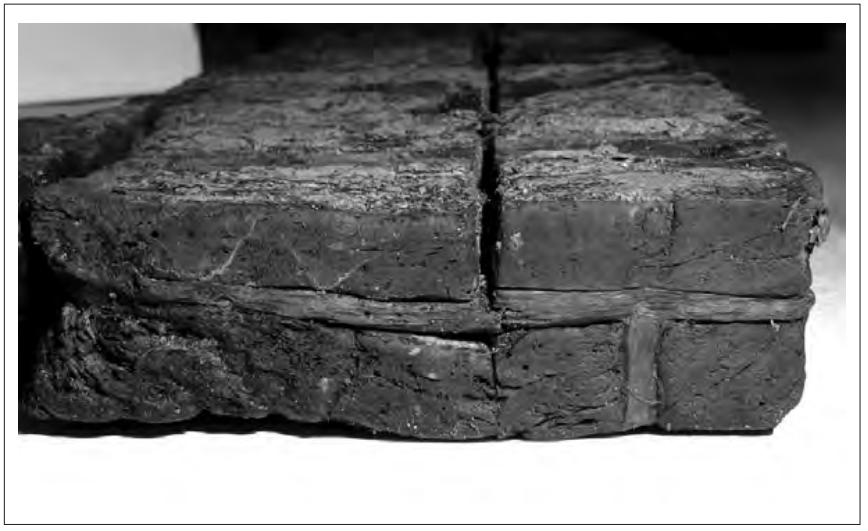

Fig. 254. Détail en coupe d'un tenon d'assemblage entre les deux planches de la paroi MR6/14 du puits BS3339 (cl. Chr. Durand - CCJ).

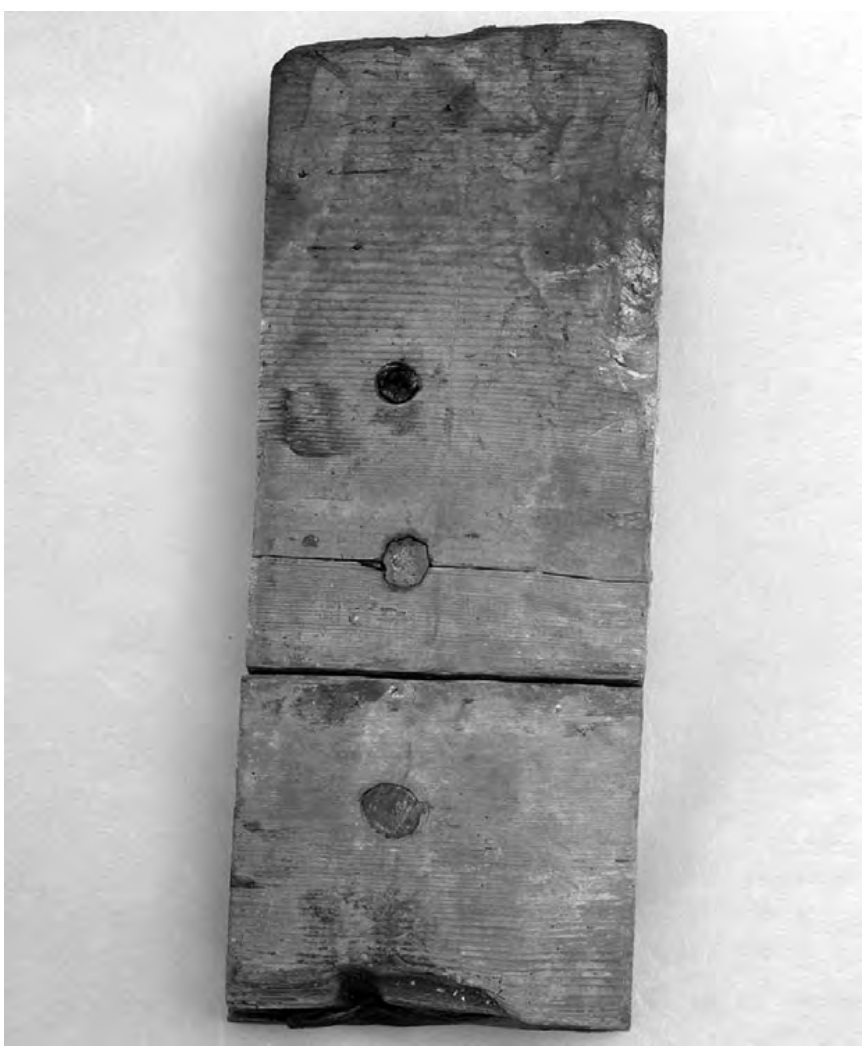

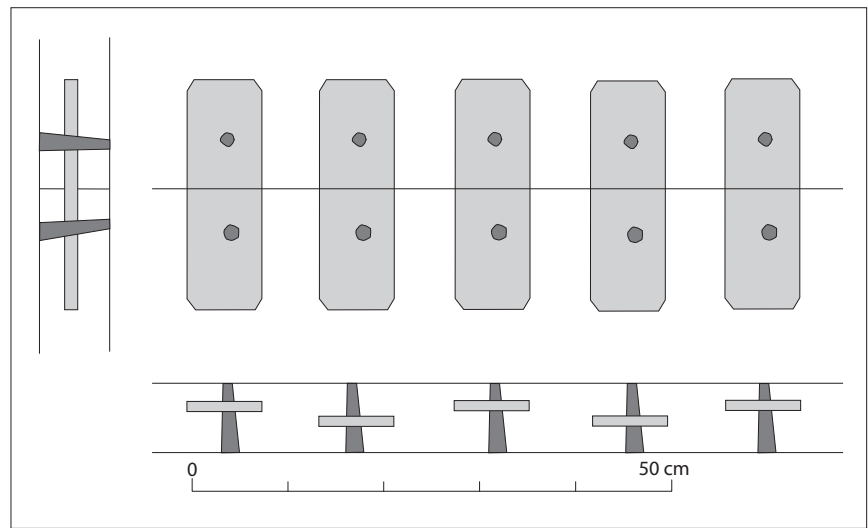

Fig. 255. (a) Shéma du réseau de mortaisage de l'épave Fréjus-Villeneuve 3

(G. Boetto).

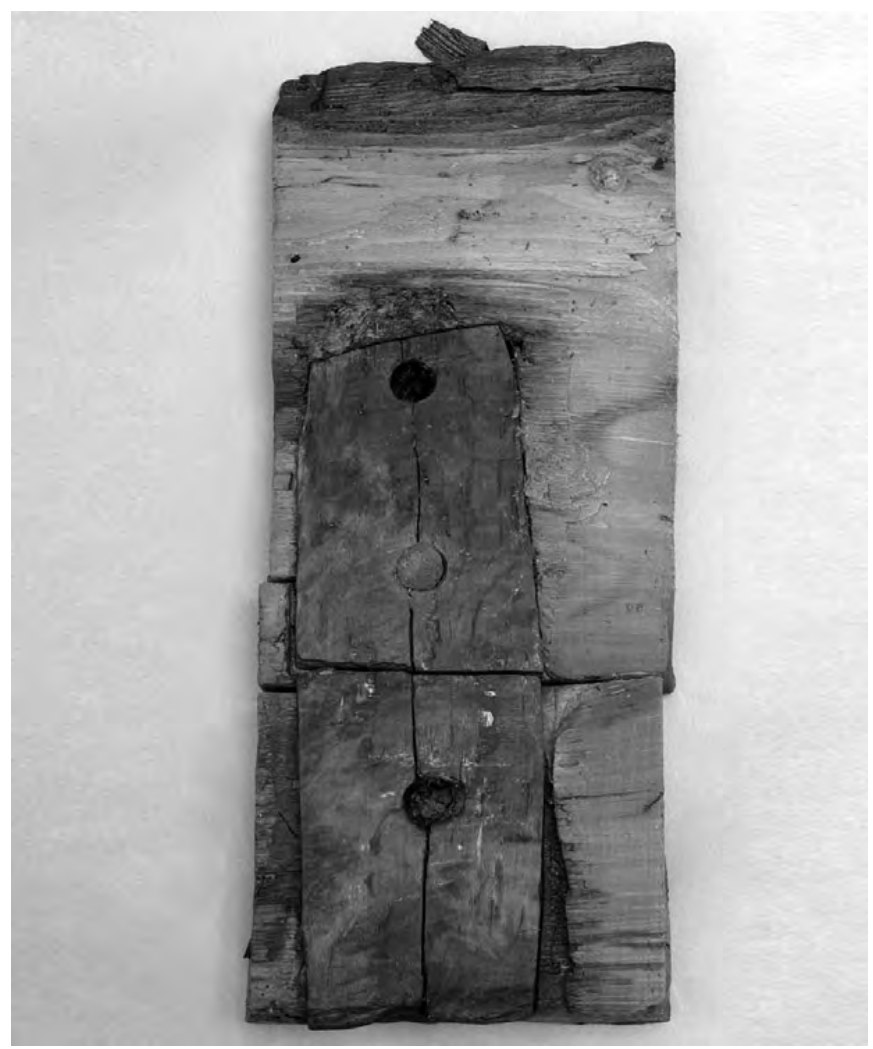

Fig. 255. (b) Détails du mortaisage (recto-verso) de l'épave Fréjus-Villeneuve 3 (cl. Chr. Durand - CCJ). 


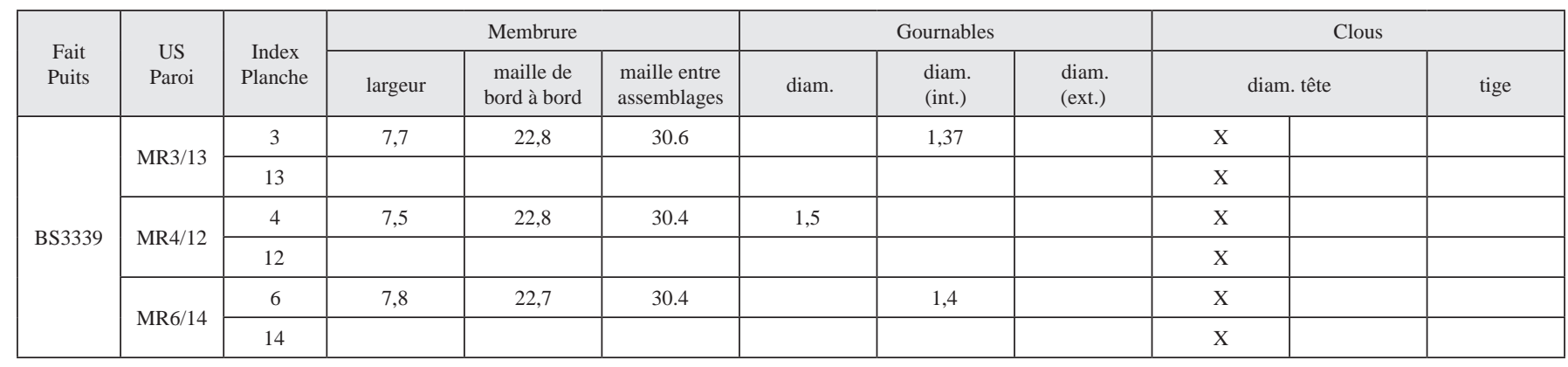

Tab. 10. Dimensions et caractéristiques de la membrure et de ses assemblages avec les bordages du puits BS3339.

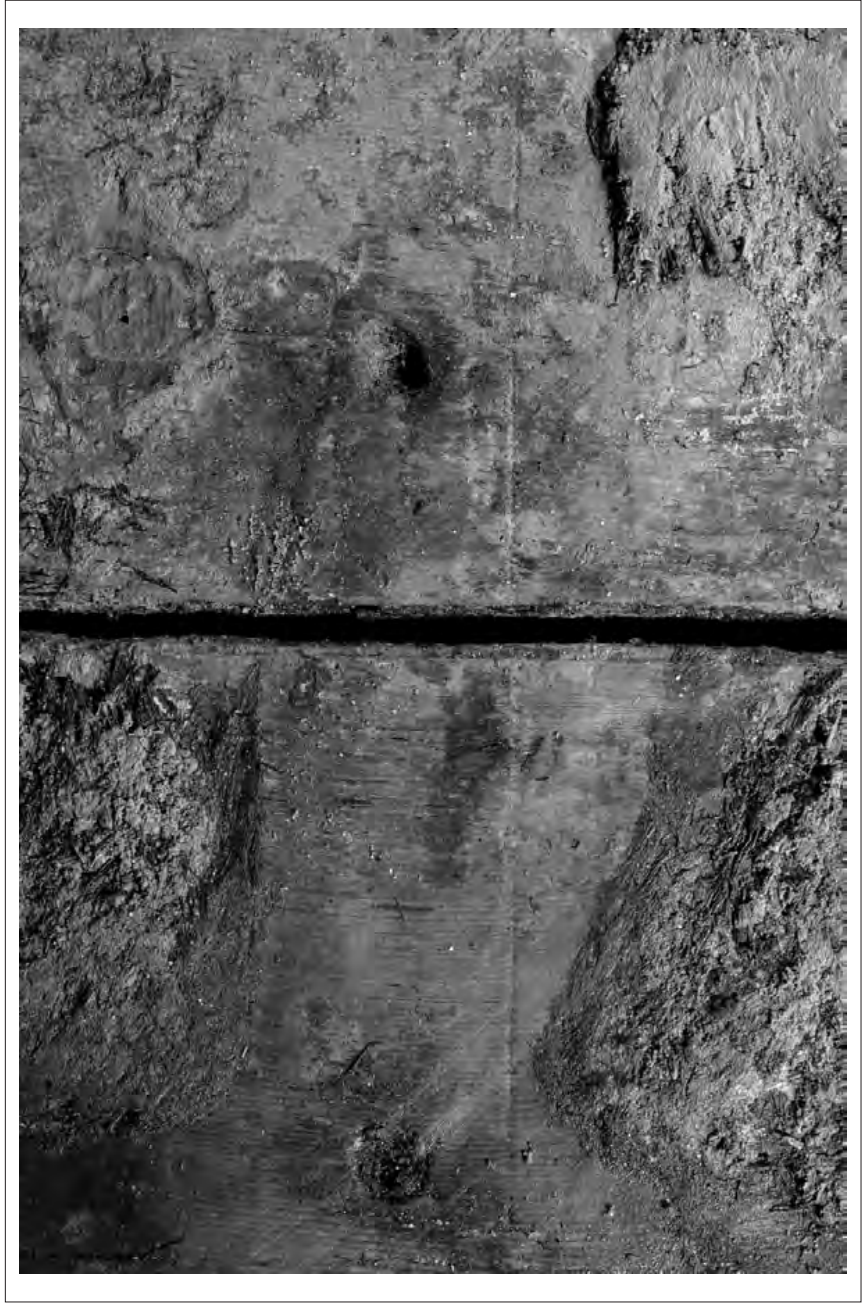

Fig. 256. Les lignes droites tracées à la pointe sèche indiquent l'emplacement des membrures sur les bordés MR4/12

(cl. Chr. Durand - CCJ).

navire d'origine (tab. 10). Les couples étaient assemblés au bordé à l'aide de clous métalliques, aujourd'hui complètement oxydés, et par des gournables en bois. Les trous circulaires pratiqués pour ces assemblages ont un diamètre de 1,4/1,5 cm. La maille entre ces éléments d'assemblage mesure en moyenne 30,5 cm (entre 25,5 et $35 \mathrm{~cm}$ ). Toutes les portions de bordé présentent sur

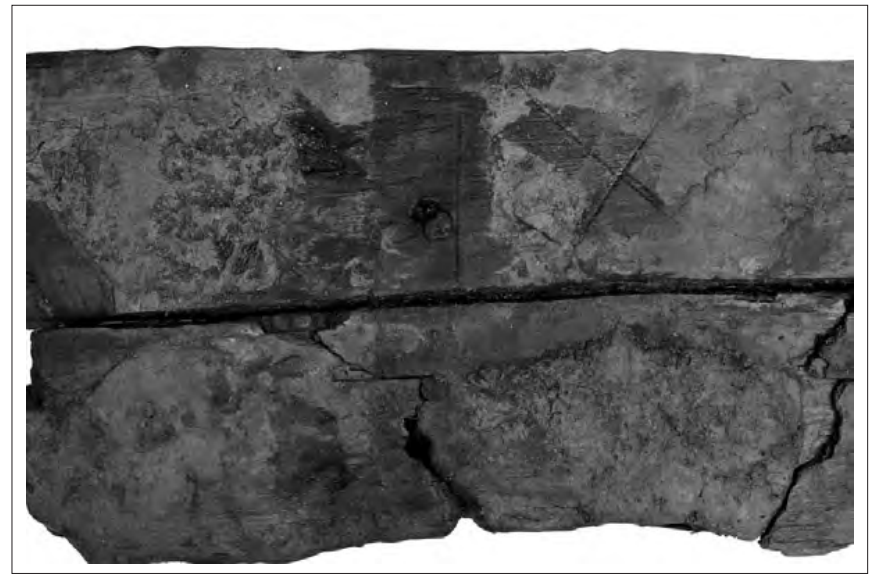

Fig. 257. Détail des bordés MR3/13 montrant la ligne de repère pour l'emplacement de la membrure et le signe $\mathrm{X}$

(cl. Chr. Durand - CCJ).

leur face interne des marques de charpentier tracées à la pointe sèche. Des lignes droites indiquent l'emplacement des membrures (fig. 256). Il s'agit soit de deux lignes parallèles, soit d'une ligne unique placée le long de l'axe central des couples. Ces marques, tracées avant la pose de la membrure, indiquent que le bateau d'origine a été construit «sur bordé premier » ${ }^{14}$. La portion MR3/13 conserve aussi le signe $\mathrm{X}$ (largeur : $13 \mathrm{~cm}$ ) tracé à la pointe sèche et situé dans la maille (fig. 257).

\subsection{Identification xylologique}

Toutes les planches de bateau réutilisées ont été confectionnées dans du pin de type pin sylvestre (Pinus sylvestris L./Pinus uncinata Ram./Pinus nigra Arn.) (tab. 11). Les éléments d'assemblage n'ont fait l'objet, jusqu'à présent, que d'une prédétermination à l'oeil nu. Il semblerait que les tenons soient confectionnés dans du bois de type chêne vert (Quercus ilex/coccifera L.), les chevilles dans diverses essences feuillues et résineuses, et les gournables dans du bois de chêne caducifolié (Quercus sp.).

14 Pour une définition, voir Pomey, Rieth 2005, 30-31. 


\begin{tabular}{|c|c|c|c|c|c|c|c|c|c|c|c|c|}
\hline \multirow{2}{*}{$\begin{array}{l}\text { Fait } \\
\text { Puits }\end{array}$} & \multirow{2}{*}{$\begin{array}{l}\text { US } \\
\text { Paroi }\end{array}$} & \multirow{2}{*}{$\begin{array}{c}\text { Index } \\
\text { Planche }\end{array}$} & \multirow{2}{*}{$\begin{array}{l}\text { Essence } \\
\text { ligneuse }\end{array}$} & \multicolumn{3}{|c|}{ Débit } & \multicolumn{2}{|c|}{ Âge } & \multicolumn{3}{|c|}{ Moelle } & \multirow{2}{*}{$\begin{array}{c}\text { Dernier } \\
\text { cerne }\end{array}$} \\
\hline & & & & quartier & faux-quartier & indét. & & indét. & présente & proche & indét. & \\
\hline \multirow{6}{*}{ BS3339 } & \multirow{2}{*}{ MR3/13 } & 3 & $\mathrm{X}$ & & $\mathrm{X}$ & & 153 & & & $\mathrm{X}$ & & non \\
\hline & & 13 & $X$ & $\mathrm{X}$ & & & 164 & & $\mathrm{X}$ & & & non \\
\hline & \multirow{2}{*}{ MR4/12 } & 4 & $\mathrm{X}$ & & $\mathrm{X}$ & & 225 & & & $\mathrm{X}$ & & non \\
\hline & & 12 & $\mathrm{X}$ & & $\mathrm{X}$ & & 256 & & & $\mathrm{X}$ & & non \\
\hline & \multirow{2}{*}{ MR6/14 } & 6 & $X$ & & & $X$ & & $\mathrm{X}$ & & & $\mathrm{X}$ & non \\
\hline & & 14 & $\mathrm{X}$ & & & $\mathrm{X}$ & & $\mathrm{X}$ & & & $\mathrm{X}$ & non \\
\hline
\end{tabular}

Tab. 11. Résultats des analyses dendrologiques des bordages du puits BS3339.

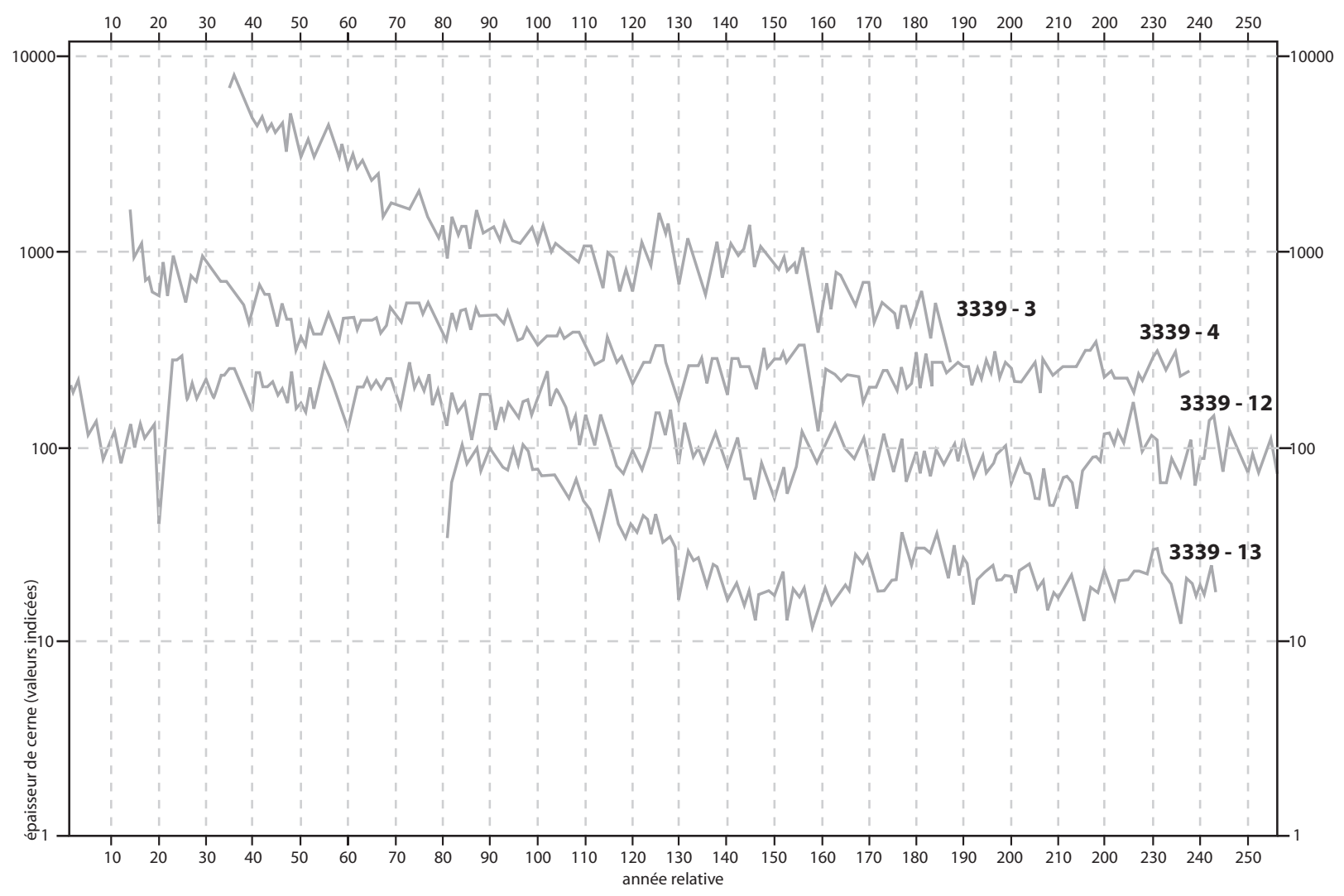

Fig. 258. Courbes représentatives des chronologies individuelles constitutives de la chronologie moyenne Fréjus 3.

\subsection{Analyse dendrochronologique}

Quatre planches en pin de type pin sylvestre ont été analysées ( $n^{\text {os }} 3,4,12$ et 13$)^{15}$. Les quatre séries qui en résultent synchronisent, autant statistiquement que visuellement ${ }^{16}$. Elles ont été réunies dans une chronologie moyenne (Fréjus 3) longue de 256 ans (fig. 258). Les écarts entre les années terminales des chronologies individuelles vont de 12 à 69 ans, mais

15 Le fragment de bordé MR6/14 n'a pas été analysé car conservé intégralement pour une éventuelle restauration en vue d'une présentation muséographique.

16 Indices issus des tests supérieurs à 5. ni le cambium ni l'écorce ne se sont conservés du fait du débit des pièces de bois. Les planches $n^{\text {os }} 3$ et 4 ont été débitées dans le même arbre ${ }^{17}$. Bien qu'utilisés dans deux parois différentes du puits, ces deux fragments de bordés appartiennent probablement au même navire. La probabilité que les bordages non analysés (MR6/14) appartiennent aussi au même ensemble d'origine est élevée (même essence utilisée et longueur similaire des séries).

La chronologie moyenne Fréjus 3 a été comparée à la chronologie Fréjus 1 (supra), mais aucun synchronisme

17 Indices TVBP et TVH du test de Student supérieurs à 8 et confirmés visuellement. 
n'a été relevé. Aucune corrélation satisfaisante n'a été trouvée avec les chronologies locales de pins antiques (Guibal, Pomey 1998, 2003 et 2004). La faible représentativité de la moyenne, liée au faible nombre d'échantillons qui la composent et à la présence de deux planches issues du même arbre en est probablement la cause $^{18}$.

\section{Deux ou trois navires?}

Parmi les fragments de bordés réutilisés dans le puits SB1262 nous avons pu distinguer deux ensembles sur la base des caractéristiques architecturales (épaisseur du bordé, dimensions des assemblages, maille de la membrure, essences utilisées, présence ou absence d'encoches triangulaires et de réparations) qui pourraient appartenir à deux embarcations différentes.

Fréjus-Villeneuve 1 se caractériserait par un bordé simple, assemblé à franc bord et d'une épaisseur moyenne de $3,75 \mathrm{~cm}$. La maille de la membrure, mesurée entre gournables, est de $27,8 \mathrm{~cm}$. Les bordages conservés ont été débités dans du pin de type pin sylvestre.

Fréjus-Villeneuve 2 présenterait aussi un bordé simple, assemblé à franc-bord, mais moins épais que celui de Fréjus-Villeneuve 1 (moyenne : 2,6 cm). L'espacement des gournables est plus serré (moyenne : $22,5 \mathrm{~cm}$ ) et la membrure large de $6,3 \mathrm{~cm}$. En plus, des gournables en bois assurant la liaison entre bordé et membrure, cette embarcation présente des clous métalliques dont certains ont été enfoncés dans des encoches de forme triangulaire. Tous les bordages conservés sont en pin de type pin d'Alep. Fréjus-Villeneuve 2 présente des tenons de réparation. La présence de poix de calfatage sur les bords des bordages pourrait être liée à ces opérations de réparation ${ }^{19}$. La vétusté de cette embarcation pourrait être la raison de son abandon, du démontage de ses structures et de leur réutilisation partielle pour le cuvelage du puits. La datation radiocarbone effectuée sur une planche de cette embarcation (\#634 SB1262, MR1264-55) révèle que l'abattage des arbres ayant servi à la construction date du deuxième tiers du Irr siècle apr. J.-C.

Si l'on considère l'épaisseur moyenne du bordé de ces deux navires, ils devaient, à l'origine, probablement mesurer entre 15 et $20 \mathrm{~m}$ de longueur. En revanche, l'identification du type et de la fonction de ces bateaux

18 La datation radiocarbone donne une fourchette large mais antérieure à la fin du II siécle av. J.-C. (FR06 \#635 BS3339-3 : 2160+/- 30BP. $68.2 \%$ probability $360 \mathrm{BC}(34.1 \%) 290 \mathrm{BC} ; 230 \mathrm{BC}(2.4 \%) 220 \mathrm{BC} ; 210 \mathrm{BC}(31.6 \%)$ $160 \mathrm{BC} ; 95.4 \%$ probability $360 \mathrm{BC}(40.3 \%) 270 \mathrm{BC} ; 260 \mathrm{BC}(55,1 \%) 100 \mathrm{BC}$

19 On admet, normalement, que les navires antiques assemblés par la technique « à tenons et mortaises » ne nécessitaient aucun type de calfatage entre les planches du bordé (Gianfrotta, Pomey 1981). est plus problématique car les données dont nous disposons sont trop limitées.

L'utilisation de tenons de réparation est assez commune, durant l'époque romaine, tant sur les navires de commerce ${ }^{20}$ que sur les bateaux de servitude portuaire ou de pêche. ${ }^{21}$. La seule embarcation de guerre, découverte à Marsala en Sicile et datée du III ${ }^{\mathrm{e}}$ siècle av. J.-C., ne portait aucune réparation du bordé (Frost 1978). Mais il s'agit d'un exemple unique et nos connaissances archéologiques des flottes militaires sont trop limitées pour pouvoir exclure cette technique de réparation des navires militaires. Pour l'instant, et en l'absence de comparaisons, nous préférons attribuer ces fragments de bordé à des navires de commerce ou bien de servitude portuaire de taille moyenne.

Les fragments de bordages du puits BS3339 appartiennent à un autre navire que nous avons dénommé Fréjus-Villeneuve ${ }^{22}$. Celui-ci se caractérise par un bordé simple en pin de type pin sylvestre, très épais $(8,5 \mathrm{~cm})$, assemblé par des tenons de grandes dimensions. La membrure, large de 7,6 cm, était plutôt espacée $(23 \mathrm{~cm})$. Les dimensions du bordé de Frejus-Villeneuve 3 sont comparables à celles des préceintes de l'épave Planier III (milieu du Ir siècle av. J.-C.). Ce navire, d'une longueur estimée à $30 \mathrm{~m}$, présentait un bordé épais de $6 \mathrm{~cm}$ et un renfort longitudinal constitué d'une première préceinte (largeur : $32 \mathrm{~cm}$; épaisseur : $10 \mathrm{~cm}$ ) et d'une seconde (largeur : 52,5 cm, épaisseur : $19 \mathrm{~cm}$ ) (Pomey 2006, 76). Une autre comparaison peut être faite avec une épave découverte dans le port de Césarée Maritime sur la côte israélienne (I ${ }^{\text {er }}$ siècle apr. J.-C.). Le bordé, de type simple, a une épaisseur de $9 \mathrm{~cm}$ mais la membrure est beaucoup plus serrée et massive que celle de FréjusVilleneuve 3. L'épave de Césarée a été classée parmi les navires de grande taille, sa longueur étant probablement voisine de $40 \mathrm{~m}^{23}$. L'épave Madrague de Giens (7065 av. J.-C.) présentait un bordé intérieur très épais (de $12 \mathrm{~m}$ au niveau du galbord à $6 \mathrm{~cm}$ à partir du $3^{\mathrm{e}}$ bordage) doublé d'un bordé extérieur d'une épaisseur moyenne de $4 \mathrm{~cm}$. Les tenons d'assemblage du bordé intérieur de

20 Par exemple sur les épaves Tour Fondue, III ${ }^{e}$ siècle av. J.-C. (Dangreaux 1997, 90), Madrague de Giens, 70-65 av. J.-C. (P. Pomey comunication personnelle ; pour l'épave Pomey 1978 et 1982), Bathélémy B, milieu du I ${ }^{\text {er }}$ siècle apr. J.-C. (Joncheray, Joncheray 1997), Napoli A, fin $\mathrm{I}^{\mathrm{er}}$ siècle apr. J.-C. (Boetto 2005), Grado, milieu du $\mathrm{II}^{\mathrm{e}}$ siècle apr. J.-C. (Beltrame, Gaddi 2007).

21 Comme sur les bateaux-drague de Marseille, III ${ }^{\mathrm{e}}$ siècle apr. J.-C. (Pomey 1999) ou sur les embarcations de type horeia de Naples et de Toulon, Ir siècle apr. J.-C. (Boetto 2009) ou, encore, sur les barques à propulsion mixte comme celle d'Herculanum, Irr siècle apr. J.-C. (Steffy 1999, 398).

22 Cette hypothèse peut être confirmée par les analyses dendrochronologiques.

23 Pour une discussion de la relation entre longueur des navires et épaisseur du bordé : Fitzgerald 1994, 178-185. 
cette épave présentaient des dimensions très proches de celles mesurées sur le navire Fréjus-Villeneuve 3 (Pomey 1978, 78-80). Patrice Pomey a restitué une longueur de $40 \mathrm{~m}$ et un port en lourd de 350/400 tonnes pour l'épave Madrague de Giens. Ce navire utilisé pour le transport du vin de Campanie au début du ${ }^{\text {er }}$ siècle av. J.-C. faisait partie des plus gros navires de commerce maritime d'usage courant à cette époque (Pomey, Tchernia 1978, 234 et Pomey 1982). Le navire Fréjus-Villeneuve 3, bien que sa fonction de commerce ne soit pas certaine, pourrait avoir été de dimensions proches de celles qui ont été restituées pour les épaves de Césarée, Planier III et Madrague de Giens, soit environ 30/40 m.

\section{Conclusion}

Les fragments de muraille récemment découverts et récupérés peuvent être attribués à, au moins, trois navires. Bien que la fonction de ces embarcations soit incertaine, nous pouvons affirmer qu'il s'agit de deux bateaux de dimension moyenne, longs de 15 à $20 \mathrm{~m}$ (Fréjus-Villeneuve 1 et 2 ), et d'un navire de grande dimension, long de 30 à $40 \mathrm{~m}$ (Fréjus-Villeneuve 3).
Dans la mesure où nous ne connaissons pas l'origine des navires bâtis à l'aide de ces bordages, leur espace de navigation demeure inconnu. Par ailleurs, compte tenu de la discrimination taxonomique qui est - dans le cas présent - limitée, aucune hypothèse ne peut être avancée sur l'origine géographique des arbres utilisés pour la fabrication de ces navires ni sur la détermination de leur éventuelle aire de construction.

Ces fragments de bordés, bien que de réutilisation, représentent une découverte exceptionnelle pour la ville de Fréjus et attestent l'importance de son port au I ${ }^{\text {er }}$ siècle apr. J.-C. Avant la découverte de vestiges d'embarcations antiques dans le quartier de Villeneuve, la seule épave connue dans la zone de Fréjus était celle qui fut mise au jour dans les années 1950-60, dans l'étang de Villepey (épave de La Clavelède) (Boyer, Février 1971). Cette découverte témoigne de la disponibilité dans la zone de Villeneuve, proche de la plage antique et du port, de bois provenant de navires désarmés et de leur réutilisation pour des constructions non navales ${ }^{24}$.

24 La réutilisation d'éléments de bateaux est bien attestée à proximité des zones portuaires antiques, par exemple à Portus (Boetto 2006, 286-288) et à Marseille (Hesnard 2004, 183, fig. 6). 


\section{Chapitre 2}

\section{Minéraux lourds}

\section{(M. Dubar)}

\section{Préparation des échantillons}

Les sédiments sont tamisés en recueillant les fractions $50-125 \mu$ et $125-315 \mu$. Chaque fraction est nettoyée par l'acide chlorhydrique bouillant. La décantation sur le bromoforme permet de recueillir les minéraux lourds (d>2,89) et d'écarter les minéraux légers (quartz, feldspaths, micas). Les minéraux lourds sont montés entre lames et lamelles dans le Beaume de Canada.

\section{Observation et détermination au microscope polarisant}

Les deux fractions séparées sont observées et déterminées (fig. 259). Le comptage a été fait sur la fraction 50-125 $\mu$.

Au total, 15 espèces minérales ont été déterminées (tab. 12). Ce sont toutes des minéraux du socle qui se scindent en deux groupes essentiels :

1/ Des minéraux du métamorphisme : staurotide, disthène, andalousite,

2/ Des minéraux des roches éruptives (granit), en particulier le sphène.

Plusieurs espèces minérales sont en fait présentes dans les roches métamorphiques et dans les roches éruptives.

On note aussi la présence d'augite verte qui est un minéral volcanique provenant des mugéarites du Reyran.

\section{Essai d'interprétation}

Deux rivières principales participent à l'apport alluvial : l'Argens et le Reyran. Le gisement se situe à l'aval de la confluence de ces deux rivières.

L'Argens draine le rebord nord des Maures et aussi le Tanneron occidental. De vastes terrains du socle sont traversés, prioritairement des granits (unités du

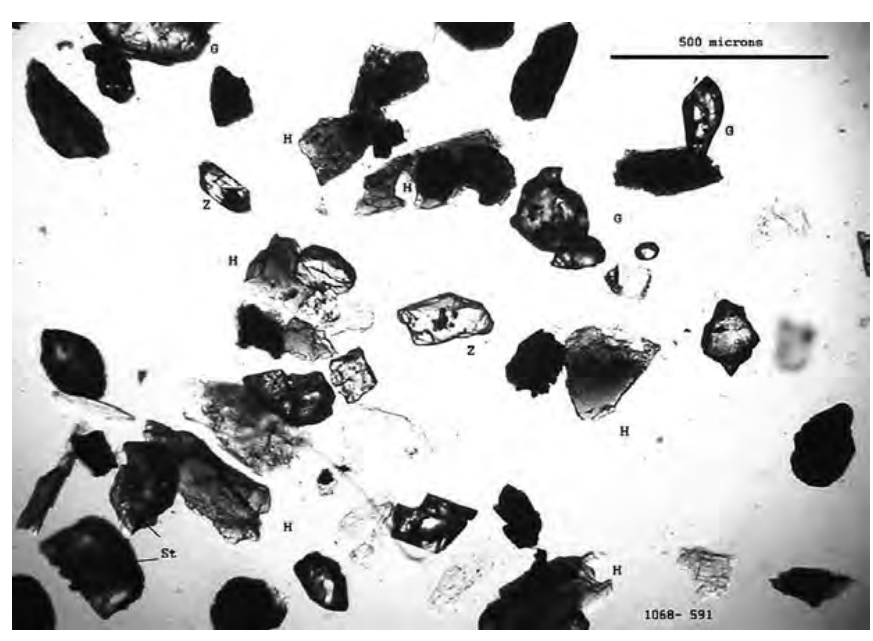

Fig. 259. Échantillon vu au microscope géologique (lumière polarisée, non analysée) montrant l'abondance de la Hornblende $(H)$, des Zircons $(Z)$, du Grenat $(G)$ et de la Staurotide (St).

Plan de la Tour, granits du Rouet) mais les roches métamorphiques sont aussi très abondantes : gneiss des unités de la Garde-Freinet et de Bormes-lesMimosas, amphibolites des Arcs.

En revanche, on peut dire que le Reyran draine presque exclusivement des terrains métamorphiques (et migmatitiques) et des terrains sédimentaires (grès carbonifères, grès permiens). Les ryolithes de l'aval du bassin ne fournissent que peu de minéraux lourds.

En somme, en première approche, la distinction Argens/Reyran se fera essentiellement par l'abondance relative de staurotides et autres minéraux du métamorphisme dans le cortège du Reyran. En ce sens, l'échantillon \#598 pauvre en staurotides se distingue des autres échantillons. De plus, l'abondance de sphènes (minéral des granits) milite en faveur d'un apport dominant de l'Argens pour cet échantillon. Les autres échantillons montrent une homogénéité globale. Seuls quelques détails les distinguent les uns des autres, en particulier la présence d'augites volcaniques (mugéarite du Reyran).

En conclusion, il ressort que les alluvions étudiés reflètent bien sûr une double provenance Reyran/ 
Argens, sur la base de ce qui a été montré précédemment (Bellaiche 1969). La distinction de l'échantillon \#598 résulte peut-être globalement d'une crue de l'Argens ou de l'étiage du Reyran. La contribution du Reyran en matière détritique semble très importante dans le régime normal de la pluviométrie régionale.

\begin{tabular}{|l|c|c|c|c|c|c|c|c|c|c|}
\hline Esp. minérales & $\mathbf{\# 5 8}$ & $\mathbf{\%}$ & $\mathbf{\# 5 8 9}$ & $\mathbf{\%}$ & $\mathbf{\# 5 9 0}$ & $\mathbf{\%}$ & $\mathbf{\# 5 9 6}$ & $\mathbf{\%}$ & $\mathbf{\# 5 9 8}$ & $\mathbf{\%}$ \\
\hline Amphiboles & 29 & 45,31 & 21 & 27,27 & 33 & 45,83 & 20 & 33,90 & 26 & 53,06 \\
\hline Staurotide & 9 & 14,06 & 11 & 14,29 & 7 & 9,72 & 7 & 11,86 & 3 & 6,12 \\
\hline Grenat & 9 & 14,06 & 16 & 20,78 & 9 & 12,50 & 13 & 22,03 & 7 & 14,29 \\
\hline Zircon & 6 & 9,38 & 14 & 18,18 & 12 & 16,67 & 5 & 8,47 & 3 & 6,12 \\
\hline Tourmaline & 5 & 7,81 & 5 & 6,49 & 5 & 6,94 & 5 & 8,47 & 2 & 4,08 \\
\hline Sphène & 1 & 1,56 & 3 & 3,90 & 3 & 4,17 & 4 & 6,78 & 3 & 6,12 \\
\hline Disthène & 1 & 1,56 & 2 & 2,60 & 1 & 1,39 & 0 & 0,00 & 2 & 4,08 \\
\hline Fluorine & 1 & 1,56 & 1 & 1,30 & 1 & 1,39 & 0 & 0,00 & 0 & 0,00 \\
\hline Anatase & 0 & 0,00 & 1 & 1,30 & 0 & 0,00 & 0 & 0,00 & 1 & 2,04 \\
\hline Rutile & 1 & 1,56 & 1 & 1,30 & 1 & 1,39 & 1 & 1,69 & 1 & 2,04 \\
\hline Andalousite & 0 & 0,00 & 1 & 1,30 & 0 & 0,00 & 0 & 0,00 & 0 & 0,00 \\
\hline Barytine & 0 & 0,00 & 1 & 1,30 & 0 & 0,00 & 0 & 0,00 & 0 & 0,00 \\
\hline Monazite & 1 & 1,56 & 0 & 0,00 & 0 & 0,00 & 1 & 1,69 & 1 & 2,04 \\
\hline Epidote & 0 & 0,00 & 0 & 0,00 & 0 & 0,00 & 2 & 3,39 & 0 & 0,00 \\
\hline Augite & 1 & 1,56 & 0 & 0,00 & 0 & 0,00 & 1 & 1,69 & 0 & 0,00 \\
\hline Total & $\mathbf{6 4}$ & $\mathbf{1 0 0 , 0 0}$ & $\mathbf{7 7}$ & $\mathbf{1 0 0 , 0 0}$ & $\mathbf{7 2}$ & $\mathbf{1 0 0 , 0 0}$ & $\mathbf{5 9}$ & $\mathbf{1 0 0 , 0 0}$ & $\mathbf{4 9}$ & $\mathbf{1 0 0 , 0 0}$ \\
\hline
\end{tabular}

Tab. 12. Espèces minérales. 


\title{
Chapitre 3
}

\section{Analyse archéobotanique}

\author{
(L. Bouby, I. Figueiral et C. SchaAl)
}

\section{Introduction}

Dès les débuts de la période romaine jusqu'au $\mathrm{XX}^{\mathrm{e}}$ siècle, l'emprise des fouilles de la Villa Romana a principalement eu une vocation d'espace cultivé. Rapidement gagné sur la mer, cet espace se trouve à l'époque romaine aux limites du rivage, non loin de l'emplacement supposé du camp militaire des Aiguières et se situe immédiatement au sud-est du complexe thermal de Villeneuve dont il est séparé par un mur. Se succèdent dans l'espace et dans le temps une série de secteurs horticoles, délimités par des murs, pouvant accueillir des fosses de plantations, des fossés aux fonctions moins évidentes ainsi que des puits et bassins.

Dans ce cadre, les analyses archéobotaniques visent principalement à la restitution de l'environnement végétal local et des plantes qui ont pu être cultivées sur place, sans pour autant exclure la possibilité d'enregistrer des déchets d'activités humaines, domestiques ou artisanales, qui auraient pu se dérouler à proximité. Les analyses poursuivies portent sur des graines et fruits (carpologie) ainsi que sur des restes ligneux carbonisés (anthracologie) et gorgés d'eau (xylologie).

La restitution des cultures à l'intérieur des espaces de production par l'étude de macrorestes végétaux prélevés sur place est assez peu commune et présente d'importantes difficultés qui tiennent à deux raisons principales :

- D'une part, les terres cultivées sont par nature en conditions aérobies et, de ce fait, ne se prêtent pas à la conservation des macrorestes végétaux tombés au sol. Seule la carbonisation est à même de permettre leur préservation mais les chances de subir l'action du feu sont moins fortes dans les milieux cultivés qu'à l'intérieur des habitats où le feu est beaucoup plus présent.

- D'autre part, le remplissage des fosses et structures de plantations est mis en place en même temps ou avant le végétal cultivé et peut donc difficilement contenir des éléments aériens de ce dernier, en particulier les fruits produits, à moins d'intrusions dans les sédiments sousjacents au niveau de la surface du sol.
Afin de tenter de contourner au mieux ces handicaps, nous avons privilégié, d'une part les niveaux humides susceptibles d'avoir préservé des macrorestes non carbonisés, d'autre part les structures ouvertes (type puits et bassins) dont le comblement lent paraissait plus à même d'enregistrer l'environnement local et les activités humaines afférentes que le comblement très rapide des structures de plantation.

\section{Matériels et méthodes}

\subsection{L'échantillonnage}

Les analyses ont porté sur 19 échantillons, divers de par leurs origines contextuelles, le milieu de conservation, les méthodes de prélèvement et de traitement des sédiments, ainsi que par la nature du matériel qu'ils ont livré (bois/fruits, graines) (tab. 13).

Selon les choix méthodologiques présentés en introduction, les analyses portent principalement sur des couches situées en deçà du niveau de la nappe phréatique et susceptibles d'avoir conservé des macrorestes végétaux gorgés d'eau. Seules les fosses de plantation FS1139 et VP1017 se trouvaient en milieu sec. Les structures ouvertes (puits, bassins) sont également concernées.

Les principales phases d'occupation du site sont représentées : fosse de plantation à amphore VP1017 et puits PT1201 pour la phase 2 (de 30 av. J.-C. à 50 apr. J.-C.) ; fosse de plantation FS1139 et puits/ bassin SB1262 pour la phase 3 (de 50 à 175 apr. J.-C.) ; tranchées (de plantation ?) FO3179 et FO3223, premier comblement du bassin BS3339 pour la phase 4A (de 175 à 300 apr. J.-C.) ; dernier comblement du bassin BS3339, fosse de plantation FS3220 pour la phase 4B (de 300 à 450 apr. J.-C.) ; puits PT2031 pour la phase 5 (XVe/XVIe siècles).

Nos analyses s'appuient sur l'échantillonnage et les tamisages réalisés par l'équipe de terrain. Il s'agit 
de criblages sous eau, à maille minimale de $0,5 \mathrm{~mm}$. Lorsque les tamisages de terrain livraient des échantillons traités uniquement à maille minimale de $1 \mathrm{~mm}$, nous avons doublé les tamisages au laboratoire, avec maille minimale de $0,4 \mathrm{~mm}$ (SB1262, US1287 et BS3339, US3342).

Certains macrorestes végétaux visibles à l'œil (bois, fruits et graines) ont été prélevés directement à la fouille. Ces éléments proviennent de structures qui ont parallèlement fait l'objet de tamisages, à l'exception de la fosse FS3214 pour laquelle seules les semences prélevées à l'œil nu sont disponibles.

\subsection{Méthodes d'étude}

Le tri et l'analyse carpologiques sont conduits en laboratoire, à l'aide d'un stéréomicroscope.

La détermination s'appuie sur les caractéristiques morpho-anatomiques et biométriques des diaspores qui permettent, le plus souvent, d'atteindre le rang de l'espèce. De manière générale, l'effectif de paléosemences augmente à mesure que diminue la maille des tamis. Un aperçu représentatif du contenu carpologique des fractions les plus fines peut ainsi être souvent obtenu en n'exploitant qu'une partie des

\begin{tabular}{|c|c|c|c|c|c|c|c|c|c|c|c|c|c|}
\hline Fait & Type & US & Nature & Ech. & Zone & Secteur & $\begin{array}{c}\text { Phase } \\
\text { d'occupation }\end{array}$ & $\begin{array}{c}\text { Datation } \\
\text { (ans apr. } \\
\text { J.-C.) }\end{array}$ & $\begin{array}{l}\text { Vol. } \\
\text { analysé } \\
\text { en litres }\end{array}$ & $\begin{array}{c}\text { Maille } \\
\text { minimum } \\
\text { tamisage } \\
(\mathbf{m m})\end{array}$ & Carpo. & Anthraco. & Xylologie \\
\hline \multicolumn{14}{|c|}{ Tamisages } \\
\hline FS1139 & $\begin{array}{c}\text { Fosse } \\
\text { plantation }\end{array}$ & 1140 & $\begin{array}{l}\text { Comblement } \\
\text { supérieur }\end{array}$ & 123 & 1 & 1 & $3 \mathrm{~A}$ & 100 à 200 & 20 & 0,5 & + & + & - \\
\hline VP1017 & $\begin{array}{c}\text { Fosse } \\
\text { plantation }\end{array}$ & 1064 & $\begin{array}{l}\text { Comblement } \\
\text { fosse }\end{array}$ & 71 & 1 & 2 & 2 & -25 à 50 & 11 & 0,5 & - & - & - \\
\hline VP1017 & $\begin{array}{c}\text { Vase } \\
\text { plantation }\end{array}$ & 1067 & $\begin{array}{c}\text { Comblement } \\
\text { amphore }\end{array}$ & 67 & 1 & 2 & 2 & -25 à 50 & 22 & 0,5 & - & - & - \\
\hline SB1262 & $\begin{array}{l}\text { Puits/ } \\
\text { Bassin }\end{array}$ & 1287 & $\begin{array}{l}\text { Comblement } \\
\text { médian }\end{array}$ & 344 & 1 & 2 & $3 \mathrm{~A}$ & 100 à 200 & 2,5 & 0,4 & + & - & - \\
\hline SB1262 & $\begin{array}{l}\text { Puits/ } \\
\text { Bassin }\end{array}$ & 1287 & $\begin{array}{l}\text { Comblement } \\
\text { médian }\end{array}$ & 344 & 1 & 2 & $3 \mathrm{~A}$ & 100 à 200 & 10 & 1 & + & + & + \\
\hline SB1262 & $\begin{array}{l}\text { Puits/ } \\
\text { Bassin }\end{array}$ & 1291 & $\begin{array}{l}\text { Comblement } \\
\text { inférieur }\end{array}$ & 408 & 1 & 2 & $3 \mathrm{~A}$ & 100 à 200 & 10 & 1 & + & - & + \\
\hline SB1262 & $\begin{array}{l}\text { Puits/ } \\
\text { Bassin }\end{array}$ & 1266 & $\begin{array}{l}\text { Comblement } \\
\text { supérieur }\end{array}$ & 307 & 1 & 2 & $3 \mathrm{~A}$ & 100 à 200 & 10 & 1 & + & - & - \\
\hline PT1201 & Puits & 1245 & $\begin{array}{l}\text { Comblement } \\
\text { inférieur }\end{array}$ & 219 & 1 & 2 & 2 & -25 à 50 & 2 & 0,5 & - & + & - \\
\hline PT2031 & Puits & 2035 & $\begin{array}{l}\text { Comblement } \\
\text { inférieur }\end{array}$ & 352 & 2 & 1 & 5 & 1600 à 1700 & 20 & 0,5 & + & + & - \\
\hline PT2031 & Puits & 2037 & Fond puits & 369 & 2 & 1 & 5 & 1600 à 1700 & 20 & 0,5 & + & + & - \\
\hline FO3179 & Tranchée & 3189 & $\begin{array}{l}\text { Comblement } \\
\text { inférieur }\end{array}$ & 487 & 3 & 1 & $4 \mathrm{~A}$ & 200 à 300 & 20 & 0,5 & + & - & + \\
\hline FS 3220 & Fosse & 3222 & $\begin{array}{l}\text { Comblement } \\
\text { inférieur }\end{array}$ & 510 & 3 & 2 & $4 \mathrm{~B}$ & 400 à 500 & 16 & 0,5 & + & + & - \\
\hline FO3223 & Tranchée & 3225 & $\begin{array}{l}\text { Comblement } \\
\text { inférieur }\end{array}$ & 497 & 3 & 2 & $4 \mathrm{~B}$ & 400 à 500 & 20 & 0,5 & & + & - \\
\hline BS3339 & Bassin & 3340 & $\begin{array}{l}\text { Comblement } \\
\text { supérieur }\end{array}$ & 630 & 3 & 3 & $4 \mathrm{~B}$ & 400 à 500 & 5 & 1 & + & - & + \\
\hline BS3339 & Bassin & 3341 & $\begin{array}{l}\text { Comblement } \\
\text { inférieur }\end{array}$ & 610 & 3 & 3 & $4 \mathrm{~A}$ & 200 à 300 & 10 & 1 & + & - & + \\
\hline BS3339 & Bassin & 3342 & $\begin{array}{l}\text { Comblement } \\
\text { inférieur, } \\
\text { parois }\end{array}$ & 609 & 3 & 3 & $4 \mathrm{~A}$ & 200 à 300 & 0,9 & 0,4 & + & - & - \\
\hline \multicolumn{14}{|c|}{ Collecte à la fouille } \\
\hline PT1201 & Puits & 1245 & $\begin{array}{l}\text { Comblement } \\
\text { inférieur }\end{array}$ & 219 & 1 & 2 & 2 & -25 à 50 & - & - & + & + & - \\
\hline FO3179 & Tranchée & 3189 & $\begin{array}{l}\text { Comblement } \\
\text { inférieur }\end{array}$ & 487 & 3 & 1 & $4 \mathrm{~A}$ & 200 à 300 & - & - & + & - & + \\
\hline FS3214 & Fosse & 3216 & Centre fosse & 498 & 3 & 1 & $4 \mathrm{~B}$ & 400 à 500 & - & - & + & - & + \\
\hline
\end{tabular}

Tab. 13. Liste des échantillons analysés en archéobotanique. 
refus. Dans la présente étude, nous avons eu recours à un tel sous-échantillonnage pour les mailles $0,5 \mathrm{ou}$ $0,4 \mathrm{~mm}$ (volume minimal trié $=100 \mathrm{ml}$ ). La quantité de matériel dans l'ensemble du refus est alors estimée par péréquation à partir du volume trié. La détermination des bois et charbons de bois est basée sur les caractères anatomiques observés sur les trois plans anatomiques obtenus soit à l'aide d'une lame de rasoir bien aiguisée (bois gorgé d'eau), soit par simple cassure à la main (charbons).

\section{Conservation et densité}

En Europe occidentale, la carbonisation est, de loin, le mode de conservation des macrorestes végétaux le plus répandu dans les contextes archéologiques en milieu sec. En ce qui concerne la carpologie, l'ambiance anoxique des milieux humides permet la conservation, à l'état subfossile, d'un nombre de diaspores et l'attestation d'une diversité taxinomique, souvent plus importants que dans les sédiments secs. Dans les contextes archéologiques, en milieu humide, ce nombre peut devenir très conséquent (Damblon 1985, Greig 1989, Jacomet et Kreuz 1999, Marinval 1999 et Schaal 2000).

La carbonisation résultant le plus souvent des activités humaines, elle a plus de chances de survenir en contexte domestique; les carporestes carbonisés seront de fait habituellement plus nombreux dans les sites archéologiques d'habitat que dans les sédiments naturels. Les milieux humides apparaissent ainsi d'autant plus propices à l'obtention d'un bon enregistrement pour l'analyse carpologique « hors habitat».

Ainsi, si les carporestes trouvés sur le site de la Villa Romana sont conservés par carbonisation et par imbibition, le premier mode de conservation concerne moins de 0,5\% de l'ensemble (tab. 13). Les contextes échantillonnés se sont en général avérés propices à une bonne conservation des diaspores gorgées d'eau, autorisant la présence d'éléments fragiles, comme par exemple des pièces de périanthe de Trifolium sp. ou des fruits d'apiacées et de poacées, et entraînant une assez faible fragmentation du matériel $(8,7 \%$ pour l'ensemble).

Si l'abondance des bois dans certaines structures est à souligner, leur état de conservation ainsi que leur taille n'autorisent pas une étude anatomique fiable. La structure anatomique très abîmée de certains échantillons peut être le résultat d'une réduction ponctuelle importante de l'humidité. La présence fréquente de pontes d'insectes dans le bois est à noter.

Les charbons, quant à eux sont peu nombreux. Leur identification a été rendue très difficile en raison de leur taille réduite, de l'abondance de nœuds et de la vitrification.

Ces raisons expliquent l'abondance de spécimens identifiés uniquement «Angiosperme » et "Gymnosperme », dont on ne tient pas compte dans la présentation/commentaire de nos résultats.

La faible capacité des fosses de plantation pour les analyses archéobotaniques, présupposée sur la base d'études antérieures en hors site (Bouby à paraître et inédit), est confirmée par la faiblesse des résultats, tant anthracologiques que carpologiques, obtenus ici sur les structures VP1017, FS1139 et FS3220. La première d'entre elles est totalement stérile au plan carpologique, alors que les deux autres présentent les densités les plus faibles de tous les prélèvements analysés, ceci en dépit des possibilités de conservation par imbibition de FS3220. Comme il a été signalé plus haut, cette inadéquation des fosses de plantation à l'enregistrement archéobotanique est à la fois liée à la mise en place rapide, en même temps ou avant le végétal cultivé, du sédiment de comblement et à son caractère habituellement sec. Au final, nous disposons donc surtout dans cette étude d'informations délivrées par les structures ouvertes, qui ont ainsi pu fonctionner comme pièges, et par des restes végétaux gorgés d'eau, les niveaux humides s'étant révélés pauvres en semences et bois carbonisés. Ces données concernent surtout les phases $3 \mathrm{~A}, 4 \mathrm{~A}$ et $\mathrm{B}$ et 5 , les échantillons de la phase 2 étant tous très pauvres. Il convient maintenant de s'interroger sur les modes d'apport de ces macrorestes, afin de mieux appréhender leur signification vis-à-vis de la reconstitution de l'environnement local et des activités humaines.

\section{Apport des macrorestes et constitution des assemblages}

On constate une certaine discordance entre les informations apportées par le matériel gorgé d'eau et par les restes carbonisés, en particulier en ce qui concerne les carporestes (tab. 13). Les rares semences carbonisées proviennent principalement du bassin SB1262 ; elles sont à mettre en relation avec la céréaliculture : restes de grains de céréales et possibles adventices. Les fragments de pignons (Pinus pinea), très sporadiques dans FS1139 et BS3339, sont les seuls éléments qui se démarquent clairement de cette catégorie.

Les semences imbibées appartiennent à des groupements végétaux très différents : plantes aquatiques, plantes des lieux humides, des sols secs/sablonneux, adventices des cultures et/ou rudérales, arbres fruitiers, possibles cultures herbacées. Les assemblages de matériel carpologique imbibé renvoient l'image d'une grande 
cohérence écologique, ce qui plaide pour un apport local des semences. Ceci est particulièrement flagrant pour le bassin SB1262, structure la mieux documentée : forte domination des plantes aquatiques ayant poussé dans le bassin, importance des plantes des lieux humides - qui poussaient éventuellement à proximité immédiate mais qui peuvent également provenir de parties basses et humides du terrain ou des abords de petits écoulements d'eau voisins - puis des adventices des lieux horticoles (jardins ou vergers) ou des abords des habitations, qui devaient occuper une grande partie de la parcelle. Bien sûr l'apport anthropique exogène existe : les carporestes carbonisés en sont certainement la meilleure illustration. Ils représentent des déchets alimentaires ou de traitement des céréales. Mais leur proportion est faible. Parmi les restes gorgés d'eau, les témoins directs d'un apport anthropique sont très limités sur le plan quantitatif : peu ou pas de restes d'activités de traitement des récoltes, de préparation ou de consommation alimentaire. Les pépins de fruits, qui pourraient éventuellement témoigner de rejets excrémentiels, sont particulièrement rares dans le site et rien ne suggère de tels apports. Les restes fruitiers les plus fréquents, les semences de ronce (Rubus fruticosus), signent un apport local plutôt qu'un apport humain : quelques uns montrent encore des traces de pulpe, ce qui manifeste le dépôt de fruits entiers et non de pépins ayant traversé le tractus digestif. Ils sont en outre associés à de nombreuses épines (Rosa/Rubus), dont la très petite taille de nombreux exemplaires plaide pour une attribution à la ronce plutôt qu'à l'églantier. La ronce est par ailleurs attestée sous la forme de bois gorgé d'eau et carbonisé. Il est très probable que des ronces poussaient aux abords du bassin, signant peut-être un enfrichement de la parcelle, et des feuilles et fruits sont tombés directement à l'intérieur de la structure où des ronces coupées par l'homme y ont été déposées. Que penser des semences de plantes cultivées ? Correspondent-elles à un apport exogène de déchets humains, au même titre que les carporestes carbonisés ? S'agit-il de plantations locales ? Cet aspect donnera lieu à une discussion spécifique.

Des constatations similaires quant à la composition de l'assemblage et au mode d'apport probable des semences se dégagent de l'observation des spectres carpologiques des autres structures, sans doute de façon moins nette dans la plupart des cas mais la résolution est largement fonction du nombre de restes et de taxons identifiés.

De façon générale, retenons que les restes carpologiques du matériel gorgé d'eau représentent en grande majorité un apport local, témoignant de l'environnement de la parcelle, alors que les restes carbonisés constituent plus probablement un apport exogène, lié sans doute aux activités humaines. De tels remplissages à dominante naturelle ont déjà été observés à l'intérieur de certains puits romains, par exemple au Fâ à Barzan dans les Charentes-Maritimes (Zwierzinski et al. 2003).

La dichotomie entre matériel carbonisé/gorgé d'eau apparaît moins nette en ce qui concerne le bois. On dispose de très peu d'éléments pour tenter de caractériser le mode d'apport des charbons et bois gorgés d'eau. La faible densité en charbons de bois, accompagnée d'une diversité taxinomique non négligeable, paraît s'accorder avec l'hypothèse d'un apport majoritaire des charbons par l'homme (depuis des foyers domestiques situés à proximité par exemple) plutôt que par incendie de la végétation strictement locale. Cette dernière possède plus de chances de se trouver exprimée par le matériel non carbonisé. Des différences dans la composition des spectres anthracologiques et xylologiques, à même d'appuyer l'hypothèse d'un apport distinct, peuvent être relevées en dépit de leur présence relativement peu importante.

\section{Restitution du milieu végétal local}

\subsection{Anthracologie et xylologie}

Les résultats présentés (tab. 14) montrent que vingt taxons sont différenciés lors de l'analyse anatomique des bois et charbons (angiosperme, gymnosperme, Quercus sp., Cistaceae/Ericaceae exclus). On remarque que, parmi les spécimens identifiables, la vigne, le figuier et le pin sylvestre/pin noir apparaissent seulement dans les restes gorgés d'eau ; la bruyère, les Cistacées, le merisier, l'arbousier, le sapin, le frêne, le pin d'Alep/pin pignon et le Genévrier sont identifiés uniquement en tant que bois carbonisés. Les chênes, le saule/peuplier, les monocotylédones et l'orme sont identifiés dans les deux groupes. Par ailleurs, les bruyères sont l'élément le plus fréquent (identifiées sur 8 des 15 échantillons analysés), suivies des chênes sempervirents (Chêne liège inclus) (7), de la vigne (6), du saule (Salix/Populus inclus) (5) des chênes caducifoliés (4). Les autres essences apparaissent plus sporadiquement.

Pendant les phases 2 à 4B, l'ensemble des taxons identifiés témoigne de l'existence de plusieurs milieux, sur place et/ou à proximité :

- Un milieu anthropisé représenté d'une part, par la vigne, le figuier et le merisier, liés à une exploitation agricole et, d'autre part, par Erica, Juniperus, Cistaceae, Rubus fruticosus, essences pouvant être associées à des champs en état de friche ou aux maquis/boisements de l'arrière pays ; 
CHAPITRE 3 : GRAINES, FRUITS BOIS ET CHARBONS D'UN ESPACE HORTICOLE

\begin{tabular}{|c|c|c|c|c|c|c|c|c|c|c|c|c|c|c|c|c|}
\hline & & & & & & & & & & & & & & & & \\
\hline & & \multicolumn{6}{|c|}{ Zone 1} & \multirow{2}{*}{\multicolumn{2}{|c|}{$\begin{array}{l}\text { Zone } 2 \\
\text { Sect. } 1\end{array}$}} & \multicolumn{7}{|c|}{ Zone 3} \\
\hline & & \multirow{4}{*}{$\begin{array}{c}\text { Sect. 1 } \\
\text { FS1139 } \\
\text { US1140 } \\
123\end{array}$} & \multicolumn{5}{|c|}{ Sect. 2} & & & \multicolumn{2}{|c|}{ Sect. 1} & \multicolumn{2}{|c|}{ Sect. 2} & \multirow{2}{*}{\multicolumn{3}{|c|}{$\begin{array}{c}\text { Sect. } 3 \\
\text { BS3339 }\end{array}$}} \\
\hline \multicolumn{2}{|l|}{ Fait } & & \multicolumn{2}{|c|}{ SB 1262} & \multicolumn{2}{|c|}{ VP1017 } & \multirow{3}{*}{\begin{tabular}{|c|} 
PT1201 \\
US1245 \\
219 \\
\end{tabular}} & \multirow{3}{*}{$\begin{array}{c}\text { PT2031 } \\
\text { US2035 } \\
352\end{array}$} & \multirow{3}{*}{\begin{tabular}{|c|} 
US2037 \\
369
\end{tabular}} & \multirow{3}{*}{\begin{tabular}{|c|} 
FO3179 \\
US3189 \\
487 \\
\end{tabular}} & & FS3220 & FO3223 & & & \\
\hline us & & & US1287 & US1291 & US1067 & US1064 & & & & & US3216 & US3222 & US3225 & US3340 & us. & 341 \\
\hline Échelle & & & 344 & 408 & 67 & 71 & & & & & & 510 & 497 & 630 & 610 & $621-622$ \\
\hline Phase d'occupation & & & $3 \mathrm{~A}$ & & 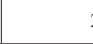 & & 2 & 5 & 5 & $4 \mathrm{~A}$ & & $4 \mathrm{~B}$ & & & $4 \mathrm{~A}$ & \\
\hline Datation (ans apr. J.-C & & & 100 à 200 & & -25 & à 50 & -25 à 50 & 1600 & à 1700 & 200 à 300 & & 400 à 500 & & & 200 à 300 & \\
\hline BOIS GORGÉ D'EAL & & & & & & & & & & & & & & & & \\
\hline Angiosperme & & - & - & - & - & - & - & - & - & 2 & 1 & - & - & 1 & 1 & - \\
\hline Ficus carica & Figuier & - & 3 & 1 & - & - & - & - & - & - & - & - & - & - & - & - \\
\hline Gymnosperme & & - & - & - & - & - & - & - & - & 1 & - & - & - & - & - & - \\
\hline Monocotylédone & & - & - & - & - & - & - & - & - & 1 & - & - & - & - & - & - \\
\hline Pinus sp. & Pin & - & - & 2 & - & - & - & - & - & - & - & - & - & - & 1 & - \\
\hline Prunus sp. & Prunier & - & - & - & - & - & - & & - & 3 & - & - & - & - & - & - \\
\hline Quercus cf. suber & $\begin{array}{l}\text { Chêne cf. } \\
\text { Ch. liège }\end{array}$ & - & 9 & - & - & - & - & - & - & - & - & - & - & - & 1 & - \\
\hline Quercus (f. caduc) & Chêne (f. caduc) & - & - & 7 & - & - & - & - & - & - & - & - & - & - & - & - \\
\hline Rubus fruticosus & Mûrier-ronce & - & - & 1 & - & - & - & - & - & - & - & - & - & - & - & - \\
\hline Salix sp. & Saule & - & - & - & - & - & - & - & - & - & 1 & - & - & - & 1 & * \\
\hline Salix / Populus & Saule / Peuplier & & - & 1 & - & - & - & - & - & - & - & - & - & 5 & 16 & - \\
\hline Ulmus cf. U. minor & $\begin{array}{l}\text { Orme cf. } \\
\text { O. champêtre }\end{array}$ & - & 9 & - & - & - & - & - & - & - & - & - & - & - & - & - \\
\hline Vitis vinifera & Vigne & - & 2 & 4 & - & - & - & - & - & 15 & 1 & - & - & 2 & 2 & - \\
\hline Indéterminables & & - & - & 1 & - & - & - & - & - & - & - & - & - & - & - & - \\
\hline Total avec Indét. & & - & 23 & 17 & - & - & - & - & - & 22 & 3 & - & - & 8 & 22 & $*$ \\
\hline Total sans Indét. & & - & 23 & 16 & - & - & - & - & - & 22 & 3 & - & - & 8 & 22 & $*$ \\
\hline BOIS CARBONISÉ & & & & & & & & & & & & & & & & \\
\hline Angiosperme & & 10 & - & - & 4 & 10 & - & 2 & 4 & - & - & - & - & - & - & - \\
\hline Abies sp. & Sapin & - & - & - & 1 & - & - & - & - & - & - & - & - & - & - & - \\
\hline Arbutus unedo & Arbousier & - & - & - & - & - & - & - & 1 & - & - & - & - & - & - & - \\
\hline Cistaceae & Cistacée & - & - & - & - & - & 1 & & 1 & - & - & - & - & - & - & - \\
\hline Cistaceae / Ericaceae & $\begin{array}{l}\text { Cistacée / } \\
\text { Ericacée }\end{array}$ & - & - & - & - & - & - & - & 1 & - & - & - & 3 & - & & - \\
\hline Erica arborea & \begin{tabular}{|l|} 
Bruyère \\
arborescente
\end{tabular} & - & - & - & - & - & - & - & 4 & - & - & - & - & - & - & - \\
\hline Erica sp. & Bruyère & 3 & - & - & 16 & 23 & 5 & 2 & 5 & - & - & - & 2 & - & - & - \\
\hline Fraxinus sp. & Frêne & - & 1 & - & - & - & - & - & 1 & - & - & 1 & - & - & - & - \\
\hline Gymnosperme & & - & - & - & - & - & - & - & 2 & - & - & - & - & - & - & - \\
\hline Juniperus sp. & Genévrier & - & - & - & - & - & - & - & - & - & - & - & 1 & - & - & - \\
\hline Monocotylédone & & - & 2 & - & - & - & - & - & - & - & - & - & - & - & - & - \\
\hline Pinus sp. & Pin & - & - & - & - & - & - & 1 & 6 & - & - & 2 & - & - & - & - \\
\hline Pistacia lentiscus & Lentisque & - & - & - & - & - & - & - & - & - & - & - & 1 & - & - & - \\
\hline Prunus type avium & & - & - & - & - & - & - & & - & - & - & 2 & - & - & - & - \\
\hline Quercus (f. caduc) & Chêne (f.caduc) & - & 1 & - & - & - & - & - & 1 & - & - & 1 & - & - & - & - \\
\hline Quercus (f. persistant) & $\mid \begin{array}{l}\text { Chêne } \\
\text { (f.persistant) }\end{array}$ & 3 & - & - & 1 & - & 1 & - & 1 & - & - & - & 11 & - & - & - \\
\hline Quercus sp. & Chêne & - & - & - & - & - & - & - & - & - & - & 1 & 1 & - & - & - \\
\hline Rubus fruticosus & Mûrier -ronce & - & 5 & - & - & - & - & - & - & - & - & - & - & - & - & - \\
\hline Salix / Populus & Saule / Peuplier & - & 1 & - & - & - & - & - & - & - & - & - & - & - & - & - \\
\hline Ulmus cf. U. minor & $\begin{array}{l}\text { Orme cf. } \\
\text { O. Champêtre }\end{array}$ & - & 1 & - & - & - & - & - & - & - & - & 5 & - & - & - & - \\
\hline Indéterminables & & 2 & 2 & - & 6 & 4 & 4 & - & - & - & - & 1 & 1 & - & - & - \\
\hline Total avec Indét. & & 18 & 13 & - & 28 & 37 & 11 & 5 & 27 & - & - & 13 & 20 & - & - & - \\
\hline Total sans Indét & & 16 & 11 & - & 22 & 33 & 7 & 5 & 27 & - & - & 12 & 19 & - & - & - \\
\hline
\end{tabular}

Tab. 14. Résultats anthracologiques et xylologiques (analyses I. Figueiral). 

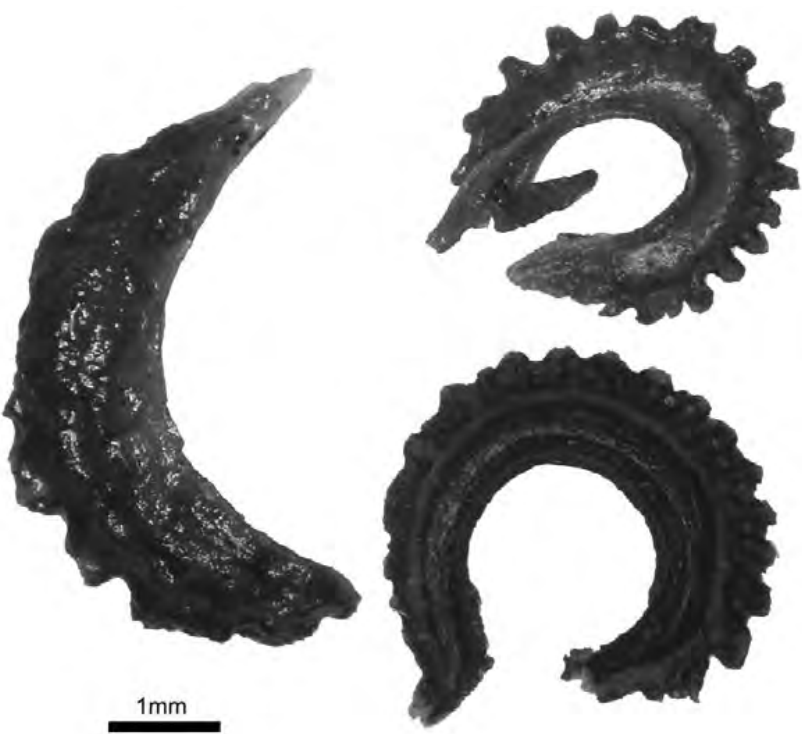

Fig. 260. Calendula arvensis

-Un groupement mésophile, tel que ceux des bordures de sources ou ruisseaux, avec saule et/ou peuplier, orme et frêne. Le chêne à feuillage caduc (chêne blanc) a pu aussi pousser au sein de cet environnement mésophile ;

- La chênaie mixte méditerranéenne, avec les chênes sempervirents (Quercus suber et éventuellement Quercus ilex) et les chênes à feuillage caduc (probablement Quercus pubescens).

Le peu de matériel analysé rend impossible une estimation de l'importance relative de ces formations végétales à cette époque. Dans l'ensemble, les éléments végétaux mis en évidence sont en accord avec la situation écologique et chronologique du site.

Rappelons que Fréjus se situe dans la plaine entre deux massifs, le Massif des Maures et le Massif de l'Estérel. À l'heure actuelle, c'est une zone exceptionnelle par la richesse et la diversité du milieu naturel environnant. La couverture végétale ligneuse comprend des milieux aussi divers que les forêts à Quercus suber, forêts à Quercus ilex et Quercus rotundifolia, pinèdes méditerranéennes de pins mésogéens, forêts de Castanea sativa, matorrals arborescents à Juniperus, forêts-galeries à Salix alba et Populus alba et forêts alluviales à Alnus glutinosa et Fraxinus excelsior (Natura 2000).

Cependant, l'identification d'un charbon isolé d'Abies (amphore de plantation) soulève une fois de plus le problème de l'apport lointain ou de la présence à basse altitude d'espèces de caractère montagnard. Les résultats anthracologiques et palynologiques obtenus dans le sud de la France ( références complètes : Chabal 1997 et Durand 1992 et 1998) démontrent que ces essences se sont maintenues à basse altitude grâce à des conditions écologiques favorables, et ceci
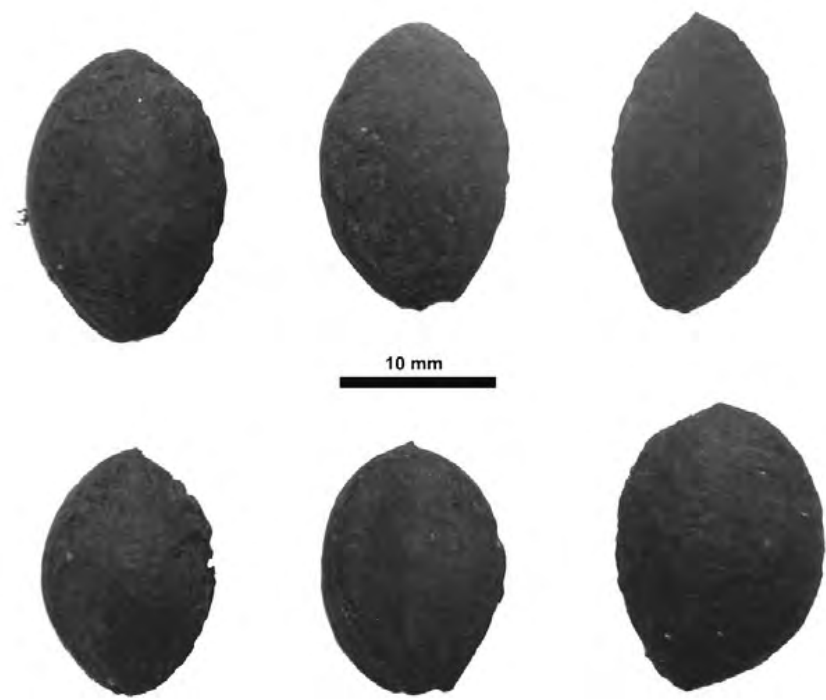

Fig. 261. Endocarpes de Prunus domestica subsp. insitititia

au moins jusqu'au Moyen Âge. Ainsi, le sapin aurait pu pousser ponctuellement dans la région, dans des endroits propices. Cependant, la possibilité d'un apport plus ou moins lointain ne peut pas être écartée. Ces observations sont valables également pour Pinus type sylvestris (pin sylvestre ou pin noir).

Il convient de signaler qu'une bonne partie des taxons identifiés ici le sont aussi à Bas-Lauvert, un site viticole antique sur la paléolagune d'Antibes, étudié par C. Delhon (inédit) : chênes, pins, bruyères, rosacées, vigne, arbousiers, frênes et genévriers.

\subsection{Carpologie}

La composition des assemblages carpologiques est très cohérente (tab. 15). Ceci est manifeste dans les structures les mieux documentées : SB1262, BS3339 et PT2031. Nous avons précédemment défendu l'hypothèse d'une origine locale de la grande majorité des semences gorgées d'eau. Dans ce cas, la cohérence des assemblages carpologiques témoignerait d'une grande stabilité de la couverture végétale de la parcelle aux $\mathrm{II}^{\mathrm{e}}$, $\mathrm{III}^{\mathrm{e}}$ et $\mathrm{XVII}{ }^{\mathrm{e}}$ siècles.

Une végétation aquatique s'est installée dans ces trois structures ouvertes et occupe une place particulièrement importante dans le bassin SB1262. Elle signe la présence d'une eau permanente, plus ou moins stagnante, sans doute en voie d'eutrophisation compte tenu de la présence régulière de la lentille d'eau.

Les plantes des lieux humides, temporairement mouillés ou inondés, sont également communes. Il n'est pas facile de déterminer si elles sont circonscrites au voisinage immédiat des structures en eau (bassins, puits) 


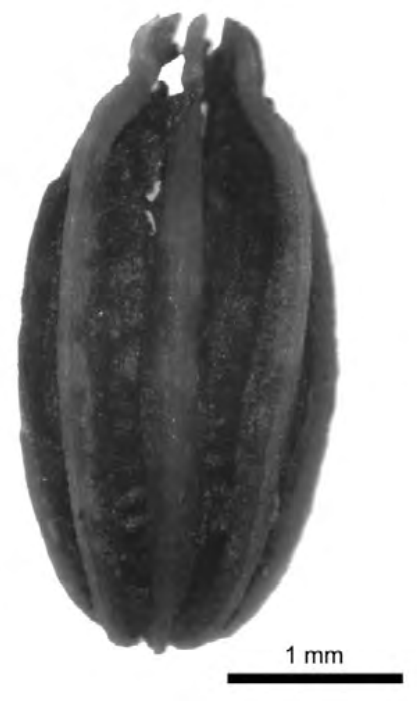

Fig. 262. Semence de Fœniculum vulgare (fenouil).

ou si elles témoignent plutôt de l'humidité générale du sol de la parcelle à certaines époques. La deuxième hypothèse est peut-être la bonne car on retrouve régulièrement parmi les essences attestées par les bois et charbons des arbres qui affectionnent également les sols frais à humides (Fraxinus sp., Salix/Populus, Ulmus minor). Toutefois, aux côtés des indicateurs d'humidité, le spectre carpologique comporte également des taxons typiques de sols secs. Pour une bonne part, ces derniers sont en particulier communs sur les sols sableux du littoral méditerranéen (Arenaria sp., Euphorbia exigua, Lobularia maritima, Medicago littoralis, Raphanus raphanistrum, Scabiosa atropurpurea, Stachys ocymastrum, Tribulus terrestris). Ces indicateurs de sols sableux, secs, sont fréquents de manière notable dans le remplissage du puits 2031 .

Les ensembles précédemment cités peuvent être considérés comme déterminés par les conditions édaphiques locales : sols sableux littoraux, soumis à l'engorgement ou à l'assèchement en fonction de la saison ou de la topographie stationnelle. Ils peuvent être distingués d'un second grand groupe de plantes, plus spécifiquement induit par les activités humaines ; il s'agit d'une part des plantes cultivées, d'autre part des groupements d'adventices et rudérales.

Les plantes sauvages nitrophiles des groupements de mauvaises herbes ou rudérales sont fréquentes et bien représentées. Malheureusement, si elles signent indubitablement le poids de l'emprise humaine sur la parcelle, elles ne sont pas parfaitement en mesure de préciser la nature des ces activités. Effectivement, la plupart affectionnent les associations de mauvaises herbes des cultures sarclées (de type jardins, vignes,
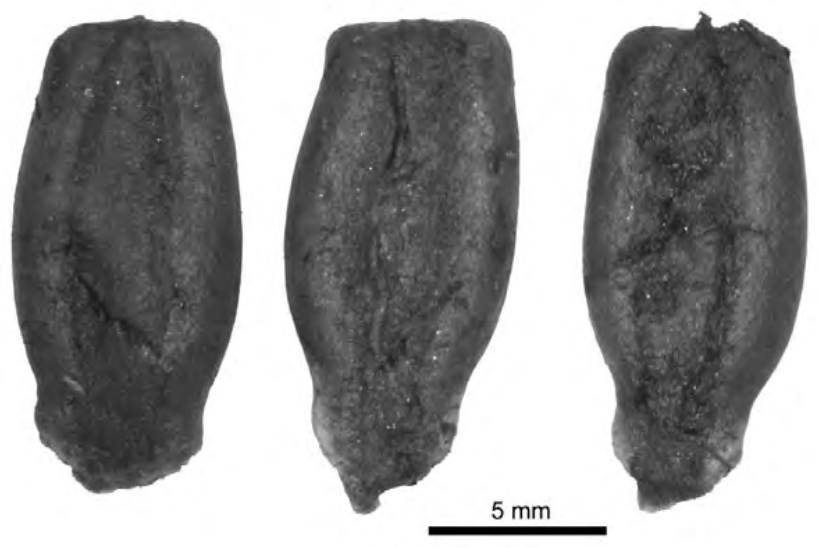

Fig. 263. Semence de Lagenaria siceraria (gourde calebasse).

vergers) mais sont tout aussi fréquentes sur les sols très perturbés et enrichis des abords des habitations ou des très jeunes friches.

Nous remarquons que le cortège mis en évidence dans le bassin SB1262 se rapproche largement du groupement des cultures sarclées décrit par Braun-Blanquet et al. (1952) pour la France méditerranéenne (ordre Chenopodietalia, alliance Diplotaxidion). Environ les 3/4 des adventices/rudérales attestées sont répertoriées dans le groupement type des vignobles du Languedoc et de Provence occidentale : Calendula arvensis (fig. 260), Chenopodium album, Euphorbia helioscopia, Euphorbia peplus, Fumaria officinalis, Heliotropium europaeum, Lamium amplexicaule, Malva parviflora, Mercurialis annua, Polygonum persicaria, Portulaca oleracea, Rumex pulcher, Solanum nigrum. Mais un nombre presque aussi important de ces taxons est également très fréquent dans l'alliance Chenopodion muralis, qui réunit les groupements nitrophiles des abords des habitations et des décombres.

$\mathrm{Au}$ total, les plantes potentiellement cultivées sont relativement nombreuses, qu'il s'agisse de plantes pérennes ligneuses, arbres ou arbustes [cyprès, figuier, mûrier, noisetier, noyer, pin pignon, pommier, prunier (fig. 261), vigne], ou de plantes herbacées (aneth, blé nu, coriandre, fenouil (fig. 262), gourde calebasse (fig. 263), laitue, moutarde noire, orge, pavot). Comme nous l'avons dit précédemment, compte tenu de la nature du site et de la composition des assemblages, ces plantes ont de bonnes chances d'avoir été cultivées sur place. Toutefois, l'apport humain exogène (à l'intérieur, par exemple, de déchets d'activités domestiques ou artisanales) existe, bien qu'étant vraisemblablement très minoritaire ; il demeure donc très difficile de préciser quelles plantes sont locales et quelles plantes sont exogènes. 
Vigne et figuier sont fréquemment enregistrés dans les assemblages humides du site, ce qui vient appuyer l'hypothèse d'une présence sur place. Bien sûr, il s'agit de fruits parmi les plus communs dans les spectres carpologiques gallo-romains (Ruas 1992, Matterne 2001), possédant d'autant plus de chances d'être apportés avec des déchets éventuels. Cependant, on a pu déterminer que les assemblages du site ne sont pas constitués de rejets fécaux, susceptibles de contenir de nombreux pépins de fruits alimentaires et ,surtout, outre la récurrence de l'enregistrement carpologique, le meilleur élément à l'appui d'une culture sur place du figuier et de la vigne réside dans leur présence également marquée parmi les bois gorgés d'eau.

Il est à noter que, parmi les essences également attestées par la xylologie, figurent des arbres qui sont bien connus pour avoir été utilisés comme tuteurs de la vigne cultivée à l'époque romaine.

Outre le figuier lui-même, la vigne pouvait être notamment mariée avec des ormes, des peupliers et des cyprès (Brun 2003). Columelle (V et VI) signale que l'orme possède l'avantage de produire un feuillage excellent pour nourrir le bétail en même temps que d'être un parfait support pour la vigne. Il fait notamment partie des arbres complantés avec la vigne en Gaule, de même que le saule qui peut être plus exceptionnellement employé dans les terrains marécageux (Columelle, $\mathrm{V}$ et VII).

De la même façon que vigne et figuier, pin pignon et prunier sont à la fois attestés par la carpologie et la xylologie (Pinus sp.), ce qui fournit un argument pour leur présence dans la parcelle. Le prunier est en outre attesté par un grand nombre de noyaux dans les structures PT1201 et surtout FO3179.

Les plantes herbacées ne pouvant, par nature, pas donner lieu à une double attestation carpologique/ xylologique, il est plus difficile d'apporter des arguments à l'appui d'une présence dans la parcelle, a fortiori d'une mise en culture. Nombre d'entre elles peuvent également se comporter comme des adventices des champs cultivés ou comme des rudérales et se disséminer naturellement. Le fenouil semble particulièrement bien attesté, ce qui peut plaider pour sa présence sur place. Coriandre et gourde calebasse sont rares ou absentes à l'état subspontané, ce qui va dans le sens de leur mise en culture.

L'image de l'environnement végétal local renvoyée par l'analyse des macrorestes végétaux est au final assez proche de celle que l'on pouvait déduire de l'étude carpologique plus limitée du « Théâtre d'Agglomération », autre site littoral de Fréjus, notamment par la fréquence et la variété des adventices et rudérales, des herbacées xérophiles et par la présence, hors site d'habitat, du figuier, de la vigne et du pin pignon (Excoffon, Devillers 2006). Cette convergence renforce encore l'hypothèse d'une culture de Ficus carica et Vitis vinifera sur le littoral à l'époque romaine.

\section{Rôles économiques et symboliques des plantes attestées dans la Gaule romaine}

Les plantes exploitées dans l'économie romaine en Provence sont mal connues, du fait de la carence d'études archéobotaniques de sites d'habitat - situation pouvant d'ailleurs être peu ou prou élargie à l'ensemble du sud-est de la Gaule. Seules quelques informations préliminaires sont publiées pour les sites portuaires toulonnais de Besagne et des Riaux et pour la villa viticole des Toulons à Rians, dans l'arrière-pays varois (Bouby et Marinval 2003). Un peu paradoxalement alors, les deux enseignements procurés par le domaine funéraire prennent un intérêt non négligeable pour illustrer l'économie des vivants, mais avec les biais inévitables relatifs à la sélection de produits végétaux choisis pour leurs propriétés symboliques et leur valeur dans le cadre du rituel, plus que pour leur importance au quotidien. Quelques résultats sont publiés, provenant des nécropoles de Saint-Lambert et du Pauvadou, à Fréjus, de la Calade et de la Guérine, à Cabasse, et de la Rue Cauvin à Garéoult (Marinval 1993).

Ainsi, et même si du fait de l'apport essentiellement local elles documentent avant tout la situation d'une parcelle cultivée, les données de la Villa Romana - au même titre que celles, voisines, du «Théâtre d'Agglomération » (Excoffon et al. 2006) - prennent un intérêt non négligeable pour notre connaissance des ressources végétales à une échelle plus large.

Nous avons eu l'occasion précédemment de rappeler que les fruits cultivés les mieux représentés à la Villa Romana, figuier (Ficus carica) et vigne (Vitis vinifera), sont de grands classiques de l'archéobotanique en contexte gallo-romain ; ils constituaient des denrées de base de l'alimentation et de l'économie végétale romaine (André 1981). Mais, dans une moindre mesure, toutes les plantes économiques attestées sur le site sont des composantes plus ou moins habituelles des spectres de macrorestes de l'époque (e.g. Ruas 1992, Matterne 2001, Wiethold 2003) : noyer (Juglans regia), noisetier (Corylus avellana), pommier ( Malus sylvestris), mûrier (Morus sp.), pin pignon (Pinus pinea) et prunier (Prunus domestica subsp. insititia) pour les arbres fruitiers, orge (Hordeum vulgare) et blé nu (Triticum aestivum/ turgidum) pour les céréales, aneth (Anethum graveolens), coriandre (Coriandrum sativum), fenouil (Foeniculum vulgare), gourde calebasse (Lagenaria siceraria), 
voire pavot (Papaver setigerum/ somniferum). Les cultures pratiquées dans la parcelle de la Villa Romana paraissent donc assez caractéristiques dans leur diversité de l'alimentation et de l'économie romaines.

La céréaliculture de la France méditerranéenne à l'époque romaine reste très mal connue mais le blé nu et l'orge vêtue semblent en représenter les piliers. Très communs au niveau national (Ruas 1992, Matterne 2001), ils sont attestés dans le Midi de la Gaule sur des sites comme Ambrussum en Languedoc (Ruas 1989) et, plus près de Fréjus, à la villa des Toulons ainsi que, probablement, dans le port de Toulon (Bouby et Marinval 2003).

Localement, les niveaux humides du port de Toulon sont favorables à l'enregistrement d'un riche cortège de fruits, attestant bien de la consommation régulière en milieu urbain des taxons identifiés à la Villa Romana. Restes appartenant au figuier, mûrier noir, noisetier, noyer, pin pignon, prunier, vigne et probablement pommier, sont bien rejetés comme déchets dans le port (Bouby, Marinval 2003). Parmi eux des fruits de figuier, noisetier, pin pignon et vigne sont déposés dans les sépultures à incinération de la région (Marinval 1993). Il n'est pas exclu que le pin pignon représente une ressource plus particulièrement favorisée dans la région car l'espèce semble indigène dans le secteur de Fréjus (Quézel, Médail 2003). Présent également au « Théâtre d'Agglomération », il pouvait croître naturellement sur les sables littoraux (Excoffon et al. 2006).

Deux plantes, la gourde calebasse et le cyprès, appellent des commentaires plus particuliers. La gourde calebasse (Lagenaria siceraria) est bien documentée par 23 graines dans la fosse FS3214 (fin $\mathrm{IV} /$ début $\mathrm{V}^{\mathrm{e}}$ siècle apr J.-C.), procurant la première mention archéologique de l'espèce en Provence. Malheureusement, ces carporestes étant prélevés à vue au cours des fouilles, on ne dispose pas d'informations sur leur concentration dans le sédiment non plus que sur la composition de l'assemblage carpologique auquel ils appartenaient.

Durant l'Antiquité, les fruits de la calebasse étaient utilisés, autant pour la confection de récipients ou ustensiles divers que pour être consommés à l'état vert.

Les mentions de calebasse se sont multipliées depuis une quinzaine d'années mais, curieusement pour cette plante thermophile originaire d'Afrique tropicale ou subtropicale, on les trouve surtout dans la partie nord de la Gaule. L'espèce est présente, semble-t-il, dès le Ier siècle, à Mazières-en-Mauge, dans l'Ouest (Ruas 2000), dans le Lyonnais, à Saint-Romain-de-Jalionas (Royet et al. 2006), en Bourgogne, à Alésia et à Cosne-sur-Loire (Wiethold 2003), en Alsace, à Bisheim-Kunheim (Reddé et al. 2005) et à Horbourg-Whir (Schaal inédit), ainsi que dans le Nord, à Longueuil-Saint-Marie (de Hingh 1993, Marinval et al. 2002).

Cette disparité géographique est due avant tout, n'en doutons pas, à la faiblesse des recherches carpologiques dans le Midi. La plante est très probablement connue dans le Sud avant la période de la fin IVe/début Ve siècle mise en exergue par la découverte de Villa Romana.

La culture de la gourde en zone méditerranéenne est tout à fait possible. Il a même été proposé que la plante ait pu être plantée dans des lieux particulièrement favorables du Nord de la France (Marinval et al. 2002). Les expériences conduites récemment par Stefanie Jacomet confirment qu'elle pousse correctement à Bâle et donne une abondante récolte de fruits verts, donc comestibles (Reddé et al. 2005).

Le cyprès (Cupressus sempervirens) est un arbre originaire de l'est du bassin méditerranéen, introduit par l'homme dans le Sud de la France, vraisemblablement à la faveur des échanges intenses entretenus avec les civilisations méditerranéennes à partir de l'âge du Fer. Ainsi le cyprès est identifié parmi les bois prélevés dans le remplissage hellénistique du port de Marseille (fouilles de la Bourse) (Vernet 1973). Il aurait constitué un arbre ornemental communément cultivé dans les jardins de Pompéi (Jashemski 1979 in Robinson 2002). Pline en parle abondamment (XVI et XVII) ; il le connaît comme un arbre exotique, dont la culture n'est pas facile. Le cyprès possède une forte relation symbolique avec le monde des morts : à Pompéi, il pouvait être planté à proximité des sépultures et les cônes étaient utilisés comme offrandes (Robinson 2002, Matterne, Derreumaux 2007). Récemment, l'utilisation de bois de Cyprès en contexte funéraire a pu être mise en évidence dans le Languedoc des $\mathrm{I}^{\mathrm{er}} / \mathrm{II}^{\mathrm{e}}$ siècles apr. J.-C. (Figueiral et al., sous presse).

Les propriétés ornementales du cyprès ont pu justifier sa plantation à proximité du bassin 3339, de même que son usage comme support de la vigne tel qu'évoqué par les auteurs latins (Brun 2003). Le cône de cyprès identifié dernièrement dans le remplissage d'un puits, sur le site du Bas-Empire de La Roquette, à Cavillargues (Gard), pourrait s'inscrire dans un cas de figure, évoquant la présence d'un arbre ornemental planté dans une cour de l'établissement (Bouby inédit).

\section{Conclusion}

L'espace agraire fouillé à l'occasion de l'opération de la Villa Romana a fait l'objet d'une étude archéobotanique, principalement destinée à appréhender le couvert végétal local et les activités humaines qui ont pu se dérouler dans la parcelle. Cette étude a porté 
sur les graines, fruits et restes de bois (carpologie, anthracologie, xylologie).

Compte tenu de leur meilleur potentiel, nous avons d'emblée privilégié l'analyse des structures excavées ouvertes et des niveaux humides, sans pour autant négliger totalement les fosses de plantation en milieu sec. Les résultats obtenus confirment ce choix. Les fosses de plantation en milieu sec s'avèrent pauvres, ne contenant que quelques macrorestes carbonisés épars. Les niveaux humides des structures ouvertes apportent généralement des informations beaucoup plus complètes. Trois structures sont particulièrement intéressantes pour ce qui est de la carpologie : les bassins antiques SB1262 et BS3339 et le puits PT2031 (XVII ${ }^{\mathrm{e}}$ siècle apr. J.-C.). Les bassins constituent également les structures qui ont livré les bois gorgés d'eau, ainsi que notamment le fossé FO3179. L'origine des charbons de bois est plus diverse.

De façon générale, les résultats archéobotaniques sont très cohérents et aucune évolution temporelle des groupements végétaux ne peut véritablement être perçue. L'analyse a montré que les semences imbibées sont certainement pour une part prépondérante, d'origine locale et témoignent avant tout de la végétation environnante. Il est permis de supposer que les bois gorgés d'eau ont une origine et une signification comparables. L'origine des charbons de bois est plus sujette à caution ; ils reflètent d'ailleurs plus largement les milieux boisés environnant la ville (maquis, subéraie/ yeuseraie, pinède).

Bois gorgés d'eau et charbons de bois permettent d'identifier plusieurs types de végétation : chênaie mixte méditerranéenne, groupe mésophile, affectionnant une certaine humidité édaphique, arbres cultivés et indicateurs de recolonisation après perturbation anthropique.

Les résultats carpologiques sont en bonne adéquation avec ces données, en particulier celles issues de l'étude des bois gorgés d'eau. La synergie des deux apporte de solides informations sur l'état de la végétation au niveau de la parcelle. Des arbres cultivés étaient très probablement présents : des figuiers, de la vigne, mais aussi probablement des pins pignon, des pruniers, un ou des cyprès à proximité du bassin BS3339. La vigne pouvait être conduite en taille basse mais également mariée aux arbres, notamment aux essences précédemment citées ainsi qu'à l'orme et peut être au saule/peuplier, tous deux bien attestés par la xylologie et connus d'après les textes antiques pour cet usage.

L'existence de cultures herbacées est également envisageable d'après la carpologie, en particulier la culture du fenouil et de la gourde calebasse. D'autres arbres et herbacées cultivés sont plus ponctuellement attestés (noyer, mûrier, noisetier, aneth, céréales, coriandre...) ; les éléments à l'appui d'une culture sur place sont de fait plus labiles. Un important cortège de mauvaises herbes ou plantes rudérales documenté par la carpologie va dans le sens d'une exploitation horticole de la parcelle. Toutefois, les informations dont nous disposons ne permettent pas de spécifier si cet usage est au plein moment de son activité ou si le terrain connaît déjà un début d'abandon, les arbres fruitiers seraient alors dans un milieu en voie d'enfrichement. Cette hypothèse se justifie par l'importance des adventices et rudérales, par la présence de plantes de milieux humides, de ronces à proximité du bassin SB1262, de plantes aquatiques qui colonisent notamment ce même bassin.

$\mathrm{Au}$ sujet des caractéristiques édaphiques locales, plusieurs témoins carpologiques marquent le caractère sableux des sols. L'humidité doit être prégnante en certains points, en certains moments de l'année : la carpologie mais aussi l'anthracologie/xylologie en témoignent (présence du frêne, de l'orme, du saule/ peuplier). Pour autant, d'autres plantes identifiées par la carpologie révèlent aussi des secteurs affectés par la sècheresse. En milieu littoral sableux de faibles variations d'altitude peuvent considérablement modifier la xéricité édaphique. La possible présence de fossés de drainage pouvait, en outre, contribuer significativement à une meilleure gestion de l'humidité du sol. Le spectre carpologique du puits moderne suggère par ailleurs que l'humidité a pu décroître depuis l'Antiquité, ce qui peut simplement s'expliquer par les effets de l'exhaussement sédimentaire. 
CHAPITRE 3 : GRAINES, FRUITS BOIS ET CHARBONS D'UN ESPACE HORTICOLE

\begin{tabular}{|c|c|c|c|c|c|c|c|c|c|c|c|c|c|c|c|c|c|c|}
\hline \multirow{2}{*}{\multicolumn{2}{|c|}{$\begin{array}{l}\text { Fait } \\
\text { US }\end{array}$}} & FS1139 & \multicolumn{4}{|c|}{ SB1262 } & \multicolumn{4}{|c|}{ BS3339 } & \multirow{3}{*}{$\begin{array}{c}\text { FS } 3220 \\
3222 \\
510\end{array}$} & \multirow{3}{*}{$\begin{array}{c}\text { F03223 } \\
3225 \\
497\end{array}$} & \multirow{3}{*}{$\begin{array}{c}\text { PT } 2031 \\
2035 \\
352\end{array}$} & \multirow{3}{*}{$\begin{array}{c}\text { PT } 2031 \\
2035 \\
369\end{array}$} & \multirow{3}{*}{$\begin{array}{c}\text { PT } 1201 \\
1245 \\
219\end{array}$} & \multirow{3}{*}{$\begin{array}{c}\text { FO } 3179 \\
3189 \\
487\end{array}$} & \multirow{3}{*}{\begin{tabular}{|c|} 
FS 3214 \\
3216 \\
498 \\
\end{tabular}} & \multirow{4}{*}{\begin{tabular}{|l} 
Total \\
116,4
\end{tabular}} \\
\hline & & US1140 & \multicolumn{2}{|c|}{1287} & 1291 & 1266 & 3342 & 3342 & 3341 & 3340 & & & & & & & & \\
\hline \multicolumn{2}{|l|}{ Échelle } & 123 & 344 & 344 & 408 & 307 & 609 & 609 & 610 & 630 & & & & & & & & \\
\hline \multicolumn{2}{|c|}{ Phase d'occupation } & $3 \mathrm{~A}$ & $3 \mathrm{~A}$ & $3 \mathrm{~A}$ & $3 \mathrm{~A}$ & $3 \mathrm{~A}$ & $4 \mathrm{~A}$ & $4 \mathrm{~A}$ & $4 \mathrm{~A}$ & $4 \mathrm{~B}$ & $4 \mathrm{~B}$ & 4B & 5 & 5 & 2 & $4 \mathrm{~A}$ & 4B & \\
\hline \multicolumn{2}{|c|}{ Datation (ans apr. J.-C.) } & $100 / 200$ & $100 / 200$ & $100 / 200$ & $100 / 200$ & $100 / 200$ & $200 / 300$ & $200 / 300$ & $200 / 300$ & $400 / 500$ & $400 / 500$ & $400 / 500$ & $1600 / 1700$ & $1600 / 1700$ & $-25 / 50$ & $200 / 300$ & $400 / 500$ & \\
\hline \multicolumn{2}{|c|}{ Vol. analysé (litre) } & 20 & 2,5 & 10 & 10 & 10 & 0,9 & 10 & 10 & 5 & 16 & 10 & 2 & 10 & \multicolumn{3}{|c|}{ ramassage manuel } & \\
\hline \multicolumn{2}{|c|}{ Maille min. tamisage (mm) } & 0,5 & 0,4 & 1 & 1 & 1 & 0,4 & 1 & 1 & 1 & 1 & 0,5 & 0,5 & 0,5 & - & - & - & - \\
\hline \multicolumn{19}{|c|}{ RESTES CARBONISÉS } \\
\hline Avena sp. & frag. & - & 1 & 2 & 2 & - & - & - & - & - & - & - & - & - & - & - & - & 5 \\
\hline $\begin{array}{l}\text { Bromus type } \\
\text { arvensis/ } \\
\text { hordeaceus }\end{array}$ & sem. & - & 1 & - & - & - & - & - & - & - & - & - & - & - & - & - & - & 1 \\
\hline \multirow{2}{*}{ Festuca type } & sem. & - & 6 & - & - & - & - & - & - & - & - & - & - & - & - & - & - & 6 \\
\hline & frag. & - & 10 & - & - & - & - & - & - & - & - & - & - & - & - & - & - & 10 \\
\hline Hordeum sp. & frag. & - & 2 & - & - & - & - & - & - & - & - & - & - & - & - & - & - & 2 \\
\hline $\begin{array}{l}\text { Lolium perenne } \\
\text { / rigidum }\end{array}$ & sem. & - & - & 4 & - & - & - & - & - & - & - & - & - & - & - & - & - & 4 \\
\hline $\begin{array}{l}\text { Lolium } \\
\text { temulentum }\end{array}$ & sem. & - & - & - & 1 & - & - & - & - & - & - & - & - & - & - & - & - & 1 \\
\hline $\begin{array}{l}\text { Medicago } \\
\text { orbicularis }\end{array}$ & sem. & - & 1 & - & - & - & - & - & - & - & - & - & - & - & - & - & - & 1 \\
\hline $\begin{array}{l}\text { Medicago type } \\
\text { polymorphal } \\
\text { sativa }\end{array}$ & sem. & - & 2 & - & - & - & - & - & - & - & - & 1 & - & - & - & - & - & 3 \\
\hline Pinus pinea & frag. & - & - & - & - & - & - & - & - & 2 & - & - & - & - & - & - & - & 2 \\
\hline cf. Pinus pinea & frag. & 6 & - & - & - & - & - & - & - & - & - & - & - & - & - & - & - & 6 \\
\hline Poaceae & sem. & - & 10 & 2 & - & - & - & - & - & - & - & - & - & - & - & - & - & 12 \\
\hline $\begin{array}{l}\text { Triticum } \\
\text { aestivum/ } \\
\text { turgidum }\end{array}$ & frag. & - & - & 2 & 2 & - & - & - & - & - & - & - & - & - & - & - & - & 4 \\
\hline & & & & & & & Arb & $\begin{array}{l}\text { ESTES NC } \\
\text { s cultivés/F }\end{array}$ & $\begin{array}{l}\text { N CARBOI } \\
\text { rêts, buisso }\end{array}$ & $\begin{array}{l}\text { SÉS } \\
\text { s, lisières }\end{array}$ & & & & & & & & \\
\hline $\begin{array}{l}\text { Corylus } \\
\text { avellana }\end{array}$ & frag. & - & - & - & - & - & - & - & - & - & - & 1 & - & - & - & - & - & 1 \\
\hline Crataegus sp. & frag. & - & - & - & - & - & - & 1 & - & - & - & - & - & - & - & - & - & 1 \\
\hline & sem. & - & - & - & - & - & - & 2 & 18 & - & - & - & - & - & - & - & - & 20 \\
\hline $\begin{array}{l}\text { Cupressus } \\
\text { sempervirens }\end{array}$ & frag. & - & - & - & - & - & 1 & - & & - & - & - & - & - & - & - & - & 1 \\
\hline & cône & - & - & - & - & - & - & - & 1 & - & - & - & - & - & - & - & - & 1 \\
\hline & sem. & - & 5 & 2 & 4 & - & 12 & 5 & 15 & - & - & 1 & 97 & 5 & - & - & - & 146 \\
\hline 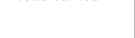 & frag. & - & 10 & - & - & - & 132 & 43 & 7 & - & - & - & 3 & - & - & - & - & 195 \\
\hline Juglans regia & frag. & - & - & 32 & - & - & - & - & - & - & - & - & - & - & - & - & - & 32 \\
\hline $\begin{array}{l}\text { cf. Malus } \\
\text { sylvestris }\end{array}$ & sem. & - & - & - & - & - & - & - & - & - & - & 1 & - & - & - & - & - & 1 \\
\hline Morus sp. & sem. & - & 2 & - & - & - & - & - & - & - & - & - & - & - & - & - & - & 2 \\
\hline Pinus pinea & frag. & - & - & - & - & - & - & - & - & - & - & 1 & - & - & - & 1 & - & 2 \\
\hline $\begin{array}{l}\text { Prunus } \\
\text { domestica } \\
\text { subsp. insititia }\end{array}$ & sem. & - & - & - & - & - & - & - & - & - & - & - & - & - & 7 & 52 & - & 59 \\
\hline $\begin{array}{l}\text { Prunus } \\
\text { domestica cf. } \\
\text { subsp. insititia }\end{array}$ & sem. & - & - & - & - & - & - & - & 1 & - & - & - & - & - & - & - & - & 1 \\
\hline Quercus sp. & frag. cupule & - & - & - & - & - & - & - & - & - & - & - & - & - & - & 1 & - & 1 \\
\hline Rosa/Rubus & épine & - & 312 & 64 & 6 & - & 1 & - & - & - & - & - & - & - & - & - & - & 383 \\
\hline Rubus & sem. & - & 26 & 24 & 4 & 8 & - & 1 & - & - & - & - & - & - & - & 1 & - & 64 \\
\hline fruticosus agg. & frag. & - & 17 & 8 & - & 6 & - & - & - & - & - & - & - & - & - & - & - & 31 \\
\hline
\end{tabular}

Tab. 15. Résultats carpologiques

(analyses L. Bouby, I. Figueiral et C. Schaal)

p. 230 à 234 . 
DEUXIÈME PARTIE : ANALYSES ET ÉTUDES

\begin{tabular}{|c|c|c|c|c|c|c|c|c|c|c|c|c|c|c|c|c|c|c|}
\hline \multirow{2}{*}{\multicolumn{2}{|c|}{$\begin{array}{l}\text { Fait } \\
\text { US }\end{array}$}} & FS1139 & \multicolumn{4}{|c|}{ SB1262 } & \multicolumn{4}{|c|}{ BS3339 } & FS 3220 & F03223 & PT 2031 & PT 2031 & PT 1201 & FO 3179 & FS 3214 & Total \\
\hline & & US1140 & \multicolumn{2}{|c|}{1287} & 1291 & 1266 & 3342 & 3342 & 3341 & 3340 & 3222 & 3225 & 2035 & 2035 & 1245 & 3189 & 3216 & \multirow{5}{*}{116,4} \\
\hline \multicolumn{2}{|l|}{ Échelle } & 123 & 344 & 344 & 408 & 307 & 609 & 609 & 610 & 630 & 510 & 497 & 352 & 369 & 219 & 487 & 498 & \\
\hline \multicolumn{2}{|c|}{ Phase d'occupation } & $3 \mathrm{~A}$ & $3 \mathrm{~A}$ & $3 \mathrm{~A}$ & $3 \mathrm{~A}$ & $3 \mathrm{~A}$ & $4 \mathrm{~A}$ & $4 \mathrm{~A}$ & $4 \mathrm{~A}$ & $4 \mathrm{~B}$ & $4 \mathrm{~B}$ & $4 \mathrm{~B}$ & 5 & 5 & 2 & $4 \mathrm{~A}$ & $4 \mathrm{~B}$ & \\
\hline \multicolumn{2}{|c|}{ Datation (ans apr. J.-C.) } & $100 / 200$ & $100 / 200$ & $100 / 200$ & $100 / 200$ & $100 / 200$ & $200 / 300$ & $200 / 300$ & $200 / 300$ & $400 / 500$ & $400 / 500$ & $400 / 500$ & $1600 / 1700$ & $1600 / 1700$ & $-25 / 50$ & $200 / 300$ & $400 / 500$ & \\
\hline \multicolumn{2}{|c|}{ Vol. analysé (litre) } & 20 & 2,5 & 10 & 10 & 10 & 0,9 & 10 & 10 & 5 & 16 & 10 & 2 & 10 & \multicolumn{3}{|c|}{ ramassage manuel } & \\
\hline \multicolumn{2}{|c|}{ Maille min. tamisage (mm) } & 0,5 & 0,4 & 1 & 1 & 1 & 0,4 & 1 & 1 & 1 & 1 & 0,5 & 0,5 & 0,5 & - & - & - & - \\
\hline \multirow{4}{*}{ Vitis vinifera } & sem. & - & 6 & 4 & 4 & - & - & 6 & 5 & 1 & - & - & 13 & 4 & - & - & - & 43 \\
\hline & frag. & - & 1 & 4 & 3 & - & 5 & 15 & 3 & 1 & - & 7 & 5 & 1 & - & - & - & 45 \\
\hline & $\begin{array}{l}\text { sem. } \\
\text { avort. }\end{array}$ & - & - & - & - & - & 4 & - & - & - & - & - & - & - & - & - & - & 4 \\
\hline & baie avort. & - & 1 & - & - & - & - & - & - & - & - & - & - & - & - & - & - & 1 \\
\hline \multicolumn{19}{|c|}{ Herbacées potentiellement cultivées } \\
\hline $\begin{array}{l}\text { Anethum } \\
\text { graveolens }\end{array}$ & sem. & - & 7 & - & - & - & - & - & - & - & - & - & - & - & - & - & - & 7 \\
\hline Brassica nigra & sem. & - & - & - & - & - & - & - & - & - & - & - & 32 & - & - & - & - & 32 \\
\hline $\begin{array}{l}\text { Coriandrum } \\
\text { sativum }\end{array}$ & frag. & - & 4 & - & - & - & - & - & - & - & - & - & - & - & - & - & - & 4 \\
\hline \multirow{2}{*}{$\begin{array}{l}\text { Foeniculum } \\
\text { vulgare }\end{array}$} & sem. & - & 105 & 102 & 38 & 14 & - & - & - & - & - & - & 39 & - & - & - & - & 298 \\
\hline & frag. & - & 78 & 52 & 16 & 6 & - & - & - & - & - & - & 1 & - & - & - & - & 153 \\
\hline Hordeum sp. & entrenoeud & - & 1 & - & - & - & - & - & - & - & - & - & - & - & - & - & - & 1 \\
\hline $\begin{array}{l}\text { Lagenaria } \\
\text { siceraria }\end{array}$ & sem. & - & - & - & - & - & - & - & - & - & - & - & - & - & - & - & 23 & 23 \\
\hline \multirow{2}{*}{$\begin{array}{l}\text { Papaver } \\
\text { setigerum/ } \\
\text { somniferum }\end{array}$} & sem. & - & 20 & - & - & - & - & - & - & - & - & - & - & - & - & - & - & 20 \\
\hline & frag. & - & 5 & - & - & - & - & - & - & - & - & - & - & - & - & - & - & 5 \\
\hline \multicolumn{19}{|c|}{ Mauvaises herbes des cultures } \\
\hline $\begin{array}{l}\text { Anagallis } \\
\text { arvensis }\end{array}$ & sem. & - & - & - & - & - & - & - & - & - & - & - & 1 & - & - & - & - & 1 \\
\hline \multirow{2}{*}{$\begin{array}{l}\text { Anthemis } \\
\text { arvensis }\end{array}$} & sem. & - & - & - & - & - & - & - & - & - & - & - & 188 & - & - & - & - & 188 \\
\hline & frag. & - & 10 & - & - & - & - & - & - & - & - & - & 4 & - & - & - & - & 14 \\
\hline & sem. & - & 3 & 6 & 2 & 2 & - & - & - & - & - & - & 2 & - & - & - & - & 15 \\
\hline & frag. & - & 4 & 10 & - & - & - & - & - & - & - & - & - & - & - & - & - & 14 \\
\hline $\begin{array}{l}\text { Chenopodium } \\
\text { album }\end{array}$ & sem. & - & 25 & - & - & - & - & 3 & - & - & - & - & - & - & - & - & - & 28 \\
\hline Eupherbig & sem. & - & 10 & 24 & 3 & 10 & 1 & - & - & - & - & 7 & 26 & 1 & - & - & - & 82 \\
\hline helioscopia & frag. & - & 1 & - & - & - & - & - & - & - & - & 2 & 5 & 5 & - & - & - & 13 \\
\hline Fumaria & sem. & - & 35 & 40 & 68 & 16 & - & 16 & 18 & 2 & 1 & - & 52 & 15 & - & 1 & - & 264 \\
\hline officinalis & frag. & - & 16 & 36 & 7 & 18 & - & 10 & 2 & 0,5 & 2 & 1 & 13 & 56 & - & - & - & 161,5 \\
\hline Heliotropium & sem. & - & 61 & 16 & - & 6 & - & - & - & - & - & 5 & 33 & 2 & - & - & - & 123 \\
\hline еитораеит & frag. & - & 45 & - & - & - & - & - & - & - & - & 5 & 7 & 15 & - & - & - & 72 \\
\hline Mercurialis & sem. & - & 3 & - & 16 & - & - & - & - & - & - & - & - & - & - & - & - & 19 \\
\hline аппиа & frag. & - & - & 2 & 4 & - & - & - & - & - & - & - & - & - & - & - & - & 6 \\
\hline Papaver & sem. & - & 50 & - & - & - & - & - & - & - & - & - & 30 & - & - & - & - & 80 \\
\hline dubium/rhoeas & fg. & - & 5 & - & - & - & - & - & - & - & - & - & - & - & - & - & - & 5 \\
\hline Polvgonum & sem. & - & 7 & - & - & 2 & - & - & - & - & - & - & - & - & - & - & - & 9 \\
\hline persicaria & fg. & - & 1 & - & - & - & - & - & - & - & - & - & - & - & - & - & - & 1 \\
\hline Portulaca & sem. & - & 40 & - & - & - & - & - & - & - & - & & 43 & - & - & - & - & 83 \\
\hline oleracea & frag. & - & - & - & - & - & - & - & - & - & - & 14 & - & - & - & - & - & 14 \\
\hline Raphanus & silique & - & 2 & - & - & - & - & - & - & - & - & - & - & - & - & - & - & 2 \\
\hline raphanistrum & frag. silique & - & 4 & - & - & - & - & - & - & - & - & - & - & - & - & - & - & 4 \\
\hline $\begin{array}{l}\text { Rapistrum } \\
\text { rugosum }\end{array}$ & silique & - & 1 & - & - & - & - & - & - & - & - & - & - & - & - & - & - & 1 \\
\hline
\end{tabular}


CHAPITRE 3 : GRAINES, FRUITS BOIS ET CHARBONS D’UN ESPACE HORTICOLE

\begin{tabular}{|c|c|c|c|c|c|c|c|c|c|c|c|c|c|c|c|c|c|c|}
\hline \multirow{2}{*}{\multicolumn{2}{|c|}{$\begin{array}{l}\text { Fait } \\
\text { US }\end{array}$}} & FS1139 & \multicolumn{4}{|c|}{ SB1262 } & \multicolumn{4}{|c|}{ BS3339 } & \multirow{2}{*}{$\begin{array}{c}\text { FS } 3220 \\
3222\end{array}$} & \multirow{2}{*}{$\begin{array}{c}\mathrm{F} 03223 \\
3225\end{array}$} & \multirow{2}{*}{$\begin{array}{c}\text { PT } 2031 \\
2035\end{array}$} & \multirow{2}{*}{$\begin{array}{c}\text { PT } 2031 \\
2035\end{array}$} & \multirow{2}{*}{$\begin{array}{c}\text { PT } 1201 \\
1245\end{array}$} & \multirow{2}{*}{\begin{tabular}{c|} 
FO 3179 \\
3189
\end{tabular}} & \multirow{2}{*}{\begin{tabular}{|c|} 
FS 3214 \\
3216
\end{tabular}} & \multirow{2}{*}{ Total } \\
\hline & & US1140 & \multicolumn{2}{|c|}{1287} & 1291 & 1266 & 3342 & 3342 & 3341 & 3340 & & & & & & & & \\
\hline \multicolumn{2}{|l|}{ Échelle } & 123 & 344 & 344 & 408 & 307 & 609 & 609 & 610 & 630 & 510 & 497 & 352 & 369 & 219 & 487 & 498 & \multirow{4}{*}{116,4} \\
\hline \multicolumn{2}{|c|}{ Phase d'occupation } & $3 \mathrm{~A}$ & $3 \mathrm{~A}$ & $3 \mathrm{~A}$ & $3 \mathrm{~A}$ & $3 \mathrm{~A}$ & $4 \mathrm{~A}$ & $4 \mathrm{~A}$ & $4 \mathrm{~A}$ & $4 \mathrm{~B}$ & $4 \mathrm{~B}$ & $4 \mathrm{~B}$ & 5 & 5 & 2 & $4 \mathrm{~A}$ & $4 \mathrm{~B}$ & \\
\hline \multicolumn{2}{|c|}{ Datation (ans apr. J.-C.) } & $100 / 200$ & $100 / 200$ & $100 / 200$ & $100 / 200$ & $100 / 200$ & $200 / 300$ & $200 / 300$ & $200 / 300$ & $400 / 500$ & $400 / 500$ & $400 / 500$ & $1600 / 1700$ & $1600 / 1700$ & $-25 / 50$ & $200 / 300$ & $400 / 500$ & \\
\hline \multicolumn{2}{|c|}{ Vol. analysé (litre) } & 20 & 2,5 & 10 & 10 & 10 & 0,9 & 10 & 10 & 5 & 16 & 10 & 2 & 10 & \multicolumn{3}{|c|}{ ramassage manuel } & \\
\hline \multicolumn{2}{|c|}{ Maille min. tamisage (mm) } & 0,5 & 0,4 & 1 & 1 & 1 & 0,4 & 1 & 1 & 1 & 1 & 0,5 & 0,5 & 0,5 & - & - & - & - \\
\hline $\begin{array}{l}\text { Solanum } \\
\text { nigrum }\end{array}$ & sem. & - & 10 & - & - & - & - & - & - & - & 1 & - & 3 & 2 & - & - & - & 16 \\
\hline Stellaria media & sem. & - & - & - & - & - & - & - & - & - & - & - & 14 & - & - & - & - & 14 \\
\hline & & & & & & & & Décombre & lieux rudé & & & & & & & & & \\
\hline $\begin{array}{l}\text { Capsella } \\
\text { bursa-pastoris }\end{array}$ & sem. & - & - & - & - & - & - & - & - & - & - & - & 2 & - & - & - & - & 2 \\
\hline & sem. & - & - & - & - & - & - & 1 & 1 & 1 & - & - & - & - & - & - & - & 3 \\
\hline 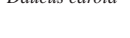 & frag. & - & - & - & - & - & - & - & - & - & - & 7 & - & - & - & - & - & 7 \\
\hline $\begin{array}{l}\text { Euphorbia } \\
\text { exigua/peplus }\end{array}$ & sem. & - & 15 & - & - & - & - & - & - & - & - & - & 7 & - & - & - & - & 22 \\
\hline $\begin{array}{l}\text { Lamium } \\
\text { amplexicaule }\end{array}$ & sem. & - & 10 & - & 10 & - & - & - & - & - & - & - & 42 & - & - & - & - & 62 \\
\hline $\begin{array}{l}\text { Malva } \\
\text { parviflora }\end{array}$ & sem. & - & 1 & - & - & - & - & - & - & - & - & - & 79 & - & - & - & - & 80 \\
\hline $\begin{array}{l}\text { Malva } \\
\text { sylvestris }\end{array}$ & sem. & - & - & - & - & - & - & - & - & - & - & - & 3 & - & - & - & - & 3 \\
\hline $\begin{array}{l}\text { cf. Marrubium } \\
\text { vulgare }\end{array}$ & sem. & - & - & - & - & - & - & - & - & - & - & - & 17 & 2 & - & - & - & 19 \\
\hline Nepeta cataria & sem. & - & 5 & - & - & - & - & - & - & - & - & - & - & - & - & - & - & 5 \\
\hline $\begin{array}{l}\text { Polygonum } \\
\text { aviculare }\end{array}$ & sem. & - & 6 & - & - & - & - & - & - & - & - & - & - & - & - & - & - & 6 \\
\hline $\begin{array}{l}\text { Rumex } \\
\text { obtusifolius/ } \\
\text { pulcher }\end{array}$ & sem. & - & 55 & 60 & 28 & - & - & - & - & - & - & - & - & - & - & - & - & 143 \\
\hline $\begin{array}{l}\text { cf. Sonchus } \\
\text { oleraceus }\end{array}$ & sem. & - & - & - & - & - & - & - & - & - & - & - & 2 & - & - & - & - & 2 \\
\hline Urtica urens & sem. & - & - & - & - & - & - & - & - & - & - & - & 1 & - & - & - & - & 1 \\
\hline $\begin{array}{l}\text { Verbena } \\
\text { officinalis }\end{array}$ & sem. & - & - & - & - & 2 & - & - & - & - & - & - & - & - & - & - & - & 2 \\
\hline & & & & & & & & Lieux secs & pelouses, si & & & & & & & & & \\
\hline Arenaria sp. & sem. & - & 5 & - & - & - & - & - & - & - & - & - & - & - & - & - & - & 5 \\
\hline $\begin{array}{l}\text { Hypericum cf. } \\
\text { perforatum }\end{array}$ & sem. & - & 25 & - & - & - & - & - & - & - & - & - & - & - & - & - & - & 25 \\
\hline $\begin{array}{l}\text { Lobularia } \\
\text { maritima }\end{array}$ & sem. & - & - & - & - & - & - & - & - & - & - & - & 414 & - & - & - & - & 414 \\
\hline Medicago & gousse & - & - & - & - & - & - & - & - & - & - & - & 1 & - & - & - & - & 1 \\
\hline littoralis & frag. gousse & - & - & - & - & - & - & - & - & - & - & 7 & - & - & - & - & - & 7 \\
\hline $\begin{array}{l}\text { Petrorhagia } \\
\text { prolifera }\end{array}$ & sem. & - & 5 & - & - & - & - & - & - & - & - & - & - & - & - & - & - & 5 \\
\hline $\begin{array}{l}\text { Scabiosa } \\
\text { atropurpurea }\end{array}$ & sem. & - & 3 & 4 & - & - & - & - & - & - & - & - & - & - & - & - & - & 7 \\
\hline Silene gallica & sem. & - & 20 & - & - & - & 8 & 1 & - & - & - & - & 6 & - & - & - & - & 35 \\
\hline $\begin{array}{l}\text { Stachys } \\
\text { arvensis/ } \\
\text { ocymastrum }\end{array}$ & sem. & - & - & - & - & - & - & - & - & - & - & - & 48 & - & - & - & - & 48 \\
\hline $\begin{array}{l}\text { Tribulus } \\
\text { terrestris }\end{array}$ & sem. & - & - & - & - & - & - & - & - & - & - & - & 1 & - & - & - & - & 1 \\
\hline & & & & & & & & Liet & humides & & & & & & & & & \\
\hline $\begin{array}{l}\text { cf. Carduus } \\
\text { personata }\end{array}$ & sem. & - & - & - & - & - & - & - & - & - & - & - & 2 & - & - & - & - & 2 \\
\hline Carex sp. & sem. & - & 15 & 6 & 2 & - & 14 & 37 & 26 & 28 & 1 & - & 5 & - & - & - & - & 134 \\
\hline Cyperus sp. & sem. & - & 410 & 2 & - & - & 140 & - & - & - & - & - & 2 & - & - & - & - & 554 \\
\hline $\begin{array}{l}\text { Eleocharis } \\
\text { palustris }\end{array}$ & sem. & - & 5 & - & - & - & - & - & - & - & - & - & - & - & - & - & - & 5 \\
\hline Eleocharis sp. & sem. & - & - & - & - & - & - & - & - & - & - & - & 1 & - & - & - & - & 1 \\
\hline
\end{tabular}


DEUXIÈME PARTIE : ANALYSES ET ÉTUDES

\begin{tabular}{|c|c|c|c|c|c|c|c|c|c|c|c|c|c|c|c|c|c|c|}
\hline \multirow{2}{*}{\multicolumn{2}{|c|}{$\begin{array}{l}\text { Fait } \\
\text { US }\end{array}$}} & FS1139 & \multicolumn{4}{|c|}{ SB1262 } & \multicolumn{4}{|c|}{ BS3339 } & \multirow{2}{*}{$\begin{array}{c}\text { FS } 3220 \\
3222\end{array}$} & \multirow{2}{*}{\begin{tabular}{c|}
$\mathrm{F} 03223$ \\
3225
\end{tabular}} & \multirow{2}{*}{$\begin{array}{c}\text { PT } 2031 \\
2035\end{array}$} & \multirow{2}{*}{$\begin{array}{c}\text { PT } 2031 \\
2035\end{array}$} & \multirow{2}{*}{$\begin{array}{c}\text { PT } 1201 \\
1245\end{array}$} & \multirow{2}{*}{\begin{tabular}{c|} 
FO 3179 \\
3189
\end{tabular}} & \multirow{2}{*}{\begin{tabular}{|c|} 
FS 3214 \\
3216
\end{tabular}} & Total \\
\hline & & US1140 & \multicolumn{2}{|c|}{1287} & 1291 & 1266 & 3342 & 3342 & 3341 & 3340 & & & & & & & & \\
\hline \multicolumn{2}{|l|}{ Échelle } & 123 & 344 & 344 & 408 & 307 & 609 & 609 & 610 & 630 & 510 & 497 & 352 & 369 & 219 & 487 & 498 & \\
\hline \multicolumn{2}{|c|}{ Phase d'occupation } & $3 \mathrm{~A}$ & $3 \mathrm{~A}$ & $3 \mathrm{~A}$ & $3 \mathrm{~A}$ & $3 \mathrm{~A}$ & $4 \mathrm{~A}$ & $4 \mathrm{~A}$ & $4 \mathrm{~A}$ & $4 \mathrm{~B}$ & $4 \mathrm{~B}$ & $4 \mathrm{~B}$ & 5 & 5 & 2 & $4 \mathrm{~A}$ & $4 \mathrm{~B}$ & 116,4 \\
\hline \multicolumn{2}{|c|}{ Datation (ans apr. J.-C.) } & $100 / 200$ & $100 / 200$ & $100 / 200$ & $100 / 200$ & $100 / 200$ & $200 / 300$ & $200 / 300$ & $200 / 300$ & $400 / 500$ & $400 / 500$ & $400 / 500$ & $1600 / 1700$ & $1600 / 1700$ & $-25 / 50$ & $200 / 300$ & $400 / 500$ & \\
\hline \multicolumn{2}{|c|}{ Vol. analysé (litre) } & 20 & 2,5 & 10 & 10 & 10 & 0,9 & 10 & 10 & 5 & 16 & 10 & 2 & 10 & \multicolumn{3}{|c|}{ ramassage manuel } & \\
\hline \multicolumn{2}{|c|}{ Maille min. tamisage (mm) } & 0,5 & 0,4 & 1 & 1 & 1 & 0,4 & 1 & 1 & 1 & 1 & 0,5 & 0,5 & 0,5 & - & - & - & - \\
\hline Juncus sp. & sem. & - & - & - & - & - & - & - & - & - & - & 2 & - & - & - & - & - & 2 \\
\hline $\begin{array}{l}\text { cf. Phragmites } \\
\text { communis }\end{array}$ & sem. & - & - & - & - & - & - & - & - & - & - & 2 & - & - & - & - & - & 2 \\
\hline \multirow{2}{*}{$\begin{array}{l}\text { Ranunculus } \\
\text { sardous }\end{array}$} & sem. & - & 1 & 8 & - & - & - & - & - & - & - & 5 & 1 & - & - & - & - & 15 \\
\hline & fg. & - & - & - & - & - & 1 & - & - & - & - & 1 & - & - & - & - & - & 2 \\
\hline $\begin{array}{l}\text { Scirpus } \\
\text { lacustris }\end{array}$ & sem. & - & 12 & 10 & - & - & - & - & - & - & - & - & 1 & - & - & - & - & 23 \\
\hline & & & & & & & & Plante & aquatiques & & & & & & & & & \\
\hline $\begin{array}{l}\text { Ceratophyllum } \\
\text { demersum }\end{array}$ & sem. & - & - & - & - & - & - & - & - & 1 & - & - & - & - & - & - & - & 1 \\
\hline Chara sp. & gyro. & - & 4870 & - & - & - & - & - & - & - & - & - & - & - & - & - & - & 4870 \\
\hline $\begin{array}{l}\text { Lemna } \text { cf. } \\
\text { minor }\end{array}$ & sem. & - & 330 & - & - & - & 60 & - & - & - & - & - & 21 & - & - & - & - & 411 \\
\hline Ranunculus & sem. & - & 575 & - & - & - & - & - & - & - & - & - & - & - & - & - & - & 575 \\
\hline aquatilis agg. & frag. & - & 75 & - & - & - & - & - & - & - & - & - & - & - & - & - & - & 75 \\
\hline $\begin{array}{l}\text { Zannichellia } \\
\text { palustris }\end{array}$ & sem. & - & 184 & 332 & - & 2 & - & - & - & - & - & - & - & - & - & - & - & 518 \\
\hline & & & & & & & & & ivers & & & & & & & & & \\
\hline & sem. & - & 1 & 2 & - & - & - & - & - & - & - & - & 2 & - & - & - & - & 5 \\
\hline Procos & frag. & - & - & - & - & - & 4 & - & - & - & - & - & - & 10 & - & - & - & 14 \\
\hline $\begin{array}{l}\text { Bromus type } \\
\text { arvensis/ } \\
\text { hordeaceus }\end{array}$ & sem. & - & 2 & - & - & - & - & - & - & - & - & - & - & - & - & - & - & 2 \\
\hline Campanula sp. & sem. & - & - & - & - & - & - & - & - & - & - & - & 23 & - & - & - & - & 23 \\
\hline Caryophyllaceae & sem. & - & - & 1 & - & - & - & - & - & - & - & - & - & - & - & - & - & 1 \\
\hline $\begin{array}{l}\text { Chenopodium } \\
\text { sp. }\end{array}$ & sem. & - & - & - & - & - & - & - & 1 & - & - & - & 130 & 3 & - & - & - & 134 \\
\hline Chenopodiaceae & sem. & - & - & - & - & - & - & - & - & - & - & - & 82 & - & - & - & - & 82 \\
\hline Cyperaceae & sem. & - & 5 & - & - & 2 & - & - & - & - & - & - & - & - & - & - & - & 7 \\
\hline Epilobium sp. & sem. & - & 20 & - & - & - & - & - & - & - & - & - & - & - & - & - & - & 20 \\
\hline $\begin{array}{l}\text { Lactuca type } \\
\text { sativa/scariola }\end{array}$ & sem. & - & - & - & - & - & - & - & - & - & - & - & 3 & - & - & - & - & 3 \\
\hline Linum sp. & $\begin{array}{l}\text { frag. } \\
\text { capsule }\end{array}$ & - & 1 & - & - & - & - & - & - & - & - & 2 & - & - & - & - & - & 3 \\
\hline Malva sp. & sem. & - & - & 2 & - & - & - & - & - & - & - & - & - & 3 & - & - & - & 5 \\
\hline $\begin{array}{l}\text { Medicago type } \\
\text { polymorpha }\end{array}$ & gousse & - & - & - & 1 & - & - & - & - & - & - & - & - & - & - & - & - & 1 \\
\hline Medicago sp. & frag. gousse & - & 3 & 20 & 6 & - & 1 & 1 & - & - & - & - & - & - & - & - & - & 31 \\
\hline Oxalis sp. & sem. & - & 50 & 4 & - & - & - & - & - & - & - & - & 1 & - & - & - & - & 55 \\
\hline & frag. & - & - & - & - & - & - & - & - & - & - & 7 & - & - & - & - & - & 7 \\
\hline Papaver sp. & sem. & - & - & - & - & - & - & - & - & - & - & - & - & 1 & - & - & - & 1 \\
\hline & sem. & - & - & - & - & - & - & - & - & - & - & - & 1 & - & - & - & - & 1 \\
\hline Papaveraceae & frag. & - & - & - & - & - & - & - & - & - & - & - & 1 & - & - & - & - & 1 \\
\hline & sem. & - & 20 & 2 & - & - & - & - & - & - & - & - & 4 & 1 & - & - & - & 27 \\
\hline & frag. tige & - & 1 & - & - & - & - & - & - & - & - & - & - & - & - & - & - & 1 \\
\hline $\begin{array}{l}\text { Polycneтит } \\
\text { sp. }\end{array}$ & frag. & - & - & - & - & - & - & - & - & - & - & - & 4 & - & - & - & - & 4 \\
\hline
\end{tabular}


CHAPITRE 3 : GRAINES, FRUITS BOIS ET CHARBONS D'UN ESPACE HORTICOLE

\begin{tabular}{|c|c|c|c|c|c|c|c|c|c|c|c|c|c|c|c|c|c|c|}
\hline \multirow{3}{*}{\multicolumn{2}{|c|}{\begin{tabular}{|l} 
Fait \\
US \\
Échelle
\end{tabular}}} & FS1139 & \multicolumn{4}{|c|}{ SB1262 } & \multicolumn{4}{|c|}{ BS3339 } & \multirow{3}{*}{$\begin{array}{c}\text { FS } 3220 \\
3222 \\
510\end{array}$} & \multirow{3}{*}{$\begin{array}{c}\text { F03223 } \\
3225 \\
497\end{array}$} & \multirow{3}{*}{$\begin{array}{c}\text { PT } 2031 \\
2035 \\
352\end{array}$} & \multirow{3}{*}{$\begin{array}{c}\text { PT } 2031 \\
2035 \\
369\end{array}$} & \multirow{3}{*}{$\begin{array}{c}\text { PT } 1201 \\
1245 \\
219\end{array}$} & \multirow{3}{*}{$\begin{array}{c}\text { FO } 3179 \\
3189 \\
487\end{array}$} & \multirow{3}{*}{$\begin{array}{c}\text { FS } 3214 \\
3216 \\
498\end{array}$} & \multirow{4}{*}{\begin{tabular}{|r} 
Total \\
116,4
\end{tabular}} \\
\hline & & US1140 & \multicolumn{2}{|c|}{1287} & 1291 & 1266 & 3342 & 3342 & 3341 & 3340 & & & & & & & & \\
\hline & & 123 & 344 & 344 & 408 & 307 & 609 & 609 & 610 & 630 & & & & & & & & \\
\hline \multicolumn{2}{|c|}{ Phase d'occupation } & $3 \mathrm{~A}$ & $3 \mathrm{~A}$ & $3 \mathrm{~A}$ & $3 \mathrm{~A}$ & $3 \mathrm{~A}$ & $4 \mathrm{~A}$ & $4 \mathrm{~A}$ & $4 \mathrm{~A}$ & $4 \mathrm{~B}$ & $4 \mathrm{~B}$ & $4 \mathrm{~B}$ & 5 & 5 & 2 & $4 \mathrm{~A}$ & $4 \mathrm{~B}$ & \\
\hline \multicolumn{2}{|c|}{ Datation (ans apr. J.-C.) } & $100 / 200$ & $100 / 200$ & $100 / 200$ & $100 / 200$ & $100 / 200$ & $200 / 300$ & $200 / 300$ & $200 / 300$ & $400 / 500$ & $400 / 500$ & $400 / 500$ & $1600 / 1700$ & $1600 / 1700$ & $-25 / 50$ & $200 / 300$ & $400 / 500$ & \\
\hline \multicolumn{2}{|c|}{ Vol. analysé (litre) } & 20 & 2,5 & 10 & 10 & 10 & 0,9 & 10 & 10 & 5 & 16 & 10 & 2 & 10 & \multicolumn{3}{|c|}{ ramassage manuel } & \\
\hline \multicolumn{2}{|c|}{ Maille min. tamisage (mm) } & 0,5 & 0,4 & 1 & 1 & 1 & 0,4 & 1 & 1 & 1 & 1 & 0,5 & 0,5 & 0,5 & - & - & - & - \\
\hline \multirow{2}{*}{ Ranunculus sp. } & sem. & - & 1 & - & - & - & - & - & 2 & - & - & - & - & - & - & - & - & 3 \\
\hline & frag. & - & - & - & - & - & - & 3 & - & - & - & - & - & - & - & - & - & 3 \\
\hline \multirow{2}{*}{ Rumex sp. } & sem. & - & 48 & 28 & 7 & 4 & - & - & 1 & - & - & - & 1 & - & - & - & - & 89 \\
\hline & frag. & - & 5 & - & 19 & - & - & - & - & - & - & - & - & - & - & - & - & 24 \\
\hline \multirow{2}{*}{ Silene sp. } & sem. & - & 1 & - & - & - & - & - & - & - & - & - & - & - & - & - & - & 1 \\
\hline & frag. & - & 1 & - & - & - & - & - & - & - & - & - & - & - & - & - & - & 1 \\
\hline Teucrium sp. & sem. & - & - & - & - & - & - & - & - & - & - & - & 1 & - & - & - & - & 1 \\
\hline \multirow{2}{*}{ Trifolium $\mathrm{sp}}$. & sem. & - & - & - & - & - & - & - & - & - & - & - & 3 & - & - & - & - & 3 \\
\hline & périanthe & - & 8 & 6 & - & - & - & - & - & - & - & - & - & - & - & - & - & 14 \\
\hline cf. Valerienella & frag. & - & - & 2 & - & - & - & - & - & - & - & - & - & - & - & - & - & 2 \\
\hline Verbascum sp. & sem. & - & - & - & - & - & - & - & - & - & - & - & 6 & - & - & - & - & 6 \\
\hline \multirow{2}{*}{ Indéterminé } & sem. & - & 1 & 2 & 2 & - & - & 4 & 4 & 4 & - & - & 18 & 1 & - & - & - & 36 \\
\hline & frag. & - & 7 & 22 & - & - & - & - & - & - & - & - & - & - & - & - & - & 29 \\
\hline Bourgeon & ind. & - & - & 6 & 11 & - & - & - & - & - & - & - & - & - & - & - & - & 17 \\
\hline \multicolumn{2}{|l|}{ Total NR } & 6 & 7768 & 955 & 266 & 98 & 384 & 149 & 105 & 40,5 & 5 & 79 & 1547 & 127 & 7 & 56 & 23 & 11615,5 \\
\hline \multicolumn{2}{|l|}{ Nbre fragments } & 6 & 307 & 192 & 59 & 30 & 144 & 73 & 12 & 3,5 & 2 & 55 & 43 & 87 & 0 & 2 & 0 & 1015,5 \\
\hline \multicolumn{2}{|c|}{ Fragmentation (\%) } & 100,00 & 3,95 & 20,10 & 22,18 & 30,61 & 37,50 & 48,99 & 11,43 & 8,64 & 40,00 & 69,62 & 2,78 & 68,50 & 0,00 & 3,57 & 0,00 & 8,74 \\
\hline \multicolumn{2}{|l|}{ Nbre restes/litre } & 0,30 & 3107,20 & 95,50 & 26,60 & 9,80 & 426,67 & 14,90 & 10,50 & 8,10 & 0,31 & 7,90 & 773,50 & 12,70 & - & - & - & 99,79 \\
\hline Nbre restes carb & nisés & 6 & 33 & 10 & 5 & 0 & 0 & 0 & 0 & 2 & 0 & 1 & 0 & 0 & 0 & 0 & 0 & 57 \\
\hline$\%$ restes carboni & & 100 & 0,425 & 1,047 & 1,880 & 0 & 0 & 0 & 0 & 4,938 & 0 & 1,266 & 0 & 0 & 0 & 0 & 0 & 0,491 \\
\hline
\end{tabular}





\section{Chapitre 4}

\section{Analyses polliniques des structures agraires}

(S. Guillon)

\section{Introduction et méthode}

Sur le site de Villeneuve à Fréjus, une série d'aménagements « ruraux » constituée entre autre de fosses de plantation (découvertes avec ou sans leur pot horticole), puits, bassins, fossés et fosses ont été mis au jour sur une superficie de près de $5000 \mathrm{~m}^{2}$. L'étude de ces différentes structures a révélé cinq grandes phases de fonctionnement, de la fin du I ${ }^{\text {er }}$ siècle av. J.-C. jusqu' au cours du XVII siècle.

C'est pour répondre à des questions de fonctionnalité et de contemporanéité éventuelle des structures, que la restitution de la paléo-végétation du site de Villeneuve par la palynologie a été menée. Très vite, pour des raisons de bonne représentativité des écosystèmes passés, le problème du choix des prélèvements s'est posé.

La principale difficulté résidait dans la possibilité de documenter la phase 2 (fin I ${ }^{\text {er }}$ siècle av. J.-C./milieu $\mathrm{I}^{\text {er }}$ siècle apr. J.-C.), correspondant à l'installation de deux rangées de fosses de plantation (pouvant atteindre plus d'un mètre de diamètre) creusées à même le sable.

L'objectif était de pouvoir capter la pluie pollinique issue de cette plantation dont la nature était inconnue. Le puits PT1201 situé entre les deux rangées paraissait un excellent piège, malheureusement la nature du comblement (sables grossiers) a rendu l'analyse pollinique impossible.

Quant aux comblements des fosses et des amphores horticoles, deux tests palynologiques réalisés dans la fosse VP1017 et le comblement de l'amphore retrouvée dans la fosse VP1304 sont venus confirmer leurs caractères remaniés et oxydés.

Si la phase 2 ne nous est pas du tout documentée, la phase 3 (milieu I ${ }^{\text {er }}$ siècle apr./fin $\mathrm{II}^{\mathrm{e}}$ siècle apr. J.-C.) par l'analyse du comblement du bassin BS1262, la phase 4 (fin $\mathrm{II}^{\mathrm{e}}$ siècle apr. J.-C./V $\mathrm{V}^{\mathrm{e}}$ siècle apr. J.-C.) par celle du bassin BS3339, des fossés FO3179, 3255 et des fosses FS3190, 3220 et enfin la phase 5 (XV-XVI ${ }^{\mathrm{e}}$ siècles) par celle du puits PT2003 et du fossé 3017, nous sont davantage connues.
De ce fait, un total de 33 échantillons a été analysé. Les résultats présentés dans les diagrammes polliniques sont issus de la détermination et du comptage (minimum de 250 grains par échantillon) du matériel sporopollinique exprimé en pourcentages relatifs. En raison de leur sur-représentativité, les spores de fougères ainsi que les M-F-N-P (Micro Fossiles Non Polliniques qui sont pour la plus part des spores de champignons, des algues ou des diatomées nous renseignant sur la qualité et le niveau des aquifères) sont exclus du calcul.

\section{Description et commentaire des diagrammes polliniques}

\subsection{Le bassin BS1262}

(fig. 264)

Il s'agit d'une structure en bois assez isolée datée du milieu du I ${ }^{\text {er }}$ siècle apr. J.-C./fin du II ${ }^{\mathrm{e}}$ siècle apr. J.-C. mise au jour dans un niveau qui vient sceller le fonctionnement des fosses de plantation. Trois échantillons (\#370, \#341 et \#265) prélevés dans le comblement du bassin ont fait l'objet d'une analyse pollinique. Si à une échelle régionale, les spectres analysés mettent en évidence une image assez homogène mais très discrète de la pinède et du maquis de l'arrière-pays cristallin représenté essentiellement par la bruyère arborescente (Erica arborea) et le chêne vert (Quercus ilex), elles montrent, à une échelle plus locale, des écosystèmes nettement plus variables et mieux représentés. Concernant le niveau et la qualité des eaux présentes dans le bassin, l'échantillon \#265 (zone B) via les valeurs importantes de Lemna minor (lentille d'eau) et de Botryococcus (algues vertes se développant en colonie à la surface des eaux stagnantes), semble indiquer la présence d'eaux dormantes peu profondes caractéristiques de l'abandon du bassin en tant que puits à eau. Dans la zone $\mathrm{A}$, à la base du diagramme, les marqueurs sont très différents : alors que Lemna minor et Botryococcus 
sont quasiment absents, les spores d'algues Rivularia de type 170 mettent en évidence des eaux plus profondes et moins stagnantes.

À l'image de la flore aquatique, la végétation locale associée au bassin présente également des variations. Globalement ces enregistrements polliniques mettent en évidence un paysage local très ouvert marqué par les Poacées, les Brassicacées, les Composées (Cichoriées et Astéroidées), les Cypéracées et le genre Rumex (oseille). Le contexte archéologique (jardin potager et/ ou d'agrément) nous incite à réfléchir sur le caractère naturel ou anthropique de la présence de certains taxons enregistrés dans les spectres polliniques. En effet, beaucoup d'espèces parmi les Brassicacées (le chou/ Brassica oleacera...) et le genre Rumex (l'oseille/Rumex acetosa...) sont cultivées dès l'Antiquité. Par ailleurs, parmi ces mêmes familles et genres, d'autres nombreuses espèces croient naturellement sur les sols acides, sableux, secs à humides du trait de côte de Fréjus. Ainsi, la détermination des taxons à l'échelle de la famille ou du genre ne suffit pas pour privilégier l'origine naturelle ou anthropique de ces taxons. Néanmoins, la présence à hauteur de 3\% (\#265) du type Cerealia laisse supposer la présence locale de céréaliculture. Étant donnée la faible production pollinique et le caractère autogame des céréales, les $3 \%$, peuvent être considérés comme un marqueur suffisamment représentatif d'une culture avoisinante.

\subsection{Le bassin BS3339}

(fig. 265)

Également construit en bois, ce bassin est associé à un réseau de fossés orthonormés créant un vaste aménagement agraire daté de la fin du II' siècle apr. J.-C./ III siècle apr. J.-C. Dans le cadre de l'analyse pollinique, un petit carottage de $30 \mathrm{~cm}$ réalisé au moyen d'un tube PVC nous a permis d'obtenir une séquence des différents faciès sédimentaires de comblement du bassin. La base de la séquence (de 29 à $21 \mathrm{~cm}$ ), dans laquelle ont été retrouvées des tiges de saules, est très organique, les limons argileux bruns foncés y sont légèrement sableux. Entre 21 et $20 \mathrm{~cm}$, un lit organique noir, très riche en malacofaune, se dépose. Les limons sableux ou sables limoneux gris à brun constituent le sommet de la séquence.

Cinq échantillons prélevés au sein du carottage ont fait l'objet d'une analyse. À partir de la détermination et du comptage des spores et grains de pollen, trois zones polliniques ont été définies. En zone A, à la base de la séquence, tandis que la courbe de Lemna minor (lentilles d'eau) met en évidence la présence d'eau dormante dans le bassin (sans doute des eaux de la nappe haute),

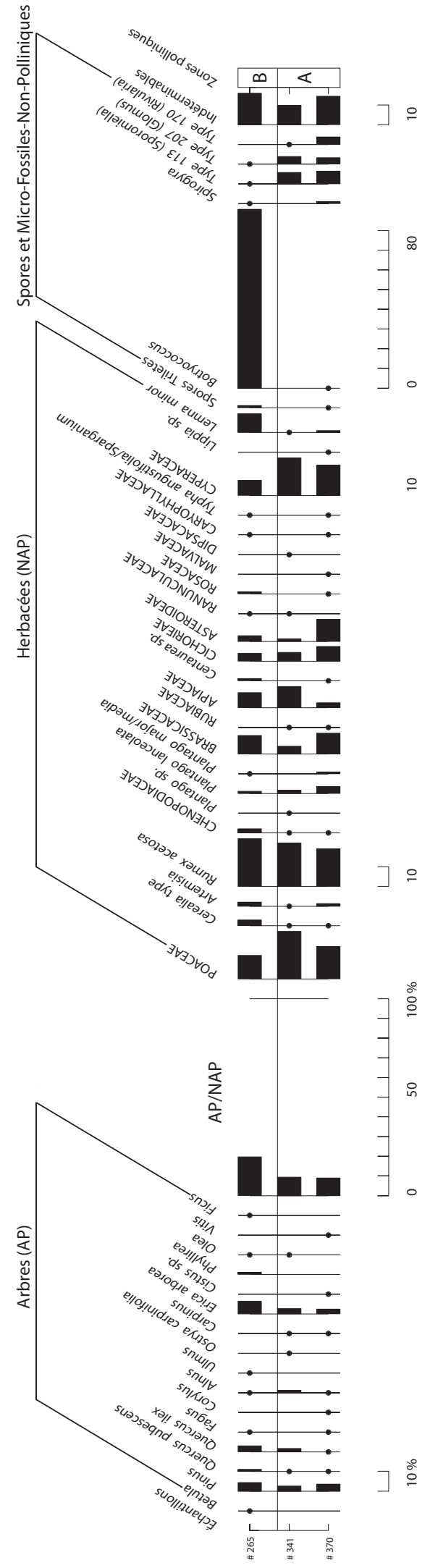

Fig. 264. Diagramme pollinique du bassin BS1262 (milieu Ier siècle apr. J.-C./fin Ile siècle apr. J.-C.) 


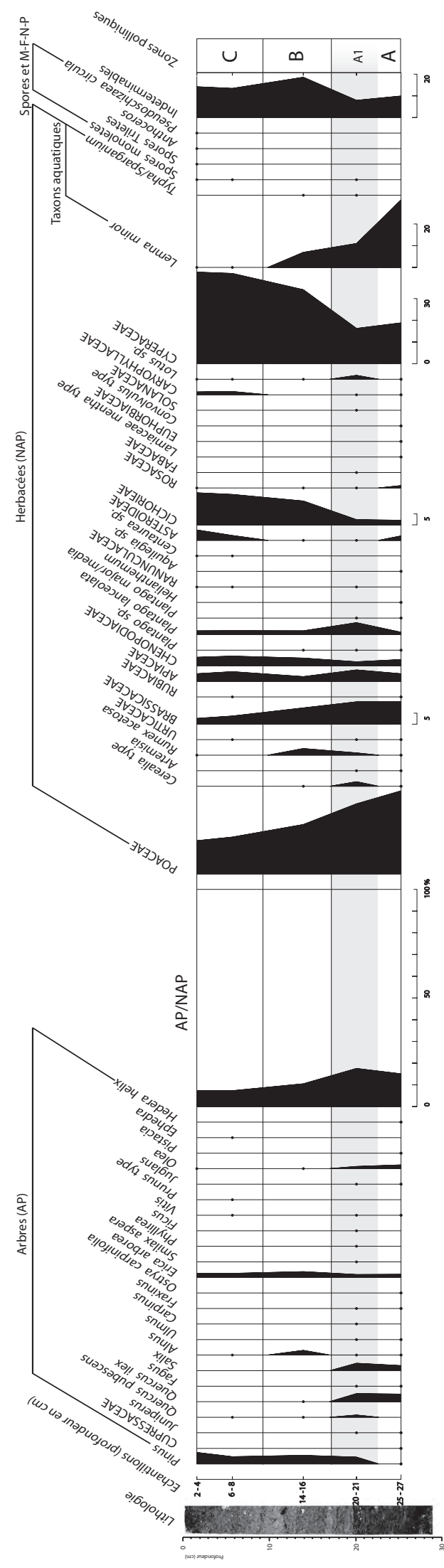

Fig. 265. Diagramme pollinique du bassin BS3339 (fin IIe siècle apr. J.-C./IIIe siècle apr. J.-C.). les valeurs du plantain lancéolé (Plantago lanceolata) des Poacées, Apiacées et des céréales, en interzone A1 témoignent de l'anthropisation du milieu environnant. Concernant les pratiques anthropiques, les valeurs du saule (Salix) méritent également d'être commentées. Associées dans le même niveau, à des tiges du même arbre et étant donné la relative absence dans les autres structures du site du signal pollinique de cet arbre (généralement présent dans les formations ripicoles, aux bords des cours d'eaux), on peut émettre l'hypothèse d'un apport issu de la préparation des branchages de saule aux abords du bassin, lesquels pouvaient être ensuite plongés dans les eaux de ce dernier afin de faciliter leur travail en vannerie.

Par la suite, la courbe de Lemna minor nous incite à voir dans les zones $\mathrm{C}$ et $\mathrm{D}$ un atterrissement du bassin associé sans doute à une diminution du niveau de la nappe. Les indices d'anthropisation (céréales, plantes rudérales) se font alors plus discrets, au profit d'une nette augmentation des valeurs des Cypéracées et des Cichoriées. Le dessèchement du bassin semble entraîner une colonisation de ses fonds, ombragés encore humides, par les Cypéracées, lesquelles tolèrent moins bien les sols sableux environnants : une série d'indices qui suppose un atterrissement et un abandon du bassin dans les zones $\mathrm{C}$ et $\mathrm{D}$.

\subsection{Les fossés FO3179 et 3255 \\ (fig. 263 et 264)}

Il s'agit de deux fossés orthonormés associés au bassin BS3339. Etant données leur contemporanéité et leur fonctionnalité sur le même réseau drainant, ils seront traités ici conjointement.

L'analyse pollinique a été menée grâce à deux carottages réalisés dans les comblements des fossés. Sept échantillons ont été prélevés sur le carottage P. 503 pour le fossé FO3179, quatre sur le carottage P. 501 pour le fossé FO3255. Contrairement aux autres structures analysées dans cette étude, fosses, puits et bassin, l'image de la végétation enregistrée dans les fossés est moins locale. La courbe des taxons arboréens, notamment celle de la pinède et du maquis à bruyère arborescente (Erica arborea) et chêne (Quercus sp.) de l'arrière-pays siliceux en témoignent, avec des valeurs oscillant entre 20 et $40 \%$ de l'apport pollinique total, des spectres semblables à ceux enregistrés à Roquebrune-sur-Argens, en basse vallée, en amont de Fréjus (Dubar et al. 2004). L'enregistrement du fossé FO3179, globalement mieux conservé que celui du fossé FO3255, met en évidence, en dehors de l'écho plus lointain de la pinède, une anticorrélation entre les valeurs du chêne (vert et pubescent) et celles de la bruyère arborescente (Erica arborea). 
Cette observation montre que les chênes subissent des dégradations (entre 8 et $20 \mathrm{~cm}$ et au delà de $33 \mathrm{~cm}$ sur P. 503, fig. 266) d'origine anthropique (écobuage,

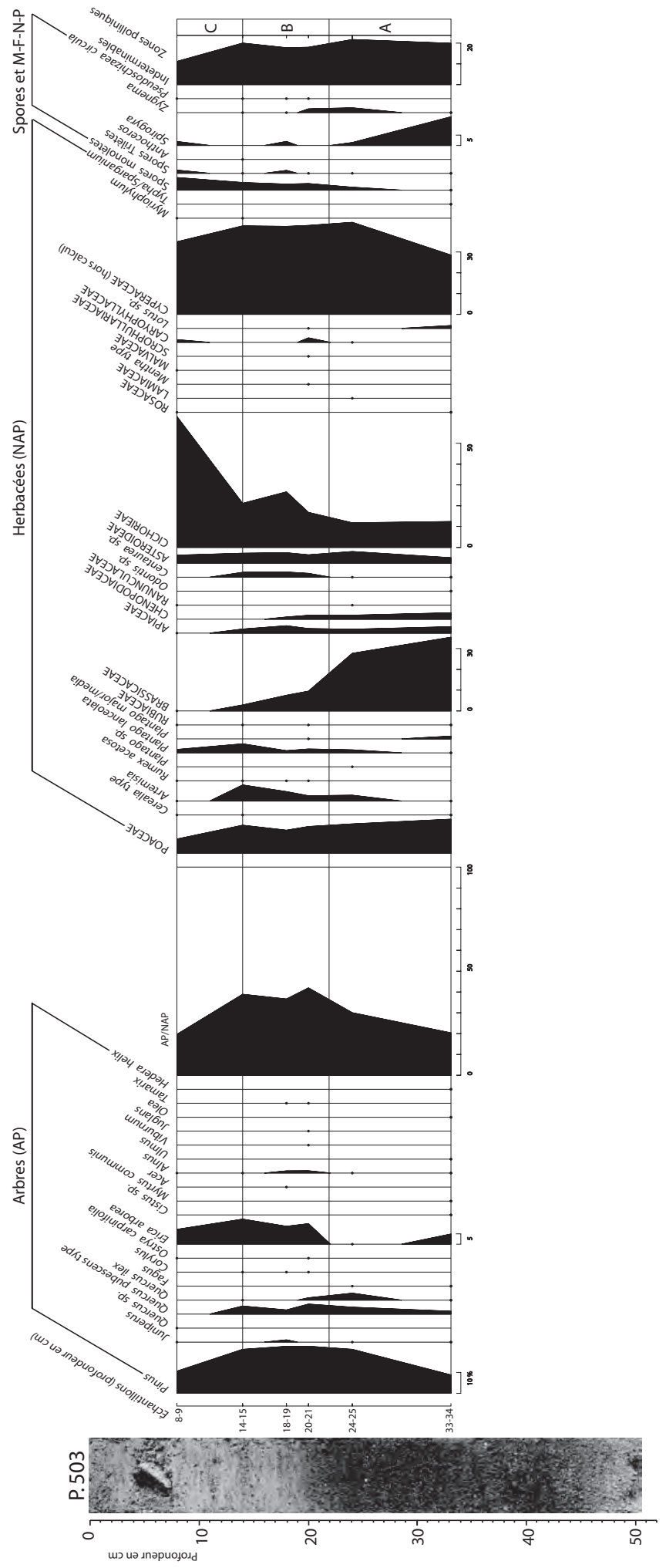

Fig. 266. Diagramme pollinique du fossé FO3179 - carottage P. 503 (fin IIe siècle apr. J.-C./IIIe siècle apr. J.-C.). taillis, défrichement, déboisement) ou accidentelle (feux accidentels...), favorisant le développement de la bruyère, pionnière dans le maquis (Lieutaghi 2006).

Les marqueurs hygrophiles que sont les spores d'algues de Spirogyra et Zygnema, lesquelles se développent dans des eaux douces stagnantes, peu profondes et eutrophiques, indiquent notamment que le fond du fossé FO3179 [niveau noir plus organique entre 24 et $43 \mathrm{~cm}$ (fig. 263)] était régulièrement sous les eaux de la nappe haute. La courbe des Brassicaceae témoigne d'une certaine humidité édaphique [zone A entre 24 et $43 \mathrm{~cm}$ (fig. 266)]. Avec le niveau de limons argileux gris clair [zone B, entre 14 et $22 \mathrm{~cm}$ (fig. 266)], les spores d'algues de Spirogyra et Zygnema disparaissent, marquant le scellement et donc l'abandon du fossé FO3179. Au-delà, la zone C marque un niveau largement sujet aux phénomènes d'oxydation, comme en témoignent les taches verticales rouge orange présentes sur les $15 \mathrm{~cm}$ supérieurs de la séquence. Bien qu'une conservation différentielle du matériel sporopollinique y soit induite, la dominance des Cichorieae associée aux Poaceae et Cyperaceae marque un enfrichement du secteur, postérieurement au fonctionnement du fossé.

Une des questions à laquelle on voulait tenter de répondre par l'analyse palynologique de ces fossés, était de savoir si l'on pouvait retrouver l'écho pollinique des rameaux de vigne retrouvés au fond de ces traces agraires. La réponse est : pas encore ! Avant tout, afin de vouloir retrouver l'écho pollinique d'un quelconque signal, il convient d'en définir la nature. Ici les rameaux de vignes sont encore en cours d'étude et de ce fait, le pourquoi de leur présence au fond des ces structures reste encore énigmatique. S'agissait-il de pieds cultivés au fond du fossé ? La présence d'un seul et unique grain de pollen de vitis dans les fossés [découvert dans l'échantillon \#27-28 de la séquence P. 503 (fig. 266)] peut en être le témoin. Cependant, même s'il est admis que la production pollinique de la vigne cultivée soit très faible, bien plus que celle de la vigne sauvage (Bottema, Sarpaki 2003), la présence d'un seul grain dans le fossé supposé accueillir les pieds cultivés, nous incite à être très prudents. S'agissait-il de rameaux disposés de telle manière à aménager le fond ou les berges des fossés, auquel cas, pouvait-il s'agir de restes de taille d'une culture réelle mais plus éloignée?

\subsection{Les fosses FS3190 et 3220}

(fig. 268)

Dans ce qui semblerait être un aménagement légèrement postérieur à l'installation du bassin BS3339 et des fossés orthonormés, une série de fosses datées du IVe siècle apr. J.-C./Ve siècle apr. J.-C., pouvant atteindre 


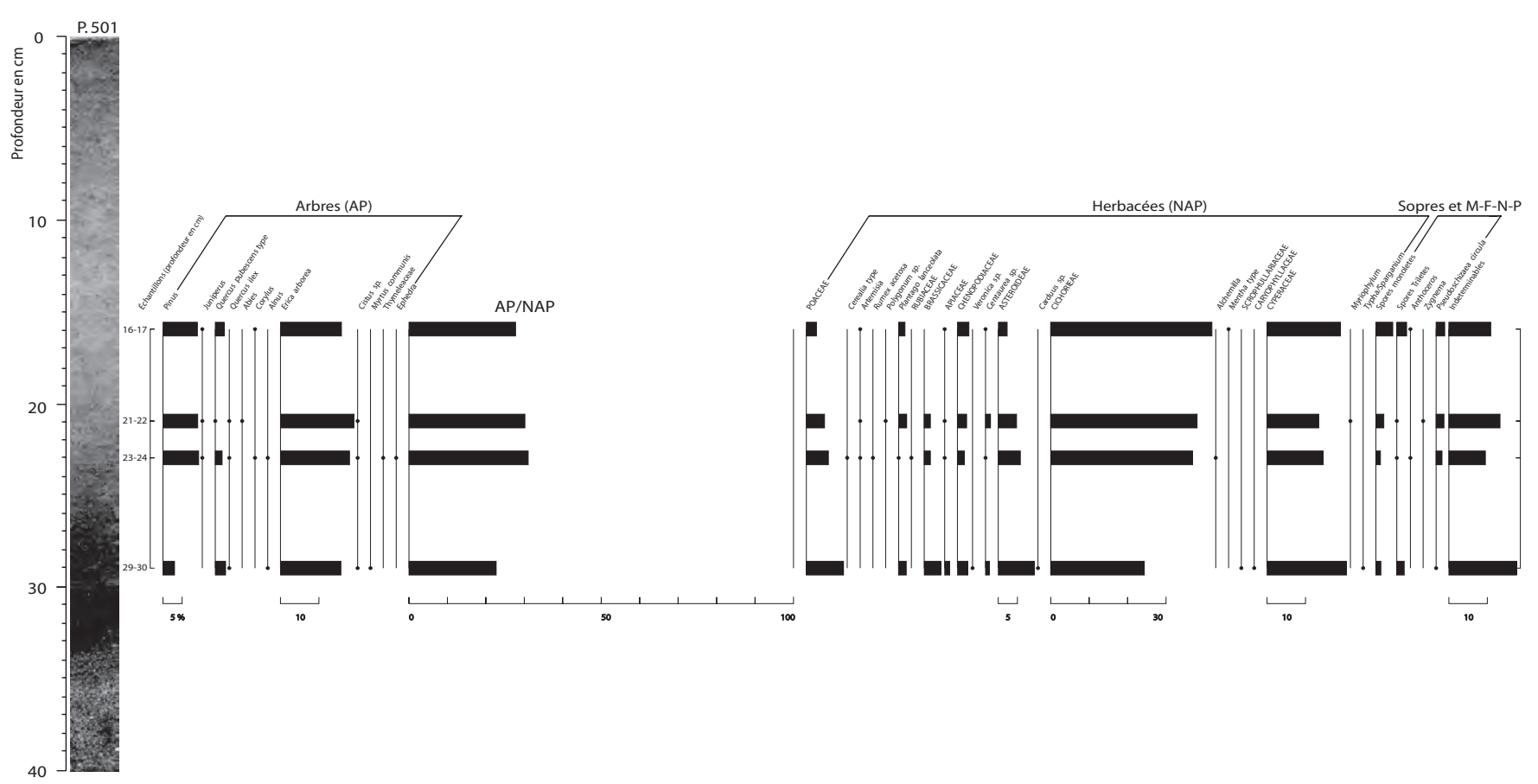

Fig. 267. Diagramme pollinique du fossé FO3256 - carottage P. 501

(fin IIe siècle apr. J.-C./III siècle apr. J.-C.).

plus d'un mètre de diamètre, viennent recouper le long fossé FO179. Malheureusement, nos données sont assez maigres et correspondent à deux échantillons prélevés dans la fosse FS3190 et à un prélèvement isolé réalisé dans la fosse FS3220. La fonction de ces structures (dépotoirs ?) n'est pas encore très claire. La palynologie montre, par les taux très faibles de la pinède et du maquis, qu'il y avait très peu d'apports régionaux et donc que les fosses fonctionnaient indépendamment du fossé FO3179 alors comblé. Les valeurs respectives des lentilles d'eau (Lemna minor) et des Brassicaceae marquent la présence temporaire d'eau dormante, ou du moins d'un haut niveau de la nappe. Les valeurs des céréales et des rudérales (rumex acetosa/oseille des prés, Artemisial armoise, Plantago lanceolataplantain lancéolé) sont le témoin d'une possible activité agro-pastorale locale.

\subsection{Le puits PT2003 et le fossé FS3017}

(fig. 266 et 267)

Les structures analysées ci-après le puits circulaire PT2003 d'environ 2 mètres de diamètre et le fossé rectiligne FO3017 d'environ 2,50 m de large, ont été datés du $\mathrm{XVI}^{\mathrm{e}}$ siècle. Ils font partie d'un ensemble constitué par un autre puits (PT2031) quasi identique au précédent et d'un autre fossé (FO3020) parallèle à
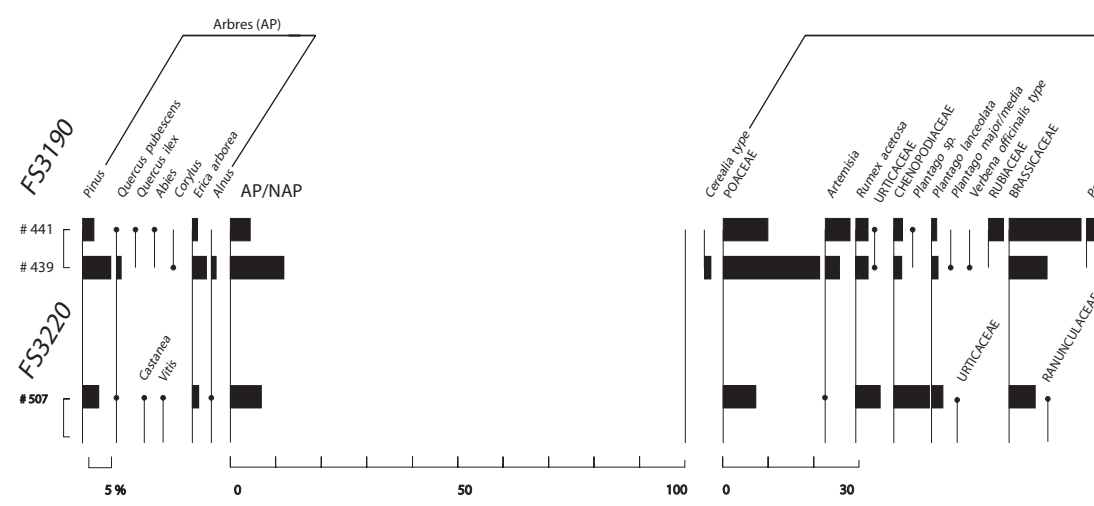

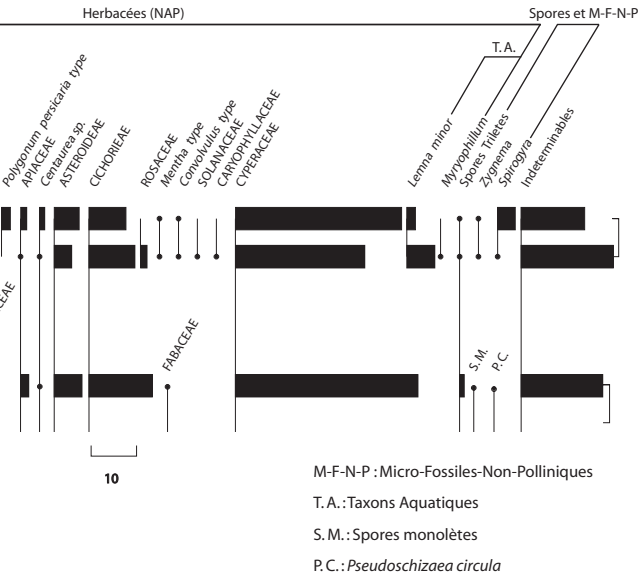

Fig. 268. Diagramme pollinique des fosses FS3190 et FS3220 (fin IVe siècle apr. J.-C./Ve siècle apr. J.-C.). 


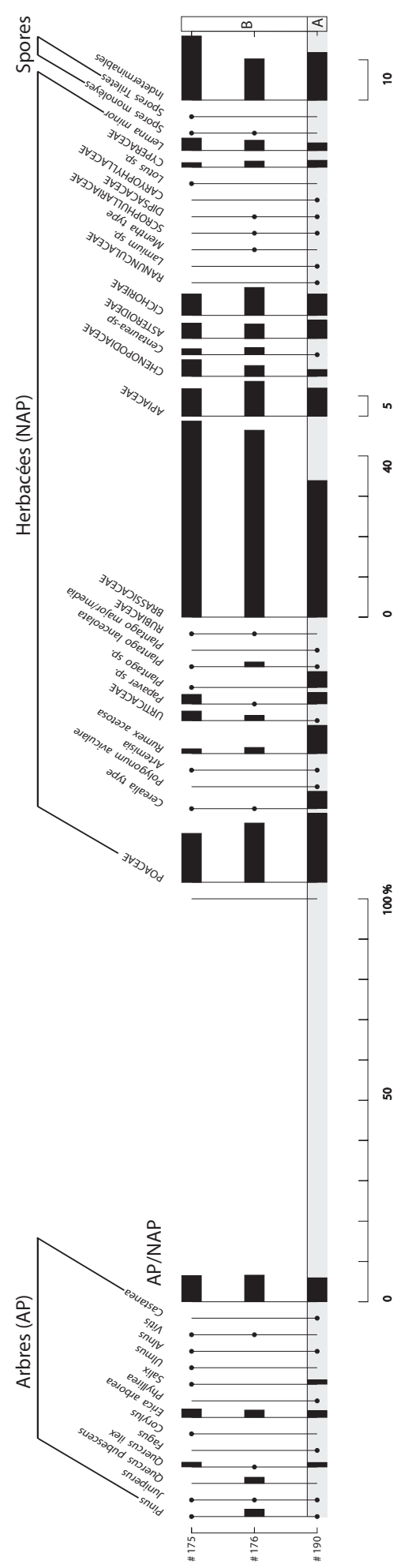

Fig. 269. Diagramme pollinique du puits PT2003 (XVle siècle).

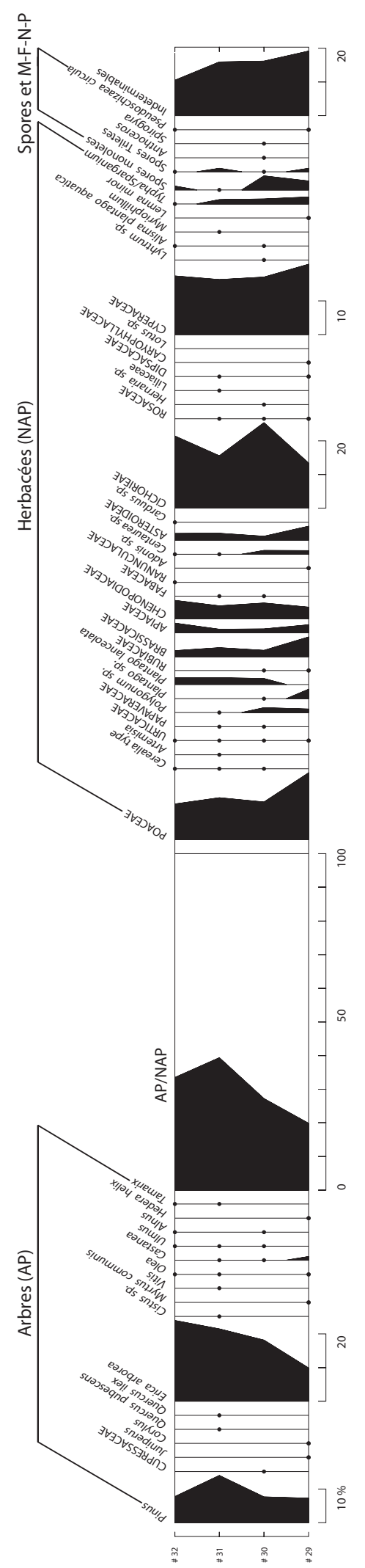

Fig. 270. Diagramme pollinique du fossé FO3017 (XVIe siècle). 
celui analysé, mais plus large de 2 mètres. Encore une fois, l'analyse pollinique nous permet ici, grâce au puits d'une part et au fossé d'autre part, de bénéficier d'une image pollinique de la végétation à la fois locale et régionale.

Le signal largement dominé par la pinède et la bruyère arborescente (Erica arborea) sur toute la séquence du fossé FO3017 (fig. 270), montre un maquis très fréquemment soumis aux différents phénomènes d'éclaircissements anthropiques ou naturels que sont l'écobuage, les incendies accidentels et/ou l'exploitation de la chênaie etc. Les valeurs du plantain lancéolé (Plantago lanceolata) des Apiacaeae des Chenopodiaceae et de Polygonum sp. peuvent laisser penser à la mise en pâture d'espaces avoisinants.

L'analyse du puits révèle, notamment avec l'échantillon \#190 (fig. 269), une nette mise en céréaliculture locale marquée avant tout par les $5 \%$ de grains de pollen de céréales mais, également, par les valeurs significatives du genre Papaver dont fait partie la messicole Papaver rhoeas (coquelicot). La dominance des Brassicaceae est encore une fois à mettre en relation avec des sols sableux gorgés d'eau.

\section{Conclusion}

La palynologie réalisée en contexte archéologique, lorsque les structures étudiées le permettent, est riche d'informations. Ici la diversité des structures, en termes de nature et de chronologie (fin du Ier siècle av. J.-C. jusqu'au cours du XVI ${ }^{\mathrm{e}}$ siècle), a permis à la discipline, au-delà d'une analyse paléoenvironnementale stricto sensu, de répondre, ou du moins d'apporter des éléments de réponse, quant à la l'utilisation faite des fosses, fossés, puits et bassins du site de Villeneuve. L'analyse nous a également permis d'identifier et de dénombrer plusieurs spores d'algues (Sirogyra, Zygnema, Rivularia...) et micros algues vertes (Botryococcus), lesquelles ont révélé la présence d'eau douce stagnante plus ou moins profonde, marquant soit la présence d'un haut niveau de la nappe (FO3179), soit le début d'un atterrissement et donc l'abandon des structures (BS1262).

Enfin l'analyse pollinique via les valeurs de grain de Cerealia type (BS1262) montre que d'autres activités humaines en dehors de celles mises en évidence par les structures archéologiques mises au jour, étaient présentes sur le site. Je pense ici à la céréaliculture. 



\section{Chapitre 5}

\section{Analyses entomologiques (coléoptères)}

(Ph. Ponel)

\section{Introduction}

L'intérêt de l'analyse paléoentomologique en contexte archéologique a été maintes fois souligné, comme le montrent la bibliographie de Buckland et Coope (1991) et le manuel d'Elias (1994). En France ce type de recherche est resté relativement confidentiel, bien qu'une certaine impulsion semble avoir été donnée récemment grâce aux efforts de quelques pionniers, voir par exemple la petite synthèse réalisée par Ponel et Yvinec (1997). L'analyse paléoentomologique d'un site archéologique peut être pratiquée isolément, mais il est particulièrement fructueux de l'associer à une analyse pollinique (Andrieu-Ponel et al. 2000) ou une analyse des macrorestes végétaux (Ponel et al. 2000). En effet, les insectes apportent des informations originales et indépendantes des autres marqueurs paléoécologiques : moins soumis que les grains de pollen au transport passif par le vent, ils fournissent des indications locales et précises d'un grand intérêt pour l'archéologue, en ce qui concerne l'environnement physique, l'environnement végétal, les activités humaines de tous ordres, etc. Pour diverses raisons les coléoptères constituent l'un des groupes d'insectes les plus étudiés en paléoentomologie : leur nombre (en espèces et en individus), la diversité de leurs mœurs, la robustesse de leur exosquelette qui facilite une longue conservation dans les sédiments, la fréquente possibilité d'identification au niveau spécifique (qui permet d'affiner les interprétations paléoécologiques) sont autant de caractéristiques particulièrement bien marquées chez les coléoptères. Cependant les analyses archéoentomologiques sont encore peu nombreuses en raison du petit nombre de spécialistes qui travaillent dans ce domaine. L'opportunité de pouvoir étudier le site de Villa Romana était donc une occasion inespérée d'obtenir des données archéoentomologiques pour une région complètement vierge dans ce domaine, puisque jusqu'à aujourd'hui l'essentiel des travaux menés concernent l'Hérault (Lattes) et les
Bouches-du-Rhône (Montmajour et Ville de Marseille) (Andrieu-Ponel et al. 2000 ; Ponel 2001 ; Ponel et al. 2005 et Ponel, Rocq 2007).

\section{Matériel et méthodes}

L'extraction des restes d'Arthropodes a été effectuée selon la méthode habituelle préconisée par Coope (1986). Elle implique tout d'abord la désagrégation du sédiment dans l'eau, au besoin après un séjour prolongé dans une solution de carbonate de sodium qui facilite la défloculation du sédiment, puis le criblage des particules en suspension sur un tamis à maille de $300 \mu \mathrm{m}$. L'abondante masse de détritus qui constitue le refus du tamis est mêlée à du pétrole ; puis, après élimination du pétrole en excés, les détritus sont placés dans un récipient rempli d'eau propre. Après décantation, les restes d'Arthropodes flottent à la surface dans le film de pétrole alors que les débris végétaux se déposent au fond du récipient. La fraction flottante est récupérée sur le même tamis de $300 \mu \mathrm{m}$, puis lavée à l'aide d'un détergent, rincée à l'alcool et triée à l'aide d'une loupe binoculaire de manière à éliminer les débris indésirables qui ont pu subsister. Les restes d'Arthropodes sont conservés dans de l'alcool à $90^{\circ}$, dans des tubes hermétiques. L'identification des fragments se fait par comparaison directe avec des spécimens provenant d'une collection de référence actuelle (tab. 16).

L'ensemble des insectes identifiés figure au tableau 17. Sur les 6 échantillons traités, seuls 4 contenaient des insectes fossiles : les échantillons \#432, 535, 609 et 610. Les échantillons \#640 et 505 étaient stériles, peut-être en raison de problèmes taphonomiques intervenus après le dépôt des assemblages d'insectes morts. Dans ce tableau, les nombres figurant à l'intersection des lignes et des colonnes représentent le nombre minimal d'individus présents dans chaque échantillon pour un taxon donné, estimation effectuée par comptage des éléments diagnostiques de l'exosquelette. L'ordre systématique et 


\begin{tabular}{|c|c|c|c|c|}
\hline $\mathrm{N}^{\circ}$ éch. & US & Vol. & Nature & Résultats \\
\hline \#640 & VP1304 & 5 litres & sommet du comblement de l'amphore & aucun fossile \\
\hline \#432 & FS3197 & 5 litres & comblement intérieur de la fosse & très riche \\
\hline \#535 & FS3199 & 5 litres & comblement intérieur de la fosse & très riche \\
\hline \#505 & FO3179 & 5 litres & comblement intérieur du fossé & aucun fossile \\
\hline \#609 & BS3339 & 5 litres & comblement localisé proche des parois du bassin & très riche \\
\hline \#610 & BS3339 & 5 litres & comblement inférieur du bassin & extrêmement riche \\
\hline
\end{tabular}

Tab. 16. Richesse en Coléoptères fossiles des échantillons traités.

la nomenclature adoptés suivent de près ceux de Lucht (1987). Cette nomenclature peut paraître quelque peu désuète, ou même inadaptée à la faune méditerranéenne, elle a été toutefois retenue à l'instigation de Coope et Elias (2000), pour permettre une harmonisation des travaux menés en Europe en paléoentomologie et pour faciliter la lecture des publications paléoentomologiques aux non-spécialistes (archéologues, géologues, etc.).

L'interprétation paléoécologique des assemblages a été effectuée essentiellement à partir des ouvrages suivants : Caillol (1908, 1913, 1914, 1954a et b), Koch (1989-1992), Thérond (1975-1976) pour les coléoptères. Des observations personnelles effectuées par l'auteur sur le terrain en Provence au cours des 30 dernières années ont également été utilisées.

\section{Résultats}

Les quatre échantillons non «stériles» sont extrêmement riches en fragments et en taxons de coléoptères, avec 94 taxons pour l'échantillon \#609, 84 pour l'échantillon \#535, 80 pour l'échantillon \#432, et pas moins de 138 taxons pour l'échantillon \#610, valeur vraiment exceptionnelle pour un volume de sédiment relativement limité. Les autres ordres d'insectes recueillis sont peu nombreux (un très petit nombre d'Hétéroptères). Les interprétations paléoécologiques seront donc réalisées principalement à partir des coléoptères.

\subsection{Habitats aquatiques}

La faune aquatique n'est pas particulièrement riche en espèces, ce qui est surprenant dans un tel contexte, et par comparaison avec d'autres sites similaires étudiés ailleurs. On note seulement six espèces de Dytiscides dont quatre dans l'échantillon \#432, tous des ubiquistes : Guignotus pusillus, Agabus bipustulatus et Colymbetes fuscus qui vivent dans tous types de collections d'eau : flaques, étangs, rivières à cours lent... Deux de ces espèces sont aussi présentes dans l'échantillon \#535. D'autres groupes de coléoptères aquatiques comme les Hydraenidae et les Hydrophilidae sont bien mieux représentés, aussi bien en nombre de taxons qu'en nombre d'individus. La plupart des espèces appartenant à ces deux familles et identifiées dans les échantillons de Fréjus vivent exclusivement dans les eaux stagnantes ou dans les parties les plus calmes des cours d'eau, c'est le cas en particulier de Helophorus spp., Helochares lividus, Coelostoma spp., Limnoxenus niger, Anacaena sp., Hydrophilus caraboides. Les Ochthebius pullulent, particulièrement dans l'échantillon \#610, avec un minimum de 146 spécimens. En raison de la complexité taxonomique de ce genre, l'identification spécifique de ces restes d'Ochthebius est malheureusement impossible et l'interprétation paléoécologique demeure incertaine. La famille des Dryopidae est particulièrement riche en individus appartenant au genre Dryops sp. Ce taxon vit au bord des cours d'eau et des mares, dans la boue qui se situe à l'interface terre ferme/eau, parfois en très grand nombre. Pas moins de 30 et 137 spécimens ont été dénombrés, respectivement dans les échantillons \#535 et 432. Il n'existe pas d'espèces réellement halophiles, quoique Hyphydrus aubei fréquente volontiers les eaux saumâtres (Guignot 1947). L'ensemble de la faune aquatique suggère donc que des milieux d'eau libre étaient présents, probablement sous la forme d'étendues d'eau peu profondes bordées par des plages de vases et de sables humides.

\subsection{Habitats de transition (milieux humides, marécages)}

Beaucoup de Carabidae appartiennent à cette catégorie, il s'agit par exemple de Tachys bistriatus, T. haemorrhoidalis, Bembidion quadrimaculatum, 
Amblystomus niger, Pterostichus nigrita/rhaeticus, Platynus ruficornis. Aucune espèce halophile ne figure parmi ces insectes, pas plus que parmi un autre groupe où dominent les taxons hygrophiles, les Staphylinides. Plus d'une dizaine d'espèces de staphylins hygrophiles est présente, avec des effectifs cependant peu considérables : Trogophloeus spp., Platysthetus spp., Stenus, Stilicus orbiculatus, Scopaeus, Lathrobium, Leptolinus nothus, Gauropterus fulgidus, Ocypus globulifer, Astrapaeus ulmi, Drusilla canaliculata, sont tous hygrophiles à divers degrés et dans beaucoup de cas vivent dans les marécages, sur les argiles nues, les sables humides au bord des eaux. Le Byrrhide Pelochares versicolor vit dans les mêmes conditions. Rhypobius ruficollis est abondant dans tous les assemblages ; il s'agit d'un tout petit Corylophidae associé aux détritus végétaux des milieux marécageux. Dans cette catégorie des insectes ripicoles figurent aussi les quelques Hétéroptères identifiés, comme les Saldidae dont Chartoscirta sp. Ces insectes bien caractérisés sont liés aux lieux humides, particulièrement au bord des cours d'eau. La présence d'un petit charançon, Tanysphyrus lemnae, est intéressante car cette espèce est associée aux Lemna ou lentilles d'eau, plantes aquatiques bien connues qui couvrent les plans d'eaux stagnantes.

\subsection{Habitats liés à la strate herbacée}

Les espèces liées aux plantes non ligneuses sont assez nombreuses et fournissent des indications intéressantes sur la composition de la strate herbacée : les deux Aspidapion sont liés aux Malvacées, A. aeneum et $A$. radiolus/soror surtout sur les Malva rudérales, A. soror exclusivement sur Althaea officinalis dans les prairies salées littorales. Baris timida vit également sur de nombreuses Malvacées. Parmi les espèces propres aux légumineuses figurent les charançons du genre Sitona, surtout abondants dans les prairies à Trifolium, Medicago, luzernes et autres Papilionacées des milieux ouverts, de même que Bruchus/Bruchidius sp. Zacladus exiguus est exclusivement lié à divers représentants du genre Geranium. Habroloma triangularis fréquente essentiellement les Erodium, un autre genre de Géraniacées (Schaefer 1949). Sphenoptera laportei est associé aux œillets, Coroebus rubi est un parasite de la ronce. Trachys scrobiculatus est associé aux menthes (un doute subsiste toutefois sur l'identification de cet insecte qui appartient à un groupe très homogène et d'identification toujours délicate). Parmi les Chrysomelidae, Chrysomela carnifex peut être observée aujourd'hui aux Vieux Salins d'Hyères où elle vit sur les armoises. Chaetocnema impressa est également très commune dans cette région, sur sols salés, sur les saladelles (Statice limonium). Chaetocnema chlorophana est associée à divers joncs poussant dans les terrains marécageux, (comme le petit bupreste Aphanisticus) alors que Chaetocnema tibialis recherche les Chénopodiacées, surtout dans les terrains salés.

Les Phyllotreta, particulièrement nombreux dans l'échantillon \#610, indiquent la présence de Crucifères. Phrydiuchus spilmani est un charançon associé aux sauges des terrains découverts secs et chauds. Calosirus terminatus vit sur diverses ombellifères des prairies humides. Stenocarus fuliginosus vit exclusivement sur diverses espèces de coquelicots, c'est donc un indicateur de sols remués et de végétation rudérale. La présence de taxons variés tels que le genre Henicopus, Lema melanopa, Cylindromorphus, Hispella atra, Chaetocnema angustula, indique très clairement que les Poacées étaient abondantes. Sphenophorus striatopunctatus (\#610) est un gros charançon qui s'observe très fréquemment au sol dans les prairies plus ou moins salées du littoral méditerranéen. Une végétation d'un type un peu différent est suggérée par le charançon Apion tubiferum, car cette espèce vit sur les cistes ; ce charançon indique donc qu'une fruticée xérophile poussait au delà des prairies littorales.

\subsection{Habitats liés aux arbres}

La faune de coléoptères liés aux arbres est très limitée. On note surtout Micrapate xyloperthoides, Bostryche lié au vieux bois mort et desséché de Tamarix, assez abondant dans l'échantillon \#609. Il s'agit d'une espèce rare qui est probablement présente encore aujourd'hui dans le secteur de l'embouchure de l'Argens, où les vieux tamaris portant des branches mortes sont nombreux. Une autre catégorie de coléoptères xylophages est formée par un petit groupe de charançons qui sont liés au bois mort décomposé accumulé au bord de la mer. C'est le cas d'Amaurorhinus sp. et surtout de Mesites pallidipennis qui abonde dans les échantillons \#609 et 610 . Ces deux espèces indiquent qu'à proximité $\mathrm{du}$ point de prélèvement une grande quantité de troncs morts et/ou de bois flottés devait être présente, puisque ces insectes sont particulièrement abondants au bord de mer dans le bois pourri accumulé sur le haut des plages. Cylindronotus dryadophilus indique aussi la présence de ligneux. Le seul autre coléoptère incontestablement associé aux arbres est Curculio sp., le balanin, dont plusieurs espèces vivent sur les chênes et l'une sur noisetier. Dans le contexte de Fréjus il est plus vraisemblable qu'il s'agisse d'un des balanins associé aux chênes et non pas Curculio nucum du noisetier. Astrapaeus ulmi est un staphylin prédateur toujours rare, associé aux prairies humides et aux ripisylves. Enfin, 
l'anthicide Notoxus trifasciatus n'est pas réellement un coléoptère associé aux arbres ; toutefois on le trouve très souvent en grand nombre sur le feuillage des arbres, arbustes et buissons (saules, aulnes, frênes...) dans les milieux de type ripisylve.

\subsection{Sols nus, dunes}

Un petit groupe d'espèces fréquente les sols nus à végétation rare, souvent sablonneux. Il s'agit en particulier du petit taupin (Elateridae) Drasterius bimaculatus, que l'on voit souvent courir sur les chemins et qui est bien reconnaissable par sa coloration bariolée de noir et de rouge. Les Anthicides Hirticomus hispidus et $H$. quadriguttatus présentent des mœurs semblables, toutes ces espèces peuvent se trouver ensemble au pied des végétaux isolés poussant sur les sols sablonneux et leur coloration est également à base de taches rouges sur fond noir brillant. La plupart des staphylins du genre Astenus se trouvent sous les pierres dans les terrains secs et ouverts. Parmi les Ténébrionides, Dendarus tristis et Gonocephalum pusillum recherchent aussi les sols sablonneux des milieux ouverts, bien que le premier puisse se trouver aussi en milieu forestier. Il en est de même pour Asida dejeani et Dichillus minutus, tous deux propres aux milieux ouverts, secs et chauds. Ditomus clypeatus est un coléoptère Carabidae phytophage, qui consomme les graines de Poacées et d'Ombellifères également dans les milieux ouverts de type méditerranéens. Une faune associée aux milieux dunaires méditerranéens bien conservés, peuplés par Ammophila arenaria ( Ammophiletum ») indique que le site étudié devait se trouver en position d'arrièredune. Particulièrement significative est la présence d'espèces « dunaires » remarquables, avec comme espèces les plus représentatives Stenosis intermedia et Catomus consentaneus, mais surtout le scarite géant Scarites buparius présent en plusieurs spécimens dans l'échantillon \#610, et le bousier Scarabaeus semipunctatus, présent dans l'échantillon \#535. Scarites buparius est un grand Carabidae atteignant 40 $\mathrm{mm}$, peuplant les côtes sableuses de la Méditerranée occidentale. "Cette espèce habite les dunes littorales à Ammophila arenaria. Enterrée dans un terrier profond durant la journée, elle en sort la nuit et le matin de bonne heure pour chercher sa nourriture composée de larves et d'adultes d'autres insectes. Ce coléoptère fait partie des grands carnassiers des milieux dunaires. Il est actif d'avril à septembre. » (...) Cette espèce constitue un des éléments caractéristiques de la dune à Ammophila arenaria »(Jaulin, Soldati 2005). La répartition du grand bousier Scarabaeus semipunctatus est comparable à celle du scarite puisqu'il se cantonne à la Méditerranée occidentale. Il est strictement lié aux dunes littorales. Comme les autres bousiers, il consomme divers excréments ; au moment de la nidification il confectionne une «poire » qui reçoit un oeuf unique. Cette espèce s'est considérablement raréfiée mais se maintient dans les dunes les moins dégradées, comme celles de la presqu'île de Giens dans le département du Var.

\subsection{Faune synanthrope, coprophage, coprophile}

Cette catégorie est souvent l'une des plus présentes dans les assemblages archéoentomologiques. Il faut signaler au premier rang des espèces classiques le charançon Sitophilus granarius, grand destructeur de céréales entreposées et presque exclusivement synanthrope. Ce n'est cependant pas le cas des échantillons de Villa Romana qui ne sont pas marqués par une faune synanthrope très riche et très diversifiée. Un seul spécimen de Sitophilus granarius a été identifié dans l'échantillon \#432. Les autres espèces constantes des habitations humaines où des denrées alimentaires sont stockées dans des conditions de conservation précaires (Lepesme 1944 et Delobel, Tran 1993) sont totalement absentes (comme Tenebroides mauritanicus, Oryzaephilus surinamensis, Laemophloeus ferrugineus, Typhaea stercorea, Mycetaea hirta, Rhizopertha dominica, Stegobium paniceum, Nicobium castaneum, Anobium punctatum, Gibbium psylloides, Alphitophagus bifasciatus, Tribolium castaneum, Tribolium confusum). Cette absence totale, ou presque (à l'exception du Sitophilus), indique qu'aucun lieu de stockage de denrées alimentaires n'était présent à proximité des points de prélèvement. Aglenus brunneus (\#535) est une espèce dont le biotope favori est l'accumulation de paille moisie à l'intérieur de bergeries, dans ce type de biotope il peut parfois pulluler; mais sa présence dans les terriers d'animaux sauvages est possible. Toutefois une espèce réellement anthropophile a été détectée dans l'échantillon \#610, il ne s'agit pas d'un coléoptère mais de la punaise des lits Cimex lectularius, autrefois bien connue de tous mais aujourd'hui beaucoup moins fréquente en raison de l'amélioration des conditions d'hygiène.

Enfin, un groupe d'espèces est composé d'insectes coprophages (se nourrissant directement d'excréments) ou coprophiles (liés indirectement aux excréments), le passage aux détritiphages liés aux matières animales ou végétales en décomposition se faisant de manière progressive. Dans nos assemblages fossiles il s'agit des Hydrophilides Cercyon, et Megasternum boletophagum, de tous les Histérides, de beaucoup de Staphylins comme les Oxytelus, les Xantholinus, le Scarabéide Pleurophorus caesus. Les autres Scarabéides Onthophagus et Aphodius sont 
des coprophages bien caractérisés, alors qu'Aphodius granarius fréquente plus volontiers les matières en décomposition. Cette communauté de coprophages est particulièrement riche dans les échantillons \#535 et 432 , avec de grandes espèces comme le Scarabaeus semipunctatus (proche du scarabée sacré), le Gymnopleure, le Sisyphus schaeferi, etc. L'abondance du petit coprophage Onthophagus furcatus dans deux des quatre échantillons analysés est remarquable. Notons que ces coprophages ne sont pas forcément des synanthropes, contrairement à la première catégorie d'espèces évoquées ci-dessus, et qu'ils peuvent parfaitement se développer dans des conditions tout à fait naturelles.

\section{Conclusion}

La richesse extraordinaire de ces assemblages de coléoptères fossiles permet de brosser un tableau assez fidèle du paléoenvironnement qui prévalait autour du site de dépôt. La structure analysée se trouvait à proximité immédiate d'une dune littorale bien conservée, mais aussi de prairies humides à végétation diversifiée, certainement à attribuer en partie à un paysage de type « sansouïre » (c'est-à-dire des sols salés nus peuplés de salicornes et de saladelles) tel qu'on le voit actuellement en Camargue, sur la presqu'île de Giens, ou à une échelle beaucoup plus réduite dans certaines zones des étangs de Villepey. Une autre partie de ces prairies devait être peuplée d'une végétation moins halophile, comme en témoigne la diversité des plantes suggérées par les insectes. Plus loin du site de dépôt, la présence d'une fruticée où les cistes étaient présents est certaine. Il n'y a que très peu de données évoquant la présence d'arbres à proximité du site, et il est très vraisemblable que les lieux aient été complètement ouverts à l'exception de quelques arbres ou arbustes évoquant une ripisylve. La présence d'eau libre stagnante est incontestable, soit à l'intérieur même de la structure, soit à proximité immédiate, dans ce dernier cas des marécages devaient être présents dans le voisinage immédiat du site. Des berges de sols boueux et nus étaient également présentes. L'abondance de charançons liés habituellement aux bois morts échoués sur la plage est à mettre soit sur le compte d'accumulations naturelles sous l'effet des vagues, soit à l'utilisation de troncs par l'homme à proximité ou à l'intérieur même de la structure étudiée. Cette structure ne servait certainement pas de lieu de stockage pour les denrées alimentaires comme en témoigne la grande rareté de la faune synanthrope, toutefois les quelques éléments présents suggèrent que de tels lieux de stockage ou d'habitation étaient disponibles à peu de distance. Enfin, l'abondance particulière des coprophages et des coprophiles indique soit une fréquentation régulière par l'homme et/ou par des troupeaux domestiques, soit par des animaux sauvages. 


\begin{tabular}{|c|c|c|c|c|}
\hline & $\# 609$ & $\# 535$ & $\# 432$ & $\# 610$ \\
\hline \multicolumn{5}{|l|}{ COLEOPTERA } \\
\hline \multicolumn{5}{|l|}{ Carabidae } \\
\hline Cicindela campestris $\mathrm{L}$. & & 2 & & \\
\hline Carabus vagans $\mathrm{Ol}$. & 1 & & & \\
\hline Scarites buparius Först. & & & & 3 \\
\hline Trechus cf. quadristriatus (Schrank) & 1 & & & 2 \\
\hline Tachys bistriatus (Duft.) & & 3 & 1 & \\
\hline Tachys parvulus (Dej.) & & & & 4 \\
\hline Tachys haemorrhoidalis (Ponza) & & 7 & & 1 \\
\hline Bembidion laterale (Sam.) & 1 & & & \\
\hline Bembidion quadrimaculatum (L.) & & & 1 & \\
\hline Bembidion obtusum Serv. & 1 & & & \\
\hline Bembidion tethys Netol. & & 1 & & 2 \\
\hline Bembidion andreae (F.) & & & & 1 \\
\hline Bembidion octomaculatus Goeze & 1 & & & 1 \\
\hline Bembidion elongatus Dejean & 1 & & & 1 \\
\hline Bembidion lunulatum (Fourcr.) & 1 & & & \\
\hline Bembidion sp. & 1 & & & \\
\hline Amblystomus niger Heer & & & 1 & \\
\hline Ditomus clypeatus Rossi & & & & 1 \\
\hline Acupalpus sp. & 1 & & & \\
\hline Poecilus cursorius (Dej.) & & & 1 & \\
\hline Pterostichus (Platysma) nigrita (Payk.)/rhaeticus Heer & & & 6 & \\
\hline Calathus fuscipes (Goeze) & & & 1 & 2 \\
\hline Calathus cf. erythroderus Gemm. Har. & 6 & & & 8 \\
\hline Agonum sp. & & & & 1 \\
\hline Platynus (Anchus) ruficornis (Goeze) & & & 1 & 2 \\
\hline Zabrus tenebrioides (Goeze) & & 1 & & \\
\hline Amara sp. & 1 & 1 & 1 & 1 \\
\hline Demetrias atricapillus $(\mathrm{L})$. & 1 & & & \\
\hline Dromius linearis $(\mathrm{Ol})$. & & & & 1 \\
\hline Microlestes sp. & 1 & & & \\
\hline G. sp. & 2 & 3 & 1 & \\
\hline \multicolumn{5}{|l|}{ Dytiscidae } \\
\hline Hyphydrus aubei Ganglb. & & & & 2 \\
\hline Guignotus pusillus (F.) & & 1 & 1 & \\
\hline Hydroporus sp. & & & 1 & 2 \\
\hline Graptodytes concinnus (Steph.) & 1 & & & \\
\hline
\end{tabular}




\begin{tabular}{|c|c|c|c|c|}
\hline Agabus bipustulatus (L.) & 1 & 1 & 1 & 3 \\
\hline Colymbetes fuscus (L.) & & & 1 & 1 \\
\hline \multicolumn{5}{|l|}{ Gyrinidae } \\
\hline Gyrinus sp. & & & & 1 \\
\hline \multicolumn{5}{|l|}{ Hydraenidae } \\
\hline Hydraena testacea Curt. & 2 & 4 & 2 & 5 \\
\hline Hydraena sp. & & & & 2 \\
\hline Ochthebius cf dilatatus Steph. & 4 & 3 & 1 & \\
\hline Ochthebius cf minimus (F.) & 10 & 2 & 2 & 18 \\
\hline Ochthebius spp. & 37 & 9 & 16 & 146 \\
\hline Limnebius sp. & 1 & & & 3 \\
\hline Hydrochus sp. & & & 1 & \\
\hline Helophorus alternans Gené & 6 & 7 & 3 & 7 \\
\hline Helophorus grandis Ill. & & 1 & 2 & 13 \\
\hline Helophorus nubilus $\mathrm{F}$. & 3 & & & 2 \\
\hline Helophorus spp. & 8 & 11 & 3 & 1 \\
\hline \multicolumn{5}{|l|}{ Hydrophilidae } \\
\hline Coelostoma hispanicum (Küst.) & 2 & & & 4 \\
\hline Coelostoma orbiculare (F.) & & & & 1 \\
\hline Cercyon sternalis Shp. & 5 & 2 & & 1 \\
\hline Cercyon sp. & & 2 & 9 & \\
\hline Megasternum boletophagum (Marsh.) & 2 & 2 & 3 & 1 \\
\hline Limnoxenus niger (Zschach) & 1 & & & \\
\hline Anacaena sp. & 2 & 2 & 1 & 5 \\
\hline Laccobius sp. & & & & 1 \\
\hline Helochares lividus (Forst.) & & 1 & 1 & \\
\hline Enochrus/Helochares sp. & & & & 4 \\
\hline Hydrophilus caraboides (L.) & 1 & & & 1 \\
\hline Berosus sp. & & & & 1 \\
\hline \multicolumn{5}{|l|}{ Histeridae } \\
\hline Kissister minimus (Aubé) & 2 & & 1 & \\
\hline Hister spp. & & 2 & 1 & 1 \\
\hline \multicolumn{5}{|l|}{ Silphidae } \\
\hline Silpha cf puncticollis Lucas & & 2 & 1 & \\
\hline Abblataria laevigata $(\mathrm{F})$. & & 3 & & 1 \\
\hline \multicolumn{5}{|l|}{ Scydmaenidae } \\
\hline G. sp. & & 1 & & \\
\hline \multicolumn{5}{|l|}{ Orthoperidae } \\
\hline Rhypobius ruficollis (Duv.) & 8 & 4 & 23 & 6 \\
\hline
\end{tabular}




\begin{tabular}{|c|c|c|c|c|}
\hline \multicolumn{5}{|l|}{ Ptiliidae } \\
\hline Ptenidium sp. & & & 1 & \\
\hline Acrotrichis sp. & 1 & 3 & 2 & 3 \\
\hline \multicolumn{5}{|l|}{ Staphylinidae } \\
\hline Micropeplus staphylinoides (Marsh.) & 4 & & & \\
\hline Metopsia cf. clypeata (Müll.) & 1 & & & \\
\hline Trogophloeus spp. & 8 & 6 & 9 & 2 \\
\hline Oxytelus sp. & & 1 & 2 & \\
\hline Platysthetus cf. cornutus (Grav.) & & & 1 & \\
\hline Platysthetus nitens (Sahlb.) & 2 & 4 & & \\
\hline Stenus spp. & 5 & & 4 & 1 \\
\hline Paederus sp. & 1 & & & 1 \\
\hline Astenus sp. & 1 & & 1 & 1 \\
\hline Stilicus orbiculatus (Payk.) & 1 & 1 & 2 & 1 \\
\hline Medon sp. & & & & 1 \\
\hline Scopaeus sp. & & 2 & 1 & \\
\hline Lathrobium multipunctatum Grav. & & & & 1 \\
\hline Lathrobium sp. & 3 & 1 & & 1 \\
\hline Leptolinus nothus (Er.) & 2 & & 1 & 1 \\
\hline Gauropterus fulgidus (F.) & & 1 & 1 & \\
\hline Xantholinus sp. & 12 & 2 & 5 & 5 \\
\hline Othius sp. & & & & 2 \\
\hline Erichsonius signaticornis (Muls. Rey) & 1 & & & \\
\hline Quedius/Philonthus spp. & 1 & 7 & 2 & 4 \\
\hline Gabrius sp. & 3 & & & \\
\hline Staphylinus sp. & & & 1 & \\
\hline Ocypus olens (Müll.) & & & & 1 \\
\hline Ocypus ophthalmicus (Scop.) & & 1 & & 1 \\
\hline Ocypus pedator (Grav.) & 1 & & & \\
\hline Ocypus globulifer (Fourcr.) & & & 1 & \\
\hline Ocypus fortunatarum Woll. & & & & 1 \\
\hline Astrapaeus ulmi (Rossi) & & 2 & & \\
\hline Tachyporus spp. & 2 & & & 2 \\
\hline Falagria sulcata (Payk.) & & 11 & 11 & \\
\hline Drusilla canaliculata $(\mathrm{F})$. & & 2 & & \\
\hline Aleocharinae indet. & 1 & 2 & 2 & 3 \\
\hline \multicolumn{5}{|l|}{ Pselaphidae } \\
\hline Bryaxis sp. & 1 & 1 & 1 & 1 \\
\hline
\end{tabular}




\begin{tabular}{|c|c|c|c|c|}
\hline \multicolumn{5}{|l|}{ Cantharidae } \\
\hline Rhagonycha fulva (Scop.) & & & & 1 \\
\hline \multicolumn{5}{|l|}{ Malachiidae } \\
\hline Malachius sp. & 1 & & & 1 \\
\hline \multicolumn{5}{|l|}{ Melyridae } \\
\hline Henicopus sp. & 1 & & & 1 \\
\hline Psilothrix cyaneus $(\mathrm{Ol})$. & 2 & & 1 & 1 \\
\hline \multicolumn{5}{|l|}{ Elateridae } \\
\hline Agriotes sp. & 1 & & & 1 \\
\hline Drasterius bimaculatus (Rossi) & & & 1 & 1 \\
\hline Melanotus tenebrosus (Er.) & & 1 & & \\
\hline Dicronychus sp. & & & & 5 \\
\hline G. sp. & 1 & 1 & 1 & 1 \\
\hline \multicolumn{5}{|l|}{ Throscidae } \\
\hline Throscus sp. & 2 & & 1 & 1 \\
\hline \multicolumn{5}{|l|}{ Buprestidae } \\
\hline Sphenoptera laportei Saund. & & & 2 & \\
\hline Coroebus rubi (L.) & & & 1 & \\
\hline Agrilus sp. & 1 & & & 1 \\
\hline Cylindromorphus sp. & & & & 1 \\
\hline Aphanisticus sp. & & & & 1 \\
\hline Habroloma triangularis (Lac.) & & & & 1 \\
\hline Trachys cf. scrobiculatus Kiesw. & & & 2 & \\
\hline \multicolumn{5}{|l|}{ Helodidae } \\
\hline G. sp. & & & & 1 \\
\hline \multicolumn{5}{|l|}{ Dryopidae } \\
\hline Dryops sp. & 12 & 30 & 137 & 30 \\
\hline \multicolumn{5}{|l|}{ Georyssidae } \\
\hline Georyssus crenulatus (Rossi) & & & & 1 \\
\hline \multicolumn{5}{|l|}{ Dermestidae } \\
\hline Dermestes sp. & 1 & & & 2 \\
\hline \multicolumn{5}{|l|}{ Byrrhidae } \\
\hline Pelochares versicolor (Waltl) & & 2 & & \\
\hline Limnichus sp. & & & & 2 \\
\hline \multicolumn{5}{|l|}{ Nitidulidae } \\
\hline Meligethes sp. & 1 & & & \\
\hline \multicolumn{5}{|l|}{ Cucujidae } \\
\hline Laemophloeus sp. & 4 & & & 3 \\
\hline
\end{tabular}




\begin{tabular}{|c|c|c|c|c|}
\hline \multicolumn{5}{|l|}{ Cryptophagidae } \\
\hline Atomaria sp. & & 1 & & 1 \\
\hline Cryptophagus sp. & & & & 1 \\
\hline \multicolumn{5}{|l|}{ Phalacridae } \\
\hline G. sp. & 7 & 1 & 3 & 8 \\
\hline \multicolumn{5}{|l|}{ Lathridiidae } \\
\hline Corticariini indet. & 1 & 1 & & 1 \\
\hline \multicolumn{5}{|l|}{ Colydiidae } \\
\hline Aglenus brunneus (Gyll.) & & 1 & & \\
\hline \multicolumn{5}{|l|}{ Endomychidae } \\
\hline Coluocera formicaria Mots. & & & & 1 \\
\hline \multicolumn{5}{|l|}{ Coccinellidae } \\
\hline Platynaspis luteorubra (Goeze) & & & & 3 \\
\hline Coccinella septempunctata $\mathrm{L}$. & & 1 & & \\
\hline Propylea quatuordecimpunctata (L.) & & & & 1 \\
\hline G. sp. & 1 & & & 2 \\
\hline \multicolumn{5}{|l|}{ Bostrychidae } \\
\hline Sinoxylon sexdentatum $(\mathrm{Ol})$. & & & & 1 \\
\hline Micrapate xyloperthoides (DuV.) & 5 & & & 3 \\
\hline \multicolumn{5}{|l|}{ Anobiidae } \\
\hline Stegobium paniceum (L.) & & & & 1 \\
\hline Anobium sp. & & & & 4 \\
\hline \multicolumn{5}{|l|}{ Ptinidae } \\
\hline Ptinus sp. & & & & 1 \\
\hline \multicolumn{5}{|l|}{ Oedemeridae } \\
\hline Oedemera sp. & & & & 1 \\
\hline \multicolumn{5}{|l|}{ Anthicidae } \\
\hline Notoxus trifasciatus Rossi & & & & 4 \\
\hline Endomia sp. & & & & 3 \\
\hline Anthicus tristis Schm. & & & & 1 \\
\hline Anthicus quadriguttatus (Rossi) & & & 1 & 1 \\
\hline Anthicus hispidus (Rossi) & 3 & 2 & & 1 \\
\hline \multicolumn{5}{|l|}{ Mordellidae } \\
\hline G. sp. & & 1 & & \\
\hline \multicolumn{5}{|l|}{ Tenebrionidae } \\
\hline Asida dejeani Solier & & & & 2 \\
\hline Dichillus minutus (Solier) & & & & 1 \\
\hline Stenosis intermedia Solier & 7 & 1 & & 3 \\
\hline
\end{tabular}




\begin{tabular}{|c|c|c|c|c|}
\hline Dendarus tristis Lap. & & 1 & & \\
\hline Gonocephalum pusillum (F.) & & 1 & & 1 \\
\hline Opatrum sabulosum (L.) & & & & 1 \\
\hline Catomus consentaneus (Küst.) & 2 & 1 & 1 & 4 \\
\hline Cylindronotus dryadophilus Muls. & 1 & & & \\
\hline \multicolumn{5}{|l|}{ Scarabaeidae } \\
\hline Geotrupes sp. & & 1 & & \\
\hline Scarabaeus semipunctatus $\mathrm{F}$. & & 1 & & \\
\hline Gymnopleurus sp. & & 1 & & \\
\hline Sisyphus schaefferi (L.) & & 2 & 4 & \\
\hline Caccobius schreberi (L.) & & 2 & 8 & \\
\hline Onthophagus taurus (Schreb.) & & 3 & 6 & 1 \\
\hline Onthophagus gr. ovatus (L.) & & 4 & 6 & 1 \\
\hline Onthophagus furcatus (F.) & 3 & 19 & 18 & 3 \\
\hline Onthophagus nuchicornis (L.) & & 1 & & \\
\hline Aphodius distinctus (Müll.) & & & & 1 \\
\hline Aphodius granarius (L.) & & 3 & 2 & \\
\hline Aphodius spp. & 1 & 4 & 5 & 2 \\
\hline Pleurophorus cf. caesus (Creutz.) & 1 & 16 & 1 & \\
\hline Anoxia sp. & & & & 1 \\
\hline Amphimallon/Rhizotrogus sp. & & & & 4 \\
\hline Mimela junii (Duft.) & $?$ & 1 & & ? \\
\hline Hoplia farinosa (L.) & 1 & & & 1 \\
\hline Tropinota hirta (Poda) & & & 1 & 1 \\
\hline Oxythyrea funesta (Poda) & 1 & & & 1 \\
\hline Cetonia/Potosia sp. & & & & 1 \\
\hline Valgus hemipterus (L.) & 1 & & & \\
\hline \multicolumn{5}{|l|}{ Chrysomelidae } \\
\hline Lema cf. melanopa (L., 1758) & 2 & & & \\
\hline Cryptocephalus spp. & 1 & 1 & & \\
\hline Chrysomela carnifex $\mathrm{F}$. & & 1 & & \\
\hline Phyllotreta spp. & 2 & & & 12 \\
\hline Haltica sp. & & 1 & 1 & \\
\hline Crepidodera impressa (F.) & 1 & & & 3 \\
\hline Chaetocnema chlorophana (Duft.) & & 6 & 7 & 1 \\
\hline Chaetocnema tibialis (Ill.) & 1 & 1 & & 1 \\
\hline Chaetocnema angustula (Rosh.) & & & & 3 \\
\hline Chaetocnema sp. & 1 & 1 & 3 & 2 \\
\hline
\end{tabular}




\begin{tabular}{|c|c|c|c|c|}
\hline Hispella atra $(\mathrm{L})$. & & & & 1 \\
\hline \multicolumn{5}{|l|}{ Bruchidae } \\
\hline Bruchus/Bruchidius sp. & 6 & 1 & 3 & 3 \\
\hline \multicolumn{5}{|l|}{ Curculionidae } \\
\hline Apion tubiferum (Gyll.) & & & & 1 \\
\hline Apion aeneum (F.) & & & 2 & \\
\hline Apion radiolus (Marsh.)/soror Rey & & & 3 & \\
\hline Apion spp. & 13 & 1 & 19 & 15 \\
\hline Otiorhynchus rugosostriatus (Goeze) & & 1 & & \\
\hline Sitona sp. & 4 & 1 & 1 & 8 \\
\hline Mesites pallidipennis (Boh.) & 27 & & & 13 \\
\hline Amaurorhinus sp. & 1 & & & \\
\hline Tanysphyrus lemnae (Payk.) & & & & 1 \\
\hline Tychius spp. & 5 & 2 & 10 & \\
\hline Curculio sp. & 1 & & & \\
\hline Hypera sp. & & 1 & 2 & 1 \\
\hline Sphenophorus striatopunctata (Goeze) & & & & 1 \\
\hline Sitophilus granarius (L.) & & & 1 & \\
\hline Baris timida (Rossi) & & & 1 & \\
\hline Baris sp. & & 1 & & \\
\hline Zacladus exiguus (Ol.) & 1 & & & 1 \\
\hline Phrydiuchus spilmani Warner & 1 & & & \\
\hline Ceutorhynchus sp. & 1 & 1 & & \\
\hline Calosirus terminatus (Hbst.) & & & & 1 \\
\hline Stenocarus fuliginosus (Marsh.) & & & & 2 \\
\hline Gymnetron cf. labile (Hbst.) & & & & 1 \\
\hline Gymnetron sp. & 2 & & & 6 \\
\hline \multicolumn{5}{|l|}{ HETEROPTERA } \\
\hline Saldula sp. & & & 1 & \\
\hline Chartoscirta sp. & & 2 & 6 & \\
\hline Cimex lectularius & & & & 1 \\
\hline Hebrus sp. & & & & 2 \\
\hline
\end{tabular}

Tab. 17. Insectes. 


\section{Troisième Partie}

\section{Bibliographie et inventaires}

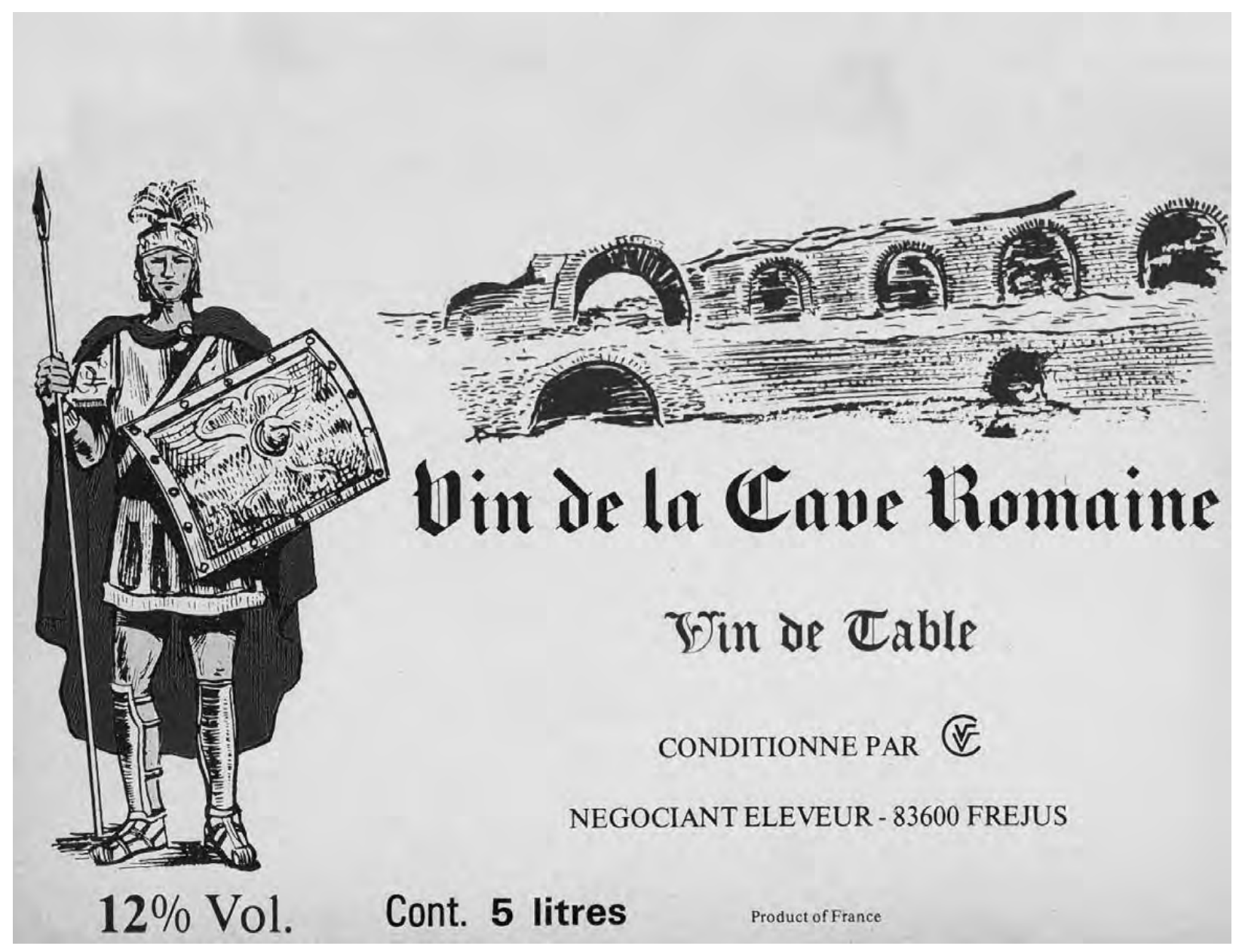

Étiquette de la cave viticole établie à la fin du XXe siècle à l'intérieur des Thermes de Villeneuve et retrouvée dans les locaux abandonnés... 



\section{Bibliographie}

\section{Sources antiques}

Caton - De l'agriculture. CUF, trad. GOUJARD (R.).

Cicéron - Correspondance. CUF, tome X, trad. BEAUJEU (J.).

Columelle - De l'Agriculture - Économie rurale. Livres I, IV et XI, trad. sous la direction de NISARD (M.) ; Livres V, VI et VII trad. DU BOIS (L.) ; Livre XII, trad. ANDRÉ (J.).

Martial - Épigrammes. Tome I, Livres I - VII et Tome II, $1^{\text {ère }}$ partie ; Livres VIII - XII, trad. IZAAC (H.-J.).

Palladius - De l'Agriculture. CUF, trad. MARTIN (R.).

Pline I'Ancien - Histoire Naturelle. CUF, Livre III, trad ZEHNACKER (H.); Livres XIV, XVI et XVII, trad. ANDRÉ (J.).

Polybe - Histoire. Collection Pléiade, trad. ROUSSEL (D.).

Suétone - Vies des douze Césars. Tiberius. CUF, trad. AILLOUD (H.).

Tacite - Annales. CUF, Livre IV, trad. WUILLEUMIER (P.).

Varron - Économie Rurale. CUF, trad. HEURGON (J.).

Vigile - Les Géorgiques. CUF, trad. De SAINT-DENIS (E.).

Vitruve - De l'architecture. CUF, Livre X, trad. CALLEBAT (L.). 



\section{Références}

De Alarcão, Étienne 1981 : DE ALARCÃO (J.), ÉTIENNE (R.) - Les Jardins à Conimbriga (Portugal). In : JASHEMSKI (W. F.), Ancient Roman Gardens, 1981, 67-80.

Allevato et al. 2009 : ALLEVATO (E.), RUSSO ERMOLLI (E.), DI PASQUALE (G.) - Woodland exploitation and Roman shipbuilding, first data from the shipwreck Napoli C (Naples, Italy). Méditerranée, 112, 2009, 33-42.

Allevato et al. 2010 : ALLEVATO (E.), RUSSO ERMOLLI (E.), BOETTO (G.), DI PASQUALE (G.) - Pollen-wood analysis of the Neapolis harbour site $\left(1^{\text {st }}-3^{\text {rd }}\right.$ century AD, Southern Italy) and its archaeobotanical implications. Journal of Archaeological Science, 37, 2010, 2365-2375.

Al-Hassan, Hill 1986 : AL-HASSAN (A. Y.), HILL (D. R.) - Islamic Technology - an illustrated guide. Cambridge University Press, 1986.

Amouric et al. 1995 : AMOURIC (H.), DEMIANS D'ARCHIMBAUD (G.), PELLETIER (J.-P.) - Terres de Durance : céramiques de l'Antiquité aux Temps Modernes. Gap, 1995, 159 p.

Amouric et al. 1999 : AMOURIC (H.), RICHEZ (F.), VALLAURI (L.) - Vingt-mille pots sous les mers, le commerce de la céramique en Provence et en Languedoc. Aix en Provence, 1999, 197 p.

Amouric 2001 : AMOURIC (H.) - Les norias en France méditerranéenne : un outil universel et conquérant. In : BRUN (J.-P.), JOCKEY (Ph.), 2001, 551-570.

Andrieu-Ponel et al. 2000 : ANDRIEU-PONEL (V.), PONEL (P.), BRUNETON (H.), LEVEAU (P.) Palaeoenvironments and cultural landscape of the last 2000 years reconstructed from pollen and Coleopteran records in the Lower Rhône Valley, Southern France. The Holocene, 10 (3), 2000, 341-355.

Autun-Augustodunum 1987 : Catalogue de l'exposition «Autun-Augustodunum, Capitale des Eduens » à l'Hôtel de Ville d'Autun en 1985. Autun, 1987, 411 p.

Badie à paraître : BADIE (A.) - L'ornementation architecturale des plus anciens monuments funéraires de Toulouse antique. In : TARDY (D.) (dir.), L'ornementation architecturale des Gaules, Journée d'étude organisée par l'IRAA à Lyon, le 26 avril 2008, à paraître.

Balachowsky 1949 : BALACHOWSKY (A.) - Coléoptères Scolytides. Librairie de la Faculté des Sciences, Paris, 1949, 320 p. (Faune de France, 50).

Barat, Morize 2003 : BARAT (Y.), MORIZE (D.) - L'archéologie des jardins antiques : le cas de la pars urbana de la villa de Richebourg (Yvelines). In : Actualité de la Recherche en Histoire et Archéologie agraires, Actes du colloque international AGER V, septembre 2000. Besançon, 2003, 117-126.

Barbier, Pichonnet 2001 : BARBIER (G.), PICHONNET (M.) - De Saule et d'Osier. Parole d'un vannier osiériculteur... Argenton-sur-Creuse, 2001, 141 p.

Barone 1986 : BARONE (R.) - Anatomie comparée des animaux domestiques, T.1, Ostéologie. Vigot, Paris, 1986.

Barouin 2003 : BAROUIN (C.) - L'hydraulique pastorale, un bienfait pour les éleveurs du Sahël ? Afrique contemporaine, Dossier spécial : l'eau, 205, 2003/1, 205-224.

Béal 1983 : BÉAL (J.-Cl.) - Les objets de tabletterie antique du musée archéologique de Nîmes. Nîmes, 1983, 120 p., 22 pl. (Cahiers des musées et monuments de Nîmes, 2).

Béal 1984 : BÉAL (J.-Cl.) - Catalogue des objets de tabletterie du musée de la Civilisation gallo-romaine de Lyon, Centre d'études romaines et gallo-romaines de l'Université Jean-Moulin - Lyon III. Paris-Lyon, 1984, 421 p., 71 pl.

Beijerinck 1976 : BEIJERINCK (W.) - Zadenatlas der Nerderlandsche Flora, Ten Behoeve van de Botanie, Palaeontologie, Boemcultuur en Warenkennis, omvattende, naasr de inheemsche flora, onze Belangrijkste cultuurgewassen en verschillende adventiefsoorten. Backhuys et Meesters, Amsterdam, 1976, 316 p., $140 \mathrm{pl}$.

Bellaiche 1969 : BELLAICHE (G.) - Étude géodynamique de la marge continentale au large du massif des Maures (Var et plaine abyssale ligure), Thèse d'État ès Sciences. Paris, 1969, 220 p.

Beltrame, Gaddi 2007 : BELTRAME (C.), GADDI (D.) - Preliminary Analysis of the Hull of the Roman Ship of Grado, Gorizia, Italy. International Journal of Nautical Archaeology, 1, 2007, 138-147.

Beltrán Fortes 2004 : BELTRÁN FORTES (J.) - Monvmenta sepulcrales en forma de alter con pulvinos de los territorios hispanorromanos : revisión de materiales y estado de la cuestión. Archivo Español de Arqueologia, 77, 2004 (nos 189-190), 101-141.

Bérato 1993 : BÉRATO (J.) - Évolution de la céramique non tournée de la fin de l'âge du Fer à la période galloromaine dans le département du Var. Documents d'Archéologie Méridionale, 16, 1993, 317-336. 
Bérato et al. 1990 : BÉRATO (J.), BORRÉANI (M.), LEGUILLOUX (M.) - La villa gallo-romaine des Laurons (quartier Saint-Pierre), Les Arcs-sur-Argens, Var. Documents d'Archéologie Méridionale, 13, 1990, 221-247.

Berggren 1972 : BERGGREN (G.) - Atlas of seeds and small fruits of Northwest-European plant species (Sweden, Norway, Denmark, East Fennoscandia and Iceland) with morphological descriptions. Part 3, Salicaceae Cruciferae. Stockolm, Swedish Museum Of Natural History Berlings, Arlöv, 1990.

Bertoncello 1999 : BERTONCELLO (F.) - Le peuplement de la basse vallée de l'Argens de la fin de l'Âge du Fer à la fin de l'Antiquité, Thèse de doctorat, Université de Provence. Aix-en-Provence, 1999, 3 vol., 721 p.

Bertoncello et al. 2003 : BERTONCELLO (F.), ALLINE (C.), BERTRAND (F.), DUBAR (M.), PROVANSAL (M.). - Occupation du sol et Patrimoine Archéologique dans la basse vallée de l'Argens. Rapport d'activité 2003. CEPAM. Nice, 2003, 27 p.

Bertoncello (coord.) 2003 : BERTONCELLO (F.) - Occupation du sol et patrimoine archéologique dans la basse vallée de l'Argens. Rapport d'activité 2003. Rapport de PCR, CNRS-MCC, 2003.

Bertoncello (coord.) 2004: BERTONCELLO (F.) - Occupation du sol et patrimoine archéologique dans la basse vallée de l'Argens. Rapport d'activité 2004. Rapport de PCR, CNRS-MCC, 2004, 80 p.

Bertoncello (coord.) 2006 : BERTONCELLO (F.) - Occupation du sol et patrimoine archéologique dans la basse vallée de l'Argens. Rapport d'activité 2006. Rapport de PCR, CNRS-MCC, 2006, 99 p.

Bertoncello (coord.) 2008 : BERTONCELLO (F.) - Occupation du sol et patrimoine archéologique dans la basse vallée de l'Argens. Rapport d'activité 2008. Rapport de fin de PCR, CNRS-MCC, 2008, 124 p.

Bertoncello, Devillers 2006 : BERTONCELLO (F.), DEVILLERS (B.) - Une vision renouvelée de la dynamique du paysage dans la basse vallée de l'Argens : synthése paléoenvironnementale préliminaire. ArchéoSciences, 30 , 2006, 223-225.

Bertsch 1941 : BERTSCH (K.) - Frütche und samen : ein bestimmungsbuch zur pflanzenkunde der vorgeschichtlichen zeit. Verlag Ferdinand, Stuttgart, 1941, 246 p.

Bertucchi 1990 : BERTUCCHI (G.) - Les amphores massaliètes à Marseille : les différentes productions. In : BATS (M.) dir., Les amphores de Marseille grecque, 1990, 15-20 (études massaliètes 2).

Bertucchi 1992 : BERTUCCHI (G.) - Les amphores et le vin de Marseille. VI ${ }^{e}$ s. av. J.-C. /II ${ }^{e}$ s. apr. J.-C. Montpellier, 1992, 250 p. (25 suppl. à la Revue Archéologique de Narbonnaise).

Biró 2003 : BIRÓ (M.-T.) - Recycling worked bone in Pannonia : data of the curation of workshop debitage and worn/damaged objects in the Roman bone manufacturing industry. In : RIDDLER (I.), Materials of Manufacture - The choice of materials in the working of bone and antler in the Northern and Central Europe during the first millennium AD. Oxford, 2003, 19-24 (BAR International Series, 1193).

Biró 2005 : BIRÓ (M.-T.) - « Native folk costume in Rome Pannonia », From hooves to horns, from mollusc to mammoth - Manufacture and use of bone artefacts from Prehistoric times to the present. Tallinn, 2005, 199-206.

Boessneck 1969 : BOESSNECK (J.) - Osteological Differences Between Sheep (ovis aries Linné) and Goats (capra hircus Linné), Science in archaeology, a survey of progress and research. Thames and Hudson, London, 1969, 331-358.

Boetto 2000 : BOETTO (G.) - New technological and historical observations on the Fiumicino 1 wreck from Portus Claudius (Fiumicino, Rome). In : LITWIN (J.) (éd.), Down the river to the sea, Proceedings of the $8^{\text {th }}$ International Symposium on Boat and Ship Archaeology, ISBSA 8 (Gdansk, 1997). Polish Maritime Museum, Gdansk, 2000, 99-102.

Boetto 2005 : BOETTO (G.) - Le navi romane di Napoli. In : GIAMPAOLA (D.) et al., La scoperta del porto di Neapolis : dalla ricostruzione topografica allo scavo e al recupero dei rellitti. Archaeologia Maritima Mediterranea, 2, 2005 (2006), 63-76.

Boetto 2006 : BOETTO (G.) - Les navires de Fiumicino (Italie) : architecture, matériaux, types et fonctions. Contribution à l'étude du système portuaire de Rome à l'époque impériale, Thèse de doctorat, Université de Provence Aix-Marseille I. Aix-en-Provence, 2006, dactylographiée, 2 vol.

Boetto 2008 : BOETTO (G.) - L'épave de l'Antiquité tardive Fiumicino 1 : analyse de la structure et étude fonctionnelle. Archaeonautica, 15, 2008, 29-62.

Boetto 2009 : BOETTO (G.) - News archaeological evidences of the horeia-type vessels : the Roman Napoli C shipwreck from Naples (Italy) and the boats of Toulon (France) compared. In : BOCKIUS (R.) (éd.), "Between the Seas" : Transfer and Exchange in Nautical Technology, Proceedings of the $11^{\text {th }}$ International Symposium on Boat and Ship Archaeology, ISBSA 11 (Mainz, 2006), RGZM. Mainz, 2009, 289-296. 
Boetto 2010 : BOETTO (G.) - Les navires de Fiumicino, influences fluviales et maritimes. In : Pomey (P.) (éd.), Transferts technologiques en architecture navale méditerranéenne de l'Antiquité aux temps modernes : identité technique et identité culturelle, Actes de la Table Ronde Internationale, (Istanbul 2007), IFEA. Istanbul, 2010, 137-150 (Varia Anatolica, XX).

Bois 1927 : BOIS (D.) - Les plantes alimentaires. Lechevalier, Paris, Vol. 1, 1927, 518 p.

Boissinot, Puig 2006 : BOISSINOT (Ph.), PUIG (C.) - Archéologie du champ et viticulture méridionale. Pourquoi les traces de vignobles sont-elles si peu fréquentes au Moyen-Âge ? Archéologie du Midi médiéval, 23-24, 20052006, 17-26.

Bonifay 2004 : BONIFAY (M.) - Étude sur la céramique romaine tardive d'Afrique. Oxford, 2004, 525 p. (BAR International Series, 1301).

Bony 2008 : BONY (G.) - Milieux de sédimentation et chrono-stratigraphie du port romain de Fréjus, Mémoire de Master 1. Aix-en-Provence, 2008, 39 p.

Bony et al. à paraître : BONY (G.), MORHANGE (Ch.), BRUNETON (H.), CARBONEL (P.), GÉBARA (Ch.) - Silting-up Fréjus ancient harbour (Forum Julii) during the past 2000 years : a tree-phase model of palaeoenvironemental change, Comptes rendus, Géoscience, à paraître.

Boon 1991 : BOON (G. C.) - Tonsor Humanus : Razor and Toilet-knife in Antiquity. Britannia, XXII, 1991, 21-32.

Bouby, Marinval 2001 : BOUBY (L.), MARINVAL (P.) - La vigne et les débuts de la viticulture en France : apports de l'archéobotanique. Gallia, 58, 13-28.

Bouby et al. 2006 : BOUBY (L.), TERRAL (J.-F.), IVORRA (S.), MARINVAL (P.), PRADAT (P.), RUAS (M.-P.) Vers une approche bioarchéologique de l'histoire de la vigne cultivée et de la viticulture : problématique, choix méthodologiques et premiers résultats. Archéologie du Midi Médiéval, 23/24, 2005/2006, 61-74.

Bouby à paraître : BOUBY (L.) - Carpologie hors site et paysage agraire en Moyenne Vallée du Rhône. In : BERGER (J.-Fr.), BROCHIER (J.-L.) (dir.), Histoire des paysages et du climat de la fin des temps glaciaires à nos jours en moyenne vallée du Rhône, d'après les données des travaux archéologiques du TGV Méditerranée, 9 p., 1 tab., 3 fig. (remis pour publication en 2003).

Boucher 1971 : BOUCHER (S.) - Vienne - Bronzes antiques. Inventaire des collections publiques françaises, 17. Paris, 1971, $230 \mathrm{p}$.

Boucher, Tassinari 1976 : BOUCHER (S.), TASSINARI (S.) - Bronzes antiques du Musée de la civilisation galloromaine à Lyon. I, Inscriptions, statuaire, vaisselle. De Boccard, Lyon, 1976, 135 p.

Boucher et al. 1980 : BOUCHER (S.), PERDU (G.), FEUGÈRE (M.) - Bronzes antiques du Musée de la Civilisation Gallo-Romaine à Lyon, II. Instrumentum, Aegyptiaca. De Boccard, Lyon, 1980, 135 p.

Bouet 2003a : BOUET (A.) - Thermae Gallicae. Les thermes de Barzan (Charente-Maritime) et les thermes des provinces gauloises. Ausonius, Bordeaux, 2003, 761 p. (11e suppl. à Aquitania).

Bouet 2003b : BOUET (A.) - Les thermes privés et publics en Gaule narbonnaise. Rome, 1993, 2 vol. (CEFR, 320).

Bouet 2005 : BOUET (A.) (éd.) - Aquam in altum exprimere. Les machines élévatrices d'eau dans l'Antiquité, Actes de la journée d'études tenue à Bordeaux le 13 mars 2003. Ausonius, Bordeaux, 2005, 169 p. (Scripta Antiqua, 12).

Boyer, Février 1971 : BOYER (R.), FÉVRIER (P.-A.) - Épave romaine à Villepey près de Fréjus (Var). In : Actes du III ${ }^{e}$ Congrès International d'Archéologie Sous-marine, (Barcelone 1961). Istituto Internazionale di studi Liguri, Bordighera, 1971, 159-166.

Braun-Blanquet et al. 1952 : BRAUN-BLANQUET (J.), ROUSSINE (N.), NÈGRE (N.) - Les Groupements Végétaux de la France Méditerranéenne. Éditions du CNRS, Paris, 1952.

Brentchaloff, Stutz 1997 : BRENTCHALOFF (D.), STUTZ (F.) - Garnitures de ceintures du Haut Moyen- Âge en fer damasquiné au quartier des Vernèdes, Puget-sur-Argens (83). Mémoires de l'Institut de Préhistoire et d'Archéologie Alpes-Méditerranée, 39, 1997, 63-70.

Broise 2009 : BROISE (H.) - Entre continuité et rupture. L'introduction des pratiques balnéaires grecques et romaines en Égypte. In : BOUSSAC (M.-Fr.), FOURNET (T.), REDON (B.) (dir.), Le bain collectif en Égypte, Actes du colloque Balnéorient à Alexandrie. IFAO, Le Caire, 2009, 9-15 (Études urbaines, 7).

Bronk Ramsey 2000 : BRONK RAMSEY (C.) - Comment on 'The Use of Bayesian Statistics for 14C dates of chronologically ordered samples : a critical analysis'. Radiocarbon, 42 (2), 2000, 199-202.

Brun 2003 : BRUN (J.-P.) - Le vin et l'huile dans la Méditerranée Antique. Viticulture, oléiculture et procédés de fabrication. Errance, Paris, 2003, 240 p. 
Brun, Congès 1996 : BRUN (J.-P.), CONGÈS (G.) - Une crise agraire en Provence au troisième siècle ? In : FICHES (J.-L.) (dir.), Le III siècle en Gaule Narbonnaise. Données régionales sur la crise de l'empire. Édition APDCA, Sophia-Antipolis, 1996, 233-256.

Brun,Jockey 2001 : BRUN(J.-P.),JOCKEY(Ph.)(éd.) - $\square \square \square \square \square \square$,Techniqueset sociétés en Méditerranée, Hommages à Marie-Claire Amouretti. MMSH, Aix-en-Provence, 2001, 853 p.

Bruzzi, Provensal 1996 : BRUZZI (C.), PROVENSAL (M.) - Impacts morphosédimentaires des tempêtes sur les côtes de Provence. Quaternaire, 7 (2-3), 1996, 129-137.

Buckland, Coope 1991 : BUCKLAND (P. C.), COOPE (G. R.) - A Bibliography and Literature Review of Quaternary Entomology. Collis, Sheffield, 1991, 85 p.

Caillol 1908 : CAILlOL (H.) - Catalogue des Coléoptères de Provence, $1^{\text {ère }}$ partie. Société linnéenne de Provence, Marseille, 1908, $521 \mathrm{p}$.

Caillol 1913 : CAILlOL (H.) - Catalogue des Coléoptères de Provence, $2^{\mathrm{e}}$ partie. Société linnéenne de Provence, Marseille, 1913, $607 \mathrm{p}$.

Caillol 1914 : CAILlOL (H.) - Catalogue des Coléoptères de Provence, $3^{\mathrm{e}}$ partie. Société linnéenne de Provence, Marseille, 1914, $594 \mathrm{p}$.

Caillol 1954a : CAILlOL (H.) - Catalogue des Coléoptères de Provence, $4^{\mathrm{e}}$ partie. Muséum National d'Histoire Naturelle, Paris, 1954, 427 p.

Caillol 1954b : CAILLOL (H.) - Catalogue des Coléoptères de Provence, $5^{\mathrm{e}}$ partie : additions et corrections. Muséum National d'Histoire Naturelle, Paris, 1954, 725 p.

Callebat 2003 : CALLEBAT (L.), FLEURY (Ph.) (coll.) - Vitruve de l'architecture, Livre X, commentaire, 56-293. Les Belles Lettres, Paris, 2003.

Carcopino 1939 : CARCOPINO (J.) - La toilette du Romain : le tonsor. In : La vie quotidienne à Rome à l'apogée de l'Empire. Paris, 1939, 187-194.

Cat. Dijon 1978 : Le cycle de la matière, l'Os, Catalogue d'exposition. Dijon, 1978.

Chabal 1997 : CHABAL(L.) - Forêts et sociétés en Languedoc (Néolithique final, Antiquité tardive). L'anthracologie, méthode et paléoécologie. MSH, Paris, 189 p. (Documents d'Archéologie Française, 63).

Chapon et al. 2007 : CHAPON (Ph.), DIGELMANN (P.), LEGUILLOUX (M.), PASQUALINI (M.), POURNOT (J.), THERNOT (R.) - La villa Gallo-romaine du Quartier Régine au Puy-Sainte-Réparade (Bouches-du-Rhône). Revue Archéologique de Narbonnaise, 40, 2007, 269-324.

Charlin, Gassend, Lequement 1978 : CHARLIN (G.), GASSEND (J.-M.), LEQUEMENT (R.) - L'épave antique de la baie de Cavalière (Le Lavandou, Var). Archaeonautica, 2, 1978, 9-93.

Cipriano, Carre 1989 : CIPRIANO (M.-T.), CARRE (M.-B.) - Production et typologie des amphores sur la côte adriatique de l'Italie. In: Amphores romaines et histoire économique. Dix ans de recherche, 1989, 67-104.

Cohen 1991 : COHEN (O.) - Impacts des aménagements sur la morphologie et l'écologie côtières de la baie de Fréjus. Université de Nice Sophia-Antipolis, Nice, 1991, 144 p.

Cohen 1997 : COHEN (O.) - La baie de Fréjus : 2000 ans d'évolution du rivage. Mappemonde, 1, 1997, 6-12.

Columeau 1991 : COLUMEAU (Ph.) - L'animal pour l'homme. Recherches sur l'alimentation carnée dans le sud de la France du Néolithique au Moyen-Âge d'après les vestiges osseux. I - Le monde rural. CNRS / Université de Provence, Aix-en-Provence, 1991.

Columeau 2002 : COLUMEAU (Ph.) - Production et consommation de la viande : approche de quelques singularités du littoral méditerranéen, de l’Âge du Fer à l'Antiquité Romaine. In : AMOURETTI (M.-Cl.), COMET (G.), Agriculture méditerranéenne. Variété des techniques anciennes. Publications de l'Université de Provence, Aixen-Provence, 2002, 109-125 (Cahier d'Histoire des Techniques, 5).

Congès, Leguilloux 1991 : CONGÈS (G.), LEGUILLOUX (M.) - Un dépotoir de l'Antiquité tardive dans le quartier de l'Esplanade à Arles. Revue Archéologique de Narbonnaise, 24, 1991, 201-234.

Coope 1986 : COOPE (G. R.) - Coleoptera analysis. In : BERLUND (B. E.) (dir.) Handbook of Holocene Palaeoecology and Palaeohydrology. Wiley \& Sons, Chichester, 1986, 703-713.

Coope, Elias 2000 : COOPE (G. R.), ELIAS (S. A.) - The environment of Upper Palaeolithic (Magdalenian and Azilian) hunters at Hauterive-Champréveyres, Neuchâtel, Switzeland, interpreted from coleopteran remains. Journal of Quaternary Sciences, 15, 2000, 157-175.

Cottam, Price 2009 : COTTAM (S.), PRICE (J.) - The early roman vessel glass. In : GOUDINEAU (Ch.), BRENTCHALOFF (D.), 2009, 185-276.

Cotto 2009 : COTTO (K.-Y.) - Fréjus, Chemin de Valescure. BSR-PACA 2008, 2009, 188-189. 
Coulon 2006 : COULON (G.) - Les Gallo-Romains. Vivre, travailler, croire, se distraire. 51 av. J.-C. / 486 apr. J.-C. Errance, Paris, 2006, 223 p.

Cullin-Mingaud 2007 : CULLIN-MINGAUD (M.) - Un atelier de fabrication de nattes à Pompéi. In : L'artisanat à Pompéi, L'Archéologue / Archéologie nouvelle, février-mars 2007, 13-14.

Cullin-Mingaud 2010a : CULLIN-MINGAUD (M.) - La vannerie dans l'Antiquité romaine. Les ateliers de vanniers et les vanneries de Pompéi, Herculanum et Oplontis. Naples, 2010, 298 p. (Collection du Centre Jean Bérard, 35).

Cullin-Mingaud 2010b : CULLIN-MINGAUD (M.) - La vannerie dans les provinces occidentales de l'Empire romain : documents épigraphiques et archéologiques. In : L'artisanat antique en milieu urbain de Gaule romaine et des régions voisines. Actes du Colloque européen, Autun, 20-22 septembre 2007. RAE, Dijon, 2010, 425-434 (28 $8^{\mathrm{e}}$ suppl. à la Revue archéologique de l'Est).

Cunliffe 1975 : CUNLIFFE (B.) - Excavations at Portchester Castle. Londres, 1975.

Cunliffe 1998 : CUNLIFFE (B.) - Fishbourne. A Roman Palace. Stroud, 1998, 160 p.

Damblon 1985 : DAMBLON (F.) - L'analyse des macrorestes végétaux et la reconstitution des environnements à l'époque du Quaternaire. Lejeunia, 117, 1985, 1-64.

Dangreaux 1997 : DANGREAUX (B.) - Presqu'île de Giens, épave de la Tour Fondue. Bilan scientifique DRASSM 1996, Ministère de la Culture et de la Communicaton. Paris, 2007, 89-90.

Darde et al. 1990 : DARDE (D.), GARMY (P.), PEY (J.) - Rue de Sauve à l'angle de l'avenue Jean-Jaurès. Fouille «AGF». In : Archéologie à Nîmes. 1950-1990. Bilan de 40 années de recherches. Nîmes, 1990, 55-62.

Degiovanni 1971 : DEGIOVANNI (C.) - Essai d'interprétation hydrodynamique de la granulométrie des sédiments sableux. Plage de Pramousquier, Var, VIII ${ }^{\text {th }}$ Int. Sediment. Congress. Heidelberg, 1971, 21 p.

Delobel, Tran 1993 : DELOBEL (A.), TRAN (M.) - Les Coléoptères des denrées alimentaires entreposées dans les régions chaudes. Orstom/CTA, Paris, 1993, 425 p. (Faune tropicale, 32).

Desbat 1998 : DESBAT (A.) - L'arrêt des importations de Dressel 1 en Gaule. SFECAG, Actes du Congrès d'Istres, 1998, 31-36.

Devillers, Bonnet 2006 : DEVILLERS (B.), BONNET (S.) - 6000 ans d'histoire environnementale de la lagune de Villepey (Fréjus, Var) : Premiers résultats de l'étude multi-proxies de la carotte Vil2. ArchéoSciences, 30, 2006, 197-203.

Devillers et al. 2007 : DEVILLERS (B.), EXCOFFON (P.), BERTONCELLO (F.), BONNET (S.), MORHANGE (C.) - Forum Julii's coastline rediscovered (Fréjus, Provence). Comptes-rendus, Géoscience, 339, 2007, 329-336.

Dietrich 1992 : DIETRICH (A.) - Les bois gorgés d'eau. In : AGORA, Les bois archéologiques, Dossier n² 2, 1992, 35-42.

Dubar, Anthony 1995 : DUBAR (M.), ANTHONY (E.J.) - Holocene environmental change and river-mouth sedimentation in the Baie des Anges, french Riviera. Quaternary research, 43, 1995, 329-343.

Dubar 2003 : DUBAR (M.) - The Holocene deltas of Eastern Provence and the French Riviera : geomorphological inheritance, genesis and vulnerability. In : Géomorphologie : relief, processus, environnement, 4, 2003, 263-270.

Dubar 2004a : DUBAR (M.) - L'édification de la plaine deltaïque du Bas Argens (Var, France) durant la Protohistoire et l'Antiquité. Application d'un modèle numérique 2D à l'archéologie. Méditerranée, 1(2), 2004, 47-54.

Dubar 2004b : DUBAR (M.) - Étude palynologique du carottage de Pont d'Argens (Roquebrune-sur-Argens, Var) : histoire holocène de la végétation en Provence cristalline ; facteurs naturel et anthropique. Ecologia Mediterranea, 30, fig. 2, 2004, 147-157.

Dubar et al. 2005 : DUBAR (M.), BUI-THI (M.), NICOL-PICHARD (S.), THINON (M.) - Étude palynologique du carottage de Pont d'Argens (Roquebrune-sur-Argens) : histoire holocène de la végétation en Provence cristalline ; facteurs naturels et anthropiques. Ecologia Mediterranea, 30(2), 2005, 147-157.

Dubar 2009 : DUBAR (M.) - L'âge de la plaine alluviale du bas Argens. Implications géoarchéologiques. In : BROCHIER (J.-E.), GUILCHER (A.), PAGNI (M.) éd. - Archéologie de Provence et d'ailleurs, Mélanges offerts à Gaëtan Congès et Gérard Sauzade, 2008, 39-43 (Bulletin Archéologique de Provence suppl. 5).

Dulière 1974 : DULIÈRE (C.) - Mosaïques des portiques de la Grande colonnade. In : Fouilles d'Apamée de Syrie, Miscellanea, fasc. 3. Bruxelles, 1974, 26-27, 37-38, pl. XXII, XXV et LXII-LXIII.

Duvauchelle 2005 : DUVAUCHELLE (A.) - Les outils en fer du Musée Romain d'Avenches. Avenches, 2005, 232 p. (Documents du Musée Romain d'Avenches, 11).

Durand 1992 : DURAND (A.) - Dynamique biogéographique des boisements forestiers en Languedoc durant le Moyen-Âge : l'impact de l'an mil. Bulletin de la Société Botanique de France, 139, Actualité Botanique (2/3/4), 1992, 627-636. 
Durand 1998 : DURAND (A.) - Les paysages médiévaux du Languedoc (Xe - XIIe siècles). Pr. Univ. du Mirail, Toulouse, 1998, $491 \mathrm{p}$.

Eckardt, Crummy 2008 : ECKARDT (H.), CRUMMY (N.) - Styling the Body in Late Iron Age and Roman Britain : a contextual approach to toilet instruments. Montagnac, 2008, 201 p. (Monographies Instrumentum, 36).

Elias 1994 : ELIAS (S. A.) - Quaternary Insects and their Environment. Smithsonian Institution Press, Washington, 1994, $284 \mathrm{p}$.

Espérandieu 1908 : ESPÉRANDIEU (E.) - Recueil général des bas-reliefs, statues et bustes de la Gaule romaine, II, Aquitaine. Paris, 1908, 478 p.

Espérandieu 1910 : ESPÉRANDIEU (E.) - Recueil général des bas-reliefs, statues et bustes de la Gaule romaine, III, Lyonnaise, 1 ère partie. Paris, 1910, $476 \mathrm{p}$.

Excoffon 2005 : EXCOFFON (P.) (dir.), DEVILLERS (B.), ARDISSON (S.), BONNET (S.), GRECK (S.), PASQUALINI (M.) - Le Théâtre d'Agglomération de Fréjus-Saint-Raphaël. Première partie, Rapport Final d'Opération, Diagnostic archéologique. Fréjus, 2005, 160 p.

Excoffon 2008 : EXCOFFON (P.) - Fréjus, Les Claus 2, BSR-PACA 2007, 2008, 195-197.

Excoffon 2010a : EXCOFFON (P.) - Le vide sanitaire et les amphores. In : PASQUALINI (M.), THERNOT (R.), GARCIA (H.), 2010, 65-69.

Excoffon 2010b : EXCOFFON (P.) - Fréjus. Avenue du XVe Corps d'Armée (les Poiriers). BSR-PACA 2009, 2010, 192-193.

Excoffon 2010c : EXCOFFON (P.), GUIONOVA (G.) (coll.), MICHEL (J.) (coll.), RODET-BELARBI (I.) (coll.) La fouille de la Villa Notre-Dame à Fréjus. Revue du Centre Archéologique du Var 2009, 2010, 123-143.

Excoffon 2010d : EXCOFFON (P.) - Fréjus, Rue Aristide Briand (Le Kipling). BSR-PACA 2009, 2010, 195-196.

Excoffon, Ardisson 2007 : EXCOFFON (P.), ARDISSON (S.) - Les thermes de Villeneuve, Rapport Final d'Opération, Diagnostic archéologique. Fréjus, 2008.

Excoffon, Berger 2008 : EXCOFFON (P.), BERGER (J.-F.) - L'Avant-Scène, Rapport Final d'Opération, Diagnostic archéologique. Fréjus, 2008.

Excoffon, Devillers 2006 : EXCOFFON (P.), DEVILLERS (B.), BONNET (S.) (coll.), BOUBY (L.) (coll.) - Le diagnostic archéologique du Théâtre d'Agglomération (Fréjus, Var) : nouvelles données géoarchéologiques sur le littoral antique. Archéosciences, 30, 2006, 205-221.

Excoffon et al. 2010 : EXCOFFON (P.), BONNET (S.), DEVILLERS (B.), BERGER (J.-F.) - Évolution du trait de côte aux abords de Fréjus, de sa fondation jusqu'au II ${ }^{\mathrm{e}}$ s. apr. J.-C., du quartier de Villeneuve à la butte Saint Antoine. In: Actes du Colloque Archéologie des rivages Méditerranéens : 50 ans de recherches. Arles les 28,29 et 30 octobre 2009. Errance, Paris, 2010, 47-53.

Faider-Feytmans 1957 : FAIDER-FEYTMANS (G.) - Recueil des bronzes de Bavai. Éditions du CNRS, Paris, 1957, 140 p. (VIII ${ }^{\mathrm{e}}$ suppl. Gallia).

Faider-Feytmans 1979 : FAIDER-FEYTMANS (G.) - Les bronzes romains de Belgique. Mayence, 1979.

Ferdière 1984 : FERDIÈRE (A.) - Le travail du textile en Région Centre de l'Âge du Fer au Haut Moyen-Âge. Revue Archéologique du Centre de la France, 23, 2 vol. Tours, 1984, 209-275.

Février 1956 : FÉVRIER (P.-A.) - Les appareils des murs romains de Fréjus (Introduction à une étude des constructions de la Provence orientale). Revue d'Études Ligures, 22e année, nos 2-4, 1956, 153-184.

Février 1959 : FÉVRIER (P.-A.) - La Basse Vallée de l'Argens. Quelques aspects de la vie économique de la Provence orientale aux XVe et XVI ${ }^{\mathrm{e}}$ siècles. Provence Historique, IX, fasc. 35, 1959, 38-61.

Février 1964 : FÉVRIER (P.-A.) - Le développement urbain en Provence de l'époque romaine à la fin du XIV $s$. Archéologie et histoire urbaine. Paris, 1964 (BEFAR 202).

Février 1977 : FÉVRIER (P.-A.) - Fréjus (Forum Julii) et la basse vallée de l'Argens. Institut International d'Études Ligures, Cuneo (2e éd), 1977 (Itinéraires Ligures, 13).

Feugère 1989 : FEUGÈRE (M.) - « Petits objets de la nécropole de Baralle ». La nécropole de Baralle (Pas-deCalais). Nord-Ouest Archéologie, 2, 1989, 190.

Feugère 2001 : FEUGÈRE (M.) - Découvertes récentes / Coq en bronze. Instrumentum, 14, déc. 2001, 39.

Fiches et al. 1995 : FICHES (J.-L.) (dir.), BERATO (J.), BRENTCHALOFF (D.), CHOUQUER (G.), DUBAR (M.), GAZENBEEK (M.), LATOUR (J.), Rogers (G.) - Habitats de l'Âge du Fer et structures agraires d'époque romaine aux Escaravatiers (Puget-sur-Argens, Var). Gallia, 52, 1995, 205-261.

Fiori, Joncheray 1975 : FIORI (P.), JONCHERAY (J.-P.) - Premiers résultats de la campagne de fouilles sur l'épave de la Tradelière. Cahiers d'Archéologie Subaquatique, IV, 1975, 59-70. 
Fitzgerald 1994 : FITZGERALD (M. A.) - The Ship. In : OLESON (J. P.), The Harbours of Caesarea Maritima : results of the Caesarea Ancient Harbour Excavation Project, 1980-1985, vol. II. Tempus Reparatum, Oxford, 1994, 163-255 (BAR International Series, 594).

Fontaine 2003 : FONTAINE (S.-D.) - Importations tardo-hellénistiques et augustéennes de verre moulé monochrome à Olbia de Provence. Revue Archéologique de Narbonnaise, 36, 2003, 249-257.

Forest, Rodet-Belarbi 1997 : FOREST (V.), RODET-BELARBI (I.) - Augmentation du format des bovins en Gaule Romaine : problèmes méthodologiques et innovations techniques. In: Techniques et économie antiques et médiévales. Le temps de l'innovation. Colloque d'Aix-en-Provence (mai 1996). Errance, Paris, 1997, 166-171.

Fournet, Redon 2010 : FOURNET (T.), REDON (B.) - Le bain grec, à l'ombre des thermes romains. Les dossiers de l'Archéologie, 342, novembre-décembre 2010, 56-63.

Foy 2005 : FOY (D.) - Une production de bols moulés à Beyrouth à la fin de l'époque hellénistique et le commerce de ces verres en Méditerranée occidentale. Journal of Glass Studies 47, 2005, 11-35.

Foy et al. 2008 : FOY (D.), COLOMBIER (A.), FONTAINE (S.), MARTY (M.-Th.), ROBIN (L.), ROUSSEL-ODE (J.) - La distribution des bols moulés monochromes hellénistiques et augustéens sur le territoire français. État de la documentation. Bulletin des XXIe Rencontres de l'Association Française pour l'Histoire du Verre (nov. 2007, Rennes), 2006, 9-23.

Frost 1978 : FROST (H.) - Lylibaeum (Marsala) - The Punic Ship : Final Excavation Report. Academia Nazionale dei Lincei, Rome, 1978 (NSc, suppl. vol. III).

Gardeisen 1993a : GARDEISEN (A.) - L'alimentation carnée à Nîmes (150 av. J.-C. et 400 apr. J.-C.). In : MONTEIL (M.), Les fouilles de la ZAC des Halles à Nîmes (Gard). Nîmes, 1993, 245-257 (Bulletin de l'École Antique de Nîmes, suppl. 1).

Gardeisen 1993b : GARDEISEN (A.) - Étude archéozoologique d'une faune de dépotoir sur le site gallo-romain de Condé (Nîmes, Gard). Revue de médecine vétérinaire, 144 (2), 1993, 123-136.

Gébara, Chouquer 1996 : GÉBARA (Ch.), CHOUQUER (G.) - Les parcellaires antiques de la région de Fréjus. In : CHOUQUER (G.) (dir.), Les formes du paysage, 1. Errance, Paris, 1996, 91-103.

Gébara, Michel 2002 : GÉBARA(Ch.), MICHEL (J.-M.), GUENDON (J.-L.) (coll.) - L'aqueduc romain de Fréjus. Sa description, son histoire et son environnement. Montpellier, 2002, 320 p. (33e suppl. à la Revue Archéologique de Narbonnaise).

Gébara, Morhange 2010 : GÉBARA (Ch.), MORHANGE (Chr.) - Fréjus (Forum Iulii) : Le port antique / the ancient harbour. Journal of Roman Archaeology, Portsmouth, 2010, 152 p. (Supplementary series, 77).

Georges 1998 : GEORGES (K.) -Étude géomorphologique de la vallée de l'Argens et de la baie de Fréjus, Mémoire de maîtrise de géographie physique. Aix-en-Provence, 1998, 87 p.

Gérard 2007 : GÉRARD (F.) - Vallange, un village retrouvé... Sur les pas des arpenteurs médiévaux. Archéologia, 440, janvier 2007, 43-55.

Gianfrotta, Pomey 1981 : GIANFROTTA(P.-A.), POMEY(P.) - Archeologia subacquea: storia, tecniche, scoperte e relitti. Arnoldo Mondadori, Milan, 1981, 376 p.

Giordano 1980 : GIORDANO (G.) - I legnami nel mondo : dizionario enciclopedico. Il Cerilo, Roma, 1980, 1184 p.

Girardin 1729 : GIRARDIN (J.-F.) - Histoire de la ville et de l'église de Fréjus, II. Paris, 1729.

Goudineau 1981 : GOUDINEAU (Chr.) - Une fouille de sauvetage aux Aiguières. Dossiers Histoire et Archéologie, 57, 1981, 52-54.

Goudineau 1982 : GOUDINEAU (Chr.) - Une fouille récente à la périphérie de Forum Iulii : le chantier des Aiguières. Comptes-rendus de l'Académie des Inscriptions et Belles-Lettres, 1982, 279-292.

Goudineau, Brentchaloff 2009 : GOUDINEAU (Chr.), BRENTCHALOFF (D.) - Le camp de la flotte d'Agrippa à Fréjus. Les fouilles du quartier de Villeneuve. Errance, Paris, 2009, 591 p.

Greig 1989 : GREIG (J.) - Archaeobotany. ESF, Strasbourg, 1989, 93 p. (Handbook for archaeologists, 4).

Greguss 1955 : GREGUSS (P.) - Identification of living gymnosperms on the basis of xylotomy. Akademiai Kiadò, Budapest, 1955, $223 \mathrm{p}$.

Greguss 1959 : GREGUSS (P.) - Holzanatomie der Europäischen Laubhölzer und Sträucher. Akademiai Kiadò, Budapest, 1959, $330 \mathrm{p}$.

Grimal 1984 : GRIMAL (P.) - Les jardins romains, 3éd. Fayard, Paris, 1984, 518 p.

Gros 2008 : GROS (P.) - La Gaule Narbonnaise. De la conquête romaine au IIIe siècle apr. J.-C. Picard, Paris, 2008, $166 \mathrm{p}$. 
Guibal 1991 : GUIBAL(F.) - Application de la dendrochronologie en milieu méditerranéen. Rencontres Xylologiques, Grenoble, 1991, 65-78.

Guibal 1992 : GUIBAL (F.) - First dendrochronological dating of a shipwreck in the western Mediterranean area. Dendrochronologia, X, 1992, 147-156.

Guibal 1995 : GUIBAL (F.) - Analyse xylologique et dendrochronologique de l'épave Dramont « E ». In : SANTAMARIA (C.), L'épave Dramont «E » à Saint-Raphaël (Ve siècle ap. J.-C.), Archaeonautica, 13, 1995, 181-189.

Guibal, Pomey 1998 : GUIBAL (F.), POMEY (P.) - Dendrochronologie et dendromorphologie. In : VOLPE (G.) (dir.), VIII Ciclo di lezioni sulla ricerca applicata in archeologia (Certosa di Pontignano, Siena 1996). Edizioni all'insegna del Giglio, Firenze, 1998, 425-446.

Guibal, Pomey 1999 : GUIBAL (F.), POMEY (P.) - Essences et qualité des billes employées dans la construction navale antique : étude anatomique et dendrochronologique. In : CORVOL (A.) (dir.), Forêt et marine. Paris, 1999, 15-32.

Guibal et Pomey 2003 : GUIBAL (F.), POMEY (P.) - Timber Supply and Ancient Naval Architecture. In : BELTRAME (C.) (éd.) - Boats, Ships and Shipyards, Proceedings of the $9^{\text {th }}$ International Symposium on Boat and Ship Archaeology, ISBSA 9 (Venice 2000). Oxbow Books, Oxford, 2003, 35-41.

Guibal et Pomey 2004 : GUIBAL (F.), POMEY (P.) - Dendrochronologie et construction navale antique. Revue d'Archéométrie, 28, 2004, 35-42.

Haberey 1932 : HABEREY (W.) - Ein römisches Barbierbesteck aus Köln. Germania, 16, 1932, 129-133.

Halbout et al. 1987 : HALBOUT (P.), PILET (C.), VAUDOUR (C.) - Corpus des objets domestiques et des armes en fer en Normandie. Caen, 1987, 255 p. (Cahier des annales de Normandie, 20).

Hallier et al. 1990 : HALLIER (G.), GUÉRY (R.), LAVAGNE (H.), GASCOU (J.) - Le mausolée de Cucuron (Vaucluse). Gallia, XLVII, 1990, 169-170.

Heinisch 1955 : HEINISCH (O.) - Samenatlas : der wichtigsten Futterpflanzen und ihrer Unkräuter. Deutschakademie der Landwirtschaftswissenschaften, Berlin, 1955, 122 p.

Hesnard 2004 : HESNARD (A.) - Vitruve, De Architectura, V, 12 et le port romain de Marseille. In : GALLINAZEVI (A.), TURCHETTI (R.) (dir.), Le strutture dei porti e degli approdi antichi, II Seminario ANSER. Rubbettino editore, Soveria Manelli, 2004, 175-204.

Hillson 1986 : HILLSON (S.) - Teeth. Cambridge, University Press, 1986.

Jacobi 1974 : JACOBI (G.) - Werkzeug und Gerät aus dem oppidum von Manching. Wiesbaden, 1974 (Die Ausgr. in Manching, 5).

Jacquat, Martinoli 1999 : JACQUAT (C.), MARTINOLI (D.) - Vitis vinifera L. : wild or cultivated ? Study oft he grape pips found at Petra, Jordan ; 150 BC-AD 40. Vegetation History and Archaeobotany, 8, 1999, 25-30.

Jacquiot 1955 : JACQUIOT (C.) - Atlas d'anatomie des bois de conifères, 2 tomes. Centre technique du bois, Paris, 1955,134 p., 64 pl.

Jacquiot et al. 1973 : JACQUIOT (C.), TRENARD (Y.), DIROL (D.) - Atlas d'anatomie des bois d'angiospermes (Essences feuillues), 2 tomes. Centre technique du bois, Paris, 1973, 176 p., 72 pl.

Jashemski 1979 : JASHEMSKI (W. F.) - The gardens of Pompeii, 1. Caratzas, New Rochelle / New York, 1979.

Jashemski 1981 : JASHEMSKI (W. F.) - The Campanian Peristyle Garden. In : JASHEMSKI (W. F.) (dir.), Ancient Roman Gardens, 1981, 29-48.

Jashemski, Ricotti 1992 : JASHEMSKI (W. F.), RICOTTI (E. S. P.) - Preliminary excavations in the Gardens of Hadrian's Villa: The Canopus Area and the Piazza d'Oro. American Journal of Archaeology, 96 (4), 1992, 579-597.

Joncheray, Joncheray 1997 : JONCHERAY (A.), JONCHERAY (J.-P.) - L'épave Barthélémy B. Bilan Scientifique DRASSM 1996, Ministère de la Culture et la Communication. Paris, 1997, 105-106.

Jourdan 1977 : JOURDAN (L.) - La faune de la Bourse (du II e au Ve s.) Marseille. Aspects de la faune de Rougiers (Moyen-Âge). In : L'élevage en Méditerranée occidentale, Actes du Colloque international de l'Institut de Recherches Méditerranéennes, Sénanque, mai 1976. CNRS, Paris, 1977, 95-112.

Jullian 1886 : JULLIAN (C.) - Fréjus Romain. Paris, 1886.

King, Cuchlaine 1972 : KING (C.), CUCHLAINE (A. M.) - Beaches and coasts. Arnold, London, 1972, 570 p.

Klynne, Liljenstolpe 2001 : KLYNNE (A.), LILJENSTOLPE (P.) - I giardini. In : MESSINEO (G.) (dir.), Ad Gallinas Albas. Villa di Livia. L'Erma di Bretschneider, Rome, 2001, 201-207 (Bullettino della commissione archeologica comunale di Roma, suppl. 8). 
Koch 1989/1992 : KOCH (K. C.) - Die Käfer Mitteleuropas, Ökologie 1, 2 et 3. Goecke \& Evers, Krefeld, 382-440, $1992,389 \mathrm{p}$.

Labaune-Jean 2009 : LABAUNE-JEAN (F.) - Objets en bronze à décor zoomorphe découverts dans le bassin de Rennes (Ille-et-Vilaine, France). Instrumentum, 29, juin 2009, 31.

Lagrand 1968 : LAGRAND (C.) - Recherches sur le Bronze final en Provence méridionale, Thèse de doctorat d'Université. Faculté des Sciences Humaines d'Aix-en-Provence, 1968, 275 p., pl.87.

Lambert 1998 : LAMBERT (G.-N.) - La Dendrochronologie, mémoire de l'arbre. In : EVIN (J.), FERDIERES (A.), LAMBERT (G.-N.), LANGOUËT (L.), LANOS (P.), OBERLIN (C.), Les méthodes de datation en laboratoire. Errance, Paris, 1998, 13-69 (Archéologiques).

Lambert et al. 1988 : LAMBERT (G.-N.), LAVIER (C.), PERRIER (P.), VINCENOT (S.) - Pratique de la dendrochronologie. In : Histoire et Mesure, Le Climat, III/3. Éditions du CNRS, Paris, 1988, 279-308.

Lambert, Lavier 2002 : LAMBERT (G.-N.), LAVIER (C.) - La dendrochronologie, une discipline alliant temps, hommes, territoires et climat. In : MISKOVSKY (J.-C.) (dir.), Géologie de la Préhistoire. Presses Universitaires de Perpignan, Paris, 2002, 1085-1099.

Langouët, Giot 1992 : LANGOUËT (L.), GIOT (P.-R.) - La datation du passé, la mesure du temps en archéologie. GMPCA, Rennes, 1984 (1 $1^{\text {è }}$ éd.), 1992 (2éd.), 244 p. (Suppl. à la Revue d'Archéométrie)

Leclerc 2004 : LECLERC (A.-S.) - La vannerie dans l'Antiquité, Catalogue d'exposition, du 14 mars au 14 novembre 2004. Musée de Préhistoire d'Île-de-France, Nemours, 2004, 59 p.

Lemoine 2008 : LEMOINE (Y.) - Découverte de forces en bronze en contexte thermal à Fréjus (Var). Instrumentum, 27, juin 2008, 13-14.

Le Glay 1981 : LE GLAY (M.) - Les Jardins à Vienne. In : JASHEMSKI (W. F.), Ancient Roman Gardens, 1981, 51-65.

Leguilloux 1989 : LEGUILLOUX (M.) - La faune des villae gallo-romaines dans le Var : aspects économiques et sociaux. Revue Archéologique de Narbonnaise, 22,1989, 311-322.

Leguilloux 1995 : LEGUILLOUX (M.) - Alimentation et élevage à Marseille au Ve s. apr. J.-C. d'après les études de faunes. Méditerranée, 3-4, 1995, 85-92.

Leguilloux 1996-1997 : LEGUILLOUX (M.) - Annexe 3 : L'alimentation carnée et l'élevage. In : BORRÉANI (M.), BRUN (J.-P.), La villa romaine des Mesclans à La Crau et son moulin hydraulique. Travaux du Centre Archéologique du Var, Toulon, 1996-1997, 244-247.

Leguilloux 1998 : LEGUILLOUX (M.) - La faune tardive du port de Marseille (Ve-VII ${ }^{\mathrm{e}}$ s. apr. J.-C.) d'après les fouilles de la Bourse (1980-1981). Revue Archéologique de Narbonnaise, 1998, 233-253.

Leguilloux 2001 : LEGUILLOUX (M.) - Les animaux et l'alimentation du XIV s. à l'Époque Moderne. In : BOUIRON (M.), Marseille, du Lacydon au faubourg Sainte-Catherine (Ve s. av. J.-C. - XVIII ${ }^{e}$ s.), Les fouilles de la place du Général-de-Gaulle. MSH, Paris, 2001, 277-286 (Documents d'Archéologie Française, 87).

Leguilloux 2006 : LEGUILLOUX (M.) - La faune. In: BATS (M.) (dir.), Olbia de Provence. (Hyères, Var) à l'époque romaine (Irr s. av. J.-C. - VII e s. apr. J.-C.). Aix-en-Provence, 2006, 93-95 et 419-430 (Études Massaliètes, 9).

Lepesme 1944 : LEPESME (P.) - Les Coléoptères des denrées alimentaires et des produits industriels entreposés. Lechevalier, Paris, 1944, 335 p., 12 pl. (Encyclopédie Entomologique, 22).

Lerat 1962 : LERAT (L.) - Informations archéologiques - Circonscription de Besançon. Gallia, XX, 1962, fasc. 2.

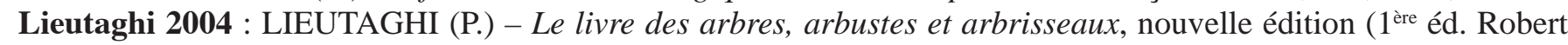
Morel, 1969). Actes Sud, Arles, 2004, 1322 p.

Lieutaghi 2006 : LIEUTAGHI (P.) - Petite ethnobotanique méditerranéenne. Actes Sud, Arles, 2006, 335 p.

Lindenschmidt Sohn 1889 : LINDENSCHMIDT SOHN (L.) - Das Römischgermanische Centra-Museum in bildichen Darstellungen aus seinen Sammlungen. Mayence, 1889.

Lintz 2001 : LINTZ (G.) - La nécropole gallo-romaine des Sagnes à Pontarion (Creuse). Chauvigny, 2001, 370 p.

Lucht 1987 : LUCHT (W. H.) - Die Käfer Mitteleuropas, Katalog. Goecke \& Evers, Krefeld, 1987, 342 p.

Lundström-Baudais 1977 : LUNDSTRÖM-BAUDAIS (K.) - Études des macro-fossiles des sites littoraux d'Auvernier - «Brise-Lames » (CH), Clairvaux (Jura) et Charavines (Isère), Mémoire de maîtrise, Université de Franche-Comté, Faculté des Lettres. Besançon, 1997.

Lundström-Baudais 1986 : LUNDSTRÖM-BAUDAIS (K.) - Étude paléoethnobotanique de la station III de Clairvaux. In : PETREQUIN (P.) (dir.), Les sites littoraux néolithiques de Clairvaux-les-Lacs (Jura). I, Problématique générale, l'exemple de la station III. MSH, Paris, 1986, 311-391. 
Manchia 1998 : MANCHIA(B.) - Les instruments chirurgicaux dans les livres VII et VIII du De Medecina de Celse, Mémoire de maîtrise. Université de Provence. Aix-en-Provence, 1998, 78 p.

Manning 1985 : MANNING (W. H.) - Catalogue of the Romano-British Iron Tools, Fittings and Weapons in the British Museum. Londres, 1985.

Marinval et al. 2002 : MARINVAL (Ph.), MARECHAL (D.), LABADIE (D.) - Arbres fruitiers et cultures jardinées gallo-romaines à Longueil-Sainte-Marie (Oise). Gallia, 59, 2002, 253-271.

Marlier 2008 : MARLIER (S.) - Architecture et espace de navigation des navires à dolia. Archaeonautica, 15, 2008, 153-173.

Matterne, Derreumaux 2007 : MATTERNE (V.), DERREUMAUX (M.) -A Franco-Italian investigation of funerary rituals in the Roman world, «Les rites et la mort à Pompéi », the plant part : a preliminary report. Vegetation History and Archaeobotany, 2007.

Melmoth 2007: MELMOTH (F.) - La villa gallo-romaine de Jonzac (Charente-Maritime). L'Archéologue / Archéologie nouvelle, $\mathrm{n}^{\circ}$ 92, 2007, 38-41.

Michel 1999 : MICHEL (J.-M.) - Thermes de Villeneuve. Fréjus (Var), DFS de diagnostic archéologique (30/11/199808/01/1999). AFAN Méditerranée, 1999.

Mingaud 1992 : MINGAUD (M.) - Artisans et centre de production de vannerie dans l'Occident romain. Mélanges de la Casa de Velázquez, 28, 1, 1992, 37-64.

Mille 2000 : MILLE (P.) - Bois gorgés d'eau et artisanat. Les puits du sanctuaire gallo-romain du Clos du Détour (Loiret). In : Actualité de la recherche sur le mobilier romain non céramique. Actes du colloque, Chauvigny, 23-24 octobre 1998, 2000, 215-235.

Montégut 1984 : MONTÉGUT (J.) - Clé de détermination des semences de mauvaises herbes ? Laboratoire de Botanique École Nationale Supérieure d'Horticulture de Versailles, 1984, 101 p.

Monthel et al. 2000 : MONTHEL (G.), BLANC (N.) et GURY (F.) - Les vanneries gallo-romaines du Petit-Creusot à Châlon-sur-Saône (Saône-et-Loire). Gallia, 57, 2000, 159-180.

Monteil 1993 : MONTEIL (M.) (dir.) - Les fouilles de la ZAC des Halles à Nîmes (Gard). Gap, 1993, 326 p. (Bulletin de l'École Antique de Nîmes, suppl. 1.)

Morhange 1994 : MORHANGE (C.) - La mobilité récente des littoraux provençaux : éléments d'analyse géomorphologique, Thèse d'État. Aix-en-Provence, 1994, 269 p.

Morhange 2001: MORHANGE (C.) - La mobilité littorale de quelques sites portuaires antiques de Méditerranée. Marseille, Pouzzoles, Cumes, Kition et Sidon, HDR. Aix en Provence, CEREGE, 2001, 96-101.

Morvillez et al. 2005 : MORVILLEZ (E.), CHEVALIER (P.), MARDEŠIĆ (J.), PENĐER (B.), TOPIĆ (M.), ČAUŠEVIĆ (M.) - La noria découverte à proximité de « l'oratoire A », dans le quartier épiscopal de Salone, Mission archéologique franco-croate de Salone. In : BOUET (A.), 2005, 153-169.

Mouraret 2003 : MOURARET (J.) - Un jardin d'agrément d'époque augustéenne à Caumont-sur-Durance (Vaucluse). In : Actualité de la Recherche en Histoire et Archéologie agraires, Actes du colloque international AGER V, septembre 2000. Besançon, 2003, 127-134.

Nin 1996 : NIN (N.) - Palais Monclar. La maison d'arrêt, Document Final de Synthèse. Aix-en-Provence, 1996.

Oggiano-Bitar 1984 : OGGIANO-BITAR (H.) - Bronzes figurés antiques des Bouches-du-Rhône. Éditions du CNRS,. Paris, 1984 (Suppl. à Gallia, XLIII).

Ollagnier, Joly 1994 : OLLAGNIER (A.), JOLY (D.) - Carte archéologique de la Gaule, L'Eure-et-Loir (28). MSH, Paris, 1994, $369 \mathrm{p}$.

Pasqualini 1998 : PASQUALINI (M.) - Les céramiques communes en Basse Provence (I ${ }^{\mathrm{er}}-\mathrm{III}^{\mathrm{e}} \mathrm{s}$.). Essai de classification. In : Les fouilles à Marseille, les mobiliers (I ${ }^{e r}-V I I^{e}$ s. apr. J.-C.). Paris, 1998, 293-309 (Études massaliètes, 5).

Pasqualini et al. 2006 : PASQUALINI (M.), MICHEL (J.-M.), BOTTE (E.), EXCOFFON (P.) - Îlot Mangin et Place Clémenceau à Fréjus (Var), Rapport final d'opération. Fréjus, 2006.

Pasqualini, Thernot, Garcia 2010 : PASQUALINI (M.), THERNOT (R.), GARCIA (H.) - L'amphithéâtre de Fréjus. Archéologie et architecture, relecture d'un monument. Ausonius, Bordeaux, 2010, 226 p. (Mémoires, 22).

Pasquinucci 1987 : PASQUINUCCI (M.) - Terme romane e vita quotidiana. Modène, 1987, 135 p.

Penso 1984 : PENSO (G.) - La médecine romaine. L'art d'Esculape dans la Rome antique. Rome, 1984, 607 p.

Perrin 1990 : PERRIN (F.) - Un dépôt d'objets gaulois à Larina. Lyon, 1990, 175 p. (Documents d'Archéologie en Rhône-Alpes, 4).

Pichon 2002 : PICHON (B.) - L’Aisne - 02, Carte Archéologique de la Gaule. MSH, Paris, 2002, 598 p. 
Piperno 2006: PIPERNO (D. R.) - Phytoliths - A comprehensive guide for archaeologists and paleoecologists. Altamira press, Lanham, 2006, 214 p.

Poccardi 2006 : POCCARDI (G.) - Les édifices balnéaires de la ville d'Ostie à l'époque impériale (milieu du $I^{e r} s$. - début du VIe s.) : études typologiques, techniques et urbaines, Thèse de doctorat en archéologie romaine. Université de Paris I - Panthéon Sorbonne. Paris, 2006, 2 vol.

Pollino 1986 : POLLINO (A.) - L'épave de la Tradelière. In : IVes Rencontres Internationales d'Archéologie et d'Histoire d'Antibes (24-29 oct 1985). APDCA, Valbonne, 1986, 171-189.

Pomey 1978 : POMEY (P.) - La coque. In : TCHERNIA (A.), POMEY (P.), HESNARD (A.), L'épave romaine de la Mandrague de Giens (Var). Éditions du CNRS, Paris, 1978, 75-107 (suppl. Gallia, 34).

Pomey 1982 : POMEY (P.) - Le navire romain de la Mandrague de Giens. CRAI, 1982, 133-154.

Pomey 1998 : POMEY (P.) - Les épaves grecques du VI ${ }^{\mathrm{e}}$ siècle av. J.-C. de la Place Jules-Verne à Marseille. In : POMEY (P.), RIETH (E.) (dir.), Construction navale maritime et fluviale. Approches archéologique, historique et ethnologique, Proceedings of the 7th International Symposium on Boat and Ship Archaeology, ISBSA 7, (Île Tatihou 1994). Éditions du CNRS, Paris, 1998, 147-154 (Archaeonautica, 14).

Pomey 1999 : POMEY (P.) - Les épaves romaines de la place Jules Verne à Marseille : des bateaux dragues ? In : TZALAS (H.) (éd.), Tropis V, (Nauplia 1993), Hellenic Institute for the Preservation of Nautical Tradition. Athens, 1999, 321-328.

Pomey 2006 : POMEY (P.) - New light on the false clinkers in ancient Mediterranean shipbuilding. In : BLUE (L.), HOCKER (F.), ENGLERT (A.) (éd.), Connected by the Sea, Proceedings of the $10^{\text {th }}$ International Symposium on Boat and Ship Archaeology, ISBSA 10 (Roskilde 2003). Oxbow Books, Oxford, 2006, 74-77.

Pomey, Rieth 2005 : POMEY (P.), RIETH (E.) - L'archéologie navale. Errance, Paris, 2005, 215 p. (Archéologiques).

Pomey, Tchernia 1978 : POMEY (P.), TCHERNIA (A.) - Le tonnage maximum des navires de commerce romains. Archaeonautica, 2, 1978, 233-251.

Ponel, Yvinec 1997 : PONEL (P.), YVINEC (J.-H.) - L'archéoentomologie en France. Les Nouvelles de l'Archéologie, 68, 1997, 31-37.

Ponel et al. 2000 : PONEL (P.), MATTERNE (V.), COULTHARD (N.), YVINEC (J.-H.) - La Tène and Gallo-Roman natural environments and human impact at the Touffréville rural settlement, reconstructed from Coleoptera and plant macroremains (Calvados, France). Journal of Archaeological Science, 27, 2000, 1055-1072.

Ponel 2001 : PONEL (P.) - Les données archéoentomologiques. In : BOUIRON (M.), Marseille, du Lacydon au faubourg Sainte-Catherine ( $V^{e}$ s. av. J.-C. / XVIII ${ }^{e}$ s.). MSH, Paris, 2001, 371-381 (Documents d'Archéologie Française, 87).

Posamentier et al. 1992 : POSAMENTIER (H.), ALLEN (G. P.), JAMES (D. P.) - High resolution sequence stratigraphy, the East Coulee delta. Alberta. Journal of Sedimentary Petrology, 62, 1992, 310-317.

Py 1993 : PY (M.) - Dicocer, Dictionnaire analytique des formes céramiques antiques $\left(d u V^{2}{ }^{e}\right.$ s. av. notre ère au VII ${ }^{e}$ s. apr. notre ère), 1993, 624 p. (Lattara 6).

Quézel, Médail 2003 : QUÉZEL (P.), MÉDAIL (F.) - Écologie et biogéographie des forêts du bassin méditerranéen. Éditions scientifiques et médicales Elsevier, Paris, 2003, 571 p. (Collection Environnement).

Rameau et al. 1989 : RAMEAU (J.-C.), MANSION (D.), DUME (G.) - Flore forestière française, Guide écologique illustré, t.1 : Plaines et collines. Institut pour le Développement Forestier, Paris, 1989, 1786 p.

Rapport du port autonome de Marseille 1993 : Recherche des sites d'immersion de produits de dragages dans le golfe de Fos, 1993, 90 p.

Reimer et al. 2004 : REIMER (P. J.), BAILLIE (M. G. L.), BARD (E.), BAYLISS (A.), BECK (J.W.), BERTRAND (C. J. H.), BLACKWELL (P. G.), BUCK (C. E.), BURR (G. S.), CUTLER (K. B.), DAMON (P. E.), EDWARDS (R. L.), FAIRBANKS (R. G.), FRIEDRICH (M.), GUILDERSON (T. P.), HOGG (A. G.), HUGHEN (K. A.), KROMER (B.), MCCORMAC (G.), MANNING (S.), RAMSEY (C. B.), REIMER (R. W.), REMMELE (S.), SOUTHON (J. R.), STUIVER (M.), TALAMO(S.), TAYLOR (F. W.), VAN DER PLICHT(J.), WEYHENMEYER (C. E.) - IntCal04 Terrestrial Radiocarbon Age Calibration, 0-26 cal kyr BP. Radiocarbon, 46 (3), 2004, 1029-1059.

Reineck, Singh 1980 : REINECK (H.-E), SINGH (I. B.) - Depositional sedimentary environments, with reference to terrigeneous clastics. Springer-Verlag, Berlin, 1980, $551 \mathrm{p}$.

Rival 1991 : RIVAL (M.) - La charpenterie navale romaine. Matériaux, méthodes, moyens. Éditions du CNRS, Paris, 1991, 333 p. (Travaux du Centre Camille Jullian, 4). 
Rivet 1994 : RIVET (L.) - Fonction et faciès : étude comparée de quelques lots de céramique provenant de Fréjus (Var), Mandelieu (Alpes-Maritimes), Aix-en-Provence et Saint-Julien-les-Martigues (Bouches du Rhône). In : Les céramiques communes de Campanie et de Narbonnaise, ( ${ }^{e r}$ s. av. J.-C. - II ${ }^{e}$ s. apr. J.-C.), La vaisselle de cuisine et de table. Centre Jean Bérard, Naples, 1994, 327-350.

Rivet et al. 2000 : RIVET (L.), BRENTCHALOFF (D.), ROUCOLE (S.), SAULNIER (S.) - Atlas topographique des Villes de Gaule Méridionale, 2, Fréjus. Montpellier, 2000, 509 p. (suppl. 32 à la Revue Archéologique de Narbonnaise).

Rivet 2010 : RIVET (L.) - Recherches archéologiques au coeur de "Forum Iulii" : les fouilles dans le groupe épiscopal de Fréjus et à ses abords (1979-1989). Errance, Centre Camille Jullian, 2010, 420 p. (Bibliothèque d'archéologie méditerranéenne et africaine, 6).

Robert 2003 : ROBERT (R.) - Autel funéraire ou votif à tête de méduse. In : TERRER (D.) et al., Nouvel Espérandieu - Vienne. Paris, 2003, 116, n 278.

Robion 1987 : ROBION (L.) - Fréjus Ves. - XX e s. Déclins et renaissances. CRDP, Nice, 1987, 721 p.

Robinson 2002 : ROBINSON (M.) - Domestic burnt offerings and sacrifices at Roman and pre-Roman Pompeii, Italy. Vegetation History and Archaeobotany, 11, 2002, 93-99.

Rodà de Llanza 2000 : RODÀ DE LLANZA (I.) - La escultura del sur de la Narbonense y del norte de Hispania Citerior : paralelos y contactos. In : Actas de la III ${ }^{a}$ Reunión Sobre Escultura Romana en Hispania. Madrid, 2000, 173-196.

Rolland 1965 : ROLLAND (H.) - Bronzes antiques de Haute-Provence. Éditions du CNRS, Paris, 1965, 211 p., 478 fig. (Suppl. Gallia, XVIII).

Rossiter 1978 : ROSSITER (J. J.) - Roman farm buildings in Italy. Oxford, 1978.

Rothé, Heijmans 2008 : ROTHÉ (M.-P.), HEIJMANS (M.) - Carte Archéologique de la Gaule - Arles, Crau, Camargue, 13/5. MSH, Paris, 2008, 906 p.

Rouen 1982 : Rouen gallo-romain, Fouilles et recherches archéologiques, 1978-1982, HALBOUT (P.) (dir.), Catalogue collectif d'exposition. Rouen, 1982.

Ruiz Zapata et al. 2006 : RUIZ ZAPATA (M. B.), GOMEZ GONCALVEZ (C.), LOPEZ SAEZ (J. A.), GIL GARCIA (M. J.), SANTIESTEBAN (J. O.), MEDIAVILLA(R.), DORADO VALLINO (M.), VALDEOMILLOS RODRIGUEZ (A.) - Deteccion de la actividad antropica durante el holoceno reciente, a traves de la asociacion de palinomorfos polinicos y no polinicos en dos depositos higroturbos (el Berruexo y Rascafria) en la sierra de Guadarrama, Madrid. Revista Espanola de Micropaleontologia, 38 (2-3), 2006, 355-366.

Santrot et al. 1996 : SANTROT (J.), DERION (B.) (coll.), DUPUIS (X.) (coll.), FINCKER (M.) (coll.) - Bronzes et fers de Dax, Landes. La cachette d'un « antiquaire restaurateur » au IVe s. apr. J.-C. Gallia, 53, 1996, 251-353.

Schoch et al. 1988 : SCHOCH (W.), PAWLIK (B.), SCHWEINGRUBER (F. H.) - Macrorestes botaniques, atlas pour la détermination de graines fréquemment trouvées et écologiquement importantes. Édition Haupt, Berne, Stuttgart, $227 \mathrm{p}$.

Schweingruber 1982 : SCHWEINGRUBER (F. H.) - Mikroskopische Holzanatomie, Anatomie microscopique des bois, Microscopic wood anatomy. In : FLÜCK-WIRTH (F.), Internationale Buchhandlung für Botanik und Naturwissenschaften. Teufen, 1982 ( $2^{\mathrm{e}}$ éd.), $226 \mathrm{p}$.

Schweingruber 1990 : SCHWEINGRUBER (F. H.) - Anatomie europäischer Hölzer, Anatomy of europeanwood. Édition Haupt, Berne, Stuttgart, 1990, 800 p.

Steffy 1985 : STEFFY (J. R.) - The Kyrenia Ship. An Interim Report on its Hull Construction. AJA, 89, 1985, 71-101.

Steffy 1994 : STEFFY (J. R.) - Wooden Ship Building and the Interpretation of Shipwrecks. Texas A\&M University Press, College Station, 1994, 314 p.

Steffy 1999 : STEFFY (J. R.) - Ancient ship repair. In : TZALAS (H.) (dir.), Tropis V, (Nauplia 1993), Hellenic Institute for the Preservation of Nautical Tradition. Athens, 1999, 395-408.

Taillentou 2005 : TAILLENTOU (J.-J.) - Vin de sable, vin des dunes. Histoire d'un vignoble landais. Ortès, 2005, $190 \mathrm{p}$.

Tchernia 1986 : TCHERNIA (A.) - Le vin de l'Italie romaine. Rome, 1986, 410 p. (BEFAR, 261).

Texier 1849 : TEXIER (Ch.) - Mémoire sur la ville et le port de Fréjus. Mémoires présentés par divers savants à l'Académie des Inscriptions et Belles-Lettres de l'Institut National de France, $2^{\mathrm{e}}$ série, II. Paris, 1849.

Thérond 1975/1976 : THÉROND (J.) - Catalogue des Coléoptères de la Camargue et du Gard, I \& II. Société d'Étude des Sciences Naturelles de Nîmes, 1976. 
Thernot, Excoffon 2010 : THERNOT (R.), EXCOFFON (P.) - La construction du monument. In : PASQUALINI (M.), THERNOT (R.), GARCIA (H.) 2010, 71-111.

Toutin 1980 : TOUTIN (N.) - Le permien continental de la Provence orientale, Thèse d'État ès Sciences. Nice, 1980, 2 vol.

Toutin-Morin et al. 1994 : TOUTIN-MORIN (N.), BONIJOLY (D.), BROCARD (C.), BROUTIN (J.), CREVOLA (G.), DARDEAU (G.), DUBAR (M.), FERAUD (J.), GIRAUD (J.-D.), GODDEFROY (P.), LAVILLE (P.), MEINESZ (A.) - Carte géologique de Fréjus-Cannes (1/50 000e) et Notice (188 p.). Éditions du BRGM, 1994.

Treglia 2002 : TREGLIA (J.-Chr.) - Flanged bowl Hayes 91 : simple bol décoré, mortier ou râpe ? In : Vivre, produire, échanger : reflets méditerranéens, mélanges offerts à Bernard Liou. Montagnac, 2002, 287-290.

Ucelli 1950 : UCELLI (G.) - Le navi di Nemi. Istituto Poligrafico e Zecca dello Stato, Roma, 1950, 474 p.

Varène 1970 : VARÈNE (P.) - Blocs funéraires de Nîmes. Gallia, XXVIII, 1970, fasc. 1, 1970, 102-115.

Varoqueaux, Gassend 2001 : VAROQUEAUX (Cl.), GASSEND (J.-M.) - La roue à aubes du grand bassin de la Bourse à Marseille. In : BRUN (J.-P.), JOCKEY (Ph.), 2001, 529-549.

Vella 1999 : VELLA (Cl.) - Perception et évaluation de la mobilité du littoral holocène sur la marge orientale du delta du Rhône, Thèse d'État. Aix-en-Provence, 1999, 225 p.

Vernet 1973 : VERNET (J.-L.) - Les restes végétaux des sédiments de remplissage du port hellénistique de Marseille. II. Les bois. Bulletin de la Société Linnéenne de Provence, XXVI, 1973, 123-126.

Vernet, Keller 1986 : VERNET (J.-L.), KELLER (R.) - Identification et classement des bois français. École nationale du génie rural, des eaux et des forêts, Nancy, 1986, $2^{\mathrm{e}}$ éd., $312 \mathrm{p}$.

Vernet et al. 2001 : VERNET (J.-L.), OGEREAU (P.), FIGUEIRAL (I.), MACHADO-YANES (C.), UZQUIANO (P.) - Guide d'identification des charbons de bois préhistoriques et récents, Sud-Ouest de l'Europe : France, Péninsule ibérique et Îles Canaries. Éditions du CNRS, Paris, 2001, 396 p.

Villeneuve-Bargemont 1812 : VILLENEUVE-BARGEMONT (Chr. de) - Rapport présenté au nom de la Commission chargée de diriger les fouilles faites à Fréjus en Floréal An XI. In : Second recueil des travaux de la Société d'Agriculture, Sciences et Arts d'Agen, 1812, 35-91.

Violino 1990 : VIOLINO (J.-P.) - Basse vallée de l'Argens, rive droite, secteurs des Tourres et de Curebasse. NIL PACA, 7, 1990, 149-151.

Virgili 1989 : VIRGILI (P.) - Acconciature e maquillage. Vita e costumi dei Romani antichi. Rome, 1989, $86 \mathrm{p}$.

Von den Driesch 1976 : VON DEN DRIESCH (A.) - A guide to the measurement of animal bones from archaeological sites. Harvard University Press, Cambridge (MA), 1976.

Wicha 2003 : WICHA (S.) - L'épave des tuiles Barthélémy B. Bilan Scientifique du DRASSM 2002, Ministère de la Culture et de la Communication. Paris, 2003, 71-73.

Zevi 1966 : ZEVI (F.) - Appunti sulle anfore romane, I, La tavola tipologica del Dressel. Archeologica Classica, 18, 1966, 208-247.

Zwierzinski et al. 2003 : ZWIERZINSKI (E.), RUSSEL (M.), RUAS (M.-P.) - Les puits des thermes : analyse carpologique des comblements. In : BOUET (A.), 2003a, 539-546. 



\section{Inventaires}

\section{Listing des unités stratigraphiques par phase et coupe d'ensemble}

\begin{tabular}{|c|c|c|c|c|}
\hline ÉTAT & US & FAIT & ENSEMBLE & DATATION \\
\hline \multicolumn{5}{|c|}{ PHASE 1} \\
\hline & $\begin{array}{l}\text { 1068, 1080, 1130, 1180, 1288, 1290, 1294, 1295, } \\
\text { 1296, 1297, 1298, 1299, 1300, 1301, 1302, 1303, } \\
\text { 1308, 1312, 1313, 1314, 1315, 2006, 2010, 2036, } \\
\text { 3027, 3071, 3074, 3138, 3141, 3201. }\end{array}$ & PO1296, PO1312, SB1288. & UNF1288 & milieu Irr s. av. J.-C. \\
\hline \multicolumn{5}{|c|}{ PHASE 2} \\
\hline & $\begin{array}{l}1017,1050,1051,1052,1053,1054,1055,1056, \\
1057,1058,1059,1060,1061,1062,1064,1065, \\
1067,1069,1070,1071,1073,1074,1075,1076, \\
1077,1078,1081,1084,1088,1089,1090,1091, \\
1092,1093,1094,1101,1102,1103,1105,1106, \\
1108,1109,1110,1111,1112,1113,1114,1115, \\
1120,1121,1124,1126,1127,1128,1129,1137, \\
1138,1141,1142,1143,1145,1146,1147,1148, \\
1149,1153,1154,1155,1156,1158,1162,1164, \\
1165,1166,1167,1168,1169,1170,1171,1174, \\
1177,1178,1181,1182,1183,1184,1185,1186, \\
1187,1188,1190,1191,1192,1195,1196,1197, \\
1198,1199,1200,1201,1202,1203,1204,1205, \\
1206,1207,1208,1209,1210,1211,1212,1213, \\
1215,1218,1219,1220,1221,1222,1224,1225, \\
1230,1234,1235,1236,1237,1238,1239,1240, \\
1241,1242,1243,1245,1246,1250,1253,1254, \\
1255,1256,1257,1258,1259,1260,1261,1272, \\
1273,1274,1275,1276,1278,1279,1281,1282, \\
1283,1284,1289,1293,1304,1305,1306,1307, \\
1309,1310,1311,1320,1321,1324,2004,2011, \\
2013,2015,3033,3074 .\end{array}$ & $\begin{array}{l}\text { FS1069, FS1231, VP1017, MR1050, } \\
\text { VP1051, FS1054, FS1056, FS1062, FS1073, } \\
\text { FS1075, FS1078, VP1081, VP1084, FS1088, } \\
\text { FS1090, FS1091, FS1092, FS1093, FS1094, } \\
\text { FS1101, FS1102, FS1103, FS1104, FS1105, } \\
\text { FS1106, FS1108, VP1112, FS1137, FS1141, } \\
\text { FS1153, FS1167, FS1170, FS1177, FS1181, } \\
\text { FS1185, FS1187, FS1189, FS1197, CN1199, } \\
\text { PT1201, FS1202, FS1204, FS1206, FS1208, } \\
\text { FS1210, FS1212, MR1261, FS1240, FS1253, } \\
\text { FS1255, FS1257, FS1259, FS1272, FS1278, } \\
\text { FS1281, FS1283, VP1293, VP1304, FS1320, } \\
\text { MR2004. }\end{array}$ & $\begin{array}{l}\text { SFO1084, } \\
\text { SFO1093. }\end{array}$ & 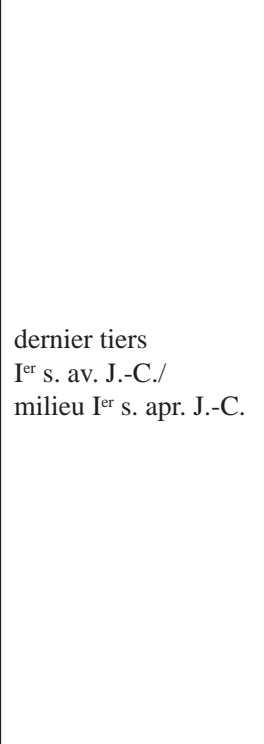 \\
\hline \multicolumn{5}{|c|}{ PHASE 3} \\
\hline $\mathbf{A}$ & $\begin{array}{l}1003,1010,1018,1019,1020,1049,1063,1066, \\
1082,1104,1116,1132,1136,1139,1140,1151, \\
1152,1159,1172,1179,1189,1193,1214,1144, \\
1223,1226,1227,1228,1229,1231,1232,1233, \\
1244,1248,1249,1262,1263,1264,1265,1267, \\
1270,1271,1277,1280,1285,1286,1287,1292, \\
2002,2012,2017,2018,2041,3009,3010,3011, \\
3032,3074,3078,3082,3083,3131,3133,3134, \\
3135,3136,3163,3184,3187,3202,3280,3281, \\
3282,3283,3284,3290,3291,3292,3293,3294, \\
3295,3310,3311,3333 .\end{array}$ & $\begin{array}{l}\text { MR1003, PO1082, FS1089, FS1104, } \\
\text { CN1132, SB1136, FS1139, TR1172, FS1179, } \\
\text { FS1183, FS1193, TR1223, FS1228, FS1231, } \\
\text { FS1234, FS1238, BS1262, FS1270, FS1277, } \\
\text { MR2002, CN3010, MR3082, PO3280, } \\
\text { PO3281, PO3282, PO3283, TR3294. }\end{array}$ & SFO1152 & $\begin{array}{l}\text { milieu I }{ }^{\mathrm{er}} \text { s. apr. J.-C. / } \\
\text { milieu II' } \text { s. apr. J.-C. }\end{array}$ \\
\hline B & $\begin{array}{l}\text { 1083, 1125, 1247, 1252, 1266, 1291, 3013, 3074, } \\
3130,3132,3300 .\end{array}$ & & & milieu II s. apr. J.-C. \\
\hline
\end{tabular}




\begin{tabular}{|c|c|c|c|c|}
\hline ÉTAT & US & FAIT & ENSEMBLE & DATATION \\
\hline \multicolumn{5}{|l|}{ PHASE 4} \\
\hline $\mathbf{A}$ & $\begin{array}{l}3040,3041,3042,3061,3062,3063,3073,3126, \\
3165,3173,3174,3177,3179,3181,3182,3183, \\
3189,3192,3193,3194,3203,3204,3206,3207, \\
3208,3210,3211,3212,3213,3223,3225,3226, \\
3228,3229,3231,3232,3236,3239,3240,3241, \\
3242,3249,3250,3251,3255,3256,3257,3264, \\
3265,3266,3267,3268,3270,3272,3274,3276, \\
3278,3279,3285,3286,3289,3296,3299,3302, \\
3303,3304,3308,3309,3312,3314,3318,3319, \\
3322,3324,3326,3328,3329,3330,3333,3334, \\
3335,3336,3339,3341,3342,3343,3344,3346, \\
3347,3348,3349 .\end{array}$ & $\begin{array}{l}\text { MR3040, MR3042, CH3063, FO3179, } \\
\text { FO3181, FO3192, FO3203, FO3211, } \\
\text { FO3223, FS3226, FS3229, PO3232, PO3236, } \\
\text { FO3239, FO3241, FO3149, FO3255, } \\
\text { FO3264, FS3267, PO3270, PO3272, PO3274, } \\
\text { PO3276, FO3278, PO3286, SI3308, PO3322, } \\
\text { PO3324, PO3326, FS3328, FS3330, FS3333, } \\
\text { BS3339, FO3349, TR3300. }\end{array}$ & PAA3063 & $\begin{array}{l}2^{\mathrm{e}} \text { moitié } \mathrm{II}^{\mathrm{e}} / \\
2^{\mathrm{e}} \text { moitié IV } \mathrm{s} \text {. } \\
\text { apr. J.-C. }\end{array}$ \\
\hline B & $\begin{array}{l}3072,3077,3139,3140,3164 \mathrm{~A}, 3175,3180,3190, \\
3191,3195,3196,3197,3198,3199,3200,3205, \\
3214,3216,3220,3222,3224,3233,3237,3243, \\
3245,3246,3247,3248,3252,3254,3258,3260, \\
3261,3263,3287,3297,3298,3313,3315,3316, \\
3317,3320,3321,3325,3327,3331,3332,3337, \\
3338,3340,3350 .\end{array}$ & $\begin{array}{l}\text { FS3139, FS3190, FS3195, FO3197, FS3199, } \\
\text { FS3214, FS3220, FS3243, FS3246, FS3252, } \\
\text { FS3258, FS3261, FS3297, FS3320, FS3337. }\end{array}$ & & $\begin{array}{l}\text { milieu IVe s. } \\
\text { apr. J.-C./milieu Ve s. } \\
\text { apr. J.-C. }\end{array}$ \\
\hline C & $\begin{array}{l}\text { 3015, 3025, 3035, 3060, 3164B, 3209, 3215, 3221, } \\
3227,3230,3244,3253,3259,3262,3271,3273, \\
3275,3277,3288,3301,3305,3306,3307,3323 \text {, } \\
3325 .\end{array}$ & & & Ve s. apr. J.-C. \\
\hline \multicolumn{5}{|l|}{ PHASE 5} \\
\hline $\mathbf{A}$ & $\begin{array}{l}1007,1008,1009,1011,1012,1013,1014,1015, \\
1016,1072,1079,1150,2003,2009,2021,2023, \\
2024,2025,2026,2027,2028,2029,2031,2038, \\
2039,2040,2042,2043,2044,2045,2046,2047, \\
3006,3012,3014,3022,3028,3030,3031,3034, \\
3037,3038,3039,3046,3047,3049,3050,3053, \\
3057,3064,3067,3084,3122 .\end{array}$ & $\begin{array}{l}\text { TR1008, FS1079, PT2003, PT2031, } \\
\text { MR3006, FS3038, TR3064. }\end{array}$ & & fin $X I V e / X V I$ es. \\
\hline B & $\begin{array}{l}1002,1004,1005,1006,1131,1133,1134,1135, \\
1268,1269,2005,2008,2014,2016,2019,2020, \\
2022,2030,2032,2033,2034,2035,2037,3003, \\
3004,3017,3018,3020,3026,3043,3044,3045, \\
3054,3058,3076,3080,3085,3086,3087,3088, \\
3089,3090,3091,3092,3093,3094,3095,3096, \\
3097,3098,3099,3100,3101,3102,3103,3104, \\
3105,3106,3107,3108,3109,3110,3111,3112, \\
3113,3114,3115,3116,3117,3118,3123,3124, \\
3127,3128,3129,3137,3142,3143,3144,3145, \\
3146,3147,3148,3149,3150,3151,3152,3153, \\
3154,3155,3156,3157,3158,3159,3160,3161, \\
3162,3166,3167,3168,3171,3172,3176 .\end{array}$ & $\begin{array}{l}\text { FS1268, TR3004, FO3017/3081, FO3020, } \\
\text { PO3085, PO3142. }\end{array}$ & & XVII s. \\
\hline $\mathbf{C}$ & $\begin{array}{l}3002,3007,3016,3019,3023,3024,3051,3052 \\
3055,3059,3065,3068,3075,3079,3081,3124\end{array}$ & FS3051 & & XVIII' s. \\
\hline \multicolumn{5}{|l|}{ PHASE 6} \\
\hline & $\begin{array}{l}1001,1021,1022,1023,1024,1025,1026,1027, \\
1028,1029,1030,1032,1033,1034,1035,1036, \\
1037,1039,1040,1041,1042,1043,1044,1045, \\
1046,1047,1048,1131,2001,2007,3001,3005, \\
3008,3021,3029,3069,3070,3121,3125,3185, \\
3186 .\end{array}$ & PO1021, TR3069, TR3005, FS3121, FS3185. & & XIXe s. \\
\hline \multicolumn{5}{|l|}{ H.S. } \\
\hline & $3048,3066,3119,3120,3178,3188$. & TR3048 & & \\
\hline
\end{tabular}


INVENTAIRES
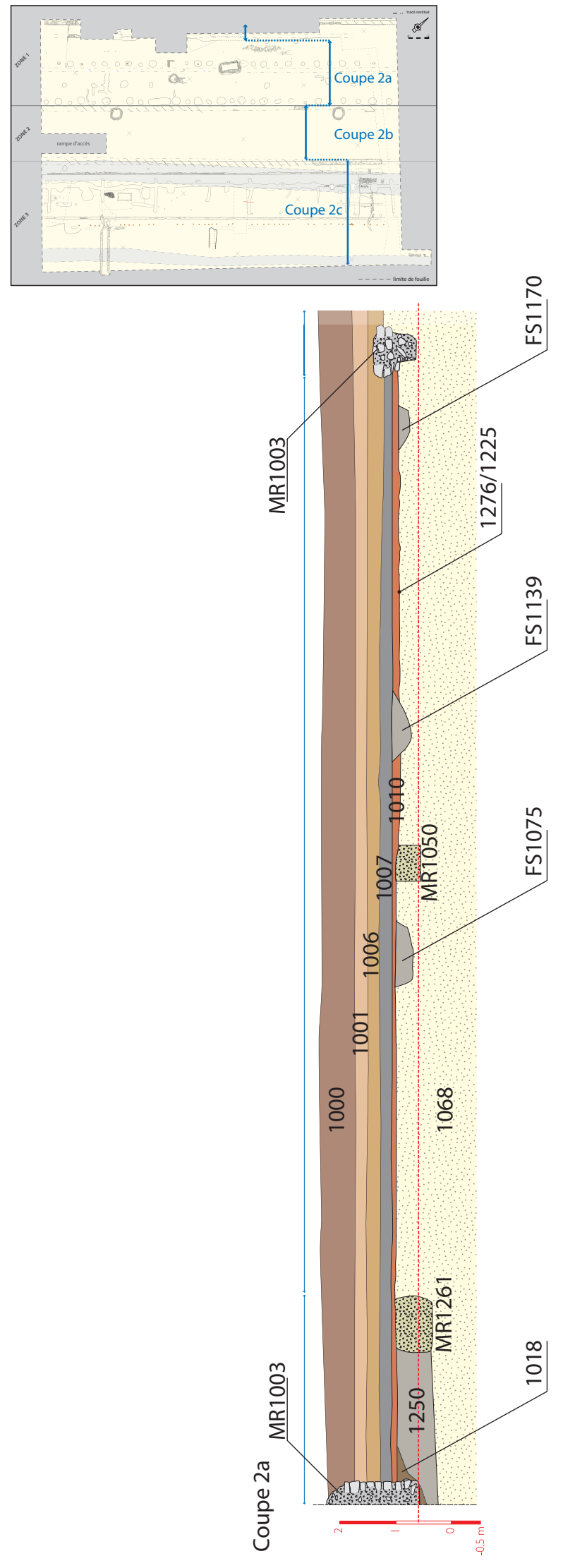

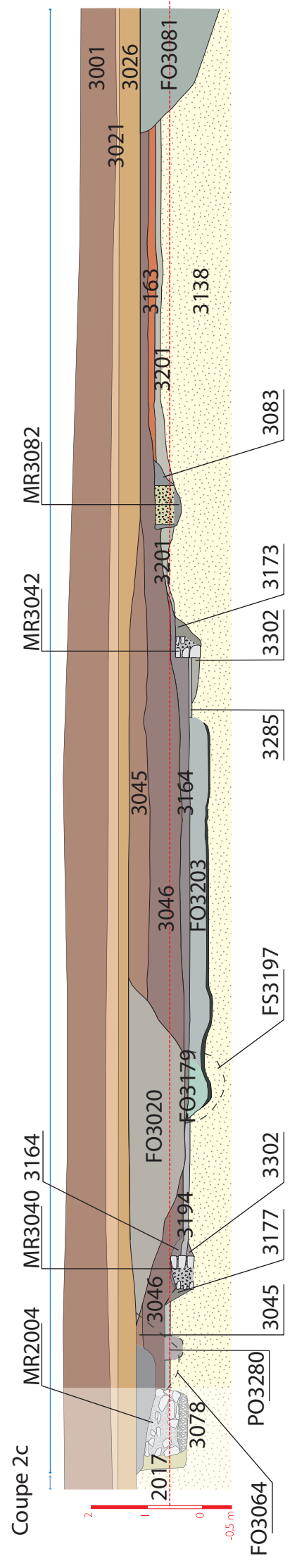

Coupe d'ensemble. 


\section{Inventaire des monnaies}

\begin{tabular}{|c|c|c|c|c|c|c|c|c|c|c|c|c|}
\hline US & Dénomination & Autorité & Datation & Métal & $\begin{array}{l}\varnothing(\mathrm{mm}) / \\
\text { Pds (g) }\end{array}$ & $\begin{array}{c}\text { Légende } \\
\text { droit }\end{array}$ & Champs droit & $\begin{array}{l}\text { Légende } \\
\text { revers }\end{array}$ & $\begin{array}{l}\text { Champs } \\
\text { revers }\end{array}$ & $\begin{array}{c}\text { Lettres } \\
\text { champ } \\
\text { revers }\end{array}$ & Atelier & Bibliographie \\
\hline \multicolumn{13}{|l|}{ PHASE 2} \\
\hline 1067 & $\begin{array}{l}\text { Petit bronze de } \\
\text { Fréjus }\end{array}$ & & $\begin{array}{c}31-27 \\
\text { av. J.-C. }\end{array}$ & $\mathrm{Cu}, \mathrm{Sn}$ & $12 / 1,16$ & & $\begin{array}{l}\text { Proue avec } \\
\text { rostre. }\end{array}$ & & $\begin{array}{l}\text { Capricorne } \\
\text { avec un } \\
\text { globe. }\end{array}$ & & $\begin{array}{l}\text { Fréjus } \\
\text { (France) }\end{array}$ & $\begin{array}{l}\text { RPC vol. 1, } \\
\text { part. } 1 \& 2, \\
156, n^{\circ} 534\end{array}$ \\
\hline \multicolumn{13}{|l|}{ PHASE 3} \\
\hline $\begin{array}{l}\text { MR1264 } \\
\text { (SB1262) }\end{array}$ & sesterce & Domitien & $\begin{array}{c}\text { 85-89 } \\
\text { apr. J.-C. }\end{array}$ & $\mathrm{Cu}, \mathrm{Sn}$ & $33 / 24,8$ & & \begin{tabular}{|l} 
IMP \\
(CAESDOMI) \\
TAVGGERM. \\
COS (XI à \\
XIII CENS \\
PERPP)
\end{tabular} & & $\begin{array}{l}\text { Domitien } \\
\text { à cheval } \\
\text { tenant } 1 \\
\text { bouclier } \\
\text { et faisant } \\
\text { chuter un } \\
\text { ennemi. } \\
\end{array}$ & $\mathrm{SC}$ & $\begin{array}{l}\text { Rome } \\
\text { (Italie) }\end{array}$ & $\begin{array}{l}\text { RIC vol. 2, } \\
\text { 190-199, }{ }^{\circ} \\
\text { ex. } 361\end{array}$ \\
\hline \multicolumn{13}{|l|}{ PHASE 4} \\
\hline 3308 & sesterce & Faustine & $\begin{array}{c}\text { apr. } \dagger \\
\text { Faustine, } \\
\text { en } 141 \\
\text { apr. J.-C. }\end{array}$ & $\mathrm{Cu}, \mathrm{Sn}$ & $\begin{array}{c}33 / \\
29,04\end{array}$ & $\begin{array}{c}\text { DIVA } \\
\text { FAVSTINA }\end{array}$ & $\begin{array}{l}\text { Buste féminin } \\
\text { à droite avec } \\
\text { chignon perlé. }\end{array}$ & AVGVSTA & \begin{tabular}{|l} 
Ceres \\
debout à \\
gauche \\
tenant des \\
épis de \\
blé et 1 \\
torche dans \\
la main \\
gauche.
\end{tabular} & $\mathrm{SC}$ & $\begin{array}{l}\text { Rome } \\
\text { (Italie) }\end{array}$ & $\begin{array}{l}\text { RIC vol. 3, } \\
163, n^{\circ} 1119\end{array}$ \\
\hline
\end{tabular}

\section{Marbres}

\begin{tabular}{|c|c|c|c|c|c|c|}
\hline Zone & US & Identification & Ép. en cm & Espèce & Description & Inv. \\
\hline \multicolumn{7}{|l|}{ PHASE 1} \\
\hline 1 & 1068 & placage? & $?$ & $\begin{array}{l}\text { Marbre blanc grain fin } \\
\text { (Luni ?) }\end{array}$ & $\begin{array}{l}\text { frag. très érodé dû à un } \\
\text { séjour prolongé dans l'eau }\end{array}$ & 1 \\
\hline \multicolumn{7}{|l|}{ PHASE 5} \\
\hline \multirow{4}{*}{2} & 2003 & placage? & 3 & $\begin{array}{l}\text { Marbre blanc grain fin } \\
\text { (Luni ?) }\end{array}$ & frag. & 2 \\
\hline & 2003 & placage? & 2,6 & $\begin{array}{l}\text { Marbre blanc grain fin } \\
\text { (Luni ?) }\end{array}$ & frag. & 3 \\
\hline & 2031 & plaque moulurée & 2,2 & $\begin{array}{l}\text { Marbre blanc grain fin } \\
\text { (Luni ?) }\end{array}$ & $\begin{array}{l}\text { angle de plaque moulurée } \\
\text { avec inscription (-M) au } \\
\text { revers }\end{array}$ & 4 \\
\hline & 2035 & placage & 1,6 & Bardiglio & $\begin{array}{l}\text { angle de placage avec arête } \\
\text { bisautée }\end{array}$ & 5 \\
\hline \multicolumn{7}{|l|}{ PHASE 4} \\
\hline 3 & 3191 & placage & 2,6 & $\begin{array}{l}\text { Marbre blanc grain fin } \\
\text { (Luni ?) }\end{array}$ & présence de fines moulures & 6 \\
\hline \multicolumn{7}{|l|}{ PHASE 4} \\
\hline \multirow{3}{*}{3} & 3254 & placage & 1,4 & $\begin{array}{l}\text { Marbre blanc grain fin } \\
\text { (Luni ?) }\end{array}$ & frag. probablement retaillé & 7 \\
\hline & 3288 & $\begin{array}{l}\text { Élément non } \\
\text { identifié }\end{array}$ & & $\begin{array}{l}\text { Marbre blanc grain fin } \\
\text { (Luni ?) }\end{array}$ & $\begin{array}{l}\text { petit prisme à base carrée de } \\
\text { section } 6,4 \text { × } 4 \text { × } 8,6\end{array}$ & 8 \\
\hline & 3321 & placage & 0,6 & Bardiglio & frag. & 9 \\
\hline
\end{tabular}




\section{Enduits peints}

\begin{tabular}{|c|c|c|c|c|}
\hline Zone & US & Couleur & Ép. en cm & Nbre \\
\hline \multicolumn{5}{|l|}{ PHASE 3} \\
\hline \multirow{6}{*}{1} & 1125 & rouge & & \\
\hline & \multirow{2}{*}{1249} & rouge & \pm 2 & 14 \\
\hline & & blanc & \pm 2 & 2 \\
\hline & \multirow{2}{*}{1287} & rouge foncé & 6 & 2 \\
\hline & & brillant & 5 & 1 \\
\hline & 1291 & blanc & & \\
\hline \multicolumn{5}{|l|}{ PHASE 5} \\
\hline 1 & 1131 & rouge & & \\
\hline \multicolumn{5}{|l|}{ PHASE 6} \\
\hline 1 & 1001 & pourpre foncé & 2 & 1 \\
\hline
\end{tabular}

\section{Inventaire mobilier métallique}

\begin{tabular}{|c|c|c|c|c|c|}
\hline $\mathbf{N}^{\circ}$ Inv. & US & Désignation & Matériau & Dimensions & État \\
\hline \multicolumn{6}{|l|}{ PHASE 1} \\
\hline 1 & 3138 & Clou de section carrée & Alliages ferreux & H. constatée : $4,9 \mathrm{~cm}$ & Fragmentaire \\
\hline \multicolumn{6}{|l|}{ PHASE 2} \\
\hline 2 & 1093 & Clou de section carrée et tête aplatie & Alliages ferreux & H. constatée $: 5,6 \mathrm{~cm}$ & Fragmentaire \\
\hline \multicolumn{6}{|c|}{ PHASE 3A } \\
\hline 3 & 1066 & $\begin{array}{l}\text { Forces à ressort en U de type Duvauchelle } 3 \\
\text { (instrument à usage personnel, domestique ou } \\
\text { chirurgical) }\end{array}$ & Alliages cuivreux & $\mathrm{L}: 8,2 \mathrm{~cm}$ & Complet \\
\hline 4 & 2014 & Pointe rectiligne de section carrée & Alliages ferreux & $\mathrm{L}: 9,1 \mathrm{~cm}-\varnothing$ base $: 1,9 \mathrm{~cm}$ & Complet \\
\hline 5 & 2003 & Plaque allongée en $\mathrm{L}$ & Alliages ferreux & $\mathrm{L}: 8 \mathrm{~cm}-1 .: 5,2 \mathrm{~cm}$ & Fragmentaire \\
\hline 6 & 2014 & Lame rectiligne ou portion de plaque plate & Alliages ferreux & L constatée : $10,5 \mathrm{~cm}-1 .: 5 \mathrm{~cm}$ & Fragmentaire \\
\hline 7 & 1066 & Clou de section carrée & Alliages ferreux & H. : $4,1 \mathrm{~cm}$ & \begin{tabular}{|l|} 
Complet ? \\
(concrétionné)
\end{tabular} \\
\hline 8 & 2002 & Clou de section carrée et tête aplatie & Alliages ferreux & H. plié : $5,3 \mathrm{~cm}$ & Fragmentaire \\
\hline 9 & 1214 & Clou de section carrée et tête aplatie & Alliages ferreux & H. constatée : $5,6 \mathrm{~cm}$ & Fragmentaire \\
\hline 10 & 3131 & Clou de section ronde et tête aplatie & Alliages cuivreux & H. constatée : $3,8 \mathrm{~cm}$ & Complet \\
\hline 11 & 1010 & Clou de section carrée et tête aplatie & Alliages cuivreux & H. : 3,2 cm - $\varnothing$ tête : $1,6 \mathrm{~cm}$ & Complet \\
\hline 12 & 1292 & Clou plié de section carrée et tête aplatie & Alliages ferreux & H. constatée $: 4,5 \mathrm{~cm}$ & Fragmentaire \\
\hline 13 & 1066 & Clou de section carrée et tête aplatie & Alliages ferreux & H. constatée $: 3,5 \mathrm{~cm}$ & Fragmentaire \\
\hline 14 & 1010 & Clou de section carrée et tête aplatie & Alliages ferreux & H. constatée : $5,3 \mathrm{~cm}$ & Fragmentaire \\
\hline 15 & 1010 & Tige de section carrée (corps de clou ?) & Alliages ferreux & H. constatée : $3,2 \mathrm{~cm}$ & Fragmentaire \\
\hline 16 & 1010 & Tige de section carrée (corps de clou ?) & Alliages ferreux & H. constatée : $4,3 \mathrm{~cm}$ & Fragmentaire \\
\hline 17 & 1010 & Tige de section carrée (corps de clou ?) & Alliages ferreux & H. constatée : $5,4 \mathrm{~cm}$ & Fragmentaire \\
\hline 18 & 1010 & Tige de section carrée (corps de clou ?) & Alliages ferreux & H. constatée $: 6,6 \mathrm{~cm}$ & Fragmentaire \\
\hline 19 & 3184 & Coulure & Alliages cuivreux & $\mathrm{L}: 1,5 \mathrm{~cm}-1 .: 1,4 \mathrm{~cm}$ & I \\
\hline \multicolumn{6}{|c|}{\begin{tabular}{|l|} 
PHASE 3B \\
\end{tabular}} \\
\hline 20 & 1247 & Tige pointue de section carrée pliée en $S$ & Alliages cuivreux & $\mathrm{L}: 4,2 \mathrm{~cm}$ & Complet ? \\
\hline 21 & 3132 & Tête de clou & Alliages ferreux & H. constatée : $1,2 \mathrm{~cm}$ & \begin{tabular}{|l}
$\begin{array}{l}\text { Fragmentaire } \\
\text { (concrétionné) }\end{array}$ \\
\end{tabular} \\
\hline 22 & 1291 & Clou de section carrée & Alliages ferreux & H. constatée : $3,4 \mathrm{~cm}$ & Fragmentaire \\
\hline 23 & 1292 & Clou de section carrée et tête aplatie & Alliages ferreux & H. constatée : $4,1 \mathrm{~cm}$ & Fragmentaire \\
\hline
\end{tabular}


BIBLIOTHÈQUE D’ ARCHÉOLOGIE MÉDITERRANÉENNE ET AFRICAINE - 8

\begin{tabular}{|c|c|c|c|c|c|}
\hline $\mathbf{N}^{\circ}$ Inv. & US & Désignation & Matériau & Dimensions & État \\
\hline 24 & 1247 & Corps de clou de section carrée & Alliages ferreux & H. constatée : $7,5 \mathrm{~cm}$ & $\begin{array}{l}\text { Fragmentaire } \\
\text { (concrétionné) }\end{array}$ \\
\hline 25 & 1293 & Corps de clou de section carrée & Alliages ferreux & H. constatée : $3,1 \mathrm{~cm}$ & Fragmentaire \\
\hline 26 & 1294 & Corps de clou de section carrée & Alliages ferreux & H. constatée : $2,9 \mathrm{~cm}$ & Fragmentaire \\
\hline \multicolumn{6}{|l|}{ PHASE 4A } \\
\hline 27 & 1131 & Lame rectiligne & Alliages ferreux & L constatée : $2,7 \mathrm{~cm}-1 .: 1,8 \mathrm{~cm}$ & Fragmentaire \\
\hline 28 & 3189 & Tige de section carrée & Alliages ferreux & H. constatée : $4,3 \mathrm{~cm}$ & Fragmentaire \\
\hline 29 & 3254 & Tige de section ronde pliée en forme d'oméga & Alliages cuivreux & $\mathrm{L}: 6 \mathrm{~cm}$ & Complet \\
\hline 30 & $3339-3346$ & Clou de section carrée et tête conique aplatie & Alliages ferreux & H. : $8,9 \mathrm{~cm}-\varnothing$ tête $: 2,6 \mathrm{~cm}$ & Fragmentaire \\
\hline 31 & 3312 & Tige creuse de section ronde & Alliages cuivreux & H. constatée : $3,1 \mathrm{~cm}$ & Fragmentaire \\
\hline \multicolumn{6}{|l|}{ PHASE 4B } \\
\hline 32 & 3164 & Épingle à cheveux à tête zoomorphe & Alliages cuivreux & H. : $5,1 \mathrm{~cm}-1 .: 3,2 \mathrm{~cm}$ & Manque la pointe \\
\hline 33 & 3340 & Pointe (alène, corps de clou ?) de section carrée & Alliages cuivreux & $\mathrm{L}: 8 \mathrm{~cm}-\emptyset: 0,4 \mathrm{~cm}$ & Complet? \\
\hline 34 & 3334 & Clou de section carrée et tête conique aplatie & Alliages ferreux & H. constatée : 7,3 cm & Fragmentaire \\
\hline \multicolumn{6}{|c|}{ PHASE 5A } \\
\hline 35 & 3034 & $\begin{array}{l}\text { Cerclage conservé sous la forme d'un bandeau décoré } \\
\text { sur la face externe de crans répartis à intervalles } \\
\text { réguliers perpendiculaires au déroulé ; la face interne } \\
\text { comporte deux stries incisées dans l'axe du bandeau } \\
\text { (facture moderne) }\end{array}$ & Alliages cuivreux & $\begin{array}{l}\text { L totale déroulé : } 48 \mathrm{~cm}-\varnothing \\
\text { restitué : } 16 \mathrm{~cm}\end{array}$ & Complet \\
\hline 36 & 2040 & Clou de section carrée et tête conique aplatie & Alliages ferreux & H. constatée : $4,4 \mathrm{~cm}$ & Fragmentaire \\
\hline 37 & \begin{tabular}{|l|}
3022, pieu \\
3017
\end{tabular} & Pointe de clou de section carrée & Alliages ferreux & H. constatée : $2,7 \mathrm{~cm}$ & Fragmentaire \\
\hline 38 & 2005 & Clou plié de section carrée et tête aplatie & Alliages ferreux & H. : $7,1 \mathrm{~cm}$ & Complet \\
\hline 39 & 3049 & Tige fine de section ronde & Alliages ferreux & L constatée : $9,1 \mathrm{~cm}$ & $\begin{array}{l}\text { Fragmentaire } \\
\text { (concrétionné) }\end{array}$ \\
\hline 40 & 3049 & Tige fine de section ronde & Alliages ferreux & L constatée : $9,1 \mathrm{~cm}$ & $\begin{array}{l}\text { Fragmentaire } \\
\text { (concrétionné) }\end{array}$ \\
\hline \multicolumn{6}{|l|}{ PHASE 6} \\
\hline 41 & 1007 & Clé double à écrous (18 et 25 mm) & Alliages ferreux & $\mathrm{L}: 19 \mathrm{~cm}$ & Complet \\
\hline 42 & 1008 & Briquet & Inconnu & H. : $5 \mathrm{~cm}-1 .: 3,8 \mathrm{~cm}-$ Ép. : $1,3 \mathrm{~cm}$ & Complet \\
\hline 43 & 1006 & $\begin{array}{l}\text { Lampe à pétrole (à partir de la seconde moitié du } \\
\text { XIX }{ }^{\mathrm{e}} \text { s., à réservoir cylindrique. }\end{array}$ & Alliages cuivreux & H. : $14,9 \mathrm{~cm}-\varnothing$ base : $7,7 \mathrm{~cm}$ & Complet \\
\hline 44 & 1006 & $\begin{array}{l}\text { Cylindre creux décoré de nombreux sillons } \\
\text { périphériques (facture moderne) }\end{array}$ & Alliages cuivreux & H. : $4,8 \mathrm{~cm}$ & Complet (écrasé) \\
\hline 45 & 1049 & Versoir de charrue à ailes latérales arrondies & Alliages ferreux & H. : $10,5 \mathrm{~cm}-1$. constatée $: 18,2 \mathrm{~cm}$ & Manque une aile \\
\hline 46 & $\begin{array}{l}\text { Décapage, } \\
1001-2001- \\
3001\end{array}$ & Clou de section ronde & Alliages ferreux & H. : $15,3 \mathrm{~cm}$ & Complet \\
\hline 47 & 3048 & Tête de clou aplatie & Alliages ferreux & H. constatée : $1,3 \mathrm{~cm}-\emptyset: 1,5 \mathrm{~cm}$ & Fragmentaire \\
\hline 48 & 3070 & Corps de clou de section carrée & Alliages ferreux & H. constatée : $3,2 \mathrm{~cm}$ & Fragmentaire \\
\hline 49 & 3070 & Corps de clou de section carrée & Alliages ferreux & H. constatée $: 5 \mathrm{~cm}$ & Fragmentaire \\
\hline 50 & 3070 & Corps de clou de section carrée & Alliages ferreux & H. constatée : $7,1 \mathrm{~cm}$ & Fragmentaire \\
\hline \multicolumn{6}{|l|}{ PHASE 6} \\
\hline 51 & 3070 & Corps de clou de section carrée & Alliages ferreux & H. constatée : $9,1 \mathrm{~cm}$ & Fragmentaire \\
\hline 52 & 3070 & 22 tiges de diverses sections & Alliages ferreux & L constatée : 1,9 à $8,4 \mathrm{~cm}$ & Fragmentaire \\
\hline 53 & 3070 & Élément cornu (éperon ?) & Alliages ferreux & $\mathrm{L}: 10 \mathrm{~cm}-\mathrm{H} .: 7,5 \mathrm{~cm}$ & $\begin{array}{l}\text { Complet (manque } \\
\text { une extrémité) }\end{array}$ \\
\hline
\end{tabular}




\section{Inventaire verre}

\begin{tabular}{|c|c|c|c|c|c|c|c|c|}
\hline Phase & US & Inv. & Nbre frag. & Frag. NS & NMI total & Type frag. & Description & Typologie \\
\hline $2 \mathrm{~B}$ & 1148 & VR016 & 1 & & 1 & bord & Assiette incolore soufflée à lèvre épaissie & indéterminée \\
\hline \multirow{3}{*}{$3 \mathrm{~A}$} & \multirow{2}{*}{1010} & VR017 & 1 & 1 & 2 & bord & Bord épais, incolore & indéterminée \\
\hline & & VR018 & 1 & & 1 & perle & Perle sphérique, ambre translucide & indéterminée \\
\hline & 1223 & & & 2 & 2 & panse & Bleuté épais+ 1 fin verdâtre & indéterminée \\
\hline 3B & 1291 & VR015 & 1 & 1 & 2 & fond & Fond épais à ressaut aplati & indéterminée \\
\hline \multirow{5}{*}{$4 \mathrm{~A}$} & \multirow{2}{*}{3341} & VR019 & 1 & 1 & 2 & panse? & Épais cobalt & indéterminée \\
\hline & & VR012 & 1 & 1 & 2 & $\mathrm{f} / \mathrm{p}$ & Jonction fond panse épais, soufflé & Is. $8 ?$ \\
\hline & \multirow{2}{*}{3189} & & & & & & bleutée, probable balsamaire & \\
\hline & & VR010 & 1 & 2 & 3 & fond & Fond plat soufflé cobalt & Is. $12 ?$ \\
\hline & 3203 & VR005 & 1 & & 1 & panse & Linear-cut violet, rainure intérieure & AR 3 \\
\hline \multirow[b]{2}{*}{ 4B } & 3225 & & 1 & 1 & 2 & panse & Soufflé bleuté & indéterminée \\
\hline & 3321 & VR004 & 1 & & 1 & panse & $\begin{array}{l}\text { Coupe ou assiette moulée imit.sig., vert moyen } \\
\text { opaque, biconvexe }\end{array}$ & AR 6 \\
\hline \multirow{7}{*}{$4 \mathrm{C}$} & 3025 & VR011 & 1 & 1 & 2 & bord & Bord à lèvre épaissie évasé, soufflée bleutée & indéterminée \\
\hline & 3164 & VR007 & 1 & & 1 & panse & Vert émeraude, parois fines & indéterminée \\
\hline & 3180 & VR009 & 1 & & 1 & bord & $\begin{array}{l}\text { Bord à lèvre épaissie évasé, soufflée incolore, } \\
\text { bourrelet sous le bord }\end{array}$ & indéterminée \\
\hline & 3194 & VR008 & 1 & & 1 & fond & Pied annulaire plein cobalt & indéterminée \\
\hline & \multirow{2}{*}{3205} & VR006 & 1 & 1 & 2 & panse & Forme moulée, cobalt,carénée et rainuré & indéterminée \\
\hline & & & 1 & & 1 & panse & Cobalt soufflé & indéterminée \\
\hline & 3334 & VR003 & 1 & & 1 & panse & Fragment soufflé cobalt doublé interne blanc & indéterminée \\
\hline \multirow{3}{*}{$5 \mathrm{~A}$} & 2005 & & & 4 & 4 & & 2 incolores +2 verdâtres épais & indéterminée \\
\hline & \multirow{2}{*}{2014} & VR001 & 2 & & 2 & & Élements de préhension (?) mosaïqué & indéterminée \\
\hline & & VR002 & 1 & & 1 & bord & Gobelet soufflé incolore & indéterminée \\
\hline $5 \mathrm{~B}$ & 3080 & VR013 & 2 & & 2 & panse & Souflé verdâtre, bulleux & indéterminée \\
\hline \multirow{2}{*}{$5 \mathrm{C}$} & 3012 & VR014 & 2 & & 2 & fond & Fond épais à ressaut aplati & indéterminée \\
\hline & 3018 & & 1 & 1 & 2 & panse & Soufflé verdâtre, bulleux (à rattacher VR013) & indéterminée \\
\hline \multirow{2}{*}{6} & \multirow{2}{*}{1006} & & & 3 & 3 & panse & Contemporain & contemporain \\
\hline & & & & & & fond & Contemporain & contemporain \\
\hline
\end{tabular}

\section{Inventaire céramique}

\section{Inventaire des individus et comptage total.}

\begin{tabular}{|c|l|c|l|l|c|}
\hline PHASE 1 & \multicolumn{1}{|c|}{ Catégorie } & Nbre & \multicolumn{1}{c|}{ Objet } & Type & foc. \\
\hline US & amphore massaliète impériale & 1 & amphore & & anse \\
\hline 1294 & amphore de Bétique & 1 & amphore & Dressel $7 / 11$ & bord \\
\hline 3138 & modelée & 1 & stockage & & \\
\hline
\end{tabular}




\begin{tabular}{|l|c|c|c|c|c|c|}
\hline \multicolumn{1}{|c|}{ Catégorie } & NR & $\mathbf{\%}$ & anse & fond & bord & NMI \\
\hline amphore & $\mathbf{4 7}$ & $\mathbf{9 4}$ & & $\mathbf{2}$ & \\
\hline amphore africaine & 2 & 4 & & 1 & 1 \\
\hline amphore de Bétique & 14 & 28 & & & 1 \\
\hline amphore de Taraconaise & 2 & 4 & & & 1 \\
\hline amphore indéterminée & 13 & 26 & & 1 & 1 \\
\hline amphore massaliète & 16 & 32 & & & 1 & 1 \\
\hline commune & $\mathbf{3}$ & $\mathbf{6}$ & & & $\mathbf{2}$ & 1 \\
\hline brune & 1 & 2 & & & 1 \\
\hline modelée & 2 & 4 & & & 1 \\
\hline
\end{tabular}

\begin{tabular}{|c|c|c|c|c|c|}
\hline PHASE 2 & & & & & \\
\hline US & Catégorie & Nbre & Objet & Type & Loc. \\
\hline 1017 & amphore de Bétique & 1 & amphore & Dressel 7/11 & fond \\
\hline 1051 & amphore de Taraconaise & 1 & amphore & Pascual 1 & fond \\
\hline 1057 & claire & 1 & cruche & & fond \\
\hline 1064 & claire & 1 & cruche & & fond \\
\hline 1064 & amphore gauloise & 1 & amphore & & anse \\
\hline 1081 & amphore italique & 1 & amphore & Dressel 6 & fond \\
\hline 1084 & amphore italique & 1 & amphore & Dressel 1B & fond \\
\hline 1112 & amphore de Taraconaise & 1 & amphore & Pascual 1 & fond \\
\hline 1121 & amphore Italique & 1 & amphore & Dressel 1B & bord \\
\hline 1148 & claire & 1 & coupe & Pasqualini 1D & bord \\
\hline 1191 & paroi fine & 1 & gobelet & Mayet 26 & bord \\
\hline 1191 & paroi fine & 1 & gobelet & Mayet 29 & bord \\
\hline 1207 & claire & 1 & couvercle & & bord \\
\hline 1239 & modelée & 1 & couvercle & \begin{tabular}{|l}
$\begin{array}{l}\text { couvercle à } \\
\text { collerette }\end{array}$ \\
\end{tabular} & frag. \\
\hline 1239 & modelée & 1 & couvercle & CNT PRO V2B & bord \\
\hline 1250 & amphore massaliète impériale & 1 & amphore & & fond \\
\hline 1293 & paroi fine & 1 & gobelet & Mayet 5 & fond \\
\hline 1304 & amphore de Bétique & 1 & amphore & Haltern 70 & fond \\
\hline
\end{tabular}

\begin{tabular}{|c|c|c|c|c|c|c|}
\hline catégorie & NR & $\%$ & anse & fond & bord & NMI \\
\hline amphore & 187 & 59,6 & 2 & 5 & 1 & 8 \\
\hline amphore africaine & 2 & 0,6 & & & & 1 \\
\hline amphore de Bétique & 80 & 25,5 & & 1 & & 1 \\
\hline amphore de Taraconaise & 36 & 11,5 & & 2 & & 2 \\
\hline amphore gauloise & 7 & 2,2 & 1 & & & 1 \\
\hline amphore indéterminée & 13 & 4,1 & & & & 1 \\
\hline amphore italique & 49 & 15,6 & 1 & 2 & 1 & 2 \\
\hline fine & 9 & 2,9 & & 1 & 2 & 3 \\
\hline paroi fine & 9 & 2,9 & & 1 & 2 & 3 \\
\hline commune & 115 & 36,6 & & 4 & 3 & 6 \\
\hline brune & 1 & 0,3 & & & & 1 \\
\hline
\end{tabular}




\begin{tabular}{|l|c|c|c|c|c|c|}
\hline \multicolumn{1}{|c|}{ catégorie } & NR & \% & anse & fond & bord & NMI \\
\hline claire & 100 & 31,8 & & 3 & 2 & 3 \\
\hline kaolinitique & 1 & 0,3 & & & 1 \\
\hline modelée & 13 & 4,1 & & 1 & 1 & 1 \\
\hline dolium & 3 & 1 & & & & 1 \\
\hline
\end{tabular}

\begin{tabular}{|c|c|c|c|c|c|}
\hline \multicolumn{6}{|l|}{ PHASE 3A } \\
\hline US & Catégorie & Nbre & Objet & Type & Loc. \\
\hline 1010 & amphore africaine & 1 & amphore & & anse \\
\hline 1010 & amphore de Bétique & 1 & amphore & Dessel 7/11 & bord \\
\hline 1010 & amphore de Bétique & 1 & amphore & Dressel 20 & anse \\
\hline 1010 & amphore de Taraconaise & 1 & amphore & & fond \\
\hline 1010 & amphore gauloise & 1 & amphore & Dressel 2/4 & anse \\
\hline 1010 & amphore gauloise & 1 & amphore & G2 & bord \\
\hline 1010 & amphore gauloise & 1 & amphore & G4 & anse \\
\hline 1010 & amphore gauloise & 1 & amphore & G6 & bord \\
\hline 1010 & amphore gauloise & 5 & amphore & & anse \\
\hline 1010 & amphore indéterminée & 1 & amphore & & bord \\
\hline 1010 & amphore italique & 1 & amphore & Dressel 2/4 & anse \\
\hline 1010 & claire & 1 & amphore & & bord \\
\hline 1010 & claire & 1 & bassine & & bord \\
\hline 1010 & claire & 1 & coupe & $\begin{array}{l}\text { coupe à lèvre } \\
\text { pendante }\end{array}$ & bord \\
\hline 1010 & claire & 1 & coupe & $\begin{array}{l}\text { imitation de sigillée } \\
\text { RI } 1.1\end{array}$ & bord \\
\hline 1010 & claire & 4 & coupe & Pasqualini 1D & bord \\
\hline 1010 & claire & 2 & coupe & Pasqualini 4 & bord \\
\hline 1010 & claire & 4 & coupe & Pasqualini 6 & bord \\
\hline 1010 & claire & 1 & coupe & & fond \\
\hline 1010 & claire & 6 & cruche & & anse \\
\hline 1010 & claire & 5 & cruche & & bord \\
\hline 1010 & claire & 1 & gobelet & & anse \\
\hline 1010 & claire A & 1 & coupe & Hayes $14 \mathrm{~A}$ & bord \\
\hline 1010 & claire A & 1 & coupe & & fond \\
\hline 1010 & claire engobée & 1 & coupe & & fond \\
\hline 1010 & grise & 1 & pot à feu & & bord \\
\hline 1010 & grise du Verdon & 1 & pot à feu & & bord \\
\hline 1010 & modelée & 1 & pot à feu & Bérato 152 & bord \\
\hline 1010 & paroi fine & 1 & gobelet & Mayet 37/38 & bord \\
\hline 1010 & sigilée italique & 1 & coupe & Consp. 33.5 & bord \\
\hline 1010 & sigillée gauloise & 1 & assiette & Drag. 18 & bord \\
\hline 1010 & sigillée gauloise & 1 & coupe & Drag. 18 & bord \\
\hline 1010 & sigillée gauloise & 1 & coupe & Drag. 35 (Vea 1) & bord \\
\hline 1010 & sigillée gauloise & 1 & coupe & Drag. 37A & bord \\
\hline 1010 & sigillée gauloise & 1 & coupe & RI 12 & bord \\
\hline 1010 & sigillée gauloise & 1 & coupe & Ri 8B & bord \\
\hline
\end{tabular}




\begin{tabular}{|c|c|c|c|c|c|}
\hline \multicolumn{6}{|l|}{ PHASE 3A } \\
\hline US & Catégorie & Nbre & Objet & Type & Loc. \\
\hline 1010 & sigillée gauloise & 1 & coupe & & fond \\
\hline 1010 & sigillée italique & 1 & assiette & Consp. 3.1 & bord \\
\hline 1049 & amphore & 1 & amphore & Dressel 2/4 & anse \\
\hline 1049 & amphore gauloise & 1 & amphore & & anse \\
\hline 1049 & claire & 1 & coupe & $\begin{array}{l}\text { coupe à lèvre } \\
\text { pendante }\end{array}$ & bord \\
\hline 1049 & claire & 1 & coupe & Pasqualini 1D & bord \\
\hline 1049 & claire & 1 & coupe & Pasqualini 4 & bord \\
\hline 1049 & claire & 1 & coupe & Pasqualini 4 & bord \\
\hline 1049 & claire & 1 & cruche & & fond \\
\hline 1066 & claire & 1 & coupe & Pasqualini 1D & bord \\
\hline 1066 & claire & 1 & cruche & & anse \\
\hline 1066 & claire & 1 & cruche & & fond \\
\hline 1066 & modelée & 1 & pot à feu & Bérato 160 & bord \\
\hline 1066 & VRP & 1 & plat & Goudineau 15 & bord \\
\hline 1082 & amphore de Taraconaise & 1 & amphore & Dressel 2/4 & bord \\
\hline 1140 & amphore gauloise & 1 & amphore & G2 & bord \\
\hline 1140 & modelée & 1 & pot à feu & Bérato 160 & bord \\
\hline 1140 & VRP & 1 & plat & Goudineau 15 & bord \\
\hline 1151 & amphore de Bétique & 1 & amphore & & anse \\
\hline 1172 & claire & 1 & gobelet & & bord \\
\hline 1223 & claire & 1 & coupe & Pascual 1D & bord \\
\hline 1223 & claire & 1 & cruche & & anse \\
\hline 1223 & lampe & 1 & lampe & & anse \\
\hline 1227 & amphore de Bétique & 1 & amphore & Dressel 7/11 & fond \\
\hline 1227 & amphore italique & 1 & cruche & & anse \\
\hline 1227 & amphore massaliète impériale & 1 & amphore & AMI 6A & bord \\
\hline 1227 & claire & 1 & cruche & & bord \\
\hline 1232 & amphore africaine & 1 & amphore & Ostia 59 & bord \\
\hline 1232 & claire & 1 & cruche & Pasqualini B & bord \\
\hline 1232 & claire & 1 & & & fond \\
\hline 1232 & claire engobée & 1 & coupe & & fond \\
\hline 1232 & claire sableuse & 1 & cruche & & bord \\
\hline 1232 & modelée & 1 & pot à feu & Bérato 152 & bord \\
\hline 1232 & modelée & 1 & & & fond \\
\hline 1232 & sigillée gauloise & 1 & coupe & He 9 & bord \\
\hline 1232 & sigillée gauloise & 1 & coupe & Vertault A & bord \\
\hline 1232 & sigillée gauloise & 1 & coupe & & fond \\
\hline 1233 & amphore de Bétique & 1 & amphore & Dressel 7/11 & anse \\
\hline 1233 & amphore massaliète impériale & 1 & amphore & AMI 7A & bord \\
\hline 1233 & amphore massaliète impériale & 1 & amphore & & anse \\
\hline 1233 & brune & 1 & pot à feu & & bord \\
\hline 1233 & claire & 1 & cruche & & anse \\
\hline 1233 & claire & 1 & cruche & & bord \\
\hline
\end{tabular}




\begin{tabular}{|c|c|c|c|c|c|}
\hline \multicolumn{6}{|l|}{ PHASE 3A } \\
\hline US & Catégorie & Nbre & Objet & Type & Loc. \\
\hline 1248 & claire & 1 & & & fond \\
\hline 1262 & africaine de cuisine & 1 & plat & Hayes 23B & bord \\
\hline 1262 & amphore de Taraconaise & 1 & amphore & Dressel 2/4 & anse \\
\hline 1262 & amphore gauloise & 1 & amphore & & fond \\
\hline 1262 & dolium & 1 & dolium & Bd 8D & bord \\
\hline 1262 & paroi fine & 1 & & & fond \\
\hline 1263 & amphore de Bétique & 1 & amphore & Dressel 20 & fond \\
\hline 1263 & amphore gauloise & 1 & amphore & & anse \\
\hline 1263 & claire & 1 & bassine & & bord \\
\hline 1264 & amphore de Bétique & 1 & amphore & & fond \\
\hline 1264 & claire & 1 & coupe & & fond \\
\hline 1264 & claire & 1 & cruche & & anse \\
\hline 1264 & claire engobée & 1 & coupe & & fond \\
\hline 1265 & amphore africaine & 1 & amphore & Tripolitaine 1 & fond \\
\hline 1265 & dolium & 1 & dolium & & bord \\
\hline 1267 & amphore gauloise & 1 & amphore & G4 & bord \\
\hline 1267 & amphore gauloise & 1 & amphore & & anse \\
\hline 1267 & claire & 1 & amphore & & bord \\
\hline 1267 & claire & 1 & cruche & & anse \\
\hline 1267 & claire & 1 & & & fond \\
\hline 1267 & paroi fine & 1 & gobelet & & fond \\
\hline 1267 & sigillée gauloise & 1 & coupe & Drag. 29 & fond \\
\hline 2012 & amphore de Bétique & 1 & amphore & Dressel 7/11 & bord \\
\hline 2012 & claire & 1 & amphore & & anse \\
\hline 3133 & amphore italique & 1 & amphore & Dressel 2/4 & anse \\
\hline 3133 & kaolinitique & 1 & cruche & Goudineau 1 & bord \\
\hline 3163 & claire & 1 & cruche & & anse \\
\hline 3280 & amphore de Taraconaise & 1 & amphore & & fond \\
\hline 3280 & amphore gauloise & 1 & amphore & Dressel 2/4 & anse \\
\hline 3280 & amphore gauloise & 1 & amphore & G4 & anse \\
\hline 3283 & amphore gauloise & 1 & amphore & G5 & bord \\
\hline
\end{tabular}

\begin{tabular}{|c|c|c|c|c|c|c|c|}
\hline Catégorie & NR & $\%$ & anse & fond & bord & NMI & $\%$ \\
\hline amphore & 503 & 51,1 & 24 & 7 & 11 & 19 & 23,2 \\
\hline amphore africaine & 41 & 4,2 & 1 & 1 & 1 & 1 & 1,2 \\
\hline amphore de Bétique & 48 & 4,9 & 2 & 3 & 2 & 3 & 3,7 \\
\hline amphore de Taraconaise & 60 & 6,1 & 2 & 2 & & 2 & 2,4 \\
\hline amphore gauloise & 204 & 20,7 & 13 & 1 & 5 & 7 & 8,5 \\
\hline amphore indéterminée & 80 & 8,1 & 1 & & 1 & 1 & 1,2 \\
\hline amphore italique & 1 & 0,1 & 1 & & & 1 & 1,2 \\
\hline amphore italique & 48 & 4,9 & 3 & & & 2 & 2,4 \\
\hline
\end{tabular}




\begin{tabular}{|c|c|c|c|c|c|c|c|}
\hline Catégorie & NR & $\%$ & anse & fond & bord & NMI & $\%$ \\
\hline amphore massaliète & 21 & 2,1 & 1 & & 2 & 2 & 2,4 \\
\hline fine & 52 & 5,3 & 1 & 5 & 12 & 13 & 15,9 \\
\hline claire A & 5 & 0,5 & 1 & & 1 & 1 & 1,2 \\
\hline paroi fine & 5 & 0,5 & & 2 & 1 & 2 & 2,4 \\
\hline sigillée gauloise & 34 & 3,5 & & 3 & 8 & 8 & 9,8 \\
\hline sigillée italique & 8 & 0,8 & & & 2 & 2 & 2,4 \\
\hline commune & 411 & 41,7 & 13 & 12 & 43 & 47 & 57,3 \\
\hline africaine de cuisine & 3 & 0,3 & & & 1 & 1 & 1,2 \\
\hline brune & 5 & 0,5 & & & 2 & 2 & 2,4 \\
\hline claire & 350 & 35,5 & 13 & 8 & 31 & 31 & 37,8 \\
\hline claire engobée & 8 & 0,8 & & 3 & & 3 & 3,7 \\
\hline commune italique & 5 & 0,5 & & & & 1 & 1,2 \\
\hline grise & 4 & 0,4 & & & 1 & 1 & 1,2 \\
\hline grise du Verdon & 3 & 0,3 & & & 1 & 1 & 1,2 \\
\hline kaolinitique & 14 & 1,4 & & & 1 & 1 & 1,2 \\
\hline modelée & 17 & 1,7 & & 1 & 4 & 4 & 4,9 \\
\hline VRP & 2 & 0,2 & & & 2 & 2 & 2,4 \\
\hline dolium & 18 & 1,8 & & & 2 & 2 & 2,4 \\
\hline lampe & 1 & 0,1 & 1 & & & 1 & 1,2 \\
\hline
\end{tabular}

\begin{tabular}{|c|c|c|c|c|c|c|}
\hline \multicolumn{7}{|l|}{ PHASE 3B } \\
\hline US & Catégorie & Nbre & Objet & Type & Description & Loc. \\
\hline 1125 & africaine de cuisine & 1 & marmite & Hayes 197 & & bord \\
\hline 1125 & brune & 1 & couvercle & & & bord \\
\hline 1125 & claire & 1 & coupe & imitation de sigillée & imitation RI... & bord \\
\hline 1125 & claire & 1 & coupe & & & fond \\
\hline 1125 & claire A & 1 & plat & Hayes 6 & & bord \\
\hline 1247 & amphore africaine & 1 & amphore & africaine $1 \mathrm{~A}$ & & bord \\
\hline 1247 & claire & 1 & coupe & & & fond \\
\hline 1247 & claire & 4 & cruche & & & bord \\
\hline 1247 & claire A & 1 & coupe & & & fond \\
\hline 1247 & claire B & 1 & claire B & Desbat 8 & & bord \\
\hline 1247 & tuile & 1 & tuile & timbre Castoris & Castoris & bord \\
\hline 1252 & amphore de Bétique & 1 & amphore & Dressel 7/11 & & anse \\
\hline 1252 & amphore gauloise & 1 & amphore & G4 & & bord \\
\hline 1252 & brune & 1 & & & & fond \\
\hline 1252 & claire engobée & 1 & coupe & Pasqualini 6 & & bord \\
\hline 1252 & modelée & 1 & plat & Bérato 421 & & bord \\
\hline 1252 & sigillée gauloise & 1 & coupe & Drag. 27 & & bord \\
\hline 1266 & amphore de Bétique & 1 & amphore & Dressel 30 & & fond \\
\hline 1266 & amphore de Taraconaise & 1 & amphore & Pascual 1 & & bord \\
\hline 1266 & amphore gauloise & 1 & amphore & G3 & & bord \\
\hline 1266 & amphore gauloise & 2 & amphore & G4 & & bord \\
\hline 1266 & amphore gauloise & 2 & amphore & indét. & & bord \\
\hline 1266 & brune sableuse & 1 & gobelet & & & bord \\
\hline
\end{tabular}




\begin{tabular}{|c|c|c|c|c|c|c|}
\hline \multicolumn{7}{|l|}{ PHASE 3B } \\
\hline US & Catégorie & Nbre & Objet & Type & Description & Loc. \\
\hline 1266 & claire & 1 & cruche & & & anse \\
\hline 1266 & claire & 1 & cruche & & & fond \\
\hline 1266 & claire A & 1 & coupe & & & fond \\
\hline 1266 & modelée & 1 & pot à feu & Bérato 160 & & bord \\
\hline 1266 & sigillée italique & 1 & assiette & Consp. 3 & & bord \\
\hline 1291 & amphore de Bétique & 1 & amphore & Dressel 20F & & bord \\
\hline 1291 & amphore de Bétique & 1 & amphore & Dressel 7/11 & & bord \\
\hline 1291 & claire & 1 & cruche & & & bord \\
\hline 1291 & claire engobée & 2 & coupe & Pasqualini 1B & & bord \\
\hline 1291 & claire engobée & 1 & coupe & & & fond \\
\hline 3013 & claire & 1 & & & & fond \\
\hline 3130 & africaine de cuisine & 1 & couvercle & Hayes 196 & & bord \\
\hline 3130 & amphore africaine & 1 & amphore & & & fond \\
\hline 3130 & amphore de Bétique & 3 & amphore & & & anse \\
\hline 3130 & amphore de Taraconaise & 1 & amphore & & & anse \\
\hline 3130 & amphore gauloise & 1 & amphore & & & anse \\
\hline 3130 & amphore indéterminée & 1 & amphore & & & bord \\
\hline 3130 & claire & 1 & amphorette & & & bord \\
\hline 3130 & claire & 1 & cruche & & & anse \\
\hline 3130 & claire & 2 & cruche & & & bord \\
\hline 3130 & claire & 1 & & & & fond \\
\hline 3130 & kaolinitique & 1 & & & & fond \\
\hline 3132 & amphore de Taraconaise & 1 & amphore & Dressel 2/4 & & anse \\
\hline 3132 & paroi fine & 1 & gobelet & & & fond \\
\hline 3300 & amphore de Taraconaise & 1 & amphore & Dressel 2/4 & & anse \\
\hline 3300 & claire sableuse & 1 & plat & & & bord \\
\hline
\end{tabular}

\begin{tabular}{|c|c|c|c|c|c|c|c|}
\hline Catégorie & NR & $\%$ & anse & fond & bord & NMI & $\%$ \\
\hline amphore & 442 & 72,1 & 8 & 2 & 11 & 16 & 36,4 \\
\hline amphore africaine & 124 & 20,2 & & 1 & 1 & 1 & 2,3 \\
\hline amphore de Bétique & 105 & 17,1 & 4 & 1 & 2 & 4 & 9,1 \\
\hline amphore de Taraconaise & 42 & 6,9 & 3 & & 1 & 2 & 4,5 \\
\hline amphore gauloise & 79 & 18,9 & 1 & & 6 & 6 & 13,6 \\
\hline amphore indéterminée & 85 & 13,9 & & & 1 & 1 & 2,3 \\
\hline amphore italique & 6 & 1 & & & & 1 & 2,3 \\
\hline amphore massaliète & 1 & 0,2 & & & & 1 & 2,3 \\
\hline fine & 25 & 6,4 & & 3 & 6 & 6 & 13,6 \\
\hline claire A & 6 & 1 & & 2 & 1 & 2 & 4,5 \\
\hline claire B & 1 & 0,2 & & & 1 & 1 & 2,3 \\
\hline paroi fine & 5 & 0,8 & & 1 & & 1 & 2,3 \\
\hline sigillée gauloise & 8 & 1,3 & & & 1 & 1 & 2,3 \\
\hline sigillée italique & 1 & 0,2 & & & 1 & 1 & 2,3 \\
\hline commune & 148 & 24,1 & 3 & 8 & 16 & 21 & 47,7 \\
\hline africaine de cuisine & 4 & 0,7 & & & 2 & 2 & 4,5 \\
\hline
\end{tabular}




\begin{tabular}{|l|c|c|c|c|c|c|c|}
\hline \multicolumn{1}{|c|}{ Catégorie } & NR & \% & anse & fond & bord & NMI & \% \\
\hline brune & 9 & 1,5 & & 1 & 2 & 2 & 4,5 \\
\hline claire & 109 & 17,8 & 3 & 5 & 9 & 20,5 \\
\hline claire engobée & 11 & 1,8 & & 1 & 3 & 3 & 6,8 \\
\hline grise & 3 & 0,5 & & & & 1 & 1 \\
\hline grise du Verdon & 1 & 0,2 & & & & 2,3 \\
\hline kaolinitique & 7 & 1,1 & & & & 2,3 \\
\hline modelée & 4 & 0,7 & & & & 2,3 & 2,5 \\
\hline dolium & $\mathbf{2}$ & $\mathbf{0 , 3}$ & & & $\mathbf{2 , 3}$ \\
\hline
\end{tabular}

\begin{tabular}{|c|c|c|c|c|c|}
\hline \multicolumn{6}{|l|}{ PHASE 4A } \\
\hline US & Catégorie & Nbre & Objet & Type & Loc. \\
\hline 3035 & commune italique & 1 & marmite & & fond \\
\hline 3035 & sigillée italique & 1 & assiette & & fond \\
\hline 3179 & amphore gauloise & 2 & amphore & Dressel 2/4 & anse \\
\hline 3189 & amphore italique & 1 & amphore & Type Empoli & bord \\
\hline 3189 & amphore massaliète impériale & 1 & amphore & & anse \\
\hline 3189 & claire & 1 & gobelet & & bord \\
\hline 3189 & kaolinitique & 1 & cruche & Goudineau 1 & anse \\
\hline 3189 & paroi fine & 1 & gobelet & Mayet 37/38 & bord \\
\hline 3189 & sigillée gauloise & 1 & coupe & Drag. 37A & bord \\
\hline 3193 & sigillée gauloise & 1 & assiette & Drag. 15 & bord \\
\hline 3207 & modelée & 1 & Pot à feu & Bérato 150 & bord \\
\hline 3210 & claire & 1 & cruche & Pasqualini B & bord \\
\hline 3210 & commune italique & 1 & & COM IT 3 & bord \\
\hline 3211 & modelée & 1 & plat & Bérato 421 & bord \\
\hline 3228 & amphore gauloise & & amphore & & fond \\
\hline 3239 & modelée & 1 & & & fond \\
\hline 3251 & claire & 1 & cruche & Pasqualini A & bord \\
\hline 3309 & amphore gauloise & 1 & amphore & & fond \\
\hline 3309 & claire & 1 & & & fond \\
\hline 3314 & brune/grise & 1 & pot à feu & & bord \\
\hline 3314 & claire & 1 & amphore & G5 & bord \\
\hline 3314 & claire & 1 & & & fond \\
\hline 3314 & modelée & 1 & gobelet & & anse \\
\hline 3314 & modelée & 1 & & & fond \\
\hline 3319 & claire & 1 & & & fond \\
\hline 3335 & amphore africaine & 28 & & africaine 1B & bord \\
\hline 3335 & paroi fine & 1 & & & fond \\
\hline 3339 & claire & 1 & coupe & Pasqualini 8 & bord \\
\hline 3341 & amphore de Bétique & 1 & amphore & Dressel 20E & bord \\
\hline 3341 & claire & 1 & cruche & & fond \\
\hline 3341 & claire & 1 & & CL REC 16F & bord \\
\hline 3341 & claire & 1 & & & fond \\
\hline 3341 & claire engobée & 1 & cruche & & fond \\
\hline 3341 & paroi fine & 1 & & Mayet 37/38 & fond \\
\hline
\end{tabular}


INVENTAIRES

\begin{tabular}{|c|c|c|c|c|c|c|c|}
\hline Catégorie & NR & $\%$ & anse & fond & bord & NMI & $\%$ \\
\hline amphore & 2833 & 95,4 & & & & 20 & 52,6 \\
\hline amphore africaine & 2748 & 92,6 & & 14 & 14 & 14 & 36,8 \\
\hline amphore de Bétique & 11 & 0,4 & & & 1 & 1 & 2,6 \\
\hline amphore de Taraconaise & 8 & 0,3 & & & & 1 & 2,6 \\
\hline amphore gauloise & 33 & 1,1 & 2 & 2 & & 1 & 2,6 \\
\hline amphore indéterminée & 26 & 0,9 & & & 1 & 1 & 2,6 \\
\hline amphore italique & 3 & 0,1 & & & & 1 & 2,6 \\
\hline amphore massaliète & 4 & 0,1 & 1 & & & 1 & 2,6 \\
\hline fine & 16 & 0,5 & & & & 5 & 13,2 \\
\hline paroi fine & 5 & 0,2 & & 2 & 1 & 2 & 5,3 \\
\hline sigillée gauloise & 8 & 0,3 & & & 2 & 2 & 5,3 \\
\hline sigillée italique & 3 & 0,1 & & 1 & & 1 & 2,6 \\
\hline commune & 120 & 4,0 & & & & 13 & 34,2 \\
\hline brune & 6 & 0,2 & & & 1 & 1 & 2,6 \\
\hline claire & 81 & 2,7 & & 5 & 5 & 5 & 13,2 \\
\hline claire engobée & 10 & 0,3 & & 1 & & 1 & 2,6 \\
\hline commune italique & 3 & 0,1 & & 1 & 1 & 1 & 2,6 \\
\hline grise & 2 & 0,1 & & & & 1 & 2,6 \\
\hline kaolinitique & 2 & 0,1 & 1 & & & 1 & 2,6 \\
\hline modelée & 15 & 0,5 & 1 & 2 & 2 & 2 & 5,3 \\
\hline VRP & 1 & 0,0 & & & & 1 & 2,6 \\
\hline
\end{tabular}

\begin{tabular}{|c|c|c|c|c|c|}
\hline \multicolumn{6}{|l|}{ PHASE 4B } \\
\hline US & Catégorie & Nbre & Objet & Type & Loc. \\
\hline 3140 & claire & 1 & cruche & & anse \\
\hline 3180 & amphore de Bétique & 1 & amphore & Dressel 7/11 & anse \\
\hline 3180 & amphore gauloise & 1 & amphore & G4 & bord \\
\hline 3180 & amphore gauloise & 1 & amphore & & anse \\
\hline 3180 & claire & 1 & cruche & & anse \\
\hline 3196 & amphore africaine & 1 & amphore & & fond \\
\hline 3196 & amphore gauloise & 2 & amphore & G4 & bord \\
\hline 3196 & brune & 1 & pot à feu & & fond \\
\hline 3196 & claire & 1 & cruche & Pasqualini B & bord \\
\hline 3198 & liguro-provençale & 1 & pot à feu & & bord \\
\hline 3200 & amphore africaine & 1 & amphore & africaine $3 \mathrm{~B}$ & bord \\
\hline 3200 & amphore africaine & 1 & amphore & Ostia 59 & bord \\
\hline 3200 & claire & 1 & cruche & & anse \\
\hline 3200 & paroi fine & 1 & gobelet & & fond \\
\hline 3205 & amphore gauloise & 1 & amphore & & fond \\
\hline 3205 & amphore massaliète impériale & 1 & amphore & AMI 7A & bord \\
\hline 3205 & amphore massaliète impériale & 1 & amphore & & fond \\
\hline 3205 & claire & 1 & coupe & Pasqualini 6 & bord \\
\hline 3205 & claire & 1 & coupe & & bord \\
\hline 3205 & claire & 1 & coupe & & fond \\
\hline 3205 & paroi fine & 1 & gobelet & & anse \\
\hline 3205 & sigillée gauloise & 1 & coupe & & fond \\
\hline
\end{tabular}




\begin{tabular}{|c|c|c|c|c|c|}
\hline \multicolumn{6}{|l|}{ PHASE 4B } \\
\hline US & Catégorie & Nbre & Objet & Type & Loc. \\
\hline 3222 & amphore africaine & 1 & & & anse \\
\hline 3222 & brune & 1 & & & fond \\
\hline 3222 & claire & 1 & cruche & & anse \\
\hline 3222 & claire A & 1 & coupe & Hayes 8 & bord \\
\hline 3222 & claire engobée & 1 & coupe & & fond \\
\hline 3225 & paroi fine & 1 & gobelet & Mayet $37 / 38$ & anse \\
\hline 3245 & amphore italique & 1 & & & anse \\
\hline 3245 & amphore massaliète impériale & 1 & amphore & & anse \\
\hline 3245 & amphore massaliète impériale & 1 & & & fond \\
\hline 3245 & liguro-provençale & 1 & pot à feu & & bord \\
\hline 3245 & modelée & 1 & pot à feu & & fond \\
\hline 3248 & amphore de Bétique & 1 & amphore & Dressel 7/11 & bord \\
\hline 3248 & amphore gauloise & 1 & amphore & & fond \\
\hline 3254 & amphore indéterminée & 1 & amphore & & fond \\
\hline 3254 & claire & 1 & coupe & & fond \\
\hline 3254 & claire & 1 & cruche & Pasqualini 1 & bord \\
\hline 3254 & claire & 1 & cruche & & bord \\
\hline 3263 & amphore de Bétique & 1 & amphore & Dessel 7/11 & anse \\
\hline 3263 & amphore gauloise & 1 & amphore & & fond \\
\hline 3263 & claire & 1 & cruche & & bord \\
\hline 3263 & claire & 1 & cruche & & fond \\
\hline 3321 & amphore de Bétique & 1 & amphore & Dressel 7/11 & anse \\
\hline 3321 & amphore de Taraconaise & 1 & amphore & & anse \\
\hline 3321 & amphore de Taraconaise & 1 & amphore & & anse \\
\hline 3321 & amphore italique & 1 & amphore & Keay LII & bord \\
\hline 3321 & amphore massaliète impériale & 1 & amphore & AMI 7A & bord \\
\hline 3321 & amphore massaliète impériale & 1 & amphore & & anse \\
\hline 3321 & claire & 1 & & & fond \\
\hline 3321 & liguro-Provençale & 1 & pot à feu & & fond \\
\hline 3338 & africaine de cuisine & 1 & couvercle & Hayes 196 & bord \\
\hline 3338 & liguro-provençale & 1 & pot à feu & & fond \\
\hline 3340 & amphore de Bétique & 2 & amphore & Dressel 7/11 & anse \\
\hline 3340 & claire engobée & 1 & coupe & & fond \\
\hline 3340 & lampe & 1 & lampe & médaillon & frag. \\
\hline
\end{tabular}

\begin{tabular}{|c|c|c|c|c|c|c|c|}
\hline Catégorie & NR & $\%$ & anse & fond & bord & NMI & $\%$ \\
\hline amphore & 250 & 54,9 & & & & 14 & 37,8 \\
\hline amphore africaine & 71 & 16,6 & 1 & 1 & 2 & 2 & 5,4 \\
\hline amphore de Bétique & 32 & 6,1 & 5 & & 1 & 3 & 8,1 \\
\hline amphore de Taraconaise & 11 & 1,5 & 2 & & & 1 & 3,3 \\
\hline amphore gauloise & 39 & 7 & 1 & 4 & 2 & 4 & 10,9 \\
\hline amphore indéterminée & 77 & 20,9 & & 1 & & 1 & 2,7 \\
\hline amphore italique & 6 & 1,5 & 1 & & 1 & 1 & 2,7 \\
\hline
\end{tabular}




\begin{tabular}{|c|c|c|c|c|c|c|c|}
\hline Catégorie & NR & $\%$ & anse & fond & bord & NMI & $\%$ \\
\hline amphore massaliète & 14 & 2,0 & 2 & 2 & 2 & 2 & 5,4 \\
\hline fine & 16 & 3,6 & & & & 4 & 10,8 \\
\hline claire A & 3 & 0,9 & & & 1 & 1 & 2,7 \\
\hline paroi fine & 5 & 0,9 & 2 & 1 & & 1 & 2,7 \\
\hline sigillée gauloise & 7 & 1,5 & & 1 & & 1 & 2,7 \\
\hline sigillée italique & 1 & 0,3 & & & & 1 & 2,7 \\
\hline commune & 186 & 41,3 & & & & 17 & 50 \\
\hline africaine de cuisine & 5 & 1,5 & & & 1 & 1 & 2,7 \\
\hline brune & 8 & 2,3 & & 2 & & 2 & 5,4 \\
\hline claire & 150 & 30,2 & 4 & 5 & 6 & 6 & 16,2 \\
\hline claire engobée & 3 & 0,9 & & 2 & & 2 & 6,7 \\
\hline grise du Verdon & 2 & 0,6 & & & & 1 & 2,7 \\
\hline kaolinitique & 3 & 0,9 & & & & 1 & 2,7 \\
\hline liguro-provençale & 5 & 1,5 & & 2 & 2 & 2 & 5,4 \\
\hline modelée & 9 & 2,6 & & 1 & & 1 & 2,7 \\
\hline VRP & 1 & 0,3 & & & & 1 & 2,7 \\
\hline \multirow[t]{2}{*}{ lampe } & 1 & 0,2 & & & & 1 & 2,7 \\
\hline & 448 & & & & & 37 & \\
\hline
\end{tabular}

\begin{tabular}{|c|c|c|c|c|c|}
\hline \multicolumn{6}{|l|}{ PHASE 4C } \\
\hline US & Catégorie & Nbre & Objet & Type & Loc. \\
\hline 3025 & amphore africaine & 1 & amphore & africaine 2 & bord \\
\hline 3025 & amphore gauloise & 1 & amphore & G4 & bord \\
\hline 3025 & amphore gauloise & 1 & amphore & & anse \\
\hline 3025 & amphore gauloise & 1 & amphore & & anse \\
\hline 3025 & amphore gauloise & 1 & amphore & & fond \\
\hline 3025 & amphore gauloise & 1 & amphore & & fond \\
\hline 3025 & amphore gauloise & 1 & amphore & & fond \\
\hline 3025 & amphore indéterminée & 1 & amphore & & bord \\
\hline 3025 & brune & 6 & cruche & & anse \\
\hline 3025 & claire & 1 & cruche & & bord \\
\hline 3025 & claire & 4 & cruche & & fond \\
\hline 3025 & claire & 1 & & Pasqualini B & bord \\
\hline 3025 & claire engobée & 1 & & & fond \\
\hline 3025 & commune italique & 1 & plat & COM IT 6 & bord \\
\hline 3025 & commune italique & 1 & & & fond \\
\hline 3025 & modelée & 2 & pot à feu & Bérato 160 & bord \\
\hline 3025 & modelée & 1 & & & anse \\
\hline 3025 & sigillée gauloise & 1 & assiette & Drag. 18 & bord \\
\hline 3025 & sigillée gauloise & 1 & coupe & Drag. $24 / 25$ & bord \\
\hline 3025 & sigillée italique & 1 & assiette & SIG IT 4 & bord \\
\hline 3164 & amphore gauloise & 1 & amphore & Dressel 2/4 & anse \\
\hline
\end{tabular}




\begin{tabular}{|c|c|c|c|c|c|}
\hline \multicolumn{6}{|l|}{ PHASE 4C } \\
\hline US & Catégorie & Nbre & Objet & Type & Loc. \\
\hline 3164 & amphore gauloise & 1 & amphore & & anse \\
\hline 3164 & amphore massaliète & 1 & amphore & AMI 6a & bord \\
\hline 3164 & brune & 1 & pot & & bord \\
\hline 3164 & claire & 1 & amphorette & & bord \\
\hline 3164 & claire & 1 & coupe & Pasqualini 1D & bord \\
\hline 3164 & claire & 1 & cruche & & bord \\
\hline 3164 & claire & 1 & mortier & Pasqualini 6 & bord \\
\hline 3164 & claire & 2 & & & fond \\
\hline 3164 & claire $\mathrm{A}$ & 1 & coupe & & fond \\
\hline 3164 & modelée & 1 & pot à feu & & fond \\
\hline 3164 & sigillée italique & 1 & assiette & SIG IT 20 & bord \\
\hline 3194 & claire & 1 & Pasqualini 6 & & bord \\
\hline 3194 & claire & 1 & & & fond \\
\hline 3194 & VRP & 1 & plat & Goudineau 15 & bord \\
\hline 3204 & sigillée gauloise & 1 & assiette & Drag. 18 & bord \\
\hline 3224 & amphore africaine & 1 & amphore & & fond \\
\hline 3224 & amphore de Bétique & 1 & amphore & & anse \\
\hline 3224 & amphore de Taraconaise & 1 & amphore & Dressel 2/4 & anse \\
\hline 3224 & claire & 2 & & & fond \\
\hline 3224 & sigillée italique & 1 & assiette & Consp. 19 & fond \\
\hline 3250 & amphore de Bétique & 1 & amphore & & anse \\
\hline 3250 & amphore indéterminée & 1 & amphore & & anse \\
\hline 3250 & amphore italique & 1 & amphore & & fond \\
\hline 3250 & claire & 1 & coupe & Pasqualini 4 & bord \\
\hline 3250 & claire & 1 & & & fond \\
\hline 3250 & tuile & 1 & opercule & & bord \\
\hline 3334 & claire & 1 & coupe & Pasqualini 8 & bord \\
\hline 3334 & lampe & 1 & lampe & & anse \\
\hline
\end{tabular}

\begin{tabular}{|c|c|c|c|c|c|c|c|}
\hline Catégorie & NR & $\%$ & anse & fond & bord & NMI & $\%$ \\
\hline amphore & 214 & 46,6 & & & & 9 & 29,1 \\
\hline amphore africaine & 65 & 13,7 & & 1 & 1 & 1 & 3,2 \\
\hline amphore de Bétique & 19 & 5,2 & 2 & & & 1 & 3,2 \\
\hline amphore de Taraconaise & 18 & 4,2 & 1 & & & 1 & 3,2 \\
\hline amphore gauloise & 61 & 13,1 & 4 & 2 & 2 & 2 & 6,4 \\
\hline amphore indéterminée & 35 & 6,9 & 1 & & 1 & 1 & 3,2 \\
\hline amphore italique & 9 & 1,8 & & 1 & 2 & 2 & 6,4 \\
\hline amphore massaliète & 7 & 1,4 & & & & 1 & 3,2 \\
\hline fine & 22 & 4,7 & & & & 5 & 16,1 \\
\hline claire A & 4 & 0,8 & & 1 & & 1 & 3,2 \\
\hline sigillée gauloise & 14 & 2,5 & & & 3 & 3 & 9,6 \\
\hline sigillée italique & 4 & 0,8 & & 1 & 1 & 1 & 3,2 \\
\hline commune & 223 & 47,9 & & & & 16 & 51,6 \\
\hline
\end{tabular}




\begin{tabular}{|c|c|c|c|c|c|c|c|}
\hline Catégorie & NR & $\%$ & anse & fond & bord & NMI & $\%$ \\
\hline brune & 5 & 1,0 & 1 & & 1 & 1 & 3,2 \\
\hline claire & 170 & 38,1 & 5 & 10 & 9 & 10 & 32,0 \\
\hline claire engobée & 2 & 0,4 & & 1 & & 1 & 3,2 \\
\hline commune italique & 2 & 0,4 & & 1 & 1 & 1 & 3,2 \\
\hline modelée & 43 & 8,0 & 1 & 2 & 1 & 2 & 6,4 \\
\hline VRP & 1 & 0,2 & & & 1 & 1 & 3,2 \\
\hline \multirow[t]{2}{*}{ lampe } & 4 & 0,8 & 1 & & & 1 & 3,2 \\
\hline & 463 & 100 & & & & 31 & 100 \\
\hline
\end{tabular}

\begin{tabular}{|c|c|c|c|c|c|}
\hline \multicolumn{6}{|l|}{ PHASE 5A } \\
\hline US & Catégorie & Nbre & Objet & Type & Loc. \\
\hline 1007 & amphore gauloise & 1 & amphore & & anse \\
\hline 1007 & amphore gauloise & 1 & amphore & G4 & bord \\
\hline 1007 & amphore indéterminée & 1 & amphore & & anse \\
\hline 1007 & claire & 3 & cruche & & anse \\
\hline 1007 & claire & 1 & couvercle & & bord \\
\hline 1007 & claire & 1 & cruche & Pasqualini B & bord \\
\hline 1007 & claire & 1 & mortier & Pasqualini 6 & bord \\
\hline 1007 & claire & 1 & & & fond \\
\hline 1007 & glaçurée & 2 & & & fond \\
\hline 1007 & glaçurée blanche & 1 & pot & & fond \\
\hline 1007 & glaçurée jaune & 3 & coupe & & bord \\
\hline 1007 & glaçurée jaune & 2 & coupe & & fond \\
\hline 1007 & glaçurée verte & 1 & coupe & & bord \\
\hline 1007 & jarre glaçurée & 2 & & & fond \\
\hline 1007 & modelée & 1 & plat & Bérato 421 & bord \\
\hline 1131 & claire & 1 & coupe & Pasqualini 6 & bord \\
\hline 1131 & claire A & 1 & coupe & Hayes 14B & bord \\
\hline 1131 & claire D & 1 & claire D & Hayes 91 & fond \\
\hline 1131 & culinaire blanche & 1 & pot & & bord \\
\hline 1131 & glaçurée jaune & 1 & coupe & & bord \\
\hline 1131 & glaçurée jaune & 2 & jatte & & bord \\
\hline 1131 & glaçureé jaune orangée & 1 & & & fond \\
\hline 1131 & glaçurée monochome & 1 & coupe & & bord \\
\hline 1131 & glaçurée orangée & 2 & coupe & & bord \\
\hline 1131 & glaçurée orangée & 1 & coupe & & fond \\
\hline 1131 & glaçurée verte & 1 & coupe & & bord \\
\hline 1131 & grise & 1 & & & anse \\
\hline 1131 & jarre glaçurée & 2 & & & fond \\
\hline 1131 & paroi fine & 1 & & & fond \\
\hline 1131 & sigillée italique & 1 & assiette & Consp. 3 & bord \\
\hline 2003 & africaine de cuisine & 1 & marmite & Hayes 197 & bord \\
\hline 2003 & amphore africaine & 1 & amphore & & anse \\
\hline 2003 & amphore africaine & 1 & amphore & africaine $1 \mathrm{~B}$ & bord \\
\hline 2003 & amphore de Bétique & 1 & amphore & & anse \\
\hline 2003 & amphore de Taraconaise & 1 & amphore & & fond \\
\hline
\end{tabular}




\begin{tabular}{|c|c|c|c|c|c|}
\hline \multicolumn{6}{|l|}{ PHASE 5A } \\
\hline US & Catégorie & Nbre & Objet & Type & Loc. \\
\hline 2003 & amphore indéterminée & 1 & amphore & & anse \\
\hline 2003 & amphore massaliète impériale & 1 & amphore & Dressel 2/4 & anse \\
\hline 2003 & opercule & 1 & opercule & & bord \\
\hline 2005 & africaine de cuisine & 1 & couvercle & Hayes 196 & bord \\
\hline 2005 & africaine de cuisine & 1 & marmite & Hayes 197 & bord \\
\hline 2005 & africaine de cuisine & 1 & & Hayes 26 & bord \\
\hline 2005 & amphore de Bétique & 1 & amphore & Dressel 7/11 & anse \\
\hline 2005 & amphore de Bétique & 1 & amphore & Pascual 1 & bord \\
\hline 2005 & amphore de Taraconaise & 1 & amphore & Dressel 2/4 & anse \\
\hline 2005 & amphore de Taraconaise & 1 & amphore & & bord \\
\hline 2005 & amphore gauloise & 1 & amphore & G4 & bord \\
\hline 2005 & amphore gauloise & 2 & amphore & & fond \\
\hline 2005 & amphore indéterminée & 1 & amphore & & anse \\
\hline 2005 & amphore italique & 1 & amphore & Dressel 2/4 & anse \\
\hline 2005 & amphore massaliète impériale & 1 & amphore & & anse \\
\hline 2005 & claire & 2 & cruche & & anse \\
\hline 2005 & claire engobée & 1 & pot & & bord \\
\hline 2005 & commune moderne & 1 & & & anse \\
\hline 2005 & glaçurée & 1 & cruche & & anse \\
\hline 2005 & glaçurée & 1 & pot & & fond \\
\hline 2005 & glaçurée jaune & 1 & cruche & & anse \\
\hline 2005 & glaçurée jaune & 4 & assiette & & bord \\
\hline 2005 & glaçurée jaune & 5 & coupe & & bord \\
\hline 2005 & glaçurée jaune & 2 & cruche & & bord \\
\hline 2005 & glaçurée jaune & 1 & pot & & bord \\
\hline 2005 & glaçurée jaune & 1 & coupe & & fond \\
\hline 2005 & glaçurée maron & 1 & pot & & bord \\
\hline 2005 & glaçurée verte & 3 & coupe & & bord \\
\hline 2005 & graffite polychrome & 1 & coupe & & fond \\
\hline 2005 & graffite polychrome & 1 & coupe & & fond \\
\hline 2005 & grise & 1 & cruche & & bord \\
\hline 2005 & grise & 1 & pot & & bord \\
\hline 2005 & opercule & 1 & opercule & & bord \\
\hline 2005 & orangée sableuse & 2 & & & anse \\
\hline 2005 & orangée sableuse & 1 & couvercle & & bord \\
\hline 2005 & orangée sableuse & 1 & pot & & bord \\
\hline 2005 & paroi fine & 1 & gobelet & & fond \\
\hline 2005 & sigillée gauloise & 1 & coupe & Drag. 37A & bord \\
\hline 2005 & sigillée italique & 2 & assiette & & fond \\
\hline 2005 & sigillée italique & 1 & coupe & timbre Xanthi & fond \\
\hline 2009 & claire & 1 & coupe & & fond \\
\hline 2014 & amphore gauloise & 1 & amphore & G4 & bord \\
\hline 2014 & amphore gauloise & 1 & amphore & & fond \\
\hline 2014 & amphore massaliète impériale & 1 & amphore & & anse \\
\hline 2014 & claire & 1 & cruche & & anse \\
\hline
\end{tabular}




\begin{tabular}{|c|c|c|c|c|c|}
\hline \multicolumn{6}{|l|}{ PHASE 5A } \\
\hline US & Catégorie & Nbre & Objet & Type & Loc. \\
\hline 2014 & claire & 3 & cruche & Pasqualini B & bord \\
\hline 2014 & claire & 1 & pot & & bord \\
\hline 2014 & claire & 1 & coupe & & fond \\
\hline 2014 & claire & 1 & & & fond \\
\hline 2014 & claire & 1 & & & fond \\
\hline 2014 & claire A & 1 & coupe & Hayes 9B & bord \\
\hline 2014 & glaçurée blanche & 1 & coupe & & bord \\
\hline 2014 & glaçurée blanche & 1 & coupe & carénée & bord \\
\hline 2014 & glaçurée jaune & 3 & coupe & bord bandeau & bord \\
\hline 2014 & glaçurée jaune & 1 & coupe & & bord \\
\hline 2014 & glaçurée jaune & 1 & cruche & & bord \\
\hline 2014 & glaçurée jaune & 4 & & & fond \\
\hline 2014 & paroi fine & 1 & gobelet & Mayet 36 & bord \\
\hline 2014 & paroi fine & 1 & gobelet & & fond \\
\hline 2014 & sigillée gauloise & 1 & assiette & Drag. 18 & bord \\
\hline 2014 & sigillée italique & 1 & assiette & consp. 14 & bord \\
\hline 2014 & sigillée italique & 1 & assiette & Consp. 18.2 & bord \\
\hline 2014 & sigillée italique & 1 & assiette & Consp. 22 & bord \\
\hline 2014 & sigillée italique & 1 & coupe & Consp. 36 & bord \\
\hline 2014 & sigillée italique & 1 & assiette & & fond \\
\hline 2014 & VRP & 1 & plat & G15 & bord \\
\hline 2014 & VRP & 1 & plat & & fond \\
\hline 2019 & amphore gauloise & 1 & amphore & & anse \\
\hline 2019 & amphore gauloise & 1 & amphore & & fond \\
\hline 2019 & glaçurée jaune & 1 & & & anse \\
\hline 2020 & claire & 1 & coupe & & fond \\
\hline 2031 & amphore africaine & 1 & amphore & & anse \\
\hline 2031 & amphore africaine & 1 & amphore & africaine ancienne & bord \\
\hline 2031 & amphore africaine & 1 & amphore & Ostia 59 & fond \\
\hline 2031 & amphore gauloise & 1 & amphore & G4 & bord \\
\hline 2031 & amphore indéterminée & 1 & amphore & & bord \\
\hline 2031 & claire & 1 & bassine & & bord \\
\hline 2031 & claire & 1 & couvercle & & fond \\
\hline 2034 & amphore gauloise & 1 & amphore & G3 & bord \\
\hline 2034 & graffite polychrome & 1 & coupe & & fond \\
\hline 3012 & amphore africaine & 2 & amphore & africaine $1 \mathrm{~B}$ & bord \\
\hline 3012 & amphore de Bétique & 1 & amphore & Dressel 20 & anse \\
\hline 3012 & amphore de Bétique & 1 & amphore & & anse \\
\hline 3012 & amphore de Taraconaise & 1 & amphore & & anse \\
\hline 3012 & amphore gauloise & 1 & amphore & & anse \\
\hline 3012 & amphore indéterminée & 1 & amphore & & anse \\
\hline 3012 & amphore massaliète impériale & 1 & amphore & & anse \\
\hline 3012 & amphore massaliète impériale & 1 & amphore & & fond \\
\hline 3012 & claire & 1 & cruche & & anse \\
\hline 3012 & claire & 2 & cruche & & fond \\
\hline
\end{tabular}




\begin{tabular}{|c|c|c|c|c|c|}
\hline \multicolumn{6}{|l|}{ PHASE 5A } \\
\hline US & Catégorie & Nbre & Objet & Type & Loc. \\
\hline 3012 & claire engobée & 1 & coupe & & fond \\
\hline 3022 & amphore de Bétique & 1 & amphore & Dressel 7/11 & bord \\
\hline 3022 & amphore gauloise & 1 & amphore & & anse \\
\hline 3022 & amphore gauloise & 1 & amphore & G4 & bord \\
\hline 3022 & glaçurée jaune & 1 & assiette & & bord \\
\hline 3022 & paroi fine & 1 & gobelet & & fond \\
\hline 3026 & glaçurée jaune & 1 & coupe & & fond \\
\hline 3026 & glaçurée jaune & 1 & coupe & & fond \\
\hline 3030 & amphore indéterminée & 1 & amphore & & anse \\
\hline 3030 & amphore indéterminée & 1 & opercule & retaillé dans tuile & bord \\
\hline 3030 & glaçurée jaune & 3 & assiette & & bord \\
\hline 3031 & glaçurée verte & 1 & toupin & & bord \\
\hline 3031 & glaçurée verte & 1 & coupe & & fond \\
\hline 3034 & claire & 1 & & & anse \\
\hline 3034 & claire & 1 & & & fond \\
\hline 3034 & claire A & 1 & coupe & Hayes 9A & bord \\
\hline 3034 & sigillée gauloise & 1 & coupe & Drag. 37 & bord \\
\hline 3034 & sigillée italique & 1 & coupe & SIG IT 23 & bord \\
\hline 3034 & unguentarium & 1 & unguentarium & & fond \\
\hline 3046 & amphore de Bétique & 1 & amphore & Dressel 20 & anse \\
\hline 3046 & amphore de Taraconaise & 1 & amphore & Dessel 7/11 & bord \\
\hline 3046 & amphore de Taraconaise & 1 & amphore & & fond \\
\hline 3046 & amphore gauloise & 2 & amphore & & fond \\
\hline 3046 & amphore italique & 1 & amphore & Dressel 2/4 & fond \\
\hline 3046 & claire & 1 & coupe & Pasqualini 6 & bord \\
\hline 3046 & claire & 1 & cruche & & bord \\
\hline 3046 & claire & 1 & coupe & & fond \\
\hline 3046 & glaçurée jaune & 1 & & & fond \\
\hline 3046 & modelée & 1 & pot à feu & Bérato 152 & bord \\
\hline 3046 & sigillée gauloise & 1 & coupe & Ritterling 12 & bord \\
\hline 3046 & sigillée italique & 1 & gobelet & Timbre illisible & fond \\
\hline 3049 & amphore africaine & 1 & amphore & africaine 1 & bord \\
\hline 3049 & amphore africaine & 1 & amphore & africaine 2 & bord \\
\hline 3049 & amphore de Bétique & 1 & amphore & & anse \\
\hline 3049 & amphore gauloise & 1 & amphore & & fond \\
\hline 3049 & claire & 1 & & & fond \\
\hline 3049 & sigillée gauloise & 1 & coupe & Drag. 29 & bord \\
\hline 3057 & amphore de Bétique & 2 & amphore & Dressel 7/11 & anse \\
\hline 3065 & amphore gauloise & 1 & & & anse \\
\hline
\end{tabular}

\begin{tabular}{|l|c|c|c|c|c|c|c|}
\hline \multicolumn{1}{|c|}{ Catégorie } & NR & $\mathbf{\%}$ & anse & fond & bord & loc. & \% \\
\hline amphore & $\mathbf{3 3 1}$ & $\mathbf{3 8 , 4}$ & $\mathbf{2 0}$ & $\mathbf{1 1}$ & $\mathbf{1 7}$ & $\mathbf{2 0}$ & $\mathbf{1 7 , 8}$ \\
\hline amphore africaine & 66 & 7,7 & 2 & & 4 & 4 & 3,6 \\
\hline amphore de Bétique & 29 & 3,4 & 5 & 1 & 2 & 3 & 2,6 \\
\hline
\end{tabular}


INVENTAIRES

\begin{tabular}{|c|c|c|c|c|c|c|c|}
\hline Catégorie & NR & $\%$ & anse & fond & bord & loc. & $\%$ \\
\hline amphore de Taraconaise & 17 & 1,2 & 1 & 2 & 2 & 2 & 1,8 \\
\hline amphore gauloise & 105 & 12,2 & 5 & 7 & 7 & 7 & 6,3 \\
\hline amphore indéterminée & 92 & 10,7 & 4 & & 2 & 2 & 1,8 \\
\hline amphore italique & 8 & 0,9 & 1 & 1 & & 1 & 0,9 \\
\hline amphore massaliète & 14 & 1,6 & 2 & & & 1 & 0,9 \\
\hline fine & 105 & 12,2 & & 10 & 15 & 19 & 17 \\
\hline claire A & 5 & 0,6 & & & 3 & 3 & 2,6 \\
\hline claire D & 1 & 0,1 & & 1 & & 1 & 0,9 \\
\hline paroi fine & 24 & 2,8 & & 4 & 1 & 4 & 3,6 \\
\hline sigillée gauloise & 48 & 5,6 & & & 5 & 5 & 4,5 \\
\hline sigillée italique & 27 & 3,1 & & 5 & 6 & 6 & 5,4 \\
\hline commune & 221 & 25,7 & 11 & 11 & 23 & 25 & 22,3 \\
\hline africaine de cuisine & 4 & 0,5 & & & 4 & 4 & 3,6 \\
\hline brune & 15 & 1,7 & 2 & & 2 & 2 & 1,8 \\
\hline claire & 158 & 18,4 & 8 & 10 & 11 & 11 & 9,8 \\
\hline claire engobée & 3 & 0,3 & & & 1 & 1 & 0,9 \\
\hline commune italique & 3 & 0,3 & & & & 1 & 0,9 \\
\hline grise & 11 & 1,3 & 1 & & 2 & 2 & 1,8 \\
\hline kaolinitique & 3 & 0,3 & & & & 1 & 0,9 \\
\hline modelé & 14 & 1,6 & & & 1 & 1 & 0,9 \\
\hline unguentarium & 3 & 0,3 & & & 1 & 1 & 0,9 \\
\hline VRP & 7 & 0,8 & & 1 & 1 & 1 & 0,9 \\
\hline dolium & 4 & 0,5 & & & & 1 & 0,9 \\
\hline lampe & 1 & 0,1 & & & & 1 & 0,9 \\
\hline moderne & 199 & 23,1 & 4 & 24 & 39 & 46 & 41,1 \\
\hline commune moderne & 13 & 1,5 & 1 & & 1 & 1 & 0,9 \\
\hline majolique & 1 & 0,1 & & & & 1 & 0,9 \\
\hline glaçurée fréjussienne & 167 & 19,6 & 3 & 17 & 37 & 37 & 33,9 \\
\hline glaçurée monochrome de Pise & 1 & 0,1 & & & 1 & 1 & 0,9 \\
\hline graffite polychrome de Pise & 4 & 0,5 & & 3 & & 3 & 2,6 \\
\hline jarre glaçurée & 13 & 1,5 & & 4 & & 4 & 3,6 \\
\hline
\end{tabular}

\begin{tabular}{|c|l|c|l|l|l|}
\hline \multicolumn{1}{|c|}{ PHASE 5B } & \multicolumn{1}{|c|}{ Objégorie } & Nbre & \multicolumn{2}{|c|}{ Type } & Loc. \\
\hline US & \multicolumn{1}{|c|}{ bord } \\
\hline 1002 & glaçurée jaune & 1 & assiette & Hayes 196 & bord \\
\hline 2008 & africaine de cuisine & 1 & & & Pasqualini B \\
\hline 2008 & brune & 1 & cruche & Consp. 1.2 & bord \\
\hline 2008 & claire & 1 & assiette & & UNG D1 \\
\hline 2008 & sigillée italique & 1 & unguentarium & timbre & bord \\
\hline 2008 & unguentarium & 1 & plat & & fond \\
\hline 2008 & VRP & 1 & amphore & & anse \\
\hline 2021 & amphore italique & 1 & amphore & anse \\
\hline 2022 & amphore africaine & 1 & coupe & fond \\
\hline 2022 & claire A & & & \\
\hline
\end{tabular}




\begin{tabular}{|c|c|c|c|c|c|}
\hline \multicolumn{6}{|l|}{\begin{tabular}{|l} 
PHASE 5B \\
\end{tabular}} \\
\hline US & Catégorie & Nbre & Objet & Type & Loc. \\
\hline 2022 & modelée & 1 & plat & Bérato 421 & bord \\
\hline 2033 & amphore gauloise & 1 & amphore & G3 & bord \\
\hline 2033 & amphore gauloise & 1 & amphore & G4 & bord \\
\hline 2033 & amphore gauloise & 1 & amphore & & fond \\
\hline 2033 & modelée & 1 & pot à feu & Bérato 152 & bord \\
\hline 2035 & amphore africaine & 1 & amphore & africaine $1 \mathrm{~B}$ & bord \\
\hline 2035 & amphore de Bétique & 2 & amphore & Dressel 20B & anse \\
\hline 2035 & amphore gauloise & 1 & amphore & G4 & bord \\
\hline 2035 & claire & 1 & pot & & bord \\
\hline 2035 & claire & 1 & pot & & fond \\
\hline 3020 & claire & 1 & cruche & anse à poucier & anse \\
\hline 3020 & sigillée italique & 1 & & SIG IT 31.2 & bord \\
\hline 3044 & amphore de Bétique & 1 & amphore & & anse \\
\hline 3044 & amphore de Taraconaise & 1 & amphore & Dressel 2/4 & anse \\
\hline 3044 & amphore gauloise & 1 & amphore & G3 & bord \\
\hline 3044 & amphore gauloise & 1 & amphore & G4 & bord \\
\hline 3044 & amphore gauloise & 1 & amphore & G5 & bord \\
\hline 3044 & amphore italique & 1 & amphore & Dressel 2/4 & bord \\
\hline 3044 & amphore massaliète impériale & 1 & amphore & AMI 7A & bord \\
\hline 3044 & claire & 1 & coupe & & fond \\
\hline 3044 & claire & 1 & opercule & & bord \\
\hline 3044 & claire & 1 & peson & & bord \\
\hline 3044 & glaçurée & 1 & pot & & fond \\
\hline 3044 & kaolinitique & 1 & cruche & Goudineau 1 & fond \\
\hline 3044 & sigillée italique & 1 & coupe & SIG IT 28 & bord \\
\hline
\end{tabular}

\begin{tabular}{|c|c|c|c|c|c|c|c|}
\hline Catégorie & Nbre & $\%$ & anse & fond & bord & NMI & $\%$ \\
\hline amphore & 102 & 59 & 5 & 1 & 10 & 13 & 19,1 \\
\hline amphore africaine & 11 & 6,4 & 1 & & 1 & 1 & 1,5 \\
\hline amphore de Bétique & 13 & 7,5 & 2 & & 1 & 1 & 1,5 \\
\hline amphore de Taraconaise & 10 & 5,8 & 1 & & & 1 & 1,5 \\
\hline amphore gauloise & 44 & 25,4 & & 1 & 6 & 6 & 8,8 \\
\hline amphore indet. & 14 & 8,1 & & & & 1 & 1,5 \\
\hline amphore italique & 4 & 2,3 & 1 & & & 1 & 1,5 \\
\hline amphore massaliète & 6 & 3,5 & & & 2 & 2 & 2,9 \\
\hline fine & 10 & 5,8 & & 1 & 3 & 5 & $\mathbf{7 , 4}$ \\
\hline claire A & 2 & 1,2 & & 1 & & 1 & 1,5 \\
\hline sigillée gauloise & 3 & 1,7 & & & & 1 & 1,5 \\
\hline sigillée italique & 5 & 2,9 & & & 3 & 3 & 4,4 \\
\hline commune & 45 & 26 & 2 & 4 & 8 & 12 & 31,6 \\
\hline africaine de cuisine & 2 & 1,2 & & & 1 & 1 & 1,5 \\
\hline brune & 6 & 3,5 & 1 & & & 1 & 1,5 \\
\hline claire & 30 & 17,3 & 1 & 2 & 4 & 4 & 5,9 \\
\hline grise & 2 & 1,2 & & & & 1 & 1,5 \\
\hline
\end{tabular}




\begin{tabular}{|c|c|c|c|c|c|c|c|}
\hline Catégorie & Nbre & $\%$ & anse & fond & bord & NMI & $\%$ \\
\hline kaolinitique & 1 & 0,6 & & 1 & & 1 & 1,5 \\
\hline modelée & 2 & 1,2 & & & 2 & 2 & 2,9 \\
\hline unguentarium & 1 & 0,6 & & & 1 & 1 & 1,5 \\
\hline VRP & 1 & 0,6 & & 1 & & 1 & 1,5 \\
\hline lampe & 1 & 0,6 & & & & 1 & 1,5 \\
\hline moderne & 15 & 8,7 & & 1 & 1 & 3 & 4,4 \\
\hline glaçurée fréjussienne & 11 & 6,4 & & 1 & 1 & 1 & 1,5 \\
\hline graffite polychrome de Pise & 1 & 0,6 & & & & 1 & 1,5 \\
\hline jarre glaçurée & 3 & 1,7 & & & & 1 & 1,5 \\
\hline
\end{tabular}

\begin{tabular}{|c|c|c|c|c|c|}
\hline \multicolumn{6}{|l|}{ PHASE 5C } \\
\hline US & Catégorie & Nbre & Objet & Type & Loc. \\
\hline 3002 & amphore africaine & 1 & amphore & africaine $1 \mathrm{~B}$ & bord \\
\hline 3002 & glaçurée jaune & 1 & assiette & & bord \\
\hline 3002 & glaçurée jaune & 2 & coupe & & fond \\
\hline 3019 & amphore gauloise & 1 & amphore & & anse \\
\hline 3019 & amphore indéterminée & 1 & amphore & & anse \\
\hline 3019 & amphore massaliète & 1 & amphore & AMI 7A & bord \\
\hline 3019 & claire & 1 & coupe & coupe à bord en poulie & bord \\
\hline 3019 & claire & 1 & mortier & CL REC 21B & bord \\
\hline 3019 & claire A & 1 & coupe & & fond \\
\hline 3019 & commune moderne & 1 & marmite & & anse \\
\hline 3019 & sigillée gauloise & 1 & coupe & & fond \\
\hline 3079 & commune moderne & 1 & & & fond \\
\hline 3079 & glaçurée verte & 1 & assiette & & bord \\
\hline 3081 & africaine de cuisine & 1 & coupe & Hayes 196 & bord \\
\hline 3081 & amphore africaine & 1 & amphore & africaine 1 & bord \\
\hline 3081 & amphore africaine & 1 & opercule & & bord \\
\hline 3081 & amphore de Bétique & 1 & amphore & Dressel 7/11 & bord \\
\hline 3081 & amphore de Bétique & 1 & amphore & & anse \\
\hline 3081 & amphore de Bétique & 1 & amphore & & fond \\
\hline 3081 & amphore de Taraconaise & 1 & amphore & & anse \\
\hline 3081 & amphore de Taraconaise & 1 & amphore & & fond \\
\hline 3081 & amphore gauloise & 1 & amphore & & anse \\
\hline 3081 & claire & 2 & pot de fleur & & fond \\
\hline 3081 & claire & 1 & & & fond \\
\hline 3081 & claire engobée & 1 & coupe & Pasqualini 1 & bord \\
\hline 3081 & glaçurée & 3 & assiette & & bord \\
\hline 3081 & glaçurée & 1 & bougeoir & & fond \\
\hline 3081 & glaçurée & 1 & coupe & & bord \\
\hline 3081 & glaçurée & 1 & coupe & coupe carénée & bord \\
\hline 3081 & glaçurée & 1 & coupe & coupe à marli & bord \\
\hline 3081 & glaçurée & 2 & cruche & & bord \\
\hline 3081 & glaçurée & 5 & & & anse \\
\hline 3081 & glaçurée & 7 & & & fond \\
\hline
\end{tabular}




\begin{tabular}{|c|c|c|c|c|c|}
\hline \multicolumn{6}{|l|}{ PHASE 5C } \\
\hline US & Catégorie & Nbre & Objet & Type & Loc. \\
\hline 3081 & glaçurée jaune & 2 & assiette & & bord \\
\hline 3081 & glaçurée jaune & 2 & assiette & & fond \\
\hline 3081 & glaçurée jaune & 4 & coupe & & bord \\
\hline 3081 & glaçurée jaune & 5 & coupe & & fond \\
\hline 3081 & glaçurée jaune & 2 & jatte & & bord \\
\hline 3081 & glaçurée verte & 1 & coupe & & bord \\
\hline 3081 & glaçurée verte & 1 & coupe & & fond \\
\hline 3081 & glaçurée verte & 1 & & & fond \\
\hline 3081 & glaçurée vert-métal & 1 & & & anse \\
\hline 3081 & glaçurée vert-métal & 1 & & & bord \\
\hline 3081 & tuile & 4 & opercule & & bord \\
\hline 3123 & africaine de cuisine & 1 & couvercle & Hayes 196 & bord \\
\hline 3123 & amphore indéterminée & 1 & amphore & & anse \\
\hline 3123 & glaçurée jaune & 1 & cruche & & bord \\
\hline 3124 & glaçurée jaune & 1 & assiette & & bord \\
\hline 3124 & glaçurée jaune & 1 & coupe & & bord \\
\hline
\end{tabular}

\begin{tabular}{|c|c|c|c|c|c|c|c|}
\hline Catégorie & Nbre & $\%$ & anse & fond & bord & NMI & $\%$ \\
\hline amphore & 107 & 35,5 & 10 & 3 & 5 & 12 & 24 \\
\hline amphore africaine & 24 & 8 & & 1 & 4 & 4 & 8 \\
\hline amphore de Bétique & 19 & 6,3 & 3 & 1 & 1 & 1 & 2 \\
\hline amphore de Taraconaise & 6 & 2 & & 1 & & 1 & 2 \\
\hline amphore gauloise & 25 & 8,3 & 3 & & & 2 & 4 \\
\hline amphore indéterminée & 26 & 8,6 & 3 & & & 2 & 4 \\
\hline amphore italique & 2 & 0,7 & & & & 1 & 2 \\
\hline amphore massaliète & 5 & 1,7 & 1 & & 1 & 1 & 2 \\
\hline fine & 2 & 0,7 & & 2 & & 2 & 4 \\
\hline claire A & 1 & 0,3 & & 1 & & 1 & 2 \\
\hline sigillée gauloise & 1 & 0,3 & & 1 & & 1 & 2 \\
\hline commune & 54 & 17,9 & 1 & 6 & 5 & 10 & 20 \\
\hline africaine de cuisine & 3 & 1 & & & 2 & 1 & 2 \\
\hline brune & 3 & 1 & & & & 1 & 2 \\
\hline claire & 44 & 14,6 & 1 & 5 & 2 & 5 & 10 \\
\hline claire engobée & 2 & 0,7 & & 1 & 1 & 1 & 2 \\
\hline grise du Verdon & 1 & 0,3 & & & & 1 & 2 \\
\hline kaolinitique & 1 & 0,3 & & & & 1 & 2 \\
\hline moderne & 138 & 45,8 & 7 & 21 & 22 & 26 & 52 \\
\hline commune moderne & 2 & 0,7 & 1 & 1 & & 1 & 2 \\
\hline faïence & 1 & 0,3 & & & & 1 & 2 \\
\hline glaçurée fréjusienne & 123 & 40,9 & 5 & 20 & 21 & 21 & 42 \\
\hline glaçurée verte métallique & 4 & 1,3 & 1 & & 1 & 2 & 4 \\
\hline jarre glaçurée & 8 & 2,7 & & & & 1 & 2 \\
\hline
\end{tabular}




\begin{tabular}{|c|c|c|c|c|c|}
\hline \multicolumn{6}{|l|}{ PHASE 6} \\
\hline US & Catégorie & Nbre & Objet & Type & Loc. \\
\hline 1001 & amphore gauloise & 1 & amphore & & anse \\
\hline 1001 & amphore italique & 1 & amphore & Dressel 2/4 & anse \\
\hline 1001 & claire & 2 & bassine & & fond \\
\hline 1001 & claire & 1 & cruche & & anse \\
\hline 1001 & claire A & 1 & coupe & Hayes 8A & bord \\
\hline 1001 & glaçurée décor au biberon & 1 & assiette & & bord \\
\hline 1001 & glaçurée jaune & 4 & assiette & & bord \\
\hline 1001 & glaçurée jaune & 1 & coupe & & bord \\
\hline 1001 & glaçurée jaune & 1 & coupe & & fond \\
\hline 1001 & glaçurée jaune & 1 & jatte & & bord \\
\hline 1001 & glaçurée jaune & 1 & & & anse \\
\hline 1001 & glaçurée jaune & 3 & & & fond \\
\hline 1001 & glaçurée maron & 1 & jatte & & bord \\
\hline 1001 & glaçurée orangée & 1 & coupe & & bord \\
\hline 1001 & glaçurée verte & 1 & assiette & & bord \\
\hline 1001 & glaçurée verte & 1 & pot & & bord \\
\hline 1001 & graffito polychrome & 1 & coupe & & bord \\
\hline 1001 & porcelaine & 2 & assiette & & bord \\
\hline 1001 & porcelaine & 1 & isolant & & bord \\
\hline 1001 & sigillée italique & 1 & coupe & Consp. 31.2 & bord \\
\hline 1006 & africaine de cuisine & 1 & couvercle & Hayes 196 & bord \\
\hline 1006 & amphore africaine & 1 & amphore & & anse \\
\hline 1006 & amphore de Bétique & 1 & amphore & Dressel 20 & bord \\
\hline 1006 & amphore gauloise & 1 & amphore & & anse \\
\hline 1006 & amphore indéterminée & 1 & amphore & & fond \\
\hline 1006 & claire & 1 & coupe & Pasqualini 1B & bord \\
\hline 1006 & claire & 1 & cruche & Pasqualini B & bord \\
\hline 1006 & claire & 1 & cruche & & anse \\
\hline 1006 & claire & 2 & cruche & & fond \\
\hline 1006 & commune moderne & 1 & pot à feu & & bord \\
\hline 1006 & culinaire orangée moderne & 1 & marmite & & bord \\
\hline 1006 & glaçurée & 2 & coupe & & bord \\
\hline 1006 & glaçurée & 1 & pot & anse panier & bord \\
\hline 1006 & glaçurée blanche & 2 & cruche & & fond \\
\hline 1006 & glaçurée jaune & 5 & assiette & & bord \\
\hline 1006 & glaçurée jaune & 1 & coupe & bord bandeau & bord \\
\hline 1006 & glaçurée jaune & 1 & coupe & bord gouttière & bord \\
\hline 1006 & glaçurée jaune & 1 & coupe & carénée & bord \\
\hline 1006 & glaçurée jaune & 9 & coupe & & bord \\
\hline 1006 & glaçurée jaune & 1 & cruche & & anse \\
\hline 1006 & glaçurée jaune & 1 & cruche & & fond \\
\hline 1006 & glaçurée jaune & 1 & jatte & & bord \\
\hline 1006 & glaçurée jaune & 7 & & & fond \\
\hline 1006 & glaçurée marbrée & 1 & coupe & & bord \\
\hline
\end{tabular}




\begin{tabular}{|c|c|c|c|c|c|}
\hline \multicolumn{6}{|l|}{ PHASE 6} \\
\hline US & Catégorie & Nbre & Objet & Type & Loc. \\
\hline 1006 & glaçurée verte & 1 & coupe & & fond \\
\hline 1006 & jarre glaçurée & 1 & & & fond \\
\hline 1006 & porcelaine & 1 & assiette & & bord \\
\hline 1006 & sigillée gauloise & 1 & assiette & & fond \\
\hline 1006 & sigillée gauloise & 1 & & Drag. 37 & bord \\
\hline 1006 & sigillée italique & 1 & coupe & & fond \\
\hline 2001 & amphore indéterminée & 1 & amphore & & anse \\
\hline 2001 & amphore massaliète & 1 & amphore & & anse \\
\hline 2001 & brune & 1 & & & fond \\
\hline 2001 & claire & 1 & & & fond \\
\hline 2001 & glaçurée jaune & 1 & coupe & coupe à oreilles & bord \\
\hline 2001 & paroi fine & 1 & cruche & & bord \\
\hline 2001 & sigillée gauloise & 1 & & & fond \\
\hline 3001 & amphore de Rhodes & 1 & & & anse \\
\hline 3001 & amphore de Taraconaise & 1 & amphore & & anse \\
\hline 3001 & amphore gauloise & 1 & amphore & G4 & bord \\
\hline 3001 & amphore gauloise & 1 & & & fond \\
\hline 3001 & brune & 1 & pot & & bord \\
\hline 3001 & claire & 2 & cruche & & anse \\
\hline 3001 & claire & 2 & & & fond \\
\hline 3001 & claire D & 1 & coupe & & fond \\
\hline 3001 & dolium & 1 & jarre & & bord \\
\hline 3001 & dolium & 1 & & & fond \\
\hline 3001 & glacurée & 15 & & & fond \\
\hline 3001 & glaçurée & 1 & cruche & & anse \\
\hline 3001 & glaçurée & 2 & jatte & & bord \\
\hline 3001 & glaçurée jaune & 1 & assiette & & bord \\
\hline 3001 & glaçurée jaune & 1 & bougeoir & & bord \\
\hline 3001 & glaçurée jaune & 3 & coupe & & bord \\
\hline 3001 & glaçurée verte & 1 & assiette & & bord \\
\hline 3001 & kaolinitique & 2 & cruche & Goudineau 1 & anse \\
\hline 3001 & kaolinitique & 2 & marmite & & bord \\
\hline 3001 & orangée sableuse & 1 & marmite & & bord \\
\hline 3048 & glaçurée & 1 & coupe & & fond \\
\hline 3070 & kaolinitique rose & 1 & marmite & & bord \\
\hline 3186 & sigillée italique & 1 & assiette & SIG IT 22 & bord \\
\hline
\end{tabular}

\begin{tabular}{|l|c|c|c|c|c|c|c|}
\hline \multicolumn{1}{|c|}{ Catégorie } & Nbre & $\mathbf{\%}$ & anse & fond & bord & NMI & \% \\
\hline amphore & $\mathbf{1 4 7}$ & $\mathbf{2 9 , 6}$ & $\mathbf{7}$ & $\mathbf{2}$ & $\mathbf{2}$ & $\mathbf{8}$ & $\mathbf{9 , 2}$ \\
\hline amphore africaine & 18 & 3,6 & & & & 1 & 1,1 \\
\hline amphore de Bétique & 4 & 0,8 & & & & 1,1 \\
\hline amphore de Rhodes & 1 & 0,2 & 1 & & & 1 & 1,1 \\
\hline amphore de Taraconaise & 8 & 1,6 & 1 & & & 1 & 1,1 \\
\hline
\end{tabular}




\begin{tabular}{|c|c|c|c|c|c|c|c|}
\hline Catégorie & Nbre & $\%$ & anse & fond & bord & NMI & $\%$ \\
\hline amphore gauloise & 51 & 10,3 & 2 & 1 & 1 & 1 & 1,1 \\
\hline amphore indéterminée & 36 & 7,3 & 1 & 1 & & 1 & 1,1 \\
\hline amphore italique & 24 & 4,6 & 1 & & & 1 & 1,1 \\
\hline amphore massaliète & 5 & 1 & 1 & & & 1 & 1,1 \\
\hline fine & 28 & 5,7 & & 3 & 5 & 8 & 9,2 \\
\hline claire A & 1 & 0,2 & & & 1 & 1 & 1,1 \\
\hline claire D & 1 & 0,2 & & & & 1 & 1,1 \\
\hline paroi fine & 6 & 1,2 & & & 1 & 1 & 1,1 \\
\hline sigillée gauloise & 10 & 2 & & 2 & 1 & 2 & 2,3 \\
\hline sigillée italique & 7 & 1,4 & & 1 & 2 & 2 & 2,3 \\
\hline sigillée marbrée & 3 & 0,6 & & & & 1 & 1,1 \\
\hline commune & 92 & 19,4 & 5 & 9 & 7 & 17 & 19,5 \\
\hline africaine de cuisine & 1 & 0,2 & & & & 1 & 1,1 \\
\hline brune & 19 & 3,8 & & 1 & 2 & 1 & 1,1 \\
\hline claire & 61 & 12,3 & 4 & 7 & 2 & 7 & 8 \\
\hline claire engobée & 2 & 0,4 & & & & 1 & 1,1 \\
\hline grise & 1 & 0,2 & & & & 1 & 1,1 \\
\hline kaolinitique & 4 & 0,8 & 1 & 1 & & 1 & 1,1 \\
\hline modelée & 1 & 0,2 & & & & 1 & 1,1 \\
\hline unguentarium & 2 & 0,4 & & & & 1 & 1,1 \\
\hline VRP & 1 & 0,2 & & & & 1 & 1,1 \\
\hline dolium & 4 & $\mathbf{0 , 8}$ & & & 1 & 1 & 1,1 \\
\hline moderne & 223 & 45,1 & 3 & 30 & 54 & 54 & 62,1 \\
\hline commune moderne & 16 & 3,2 & & & 7 & 7 & 8 \\
\hline glacurée & 173 & 35 & 3 & 29 & 43 & 43 & 49,4 \\
\hline glaçurée décor au biberon & 1 & 0,2 & & & 1 & 1 & 1,1 \\
\hline glaçurée marbrée & 2 & 0,4 & & & 1 & 1 & 1,1 \\
\hline graffito polychrome & 1 & 0,2 & & & & 1 & 1,1 \\
\hline jarre glaçurée & 28 & 5,7 & & 1 & & 1 & 1,1 \\
\hline porcelaine & 4 & 0,8 & & & 4 & 4 & 4,5 \\
\hline
\end{tabular}

\section{Inventaire de la faune}

\begin{tabular}{|c|c|c|c|c|c|c|c|c|c|c|c|}
\hline Phase & $\begin{array}{c}\text { Moutons/ } \\
\text { chèvres }\end{array}$ & Porcs & Bovins & Chevaux & Ânes & Poules & Chiens & Rongeurs & Murex & Total NRD & $\begin{array}{c}\text { Frag. } \\
\text { Indéterminés }\end{array}$ \\
\hline $3 \mathrm{~A}$ & 31 & 7 & 6 & 3 & & 3 & 1 & & & 51 & 6 \\
\hline $4 \mathrm{~A}$ & 25 & 29 & 10 & & & & & 1 & & 65 & 21 \\
\hline $4 \mathrm{~B}$ & & & 7 & & & & & & & 7 & \\
\hline $5 \mathrm{~A}$ & 16 & 6 & 11 & 1 & 2 & & & & 1 & 37 & 3 \\
\hline $5 \mathrm{~B}$ & 15 & 1 & 1 & & & & & & 1 & 18 & \\
\hline $5 \mathrm{C}$ & 1 & 1 & & 1 & & & & & & 3 & \\
\hline 6 & 15 & 4 & 6 & 3 & & & & & & 28 & \\
\hline
\end{tabular}

Nombre de restes déterminés et indéterminés par espèce et par phase. 
BIBLIOTHÈQUE D’ ARCHÉOLOGIE MÉDITERRANÉENNE ET AFRICAINE - 8

\begin{tabular}{|c|c|c|c|c|}
\hline \multirow{2}{*}{$\begin{array}{c}\text { Phase } \\
3 \mathrm{~A}\end{array}$} & \multicolumn{4}{|c|}{ Espèces domestiques } \\
\hline & Bovins & Moutons/chèvres & Porcs & Équidés \\
\hline plus 5 ans & & & & 1 \\
\hline plus 3 ans & 1 & 1 & & \\
\hline moins 3 ans & & 1 & & \\
\hline $18-24$ mois & & & 2 & \\
\hline $4 \mathrm{~A}$ & Bovins & Moutons/Chèvres & Porcs & Équidés \\
\hline plus 4 ans & 5 & 5 & & \\
\hline moins 3 ans & 3 & & & \\
\hline $4 \mathrm{~B}$ & Bovins & Moutons/Chèvres & Porcs & Équidés \\
\hline plus 3 ans & 2 & & & \\
\hline $5 \mathrm{~A}$ & Bovins & Moutons/Chèvres & Porcs & Équidés \\
\hline Adulte indéterminé & 2 & & 1 & 1 \\
\hline plus 3 ans & 2 & 2 & & \\
\hline moins 2 ans & 1 & & 1 & \\
\hline $5 \mathrm{~B}$ & Bovins & Moutons/Chèvres & Porcs & Équidés \\
\hline Adulte indéterminé & 1 & & & \\
\hline plus 5 ans & & $1 / 2$ & & \\
\hline plus 3 ans & & & & 1 \\
\hline $5 \mathrm{C}$ & Bovins & Moutons/Chèvres & Porcs & Équidés \\
\hline plus 10 ans & & 1 & & \\
\hline plus 5 ans & 1 & & & \\
\hline 6 & Bovins & Moutons/Chèvres & Porcs & Équidés \\
\hline Adulte indéterminé & 1 & & & 1 \\
\hline plus 5 ans & & & 1 & \\
\hline plus 4 ans & & 1 & & \\
\hline plus 3 ans & & 1 & & \\
\hline moins 3 mois & & 1 & & \\
\hline
\end{tabular}

Nombres minimum d'individus répertoriés pour les quatres principales espèces domestiques.

\begin{tabular}{|c|c|c|c|c|c|c|}
\hline $3 \mathrm{C}$ & Moutons/Chèvres & Porcs & Bovins & Équidés & Poules & Chiens \\
\hline Crânes & 1 & 1 & & & & \\
\hline Dents isolées & 2 & & 1 & & & \\
\hline Cervicales & 2 & & & & & \\
\hline Thoraciques & & 1 & & 2 & & \\
\hline \multicolumn{7}{|l|}{ Caudales } \\
\hline Côtes/Sternums & 3 & 1 & & & & \\
\hline Scapulas & 2 & & 1 & & 1 & \\
\hline Humérus & & 2 & & & 1 & \\
\hline Radius & 1 & & & & & \\
\hline Ulnas & & & & & 1 & \\
\hline Pelvis & 12 & & 1 & & & 1 \\
\hline Tibia/Fib. & 4 & & 2 & & & \\
\hline Métacarpes & & 1 & & & & \\
\hline Tarses & 1 & & & & & \\
\hline Métatarses & 2 & & & 1 & & \\
\hline Phalanges & 1 & 1 & 1 & & & \\
\hline Total NR & 31 & 7 & 6 & 3 & 3 & 1 \\
\hline
\end{tabular}

Répartition des restes de l'état 3C par segments anatomiques (NRD). 
INVENTAIRES

\begin{tabular}{|c|c|c|c|c|c|c|}
\hline $4 \mathrm{~A}$ & Moutons/Chèvres & Moutons & Porcs & Bovins & Équidés & Chiens \\
\hline Chevilles osseuses & & & & 1 & & \\
\hline Crânes & 3 & & 1 & & & 1 \\
\hline Dents isolées & 2 & & & & & \\
\hline Cervicales & 2 & & & 3 & 6 & \\
\hline Thoraciques & 1 & & & 4 & & \\
\hline Lombaires & 3 & & & 3 & & \\
\hline Côtes/Sternums & 2 & & & 2 & 2 & \\
\hline Scapulas & & & & 2 & & \\
\hline Humérus & & & & 2 & 1 & \\
\hline Radius & 1 & 1 & & 3 & & \\
\hline Ulnas & 2 & & & 2 & & \\
\hline Pelvis & 2 & & & 2 & & \\
\hline Fémurs/pat. & 1 & & & & & \\
\hline Tibia/Fib. & 2 & & & 3 & & \\
\hline Métacarpes & & 1 & & 2 & & \\
\hline Métatarses & 1 & & & & 1 & \\
\hline Total NR & 22 & 2 & 1 & 29 & 10 & 1 \\
\hline
\end{tabular}

Répartition des restes de l'état 4A par segments anatomiques (NRD).

\begin{tabular}{|l|c|}
\hline \multicolumn{1}{|c|}{ 4B } & Bovins \\
\hline Radius & 1 \\
\hline Pelvis & 2 \\
\hline Tibia/Fib. & 1 \\
\hline Métatarses & 2 \\
\hline Phalanges & 1 \\
\hline Total NR & 7 \\
\hline
\end{tabular}

Tableau 5 - Répartition des restes de l'état 4B par segments anatomiques (NRD).

\begin{tabular}{|c|c|c|c|c|c|c|}
\hline $5 \mathrm{~A}$ & Moutons/Chèvres & Moutons & Porcs & Bovins & Équidés & Ânes \\
\hline Crânes & 2 & & 1 & 2 & & \\
\hline Dents isolées & & & & & & 1 \\
\hline Cervicales & & & & & 1 & \\
\hline Thoraciques & 2 & & & & & \\
\hline Côtes/Sternums & 1 & & 2 & 1 & & \\
\hline Scapulas & 1 & & & 1 & & \\
\hline Humérus & & & 1 & 3 & & \\
\hline Radius & 1 & & & & & \\
\hline Ulnas & 1 & & & & & \\
\hline Pelvis & & & & 2 & & \\
\hline Fémurs/pat. & 2 & & & & & \\
\hline Tibias/Fib. & 2 & 1 & 2 & 2 & & \\
\hline Métacarpes & 1 & & & & & \\
\hline Métatarses & 2 & & & & & \\
\hline Phalanges & & & & & & 1 \\
\hline Total NR & 15 & 1 & 6 & 11 & 1 & 2 \\
\hline
\end{tabular}

Répartition des restes de l'état 5A par segments anatomiques (NRD). 
BIBLIOTHÈQUE D’ ARCHÉOLOGIE MÉDITERRANÉENNE ET AFRICAINE - 8

\begin{tabular}{|l|c|c|c|c|}
\hline \multicolumn{1}{|c|}{ 5B } & Moutons/Chèvres & Chèvres & Bovins & Équidés \\
\hline Chevilles osseuses & & 2 & & \\
\hline Crânes & 1 & 9 & & \\
\hline Cervicales & & 1 & & \\
\hline Radius & 2 & & & \\
\hline Tibia/Fib. & & & & 1 \\
\hline Tarses & $\mathbf{3}$ & $\mathbf{1 2}$ & $\mathbf{1}$ & 1 \\
\hline Total NR & Repartion & & \\
\hline
\end{tabular}

Répartition des restes de l'état 5B par segments anatomiques (NRD).

\begin{tabular}{|l|c|c|c|}
\hline \multicolumn{1}{|c|}{ 5C } & Moutons/Chèvres & Bovins & Équidés \\
\hline Crânes & & 1 & \\
\hline Radius & 1 & & \\
\hline Pelvis & & & 1 \\
\hline Métacarpes & $\mathbf{1}$ & $\mathbf{2}$ & $\mathbf{1}$ \\
\hline Total NR & & & \\
\hline
\end{tabular}

Répartition des restes de l'état 5C par segments anatomiques (NRD).

\begin{tabular}{|c|c|c|c|c|c|}
\hline 6 & Moutons/chèvres & Moutons & Porcs & Bovins & Équidés \\
\hline Crânes & 1 & & & 1 & \\
\hline Dents isolées & 1 & 2 & & & \\
\hline Cervicales & & 1 & & & \\
\hline Lombaires & & & 1 & & \\
\hline Côtes/Sternums & 1 & 3 & & 1 & \\
\hline Scapulas & & & & 1 & \\
\hline Humérus & 1 & 1 & & 1 & \\
\hline Radius & & 1 & & 1 & \\
\hline Fémurs/pat. & & 1 & & & \\
\hline Tibia/Fib. & & 1 & 1 & & 1 \\
\hline Métacarpes & & & & 1 & 1 \\
\hline Tarses & & 1 & & & \\
\hline Métatarses & & & & & 1 \\
\hline Phalanges & & & 2 & & \\
\hline Total NR & 4 & 11 & 4 & 6 & 3 \\
\hline
\end{tabular}

Répartition des restes de l'état 6 par segments anatomiques (NRD). 


\section{PUBLICATIONS}

\section{DU CENTRE CAMILLE JULLIAN}

http://sites.univ-provence.fr/ccj/spip.php?rubrique79 


\section{BIBLIOTHÈQUE D'ARCHÉOLOGIE MÉDITERRANÉENNE ET AFRICAINE (BiAMA)}

Editions Errance, 7 rue Jean-du-Bellay, 75004 Paris.

http://www.librairie-epona.fr/

La BiAMA prend la suite des Travaux du Centre Camille Jullian
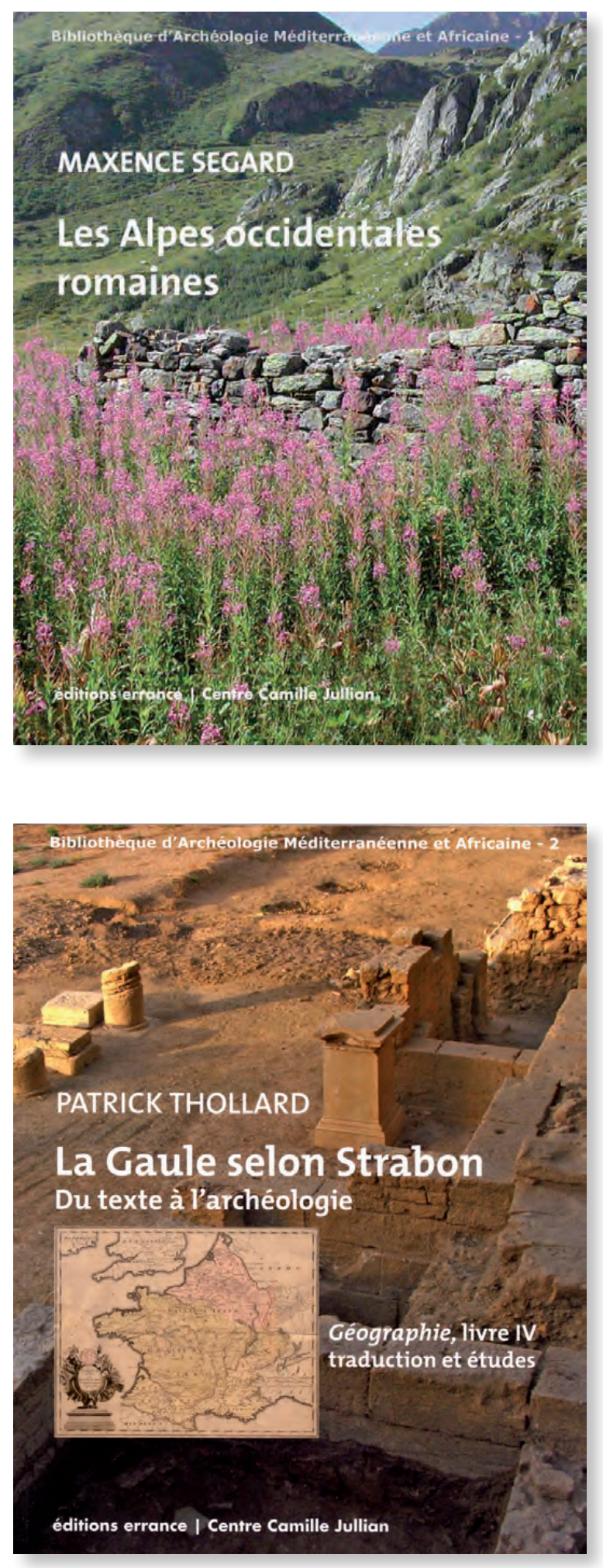

1. M. Segard, Les Alpes Occidentales à l'époque romaine, Développement urbain et exploitation des ressources des régions de montagne (Gaule Narbonnaise, Italie, provinces alpines), Paris 2009, $288 \mathrm{p}$.
2. Patrick Thollard, La Gaule selon Strabon : du texte à l'archéologie (Géographie livre IV). Traduction et études, Paris 2009, 265 p. 

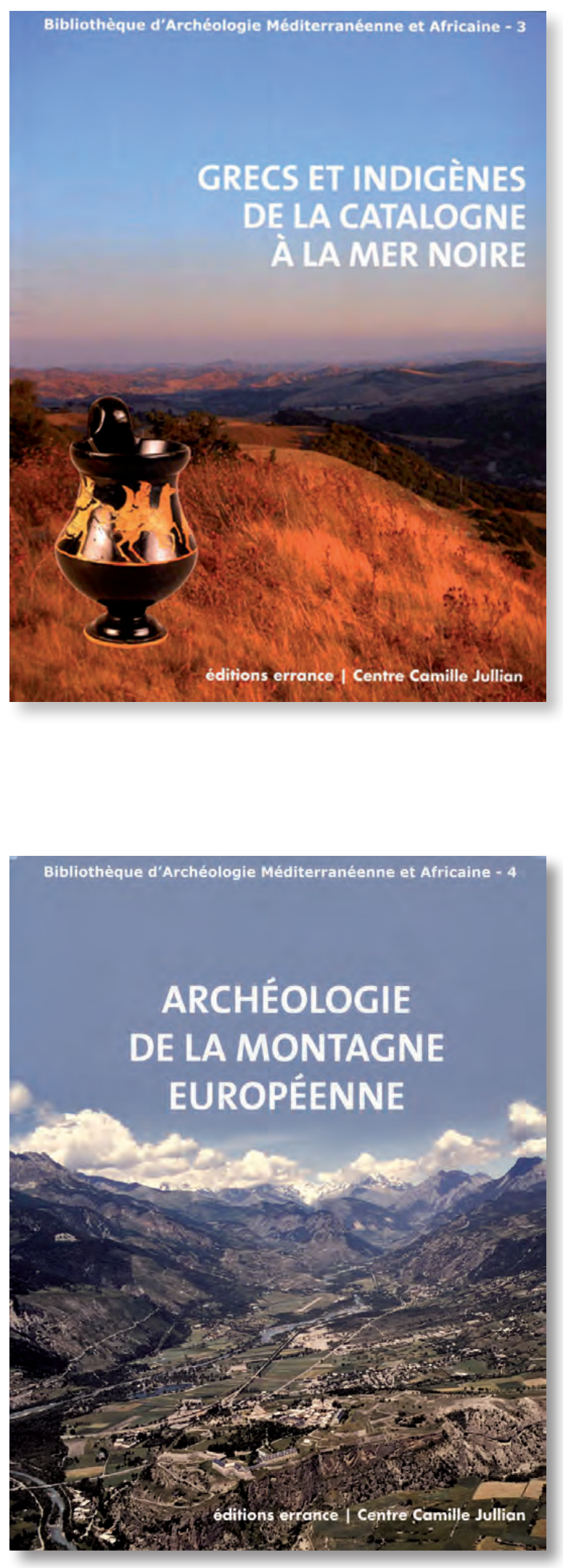

3. Grecs et indigènes de la Catalogne à la mer Noire, actes des rencontres du programme européen Ramses (2006-2008), édités par H. Tréziny, Paris 2010, 716 p.
4. Archéologie de la montagne européenne. Actes de la table ronde internationale de Gap (29 septembre-1 ${ }^{\text {er }}$ octobre 2008), textes réunis par Stéfan Tzortzis et Xavier Delestre, avec la collaboration de Jennifer Greck, Paris 2010, 333 p. 
Bibliothèque d'Archéologie Méditerranéenne et Africaine - 5

APOLLONIA DU PONT (SOZOPOL)

La nécropole de Kalfata (V.III S. av. J.-C.)

Fouilles franco-bulgares

$(2002-2004)$

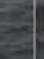

$=$

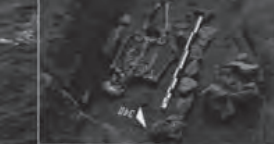

éditions errance | Centre Camille Jullian

sit

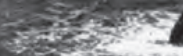

d'Archéol f̂le-Méditerranéenne et Africain

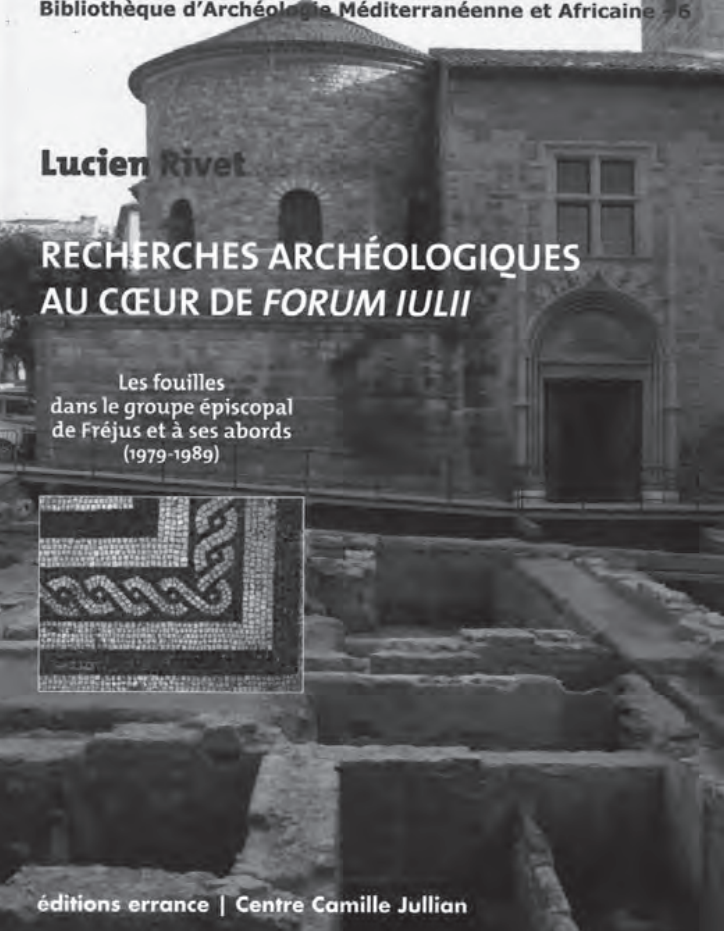

5. A. Hermary (éd.), Apollonia du Pont (Sozopol) La nécropole de Kalfata ( $V^{e}-I I I^{e}$ S. av. J.-C.) - Fouilles franco-bulgares (2002-2004), 2010, $432 \mathrm{p}$.

6. L. Rivet, Recherches archéologiques au coeur de Forum Iulii - Les fouilles dans et autour du groupe cathédral de Fréjus (1979-1989), 2010, 420 p. 

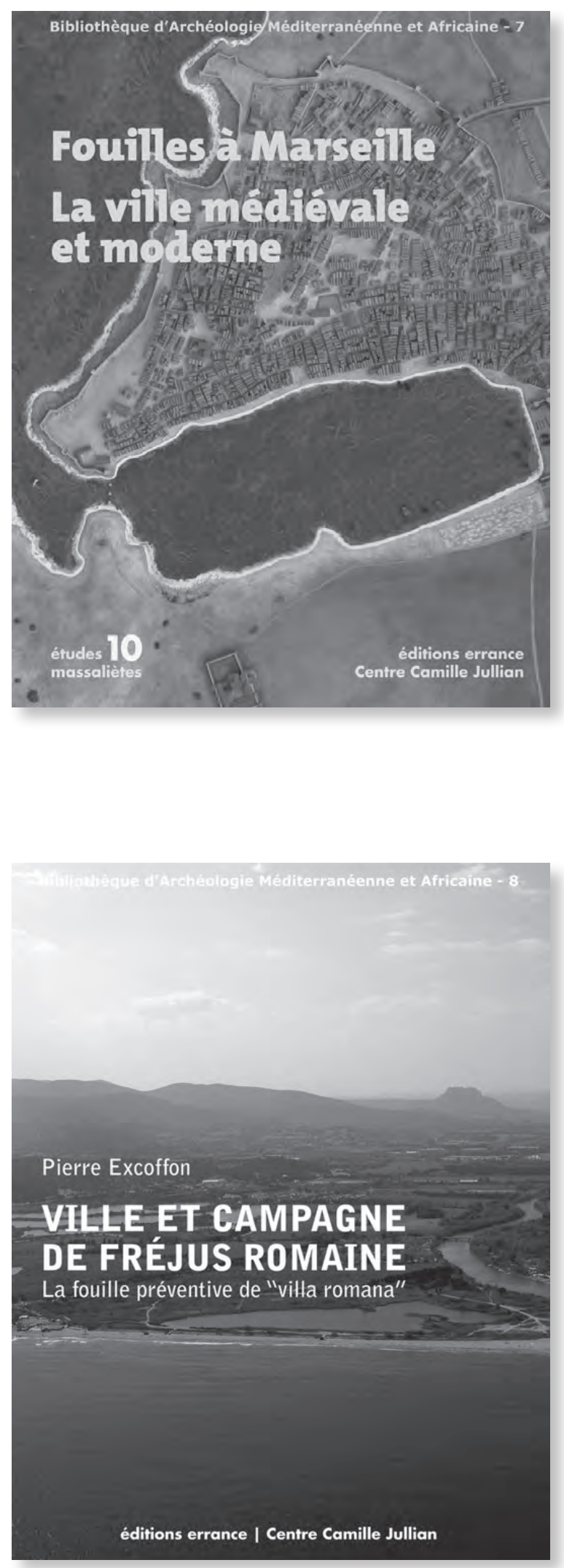

7. Sous la direction de Marc Bouiron, Françoise Paone, Bernard Sillano, Colette Castrucci et Nadine Scherrer, Fouille à Marseille, la ville médiévale et moderne, (ÉtMassa 10), 2011, 463 p.
8. P. Excoffon, Ville et campagne de Fréjus romaine. La fouille préventive de «Villa Romana » 2011, 306 p. 

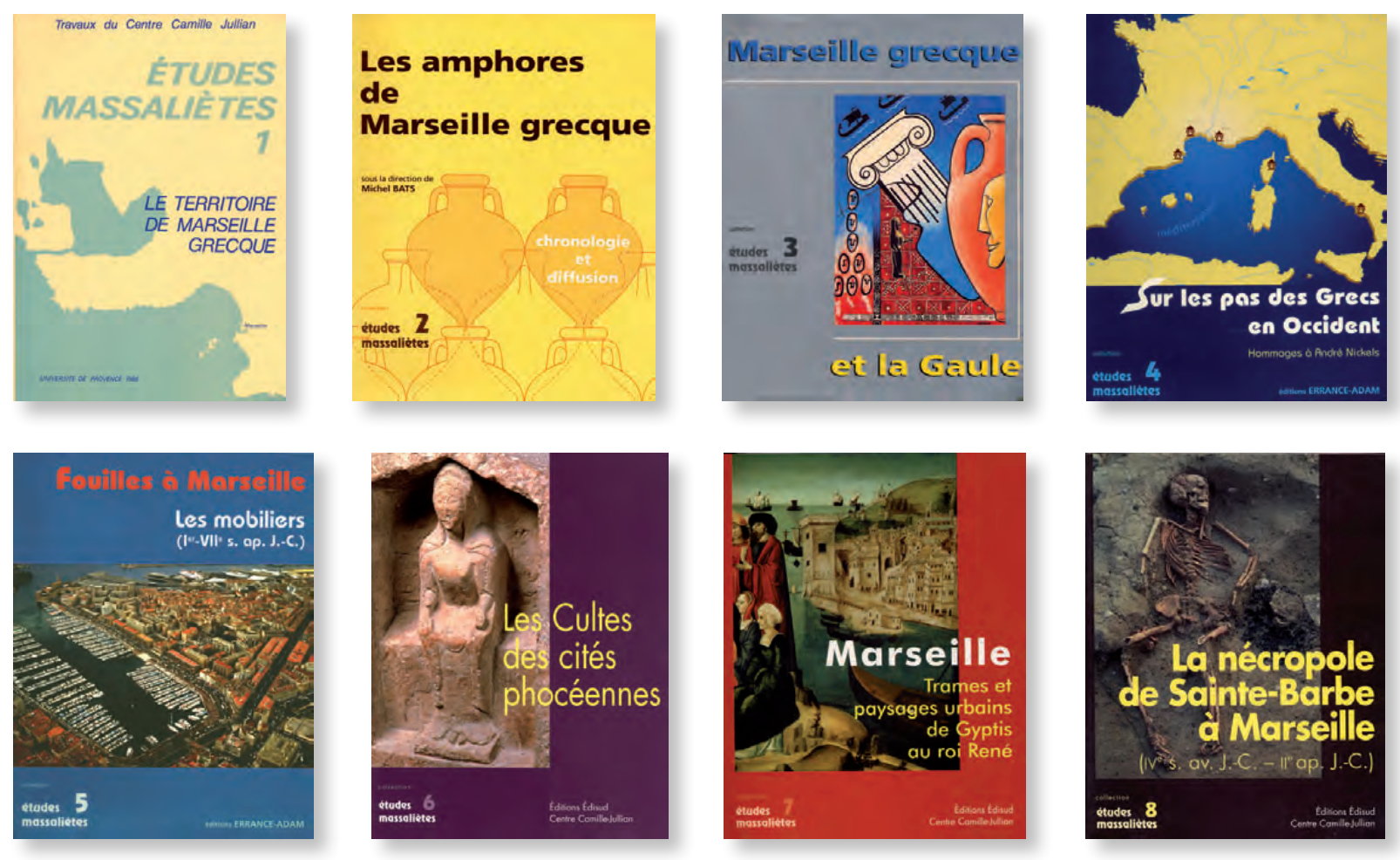

\section{COLLECTION ÉTUDES MASSALİ̀TES (EtMasSa)}

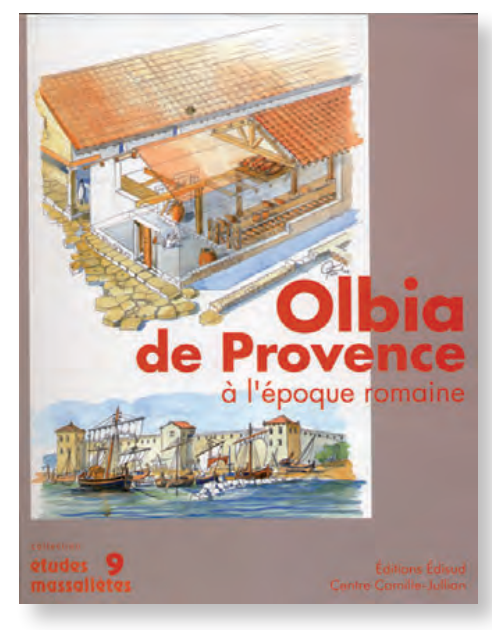

1. Le territoire de Marseille grecque, Actes de la table ronde d'Aix-en-Provence, (26 mars 1985), édités par M. Bats et H. Tréziny, Université de Provence, Aix-enProvence, 1986.

2. Les amphores de Marseille grecque, actes de la table ronde de Lattes, 1988, édités par M. Bats, Université de Provence/ADAM éditions, Aix-en-Provence/ Lattes, 1990.

3. Marseille grecque et la Gaule, actes des colloques de Marseille et Aix-enProvence, 1990, édités par M. Bats, G. Bertucchi, G. Congès, H. Tréziny, Université de Provence / ADAM éditions, Aix-en-Provence / Lattes, 1992.

4. Sur les pas des Grecs en Occident. Hommages à André Nickels, édités par P. Arcelin, M. Bats, G. Marchand, M. Schwaller, éditions Errance / ADAM éditions, Paris-Lattes 1995.

5. Fouilles à Marseille. Les mobiliers (I ${ }^{e r}-V I I^{e}$ s. ap. J.-C.), vol. collectif sous la direction de M. Bonifay, M.-Br. Carre et Y. Rigoir, éditions Errance / ADAM éditions, Paris-Lattes 1998.

6. Les cultes des cités phocéennes, actes du coll. d'Aix-en-Provencel Marseille, juin 1999, édités par A. Hermary et H. Tréziny, Édisud/Centre C. Jullian, Aix-en-Provence, 2000.

7. Marseille. Trames et paysages urbains de Gyptis au Roi René, Actes du colloque international d'archéologie, Marseille, 3-5 novembre 1999, textes réunis et édités par M. Bouiron et H. Tréziny, B. Bizot, A. Guilcher, J. Guyon et M. Pagni, Édisud/Centre C. Jullian, Aix-en-Provence, 2001.

8. La nécropole de Sainte-Barbe à Marseille (IV $V^{e}$ s. av. J.-C. - II ${ }^{e}$ s. ap. J.-C.), vol. collectif sous la direction de M. Moliner, Édisud/Centre C. Jullian, Aix-en-Provence, 2003.

9. Olbia de Provence à l'époque romaine, vol. collectif sous la direction de Michel Bats, Édisud/Centre C. Jullian, Aix-en-Provence, 2007.

10. M. Bouiron et al. (éd.), Fouilles à Marseille. Approche de la ville médiévale et moderne, 2011, 464 p. (= BiAMA 7).

Les volumes sont disponibles en format pdf sur http://sites.univ-provence.fr/ccj/spip.php?rubrique83, grâce au soutien du Centre de conservation du livre à Arles (e-corpus). 


\section{REVUE ANTIQUITÉS AFRICAINES,}

CNRS Editions, 15 rue Malebranche,

75005 Paris - http://www.cnrseditions.fr

Dernier volume paru, t. 44, 2008 [2010]

\section{COLLECTION}

ÉTUDES D'ANTIQUITÉS AFRICAINES

CNRS Editions, 15 rue Malebranche, 75005 Paris - http://www.cnrseditions.fr
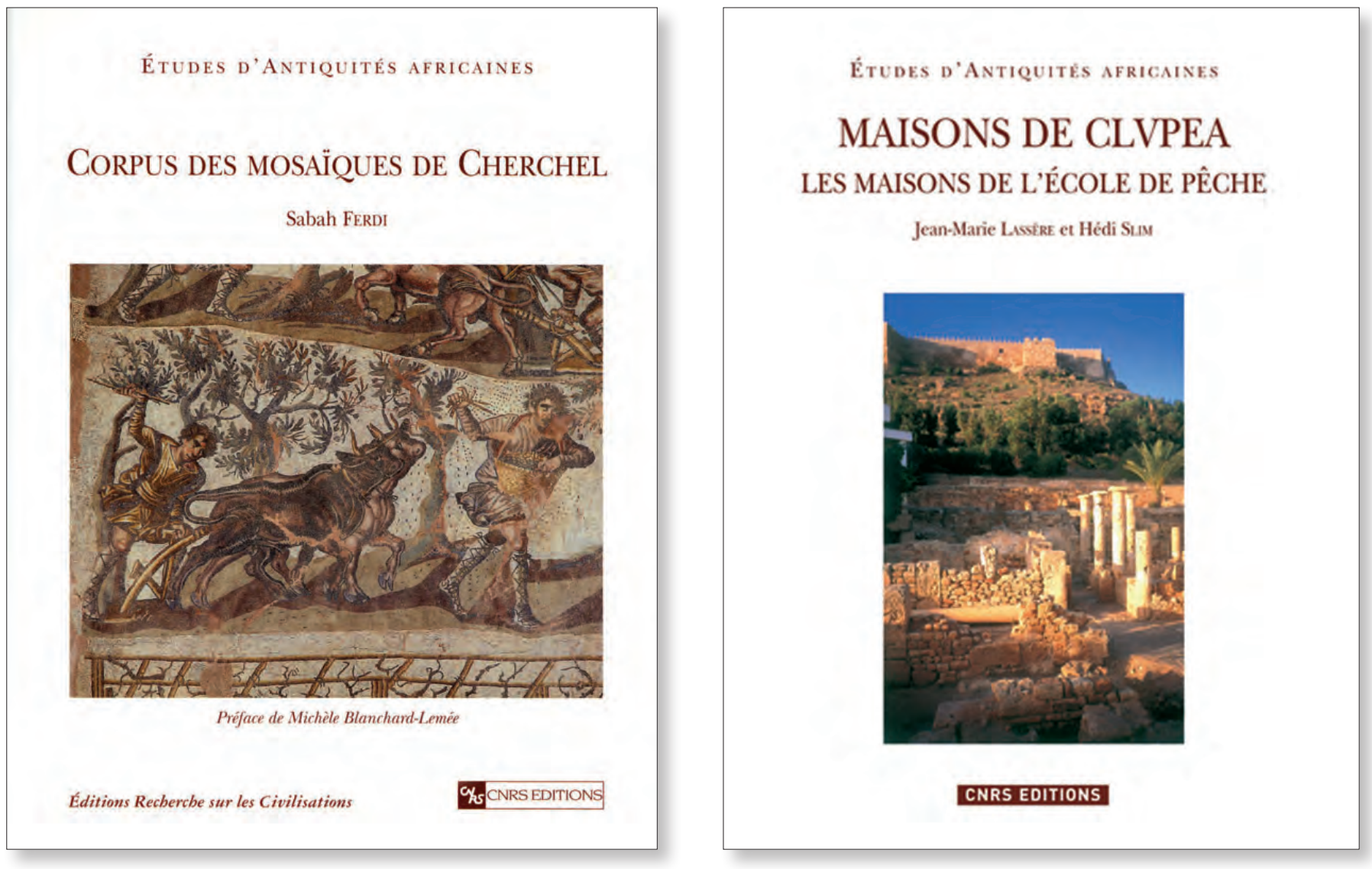

- Inscriptions antiques du Maroc, I. Inscriptions libyques, par Lionel Galand. Inscriptions puniques et néopuniques, par James Février. Inscriptions hébraïques des sites antiques, par G. Vajda, 1966 (épuisé).

- Jacques Revault, Palais et demeures de Tunis, XVI et XVII siècles, 1967 (épuisé).

- Alexandre Lézine, Carthage-Utique. Études d'architecture et d'urbanisme, 1968 (épuisé).

- Jean Deneauve, Lampes de Carthage, 1969 (épuisé).

- Suzanne Germain, Les mosaïques de Timgad. Étude descriptive et analytique, 1969 (épuisé).

- Jacques Revault, Palais et demeures de Tunis, XVIII ${ }^{e}$ et XIX ${ }^{e}$ siècles, 1971 (épuisé).

- Georges Souville, Atlas préhistorique du Maroc, 1. Le Maroc atlantique, 1973 (épuisé).

- Pol Trousset, Recherches sur le Limes Tripolitanus du chott El-Djerid à la frontière tuniso-libyenne, 1974 (épuisé).

- Jacques Revault, Palais et résidences d'été de la région de Tunis (XVI ${ }^{e}$-XIX ${ }^{e}$ siècles), 1974 (épuisé).

- Henriette Camps-Fabrer, Un gisement capsien de faciès sétifien, Medjez. II El-Eulma (Algérie), 1975 (épuisé). 
- Charles Saumagne, Saint Cyprien, évêque de Carthage, "pape » d'Afrique (248-258). Contribution à l'étude des "persécutions » de Dèce et de Valérien, 1975 (épuisé).

- Michèle Blanchard-Lemée, Maisons à mosaïques du quartier central de Djemila (Cuicul), 1975 (épuisé).

- Abdelmagid Ennabli, Lampes chrétiennes de Tunisie (musées du Bardo et de Carthage), 1976.

- Jean-Marie Lassère, Vbique Populus, peuplement et mouvements de population dans l'Afrique romaine de la chute de Carthage à la fin de la dynastie des Sévères (146 av. J.-C. - 235 ap. J.-C.), 1977 (épuisé).

- Jacques Revault, L'habitation tunisoise. Pierre, marbre et fer dans la construction et le décor, 1978 (épuisé).

- Colette Roubet, Économie pastorale pré-agricole en Algérie orientale. Le Néolithique de tradition capsienne, l'exemple de l'Aurès, 1979.

- Henri Morestin, Le temple B de Volubilis, 1980 (épuisé).

- Jean Lassus, La forteresse byzantine de Thamugadi, 1. Fouilles à Timgad 1938-1956, 1981.

- Maurice Euzennat, Jean Marion et Jacques Gascou, Inscriptions antiques du Maroc, 2. Inscriptions latines, 1982.

- André Mandouze, Prosopographie chrétienne du Bas-Empire, 1. Prososopographie de l'Afrique chrétienne (303533), 1982.

- Hélène Benichou-Safar, Les tombes puniques de Carthage. Topographie, structures, inscriptions et rites funéraires, 1982.

- Zeineb Ben Abdallah et Leïla Ladjimi Sebaï, Index onomastique des inscriptions latines de la Tunisie, 1983 (épuisé).

- Roger Guéry, La nécropole orientale de Sitifis (Sétif, Algérie). Fouilles de 1966-1967, 1985 (épuisé).

- Ginette Aumassip, Le Bas-Sahara dans la Préhistoire, 1986.

- Denis Roques, Synésios de Cyrène et la Cyrénaïque du Bas-Empire, 1987.

- André Laronde, Cyrène et la Libye hellénistique - Libykai Historiai - de l'époque républicaine au principat d'Auguste, 1987 (épuisé).

- Yann Le Bohec, La Troisième Légion Auguste, 1989 (épuisé).

- Maurice Euzennat, Le limes de Tingitane. La frontière méridionale, 1989 (épuisé).

- Yann Le Bohec, Les unités auxiliaires de l'armée romaine en Afrique proconsulaire et Numidie sous le HautEmpire, 1989 (épuisé).

- Jean Peyras, Le Tell nord-est tunisien dans l'Antiquité. Essai de monographie régionale, 1991 (épuisé).

- Véronique Brouquier-Reddé, Temples et cultes de Tripolitaine, 1992 (épuisé).

- Lilianne Ennabli, Carthage, une métropole chrétienne du IVe à la fin du VII siècle, 1997.

- Michèle Coltelloni-Trannoy, Le royaume de Maurétanie sous Juba II et Ptolémée, 1997.

- Liliane Ennabli, La basilique de Carthagenna et le locus des sept moines de Gafsa. Nouveaux édifices chrétiens de Carthage, 2000.

- François Baratte, Janet Lang, Catherine Metzger et Susan La Niece, Le trésor de Carthage : contribution à l'étude de l'orfèvrerie de l'Antiquité tardive, 2002.

- Nadine Labory, Inscriptions antiques du Maroc, 2. Inscriptions latines - Supplément, 2003.

- Hédi Slim, Pol Trousset, Roland Paskoff et Ameur Oueslati, avec la collaboration de Michel Bonifay et Jean Lenne, Le littoral de la Tunisie. Étude géoarchéologique et historique, 2004.

- Sabah Ferdi, Corpus des mosaïques de Cherchel, 2005.

- Lieux de cultes : aires votives, temples, églises, mosquées. IXe Colloque international sur l'histoire et l'archéologie de l'Afrique du Nord antique et médiévale (Tripoli, 19-25 février 2005), 2008.

- Jean-Marie Lassère, Maisons de Clupea. Exemples de l'architecture domestique dans un port de l'Afrique proconsulaire. Les maisons de l'Ecole de pêche, avec une étude de la céramique par Jean Piton (sous presse). 


\section{COLLECTION}

\section{ARCHAEONAUTICA}

CNRS Editions, 15 rue Malebranche, 75005 Paris - http://www.cnrseditions.fr
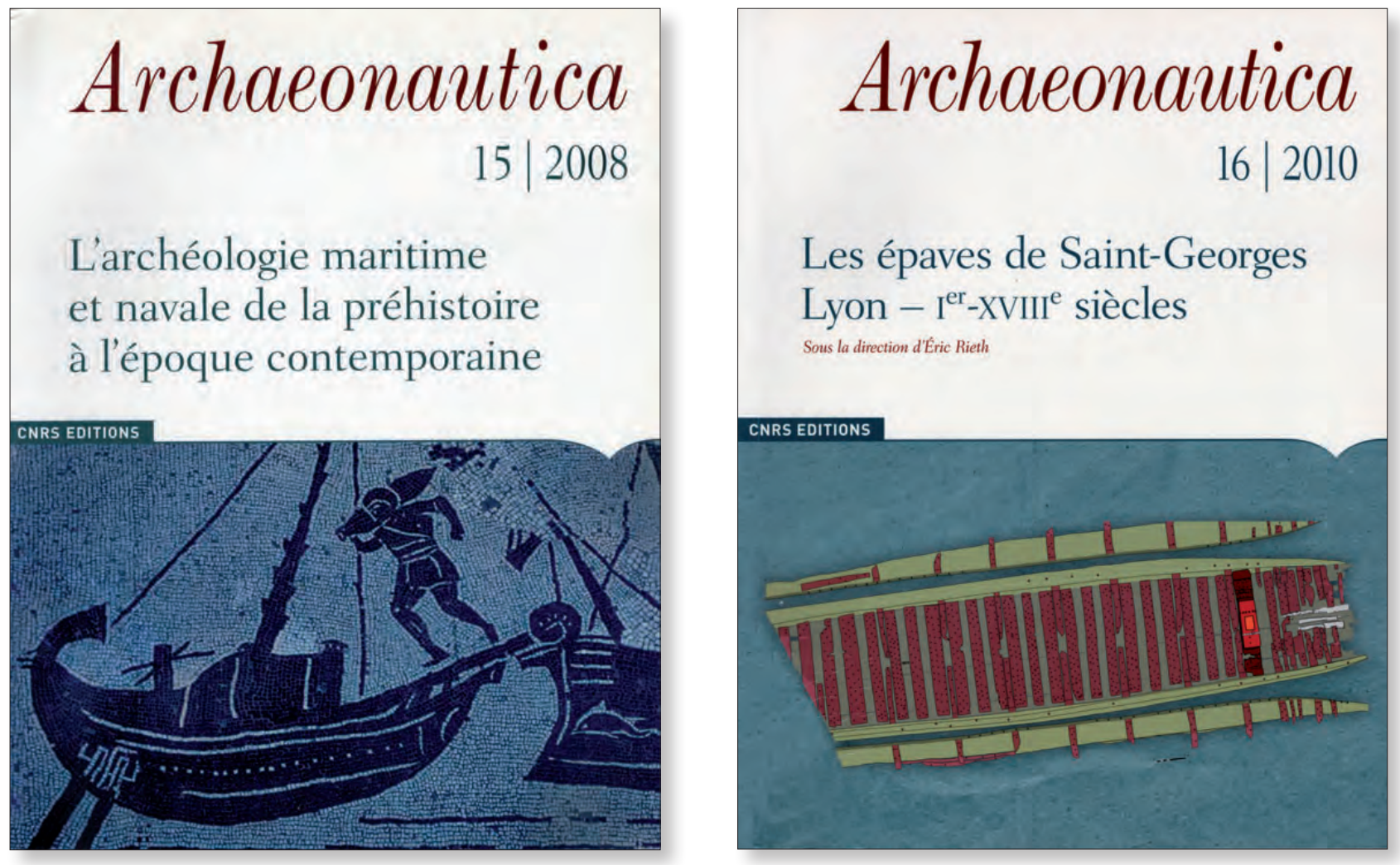

1. D. Colls, R. Étienne, R. Lequément, B. Liou, E. Mayet, L'épave Port-Vendres II et le commerce de la Bétique à l'époque de Claude, Paris, 1977. 148 p.

2. Recueil d'articles, Paris 1978, $312 \mathrm{p}$.

3. Les épaves de Gruissan, vol. coll. sous la dir. de Y. Solier, Paris 1981, 436 p.

4. Recueil d'articles, Paris 1984, 296 p.

5. M. Corsi-Sciallano, B. Liou, Les épaves de Tarraconaise à chargement d'amphores Dressel 2-4, Paris 1985, 180 p.

6. Recueil d'articles, Paris 1986, 216 p.

7. Recueil d'articles, Paris 1987, 212 p.

8. A. Hesnard, M.-B. Carre, M. Rival, B. Dangréaux et coll., L'épave romaine Grand Ribaud D (Hyères, Var). Paris, 1988, $182 \mathrm{p}$.

9. M. Guérout, E. Rieth, J.-M. Gassend, avec le concours de B. Liou, Le navire génois de Villefranche. Un naufrage de 1516, Paris, 1989, $171 \mathrm{p}$.

10. Recueil d'articles, Paris 1991, 272 p.

11. Recueil d'articles, Paris 1993, 185 p.

12. C. Baudoin, L. Liou, L. Long, Une cargaison de bronzes hellénistiques. L'épave «Fourmiogue C »à Golfe-Juan, Paris 1994. 144 p.

13. Cl. Santamaria, L'épave « Dramont E » à Saint-Raphaël (Ve siècle apr. J.-C.), Paris 1995, 195 p.

14. P. Pomey, E. Rieth (dir.), Construction navale, maritime et fluviale. Approches archéologiques, historique et ethnologique Actes du Septième Colloque International d'Archéologie Navale - Proceedings of the Seventh International Symposium on Boat and ship Archaeology, Ile Tatihou 1994 (Saint-Vaast-la-Hougue). Paris 1998, 335 p. 15. 2008, L'archéologie maritime et navale de la Préhistoire à l'époque contemporaine, Paris 2009.

16. E. Rieth (dir.) Les épaves de Saint-Georges - Lyon (IIr-XVIII ${ }^{e}$ s.) : analyse architecturale et études complémentaires, Paris 2010. 335 p.

La collection $(1,1977$ - 14, 1998) est disponible sur le portail Persée (barrière mobile à 3 ans) 

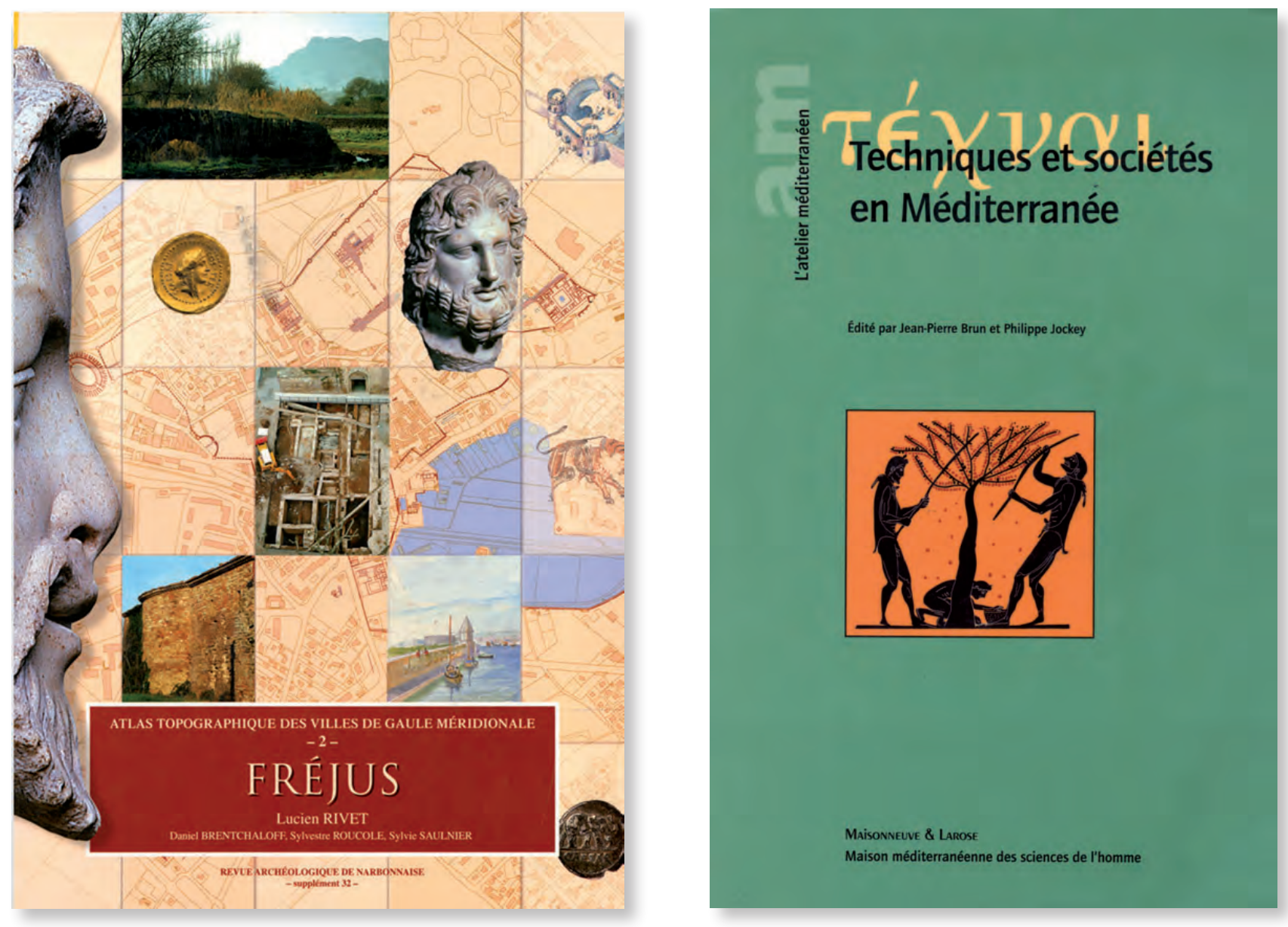

1. Le territoire de Marseille grecque, Actes de la table ronde d'Aix-en-Provence (26 mars 1985), édités sous la direction de M. Bats et H. Tréziny (Études massaliètes 1), Publications de l'Université de Provence, 1986, 1 vol., 177 p.

2. Ugernum. Beaucaire et le Beaucairois à l'époque romaine, ouvrage collectif sous la direction de J.-L. Fiches, Cahiers de l'ARALO n ${ }^{\circ} 15$ et n 16, Caveirac 1987, 2 fasc., 120 et 128 p.

3. Inscriptions latines de Narbonnaise, Actes de la table ronde de Nîmes (25-26 Mai 1987), sous la direction de N. Darde et M. Janon, Ecole Antique de Nîmes, supplément au n 20, 1989, Nîmes 1989.

4. M. Rival La charpenterie de marine romaine, éditions régionales du CNRS, Marseille 1991, 1 vol., 333 p., 112 pl.. 5. Fr. Gasser, Histoire des paysages et de l'environnement dans la basse vallée de l'Arc, CRDP Marseille, 1989, 1 vol., 116 p., 15 fig.

6. Ph. Leveau, L'aqueduc sud des Alpilles, catalogue d'exposition, Musée de Salon et de la Crau, 1990, 1 vol., 50 p. 7. Les amphores de Marseille grecque. Chronologie et diffusion, Actes de la table-ronde de Lattes (26/3/89), sous la direction de M. Bats, (Ét. massa. 2), éd. A.D.A.M. - Université de Provence, Lattes/Aix-en-Provence, 1990, 1 vol., $295 \mathrm{p}$.

8. Le village gallo-romain et médiéval de Lunel Viel (Hérault), ouvrage collectif sous la direction de Cl. Raynaud (Annales littéraires de l'Université de Besançon, n 422), Besançon, 1990, 1 vol., 53 p., 153 fig.

9. Ph. Columeau, L'animal pour l'homme. Recherches sur l'alimentation carnée dans le sud de la France du Néolithique au Moyen-Age d'après les vestiges osseux, 1. Le monde rural, Saint-Didier, 1991, 1 vol., 186 p.

10. Inscriptions latines de Narbonnaise, Actes de la table ronde d'Alba (Juin 1989), édités par D. Darde, Nîmes, 1992 (Ecole Antique de Nîmes, supplément au n²2, 1991), 1 vol., 63 p. 
11. Marseille grecque et la Gaule, Actes des colloques de Marseille (18-24 novembre 1990), publiés sous la direction de M. Bats, G. Bertucchi, G. Congès et H. Tréziny (Etudes massaliètes 3), éd. ADAM-Université de Provence, Lattes/Aix-en-Provence, 1992, 1 vol., 504 p. (épuisé)

12. L'origine des richesses dépensées dans la ville antique, Actes du colloque d'Aix-en-Provence (11-12 mai 1984), rassemblés et publiés par Ph. Leveau, 2e édition, Publications de l'Université de Provence, Aix-en-Provence, 1988, 1 vol., 285 p.

13. B. Bouloumié, Saint-Blaise (Fouilles H. Rolland). L'habitat protohistorique. Les céramiques grecques, Publications de l'Université de Provence, Aix-en-Provence, 1992, 1 vol., 279 p., 74 ill.

14. Archéologie et environnement : de la Sainte-Victoire aux Alpilles, ouvrage collectiff sous la direction de Ph. Leveau et M. Provansal, Publications de l'Université de Provence, Aix-en-Provence, 1993, 1 vol., 550 p.

15. Sur les pas des Grecs en Occident, Hommages à André Nickels, textes réunis et édités par P. Arcelin, M. Bats, D. Garcia, G. Marchand et M. Schwaller (Etudes massaliètes 4), éd. ADAM-Errance, Lattes/Paris, 1995, 1 vol., $492 \mathrm{p}$.

16. M.-Br. Carre, A. Hesnard, V. Robin, A. Tchernia, Recueil de timbres sur amphores romaines, t. 1, Publications de l'Université de Provence, Aix-en-Provence, 1995, 1 vol., 194 p., 4 pl.

17. EYKPATA. Mélanges offerts à Claude Vatin, textes réunis par M.-Cl. Amouretti et P. Villard, Publications de l'Université de Provence, Aix-en-Provence, 1994, 1 vol., 210 p.

18. A. Chéné, Ph. Foliot, G. Réveillac, La photographie en archéologie, Marseille, Edisud (à paraître)

19. Languedoc occidental protohistotique (VIe-IVe s. av. J.-C.). Fouilles et recherches récentes, ouvrage collectif sous la direction de D. Ugolini, Publications de l'Université de Provence, Aix-en-Provence, 1997, 1 vol., 239 p.

20. M.-Br. Carre, A. Hesnard, V. Robin, A. Tchernia, Recueil de timbres sur amphores romaines, t. 2, Publications de l'Université de Provence, 1998.

21. Techniques et économie antiques et médiévales. Le temps de l'innovation, actes du colloque d'Aix-en-Provence (mai 1996), réunis par D. Garcia et D. Meeks, éd. Errance, Paris, 1997, 1 vol., 240 p.

22. Fouilles à Marseille. Les mobiliers ( er $_{-} V I I^{e}$ s. ap. J.-C.), ouvrage collectif sous la direction de M. Bonifay, M.-Br. Carre et Y. Rigoir (Ét. massa. 5), éd. ADAM-Errance, Lattes/Paris, 1998, 1 vol., 443 p.

23. J. Guyon, N. Nin, L.Rivet, S. Saulnier, Atlas topographique des villes de Gaule méridionale. 1, Aix-en-Provence, Montpellier, 1998 (Supplément 30 à la R.A.N.)

24. B. Sabattini, dir. La céramique attique du IVe siècle en Méditerranée occidentale, Actes du Colloque International d'Arles (7-9 décembre 1995), Naples, Centre Jean Bérard, 2000 (= Collection du Centre Jean Bérard, 19).

25. J.-P Morel, C. Rondi-Costanzo et D. Ugolini, éd., Corallo di ieri, corallo di oggi, Actes du Colloque International du Centre Universitaire Européen pour les Biens Culturels, Ravello, Italie (13-15 décembre 1996), Bari, Edipuglia, 2000 (= CUEBC, Scienze e materiali del patrimonio culturale, 5).

26. P. Leveau et J.-P. Saquet, éd., Milieu et sociétés dans la Vallée des Baux. Études présentées au colloque de Mouriès. Montpellier, 2000 (= Suppl. 31 à la R.A.N.).

27. L. Rivet, D. Brentchaloff, S. Roucole, S. Saulnier, Atlas topographique des villes de Gaule méridionale 2. Fréjus, Montpellier, 2000 (=Suppl. 32 à la R.A.N.).

28. P. Lévêque et J.-P. Morel, dir., Céramiques hellénistiques et romaines. III, Paris, 2001.

29. Ph. Columeau, Alimentation carnée en Gaule du Sud: VII ${ }^{e}$ s. av. J.-C.-XIVe s., éditions Université de Provence, Aix-en-Provence 2002.30. J.-P. Brun et Ph. Jockey, éd., TECHNAI. Techniques et sociétés en Méditerranée, Hommage à M.-Cl. Amouretti, Paris, Maisonneuve et Larose, 2001 (MMSH, coll. L'atelier méditerranéen), Aix-en-Provence 2001.

30. J.-P. Brun et Ph. Jockey, éd., TECHNAI. Techniques et sociétés en Méditerranée, Hommage à M.-Cl. Amouretti, Paris, Maisonneuve et Larose, 2001 (MMSH, coll. L'atelier méditerranéen), Aix-en-Provence 2001. 
Achevé d'imprimer en juin 2011 par Printer Portuguesa à Rio de Mouro

Dépôt légal : juillet 2011

$\mathrm{n}^{\circ} \mathrm{d}^{\prime}$ imprimeur :

Imprimé au Portugal 

